1
$y$

1. 8 1.

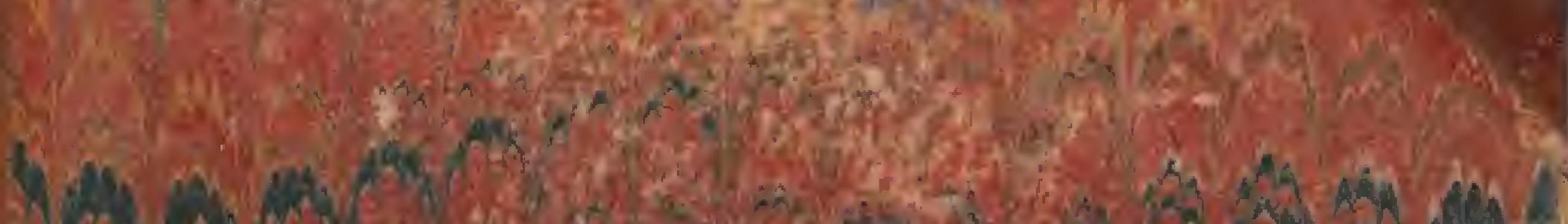

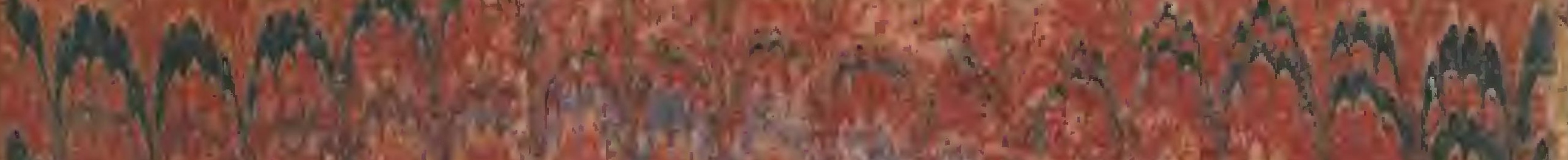

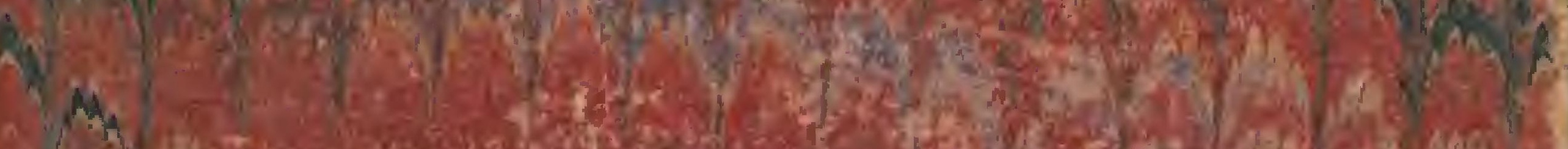

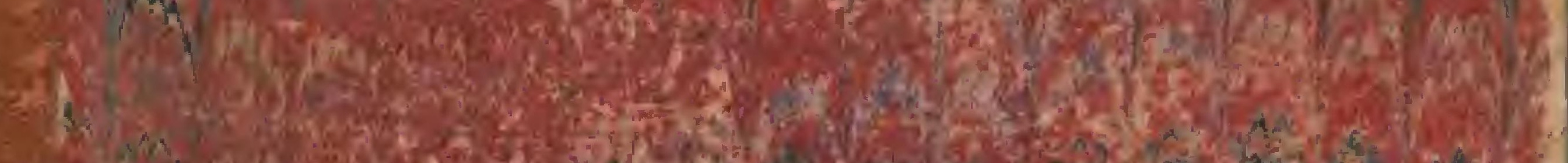

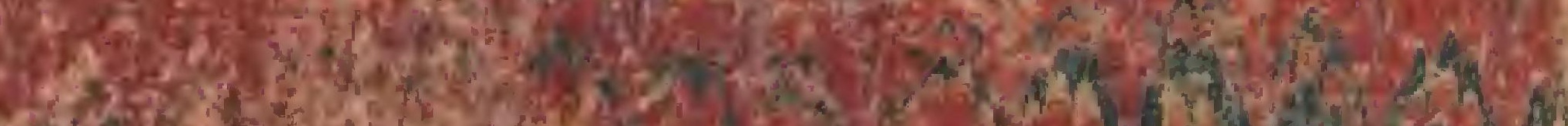

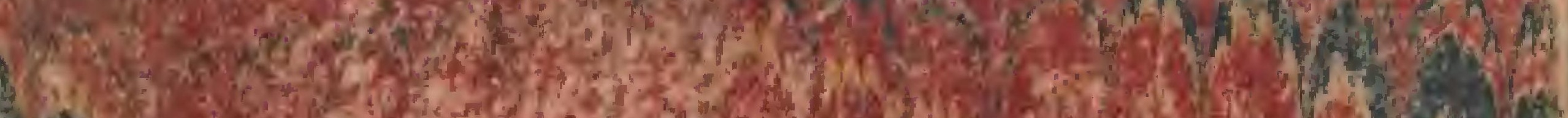

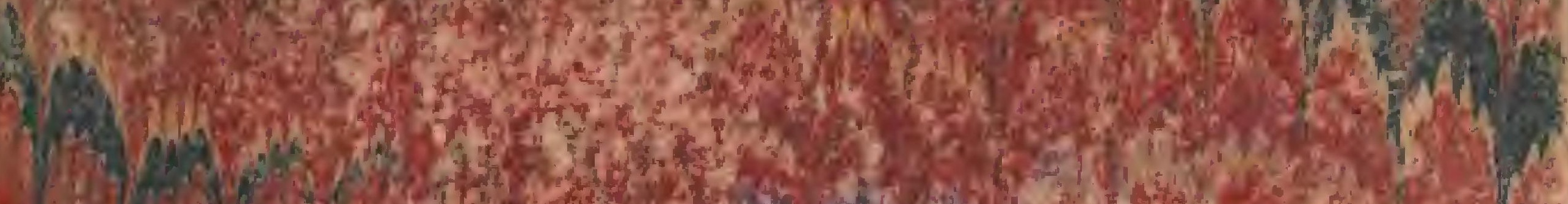

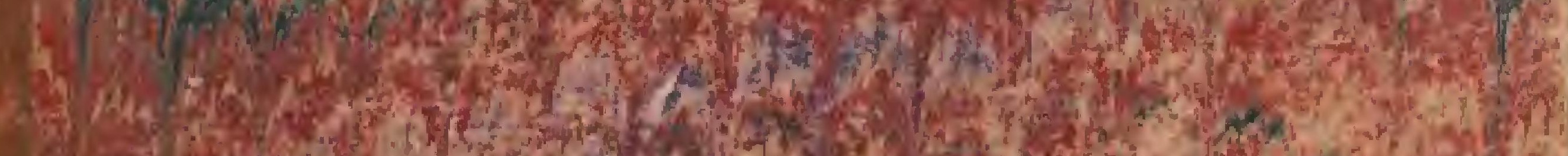

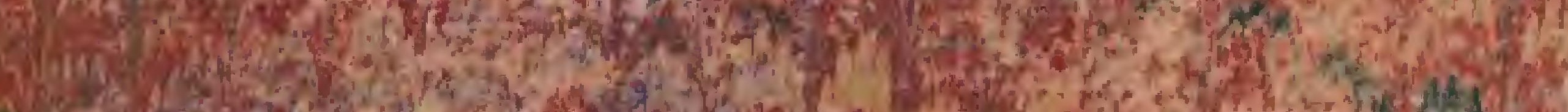

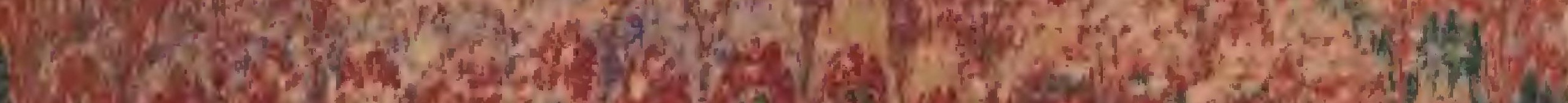

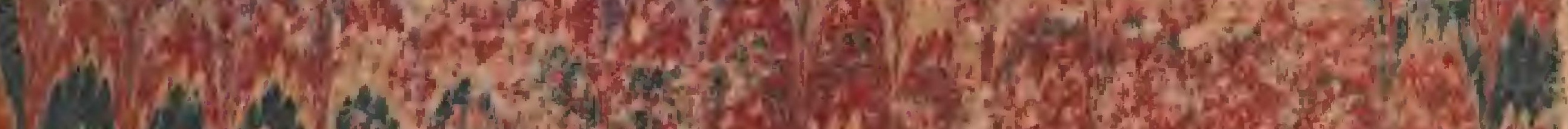

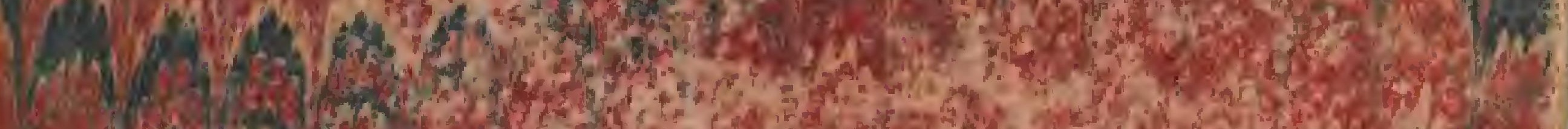

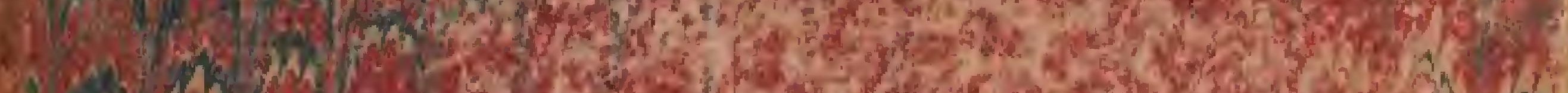

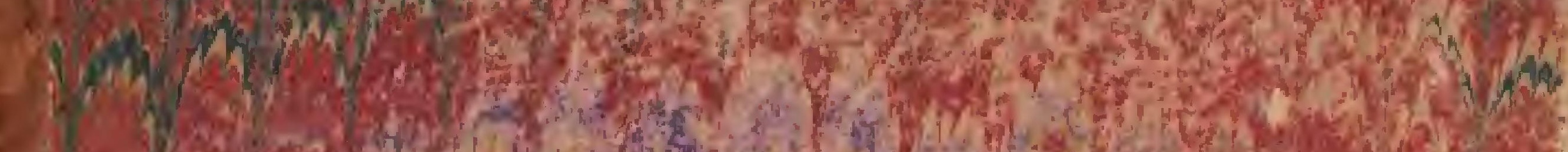

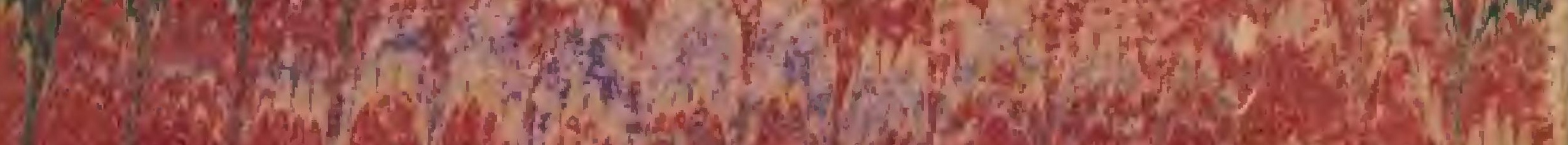

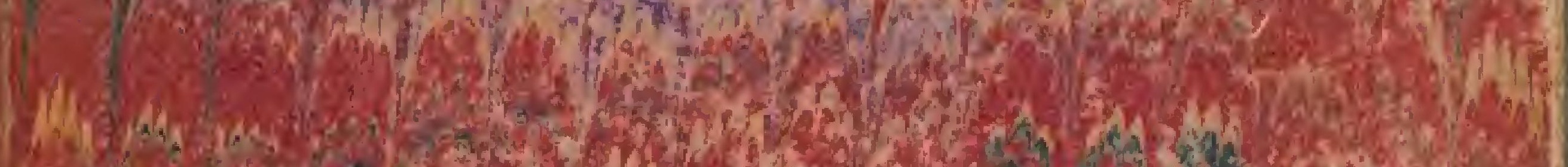

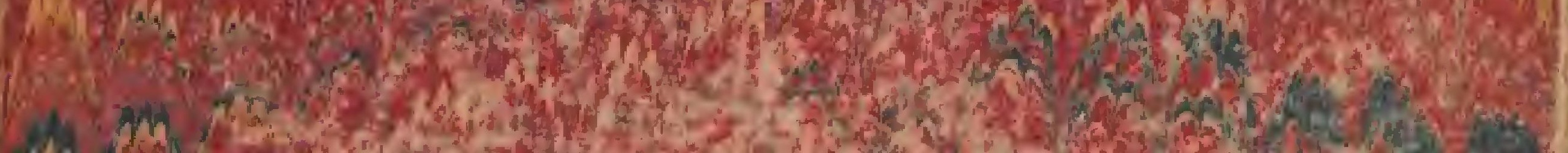

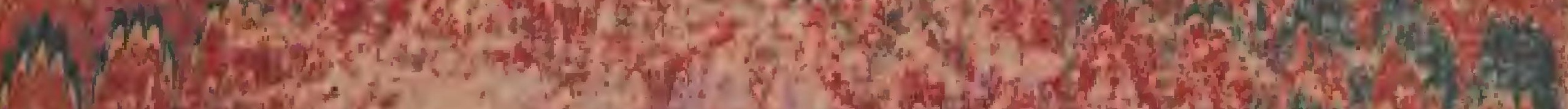

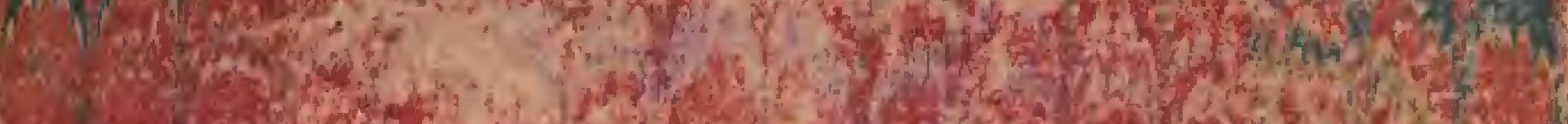

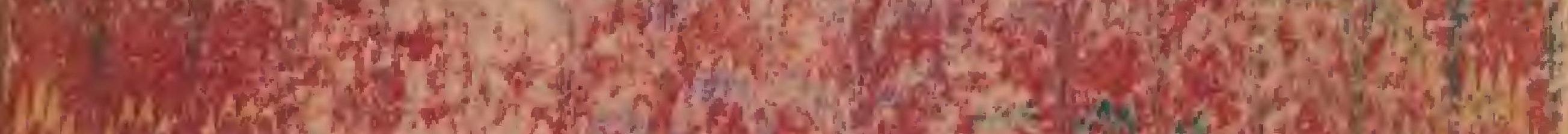

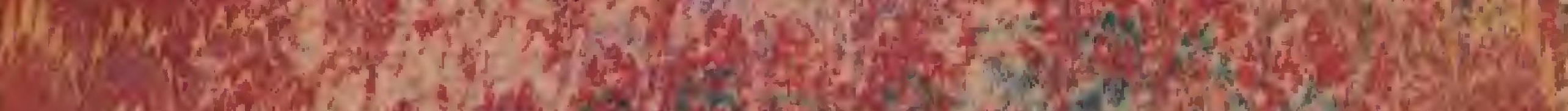

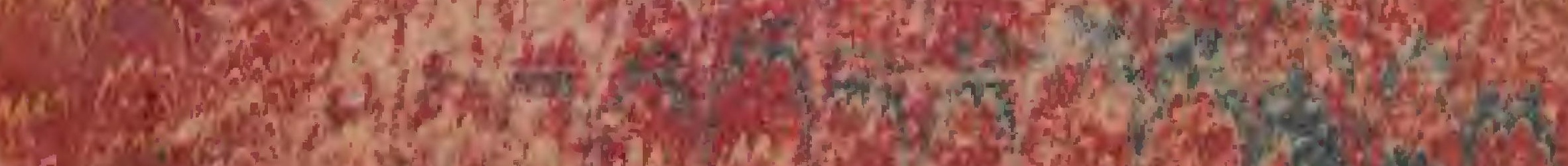
19.

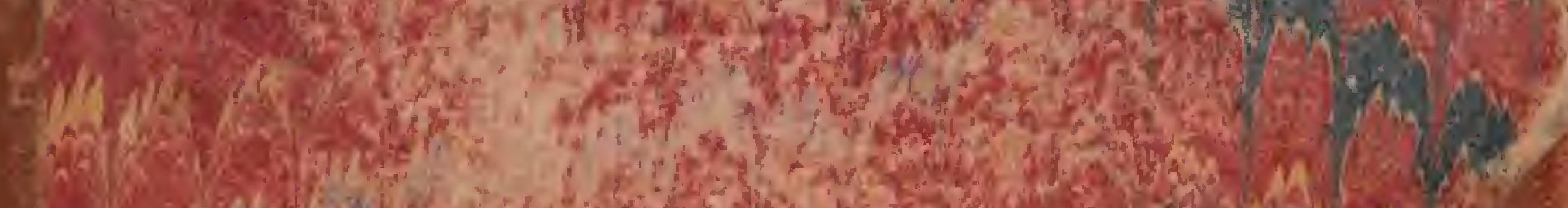

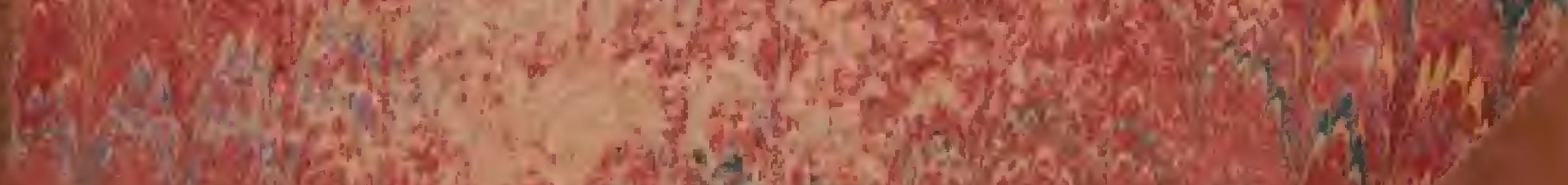

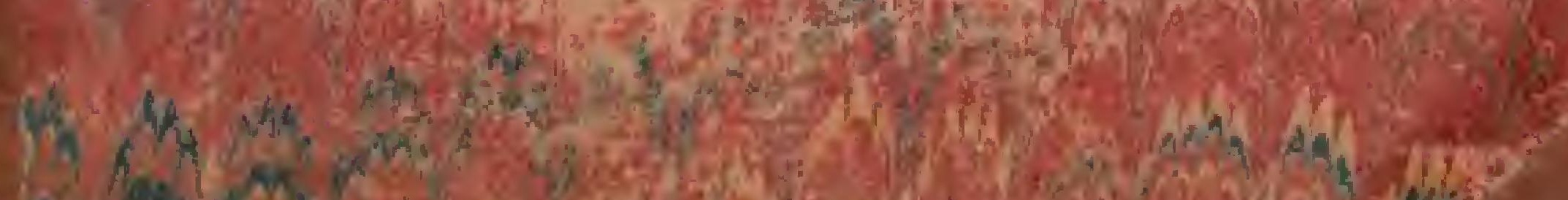

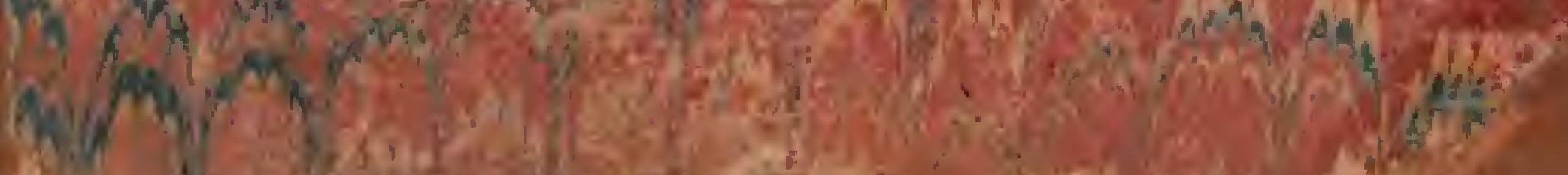





RAFRLPS LIRRAY answorise at

MATOHOL LAPARY SNKGADORE 


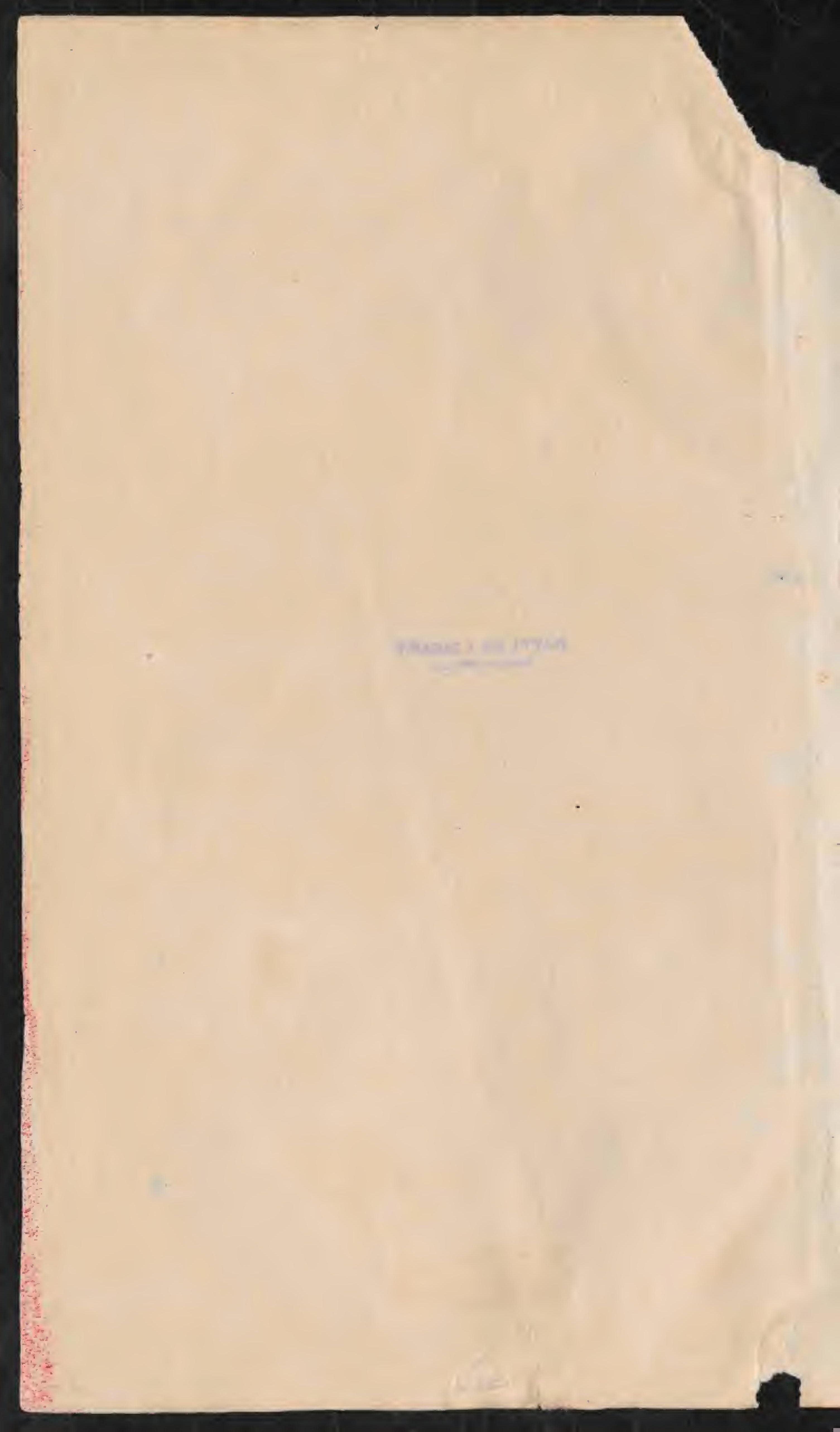




\section{VER HANDELING}

D $\mathrm{E} R$

Z EE-HOREN K E NS

E N

Z E E-GEWAS SEN

In en ontrent
A M B
O I
$\mathrm{N} A$

En de naby gelegene EY L A NDEN,

Mitsgaders een naalieurige Befchryving van

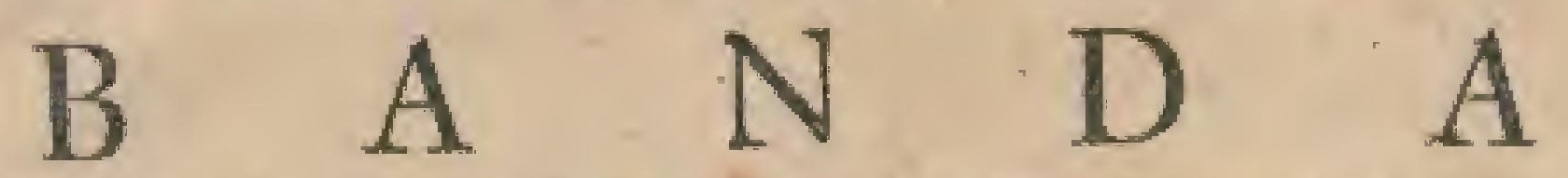

en de E Y L A N D E N onder die Landwoogdy begrepen.

Als ook der Eylanden

'TMOR en SOLOR, CELEBES ofte MACASSAR, BOR NEO en B A L I.

Mitsgaders van de Koningrylen

TONKIN, CAMBODIA, en SIAM.

Benevens een Verhaal der Zaken in de voornoemde Eylanden en Koningryken tot nu toe voorgevallen.

Mot zeer nette Prew verbeldingen en Landkarten werrykt,

DOOR

\section{FRANCGOIS VACENTYN,

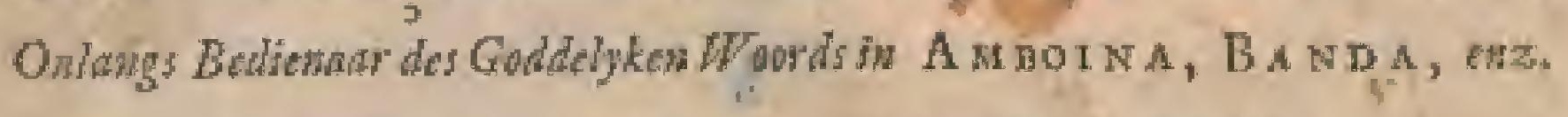

A.. DERDE DEELS TWEEDESTUK.

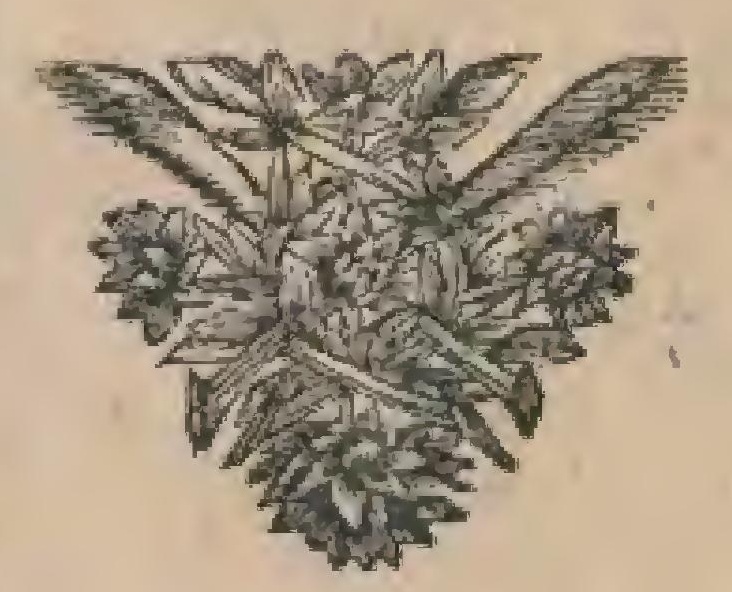

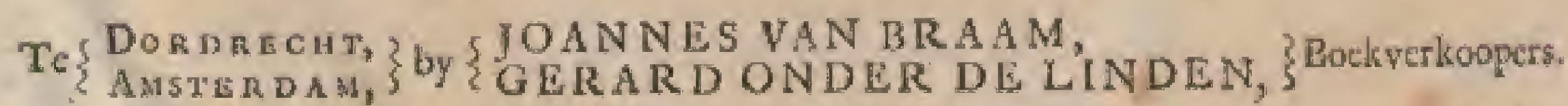

M D C C X X V I.

MET PRIVILECIE. 



\title{
VERHANDELING
}

\author{
D E R
}

\section{ZEE-HORENKENS}

E N

\section{S C H E L P E N, \\ O F T E}

\section{U B B L E T T E N}

TH
A
M
B
O I
$\mathrm{N} A$.

\section{E L F D E H O O F D S T U K.}

$B^{E}$ fldy

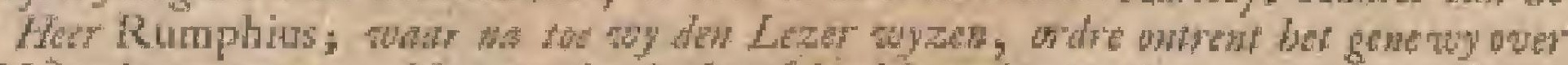

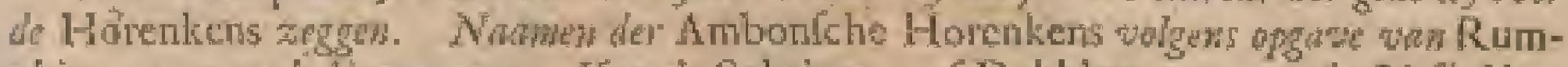
phitus, en wan do Luropeers. Fan de Schelpen, of Dubbletten, wat de Liefhebers

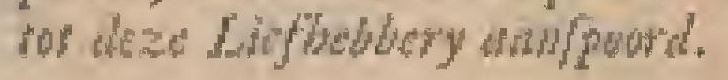

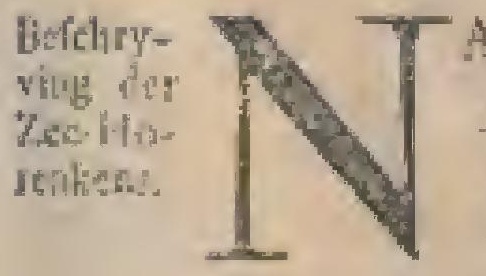

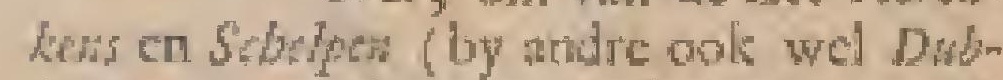
brers, om dit zy twee ledig zyr, be-

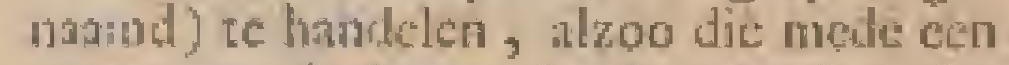
voasnam decl wan de Trworndere der Zee uitualicon, en 'I natit quter be for

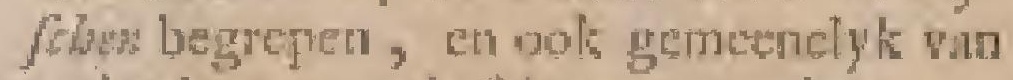
andre "er wetens befotuten werden.

Men moce wan om nice rerwagten, dar wry dic zon witrocrig, als wel cot dic Wert behnoren zow, allien befchryven: [i]. DFET.

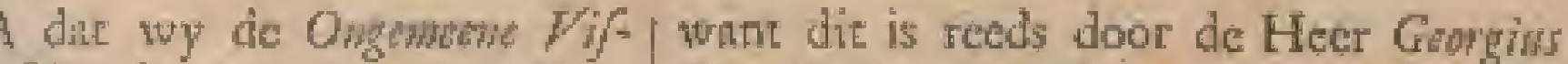

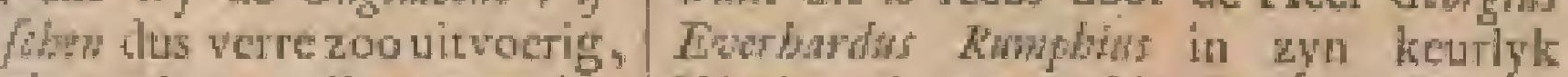
als wy het noodig agecn, be- Wherk, de Amborm/cbe Rarin-Kamer, $A^{0}+1795$, migegever, gedan, en verder door tocdoen warl de Heer Borgetneefer Hewdik d' Apser tot Deff, dopr wichs bezorging, lice an da dood wan de Her puntion in den iever en de omvermocide en nete na- bonlohe

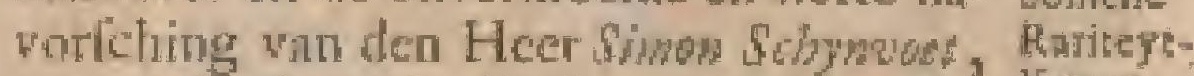

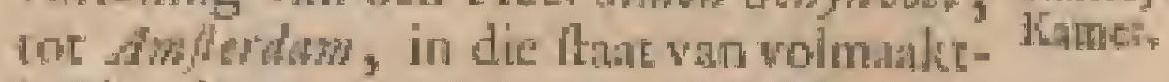
heid rebmgr, gelyh nuen dat Werk jegenwnondig, ther alles ${ }^{1} t$ gecil deze en geenc Liefhebbers nog zatdzan wit andre Werdds-declen, en Gewelten, in $\checkmark \mathrm{YY}$ 


\section{It 8 Verhandeling der ZEE-HORENKENS, enz.}

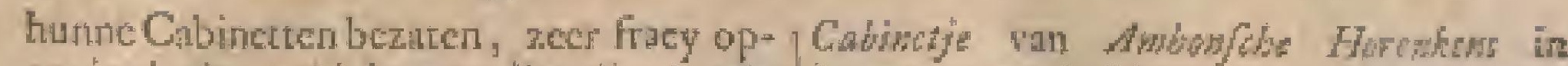
geciert zict. Al bet wellie die lanthe hare zoorten befichryven, en by die ge-

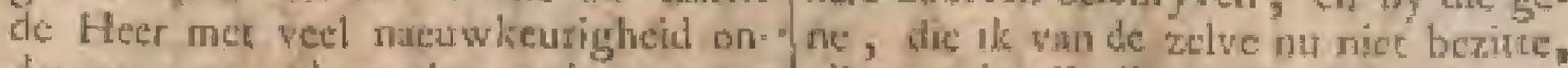
derzogr, over il opgebaggerd, en woor-allecr, dat if die nu nier heb, "er byzoo werre die Iorersliens loen, buiren de roegen.

Oofferfobe, nog belend waren, 'er by gewocgd hecf.

Wy wyzen derhalwen dew Lezer, zoo Van terre als de Betchryving dezer distoryde Heer fobs, en anok der twen reeds bekende an-

ftumdre Horenkens, "t zy uit Wef Lidicn.

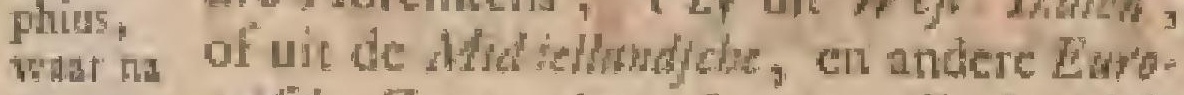
toc wy peifobe Zeer, betref, ror dit heellyk by de Heer Rawnbing gehouden, de nha-

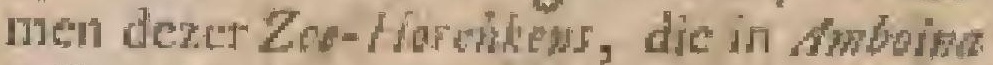
vallen, oponemen, en dar en hoven er dic gene byvocgen, die by de Heer $R$ unphis, conden, overgellagen of niet bekend gewedl zym, en die if bezite, en toonen kar.

orde Om dit dan met cen netre ordre; thic ontrent"t ment volgen kan, te behmudelen, zal ik, gever de by dit opnoemen der Amboufbe ZeeHornt- Horenkens, te gelyk ook voor eerth mys kens zet geA.

Ten andersi, zal ik by ieder zoone, van welke ik fpreke, die rene, die ik meer bezitte, dan die in "t Werk way de Hew' liwholis geneld werden, "er" ook by platezen.

Ln ra dat if over alle de Oofer/ate Fomukns, die in Amboina of in 't Ospon vallen, en die ik beztte, gefprolien zal

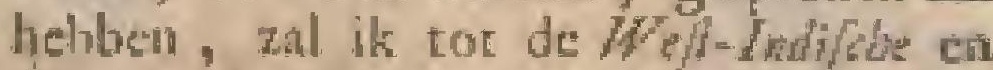
Exropeifobe, elie ik besite, en verder of kenne, af gemeld vinde, overgara.

Wy beginners diln met het tweede Namen Boeks wan de Heer Rnallios in her cwee der Amde Hoofdtuk, radrasm geronden heb- Hoichbende, on aall de cene zyde de Indfrde, lens vol.

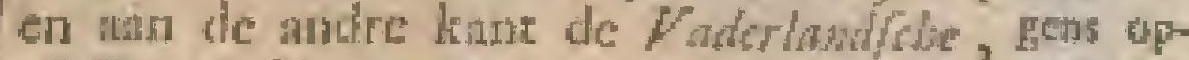

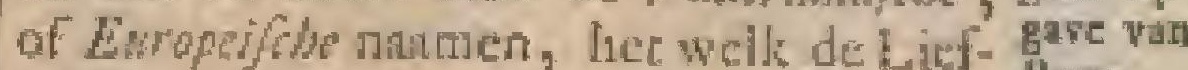
hebbers hier te Larde, an in Wadiem, een phiwi graot licht antrent dere Liefhebbery ge- yan de ven zal, hier op to noemen. piers. 


\title{
VER H A D E L I N G
}

\author{
D E R
}

\section{OOST-INDISCHE, \\ ZEE - HOORNKENS.}

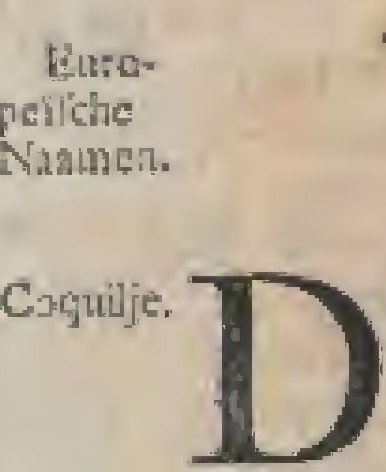

- Inalifibe Natutar.

Lib: II. Cap: II.

E Papedo-Hoors, of de Patrlemoer-Hoorn, die ik groot, en middel-bata zeer fracy bezit.

Dito kilene, doot de Zeegeparriemocrd.

Dito kleene, ongeparlemoers, dic zeer zeldzaam is.

$$
\text { Cos: } I I I \text {. }
$$

Het Romals Gorita.

Doeker- Metenvleugelter $z$ de, en agter tmal. haific. Dito, dog zonder vleugel of te glad res zyden.

Dito, met knobbels, en breed agter.

Ook zyn 'er Krad-Goria"s; dog Jeze vallen in de Maddhoffor Zet. Ook hebbe die lantfe niet.

Van deze hebbe meer dan Ratuphis.

Een gecle Rown Gorita.

Een zoort, die wan agteren rondagtig en ghal is.

Beide deze zootten wallen in de meefte Zcën yan Ambind, en de latate vooml tultchen Cum, Oma, en Homimow, en ook tuffchen de hoeken wan Tial en Ho7ophorr, datr men byzonder groote grezien heef. En dit is de Vilch, wan welke men beft volgens Plinis getuigenis, th: 9. $t a p: 29$. de Zet-kunde yelect heefe, gelyle die Gyaldus cap: 3. de ro Awhtica, onk zegt.

Diwerd Het Pof- Hoorwhe.

$$
\text { Colp: } I V \text {. }
$$
de zelve Deze vallen op Ambina, Owa, en
Naln. Howinos.

Het 9antrowy

$$
\text { Gipp: }
$$

Dit walt ontrent Manipa, en Bonod.

$$
\text { Cap: } V I_{\mathrm{s}}
$$

Debonte Mata Bolan Bezar, of "t groot Man-wog,

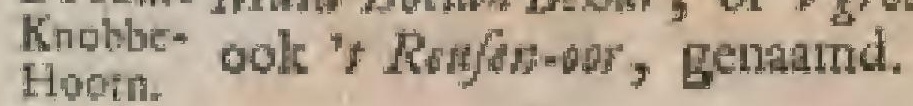

\section{Indifobe Nuarath.}

peilche

Deze vallen op "t Eiland Oma, en el- Namen ders meer.

Des zelfs dekel, of de Fons-Novel.

Hier wan heb ik meer de ros gemaneläe.

De hooge of fterk groend.

$$
\text { Crp: } V I I \text {. }
$$

Dito, kewn Wan-boum, met het Mawnetjt.

De Bia Pejola, of Petool. Howrent.

Deze vallen beth op" DeNaf Ahora op 'I Eiland Oma, en op 't Eilland Nonfi-Laes.

lik zie van deze op de Plat XIX. Fol: 70. vicr byzondere zooten.

Dog ik bezite dare af zefthicn, a zerenthich, verfehillende zoopten, waar onder de Onngie zeer zeldzan is; gelyk ools die met hate oogen 'er op.

Gondo Oxw, of gloejtote Ovens.

Dito, kleene zoort.

GowdMonden. Zirver Ovens.

Zilver:

Met alle de verdere op de Plat XIX. Monden. No. I. 3. en 4. "er bygeroegd.

Buten welke it nog wel vier at vyf zecr zeldzame Ziluef-Moshow beritec, onder andre cen pek-zwarte met witte vlejken.

Deze Gord- en Zifuer-Moulen, willen op de Eilinden Oms, Hownoa, en op Letiwor.

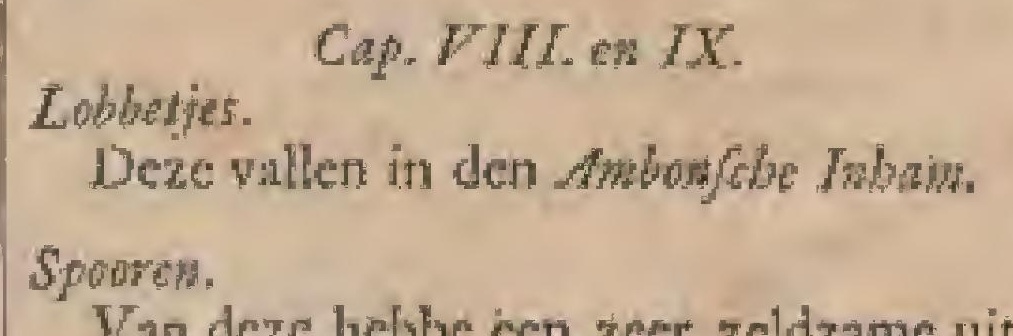
Dollyntjest of Bastd: Mandineketis: De

Van deze bebbe cen zeer zeldzame uit keene Ambahn gedrage, die zeer groot, envan zonnedrie n vier omgangen, of kringen woor- Hootr. zien was, komende 't nath ant de groote Zonne-Hoorn, by de Letter $\mathbf{K}$ op de Platit XX. te zien; dog bezit diesu niet; Deze vallen ook in den $A$ indong be $/ n-$ VW 2 bain, 

de andre Eilanden.

Thagraca Tollon.

$$
\text { Cap. X. Plat XX. }
$$

Drolle, Waan than hier by Rumptrins vicr zoorof Pyns- ten voorkomen, die il hebbe, ce weten, die by de Leters A.B. C.D.; degg de E. hebbe niex, ook lehynd my diat een $N d f$ farwar te zyn.

Wan de zelve zyn 'er verfolucide zoorten thog, tor elf toe, bygevoegd, wat tan 'cr cenige, eld cenige nict bezit.

De papolche Tol, ofde Moorfhr Trmal.

Van dezc heb swec byzondre zoorten, zyonde de ecine zoort van binnem platter, meer geribd, witter, an de ecne ook incer gedoortyd, of gelknobbeld, dan de andie. Ook is er equ kitene zoort meen, dan die ik hier vinde.

Deze vallen op de Paptefole Eulandes, op Masipa, Kalass, en elders of de Eilainden.

\section{9e7ke- De Crrmulse Marl-Proma}

Tow Deze hebbe nu riet.

Zy valt op 't Eiland Geran, ook wel op andere Eilanden. Dane syn 'er die zwart, cn andre, dic lever-verwig zyn.

$$
\text { Cap. } H I \text {. }
$$

Stecke Gede Doyers.

Horeds. Deze wallen op de Kuft wat Hitoe.

De Oratigic Doyer"

De gracuwe of bicele Dopers. jhins:

Tik hebbe whin deze zoore meer als Rugh-

Debruine Doyer, die witgebandecrd is.

De gecle er rofe, nuet cen lichte witte band, een licht-gecle, en nog rweederley vatale Orangie Doyes.

Gedrulkte Doyers.

De gemene ing de bruise of leververwige glades agg buiten dic beyit ik nog vier andre zoorten, reweten, de bruine; dog too plat nier uts de gencedne:

De graeuwe.

De wite.

De bleck-roffe.

De gemaruerde en van binnen liclitPurpre.

De atre De zwart-gefpitkelde Doyf, methar Matip. klecner zoort:

D- xetur Het sonm-Mondit.

Nuan, Hier af heb heer de gracuwe vos-gemanerde Doyer.

De welle De witte Dopr.

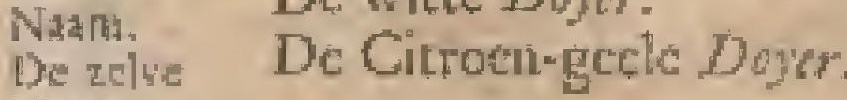

Natur. De Bira Sarafia.

What vart vicr byzondere zoorten bezit, hamelyle, die op de Plata XXIJ.by

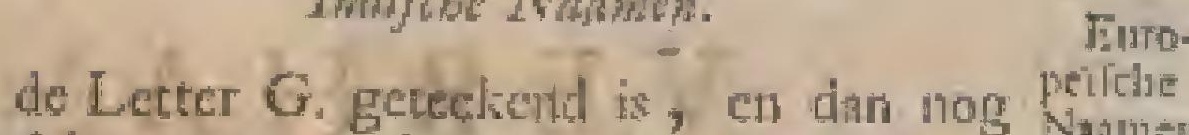
Arie zoorten anders gercelecind, Dan je witte ftrecpen, of pilkels, op een bunitic grond.

De Rood.Opg:

$$
G a^{n} X / l \text {. }
$$

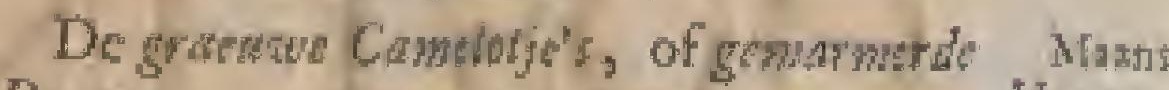
Doyers.

Van deze hebbe verlicheide zootren.

\section{Poelo Rbins.}

Heb van dezo nog twee andre zoorten, dan hics gemeld werden.

Gribde Camelofe"s, by Letter I4

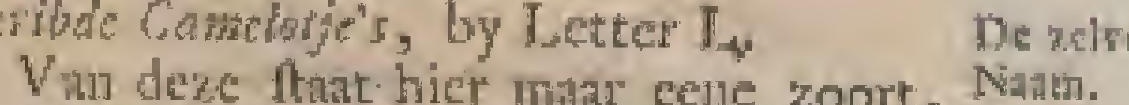
cn it lieb er twee a drie zoorten meer afe

De sumpte gerbate Doyer, by Letter M. De heive

Alle deze zoorten vilten op den fock Nam.

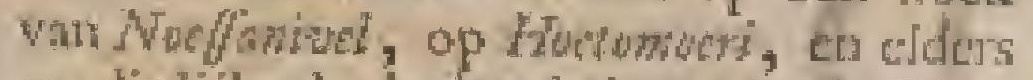
op dit Eilend, inden Jwhom, by te $/ F_{j-}$ wifoe, als ook op Hihot.

De gerihie Doyg met zwarte en witte De aelwe vlekken, Deze heb nu niet; dog ith heb bier uf meer, de graeuwe geribude en gekatcelde Dojer, die zeer zcldzatim is.

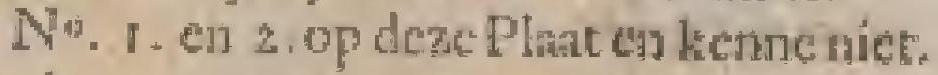

No ${ }_{3}$, is de jechic Man-Hown; die De zelro hebbe.

No. 4 kenne, dog helbe die nut riet, gelyt dit ook geon Oolarfly Horn is.

No. , . cn B. kenge; dog licbbe dic nu niet.

$\mathrm{N} o, 7$, is de breede 2 wart gebondecte Doyer, dic hebhe; als ook No. 6.

Ik heb 'er verficide meer tot $N$. 7 . behorende, en nog wyf verfeheidegeparlemoerde van binnen, en etrelyke gemarmerde.

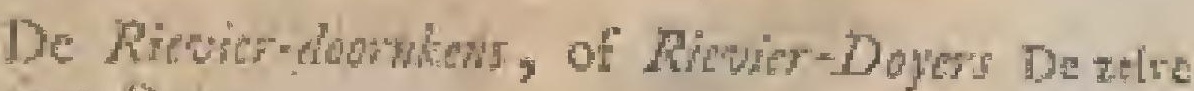
met Downs.

Onder ateze zoort พan Dopers bohood ook cea zoon r, die Jicr nier gemelet ltast, en welke it meer bezir, en die if noeme. Batasifhe Ahkwhen; zynde glad ge- De zelve

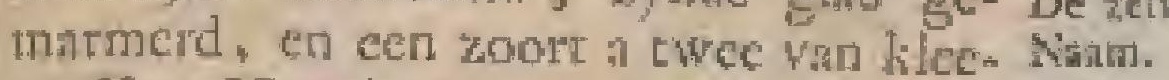
ne Fort-Toomkens.

De Dover valles in tea Jhom vat Awbona.

$$
\text { Cap. XIIL PJaAt XXII. }
$$

Decasket, of blomksod, ofdegelownde Odenthop.

Vun deze zijo "er twee zoorten. Eene met, en eene zonder thetjens.

Men vind ze veel middelbitr van groo- De te, als $\mathrm{No}_{1}$ I. op deze Plata geteckend; neheyut dog de groots iltet hese onderlichcide storthnetiens loed. 


\section{OOST-INDISOHE ZEE-HOORNKENS.}

\section{bulbete Nadm}

netkens 'er op, en woor al te le leire zyn wel hec zeldrante.

Ook Is 'er een zoort, die ik van dit Jahy" eertt heb lecren kennen, te weten, ecth widdelbate zoort met ectn nerje, en met zwartagrige dwars-banden "er op.

It bezit de groote, de middelbare, eń de klecte; en geloove, 10ot zoo werje ik

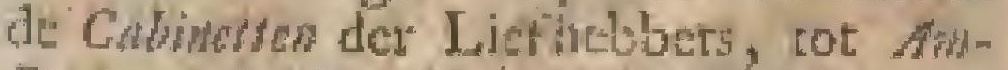
Ferdem, in den Hige, tor Hodrlem, en dders befinouwd helbe, dat ils het klecilAte en traeyit geteckend Srombodid tar 'er bekend is, ecn lraltwe pink beneden lang, cnmecennetic, bezic, ook heblye nog twec paren, dic wat grooter zyt.

Deze zoort vale op "t Eiland $O$ ma, op de saritad พun 't Dolp Harodo, ooli op "Dorp Ona.

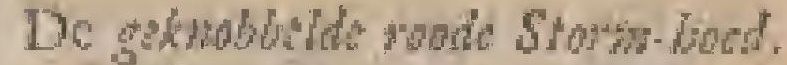

Bezit twee parr wan deze.

Dezc valt mede op dit zolve Filntad, als ook op de Eilanden Mamin , on Lohoo, en wel "t meet op "t. liland Bagron.

Her is iet zeldzams, dat ile, in de zes a scyen en dertig Jarren, dac if-, of is Oofl-ladien, of hier te Lande, een Liefhebber "an deze zeldzasabheden geweeft ben, noit een klecne rods Storm-boed ergetis ontmot, ch ook noit gehoord, of gelesen beb, dat zy by iemand gezien is, of van ierand bezcten werd.

En rogtans is het zeker, dat zy "er" ecrtt klew moeten wesen, etr zy zon groot, als men die zier, geworden zyn. Higter noet hicr bywegen dat ik den 6 . October, $A^{\circ} .1723$. de ecrfte mal ғал myn leven er ecr, ontrent ecu wuylt groot, dog klcencr en dichter van knobbels, das de Ooferze, (alzon dit een $W_{e f-I s d i f b e}$ teheen) ontmoet heb, by de Fecr Fowel, cen wan de Medeleden pan ons gezellchap hier, zynde de zclue zeer fracy; man na evenmatigheid, wat dik van Jip. Ook heb "el" zoo cen by de Hecr Sebywat gerien.

De zelve Turk Prier.

Natin. Het geneene zoort, the rood is, heb een prit.

Van doze zeldzame. zoon bezie bik ${ }^{5} \mathrm{er}$ mect, nog een lichter pirs, ledes byzonder van teckening, en ils weet niet, dhe ik "er onder alle de Liefthebbers hier te Lande, welker goed by my gezien is, enige onrmoer heb, dantweet drie, ecn

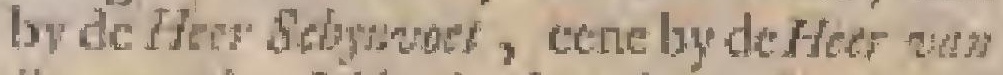
Serguther, Lid uit den Ow-Rrad tot Dorimely, en by myn Her Fuer alhier. Ook heef dic Heer Ao, 1723 , een phit rect leene diergelylic uit oof-Jidian, hoedanige noit neer gezien heb, gekregen, Een zeer kleen heeft de Heer Crenta.

De Achlige, of gehomite Cram/che cosken.

Hitr van hebbe tween driederley zoolte, zynde dic cene mar met cenerrey, en de andie mer twee reyen doorns getecfiend. Onk heb en bruine, en een gracuwe zourt, val de bruine cen met twec, en een mer dric reyen dootns, en de witte zonder de zelva.

Deze wallen op "c Eiland Corom, en

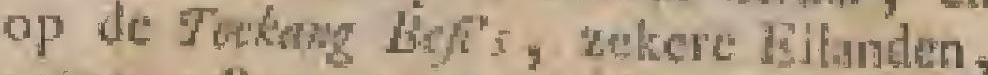
oncrent. Bortom ; als mede op it Lilland SWMARr.

No. 2, cn 4. Jenne, niet; dog No. 3 . zal naderhand onder de Wefler be fownhezs 멍 zyo plates melden.

\section{De Swatzers broct.}

Deze vallen of 't Eiland Gerwo.

Van deze zoort heb ik 'et neer.

"Twee paty" graeuwe kolt-getakte.

Een pailt wir en ros, en ecen kleanc, zece' teldzain.

Twec par zwarce zeldzame hortgetalite, met eenzecr witte grond, en zeer zwarte wlekken.

Vicr para zuste zeldzame fort-getakte, breal wan wlekken ; en

$T$ wee zeer belder wan verwe, zeer ther $k$ by de andie uieltekende.

Drig pair gratuwe swirzors-Btodks zonder tatsen, gechugig, en wat Jwart van knobbels.

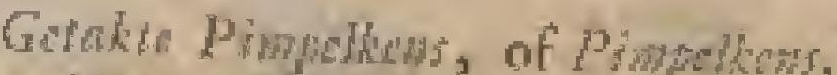

Doze vallen op her Driwa-Litand, ontrent 't Eiland Oma legrgende.

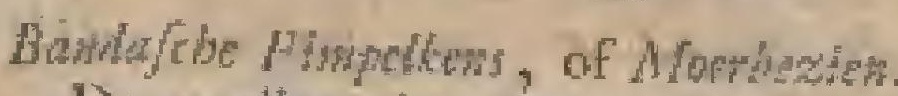

Dere fialten nict alleen in

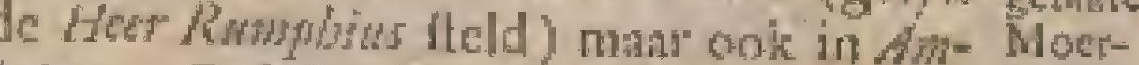
twin. Ook bejite it dat wan vertehei- beyen. de zoorten, Janrelyk:

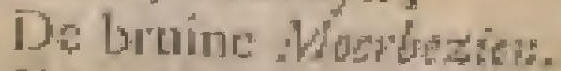

be violetec dito, zynde van bimen 200 .

De gede Mootharid, dic appetbloezen wan bisnets z

De gete wit wirn bimen.

De Bultard-Violette Marbation.

Newens nog verfohede andere wat verfehillende werwert; en nogeca zoort *in gedogrnde Thinkes hier toe behoorende.

Ook heb mu onlangs by de Her wan Segowan, cen witte Mocrby-Nodr, die gehed of zich zeluen is, en na de vorige nict gelyk , en nog cen wic part by de Heer do homing, antmoer. En ilizelíhels "er nu onlangs cen par gekregen, die graeuw en laig-youp, onder of van binnen liche-Purper on zonder weerga z.yn. peifithe Natrieln Detelve Natich. desiorएट्11-\$12.

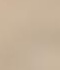

Eertie

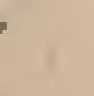

.


Fung-

putiche

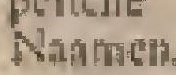

Diro.

$\$ 22$.

\section{Indiche Naawein.}

Nowdige Pinpelkens.

Van deze zoort, valliende op Leytimor's Stranden, bezit ik" "er werlcheidene, dic verlichillen.

De Klene Gel-Mondem

keene Deze liebbe; en, buiten de gemeerie,

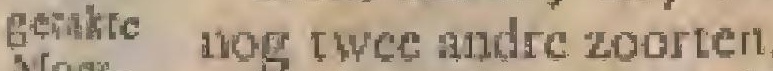

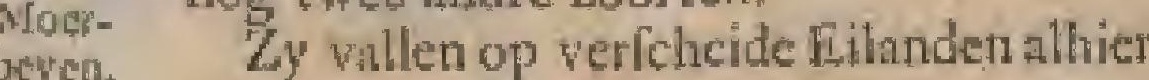

Oor. Harge Ooren, of Nawikens.

Hoons, Deze vallen op de Kutt var Hitoe.

of Oor- Van deze hebbe twee verfeheide zoor-

liezej. ten van de getueene, en buiten de zelve hebbe nog een zoort, die wel de tireyfte an zeldzanmite is, en die ik Peoken's noeme, ond dat zy wel wat ni ecn $P$ erer gelyken.

Padde- Parderi

Hoosss. Deze wallen in den $I n b a n$ vaf $A m b$ ond

Hoog- $h i k-V_{\text {njed }}$

Natereth

Sethild- Knodidetw. pad-

No. 1. Op deze plate geteckend, en zal dic onder de Woflowebe op zyn plats milden.

No. 2. ch 3. De Schiphds-fant of de

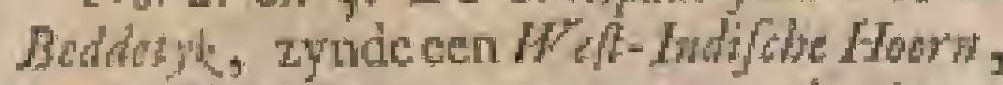
van welke er ecn a twee praren bezitte, gelyk op zyn plats zeggen zal.

No. 4.5. en 6. mede-zoorten van dicn.

\section{Gat. XV. Phat XXV.}

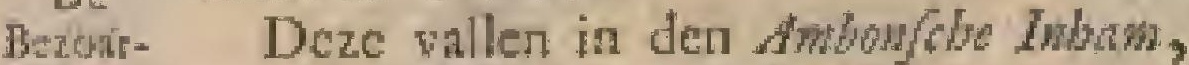
Hootin. en voomamelyk op Horkonido.

Buiter dere gemeene zoort bezitik,

Drie Appelbloeffene, die zeer zeldzinam zyn.

i) Babisms.

Wene Heb deze, en wan dezelve ook zocr gurlutite kleene.

lyezar- Dezezyn er ook geribd, en byua zonder vlekken, die $\mathrm{N}^{\circ}$. $\mathrm{F}$. nangewezen werden.

De Bedlekes, No. I. op deze Pluat Destour angehald.

te Bezoar Wan deze heb ik de groote en de klecHoom. ne zoort; dog van de groote heb ik -rog twee zoorten meer, dic its noenc.

De groote zeldzame Bedlekws.

En de gebandecte Btaldeks.

No. 2. De geltrecpte Beddedess of $\mathrm{Bl}$ zonts, kentue, dog hebbe die niet, ook houde dat vow geen Ooft-Indifcbe, of Ambanche Hoorn; dog lacb deze zoort lyy twee a dric Liellhebbers hier tc Lande, en nog en andre zoort op Buawia, welkers vlammen ingedrukt, of ingekorien waren, en by de Hoer $V$ ou ook een zerer fitey patr "er wan gezien.

\section{E L I NG DEA}

Jndfob Waames.

Euro: pelifhe Nitan

No. 3 . en 4 . zyn mede geen Opfarfes mate Wellerlob.

Soonplons.

Van dezezyn verlcheide zoorten, by Dwark

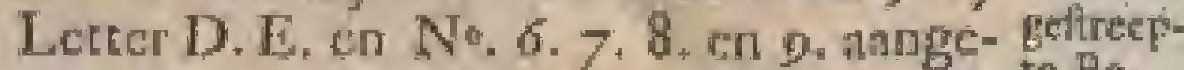
wezen; war vat No. 6 . en de latate te Bezoor voor al wel de zeldzamite is en win welke ik "er vyf a zes, ieder byzonder van mad, bezicte. Ook hebbeilewerfcheide zoomplens, die wit zyn, enweinig voorkomen.

\section{Cap. XVI. Plad XNVI.}

De getade Casket, of de Oenam Hown. De Krü-

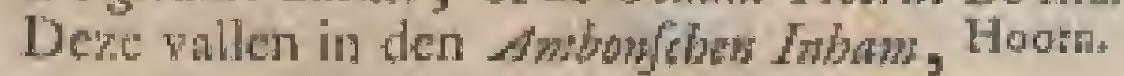
en op neerandre Eilanden; $\operatorname{dog}$ op Aros, en Noen Gmanca zyn die zeer groot; mant de kleene, die wel de fracifte zyn, voor al als $z y$ rich wit wan grond, en zwart var takken vertoonen, vallen in Bamda, en in de Eilandern, de Toekang $B e f i s$ genothand.

It hebbe de groote, en de klectic.

Het Harte-Howatic, No. I. getcekend

Hier vun heb ik "er verflicide, en een zoo groot, dac ik noit diergelyken wetc gezien re lrebben.

De 7 enh how met of zonder hair.

De gedroorde, of deroode celrande Perr. DeVoet-

Var deze zyn 'er', die rood, die geet, Hoon, ch die grasuw zyn, en weele met Molch of de gem "er op. Pęr.

Dexe drie zoorten heb ik, en wan de lante drie verfohidene, en nog twee andere zoorten op zis zelfs.

Zy wallen ontrent $B a t v e$, in den $A m-$ bostchen Fabno

De sutre Drat- Bown. De Bran-

Il bezirte niee alleer deze zoort, die datis. 2 wart is, mar ook zeer pechnderc, tot deze toort behoorchide; en dara onder

Appebloctreme met, en zonder Takien, Purper-getakte.

Zwarre glidde, zonder Takken.

Geelngige, en reel meer andre.

De gelligte Bramdaris.

Dentipe

Dit is en graeuwe Hoorn mer een Nami. brede lip. Ik heb 'er drie, cu vind ze frier niet geneld.

Het Seorpiochit.

Dit hebbe, zoo witte, als zwarte, en wel werlcheide van ieder, ch elk al wat byzonder.

\section{De Gedrobede Pert.}

Van deze zyn twoe zootten.

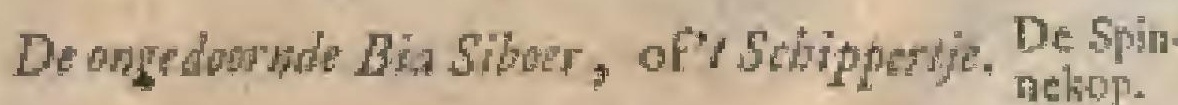




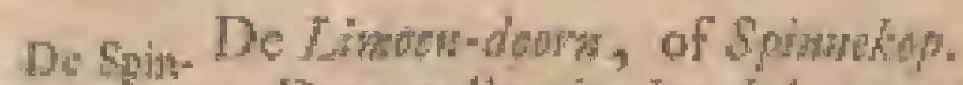

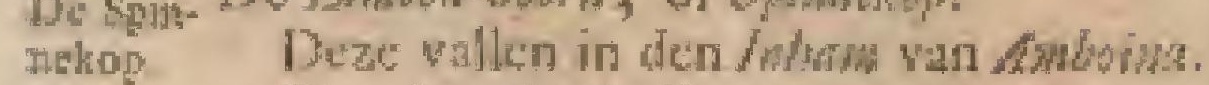

Ven deze bezit ils meer.

1 Panr wite.

1. Pasr zeldzane zeer kort - gedoornde.

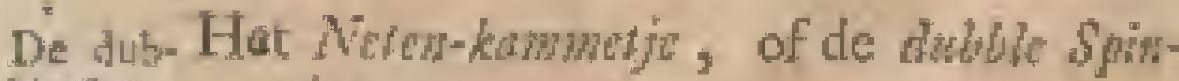
be Spin- widop.

netop. Dit is zeer zeldzam. Het walc in den

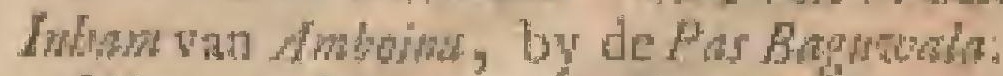

Hier van bezic ik een fracy par, en nog cen, uitumemende grootc, cn heb'er nog cen part van gehad, zyride zoo scel alleen, ats vicr Liel heblues, hier gemeld, te zamen toen bezaten.

De perdre Hoons, hicr by No*2.4.

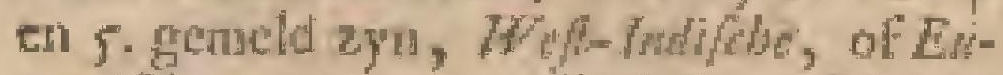
roveifo, was" wan dithalyen hier ma breeder.

Alzoo 't Cap. XVII. allect over cenige Dekzels zan Huepias hindeld, gann wy over tot het volgeade.

\section{Cap. XWII. PlaAl KXYII}

De De genlekte Orip-Woon.

Eclate lik hob tueer, de groote geribde bruiHoorn. ne zonder vleikken.

DE [pier witte zonder wleklken.

lis con wismustende groote braine zonder dito, behalven dat ik nog een bruine zoort, die ongemeen groos, en in 't Cabivet wath de Heer vah Serwart nut is, kenne.

Dege- De Dik-liphige Orte-Hourm.

katubel- Hicr van heb ik ${ }^{\prime} \mathrm{er}$, die dits, en ook de Bel- die zeer dun xym; dog buiten die germeeHorr. ne zoort heb it 'er nog een, die zoofyn, De als zyde is.

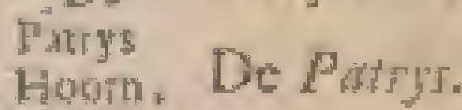

of the Kin-

vite- $\mathrm{E}_{\mathrm{T}}$ *

Dit aelie De Ajow-Gisl.

Natn. Deze ryo'er, dic geltecpe, andre die angeftrepe, en een derde zoort, die fichoon gewaterd, of gemarmerd $\mathrm{z}, \mathrm{n}$, en nog ecm, die ingegrocft is.

De urie lanafte zoorten heb it ; dog van de gemarmende hel it "er eene, dicrgetylic ik van tweyherd mote meer" gow zien heb.

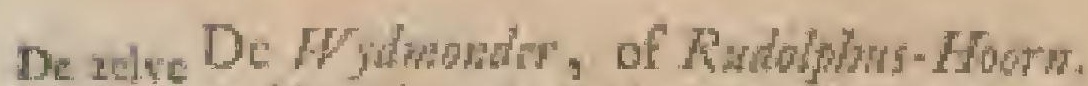

Naan. Van dece heb ik 'er wel drie a vier byzondare zocmen nicer, dith hier gemeld vinde; en onder andre tonamige, die glad, en ongebandeerd, andre die getinndeerd, weer ande die geknobbeld, en cokeen zeldzame, dic witagrig gebalsdeerd is Ook cen panr witte, djo wan binnen pars zya; ch thog ectn grootc vant the zoort, dis zeldzam is.

\section{De $K_{4}$ of}

holbo Niswew.

Finto= peifliche Nantsed. Delinot-

Wan dere heb de genectac witte, ook Huorn, de zeldume Cisoen-gecte, cerige glad, of de

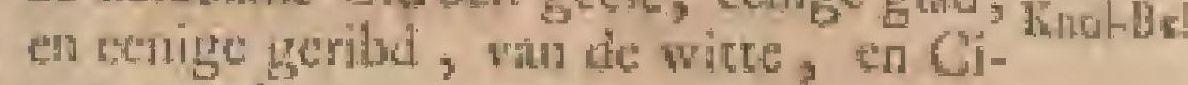
truen-gete.

Buiten deze bezit ik meer.

firn geribde bruine.

Een A prelbloefienagrige

ben ongemeene en groote geribile, dicos weerga ik net kente.

\section{Het $H_{\text {ith }}-E_{y}$.}

De zelro

Hicr af zym werfcheide zooren, zom- Nain, mige zeer licht, andere dontates wan wer wo her Achaco teckening, ook de Kivits-ejecen met te Bakje. banden, dic zeldanam $2 y n$; dog beziute meer, dan die Jicr geneld winde.

Het kleco Spier-wic Kiviç-Ey.

\section{Blatisken.}

Deze vallen of Holdhes, op te Eiland De retie Oma.

Van deze heb ik de Spier-yitue.

De gebanderte.

De Staten-vliggetjus, dic zeer zeldziam ayn; en diar van drie groote, en cen kleche.

De Ton

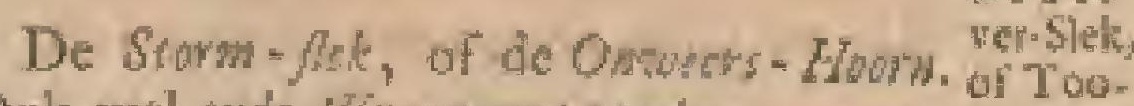
Ook wel owde Hyen met mades. Terar.

De $F_{y g}$, of de $L y H$.

DePeet.

Hoori,

of Spratiliche $\mathrm{w}_{\mathrm{y}}$ Befl.

Het Nadikts.

De:

Wervel.

Hoorn.

of Per-

fpetief-

sick.

De Arolaria Major, of de grouk Doas- De groon kens. phl

\section{De Kene Dooshos-plet.} Silk $k_{\text {r }}$

De kilesne dito.

De Stangerjes. De

Van deze vind menvericheide zoorten, but-5let. als, brutine, witte, gevlatnde, cn meer andre zoonten, die ik beritic, behalven nog peel nodre, dic ik nier bezit; naar by andre Lief-hibbers gezicn beb, hocdemige dic, by de $\mathrm{l}$. en $\mathrm{R}$. hiev getee kend zyn.

Ook befooren nog velandre Slekken is de Pottdie heble, hier roe.

Zy vallen op Ceraw's Noord-Kxf, an ook op de andre Libanden van Ambrima.

Het Kogken-ogs, op deze platar met.Ler- Dethe ter Q. gereekend, en yerkeerd ruet de getute

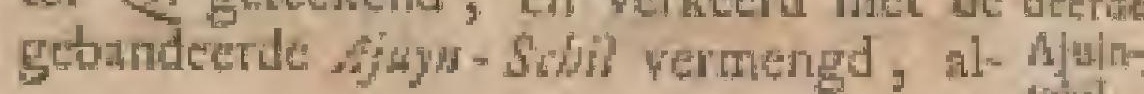




\section{4 \\ AMro- \\ pestich

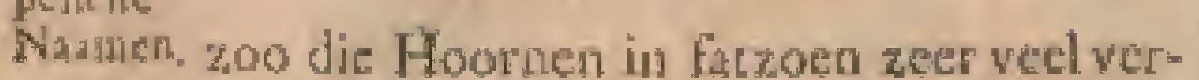 chiliers. \\ Cad KIK PTat, XXPIL \\ De De Arocjehe Tround. \\ Arocie Deas heh mu niet, matil heb die cer- orTrunt. ryus wel beeten. \\ pet. Jdeiti. Gunkt

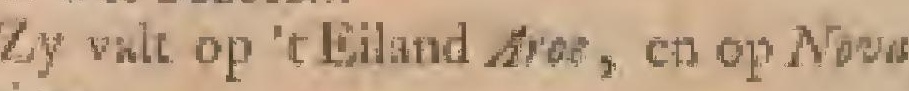

\section{De Tranter, of griph-Lown}

ran deze bezic ik "er verfeheiden, die ju aller deelen volkomsin, en tuicmuntend vin techening zyn, en woor al ecne, thens Weergac it nier kenne; an jog eenc, de Icleerith die kentat.

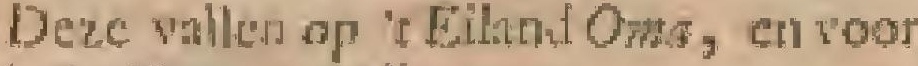
al in 'c Dorp war die diatis.

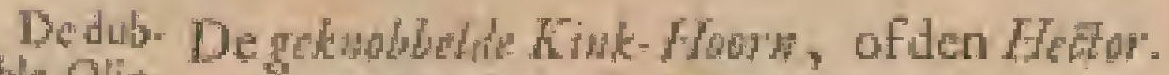
ba Olic- Wath deat heb in "es" dric.

De De roul.geknobelle Kink-Honn.

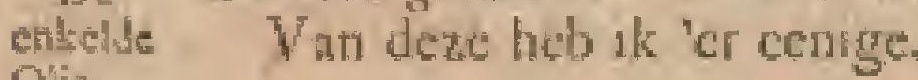

Qhic-

koek, of De Ord-koek wat hosmen.

de rehul- Doze alle hebils; dos heb nog andre

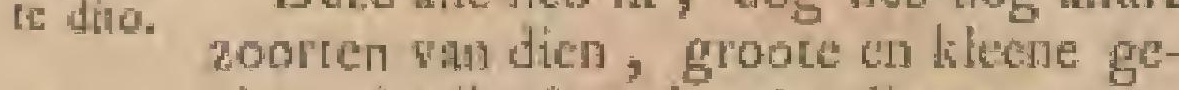
zich, diw ik niec heb; dog lit waren geen Oofroplas

De cefronde Ohe-kon, agter ath op de

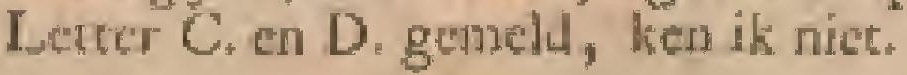

De aelve De bathard-porper-sid.

Num. Deze walt in den lmbaw van Ambome ana de overzyde van " Catteel Vietoria.

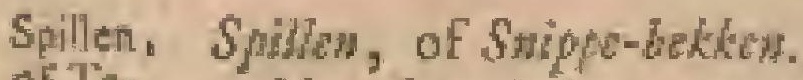

of Ta- Van deze is 'er mog ecn groote glatide

pylien. gehrobbetde; cn ank nog em byzonder gronte zoore met ingekorwane riblocis, dic it bevorens gehad heb; thog die ut de Heer win Segrubro beaic.

Ook hebbe ik nuer, dan hier gernete werd,

De Temeromentupid

De zeldzanc dume bruine klecnestor.

De kiecne geknobbulte dico.

Dit is ech rosagrige Hooth, die ved larter, ager zoo lang niet, en ook wha cen Sijppelbes voorzen is.

De retic De flompe Sirit.

Nami. Vam deze heb tocer ean gedagtige.

De aclve Hastige Dh-hing of Bardmamekns.

Nàn. Dit folytud een Werus-Hoorn te zyn. ก) nitet.

De grootlle zoort var Ramblim hen-

De zelse De duble Parsubrom.

Nงมต

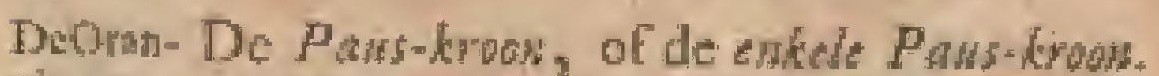
fre-pen, Deze beide zonten, op Ceran, op felpe. Gajbdo, ca habey, en elders vallende, Alyter.

\section{E L I NG D ER}

Nallihe Nawn.

Fute-

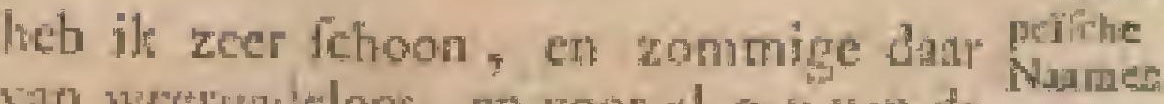

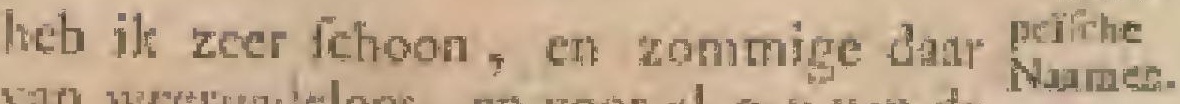

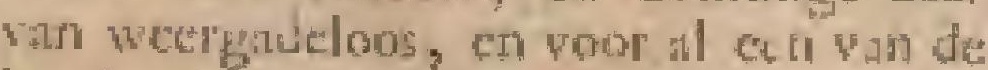

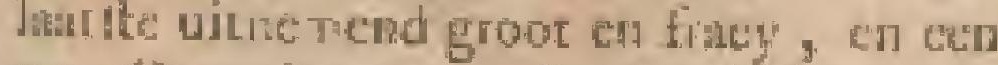

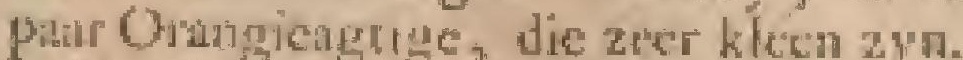

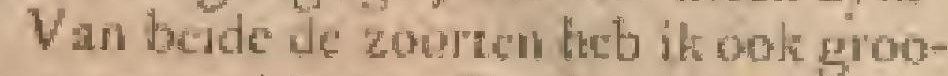

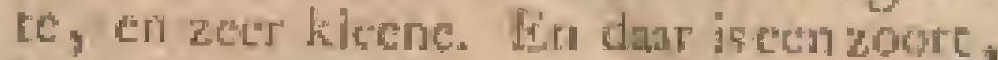
but nut gemeld, dic zeer heldem-rood

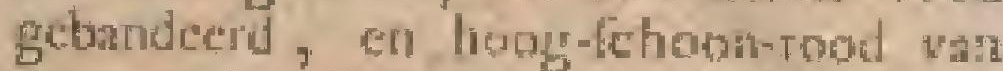
duppen is. dic ils beze, th die ik zela7alas berinde te zyo.

De bafcard-Paws kion.

De Bablowifob Tonms.

Pintin-

Bethince de fermene, bezit ik hier ded. vad strectr,

Hen leper-verwige wit-gefpildedde, die wecigindeloos is.

Ech wille.

Ook hobbe er, die zeer klech, cr zeldzum

De geterthe klewe Tromper. De RFftesbiry. Hoñ

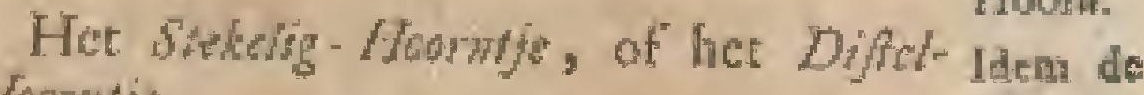
Hoorntic. Lelpe

Vas deze hebbe ik bruige, en wilte, Nam. welke lantle soort ik neer hebbe, dan hier gemeld werd. En de Heer wan stre gua wit bezit er ecn puth, dic ongemeen fraey, wan binteng bletel on al uit pewert, co 2 y wuper un dwdin gezonder zyn.

De Zer basen, of Kirdakent.

DeBond:

Vin deze heb ik cen root meer, als pen; ow hice gemeld ale.

Tor deze zoore yan 7 an boten mige de

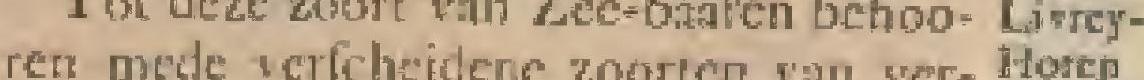

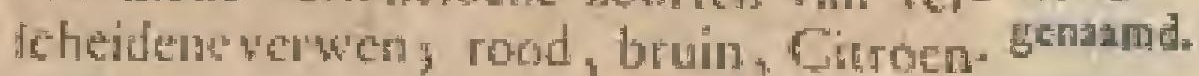
geel, Orangie-agrige, enz. die bazime.

De Bewes - J h new

De relve

Heb 'el Ewee aborten vat, en nog Vam. mect, dan hier gemeld iș

$$
\text { De Baravilde Bocren-gargen. }
$$

Fet gebarderd Trompotic,

Hic kleen zwart gebardeerd Hoorntic. Nam.

Heb "er" eet par van, ca dix jombekenkt

Het Fingrie.

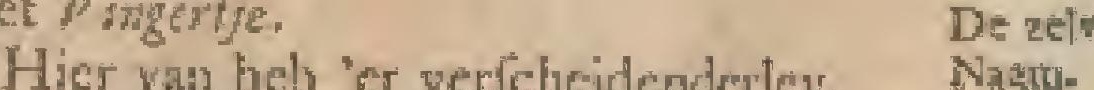

De Gamon, of her Tormer.

Dostind-

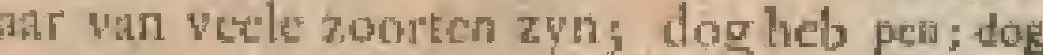
'er Lwee Lienourenda "Zoorth vali in leng- deze

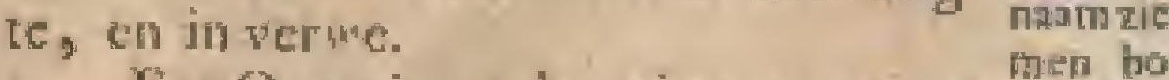

Een Orangic-roode, witte, ct zuwat- ven al by gebandecrits.

Een 1 itrocin-verwige met roote en deken. wite batiden

En behriwan deze litbbe nay neet.

De xwarte gladde now gecle bunden. 


\section{OOS $x$-INDISCFE ZEE-HOORNKENS.}

IIIT:

peitche

Nusract,

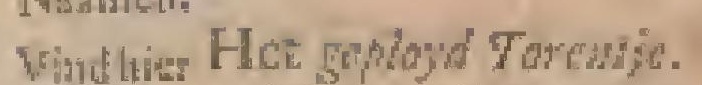

fren Fit geribd Tombs af "t geribd baf-

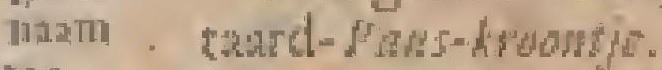

tot.

De

Sthicil =

Vlag-pen

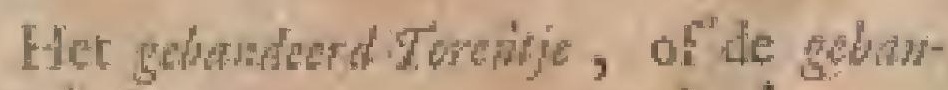

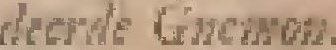

Warn deze datalte zoorte hed ik "er ver foheidenerley, sh dichalyen werfohedo mect, dan hïn yemeld Ranil; als mede

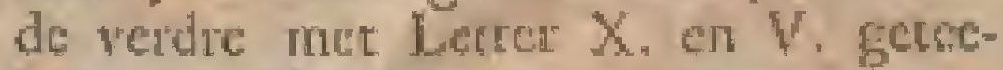
Jend, welle lathe equ roote wat de

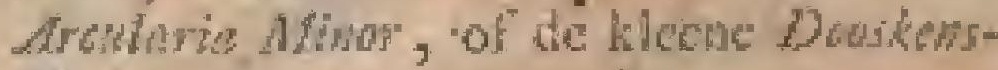
Fown, is.

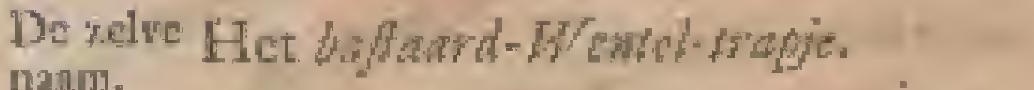

DeOTut De singho.

Hown. Dir is cen Crylow/fe Hown, die me] gezien heb, en kenne, maar nie berit.

Ontrein de Pecr-Wiflohery wan Foercory, wangd men zeer veel vin deze 9 hat

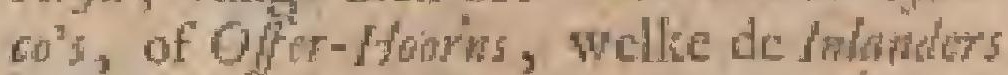
hier, en ook de bugalms, tot arin- en dur m-ingem, col de latile tot let lohieten met de boog, gebruiken, on zyn dic fehoonct, ats win hes belte Yvoil.

Goder dexc Hoorss vind men, neunIyks on de honderd Juren ceos, een Konimgs-Howri, dic wn gedante wel evej ectu, als een andre Sjanto; dog even cens als de werliterde Hoorn is, en zich

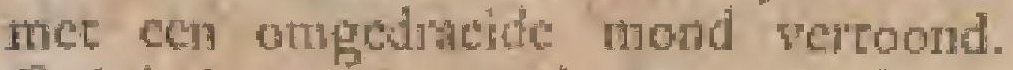
Onk is hy groen wun butuch, rood wath binmen, gande op de grond rome, wat. op dian slle do andre berm rolgen.

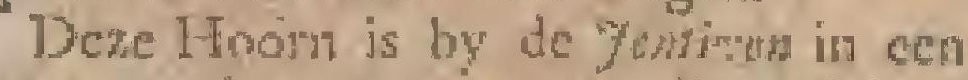
groote agting, ch zoo weerdjg gefolnt,

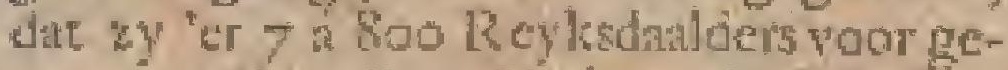
ven; en uil zulken Fionon wicrd de $k_{0}$ njug wh Golcunde in de vorige cyden, rocin die nog den Ryk op zig zelven sun; gevilte.

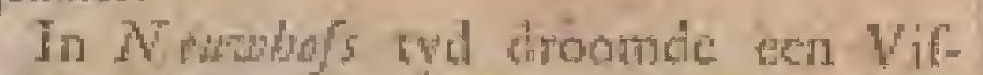

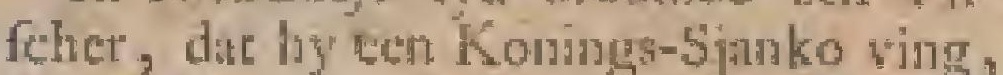
"E gecil ly kegen -2yth thaker zeide, die, zoo hy dic vagen mogt, de helfe ser van voor 2 ig besplat:

Dages er an ging die troomer mer den rhderen wit Wiftches, en" vimg "eJ con; dog wihtedenaluden "erices valu gcven. Hy riep Jem wel voor "t geriche; dog woggeloos, alzoo ly gecn bewys wan yyt recht dita wat hit.

* Hy verkoge den zeluen nan de Hea Whewhof nor i 70 . Ryhsdaldets, en cen wat de Rechecs buod hem andtonds 20. Rykstalders wintz.

\section{Cap. TX. Plat. XXX.}

De Mrathricm.

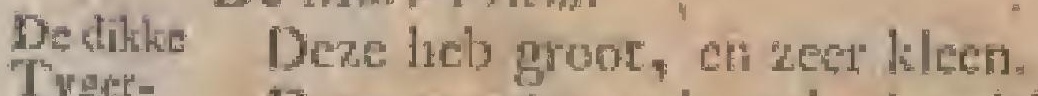
Tyat- Drze werten ook wet uitgedrild, co

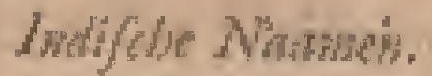

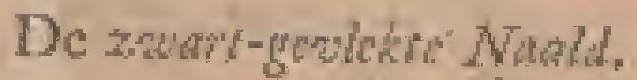

De graenterarige Nadd.

or toodagenge met banden, wonde

Ith heb oof meer ectie, wie Citroenged, zonder vlakiken, en gebandeerd is.

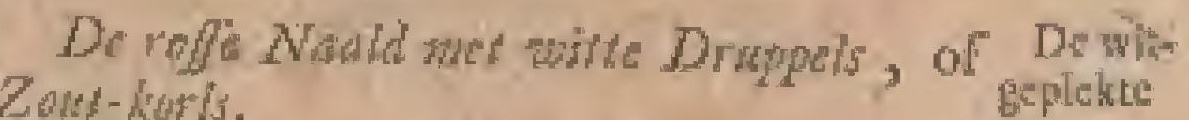

Van deze heb ik sea vyf.

peri.

De gedoonwle Nald.

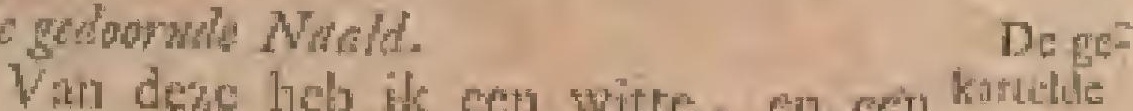
grieuwe.

Pinteritus.

Natis

Van deze syn "er witte, en bruine val penned. Tellye:

Bezit een parir zeldrame brune, dog geloove dat her $/$ ofl-thdjole zy.

Do Gegranterdo Nadd.

Defone Nold, of Zegl. Nudd.

\section{DeGc-}

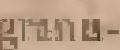

lecrdets

Nind

난다.

De Zayl-

Nald:

Thyturs.

Heb twee a dtic zcldzane, hier, onder pes. natift behoorende, mecr.

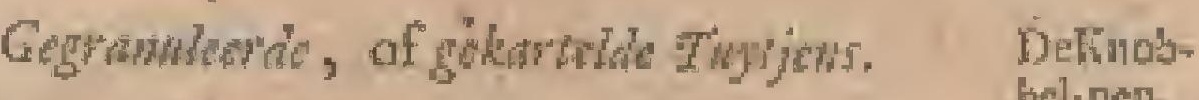

De Trowndfobrof.

Hier vin orters ; die niătis. f. fracifle col zallende zuyd-zyde, op Kcllemors: Ool vallen "cr' zeer groote op de Ejlanden $7 w a$, ch Simatra.

Th bezit een witte, die zeldzan is, mect.

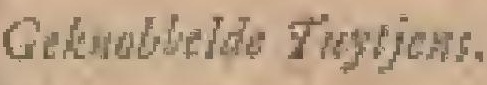

De Gedoogule

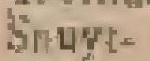

Brenta Tayjoms.

p되].

De wire Tromshe forogf. nit: Indiche

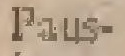

De Rierer-ndald, of Sinot-Hoorn. De SlakIk heb cen zwatte, ef ecil witte ge- ken-pem, bandecerde.

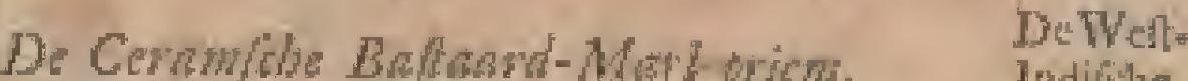
1tictiche

Deze hebbe nu mede roice. P'ause

- De hoble Moras-nath, of de Keep- Een wall.

Hebbe mect, dan lrier genctd Atitin, salake-

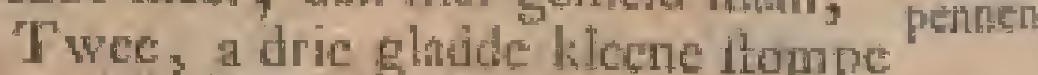
gebin deerde Notalden.

$X x$

In 

lem.

Een gecl-agtige.

Eea hecrlyke gewolkte, en hppelbloeflente.

Eeñ mít econ icdele teekening.

Een Jileen zeer fracy getcekend Hosentje.

Van deze heb it "er drie, en het cene felynd wel eca Adnuthal vain deze zoort te rytn. flase.

Ook bezitte ik meer, dan hier gemeld

Twee part roffe geribite wit-gematmerde groote Ruipers booren.

Een ning grooter rolle ghidde, gefipiklelde uitmuntende Kuipersboor, mede als een Adrmirat te rckener, en maitt ma de Orangic Adniranl, lanewel hy langer, en Boor-agriger is, zweenende.

\section{Cop. XXI, Phat XXXK.}

De Degrote getronds Bat, of de Tepllat. Tegel Hien van heb meer:

bak. Vier uitmuntende bruin-gevlamde op ean geele grond, en ook een gebundecrde 'er onder.

De klecue $T$ erdhat.

Deze wallen op Cerim, cn heb er wan de groote verficheide zoorten, en wan de liluenc mede.

\section{Gede Burer-tyegen.}

Gede Bezite meer, don hicr gemeld is.

Tudeth Eern wice Boter-weg, mec treele zwute fpilkels of lippels, dic cygener eot de wite Boter-weggen kan gebragt werden, dog plants hen bier, on dit hy, wat geel van grond is.

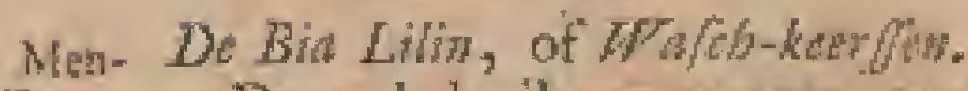

nille- Dete heb ik ongemeen groot, en Tooten. fohoon.

De De arile Botcrowgen.

winen- Dichier $k$ walyl de Mulycq-Horen geTyges nand werd.

De Tygers.

Woik. Vyger deze bezit ik deze ongmeene bogm. fukken:

Een heerlyke donker - blucuw gewollete.

Een mer cen zeer brectie wittebud ii) "t twidden.

Een Cyfrer-hoorn, rosagtig, watr op" men ziec ftan deze getrllen 717 . 177 en, angeketrd zynde, 877 .

Nog ecen dito, met een emliel'dicrgelyli getal.

Wolkiens.

Agmate

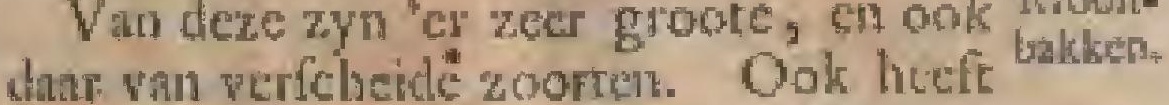
men vericheidenerley kilene; dog de neldzatumfte zoort zyn,

De roode Wolkjens.

Dic ile ech patr meer bezitte, en wan witelke ik hier micts gemeld vind.

\section{De Ejken-bodts-Tou.}

De 고레

Hebbe deze, en ool die, met bander, maam. dic zeer zelizam is, wat vata 'cl zevet heb, en ook meer.

Een gecle.

Een roffe.

De Olyon-Toot.

De relve

De Obwon-dand-Toof.

De zelte พaาin.

\section{- PHA XXIL,}

De wilde

De Vleder-ways.

Mulycą:

Van deze zyn "er wer[chcide zoorten, hoorn. met en zonder banden.

Ik bezic 'er van ongemene fracije roodegenamerite, groote, enklene; ook gricuwe, gecle, blteuwagige getpilkkolde, zwart-gewolkte, on dierlialwen zes a zevenderley zoorten meer, dan hier gemeld ftant.

Wan deze berit ik nog niecr.

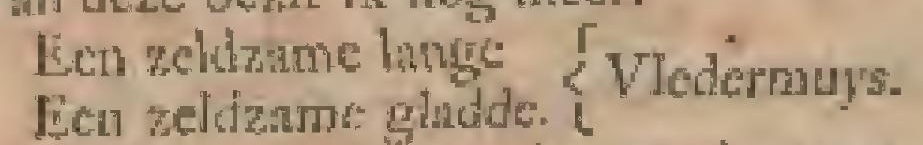

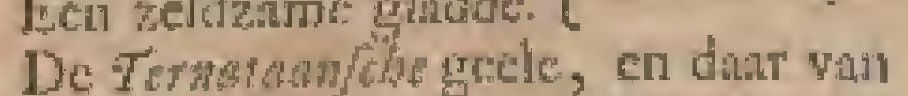
twee zouticn, zynde decene zoore rolfer.

Herpew.

Deze zyn "cr verfchedtencilcy. Bui- co ook ten de drie gemeerie zoorcen, hiet ge- Harptin. meld, met crizonder tanden, iteekcnuit.
De Appelbloczeme
De lever-verwige.
De rebandecrde.

Deze zeer xeldzane bezic mede; on hec is vier all vat Janten geleden, dat it ook cen witte had, die il noit neer gezien heb.

De Ring-boors.

DeHarts:

Dany" zyo "er ook met gecle banden, "Tyger. die hebbe.

Var dezc gemeenc zoont hob ik "cr", die buiten gemeen wit en, zwatr, en ook zecr groot wat wlekken zyn; en notgeen, 
OOST-INDISCHE ZEE-HOORNKENS.

uitmuntend wan witteen zwarte teekening.

Daur zyn "er ook van deze zoorte, dic ros whllen en zeer zeldzan zyn, welke ik meer bezitce, dan hier gemeld vinde, to weten, twee ongemeene rofic, en nog enr ongemecne $z$ warte en witte gebandecrite.

War by nog votgen moct een gecle zoort, die ilk heb.

Zy vallen in de Uhaders, en op $H o c-$ washobl.

De gelartede Ring-born, of de Segrye horis-born.

Van daze heb ils "er. cwoe meer, en deze zoort is onbekend.

De tutive De Harls-boon mot banden.

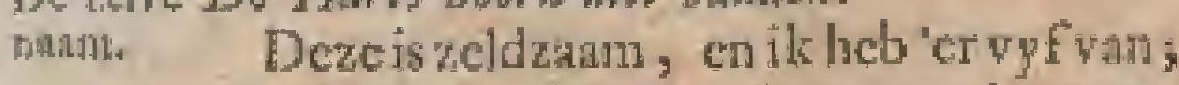
dog bezit verfeteide uftmuntende zoorten, by Rumpliws nice bekend, en die ik ook zeer zelden, en zommige noin inces, hebbe gezicn, als

Den Admiraal wan de Harts-hoorns mer banden; cen ongerneen fturk, whate en hice en doar met wit. Hier van theb "er cen.

DenSchout-by macht. Deze 垎ajede zwht, en mer vleklen; zommige met ecn nelje. It heb 'er dric jagr van, iederbyzonder, en

De nagemenene leverwerwige Schoutby mache. Wat ran ik "er een lieb, en noit cen andre, din by de Heer Krggelan, (nu in handen van de Hecr wan Seguantil) en "er nog ecr elders, gezien heb.

De zwarte Harts-boon met bander.

Deze is mede zeer zeldztiant, zynde zecr zwart vath grond, en donker van banden; fialr de gemeene wit Fan grond en fyn-zwart win batnden is. Deze nocme it de ViceAdminals wat deze zoort, en bezit er zes a zeren tran.

Spelle- De Gude Iaktis.

werks

Hooras.

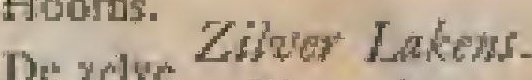

Dan. Van deze uyn verficheidencrlcy zoorten, die heb, en nok enige, dic nier bezitte; dog heb meer, dun hier gemald werd.

Eien Appelbloczeme.

Hocwel hy wat na een Brumet, of Hoendlet-veder, gelylit.

De retve De Segru Houn.

tamin.

Deze bezit meer, en wel vyf 'er vat, ioder byzonder wan teekening. It heb 'er noit cen meer pexien.

De relwe Gepleke Kabjon:

טล⿻上丨เ

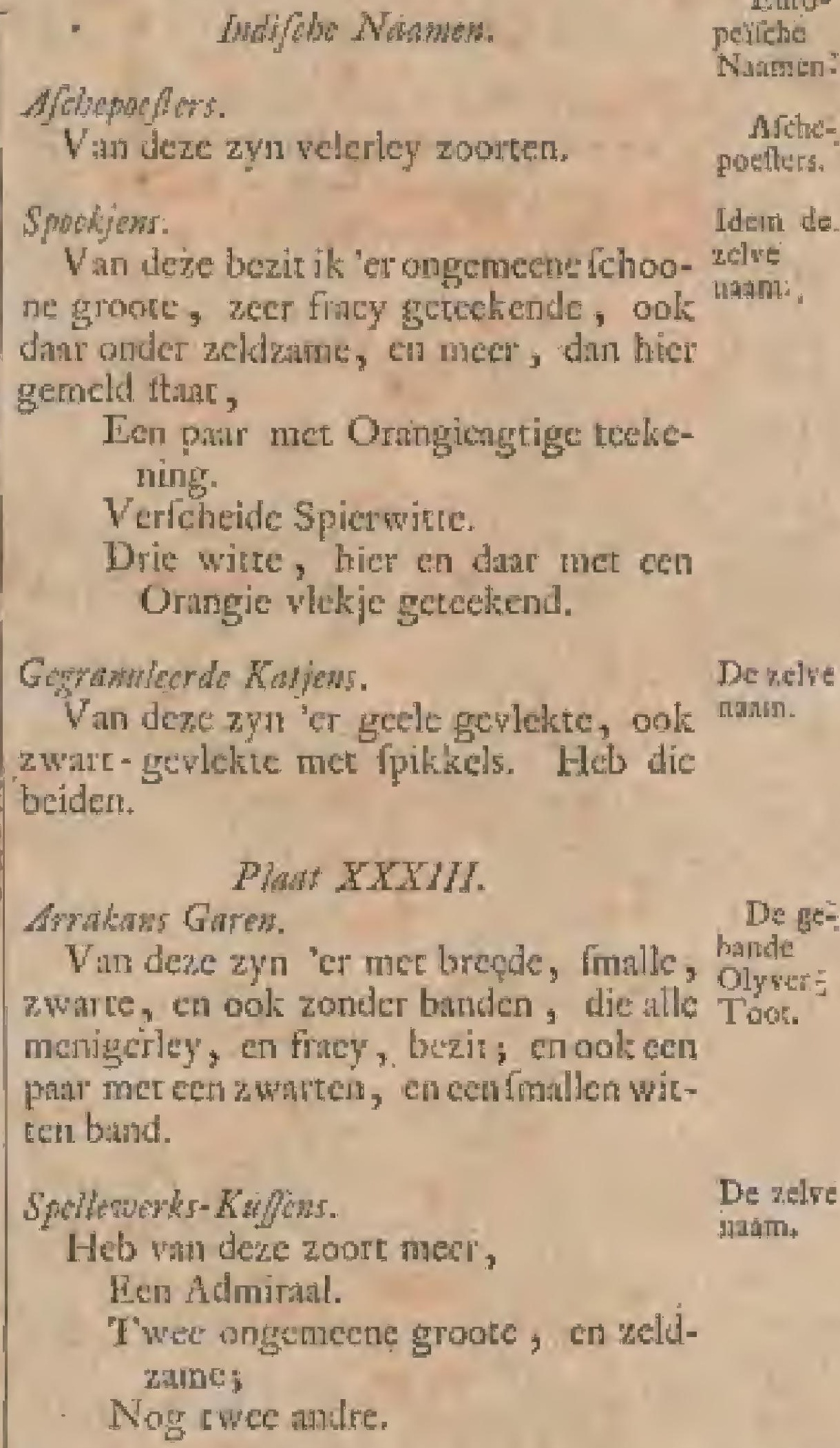

Een patr met Orangiengtige teckening.

Verfcheide Spierwite.

Drie wite, hier en dar met cen Orangie viekje geteetend.

Gromathlecte Katjens. Denelve Van deze zyn "er geele gewlekte, ook manon. zwart-gewlekte met fpikkels. Heb die beiden.

Arakans Garen.

\section{Pladt XXXNL}

$V$ an deze zyn 'er mee breode, fmalle, bande 7.warte, en ook zonder batden, die atle Tort. menjgerley, en fracy, bezin; en ook een pati met ect zunten, en cen fondlen whten bund.

\section{Spltowerk-Ku/fors.}

Heb wan deze zoort mecr,

Eer Admirail.

T'wee ongenecne groote, en zeldzanc:

Nog cwec andre.

De relve Diăm.

Groen Kanzus.

Van deze zyn 'er vertheidenctley wan nation. verwen, alle de welke ik heb, en buiten die nog ver icheide uitmuntende, zynde cen veel grooter, en een byzondre zoolt, en

Een grooto groche Kins met drie ttippel-banden.

Een dien, mee vye ftippel-banden.

En twee, mee twee binden:

$V$ an de gemeere zoore heb ik ze,

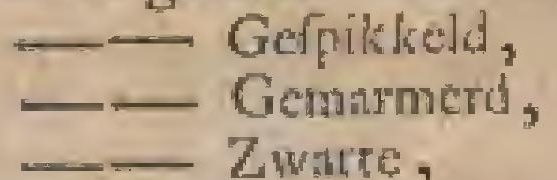

En blecke, of levervetwige.

Firen-joretes. Destrots Dic verfcheide, met en zonder ban namu den $z \mathrm{Fa}$

Heb ook meer ech gekarteld Vljegenfeheetje, en het rood Viegen-icheerje, dat beide zeldzan is. Il Jueb ear twee byzondre paturen var.

Maggen-abericm.

Det welte

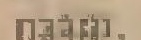

Figich fetreten.

De eftre

Deze riet men weinig, hoewel ik ze tham. ook het;

Dog de befte en groonte (die ik nu

$\mathrm{X} \times \mathrm{x} \geq \mathrm{z}$ jice 


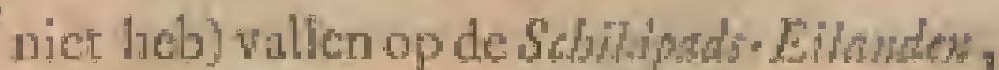
die cenzuniden vat Ambonat leggen, en deze zyo ongeneen groot.

Gepklkte Burno Mofgrach.

Tooten.

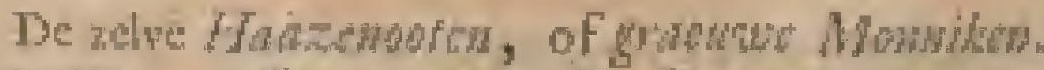

nam. De zoore by D. D. en kenhe niex, by Ahwaths gemelu.

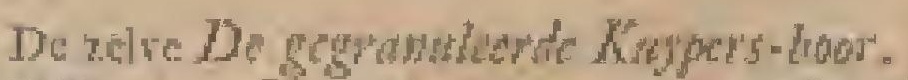

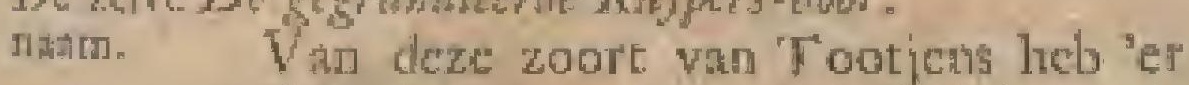
verfcheide meer, dan hier gemeld itam, alls

Geribde Tootjens.

Een pats gebandecte blecke Appeltyoczene.

Wesclieide rofte Toptjens.

Dric Tootjens met een bard.

Een par viokete Tootjens met een witten bind.

Twew para Toot jens, qeer Fracy gemiativerd.

Drie zeldzame geele Tootjers.

Ean zeldanm bu wo Tooje, geribu, cis met wite wlelken.

1) rie Dadt-Tootcr.

Twe'e par gracuwe A gatatc Tootjens.

Twee zeldzame bruine dito.

De De Agediche.

Agice Hier van bezit vertcheide fraeje zoorten, en meer dar hicr gemcid ftitin.

Roode Agnate Toofens.

Roode gefpilikelde Inforw/e Vloertjens ; whtt yan zeer groote zooTteri zyn.

De Fdimze Talatande dito.

Eeta nitamurend fracy gebandeerd, en bloed rood, Malsăs Vloerte met twee breede banden.

En cen Cicroen-geel, met cen witte band,

Een blactu en zwart uitmuntend Tootje.

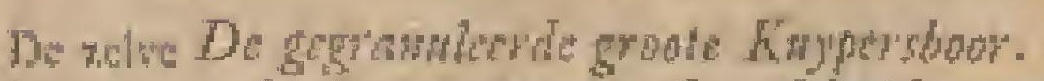

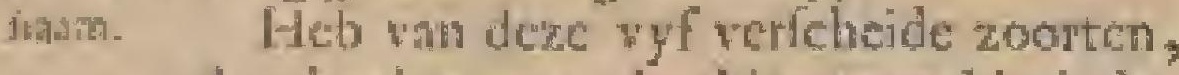

dog bezie meer, dan hice geneld winde;

De geribde blacuwagtige gebundecr* de Kuypers-boor.

De aclive De Ruetier-Pans-kroos.

मhathit. Deze heb mode.

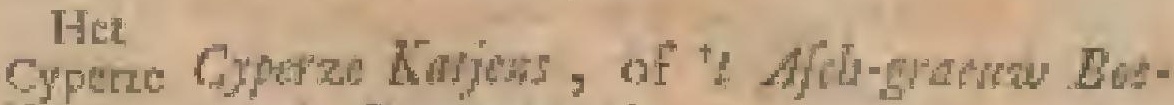

Bht- ro's Boterwergetia.

Tootje. Ware ran een par heb.

Derelve Mdas-Ooress.

Tism, 1 theb ze afgeflepen an onafgelleper.

$V$ in dere heble meer.

'c Kleene larume Midtors-Oor.

Hec wit ithen Mishs-Oor.

De Heer van Sngesum bezie een pas

Erro:

pelifie

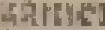

Bruine

Took:

Wat deze helo ik rerlicheide zoorten, en niter dan de gemeene.

Een gropte rolle Bruines.

Eet licht-rote groote dito,

Een Orangre Busiaec.

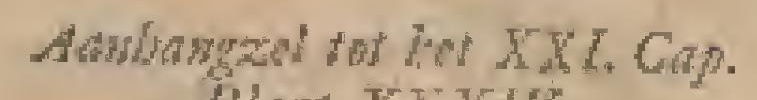
Plat $\mathrm{XIN}$.

De Ornygie Alwirad, by Leter A. De telwe

Van deze plage "er manr eche bekend mast.

te $2 y n$; en thu beris is "er drie, dog zy vesdienen eer de ntam wan de Appelbloezeme, dan var de Otangic admiral.

'Zy wallen op 't Eiland Horoa, en op Forinoc.

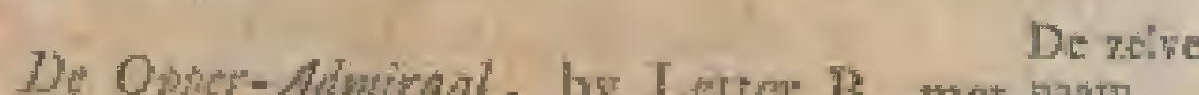
. cen fyn geel bandje oncrent in "t midden, ulfichen tweebrecder, en ecu frialle agter.

Deze heb nu wiet; matr hob er cen gehad.

De Ahmiral, by Letter C. met drie De zelie of ma men dat rekend, twee breede aaith. bratiden.

Deze breit miche niet.

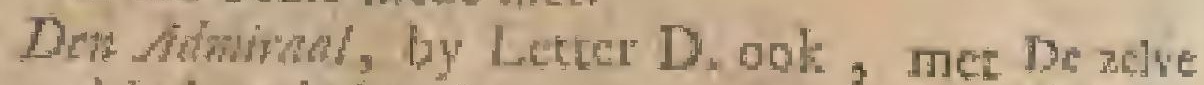
drie brecde bandk:

Deze heb mede aicr.

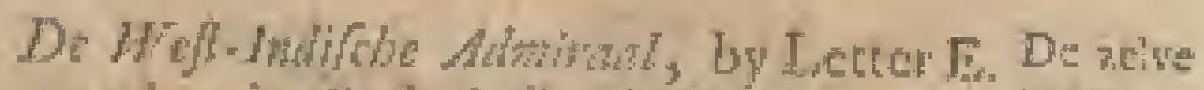

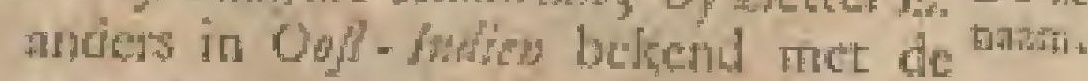
nitum Tan

Den Admitanl wan Owd.

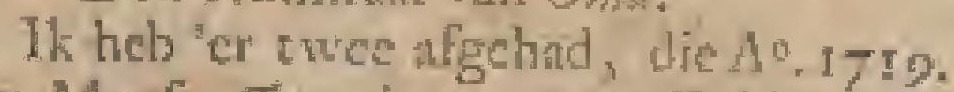
by Montr. Tocale voor 2- Culder gckoge zyn, dat, met hei ongeld, of. Galden, en 12. thaiversbeloopt; dogdewe bezic nu de Hi". Whin wegremat.

De Viem,Adairad, by Letter F. De atwe Deze helo mede niet.

H解.

De Gurifde Tor", by de Lerer $G$. De relre

Deze heblye ook nict; matr dit is ook batk.

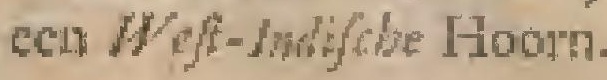

De Krowhinn, by de Letter H. De relve

Zy wallen op Bowod, ook op de hock thatis. van Noghtsted.

Hicr ran zyn wye a zosdericy zoorten, dic heb.

Onder anderen heb meer dith de gewecte

In gecl-graeuwe Kroon-hoorn,

Een kidene Kroom-hoorn , die zcet zcidzanm, wa by nat allic is, die men by de Leter I rict.

Van de geel-graentwe zoot heb it "et"

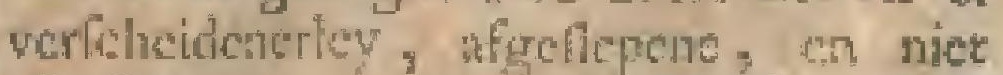

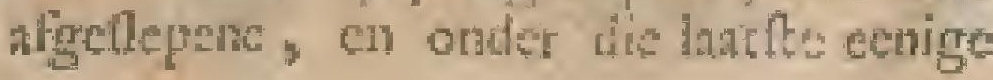




\title{
OOST-INDISCHE ZEE-HOORNKENS.
}

\author{
Indifle Nasmen.
}

met, en ook zonder banden.

Var de kleene heb ik 'er drie, en de wete nice, datik dic oit by iemand a,rders gezien hebbe, dan dae de Heer vati Sigwant 'er $A^{0}$. 1723. ook een parar uir hodien geteregen heefe.

De Achat - Toot, by Letrea IL. of deze plant gemeld, dic wu net licbbe.

Wat dic, by de Jetter $\mathrm{K}$. geteckend, angant, ik kenne den zelwe ; colte heb hem; ook is dat geen Ooffords Hoorn.

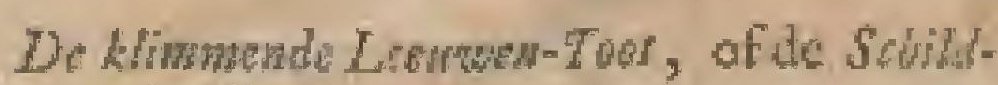
pids-Toor.

De relie Deze heb mede, ook is dit ees $W_{g} /$. nain. Judflebe Hoorn.

$$
\text { Gap. XXI. XXXP. }
$$

De De Burshank, her Mitnueken.

Dutwels- Dezezyn'ergroot, en klect. Ik hebtelaeuw. be de thatite zootr, die de zeldzana fle is.

$7 y$ vallen in Bande, op Bonos, $\mathrm{Me}$ wipa, en clders.

Heb meer, de kleene Dutrels-klienw.

De retwe De Brots-hade, het WyEken.

naz⿰l. Deze, die wat dumer en fyner zyn, bexit if nedc, hoewel nug her reche Fier, alzoo 'er twe zomten van zуп, พan welke de ecne mer inkerwingen zig vertoond.

De zelve Het ged Siswojen.

naam. Ditit zynowk gcmarmerde, en heb nog een geribale by-zoore.

De De withe krab.

teplicicicis

Krats.

De zeine De gede Gebucbelde Krat

pointh+ Dere heb niet

De groote Krab, by Leter H getee. kend, heboe numet; mar heb zogehad,

\section{Plart XXXYI.} nięt.

Die, by de Leter G. geteckend, heb

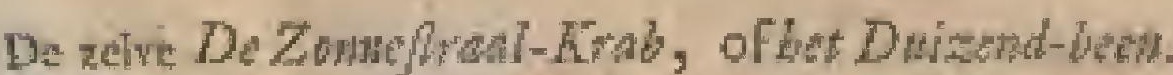
आzant.

De - Do Pothera, of Scorpion.

Podigra- Vardeze heb "er, buiten de gemeene, Freelt. weer,

Fen die Orangic van bintica is.

Een reldzame witte, zynde wat Krab+ngtig.

Defroo- $D_{e}$ Eroote Talan-Horn.

te Lap- Deze heb nu niet.

De Pur- De Pwore Thlas-Koon.

fre Lup- Deze is klecentr, en van binner Purper.

hoota. Ik heb er twee vangehnd, die $A^{0}, 17^{1} 7$. Joor de Heer de Koning , voor de Heer

bollowo Namen.

\section{Peifitio-}

Nivincon:

Gan Cifrers in Zederd gekoge zun.

Zy zyn zom zeldzakm, en ik week nier, dac ik ze mect" by andre Lief hetobers, diti by de Hecl Llmolf ecr, getren heb.

Deze beide zootem vallat op caysho op Cram; co oole op Sor:

$\mathrm{Het} B$ ermande

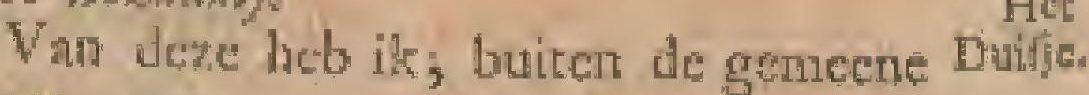
zoots, пroce".

Fen reer zeldratm blactw, en

Len finty gefoikket beztantjo.

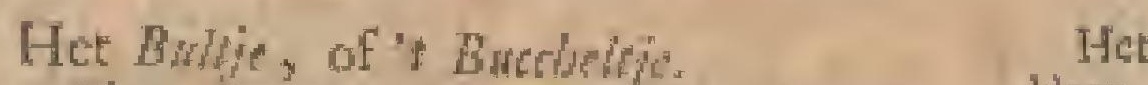

Van deze ayn "er verfelteidenealen kisen

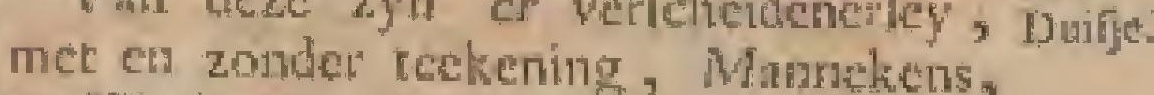
en Wyshens, die beide hab; dog heb mettr

Het wit Burchelje.

Het opgerold Bezansic. De alie

Dic try Hes

Dic by $\mathrm{Nu}, 6$. en 7 . op deze Plat kell- keen nes en twyfiel of dic hrbbe. Duifje

Het Sprodjo.

$$
\text { Plant XKXVKI. }
$$

Her van zyo drie-derley zooften, die torkeh.

hebbe, en, by gevolg, twee meer, dan die lier genseld itatn; want dat is cen ZOOT

Die dik van $L$,ip, en de gemeene is.

Een, die dun, en wanbinnen wit is;

Fin hug een zoort, tie is nog dumber.

Duiten deze bezit ik nog ancer.

Een uitusurend zcldzhim parr, dat van binnen donker-Purpey is.

Vin welke de Heer do Man tot $A_{n-}$ Aerdem "er ook ecrige heet , zonder dat itk die anders bier te Lande, bowwed ik 'er nog een by de Heer van der Sid an Mmborina gezica heb; en eetr hier nog by de Heer Finest.

Het $W$ yartie.

Hit geHer and yericheide zoorten. Een knobbeld

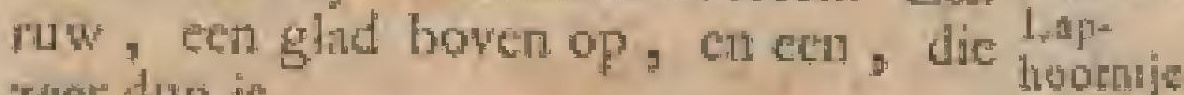
wecr atun is.

Het lat lte heb nu niet.

Ik bezit "et een wath de geneene Wy2erties,

Dut zeer zeldzan, en als mee ech Ster by "t Wyert je getecktond is.

Het Laboenes Hownte, of it Lompeze De relwe Govar. Vau deze zyn "er met cen zeer nant. fracje reetiening, en ook zonder de zelve.

\section{De Conati.}

Ik rie hier maar drie zoortch wan by De zetre

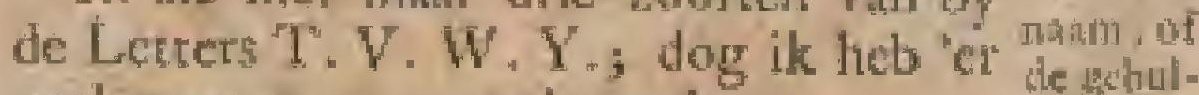
veel meer wanz on onder andre,

$$
\mathrm{X} \times \mathrm{x}
$$

Een 


\section{Indifele Nanmen.}

Pei Tultic

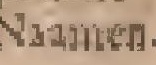

De

geboinde

Catiat.

De E

blowinde

Custio.

De

Singar.

Des $\lambda_{4} \mathrm{ct}$

Natit?

Een parr zeer groote; en

Len pian val binnen zwart.

Die by Letrer $V$.

\section{Dic by Letter W.}

Die by Letter $Y$.

Hier van heb meer, een ollgemeen gemarmerd par, en nog een zoo geteekend.

De breede gebandevide Canari.

No. 2. De Urangic-vlag genaamd, en

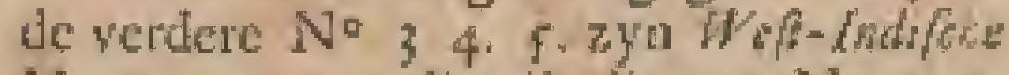
Hoons, vin welke ik dic wan $N_{0} .2 .3$. en No. 5. manr kenne, dog waar wan hier Mit brecder.

Alerley Camari"s villen in den $T w b w$

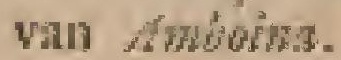

Cap, XXIh. Phat $X K X V / R$.

De Kip - De Klip-Kods, of al Lik-Hogn.

Hoorn, Hicl van zyn Wannekers, en WyEkens; dog buten degemecne buzic meer.

Eun pati Tyger-vleklige, zerr zeidunat.

Fien blateuwagtige, dito.

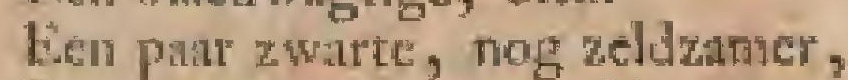

Een gracuwe Toralad ecinge oogen, als mar ace zyden.

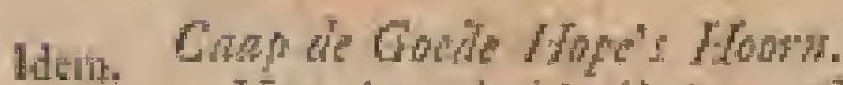

Vin deze bezic il "er wyit zes par. en nog eer enkelde, ieder byna wat verfohillende.

Eit behatven dezc hob ik nog twoe a drie byzondre zoorten way teekening, en gredrante mecr'.

Deze Hotens vallen op Cram, op de Stranden vitn Caybubo, en dat ontrert.

Ik heb by de Hect Hotmolt een par Purpre Canp-Hoors, en die noit nders gezich.

De De Faffor Gamp.

Giret- of Wandere hebr if "er teven ftukg.

parts- Doze vallen dart mede.

Hín:

\section{De De Argits.}

Mrgis:

Hoornt oogen, boven alle, die ik crenens gezien heb, uitusunt, behalven welke ils nog zes pian "er watn heb, dic reer goed, en what onder "er ook met thublule oogen zyn. lioet

Deze wallin op Howisua, en Norfo-

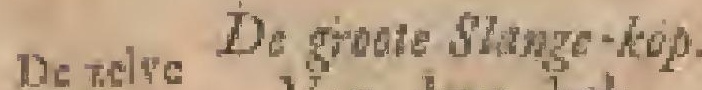

Nann. Van deze heb, buiten de gemeenc zoort, incel:.

Len reldzane Tematanfore Slangeknop.

De fyne Slange - kop, nls Carct geteckend.
Jahlde Nadmon.

FAFo:

perithe

Namert

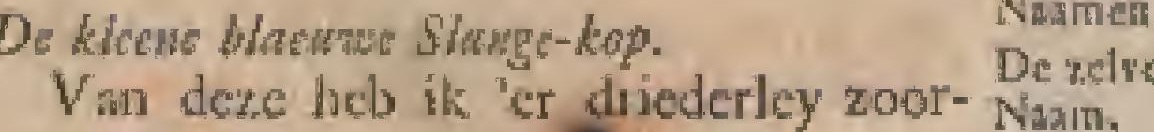
te, als

Lene, met eest fureep in "t midden.

Lene met cen brume whet in "c mid-

dैen, en

Ficre zonder icts "er op.

En dan heb it buiten de gemeene nog ñ)er,

De Slange kop mer banden.

De roode slange-kop.

Jamborzen.

Hoog.

Von deze zyn "er witue, en blacume, ruggen. dic hebbe.

Zy vallen in den Krbam wan Ambowa.

Mollow.

De velte Onan.

Buiten de hier gemelde heb nag

De graeu we met blaeu we bandes.

De rofte met witu binder.

Len uitmustende graeu we Mol, of de Argus zonder oagen, hier in Woland by niemand meet, dat ite wete, behend; dog by de Heer He molt heb ik ten hlecne gezien.

De Vlenfl-Hoorn. De zelto

Deze is "er zwatr en ook licht Nom.

Zy wallen ap Holdiboe, op "t Eiland Oma, gelyk ook de dric wolgende Hooms

Do Zow-Kow.

Hier yan bezit iti treer , Deteive meld is

Een Cirroen gecle zeldzame.

Arabigle Leperst " De telve Hier wan zyo verfcheide zoorten, dic Nami heb.

Nakkerlakkess.

De relire

Van deze heb ik "er fvne co grove Nam: byzonder grooke.

Granted Maflen.

De rellie Naมา.

Roude Maferm. Do rew

Nầ่นก.

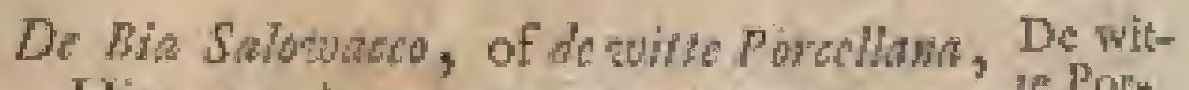

Hier vatis is cen growe zoott met een te Popbreede dikike lip, en een fynerzoort, die Hoorn. van binnen zoo bruin nice is, en dan nog cen Spierwite zoort wan binnen en buiten, die alle bezitue; dog behalven deze bezit nof meer, dar hier voorkomt,

Een witte Porcellana, die van binnen Appelstoczem is. Een zeldzatam ftuk,

Cap. $X X W$. Plad THXLX. Wito Oag joss. De zelse
Ster- Name. 
De telive Stertatyons.

กงมงก*

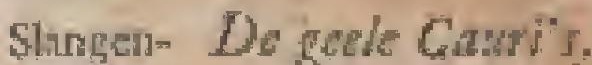

hoofdent

Dhenwe Di Hern Camp's. .

Citur:

\section{Cardaris-Ejert.}

Van deze zyn verfcheide zoorten, die hebbe, nok bezit meer

Ecro utumorende 7.00T.

Me" Drankondogrie.

Hier wan bezil jk, bulten degemeene,

Ren ubmuntend dterk van teckejag.

De zelve De BTatideregen.

Diaำ.

De zelye De liablis, of Garmelts.

nam. Van dece heb tivinuncude groote.

De kee- De blewa atgus.

\section{Eien}

grootcr Het Patrandw-Ob.

woort, thob 'er.cel par vall.

noerend

de redve

matian.

Idere Ryd-Koth.

de zatre

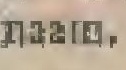

Inopers

Horlig Van dete zyn verfchaide zoorten, die Tiropje. beb.

Het glad Hitie difo.

Eлopic.

De zolse Frakers?

De nelve Pecritur.

De zelve Bowtects.

De zelve.

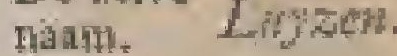

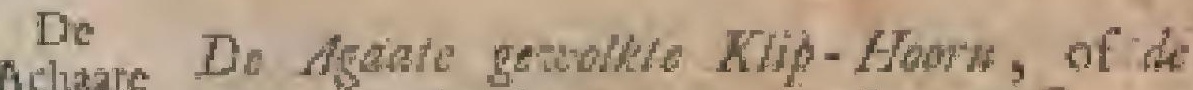

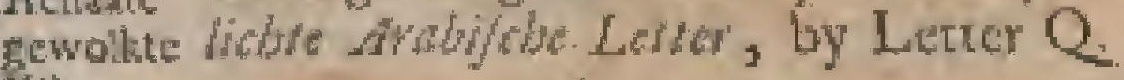

Kition

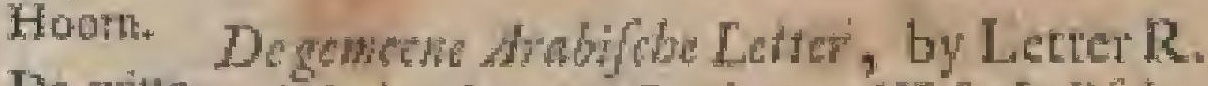

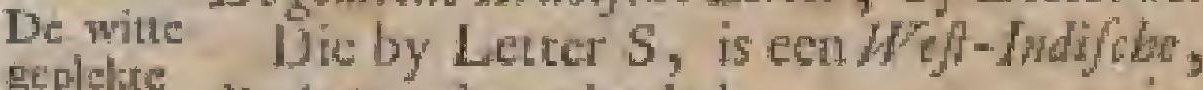

gepline die ken; dog miet heb.

Dit meclle roedje valt al mede in den Hown van Amboin, noor al het licenc.

\section{De Cop. KXY. Prat TXIX}

Didel, of De Porpbr-agtige Satrife Rol, of Gylmat Olyre.

Denwar-Zunate Sarync Rolew.

te Datul.

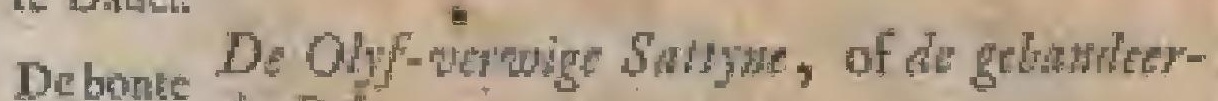
Meliake de $R$ d.

Didel.

De De onpangarde-salyme Rot.

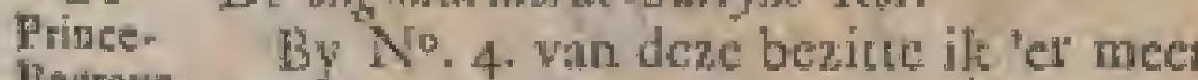

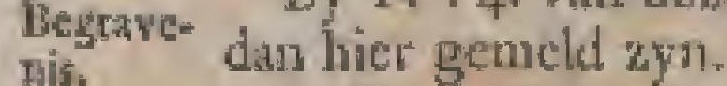

De violette Satryne Rol, dic valo binmen 200 is.

\section{PRIS}

Holifor Nawhen.

DeOrangie, of Irabelle Satrone R of Naimeli

Twee ongeneen litiet semprmete.

En de Hect wh Sarwant bezit nog een parr graeuwe of gechigtige gebuliderde, dic noit mer gerien lieb.

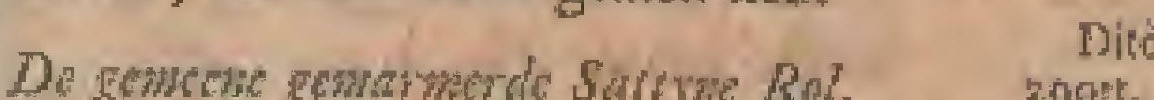

De rede gefoldedle Sentyse Rol.

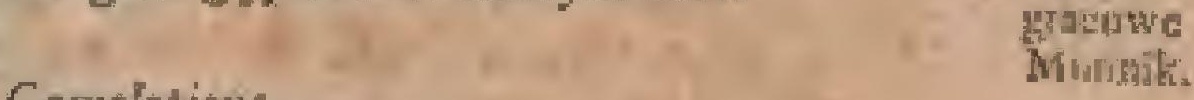

Comelotions

Catine-

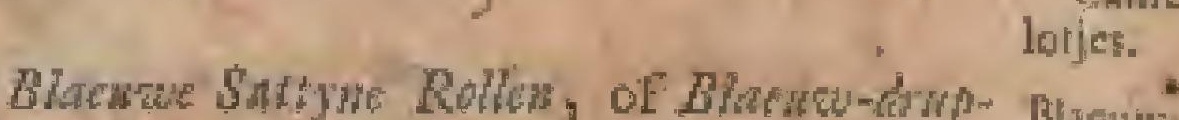
$p e$.

Grove Glimwnits, De zeive

Noche Glimmeth. De aelve

De Acbatajens. $\quad \longrightarrow \quad$ De reto

Makmi,

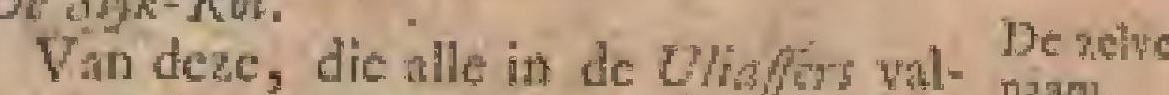
ch, heb nog verleheide and 200 men mam. live nier gemeld.

\section{Cap, XXVL. Plad IL..}

Patha"s, Lambers. De zelve Hier van beztere werficide zoorten wann of ook Kip: ook Kitectipt

Matoly's Obren, of Zer-Obren.

Hier van heb mede rerfetueide zoorten De binge te weren

De' ange; S Groote, silhelp.

De ronde, Kleene,

Len par ongenecre grobte, dic by

mienand zon gezien heb.

Zy vallen in den Lhban wan $A$ wholig, en elders.

Sclibid-puds-Lwoen.

Deze teb nict.

Stlild:

Het dekzel by Ietter N. kentio, en polken heb het.

Dat by M. en $O$. heb nu niet.

De Sols-kop, of Fowbuid.

Waar van ect zeldztatin flute hob. Jappen.

Het Melkwogio.

eldzame bertrik "er ecaphas. Oor-

Ook zyn 'cr guevwe ran, die via Schelp. niet lich.

Heb tog een meenigke kleene, hier nict genelde van velerley fatzoen.

Con XXYI. Ploat. IXX. Dezetre Pukken, by Leter A.

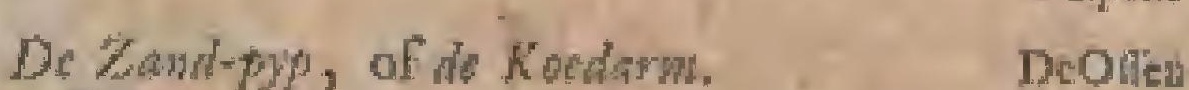

Deze vallen op stwabe, op Ceram. Darm.

De Boos-rearw, by F. en G.

Heb die by de Letter $\mathrm{G}$. en $\mathrm{H}$, niet. 


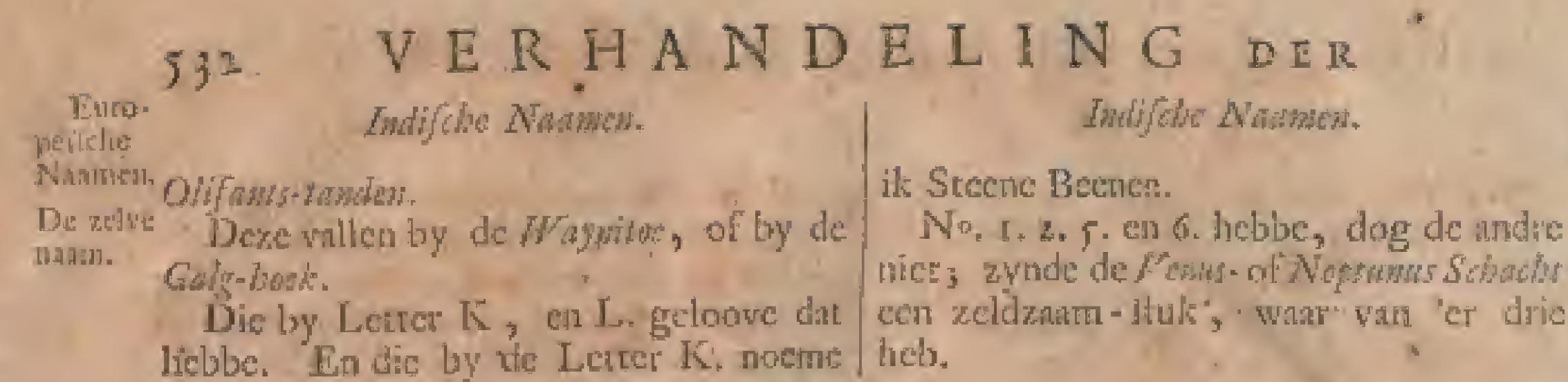

lieble. En dic by te Lener K: noems theb.

\section{VER H A N D L I N G}

\section{D $E$ R}

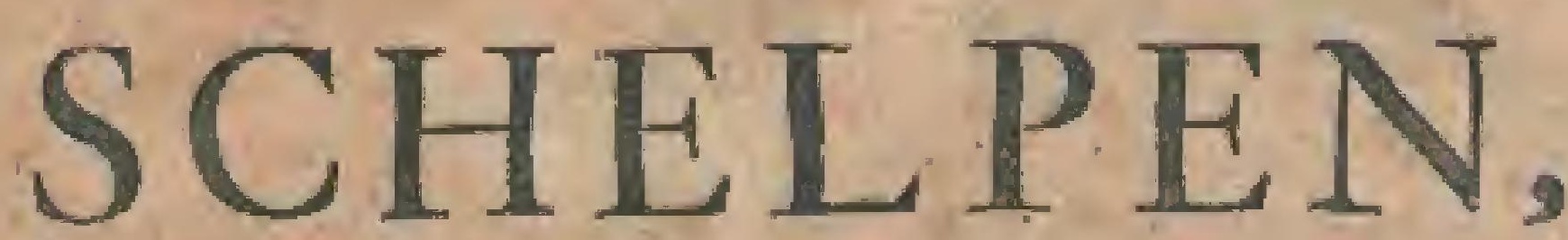

O F

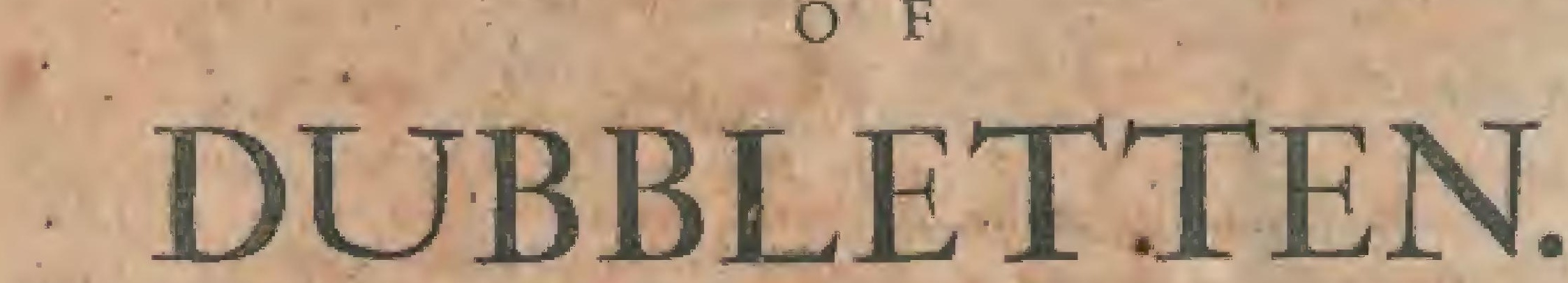

Van de

Schelpin

ar Dob-

De DE Nagel-Srbelp.

Misi- Win deze bezitte ik verfeheide

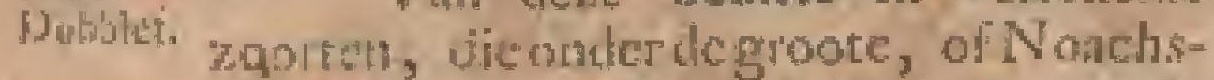
Sohelp (dic ontrent 't Eilun Jonus wallen ; en ook onder de kleene behooren.

Van de exthe zoorte heb ik 'er twee

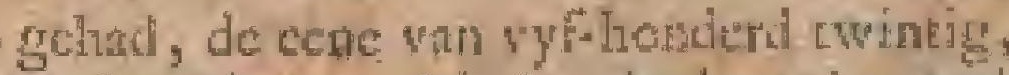
en de undre van drie-izondert tigtig pond zwatr. Daar zyo 'er' nog weel grooter. Ook hobbe ik dar ran tweederley middetbare zooren gelnal, mer en zonder Nagels, wallende beide op 't Strand wan Suel, by de Pas Ragkwala gelegen.

Van de kleene zoore bezis ik ex

Wistc

Roode $\{$ beide zelktitim

Gap. $K X X X$. Plat $X I N$.

De zetwo Die by Lettut B, Nodds-Scherf.

Hank Dere heb nu niet.

Lielitre

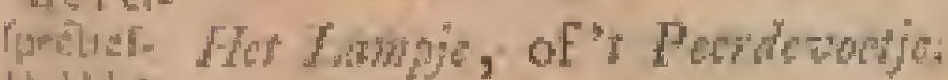

Lulublut:

De elre liet Scinglot.

Hin Her Hortio.

venus- Dete wallen op Porro, en Mtritg.

Herlis. Hier van zyn verfolicide zooren, die zeldiand zyo, als

Het Venus-Fartice met Purpe ftippen.

Her Penper-Harge, of her Atippelbloczcme.

It heb dese nu niet, mar habbe dic bejde bereten, en de $2 \mathrm{el}$ wetyr, Aw $171 \%$. den 19 Oetobes, in de 36. Lade onder niyn gaed weilkogt.

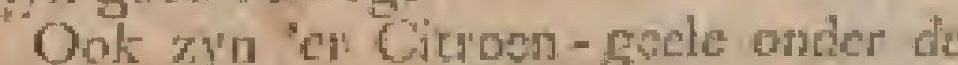
Liefhebbers; en ecn zoore met an zolder enden, en en die onder thot is, oets subble Hitries, dic nu suct heb.

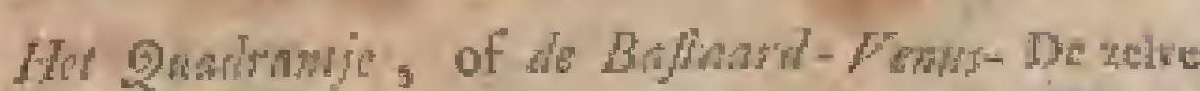
Scbelo wethin. riam.

\section{Gan, TKX, Piad ILIL}

Gladk Gapers.

DEJ

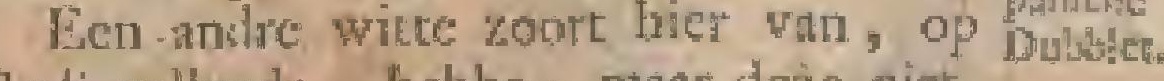
Soth villende, heble; fiatir dezc niet.

Oole hebbe theer

Een Orangie Sarifle Seliclp.

Quather, of Poffors. . " De active De zoort by de Letter 1, wect diet det wam. liebloe.

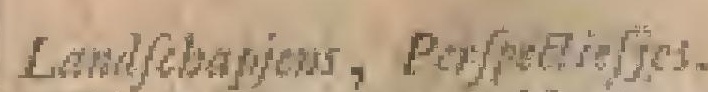

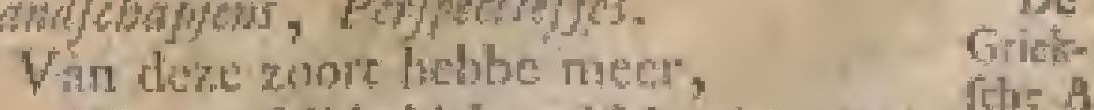

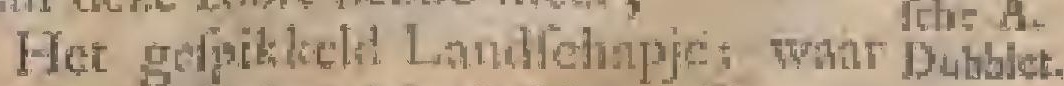

man ik "er dric hebbes $2 y$ oyn zefdzatar. 


\section{OOST-INDISCHE SCHELPEN, of DUBBLETTEN.}

Jislshe Nownen.

De uelwe De Camari-Seblp.

Natan. Deze is byna onbekend, heb er drie van. Zy is zwart geribd, wat wit beneden, en als ecen breede Amandel. En nog cen grot-geribd.

\section{Platat XLIL.}

De zelve Do Schelp wat oogen.

Natiा?

De Strik- De Later Sebels.

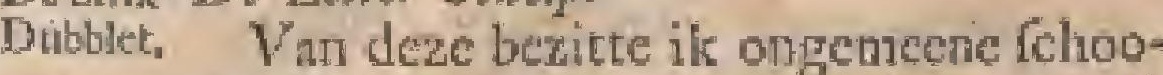
ne van werne, en van teckening. Itk vind hick viel zoorten angehald; dog bezitte "ct mecr",

Vyf pair Orangic-gede, zect zeldzมกลา.

Drie parar gekatmelotte.

Een paar z wart en wit, dito.

Vier puir donker zwarte,

Een weergateloos wit parar met zwatte groote wlekken.

Een enkelde, geteckend met en V.

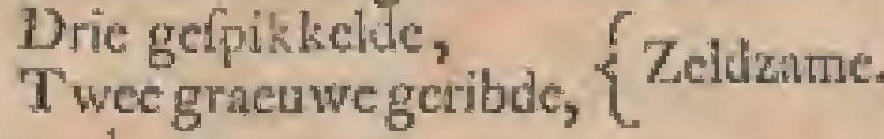

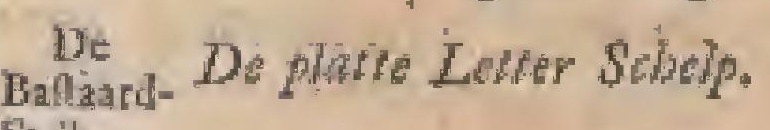

Striliz

Dubblet.

De klee- Hot klen gelued Wafelyzer.

गié Lip- Hier yan zyn twee zoortell, de eerfte Dublet heb by Letter D.

De Lip- Het groot Wafelyzer,

Dutblet.

Een foort De Tirers-tong.

var Lip- Deze hebbe niet.

De relve De gedaride Tygers-tonis.

naalk Ik bezit nog twee audie platter Tygerstongen meer.

De relte $D_{e}$ Remies, by Letter 1 . en $\mathrm{O}$.

nam. De latifte hebbe; dog de eerfe nier; ook keme die niet.

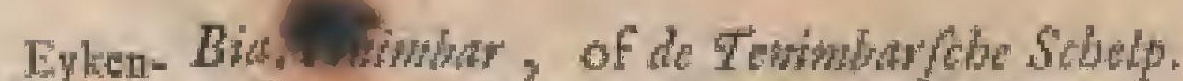

Houts- Deze mifé nu; dog is niet zeldzana.

Dubbiet.

Tour Het Xoda"s Seblype.

te $\mathrm{Br}$.

Wan van 'er twee zoorten, die hicr ook angehanid zyn.

Degetan- De wito Remis Schelp.

deVentis. Dere kenme ik nict, of "t moeft de ge-

Dubhlet. meene en beliende Venus-Dubblet zyn, dat cen heel andre Schelp is.

\section{Cap. XXXI: PlaAt XLIV.}

De De grate st. Jacols-Schelo.

groote Hacolos Heb "er dric van als auder hialve pialm schelp. van cen hand.

De boute De bonie Mantet, of St. Gacobs Siblp.

Mantel. By Letter A. en B.

Van deze zyn verfeheide zoorten. Ik III. DEEL. zie "er hied" dric angehald, dog bezic 533

Furo: pelirtie Namier: गJeer.

De groote Otangic bonte Mantel.

En diar van drie onderficheide zeer zeldzame parten.

De roode bonte Mantel, zeldzaam. Heb 'er cen par.

Van die zoorte by de Letrer C. bezite DeWedt: mede meer.

De ficht-roode Konings-mintel. borte

De Orangie glidde Konings-mantel Mantel, met fyne nagelliens, werichillende Jacobs

- Yara die zonder nagelliens. seluetp.

Ook zyn "en" Citroen-gecle, die ik sehad heb, dog die A. 1717, door den $\mathrm{H}$. Auditeur, John Bomand ac la Fallo, gekogt zyn.

Op Caibobo wallen de roode St. Jacobs Schelpen.

De Rur

De re

Heb meer de reche $\mathrm{Y}$ s-dubblet, die Dublet, geen ragels hecf, en hier niet anoge- aret $\mathbb{N}_{2}$ hatil is.

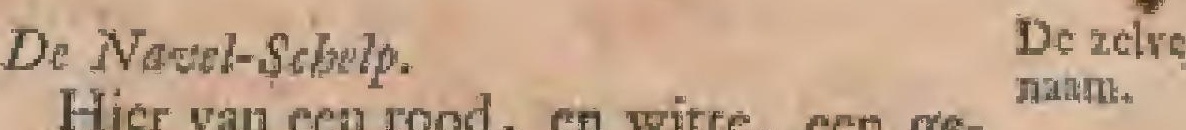

rood, en witte, een ge-

De

De Bia Corcoeram.

De zelve heb die nict.

Roude Aordbeith.

Roodi. Arratbry-

Witle Atrdberitin.

Dulbat:

Daas zyn ook Citroen-gecle; dic nu Aardbey niet beb, en de witte ook niet.

Hot Dabbl-Hantic:

De rellye natisin

De Arke Noudy.

De zelwe niats.

De Bafadid-Aik.

De reive

Hier vall zyn verlicheide zoorten, en naan. vier a vyf zoorten der zelve van Letter $\mathbf{I}$. tot Letcer $\mathbf{N}$, angehald; $\operatorname{dog}$ ik bezitce me्tr

De Baravifone witte Balthard-Ark.

De kiene bown Mantel.

Dit lchynd de Wy-tas te zyn. Heb gewolkte 'en drie, dog twee byzonder. bonte

Het zldzacm geridd Bheken. vict af, en nog een Appelbloezem par.

\section{Bineks.}

Van dere bezitiemear, be zelse en nog cwee kikene, cen geribd, en ecn

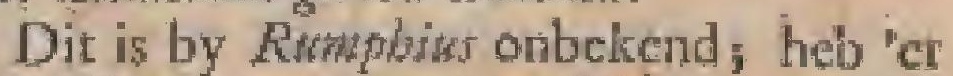
e, Măm.

Itere Yyy 
Natmen. groen ; eds nog een zeldzan ros met Francie teckening ter zyden.

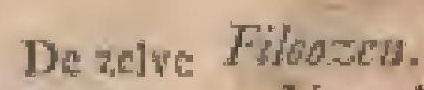

nam. Van deze zyn' 'el wite, Purpere, en Orangie. Berit nu mande eerftech cwcede, en wan de eerlte zoort reer groote.

De relwe Zounte gedondecide Filoozen.

Nasth. Hob er twee af. Zy zyn bruin, cn onbelient.

\section{Gap. XXXIL, PldatILV.}

Derelve De Compass-Schels.

manm, en Van deze zyn ook blocd-roode, en wok the bleck-Purpe, wellec nu niet hebbe.

Mabiblet. Zy wallen op Corah in de bogt van Gat

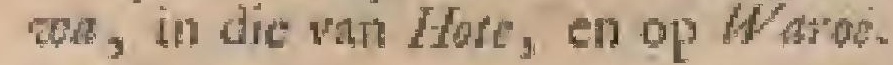

\section{Gap. XXXIV Plat $Y L V$.}

De zelve De Bacabla-Scble.

Nam. Warr yan hobbe, de groote gracuwe, De Hairige,

De Orangic,

De bliteuwe.

Diar zyn ook roode gematmerde cu - bherwegenamende, dog heb die nu nié.

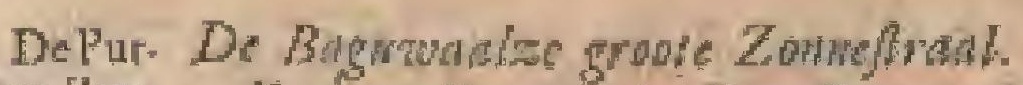

pre 7on- Deze wallen op de J'ss Bagronta.

ne-liral, Hicr van heb moer.

of de

Foote

Tonr de

De Peul

De Balavilche blacuwe effene groo-

Duhblet, Ds Mes-Sehelp. te Zonneftrot.

De whbolde effene dito.

Pooligh

Mes.

De Reto De harde Torg.

ben-tong,

of ite

Segrein-

Jübblet.

Do De Zome-/ndal

Dezelwe Deze is er menigerley.
Nalnz.

De zelve Tongen, of Gowde 7omgen.

Natu, Zy vallen op . Masips, ook klecrie in den 7 bas war Amboina.

Deze zyn zeer zeldzanm, dog heb 'en verlcheide; hoewel ite ecu zeel" groote nu kwyt ben.

Ook heb nog cen zeldzame platte gracuw-geftecpte Schelp.

En kenne nog twee wirte Tongen, Roos- onder de Dowze Lief hebber's.

Dulstet- Hammedens.

ten. Dezezyn'ergrotect klene, nok witte, roode, Appelblocteme, Citroen-geele.

Do relve

De Appelbloczeme leb nu nict.

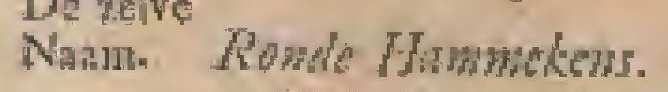

Heb 'er ecn Appelbloszen fehoon, en De zelwe cen bleck par, meer van. nisaln, of

de Boon-Bard-ksypers.

Dubblet.

Eanspery?ticte Nasisch:

Deze zyn by de Leter A Plat XLVI. Cap $M X X Y$. Fal XLV.

Orgel-pjow.

Goot:Dubblet: ten.

Wudolekten.

Eeurigdurende

Wan wan by Leter O. en P. rog twee Gapers. zoorten, die ik niet wel kenne.

De Bia Catsio.

De rethe

De verdere zoorten kenne wiet, dan alletn.

Nath,

De Zeeponaden.

De relre

Nạm.

\section{Cat XXXY. Plaa XLVT. Ds}

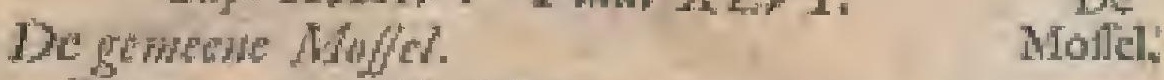

War $u$ an werleteide zomiten zyn, en dic hier toe Letter E. toe aragehald werden.

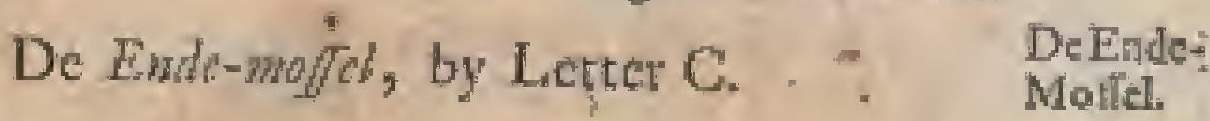

De strenglente.

De:

Sreef-

Multel.

Het Fogelise.

Het

$V$ an dezo zyn "erzwatte, en roffe, die gevlethte beide bezit.

\section{Cap. XXXYI. Phat XLVI.}

De $B y-s d h c h$, of $d e$ Holfer. Dethan

Var deze zyo vericheide zoorten, met, Dulbilet: cnzonder Nagels, witte, gracuwe, Purpre, of Parze.

Miffe deze meelt alle, uitgenome de witte cri de Puspice of Pantze; dog heb een ongemeene groote vitheentze.

\section{Cap. XXXFLI PlaAXILIL.}

De stok-Oefer.

De $S e r i-O f / g_{+}$

Waแt พan twee goorten. Lalter:

De Zadal-Swholp.

Waar van twee-zoorten. Pooliche De Dik-fon/ge Ochar: Zadel.

Ofdere heb, wete if niet, alzoo die takieflewit de Teelieming niet wel kenne, ten $z y$ thekam. her de Rors-dubblet $2 y$, die hebbe; dog die volgd hier na.

\section{De Hawkan.}

Heb hier" "De He?

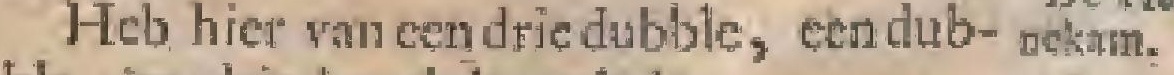

De Lasamishop. De retre

Van deze zoort bezite ik ech uitmum-Nam. de Orangie; ook witte, en Purpre zeer dun gedoornde, en zonder doomen.

De Pantchor-Schls, of Zildere Ta- Destre fellordew.

Naath.

Dere wallen op Banoa, welke ik nu niet heb; mar wel een kleene, en een Citroen-gecle. 
H.11,

Nasmen.

\section{OOST-INDSCIE SCHELPEN, of DUBBLETTEN.} Whishe Nanmon.

De Peerlemoer-Schelp valt ook op $A$ rec, Mcfowd, Babrin in Poyph, an Toutcktyos, op Ceylon. Op alle welke plitatzen ook (choone Peerlen vallen.

In den Inham vat Amboina, by de Lo. thi, en ontrent Hoekomilo, wallen oole Pcerlkens; dog zecr kiletne.

Deparal-

folle Ha- De Cris.

net, of Deze hab mede.

Inditiche

Cris , ook

de kivis-

Dulbb|tat:

\section{Do De Wimkel-Fask.}

Vesus- Dic zeldzaam ftukbezit ik, ook meine

Sthálit- "t zelwe by de Heer wath Segwant gezien Dubblet. te hebben.

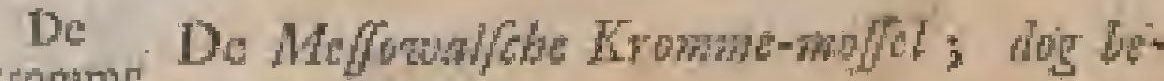
Nuactis. ar den $\mathrm{Ha}$ hel.

Niti, of

de Halpel De Barn-Acer-Oefer.

De redre Deze lieb nict.
Nism.

Nism.

De relipe De Myter.

Natin. De Schelp by $\mathbf{N}^{\circ}$. I. kenne nict.

\section{Phat $X L Y I I$.}

De telwe De Orangir Lazarns khp.

Naptit.

No, I. en 2 kenne die, en hebze Orangic, en ook witte tracje met Appelbloczem, ap Rotsjes, en op een Lobbej jes. Hoorn.

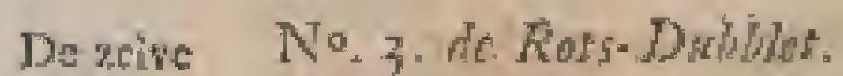

$\mathbb{N}_{\text {und, }}$ Deze lobbe, en ook ecn fenk, dat zonder weerga wan fracyheid, on vary grootte, is.

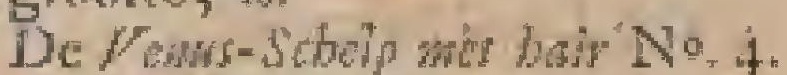

Heb 'er" rerfcheide van.

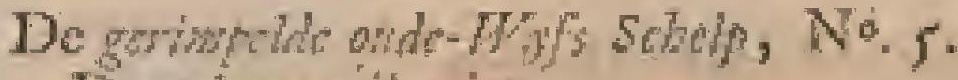
Deze temse it niet.

De No. - S. Groute Bonte Mantels.

Corato Der kenne; dog heb dite nier:

Dubilet. No. o. Gulyle wel een Cathagernze: $\operatorname{dog} \mathrm{N}^{\circ}$. I I. kenne niet ; en No. 6. of de geribde Vejus- Dubbike kentie zeer wel dog were niee, dat ik dic oit volkomen, dat zy fow , gezjen hebbe. Jk heb "er เwee a drie witn, die niec thuter.

\section{Mand $X L I$}

Buiten-gemeene Hoo'ns nog, De Weruel-trap.

Vandeze zy "er in de Weeted bekend.

Ficn by den Groor Hettog wa Tof cantus.

Twee by de Hecr Audireut de "/t Fallie

Een by de Heer Pancras, Burgeritjeciter in zyn Ed: J cwen tot AnAcrdam,

Twee bo' ik 'er by de Hect Wouto
Jadflat Notwor.

Fakenitg gezien, die zedert gekomen zyn in hateden van den $\mathrm{Hr}$ : Whirat en de andre is merkogt wout ha Guld:, aizoo hy zeet licht was.

Een in Engrlard uit het Calvinet wan de Heer Oeess, 200 vat ande verftan hoblo.

Een is "er hn "t Cubinet van de Hect Adr: wan der Sit; dog werkogt op? Bunaria.

Een bezir ik "cr mede.

Eet onder de Heer Wefereres, Advocast der Oof - hold/de Mantrechappy.

Een by de Heer Advociat, Foban wa dor Burg in 's Gratembage.

En een kilene (nerens nogeen bruine battatar dito, welke de Hect Shlot heef bezit de Hecr Budiker.

Marar de grootfle, die il on gezien licb, hete de Heer Pitte Whats, oudSchepen tor Baravia, die by na cen vinger ling is ; dog in de telve is een git, dat hy gekiegen lieeft, uit de hand wan een Juffr, die hen bezne, vallende, war door hy zoodanig is gefchonden, dat "er" geen middel is otr hem te herttellen, on welke reden ik deze nier mede onder de Wentelruppen, die bekend $x y n$, optelle. Anders zon th deze boven alle de andie, (want van ik 'er zeven gezicon hebbe, dat weyreng Licden gebeurd is) ftellen.

Ook heet ue Heer is Fille, (zoo meine) als ook de Heer Faeb Ellas bichot, ean Bartatard zoort, die ros, mur heel zeldzanar, en by geen Lieflueblen zoo bekend is.

Van de ande Hoornen op defe Plat by de Leerem B. C. D. E. angeliald, kenne ik er gest eene.

Dic var Leter T. geloove it ta hebber, zytade de omgewonde Hoon genanmd.

De geroornde Pleti-Hoorn.

Deze hebbe zeer lieurlyk, en etrelyke parten, groot, cn klcen, "cr wan. Ook bezilte ij ran dezclve

Fen zoon, met velelid.

Eeng dito zonderviektion.

Die by H. I. K. zyndth

De gebandecide Achat-Ioora; deze hebbe.

De Olickock-Foorn.

De gebundeerde knobbel-Hogrts.

Deze lientue it wel, dog de ecrtte heb ile niet s zoo geloove; mar de tweede gelone dat beritue.

Dic by de Leeter Is is de Morgettflar, wair van bevorens al pehandelif is: en welke bezir vin werfcheide coulcuren; en fitzonen.

De Jionfor Hoorn, by Letter M.

Deze noemen wy de Caned-Hoom;

Y y 2 
Eniro petscive Nitantiti

van welke ik'er twee a dric hebbe.

By alle welke Zec-Hoorntens ik nog voegen moer, uls dat in ele tocbehoo Fendic.

De selpe De Zet-Aprd.

nintar Hier ran heb its wel twintig-derley zoorten, en daar onder er cen gethad, 200 froot als een 'Iufelbord; dog mitte die tu aile, alzoo $\mathrm{zy}$, onder andre gocderen, mede aumgeduild 2 yn.

Deze kome Lib. $I$. Gap. KKVIIJ yoor in de Rariog-kamer" wan de $\mathrm{Hr}$, Rumphibs,

De De Thland.

Turke Valleze zys 'er twee zoorten, ecre

l'ullarid, mer cenige ophtande banden eulichen de knobbels, en cenige zonder banden. Ih mis die nu bejuen ook, door "t zelve ongeval. De relwe Her Doods-Hoofd?

Natur Hier rata heb ik 'er een patr" Enzy komen by de Heer $R w m$ whis , Lib. $I_{4}$ Cap IIT $X$, vool.

Destre Dekene Zusher.

Nans. Men heef ouk zeer groote. It hel eca klecre.

De antwe Zet-koclen, of Pasmedekes.

Eнăani. Deze heb nu nice.

De zetwe Zers - Netjers.

Itatia, Wan deze hel ik 'er' ecn.

Datr ziet men mu wel de voornam fte How when, dic in $A$ mbina, en cliders om dc Opts, wallen, zoo, volgens her geene de

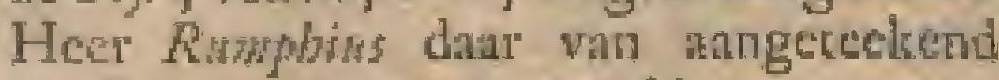
hech, en van zynen necrfligen wermeerderam thar nog uit andere Cabinetcen bygevoegd is, ats ook uit cen groote menigte van nog andere zoorten, die ik uit Arrbons nede gebrage hebbe, en nog in myr Cabinerje bezitte ; mat men moer nier oordeclen, dat ik het nu alles, dat 'er van de Oofwelle zoorten by deze en gene Lief heblers zoude nogen berutten, bysen ferameht heblut: want her is zeker', dut den ecene dikwils 't eene, den andren " $t$ anthe fluk, dat by gecen ander nog beJend is, bezit. Weshalyen men, om cen volmaktke Werk hier vas op te ftellen, een nette lyft war alles, dat alle de byzondete Liefhebbers bezitten, en dat, not tanteekching van de byzondre platitzen, datr deze of gene Hownes vallen, noodig had ; mant lier thr zou weel mocyte zym; die my, mogt ik het weten, niet vervecien zou ten dienthe wan alle Liefhebbers te ondergaan.

Bydoorlooping wn he Werk van de Hecr Rumblits, en de Odferfle Hoornkens, en Schelpen, das uit hicr angehatal, bevind ik cen getal wan min dric honderd Zet-houshers, en van de Sibel-
E. $L$ I G DER

pow ruim hontend zooren, ook fchynd de Heer Romplas swolgens 't gene wy Lib. 11. Cap. XXIX. lezen) 'cr man' 360 zoorten gehad te hebbers dat hier made nict vell verichillen $z a l$, alzoo "cr" hich vele na zyn dood bygeroegd zyn. By naworlching nu, bevinde ik dat honderdtagrig zoorten van Hownkens, entwee en dertig Sibelpon, meer bezute, an heb bevorens drie honderd zoorten van Hourns en Sebelpon neer, dan de Hecr Rumplisus, gehad. Hoewel ik nu vecl zooten, en zelfs "er een groote menige hob, dieveele Litefhebbers nict bezirien, mis ik cgter nog deze navolgende, Zee-Hoorens.

De Zonne-Horen.

De Zee-Ton.

De Arocze Trompet.

Het Rievier-Paus-Kroontje. Dit hebonlangs bekomen.

Den Opper-Admirant.

Den Admiral.

Des Vjce-Adnirat.

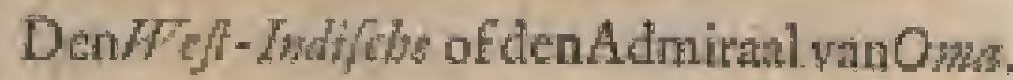

De gebulte Krabbe.

De groote Anboy/cbe Lap-Hoorth.

De geele Aardbcy.

De Purpere dito Lap-Hoom.

De Appelbloeteme Zee-appel.

Groote Bigyne Drollen.

Zeer groate gebnndecrde en geribde OlíHoorTs, met wlekken.

Zeer groote rohe geribde Olic-IMorns, zonder vlefkiken.

Getnkte Knollen.

Jokjens.

De Wef-Judifhe Paus-lioon, of Cerame witte dito.

De Ceranse getakte Marl-Priem,

De geknobbelde groote Spil.

De geribde groote dito.

Do Mouples Tulbanden mer pooten.

Gmensuc ros" gebandecrde Dadels.

Zeer groote Bruinetren.

- Zeer 


\section{OOST-INDSCHE SCHELPEN, of DUBBLETTEN. $\$ 37$}

Zeer groote Zome-korls,

Groote Goude Tongens.

Zeer groote bonte Knobbel-Hoorns.

Een zeldzaroe gefpilk kelde Lap-Hoom.

\section{Scheloer.}

De Citroen-geele St. Jacobs-Schelp*

De bleck-roode, Compas-Schelp,

De St. Jacobs-Schelp met doornen, Purper-verwig.

De Bloed-roode, dito.

De St.Jacobs-Schelp mer doornen, fpier * W"it:.

Het Hertje met roode ftipels.

De fpier witte St. Jacobs-Schelp.

Hee dubbel-Herite.

Her Appelbloezert, dito.

De Kuis. Deze heb onlungs bekomen.

De Soelize bruine Schelp.

De ftompe Nagel-Schelp.

De Neptunts-Schacht. Heb er dric onlinus gekregen.

Orangic Filoozen.

De Strenfoluede.

Veel Hollters.

Appelbloezeme Hammekens.

\section{Zadel-Schelpert.}

De groote Parlemocr-Schetp.

De lange dito.
He deze Howner, ou Sohelper, en wog vecl meer zoorten, heb ik te vorm bezeten, en onder andere een Dockes.

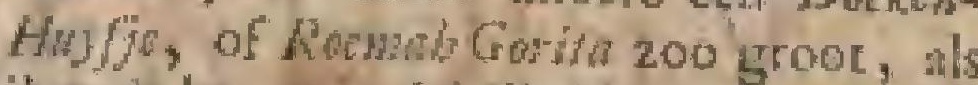
if not by esuig Licthebter gezien hebbe, die alle in ecr groor Cibinet geweeft zyn, dac ik by myn ecrite honite uir Isdia racde gebragt, en toesl atan eer groot Heer weg vereend heb, ap hope พตภ da: door cen van myne Z wagers met cen goed Anpt tha hales te helpern, dat my wel beloofs was ; matar diar niers op volgde; cri dat my, om de rehlizamheja der tukken, die dist by waren, maderlnand zecr berous de.

In dic Cabinet zyn ved groote "Doeke Aryjger, en uitmuntende andere fubken geweet, ats verfcheide yok-jems, bloedroode, bleek - ronde, en geneene dog zecr groore Conpass-Stocipon, hecrlyke Nage-Dhbliswer, en meer andre fracje Hoorns en Scbelsen, die it noit datr na meer heb konnen lirygen, en tor het werzanclen van welke dik wils het gehcel leven van een Menleh niet genoeg is. It leve nogtans in die hope, dar ik metier Iyd nog wel dere en gene frueje thukken by myn Oofojol goed krygen zal.

OndertuTchen vind ik in deze Lief. Wat de heblery het fracyfle, dac, hoe veel men 'er' Liethesook wan berit menegter noit alles heefe, en bers we wat men zomtyds by de klecnlte Lief dexe hebbers ongenmecne itukken wind, wic bery samzelf in de grootle Cabinerten, ja by geen fpoort, een inder Liethebber, voorkomen; 200 dat ools de alerminfte iets heeft, warr mede lyy zig kittclen, en zynen jewer, hot klecen anders, on dat gy nog weinig bezit, opbeuren, en zig tot het verder havorfchen van dere zeldzanosh hoden arazetten lath ; mar het zal tyd werden, dat wy ook wan de andre nitlandiche Zeezeldzatanjheden, die wy bezitten, iets zegget. 


\subsection{VERHANDELING DER \\ VERHANDELING}

D E R

\section{WEST-INDISCHE \\ E. N}

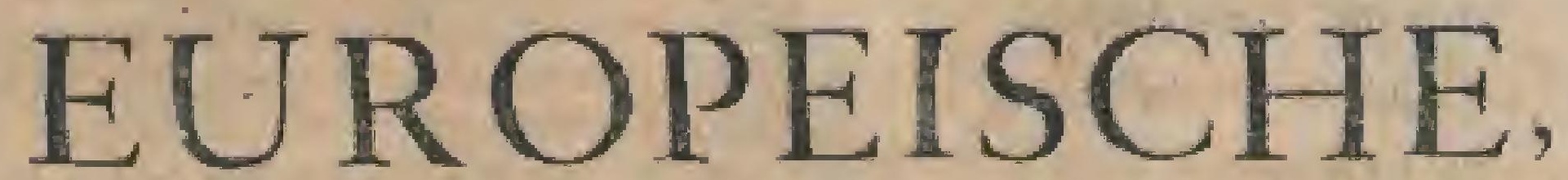

\section{Z E E-HORE N K E N S.}

\section{TWAALFDE HOOFDSTUK.}

T Wiandfche Zee-Horenkens. Warar zy al vallen. Zos in Wolk-Indien, als in Europa. Wett-Indifehe, of turopeiche Schelpen. Van de Zee Boomen, enz:

Zee-Bhemen. Vertteende dingen. By atie man metr Uytandfo Horens afgebeld

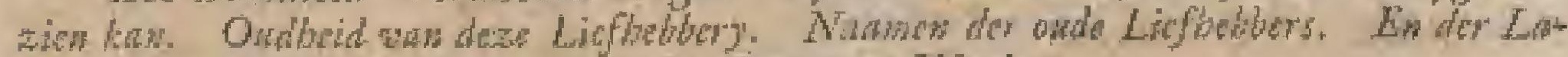
7es. Horens, in Jonlton afgebeid. Bonannus Werk.

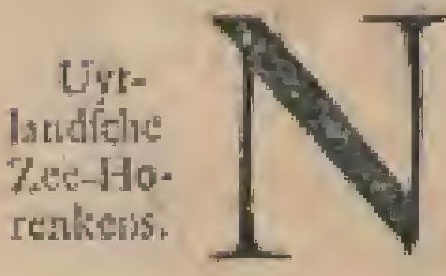

A date wy wart de Ouflerfle Zer-Horenkens, ch Scbelpent, 200 uitwoerig, nis wy het noodig ondcelden, gethadeld, on aangewezen hebben, welke wy dar van nier, en fun nog bezirten (altoo wy die alle, wan welke wy her trgended nier ter nederilellen, hebben, \} zal hee niet ongerymd zyn,

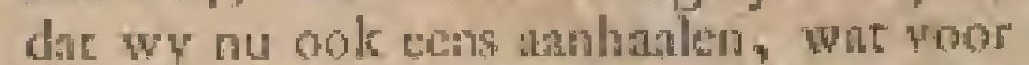

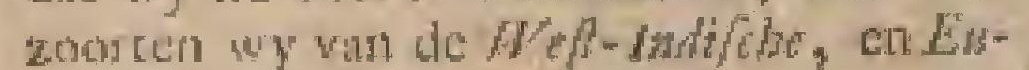
reseifche onder ons luebiter.

Hoe fehoone Hownes en Sebelpen Am. boina, en andic gewelten in 0 of -Indian, ook geven, mocten wy echter bekennes

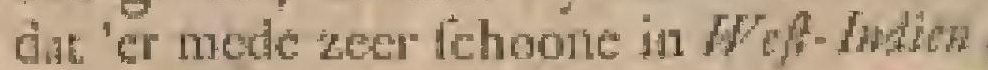

Waas zy en voor al op 't Eiland Chreçao, fwas al val en. watur ik wouderlyke felooone Appelbloe. zeme en Citroen-geele flukken van een fterke verwe, en fheje teckening, gezien helbe) in $A$ gman, en in mecrantre phatrzक्ष vallen.
Onder de Wedi-Irdifibe zullen wy de Zoo in

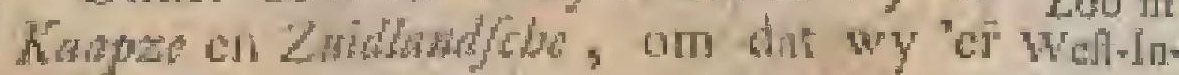
daar weynig yan hebben, mede rekenen, dien.

In Erap ops vallen mede zecr fracje Hoornen, en onder de Jirropeliche geven wy de woorrang aan die, dewelke in de Mil dolloudfetse-Zere valless.

In Engrelatd, sls mede op verfcheide As in

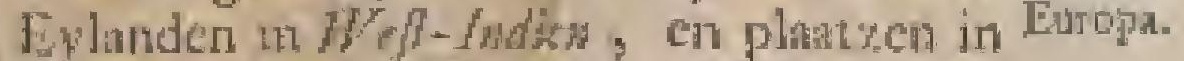
Sffict, onder de Engelfow behoorende, wint metn mede zecr zcldyame Horeskens, war by men dain cindelyk dezcen

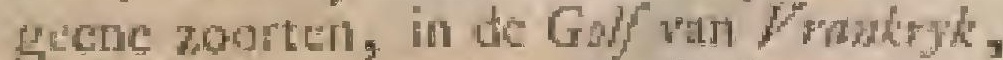
in de Baev van Codis, in de Strabs Dawids, els in Groesland 7.elf wallende, wel voegen mig; dog suu alle die zoorten zoo net te onderfcheiden, of dat ik ieders byzonder Vaderland answyzen zonde, is my ommogelyle, alzon ik dat wan weelo nice weer; matr an welke hee my bekend is, zall ik het atsaliaten.

Karp: 


\section{WeST-IND: en EURop: ŹEE-HORENKENS。}

Kappe Howns.

Aan Facp do grede flope heb ik A0.170, ten Huize van de Hecr Elseviz", cweede Perzoon aldata , een Dockn-Hayje zoo gtoot, als my noit voorgekomen is, gezich.

Het was wel mcer ats cene, of weynig uninder als twee Hout-voeten lang, en wan agteren was de rug, dienders pas ech vinger breed is, wel drie vingeren breat.

Men had die dat an Strand gevonden, en dar was een zeer groot gat in geflagen.

De Heer Elavier had we wan ech ander, dien ze tocbehoorde, laten hatlen, orn die ant my te coonea, zonder dat ik verder wete, war die vervaren is.

$$
\text { De Kadpze Alibugk. }
$$

15 heb "er cwee vat.

\section{De Kalaze noitc Silk.}

Dit ryadte cenige, die pan deze Kuf bezitie,

Ik hebs zeves van deze zoort.

Op de Stranden wan bet Zudaland walten ongermecte fracje Hoorns, wat van 'er zeler Liefhebber in Zedand' vecl bezis 3 dog a bezit 'er drie wais te weten, Her Zwhlands Trompeljic.

Het is wit wan grond, $z y$ zyn met uwatec vhmmeis, ch fracy getcekend;

It zal nu de Wefi-Mdiflis en Europe: fohe zoorten, matr zoodanig, als dic in inyue Laden poorkonen, oproemen.

De omgetakte Krel-Heorn, of de spachlobe

Hoorn, een zoort wan Scbihpuds-Mantes:

Dit is een Hoorn als een Krul - Hoorn van tatzoen, zonder brullen of takken, mee zwarte en witte bunden. Deze valJen in de Bacy van Godix. Jk heb ier verfchcidene van.

\section{Arwinze Kral-Howns; zonder Zakken,} of Krwllen.

Van deze zyn "er werfeheidene zoorten, van verfeheidene verwen, met, en zollder banden, wat wan ife "er verfehcidenerley, en ook met Orangic bunden, graeuwe, witte, enz: bezitic.

\section{De avirite Moor wet boden.}

Van deze zoort, wallende op Camyo, hob ik 'er verfeheidenerley gebandecrde, met enkele, en dubble banden, en een met cen witte brecte band, ook ecen gheute.

Ds Bohard-Gwincefor Toot.

Wan desc, mede op Crrofto vallenule, heb ik 'er veele, groote, ci ook fracjc.

\section{Do soldat}

Wan deze heb ik "er vier, dog ecnen zeer grooten, heerlyk geparilemoerd.

Her is cen fchoone Hoorn, die in zyon eigen couleur glad, en zwarecn wit geteckend is, gelykende wel nil een groote Naftawer, of Petola-Hoorr.

\section{De Krol-Hoors}

Deze valt op het Doggerzand, is gedagrig, en ook wel wir, zynde 'r bisnenlyfals een Knol; doch voor inet een lithge tuye, ngter mede met lange gieren; en knobbels uitloopende.

\section{De Wik-INdigor Trompot.}

Deze is wan teckening als de 0 of - Jht fobs $\mathrm{dog}$ korter in ech gedrongen. If heb "er een wan, en de Heer $F_{\text {agg }}$ heefe cen zcldzame, die Appolbloctem is.

De Wed-1wdiche gwowe Topda'k.

Deze is by na als de Ambanglo, op de Plate No. XXXT. Letter A, dog wat ronder, de cene geel-agtig, en de andre bruiner van verw, en een weytig anders War Tepel, zonder doorns, of kroon "er agter aan. Ook zommige zonder Tepel.

Zy valt op Curapa, en ik heb "er ecr patar van.

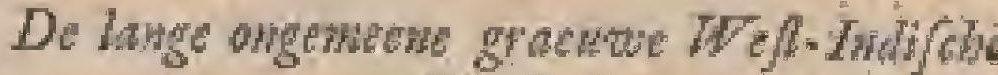
Tophak.

Deze is reel fmaller cu fungwerpig, met een "T'epelic, dog zonder kroon.

lk heb 'er oolk cen parr wat. Zy vallen mede op Curafas.

Vandeze zyn nog malre zoorten, en zelf zer fraje gevlamde.

De Franche Bel-Horn, of de S. MatoJabe Hoorw.

Dit is ecn fracje dikte Hoort, wit wan grond, met breede rolle vlekken, zyode Fils een korte in een gedrongen Trizon, of Tromper. $\mathrm{Zy}$ mallen in de Bogt vant Drankyk. It heb 'er' een parat kicene, en nog een ander' veel klecher' wan.

Den Admath der $W_{c h}$ - Indjobe gecle Bo vorwegen.

Dit is ecn gecle Hoorn, als de HartsHoorn van firtzoen; dog de cene is agra plat, en d"andre nuet cen turtjc, beide mer veel itippel-banden.

Ik bezit "er twee af, ieder wat byzon: det. Watr zy wallen, weet ik niet.

Do groote gedornde, of korf-getakis Lap Hown, wan de Hecr Foot, als cen Weft-ludjebe my vercend.

De grature geknobolde Lath-Horm.

Hier wan heb ik ier ecn parr switre, on aen gecle. Hy valt mair balf zoo groot, 
als de $A m b o w / d e$ Lap-Hoorn. Waar zy wallen, weer ils nice. Agrer tun zal thog een groote gedoornde zoort volgen.

\section{De Verkens-bek.}

Dir is cen zeldzan ftuk. Heb er mat twee van.

\section{De Wejt-Indirbo Argus.}

Deze is dunner, ook donkerder vatl grond, en witter wan oogen, als de Op/tIndshibs.

lk heb 'erdrie wan, diewolkomenzyn, en twee afgeflepene; dog een die ongemeen fracy, zeer helder van grond en byzonder wit en growt van plekken is.

De fiene roode getalle Lap-Hown. Varjdeze heb ik "er twce paar zeci fracje. Zy zyn kleen, niet boyen een kleene hand groot, en zeer glad op t tyf. Ook heb ik 'et 2 a 3 par kleche wan.

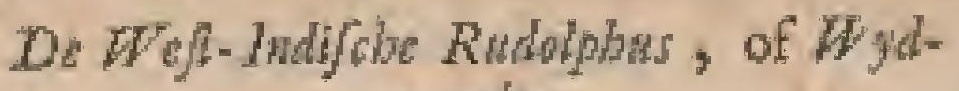 monder.}

Hy is van binen wyder op, en platter als de Ooft. Indifobe, ook is hy man de eche zyde wat flucuw Orangie, dog van buizen vol zwarte en witte ribben, en na ngteren wat geknobbeld. Ik heb 'cr dric van.

\section{De recle getakde Lop-Hoorm.}

Van deze heb ik "er een, a twee.

Di with Rowpe Zwhtors-brok.

Van deze heb ik "ęr ecr parar, en het fchynd my toe de zclve te zyr, die in Rumpbus Rariteit-kamer angehald ftate in de Phat No. XXIV. Num. 1.

Oolk heb twee zeer groote dito, mot langer doorns, als de kleene, en nog een lever-verwige kleener.

\section{De Wofl-1ndilo geribde Casket.}

Van deze bezic ile ${ }^{\mathrm{c}} \mathrm{cr}$ twee.

Zy zyn matr ecn vuift groot, zommige rood, zommige bruin net witte vlekken. I'k heb ze beiden; tog de ecue is ongemeen fracy.

In de Rariteit-kamer wan de Hecr Rumplins, is zy angehanald op de Plaat No. XXIII. by $\mathrm{Na}$, 3 , en die van $\mathrm{No}^{2}, \mathrm{z}$, kenne ik wel; dog heb die nier.

\section{De Bedde-7yk.}

Hier van zyn weelerley zoorten, met en zonder takken. Van de eerfte heb 'er een, en wan de last the zoort dric, de fricyfte vati deze zoore, bezil de Heer wan Segruart, en de Heer de Koning; immers ik heb "er noit beter gezien.

\section{De getakie snippel-bed.}

Van deze heb it "er twee, zynde de zelve, die un de Rariteir kamer, op de Plat No.4, woorkont.
De $W_{e}$ - hadfobe geknoblde Stom-bod. $V$ an deze bezit ik cen weergadeloos paar; zeer helder wan grond, en wol heldre biuine knobbels.

\section{De gedoormde Sriphel-bek.}

Van deze, op de zelve Plat $N_{\text {w }}$. XXVI. No, rigemeld, bezit ik eengroote, en ertelyke nudre.

De Wofl-Ind/che Buere-Yongen.

Deze is korter in een gedrongen als de Oofl-Indifbe, en licht-wos wan verwe.

Heb een zeldzame met een witte frualle band byna boveri atan.

De olugel-Hown, of Kemphan.

Van dezezyn 'et werfeheidenerley, dog beb 'er drievas, die lever-verwig zyn th heb "er gezien; die uitmuntend, heerlyk, en var cen fterke Appelbloczene verw waten, die wy ook op zyn phats melden zullen. Agrer atn volgd onder de zeldzame nog een ongemeen part.

De Weft-Isdiche Brandaris.

Van deze heb ecn bruine, en cwee grateuwe, de ecne mooy groot.

DeWeA-Tudiche lever-veraige Brandaris, mell wel zowarte buth ; een fchoon ftuk.

Ik bezit "er een ongemeen ftuk van.

Do Wall-Indifbe gemamende Tuat.

Dit is een zoort wan Tooten, zonttyd's gemarmerd, zomtyds mee pikikels, en ook met groote wekken. Ik heb "er wy ver foheidene wan.

De Wofladiche Kroon-Hown.

Heb 'er vier vali. Hy is ros var werw, cti wit.

Duar zyn ook gete en Orangit-agtige; dog by andre Liethebbers.

De zeldzame lowe gedornde swppellek,

Heb "er dric wan.

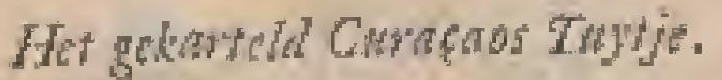

Heb "cr [wee pat ఛ"an.

$$
\text { De roffe-plate Zed-Appl. }
$$

Bezit "er cen parr yan.

De Agrinse nagghander de Lip-Hoorm.

Heb verleheide wan de zelwe.

De Argunze gelatoderde Lip-Hown.

Deze is ved klecnet dan de vorige, en war anders wan fatzoen. Ik theb 'er ettelyke van.

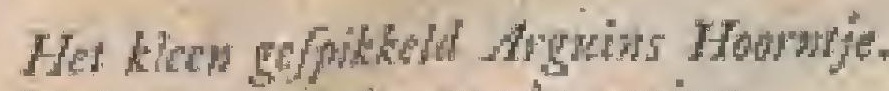
Heb van dere 'er mede cenige.

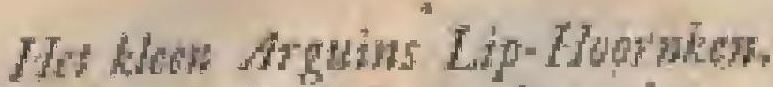
Van deze heb ik 'er ook cenige. 


\section{WEST-IND: en Europ:}

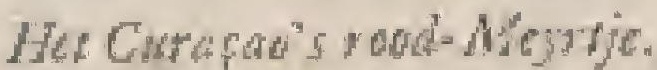

Dit vale wat groder, en wat bruther, atg "t recht foode Neyrje, watr van mede een parar bezit.

Ihat Apolbloam Dadel, of Sipwantootic.

Hier wan heb ik 'er twce.

De gladde Spil mer tanden; by Bowan. nits, in de III. Clafis, No, I I. to zien.

Hicr war bezit if 'er eeil paar, en weet 'er nog mal" ewee part zan. Het cen, met nog een grooter roort, hecf de Hecr Francois Kigelar, in "s Grawhbage bezcten (dog is $\mathrm{nm}$ in " $\mathrm{E}$ Cabinet vali de

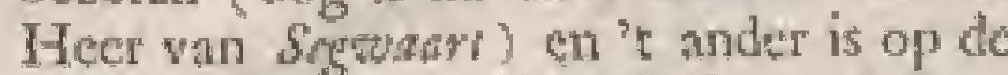
werkooping wan de Heer Leder verkogt.

De Purpowa, wallende in Cadis; my vereerd door de Heer $V_{0 e t}$

Kinderlens yis we Luthen.

Van deze heb itk er cen paras, my door de Heer Kiggelar gefchonketi.

De kleme Mowfbe THWhal.

Dit is een moye zoort van Alikwiken, of Slek ker, die rood, wit, en ook fchoonrood en wit gemarmetd zyn. If heb 'er vyf wan.

De klewe Moor fla Tompl.

It: heb "er vier van, en zy zha bJacuwagtig; dog de huid iș "er alfgetrokken. Anders zyn zy bruin.

\section{Fiet zeldzan Minta-Obt}

Van bimen aan de room Appetbloeffem. Ik heb 'er twee a duic.

Het werkerd gect Hoorwit.

Diatr zyn 'er ook, die groen zyn.

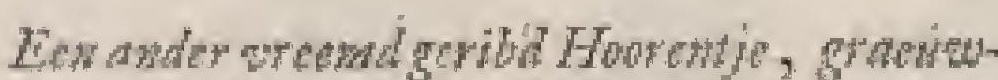

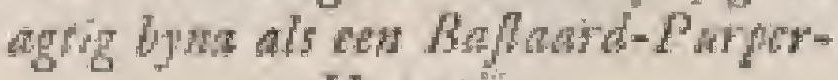

Ik heb 'er ecn var.

$$
\text { Hownte. }
$$

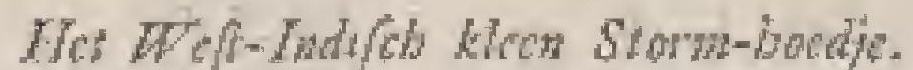

Van fatzoen verfelyild die niec van 'e Oop-Iriffeb kieen Storm-hoedje; dog 'e heefe, in de platts wan cen fyn gebreid netie, groye ilbben, die cen fpierwiten grond uitnaken, en war op gecle wlek ken zyn. Ik heb 'er drie, en 't een is zeer kleen, en nier grooter, a als "L uiterthe lid van myn middelfte vinger; dog de 2 andre zyn nog wel cens zoo groor, en zeer fracy.

\section{De Oraneie Kupers-bous.}

Ile beb "er een paar vath.

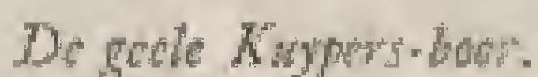

If heb ter ook een parr van.

- III. DeEL.

\section{ZEE-HORENKENS.}

De Spror cothe Kaypers-bow.

Jk bezit 'er cen part van, en ik heb dic noit by jemand anders, dan by de

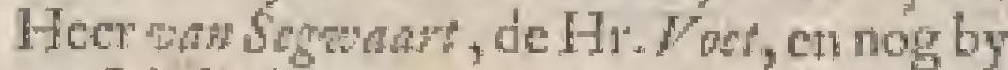
een Liethebber, oen prar of twee gezien.

De Cirrom-gele Doyer.

Ik Heb er cuec war de zelve.

\section{De Oramge Doyer.}

It lieb 'er oole rwec vitr.

De Geriandla Doper:

It heb 'er ook cwee van.

Bowio Doyers.

Ik heb 'er erelyke was, en zy vallen op Curapar.

It lacb "el" drie van.

$$
\text { Hot groú Baylye. }
$$

Een zoort van gevleke Bezonts, wh welke ife 'er' twee hebbe.

\section{Jot ged Beddekn.}

Hiet van heb te 'er een parm, wan de Hecr Groen tot $A m / e w d m$, gekregen, gelykende zeer wel na de Horen, die men by Rwwphins Tab: $K L L X$, by de Letrer $\mathrm{C}$. vind.

\section{De klene Wydmonder.}

It heb 'er dric pant' var.

\section{De blatume Rnol- Hown.}

Dere valt op onze Stranden. Heb "ez ecnige van.

\section{De gete Dojer.}

Deze vallen onk op onze Stranden. It heb 'et ool ecnige vin.

\section{De Whatue Doy:}

Heb 'er mede eenige, en zy vallen ook op Selewelngen.

\section{De Hollandehe Sld}

Vati deze heb ik er velertey zooten, en van cen fracje rceketing.

\section{Do wrewda Boencu-Jongen, uit de Bacy} van Caritix.

Deze is klech, ais cen kleene BoercJonger van gedatinte;

Ik heb "er drie byzondre patren wan.

\section{De Karakd}

Deze valt eot Cerless, en heb "er cenige wan, mar dair vallen fehoone bruine in de Middellawdze-Zes, die wan onder Appelbloeffem zyn.

De Heer la Foilhe in den Hage heeft "er verfecheide wan, ook lieefe 'er de Heet wan Segwart een. 


\section{Verhandeling der W'EST: en EuR: ZEE-HORENKENS.}

Het Katroy g gebanderd Tollotio.

Dir is een zoort van een dik zeer fraey zwart Orangic, en wit gebandecrd Tuitje, of Tolletje. It heb 'cr twee vant. En 't eene is my wereerd door een wriend, die 't zelf op 't Strand wan Katwyk gevouden heeft. Het is by Bonaumas in zyD III. Clathis, No. 66. te zien.

De Heer Kirgclatar, (die "er meer van bezat, gelyk ook de Heer de. Konting tor Dordrelbt, dic 'er alleen vericheide, en zoo meine, wier zoorten wan heeff) vercerde my 't ander; dog 't zeldzaamfte van allen bezit de Her Vervel, Apotheleralhier.

\section{De groene gelonderde Slet.}

Van deze bezit ik 'er een parar, dic my de Heer Sebywoot vereerd heeft. 'Zy is angemeen fracy, en ik heb die by niemand meer, dan by dien Heer, enby den Heer wan Segwant, gezien.

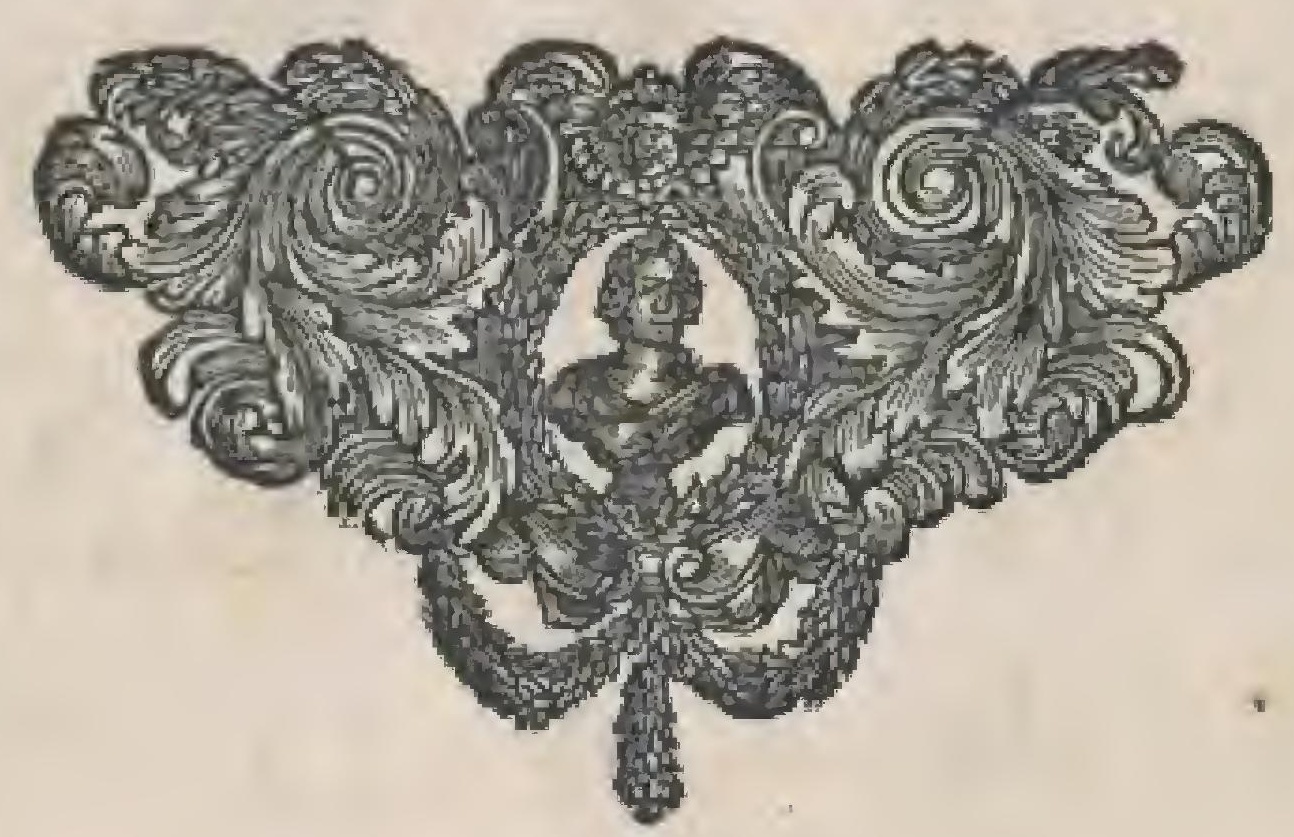




\title{
VERHANDELING
}

\author{
D $\quad$ E R
}

\section{WEST-INDISCHE}

E N
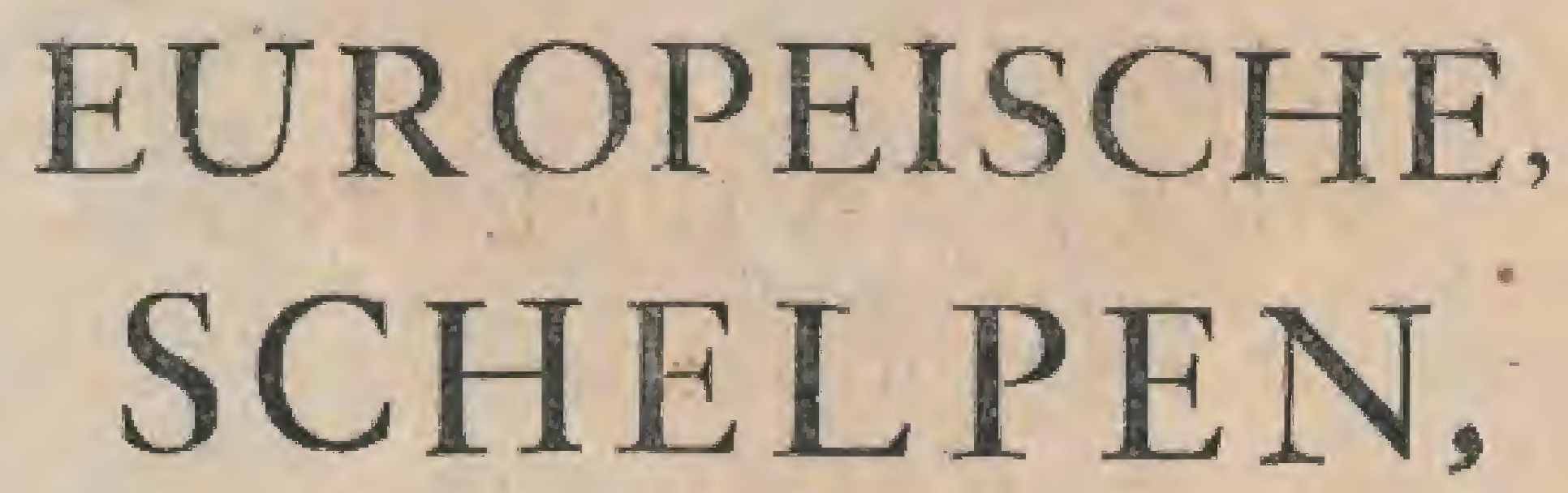

O F

WVatin-

itt tethes, of

tituroper

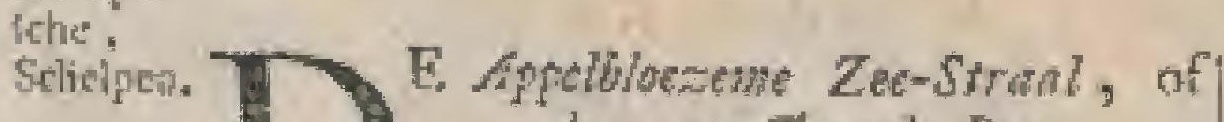
de gropte Tour do Bra.

Deze, en the volgende hedr my de Hect Aberis Sebr, tot Amprans, wereerd.

\section{De Alama's Dwbits.}

Dit is een fchonne roode Schelp, (it cen Polferkas d die op Del Mina in $A f r-$ ca, en op Curaca, walr.

De Heer Seba, en de Heer Segecld in is Grawenbate, nils nok de Heer van isto-

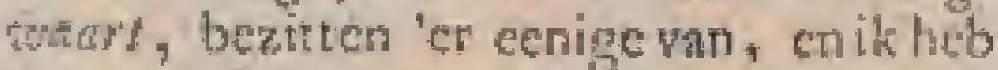
'ег ли ook cen parar foode van, en een rchoone wan een Gredelyn werwe, wat nis 't Appelbloczen trekkende, die my reel geld koilt, endie ook teer zeldzatim is.

\section{De. Fram clo Quaker.}

Dit is een brenine, en kleene Sehelp,

It heb 'er eco para van, dat my vande Heer fe Katsige vereet is.

De Ficlete grooit Noord-Kapose Mofel.

Iyen ongemeen fracy ftuk, wat whect

para heb. Wén noemdzeook wel Yilands ec Mofielen; dog de Hecr Far bezir nog

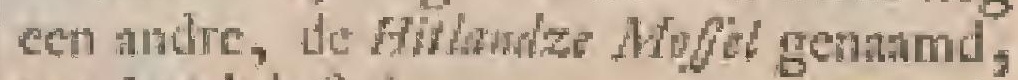
een heerlyk fluk.

\section{Holdowlog Mofw.}

Van dere hel vercheidente fracije, en Hacy gellepene ettelyke puren.

\section{De klewe Nowd-Kadpe Mofl.}

Wan fatzoen bynalsonze, donliet van verwe; mitut tecl brecter. It heb 'er mede een paar trar.

\section{De Hollanlohe $S$ ly-Mo/fl.}

Deze is bleck gruen, platrigtig, ch bred; hebbe "cr cenige van.

Ool is "er rog eten gronter zoort van cen ander fatzoes, en verw.

\section{Do scherehaze Mofel, of Braed-par.}

Dere is zwata, dog fomal. $1 k$ hob ef eenige van, en drie geparlemoerde, en een diergelyke, wan Prand foort gekemen; mants byna de helf grooter, alls degemeene.

$$
Z z_{2} z^{*}
$$


544 VER H A N D

De St. Yacolus Scholf, wir de Strat Davids.

Dit is een frateje geribde roode Schelp, watar wan ik cen groote door guntl wan de Heer Poct, en nog twee andre mede uir zyne hand gekomen, bezir. De kleene zyn wan deze die mooyste; dog de grootthe hecft de Hecr Sebywoet.

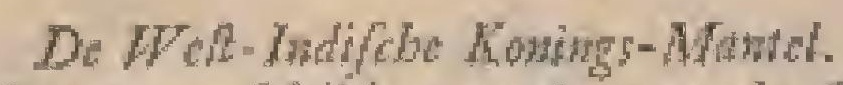
Deze verfchild weynig wan de OoffIndifche; als dat $z y$ wat lichter van verw is. Ik heb 'er drie van.

De groate Greenlandze Quaker.

Deze is gracuw, geribd, en redelyk

\section{E L I G DER}

groot. De Heer Voet heeft ze my vercerd.

Ik heb'er mathe een van, 't gecn my door de Heer Kiggelaar vereerd is.

Het pruin Poffertic.

Hier wan heb ik 'er een pant.

Een zecr fraey par bleck-Purpre Mofficls.

Dus bezic it san de IFel-Imaliche, of

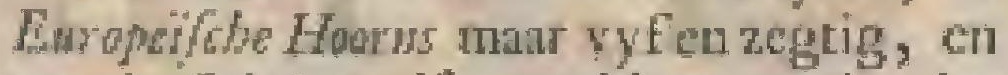
wan de Scbelpess elf, een kleen getal, by 't geene andre Lief hebbers beziteen.

\section{VERHANDELING \\ ZEE-BOOMEN, \\ ZEE-BLOEMEN,}

En 't geen daar verder toe behoord.

Yin T. Ot de Krinm der Zere-Howrakens, de Zer- behooren mede de Zee-Bumen, cำ:

dere zeldz voortbrengut. Endaam ver wonderd het my zee, dat de Heer Rumplats in zyn Rariteit - ktnuer niet zoo uiewoerig darar van, als wel vas de Zee-Hoovalens, freekt, angezien by een fehoonc Zetibrin had, op de welke ik in myo jonge Jarren, na dat pas in Anbory getcomen was, een Gediclat gemaakt heb.

It zal dan manr kortely ls noemen, wat voor $2 \mathrm{et}$-Bown ik nu nog bezitc, die if uit Ambina nedegebrage hebbe, ofte die tier, mynes werens, vallen.

Da grode brede zwarte, ongerale ZieBowen.

Deze vertoond zich als oen zeet grootc. Wacjer, met nlic zha Leden and ext.

Hice พatr bezit ik 'er wer zoer traeje, die angemeen groot zyn, ên een wan de zelve is roo groot, ats cets Thee-tafel, geweelt, toen ik die eerlt kreeg; dog door 't wervoeren nu en dan heef by zeer veel geleden.

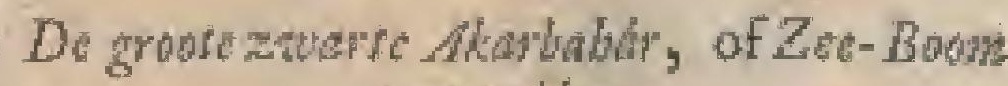
wat radeps.

Hier wath heb ik twee kleene, en bezit takken wan de groote, zyodic fracje vercierde-Rotrings, en een "er wan heb if in Indien voor myn Rotting gebruilit. Het is ecn Coralugtige flaff, hoewel het ten deelen ook Hour is, dat met der ryd Corital, of Stcets wetd.

De kecue brede wuarte Zee-Bown.

Wan deze zoort hobik "er vicr, endant

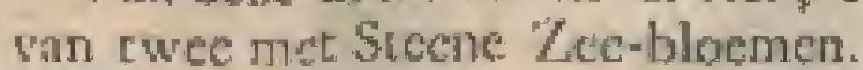

Oots rertoone van die zoore cen nete afreekening by de Letrel A A ; in de Plat No.yr.gemerkt, gelyk men dic wan de 


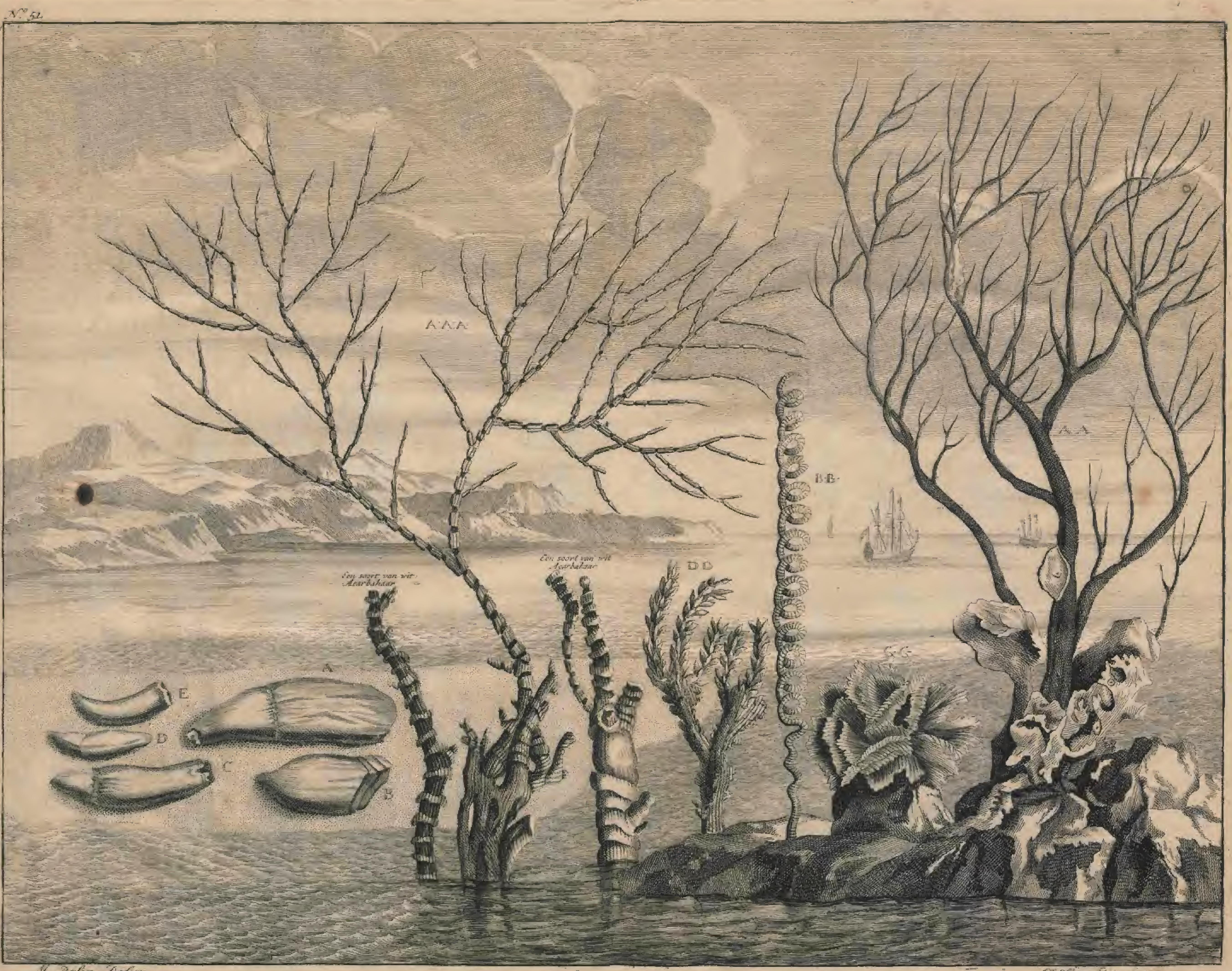

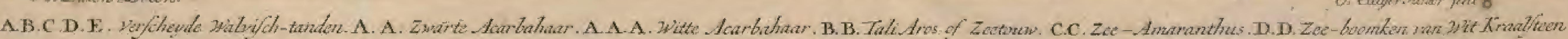


Hicr is nog een zoort, die op Steenaguge Bergen ontrent de Zee-katnt, en aildus op 't Land, en riet in Zec, grocid, werdende daarom de Berg-Acarbaliur genatand, dog keme dat niet, als uir vethaal der Inlanders.

\section{De gratsu-aglige, of Afowerwige Zee-}

Van dezehebik'ereen, met cen MoerNagel van Steen, ch nog een lang gewalleh "cr by. En ven deze zoot nogeen met een kleen Appelbloezem Zec-Boompje, en nog een wnder gewaich diar by.

De Koper-aglige Zer- Buom.

Hob 'er rwee ran, even eens wan werw, als Koper, of Methal, en een met een Hinekam " $\mathrm{cr}$ in.

Hier ondes tehynd de Goude Acarbithit te behooren, war van hier ma brecder.

\section{De zavare Bafia Ze-Wheje:}

Wan deze heb ik er nu geen. Deze zyn zeer dicht, dik, en egter doorzigtíg; gelykende wel een rouw - Wayer

\section{De roede Zer-Boom}

Hier wan heb ik'er een; matu datr walt een ghadder en beter Coraaligtige zoort in de Mdddandflae-Zre, cin ook in 't roode Merr.

De witta Acrbabitr of Zt-Bom.

Deze is wir geribd, betande vit kleene unklen het woorlte vin een pink dik, cri ook dilker, met verfcheide wwarte banden ann ieder Tak.

Van dezc zoorte heb tul geen eene Boom; tohar heb 'er hog cen groot dif thuk war, en ook cen fluk vwin de gladde wite Aoubahis , alzoo het beide in de Genceskunde gebruikt werd.

Ilk vertoon dete Boon, by de Letters

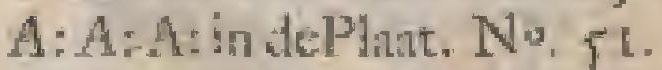

Daal is nog een dunne zoort votr graeuw Acarbahâi, "uls of 'E roode Rysken's waJen ; dog kenne die nies, gelyk mede die zoort, the wel na Heidegelykt, dog wel de Goude Acarbahatr, en robet zeggen, dat die zeer fracy gehal hebbe, eveneens als een Goule folnatryn Tak, die wel cen voet lang, en twee dumen biced was.

Fhe gerbatd Srom-land.

Hicr van heb ik 'er ecr, dat fracy is, op ryn Rlipic.

Ookgeve een afreckening wandit Talt Aros, zoo ats "c in zyne bogen zig vertoond, by de Leter B: B:inde Plate No.j I.

Hot pech snow iawe.

Hier van heb 'er twee an cen Stect.

De Spok-facme Akorlabar.

Dewe heb nus nict; marti heb "er verrehedde van gezien, lijer in $\lambda m b$ an gevallen, die 'erereneens, als de wite Spekftecn uit zagen, en die half A ppeibloefFenr, er half wit, waren, en een, dat ten declen nog zwart, en cen, dant honderd Rylisdalders voor geboden was.

\section{Kleche Zee-Bowkens op Klptom, wets .} witre Zec-Blocmes' of op.

Hier wan heb ik 'cr' vier' cn nog een zeldzame Bloen op ecin Kipje.

In Asiosin wilen wat voorby deGalg- Zee-

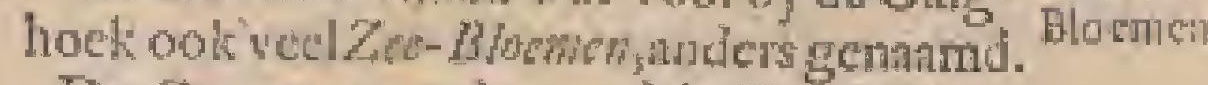

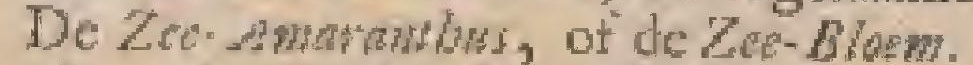

Ik lucb "er wa deze verleheide zecr fchoone, yoo op een Sicen, als buiten de zelve, groote, en klecne; en ook wel andre Stecmen met de zeltic, zoo als zy cent beginnen.

Ik vercoone dic Amitumathis, by de Letters C: C: tu de Plant No. 5 t.

\section{Krank-Brondens of Sfowen.}

Van dero bezic ik "erzes lrneje, enwertoone "t fatzoen

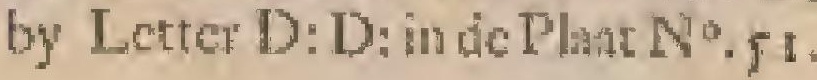

$$
Z e c-K_{0 Q l} \text {. }
$$

Vat dere heb it tweejonge Koolticns.

$$
\text { Zec-Haw/bocrew. }
$$

Die ifk zecr fisey gelual hebbe, hoewel 'er nog ies wan bezit.

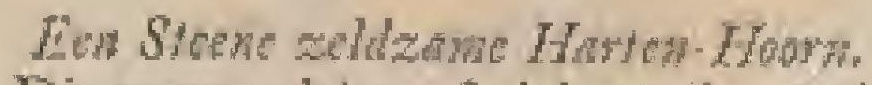

Dit weergadeloos fluk bezit ik, en lieb het noit meer gezien. Onder is deSteen of hy ritn Koper was, er boven is de Hoom zelf uit fyne doortikens beftande, die nogtetis breede takken, nils was het de Hoorn van ect groot Herr, maken.

\section{Neptome-Mtests}

Van deze heb ees groote lehooine vel ecr gelind.

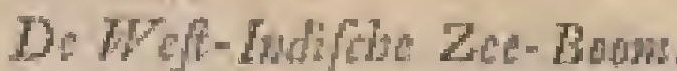

Deze is geel en Purper. Hcl "er verfcheide klecne wan, vas welke zommige allecn op zig zelue, andereby ande Boonjkens, of Steene gewafichen, en ook cenige als cen Fontunge op Schelpen, gegrocif ayn.

Deze zyn onder de vorige reeds geteld.

$$
\text { De Zee-Calophus-Noot, of de Calopt }
$$
Mallswa.

War van if 'er een bezitte; diens of tcekening, by de Letters E: E: verroone, in de Plint No, ff:

$$
7>23
$$




\section{VER H A N D E L I N G DER}

Deze is een heerlyk tegen-gift, en woor eene Noor is op Maralh wel $400 \mathrm{R} y \mathrm{ksd}$. beenald.

Ln Keyzer Fudalf de tweede bood re vergects yoop Giuld yoor ene Noot, dic toen onder de lirfgemanen van de $W /$ fors (Nazaten van Wodfert Hewanzen,

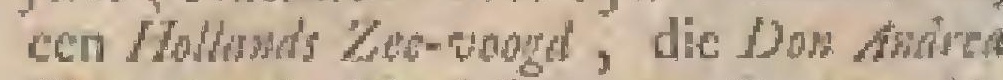
Mulado de Memefí voot Bandam $A^{9}$. 1 6oz. zoo kloelmacdiggehagen, en deze Noot van een Pasgerasig tot een gefchenk wan dankbarthetd beteonen hod, man al-

- leen beruftende, en de enigfte, die toen in Luropa bekend was.

Ly vale in de Maldiws, en oole clders.

Dotar is 1 og cen lelecher zoort wan ZecCalappus-Noot, ontrent als ecn Kaftanic van groote; dog kenne dic niet.

Srecne rowde Makronm.

Wan deze heb ik "er twee an dric. Zy zyn wir, en wol fyne grocwen.

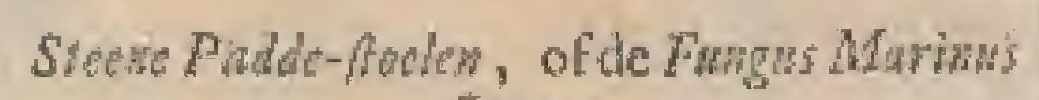
Sancht.

Hier af heb 'er nog cen.

Roul Strand-Corant.

Dit zyn geen Boomen; mast fukken wal pyplens; die ap Latile ontrent het Zuiker-broodje, cen groote fpitse Klip, wallen, en die men mee bet rechtgiad $\mathrm{Co}$ tital biet vermengen moet.

$$
Z e r-b a f h
$$

Van welke nu niets bezit; alzoo alles 'er' van weg vereerd hebbe.

$$
2 c e-N e l j c s
$$

Watr wan 'er nog cen liebbe.

\section{Suthe Kollen.}

Ih heb "cr grootc, en ook klecue.

De Jicene vallen in Ambina; dog war de groote vallen, weet ik nitet.

\section{Zec-Nateles.}

Wall deze heb ik "er verfheide fracije bezeren 3 dog helbe "er nog man anige vat, cur ook cen Srene Moct-Nagel.

Men zict nu cn dan ook werfteende dinDingen.

gen. I] bezit dan van.

Hot watded hais.

Dere Howtn wind ik by Rumplisu nict,

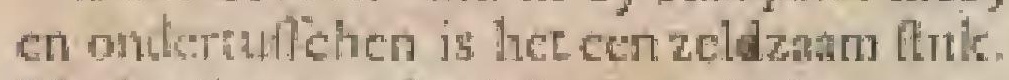
Hy hetet cen gehed Steenen-huis op zyn JyF, dat by overnl mede vocrd.

Ilk hed cor twee van.

$$
\text { Firfeend Howt. }
$$

War wn een fuk bezit.

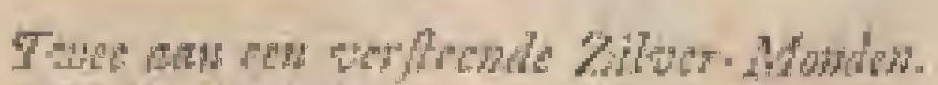
Welke il hebbe.

\section{Den Amignishs.}

Een groene wol-agtige Steen, zeet zeldzan, en wan welke de ouden het onverbrandbaar Linnen maikten. Heb "er zeer weinig wan.

Bethalven de hier angehalde Well- my n

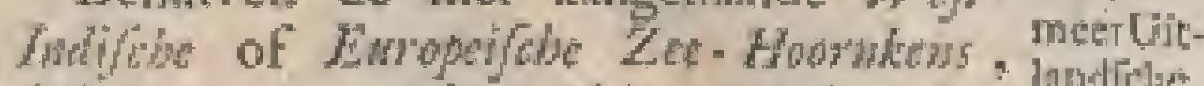
Soblpen, en andre zeldzatmbeden der Hootns Zee, bezitten de Liefhebbers hedens- afgejeelat daags in hume Cabinetten een veel groo- zien kam, ter" getal, die 't my omogelyk is, on alle op re noencen, behalwen dat 'er veel wan in de Werken van Pbilippes Bumbme, Lifer, en mes" andre, Yan welle wy nader fpreeken zulken, zeer wel geteekend konnen werden gezien.

Zommige Menfchen zyn zeer verwonderd, hoe men zoo dwass $z y n$, of wat mee ' $\mathrm{er}$ angenaans in vimden mag, ofn 'ar zyn tyd mete door te brengen.

Wy zullen lier op niet anders antwoorden, dan mee het belend Latynteb

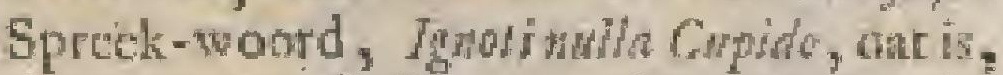
dat men geen liefde, woos't geen men niet kend, heeft. Heeft God, die gronte en wyze Konftenar, zich willen hezig honden met deze kleinigheden te fohcppen, men moet niet meinen, dat luet durntsheid is zich datr an te verlultigen: want men heet immers zoo veel foof van verwondering over die kleine, ots over de grootfe dinger.

Het moct ook zullken Megten Licf- Oullieid licblery njet zyn, was mede zoo ved win derze wyze groote Mlnmen in de Wereld, bery. al van ouds her, hun tyd verfleten hebben.

De Gridele Dicbter Howern fpreckt in $2 y+0 d y /$ wan het $\mathrm{Hol}$ of de Rots vain de Godin Calpho, met Zee-Hoprakens opgecierd. Dierhalven zyn zy dan toen al bekend, en van opmerling geweelt.

Albouatu, en wooral Arifister, Aliatirs, Suldas, de groote Cictro, de wermaarde $\mathrm{N}$ avorlcher wath illes, whe de $\mathrm{Na}_{\mathrm{A}}$ ture zcldzams gaf, Plinis, Howating, Strobo, Lishise, en meer andiere onder de oudeti, hebben zich daar mede nice alleen opgehouten; mair zommigen hebben al zeer uitwoerig, hocwel andte er mitar Ituks.wyze over gefohreven, onder welke Arifotelcs, en Plisits, vitmunten, nict regenfunde bun Schryen by de nerter Werken wan Rumpliws, co Bonamm sws, niet kan wergelesen werden.

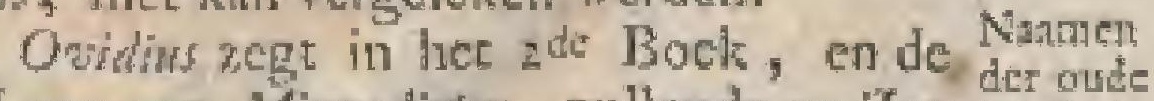
II van zyn. Minhedgen, zullende op Zee Lielhebgaan:

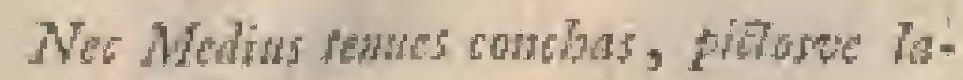
pollos.

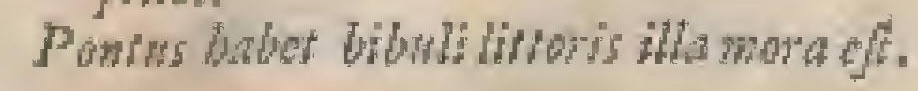

Dat is: Na orize Vertalinge.

In ${ }^{*} t$ 


\section{ZEE-BOOMEN, ZEE-BLOEMEN, enZ:}

In 't midden wan de Zee zice men geen dunne Horeus,

Geen Pikkelen, nog van de fracje Keijen Torens.

Men heef die muar alleen tan liec bekabbeld Strind.

Dus zier men dat deze Dichter al mede vin de Hoorns kennis moet gehad hebben; dog had lyy de Gorita, of het Doekw-buyjic, (cen Hootn, wan welke de Menrehen de Zcyl-konit leerden) gekend, zou hy dir niet geregr hebben, alzoo die Hoorn zyne Corwn in ' midden vat de Zee zeer licht had konnen ontmocten, behalwen dat weel andre Hoorns alleen midden in de diepte der Zee gevangen, en met Bobbers, of Vifch. Fuiken, op drie a vicr honderd radem diepte opgehatd werden.

Hy fpreekt ook elders wan Schelpen, die hy op "E Land had zien leggen, en van Ankers, op de toppen der Bergen gevonden.

Ook'zegt Ciceto in zyn Briegos wan don Redenat, en Valeris Mawims, hi. 8.

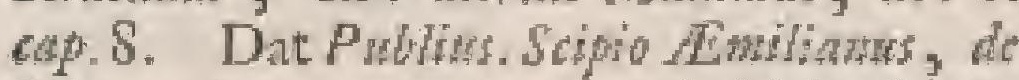
Nomantincr, met $z$ yn goede Vriend, $C$.

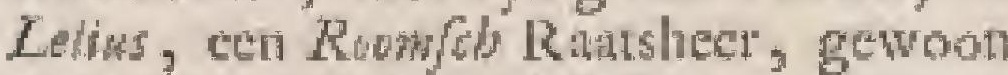
whs ontrene de Steden Cajeta, en Latrentwn, ann Strand te gan, om Schelpen, en Navelen te zoeken.

Suntoutus eap. $4^{6}$ en Sextus Anrths Figar, teckenen nat, dat den Keizer $C$ Caligula zyo Krygsmagt op den Oever ontrent de middelte mond wan den Why in flag-ordre gefteld hebbende, de Soldanten belafte, in plants wante vegten, Schelpen, en Kink horens in hunne Boezemen, en Helmetten, te verzamelen, keurende dien Krygsbuit wan de groote Zee weerdig, om die op "t Roons $\& b$ Gapiloliun, en in 's Keizers Hof, tot een zonderliag Cierand op te duiren.

Wat Arifoteles, en Prsist, over verfcheide van deze Zee-Hoornkens gefchrewen hebben, konnen de nicuwsgerige in hunne Werken nutzien. Gelyk de eerfte op to verzoek van Alexader de Groot zyn Hilhoric der Disren, (die net het Reyzen, en morfchen wan alles zoo kec Schatten an dien Vorft gekoft heeft) ondernatr, alzoo is "t zeker, diat wy doo beider dood veel wan dat Werk in zyne volmaktheid verloren hebben. Plinins heefe over de 160 , zoorten opgeteld; mar de selpe vry werward befichreven, hocwel hy vas werlcheidene Hoorns in "t gemein zeer fracije dingen ter nedergefteld.

De later tyd heeft geen minder Liefhebbers gegeven;

Finder Onder deze tellen wy Gelesw, ArotenLatere, wa, (eigentlyk Abe 1 Sina genaamd) Diofonder, Mutians, Jacobar Bontwi,

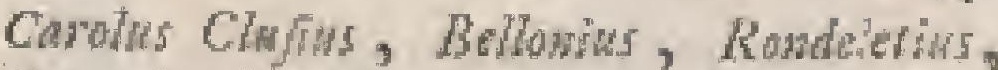
Conradus Gefherus, Adrowandws, Bocbarthe, Frandfors Pyard, Robberias Cous Haniwas, Jicafina , en Nicoldas Nirepfors; Alle welke over de Hoornen en Schelpen, cn zommige mar over de Reukwerlies, van have dekzels gematis, getclureven bebben de voorasindle wa-

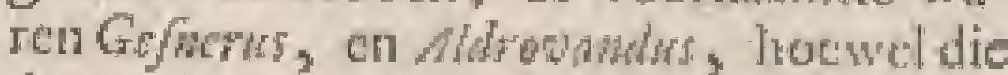
dat mede mani ftuks-wyze gedann hebben. In de voorleden Eeuw hebben hier ovei ook gefchteven Falpus Collans diens Werk $A$. $r 616$. re Romen is gedrukt; dog de Hoorns, door hem in Prent vertoond, zyn weinig in getal, en nier treal byzonzonders. Men monet die echter, 1ja die cyd, als een van de befte pryzen.

A0. 1660. (of wne ect' kwam 't Werte yan Yonfon cie, watr in mede over eenige, dog mara gemeent Hoorns word gehandeld.

$1 \mathrm{k}$ vind by hem age Platen, zeer net deze en geene Hoorns af becldende.

Op de eerfte Tub. $X$. gemerkt, vindede Hoors: Nawhile, en zyn Wirch, ofreden Polpote, in fonde Proptsa, de gedoninde en de onge- beeld. doornde, "Hachingt, of de Kimboom, zynde in gedante, gelyk ook zyn Strombus, een zoort vall Trampetom, de Mhts Actearus, of de gedoornde Purper- dog eigentlyk een zoort wan een klecne LapHown cn ditn ean geribde Olie/Torm.

Op Tab. KI. komen nog vier byzondre zoorten van Muticts, werlcheide Tawbi wes, of kleene Hownens met veel gieren (cn dan onder al fracije) ecnige Trobs, of Talon (onder welke zyo groote Tal met fraeje knobbelties in zewen reyen voorzien is ) en dic graot on klecn, ook eenige Sicken, of Werol-Hoots, of Perfrewow, cnettelyle Aikruhen, of zoorten van Doyets, dog de fratey fte var alle de Hoorns op dat bhat is zyn groote Thrbo, zynde cen lange Hown met veel gieren agter, als cen dunne Trompot, voor arr dik, en mer een wy den en fcherpen bek, onder welke Hoorns hy ook twee langwerpige Schelpen vat weing belang mengd.

Tab. XII. komen voor verlehcide Co. chlea, of Slekker, mitsgaders drie a vier zeldzatice Hoorns, die ik nier Jemne,

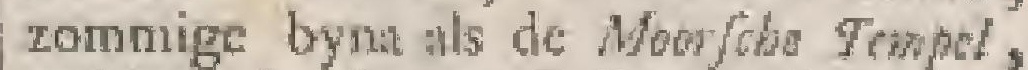
undreals de Sartyon Rols, of Dadels, die hy al mede, zeer verward, Slektey noemd, war by hy ook eenige Zec-Appels, en jets meer, tot die zoore behoorendto, voegd.

De cerfle Hoorn op dat blad s die lyy zyu geribde of geplayde engersuclde stek rocmd, is de fracylte; dog kenne dic niet. Tah. $X / H$. vertoond ons mode eenige Zce-Appels, en Schelpen, als de Padriomoer-Schlp, tot zevenage ftuls toe, die 
548

V E R H A N

niet kenne, meelt ronde, alsde Qwaker, van gedante, zommigegefclubd, andre fenareld, ch cenjgc geribd, als ook twee

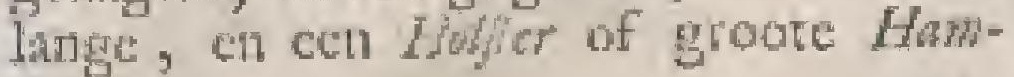
Diblat.

Tah. XNF. Dont ons zicn cerige Chowic, of Ganis, Oefters, Aeche Lazwrusklaphen, en vier it vyf zoorten van kleche Sr. Yarobs Sebelpen, onder welke"cr twee a dric fritey geteckend, en geribd zyn.

Tab. XV. Vertoond ons ecnige MoftWn, Orakers, Zet-Poklen, Nawels, en Orgel-popess.

Vol. $X V$. Leverd wit verlcheide zoorren wan Holfurs, of Ham-Dibliten, tor nge Atuls toe, en vyf a zes Palde, of Khp-Klevers, anders ook wel Lantios $\mathrm{ge}^{-}$ juklnd.

Thb. XVI. Verwolgd nog met dric Patelle, wat" onder dic van Copros fracy, cin dik geribd, en ook een ongeribd is. Men hecfe diar op ook wan het Zee-Oor, of de Malol-Ooren, wwee zoorten, nils mede ecrige Porchlsna's, of Klip-Horms, en Canvi's; dog de belte is de Cunba Perfica, zyde cein dikke Dodef, mar deze, en de Porchlarats, noend byzeet lswalyk Combas, dut Moferes, of Dubletenzyn.

Hy vertond hier ook ecrige \$lanzet yes-Hooraen, dic verfteend $7 y n$.

En dar hebt gy alles, dat on Jon/wo van dezc geringe zoorten, nog zect verward, vertoond.

Ao. 1665. Schreef Rebefort in zyne Hiforit der Antles, ook over age athien Hoonnct; dog var weing belang

Ao. 1635 . cn 1686 . (of wat eer nangezien Bongmas al wan hem weet we lpreedeen' heeft Marima Liffer, een Engelsman, zytue Huforia Concthorm uitgegeven, cen zeer fracy Werk; dog matr in Ilast, ronder eenige belchrysing, (zoo vere it die geaien Jeb, en bezic) dan allecen met byrgeging del platzen, ware wy willen. Hy vertoond dar in ecn getil wat duizend agt en hegentig Hoomen of Schelpen, dut zeer veel is.

Facolus Petiver, cen Londers Apotheker, of Drogit, en Lid wan het Kounklyle Gezelfehap aldaw, heet $A^{\circ} .1702$. mede en Wrete laten vicgan, dat hy Gazobylatwm Nature, of Shatkamer der Nature, noemd, watr in verlcheide Hoons, enz. zeer fracy gefneden vertoond werden; matr mede zonder befebryving; hoewel met mawyzing, wan what by die bekomen heefr, en na imyn gedagten iry wat werward, ch zonder cenige ordte, atangezien dien Heer Planten, Wiflchen, Ciptlen, Hootns, Penningen, Geftemten, enz. alles onder cen vertoond. Ook heefe hy (immers zoo verre debladenaangat, diekgezien heb, ilzoo die wan $T a b$. $X X_{\text {, tot } T a}$. LI, onduken zeer wei-

\section{E L I NG DE}

ñjg Hoorns "er onder, en onder de zelve gown fakken wath ham.

Dus fprecke men ook met lof van Joh. Woodruaurd, P. Boccote, N. Sheno, Yac. Grandins, en Morlon.

Veel heerlyher en nitwoeriger is bee fhantWerk van den fezwit PJilfops Rowawne, nutwetk. Receatio Menis Es Ockl, of velultiging des verttands, cл der oogen, voor de Naeuwkeurige Navorlchers wan de Schnal-Dieren. Dit is $A^{n}$. $16 S_{4}$ te $R \theta_{-}$ hen gredrukt vol keurlyle Planten, en met cen zeer nette belchryving wa zune Hoornkens en Schelpen, in "t Lays, en in "t Jaliaas/bb, voorzien. Het befte Werk dat tor dezen tyd toe genonikt was.

Hy geeft ons cen netre en kante fchers wn zyn Werl, wask by men zien kan, wat over hy al fpreekt. Hy verdecld het in vien Declen.

In he cerfe toond hy, dint deze Lief. hebbery der Zee-Hoorvikens zoo negr, en Kinderlyli niet is, als zammige zig verbedden; mat dat zy zeer wexl nuttigheden uitleverd.

In het tweede Deel befcluryfo by de namen, gedanten, de warwen of te couleuren der Hoorns, mitsguders de platzen, wan $\mathrm{zy}$ vallen; dog reel beter had hy gredan, indien hy, (gelyk in 't Werk. wan de Heer Rumphis getchied is zyme Phaten by cenz zeker getal Hoomkens, die hy belchreet, vervolgensverdecid, eis er die 200 bygevoegd hat.

In hee derae Deel iteld hy artrent veertig fracije zaken tot de Hoonkens behoorende, woor, en loft de zwarigheden, die zig das ontrene opdoen, op; cononende onder nndre, datde Pecrien in de Pecrl-Schelp, nier van den diuw, als de Kinderen der zelve, gelyk Plints nimer veele gcloofide, matr door cen nateutly gebrek, en cen riekte, die Vifh cigen, vontkomen.

In het vierde Deel geeft hy ons een zeer fracije, cn nette afbeclding w way vy honderd zesen swintig Hooros, of Schelpen, (wat onder er egter werfeheide wan onder en vas boven vertoond werden, en dus dublocld woorkomen, dic hy in 't tweede Ded befchreven had.

Hy verdeelrze in Hoorns, of een-Schtlige, en in Schelpen, ofre twee-Schalige, die anders on dat zy dubbeld zyn, zecr wel Dulbletten genand werden.

Hy vertond de zelse in drie Claben, of ordres, in welkers cerfle men twintis zoorren eer-Schalige, of Hoorns, ontmoet.

In de twee Claffis zict men honderd Schelper, en in dederde vierhonderd zes Hoorns, onder welke 'er veel, die wy reeds belichreven hebben, mat oak zeet vecle komer, die niet kenne, en ooft 


\section{ZEE-HORENKENS VAN BONANNGS}

treele, die by geen Liefhebbers ontmoet heblue; dog heb entej ook cenige der zelve by desen en geenen gezicn.

Om dat nu dese necritige Man wel "r beft en uierocrigh oner dese flof gehatialeld heefi, en om dae tyo Werk zecr weinig te bekomen is, zal ik laier bok een korte dehets wan de zoorten, over welke by fpredst, en the hy ons in Plat vertoond, volgeds hare $N$ ual, irlalien.

\section{De I. Glet/s,}

N.

I S Is de Papela of de Porlemor-

2 L Bow , by ons bekenil.

3

4

$5\}$

7

8 \{ De grove an fyne Obfats-7ath.

to Is de grooteronde Parlontoc 5 dido

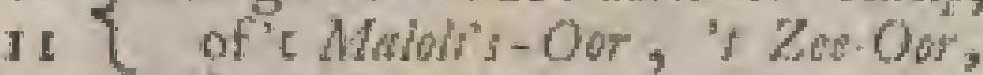
die hy onder en boven restond.

it De $5015-K a p$.

1) Het Doken-bwyfin; dor kech.

14 Eenige Bahni, Zee-Droytis, of Ir $\{$ Zet-Pokks.

16 Het Dowls-Howh.

17 De Mowze Tuloand met permen, liet Wyfje.

18 Dito zondel pennen, en de rechte, of 's Minneken.

Io Een andre Zre-Aptel.

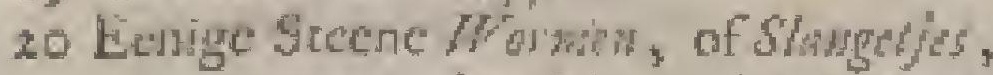

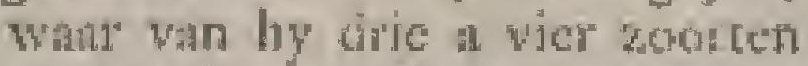
Yertoond, en ook nog eeri zoost van Pokken,

\section{De II. Cla/fss.}

$\mathrm{No}$

I De Pent Schelp.

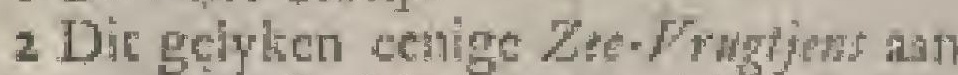
en ttętije, met cenige Doyers "cl' काin.

3 Groore St. Facols Sdblpct, of Bon4 \&

f (Andrezoorten wandien, watr onder

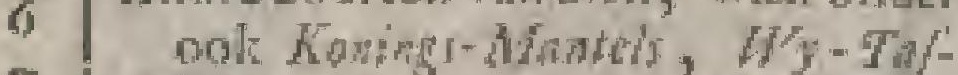

7 /hes, cn Eers groote No.s. wh-

- Jende op de Kunt van Frahork,

10 root, en ook ged vals verw.

if Deze ged met zware thippers.

12 Dede en $W y$ - Tabd.

13 Andre zeer fracip zonten van dien, * mer zwarte bioden, en roode flippels.

44. Daze met wite ribben en $z$ wate fiupels, en met roode gecle 'er'

L tufichen.

III. DEE.
$N_{0}$

if Dit ecn andre zoort wa Kotimgs-Mawh tols, nee drie bonden.

16 Dit is den Ron-werwige met vier wit= to overlangze bithich.

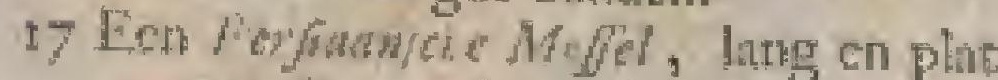
anth de eene kant nitlooptiade.

18 De Cowal-Didber ner knobbels "ct op, vallente in de Ayrejge Zae, by Carien; zynde een roort yan Nowed-stbelp, dog van gedaance als de t.aragendede byut

19 Een Cattricie bruine Mo/el, die niet kantic.

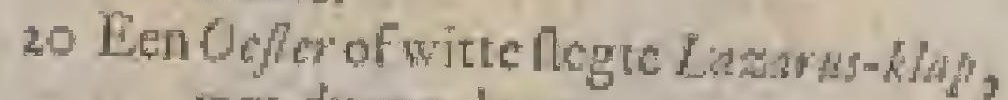
met dunne doorns.

21 ( Andie diergelyke dog van andrever$22\{$ wen, als rood, - c11 wie gemengd.

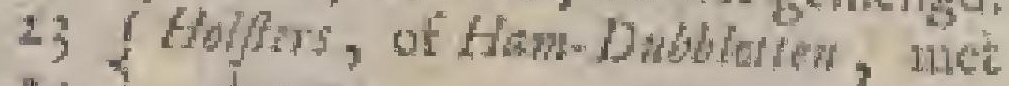
$2_{4}+$ dogns.

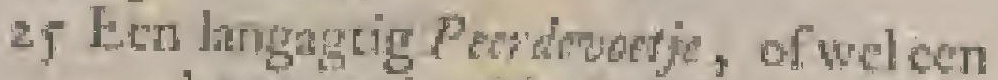
latngwerpige $N$ uges-Siblor, vallende in de Gulf wan Trawkyk.

26 Een andre van de zelre zoor.

97 Een Sten, watur atn de Polken groejert.

28

ag Eanige Mofwats.

30 (

3 I Dit is een Hoom, die by deDubblesten miet thuishehoord; zyndeals. con Parto- of Pourlewoer-Horn, wit ran vesw, in Jalien vallende?

33 Slecne Nawd-Hownkn, bruiti

34 of zwartagtig van werw, vallen-

4 de in the Mifldritadfohe Zec.

35 Langwerpige schelper, als de $B a-$

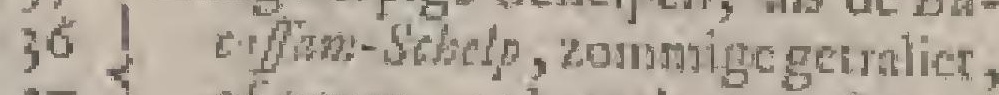
37 of gener, ook geel, en ook rood 38. ( van verw, kenne die niet, $x y$ vatien in Porragal.

39 De Z $Z$ e-Noor, zynde een geribd $P_{\text {of }}$. farjo, wallende in de Fonilcbece. 4o $r$ Mb/elcr, die niet keme, dog byon $4 \mathrm{I}$ als onze Sobrelinge.

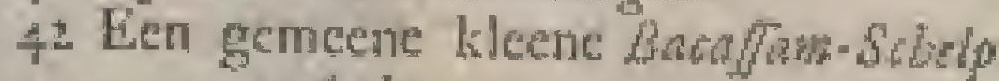
wn Ambon.

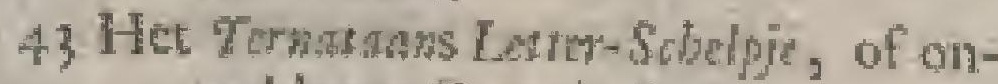
ze klecre Tour de Bra.

44 Een ander keen geribu Schelpije, als cen $N a s e l-s i b l p$.

45 Een andre zoor r wan dito.

46 Een kleen Lewer - Selcigie, bynt als $N^{\circ} \cdot 43$

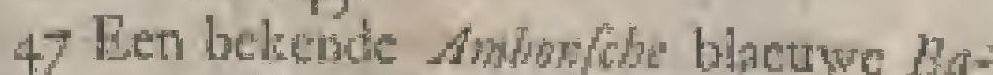

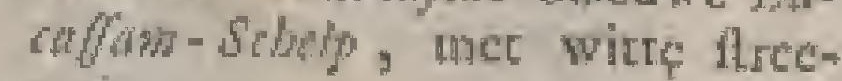
pen.

48 Een zonre wath Poffers, of een Chand Lewis wan hondelerius.

to Fen get Hon re zonde, tanden.

ro Ook een kleen $K$ wetherjie.

ji $\{$ hrokkers, die niet kenne:

$5 \frac{1}{1}$

A 就采

$1+\mathrm{De}$ 
ff Ect diergelyke, wat dicht-geribut.

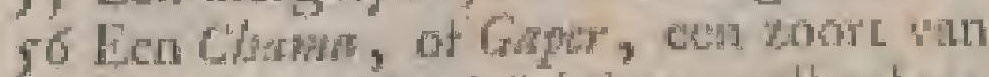
phate Nagel-sidelpen, whende in Midhlumlate Zte.

57 De Orgel-pyp.

58 Het /orelije.

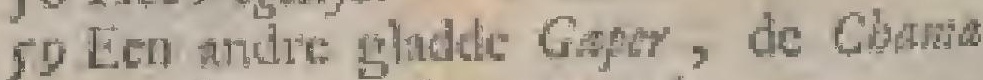
Gigcwerydes genument.

60 S Len zootr wan Londfabopes, of do

$61\{$ Grichat $A$ Dubblet, woor mat getand. Yder byzoncer van teeliening.

62 Een diergelyke van en Goud-werw, mat een wicte Stare thek fugter aan, en voor then fyn vars butuen.

63 Een Dubblet, die gebandect, of 't lyt mee tandjes is, donker-gect

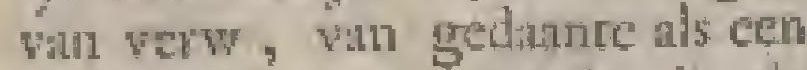
groote Konings-Mand, in de Botry wa Gader vallonde.

64 fracy nelwandecte $\AA$ withers, getec-

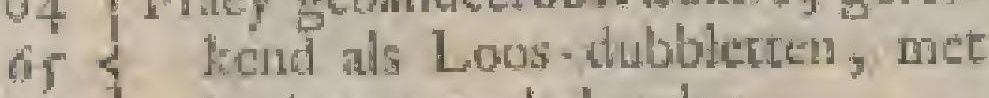
66 bruine en feele banden:

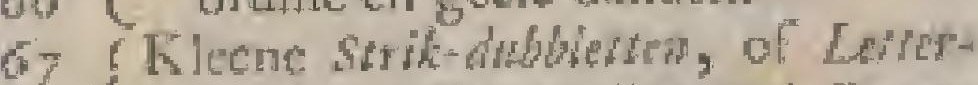

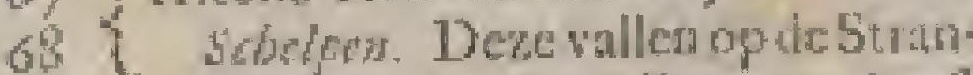
den van Napels, De cene heeft twee banden, met tenen 'er turferien beiden, wen de andre $\mathrm{yyF}^{5}$, nirt en gewolke teckening 'er tulfchen beiden.

60 Een zoort valn fyn geribde Labare\%, met dric fyod wass-banden, woor Lwee, en agter an weth.

7 De witce ltampe Nagel-Schly.

7. Twee geribue kilecne Sebripos, die 72 niet kenne.

73 Hen Tufarnfbe Sohelg, ech zoot van $\operatorname{cen} \mathrm{ha} / \mathrm{am}-A \mathrm{~h} / \mathrm{s}$.

7.t Een Irdifhe geribde, dog my anbekende, ieleene sehelp.

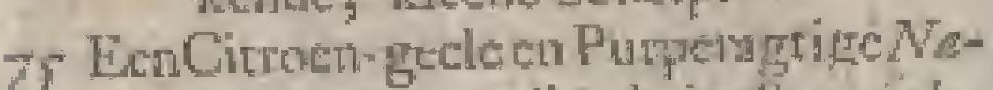
wol-Sekdp, wallende in Parright,

76 Een grooter Navd Stirla, gelybende

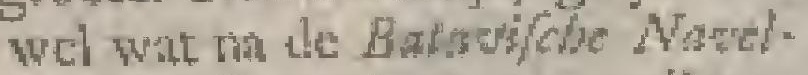
Scblo, die vel grooter endiepert geribd is, dan de getectie $N$ nwed-Schlo.

77 De lange Molf wan Rondeletis tnet vier overlangac-banden, en twee breede witte dwars-baden, gelykende wel wat na de groote Tour de Bras sog therk gener; of getraliet.

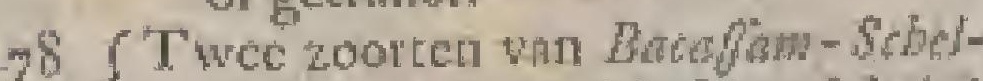

$7 y$ \{ pers (ende met Mofeh of hair) ontrent Siches waljende.

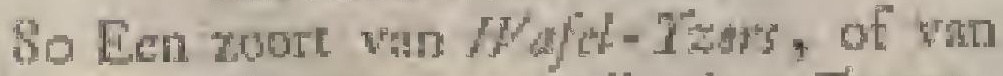
Tiyers-iorgen, vallende te Taramie.

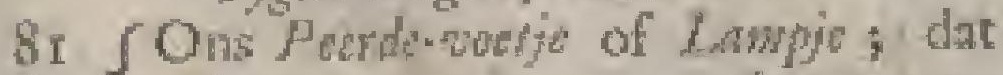

82 \{ Jy san agteren, envan boven vertoond.

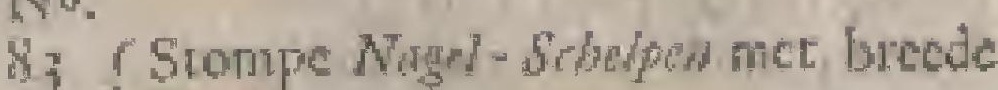
$b_{4}$ L ribben.

Q5 Len hanker raec wite en brtine brecdre bytrden, vallende in de lidy Yan Gadis.

86 Een zoort wa kieene gebandecte, hoog- of du - greribute Minge

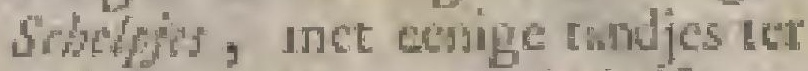
zyden, en tot over de helí gebardeetr wan voken af, ma agter roc.

8- Fen Dubblet, die ik niet Jeth.

SU Een OJer-bst, oen zoot: wan grooth Harries zonder tanden; dog my onbelicnd.

89 Een Dubblet, byna als wen fyne Gorregeents.

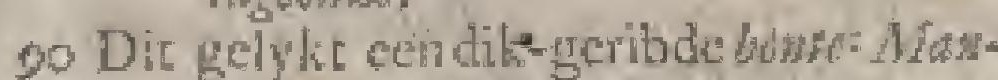

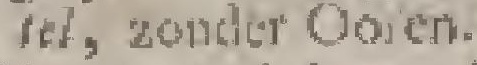

of (Dil zyn medebyzondre zoorteh "m 92 bowe-liamels, diengteran rond, Q1 zonmige met twe sindre net 24. (meer bainden, en zommige, dils vin ribben, zyn.

95 Is cen Canagenfich met nagellens.

06 Dit is cen zeldzame Schelp uit de Boge van Vratherge, of te Marzalle vallende, helberide vel scyen mer korte ragels rot halwer weg

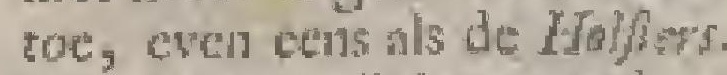

97 Een kleene dik-geribde en getoornde Schelp, met reyen "er op, die nier tense; zynde cen zort wan Venus - Hoory mer tanden ter $z y-$ den.

go Een $Z e \varepsilon-\lambda_{0}$, byna als ecn dubbel Hatic, wol groote zwarte fpilebels ap en wirce groud, of als cen zoort vin Aurdbeijen.

09 Ees cont wan kleces $K$ reaken, dic nict heme:

coo Een grocte Ze-Nod. Van futzoen als $N_{0}$. ght dog met dwats-butden, en zonter 2 warte fpilikcls.

\section{De Th, Cladis.}

Handelende van de zoort van For fobolghe

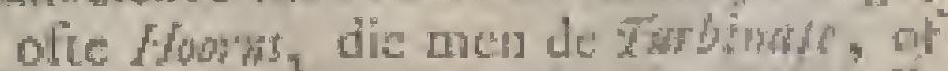
Theartige neend, getre te 1. Cinflis

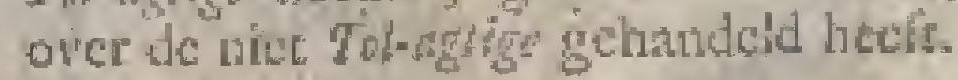

No.

I De gebandecte Fipel-usk, net twee

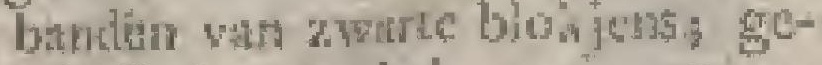
lyli ik 'er eco teb, en met een kroon angter.

$\$$ Een dito zonder litoon, en byna zon-

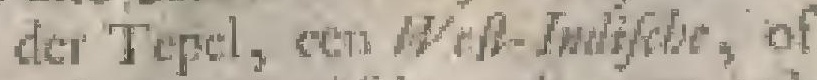
ook cen bowlebe, dian zy ook. zoo watlen.

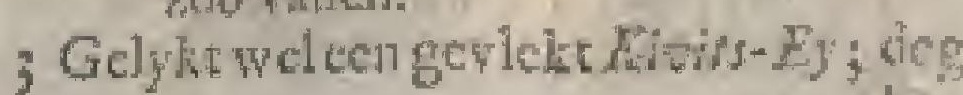




\section{ZEE-HORENKENS YAN BON ANNUS,}

Na.

kenne het nier. Deze zow op onze Strandeth, en ook in Sichicm, villen.

4 Een zoort wan ydel-gelpitkelde Do-

- yers, die nier kenne; zy is wat grooter, als de sdrat

of Een Sleke, als de How

6 Een Jleen glad Vhtmmisp, of een wilde hinglog zonder takken.

7 Een Doyer, of Sichk-Hoon wic'troode Mir.

- 8 Een dito gew jamd, tot latfe wegen tọe brced, en anterdin linal gevland; dog kense die Hoom met. Het gelyk wel cen zoompje.

b Een gladde Pfrou-Fiora, wan groote als de Soldat; dog byna zonder teekening.

10 De wilde $M$ la/jcb-Hoorn, zonder tak ken, en fremarmerd.

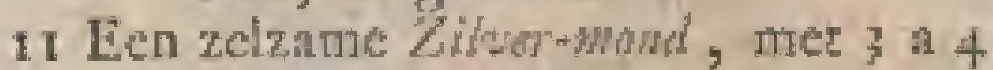
dikke dwars-ribben; kenne die nict.

12 Een andre zoort

I Een andrezoote, byn als de Morfabe Templot.

$14 \mathrm{De}$ Dekads der zelue.

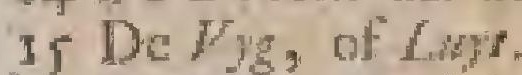

I6 De kleene geribde OHe- $/ 00 \%$, en met vlelikers.

if ficn and zoort.

Is De gemente Ole- / Wurm, met de dikke Lip, en Zout-korls.

19 Een zoot vin Sproutjo;, dog nog wat ntiders.

20 Kenne dere in " $\mathrm{geheel}$ mice, ook is dive nict wat nitedredd.

21 (Een dik-Jjppige OWt-Hoors, zonder

\{ Zout-kots.

22 Een dito dito mede zonder veleken, vallende in Spanjon.

23 Een Trumbl-Scbroef, dic glad is.

24 Len dito groorer wan gladde bogten.

$25 \mathrm{De}$ groote geribde en gebudecte Olie-Hoory, tact vlekken; dog wat whaker wan ageren, als de onde,

26 Een ardie met groote dikke Ribben, tonder vlekken.

27 Een ichoone grootel/eret-Stek, of $N$.

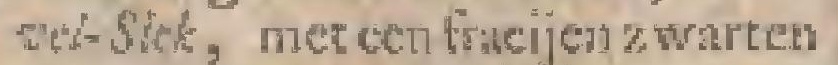
on witten bresten buiten=toom.

- Her is cen Jodifobe , dog kenne die niet; of 'I moett de gemeenc 2 yn.

28 Dit is wantehynelyk een diengelyke zonts, $200^{\prime} t$ niet de zelve van boven is.

22 (En groote gewaterde lichoone $D$ i-

30 L. My, Jic rwart wh bactedwarebnaden op een witte giond is.

3: Is het Labhrie.

32 De Tenatultos Sappe - Lek (gelyk ik
$\mathrm{N}$

dic heb) an 't klocen.

33 Een roori van kicene Buchblyes, als cen Atompe Canst.

3. Een Gunn het een Lip.

3. Hec Dhinthornkon.

36 Len zoor van klecne Ole-How met ceal Lip, en Zout-koyls.

37 Een yoor yan Orughtepennu, of enlicklè Pans-kroones.

38 Her Fnoddeden.

39 Een glad Fatje, Trompets- wwze onder.

to Een Germon-Horm.

41 Een Fuge mee 2 watte fyne banden, op econ wicren grond.

42 Een dito ander zoorr, wat gladder en ronder win gieren, en gettippelde banden by elke gier hebbende.

43 Een zoor van lingwerpige Noritas, of Alikwiens.

44 Het oude $N$ y wer randen, of de TouDeF-SLk

4) Een zoore van kortefurjes, vol terte ftecpen, en mes dric dwasbniden.

46 Een Hoorn, by na als cen Bablon:febe Torew $\mathbf{j}$ dog boven wyd van bek en hockig. Hy walt in de Midldardfle Zee, en in Portugal.

47 Een zoort van een Knodhdes.

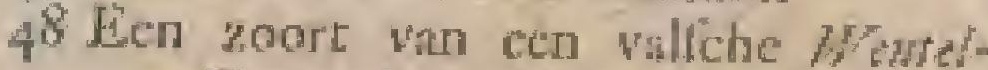
Thap; dog anders van mond, dic tanden, en ter Lip, heeft.

49 Een Honrs, als eer itompo Catari, even eens gettippeld, als "t kleen gethippeld Arons Bowric.

go Een zopre wan to whlls'; dogr wat anders, of Dadel-agtig van gedtante.

it Eon gekartelde $A$ romile.

$j^{2}$ Dit gelykt wel cen Bullere, of geverkre Broar, met een dikle Lip.

53 Dit gelytit wel eco hagwerpig Zoomple.

S4 (Dit zyn zooten van Dogers.

55

56 Een gladde Trommel-5edroef.

57 De himpers-boor met ltreepen, van de belte zoort, en de andie.

58 Een Zilver-mondfe.

io Ecr Mroinin Major.

so Een dito andre zoore zonder kroon in 't midder.

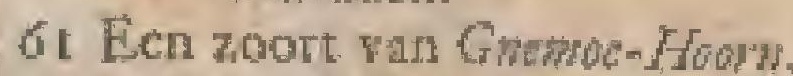

62 Sit zyn Alkwiken, my onbelkend. 63

64 Verrheide Gnomot-Howonkens.

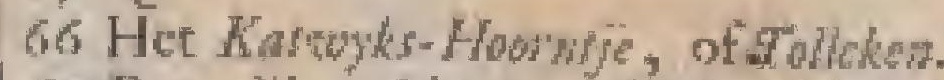

67 Een dik zeldzaan Tibje, dat nice kenne.

68 Een kleen by ons belend zwart Twitie. 69 Her gedoornd Twile van o17s.

$7 \circ$ Een zeldzaam zoompje met batuden $A$ in: 2 
wan wlektien, ats Bctdekeles, wyd van tiond, vallende in lodits; dog ketrine dic nice.

7 Eea zoort van Krddikns, ook wit Indien.

fi Dit gelykt wel cen breede lange Cawoth, dog is nog wit anders.

73 Dit is een zoont wan $t$ Diffel-Gow by

74 De Gnemor-Horty.

75 Een zoort wan Baflary-Purper-Hofew, met di ie bahden agter.

76 Een getakte Gerawze Casket:

77 Een zeld asme lang werpige gekartelde Sliksth, die nide kenne.

78 En andre zoote vari Gwent $/$ own.

70 Ecr zoort wan Bablasicbe forens, die niet ketine.

8o Een zoort van linge Gnewge Hown, die nier kejne.

SI Dit is ook een zoort 'er van, die niet kenne.

8. Een zeldzam gedoond Titje, my onbekend.

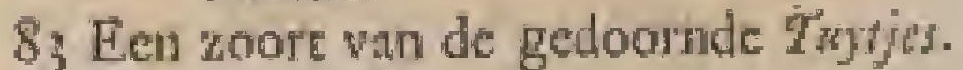

84 Een glad Twityt.

Sf Het Duivds-Klathtotis, met vier takken. Dit valt in Ehrona.

66 Een zoote van gladde Bedderyem.

87 Een kleener Dutwd-kidutije, met drie talken.

S8 Eet zoort van ftompe Shilos, of ook wel wan Weflatifle Mooren. Deze walt in Toreasen.

8o Een Tol, of Bagtine. Dral met ribbebanden. Deze vale in Bringunitn.

oo Een dito met knobbel-banden.

g1 Een andrefyin-gebandecrde met groote vlakken tufichen de binden. Deze valt inde Middandedr Zee.

92 De Zre-Ton, Peerl-nerwig.

03 Een Tol, of Bagrnen-Drol, thet wy a zes banden, dic zwart en wit zyn.

D. Een liarte dikke geribde Aliknik, die VTy groot is, met zwarte Itippels op zyn lye na voren toe. Hy wate in sishism.

9) ('Twee andre my onbekente zoor06 ten, wit Whiles.

07 Verfcheide zooten van kleene Tol-

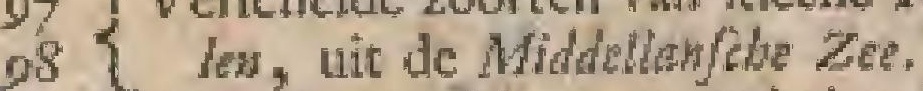
on Een zoort was Tollen, my onbekend. Ioo Een zoort van Moorflue Templls. 1on Een Hooris, als de Aroese Trompd. ioz Een groote To', of Basyner-Drol.

103 De Mars-Horn, of Olikoek.

Io4 Een zont van klecne Wed-Indj/che Moren.

Ior Een Voet-Howm.

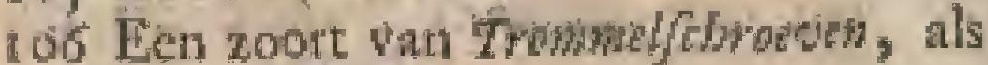
een Turstie.

tof Eer Natid mer zwarte vlekken.

108 Een wit-gokarteld Tuyb.

108 Een wit-gukarteld Thyl. banden.

I I Do gladde getande Spil.
Nó.

1 to Een dun geriba Noalde.

I II De hage walche Wewe-wap, tit de Adriathol $Z e$, veel linger en dikker als de Sobevelojighe

II $T$ ( $\Gamma$ we byzondre zoorten win Thit-

113 L jos, byna als Trominflforoven.

11.7 De groote trowhel/ebwew, yder

II) 2 byzonder.

I 6 Een lange Hoorn, van fuczoen, als de verkeerde Hoora, dog viry langer.

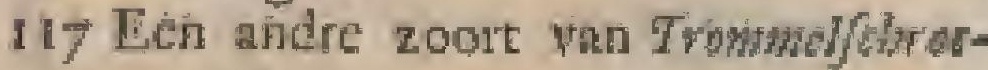
wer.

118 Een zoott van de groote $N$ ied ber met zwarte wekken.

2 I 9 De dubble Paus-lroon.

t 20 Ue enkele dito, of de Orohiric Pew.

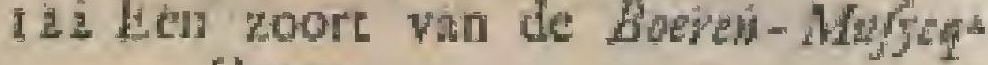
Hours:

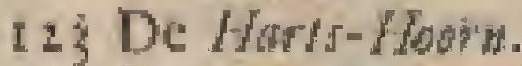

124 Een zoort wan ydele Vloye-/cbetion, dis viget kentic.

i 2 Een Hoorn als "t Larbogates Hoor wiz; dog geel, grokn, rood, bruin, Cirroch. werwig, alles onder een gemengd, by Lecter A. En nog een ander onbekend getibd "er by, by Lecter 13 .

I 26 Een kort Agerate Dabje, Dyy onbekend.

I27 Een dik geribd Tostje, met ecn brecde wiredwars-band, en rwee fy. ne overlangs, my onbeliend.

128 Een Tobje dat agrer plat, en anders byna als een Bomw-Mu/gag is.

129. Een Towfe nee drie groote wate wekJen, als een kteen shilewerkn/for ; dog seribd. Ik kenne dit hict.

130 En foot met wetkken, en zwarte ftippels, die niet kenne.

I31 Een 7ror met Goude en rolle ZoutJorls, plat-getopt, en thy onbekend.

13) Een rofle en gecle met tippels gebanlecrde Tyger-Toot.

I3 De Haws-Hoorm.

I24 Een liken Toutje met entige fyne dwass-banden, en in 't midden, enagter, breedeknobbels hebbeinde; en 'r geen ilk niet kenne.

¿35 Een Goud - Likenze Hown, van de genteene zoort.

136 Een groene $K a a b$.

137 Een dito; dog vodr gekarteld, en tiny onbekcind.

138 Een zoort wan Boere-Melgegred, agter met een fracje top.

139 Een kleene zobrt wan de fracje groene Kars, met twee ftip-banden in "t midden.

$1+1 \mathrm{De}$ 


\section{ZEE-HORENKENS VAN BONANNUS.}

No.

If i De lange dune zeldzame Dithl.

142 Een Brisiff he gemarmet de $b_{a} d$ l.

143 Een langwerpig Alikwikje, dat nict kente.

144 Een Cafuri, byna als de mythe, die zwart vam binnen zyn, vallende wat gruoter, als de gemectie.

145 Een Hoom, als een korte fin engedronge Bablowifbe Torn, die ik niet kenne.

I.16 $\{$ Twee zoorten ran Burbeljes, een

47 Bemarmerd.

148 ( T wee Hoorns, byna even eens als

14.9 \& deverkeerde Hoorn, of bynals cen glad zoompje.

tro Een zoort wan grooce Conar's.

Ifl Een gla zoompic.

I $)^{2}$ Ein gemarmed dito.

153 Een kort gedrongen gemarmerd dito. 154 Een buitic

15 De Middibare Stormbot, met een netic.

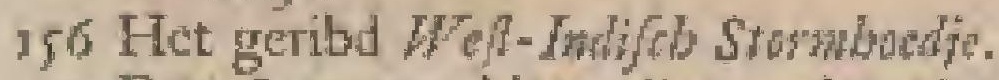

I57 Een Porrages klecen dito, dat nict kenne.

If 8 Een glaginde Oven, met cen breedgellipte mond, my osbekend.

159 Een Hoon, weing van een Olde-Horow met Zout-lkorls verfehillende.

160 Een dito, mer ribben; sen zonder Zout-Korls.

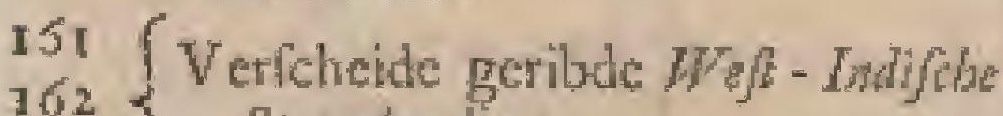

$162\{$ Stornhoedjens.

$164\{$ Irdifbe verficheidenetley Doyers.

$160 \mathrm{De}$ formitiche Slek. Een Thafle Hown, die niet kenne.

$167 \mathrm{Een}$ zinore wan Kadj/be Tollew, die nict kenne.

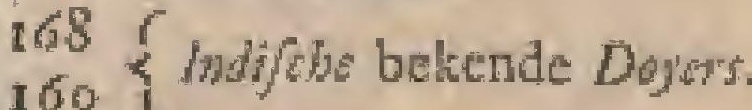

$170\}$ Een onbekende zoorte wan Mhkwi$171<k$ ks.

172 De Batortifbe Alkuik, die gemar. merd is.

173 $\{$ Alerbigen, dickenne.

175 Len zoot van de Arotlon Major. 176

177 Verlchedde zoorten wan Ahkwiken,

178 en datr onter enige met ge-

179 knobbelde banden, alle my on-

180 bekend.

I $\$ 1$

182 Een $A m b$ weldzan Jieen gracuw Hoorentje, mer een wyde mond, zynde als cen kleene Kikwerds.

183 Een rofle geribite Olie-foom, zonder teckening.

$\mathrm{I}_{4}$ War dit is, Isam ile riet zien, 't gelykt ecn bonte Krobli-Horn.

185 Een 16 th met brede ribben.
No,

I86 Een gedoorrde Boldeyk.

1,87 De korte dikke my onbekende Trom: pot.

I 88 De lileene rege Trompd, by anis bekend.

189 De korte dilke zeldzame gevlande Weft-Indifhe Trowper.

ino De Doggenandze Hown.

igI De Patrys.

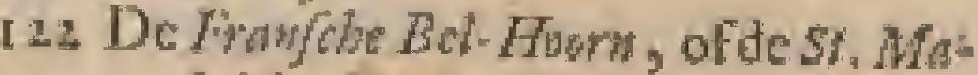
Tor ho How

193 De zeddanc geknobbelde Trompet.

194 Een thompe onbelcende Tranpt, met fpikkels gebandeerd.

I pr Een Hoorn, geknobbeld nls "t Wh:dolsh Hus, in Sordingon vallende.

196 Een Sick, zynde cen zoort van PohJorens.

197 lien zaldzam Zowpis, wit, mat drie overlangec zwarte whinmen, en vour an wyf knobbels.

198 Een genurmelde Dorer.

I gy ten kleene $T$ ol, wet drie breede witte, en veel frinalle banden, uit de Mhlolondbe Zus.

too Een andre gemarmendé Doyo met drie breede binder.

201 (Een Fol, die nier kenne, en die hit 202 de Mrdelanflo Zar gelionen is. 203 Deze gekamelot.

204 Verfecheide Deyers, gebandecrde, 205 geribde, en beknobbelde, die 206 (nict kcrne; ook zornmigeals net Zoul-korls.

207 Een gekrrelde Zilver-mond.

208

209

210 Verfcheide fracje Worval-Hows, 2 II dic nier frenege.

$2 \pi 2$

213

214 Gladde Dojers met een wyde monid $215\{$ met tanden.

216 len diergelyke zoort, met moye zwarted wars-banden, alsecn rad.

2.7 Een geribde zoort wan Dopers.

2 I B Een zoort met peukeltjes, die nier. kenne.

219 Werkheide Doyer met brecde wit220 \{te zoomen, en ook met reel ban221 den naalt een No. 220.

222 Len zeldzume ronde gekartelde $T h$, met groote witte knobbels, uit het roode $M$ eir.

223 Een diergelyke zoort, en mogelyk de zelve vañ onderen.

224 Eengladdeeften Dorer met vlekken.

225 Gladde effene Dower.

226 Geband: fyne Doper. $\{$ Sirilian/che

227. Een brced-geplakte $D:$ :

$228^{\circ}$ Een gerpiklielde Doyer.

229 Len gedoornde Lop-Horm, met een A 32.23 
554

\section{VERHA NDELING DER}

$\mathrm{N}^{4}$.

rey doornes, en een krountigter

2,0 Dit is de rechte Sarmatylhe Stot, by Jom/fos mede te zich.

23r De Rlp-kens, of Khp-Hosn, de Likbotory.

$33+$ Den mdje zoote vaij dien.

$23 \operatorname{Canh}^{2}$.

234 Len zoort van gebandecric Kakkelakken, my onbekend.

235 Een kleenegebandeend Bhonev+rag.

236 Een Ezelly.

237 Een zoort van BhowT- Megen, of Mazden met Beddakens.

$238 \mathrm{Het}$ Argrin gebunteetde Hoorntje. 239 Len diergelyke zoort; dog 1tog war anders.

240 Cen zoort wan Campis net een wlek, 241 \& die bekend is.

$2 \neq 2$ lien gemarmende dito, onbekend.

2+3 Een Kahkrlakjog and g getpilikeld.

344 Andie zoorten van diers.

246 Een zoort met flippel-banden.

$2+7$ Een klecne Zorr-korl, tuet een witte ftreep ins 't midclets.

248 Een zwar-geipikthelde en gerbite Hiacnot.

249 Hec Be/lasrl Folge, of Weversin Spotlife.

250 Een zeldzame klene graeuwe $K / p$ thats, vol ployen.

2f t ben andre Sicilinatchedico, getibd.

arz De wite Porcollana.

253 S Verlicheide zooren wan Zout-kars,

$2 \int \frac{1}{4}$ ecn mer $z$ wate, endedarilsmet witte richico.

25s Eem kleene gladde Kakkeriht, zonder takkining:

2 g E Een Klip-How, of LiBbarn.

257 Len Zout-kort.

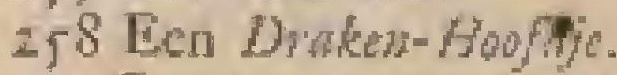

z jo Len zonrt wan drobiflue Lellers, met cen Tnuije.

260 Een klecne dikke Isdifobe Son-korl.

261 Een Perforndo Kliphown, met groote viekken

262 Een Mol met wlanmetjens, of Goude whamen, bancden พan de $A$ methift werwe, en van buiten blace dog kenne die niet.

263 De Arous.

364 De Mozowhicket KJp-Lform, mek een breede theep in 't midden, ca vol ronulc dubble oogen.

265 De Wef-Twlifhe Atgris.

266 Een Tepel-bat mer wertcheide overlingze, en drie broede dwatsbunden, alle wit , de grond $z$ wart en wit gebandeerd, zonder tenel, gracuw, fnet solic tandtjens ain de mont.

267 Een zecs groote Arabifelst Larler, mer ecn breede ftreep in 't mid. 280 onder, en wan bowen.
No.

den, en met zes groote vierkahte prerlien ; zynde als ten forks, en centigain Pterper = ver wit

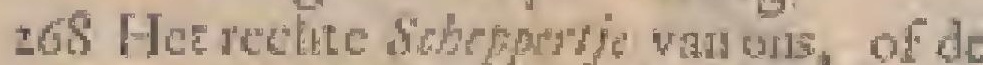
Limoth fows zonder doorms, uit de roode Zee, en wir zyonde.

2Gy Het Neris-Kommetie, of de Duble

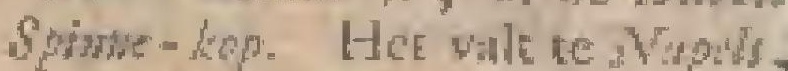
tell is vath buiter gruedw, ela wan binten wh-

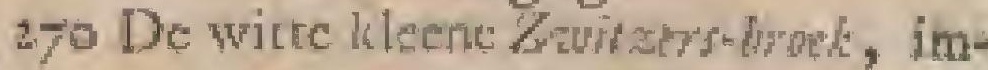
mers ino een zoort.

27I De hrul- Gourn wat Cidis, zother takken, mes zwarte batren.

272 CDito zooken, als de sirsing/LL, en 273 $\{$ de eerfte vilt te Tarart.

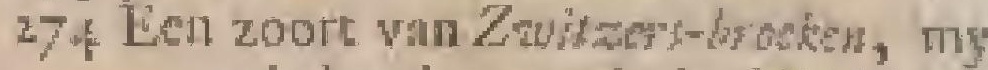
onbelkend, cin uit de WhithortZee.

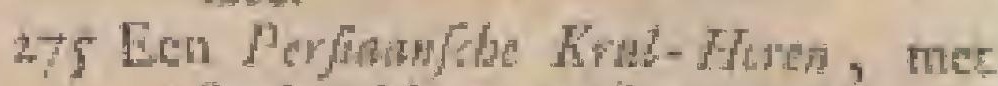
dieyle taken, en wwats whomen. Hy is geclagrig, en walt in de Goif Fan Perfien.

270 De grnate roffe ca geele Brandsris.

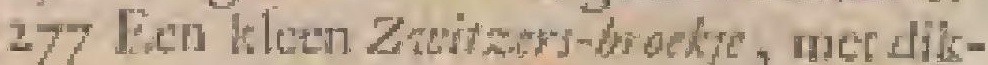
ke breede owertangze ribben, vallende in 'c roode Mert

278 Een zeer frueje Hoorn, ils ten dik in eet gedrongen zoompie, met een

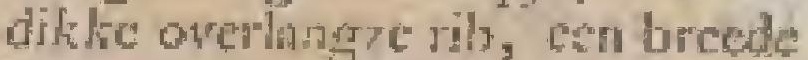
lip rod", en lwee zwate brede banden in "t midten. Zy valt in de Widtounte Zec.

270 fHec Naws of , de Opr-Loory wan

25t De lart-gedoornde Swrpe-prk. De-

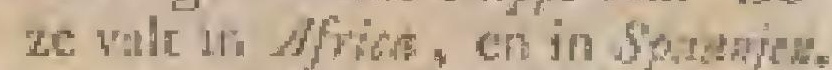

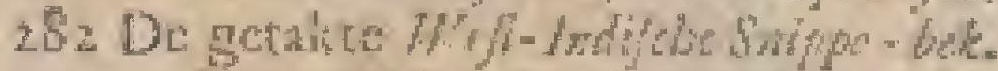

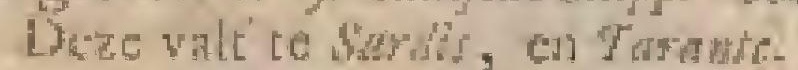

283 1s bynkeren ecen ats No. 281 , wals mede jn Abira, en is van bimen. Appetbloetem, co พas buiter wit en gecl-agtig.

284 Een thompe in een getronge LapHoon, die nice kenme. Hiy is nies breed van Lip, hectic rosde vekken op cen witren grond, en vale diep in Zee.

28 . Een zeldzame zoot van Cofl- Hows. dogzeergetikt, ol gethoornd, van binnen wit, en wan butej [3]per-ngtig.

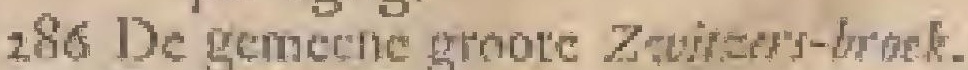

287 De groote batland Pupter, wit de Goll van Peifica.

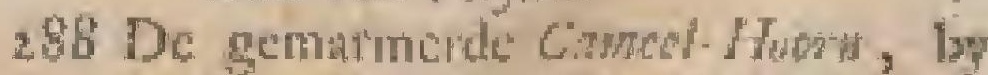
Nupbirs op "e litathe blad der zeldzitme Hoorns, wili op de Wendedrot ftate, the zien.

280 Eea zoort war ofig borken, of Mors, met ecu breode lip, an mer grogte dwars = ribben m my onbeleret,

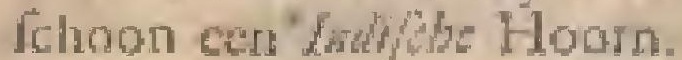

$290 \mathrm{De}$ 


\section{ZEE-HORENKENS VAN BONANNUS,}

No.

200 De Vhkons-lek.

zor Een zont was srowpins, wit zynde.

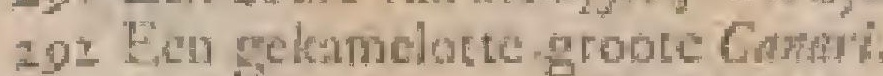

293 Een Flemilys, of wide Mrghad, mot roode cos ande vlektco, die niet jennes.

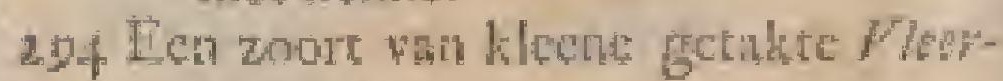
mistack.

295 Een zon I van Boddetykw mer doorns, en witre binden voor, en cen breede sher.

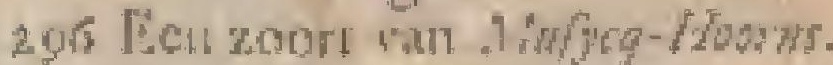

227 De secher $\mathrm{N} / \mathrm{h} / \mathrm{kg}$ Hown.

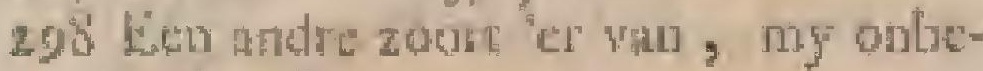
Ficind

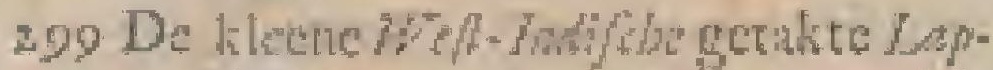
Hoors, surter net twe a drie kromnen waus tikken. my bekend.

joo Eer roort wal cen brof Sortedje, of

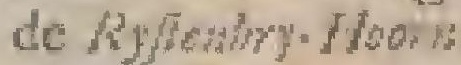

30 IEen zood ' $\mathrm{El}$ rah, net een wyzertje ter aviden.

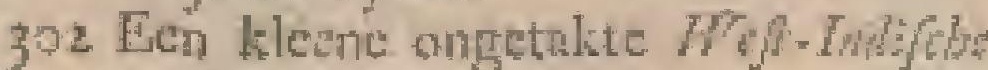
Lap-Heora.

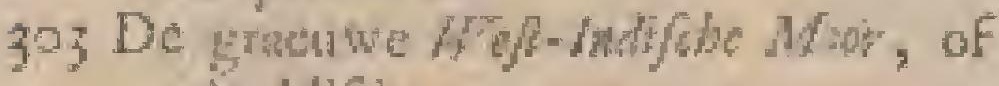
da 1 bifis.

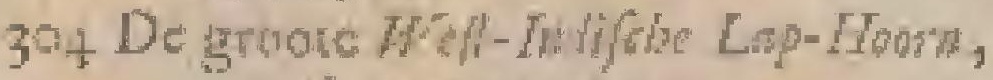
1wet doorns nglel" sals.

305 Een zoorr wn piamujew of wilde Muftetrow.

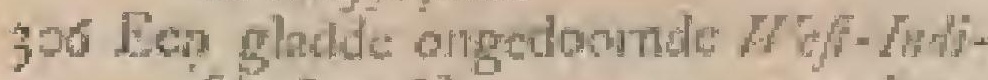

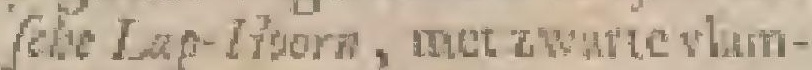
men op cen witic grond; wit-en Olimgug vinn werw.

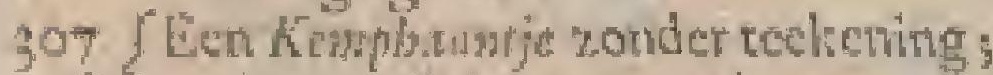

308 a dog geribd, ch endonton, die gront is, bouren op. Nevedseen ander mee tweedoorts.

30 D Een dito nuet cen lange vleugel, af

3.o wyzer ter 7ydentir, cnmetroode vlekten, en die hoorn vinonder mint boren vertoond.

3 i De Zomefirad Krabs.

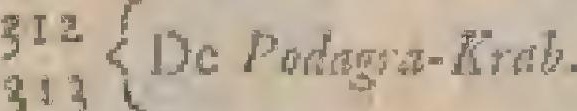

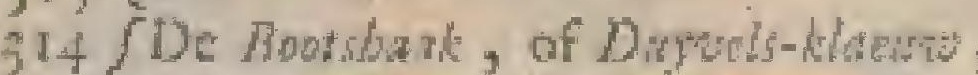

315 . vin onder en boven vertoond.

316 Len shok, zynde ech zoore yan $p^{p} 0 / 2-$ Jforts.

317 De Mathrim.

318 Dit is cen 200t van fracje WdiWhoshs, nuet gionote, witte, cin briline vlakken.

3 ti Het Wolke, of het $A$ geate Badye.

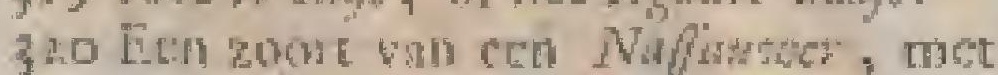
ves fine banden, con duars-vlele len "er ewer henen, wit cu groen

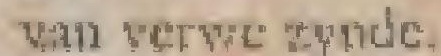

3 i Een zoont yan een tijk-gedoorade

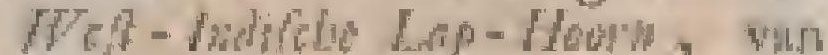
binnen wit, onk wel Appolitodfill, en צan buiren Ecel-ightigr

3az Eeth fyne moye Comar:
No,

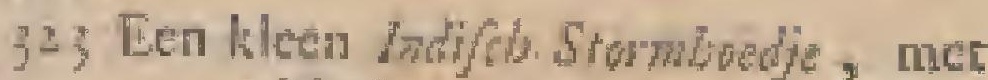
een Netje.

324. Eem onbelend gemarmeld Hoorn: ken, byjats als cen Soumpie, of Ditzentat.

325 Fon glad Kahkorakjo.

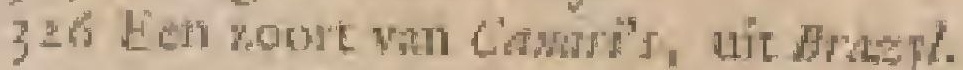

$3: 7$ Een vreende gekartelde zont wath Trummo Strorew, zynde ujt drdiew; dogmy onbekend, tell wat Te het de gemarmerde gyrn.

328 Dit gelykt weleen zoct van dilecne 329 brwbole, die nict keme, wan onder erl yin boven wertoond, die bect ook verkcheide bolktels.

330 Verfcheide zoorten van zellixame,

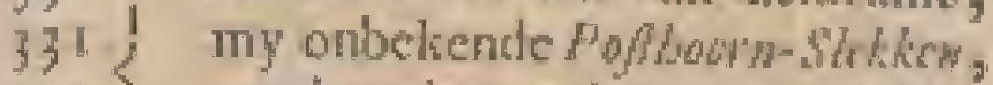
332 metbrectemonden, en rerchei333 L den wan banden.

334 Dit gelykt exn zooje wan cen Bokfe, of Bezuar, my onbekend, cn mee fangwerpige zwatc waklen geteekend.

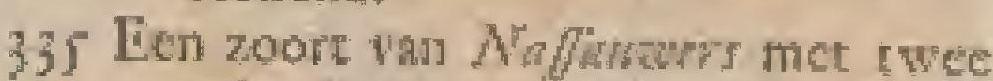
witce bander, controine be theepen 'et iuffehon in.

336 Ecu Brozy/ho k walyli-geter licrde Hoon, wol llompe goons, of bohkels.

337 De Gandede Tas ; Iondagtig van ver w, met 13 hander, en ince wilte en 7 watte blokjens.

$33^{8}$ Eer Arangifdo, nict wel afgebed, en my obberiond.

339 Het baltand Wevers-Spreige of yokfe, synde grooter en distiej, als de vorige. Een $b r d z / f h c$.

340 Fen klem Somper of an Besoms.

341 Een zoort wan een gelsnoblyelde Hoorn, bynatsecn Wooch-Sirl. die niee kenne. Het is een $B r$ at sylehe.

$34^{2}$ Een $200 \mathrm{rt}$ wan klecse Lap-Hownkens, miy onbeliend.

343 Een zont van Hoornkens, nis ecn Krodd ake; don met breedezwarte duras - lyanden en fyot or we fchen, 't welk ik nict keme.

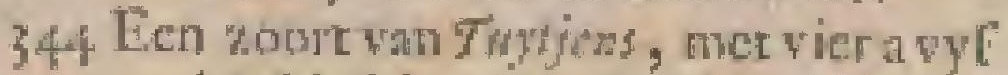

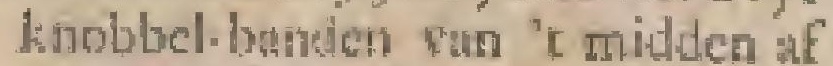
"er omgellingerd.

345 Fen zoot van Cond's.

$3+6$ Eel zoort wan de kltoene graeuwe Mors-Hoorn, met cen breede Lip en wyde umna ; my onbekend.

347 Een Partheaflon Hown, en zoont

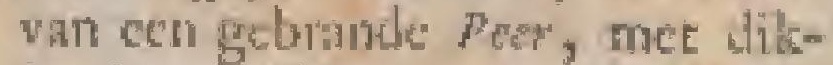
ke dwars-riblen, my onbeliend.

"4S Een Dubblet, als een Lardfobie, (k walyk ander de Hoorns gemengd ) met owerlangecen dwarsbmoch, ads met ruit jens. Het walt

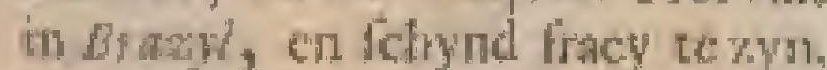

$34 \mathrm{E}$ 


\section{$55^{6}$}

No,

349 Een Brazy/dhe groote dunne LotiepSebelp.

3 o Ecn zeldzarm getinobbelu Hoornken, als cen koddek m.

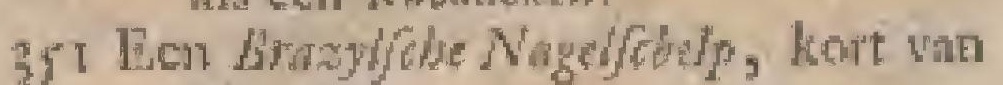
- Nagels.

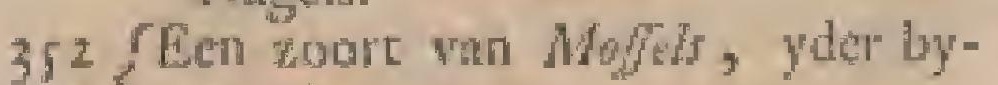
if $\{$ zonder.

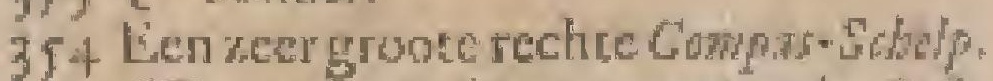
355 J Twee zer fracy geteckende Pofs 350 L bow - Sleken, de cerfte met dwitsbunden wan een fraeje watering, en de andre mex een dubble l'ur-

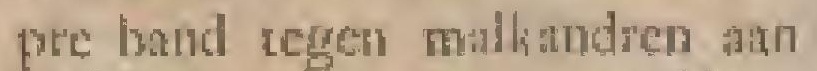
de bituen zyde, enzoorond loopende.

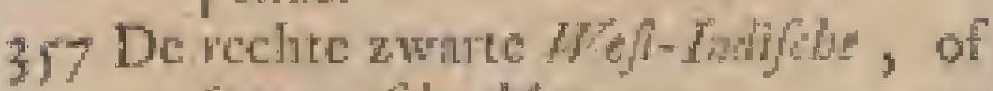
Gatapofole Mor.

$3 f^{5}$ Eeth zont fin Hazthoren met brede $z$ warte overdugre cri fyne dwals-bunden over "L lyt, op oen wiuten grond.

39 Een zoot van fracie klene $I$ il: Heorn, of klp-klesersmet ongjens, en cen brind in "t midden oner litrgs.

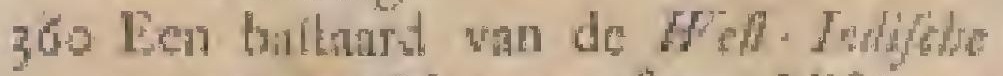
zwate Mooren, of een Mifises.

36r Een zhort van Admirals, van teeketivis bytm als de Urangie $A d$. whirad, dog mer rwe brecde witto bandien, en zwartewlekken beneden de bunden "er langs ; dog

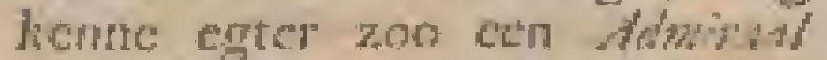
nict; whatom hem "er ook giet otvider relle.

36z Een Hoorn, my onbekend, zyute

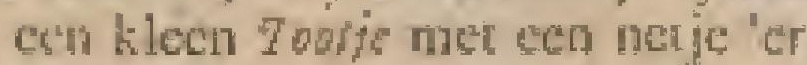
orer.

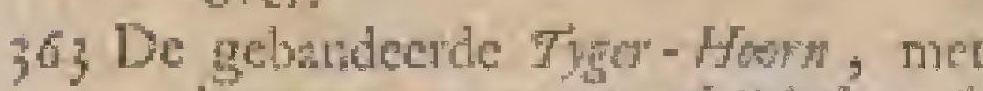
binter van zwarte fpikikels tuffehen drie breete zarate, overwelke ook zulke friksch banden hemen lonpen ; dog beno dien nier.

364 Den witec Foos met Gond-Irakenze Wekken, wan fitzocn allo die by Rumblins op de Phat XXXIV. by Letter $\mathrm{K}$ verbichd is.

365 Een Teote wa fatzoen als de 7 ice Adsiral, zynde wit, en wabinnen Visler.

366 C De Zomehwom, van onder cn bo367 \{ wen verteond.

368 Een zhor wan gek nobbetde $W$ Jidnowders, als exn zroor, dic bezirre.

369 Een Dialed net een brecde zwaste band.

370 Een zeldzane Bewohr, met zwarte rlekken, bystis als ecin Beddhen, ot Risilic.

37 Een Nahawer, of Petala-Horm, mer een broede wite lrand.

372 En dito mee vier banden, dite wile en

\section{E L I NG DE}

Nis.

373 Het Powhific.

$37+$ ten Aord by a die klech is.

375 lich dito die groot is.

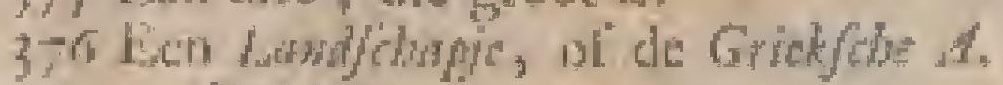
Dubblet.

37. Jin zoon vast de Tyers-dare.

378 Een onbekende tiumn, ot Dubblet met zwarte Tygr-vleklici, kwitlyk getcelienct.

379 Een gebathed Tugte.

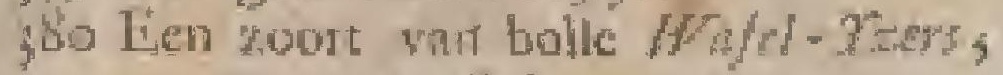
groot, neribul.

38 E Een geknobbeto Hoom, als cen seburite.

$382 \mathrm{Fen}$ gebandecte Sankr, nut drie overlaugye brecde banden van isne itjppen.

383 Een Howryne, uls ecn Brothethe, iny onthekend.

$39+$ Deth Hoge!

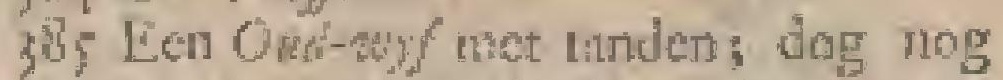
wat anders als de vorige pouverWh.

356 Een 7omt wh geribde Dojes.

387 lien zoort van Perwas, of Nulfatswon, in 't midder breed, wit met eqedangze wlammen, en mee met zwatco dwis-banden van blokings.

388 Een roort sth zeer freje Dowts, mer breede truine ch witu: 7.wart-gezoomde bunden, als de velingen van cẹt Rad vertoonen-

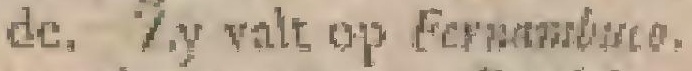

380 Een indre zoore wh felols's, met

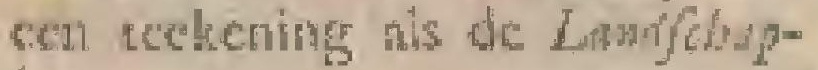
fit:

300 (Dilesucr fracke Dorers, de cerlte $391<$ neet reer zwate halle bander, 503 I Als de vellingen van еел Rad, de

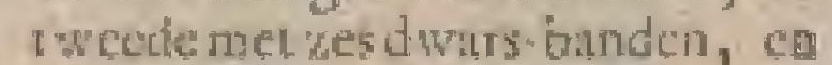
de derie tyma als $\mathrm{No}^{3}, 8 \mathrm{~s}$.

393 Eer zont vain cen gevlekte OheHown met de Lip, dog met zwarte blotijens overlang sereekend in cenige reyen.

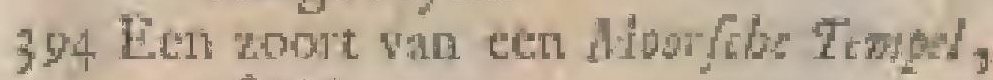
of Tul.

3 or Een Braylfhe Nagel-Sclest.

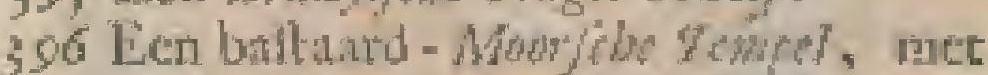
drie dwire knebbulatanden, en met overlangrezect brede ribben.

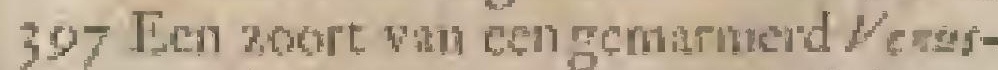
Hortic, en met watrit vekjens.

$3 D S$ Een Brazylfise Soldo byan als ecm

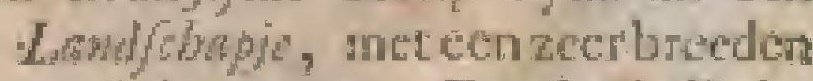
geribien zoom. Fendrapje Dubblet.

390 Een zeldwame znot van een fruy-

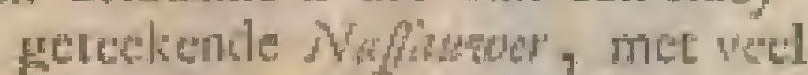
wit voor ath, cest brede wite operlangere vich in to midden, etr 


\section{LIEFHEBBERS VAN DE ZEE-HORENKENS.}

N:

een fimiller witte dwars-band 'er onder".

4oo Een zeldzame wit-geknobbelde dito, met een witte Boom-ftan, vol knoten ser op. Zy valt op Forratubuce.

40 Een atudre dito, woor mer een breedeth band van witte wlekken, en in 't midaten ect breede. witce dtreep, dog agter vol witte vlekken.

402 Een andite dito, met twee breede en cen fmallen bond in 't midden op eten witcongrond. Alledezerallen op Firmatubico.

403 Fen Zec pok.

In een nader Deel, by hem genamd, Obfondiones circa Virontia, qua in Rebus now Fivowibns reperinater, ("t geen te Ronen A. 16 gi gedrulke is) geef hy ons in des zelfs cweede Deel nog echige ammerkingen over werfcheide zaaken, de Horcnlicens rakende, behalwen dat hy "er ook nog 47 in Plate vercoond, th betch'yf , aver welke by bevorens niet gehandeld hiad.

Hy rerdecld dat tweede Deel weder in wyF Hoofutlukken.

In 't eerite wy ft hy an 't wermale, dat het Decl der Horenkens atn den Befcholtwet gedf.

In hec twoede hath hy an de Licflobbers van eenige Cabinet ten mell-Iorenkens, zyoude cen herhaling der geene, die hy in zyn eerfte Deel Capp: I 2 . al gemeld hid, mane die liy hier wel zoo ordentelyk vondAck, en watr by hy nog ecrige, hem bevorens nog onbekend, vocgd.

In "e derde Hoofdtuk vertoond by deze navolgende Horens, die ander de vorige niet gevonden werden. Als

No.

I Len zeldrame getcekende Patela.

2 Ecin llule won cen Babbors met verFiheide polken enz:, "er antr.

3 Vertoond by eent $y_{\text {and }}$ dic Zec-pokken of $T$ Hhen, $z$ oo als men die met " vergroot-glas ziet. $Z y$ is wit, en held na de Anethift-verwe.

4 Vertonth hy dic wan biancen.

5 en 6. Len Bratiladw/Ge Dubblet, als ech Foffer, of 9 rader, met in an 11 ribben, en ter linker hand wier tanden hebbende, wel zoo kloek als de Conebia $V_{\text {eneris }}$ of de VenuSidp met hair, by Rumblits Fol. I $5^{8}$; in ale Plate XLVIII. No. 7. te zien. Dog deze tandender BraJhangbe Venus-Scbeth, zyn vry diker, en ftan verder vaneen.

7 Noemd hy cen Fidfore Dubblet. $\mathrm{Zy}$ III. DEEL.
No.

is wan faczoen als een 7 apayche Mar-Dubble, war mede te $7 a$ powders fpeelen; $z y$ is boven op wit; dog de hecle Schelp overdwars gekamelot. Dat zich zect friey wertoond.

8 Ecn Brashihm/cho groote Poffer of Orake, met fyne en groove ribbeth. $Z y$ is vin groote als een hand - palm, van werw wit, cn trekt na 't geel, en ook wel na 'E donJicer

9 De zelve ofy een andre wyze vertoond. Io Bets Arrhorida Dubblet, zyode cet zoote wan St. Fatubs Schelpen, byial als cen Komis-mand.

I I Sehynd my toe te zyn een wir Blansfe mec zwarte ftrepen of buden.

i2 Een Bongmawh die tuffchen de ditke ribben in onder 4 , in "e midden 5 , datar nat 6 , en dan wees" o Purpre knobbels hecft. Zy komt uit Brazu, en dnar zyn "er 2 af, in to Cabinet des groot Hertogs wam Toronen

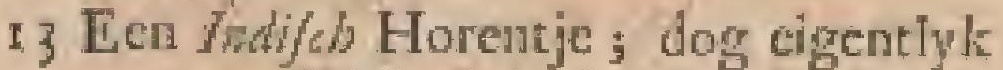

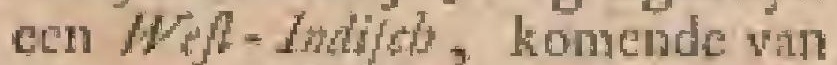
Agriw. 'r Is glad, mer banden 'cr over", dik wan $\mathrm{L}$ tp, en by de Lief hebbers bekend.

I 4 Is een Hoorntje alsecn $M e l k$-wapit, van groote alsecn gecle Doyer of Sithe Hoorn. Het is valn een Vlectchrepwe, trelkende na den geele.

if Gelykt ecn witie Porchllan.

I 6 Fen zeldtame Hootn, na een omgerold blad gelykende. Zynde vol dwars-banden, en van binnen wyd open.

E 7 Een Hoorn bym als een $D$ add, wyd van mond, met drie ryen wan Giftatic-bruine wlekken 'er op.

I8 Een Doyer, of blekte-Hoom, vol ftrecpen vath ageren ta boven of na voren over de geheele Hoorn: loopende. Van binnen is hy Violet-werwig.

1. Een $V$ ents-Hoorn, wan fitroen ma cen Fles $b$-Hoorn grelykende; dog meeft wit en helder wan verwe.

20 Een andre $F_{\text {en }}$-Hoorn, dic van agtet, een top heeft, en vol britine ne wlekken over 't lyf, en ook wol fyne ruit-ftrecpen is.

2. Een Antricante witte Porchlond.

22 lien kleen Trompetje, wan firzoen als een Soompie, dog vol fyne banden door malkanderen.

23 Is ecn Aivbon/che Dubblet met dikke ribben en brunevteklen, dieroswerwig zyn, gekarteld.

24 Een Bemeene Ambon/che Stril-Dübblee.

$\mathrm{Bbb}$

${ }_{25}$ Eent 
No.

25 Eew zeldzaam kleen Hoomije met 3 in reyeh knobbelen, en mer ecn zeer kleenen mond.

26 Een zeldzane Dodel wan binnen wit, ca van buiten met 3 reyen witse vlekken geteekend.

27 Te Papoufde: Oefer; dog cigentlyl

28 $\left\{\right.$ den werkeerden $H_{0} / \mathrm{hel}$, wan beide zythe zyden vertoond.

29 Gelykt cen zoort van Folkbounts to zyn.

30 Een zeldzame Indifcle Dadd wol zwarte itippels op ecri witten grond.

3 I $\{$ Een Tuy-Shl mer een wyden ronden

32 ( bek, an wederzyden vercoond.

33 Een andre dito, mutar vol bruine Ga-

34 melot-shamen over "r geheel lyf, op ean witem grond, zy werd an wederzyden vertoond.

35 Een ge jeene kleche Patells, va buiten vol ribber.

36 Ecn lichte Gilwder, yan futzoen bym ats de Orthgie Adwotrol, dau lyy oole wel ma gelylir, zyodemede met Appelbloczene verw, en met zwarte dwats - Fchrapjens bands-wyze gereckend.

37 Een Hoom, byna even eens wat fittzoen, als de verkecrde Hoorn, helbbonde van bimen twee tanden in cen wyden liangwerpiger mond.

$38 \mathrm{I}$ s en zcer fracje Hoom, zynde de Acbalshamper, wol fync zwarte dwars-bunden op cen wit-agtigen grond, en met kleene bruinewlekken bezneid.

39 Een uitmuntend fiaeyc, en zeer lichte Corizan, of Hup, wath de leververwige en funcilte zoort.

40 Een zoort win Ziber-Ovens, hebbende agt reyen met knobbels.

41 Eell Tol, wit wn grond, met verfeheide dwits-ribben, en hier en dat net brthe vleliken.

$4^{2}$ Een zoort van Buylyers, of Bezowr met vlekten, dog deze is Alchverwig, en wyd van mond.

43 Een Stecue Siongete, of Wormktw:

44 Witce Zesater, Zee-appels-wyze.

45 Een onbekend Hoorntjc, zegt ly, dog 't is de Nepums-Schabl. By andre onder de Venus-Hoonen getteld.

46 Een zeldzame zoort van cen $P_{0} / H^{2}=$ renfic.

4) Een groote diergelyk; dog zeet zeldzame Hoorn, zynde als een groote en dikle Poff-Hoow, met neel dwars-banden of verdeclingen. Zy is my onbekend.

In "t vierde Hoofdituk fielil hy een vrage voor, of deze Hogrnkens wel zoo net.

\section{E L I NG DER}

in Prent gebragt zyn, als zy in de nature roortgeted $2 \mathrm{yn}$.

In "t. vyfic vrage hy, of de Hoornkerds tinden eri oogen hebben.

Verder handelt hy niee allecnover verfcheide zaken tot de roorteeling der Hoorntiens, fortar ook tot die wis deze cu gene Intecta, of ingekorkene Dirrkens, mitsgades ook tot andre Philofophifche zarken, husne betrekling hebbende, en voor al ook tot die Dierkens. die men met hee vergroot-glits zien moet.

Ne.

1. De groote Wen-Jwdjelle Lap-Hoom, mer veel knobbels agrer.

2 Een dito, minder gek nobbeld.

3 En ongemeene groote Proot, als een Soldat, randelielf at, en vorder ua beneden toe, mer grooteknobbel-bunden, die op ietier bogr ver-

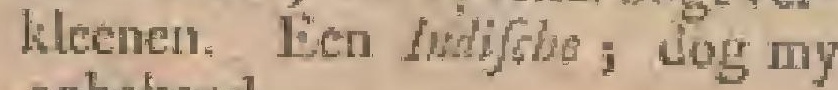
onbekend.

Wameer nu alle deze zootten, nattreklings woor af wan dic Hoorns, dic hy van onder en wan boven vertoond, eens optrekle, zoo geefe hy ons eigentlyk it "e geheel matr vyf hondert en vyfthen vertcheidene zoorten op, dat al wry weel is ; notat onder welke echter gecn ecr Hoofdrtuk, dit uitltedic, of by de Liefhebbers dant voorbekend flant, vinde.

Oots wentchte ik, dac by deze en gene Hoorns war netrer en uitwoeriger beEchreven, en dat hy oole de Scheinen en Hoprns ieder alleen gefteld had.

Hy hituld in dic zyn Werk ook de natamen van deze en gene Liefhebber in $/$ ia hen, en clders, die frneje Cabinetren tonen bezeten, en zig met die Liefhebbery verluftigt hebben, nitn, noemende dere notvolgende op, en dar onder verfcheide groote Mammen meldende, als:

\section{Doter Formits, of eon der Form in} Hollawd.

In hee Edel Huis der Cakcolterit te Botwlognion, en das na bezeten door $A$ drownades, en den Marquis

\section{Fitdinat $C a / N$, te} Bonlogniv.

\section{Yand Zano, cen Kruid-kundige.}

\section{Den Grawe Gaprore.}

\section{Herowats Formo.}

Mufandus, to Jerond.

Septaliantu, te Milaws.

Finest Fiwian, te Florane. 


\section{LIEEHEBBERS VAN DE ZEE-HORENKENS.}

Co/mus Rofominu, te $P$ in.

D. Nertidichon, tot Psprs.

Canills Pichi, te Anowd.

Den Prince Pasplybo, cot St. Pantas, te Roment.

Pertes Bllorins, te Romen.

De Princen Perh, ér ditir na de Prins Sobilli, te Remeri.

Agrallyn Scilla, te Rowen.

Den Ridder Corweshis, te Rathn, en datr nia de Jonge Hereog tha \$lrozaa, Led genaand.

Andreas Bonoticins

Mronies Magminas te Romm.

Andiabius Dions

Trancions Goldus ?

DenPtins Vinginias Orinds, en dar ma den Mitruis $V_{\text {ighlitu }}$ Spada. den Ridace Urband te Roms Rocitus. En in 't Room/ch

Collegie was Kircberas, with by wy nog woegen:

\section{Pindtus, te Napels.}

Frandifors Maria Micui, te Genta.

Den Ridder Baldazat Sozyifanes, te Pijlorim.

De Nere wa den Candinal Gerleri.

De Hertog was Snxh had 7 Kamers met reldxamheden, ch dar onder ${ }^{\prime} \mathrm{cr}$ een thet Hoornkens.

Job; Fred: Spor. Boel werkoperte shondsburg.

Phllp Spener, te Lewhot.

Een Edele zeer geleerde, zeer Tialkundige, en vermatrde Dane, tot Lopfoh.

Toeplins Kals, tot Wratilawi.
De groot Acrtog win Tof

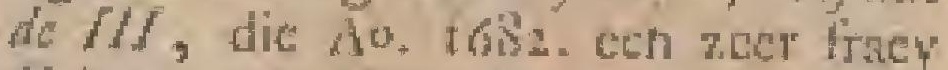

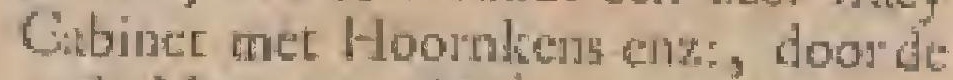

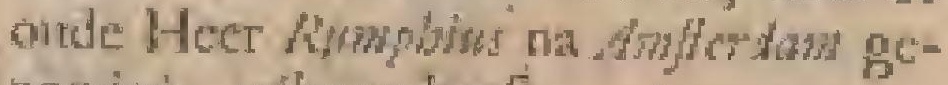
zonderi, geliogr heeft.

Na dexer Bonamm, en meer andes beichryingen orer de Zee-Hoornkens, Kqwam $A^{\circ}$. I 705 . De Andon/cbe Rarteci-

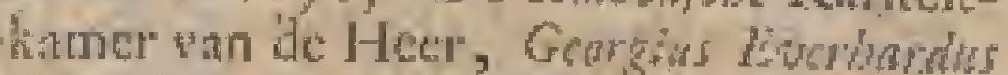
Komplitw, na 's Marss dood alzoo hy $A_{0}$. $170 x$. den I Juny orerteder is' in 't licht. Dit is het allerbelte Werk, dat tot nog toe ovet die itofie gefchreven, en wath in alles zeer net werhindeld, cu byzonder wel afgelweeld is.

Ondertuifchen heef ook zeler Erigels-

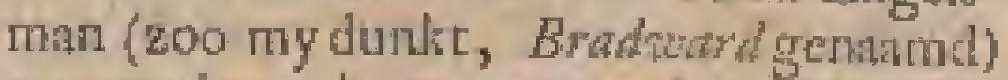
over ecrige, dog zeer weynige, Hoorens (die Jy ook afgebech heete) gelchreven; dog das heef men al mede nict weel atrit. $A^{2}, 1706$. Heet de Heer Lewins $\nabla_{\text {in }}$ cent tót flomles in zyu Wonder. Toncel der Nature mede one de Zce-Hoornkers gelehreven, cen Werk, dat mede zynen Lof verdiend; dog dardoor den situbew, die zoo grobten Schac van alles bezir, ongemeen zou konnets verbetert werden, indlen men alle de Platen, dar toe vereiletit, of dievath zyme uitmantende itukIxen allech, mat darby hadde.

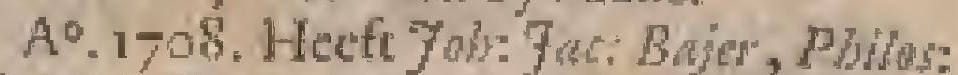
G Med: Dograr, en Profedor der GenecsKunda tot Ab/of, whin wegen de Rept-

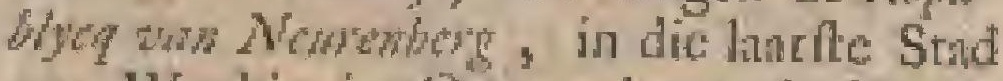
een Werkje in Quarto laten drakken, wax in hy over zuldzane opgegrave dilsgen in "t Noorden, en onder andie over derige dat onder gevondenc verfecnde Hoorns, Schelpen, enz: gefobreven heeft. (een teclien, dat $x y$ dar al mede vallen) wala van thy er nok zes platen hect bygevoegd, dog dit Werk is wn weinig belang. Van diergelyken and, dog ongelyk fraejer, is 't Werk varl de Heer Sebendsertes, Ao. 1723 . gedtukt, en meet over verfteende dingen gande.

Ook Ipreek men yan yol. Grorg: Lieblexegt, als cen groor Licfhebber in Dwitsland.

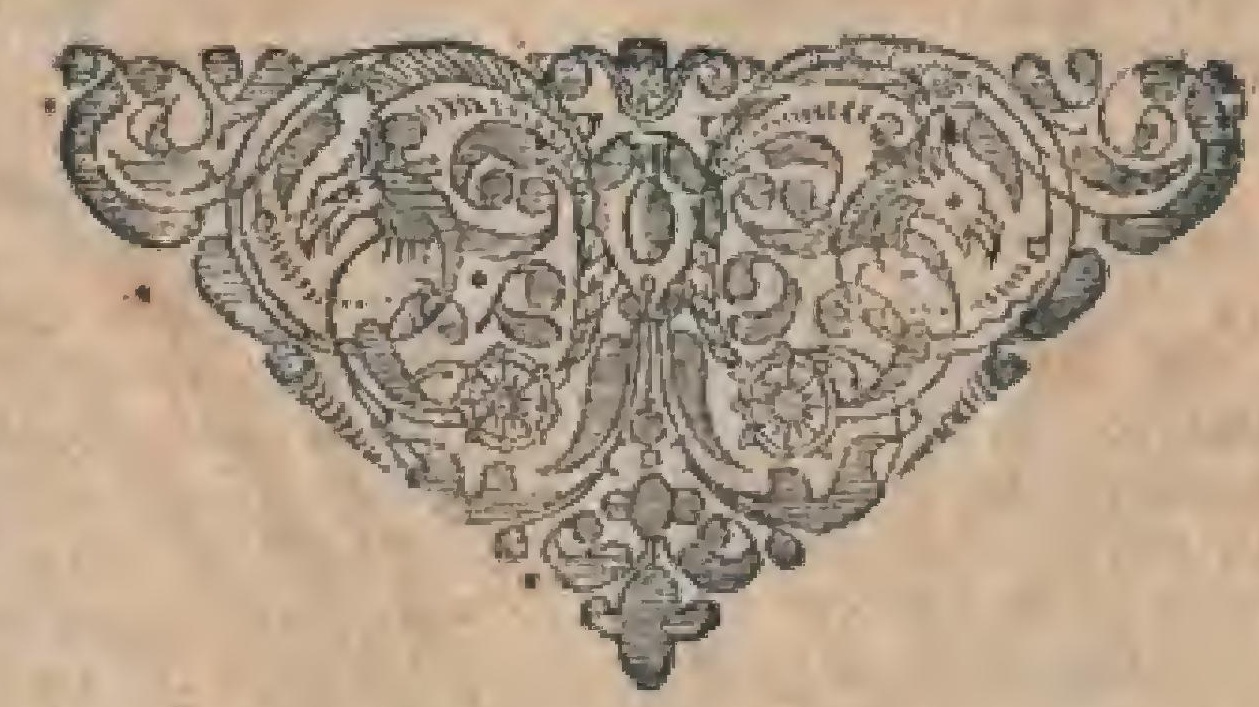

$\mathrm{Bbbb}=$ 
DERTIENDE HOOFDSTUK.

$D^{E}$

Indifche, als wede de Hollandze of Europeifche werdse Liefodbers, Amfterdamze, Delface, Haarlemze, Hangze, Rotterdanze, Dordrecheze, Zceuw2c, en Zwolze Lighebers. Zaldame Horens wat de Few Wybers. Zels-

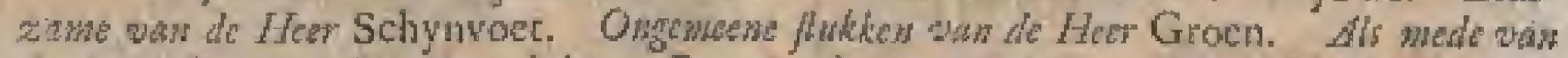
de Heer Schot, De Her Seba. En vaw de Hew Schuyt. Trate Horens qan de

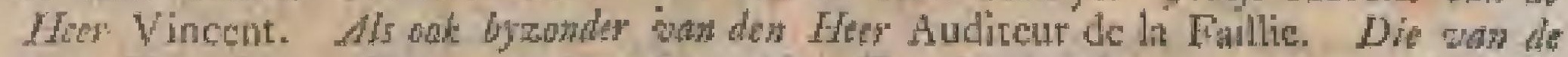
Her Kigrehar. En wen de Hes Segueld. Fan de Heer Bart, en wan do Her de

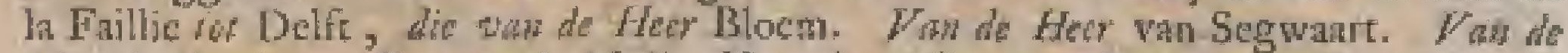

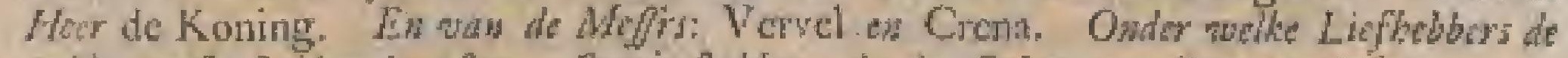

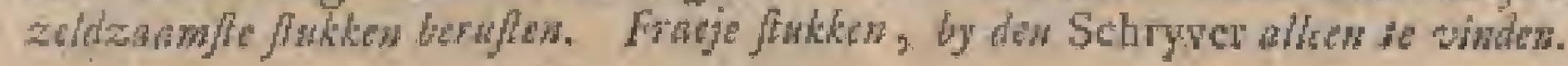

De Indilithe
I $N$ de voorledene Eeuw had men veel Licfhebbers, zoo in ladien, als in Hollowl, dioin deze Eeuw nog nerkelyk togenomen zyn,

Der oudte Lief hebber in $W_{d} d \%$, dien ik kenne, wis den outen Hecr Rumplius, en naderhand zyu Zoon, de Heer Pardos Aughos Rumphiss , dog de ouden Heer begon data al in, zon tins by in hallen lewart, te weten พan $\mathrm{A}^{\circ}$. $165 \mathrm{~J}$.

Juffi. Zara Gropzon, Huiswtouw wan D. Browderins.

Vrouw Catborina Han Hoggern, Gemalin van de Heer Robbert Padbrigge, in zyn leven buiten-gemeen Rand wan hadien, en Landvoogd wan Amboina, die A. ${ }^{2} 68$; betron te Lief hebberen.

Marbys Molknom, Opper-wondhecler in Andwa, die ontrent de zelve tyd begon; mar die in den brand van Ambona A0.1686.1687, gelyk ook de otide Heer Runzisus, oen Schat van zelcizane flukken verlooren heeft.

D. Cornelus was der Shat, Bedienate dos

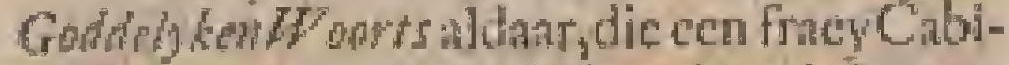
net theza, en ontrent deze ryd mede begor. A'. 1686. Kwati ik dar, ca heb zedet die cyd tot $A$ t. 1696. twee ongemesne fracje Cabineten verzameld, wate by naderthind, by myn twecder togt ma Iwdich $\mathrm{A}^{\circ} \cdot 1705$. nog ecn vry grooter Calbinet gevolgd, d:ut $A^{\circ}$. I7I 4 . door my overgebrag, en war van een zcer groot deel angehuald is.

De Hear Pierer Rodfladr, begen chtrent A0, 1686 , dog heef nadethand, Landroogd van Fermale geworden zynde, gelegenherd gehad, om zyn Cabinet zoo merkelyk te werbeteren, dat zeker Schipper (zoo zyn Ed: my zelfop zelkereyd zeide) thich duizend $G$ taldens te vergeets dnar woor geboden heeft; dog ik heb dat noit gezicn.

De Ed; Heer Jobnanes Plilphus Sip. man, nu buiten-gemeen Rand van Isdia ;
| en oud Landwoogd wan Maca/far, begon ontent Ao. 1604 a $160 \mathrm{~s}$, vertrok kolt dau na met een freycy Cibinet ria Hollow, en kwitm eenige Jatien 'er na als Onderkoopman weder uit, hebbende zedere dien tyd verfohcide Cabinetter vergaderd; dog die zyn Ed: meeft aith deze eri gene Heeren op Batavil, en voor al aats den Opper-Lindvoogd san hitien, de Heer Tob oan Houm, vereerd heati;

Dasid sum Larmen, Onderkoopman, in $A$ mbossa, begon ontent 504 a 1705 , en had cen wa de fracylte Cabineten, die ik oit gezien heb; en onder andre twee Orangic Admirals, datar alle andre, dic ik oit zag, nicts by zyn, zoo heerlyk waren zy wah glans, en zoo therth on levendig van Appelbloczem. $\mathrm{Hy}_{\mathrm{g}}$ is, nu cenige Jaren geleden orerleder.

Yohan Frederik Meger, cen Bockhouder, begon A0. 179 ra 1706 , by welkenik zeer frieje Atuken in Anboina gezien hebbe.

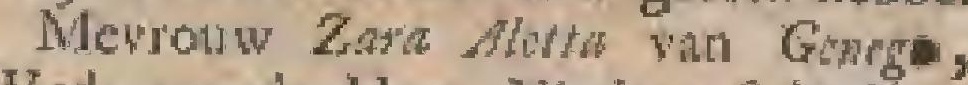
Wed: wan de Hecr Nicolares Sebaghe, in syn leven buitest getmeen Rand van $/ n$ dow, en Landroogd wan Anbim Deze Mevrouw heef een zeer frney Cabinet gehod, watr in wee Wowd-iraspen wil ren, die met her Cabinet noderhind in handen wan de Heer Whoter Valkenier, Bewindhebber der Onf-Itdifhe MatIchappy tot Amferdom, geraakt zrn, al war dac Cabines A 1704 gezien hebbe.

De Ld: Hr. Adrian wan der stel, Extraordinaris Raud wan Indich, en Landwoogd van Awhoim. Dete Heer bad uitnemend wecl, en zeer fracy gned.

De Hecr Jolwoir, Gehomichrywer van de Rand van Jufticic tot Batara, die een fracy Cabinet had, was ran wy in 't vervolg ięt naders zuilen zeggen. Zyn goedie is tot $A$ miferdsm verkogr, cndal' onder zyn twee Wout-l-trappen geweeft.

De Heer abrath it Deder, Schepen to 


\section{LIEFHEBBERS VAN DE ZEE-HORENKENS.}

Batauia, hecteen fracy Cabinet; dat dar nog is ; dog zyis Ld: is $A^{\circ},[-4$ l overleders.

De Heer yoban Adolf Merntzen, gewezen Schepen tot Bahato, had A0. t7. 2 cen fracy Cabinerje, en wertrok datar me-

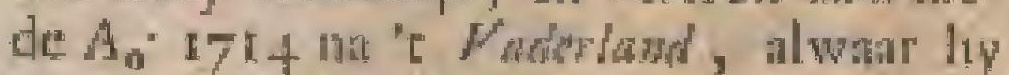
tot Dabluzen overleden is.

De grootite Liefhebber vin Jadich, die zoo veel allecen, als alle de andre te zamen, nog bezit, is de Hecr Pieler $/ / y$ bers, oud-Schepen cot Batawa, dicn ik $A{ }^{2}, 1712$ lectde kemnen; en darik cen ongemeeregroot en fracy Cabiner gezien heb

DeHol- In Foldond, Zedand; en elders heefr men jandlehe, mede vecl fincje Lief hebbersal wan ouds geof Euro- had. Ik zal ze yder onder hunne Seden peifelie noemen.

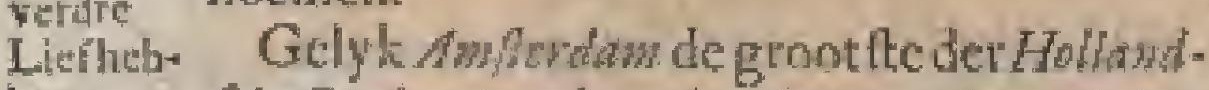
bers, fobe Steden is, alzoo heeft men win ouds her dat ook veel groote Licf hebbers gehad.

Den Ars Swammerdam bezat onerent het midden der voouledene eeuw ecn fracy Cabinet.

De Heeren faneaburg. Folkots, die veel Hooms $\{$ dons Savry in Platt liet brengen.

Oters, cen Konft-Schilier",

Amfter- De Heer Borgermeefter Nicolais W jisen. dasthe De Hee fowar HWw, Geheimichrywer. Nogen Hecr Majoor Wilzen.

De Heer Blacta, Geheimflaryer.

De Heer Hermanas wan det Burg, ecn Dingilt.

De Her Mf, Gathan Paneras, Borgermeetter, en Hewindhabber, eier Oof-hd: Matalehppy, wiens Calbinet den 20. Marart 1726. aldatน op "t Oude Hecres Logement verkoge is.

De Hecr $W$ outer $/$ alkenicy, Bewindhebber der Oo/. Ind Martchappy.

Juffi: Pronella de he Com, Wed; wan De Heer Profelfr. Rays.

De Heer Simon Schynoet, die bsver allen in kenus, en in 't bezic van fracje ftukken aldar uitfteckt, behalton dat zyot E.echongenesen schat ran kennis ontrent veel andre ziaken (war wain veel Proedfukken datar, chelders, bekend zyn) bezit. De Heer Rocters.

De Heeren Fithma's, Gebrocders.

De Heer Yoh th Jous.

Alle deze Hecten (wan welke it nu nog mar de Heer Roys, en de Heer $S d y$ wow in 't leven kenne) hebben ongemeene fracje Cibineten bezecen, wan welke ilk "er geen weet, dat aldar by dat win de Heer sclynwed te vergelyken is.

Jn de latertyd, en in deze Eeuw, zyn "er nog meer andre Lief hebbers bygekomen, die nede zeer fracje Cabineten nu nog hebben, Dexe zyn de narolgende:
De Hecren Jacab Elas sobol.

Whine Groen,

Alboths bets,

Jouswer Lrder, A' 17 to. overleden; dog verwanuen door zyn Zoonen, deMelirs. Amold, ch Lenrik Lrder.

N: Ten Cale.

N: De Hars.

Chryflakewher, die groo te en uete Licthebber, zoo daar in, als unde Penningkunde.

Bathazar Sibin, enD Drogit.

- Ni Rerner.

Whatik Oorrmoths.

Philip van der Potrte.

Ni feroede.

Pirrer wan den Itewel.

Ook is my onlangs door cen Zerres Her van weel anazien gezegt, dat de Hecr Wefleween, Advociat de Ouftodifibe Matichappy, mede ecn Liethebber geworten, en bezitter van een zeer fracjen Wearel-rap is.

Alle deze Hecren bezitten mede Cabinetren, wat wan ik "er verfcheide gezien hebbe, moetenue bekennen, dat ikby de Hecten Sobut, Groen, en Jeb ongeneene frueje ltukken, dic my zecr veel getroegen gegeven hebben, berchoude.

By alle deze moer ik als een Liefhebber ool noenen Yonswes Ros, eenige Schoonmaker der Hoornkens tot Am/ir: dow, en die dat ools weergadeloos doce.

Tot Delf had men in de voorledene Delfat. Eeuw, de

Heereil $N$ : Kamwing.

Ne de la Fille, Hoofd orfficier, cen zeer g1 oot Lief hebber.

Hewhik d" Arquet, Borgermenter, en Arts.

N: "s Gideredidt.

Deze Hecten heblon ongemeene Cabinetten bezeten, en nu kente ile dars allecn nog matar de Heer Connelis do la Falde, Oud-Schepen.

Dog wat dien Heer bezit, wete ik tiet, dan alleer, dac zyn fid: zecl fracy goed hect, walt van ik ecnige nitmuntende ftukken gezien heb.

Tot Harrm kenne ik allecn denalom. Han: vermanden Heer Lewins Whem, die al lemae. in de vootledene Feun, tot Amftrdaw roen womende, begon, en die alleen zoo veel bezit, dat mers by een grootemenigre van Liefhebbers de vierde part nies vind. Ook litefr dien Heer ongewecene fchoone en uitmuntendo fukken, behal. wen dat by cen ganfine Zee wan Wiffehen, Dieren, ens: in fletten met vochten, een wedrgadeloos Cabiuet mer Capellen, en ungekorvene Diertiens, en eem onrindigen Solate wan veel andere zeldzanmheden

Bbbb 3 bezis 


\section{VERHANDELING DER}

bezit, die mien by nicitatid, danby Hem wleern, wind, dit ook de reden is, dit suel Varften, en Grooten der Wereid, zig werweerdug hebben het zelwe o⿺ ga: bezien, gclyk zy ook, nict zonter werbatzing en grode gethofgen over 's Mans onvermocider, en onvergelykelyken yuer", mitspaders ower zyn metheid in alles, te rug gekeerd zyn.

Hier plagt ook de Heer d'Orable te zyn क dog die is oresteden.

Ook is "er cen Heer Baars, die frieje dingen worzamelds dog zyne Licflicbbery (zoo my berichic is) gaue meeft over zeldzante Vogets, liger, en ook ten decten ower Zec-Hoornkens.

Hathe In "s Gravonbage had men vanoudsvericheide Hecren, als:

DeHedren, Besjown Fagh, Ratishecr ip - den Hove wim Hollawd.

Deforstels, Opticnder wan's Konings Howen.

Welke beide Heer in zee traje Cabinetten bezeten hablen.

Nu heeft men darr,

De Hecren, Joban Bernard de la Fallie, Audiceur van de Kimea von Reckening.

Franfors Kigreliar , Commes ter secretirye tom den Heer yan Benumon; dog die ons in lict jagr 77 is ontwallen is

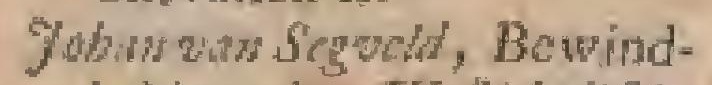

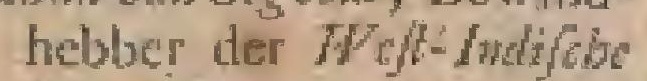
Maatichappy.

facol Bar, ook i 725 overledern.

De Cabinetren ran deve Hecren heb ik gerien, dic alle zeco fracy zyn; mar de Heer de hallit tume verre boven deze, en boven veel andre, in 't genl, en in de fracje zootien, wit; hoewildie twee volgende Hecren verfcheide tuklien bezitcen, dic ik by geen andre Juich hebbers gexien hebbe, en wel voomanelyk de Heer wan Segreld.

Naderhand is my door deze en geae Lieflucbbers bericht, dat hier zedert $10 \mathrm{~g}$ zouden bygekomen zyn.

De Hoag Ed: Heer, Joban JTewith wan Wafmadr, Heere van Wajenas", $O b$ dom, Sce. Be. \&cc.

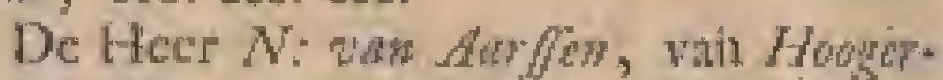
beide, Hect van Fosbol, Sc. Sc Sc.

$\mathrm{De} H e c t, \mathrm{Mr}_{\mathrm{r}}$ Jobin wan der Burg, beroend Adwocat,

Dog van deze Hecren (welke ik valt ftelle, dat ongemeene friejc Cabinetren bezitten) heb it noit iets gezien, ende kan derhalwen van han Eofilheden zeldzambeded (wellio ik, by myne werhuyzing tegen May 1726 . by dere of gene gelegenlieid nog wel eens hope te aullen

zien) in "t gehed niet oordecler, dith diste alleen zeggen dall van cen vooman Licfhebber, en zeer ninzienelyk Heer in Zetland gehoord te hebben, dat de Heer en

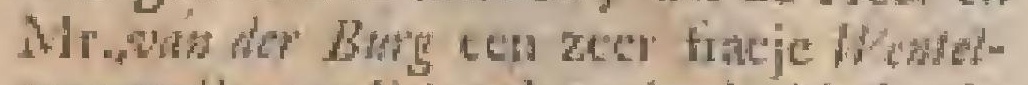
trap, welke zyntid; ook getien hadde, bezir.

Ook kenne ilk char als cen Lied luebber, die ac ook fehoonmalien lan, Mtonlí. Goske, en Beclithouwer of Beeldgicter dog wat Hy bezit, wete ik niet; maar heb her haze Moftelen gezien, dic lyy ongemeen fricy fchoongemake had.

Te Rutudam is we nodite Lidhebber: De Heer $N$ is bolle, Ares.

De Heer $N$ : Grifire, ecr Drogilt, nog levende, $A^{5} \cdot 1724$, en roen 86 . Janren oud, en zeer goed keurer.

Den Heer $N$ : Lufhed, Arts; diecenfraey Cabinet heet.

De Heer. $N$. Bhom; Cafteleyn op de Adminliteyes Werf.

De Hect $N: K$ is wn Aierep.

De Hect Hortik idn Ran, Drogitt, ortrent de groote Markt.

Tot horn liad men wan ouds den Konft- Hownat Schiluty,

De Heer $N$ : Bromblor

De Heer nas Sugran, Borgermedter, die cen frucy Cabinet is lad, "c gecn nu de Hect Revither (zoo men my geacge heef. bezit:

Te Dordrebt heef nen zes Lieftebbers, die yter mede ent Cabines bozit- Dordten, wanr in men al verkicheide ftukken ontmoct, dic zeldzatm, fiacy, cn 200 angemeen $\mathrm{ZYM}$, dar men die by gecr andre Liefheblers vind. Deze $2 y$ t:

De Hect Burbolomas on Segudasd, in den Oudrand, Schepen, mitsgat ders Untangerder Verponding, \&c. Dezen Heer heert het grootIte, en ecn zecr fivey Cubinec,

De Hecr Karel Babart Fort, Kanlt. Schilder, en Commies ter Recherche allies. Dezen Hecr heeft mede cen fracy Cnbinet van Hoornen en Schelpen, en nog cenander win d' Hiwhandfote ingekorvene Dicrkens, zoó keurlyk nee verzameld, en opgezer, ditt ly dat in zyn wectgac niet heet; gelyt nede nies in hee afteckenen wan de $N$ ierIandat Rupen, Popjens, ch Capellekens, met cen zeer nette Befichywing "er by ; eer Koninklyk Werk, en weerdigom van ulle keurilyk Liefhebbers gezien ue werden; behalven dat dien Heer ook twee groote kaf fer met wel Aefen vol Gedierten in vogten, en met Vogels, die zeer fricy zy, nis ook reel freje Mineraten bezit.
Roltesdarize. 
De Heer Willan de Foning.

Deze Hecr heer opk een zeer goed Cabitiet van Hoorns, en Schelpen, watr onder fracje fulkten, en zommige zyn, dicuemand, dar ik wete, beefr.

Ook hect hy cen fraey Cabinerje van We/2-Radifor Slangen, Vogels, enz:, in Airfen, dat verdiend wan Lief hebbers gezien te werden.

De Hec Awori Forwel, Apotheker, heefe cen fracy Cabiner, en, ni de korte cyd, dat zym $\mathrm{E}:$ "er is angenceft, bezit by Gige ftukken, die ik by geen een I.tefhebor in Holland gexien heb.

De Heer Prilippus Crena, Commies op "c Comproir vau den Hecr Ontfunger der" Convoyen en Licenten alhies.

Deren Heer heefe wel het minfte vinallen; dog heeft mede, naden korten tyd, dat $2 \mathrm{yn} \mathrm{E}$ : aan deze Liefhebbery geweelt is, al wy veel goed, waar onder mede ecrige frieje tuklenzyn; dog in de Manut November heeft hy ons 2 it i Laden, weike 2yn E: cerit belomen had, getoond, want onder verleheide ftukken waren, dic veen Licfhebber, dan by alleca, bezic.

De latifte dezer Licf hebbers is de Schryvel zelf, die cwee fraeje Cabinetjens bozit, watronder vecle fukken zyn, die werdienen van Liefhebber's gezien te werden.

Zyne Liefhebbery begon al $\mathrm{A}^{\circ} .1686$, in welke tyd hy rericheide feurlyke Cabineten bezeren heef, wan welke hy ${ }^{\top} \mathrm{er}$ twee ann twee byzondre Hecren werecrd heeft, war in verfebeide flukticy waren (gelyla wel te denken is) die hy daar noit mect gezien heefe.

En alzoo hy nu ma der Hare vertrekt, is hy vervangen door de Heer 7 oames $E_{u}$ genhe Foet, Ansalhier. Dexe Hoerverzanch allerley fracjedingen met veel oordeel', en reekendbdic zecr frey jal 'L leven.

Onder deze Licfhebbers doer men iers, dat ile niet wete, dat in de ncidre Steden gedan werd, re weten, dat wy ordenteIylk, de centle Wocmsdig in icder Mland, is Whiters ten twee, en 's Somers ten urie nuren na de middig, by een-komén, om clkatuders Cabinetren, met "t geendatr ondertufichen mogt by gekomen zyn, to zien, en om dan over die Liefhebbery, tot verder uitbreiding, enophelderiog der zelve, mee malkanderen te preeken, Een gozelichap, onder ons $A_{6}$. 1720. in de Whiger ten Huize wan de Heet wan Segwudrt begonnen, en war in wy veel genocgen vinden, gelyk her ook cen klant bewys is, da evy uitdokkelyk ons Werk จап dere zatak maken. Fn dit ons gefelchap hebben wy den 4 Augft. $A 0.17 \geq 3$. ten Huize woornoend ook de natam van de Lithebbers van Noptwh-Cabind gegewen; om andre Lief hebbers dnin toe mede op te wekken.
Men hęef ools groote Liefluebbers in 7 entw Zeeland, wan welke ny deze door zelker fohe. viend opgegeven zyn,

De Hecr Ga/far onn Gincrs, RaAdpendionaris vas Zeclind.

De Heer Whaw wan Cirers, Borgenecfter, en Bewindhebber det Oof-Indifbe Mantelipapy to Middlbm, alwar deze twee Hecren Gebroeders yder (zoo ny bezegr is) oen uitmuntend Cabinet, waat in refl zeldzame an onbekende ttuklien zyn, bezicten; dog kandar whn niet oordcelen, alzoo noit de ecre gelsad hebbe, om jets dajar van te zien.

De Her Anton won Dishoch, woonende tor Wh/fagon, die cen zeer Cabinet ( 200 hoore), en wair in vecl Zuthats, en $W_{h} /$ Jwiflo goed is, heele; dog lint datt over al mede, alzoo dhar noie iets af gerien heb, nice oordeclen.

Sr. Pieter wan don Hewel.

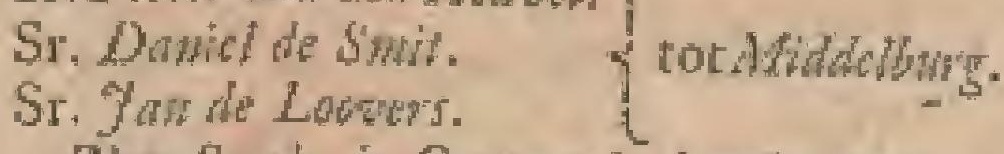

Tot Swol, in Overysel, heeftmen nog twee I iefhebbers te weten,

De Heer Hewrk For, Borgenjodter, en EnzwolPollmedter van Orew/l, en lithLiel. Broeder vanden bovengetnel- hobers. den Hecr Cand Bonchard Fot.

De Her en Mishl Wort, Gencensman vin Sruol, en Zoon wan den boten - gemelden Heer Cart Bonlusil Wet.

Wat deze Hecren bezinten, wéch $\mathrm{jk}$ treet; dog weet, dat zy yder een Cabinet wan Hooms, en Sehelpen, hebben.

"Daar zict men nu een Lyft wan de vootThat mofe Liefhebbers, die il licne en diejk weete, dine 'er in de voorledene Eeuw bekend waren, of dic "er mu nog in wezerizyn.

leer it mu deze tofte affcheide, moet ik nog jęs wan ecnige zeldzatroc Auklen, dic ik by deze en gene lndifle, of Hortand/cbe Liefhebbers, gezien heb, zeggen.

Onder de hallabe heefe niemmd theer fracje tukken bezeten, als de Heer Landvoogd van der Stel in Anbona; dog die op te noemer is my onmogelyl; want zyn Ed: had Solders vol wan allerley zoorten. Hy bezat ved Orangic Admirasls, incer andre, die my ontelioten zyn.

By de Hect Whers, op Batdeta, heb Zelaif: A. I71 3. deze stukker, die frtey wa- zame ren, gezicn. Foorn. Ecn zcldzame gemeen-groote Krol-Hown, Heer

dog zonder krullew, of takken, mec Wybert.

drie zwarte en ros-agtige baden, en met vier a vyf krullen wooran, zynde zerr zwar en dik. 
De Syavko, whar vanzyn fd: "er verrcheide hadde.

Eenige verkecte Hoons, en eet nut cen Zce-boompje 'er in.

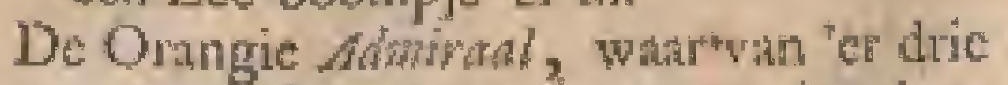
waren, de cene wy groot ; dog doower, als de andre, en geen wan alle heet fracy.

Gacp-Hoows. Van deze waren 'er vier, een zeer groot, twee retelyl, en de andre mast matig.

De Oppr-Admirad. Van deze was "er cen klecne, dic goed wos.

Twee Beddckews, mee ingegroefde vlammen, war wan de wecrga noir, dan by de Heer Solywses, en by Heer $R_{\alpha}$ rel Bochdrd Foot, gezien hebbe.

Ecn zeldzane zoort van zeer witec LapHoon, dic noit meer gezien heb. Wan deze was 'er ecn parar.

Een parr Japanche gladde Orangie dito, bymals een zoart, die uic $W_{e f}$-hollem komen, en die wy de kleene gedoornde $W_{\text {ed }}$-Mdifbe Lap-Hoom noemen.

Een pant rofte Bablonilebe zeldzame Torens met dric onjgangen.

Vecl traje zwart-getalite wite Krabourakess.

Een pur zeer fraey ros en wit gelamelotte Tepellyaklest.

Een ongeneene groote Ichoone $\mathrm{Mu} / \mathrm{geq}$ Wasin.

Een par bruine zeer groote geribde OlieHoorms.

Een groote gevlerkte dit

Zes of nge groote en byzonder fracje Trompelten:

Een pare Goude Lakens wan 't Eiland Dinding, veel brainer, als de onze.

Een titmuntende Orangie Gmose-Hoos, zecr lang, en fracy, ecn zoort van $A d-$ morals wan dic Hoorns.

Fen Gumeglebe Toor, fritey groot.

Een zeldzinc en knolagtige $A_{f i n}$, of grootc Olic kock.

Vande Oris-kek mee Corinthen, of Krenten cen fracy groot part.

Vyf Wef-Indighe frncjc geribde Stombotders.

Een ran dito zoose, zecr glad.

Verfchede Scbourew bydobt, die zeer fracy water.

Verfeheide fracje gebanderde Harts Hotrs met banden.

Een weergadelooze baftard - PurperHoorn unt het roode Merir, die zer gioot was.

Een Orangie zeer fracje Arabifor LAth.

Een zeer groote, dogbefchadigde, $W_{\text {w }}$ tal-Trap.

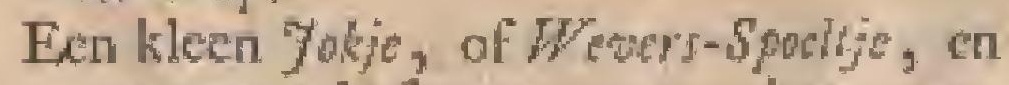
nogeen recht fincy groot wat deze zoort.

Twee ongeneene groote Compar- $\$$ dbelpen.

Ecu patur ichoonc hoog-roode Dudbreren,

wan gedante als te Lawlohophen, of Griafle A Dibleren, wet overiangze groeven, vallende in . Wot dit dchynd my toe de Alloma Dibllet te zyn, dat een licht-nood Pufferle is.

Een para Violette gladde dito, exca cens wan gedaute.

Ecr par gecle zeer lange zeldzane $M o f$ for $n$, met cen brute oval "er op.

Een paar groote geheel robde Kroblen; dog zwart van rand.

Een buiten-gemeene groote hang gedoornde Purpre en zeer zeltzane klap.

De Heer Helmals, heete verfcheide zeldzame tlulken gehad, die op 'c lante zutltur woorkomen onder yderzoort wan zeldzame Hoorns, en wat Lieflucbbers die al beristen.

Wat zeldzame ftukken, en frucje Hooms de Hecien d'Aoquet, wan Sirhelen, Bheun, Juder, en Julfi. Oortmins, gehad hebben, kan men wit hune Catalogi, volgens welke dic verkogt $2 y n$, zicis.

Ao. 1720. Hebbe onder de Hoornkens en Schelpen, wan die groote kenner en uitmuntende Liefhebber, de Hecr $S_{1} b y-$ wor, deze ongemeen fricy geronden: HOO $O N S$.

De Ophe'-Admmal, by Rumals: op de Plat der Manizad's by Letter B. deze is matig groot.

De Alwival, by Leter C. te zion, en zeer groot.

Een andre dito. Dexe is de klemfte.

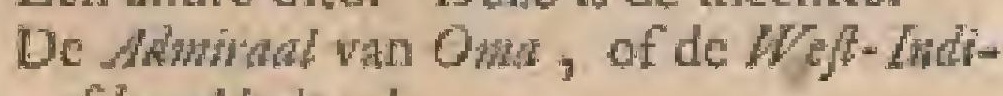
fobe Adwiral.

Dric Vice-Admiradijes.

Een Scbour by nachi.

Eenige zwarte Horts-Hons met banden.

Een zeer groote uitmuntende NephmsSibudf, de grootlte, die ik oit zigg, en wel een lpan lang.

Een frate groote Arke Noachs.

De werkerde gevlamde Liys-Hoot Patar.

De Kracl-Nastias, of 't Krad-DodenHuyfe.

De gemarmelde ftompe appelagtige en leverwerwige Titon of Tromint.

Een wit-agtige dito.

Verfcheide Sjongk's, en de Eyer-net "er van; nils ook een zeer klecrie dito,

Verlcheide Verkens-Switen.

Verfeheide groote en klecne Kemphanew.

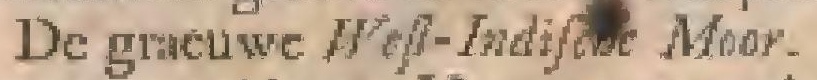

Een zeer zeldzame Hoorn met ved digte rofic banden op een geel-ngtige grond,

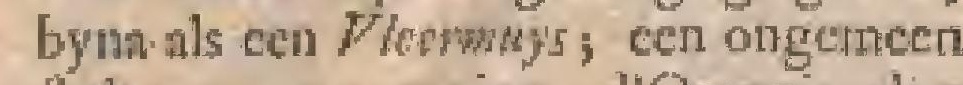
fluk; $\mathrm{cn}$, zon meine, d'Orangie-vling gensand, doghebbe een diergelyk by de Heer Seba gezicn.

Twee 


\section{LIEFHEBBERS VAN DB}

Twee zelúzame Hootss net groote inkervingen, welle ik nier kenne.

lenge $W$ eff halfobe Hoorns, als die men by de Hecr Ramplins op de Plane der Almiranls, ofopde Plans No XXXIV. by de Lecter K viet, aynde ten zoort

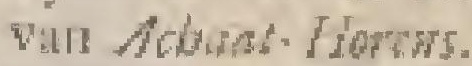

Jen wite ros-gemartiedebufen-gemecne groote, en ecer fracje 7efolfok, diergelyke ik ajoit meer gezien hed.

Verloherde andre zeldzanc Topobolon tar alle ley zoort.

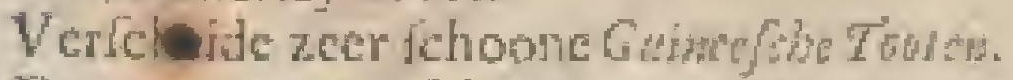

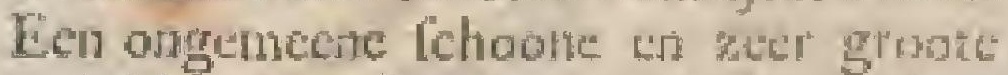
dubble Pots-kroon, met ecr byzontren wilten grond.

Eest ongeneencedito, net roodedrupten.

Een fracje on viy groote stert.

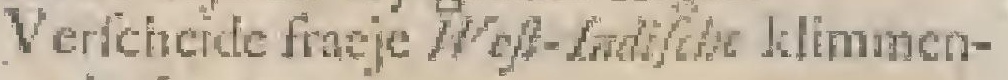
de LeEWUin.

Drie buiten=geneene zeduame Narefs, of Wervel-Hown.

Fen in twee Berous of Beddakns, met gindde viturness.

Eeritito, wet ingegrofide vlanmen,

Een Crret-Hocru.

Tuks Papis, twecltuks.

Verlcheide fracie geele borer-wergess.

Een onvergelylielyk troote Soldart.

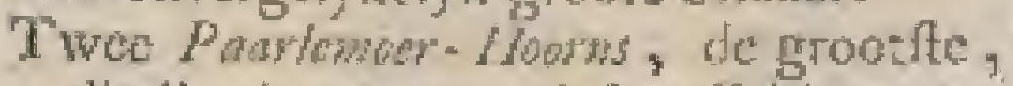
die ik oil zeg, en tic het Cabinet vas

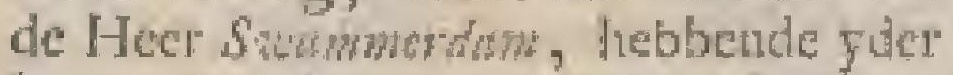
honderd Gulden ven fropien gekolt.

Twee zeer ganote en frney gefinede bonte

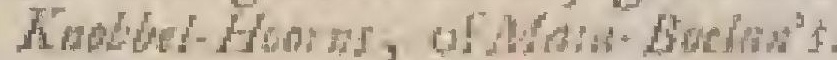

Een groot, twee lileene Sh unten-Whgevoles.

Verlcheide hectly ike gefnedeno Beelicaiffen $v$ ता $B / k$ s.

Twee Camed ILorns.

Ecu Spoche, 't ectelte, dat hier te Lande bekend is geworden.

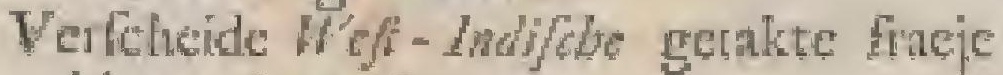
klecne Lap-flowns.

Ecn byzonder groote Appelbloeflense Hocrlay.

De Orangie Podagrats.

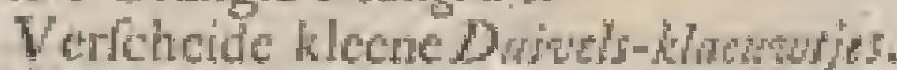

Een pan' Onungic-ngtige Spookj.

Degroote witteHafpl, een ongeneen ftuk.

Twee zecr groote wite $N$ apjest.

Wercheide gruote Italaando Rood-getlippelde V toetries.

Een rect fehoon Nape, wab buiten Orangie, val bithen Pratlemoer.

Verteheide fchoone Mans-Hoom, Doytrs.

Verfeheide fchoone Bugre Drollan wan allerley zonit.

Een in twee /Wefler-Midas Ooren.

Velerley fracje Brandhrigh, gok "t wit Sempontis.

Een piar kicene Toojous wic wan grond, met een breeden, en een zeer inalken geelen band, war wande weer-ga by de Hecren $V_{\text {inemt }}$ en Grow, dog met 1II, DEEL.

\section{ZEEHORENKENS.}

ect weing verandering, gezten, en watr valu ook cen parar laeb.

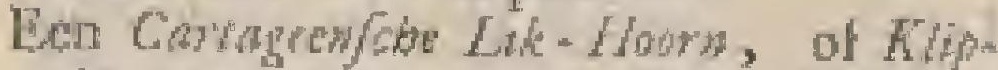
hever, zeldrana, en alleen by dere Heer, de Heer sebr, en de Heer $K_{0}$ nisg, te rinden.

Eer par groene zwart-gebandecerde zeer fracje Sleken, die nienand dan dezen Hecr, nevens de Heer wan Segwiats, ch tily, (myns wetens) bect.

Een kleen geel Papedo-Horenken. SGHELPJN WAn zyn

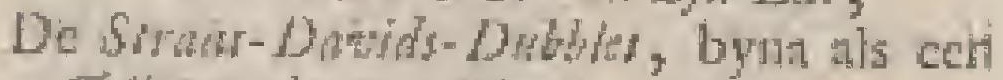
Folpos, de grootlle dic oit zang.

De Bloed-roode en blecte Combas - Sclid. parjog li leener, als uhevan de Hecr Śba

Enen Whaldowe; en cen dito op cen Hanen-kutm.

Nenums-SMnf Doos.

Lein a twee Grangte Lazows-kappos.

Vericheide fracic Vows-Hatjors, een a twee nue roode thippels.

T wee fracje geribde groote Schelpen, als de Tus de $B$ rat.

Orangic St. Jacobs-SCbelow, mee doonkens, twee a dric fluks.

Een zeer groote Goude Tong.

Twee Ciroki-geele dito, zeldzam.

Verlcheide Crifer.

Redors Dwhrest, in "e midden zecr fracys dog my onbetient.

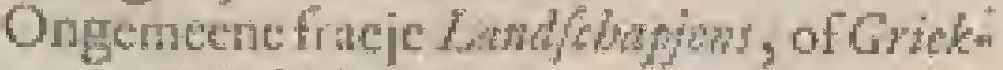
os $A$ Dubblecien.

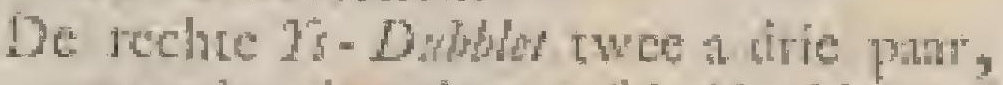
en onder de zelwe verfeliejale blene, dic van de andre verfífillen.

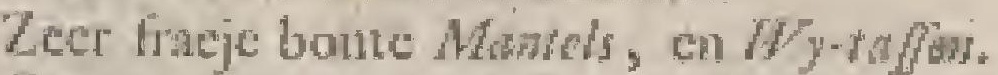

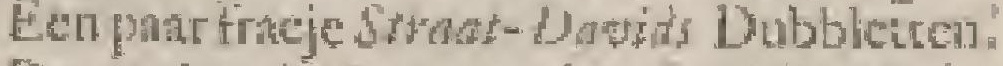

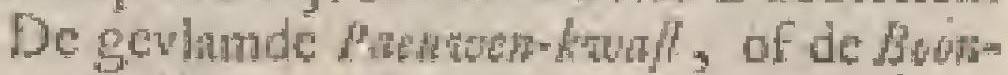
Dublet.

Een Forit-Dublvet, donker-Purper.

Vericheide fracje enkelde en dubble Has- $^{-}$ nent kammen.

Een parr Tyger-Dobletem.

Een a twe zeer fraeje blatuwe For do Bra's of Zomeftralers.

Eenige Appelbloezeme, diro.

De geribue Fens-Dublet wolmakt.

Een andre, diebruin, zeer zeldzan, en fraey, dog my onbeliend was.

En vel andre ftukten, my ontichooten, dog war van 'er oole veele in "t Werk van Rumpbus voorkomen, cn war yan 'er bier agrer nog wel eenige, ge' lyk ook wail andre Licthebbers, zulJen volgen.

By de Heer Grem, zag ik in dat zelve Jat 1720 , ch ook $A 0 ; 1722$ dege frichjo thukken.

Ees Orangic Admwan?

Wen Achast How's.

Een klecn ros Vice-Admiralth.

Drie gecle Foosen met gecle geflippelde bunder ; een $W$ ed $/$-londshe zoort

$\mathrm{CcEC}$

Twoe 


\section{VER H A D}

Twee zeldzitric $W_{\text {ef }}$-Indifob MidatOowe.

Een Appelbloezene Kemploas; de frowe fle die ik kenne.

Eea dito, wat facuwer van Appelbolocferm, dog mede zeer levendig.

Vertcheide gladde zeer wreemde Tromptfor, bynals de Aroter.

Groote dicp-ingekepte roffe Horens,

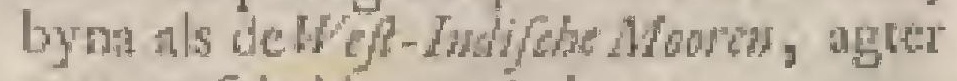
met vericheide omgieringen.

Twee Githerlde Touich.

Groote Risg- of Harls-horens met $\mathrm{Ap}$ petbloeflem, en een paar kleche net iterke banden.

Een par dito, flacuw Appelbloeflem.

Еел zcer groot, co byzonder frimy, litHavas Wloctic.

Een par gladde ronde zeldzame Spllex:

Twee Vorkent-bskew, en ecn fracjeslok, dic onder Appelblocfiem is.

Eedi groot Beddeken mee banden, en een mer bedtien, die zeidzatm 15.

Twee bruine Woll-Indtche Kroon-Horens, en een fracje gecle dito.

Ecr klecr zeldzatro Wentel-naldie.

Ses Zownpist met maden "er over, en cen met een halven natd.

T wec par dileene Tronsptien met zwate Aippels. Twee zaldzame zwarte Sickken.

Een $W_{c h}$ - rodiche geknoblelde Sformbord. Eenzeldzame Beddelyk. Eengroon zeldran Bubis,

Twee $\mathscr{W}_{\mathrm{e} f}$ - Huld be geribde Caskent. Een Staten-Vlargetfo. Groote Appelbloefteme Moer by yen.

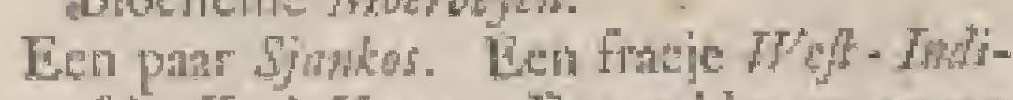
fob $K$ rwh-Hores. Een zeldzam groen werkeerd Howhe, en mecr wan die zoort.

'Twee zecr groate grteuwe zeldzanc verkeerde Lafl-Harens.

Twee gevande kleetre dito, dito.

Len Wef-Thdilche gecl-getlek te en gedoornde Swippon-bek, wan de Hect dor ville.

'T wee a driegedoornde snopheklez, by Rumbling tab. $X X Y$ I. No. 5. te zien.

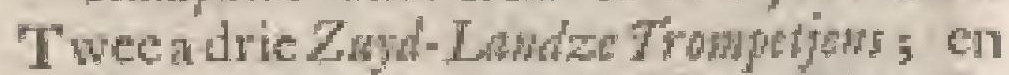
een ougeneene wan de Heer downille.

Twee Nepunu-Subablen. Een fracje roffe Moor.

Een geftecpte Bezoa*. Zeer fraeje gefnede Coguliges.

Twee zeldzane Storm-boedfens. Verfcheide fracje klimmende Leenuen.

Fracje Kemplaanen.

Ficn getalste zeldzame Knol.

Een par Foljows, of Wewer-spoelitens. Een groote, en twee kleche Ha/pels.

Wen kleen gtacuw Tootje net een breeden, en een kleenen band, en nog een dielgelylice; en nog twee par zoo by de

\section{E L I NG DER}

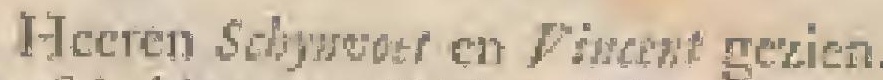

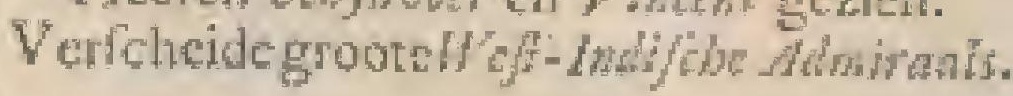

SCHELP IN WA

Een ongemecne groote en frucje Appelbloefleme Tour de Bra.

Fen fichoone Goude Jong.

Eeth groute zer fracye ros-reteckende Q Buker.

Twee groote $2 \mathrm{f}$-Drbblets.

Een kleen Foeti-blad je, Jirbed of Orangie van verwe, op een rotsic, cen ongemeen futs.

Eco zeldume bruine Compas-Schelp, zortder weergn.

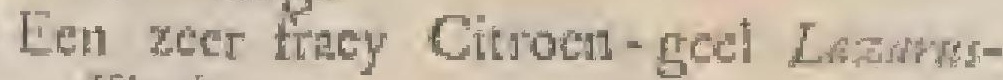
Klapis.

Een uitmuntende ghtade Tyger-Debblet; als de Gribse A. Dobble dog pititer.

Een ongensecne fests. Citrocin gecle $N a$ -

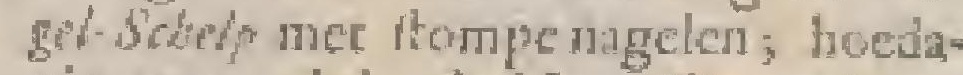
nife eene ooli by de Heer Pinent is.

Een drie-dubble, byna als eco CompasSibrlp, mode weergadeloos.

Twa Prit-Dwhblem. De groot the Are Noachs, die kenre; en Jog eco fiacje diro.

Een zeldame Eylen-Hows-Dubl, of bia Towwhy, met fineje itrulen ter op. Een zecr finey lluk, ecn Cedo Nals.

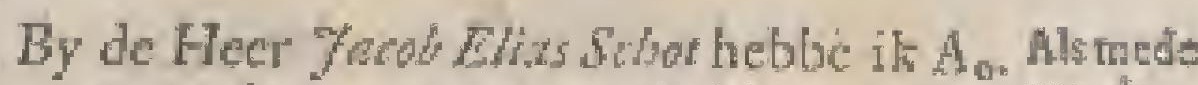
1720 . dezcongemeene ftukken gezien. vat de

Een Orangie Amhar, die uit 'c Cabi- Schot net wh de Heer $d$ "Acther geliomen, en de eerfte is, die hier beliend was. $\mathrm{Hy}$ is zecr fterk wan Appelbloefien.

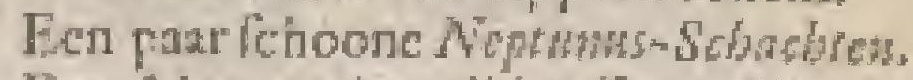

Een ichoone Appelbloeteme $K$ ewhyar.

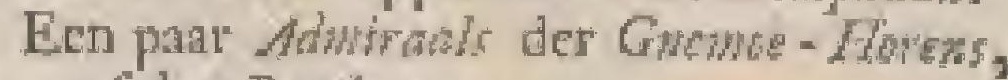
of der Bam-powen.

Werfcheide groote Raap-Hows, en die zeer ichoon geteckend.

Een zcer freje groote Argm; en meer andre wan die zelve zoort.

Verfcheide Appelbheftenc geribde Tooten, die ik niet kenne, en niet wete meer gezien te hebben.

Een Opher-Admiral.

Een ros-agtig gracuw bafterd $W_{\text {ond }}$ Itafie, eern ongemen en zeldzam fluk.

Zcen fraeje Na/fowem.

Een Orangie-antige $R y / f e-b y$-Hown, of Sproty, zeer fracy, en zeldzam, ja weergaddoos.

De gracuwe Wef- Trdith Noor.

Een zoort wan cen langartig Stompe, wath agteren als een $K m$, cra met gropeven.

Twee par Cripes.

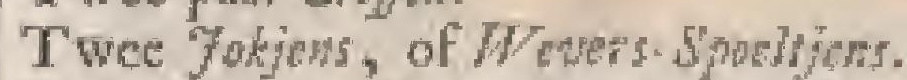

Een zeldzame fchoone en groote brainet, met veel witte en fracje bruine blotsken ${ }^{3} \mathrm{er}$ in.

Een klocne rechte Goud-Lakenze Hoorn, 


\section{LIEFHEBBERS VAN DE}

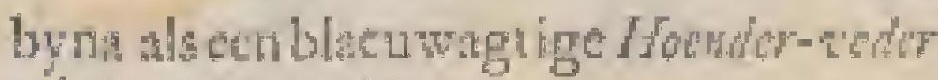
of Brwhe zetdatim.

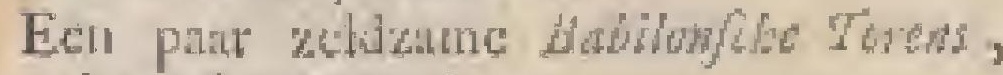
byma leververwig.

Fraeje klecne getilice Laf $/$ hown.

Ecul leververwige tracje Arke-Noubs.

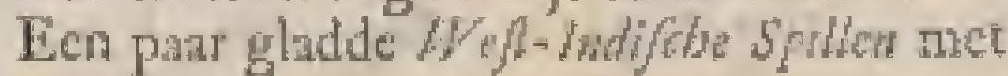
tanden.

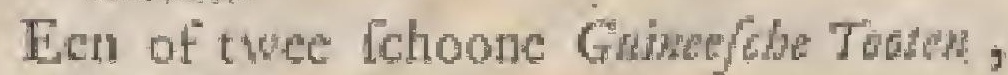
zeer frity.

Een phat niddelbare groote Spiter.

Eenige frneje thifes, of Buchelijes, en een met eer mainnelien "er op.

Een uitmuntende Canari thet tanden, fracy gemarmerd.

Twee par gevlimde geribue $W /$ a - Lhd for Cokerten; dog "L cen palar groot, en thicmuntend fracy.

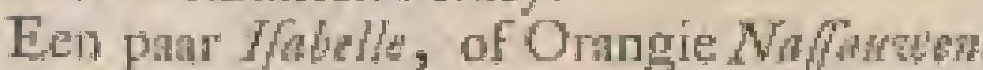

Een par zeldzame gratuwe verkcerde Lwy-Hoors, of Vyren, wry groot, weet niet dat die meer, dan by deze: Heer, ende Heeren Stownwor, Finemt, en Groen s.pn.

Vericheide verkerde gete Hooms.

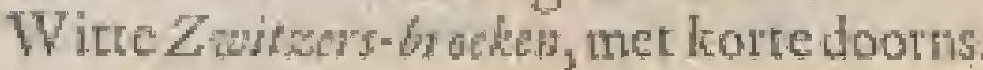

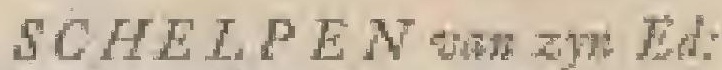

Verfcheide paren tracje $B \pi a b a m-S c h /$ pen

Verlohide Sren-fobren.

Twee a drie fraeje gedracide $\mathrm{Haj} / \mathrm{f}_{\mathrm{s}}$.

Eejige Perlabluth.

De Strat-Dowids-Dwble*.

Een timemende Orangic Lazarus=Klap.

Ertefyke roode Dof Mfrafle Dubbleten wat D. Adama, zyode een zoort wun roode Pofferkins.

Een zoldzatm gekartilecrd $M_{a r e l}-7 \mathrm{z}$.

Een groote Appeibloezerre To As ds Bro, en ecnige patren kleese dito.

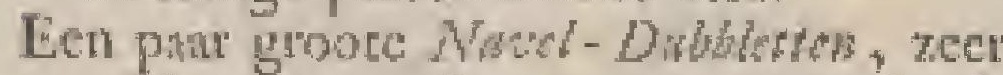
zeldzanm met diepe groeven, vallende on Batain.

Verfcheide andre van eco zoort, die nog wat anden"s is.

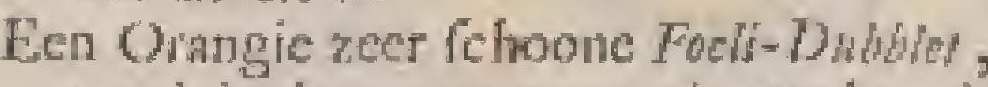
een duin lang, en twe vingers breed,

Een Appelblocfertin en wit geioornd S\%. Yachls-Selfolge, als een $W_{y}$-Tafbje, ongencen, hoedanig een nu de Heer de for Folde in den Harg ook berir, en $A^{\circ}$. 1717. wan my onder andre Dub. blecten thoorns gekagr hedt. Ook heeft ' $\mathrm{cr}$ de Heer Seba een. En (zob geloove) de Heer Finch een diergelyk.

Een groote Totar do Bra, als de geneene kilene, of als de Termandede IetrerScledp; trekkende wat na den blactwen.

Euclyte fohone Smina/des st. JacobsSchelpen, Citroen-geel, en met wit opwerk.
ZEE-HORENKENS.

Een pan groote Comprs-Sobrher ; dog geloove dat de Heer $K_{\text {gog }}$ dante ga ovtlie heett.

Fen puar bloed-roode dito.

Werleferde fchoone Goude Tonsen.

Veel fchcone bonte Mands.

Encly lic fchoone joode, groote Orangie. en andre, ook cenige Crroen-gede $\$$ Jarobs-sebifon.

De reldzane witte geribde $D_{\text {eras }}-D \mathrm{w}$ blet.

Verlcheide fracje $X s$-Dwbleter.

De Heer Mrras Seb heef medezec fraje Hooms, onder welle njy roorftat Zela deze zellzame fkukken $A^{0}$. 1720. en 1724, Hoorn gezicn te hebben: De Orangic At toniral wan de Iecr dor- Hece whe voor 60 gulde ingekork dog beba. in handen van een ander.

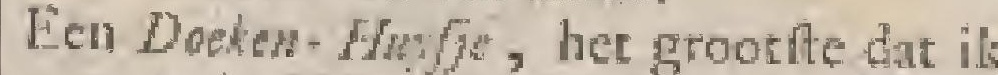
wete in Hollawd heel gezien te fiebben; ten ongemeen frucy ftuk. Het is ge

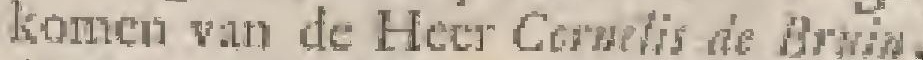
die beroemde Reiziger, en is veerdig wan alle Licfhebluers gezien te wer den. Het is ontrene drie hand breediten con, wat toyne gilling, nog wel zoo lning.

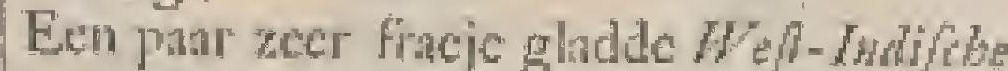

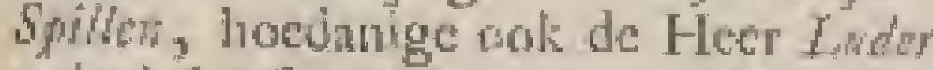
gehad heete; en eene onvolkoncte diro.

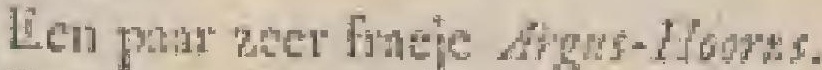

Ecu pald hap-horns.

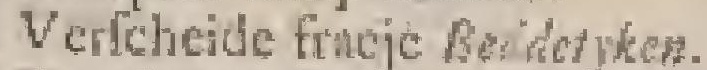

De gladde Tronph, at ect diergelyke.

Twee a drie Candol-Howns.

Vericheide buiten-genteen-groote $H_{\text {ints }}$ Hoosis.

Twee $\sqrt{ } / e f-7 \mathrm{hl}$ : grootc gecle gebanderde en gefpilkelde dito, en ex uirmunde groote din wan,

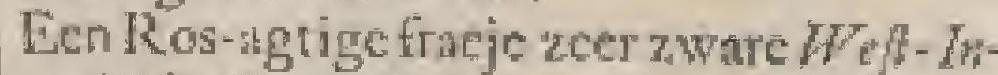
diche Tronupt.

Verfoleide groote fraeje Sledken, tuit de Middeladfle Zee, met utten.

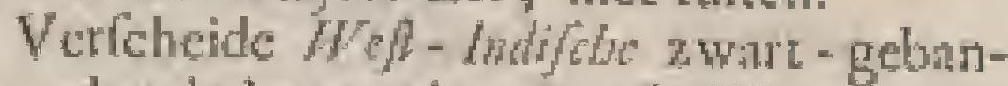
deerde lerer-wige bradarifon.

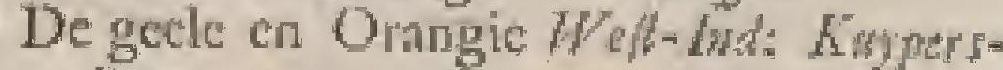
Boor:

De Opper-Alwiral, zecr goed, en rolkomen,

Verlcheide Grinedeforters, cn cone die fracy groot is.

Een piar Carbagecufobe Lik-Hoow, of Khp-Hoorns.

Een fracy Draken-Hoolde.

Dezeldzame Zowe-Hoorn; zynde uit myn angehald goed gekonen.

Eenige Acbacte Hoorns, of 't blatd der Admiraals by Romplins op de Plaat No. XXXIW. by de Letter K. te zien.

Een part Jokjons, of spoldits.

$$
\text { Coce } 2
$$

Vecl 
Vecl fchoone Brambrif/en, ook 't wit Scorpiosntit.

Eemuitmuntende fehoone half-zwarte, en witte Brandaris.

SCHELP EN Wan क्या Ed:

De groote bleck-toode Gompas - Sulp. Een teer groote Appelbloelfene st, yacobs-Scbelp of $W y$-Tas met doorns, nis die welke de Heeren do la Fulicen Srbot medu hebben.

Zeer gruote en zecr volkomene Noget

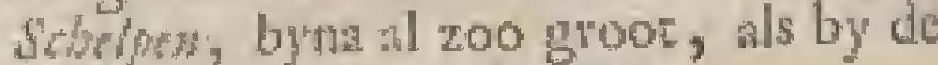
Hecren, Virent en Kiggeladr.

Vertacido roote Let Arime Schelpen van D. Adathat

Verlcheide Appelblezene groote Tou

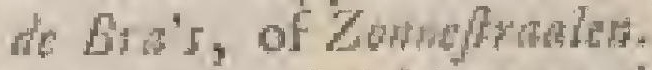

Fen a wee entel-blaeuwe donkere dito.

Leo blecke Orangic fehoon-getatic $L$ ozarks-klap, cn verfoheide andre van die zelve verw, en dar onder rechte Orangie.

Vertcheide Hanekamman.

Nownmes Swaiffows.

Twee fracje Nophans-Schacbien.

Een biltard-Cris.

Verleheide fracje $K_{\text {orings-Mantels. }}$

Zecr groote baltward- $W$ afel- $Y$ zess.

En van A. I7I9. Heb dete ongemene fukde Har ken by de Heer Sebaid gezien. Schatid.

\section{HOORNS.}

Vertcheide Si. Maloze, of Frawleb Bot Hoorns; die ook in Grined wallen.

Twee groote $W$ eft-lidifhe Spilen met tanden; dog de eene mat volkomen.

Een folioone Wef Imdj/fe bruine Toos, dic niet kentre, fracy gensmineld.

Gracuwe en bruine gladde platte zeldzatthe Doyes.

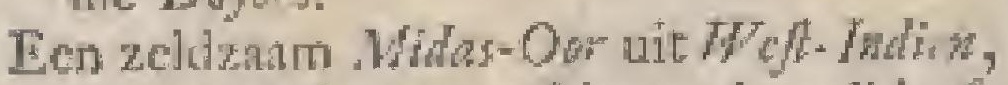
grteuwagrig, en ran binnen A ppelbloeffem.

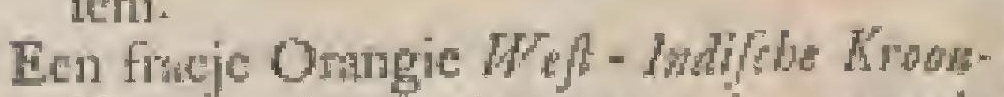
Hoorn, hoedinig eene uitmuntende gede ik ook by de Heer wan Stervalat Finde. Deze is wry groot, en fchoon.

SCHELPEN van zyn LA:

Een gropte Appelbloefleme Tore de Dran

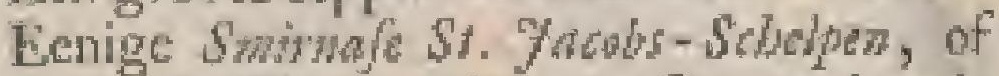
Wy.Ta/leben, wit, en flacuw Appelblocfen 'er op.

Eenige Orangie Dabbletjes.

Fracje In 't fatr 1720 . zag if onder bet onHowns eirdig getal fracic Hoorns wan de Heer van de Dinewr, tot Harlom, deze uitmuntende Fingent, ftukken.

HOORNS.

Twee Orangle Adrairals.

Een Opper-Admianl, fracy wan gioote, er goed.

Twee Znjdand/be Frompryes.

Een $70 k g$, en tweendrieklecrebuftaraddito.

Hen grootc en een kleence gevlamde verkeerde Lay-Hodr, weer mooy.

Een part bunin - gevlatodo floyke zeldzame Mlolls.

Verlcheide Appelblocfeme geribde $D_{\mathrm{A}}$ del-Towrits.

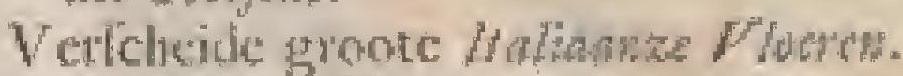

Vicr Mhante Horeths.

Drie Jorken-bakkn.

Twee a drie gladde Hooms, als NewdHorens, zynde dik en lever-verwig.

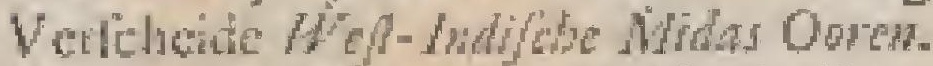

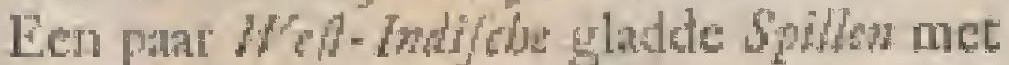
tanden.

Een patar middchatige Noutht, of Dosken-Fushe.

Een grootedito, ontient I o duimen lasg, de winfte, frneylle en grootfte, die ik Incone, buiten die wan de Heer seba, dic wel wat grooter, matr gecler is.

Een $K_{f}$, dic vin binnen Orangic is.

Een gede groote lifimmende Lanw, en twee kleene dito, als klimmende LeteTuen.

Een Buykje, of Bezont wet cen nand in 't midier.

Een a twe fracje sobuth by Wabt.

Vier Zownphems met monden "er over bener.

'Twee at drie zeer groote $H_{67}$ - Heorit met bandeil, de grooulte ruym een halve voet laig.

Twee geneene, en twee blitcuw-aǵtige, Dwroli-kidewen.

Dric geele Torten, met gete ftippel-banLen, en gecle vlekker, cen zoot vats Wot-Jadfelse Admirals.

Twee a drie Slaken met roode tuiten.

Twee zeldzame Horcos als Vledermuizen, met is a is fyne rofle banden; dog de ene wit geckr wn bandeth, en. hebeen diergelyke, rooder wan banden,

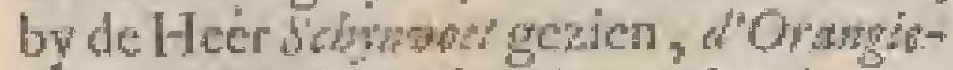
wag genand, en by nuenumdanders.

Twee a drie dito gracuwe, met en werkicerden bek.

Dric a vier gladde Horens, van fatzoen als een klecine Traspet.

Een prar verkecrde geele Hoomkens, en nog i dito.

Twee Happls.

Twee a drie fracje Kaap-Hoorns.

Drie Garef-Hom'ns.

Dric a vier Kaw wat Hoornkens metbanden.

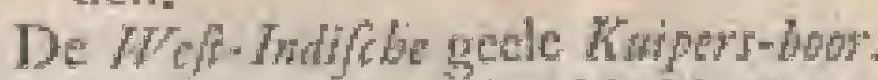

Ecr pant groore Gelinobbelde Trompettey. Een zeldzam klacen. Hoornlien mer drie orrwentelingen of kringen pgter, dat nice kentic.

Een 


\section{LIEFHEBBERS VAN DE}

Fen patir klecne gecte Ioornkens met ech in twee bruine banden.

Twee Goude LAtews met drie bander, ieder byzonder", en zedaziam.

Verfoheide reldane Dojes van verlcheide verwer.

Ook groene gemarnelde dito.

Een a rwee par diep-ingegroefde kleme Hoornkens.

Ettelyke zeer fracje reche, ook Bocrenen wilde groote Mo joguter.

Een a twee Shate-Vlrggejpes.

Twee Ohkoken met Corinthen met reed Appelbloeftem.

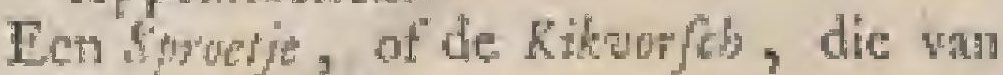
birncri zwatt is.

Een groot lohoon Kemphasule, die leververwig, criecn Appelblochem is.

Een Eyken-houss-Toof mer een band.

De wite hort-getakte zelutane Switsers-Jirek, en zecr fraije klecne frolHownent

Eenige graedwe Mobrew, of Mifres.

Een rwarte Moor, wel een voct lang

Drie groote gebandecrde Morten, ydet byzonder.

Verlicheide getalkte rofie en bruine Bratm

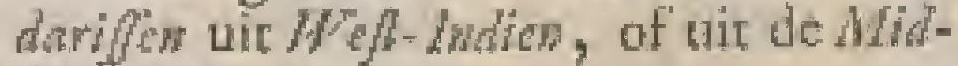
dehudfor Zee.

Een zeer groote Soldat, met de Vifch "er'in overgekonen, enventeheide kleonct dito.

Een Appelbloefien Brandarisia.

Het wit Seorpioentie; en cen 7 wat.

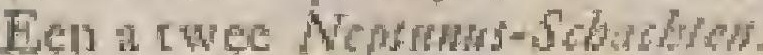

Een zeldzane graeuwe kot-gedronge Dadol, als de porfacalcbe wall Jonfon byna.

Verfoheide fraeje Bodderken.

Een a cwee Sabr-Figgetjes.

Een groot Beddekes mer batuden; dog die met groote Dobbelthenen, of Beddekers, niet.

Een geftrepte Bezoar.

Een paar oroote Talang of Lap-Horess, cen Manncker, en Wyfken.

Een zeer fraje gevederde klene zeer donkere Trompt.

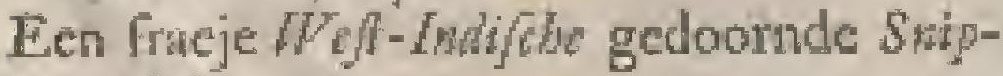
pendek.

Twec lilecne Arken Noads.

Eenige groote Franfla Bej-Hoom, en cen zeer liteene.

Viet a vy f Argus-Horens, en een vry groot var oogen, en fracy.

Drie a vier Sforktots, of Offer-Horher.

Twee grade Hervel-Horess.

Een Brokge met een dolke natad in 'c midden.

Eenige zwartagtige /lars-Horeas mes bunden.

Een uitumutende folmone groote Meterkam of dubble Spinokop, volkomien wan tanderi,

\section{ZEEHORENKENS}

Eef dito onwolkmen, en $\operatorname{mog} 2$ part kleener, mede volkotinen win finden.

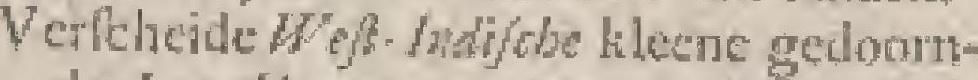
de Lap-Hown, en cen a tweenet hui$20 \mathrm{cos}$ ' of:

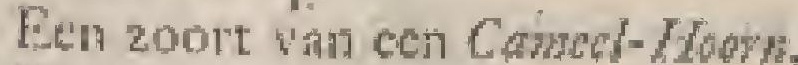

T wee gelalk horiter.

Een gemeene wry groote diro.

Len a twee Ternatusholde zeldzame getakte Vhemsayerw.

Groote doorgeneede $P$ asudg- of Parymor-Horn ; co cen dito traey uitgegelineden.

Twee a drie Zet-7ionuen.

Een palar keene witte, of greneu wagtige Towiens met een breede en cen Imallie gecle band.

Een hecrlylic en groote $/$ roon-Horem, en moer kleene.

SCHELPEN vas z"w Ed:

Ean Kewh-Hartje, rondom friey Appelbloeffem.

Een thet Purpre Aippen.

Een Citroet-ugel, fraey ; dog nien re ferk

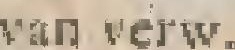

Een zeer grootte volkomene NapelSclbelp.

Zeer frieje Poffers, of Quakers.

Len patr Compas-Sabelpes.

De bloch-roote, en de bleck-roote dito.

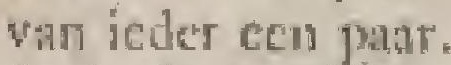

Drie donicre zeldzame groote Zownd $f_{\text {rad }}$ las, of Torr de Bri's, enled blaeuw.

Verfcheide groote Apretbloczeme Tour de Bra's.

Verlicheide heolyte Orangie Lazaraskiapon, ook crikelc en dabble Haane kamsmen.

Vicr a wyf Citroen-gecle zeldzame Dubbletter, of stesc-blochen, luedanige mede by de Hecl Luder verkogt zyn,

Twer Crifen, cengroote, encenkleene.

Verlchcide Penl-Dubbrien.

De rechee stentyode nog in de Steen fteliende.

Twecongemeane, en twee gemecnestrat Davida-Didbletten.

Een fracy paar Sraat-Davids-Dubletrom.

Twee a drie goede Goude Tongen.

Een withe Toss.

Een in een gedrongen Cirroen-geele $N a$ gel-Sehelp met flompe nagelen.

Eern dito, met wat Appelbloeflern, zeer friney.

Een zecr groote, en zeer volmakie $N$ e. get-Diblict.

Twe kileene Rotj-Dublewer.

Een gedoornd $W$ y $=$ Tasje wit en zwart, rood-agtig van verwc.

Een a twec zoorten Awhow/Chr, byna als de Cariagen/be.

Verfcheide fchome bontc-Mantels, en cn groote St. Jacobs-Schelpen.

$$
\operatorname{coc} 3
$$

Een 
Een zeer gronte gedoonde wolnatite

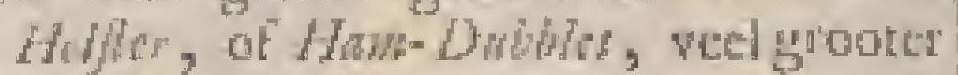
औts di: nyic.

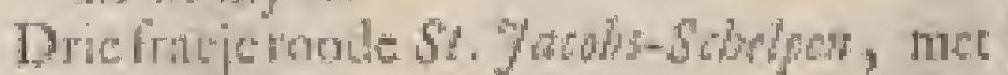
witte ruitjes.

Een frace lterk-roode, matig-grootc, dito.

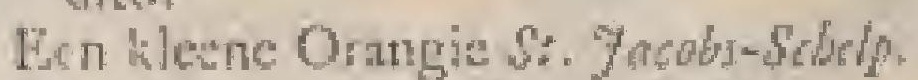

De groote geribue Fenth-Dublot.

Vertcheide fracje Moffels.

Len Appelbloczen-agrige Forlie-Dtbblet, dic mooy is.

Mirsgaders veel andre heerlyke ftuklicm, die my, dool te groote menigte vath alles, entfehomen zyn, alroo die mar onthouden, en nice sungereckend bob.

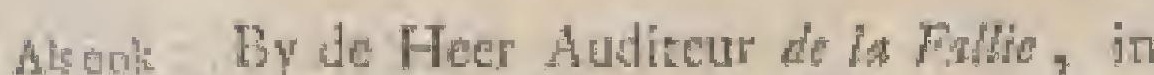
wyzonder den Hage, hely AO. 1718 . een groone whin de Sehar van frape en zeldzurne Hooms geHeur Au- seles, watr" var my dere in 't gehengen latilitin sog hatgen.

\section{HOORNS.}

Twoe zeer frutge Opper Alwmals, yder byzondel wain vero en teakening; dog de eche fraejer, als de andre.

Een zer zeldzamue Hoorn, by zyn wel Ld: Gelo Nrmi genand, van groote by an als cen Orangic Adwiwn; $\operatorname{dog}$ korter in een gedrongen, en war dikker, hebbende kleene gecte, witue, en bruin-agrige bandjens ketens-wy ze aver de gelacele Hoorn, die my zeer zeldzan, enfiney, voorkwan, zynde cen ongemeen ftuk, dat niemand inders bezic.

ken Orangie Almiral, welke ile nietgezien heb, notar die zyn El: (200 my bericht is) nadertand bekomen heeft.

Twee zeer fraeje $/$ Tent?-mapent en nog cen bartaurd zoort.

Verlchesde gettreepte zeldzame Bezontis, of Brideters.

Een fincic z wate schon by Nacho.

Een zect tracy genawncrde Athe Nonds.

Yed retende my onbelkende Hoomis uit

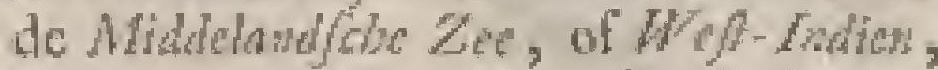
die zyo wel Id: zeide nithet Oofen bekonien te hebben.

Veet roode Meritens.

Veel ongemeene A ppellbloeflituc Sirken.

Ongeneene Citroen-gede entracje branje Sicheren, nevens lyeerlyke LazarasLlappen.

Het gedoornd $W_{y}$-Tasja.

En van de Schelpen flat my nog cel ongemene Bia Teminkas, of anders de Fylen-hants-Dubler woor, die vrygroot, ch met twec a drie zwartedwas-buden; mas beneden ara den buiten - zoon net een fimeje hoog-Orangic band, wel cef pink breed, geteckend is, en die pas "er Wht wan 'er nog cen beeft; Jog dic dar wat fratler, en nog wan cen ngter-kant voorzien is. 7ynte aen wolverlyk fiacy en weergestedons thut ; hoewel de Hect Gracn een diergelyk heef, dog die dac tehoon Appelbloeften nise heets.

De groote, en onnoemelyke meenigte wh tracjigheden, diectezen Iteen bezit, is borzak, wat iny veet indie Hoorris ch Schetpen antictioten $2 \mathrm{ym}$.

In 't Fatr 1718, zatg onder de Hooras en Diewan

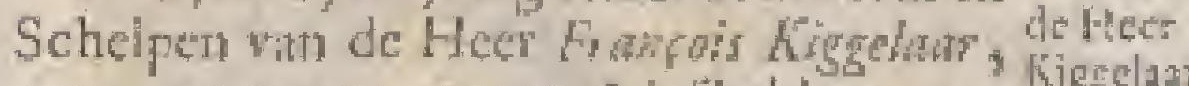
en ongemen gront Lichthber, an nacuwkeurig kither van be zelve, deze ongemeene itukken.

Een hecrlyke zoore wan groote zelduane Doyes, wan godance ais cen plar

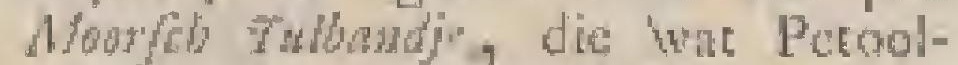
thrig 2ju, sen ongenem dichoon groen iluti:.

De groote zeldzame gevlande, en geknobbide Trinom, of Trownd.

De Sha met cen verlecende bek, die nu

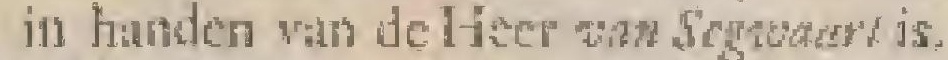

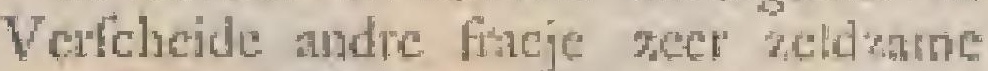
zwart-geteckende feklem, byra als de Batuifles Ahrwikn.

Een zoore wan zeer linge Zoumpens, zynde fyn-geribd, nog wel cents zongroot, met een brede Lip, als de Wha-Oora, nit de Middelandfolie Zee.

Een feloone zeer groore Ferhas-bik.

Een dito, dito mes een gronte fecrt.

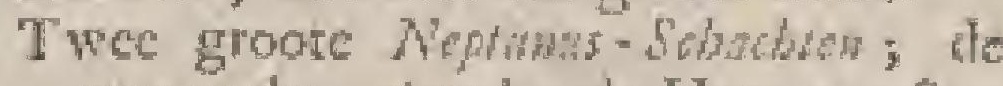
cene reche, (nuby de Hecl wan Szm-

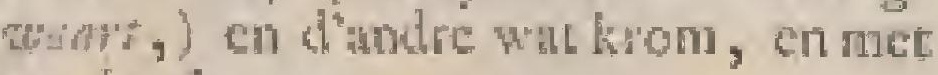
acu bocht.

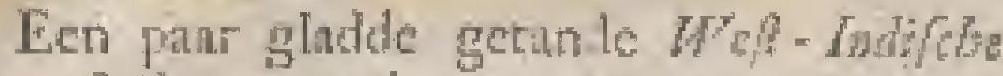
Sph, en bok nog cen piar gromter zoot, zondertanden. Decerftekome in Banasmos voor, en is by de Heer Luder ook verlioge; dor de grooter zoort kome in Bomamms nuet voor, deze bezit nu de Hecr won Segudat.

Twee Johjen of spolfors, die de Hect was Segwart nu ook hect.

Twee Pies Adurads.

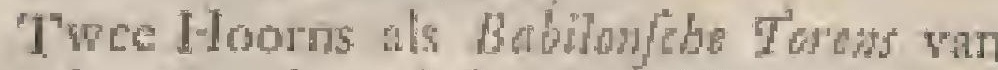
lengre; dog glid, met kiecne bruine wlekken op en gratuwen grond, on byma als ect zoort van dunne Trompet terin

Verfcheide zeldzame Arken Nodeds.

Een Orangie Ahwall.

De Grimefobe Tos, werfeheitene vandien.

Een rmeje Haris-Joorw mat bander, en 1 hog cen goede.

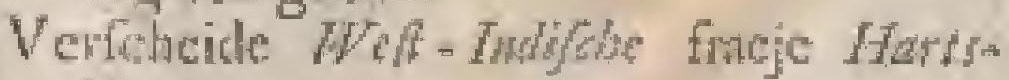
Hatris,

Een it twee groote Maliandele Forran.

Een Hombyna als de lifimnende Lewn; dog kletner.

De gedrucida $/$ Japel.

Verleheide Krm-Hogns uit het Wajts, 


\section{LIEFHEBBERS YAN DE ZEE-HORENKENS.}

of tit de Middelasdfobe Zee, en ook । Ean groote witte $S p h i$.

ecrige met 7 warte takken.

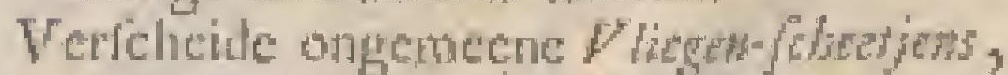
ook groote Vliegen-fcheetjens, en groote Vloyen-foheetiens fog anders ats

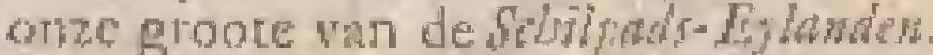

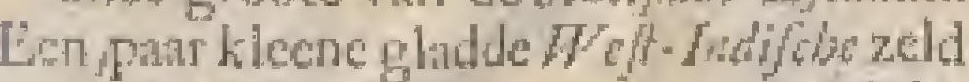
rame Siorm-bodym, of uit de MiddeJondze Zic.

Letr weergadeloos Blatso met cen fehoonen tipjep wirten dwars-band, centtroo bred, linade wafichen rwee lyne swarte banders.

De appelbloczeme Cavalo', of Sink, tait de Middelandele $Z$ re , nu by de Heer vin Shredrt.

Een zeldzame dikke leore fompe Trosupet.

Fun Scbout-by Nacht, en een dito leververwig.

Een lineje diso, die zwajt is.

Ver cheide Wef-Indifbe Torem.

Twee Guinelobe Thert.

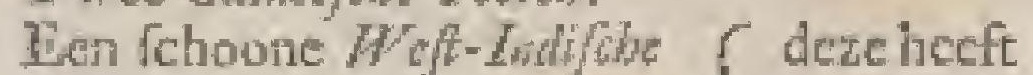
Froon-Floth

Fen dito, dito Ornigic, dico zcer fracy.

Een patr geltrecpte $B e z a r ;$, of Beddekens.

Vertcheide fracje Beddetylen met knob: bels, chz.

Verlcheideverlecerde graeuwe Hodrns, of Lay-Hoorns.

Een Appelblonfon geribd Tooje.

Twee Cand Hows.

Twee langwerpige Znhlander, nls baftard-Pauskroonen wan fpikkeling; zeer fracy.

Ees fchoon Docken

De grncuwe hoor.

Een violer Quahdrate.

Ean felwoone groate Kemphass, wet een vinger, zynde lewerverwig.

Een paur fracje gevlande Tepl-bakdes, nu by de Heer yas Seguart.

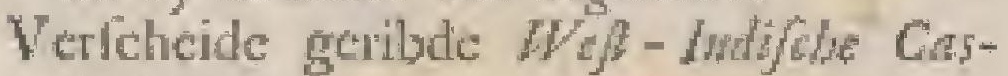
ketren.

Verfocheide Mida-Ooren wit de MiddAarildo Zce.

Ecn parr keene Appelblocfenc, die mu de Heer pan Serwast heeft.

Ver[cheidc fracje Carakollow, anders dau de voringe.

Een paar Tyger-Slekten; cn cen par zeld* zame groote groene en zwart-gebandecrde dito anders Koe-oogen-Sichken genatand. Nu in hat Jen van de oar Segwart.

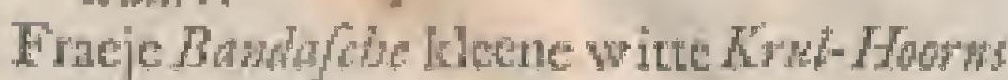
mer zware talken.

Hen par fineje frow bo Bd-Herenkens.

Een pulur dito, dito fyne geftrecpe, zeer mony.

Een pan $W y=T a / f e n$ :
Tweo witte lecte Lort-gethite Switstro broden.

Twee grooter yoor getalke dito.

Verlcheide werkecrde geele Hoorns.

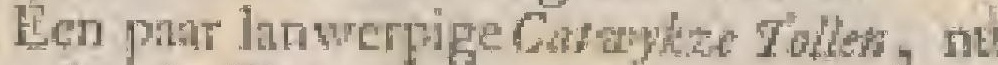
by de Hee" way Seguant.

SCLELPEN Man ty N

Een zea groote fohonie $\gamma_{5}$ Drblet, de grooulke, en freyste, diciblicnne, пu in hunden van de Hecr som Serrwart.

Hen groote Compas-Seblp, zonder wecrigat.

De blocd-roode dito.

De bleck-roode dito.

Een parr zeldzame ingekorwene Stats-koppen, dic op clikanderen paren.

Twec Smondelse St. Jacobs-Seblow, Citroen-ged, ent wit.

Een klene Appelbloezene groote Toly de Bra.

Fen geel-agtig $V_{\text {ents-Lat }}$

Een Appeibloeffem dito.

Een Fraje Orangic Lazarw-klap, op een Klipic. Nu in handen vande Hecross Segwant.

Eenige fracje Hanew-kwwen, en oen vier dubble. Nu in handen van den evengemelde Hees:

Een fracie bruine bonte en wirte Bowtकhathl.

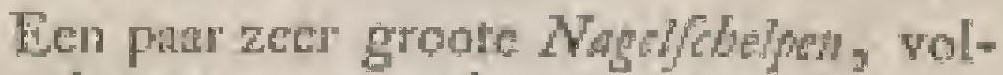
komen var nugelen, en cen Citroengeele, te zamen, nu by de Heel war Sewan.

Twee Dubletwy, eveneens als de Cartis getorist.

Twce Bom-Dnhleter.

Twee $C r i f w$.

Een zeer groote bruine gentuthede $P$ of fer, nu by de Heer wan Segwatsayt.

Eell a twee groote, en meer andre $M g f$ fels, die fincy zyn.

De wite gerible Wens-Duller.

Die Cabineten van tezen Hetroyn in Juny 1723 . in den Huge verkogt; en 't verdre knt men in die Catalogus zien.

De Hecr Sigweld in "s Gratrwhge bezit mede zeer fracje co ongemecne fuleken. In taa die by geeri and zyne frieje Hoorns heb il nog deze on houden, $A$. 1718 . en 1720 . gexien to hebben.

Een Hootn, als een Krool thet een tuyt, zynde wit, en ageer dnie a vier in gegegroefde kringen hebbende.

Een Citroen-geel arompie van Crracas. met wwee atrie omgicringen met takken. Dit zag nergens metr.

Een dito, dito grooter Hoorn, die rjec kenne, ook vin daar. Deze hecfrook nicmand andets. 


\section{VER HANDELI NG DER}

Verleheide Kempluawe lever-verwige, 에 ecr zeer freje, die Appelbloefer, en de kleente wan de dre is, die il kenue.

Eer Appelblocleme getnkte kleme LAPHow; dog zondier lap 'or ann.

Twe zeldzame Hoons met fnuiten, by nats den Admintal qun Oma, beververwig, zynde eet zoort vin Trompertes:

Een pala zeldzame loote witte Switzersbroekn, wit de Maddelswlde Zes.

Twee dileene witte zwart-getakte hrolHorens.

Twee dito, veel brutiner, dicowan grond.

Twee groote kort in een gedronge z warte brede Moores; hoedanige nergens gezien heb.

Drie a vier Amginte Teph-bakkn.

Dric a vier andre dito, rond, bruin, en kicener, en dric a vier nog klecter dito.

'Twee liche geribde Hen-Judiche Casketten.

'Twee wat zwancler, ditó.

Een part zeer klone Asmbor/che dito; thet nerjens.

Twee roode geribde Arewas Tolfin.

T'wee geele verkeerde Hootis.

Twed par Griffer.

Een Appelbloczene $Z$ ud - I dere heef sits-bint

Een ditó,.... Stompje. J Jecr.

Een ged.... dito.

Vier Franche Bd-Houns, neer fracy

T"wee groote /aliaan/de roode Yhorlews.

Een patr bruine latimnende Leswer.

Drie geele kluene diro.

"I"wee groote dito," mee groote druppels.

Een Neptunu-Sebaht.

Een grootc zwarte Moor met eene band, de grootlte, en bette, die oit gezien heb, zynde wy latnger als een fpun, en wry dik,

Twee groote Tromptiten.

Een wiolette Slok, die niemand mecr heft ; dog rwyflel, of 1 k dic ook by de Hoes Sebot gezien hebbe.

Ech it twee zeldyane Luy $=$ Hoorts.

Twee parr groote $W e j-I$ mafobe geele Kuipers-boren.

Twee geknobbelde Bedideyker.

Een pur igeknobbelde graeuwe Laphowns.

Fen zeldzane groote gekartedde Dojer.

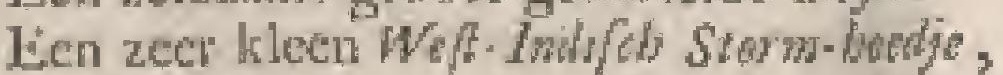
of Casketje.

Een zeldznme plate Rhdolfus, of $W_{y d-}$ monder, cen zoort wan Beddethen.

Een zcldzame Miglog-Hown zonder Mufycq-nooten.

$S C H E L P E N$.

Swhwohe St. Jacos Schelpes, wier par, Een fchoone getakte Switzers-brect. lichonde, Brwhit.
Verfcheule gecle Orangie, con aok witie.

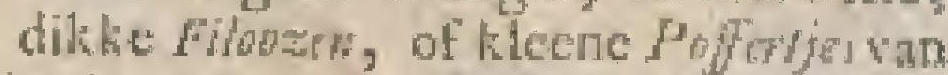
Cunato, die by nicmatid gezien hels.

Een groote freje Purper-argige Mfofe!

"wec Crillo.

lien part diep - ingelsorncole Dubbletion

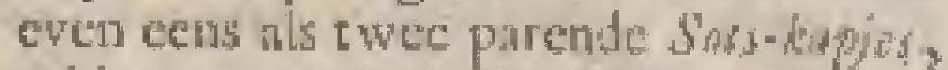
zeldzatur, ch heb die alfecn ook by de Heer Righehar gezien.

Drie roode schelpen van $D$. Adama, wan De' Him.

Een groote Compats Shlo.

Agt Hand dommen by cea, en nog twee it drie andre.

Eeten ichoone liche-Purpre Sf. FacolsSilkelp.

Een zeldzame Lasaras - kidp onder talekets.

My ftat voot $A^{0}$. 1718. by de Heer Wen de Jacol bart in den Karg, woonernde in de Hegt

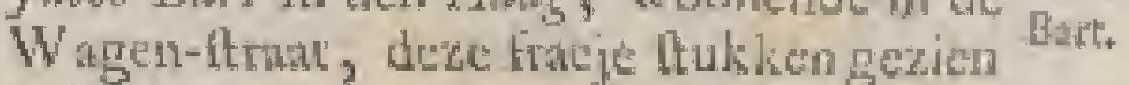
te hebben.

\section{$H O O R N$}

Ext para groote 2 warte Mortw.

Een witnemend-groote, dog wat ge-

Twee minder diro.

Een pans white zeldzatine shlien, die noic by ienand anders zig. $\mathrm{Zy}$ waren valt de Heer Fuge' gekorinen; dog Ao. 1720. vond dic niex meer by 2 कis $\mathbb{E}$. Een zeldarie Appelbioctieme steh

Een zeer fehoone volkamene Na/farew. Een patr graeuwe zeldzame Tuobr, als Hats-Hoons.

De Hecr de lis Falle tot Delf, hecit zekerlyk een zeet fracy Cabinet met zeldHoornkens; dog wat dich Heer bezit, rame weet ik niet, dan atteen dar ik weet Hoorns dat zyn Ed. deze fukken, war Wan eeni- Heer de ge gezicn heb, heeft. la Fallie

$$
H \circ \stackrel{O}{H} N \mathrm{~s}
$$

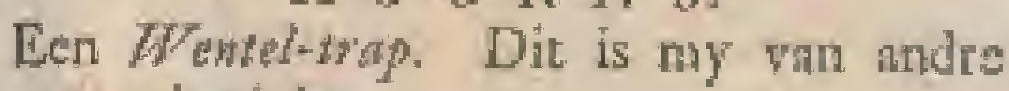
zoo beriche.

Een Opper-Admiraal, by my $\mathrm{Ao} .1717$. gekggt.

$$
\text { SCHE } L E N \text {. }
$$

Een zeer zeldzanc en ongemeen fracje Koning -MANACl.

Een donker blacuwe groote Tour at Bra. Een zecr Tracje Citroen-geele Dabler, uit de Midduladfos Z Ze, dieniue kenne, welke drie ituken gezien heb.

Van de angencene fukken, ghie de Dievah Heer Blom tot Roterdam bezit, komen de Heer my deze ac bimncr.

$$
\text { HOOR } N \text { S. }
$$




\section{LIEFHEBBERS VAN DE ZEE-HORENKENS. 5753}

Een geribd Appelbloeflem fracy Toof, inders de Dadel-Toot genantind.

Twee fracje zwate en wit-genarmerde lratken, wat grooter als myn Znyd. lawders, en in Bonamus te vinden, $N_{\mathrm{g}}=220$.

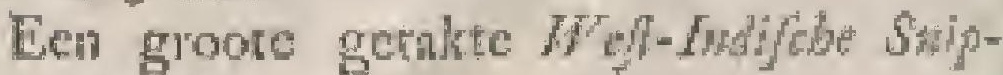
penbel.

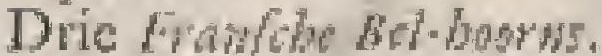

Een groote Kikvorfeh met wericheide brume bunderi op ecn witte grond.

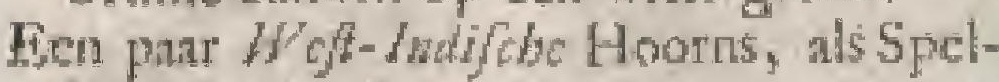
lewerks - kuffens met wite banden win vlekskens.

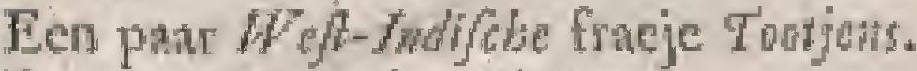

Een par Garwyke Tollen.

Len greterwe Radulfos met een witten band, en van birnen Orangie.

Een dito ronder band, wan binnen wit.

Een parr wite klocne lange Tholbaher wan Cirrofato.

Exn parr bruine kleene dito.

En zeldzame witce $/$ eferze Krul-Hoorin mer rakken, zonder kruilen.

Een groote dito, zynde dik en zonder eenige takken, byn als die van de $\mathrm{Hr}$.

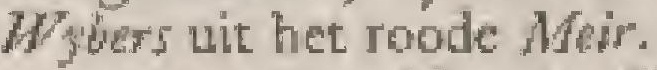

Een a twee zeer zeldzame Adr rithry, of Sleke-Hoons.

Eenige "warte Mooren met banden, en een zeer fracje, feltonn van band.

Twee a drie kleche eractwe Mooren.

Een zeet groote fepl-bal

$$
\text { S C } A E L P E N \text {. }
$$

Een groote Hashowam.

Een reldzame gracuwe wcengudelooze Bult-Dwhitot.

Een volkonene Appelbloezene $K$ rnb met pooten; Een ongemecn ituk, en verTheide andre, welke ik vootby gac.

Een gebucchelde dito, als een Kempbaingtice.

'Twee zect groote Hom-Dulblotem wan Chreno.

Dievan De Heer wan Setwant beztr inzyn uitde Heer nemend fracy Cabmet deze zeldzitme ftukWan Seg- ken, zoo verre hee ny heugd die gezien wast te hebber:

$$
H O O R N S \text {. }
$$

Vier Odie-Hoorus metr rothe batiden.

Twe zer groote dito, met brede ribben, ongemeen.

Een patit kleenc, en nog dric patit grodte Carel boors, watr onder zee fricje.

Een patr zeer moye Bayghedrollen, of Tolks.

Twec grote zeldzame geribde Spillen, ongemeen fracy.

Een parr groote getsnobliclde dito.

Zeer groote bonte Knobbel-Hoorns.

Twee zeer groote, en vier kleene Napjens.

$$
\text { III. DEEL. }
$$

Een fneuw-geribde nove groote stot.

Een; zeldzan par 7 gers, als Woye [cheeten.

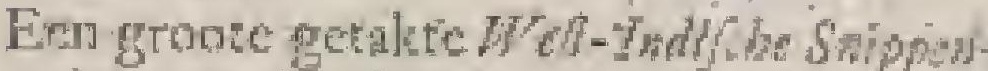
bek; en drie bonte gebnderde dito.

Twee paar groote Orangie Brwincten.

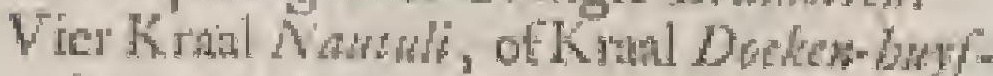
jens, mutig groot.

Een parar groote Docken-hwyfons.

Een puar geneene fraeje dito, en nog

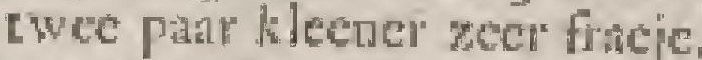

Twee patr Honfolo Bd-buteris.

Vier kleene spuriaf he Horenkens.

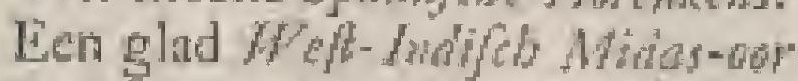

Een groot Zaompje met cen natd 'cr over th nog etrelylie andre zoo.

Drie enkelde W fo Ludflche Casketwen, yder byzonder.

En ongemethe groote gedooride Beddeyw, de grooulte die kenne, en mer andre.

Vyf a zes geflecpte Bexant, en enige wan werlcheide gronden en whamen.

Zes Fotwhese Tolen, en nog twee grooter zoort.

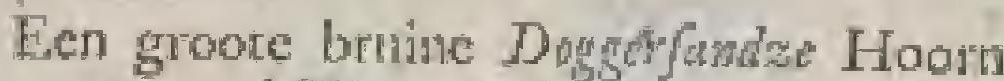
met veel Wormen er op.

Iier ongencene groote Aar-micm.

Negenderley $Z e c-A p p d s$, en datt onder cen parr Tulbander.

Een para Orangie gebandectde Dodss, weergadeloos.

Een rechte blacure Liwork- doors.

Len zeer groote baltatid- Wented frop.

Een pint wit te geknobluelde Lap-ban.

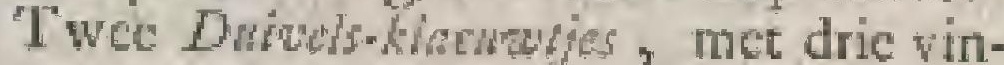
gertjes 'cr nan.

Een par flacuw-Appelblocfieme Hownbatamen.

Twee Nialden met witte druppels.

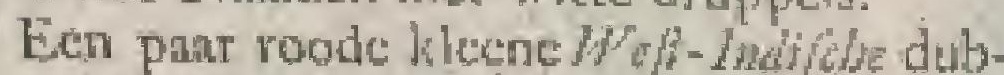
bet-gerake Lap-horess.

Een pair gecle dito, dito enkel getrkte; diro met een wit-agtige band boven by de knobbels; en nog vier andredica. Ecri zeldzane gefpikliclde Lap-bosm, by Ramplus Tab. XXXVII, Na. 3. to zien; an dere lveeft de Heer Grow ook. Een wite en Appelbloefleme Kenplond Drie leververwige diroos.

Een paar kleene diroos.

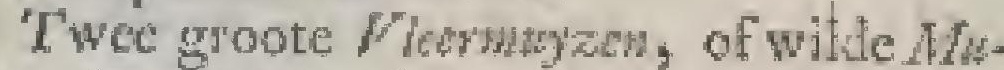
Jogurs; roode.

Een geele gearulite Doyer.

Een ongemeene fincje Argmze Krwhboors zonder krullen; dog met fterke Appelbloefieme batren, of echerves over dwars, en met vecl banden en ribben "er ower hencr. Een zeer zeld. zatam ftuk.

Een kleen wit en zwart getalkt Kmyborentic.

Dric Orangic Podagra"s.

Een ongemeene Tepol bal met dric overDddd langese 


\section{$574 \quad V E R$ H A DELING DER}

lange brecde banden, wectgadeloos.

Verlchide gemamerde wit, en rolle ditoos.

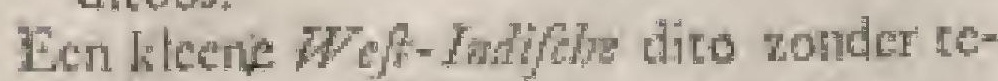
pel, en wats de hage zoorevan Curacad. Een parar groote dito.

Ecn pan Aighshosw met brede brtine banden, ern met een witcte dito.

Verlcheide andre frieje direos.

Een patr groote roode /falionafebe Vhattiens.

Eenige paran roode gejpikkeldu $W$ othjen, of Achate-buljoms.

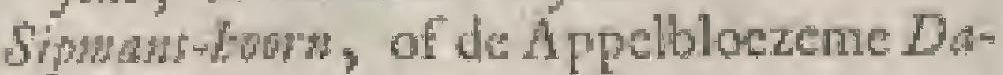
del-ton:

Een Achate Hown, by Rmmbia Tab. XXXIL. by Leter K. re zicin.

Een patr zeldzame Boteramggen, Hartsboors met groore fippels gebandeerd.

Een klecte Learven-100\%

Eer patl zecr zeldzan gemarmerde dicoos.

Vier frocje Gutucefore Itores, war onder dric gronte.

Een par zeldzame geele $V_{b}$ l'borens.

"Twee patr zwarte, en en lewer-werwige Zer-tons.

De Guralane Folk foot,

Een groene Kass met drie banden.

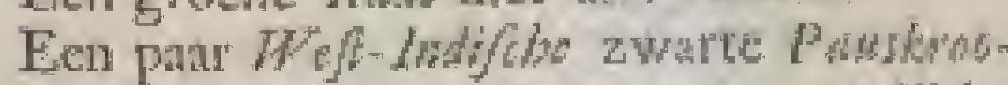
wen, zynde een zoort fan grootedike Tuycen.

Een par kleene wite geknolubede Hoorns, met eene rey knobbels, en byran als Moorties.

Een patr zeldzame zeer groote Lohk zonder cakken, Draken-fecrion genaamd.

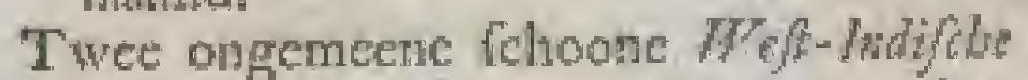
Orangic Kroonloorms, en cenige andre,

Dric part zwatse, cn Appelbloefeme zeldzane Dopers, of Mans-borews, gemarmerd.

Len groote fchoone gemancrda $V_{j}$, en nog eenige andre.

Een pital lingze of verkecrde Horem.

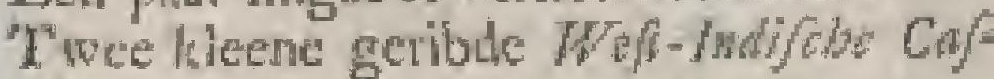
heltin.

Twee groote $W$ ef - Indifote Adrairtals. Een zoort wan geele Foorw.

Fen parar groore Siddanter.

Een potar keene, dog zeldzame dito.

Een par witte Zwirsers-bokes.

Eenige zeldwathe Zuydlandze Trontetits.

Ecr ongemene fohoone zwate gevalke wite Brandars, en nog zoo oen dito wat minder.

Een part Rievier Pous-krowes, cn dic gednornde Rievier-Minswikn.

Vier Citroen-geele ongemeane Kwollos, de cene diep-geribd.

Fen groote geknobbelde Lap-boren, en twec dito met bulten, en zes vingers.

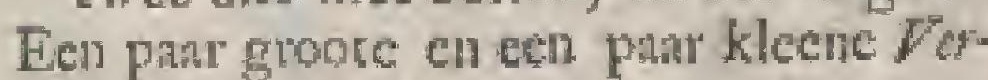
kens-bekkm.

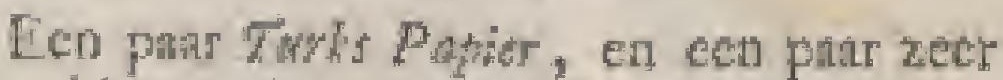
klectie dito, zeer zeldzan.

Len sruote geribde Oh-bow met witte druppels.

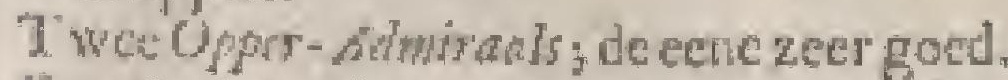

Een Ondo-Adnisanl, mede zeer goed.

Hen Urangie Alatinat, die goed is.

Twee Omaze Adhinists, villende op 't Lilind OM, cn want van "er de Heer Sidymoul cen herfe.

Een Vice-Admirad.

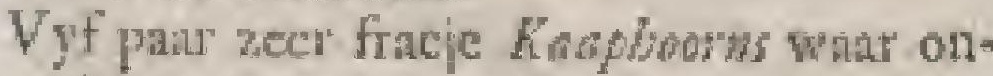
der twe para ongetnenc.

Een ongemeene groote Mufyo-kown.

Een lchoone Olikeck met Rozynen.

Len Vice-Adwinal, en cen bultard dico.

Vea Arginze Krul Horems.

Vyt Giperze fintions.

Drie gracuwe gelepene Kroon-berews.

Len paar zecr zeldzume kllene groen- ge"lede Krow-borens, die zyn Ed: en ik, alleen bezirren.

Fen par geverude bruin en goele Toplwakken.

Een pan yolens, of Wever-forthons. Een Nentutas-Selseds.

len wonderlyk fraey uitgewerkt en door-

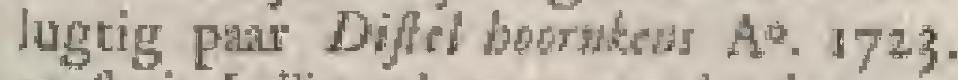
certh uit Imien gelsomen, onder de natim val Wentel-ingpon.

Lien wiste zater diklke Morby botrn.

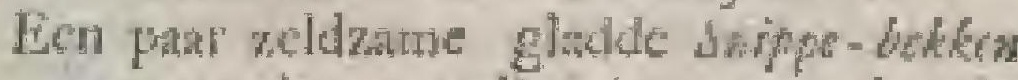
met tanden; welkers weergate by de Heer Lsder ook werkogt zyn.

Fen geknobbelde Orangie $D$ ydander.

ten par Kogem-oogen-Sicken.

En Garach, die onder Appelbloeficm is.

Een pan Tyger-fekhes.

Euclyle dikhe Pofl-boren-/ikken.

Die Camen butens.

Een piar gemarmerde getalic $Z$ rth broken, byina als Stompjens.

Een graeuwe Slek, met cen ver lecrden bek. Eer ongemeene kart-gedrongen krobsboow, cwen cens als cen Hais-hoorn, mer cen fronlle band woor, cn in 't mid. den, ar met een fyn netje over "t gelecel lis.

Fan zeldratme rofte Vloyen-fobet.

Ech ongeneen feboon puar blact we $/ \mathrm{W} / \mathrm{k}$ jes, of Achate Kakjes wonderlyk facy. Vicr Offer-Horem, of Signko's.

\section{Sobcines of Dublewer van zyn Ed:}

Een piar Hojpls.

Een ongemene fehooke bruine groote Poft

Een weergadelooze vry Enote Orangic Nagel-jels, kat en ftomp wan nagls. Twee pant Adoma Dubbletten.

Ecn Orangie Magel-Dwhht zonder nagels; dog fterk van Ornngic.

Een Appelbloderne tompe dito, zeer heerlyk.

Fien 


\section{LIEFHEBEERS VAN DE ZEE-HORENKENS.}

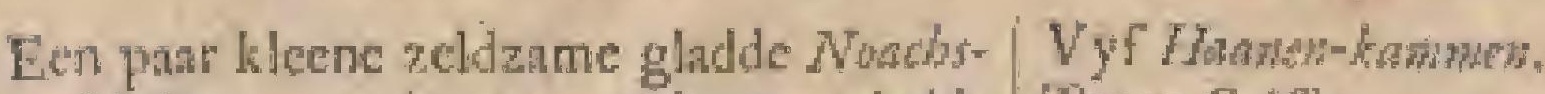

felotpu, en de nog zeldzaner gladde dico.

Drie witce baftard Asken, en rwee parar brtuine Apken-Noals.

Een ongemeen paar zeervolanak te grooto wite Nage clelpon.

Een Citroen-gecle dito. .

Een ongenatene Purpre toeli-Dubld.

Een puat klene Compas-/chelper.

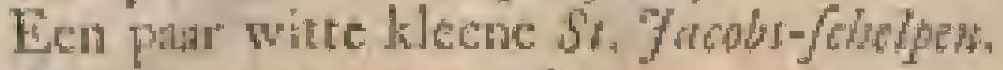

Len past zoer groote dico.

Dric a vier ros-gemarmerde dito.

Een panr blecke peetiche Dubbietten.

Een groot wit plat Wafel-Ter vol ribben, hoe langer hoe meer vermindevende ; zеé zcddzain, cu my onbekend.

Een parar groote Ra/fen.

De zeidzame geribde Vomu Dubblet.

Ertelyke fchoone Bonromantels, cen para Krat-Dubbleten, en ook tracje $\boldsymbol{N o}^{\circ}$. wingswatnte's.

Een zeldzame Dubblet alsen $W \mathrm{~h}_{\mathrm{d}}-1 \mathrm{zer}$ vol kringen, atude enekant geifoornd.

Een zeer gloot Lawicr blad.

Len ongeneene Venus-Dubblet zonder tanden.

Een par groote blacuwe ca wite Fun de $B r a ' s$.

Een blacuwe dito.

Een par Appelbloezene dito.

Een fichoone groote Goude Jost

Een Ppier-svitte dito.

Een ongenten fchoon Appelboeffent Honmekn, of Ros-drobles.

Een para geribde Orangie $S t_{*}$. $/$ weobs-/chet pen of Koning mantels.

Een burlandze Mo/fol met ecn Lazarus$k$ klap $_{4}$

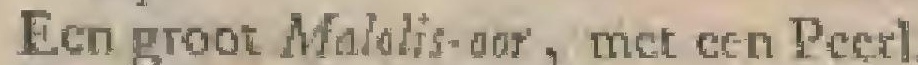

Twee parar Weller/de lange $M o / d w$.

Twee parar dito geliepenc diso.

Fon groote en klcene Cris.

Klecne zeer moye Molfeles.

Een purpre Lazary-klat.

Ecn groote gecle $\mathrm{Nagel} / \mathrm{cbel}$.

Een an twee pant groote Zilvere Tofolbotdem, een zoort van groote Patrlemoer. fchelpen.

Een thiten-gemecnc groote semarmede Poffr.

Een geflepe graenwe Nordz dito.

Een Orangie Lazapuraho op een Khipje.

Twcedito, met witte doerns, ongemeen fracy, en zecr ved andre van die zoort, die vithatien.

Een drie-dubble dito, op Cornal-fteen gegrocid.

Een kleen zeer wit en zeer. fyn+gedoond Lazarus-kapie, zeer fracy.

De Tchoonlte, grootite en withe $y_{s}$. Dubble, die kenne; en nog ecte half 2oo groot, en wat gecler.
Twee Crifor

Wyf Ambonze platic Luter-/oblpes, of Herman: Dublletten.

Een lurput geftipt Fenes-hatjo zonder randen, en beneder Purper.

Een ongemecre fraje Purper en wit gemalnierde Barafom-/obels.

Een dico, dito blacuw, wit gemarmerde dito.

Ben Carthangena ongencene Dubblet.

Een pan Batron-bori-Dubbletien.

Een $F_{j} g$ Dubblet, van my getiomen; en van welke jk "er nog een pair hebbe.

Een ongemene Poffor als de Griekize $A$. Dubblect, met eetr zeer breede blacuwc en ecn witte band. Een weergadeloos thuk.

Ecu dito flacuw gemarnerde, dog platter. Een geele klecne Lith- Uwhich.

Een bruin-overlangs-geilrecpte Dubblet, even eens als de Gided $A$. Dubblet. zeer fracy.

Een groote zeer gladde witue Porcelyne Pofror, ongetucen.

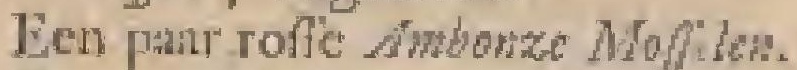

Ees patrandre dito.

Vier kieene roode zeldzame Muglkens, zeer vel ongemeene bichlowlze fracye Molfon.

De Heer Cafd Bardard Voet bezit meide

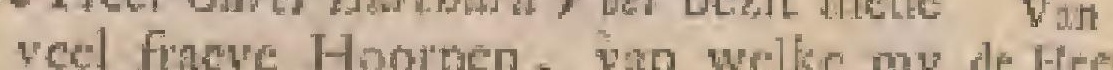
deze te binnen komen:

$$
\text { HOORNS... }
$$

De rechte Opper-Adminal, klecn ; dog zeer helder en reyn.

Een parr ongemeene fchoone genarmerde Pygen.

Twe Cart-Horns

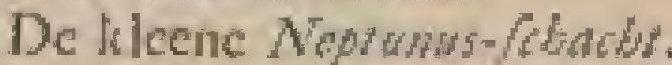

De zeld ame z wart-gebandecerde stok van Cadis:

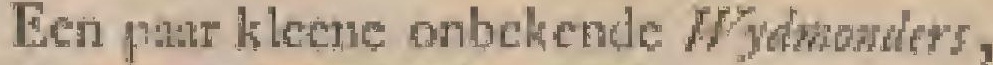
met twee reyen knobbels.

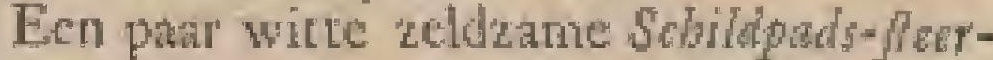
tens.

Een Canp-boon.

Een par litene freye witce Fra-bogwkens iner zwate takken.

Een patr kleene Cryapare Tpellaken, byna zonder tepel.

Fen gladde dito zonder rejel.

Een para Angas-boows, cn ecn parr klecne dito, een vimger lang.

Een kileen weergadeloos Toofic, byna als cen Cypos Kable, mec twee wite bn den

Een poun zeldzame gecle Fuyder s- boven.

Een part dito, dito Dadels-gewyze, en lang.

Een gracuwe Zee-10\%.

Een ongernee ros ca wit-gevlande Tepd$\mathrm{D} d \mathrm{dd}:$ hat 
576 VER H A D weergadelooze fracye Hoorn.

Een witigtig Harpje.

kenige Argatinze witte Pal-kroonen.

Een Groenlanze Howrn met en groenc brecde ronde Lip, zeer zeldzain, en wat na een Doggerzandze Rivol-hoen trekkenile.

Twee klene fracye Verkans-/nuydem.

Een zeldzame As guinze bilthard- $K$ ww boorn zonder taklien, wat Orangic.

Een parr Doff-lndifice ditoos.

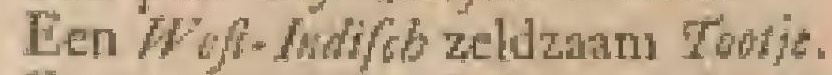

Een groore Wefl. Indiflche gedoornde Ship$p=d e d$.

Zes kleene ditoos.

ken witte $V_{Y g}$ of $L$ tivit, ongetneen.

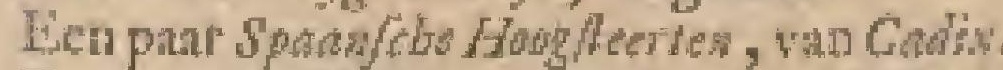

Een groote bleck-geele geknobbelde Beddesy met roffe batuden.

Een groen Kaasis met cen breeden helder witten band in ' $\mathrm{m}$ mididen.

Twee par witce Arguists Trommelfollowen.

Een Olie-ked net Corinthen.

Een baltard-dito.

Een partur fincje Troonberens.

Ecu Fron/dic Bel-booris.

Vier Ornugic Arginine Krul horens.

Vier witte getakte ditoos.

Twee WeA-Indi/che zeer klecne en onge serte Carshejes; zecr fracy.

Een prat dito, dito, dito met gebergten getecliend. Zeer zeldztam, en noit meer by my gezien.

Twee paar zeer fracje Agate Tooten.

Een par Kraal-Noutull, kleene, ontrent een winger larg.

Een paar Mufyeg-borens.

Een pat plat-gebucchelde zelzame Zouthorls met vecl frieje oogiens.

Ëen paar zwate gladde Bratudarifen.

Een paar bruine Arguinze Nadides.

Hen pas" gellepen Midar barm.

Een patr gladde bruine Zwillandze Trompetews.

T wee kieche witte Midas-oorem.

Ees fracje kilecne Arke Noachs.

Len paar We/s-Indifche geribde Gasketten.

En parar kleene geribde en overlangs gevlande Casketten, blacuwagtig van werwe.

Een paar zeldzame geribde Wtherze Voethorens, by ria als de Vemus- of Vonte bom met biair.

Vier zwante Moores.

Een pras Parphra"s, van Godis, zonder doornen.

Een pan' blicuwe kleene gevlamic Gaf detis

Zeer klene bruine Rudulfur-borems.

Een groote Mufyeq Hoorn, en nog vier kilecne dito.

Een parar pinte Wydmondors, een $W$ of

\section{E L I G DER}

Indifle Hootn, zeldzantm.

Vier Spanete Pe Pmparats.

Twec Wan-borens

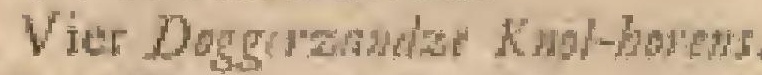

Een Hoorn, Furds lapier gonatud.

Een kleene dito Arableh lopicy, weergadcloos, en noit mear by my gerien. Hy is wan 'e zelve latzoch in " $k$ kleen, als de groote var ' $t$ Torks Pupier, dot nog een weidig anders, en zetr fraey mer 6 a 7 treyen blokjens, bymals de Gwisec se Toot, zwart en wit geteckend tegen malkanderen, vercierd. Hebbe nolt de weergae geziera; de zelve is ontrent en halwe pink lang, en zeer glisd en helder van grond, en tcelenng.

Een geelageige of graenw-gete $W_{e j}$ Indifhe Takd-bak nuet een tepel, en ydele brane vlanmes. Een reldzarm ituk. Een ongemecule zeldzume Porrys met vesfelaeide dubble bander; en ook zon een bruine dito, bejde ongemeen, en noit 200 meer gezits.

Een kileen eli zeldzantro Horent je byna als een brecd-gelipte witte Bromiaris; dog broin; en nier 5 a 6 opllande verdeclinger of den rug.

\section{SCHLLPEN}

Een forge met Pufpe lippen.

Twee Tygertrongen.

Een fpierwite fehoone Tong, even eens als de Goude Tong, ongemeen.

T wec wite Aarobey.

Een fuar groote roode Fowr de Bra's, of Appelbloezene Zomnelluten.

Een bruine plate zeer groote Poffer. Zeer teldzatm.

Twee paar gloote gracuwe ditoos mede zeldzattu.

Dric witte grerbde St. Jacoly Schol en met roode doornen, en 'c cene agter Orallgie; mee dric ltappel bander agreran.

Een groote witce zeer zeldrame $\$ t .7 a$ cobs \$clup, cn tweeGredelyne ditoos, cen zoort van Kowngs-mamrels.

Growlamda Dubbletcon als Poffor, groot en fracy.

Een witte dito zecr zeddzan.

Fen groote ongomene fohooric Srat-

Dnrids Schlls, dric duimen breed, of byra een harnd graor, zeer bruin, de frey fte groote, die ik oit zng.

Een dito, war grooter, dog flegter, zynde licht-ros.

Vier piar ditcos, zeef fraey.

Vier Srram-Dawials AWhmiken.

Een ghdde langwerpige Schelp.

Een paar wite onbekende Poyferkens.

Een Shen-fhede.

Twee pala Nowdze Moffls bleck violet, en fehoon gateckend.

Vier $\gamma$ sinudze of Noordanpze ditoos, byzonder fraey, en fchoon violet. 


\section{LIEFHEBBERS VAN DE ZEE-HORENKENS.}

Een Spanyld dito hoog violet, zeer

Len pant wirte linge Tepdbakea wail Co. breed, en van Cadis,

Fen par geribde Vems-foldpen, dog defect.

rapho, thet een tepet.

Een zeer groote brune dito, watn Grordfoto, en eet klatener.

Een groote ongemeen fchoone Citromgecle Nagel'forso met Atompe nagels; en een kleene dito zeer fracy.

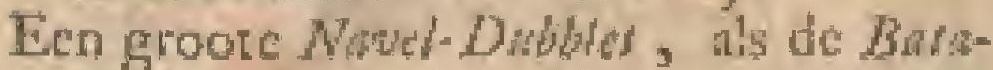
wijche, acer gekarteld, en 2 klcene ditoos.

Vier wanneties Doblewen wan Cadis, en en dito vol pokken.

Een gladde Dubblet met witte dwarsftreepen.

Een panr matige 7 -dubbleten.

Twee groote St. Jacols Schojpen.

Vel weergadelooze hierandiche Mofelew. Origeneen fracy.

Ongemecn-fracje Brodponnew.

Een ongemeene fruje Compas-joblh vol fracje vlekken 'er op. Zeldzatm.

Vande De Heer de Konitg bezit verfchcide Her de Hoons, dice fracyenongemeen $2 y n$, wan koulng welke iny deze tẹ voren komen.

\section{HOORNS.}

I' wee uitmuntende dog verlcheide geteekende Carapes.

Gevlamde Sicbllpads-furten, of ongetake Krol-Hoprms, wan Cadt, wet zwarte banden.

Zes fracje Kroos-Hootns.

Argomze Hoorss wan dic zoort ran velerJey verwe, ook Appelblozzeme.

Zndomze Trompetjens.

Een Admiral wan de Dadels; zeldetam.

Diggerzandzi Knol-Hoorens verleheide zeer groote, en kileene.

Twee klecne battatid- 7 ogioss, of spoelkens.

Een par geksobbelde zeldzame witte Wyd-mowders, zyndecenzeldzame zoort van Mochpos. Hebbe die noit meer gezien.

Een par zeer grootc groen-gebanderde Mafelen, die ook noit meer gezien lieb.

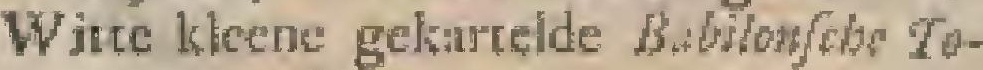
rome พat Cumand.

De gedoornde en ongedoornde $W / N-I n-$ dirce Snippebek.

Arguinze genurmerde Doyts.

De zwart-gebandecrde Slek wan Cals.

Dunne Molder-Howns.

Een groote Hoorth, byna als cen Aveze Trompo, van buicen wit, wan binnen rood, als de Sjangko's; dog wit gefchonden.

Een par zeldzane witte batind-Nondew mer veel $\%$ warte banders.

Eeis par ongemecne wicte baltard-o/fe keeken, met vyf onctlangze dikke ribbeo, en geel van mond, welke it niet wete by iemand gezicn te hebben.

\section{Ler paar groote frande Bel-Hoorns.}

Een Ohekot met Rozynen.

Verdcheide ongemene fracje groute gedoonde Boideyken, en een er ouder die blacuw, cti zeer fracy van Orangic binder en verwen, en die de vitmurtenfle is, die ik kenne. Ditar zyn er I 3 a 14 , ieder om het fracylte.

Een par dubble Arter-konmeties.

Een piat geele Wej-Indiflse gerpiklielde rejdzame Haris-Hown, de ene mee cen tuif, eh de nndre plat ingebogen ngter.

Een rofle $\mathrm{en}$ wit-gekartelde zeldzame To

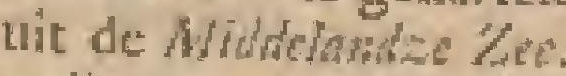

Een dito groene wat klectej.

Een groole, en cen par licene FokensJnyism.

Zeven Katry,kes Tollen, byon yder werfcheiden, en dar onder zeer zeldxame.

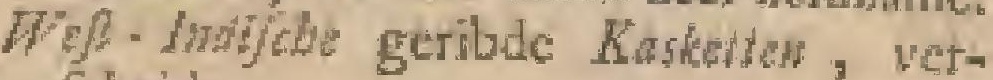
feheide.

Wh-Lhlifle roode gerakte klene LapHorens, cu ook ongetnlite.

Een geelagrige dito.

Een zeldzame zoort wan een witte Hoorn, die agter als een Zwiturs-brot bedoomd is met dric a vier ongangen. Deze is zecr zeldzam. Dani zyo 'er hice twee van.

Barawfab Bowe yonem.

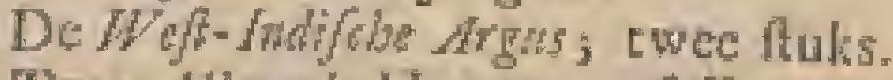

Twee Vlagel-Hoorns, of Kempharater, gefpik kelde.

Een zeldzaam geribd Buykje, met twee zeldzame ribben 'er over benen.

Twee rolle diro.

Een parar rofic geknobbelde Lap-Hoorns. Een Airk.

Ees neldzame dikke Shk, met ver bratne banden.

Een gevoomde Plek-Hoorn.

Een Hoorn, dic by Rusphins op de Plate No. XXXIV.bydeK, ifgebecld, en de Alhat-foorn genalamd is.

Een zeer groote geribde $W_{\mathrm{O} f}$ - halfob Cohd.

Een Kuybers-bor als een Dadd

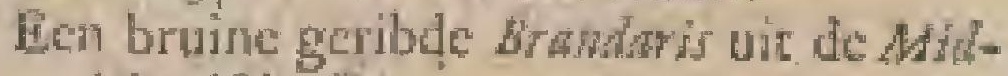
delendfobe Zre.

Een klecne Z $Z$ 6-

Len witte dito.

Het fyn geribd Milas - Oor wit $W e / f-L_{n-}$ dies.

Wel-Indflo graeuwe zwart gevlekte Nanden.

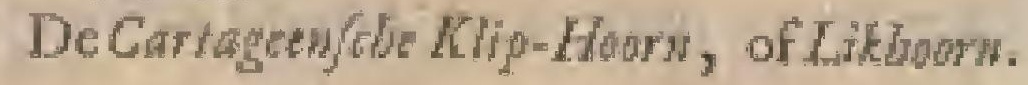

SGHELP IN $N$ wa zN Ed

De ongemeste zeldzame groote diep-inD d d 3 
$57^{8}$ V E R H A N D

gekepte Nad of $W$ orvel-Hoom met diepe inkepingen, de fredethag gcmand, en jevens ecnige zelasene gebragt, weergadeloos; en met taitdeus op zyde; zynde als een groot $W / 6$ fel-2zer, ofalseen Tygers-1wing, ontient its cen hand-palm wara grootre, en tulfoher de twee ch dric duim breed, hebbende zeventhien omgiteritgen ant yder zyde.

Een zeer groote, weergadelooze Adrdbcy, ongemeen groot wan wicker, ch die ongencen tikt wan rood op eer zer wate grond is, ditergelyk ili noik ueer gezien hebbe, welke twee fukhen weerdig zyn wan alle Lief hebbers gezien te werden.

Twee pata fracje groote Nowdat pecrze -Weffels.

De Delminaz: Dubblet van $D$. Adma, een par.

Veel fracje Mold-foldowen.

Een par Shatt-Dawid-fablpos.

De grootle zoort wan sir. Jocobs-/chlpen; Wit.

Een lever-yerwige dito ingebogen.

Moffls van Gadis.

Grombudar Quakers.

En Noordac Verus-Labhadr.

Een Spantace wirte gladde Dubblet met dric fyne bunden overlatigs.

Een zeldzame witte Schelp net dwarsribben.

Een Cartagenze Dubblet.

Een Grit.

Een pur bleck-pecrlche Dubbictien.

Lin veel andre, my onichoten.

De Hecren Vewel en Crond, (die matr over cen Jan of $t$ wee begonien hebben) beriten deze zeldzame ftulkiken:

cu Crena.

De Heer Verod deze:

Een Admitad?

Een getalete Stomboed met cen net 'er over; dog wonderbarlyk fricy en zeer brum gevlant, diergelyken in noit by reen Liefluebber gezien heb.

Een paar Weff-Indiche Casketen, ongeribd, dog vol gladde rofle dwars binnden; by my al mede onbekent.

Een /fay-Hoorn met banden, tot halfwegen coe gegranuleced, of geknteld.

Een ongemeene fracye zecme Zetorder.

$\mathrm{T}$ wee ongemene groote ronde roode gekntrelde $Z \mathrm{Ce}^{r}$-Aprels; weergadeloos.

Een weergadeloos zcerdicht zwart, geel, en roodgebandeerd, en zeer fracy harwhe Toldeks.

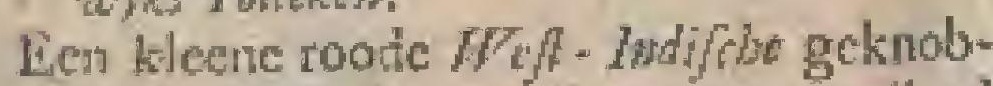

- belde srorm-bad, diens weergac its al mede noir mezicn heb; dan by deHeer Sobywor, dog vry grooter, dan deze.

\section{E L I N G DER}

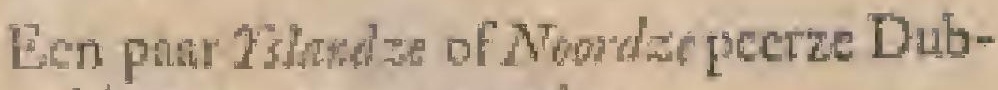
blerten, en mect andie.

De Hecr Grena bezit deze:

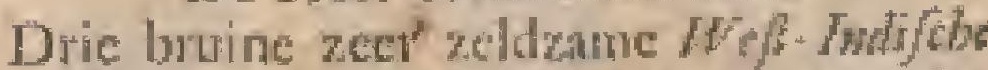
Khp-kferes, of Lids-Hoarns; die by geen Liefhebber gezien heb; dan dat ik "er ook een by gifec wim zyn E. bezit.

Een pant weer frateje Montide Toven.

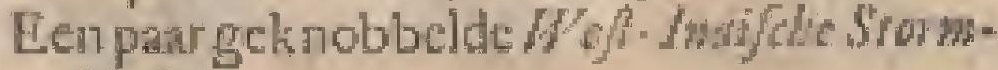
boedest.

Een Girren gedle Ileene Dubblet.

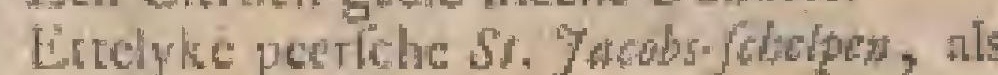
Koning-wantels.

En meer andie, die my niet te birnen froruen.

Een grone verketde Hoorts; zeldzann. Her Tuks Paptor, ontrem een halwepink lang, een ongemecn lluk, cn dat ik zooding by geen Liefhebbes gezien, novg in geen schritien zoo kleen meer ontmoer heb.

Ecin zeer zclútzitne Hoot'n, wan forme by thals cen Bykje, of gevlekte Bezodr; dog wel zoo rond. Len weergadeloos ftuk.

Ren parar witte kort-gedoonde Hoorns, mede zonder weergac.

Een parr peerche $2 h$ hadze, eñ meer andre fiacye Dubbletren, welke alle onmogelyk atulitien hatn.

Een Citroen - gebe zeer zeidzame Zots$k i p$.

War do Sebryer bezit, heef by beworens al ten declen nangehald, en verder by de zeldzame flukken, in Prent gebragt, en inger an gecoond, hocwel er wan tyd tot tyd ung weel zeldwame thkker, welke alle hy onmogelyk hicr melden kan, bygekomen zyn.

Bevorens hebben wy reeds getoond, wat Lief hebbers cie $W$ eutd-rrap beziten, nu zullen wy voortgain, on te zeggen, wat woor Lich hebbers dezc en gecne andre ran de zeldzatimfle ftukken onder zich hebben.

\section{De Orangic Ahirat is in banden vin deze Heeren.}

De Hoer Latidwoogd, Adrian was der Sil, in $A$ whoin heefe 'er ved nagelaten; dog weer het getal niet.

De Heer Wybers heef 'er. - . . 3

De Heer Anditew da la Fandr. . . I

th hebbe "et".

3

De Heer Sibut. Die 8ogl

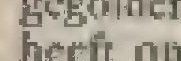
de verkode verkode Hert

De d'Acquet 


\section{LIFFHEBBERS YAN ZE ZEEHORENKENS,}

De Heer Kiggan.

579

De Hes wh Segwatel. . . . . I

De Hecr Gross.

De Heer Raadpenfionaris Ga/for wan Ch-

ters, (260 my bericht is) eco.

ook zeci fraty

De Grimedolo Tou is by dezc Hecret.

De Heer Borgenecter What wan Gitors.

Onder De Hect Fincent.

twetke

Lifef heb- De Hecr folda.

bers die

zel.j. De Hecl Helmoht

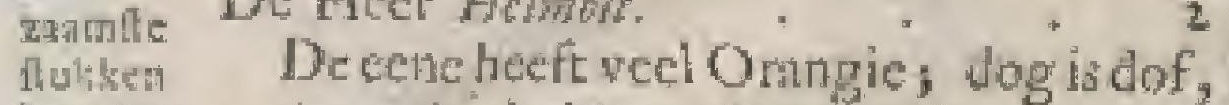
ber usten. de ander helder, dog te wit.

Onder de Horchkess van de Feer Doughlar, $A^{\circ} .1722$. verkogt.

Dand wan Locm in Amboind overleden, liet na de twee lehoontke, die ile oit gezicos heb, datr al de atudre matar doode by $2 y n$

De Oppr-Adwind werd bezeten by deet Hecten.

De Hecr Auditeur de la Falle. yder wan do twee byzonder; ch nog cen derde bathati-zoort.

De Heer de la Fillie, tot Delff.

De Heer yat Elas schot.

By Ruti-

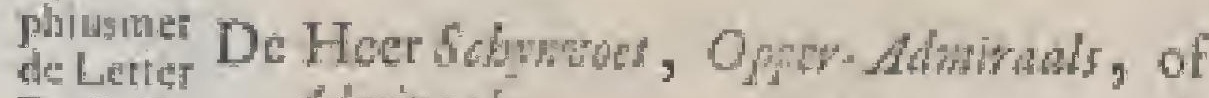
a. Getter D Eeinerk

Admitals.

De Hecr Holmoh, tot Gronithen. deze is folmow, cn wy groot.

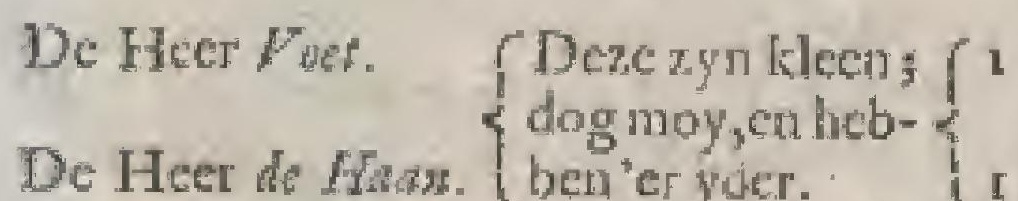

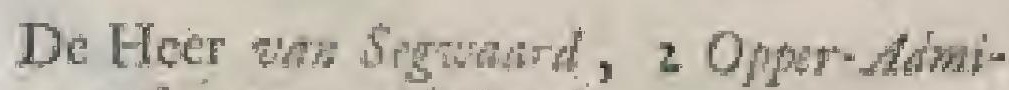
rans, en i Ahimal.

De Heer Sebs. !

De Heer Vincent.

Appelbloezeme Remplatutjes, of Flatgel-Hooms in by

De Hecr Grow, die de befte heeft.

De Heer subat.

De Heer Segreld.

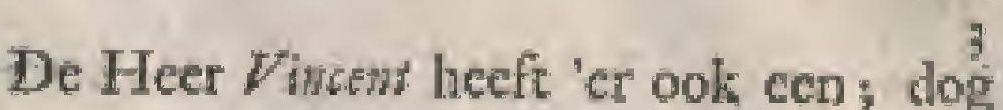

De Hect Sebyrebt.

De Heer Sobe?.

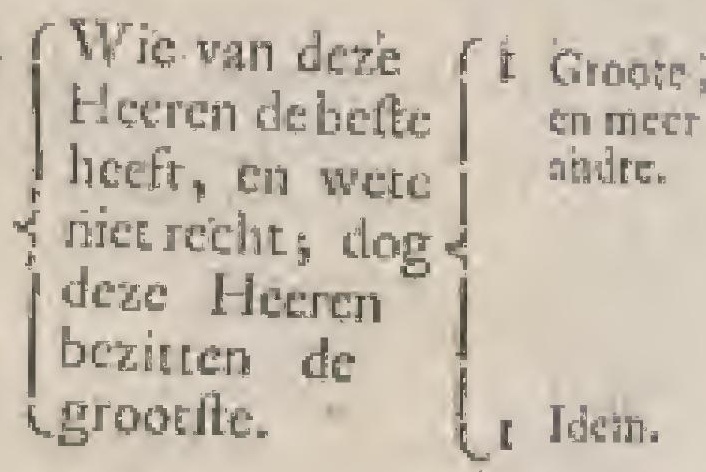

De Hecr Seba.

De Heen van Siguadrd.

De Heer Groen.

I let

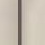

\section{De Purpre Calo-Hom.}

Dexe zag by niemand, als by de Hecr Gelmah cen parar, zyndevan onder fler putper.

Zeer kleenc genette Sromboedgen.

De Hecr Helmolt.

16.

2.

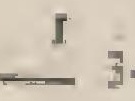

Dito $h t h-h w d / b$.

Do Heer $V_{\text {Q }}$. . . . . . Ne.

Zect groote Dokes. Horw, of Nawh, werden bezeren by deze Hecren.

De Her Seba heeft de grootke. I

De Hoer Firen de grontfe diat nat dog fracyer, el zecr wit, hee moyte fuk hier te Lande, 10 duym lang, I

Dito Hecr, twee wat lilecher. 2

Zk. . . . . I

De Hect qaa Stgatam. . . I

De Her Kigelar. * * * * I

This papdr, bezitcen dezc. IK.

4 ronder.

De Hecr Silywerot. . . . 3

De Hect vaw Serwalad. Fin pas

3 kileenc *

De Hect Vot, "t Arabjo tawk-Pd-

pier. ". ".

De 
De Hecr Crusa, een zecr kleen en ongemecs 7 atk Papier.

Ahimals wan Ona bezíten.

De Heer wan Segwaat.

De Hect Scbywet.

De Hect Sebot.

Sproetho, of Kikworfoln, die van binnen Purpes of zwarc zyn, of Ry/fenbryJosns, bezeten by.

De Heer de Hadw.

ik.

De-Heer Hast.

De Hecr Helmalt.

De Hect Shbot, ecri uitmuntend Orangieagtig over 't lyf.

De vitte Porellan, van binnen Appelbloetlem bezit allect.

I..

De gecle Weft-Indj/lo Hars-Hobrz met vlekken of fpikkels, bezicien,

De Heer Sagerd.

Groote. De Heer Grosn.

Matig De Heer wan Seguadrd. * . $\frac{1}{2}$ stoot.

Filecte.

De Heer de Koning.

Zeer It.

fricy.

Dito,

De genkte Knol bezitten.

De Hecren wan Cithers. Op myue werkopping ingekogt $A^{2}$. 1717 .

De Her Helwoll.

De Heer Groem.

De Hect Dimesil.

De $V$ te $-A d m i n a l$ werd bezeten by.

De Heer Scbywoer.

De Her Kiggeiala:

De Heer wan Siguaart.
De Hect Siguld, een baltard-zoont. i

De Heci: Grow heefe en kloen ros Fice- i. Allowitalite.

De gracuwe $M o l$, of de $M g$ grs zonder oogen.

Hetwoh:

Itis.

Gladde gerande en ongetande $W / f$ Indifbe Sthlon bezitten.

\section{Groote} entubo-

De Heet Sebot.

De Hecr Kipelad, ecn parar groote, en ecu parar klene, * * * 4

De Heer $V_{\text {rmemi. }}$. . * * 2

De Ieer Seba. . . . 3

IK. , , ; ; 2

De Adwhad der Gremog-Hown, of Band - I3 penton; zoo de Orangie verwige, als ook de Citroen gede zoort, bezitter.

De Hecr Wjhes de Orngie. . , . I

De Heer Scha dito. . . , , 3

U, een Orangie, en cen Cirioen-gecle. 2

Guvlamde Cothetren, of gelteepte 5. bezours bezitten,

De Heer Sabot. , , , 4

De Heci wan Segwand. : + 5

De Hecr Sebyout. . . . 2 een glad, en ook ecn ingelecpt, dat by nicmand, dat ook by de $\mathrm{Hecr} W_{S^{*}}$ bers, ing.

De Hect Wy hers, twee ingekecpte. 2

De Heer de Konnt, een geel en bruitgevlamd.

De Hecr Kigglatr. . * . 2

De Hear Fot, kloene, blacuw en bruin

B. En heerlyk groot par. "

De Heer Grow. . . . i

De Hecr Audiceur de la Fable. 4as

De Heer Fow. . . . 2

$\frac{2}{c_{0}}$ 


\section{LIEFHEBBERS VAN DE ZEE-HORENKENS, 581}

Cumed-Hoorns, of ltompe Lnp-Horew, bezicten deze.

De Heer Viwemt hed ecen zeer byzondre zoor wan dexk.

De Herr Kiggehan. . , 3

De Heer Vimit. , , , $\quad 4$

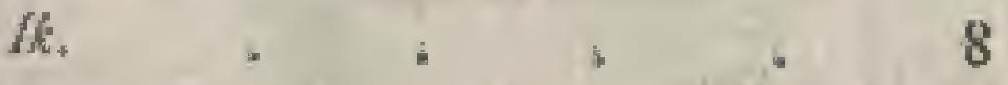

De Heter wan Srguan. " * 3

De Heer Grou.

De Hear Bloem. a , \

De Heer Sels.

De Heer Ferwl, cen wergadelooze. I

ik

De gelpiktelde Lap-Horen.

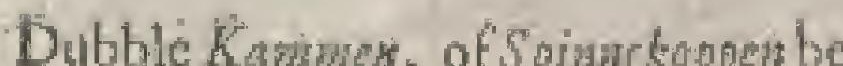

De Herr wan serwat?

3

政

De Hect Fincew, ecn uitmuntend tuk. Groble batol:

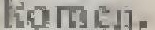

De Hect Helmolt. " , * I

De Hecr Groen. , . , 2

Grook, De Heer Scbynowt, , , , 1

De Hecr de Koning. : : : , 2

lk, ecn zect grook, cn i par kleeners

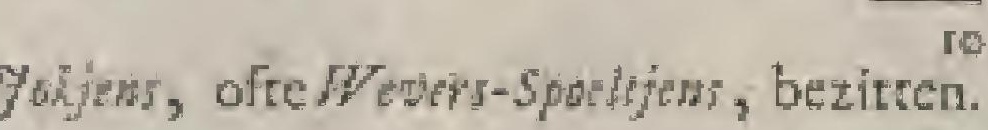

De Hect Schot.

De Hect Wybers.

De Heci Sdywot.

De Heer Kigglawr.

De. Hecr Graem.

De Hecr $/$ incent. en twee at de kleene, ch ik een Appeibloeliem dico.

De Heer Grem.

De Heer Kivgeladr.

NepuMs-Sebabt bezitten.

Onder de Heer Dohglas Horehkns. $\quad 2$ De

De Heer Scbyopet.

I

De Heer Sthot.

Dog ed 'er vor

thetrin tiu de Hect จan Seg พลaก!.

2

De Heer dorville. , , ,

De Heer Soba. " . . " z

De Hecr Segueld. , , I

Schoone Kwon beziten.

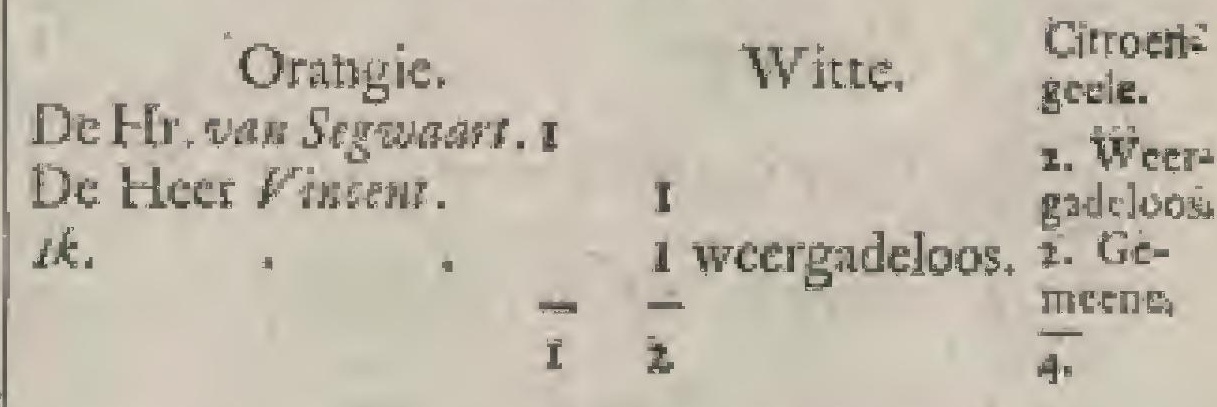

\section{De Ferkens-junt, betitcen.}

De Heer Vimetst.

De Hecr de Koning.

De Heet Grom. eti cen met een groote ftarr:

De Hecr wan Segratard.

Ik.

De Heer Stymoget.

De Hecr Foet.

Katsulat gebandcerde Toles, of baftardSranterulaggen bezitteta.

Meet De Heer de Kowng

dent.

III. DEEL 7

(Dec Dito cen zeer kleen.

Eees
De Heer Schywoet. . . *

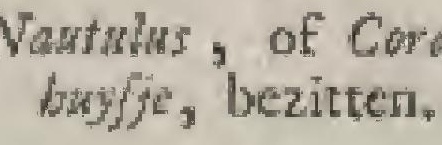

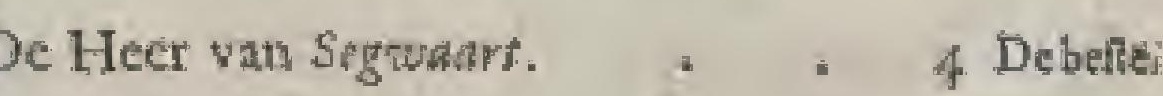

De Heer scbywot. , , ,

De Heer Voet. * * * 2 Klecpeti

\section{Siank's of Ofer-Horths:}

8.

De Heer van Segwant. * * 5

De Heer Piment. , , 324

De Hect Groen, * , *

(t) $\frac{\text { I }}{t i}$

Van 
De Del Muaze toode Dubblet ran $D$. Adroma bezitten.

\section{De Hecr Saba.}

De Heer Sryeds.

De Hect gan Seguard.

De Heer Sho:

De Hect de Konigg.

ik.

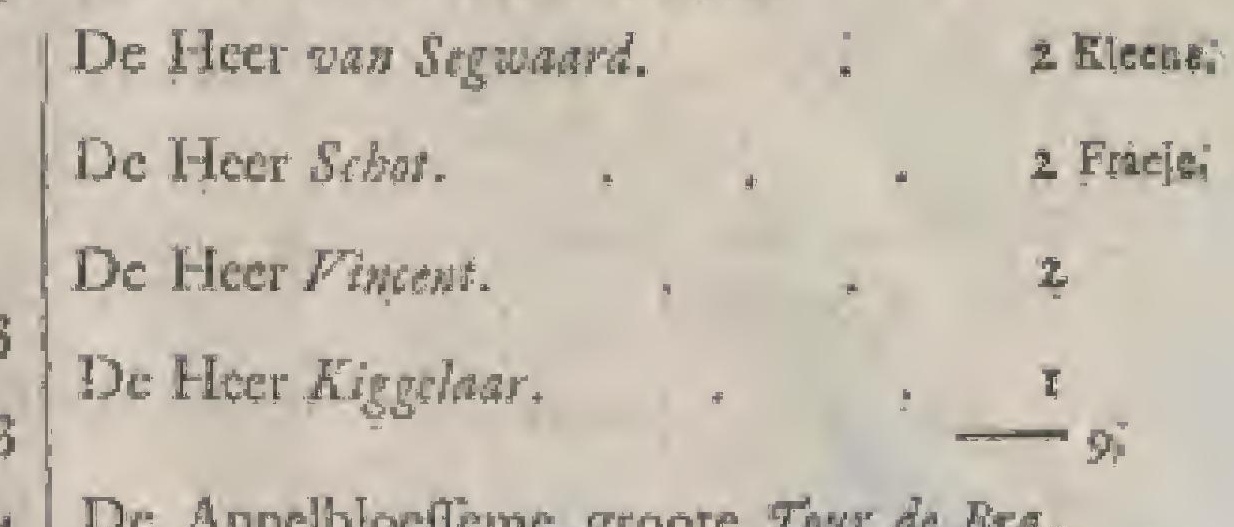

2 .

\section{De Goude Torg bezitten.}

De Hecren wan Cirlers (gekomen win my

by verkooping $A^{\circ}$. $17 ! 7$.

De Heer Groen.

Dc Heer wan Segward.

De Heer Fincan.

De Hecr Seba: bezilten.

De Heer Foe?

De Heer Dint Doet. , , I

De Hect Sebrif. , , I

De Heet Sclot. , , I Groote

De Hecr $K$ iggetar, , , , ,

dis.

De

I Erocifte: en befles van ellanst

of meet De Hect Schot.

Grooter De Hecr Audireut de In Fallote.

Deze is van myin Goedje $A^{\circ} .1717$. Goon zyn wel Edigelogt:

De donler-blacuwe groote Forr de Bra; beritten.

De Heer Scbonow. : * : 2

De.Hecr Vincest. $\quad$. 4

De Heç Sebra , * : , t

De Hecr de fo Falle tot Delft.

Ih en blecker Bataj/bbe zoort. $\quad 4$

De Hecr Kigglar dito, dito. $\quad \frac{z}{2}$

Fenus-Hartichs met roode fpitkels, bezitten.

De Hect do Konish.

De Heer Solyowbet, $+\quad 1+2$

De Heer Seguadat. : :

Eneen. De Heer Vracou,

De Hecr Viment. , . I I

De Hecr Sebat.

$\langle k$.

De witte Tong bezit allecn.

De Heer an Segunant, . . . I

De Hecr Carel Buthart $V_{0 \text { t }}$ de atlerbefte.

De Hect $Y$ inem. $3:$

Verkeerde $M a / f o l$ beximen.

De Hect Grom. cn nog een met cen Appelblotfeme rand, en een Citroen-geel.

De Heer Kegrolar cen Appelbloeften, en een gedigtig.

De Heer Aaditeur de la Follic. I en een Appelbloefem (beide van my gekomen.)

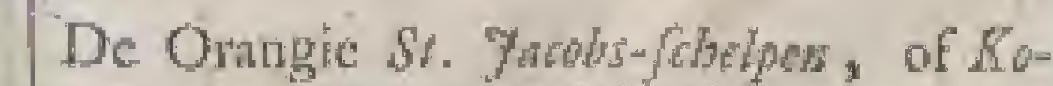
Ming -momels beziten.

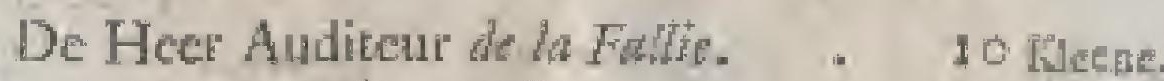
(var my gelgomen)

De Heer selymot.

(1)




\section{LIEFHEBBERS VAK DE ZEE-HORENKENS. $\quad 583$}

Filene. De Heer Helmols.

en cen zecr groote fiaje.

De Heer Subor.

Eletio:

De Heer Aigselarir.

De Hest Vinemt:

De Heer $S_{b a s}$

Żestoreres

Eth พiler

kiliche.

\section{$32+34$}

Gieroen-gede dito bezitten:

De Heer Audieur de la Fallis. ZeldiztTre a die niec kenes.

De Heer de la Fallie cot Delft.

De Heer Subut.

$2+3$

I

2

W

(zoo nict beter wetc) merd allecn bezite; en volgens deze $\mathrm{N}^{\mathrm{o}}$.

in Prent vertoond.

$H O O \quad R \quad N S$

I Een groote Appelbloczeme of licht- Erate

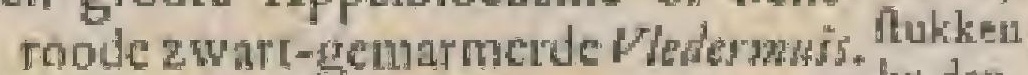

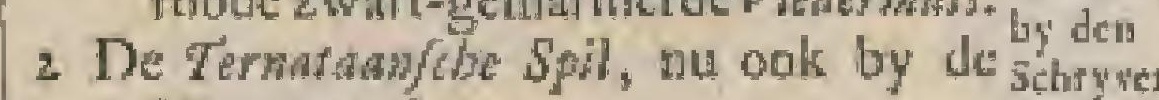
Heer wan Segroad. mat. al-

3 - Gratuwe Lit-Hoom, of KIp-lecn be pine korls, beneden met Atauwe zwart- den, en if Rons, beneden met Hatuwe zwart- Pient yolagrige wlekken.

104

\section{Compos-lehelpes beziteri.}

De Her tan Segram.

Dere? De Hecr Kiggelatr. zyn de

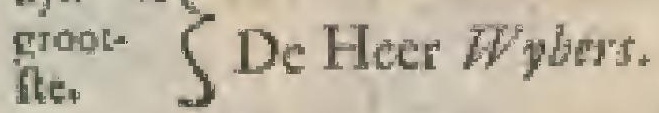

De Heer Vineint

$1 k$.

9.

Bloed-roode; en bleek-roode Compasfoblpen bezitten.

Hek-

raode.

De Heer Helmoit.

2... De Hecr Kigglaar. . : . I

4. . De Hecr Finen/. + . . 2

I. . De Heer Seht, en bloedroode

De Heer Sdbot.

2 7.... 7 .

De Heer Groen heeft ecn zeldzame brutne allecen.

De zeldzame gedoornde Purpre of witte $W_{J}$-Tas, bezituen.

Wiste.

1. . De Heer Muditeur de lat Folle. (beide van my gekomen)

De Hees Sola.

De Heer Schot.

1. Wit De Heer Fuscest heef 'er een wit en en zwatt; zwath of Loodagig.

\section{4}

en kicene (doorgans-door de Zee ge- N", net partemocrde, (dog nu) ongeprarle- tront. moerde Papelo-Hown, dik-rchalige Gorina-Howr. Deze is mede by de Heer Sebrrwot.

5 Een Appelbloczene ongetakte Bras* daris.

6 Een dunne zeldzame breirye Spit.

7 Een lpierwitue Trommet-jobrof. wifhe Forem, zeldzaim. En een diergelylke by de Heer Graen, dog anders van couleur.

9 De Almiral der Spelleturk-knjow, zeet fracy.

to De Admirad wan de Selowten by wabt, ongemeen, met Pik-zwarte bander op een zeer helder wirten grond. wan rolle Kuppers-boren met zwarte Alippelbanden, nat na den OrangicAdmiralgelykende, is ongeneen.

I2 Een Citroen-werwige Gwomon, of Band-pon, dico, met roffe banden; en een Orangie dito, met zwarte cn witte banden zeldzaam.

13 Ecn graeuwe gebanderó $\mathrm{Mol}$, dito by allen onbekend.

Verfcheide Zegrew-Hoorns, als:

I 4. angemeen groote, gracuw var grond, zware wan knobbels.

15 b. Deze trekt wat meet nat 'A Appelbloezeme, diro knobbels.

if c. Dete is graeuw, zonder zwarte knobbels; maar inct een roftegeAippelde knobbelband over dwars. rofte knobbels.

18 c. Deze is over 't geheel licham rós. 19 Een part orgemeene groote SralenVhagestas

Eece 2

20 Een
8 Een leverwerwige gefpilakelde Babilo-

i1 De onbekende Admiraal, een zoore

$17 \mathrm{~d}$. Deze is graeuv mer een dubble rey 
584

VER H A D

20 Een Violet-purpre Wydmowler, of Rindolfus.

21 Een zeldran ged Torke met groote witte wiliken als eew her wat een Merrifeh, con.

22 Len zeldatme grote groene Kans net vyf flippel-bandes.

23 Een dito, dito, met vice dito.?

24 tien geknteld graeuw Vlager/ontere.

25 Ewee gelartelde Hart-Herns, cven als Zegreyn-Leder,

26 Twee bleck-groen en wit-gevlekic hrour-Howns deze heeft ook de Hecr van Serwart, "par, cin de Heer $V$ inent I van my.

27 Een par Otangic Nafou cen pitar am ete Hecr Foncent vereerd; zyn anders onhekend.

28 Een witte Krab, als cen PodagraKyap bynil.

29 Een bhacuwe zeer lichte $k$ tip-kants.

30 Dric ongemeene dito, dito, als een Tyger geel-gewlamt.

31 Een panr zeldzame Slange-kopen; een zoont van Klip-kouzen.

32 Een wite kleene Percllawa, wa binnen Appelbloezen.

33 Een prar granwe zeldzame Moerbyes, vin binnen Aprelbloerem.

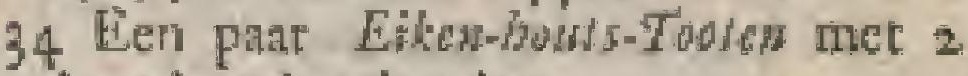
breede witce banden.

35 Een zeldzame Tulbud-Hoors.

36 Dric witce Scophochtjes, zeldzaam.

37 Een angemeene grootc dito $z$ wart, en nog cen zeldzame zwarte.

38 Een zeer groot Herien-Horenken, als met een Steen-rupze er over.

39 Een parr uirmuntende gecle Spokjes.

40 Een zwart-gemarmeld hẹcrlyl dito, zeer groot.

41 Ecn pnar blcek-purpre Lobbekens.

42 Een ongencene zwarte Brandaris.

43 Een donker-rolle felroone HarsHown, en nog een geelagtige.

44 De rotic shoou by nache. Deze is ook by de Heer van Segrodar, en 200 geloove by de Heer Graes.

45 Een pit Appelbloctlome dubble Par kroostips.

46 Een blacuw Besantic of Difje.

47 Een rhoon ros Touje mer cen brede helder-witten band in het midden, en agter an een gemarnelde dito.

48 Een geel gemarmeld Zootje, en cen diergelyk bruin.

49. Een parr zwartagtige groene Kanjats, met een witu band in 'c midden.

50 Een fracy Agare Balje mer breede donkere en fyne dito freep-banden op cen wirten grond.

$f^{\text {I }}$ ben brin Spondy zonder teelening Die mede by de Hecr wan Seguart.

52 Een dito, dito mee wittc welijens.

\section{E L I NG DER}

53 Len fracy dog wat divers part klene

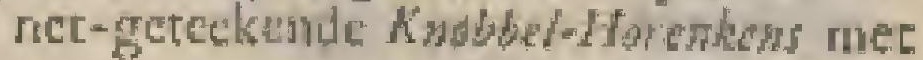
witce, zwate en terk-grocne blokjens,

54 Een wondeslyk fracy groct1-en bruin hoblrd-Horkden, met theuw wit gemengd.

55 Een dito, zeer fyn van reckening ats of "t cen Na/Jan was.

56 Een dito van groen, zwart, en wit ongencen fterk, en hearlyk ugen malkindren fpectende.

57 Een puat geele Thuaranche Vhermaizen.

50 Een rosamgrige dito.

59 ben wonderlyk finey $W_{d} / t-J a d j b$ rond Kasketje of Storwbocdic.

60 Een gede $W$ oh - Hown, wan my de Cyfw-Hown genand, on dat 'er klan op ltant 717,577 ata de eene, en $\$ 77$ alan de indere $2 y d e$.

$6 \mathrm{I}$ Ech blaerwe $W_{0} l$ - How ; bleckblaeuw en zwart gemarmeld.

62 Een lange graenwe Fledermuis.

6. Een zelizame gevlande dito, byna als ecen Wrdmowder.

64 Een par zeer grooke witte Canari's, met fyne gecle dwars-banden, en van binnetn pecers.

65 Een par dito dícos, wan binnen zwart.

65 . Een zeldzame getcekcnde HartsHoorn wit en zwart, zonder lawten.

$6_{5}$ b. Een parr kleenc gracuxve Toutjom, met 3 bruine ruit-basden, zeldzam.

66 Een weergadeloos fracy-gerceliend en Complect Trompetje.

67 Een zeer klecn dito.

68 Een hecrlyke. Dadel, bruin cn geel gemmela.

60 Een dito dito dito, gracuw en zwart dito.

70 Eecn wonderlyk fracy pagr ros en witgemarmelde Kinpers-boeren.

71 Een Orangic Beren-gongen, met een Fynen witsen band.

73 Een pard gecl-genuarmelde Doyer, of Slekhes-Hooms, pan biunen bleek-purper.

73 Den Adniral der Hwauncle Vhot lens, met 2 breede fterk-roode banden.

74 Een zeer ferk-genarmelde blacuwe en zwatre dikke Dadel-Tö, of $A$ gent7 oosjos.

75 Een dira dito, Tood ch wit AgatToutjon, of Brwhetic.

76 Een zeer fracy geel $A g a a t-b a k g$, wet cen witren batid. in " $L$ midden.

77 Een zeer kifen Buibje.

78 Een piar klecne graeuwe $\not W d-m o w-$ derkens zol zwarte dwars-banden,

79 Een graerwe gekartelde Zilwer-mond, met z warte overlangze vammen.

So Een 


\section{LIEFHEBBERS VAN DE ZEE-HORENKENS, $\quad 58 \%$}

So Een patridico, dito wat lichter gratuwe dino, endico.

81 lien dito Zilser-mond, "t halfly f wart met witue vekken, en "thalf lyf ower. dwars gracụ .

82 Ecnzer groote geribde gneuwe Knol.

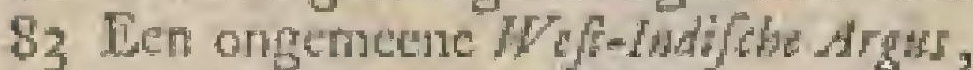
ucer groor war winte wlekken.

84 Etn wite Botr-Toot met ydele z watiefpikliels.

S5 Een Wef-Iwhebe Frh-Bbon me awarte dwassanden; diergejyke by gri ool by de Hecr won Sepwatr.

86 Een weergadelooge $A_{3}$ tres in witheid van grond, ea zwartheid win wlek ken.

87 Dre Negrans-Sichagled, de cene wat belchndigd.

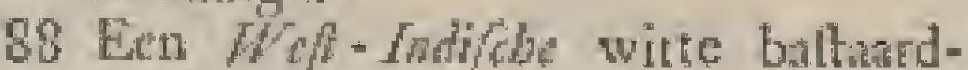
Zutwers-hed, of Morgenfar met gezueyde gecle welkition, ongemeen.

89 De Admiral van de Holbons, of Agater-bakm, bleck-gnuw; dog helder yan grond, then 16 brubedwarsbunden, toce groote witce fpilk kels ser op, wonderlyk fincy.

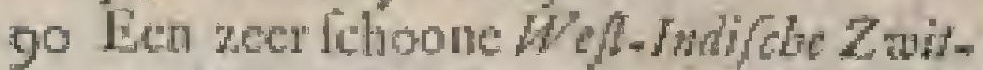
zass-brock, of Morgenfar, tulfchen "I ros en purper, ongendecn fracy.

9t Een zeldzanm pair Komploawties, of Hengel-hoorn, Orangie vall couleur.

92 Een par zcldzane Knol-Horens, yoor mat lpits, co agter met dicpe gicren; dog meine die nog elders gezien te hebben.

93 Len par Dogerzandes ytu cen wonderlyk fatzoen.

94 Een zeldzane gevlande Bocres-MotJich.

95 Een pant andre geknobbelde Doggerzanders.

$96 \mathrm{Een} z e l d z a t i m$ romgev lind Agatje.

97 Een paar wer kleene $S t$. Maloze $B d z$ Hoorn.

98 Een weergatclooze lever - verwige Zots-ladp.

99 en 100 Een pam zect kleene wit en ros

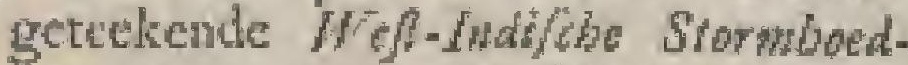
Jems; en nog cen dito klecn zeer fracy bruin getcekend.

100 Drie verfeheide coorten wan Orangie Atmiraals.

IoI DeWenteltah, op tweederley wy$z c$, wan boven en bejeden, net na $z y$ ne gioote, (gelyk ook alle de vorige Hoornen) geteckend.

'202 Een panr Telinga-Maloli-Hoorm, of Reuzew-Oores; weergadeloos groot en rchoon.

Een menigte andre zeldzame welke ik voorby grac.

SCHELPEN of DULBLETTEN.

Welke if meyne allecn te bezitten, en hier in Prene vertoond.
1 Een part ongeneene therk-Orangie $\$$ t: Gacolbs-folpen, weer groor.

2 Een parr clito roode, diro ditgo.

3 De Whithak. Deze is ook by ide Herer vass Siguaden ende Heer Groes.

4 Een weergadelooze groote en heerlyke Rous.Didbick.

5 Twee pas Batawifhe pecrfehe Zowufratus. Heb cen diergelys para an de Heer Kigglan vereerd.

6 Een Orangie-gecte gemarmelde SiritDublet, ils nuct een netjéch over.

7 Eendito, dito, dito, dito bruiner van teckering,

8 Een dico, diso, dito, dito anders vân teckening,

9 Eco parr dito, dito, dito, díco, dito:

to Een wonderlyk paar Strik-Dubbleten zeer fiacy gemarmeld.

II Een frieje Srrik-Dwbblt met donkre vlekken, en reldzanm wan teekening, met een $\mathrm{V}$. "er op.

12 Len excellente met bruin zect Aterk op cen witren glond geteckende sirikDithler.

13 Een patr zeer Dilling-geteckende strik-Dobbliter met cen rand onder.

14 Een fracje donker-zwarte Sirik-Dubblet.

15 Een weergadeloos par Mofelow als de Sibrelingze.

I6 Een pair ongemeene Lawd chapions of Grieks $A$. Dubbletren, als Krvits. Everas gefprikledd, dog "c eenc wat zwatter ats "t ander.

I7 Een pare weergadelooze bruin en Orntrie-geelagtig geteekende ShikDubloties.

18 Een graeuwe cfen Strik-Dublet met zeer flacuwe bruine overlangze breede flraten.

19 Een par gracuwe gelpiklkelde SirikDutbletes.

20 Een ongemeene Sollifle Dubblat, Orangic-agtig yan verwe.

21 De Vrede-wlag wan de Heer de Koming alhier, zonder weergae; dog hebbe $\mathrm{e}$ patr dat wry kleender en zoo diẹp nier ingekcept is, 's welk hicr na op No. 29. volgd, en 'ex" al 7eer' na gelylke; dog is zoo groor, nog zoo fracy niet.

22 En Gredelyn zeldzan Forb-Dub. betje.

23. Een zeldume Aarbey, fchoon van groote, en met een bloed-rooden breeden band aari zyo boven-rand, en groot ran korls; dog de fehoonfte van grootte, witheid wan grond, en grootheid van fchoone roode en ydele fpikkels is by de Heer de Kontug hicr.

24 Een hecrlyk Orangie Lazaras-klap, of Dubles.

25 Een par bruine Pofferkew met fyne operlangzc banden.

Eces 3

Een 


\section{VERHANDELING DER LIEFHEBBERS, enz.}

26 Een ongemeene groote, en fracy geseckende, zecr bruane Fonings-mankel.

27 Een part zeer fricje $V_{y g e n}$

28 Een parr zwart en flacuw gecl-gevlande Banrd-knypers of Boss-Dablivettem. Dog deze is grooter en becer by de Hecren wan Segwart, en seljonwoes.

29 Een par zeldxame Baraiflye zeer groote geribde Navel-Driblertem. En die onder andre Liethebbers zyn, heb ik aan ben vereerd; ten ware nderhand by andre bekomenzyn.

30 Een par zeldzame geribite AmandhDableter.

Dan hebt gy Hecren Licthebbers, her geene wy woorgenomen badden wandeze itoften te zeggerl:

Wy thuiten hier mede bet Hek, wan de Ambor (che Lindoogdy, als mede van deftells, $Z \mathrm{er}$, en Thrim. Meynende, dat wy het voormamlle, dat "cr wat Amborm, zoo te liand als ter Zee, of wan bare fowoonders, missgaders van alles, dant voorkomende, te reggen vilt, zoo net en kort als 'e ons mogelyk was, en zoo uívoerig, als de zaak zalís vereylchr, hicr itangetcekcnif hebben. Zullende nu tot de Befelorywing wan Bamba overgan.

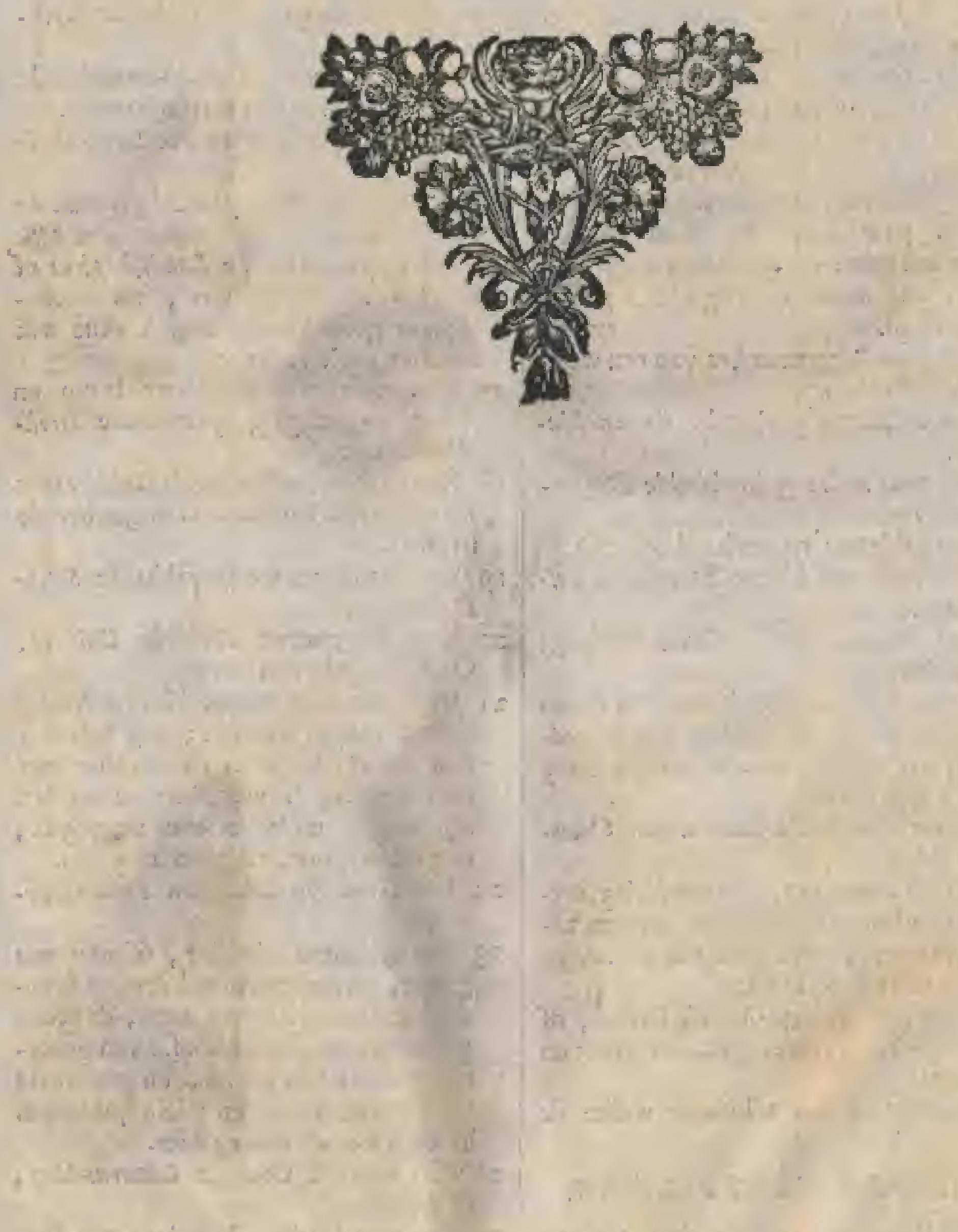

NAUKEU- 

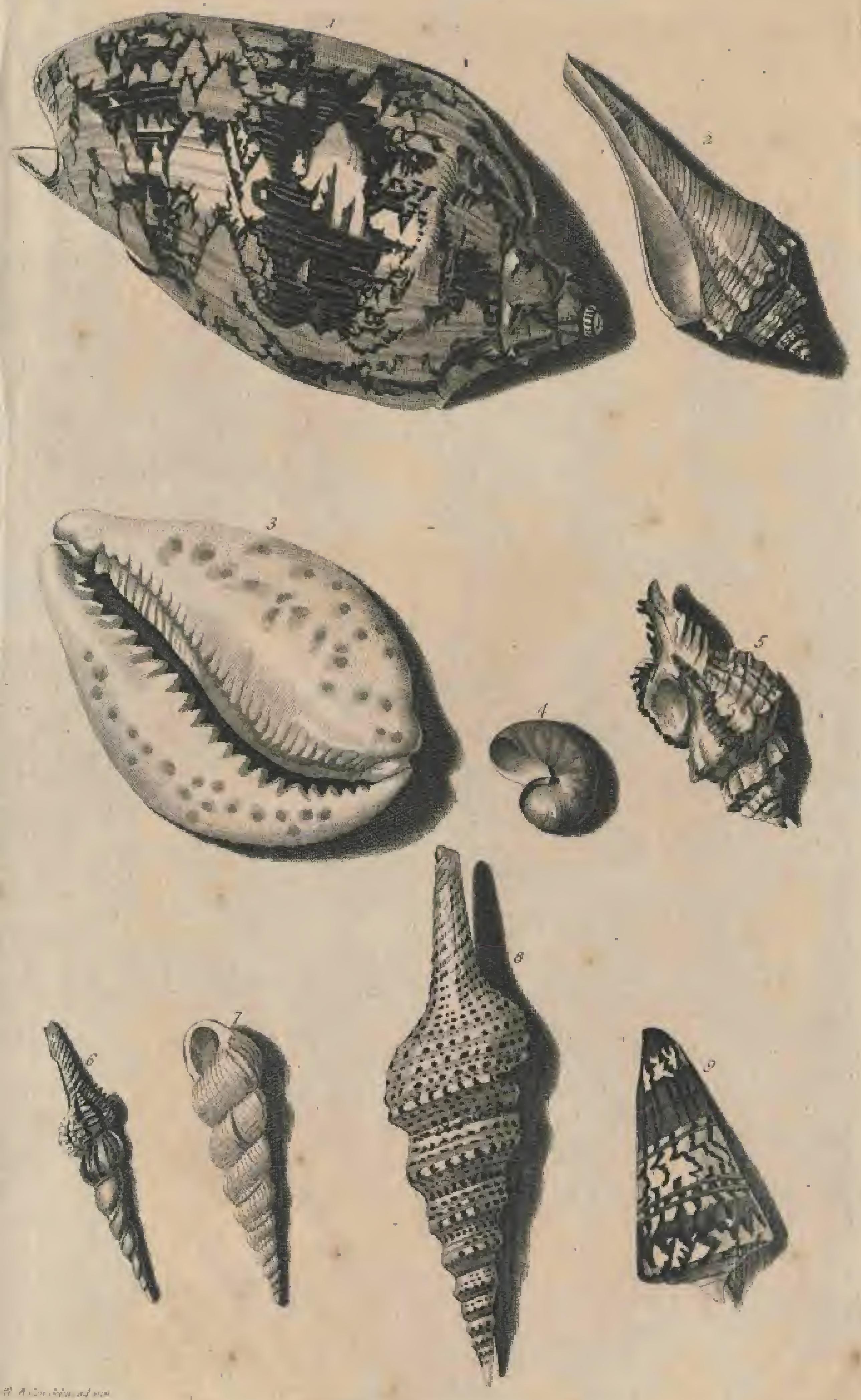


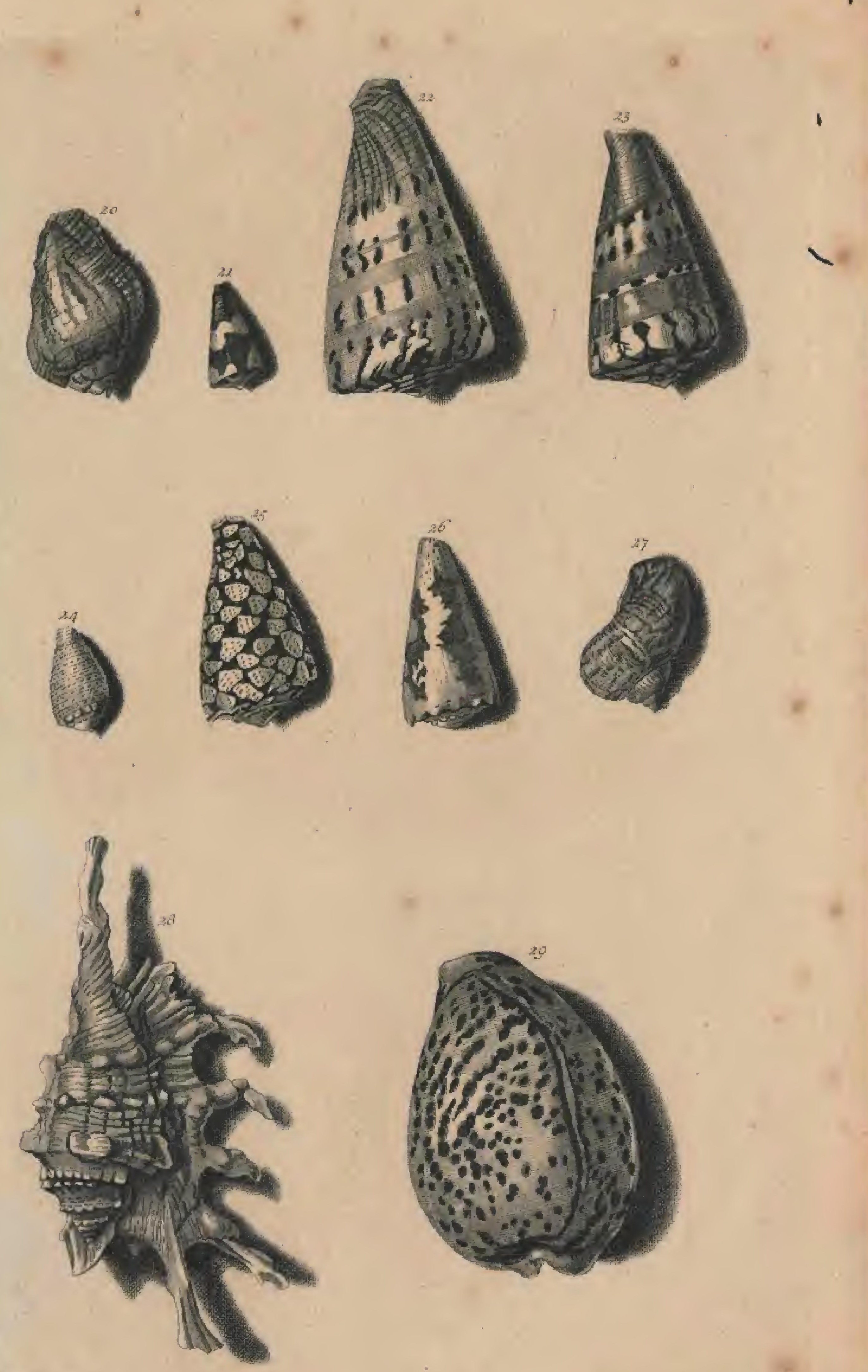

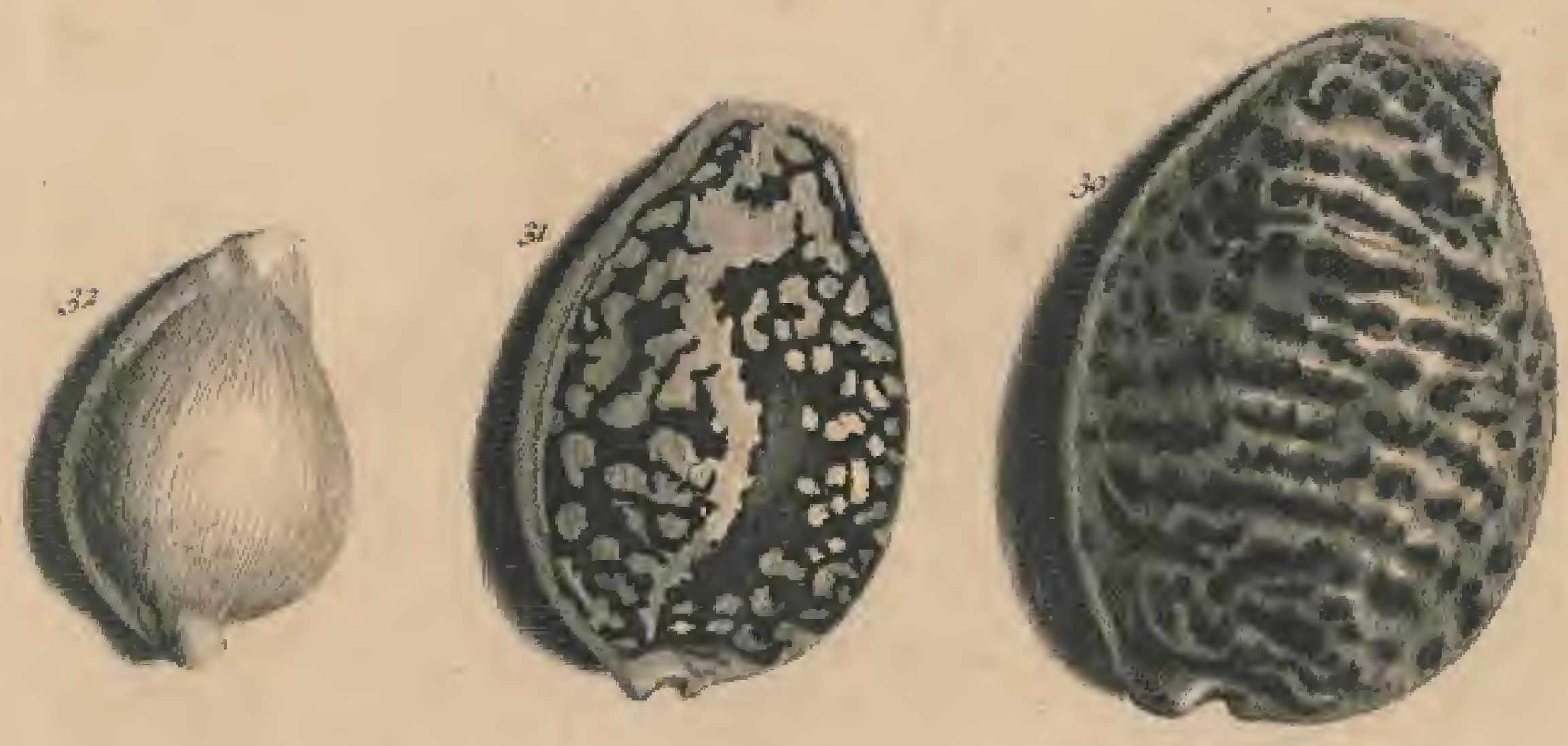

)
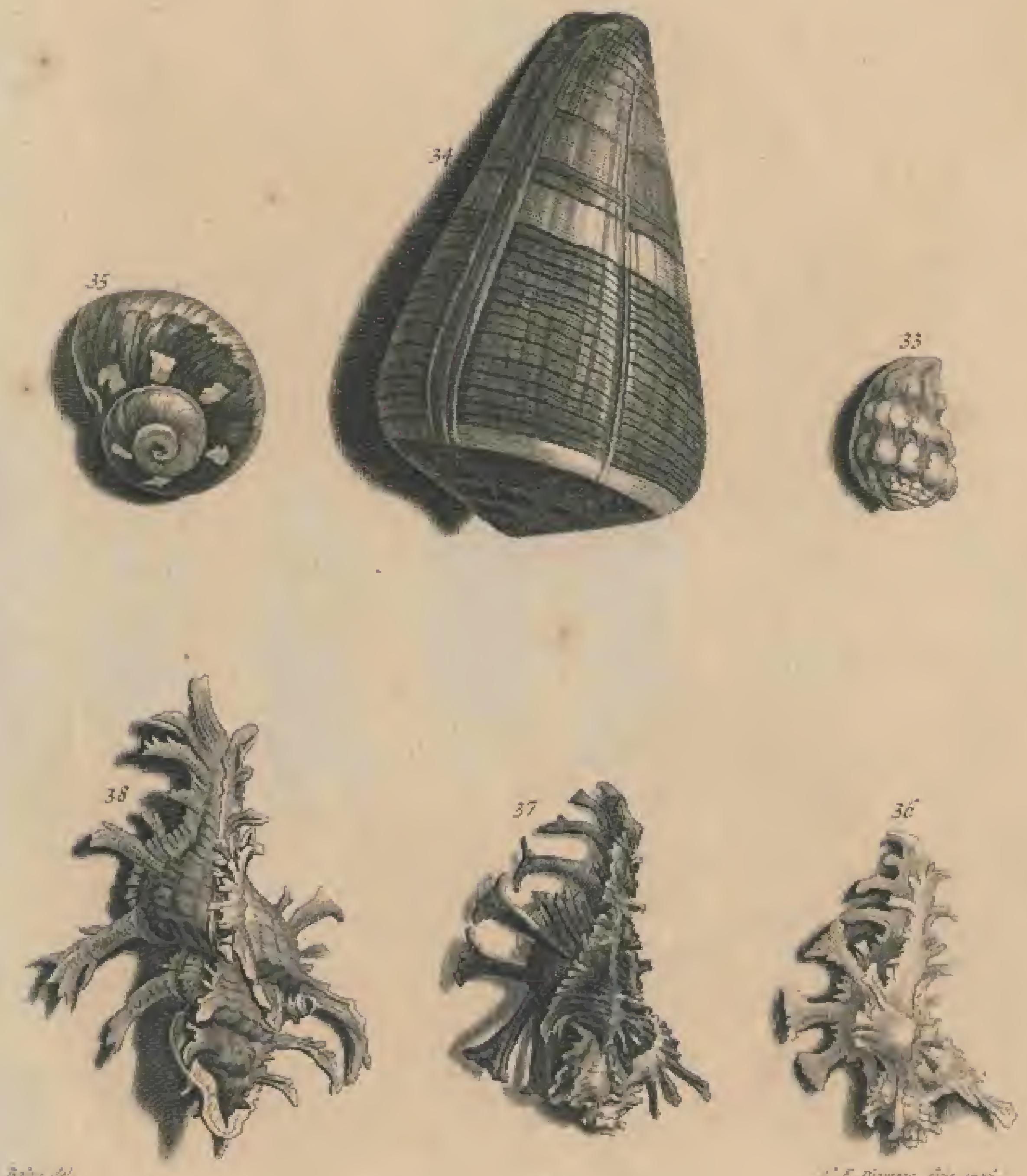

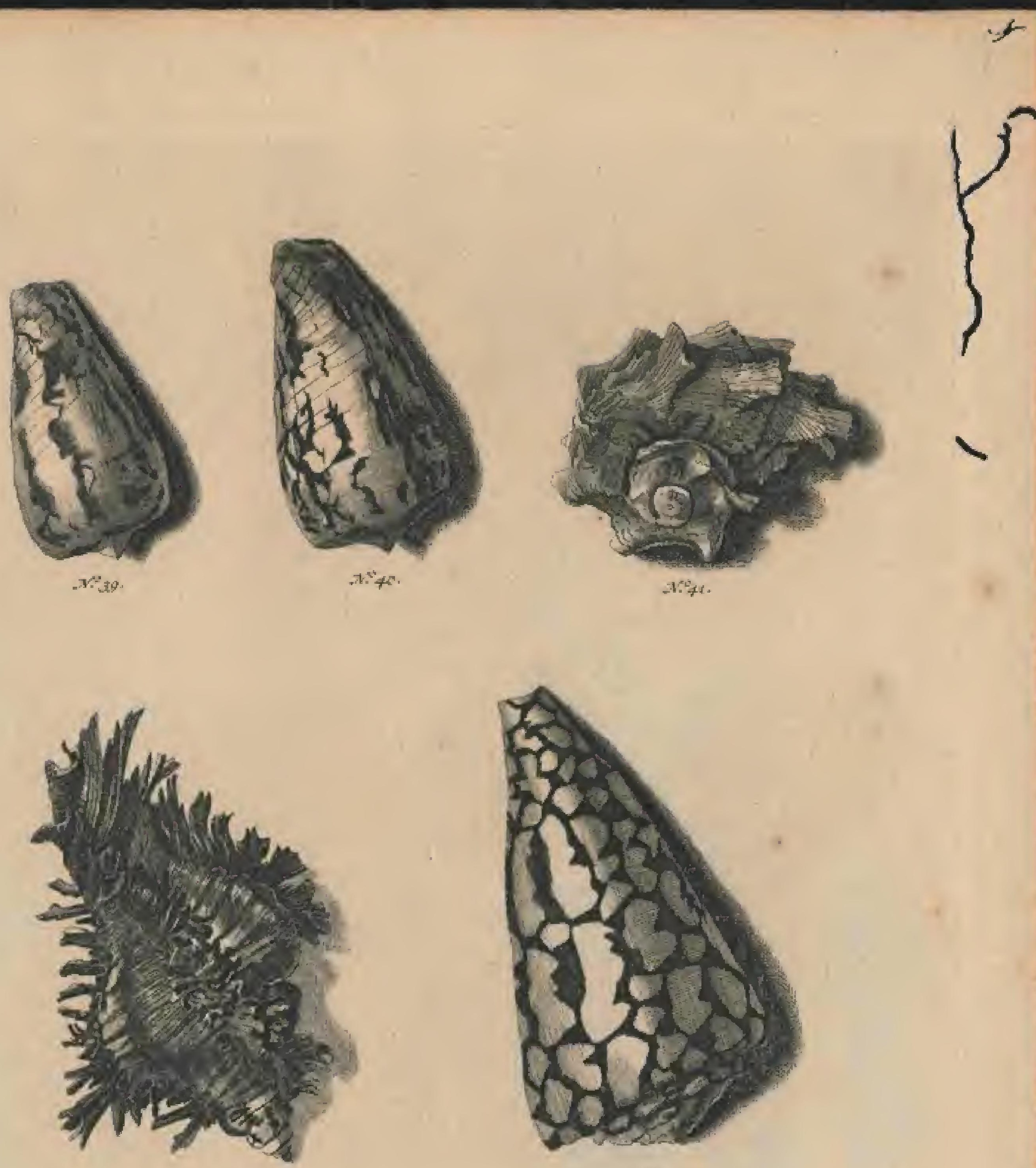

$x+1$

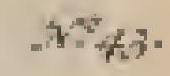
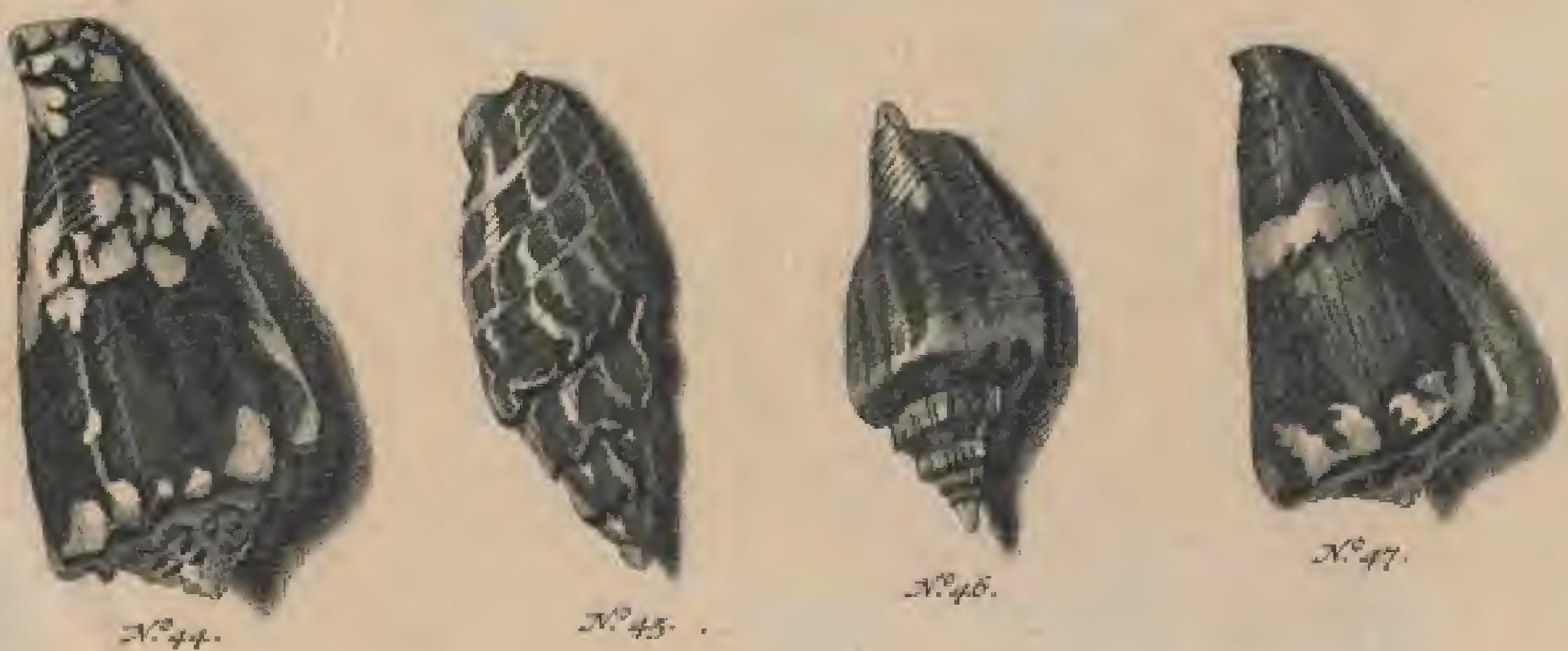


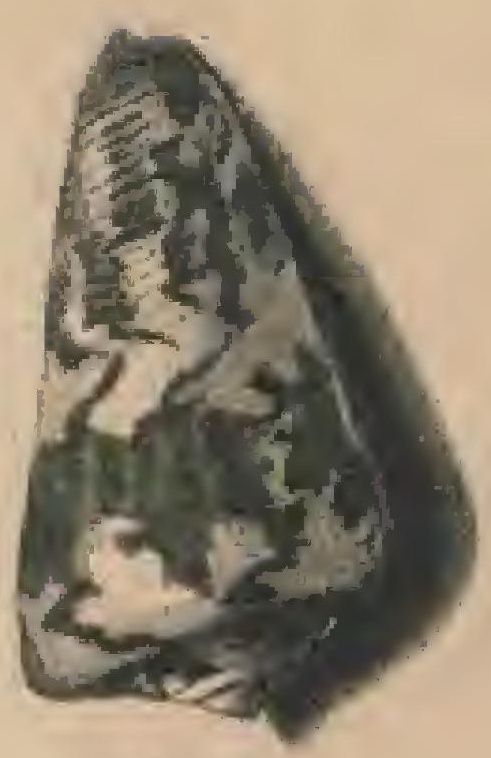

w"
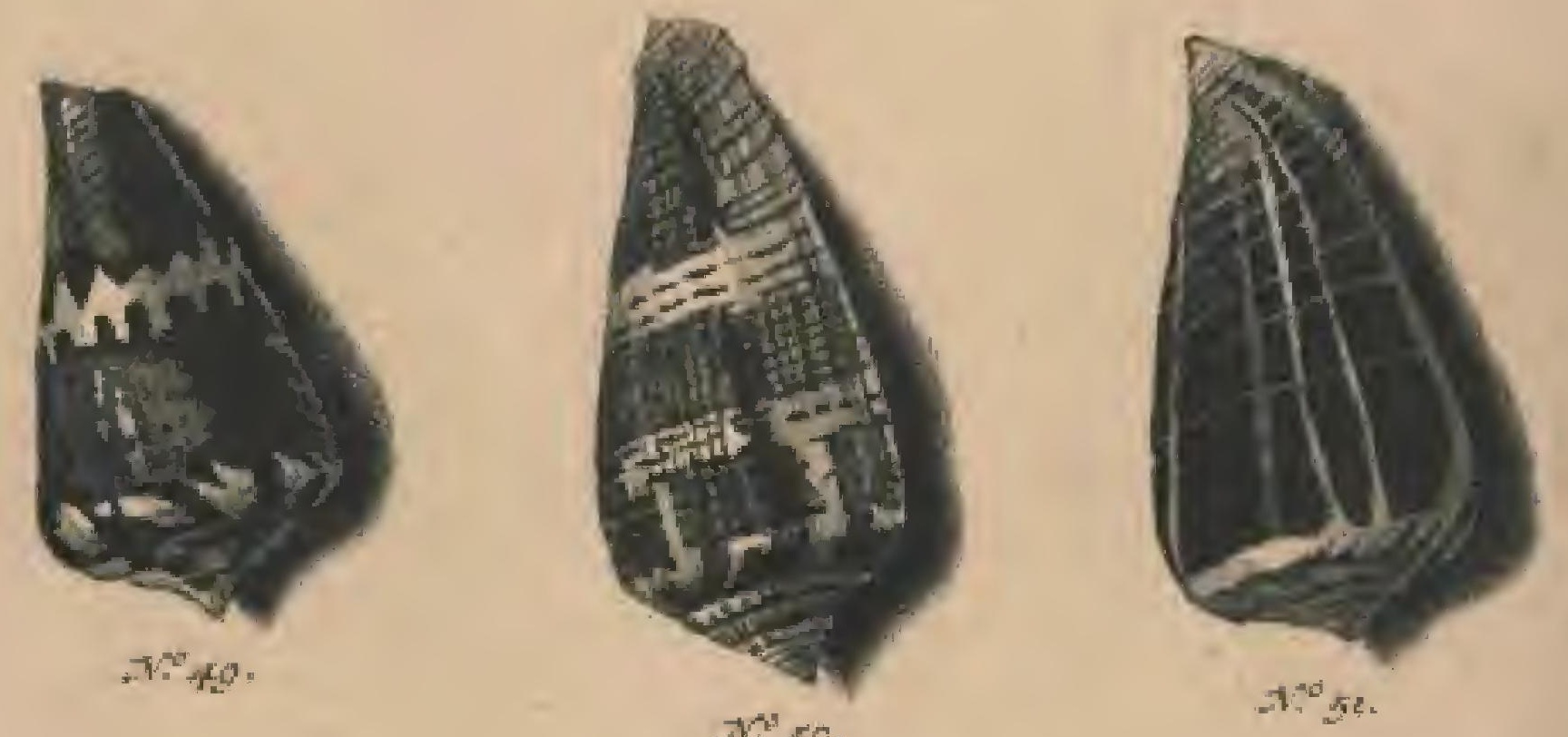

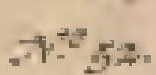

$x^{2} 3$.

Ant.

N.

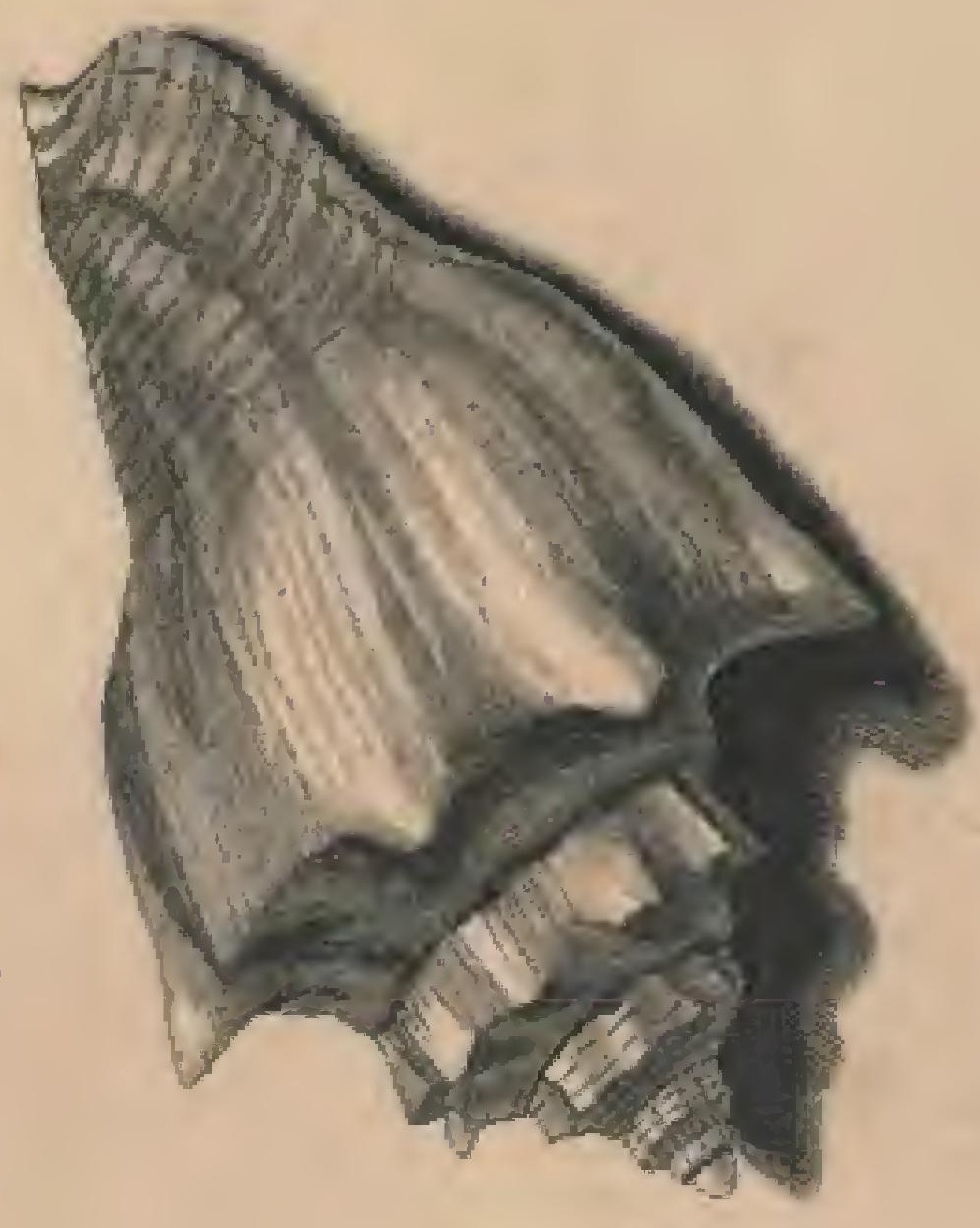

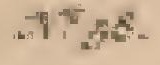

3

$w^{2}$ sh
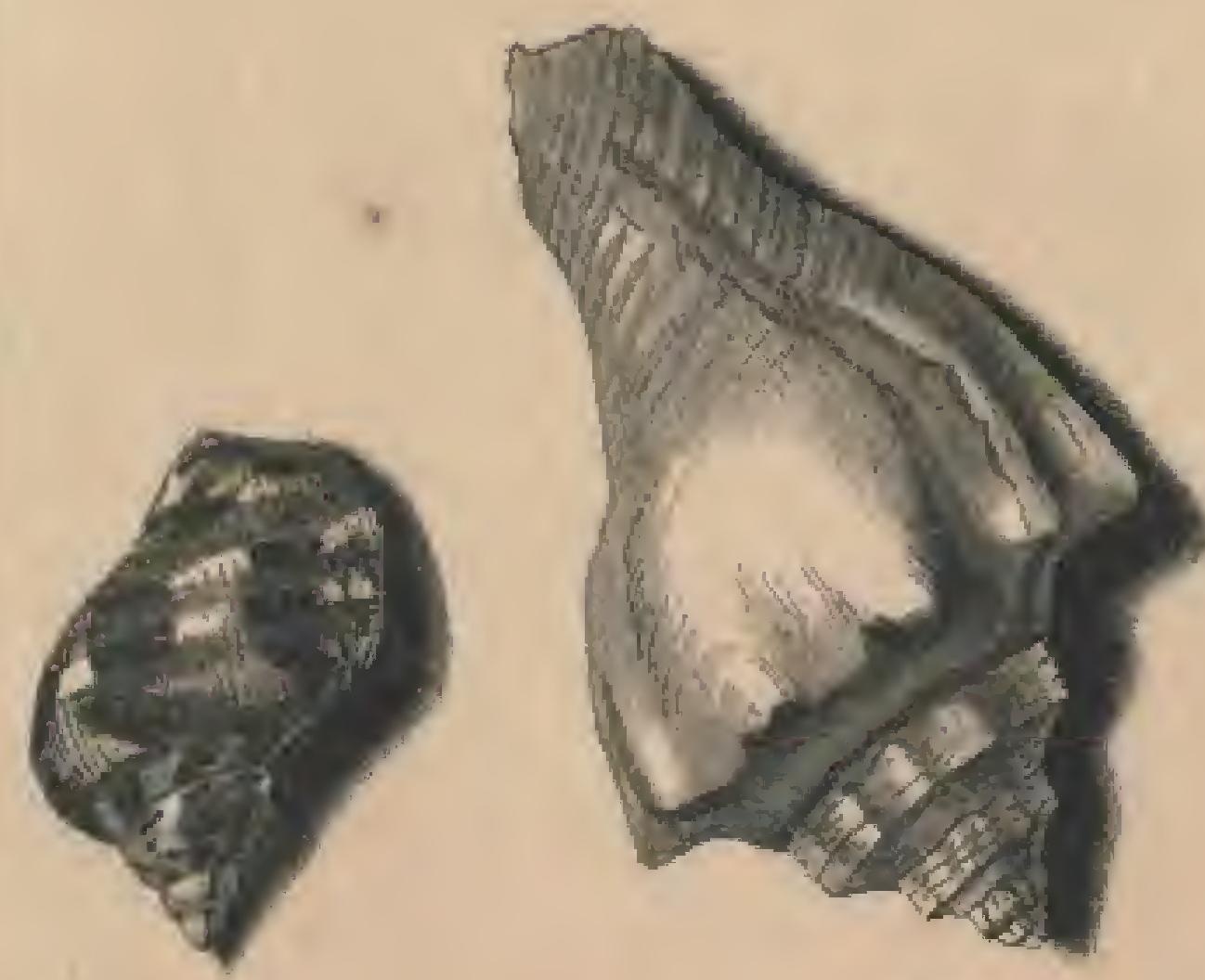

N. 67
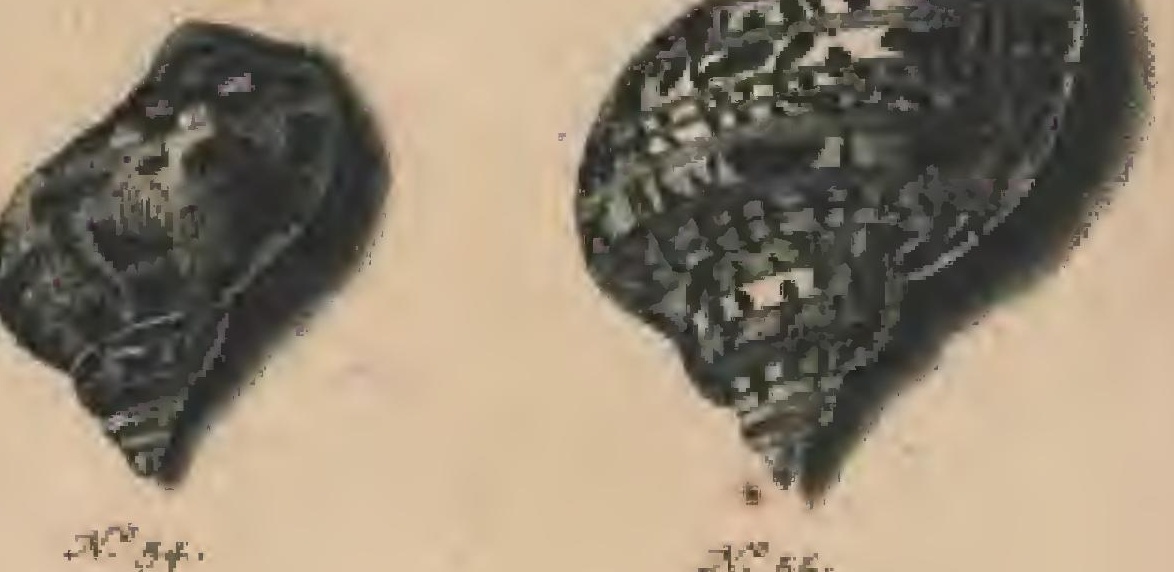

. 

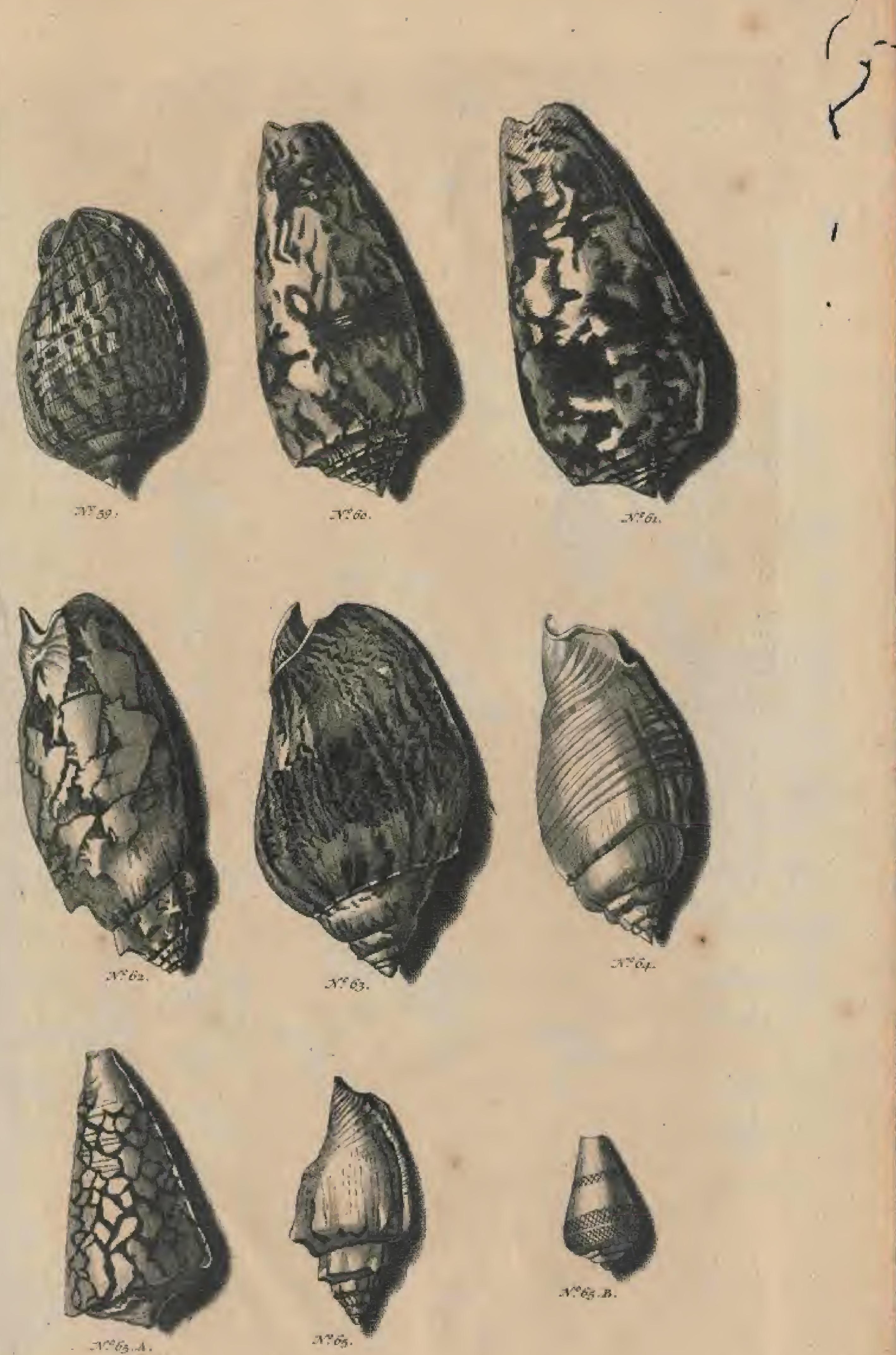

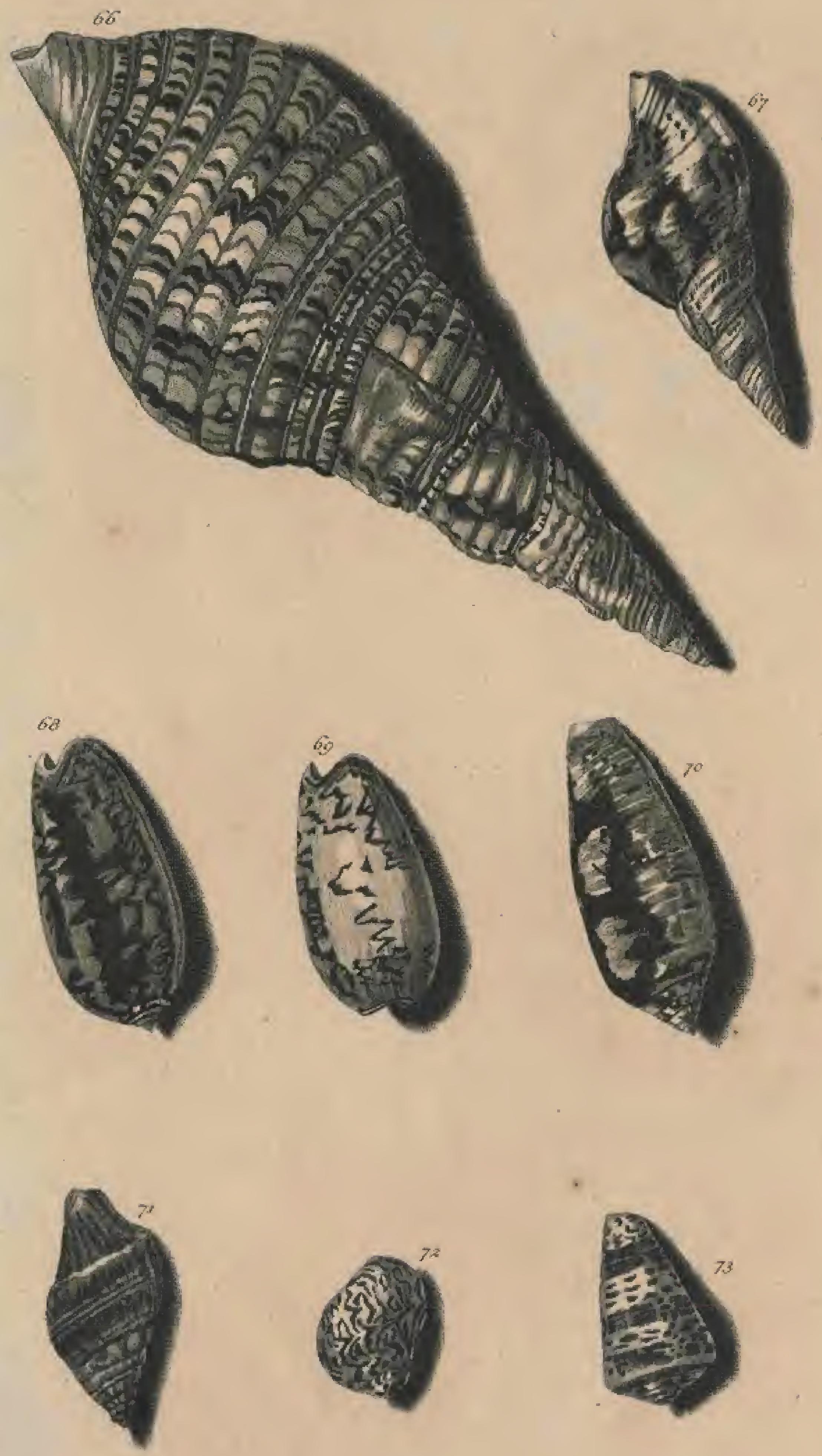


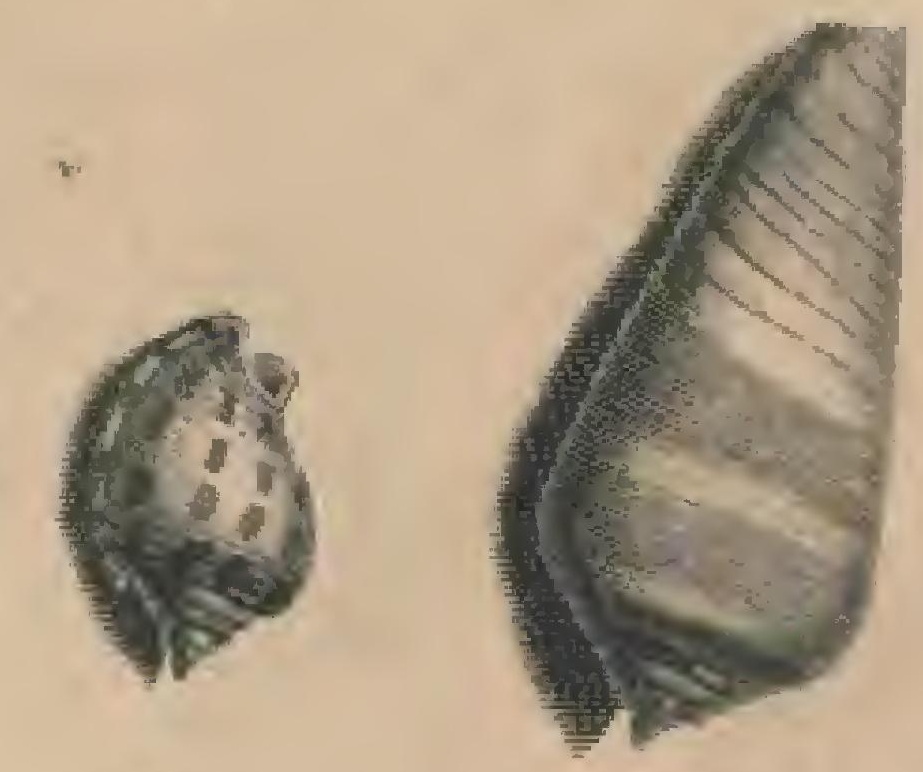

$A 7$

.1770

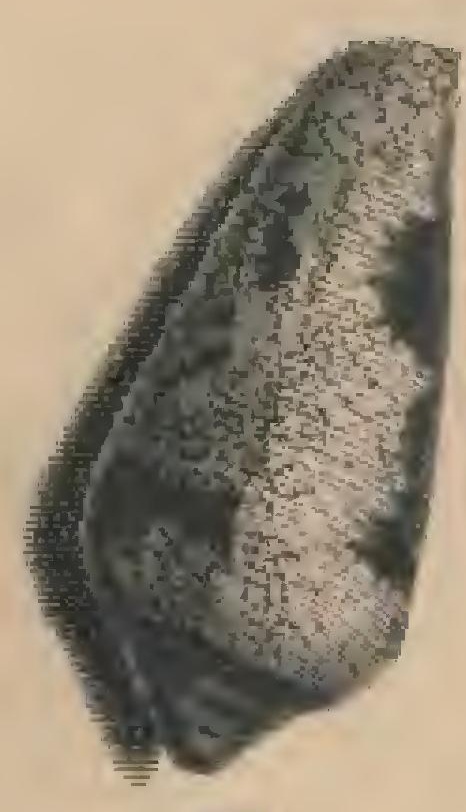

$\left.W^{2}\right)$

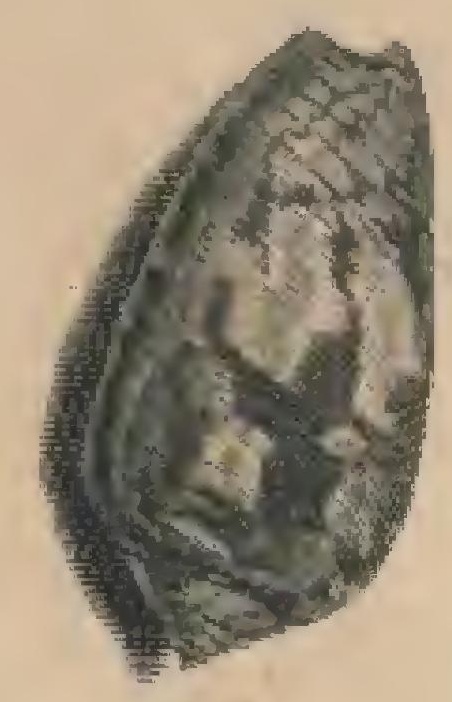

(1)
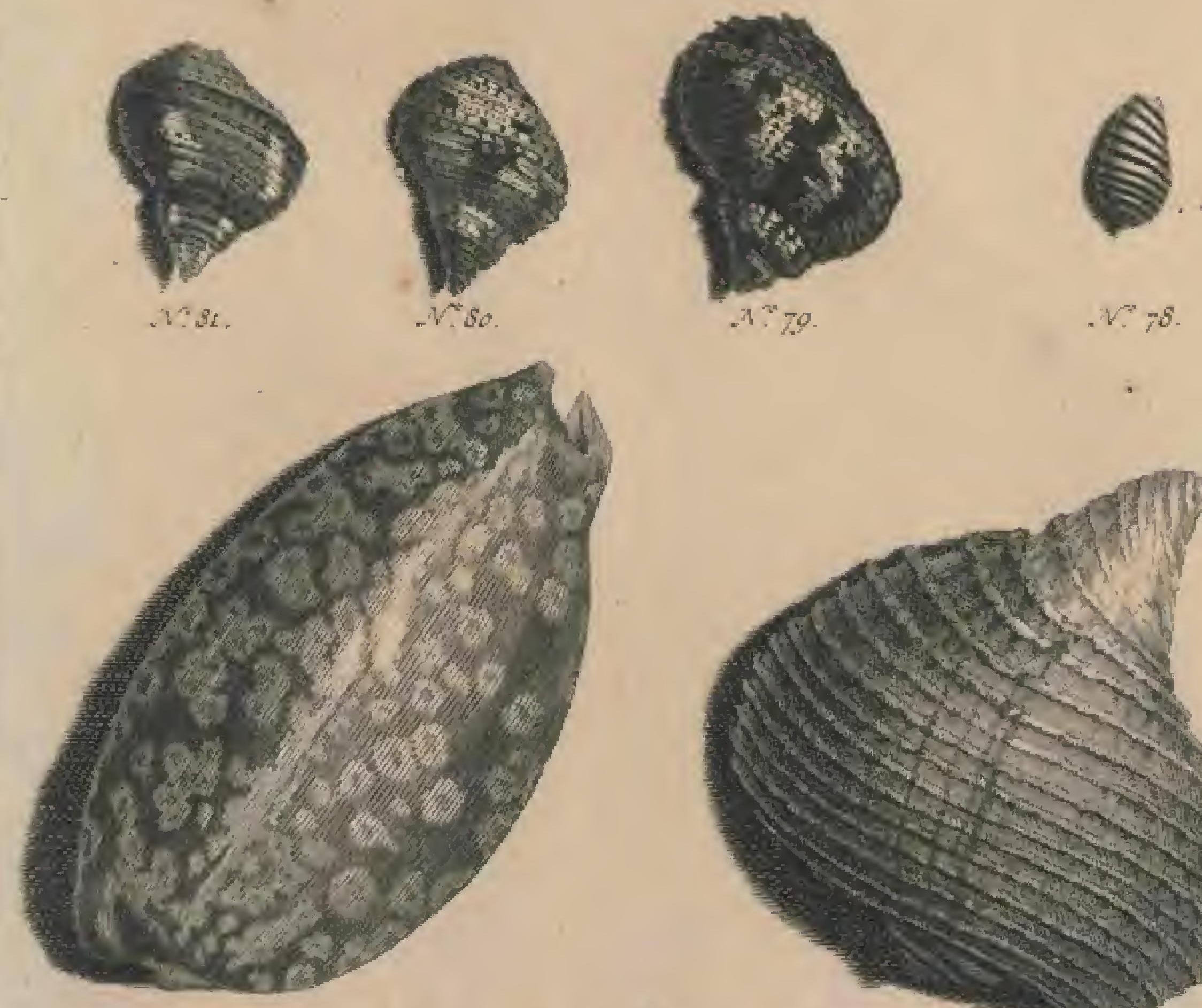

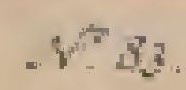
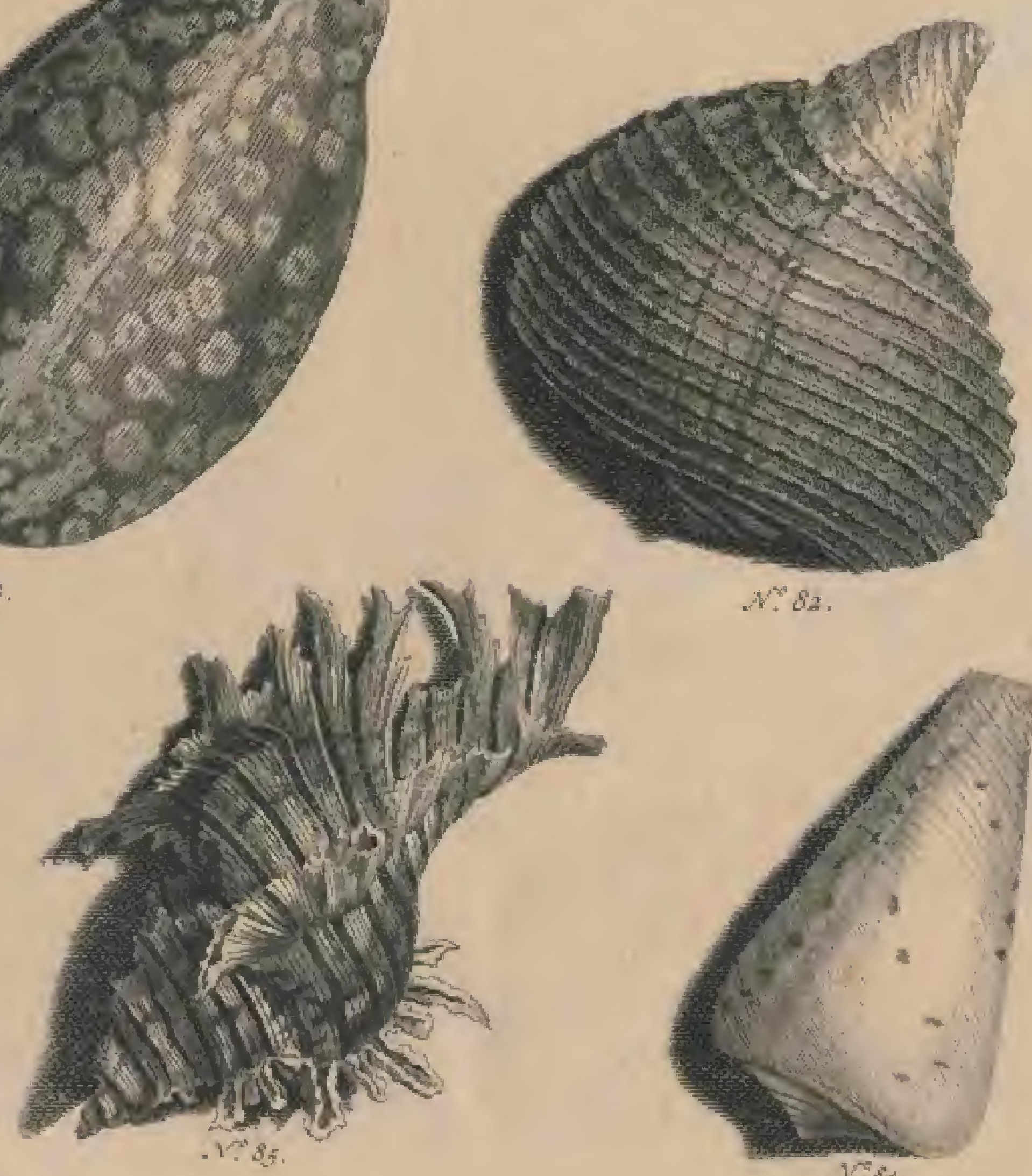

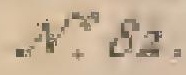

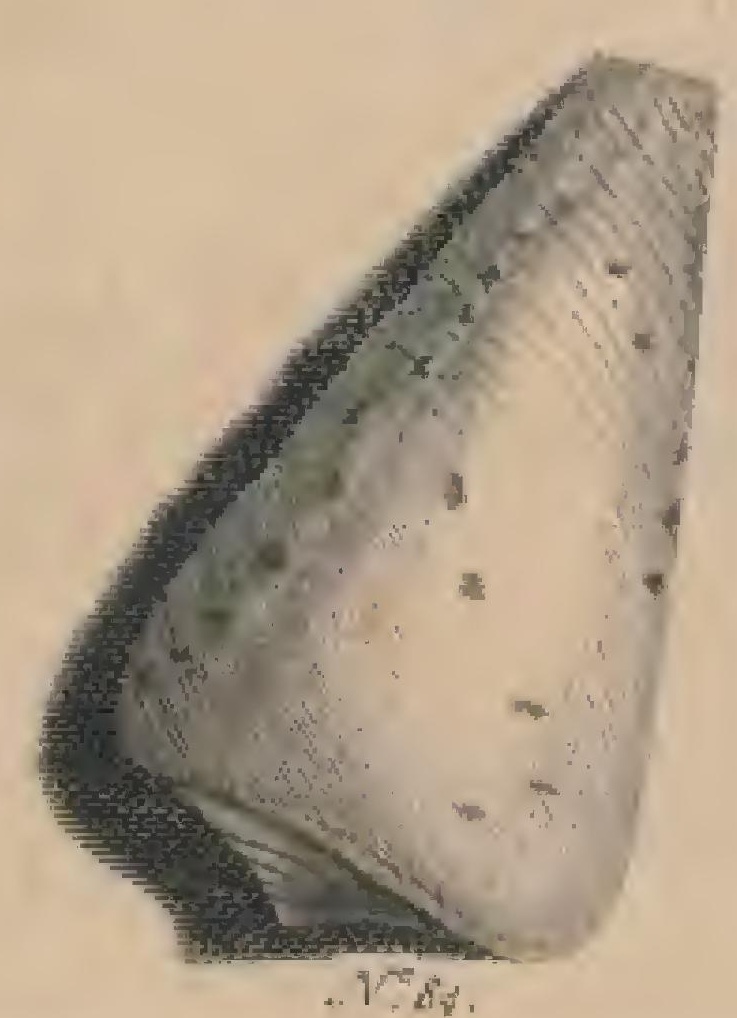




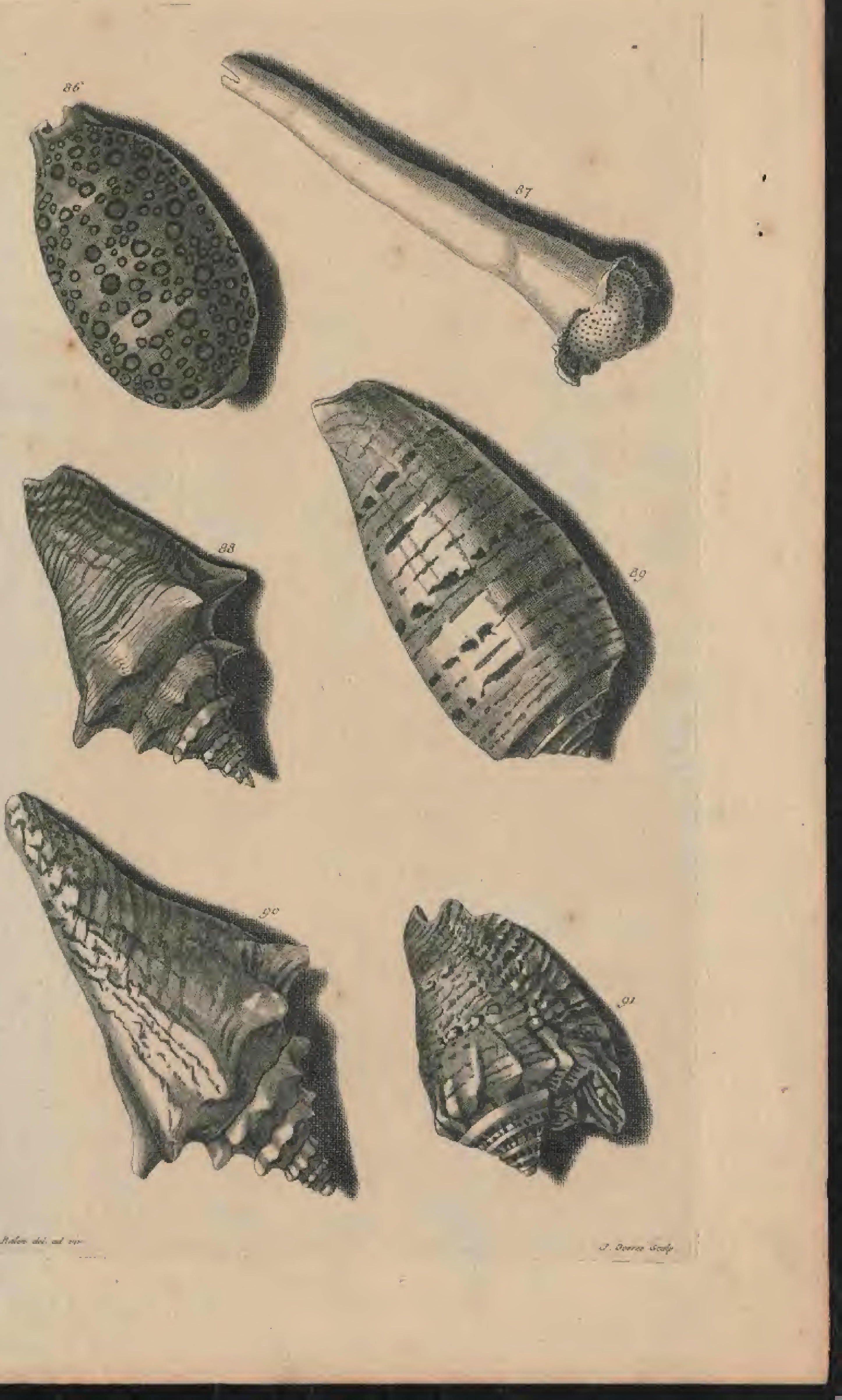



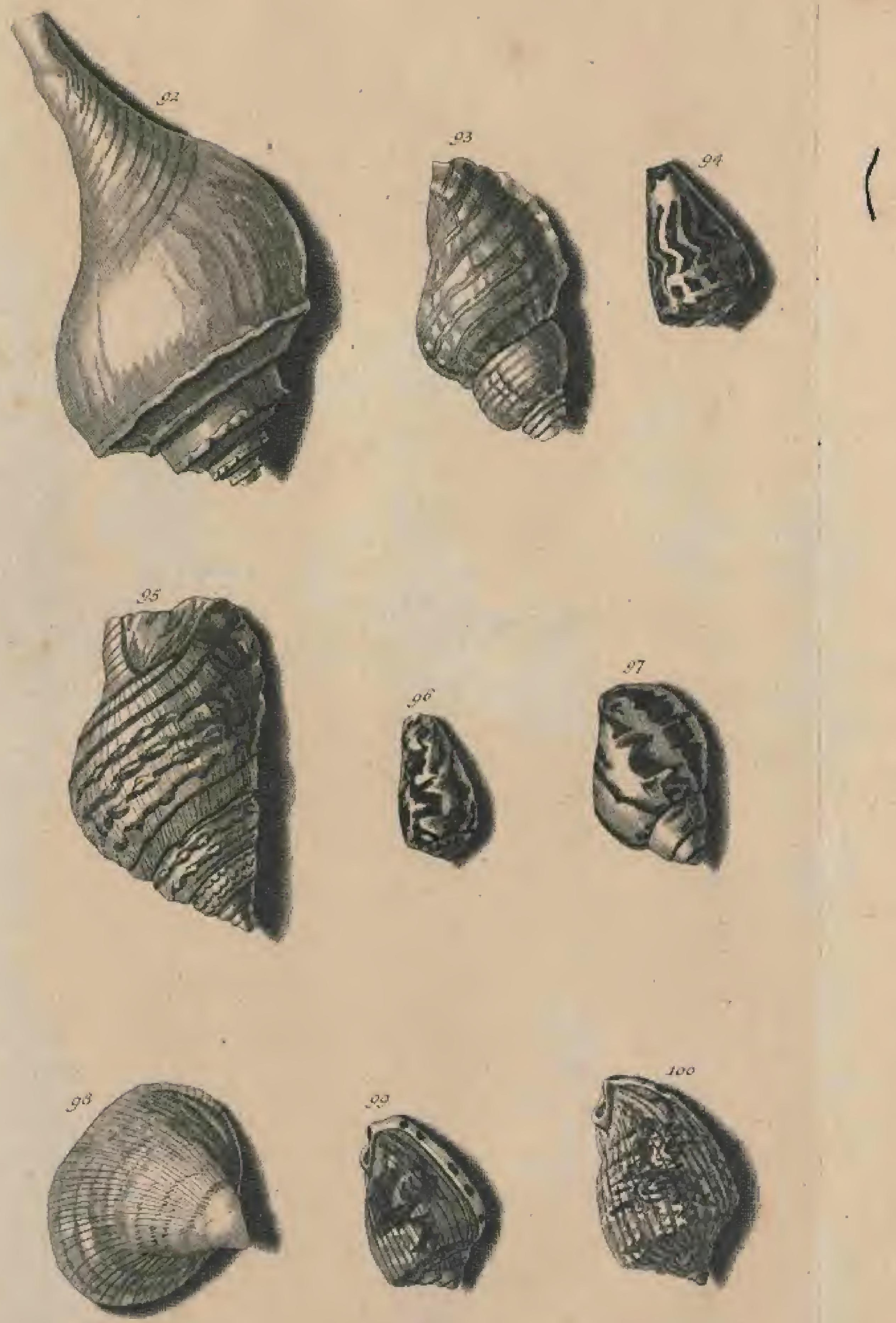


$$
\text { 藏 }
$$



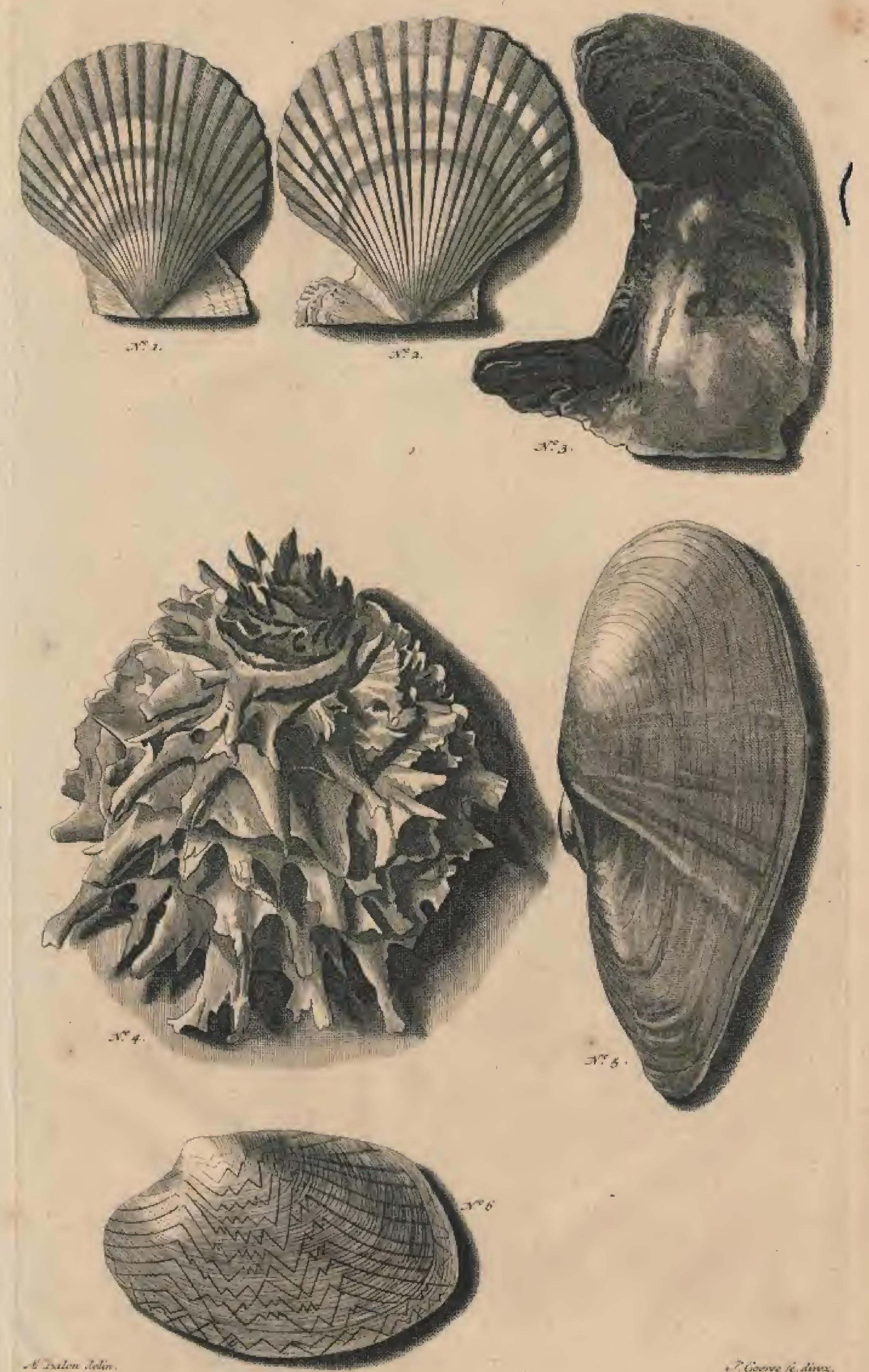

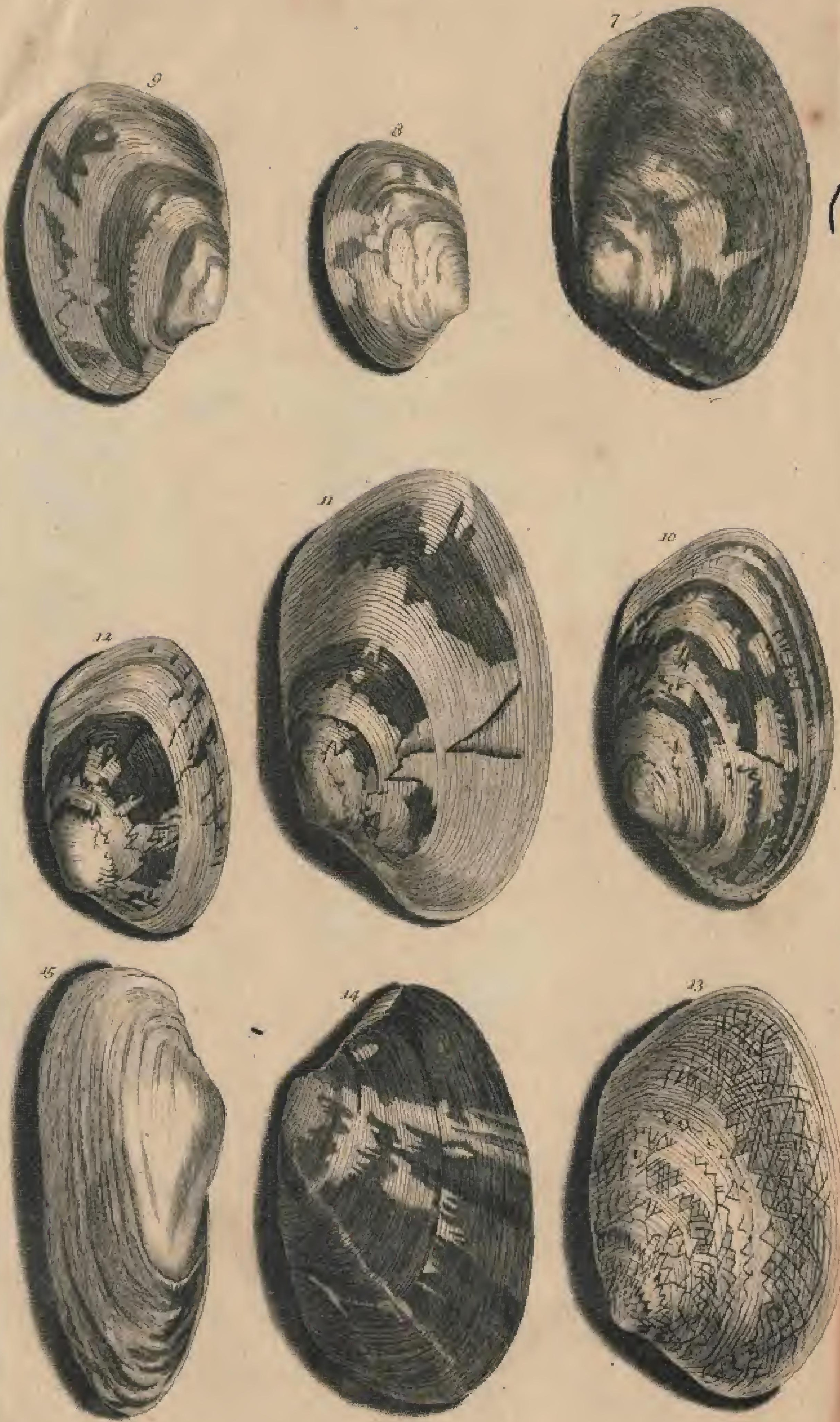

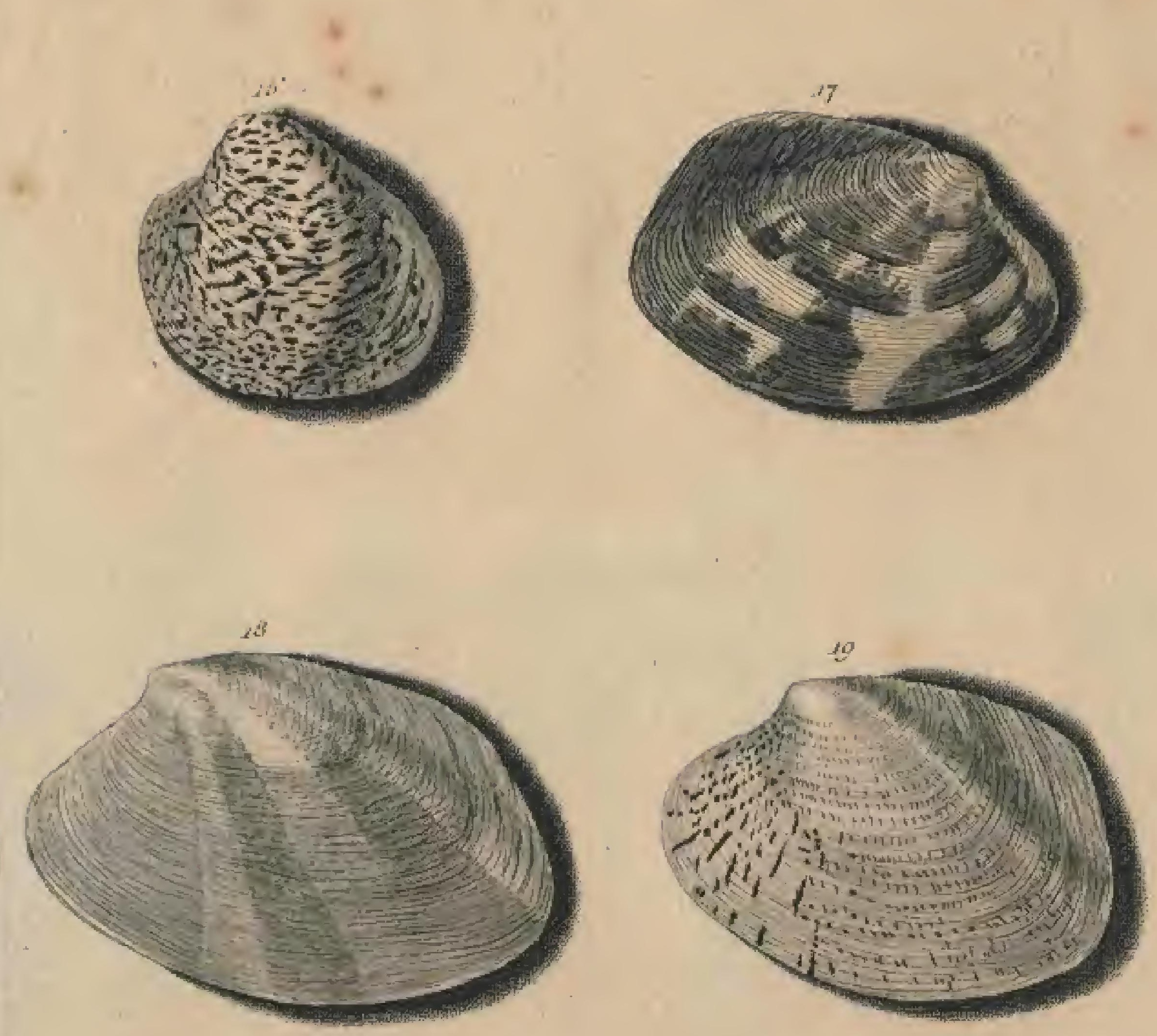

0
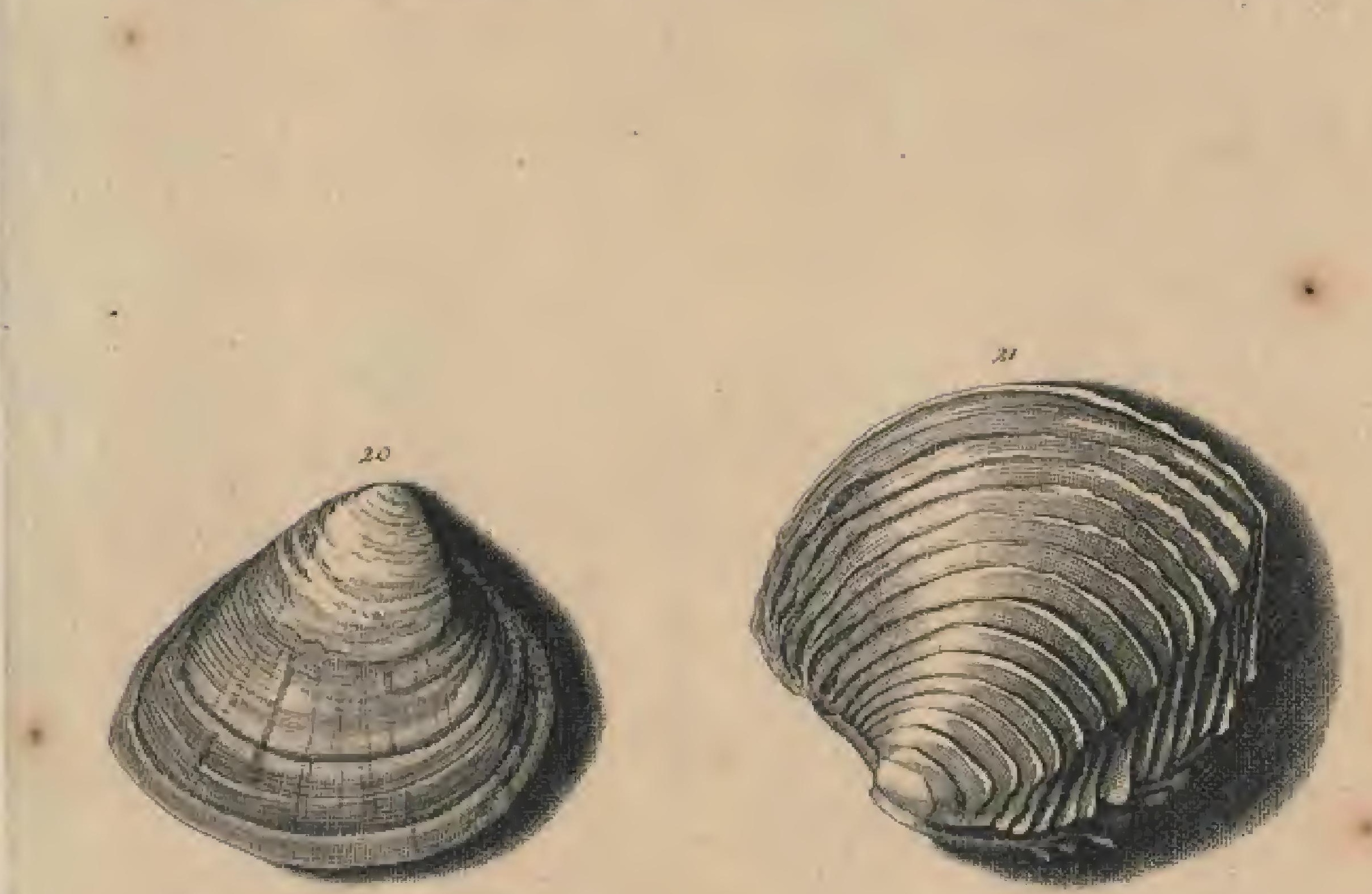


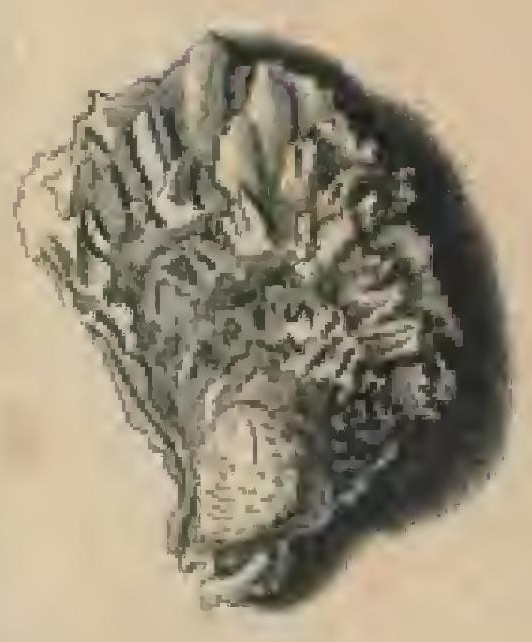

$x^{2}=$

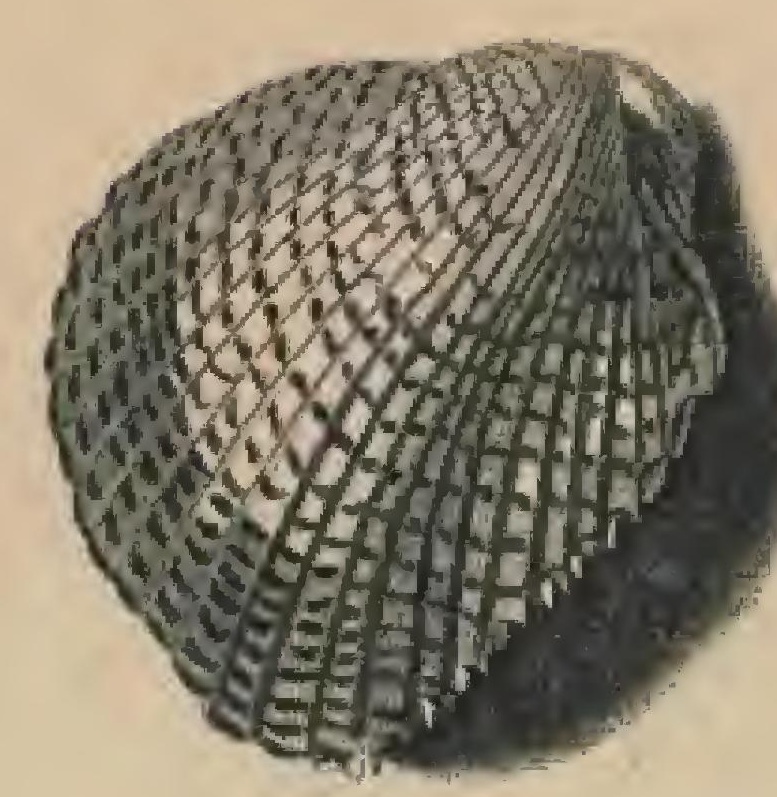

$x+3$

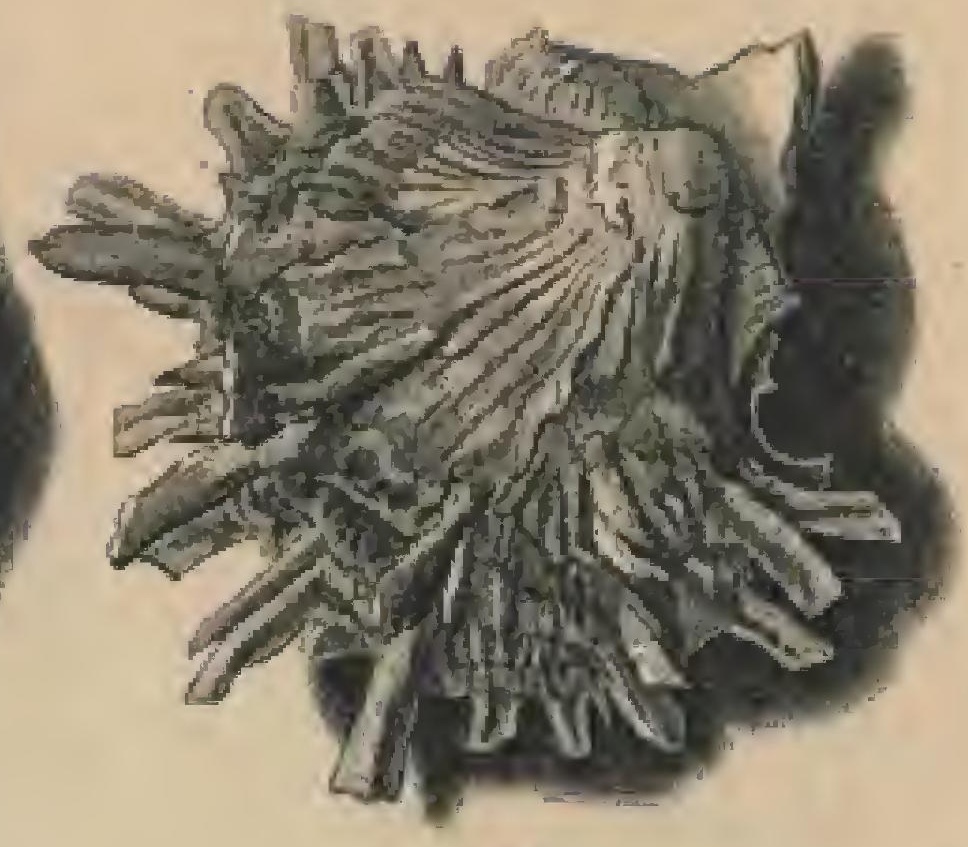

Nox.
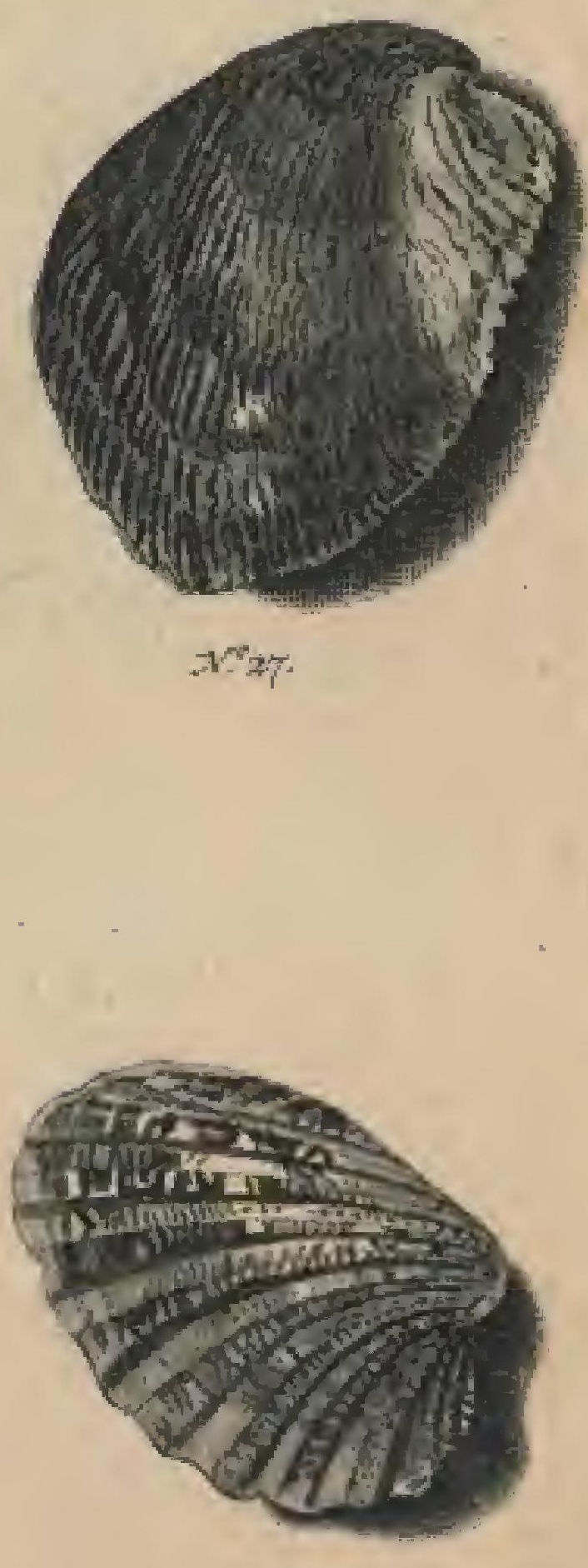

wos
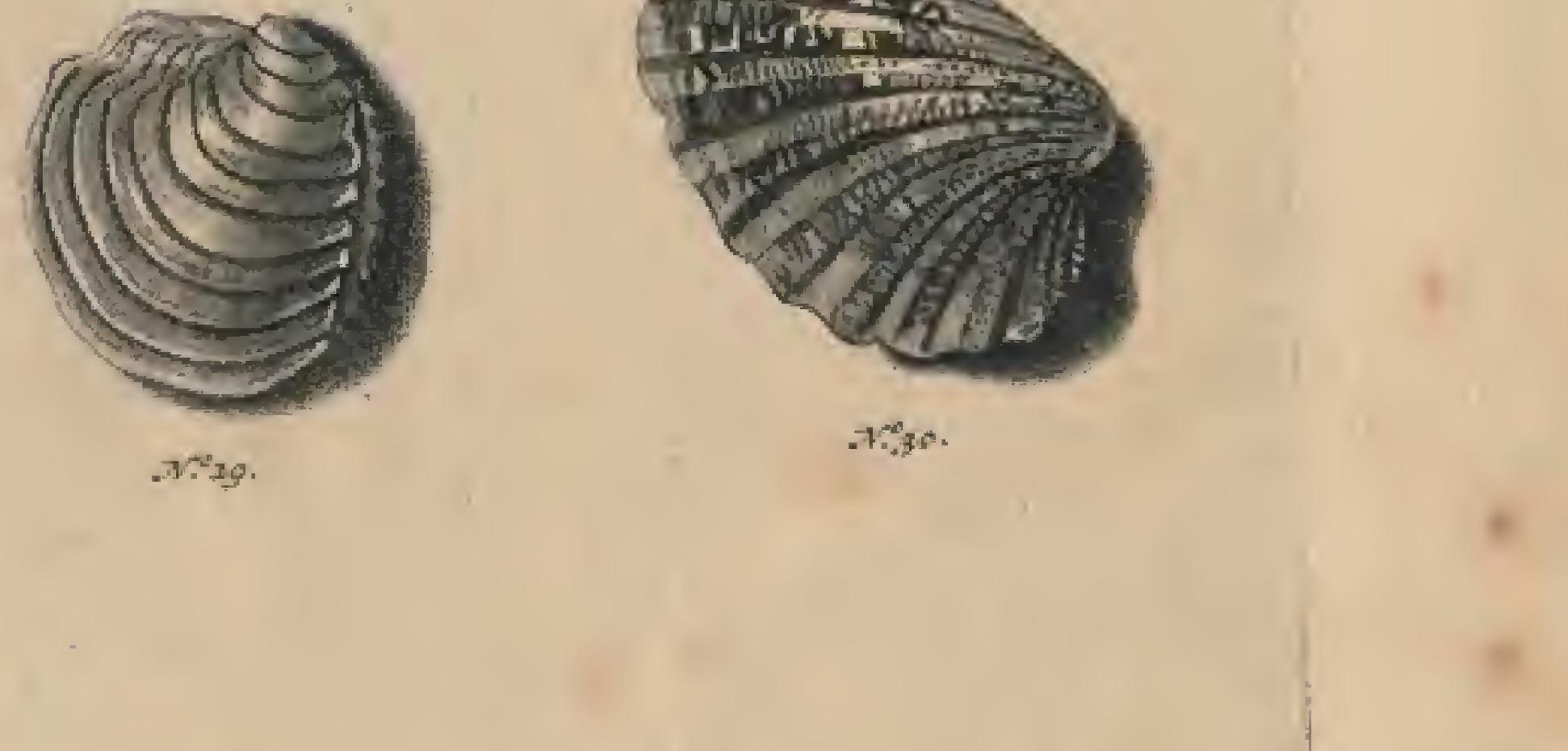
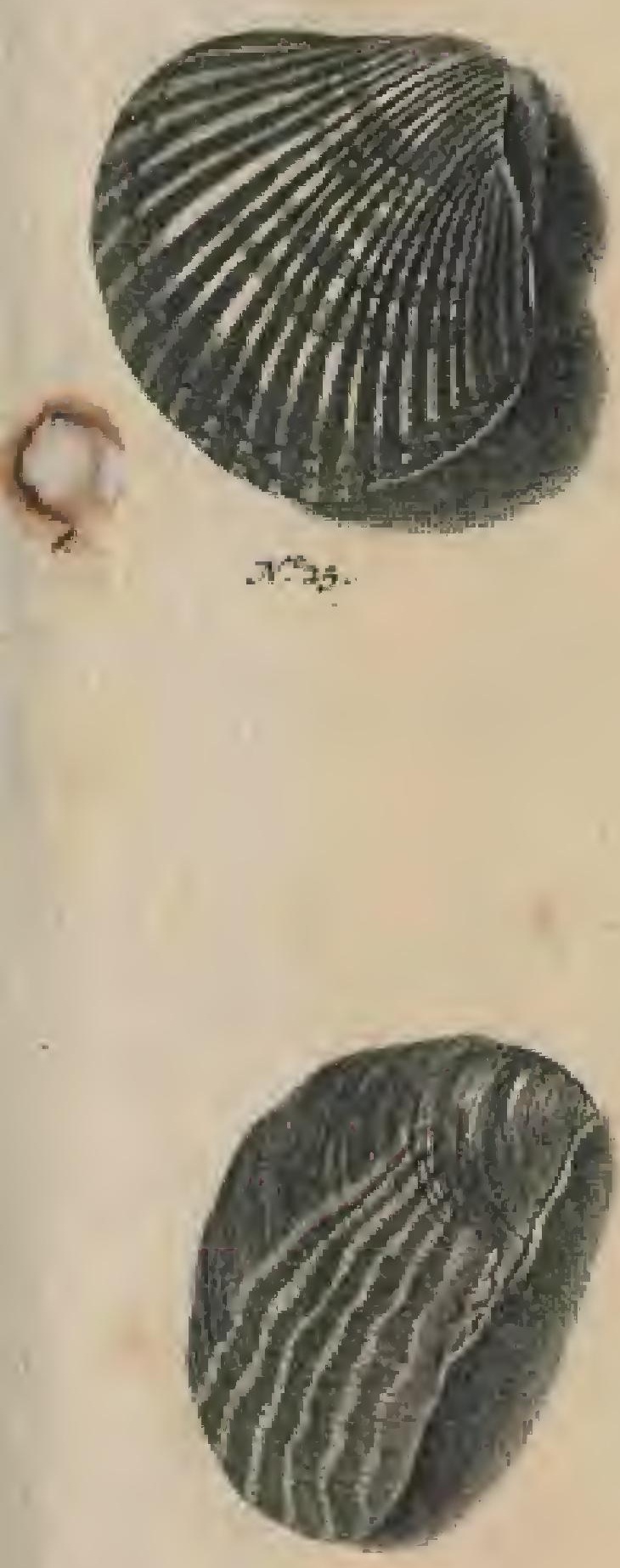

$-w^{2} \geq \bar{s}$

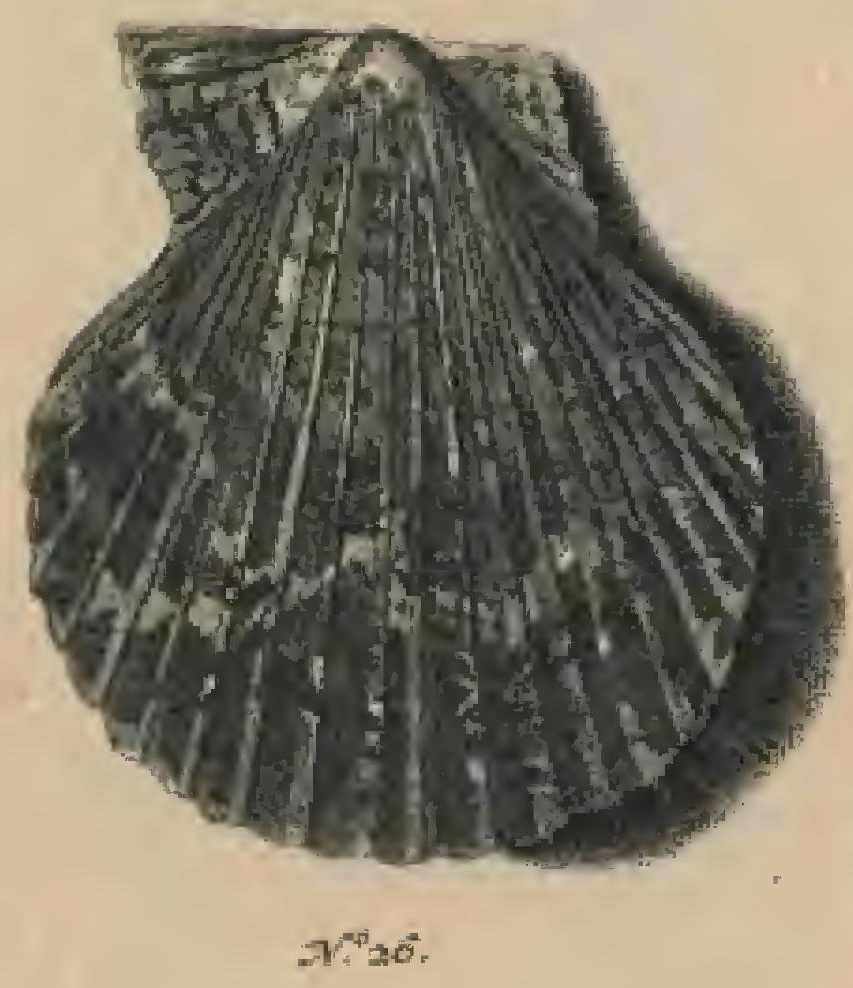




\section{NAAUKEURIGE VERHANDELING}

\section{$\mathrm{V}$ A $\mathrm{N}$ \\ B
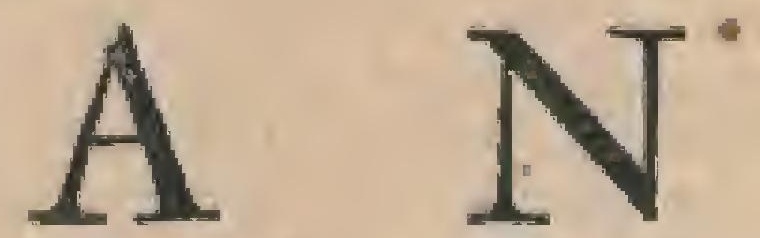 \\ D

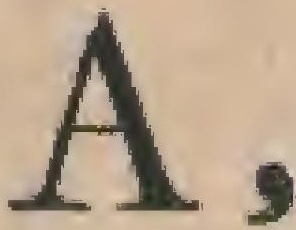 \\ Behelzende een Nette Landbefchryving VA N DE

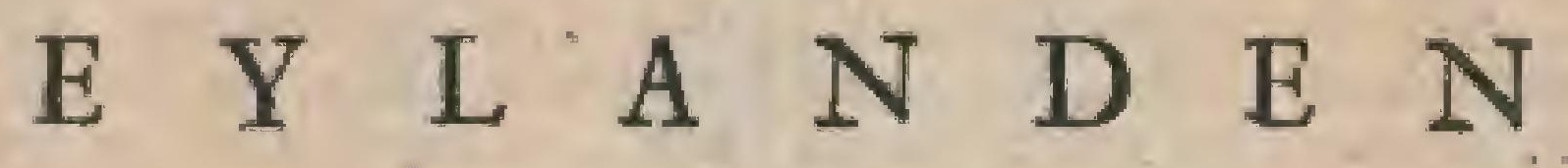 \\ Daar onder behoorende,}
A L S
M E D E
E E N

VER HA A van de Z A A K N,

Tot nu toe aldaar voorgevallen.

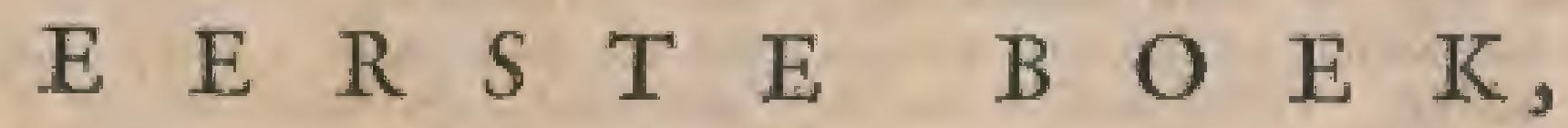

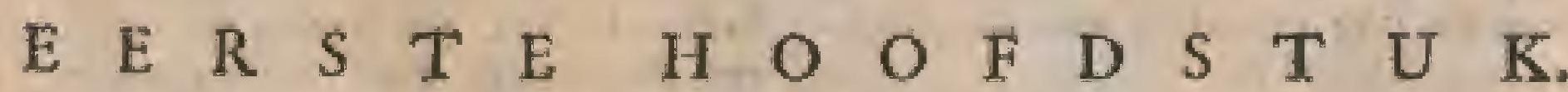

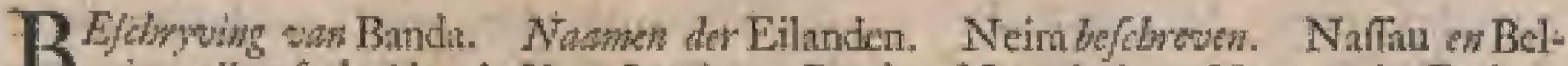
gici alle afgebeld". "I Hog Land wa Banda of Lonthoir. Nawer der Perlien.

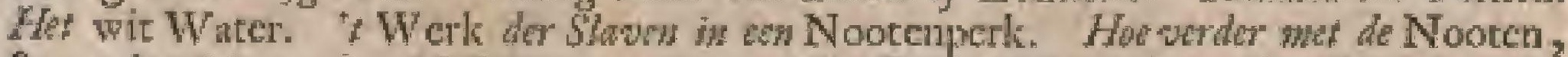

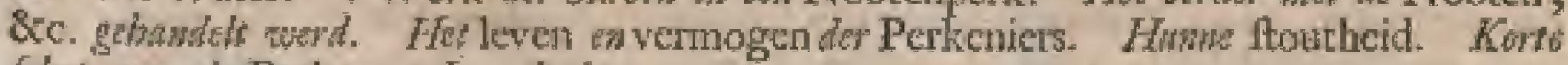
jebets wan de Perken of Lonichoir:

Befthtyving valh

B N D $A$ de nate Provintie of welke ons te fipicken valt.

Dien mam draigt de gatulche Landtoogdy, hocwelze mar man een Land, gelyk wy anftonds zien zullen, eigen is.

Hee beftat uit zes bewoonde, en vier onbewoonute Eilinden.

De natmen der bewoonde zyn Neira, Notrian let 't Hooge hand wan Bandit (doch wan den dabler. inlander Budan gentame) de Goenong Api, Poclo Ay, Poelo Rhun, en Rafingeyn.

De onlowoonde zyn Poclo Mamuok of Poelo Pifang, Poclo Kapal, '. Vrauwen ciland, en Poclo Seyrhata, welke twee linttice ook wel Nalacan en Saliano, van ouds genatam wierden.

Dere Eilinden leggen op 4' grand 'Zuider breedie van de Linie, en tuffchen de 25 of 30 mylen vun Antomi.

111. DEE L.
Het eerfe, dat in opmetking kont, ${ }^{2}$ eiva behocwel geenzins het grootite, is her Ei- feclusewer. land Neirn, om dat de Landwoogt, en meeft al de voomame Bediender der Mantichappy, hicr hun werblyl en woonphant, theyens wecle andere borgers, of wrylieden, habber.

In oude cyden, zoo my wit cen berige wan de Heer Hesm ik wan Bergel blyki, plagten op Neira verfeheide fteden te weren, dic door de langduurige ootlogen der hardnekkige Bandinezen verwoelt zyn. De voornamite yan deze en de hoofdhadt dezes Eilands was Lubetncka, onder welle nog drie undere, Liftor, Gioe, en Luera genanuc, ttonden.

Dit Labetacka, in "x Noorden dezes Eitunds gelegen, whs zeer volkryk, en plagr oncrent in 't jat ispo. en bevo= rens, eene lyn mer die warn de thadt Nein, in die ryd nog zoo magrig niet, als L-2betacka, te trekken, welk Neing toen onde: 
onder zich ook nog dric lteden, teweten heden; natr hooger op lan men niot Ocrien, Sjak, en Rntoe, had. Zy wal- komen.

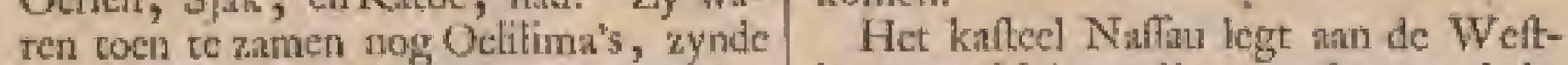
een wan de twee ftengen van regeeting kant van Neira, digt man llmat heb(even ils de Hockie en Kabeljuwwe, de Guelphen en Gibellinen, \&c.) dic dur te dier tyd thand grepen, gelyk in Am boina, dar het de ftreng, of pirty, des Mooten, gelyk de Oelifiwi's die det Chriftence is, hoewel vin de negen koninklyke Raden in Ternate (dic Mooren zyn) oorlpronkelyk.

Exnige jaren dat na, ontrent 't jar r 598 . of i rog. wielen die pin Libetackit, met de onderhoorige fteden, wan dic van Neirn atf, houdende het zedert met die gene, dic zich Oelifiwas noemden.

Ocli-Lima beteckent in 't Amboinedch een vyfgetpanlchap, of een gehuge van wywen, Oeli-Siwa, een negengelparichap.

Zedert dic afrallen liebber die wan Neiri, die toen de magtiglte en vry wermogender, dan dic van Labetacka, waren, geduurig raec hen geoorloge.

Men vine geen huizen, nog gedcriktekenen meer van al deze ftedekens, dan dat 'er op Neira, wan de Noordzyde, nu nog oen frat is, Ratoe, dat de koning in ' $\mathrm{J}$ awanlch beteckent, genamt, dic men ook zegt dat dezen maam draigt, on dat hun koning eertyds daar zou gewoont hebben. Verder is alles door de oorlogen werwoeft, dau dac by 't perk Labetackit nog de nuan ran dat ltedeken overgebleven is.

Het eiland Neira heef an zynen Wefthock de Groenong Api, of den Vuurberg, in "I Zuiden het hooge land wan Banda vlak"er regen over, zynde zelf' in "t Noorden gepratilt, en in 'LOoften dratait den hoek van "c hooge land, war op het ftedeken Celamme legt, wlak voor" "t Oolkergat, of voor Neira's Oollhoek, en ontrent Doft ren Noorder heefe men Poelo Pifring, en cen weinig Noordely= ker Poelo Kapal leggen.

Het eiland Neira is in zich zelven klein, belande in zyn breedec ftyf cen halpe myl, en in de lengece een myl, zoo dat ik giffe, dat men het in twee mylen en een half gemikkelyk zou wond cheppen.

Men becte van ouds her al op dic ciNaflas, land twoe groote valtighedent of kaftergica. len, Naffiu en Belgica gename, gelnd: Wameer of door wic dic gebouwt zyn, blyke my nergens klata. Naffu fichye my natil toc wat de Portugeczen gebouwt, en dasar nat in "t jatr' 1610 . door de onzen verbeter en wernoemt te $z y n$, alzoo die, gelyk wy hicr na zien zullea, het dalar vonden. By 't begin der Bursdafche Refolutien of Bentuiter in ' $t$ jatr I 6 I 9. en by de Digregilters, ate in "t jout $\mathrm{t} 627$. aanvang neman, leeft men al wan deze twee en meer andere valtigbeade vier bolwerken, de Admirats punt, Zeelandia, Delfe en Rotccrdam, wate wairde erite in "t Zuidweften, de rweede in "t Noordwelter, de derde in "c Noordooften, en de vierde in 't Zuidoolter gelegen is. Yder vain deze Punten of Bolwerken is net agt metnle ftukken kanen volwien; en op zommigen plagt men een limoenboon te bebben. Dit lialted beNat van binen een lengte wan $17 \frac{1}{3}$, en ecn breedte van 13 rocden. Ann de zeekant, of an de Zuiuwelt zyde des kaftecls, op de gordyn, itat liet buis พatr der Landwonge, 't geeri wan verlcheide braye wertrekken, en voor ain wan een grootc Zut woorien is, in welke ik, by myn anwezen, het itbeddzel win den Opperlandwogt, de Heer Yan Pitofy Corn, met het halve lyf, met een ged zyde wambais cn ecti groote wyde broek (bynin even eens, als nu nog de helbuadiers wan den Opperlandwooge op Bacavia gekleed gatn, hangen zag. Ontrent de punt Zeciandiu heete men we wapenkamer, en vender in dit $F$ nt verfcheide comptören, en cen thaje bezeting na gilling van I go matn. Uok woont de Cipicein, Lieurenant, en Varndrig, in 't zelve. De ree- of waterpoot is tegen nwer het hooge Land, pas buiten de welke men een gragt zier, doch zonder water. In de nuur wat deze poot that met yzere letters $A^{0} 161 \%$. warfolynelyk dat die "er toen gezet is. Wameer men op de gemeene weg na 't Zuiden gate, beeft men cen korten anderen weg, die na een frati warerpas loopt, wal op mede eenig gefeliut legt, ther het welke men gemalkelyk wan de overzyde fichieten, en dus de Reede der fohepert, die cr whak woor is, bevryden kun. Voor dit Waterpas, 't geer ontrent tegen over groot Walingen komt, legt een groor Rif, over 't welke men niet, als by hoog water, komen kan. Opdit Rif plegen zich wel cenige Docjotgs (ecn zelker foort wan viffehen) to houden, co op 't wier, dit men dar op ziet, to azen. Wat dit voor viffchen zyn, zullen wy onder die van Ambaina befchryven.

Ten Noorden van dit Kufted lieeft men, pas ter zyden den gemeenen weg, die lings het zelve loopt, op eenen redelyk hoogen heuwel bet kalteel Beigica, tuffichen 't Predikants huis, en "t Gerecht, cen nam, gelyle oole die wan Notialu, door de onzen wel gegevers, doch ik kn niet na vorlchen, wanneer, of door' wie, 't zelve gebouwt, hoewel geloove, dit door de onten, nicr lang ha de verovering val Neira, $\mathrm{Se}$, ge- 


\section{B $A \quad N \quad$ D $A$.}

fchied $z y$. Het is in zich zelwen een frai belnopt Kafteelrje, niet al te groot, mat net, wan fratuj rondeclen, of toorens, die wit gehonden werden, en wan goede regenbakken (hoewel die zedert de arabering in ' $\mathrm{t}$ jata 168 ;. geberften zyn) woorzicn ; mar dezevefting, fchoon "tkafted Nafliu, en de gariche vlakte in 't Zuiden, Ooften en Welten beftrykende, is echter niet al te kjygskundig gebouwt, angezien pis tgter "t zelve een heuwel gebleren is, wry hooger, dan die, watr op Belgicalegt, en. die ook volkomen over het zelve gebied.

Dit was de reden, dat men op Batavia jn " $\mathrm{j}$ jar 16,7 , niet alleen goedgevonden had trelve af te breken; mar ook den Ingenicur en Valandrib Ceorg Everbord Rumpl, wit Amboind in "t begin wan Januati des zelwen jans derwarts zond, met litt om op dien hoogiten heuvel een nienve Redenit, die al de andere fterkten, en 't gantlch Eiland bettryken zou, te keggen; doch lyy wertek weer van dar den tien Mey, zonder dat ik heb kannen merken, dat een wat beiden gedchied is; want Belgica is in wezen gebleven, $\mathrm{cn}$, in de jaren 1687. en 1688, heb ik. op dien hoogften beuvel geen Reduit gezien, mar wel bevonden, dat door arbeidswolk digelyks arde van dien heuvel afgekruid, en de zelve dus hoe langs hoe meer vereffend en weggenomen wierd, hoewel 'er nog geweldig reel van weg te krujen vicl; man' dan zal 'c kafted Belgica "c ganfich Eiland zoodanig bettryker, dat, fchon eenige vyanden 't Waterpas, en 't katecl Nahia, al veroverd hadden, zy 'er nicts ter weteld an zouten hebben, augezien men hen van "t liafteel Pelgica plat zon konnen fehicten.

Benoorden het kafteel lege an 't einde wan de ftrant Rutoe, en darir oñ henen, de Papenberg, alwar de magtige en volliryle Negry Ratoe gelegror hect, die door de oorlogen met de Hollinders, in ' $\mathrm{t}$ jatr $\mathrm{I} 609$. en in de wolgende jaran,

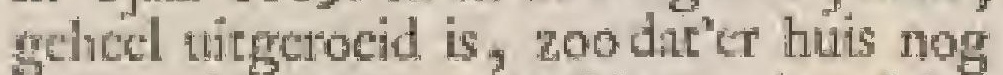
inwoonder wa overgebleven is. Men wind op dicu berg nog veel Mooriche graver, cn griffecnen aun 'thoofd- eli woten-cinde der zelve, zynde bog de cenige aloude overblytzels en bewyzen, dac hier Mohlnammedanen gehuisvelt hebbers.

Men zict "er ook eenige diepe grocten, en kleine lyontsen; docli wangeen belang.

Hy wert anders niet ved bezogt, om dut de bygeloovige Bindaneczen, watar van'er nog echige van de vrouwelyke luxe overgebleveir zyn, hatur nalkroolt, fchoon Chriften, nog dagelyks inboezemen, dit het by deze griven fpookt, en dat men op geenc dezer graven wateren, of zyn gevoeg dotu noct, zoo men daar van geen doodelyke zickte, ja de dood zelf, op zyn hals halen wil.

Dit is eenverhat, dat ik zeer wel geloove, zonder datam hier ontrene cenige werking, 't zy wan den Duywel, "t zy van fpook, de minfte plats te geven, filzoo 'c niet onmogelyk is ook deze graven (gelyls ik wete atu andere Mootflie gratwen, oni ze voll diergelyke onreinighe. den te bewaren, gefchied te zyn) zoo therk te vergittigen, dat de opltygende damp, na 'r wateren, alan zulk cen de dood zeer licht, en fchiclyk, hecft konnen weroorzaken; watrom ik myn goede vrienden altyd geranden hebbe, om het bygeloove wel te werwerpen, maar ook, noll op deze grawen veel te gatan, en 'er voor al doch niet te wateren, of hun gevoeg te doen, om dus zich zelven nict moetwillens in gevar, of wan hun leven, of van eun fware zielete, te brengen.

By dezen Papenberg, an de zyde van "t Zome-gat (cen kleine ltrate of doorvarte tufehen Neifa en de Goenong $A$ pi) is een bron wan warm water, dic al vry heet is.

De Lundwoogt, en den Opperkoopman wond ik in de paren 1687. en 1688 . buiten het fort Nulfu wonnen, den ecriter pas Beoofter en det anderen pas Beweiten hec zelve, "t geen $z y$ mogelyk zedert de Fwase ardbeving wan to jar 168 ; zullen hebben gedasn, weezende anders door de fwatate beweging het Fort op hun lyf te krygen.

Men heett op Nein 2 of 3 groote ftriaten. De cene loopt, met een kleine drajing, vain de timmerwerf der Marlchappy, die in 't zuidelykfte wan dit Eiland lege, Noorden op, woorby verfeheide huizen, als dat wan den Opperkoopmai, en de Hollandfche fteene Kerk, anu de eene, en voorby "t kafteel Nafiu anu de andere zyde, tot in de belommerde ftriat Ratoe, en zoo met de zelve roc atn den Papenberg, ten cinde. De tweode ltrat loopr Oolt op, litigs het Gerecht, als ook langs den heuwel, watar op Belgica legt, hee Prediltants luis, en langs meer anderc, al cen trani ftuks wegs heenen, tot men ere rechter hand zich na thand, of met cen dwarsteegje na 'c Zuiden wend, en zoo, langs een fchoon en ruim ziekenhuis, dat men ter linker hand heeft, atan thrund kowi, datar men dan, Weft op, weer langs cen indete ry huizen, en langs het armentuis gat, tot men de vifohuarke (diens opziender een Jood is, buten welke 'er nog oen op Celirnme plag te woonen) op den hock paffecte.

Wanter men by deCorps du guarde komt, en 't huis dwar de Heer Land oogt wan Zyll plagt te woonen yoorby is, hecte men de vitchmark, turfchen welke, en 'c kalteel Naffan, een fraai groot piein, A 2 
en verder zog ton ltrand, als na 't huis van den Predikant, alles wlak en open is, ziende het huis des Landwoogts rege tegen 't hais des Litutentuts, in "r loafted Nallau; man. Indren men die twoede Atrat reat ait loopt, kome men by "c perk, dat Gen Borger - lieutentant Tobins "Harde= cop, in 't jatr 1687 . cn cenige Jaren " $\mathrm{cr}$ wh, croegrekonen hect.

Alle de huizen op Nein zyn doot de bank van zecefteen gebouwt, die inet lealk, dic $z y$ dar owervloctig zelf branden, ecer wcl watk guzet, beltreken, en gewit zyn ; doch zy hebben alle, tuit vreeze der andbewing, mitur eene verdieping, en zyn mer Atap (wcinige turgezondert) gedele. De vloeren dezer hutzen finatken' ry vecl van zuiker, cn kalk, die wel doortreden col gemengt is, welkezy, wel geiegt en glad geftrelien, haten droogen, die dan zeer wel bia graauw martner geJjkt, en zeer eftion en gelyk is.

Zuilke woonhuizen gifle ik dater in "Ejala 1687 . omtrent 70 of 80 groot en klein waren, wratr van de meefte al woor viy goede huizen paferen konden.

De Hollandiche Kerle that natif en Gabba Gabba loots, die tufichen de zelwe, en "t huis van den Opperkopman, plagt te ftath. Zy wiert in "t pas genchde fatar, alzón zy door de :urdbeving nog zeci gefehonden, enfrict bequan tot het waarnemen wan den dienft was, zoo verre weder in ftant gebragt, dat, datr men bevorens in die looes 's amorgens Duits, en 's middags Malcits, plagt te predilien, men dat in " $t$ jar 1658 . weer in deze ftecne Kerk begon te doen. $\mathrm{Zy}$ is van bisnen friai ruim, moi licht, en van vericheide geftoeltens, gelyk ook wan een goeden Predikitoel, wowzict, en gelykt, win buiten ann te zien, wel cen widerlands huis met een vaderlandzen voorgevel.

De opesbare wegen hier tyw wiet befriat, matechter zeer goed con bard om te begari. Ook kan men, Ratoedoor, cn zoo na de Papenherg al opgande, vant agteren in Belgrica leomen, en, 200 men wil, ook dab langs wlak op Nuffa aan den heuvel afgant, twatr meet heb ik, om den anderen avond dit heern, by de Papenberg tot aаn "t einde van dezen heuvel na de coftzyde, fchoon ti wat fteil is, orgyereden, dian men, by en grones witte put kome, en by cen klein fteenen huisje, al wan cen fraje hoogtc in zee ziet, alwar men dan gewoon is wat te ruften; en wan day ryd men allengsliens dezen beurel and die zyde, na 't ftrand toe, of nas 't Zuiden, af, alwant men daic bekent Marigga 's bofch, dasr dic wakkerc adminal $/$ crboesen met wo weel brawe mannen het leven zoo decrlyk onder de haden der verradelyle Banda- neezen liet, en verder een fratjen thuin der Mateliappy voorby, en zoo langs ftrand benen ryd.

Wat den voornoemden thuin angat, hy is langwerpig vierkant, een moi fuk lands, met verlcheide fraje fituiboonen vercierd, en met een fchoone mulir van kratal- of zeefteen, ontrent 8 of 9 vocten boog, die' er een fraal ciertad aan goeft, omringt. Deze thun lege pas agter het ziekenhuis, "L geen men cwen ha den zelven vomby gant, en dan komt men weder langs ftrand tot yoor "t Kallecl. Dit is de cenigfte wandeling, co verfte uit lpanniog, die men op dit Eiland nemen kan, ten wate men zich in een der rwee Nootenperken ofte boftchen (alzoo 'er op dit Eilund geen meer zyn) die mede an de Ooftkant leggen, en recr lehoone jik wan de grootite Nootenmulchaten witleveren, wilde gann verluftigen.

Het eene van deze Perken (welkers natm ny nier voorkont) weleer den heer Tolias Aardecop tocgekomen hebbende, is $i$ too roeden enoot, leverd I joo pond Toelie jaarlyks (hocwel "t woor 'c branden wan den beig wel roooo pond leveren kon) heeft 50 dawen, houwel th op 45 zielen mut geftelt is, en is nu ontrent 6000 ryksdailders watign, fchoon 't woor 't branden des bergs op $7000 \mathrm{R}$ dets $\mathrm{ge}$ fchat wierd, en zelf wel voor meer werkogt is hiowik Moyer, een pertenier aldar, verkogt dit aan den jongen in Borge (Wwager van den Predikant D. Boterkooper) voor $7200 \mathrm{R}$ ders, en die verkogt hee weer ann den Borger-lieutenunt (dat hicr de hoogite Borgerbediening is, alzoo men "cr geen Caprein heeft) en Confinurier der E. Maatchappy, Card Horder, foop 6000 of $6400 \mathbf{R}^{d e r s}$.

Het ander Perk, Jubetacka getuant, en in de jawen 1687 . en 1688 . door eenen Anoui Charzon Soe bezeten, was matr 600 roeden groot, levetcie 4 of roopond Foelic, had 45 flaven, ftont poor 30 zielei bekent, en whs $3000 \mathrm{R}$ Lers warrdig.

Ontrent deze Perken, en op andere plaatzen van dit Eilund, heeft men ook hartebeften, op welle ilk wel beb helpen jagen.

Het is iets zeldznams, dat men in ganlch Bunda gecn kilkrorlchen, nog wuorvliegen zict, die men anders by na over al in de buitenprovintien wind.

Ook is 't wonder, dat men op dit lind wan Ncira nog zulke feluoone Nootenthuinen, of Perken had, aangezien "I ganfelae land serbrand, dor", en zeer rwavelagtig, byzonder nal de zyde wan de Goenong Api, is, en alomme nict anders, zelfs langs ftrond, dan een gecle en fwavelagtige grond, als puimftect, vertoont, 't geen ools de oorzatk is, dat 


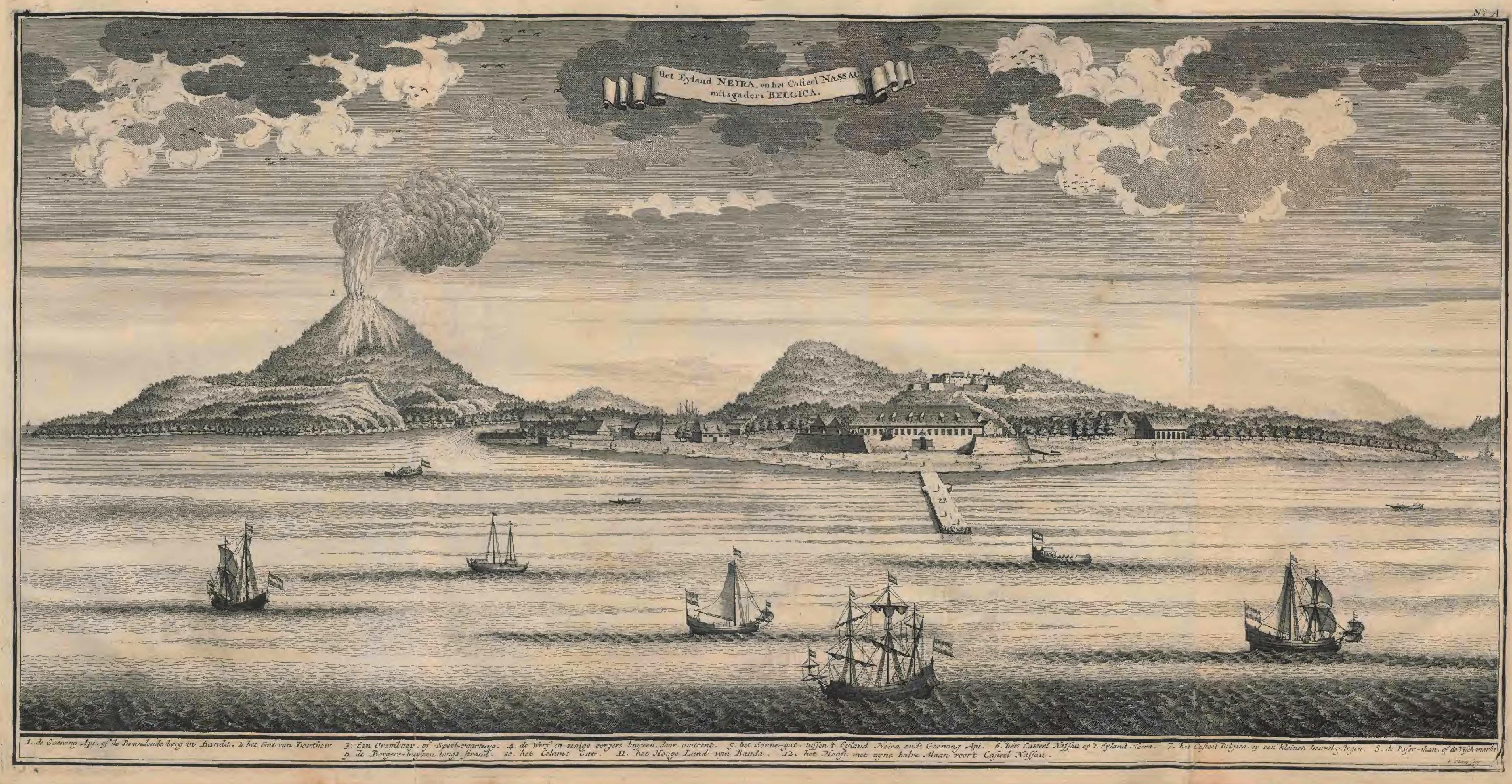


"er de kutuden en andgewaften zoo wel niet tieren, als wel groote Manggis, Djamboes, en andere bomen, die, alzoozy diep gewortelt zyn, "er wry weeldrig groejen; hoewel diar mede her

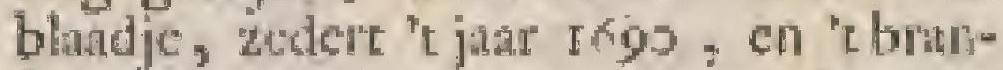
den van den beig, gelyk wy hier na breeder zullen zicn, zecr omgekeert is

Tulfichen Ncira en "t Hooge Land is een goede Recte woor de fehepen, en een zecr vermakelyl gezigt an weerzyden. op. die twee Eilitnden. Zy konnen an wederzyden ook, 't Oolteren Weltergat in, en op de Reede ko= men.

Aan Neira 's Ooltkant plagk in oude tyden een Iteene Reduit nee verre van 't zickenhus te ltan, doch door lwate vloeden, en 'E fterk andharn van de zec, is dic met "er tyd geheel weggelpost.

Afge Een thette reckening van het eiland beeld. Neira, gelyk men het wande Reede ziet, als men tuffehen 't zelve en "t Hoog Litnd legt, vertonen wy onder letter $i$.

Na het eiland Neim komt het Hoog Land ran Land wan Banda, als "r groorfte wan alle Banda, of de ellanden, eerlt in opmerking. Hee

Lonthoit. werd wan de Inlanders "t land wan Bandan, of ook wel win de anzen Lonthoir gename, on dat hier van ouds cen ftade wan dien nam was, en om dar her $\mathrm{Ne}$ derlands comproil, daar ons Opperhouft huishoud, eri de fieceryen van den Borger ontfangt, tot nog coe de nam wat Lonchior voert.

Dit Eiland, ontrent een quartier uturs deheppens Bezuidei Neira gelcgen, is langwerpig, loopende meett Onit en Wed, hoewel het zich in "1Oolten wat na "i Noordonden halve Maans wyze ombuige. Her is onetent z: nyl lang, en ontrent een halve myl breed, zno dat het na gifing 6 mylen in zynten omtrek is. Hot legt, rege tegen oxer Neiri, in "t Zuider, en is zeer laogg en bergagtig, hoewel het an de Welteant wat lager is

Voor af, zullen wy cens zien, hoe "thiér wan ouds was, en daur ha vertoo. nen, hoe "t nu is.

In oude tyden plagt men cenftadt atn de Noordweltzyde dezes Eilands, Lonthoir gename, onder welke de ftedekens Madiange en Lukfoy ftonden, te bebben. Doar beneven wis "er een ftedeken, Gammer, dat in vicr campons, of gehugten, verdeelt was, en onder het welke "tdorp of ftedeken Woena flond.

Men had roem an de Noordzyde ook liet ftedeken Ortatian, of Orontatte, 'tgeen men wil, dat eigentlyk Otrangda' tang, dat is, "t volk komt, genaamt wierd, om dat men van het zelve, ils wat hoog gelegen zynde, de vreende varutuigen wat verder in zee kon zien ankomer.
Het plagt, in de jaren if ro. en is 60. cen wan de grootite fteden vin dit land, en ecn van de voornaitrite hondelplate. zen te zYn; doch wis in de jauren 1600 . en i 610. zoo kleiri geworden, dat, daar het in voorige tyden wel rooo man tterk, en boven anderen mer ved woorrechten begunftigt was, het toen pas $70 \mathrm{man}$ opbrengen kon; 't geen dhat van dan gekomen is, dat die van Lonthoir al hun woorechen allengshems ingepaliar, en zich van hen meeler gemakk hebben. Deze zes fteden waren Oelilis กา 's.

Up dic zelve Land heef men ook aan de Noordryte Combir en Reni Rane, (anders Ramin genaame) en ann de Ooltzyde opencen heuwel van ouds her Celáno gehad w welk Selímo dit Rantin, hoewel her eigentyk eor Combir behoorde, in "r jarr 1500 . nog onder" zich had:

A s menden Oolthoek des Lands na de Zuidzyde omging, quam mera by defteden Oudendender en Wryer, wrelke latitle nog twee thedetens, Bogton en Oeman, onder zich had, makende re zatmen, mer nog dric onbekende in naam, zeven theden bit, dic alle Oclifina's waren, zoodac'er in ouderyden in "r geheel twatlf of detrien theden, groot enklcin, fchynen geweetk te zyn; hoewel ik geloove, dater bevoorens wel meer waren, matardat, ten deele doon gebrek van nerre anteekening, en ten decle door de verwocfting vandit Land by fware en langduurige oorlogen, vecle zelf hare na. men verlooren hebben, en uit de wereld geraakt zyn. Hier toe geoft my cenige analeiding, zoo de velting Lakoy, dat geen Hollandze, mar een inlandze nam is, als ools de Perken, nu Walingen genatint, doch valu ouds de nian wan Walan (of Waran, dae in "t Ambonfch en Bindalch, Banda beteckent) gevoer: hebbende, "t geen zekerly' beide mede Aledekens, of viekken der Bandineczen zullen gewecti $z y$ n.

Ook noemden $z_{y}$ Ceram, Waran Ela of Waran lla, dite is, groot Banda, om dat 'er veel Bundache volkplantingen op waten.

In tyden van oorlog was de ftadt Ortatton altyd neutral, of onzydig, cn waren de verfchillende Partyen altyd gewoon data by een te komen, otn wrede en verbonden tulfichen de Oelilitna "s en Oelifiwa's te matken, ahwar $2 y$ dan gemeenelyk onder een grooten boom (die by de Ouden lieilig waren, en ontrent welke zy meinden dat jet Goddelyks gevonden wiert) plagten te vergaderen. Rondon dezen boom was een lteene vierkantige voet, die ontrent twee vocten hoog, en van binnen met aarde gevuld was. Boven op die voet zatel deOrang $A_{3} \quad \mathrm{Kaja}$ 's, 
Kajis's, of Hoofden der fteden en dorpen, yder na zyn rang; doch de andere hier toe geroepene uit de gemeente, Orang Boedjang, of de ongehuwden genaamt, zaten op dearde beneden deze Atecne vodt.

De Oelilima's zaten on de Ooft-en Noordzyde, en de Oelifiwats om de Wett-en Zuidzyde , doch de vreemdelingen ftelden $z y$, daar $z y$ die wilden luebben.

Woor den oorlog met de Inlanders zelf, en met de Hollanders, vergaderde men onder dezen boom tweennal ter week, Dynsdags en Saterdars. Op deze dagen hadden de vrouwen dit voorrecht, dat dan geen matrinen op de woet wan deze boom mogten komen, of, zoo zy dar deden, verbeurden zy yder reize $;$ Cati (dat is ruim 6 pond) Foeli.

Men bidl oole de gewoonte, om op de marktdag al de Gantangs (een zeker foort van maten van ecrige ponden, doch bier en in Amboina vin ry! pond) en mindere maten, na te meten, de welke zoo zy nict wan het nette gewigt bevonden wienden, verbenden zy cen derde "er wan, doch zoo zy' 'el" tegen fpraken, zoowat, wolgers uit / pratk dei Orang Kaja's, en der Moorfche Patpen, die hier zeer groot bewind in hadden, al hun goed, dat op de markt was, vert beurd.

Hedendalags is de gefteltenis wan dit Eiland aldus. Men heefe ande Noondweltzyde het Comptoir, Lonthoir genaani, alwarar gemeenelyk wan wegen de E. Matfohmpy een Koopman gephatet is, om de Nootemulchaten, en de Foelie, van de Vrylieden of Perkeniers te ontfangen. Deze woont in een zeer fchoone breede fteene Logic ofte Huis, ontrent de ftrand; maat echter centge treden hooger gelegen; doch als men wan 't zelve na ftrind gat, kome men by een watcrpas, "igees het natuw tuftchen die Land, en deGoenong $A$ pi, (atan welkets Zuidzyde beneden atn de voet des bergs een lehans, Kyk in de Pot gentamt, en met een Sergent, cenige foldaten, en ftukken gefchut bezer is y ook zoodanig beltryken kan, dat dast geen fchip zou konnen pafteren, zonder onder "t bereik wath een wan deze tuktien te getnken: want zoo zulk een fchip, om "t grool Rif, dat zich woor Lonthoir uirltrekt, het na de wal van de Goenong Api, of de Vuurberg, hield, zoo zou het daar alzoo wel, alsdoor 't Lonthoit's gefchut, gegroet worden.

Voor liet ftrand ran Lonthoir, zoo men die fmalle boord 't itrand noemen mag, gelyk ook ter zyden, ecen ftuk weegs om de Welt, flrekt zich en zeer brecd Rif in zee vir, zoo dat men over 't zelve nict, dan met kleihe vartuigeth, komen katn; doch met boog water kn men met fonken en chaloepen "er over heen loopen. Als it met de landfichait 'er' na toegebrage wiert, wiert ik in een klein baaitje wat Bewelten de Logic atan lathd gezet, alwar ik gern rool land ter wercld, en tmy ten ecrlten wan de voet wan den berg wond, dic men met 313 breede en wry vlakke trappen niet alleen opgann; mair ouk gemakkelylk opryden kan, doch "tafryden, hoewel ik het ook dilkwils gedvan heb, is zoo gemakkelyk nict, ja zeer gevarlyk, alwoo 't my wel gebeurt is, dac, voor al by nat weder, de igterfte voecen van myn paard niec alleen uitgleden, matr dat 'c zelve alzoo ettelyke trappen an ecn afgleed, ocr het weer op $2 y n$ agterfte voeten quam; "t geen ik, jong zynde, mededecd, om dat ik het Opperhooft, die met my ofen afreed, dit zonder gevaar my voordoen $\mathrm{zag}$, en om dat ik meinde; dut ik mede doen kon, en doen moett, "t geen ik een ander woordoen zag , mar, op zekeren tyd door den heer Landwooge gewartchouwc zyode, dac ik, indien zoo een paard $z$ y noorfte vocten, gelyk lige gebeuren kon, of mar een wan de zelve, by "t afiyulen quanen uit te glyden, zeer lich mee het zelwe van bowen tot beneden zou konnen voortrollen, en dus myn leven verliezen, zoo kreeg ik zulk een folrik woor het afryden, diat ik het zedert noic weer heb durven doen.

Half weg dezen erap is een bron, die geftadig water, hocwel wan weinig belang, geet.

In 'c hangen yan dezen berg heeft men de Negry, Lonthoir gename, die zich tot boven opden berg uitfrele, whoewel men "er ook teene wponingen heefr, zoo zyn het, ecnige weinigge uitgezondert, in wergclyking wan die wan Neira, zeer degte huiskens. Ook is het cen groot ongemak, dat men woor yder huis byna 2 of 3 buiten, en 2 of 3 biunentrappen vind, met welke men op een voot" - erfje voor "t huis gelegen, treed, "tgeen by een vifitatic, of huisbezoeking der Ledematen, cen zeer mocjelyk op- en nederklimsten gecti.

Weft en Ooft op ftekt zich die Negry ute, doch wel de langlte wandeling heeft men on de Wett, een klein halt uurtje verre, pafferende onderweeg een moerigen thuin van "cOpperhoofd, wax op cen byzonder thuinicr paft ; zoo al recht uti, langs een gelyken en redelylis brecden weg gatnde, eindigt men an een plants, wan welke men wan een fchoone hoogre zeer theil in zec, de eilanden Ay, en Rhum (want Poclo beteekent cen eiknd, en darom lase ik "er dac Malcits wooth af) zcer klatar, en vak woor dic 


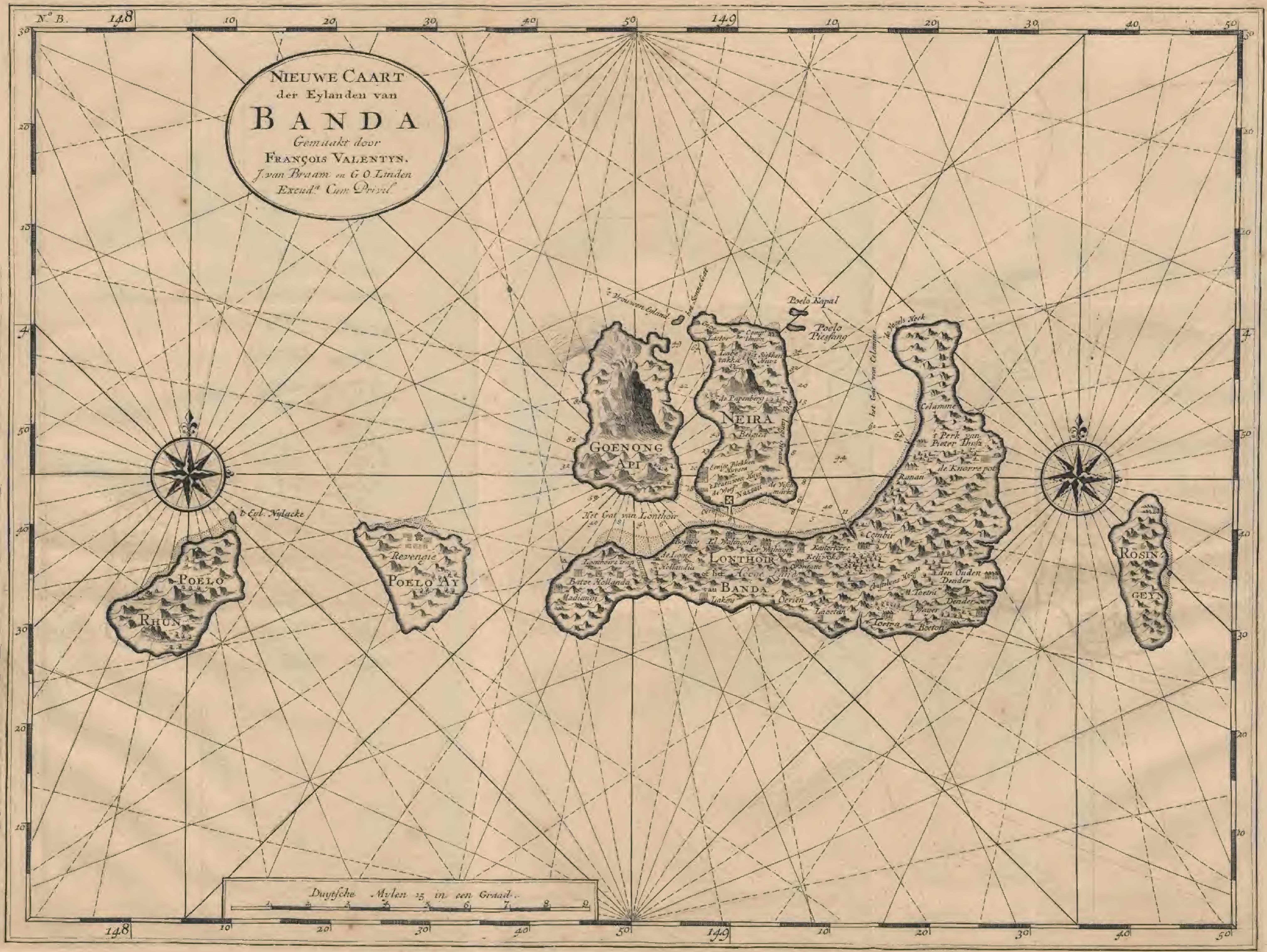




\section{B A N D A .}

Acile benaden onk een groote klip in zee ieggen ziet, dic Batoe, Hollanda, of de Hollandehe klip, genatrt wert, om dat de vertadertche Bandanezen vecl Hollanders, in die eerfte oorlngstyden bou'en op dic hoogte gerakt, en van de gelegenheid des Lands jnog onkundig, van ileze Iteilte afgejatat, ein gedrongen hebben of wan boven neder in zoe, of op deze klip, zich te beriten te fpringen.

If heb in " $t$ jar 1687 . op Celamme een oude vrouw gezien, die my verhande, dit gezien tehebber, alzoo zy coen cen meisken wan 12 of 14 jutren zyn kon, onl zeide zy woor de Hollanders te dier tyd gevluge te hebben

Bowen ap den Lonthoirzen trap gekomen, gas men dezen weg na 'LOoften, vooiby "t lusis des predikanes, na de Kerk, dac in 't jar 1687 . nial een groote Loors was, ontrent de vefting Hollandia gelegen, want in te dier ny een Sergeant, Dirlof Blat genatme, met eenige foldaren lag.

Deze velting, is wry ouี, aengezien $z y$ in de oudfle fehriften der Secrecary van Banda, die in 'r jatr 1610 . beginnen, al bekent was, zonder dar darr ecrigzms bleek, wannece, of door wic, zy gcbouwt is; Mlleenlyk ziet meth, datzy, te vooren Louhoir genasm, de nam van Hollandia in " $\mathrm{c}$ jagr" $16 \pm 8$. van den Heer Landvoogt Piek Vlak gekregen heeft. Zy is oud enveryallen, hocwel wan eenig gefchut werzien, doch van zeer weinig belang.

Hier ontrent fluit men ten cerften an "t boich, zoodat men geen gelegentheid heeft wan verder, ten $z y$ men ir 't boich $z y$ wil, re wandelen, behalven dat hier" geen huizen meer zyn.

Men grate hicr een foort wan foode puimfteen uit de grond, whar wan merr redelylic goede itecot musen róndom de huizen make.

Aal de binnen- of Noordzyde, gelyk ook verder buten om, ant dezuidzyde, is dir ganfch Eiland in Nootenmurchatthuinen verdeelt, die in "tgenseen Perken, gelyk ook de bewonners wan deze hofltedin (want datt zy to foone thene huizen by Perkeniers genaame worden, ons dit" yders pontie, of ituk litad, net ifgeper ht is, zonder dae by rerder komen mag.

Dezo ufperking is door den Landwongt Deetro Pierer Vhat, ontrent de jouren 1627. of 1628 , eerit in zeer veel keine Perken, onder zekereletters, grefehied, on dat die cerlte Perkeniers het termogen niet hadden wah zoo ved flaven te huuden, als rot gruoter Perken behnorden , inar met er tvd, en door narrfigheid , thogtans cen ltuiverte owerwinnende, kogt een kleine Perkenier nu en

dan een Perkje by het zyne, en zoo zyn cindelyk, by 't angrorien wau hume magt, dar tuic deze anżienclyke Perken, gegroeid. Wy zullen die, zoo als ons die van een Perkenier van werfland opgegeren, en in de rang, waat in $z y$ wan ons mentgmal gezien, en bezogt zyn, lataten volgen, en van de zyde van Lonthoir af een begin manken.

Het natte Perk, datr an zich ver" coonende, zoo als men Ooth op gate, is Natmen

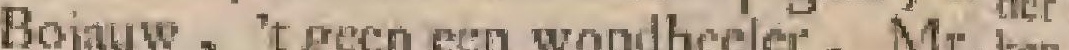
$7 a n$. . genathe, in "t patr i $68 \%$ ". bezat. Het is 1100 roedent groot, leverde in "t jatr" $171 \mathrm{t}$, en dar ontrene, 9000 ponden Foelic, goede en quade gewalien doot eell, en vicrmal zoo weel Nooten uit, welke proportie altyd zoo volgt. Tot Ait Perk behooren 100 Aataven, hoewel het mar op 60 zielen by de zielbefchryving, die jatrlyks gerchied, bekent ftat, en wiert coen geonde: te 14000 Rykidaldets of 33600 gulden, wasdig te zyn.

Her matte Perk daar aan is klein Whlingen, in " $\mathrm{t}$ oud Bandances eigently Walan genaame; groot zunde 8 ;o roeden, en in de javen $1687^{\circ}$ en 1088 van eenen fan wan Surkel beneren. Hier toe behooren yo flaven, howel het matr of $4 r^{r}$ ziclen gerekent, en toen 1 Loso Ruer watidig gefchat wiet.

Zujk cen Perkgeefr, by cen groor gewas, wel eens 12000 ponden Foelie, welk gewas gemeenelyk in tugultus of September wale, das "t likeine ordinatr in Maare, Apuil of Mey kome $\frac{3}{3}$ mitar wy ftellen hier mats 800 ponden, om dat wy goede en quade gewalten door een rekentí.

Bowen klein Walingen, wat hooger in 't gebergte, alzoo atle de tridere hivizen dezer Hofiteden am ftrand leggen, hoewel de Nootcribafichen al mede of in 't hangen wan, of bowen op 't geberge zyn, heef men het Perk Oriatun, of Orontaten, dat als bowen in 't gebergte witkylst. Het is 7 ro roeden grom, lewert 6000 ponden Foclie, hedt 102 flawen wan nooden, hoewel het maar op 64 zielen gettele is, en wert gefchat $10000 \mathrm{R}$ des witrdig te $z$ wn.

Beneden ann itrand weer woort gande, hoewel menatniltonts al egen "r gehergre is, en mar ecn forolle weg er langs hecti, wolgt natt ann klein Walingen, het Perk grom Walingen, een tchoone plants, zynde 1 t 400 roeden groos $\mathrm{Zy}$ levere jaralyks 8 of yooopond Foclie, vereilcht toe hat dienft ro flawen, luewel $z y$ matr op 70 zicken bekent that, en wiert gefchat toen 1 jooo R des wardig te zyn. Hier plage in oude tyden een groote Nerry, en cen zeer leerke handel van Foclite 
Foclie en Nooten te zyn; cn men wond er in " $t$ jar 1697 . nog een groot atrker wau een Portugeefehe Carake voor lteggen; ook plagt hicr ontsent "t jart 1630. nog cen Reduri te wezen.

Natt hicrann legt het Perk, Spantjeby genaant, 't gecn mat het Perk, Calla Boola (dat is, houdde mond toe, doch cigentyk Keli Woko, 'E geen in 't Bithdaneefch de Wolkberg bereckent, on dat het vecl met wolken bedekt is) dat ten decle boven Spiantieby, ten decle boven Cay Tortorte, en aldus mede wat bowen in 't gebergte legt, an 2000 roeden groot is. Het levert parlyks 3 roo of 4000 ponden Foelie, en ('L geen ecns voor al wan alle de Foelie-leveruntien gezegt zy) wiermal zoo vecl Noorea. Het heetr 60 llaver, is 80 ziclen ftetk, cin zyndeze chec woot $10000 \mathrm{R}$ der, wh ook wel voor minder, verkofer.

Dit Oronurce en Calha Booki, guam in 'e jarr 1687 , de Weduwe van $N$. Kages; docli Spanajeby toen, gelylì wok Cay Tortotre, cenen Jaob wan Cordan (anders le Faucbour genaane) toe.

Na Spatrtjeby volgc Cay Tortorre, dat ontrent in "t nidden van de binnenzyde legt, en mynes oordeels een van de fratifte, grootle en woor van geheel Banda is. Het is 1 soo roeden groot, levert dat eens 6000 , dan eet1s roooo ponden Foelie, en "t werd mat op 80 ziclen gefteld, hocwel 'er' 170 flawen toe behooren. Het is laetlt woor I3000 Rdes verkogt; en in ' $\mathrm{cjatr} 17 \mathrm{I}$. wierden 'er 15000 R ders voor geboden.

Naaft her and kont men wan "t Perk Combir, on "t jaar 1687 . wan eenen $N$. Prutbry bezeten, mede exn fehoone en vermakkelyke plats, te mecr, dewyl hier de hoofdbron is, wan war $2 y$ alle hun drinkwater, zoo wan dat Eiland, als wan al de anderen, gewoon zyn te hallen, loopende gettadig mee een fraje lrian, zynde de eenige plaats in ganlch Bandit, dar men zich, nict in oen rivier, mat onder den chup san die alcydloopende kman, doch buiten de Pagger, in een put, zoo diep, dac men "cl tot zyn middenlyf in Itat, walfehen kan, war in zich echrer de Bandarche juffers alzoo ved konnen verheugen, alls of zy zich in den. Fritichen en beldenfwlietenden Ambontehen Olifint, of WayTomo, gewallichen hadden, hoewel tret wonderlyk ved yan den anderen verlchilt. DitPerk is 1200 roden groot, Therr 4000 pond Foedic, heeft 100 thatwer, fehoon t matar op bf zielen geftelr is, en is pooo Rutss wardig. Men heeft hier ook een Reduic, watr op ecnig krygsvolk, ter verdedifing van deze algemeene waterplats, hegr. Wie de zelwe gcbouwt hedt, of wantecer zy datr geplatitt $z y$, blykt nergets, nutar wel, dat zevry oul is.

Naaft hice now rolgt het Perk Rane, of Ranin, "dat in "t juar 1687. doon" $A$ M Fermace bereen, en $1+$ po roeden groot is. Het levert poos pond Fochie, vereichte go tlatwen, fchoon het mitar op rf zicten geftelt werd, ch was toen toobo $R$ den wardig. Het is mede cen fehoone plats, miar zy legt juift zoo anngenaan op 'c gezige nier, als de 3 of 4 liatflgemelde boveden tain terand geplatitle l'erkẹn.

Hicr nn, of matr een weingg verder, kont men by het Perk Colamme, at Celanto, dar by Pierer 7 bysten in "t jatr 6087 bezecen wiert, enzzos roeden groot is. Heflewert 4000 ponden Fodie, vereilche 70 llaven, fehom her mar op 64 ziclen

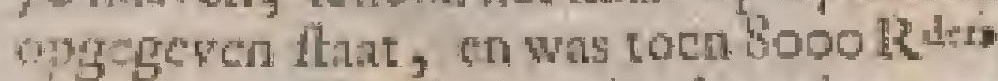
watedig. Het haris, dat beneden nat ftrand, enool tendelen tegenden berg nugchouwe is, gelylit wel cen kicine Reduir, en men zou het, des noods, 'er voot konnen gebruticil.

Dic is hes latte Perk and de binnenzyde, alwair" 't had zich als met cen hilwo Matn wan "r Oofter na 't Noorden ondratid, en echen hoek makt, die gemeenclyk Tandjong Bocrong, of de Vogelhoek genaimt word, die al wy hoog, en gevarlyle is, om met ecn Orembaey wooby te waren, nls men àrer hand na de Perken; an die kant leggende, zich begeven wil.

Wanneer ner nuwerder nade Perken, wan de Zuidzyde van thet Hooge Land, dat de Perkeniers agter land noemen, te land voortreizen wil, moet men ecen frajen heurel op, een tocht, dic men gencenclyk te pard, matr met reel geWatt, doet, om dat het een legte en vry feile weg is. Bowen opdien heuvel heef men een dubbele Reduit, in ${ }^{5} \mathrm{t}$ jar $162 \mathrm{~b}$. door de Lindwooge, de Heer Vhat, gebouwt, en ran cenigk krygswolk voorzien, zoo dat het that die. Noordzydie des lands voor vicemdelingen nict wel mogelyk is, on binnen te komen, of te landen, anngerien 't gelchut van Lonthoir" het Welter-, endat van Celanine het Ooltergat, gelylet de Reduit Combir hec midden, bellyyt.

Van Celanme nu boven op 't gebergre voortydende, on ager land te konen, is men genoodzank die hoose en. Itcile hoek der Wogeicn, langs een pad, dat niet baven de rwec vecten, of datr ontrent, breed is, zoodanig vootuy te treliken, dar men ter vechier hand het zeer theil gebergte als tegen zyn lichan beet, en ter linker hatd theil neder in zee, en op yflelyke rotzen ziet, dae cen vervarly] fezige, en cenverichrifliclyk denkeda, vooral an yemand, 


\section{B A N D A.}

die dat eerft voorkomt, geeft. Het / Eilands, dienende wel mede, orn vreembette hier wan is, dat die yfielyke fmalle weg niet ling duirt, en dat men'er in 20 of 30 treden over is.

Hier van daan daalt men allengskens, door heevermalselyk Nootenboich hecnrydende, na een plats, de Knorpot gentamt, dar ook eet klein riviertje, hoewel yan zeer weinig behung, en de weg ook zoter moejelyk om op en af te ryden is ; bnedanigen moejelyken weg men nog wat verder op, eer men Dender bereikt, heetr.

Men komt dan al verder, door het bofch benen, opeen gelyken weg, daar ons, onder de Nootenboomen rydende, de fchoone Nootenmufchaten dikwils tegen het rangezigt, op geen onaangenaame wyze, anquamen, en op welken weg wy, na een uurtje rydens wan Celamme, na dat men langzaam, of hard annryd, de Reduit Dender, daur ook een klein rivicrtje of fpruitje is, paflecrden. Dit is medecen oude Reduit, van welke men in 't jaar 5627. al in het dagregifter der E: Maatichappy leeft. HeE heugt my zeer wel, dat ik de Perkeniers, daar ontrent woonende, heb hooren zeggen, dat de Landwoogt, de Heer Willem Yanszami Admiralal, de zclve zou gebouwt hebben. Het legt digt by de zec, en dient, om met zyn gelchut en krygsvolk, alle vreemdelingen te weeren. Digt by deze Reduit legt het Perk Denner, bok wel den ouden Denner, en door de bank Dender genama. Het is t 100 rocden groot, levert yooo ponden Foclie uit, en 't vereilcht, fchoon maar op fo zielen bekent, 80 farwen, zynde toen op 8000 R dess gelchat, car in 't jasr I 687. wan Jacols Mhertfe Exling bezeten. Het huis legt mede dige aan zee, hoewel 't Perls zelfs too ata "thoogfte gebergte des lands, Chaiteleins hoogte genaamt, zich uititrekt, alwatar men zeclfs moestuinen heeft, waar wan ik vericheide maalen falade, door een Alaaf byna van den top des bergs gehaalt, gegeten heb.

Zces digt hier by, doch een wweinig meer landwatrt in, legt het Perk Dennel Hoetan, dat is het Bofch-Denner, genamut, zynde rzoo roeden groot, en in 't jaar 1687. door $N$ : Casis bezcren. Het levert 4000 ponden Foclie, en ftat maar bekent op 45 ziclen; doch heeft Go fladven van nooden, en wierr toen op 7000 R'der gelchat.

Een klein latif uurtje werder rydende, komt men by de Reduit Wajer, die al vry fterk, en zoo oud is, dat zy in 's Compagnies digregifter, newens de Reduiten Denner, en die vas Poclo Rhus en Rofingein, genelt wert $\mathrm{Zy}$ legt als in 't midden van de Zuidzyde dezes

II T, DEE: delingente weeren, mar dit Agter-Land is van natuure, vermits 'toweral slippig is, zoo fterk, dat zelf geen Urembaley, als de Perkenicrs het mer hun eigen volk matar beleren willen, hier ergens zou konnen ankomen, al'zoo 'er geen baayen, daar varttuigen konnen blyven leggen; en man zeer weing platzen zyn, daar zy kotinen aarkomen, Ichepen kounen het hier ontrent nies houden; ja zelf hebben de chaloepen, die dar de fpeceryen innemen, groote mocile, om dat, al af en an houdende, zelt by handzaum weder, te doen.

Hier legt mede een Opperhooft, on de speceryen te ontfangen. Het is een onderkoopman, en zyne logie, of wooning, at vry net.

Het eerite Perk, dat men datr heeft, wert Babi Mandi (dat is het Verken wafcht zich) gename. Het is 1200 rocden in zynen omtrek, levert 7000 ponden Foelie, ftat op 't getal viln 40 ziclen bekent, doch heeft 7 oflanen wan nooder. De Perkenier, die het in 't jaar $17 \mathrm{tI}$ bezat; hald bet yoor $7000 \mathrm{R}$ dero gekocht, mate "t was toen meer watrdig, gelylk hy het ook voor 10000 Rdera verkochr heeft.

Hier was te dier tyd nog een Perk, in verfcheide parceclen beltarande, ent toen door ecnen de Moer bezeten, diens hoofdnasm my onbekent is. Het is 3000 rocden groot, levert 7000 ponden Foelie, heett yo flatwen van nooden, hoewel te maar op 6f ziclen ftaat, en is 11000 $\mathrm{R}^{\text {ders }}$ wanardig.

Dar was toen nog een Perk, vancenen Sheewors bezcten, doch my mede in naam onbekent, dat 840 rocden gront was. Het leverde 2000 ponden Foelic, had 45 Haaven, fchoon dit Perk maar op zo ziclen gerekent ftont, en was 4000 Rders watrdig.

Men heeft hier nog een Perk, Boeton gename, "t geen 700 rocden groot zyne de, 3000 ponden Foelie leveren kon. Tot her zelve behoorden 44 flatwen, hoewel 't maat op 30 ziclen gerekend ftont, en "t was rooo Rders waardig.

Wat verder oprydende, kome men, nà 't pafieren van een moejelyke platsts, by cen P'erk, de Laoetan, dat is de groote zce, genaamt. Dit is zooo roeden groot, levert 8000 ponden Foelic, heeft 120 flaven, fchoon 't maar voor 48 zielen bekcrt ftaat, en is 13000 R ders waardig:

Nog wat verder, komt men op Oerien, das mede cen vry onde Reduit is, de welke de Prefident 'fan Yan/z Vi/fber, in de jaaren 1628 . of 162 . gebouwt heeft, en die daar om de zelve reden, als al die andere Reduiten, geltele is. Hier wond ik in ' $\mathrm{f}$ jal 1687. een-final Opper- 
hoofdje Eny Cmipptsis, zynde cen AfIftent, die onder "c Comptoir Lonthoir behoort.

Men heeft hier mede ecn Perk, Oerien genamint, doch beftainde in wel 6 of 8 kleine Perikskens, waar van "er zommige 100 , andere 200, 300 en 400 ponden Foclie leweren.

Ook is'er een Hoofdperk, Toetra, na cen fteilen hoogen berg, genaamt. Dit is 1400 roeden groot, hoewel het meeft wild en woeft land is ; het levert 3000 ponden Foelie, heeft 35 thatwen, doch that, nog volgens de oude opgawe, bekent op 80 zielen, en is 4000 R ders watardig.

Dit Perk van Toecra zal ik wiet licht vergeten, om dat ik met cen Perkenier van Lonthoir, op zekeren namiddag ten 5 uuren van Ocrien te pard dien berg opreed, na zyn zeggen itat makende, om ontrene 6 uuren op Lonthoir, matr "tgeen ons felitikkelyk buiten onze giszing ging, te zullen zyn.

In topklimmen wond ile den berg zoo fteil, dat wy, wat hoogergekomen, wan onze parden aftygen, en die aun onze flaven of bedienden, zoo wy niet van bover neder wilden tuineten, geven moeften. Wy klauterden dan een ltuk weegs te voet den berg op, en gingen toen wel swoder te pand zitten y mar, een weinig voortgereden zynde, vonden wy zoo weel Nooten- en Vrugrboomen omgewaid, dat het byna onmogelyk was om "er te voet, ik litat ftan te pard, door te geraken. Zoo lang liet ding was ging het nog henen, mast toen het donker wiert, gaf ther een elendig leven yoor ons, en nog weel elendiger voor ons volk met de pararden, om over deze boomen te kliuterten, en de weg te konnen vinden; watr door wy wan de zelve getwed enal afdwailden, en cerft ontren: Io uuren "s naches op Lonthoir, en de parden wy later, anquamen

Behalven dit Peik Toetra heeft met op Oerien nog het Perk Sammeren, aldus nat het aloud Bandanees ftedeken, Sammer, dat ook datr ontrent lag, ge. name. Het is sooroeden groot, levet 5000 ponden Foclie, heeft 40 flaswen, en 45 ziclen tot her zelwe behoorende, en wier toen geoordecle fooo R ders wardig te zyo.

Een wenig verder Welt op plagt men in "t jat 1657 . en later, de Reduit Lakoy te hebben, en hier ontrent was her, datde Nederkanders den 2 Ifen Maart 162. dit Eilard eert beklommen, en verowerden.

Als men den Wefthock dezes AgterLands, of der Zuidzyde, om, en zoo Noorden ann gat, komt men by het oud Madiange. Dant na paffecrt men die vermaarde klip, Batoc Holland, dic wy bevoorens, boven op Lonthoir zynde, belchreven. En als men, nog een ftuk weegs woortgande, woorby de Noordwedthock dezes Lands rehept, komt men weder voor Lonthoir

Bowen op den berg wan Lonthoir heef men al mede cenige Perken, alle welke ik juilt niet by haare eigen namen, matar by die van hare beziteers kenne, en die it derhalven hier ook zoo zal opgeven.

Men heeft "er een Perk, in "t jaar 1688. by eenen Latharis bezeten. Dit was z 200 roeden groot, gat jarrlyks 6000 ponden Foelie, had coo liaten, hoewel 't matar voor 60 zielen bekent itont, en was $10000 \mathrm{R}$ ders wardig.

Het Perk wan Lutas Claasz de Fong, 1000 roeden groor, leverde 7000 ponden Foelie, had go flaven, hocwel in de zielbefchryving mar op roxiclen geftelt zinde, en wiet toen $\mathbf{I}$ I000 $\mathbf{R}^{\text {ders watr- }}$ dig gerehat.

Het Perk wan Tbowas Brastszon, ontrent het kaftecltje Hollandia gelegen, was 1200 roeden groot, leverde 8000 powden Foelie, had 1 io flawen, fchoon matar op 60 zielen ingeboekt in de zielbefchryving, en was een fomme van 12000 Rder watrdig.

Het Perk van ? Roos, whs to00 roeden groot, heverde 5000 ponden Foelie, had 60 llawen, ftont ic boek yoor 40 zielen, co was yooo $\mathbf{R}^{\text {dexs }}$ wastig.

Behalwen deze groote, zyn hier nog wel zs kleine Perkeniertiens, die maar 6,8 of Io ziclen hebben, en ook cen cvengematigde leleine leverantic van ipreeryen doen, hoedanige 7 of 8 kleine Perkskets ook nog op Celamme zylu.

Van groot Walingen af, tot Celarme toc, leweren deze Perkeniers hunne lpeceryen op her eiland Neira, annden $O_{\mathrm{P}}$ perkoopman, of tweeden perfoon der Lindwoogdy.

Van klein Walingen af leveren de Perken Ortattan, Bojuww, en de verdere Perken op Lonchoir, an 'cOpperhooft tot Lonthoir, en men rekentze groot en klein, hicr onder behoorende, op $3 x$ Perken.

Die wan Denner, Denner-Hoctan, en van de Laoctan, leveren op Wayer, en die van Oerien, Toetra en Sammeren leveren ann een Bockhouder aldaar, die onder Lonthoir mede that.

Men hecf in Banda tweemand "s jats Het wat Witwater, het eertte, of 't klem Wic- water. water, in Juni, en 'tgrootfte in Auguftus of September. De zee is dan by dag even eens als anders; maar' 's naclits als witce melk, cn zelf is do lugt datr zoo licht van; dat men geen onderfoheid tuflehen de zee en de lugt ziet. Om "s nachts 
"s unclits land te onteklien is dit wiewater zeer goed; wane in "tzelve doet zich dat zeer lwilt op. In al de yyd werd 'er' geen vifch gevangen; doch dar nawet zoo weel te meer. De vifeh is yoor dit helder water fehuw; ook doet hen die helderheid in "t water het vilchtuig cal de

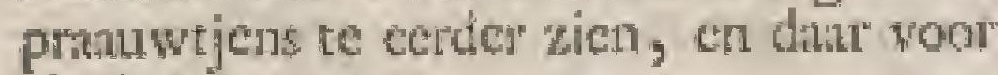
ylieden.

Men oordeclt, dat div water uit den grtooten boezcrn wan "c Zuidland by Nova Guinen komt. Men ventement het in "t Zuiden van Aroes en Key ont 'Tenimber' en Timor' Lnoet, In "t Weflen loopt het tot Timor, en in "Noorden vertoont het zich tot het ciland Ceram ontrenteszelfs Zuidkult, loopersde niet Benoorden, max wel Beztiden de Liaferze eilinden, en Amboina, dar men die. melk-zee kfaar wan de bergen 's nachts ziet: want nuders en weet men wat dit wic water cigently in Amboina niet, dan dat men luet in 3t jatt 1656. 'er cens geluad hecfe, dat zeldzan was:

Het tertoone zich meeft ontrent de eihaden van Banda, en is niver alleen quat woor de vilchwang t, mar doet de varrzuigen ook ecr, dan in ander zeewntel, vetrotten; zoo dit 'er in de vuikardige quallen, bezantjens, en andere zeellym, die dit warer, als "E afnecter, op ftruid opwerpt, een booze houtworn fetyyt te zyn.

In de tnd van dic wit water is 't ook gevalurlyt zich des naches met kleine of shdete varturigen op die zee te begeven; wane fchoon het al ftil zyn mogt, yernectot men nogtith zect fware dyairgen, die door deze en gene zeedamper, uit de grond der zee opwellende, wan zelf voortkomer, en zulk een wartuigje zeer ligt zouden omwerpen. Deze dyningen echier liceft men jecgens zoo fwar, als ontrent het eilard Tenimber".

Dit wit water menge zich in die thd met geen stuter water, dan alls het bogine af te nemen, wanthect hot cerft langs ' 5 cillund Ombo on 't land wan Ende henen loopende zich eindelyk met diteepen in zee tot by Boeton toe, en daar na zelf tot Salcyer en die letht van Cclcbes zien fart, dau het zich dus allengskens in "t ander zecwater verlielt, of dastr mede vermengt.

Nadit nti dit wit water, en de regen, in Banda lswetr of weinig is, leveren de Perket ool ved of weinig Foelie en Nooten uit; want zon 'cr fwhare tegen valt, wallen de Nooten af, die maders $y$ milanden aan de boomen moeten langen, 't geen men echter meer bowen in het daunpig gebergte, dan ontrent de ftrnden, werneemt.

De Maven in yder Perk winden den ganchen dag hun werk.
Als de Nooten. ryp yyn, en an den it werk boon beginnen te fplyten, zoo dat de der HazFodie zich fichoon rood van couleur, en ven in al glimmende tegen de Nootenfelial, Nouterdic kool fwat is wertoont, don gan pet de thiven van 's morgens wroeg yder met ecil mandeken na 't bofch on Nooten to plukfen, komen in 't geueen 's awonts ten 5 uaren พan 't gebergte tw beneden, alwh'u' dan cenige al deze geplukte mandes met Nooten, of eigentlyk die Nooten in haren bolfer (Joch nict anders dati oude) over cen zec foherp mes, dat elgens an $f t y f$, of tegens twee louten, in de grond itatude, waft gebonden, en dicus fcherpte nh bowen gelegt is, zeer gefwind (dat een flug is) henen halen, en dus die boliter, by een omwrikleing, tot op de Nootichale toe, klooven, en "er dus de boliter afwuecken; "t geen met weel oorded in "t werkiezen der Nooten dient re gefchiedera: want zoo "t cen jonge Noot was, die 'er zomtyds ondeloopen, zoo zou de finede door de Noot, en alles, henen gat, en den was het ook om ecr winger of twee van zoo een flate re doen; doch datr werd al vry wel op gepalt.

Ais al die Nooten zoo ontbolftert zyn; werpt men de zelve met de Foelie "er nog wan in cen mandeken, en dar na vergadert men de boltter op een hoop, wat. op dan cen foont van champignons of paddeftoelen groet, die gezege werden door hatren 1peceryigtigen fmak alle andere paddeftoden te bowen te gann. Inmers, zy worden in Banda van de liefhebbers en kenders zeer geprezen; doch ik lueb datar zulken lckkerny nict in geronden ; matr wel, dar de Noorenbollier", in riempiens gefneden, en met kan ncel geftooft, cen lek-kere fehotel ceten uitleverde.

Wannecr de Barren nu met het ontbolfteren van alle die Nooten by dig nog gedan krygen, dat $z y$ in I of 2 unten weten af tehadpelen, dan is 't hun avondwerk nog de lioelie van alle deze Nooten af te doen, die byzonder we vergaderen, en ook de Nooten byzonder by een te docn, wiar wan de Foelic dan in de zoll gedrooge, en met de Nooten op de nthvolgende wyze gehandelt word.

Men heete, kleine hokken of petak-Hoc wetken, met een parapara of zolderken wander met latwerk van gefplete Bamboezcn, ofte Nouten, rieten, watr op de Nooten, die dan nog handel valt in cen fchelp zitren, gedroogt wor-word. den.

De ectfe droogperale is voor de natte Nooten, die daur een week in moeten leggen, cn dan gan zy in de eweede petak, weer voor cen week, yan daar un de derde, wecr voor een week, en in de vierde petak worden $z y$ in de vierde

$$
\text { B } 3
$$


week wolkomen droog. Dan gaan $z y$ in de wyfde petak, onder welke wat minder" droog vernoliemt hout gettookt were, en eindelyk in het zesde, of het groot hok, waar ontrent zeer Hatuw geftookt word.

Onder alledeze petakken, of hokken, met hatare doorlugtige zolderkens, wond een matig vuur geltookt, niet min iets te branden ; matr enkelyk gerigt om de Nooten, die 'er boven op leggen, wan binnen is thatre fehelp zondanig te doen droogen, dat zy in de zelve beginnet te rammelen; die dara na dan, 3 of 4 weken woor de levernntic, in ftuk gentigen, de Nooten date uit genonen, en weer in vette, middclbaare en mugere geforteert en onderfcheiden worden, om ze an de E. Maatfchappy, yder op her Comptoir, wat onder hy behoort, te leveren. Dit droogen gefchied in 6 of 8 weken gemenclyk, blywende dan de Nooren nog wel's of 6 weken onder de Perkeniers.

Het groot gewalch, dat in Augultus of September, hoewel ook wel eens in Mey of Juni, valt, en wel een quart meer, als "tkleine geeft, wond ontrent half' December'; co 'c kein gewalch, dite ontrent Maart of April walt, ontrent half Juli, in de voomoemde driederlei foor ten afgelewert, volgens welke leverantic yder byzonderc foort vis Nooten, in een mandje, in een doorgezangde legger met zecwater, dat met kalk zoohning gemengt is, dat zy, als verte melk, er pas anhangen blyte, driemal ingedompel, endun zoo ook yder foort in een byzonder Nootenhok geworpen word, war in zy zes weken digt toegefloten blywen, on te fweeten, in al welken tyd men 'er niet eens nit omziet, en das na (alzoo de kalk de fouten der Nooten ontdekt) werden zy weer in goede en quande, of ith dic drie woornoemde foorten onderfcheden. De Perkeriers nogtans lyden hier by niets; matr worden wolgets bare gedane leverantic van vete, middelbatre en mugere Nooten, betinlt, en deze latite fortering loopt yoor rekening der E. Matitchappy. Indien 'er te ved kalk by dit water gedann wiert, zouden de Nooten "er in verbinden, "c geen een giootc fchude an de E. Martchappy zou konnen geven. Dit indomplen in de kaik getched, on dat de kalk de geeften der Nooteti door 'E fluiten yan der' zelver pori, of uitwazemganjens, inhoud, en die niet atleen tegen "t verderf bewaart, en der zelver gebrekes ontdekt; mare zulk cen gekalkte Noot kan ook nict verplant worden, om dat zy geen fchelp heeft, alzoo zy niet anders, dat in hare fehelp, groejen en woorzetten kan. Ook moet de Noot, als zy verplant wort, nict geheel onder, matar bowen de arde leggen, of zou anders niet groejen.

De Foelie, gedroogt zynde, word mede in drie foorten, te weten, Klimfoelie, zynde de befte en van geplukte Nooteu, Raspfoclic, diede twcede foort en van afgevalle en opgernapte Nooten is, en in half rype Foelie, onderfeheiden, en ook zootanig an de E. Martichappye gelevert, die voor de lakt fite foort, Gruisof Stof-foclie genant, mat de helft wan de prys der andere Foclie betalt, hoedung zy ook met de betaling van gebroken Nooten, fchoon ook nog zoo zeer doorgegeten en vermolmt, handelt, gewende ook daar woor mast de helft wan 'r geen zy voor vette, dat is, gladde en gave Nooter, zonder rimpels, en ook voor de middelbare en magere Nooten betalt. Er fchoon die vetue Nooten zoo genant worden, gelyken egrer de middelbaete en magere van buiten veel verter on olingtiger, fchom zy meer, dan de andere, gerimpelt zyn.

In voorige tyden, ontrent 18 of 20 jaren geleden, plagt men tnet het wegen en betalen dezer fpeceryen anders, dan nu, te leven.

Men rekende dic toen by zoo veel Catt; Bandan, of Bandatche Carti 's, yder s/ Hollandfehe ponden fwatr, en de Nooten woog men by weegzels, yder wan 28 Catti Bandar, of $16 \mathrm{I}$ Hollandliche ponden, dat net met het gewigt war cen lokkil (zynde butijens wan matten, of boombladen, war in de Foclie alleen gemecrelyk overkomt, en in welke zy op dat gewigt afgetrapt, hocwel matr op i6o pond gerekent word) overeenkome. Men betalde toen voor zoo een Catti Bandan Foelie 2 gulden I 4 Ituiwers, ligt geld, of 60 lige ftuiwers, in een Rylsdaalder wan 48 fware ftuiwers gerekent; maar dan was'er de tiende van de $\mathrm{E}$. Mantchappy, dic ontrent "deel bedratagt, al afgetrokten, zoo dat het 42 ltuivers bleef. Ook ontfing men die zelve prys woor 10 Cacci Bunda Nooten; of $5 \frac{y}{4}$ pond yder:

$\mathrm{Nu}$ in tegended ontfingt men voor yder 1 oo Hollandiche ponder goede Foelic van de E. Matichappy if Ryksdaulders en I8 ftuivers; doch voor Stof-foelie, hoc flegr ook, 7 , Rylssdanlders en g fluivers, dus koft hat een pond Foclie 7 , fluwers, en zy verkoopen die weer yoar 3 guldens 12 Itulwers, en woor ro pond Nooten krygen zy ontrent zoo veel als voot I pond Foclic; en dus voor rooo Hollandiche ponden Nooten, of wyf weegzels, fer wan 200 ponden, "I $z Y$ wette, nid" delbatre of mageje, oole is Ryltsdatlders en 18 ftuivers ; doch voor dat zelwe gewigt gebrokenc en doorgegetene 
Nooten, mede matr de helf wai die prys; en dus koften hatr 2 pond Nooten iftuivers, dat $z, y$ i pond vont 2 guldens 18 ftuivers werkoopen. Een groote overwinft.

De E. Matichappy, als Landheer hier zynde, plagt in voorige tyden ook wan atle andere vrugten der Perkeniers de tiende te trekken, behalwen dat zy nog de tafel des Landsvoogts wat vitugten woorzicen moeten; maar dut is afgelchafe, en de ticnde is alleen op de ipeceryen gebleven, welke gemeenelyk twecmal, en ook zomtyds wel voor een enkele reize dricmal, "s jars geplukt worden; doch watr op geen valte ftat te makacen is; matrir wel op twee gewaflchen, een groot en een klein, gelyk wy hier wooren reets gezegt hebben:

By verkooping der Perken word mede de ticnde an de $\mathrm{E}$. Matifchappy, miar zoodinig betali, dar zy wan een Perk, rooo $\mathrm{R}$ ders geldende, mat de tionde van de helft betalen, alzoo 't ander woor de goederen, dar toe behoorende gerekent wort, welke goederen zy beroorens verte boven hance warade plagten op te geven, en dan naar mate van dien veel te weinig man 't Perk zelf te betalen, 't geen nu dus gematigt en gemiddelt word.

De Nooten woert men in geen fokkels over, als de Foclic, mar zy worden in hokken overgebragt, vorder op de wigt overgelewer, met een per Cento afflig; mat de Foelic levert men by fokkels, zonder ecrigen utiflag, newens wolke aleyd een brictje, met de namen der gecommitteerden 'er by, overgat. Men doet ook by yder fokkel, of deszelfs bliden, ontrent 3 kannen zeewater, volgens ordre wan batr Edelheden wan den $4_{4}^{\text {fter }}$ December 's jars 167 . whar mede zy gemengt zynde, zoo word de Foelie 'er dus ingetsap, endit oordeclt men tot behoudens der zelve te dienen. Een fokkel Klinfoclie heeft drie ooren. Een dito Ratpfoclic twee, en icen dito Gruis foelic matr een oor.

Het plagt in oude tyden met het koopen van deze Perken wry flordig en tlegt toe te gatan. Yemant, die wan cen foldate man" een rryman geworden wis, en geen duit in te wereld hal, wiert anftontseen Perkenier, en kogt een Perk van 6000 of $8000 R^{\text {sets }} \cdot \mathrm{Hy}$ nam de helft van den armen op, die hier al wry ryk is, en de helft bleef op bet Perk ftan. Daar op wis hy aanilonts ecen groot Hecr : want zulk een Perk gaf wan zyne fpeceryen een traje inkomft; cn de verdere vтugeen, brigten by verkoop ook al wat op; behalwen dat ${ }^{3}$ er nog 20 Perken het woorrecht alleen hebben, om Arak te mogen branden, en die aut de
E. Matichappy, en andere, te leveren. Als zy nu mar zorg wool de renecn wan de hoofdlom, die zy voor "t Perlk gegeven hadden, drocgen, zoo waten zy gewoon wan "t overfichot als Puinsics, en dit in een tyd, dat de Perken in zig zelven nog zoo veel niet waren, alls zy naderhand geworden zyn, te leven; war door 't dan by hum overlyden ook wel gebeurt is, dat den armen, en underen datar by fchade leden, yoor al wanneer zy zulle cen Perk verie boven zyne watrde ingekocht hadden.

Jegenwoordig zyn de Perkeniers ury vermogender lieden, vermits hunne Perken, door hnine groote nartipheid in het anplanten, merkelyk in waitde verbetert zyul.

Wannecr de Her Birguanter ontrent. 't jan 1700, bezitter van klein Walingen wiert, gaf dat jaarlyks 3000 ponden $F$ oelie, doch alzoo hy en narrtig man in 't auplanen wis, gaf het, woor dat hy uit Bandit vertiok, en het an een ander overlice, 8400 , en taderhand wel 12000 ponder Foclie.

Men moet echer hier by zeggen, dat Banda in "t jant $17 \mathrm{I}$ t. zoo wel beplant en Hetleve de ftate van alle de Perken dar' zoo tref- Het feve felyk roed wis, en zoo weel opbngt, mosen als men oit zou kounen hoopen, miste- der Perzien 'er nu niet een ftukje lunds onbeplante kuess is. Dit geeft, an die groote Perkeniers voornamelyk, een vry groot inkomen, wat op $z_{y}$ heerlyk leven, en nog een Cchoone ituwer overleggen. Daar is niec lekkers. Wan fpys of drink, dat zy niet hebben, en zy zyn gewoon, voor al als de Rhepen wan Batavia komet, met de fcheepswienden, en mer die van Neira, en de andere Eilanden, wykelyk te galtreeres eu wrolyk te zyia. En' $t$ is geen wonder; want zy winnen "t rykelyk, en "t kan "er atf. Zy hebben de fchoonfle en vetfe fchatupen, die mien wenfelien kian, die zy van de Zuidoofter Eitunden kirygen, en verder allerlci vee op hatr eif loopen. Hollands bier, Luiks bier, Mom en keurlyke Wynen, wind men by hen zoo good en overvloedig, als by menig Landvooge.

Dit milakt bun ook, die wan ouds al de liatm en de dand, mint roen nog zoo voel magt nict hadden, vTy ltout; dat in zommigen nog verder gain zou, indien $2 y$ zomtyds niet wakkere flagen en tegenfpoeden, door 't wegloopen wan thatven, kreger ; alzoo 'er zomtyds 20 of 30 en meer gelyk (hoe Aterken wagt men ook 's naches op de wartuigen houd) met Orembijen komen weg te loopen, die zelden weesgekregen worden.

Al voor eenige jatren was deze Perkeniers toegeftatr, om 490 Macafiarze Gawen na Banda te woeren. Zy hebben

$\mathrm{B}_{3}$ 


\section{I4 B E S C H R Y V I N G E $\vee A$ N}

"er nu al over de 1400 gebragt, en zy baalen nog al, om dar getal wan 400 (zoo zy zeggen ) te vervullen. Hatr andere thaven hebben zy meet wa Nora Guinea, de Zuidoofter Eilanden, Timor, cnz.

Het befte, dat ons van de jegetrwoordige Butudache ingezetenca workomt, is, dat zy, "t zy Swarten, "tzy Mixtiçen, meett alle, goed Duitich fpreken, zoo dat zy Sondngs ook de Pralmen in die tan gewoon zyn te zingen.

In de tyd wan de Heer Jandwoogt wan Huante $Z$ wl warej en zommige ran deze Perkeniers vry ftout en weerbarlig. Wat dic Heer hen ook dede, en fchoon lyy mier anders, dan hun welzyn, zogt; hee was quand by allen, weingen utgezondert, en inen Ichamde zich nice zeer veragelyke vertellingen wan zyn Ed., en Van zyn fles twet de zilvere fohroef te doen, watar door zy zwn rotang mee cen zilvere knop werltondra, die hy wel zonyds een dronken arbeider en luinard in dientt der E. Martchappy orep den rug lei; doch naderhand zyn zy nog flouter en hoogmoediger geworden; man God heet hen zulken Landvoogt gegeven, die hen zon geplaage, getreden en getropt heet, dat zy wel duizendmial het gebeente van den Heer van $2 y / 4$ beweent, en om hem gewenf ht hebben. Een zat die wy hier no nog met een woord, als wy in het byzonder vun de Landwoogden van Banda fpreken, zullew anhaslers.

Nu zallen wy hicr nog een lyfje wan al de bekende Petken op "t Honge Land, met 'cangemerkte op yder Perk, fichets? gewyze byvoegen.

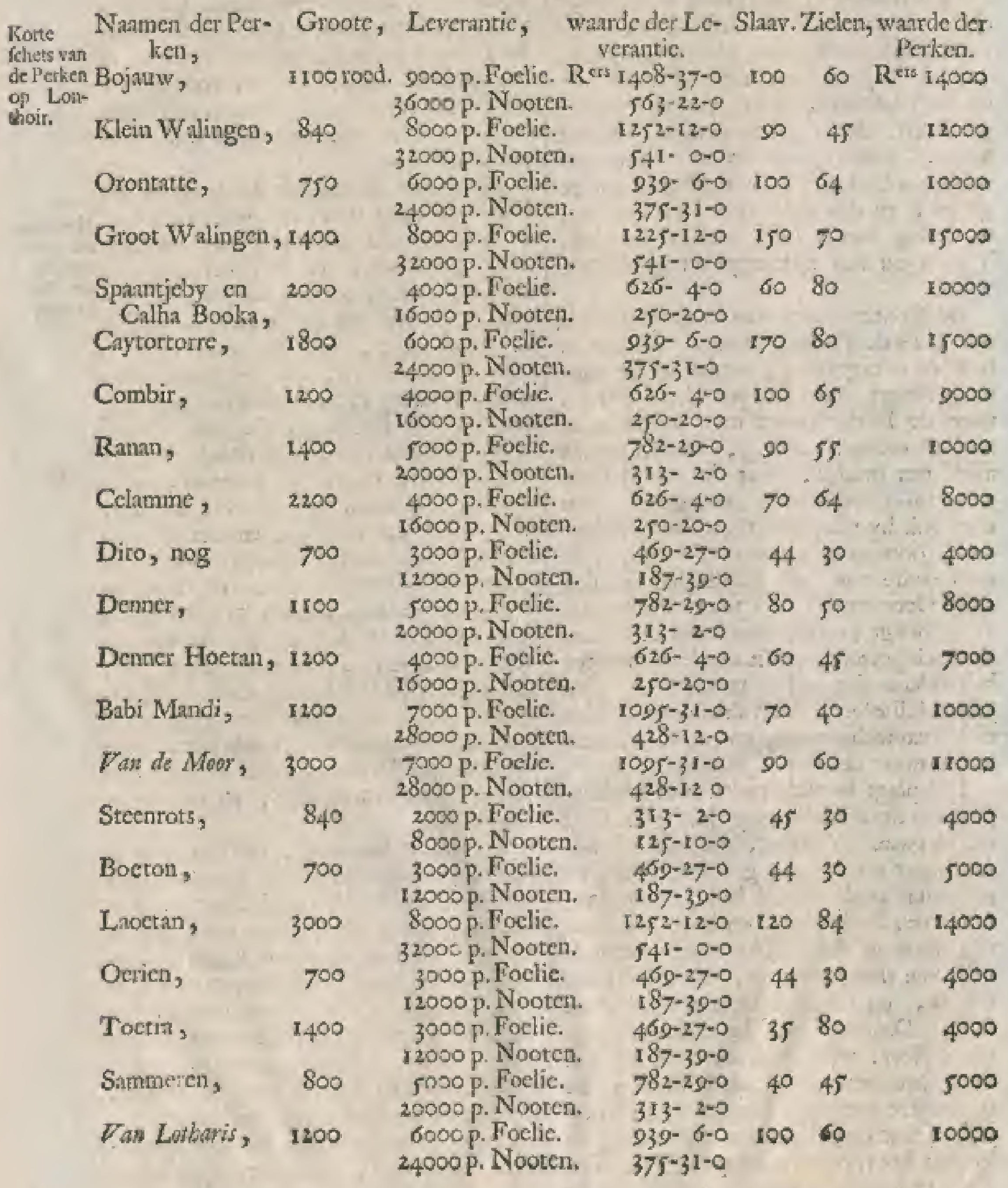




\section{B A N D A.}

\begin{tabular}{|c|c|c|c|c|c|c|}
\hline Lec: Classmen, & 1000 & $\begin{array}{l}7000 \text { p. Foelic. } \\
28000 \text { p. Nooten. }\end{array}$ & $\begin{array}{r}1095-31=0 \\
428-12=0\end{array}$ & 90 & 50 & I1000 \\
\hline Thow: Branda: & 1200 & 8000 p. Foelie. & $12 \sqrt{2}-12=0$ & tro & 60 & 12000 \\
\hline . . Roos, & 1000 & $\begin{array}{l}32000 \text { p. Nooten. } \\
\text { 5000 p. Foelie. } \\
20000 \text { p. Nooten. }\end{array}$ & $\begin{array}{l}541-0=0 \\
782-20-0 \\
313-2=0\end{array}$ & 60 & 40 & 9000 \\
\hline$=.+$ & 2400 & $\begin{array}{l}12000 \text { p. Foclie. } \\
48000 \text { p. Nooten. }\end{array}$ & $\begin{array}{r}1878-16=0 \\
791-20=0\end{array}$ & 200 & I 20 & 20000 \\
\hline & 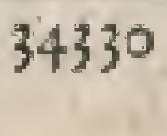 & $\begin{array}{l}142500 \text { p. Foelic. } \\
568000 \text { p. Nooten. }\end{array}$ & $\begin{array}{c}22227-6-0 \\
8796-22-0\end{array}$ & 62 & 143 & \\
\hline
\end{tabular}

Hier op latten wy nu tot flot van dit. Hoofdftuk een teekening van alle de Ban* daffche eilanden, onder de letter B. volgen.

\section{T W E E D E H O O F D S T U K.}

TEt Eiland Goenong Api beflareven. Whameer die Berg gebrand beft. Droevig H geval door den zelven veroorzalk. Berigt was Maurits Hendrikfz van der Spelt. Als mede wah. D. Feilingius en den Vaandrig Bufton. Groote Slangen, enz op dits Eiland. De Schans Kylk in de Pot. "Vrouwen-eiland, Des Schryvers admerkeng op de dood wan Plinius, en of 't gevar wan de Hecr Feilingius by zyn togt na dien Berg*

Het

Ejand

Gocthong

Api be

felurevel.

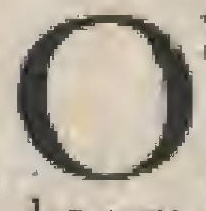

$M$ nu tot de befchryving der andere Eilanden over te gaan, zal het niet ongevoeglyk zyn, dat wy die wan de Goenong Api, dat is, de Vuurberg, in 't Maleits, laaten volgen.

Dit Eilandeken legt ten Weften van Neira's Wetthoek, en zoo digt daư ann, dat men over de opening, of 't kstraal, tuffchen Neirn en dat Eilind, met cen funkje val cen lei gernakkelyk wcrpen kati.

Dit gat tuffechen beide deze Ejlinnden noemt men gemecnelyk het Zonnegar, aan welkers Noordzyde een klein eilandeken, 'tV rouwen-eiland genaamt, is. Het plagt woor 100 jaares 20 of 30 vadem diep te $z y n$, zoo dat'er een fehip door kon, doch is nut te ondicp voor fehepen. Men wil, dat dit door 't uitwerpen was fteenen en afeh veroorzatke zy.

Ten Zuiden heeft het den Noorthoek van het Hooge land van Banda tegen over zich leggen, en word dat gat, tuffeben deze twee Ejlanden, zynde ontrent een gooteling felhoot wyt, gemeenelyk het Lonthoirs gat genaamt.

Hoe groot dit Eilandje in zwn omtrels is, weet ik nict, aatigezien ik het noit rond gefchept heb; mant gis dat men geen balwe myl er toe van nooden heeft.

Men had hicr op in oude tyden weel dorpen, en bewoonde ftedelens, an ftrand; dach ' $t$ is door 't menigvuldig branden des Bergs zoodanig verwoeft, dat datr van nicts meer overgebleven is, zoo dat ook der zelver numen al mede onder de afthe des Bergs geruaks, of met des zelf vuurdamp en froook vervlo. gen zyn.

Het ganfich Eiland is maar een dikke allengskens opgaande, en al redelyk in de hoogte verheven berg. Hy is net 5 g treden hoog; maar her hoogite gebergte op 't Hooge land van Banda, dat men by, en boven de Perken Combir en Ranan heeft, is 654 treden: want als men daat boven op flat, , kan men over de Goenong $A$ pi heen tot in zee zien.

Deze Berg is van buiten wel met een wild en woeft bofch bezet; maar in zyn biznente een Fchrikkelylic Vuurberg, die nu en dan ook affryztelyk gebrand heeff.

Het verfte geheugen, dat men daar af heceft, is, dat hy in 't jaar 1586 . en datar die Bers na woer 1598 , nan den top begon te getrand branden, en vuur uit te werpen, zooda- Geeft. nig, dat men dan eens de heldere vlam, dan weer eens een fwarten dikken damp, en dan ook wel eens cen lichtgnalauwe pluim 'er boven uit zag komen. Hy brande ook in "t jaar roog. toeu Verboe ven, onze Zeevouge, hicr quam; matr in het jatar $161 \%$ is dezen Berg, na ne al if jairen lang van binnen vry flerk gebrand te hebben, in Maart, juift op de zelve dag , als de Opperlandwoogt van Nederlands Indiën, de heer Gerard Reysfo, met zyn wloot uit Amboina herwaarts aan t'zeil ging, met zulken berte en geweld opgefprongen, en heeft zulke fwatare fteencu, en groote vuturwammen, ten decle na de zeekant, ten doele na 't eiland Neira, en na "t Fort Naflius, uitgeworpen, dat men, van wegen de 
menigvuldige afiche, dic "er in te Kaftecl. en op de Bolwerken gevalten was, de ftulken naulyks gebraiken kon, watr door ook dic vall "t Katteel-in gevast Aonden, oni van de Bandaneezen, die wan Lonthou', en andere platazen, ferle overquamen, overvallen te worden; dat door de komft van de vloot des Opperlandwoogts echter belet wierd.

De rehepen dezer Floot ontnoetten toen, ecr $2 y$ ecrs by dit Eiland guamen, ftukken gebrande fieen, uit dien glocjenden owen gevlogen, van welke zommige wel en wadem lang, en wan zulken heir kleine puimiteen ontingt waten, dat men "er met een boot qualyk door kon komen. Ook ftont het water te dier tyd *an de wout wan die Berg nog en kookte, gelyk men veel viftehen, diedar in gekookt watren, drywen zitg.

Ontrent dezen tyd (gelyk woy hier ma breeder mullen zien) myo de Bardaneezen dit Land ten decle quyt perakt. GeJyk dit au by 'efpringen wan dezen Berg gefchied is, alzoo is "er by hume bygeloovige Nazaten nog een watte hoope en voorzegging, die heimelyk onder hen voortgezet en levendig gehouden wond, dat deze Berg nog cens fpringen, en det dan dit Land, goor de Hollanders zoo verovent, weer het hunne worden $z a l$, hoewel de tyd bet tegendeel geleerd heeft: wrint fclioon hy zedert wel gebrand heeft, is echiter bet Land in de magt der Hollanders gebleven. Ook zou mer moeite hebben, om een ouden Bandanees hice of dair rogg in een hoek te vinden.

Men zag toen, en menigte jauten " $\mathrm{cr}$ na nog, fwave hoopen van fchitkkelyke groote fwarte klippen in zee leggen, die, wel ecr gloejend uit den Berg geworpen zyode, zoo wan zyn top zyn komen afrollen. Het vur wertoonde zich niet alleen bowen in ' $t$ gat atn de top,

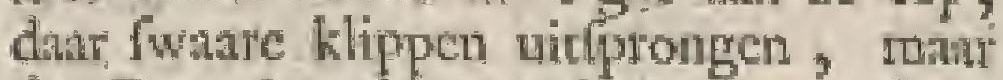
de Berg brandde rondom, en flocg zyn wainamen zelf tot wan de voet hier en daar doot fcheuren en openingen uit; war door al de dorpen, dic dast wel cet waren, vemiclt en verwoett zyn, zonder dat men datr weder nieuwe heeft durven anteggen; matr men heefe "er zedert cenige dhaven wat Perkeniers op: gelund, die zich daur, met thuinen man te queeken, battatas en andere buiggewaflen, ats ook kalappusboomen, wh te planten, bezig gehouden, en bevonder hebben, dat die gewallen op die ver= brande klippen, en onder dic puimfteen, zeer wel voortgroejen willen. Ook zyn die fwarte klippen, eer zy nog puimften geworden zyn, weer goed tot het matken wan muuren, aangezien zy de kalls zecr wel vatten, an vry drooge muluren geven.
Het gat boven in zyn top vertoondo zich na " $t$ Welter toe, en was zoo groot, dat men er luet gandeh Katted Naflu wel zon hebben konnen inzetren. Ats men 'er tocn birquth, wond then aan de Ooftzyde ran binnen zeer hooge, groote en fteile klippen, die.zich als muiren rondom zoo yerritúlyk opdeden, dat men fchrikte hier in te zien, anngezien men tich by dat gezigt als de Hel zeer levendig verbeelden kon. Echter zag men hier en datar op de grond in date gat toen, en ettelyke jazen er ni, gras groejen, 7oodanig dat men dar uit obldeelde, dat het branden niet lang duteren zou, hoctwel men vecle jmaren datr na Dog aldmpen, en cen zect ligte en heldere rook by rehoon weder daun uit wiegen en opltygen zag.

Als men in " $\mathrm{tgat}$ quam, dat rondom met afch bedekt whs, zalite men $70 \mathrm{~m}-$ tyds tot de knyen 'cr' in; matre het wonderlykifte was, dat men de wilde kocjen en werkens in dit gat her gris afweiten zag, gelyk aan de mift, dic men 'er Icg* gen vond, te zicn was.

Aan de zyden van dit gat zict men alomme, gelyk ook van binnen, in dien garpenden oven, de geele fwavel als werIytde antimosie nevens de witte fchumagtige alluin an die verwarlyke rotzen hangen. Ook brand deze fwavel wel, als $2 y$ by " $\mathrm{t}$ vur komt ; doch riet heel fterk, on dat zy onzunter is. De onkundigen, dezen ăhim ziende, houden die voor falpeter; datr nogtans veet natuurkundigen oordeden, dae de fwayel en aluin de regte onderatadfche brandtofte is.

Defchepen, win 't Weften na "t Lonthoirs gat komende, konden dezen oven, en zyn geele rotzen, gemalkkelyk zien.

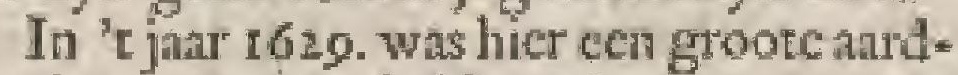
beving, en een half aur "er nit een wat tervloed, die zeer fwas was, en by thil weder quim. De zec werhicf zig tuffchent Celamme en Neira als een hoogen berg, die aan de cene zyde regt op i Kafted Nartar narwicl, alwatr "f water 9 wocter hooger dan cen gemeene lpringyloct, en "t Kalteel bitnen en buiten bilf vol, switter ftont. Het hooft voon 't zelpe, yat fware lteenen gematkt, whs, mer een groot ftule wan de barm, wweggellagen, gelyk ook veel fwame fteciren, door den Merzelar reeds toebercid, en een yzer ftuk gefchut van 3500 pond, op 't plein des Ralteels gelcgen hebbende, 36 wocten wath eyn plats werwoert was. Ook wierder werfeheide huizen, ontrent ftrand, in ftutken geflugen, en in zee gedreven, gelyle dat ook thuis wan der Fiscal

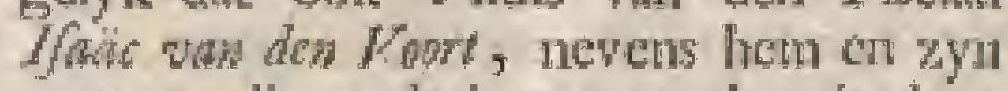
viouw, die mede in zee gerukt wierden, owcrguam, alwar by gebieven, doch zy 


\section{B}

\section{A}

\section{N}

A. door een andere bat weer op land gefmeten is. Het lchip den Bricl, dar leggende, draide alleen driemat rond. Doch op Lonthoin is mede een Fwat heofd nevens verfeheide dikke muuren weggefpocld. Het liep dati 13 voeten boven een gemeenenfpringvloed, vocrde een Jonk, ngter den hoek vin Madiangi leggende, regt agter de tteene logie; on buiren in zee witt men 'er niet af.

In 't jaar 1632. Fprong dees Berg weder, dat ook met verlcheide fware andbevingen verzeld ging. Men voelde de zelve vertcheide mal in de manden April, Mey, Juri en Juli, doch voor al vernam men den 16 dea December "s nachrs een vuur, dac uit den liemel viel, wan cen berfte, cerll cenige flagen, als die van een kanon, gat, en dair na als eenige chngien wan muskettery hooren liet ; war op den $27^{\text {flitu }}$ dito weet ecn fchrikkelyke rardbeving volgde, die an de huizen aldaar groou lehide deed. De Goenong A pi wierp klippen zoo gront, als kileme huiskens, uit, en vecl der rotzen, over 't Vrouwen-eilandje (dnat' ontrent) overhangende, zyn door ' $\mathrm{rge-}$ weldig chudden, dat twee dagen duurde, op 't zelve nedergeflort.

In bet jaw 1683. ichyne "er ook cen fwatte brand inwendig in dezen Berg geweett te zyn. Immers in 't latate volgde 'er ecn afgryffelyke antobeving wit, loor welke de bergen fcheurden, werfcheide huizen, gebouwen, en pakhuizeti onder de voet gerabten, en weele genoodzalkt wierden hunne fteene buizen te verlaten, en zich in planken opgefligen tenters (hoedanige ik "er in " $\mathrm{t}$ jatt 1687 . en 1688. nog verfeheide gezien hebbe) roornamelvt 's nachts te behelpen, om niet levendig, "t zy wakker, 'tzy in flap, onder de inftortende huizen begraven te worden: want ik hebbe in "r fists 1.687 . zeer geloofwectdige ingezetenen hooren zeggen, dat toen de beweging wan het ardoryls zomtyds zoo fwar geweeft was, dat de hoeken der muturen พan een huis, dar zy te zamen fluicen, zoọ verte van een weken, dat "er' byna een menfoh door zou hebbem konnen gatn; dic zich dan met een ugenbeweging weder toe zetreden.

Ik hoorde toen wan den Wondhecler N. Proof, op 't reilind $A y$, gemeenelyk Poelo Ay genitimt, leggende, die by deze ardbeving mede geweeft wis, dat hy, op de pune of op ' 1 Noord - Oofter Bolwert wan 't Kaltecl Revengie, juift, als de ardbering manguam, zittende, de zelve, onder hem zooding wan een ficheurde, dat de pollevy way zyn eene fehoen geheel in dic fcheme by ongeluk geralkte, en door eten andere tegenbeweging wan "t andryk"en glid af

II I DEEL genepen wiert, zoo als tiy, door de fwatheid dezer beweging, ook een groot deel wat dat Bolwerk in de gragt zag nederftorten.

Zy hat op Lonthoit ook ocn buitengemeene groete liph, die boven op den Berg lag, zoo fterl ant 't bewegen gebrage, dite $z y$ van bowen af tot beneden op her ftrund, langs yericheide huiskens, zonder eenige fchade te doen, gerold was; welke zy, zoo zy ze geratkt had, verplettere zou hebben: Ik hebdezelve vericheide mitlen daal met weel verwondering zien leggen.

Door deze mardbeving zyn ook de regenbalkken, in de Katteelen Belgica, Revengie, en elders, gefcheure, en by nit bedorven', zoo dar men'er na dien tyd. het water' zoo wel niee in heef konnert bewayen en goedhouden

Daar $2 \mathrm{yn}^{4} \mathrm{cr}$, die geoordeelt hebben, dat deze atrdbeving zelf tot an 't ciland Ceroewa, oncrent 40 mylen Bezuiden Banda gelegen, gewerkt freef, on dat dat Eiland toen halt weggezonken is, met al des zelfs ingezcrenet 'cr' op, zoo dar de andere net - liunne wartuigen na Banda quamen vlugten ; - doch ik houde dac voor een ander andbcving op zich zelven,

In 't jomi 1688 . ben ik voorby dezen Berg menigmaal na het eiland Ay gevatren, en zagr toen bowen op den top een groenen boom itan, die men my zeidé ten limocnboom to zyn.

In dicri cyd heb ik onk wel cenige zage bewegingen van aardbevingen gevodt, en eens op loclo $A y$, in 't Kalleel Revengie "s nachts llapende, cen zeer ituare vernomen, watr door al de lampen op "t eiland uitginger, "t welk my ook, whugtende na de groote voorztal, eer grooten fehrik, alzoo darar alles wan ftecn wis, nasjatagde.

Twee jatien darar na, of iń 'i jar 1600. bcgon dees Berg wederom afgryzelyt te branten, en niet allecn veeffelyle Wlammen, matr ook zulke groote fecnen, boven uit, en al om de Weft, te werpen, dat men folyrikte dic te zien.

Ik heb folrippers, die toen op dic Reede lagen, gefproken, dic my verklatden gezien te hebben, dat ert Iteenen, in har befig grooter dan hunne fcheper (war onder er wain 160 woeten lang watren ) wit dezen Berg, zoo hoog boven den top, als de top vin den woer des Bergs was, geworpen, en zoo langs dien Berg nog glocjend ra berieden gerolt zyn, nemende nog fwate boomen en thruiken, die 'er wan in brand raakten, mede, hoewet ook zommige wel weer regt in hat gat, andere ook ten grootiten decle, tha de Weftavde in zec vielen, wall door, in die 6 jarten dat C 
hy gebrand heef, "er een dicpte wan 80 waden wan de Wetteant des Bergs niet alleen verefiend, miar zelf nog al em fraje hoogte op gekomen is ; zoo dat decs Berg, by een goede marekening meer loffe uit dit gat uirgeworpen heef, als by wan zyn top af tot zyn woet toe lchyor uit te komen mataken.

Vermits nu al deze ftoffe van "r Ooften na het Welten geworpen is, was dar een groot geluk woor de ingezetenen van 't eiland Neira, die pas Beootten dien Berg, en als'er' aas or onder lagen: waut zoo hy die ftoffe zoo wel na "t Ooften, als na ket Weften, uikgeworpen had, zou diar alles door die glocjende feenen, ten decle verbrand, ten deele verplettere, en alomme zoodathig gedelit geweeft zyn, dat het, nin allen fehys, "t leven tan alle de ingezetenen wan Neim gekoft zou hebber. Matr vermits nut Nein in "tOofter wan dezen Berg legt, en al deze ftoffe meeft uit eco gat, dur trat "t Ooften War binnen in den Berg ingalt, with onderen gehaalt, en zoo nu "t Weften uitgeworpen is, zoo is ook de vrecze, dut hy den grond wan. Neiri zoodanig aitgeholt heelt, dat hot met de minite anrdbeving zeer ligt zou konnen inftorten, en $z Y$ alle dus levendig in dien onderaardichen vuuroven zouden konnen begraven worden

Dit elland Neira is echter net geheel was alle ongemakken bevryd geweet: want de alfche is dar wel dry wocten hoog op de ftraten, en in ' $\mathrm{t}$ Kaffeel Nattu, enz. gevalien, whar door alle de vrugtboomen bedoryen, en neelt geheel urgegan, en dic twee voontocnde Perken, op dit Eiland, fchrikkelyk wan gedante verandert, en te dier tyd wel twee derde in wardy wermindert ayn. De llagen, die dees Berg zontyds gaf, waren zoo fwat, dat ganlch Neita, nis of "er cen lterke atardbering was, , zooding "er van dicunde, dat de toegefchovene grendels dex deuren 's morgens bevonden wienden te rug geweken te zyu ; woo dac de ingezerenen, in doodelyke benaauwhed zitcende, vresden met zatk en pak, zoodat nog buger anhich, ma "t Hoog Land te wallen moeten ophtr. men. Dit fchrecf my een wriend wan danr den 20 litn Septenber des jaars 1609 . aa welken teyd hy nog ettelyke matnden gebrand heett.

Dus brandde die Berg zes juaten ant een, zonder eenige culfehenpoozing,

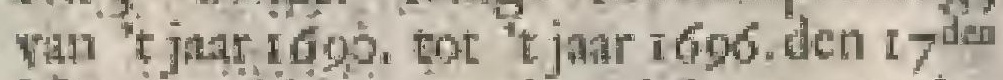
Mey, en hicht toen plotrelyk op, tot den $22^{\text {fien }}$ dito, op wellke dag 'er turce porfoonen opliommen. Wier wedertaten men in dis rolgende Rehas zict.

\section{Extrat wit bet Bandaas} Dagrogifer, bobelaswic bot droevig on whe smin anmorkdyk worwhl, op den $22^{\text {tem }}$ Mey des jaars 1606. Aor don Gomme Apt owworzankt.

$$
\text { Dyndig den } 22^{\text {then }} \text { Mos. . }
$$

" ${ }_{3}^{\mathrm{P}}$ den middag de klak 12 uten Drovide "wondering, twee perfoonen an de Z. deor bers "O. Kant den top des Bergs beklimmen, putren ", en zoo als zy bowen op wiren getso-weot"men, een ftolk met een klein rood vlag- ${ }^{2 a a b i t}$ "getje oplteken, welk wlaggetje zoo dra "Wan haar niet was geplant, of de Berg, , die nu al yyf dagen ling geen brindende "ftoffen witgegeven hid, en tut yder " eens groote blydíchap geheel uitgegan "en geblurcht fchecn te zyn, wierp, op 3. dit oogenblik, zeer fchielyk, fel cn s Aterk zyn brandende ftoffen woer uit, , 200 dat al ten eerthen de Berg rond. , omme met vutr, fwatre dikke dampen, , en afichen, overtrokken geworden is.

,Welk onverwagt treurlpel den inge3, zetenen, die meet alle de vermetelheid , der opklimmers, endediar opgevolgde 3. gruwelyke wertooning, wan de ftraten g thazagen, cen rechtvardige ftrafte 3rods toegerchenen is, ats die nier toe , cin last, zyoc gehcimenifien te onder, zoelien, en, behalven dat zulke ftraften ", datr over zoude mogen belchike wezer, wiert men ook, wegens de fterke en ", lange atrilyoudinge, meer en meer mer , werthrentheid bevangen, en bevreet, , dat het heele Land datar door in cen "drocrigen ponel zouden komen te ver"anderen, alzoo by metifhen gedentaen "noit vin dicrigely ke uitberttinge gehoor: "wats ; want hebbende een groot uur, "en onophoudelyk, met cen ongeloote", lyke kragt, altyd even fel, zyo inheb"bende brandende ftoffen, vermenge ", met groote fteenen, zoo onder Be= "duntige fware higen, nier ongelyk den "donder, grof gerominel en gedruilch, "als heldere blikzemen, zeer hoog in de "lucht gedtewen, dala uit de glocjende 5, uitgeworpen ftemen zoo fterk, als de "regen, weder nclerwates daalden, en 3 die, mer her vallen en fpringen, den "Bers in ecn wolkomen glood geftelt "hebben, woo heeft hy bot wederom " opgehouden, en geen de minfte ltofie , meer, belialven mair ecnige watze, Ming, uitgegewen.

"'s Avonds, nat owernl onderzock , goulata te hebben, wie de vernetcle "Flimuners syn geweeft, wiert men van „twee flawen, die an den woet wan de "Geenong Ap om hout te kippen ge2) weeft $x y \mathrm{yn}$, bericht, dat 's morgens ma 


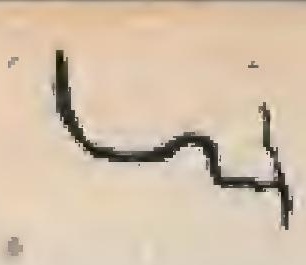

B $\quad$ A $\quad$ N $\quad$ D $\quad$ A.

79 9 uren twee Europiatnen, hebbende y. Yder cen Bimboeze ftok in de hand, y, an de Z. O. kant wan gemelten Berg 3w wen opgeklommen, en, zoo nls zy ", boven op den top opgekomen waten, , hadden z $y$ en rood wlaggetje op eender "Bamboeze ftokken opgerigt, en datr op , de hoeden in de bund rond gefwanid, 9, way ma zy woorts (zoo atls nict beter "hadden kunen zien) hattig natar de y, rugge ofte klip, die wat benedenwaarts , ana den Berg van de Ooltkunt hangt, 2) warengeylt, welke zy ook, terwyl de "Berg al zyn eerften fatg en uitberitinge \% deed, bercikt hadden; echter, wegens , de grouwelyke uitberitinge, dar onder 3, niec weilig lonnende foluilen, hidden 9, $2 y$ zich nanr omlang willen begeven, , alzoo het geweld onmogelyk te ontg" vlugten wiss, waar door din verder den „s certten wan de gloejende fteenen het " been, den anderen het hoofd afiellagen, y en zoo vervolgens beide hun lichamen 9 geheelyk verbrand , het gebeente ge"s kneuf, en van den cenen hec ingewand 's, uitgefchud zynde, zy om lang waren ") komen rollen, en zoodanig wan de voct 2, van gemelden Berg wan hen (als die 3) illes klaut atngezien hadden, en met s, het ophouden der uitwerpinge na hen 3) toe gingen) gevonden waten.

, Kort dar op wiert van den potthou" dende Sergent, wan de fchans KYk in „3 de Pot, an den Goenong A pi gelegen, ;bericht gedaru, dat Corpornal Preter "Hewdridg wan. . . en den fchilder"salt Facol Mator vin Switzerland, dezen "s molgen met verlof in 't bofeh wuen "geginn, on " $t$ cen en "t ander wild 3) (dar xich aldatr nog vind) te lchieten, "en dewyl hun werlof niet langer dan tor , den middag was ftrekkende geweelt, $2 \mathrm{en} z y$ ats nog nietwedergekecr waren, " wermoede hy, dat $z y$ de genen waten sgeweet, die den brindenden Berg be= " klommen haddea, gelyls ook zulks "s andeten daags, zynde

$$
\text { Wowsdag den } 23^{\text {ften }} \text { Dito, }
$$

"by nader onderzoekinge gebleken is;

, Dezen woomiddag revertecrde van "Poelo Ay, de Ecrwatrde Abrabam Fer9. Ningins, benevens den Schipper wan y) 't Phatehip Ooldhuizen, Hewdrik Sprismger, en den Guarnifoen boekhouder. "Jon Stumats, bericht an den E: E: "Achtb. Heer Prefident gevende, dat zy , op gifteren middag wh 'E ciland Ay m met de groothe verbmiftheid de [chrik, kelyke uitbertinge des brindende Bergs , lradden stangezien, watr uir, alzoo de y vaturige Aloffen een groot uur tha den 5) Anderen, door thans een onbegrypelyke 3) groote kmgt eì geweld, onder gedur, rige lwaure layen, en onophoudelyk
, fterk blitzemen, zeer hoog in de lucht w wierden gedrever, zy zich in zyn ge, heel verbeeld hadden, dit een ftryd galler hoofdltoffen te zyn, war op ook nom de N. W. door de dikke duiftere "dampen (die door hatar fwatute, rist "tegenftande het hard wattde, chiclyk 23 weder nederwats floegen) geen luclit "nog zec incer te bekemen waren; 3) weslalwen $x y$ ook watn de droevigfte "gedagten warken geweett, dat de Berg y an de Ooftkint moeft geberfter, en "'teiland Netra, als dar digt thin gele2s get, nede vergan zyn.

"Den volgenden dag, wezende

$$
\text { Donderdag den }{ }_{4} \text { licn }^{\text {Mey }}
$$

nde klok half twoe auren 's wchtermid"dags zag men, met onftelteniffe als "Yooten, een perfon ath de O. Z. O. "sant bowen op den top des brandenden "Bergs than, dienatr cen half unt lang , ditur op verblewen, en t'elkens met eci "f fulcje linmen om zich gefwatid te heb") ben, and de O. Z. O. knt weder' on , ling quim, wezende de Matroos $M d h^{\mathrm{a}}$ ", tits Hendrilyz odn der Spelt, die onlaugs " van hier verloft geworden is, on met " het fchip, de Fluit Oolthuizen, wiat " op reeds befcheidor is, natr Batayia te "vertrekken, die anitonts wan den EE. 3, Heer Prefident Baltbajar Coset ontbo,y den, en voor zyn Ed: verfehenen zynde; "wen overltan wan den Opjerkoopúin 9. den E: Jaedus de Witte, en den Gehein"Ichryver provifioned Gownad Frdite "Hofman, wan welgemelte Ed. Hecr Pie"f lident gevrangt is, wat hem hadde be "wogen, zalk een vermetelen en reulke" loozen dad te beftian, "dala hy her vers "foluikkelyke wederwace der ewee watr. "2 balzen van eergifteren nog zulfs hadde 9 aungezien, en diat omme de rechtvat"dige Atraffe der geeneis, dic God i ef2) zoeken, en dic de zelve ligtelyk wel „, verdicne lebben, zoo als'over de anderen, nook over hen land konnen komen? wor", ders, wat hy Mowrits op gemelten Berg "gezien, en wan des zelfs geltale en ge "lehapentheid angemerkt hadde. Dati $n$ op lyy verbalt heefe " $\mathrm{t}$ geen liser volge.

Bericlot, gedaan von Maurits Hendrildz wan det Spc.lt, Mat troos in dienf der E: Marjloapy

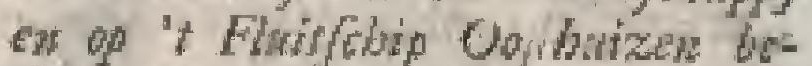

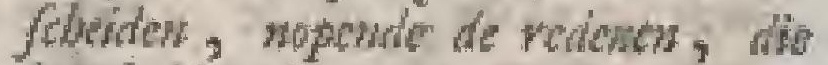
Wh boblen berogen' den brawdenden Berg te bekinmen, ch wat by dadr op reydors beft andeneth. . .

Betioht

Eggende woor erft, dut de bewegen= win Mas "O de redenen waten voortgekomen ait tits Hent, zyn cigen wry gemoed, zonder yemants drikf spent 3) xan- 


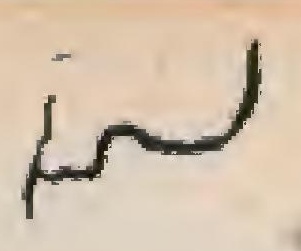

5, anratinge, en alloen ten inzichte by s, zyn Kamenat, dic eergilleren dit ook ,3ride onderftaan, en dastr op dood was , gebleven, garne voor zyn, vertrck , wan hicr nog eens hadden willen zien. "Dat overzulks, "s morgens na negen , unuren, aan de Z. O. kant wan den Berg , hadde begonnen op te klimmen, doch 3, halwer wege gekomen, en door de be, klommen iteilte heel wermoeid gewor, den zymde, hadde hy zich ontrent an, derhalf uur in een grippe, die hy datar , vond, te Aatpen neergelegt, en, met , dat weder ontwakk was, de Atoute , daad, die hy ondernomen hadde, by , zich zelfs amigemerke hebbende; woor , al ook, om dat 'topkomen wegens de , groote fteilte wat onmogelyk geleck, , wel weder genegen geweet Was te , rugge te kecren; doch de trouheid zyns 2) gebleven kameriats indngtig werdende, 3, hadde hy vilt belloten tot boven toe te , Klimmen, en te zien of hem norg er2, gens mogte winden, warneer ook op zyn , fuien is gevallen, en, God om vergit23 fenifte en een goede uitkomft gebeden , hebbende, den Berg al fehuins na de ,O. Z. O. kant opwanres tot den top ge, klommen is, van war nair binnen cie , kuil (die de ftoffe uitgeft) hadde ge, zien, die natar de diepte wan boven in , zya omkring wel driemal zoo groot, , als het Katteel Naffauw op 't eillind 7. Neira, was, loopende de gedagte , brandkuil ityl nederwarts als een trech, ter, bchalven dat in hot gat eenige 3) groote uittekende klippen hingen, dic , ook al meef door het vuur doorboot z, waren, en gcleek de ftoffe, ofte de 2, grond in gemelte kuil, matuntyke , twatel te zyn. De rondte, ofte kring , om gemele kuil, was niet breeder, is dan drie of vier voeten, "t welk hem , het rond gaan belet hadde, zoodat hy क, verder niet, dan van het cene heuveltje , tot het ander, O. en O. Z. O. wan den 3, anderen gelegen, hadde konnen komen ; , ook had hy in genclte kuildriefteenen 3. laten rolleo, om te ontwharen, of die, ,y eer dat op de grond quamen, gehoort ,zouden konnen worden, doch had zulks , nict konnen vérnemen, door dien ge,y duurig wan bowen ftecnen inkalfden; , en, gedurirende zyn bowenzyn, was hy 2, ook geen de mintte brand, nog gedruis, „, uir neergenclte kuil, behalven cen 3, weingje rook, gewar geworden, en 2, was de wloer, of de grond des Bergs "zelfs bowen op, alzoo koud, als hice wbencden, "t welk angetmerkt hebben, de, zoo was hy aun de O.Z. O. kant , recluc weder on lang gegaan, en hud 7halverwegen een hoed gevonden, die „3 bekent wiert den darar op gebleven Cor,poral to ebeboort te hebben; doch had nde doode lichamen nieuwers konnen "winden.

Na dezen togt zoo der twee omgekomene perfoonen, als die van dezen Matwits Hendrikfo wan der Spolt, bekroop ook den Ecew. Heer Mrabam Feilingins, en den Vandrig fon Buflow, de luft, om dezen Berg, na dat lyy in twee etmal niet gebnud, nog geen ftoffie uitgeworpen had, op den 2 fifin dito ook te beElimmen. Zyn Eerw, cigen optel wan dezen yltelyken en gewarlyken togt hebben wy goedgedagt, zoo als ik dit wit Bunda ${ }^{2} \mathrm{c}$ jats daar ani ontfargen heb, hier by te voegen.

\section{Waaragtig verhaal en on-} fandig bricbl, rakende de zeld zame rowderen, die Moyr I Jan Bufton, Daandrig in dieng der E. Natuflappy, en Bevelooerond Biofd der krygsireden wan it Kalled Hollawha, in "tophlimmen wan den Vuarberg, als wede op de wher fe boghte, benevens my ankgement beeft.

"A Angezien het de Hecre onze God, Als mede "A zomwyle behaigt", de lang ver- vin D. " borgene wonderen ayner hand en wer-Feilingus "ken, wan het oogdes mentchen te ont en den "dekken, op dac ayne Goddelylic Al- Bultoh "mingt des te roemwardiger en heerlyleer $\eta$ uitblonke wegens cen gehoorzanmeid, , , die de ganlehe gefebapene natuur aun 2) "t bevel en de opperife ordre haves Ge"bieders ecrbiediglyk bewyzen moer, "zonder het minite tegenfpreken, zoo "beliett het Hem mede insgelyks, wan2) neor $\mathrm{Hy}$ het de allerbdte gelegentheid "des ryds agt, in den fwakken en itorffe"Iyken mentch, die wegens vreeze, "kleirmoedighcid en natururlyke onmagt, in in geen thant is, ondernemingen van 3) groote gevamen uit te voeren, indier " mate den Geelt der fterkte ende kloek"moedigheid te fchenken, dat hy de "uiterlte butenfpoorigheden van de at"lerwasrchynelykitc ontheilen onverzage "beftat te ondergan, zoodanig dat zont", mige zelfs dar in omkonen, "t welk "y dan juift aldus uitvallende, zoo meenen zommige werftandelooze menchen, dut "God har ftratt wegens geplecgde ruk"kelooshid, "t well in vertcheidene 3\% velwoudige gclegentheden en woorvat"len, die onnoodig zyn hier wit te druk"keln, zyn betcheid en warheid heeft - matr dat dic tot 't onderwerpzel ( wat "van ik hebbe woorgenomen te fpreiken) "geen oprich of betrekinge knn heb"ben, zal blyken by "tgene dan over "hebbe voorgenomen te fpreken : want ") behawen dar men tor nog toe geen wafte 


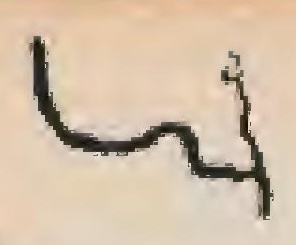

B A $\quad$ N $\quad$ D A

, ftellinge en heeft, tot hoc ver de kloek3) moedigheid (die cen gave Gods is) „2 zonder te misdoen, of te zondigen, met ween wettelyk vetlof en vryheid komen y, mag, als matr alleenlyk in zoo verne 3, het werftand en de voorzigtigheid (die ", beide wel konnen dwatien) ons yan te эy vooren watrichouwen, radeniat een , de zelve zalk na de verĺcheidene gevoc"Nens, die "er wan oordeclen, oole ver. , fchillige bevatingen onderworpen is, "de eene zoo een uitkomft belluitende, ") de ander her tegendeel ftellende, zoo 22, houde ils het nogtans daar woor, dat een. "menlch, zoo fchigtig woor eigen ver"derf, in diergelyke fwate "gevaren "(waar af het volgende werhat zal mel"den) nict ligtelyls zich zal inlanten, "swart butten hy, na het lchynt, ca ge"Jyk "er var veele gemeent word, zich ", badde komen houden; als alleenlyk, "zeg ik, wic krigt was een onwerwinne "lyke beftictinge wan cen onzienelyke "m ugt, dic hem dan, volgens zyn wel„behagen, diar van hat at- of 'er doot " omkomen, en dan walt nog het befuir, , isangande den ongelukkigen, die dar door is omgekomen zoo moejelyk op "te makaken, van dat hem zulks tot een misdandige ftraffe zoude wedervaeren "zyn, als "t fwnar valt uic te vinden de , inzigren, die God dar toe gehad heeft, , om hem cen diergelylke foort wan dood ", te doen fterven, war van ik de oor2) zalke dan eenlyk toelchrywe aan de recht"veerdigheid wan den Beluiter, zonder , eens weel te letten (niet in alle, maar zin zommige gevallen) ta de uitkomf, , die van de zyde wan den mench, wols. gens dirtgelyke ondememingen, is te , gemoet gezicn, als mar voor zoo "ver, indien zyn woonsemen zondig is, "en hem dat door exn uiterlyk gebod "belaft word nit te lanter, nadien by ten , hoogften ftrutbaur is wegens de oucr, tredinge, welk gevoelen ik acht recht"zinnig te wezen, nademal zoo een s) atnmerking wat ect maluwe af hanke"lykhend, die het fchepzel tot zynen 3) Schepper beett, de ruime Almage van "God kngtig werbeerlylkt, doch om my , in 200 een wate floffe niet in te laty ten, 200 zal ik anttonts tot werhat y, war de zaak komen, ten welken einde s, ik deze aalimerkinge hebbe laten woot s) af gaan.

Na een weelvuldig overdenken, hoe, danig het wel met den Vuurberg moge "gelegen zyn, wiert ik cindelyk driftig ngematst, om zelfs rot boven in deo n top toe een gezicht uit het oog tegatn "nenen; in welken tyd hy, zedert den $3,22^{\text {fton }}$ tot den $2 y^{\text {plem }}$ roe, hadde opge"houden, zonder in dien tweeden tus, fehentyd, vuur of rook uit te geven, "gelyk als hy ook nog zelfs op heden

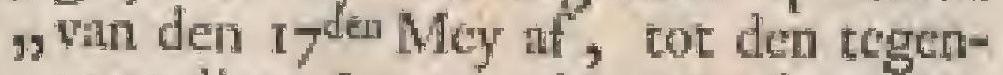
3, woordigendatum, nier meer dan ecns; ,zyode op den $22^{\text {tet }}$ heef titgefmeten; "War in twee rimpzalige wanghalzen, ") die door een wervaarlyke uitwenpinge "wan gloejende fteenen, zoo als $z y$ al "weder atan 'c afgain waren, hoewel nog n zeer digt onder den top, beklagelyk , omquinnen. Ik dagte dikwils, indien s, ik my wo dien woorigen tilftart bedient "had, zoo had ik zyoe wonderlyke wer${ }^{2}$ kinge al buiten gevas befchoud, en y, men hadde al iets vertelt, dat tot dien 3tyd toe onbekent was, man hier ftreed " de vrees mer de geeft, welke latilk, yalle fehrik wer wan zich zettende, en be, denkende, dat het ophouden wan vutr, inyten mogelyk nog wel eenige dagen ", konde duuren, eindely k vaftely k benoot "(in de vreeze Godes) dapperlyk alle " gevall te gaan afwagten, ende om dat "de eenzamheid, op zoo ecn fchrikke"Iyke manzienelyke hoogte, een zeld9, Zatme vervatio heid werwekt, zoo kreeg " ik even by geral, een Viandrager, met "name Monfr. Bufon, an wien ik myn ऋ voornemen ontdekte, by my. Ik ver"zochi hem tot myn gezelichap, hem "Aterk hier toe, wegens een byzonderen "dient, die hy hier mede mogelyle ana "har Hoog Ed. tot Batavia, benevens yden Achtb. Heer Prefident in Banda "zoude toebrengen, anmoedigende, "Lgeene hem zoo behagde, dat lyy "Atraks de tocht met my eens wiert. "Wy begaren ons din op de reis, en " lieten ons met ecn pratuw wan Lonthoir "Op de woet van den Berg annzetten, ggezint zynde ain den Noordkant onze "opklimminge te beginnen. De cerfte , hoogte, als cen wall by na rondom den "geheelen Berg uicttekende, ende war "tuftchen in den Berg gelegen is, waren 3) wy nawwelyks te boven gekomen, ofte , zagen tchrikkelyke ftecnen, zommige w, van een vadem, andere wan wat meer, , ook eenige พan wat minder lengte. Zy w waren nog gehel mer fwavel overdelat: ,Wy namen ecn mes, ende zogten de " dikte wan de fwavel uit te vinden en te "ontblooten, matr bevonden, dat hy 2, Wis van een zeer harde waftigheid ea "Atoffe. De plats, alwau den cenen " mer zyn wal was neergekomen, geleck " een kuil, die men, tot een half mans ") diepte, wel een wadem in "t rond mer $n$ een fpade had uitgegraven, צas wat "w hy nog meer als cwee vadem door het , zand was heenen geploegt, ende ten w latatifen zyn rult krygende, zoo was hy "wel tot de helft van zyn dikte, in de "grond gezakt. Al vender voortgaende, ") vernamen wy het geluid van een uitge"holt aardryls, brommente als cen holle C 3 
, kclder en gewelfzel, buiten twryfel "door dien de ftof van onder geloelyk "was verbrand en uitgelatitit, "re geen "fchriklelyk on te hooten was Wy , trokken dan at worders, tot dat wy him " ecn hoogte quamen, gelegen mats ate ${ }_{3}$ Noordkant, die wy, wan tonderften कFan de buitential af tot den top toe wde helft rekenden te zyn. Tot bier 2, haiden wy cen groote moeite, van , wegen de ongemakkelyke we, die dan "ryzende, nu wederon dalende, net " tuflcheninleggende groote grippen en "fcheuringen, door den regen gemaakt, , onzen voortgang en fpoed geweldig ", verhinderde. De dorft greep ons ook m zoo fterk ana, dut by na onze keelen " van een werhitte drooget toegingen. In " deze bange verlegentheid was eer foopje "onze eniglte hartsterkende werquilkins) ge, dat cen fhaf wan den Vuadnger , ons in een botreltje nadroeg. Allier "wonder wy goed dien laaff weder me"neden te zenden, hem fterk behaften"de, eetrige klappers te gaan haten, die , wy in her weder te rug kerren wan de ", hoogte des Bergs, op die bettende g plats verhoopten te gemoet te zien " $\mathrm{Na}$ dat onze lichamen van latare ver, mocitheid redelyk geruft hadden, be", foten wy laidkeels tot den Almagtigen ${ }^{3}$ God, zonder wiens verlof, nog rook, " nog flecnen, ons berchidigen konden, " cen Gebed te doen. Ik dankte Hem 3 voor ons beiden, dar by ons zoo over 9 al goedgunitelyk met zyn krigtige by2y thant woor alle gevar behoed thid; ende 3) werzocht verder zeer nedrig, dat zyne 3) goedertierenheid en befeherminge ons ", wilde omwailen, en wyders behouden "2, eu gelukkig ua boven geleiden. Dit 37 gedau zynde, werhatten wy onze woort, gang, ende, gefterkt in God, hndden , zoodanigeen klockhertjg gemoed, want "Noor alle vioes verichrilite, en te rug 7) deinsde. Hier was inmiddels geen kle5, nen arbeid voorhanden, otn die affgy/lic"Iyke theile te owerwinisen. Derlalven "was 'I noodig onze natuurlyken gang, "in cen niedw fatloen cn mode te werwomderen. In planeze daw van den ftok 2) tot cen fteunzel in de hand te houden; "Itaken wy hem van achter den broeks" "3and uit, en klauterden als vreemde 3) menleter op handen en vocten ra bo3) ven. Hier en datar wonden wy eer theen, ") die met zyn val zoo diep het fwrate 2; Itor ingezalkt was, dat hy ons brquat7 melyk woor een werzekerde zit- en rult7) platits verltrekte. Doch hoe hooger wy "quamen, hoe meer de oogichynlyke so gevaren ook toethmen: swant, in 2. Plants van zitterde nu en dan te konnen m rulten, zoo moed her voortgan volw gens de gewoonte der leidekkers, die
, wan de hangende ladderfpost al ftande , op cen verheven dak, zomtyds wat , riften, gefchicden : want terwyl wy , thet gen de minfte geruttheid, on niet , van boven nederwarts te ftorten, ors "derfden omkeeren, madien den Beres al", datir nict anders ils valu thot, wheh en "klcine gruisftecoutios, dic :an onze ", voeten geen de minlte waltigheid garen, , en ook arritonts (al khoon wy zelfs „3 naukeurig en woorzigtig op onze hode "waten) uirweken, overdekt is, zoo "hatdden wy nog dar en boven cen zeer 3) groote fteilte te betlimmen, die ons, "2, niet jegenitadude wy met het licham ", uitgerekt, en met btide de handen uit"geltrekt, dus alle buide wan nedrigheid , deden, dreigic, zoo hantt wy het ach", terlye op heis uicgeitrekt hadden, wan "boven neder te ftumten; weshalven wy 20 dan onze armen ombelzender wyze uit,breidden, en met onze buile en anuge"zicht, zoo lang wy witen, eens mi cn "dan verkwer te nutten, zeer opmer"kende in ons bewegen zynde, on niet "wan acheren over te fwikken; en aldus "T. Thanken wy dool ecn byzondre be* 3) watring wan God, na dat wy wa thicn ", Luten at, in. deu woormutd gftond, "gezulkelt, en met onze handen en , voeten in de alcli gegrobbelt hadden,

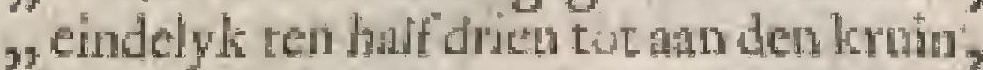
"alwrit de hoogte cindigt. Help God? "help menichen! wat openbande zich ", hicr ocn afgit flelykewercooning, want , denkende, hoe moenig duizentmal hy , eco fwaten dump nuden hemel al roo"kende en Imookende, als of daar pile "gebrand wiert, en diw woer nee klarare 3) vonken wuurs vennenge, en gehecle 3) Wammen uiefpouwende, tot bowen in "de lucht toe opgefchoten, ende zort"s tyds ftukken wan rotzen, met het bits", nentte wan her gebergte, atflcheurende, 3, uirgebrankt had, how hy die gezengde 5) Iteenen met cen hol geluid in de wol"ken dede vliegen, ter wyl dien diepen , grond zoo thont te blatken en te branden "3 "t geen het klocklte en matimoedigfte "hart kon doen nederzinken) zoo,gaapte „2, zyn mond hier by zoo yzelyk en afs, gryzelyk, theven ents of hy de gunfche "Land voogdy dreigde in te noliken. Wy "belloten hier op met ons beide tot God 5. Almachtig weder een Gebed te doen, ;, en fineckien mex een ziclgekropre nu,2. lprak, dat by ons weder benedenwats "behouden wilden gelejden, na dat wy "s dar geenc, "t welk wy daar hadden ata "to nerken, gerien hadden. Hicr op, 's, re weren, ma dit Godwugtig kortfondig , bedry, dronken wy bede en zoopje, , dat door een that, dic it wan yemant ,5 tot myn diunt had, ons wiert binges, thingen, terwyl dic van den Vuandruger, 
<smiles>[AlH2][AlH2]</smiles>

(4)

B

A

N

D

A.

23

"om eenige klippers halverwegen te "brengen, onderufichen wan ons ge" lcheiden was. Wy ziten diar een wyl 3 te ruften, om, "t geen in de mond te , zien was, natukeurig af tekylken, met st my hebbende papier, pen en inkt, om 9, $z$ oo dien verderffelyken vyant, dic in m $2 y 0$ boosheid t'zedert zes jauren volhart , heett, tot in zyn keel, ja, indien her "mogolyk wis, tot in zyn ingewand ,2elts, te lecten kemnen. Wy nigreden ,ons dan weder op, en zagen an die szyde, alwar wy opgekomen waren, , met de grootife verwonderinge des we"7relds, hoe dat een Berg, die zoo veel ", faren gebrand heef, en zulke uityte"kende hoeken, tot zelfs in de zee, eenige "Foeden ling met zyn tirwerpinge ge29 make hoet, mari zulken ongeloofe"lyke ondiepte konde hebben, dat wy , echter op ons gezichte fchuldig waren "te gelooven, maar begrepon oen weinig "daar na genoegzatam de reden en oor" 7aik, want, na de allerbette gifling, ") dic il makke, was hy geen 40 wademen ,diep, zoo dat de diepte, wan dar zyn 3, lichum begint, geen vicrdepast wan de , hoogte uitmaken kan. Hier zag men , ande Noordkant," vier nevens den an, deren itaande brandrotzen, vaty onder "tot boven toc met een gelyke uitge, zette breedte. Zy waren alle zeer ge, kartele, en uitgebrokkelt, Itande in ", cen ingetroklken halwe maatrs rondte, 5n de twee middelite zeer digt neerens den ", anderen; maa" beide de buitenfte, die "de twee middelfte benloten, hadden een 2) weinigje aftater Dit is voor den lezer 5, atanerkelyk, dat agtel deze rotzen, , alwar binnen in den Berg in de uits, gebraride holligheid gezien word, zich , een foheuragtige klip opdoet, die met , een uitgebuiktheid alienlssken rondelyk , inloope, en nier boven twee fchreden " voor ower Atcekt, doch in zyn lengte , met een fyckronde bogt of omloop , draaid; betiande, nal gifing, ontrent „3 ecu rocde lands, watar op deze vier ge", melde rotzen ruften, zynde na gilling ,by de zes wadem beneden de boven" Atande tuffehet de $\mathrm{N}$.en 0 .zyde lang. "Hiar hougte was, hat de bette overleg" ginge, niet boven de twee vadem ; , doch zy hadden meet een gelyke uity) gezetheid van twoe videm, doch in 3) baar verlieventheid nog naauwelyks zoo 3, veel. De rug, of de bowenvalke was 3 tiiet heel breed, warom cen redelyk s. gebeent maxajyerfoon, uitgenomen de grwec in "t ridden ltaande, huar zoude "s konnen befchreiden; hier agter ver, toonden zich, onder een vigreholden , thand, de twee uiteinders van de at3. Gryllelyke atgrand, als cen wevers"f froel, met cen allenkskens nauwer "ende fmal tortoopende. Deze is an 3 de Ooftkant gelegen, en heeft meelt w geftadig na Poelo $A y$, beneveris over s) de Weltkant, zyne floffe uirg fineten. ,Van datr na de Zuidzyde gatude, zop "hecft men mede een allenkskens felhut$s$ nende en uitbuikende ronde rots, die ") Van dar, alwar de uitgeholde rand 3) met een getyke rondom dicploopende "wyte eindige, wan onder, daur de bo, ven wyte begint coe te loopen, uit"Atecke, ende te voorichyn kome; win ", hier af zoude men yemant, met eed " touw om 't lyf gedkan, bentedenwatrts 3 , tot der grond der gemeene opening 9 (inditen het door de hícte en frnoo$\rightarrow$ kende (waveldimpen niec belet wierd) ", konnen aflaten. Wy zouden het al"Lus zect" gemakkelyk gepeile hebben, s, zoo ons een dieploot ter hand geweef 3) Was. Dit gat, leggende onder de "Ooltzyde vin den Berg, heef zyn "meelte werking komnen doen thit de s Wellist, als mede na Poclo Ay, "werwart bet zich getcheurt uititrekt, "bentwens een gedeclte, tuffichen de $\mathrm{N}$. „en W. zyde, en zoo kone men dan , ten lataten tot dien derden afgrond, ndewelke mede een fchrikkelpke Icheur $\%$ is, zynde gelegen in 't midden wan do "diepte, en den grond wan "t bovente ngat, namentlyk de holle mond, al" wat hy als een uitgegraven kuil zer "fehiclyk natu toe loopt. Deze af"grond legt in "t langwerpige, en be"itrykt met $z y n$ een einde de Weft-en w met het ander de Ooftkant. Wy zagen , in het zelve als in een dikke dufferen " onderatidechen kuil, zynde een zeer "natar gezicht. Dezen afgrond kan zyn ", fteenen uitichicten na de O. en W. Kant, , en ook lynicelar in de lucht, 'c welk "men 200 menigmal by ervatentheid "gezien heet, dat cen afgryzelyken "Afchdainp, met gloejende fteenen ver, thengt, zich weeltyds in het middet , det mondopeninge vertoont heeft, met " fpitze fwarte dampen en tippen, op de "wyze van een piramide uidehiecende, "w welk fatioen hy wan dic geicheunde af"grond, voorwaturs tufictuen door de "rook, met een fehielyken uirfchietende "drift heenen gegann en gedrongen zya" de, ontfangen heefs.

Hy ltan zoer weinig feenen ma de „N. kant owerfinyten, om dut hy (gelyls , hicr even te wooren gezegt is ) met zyn , een einde ata de $W$. kant, en met het , inder tegen de 0 . kant lcgt, watrom " de fteenen uir den atgrond juitt zeer net "F Ehuins tuffehen de breeste wail de "2) (cheur moeten beenen wliegen, 't welits , niet als by een zeer enkel geval ge"fchieden kan, alzoo zy noourakelyk , tegen den cenen of den anderca kat

, vale 
, Wun de [cheur moten komen en an, vliegen.

, Dezen afgrond zoude it onk houden , woor de voornamite fchatkamer van s) die heliche wuturwertsen, cnde, gensterke door de ervarentheid, zoo ge" loof ik, dat hy in zynen boezem alle " die brandende mynen, ideren, fwavel, "en filpeterkelders bethuic, vermits men , zelden, of mogelyk ('indien men darar 3, op geler had) noit, door de twee an"dere garen fteenen heeft zien witwhie"gen, war of hy de cerfle voortoche n niet genomen heef ; matr ten opzicht " wan den rookdamp, dic, wegens haare , ongeloofelyke angevoerde tterke finel"heid, doortocht gezogt heefe, zoo , hebber zy ook niet minder, als ge, weldige trekkende foboorfteenen, J har y, belt gedaan, om dien tmook wan bils* , nen door has keclen uir te wazemen. , Ende dit is, wel het voornamite, s, noopende her genen ik ontrent de drie 3, afgronden alhier bebbe te werhalen. y, War uit dan ligtelyk is af te nemen, , wanneer men op de gelegenheid dezer "dricafgronden zy ne gedagten laat gatan, " hoe ligtelyk en bequamelyk dic afgron, den (chat wy zoo dikwils hebben geg. zicn) dwars door en in malkanderen shebben konnen arbeiden, en haar s) ftecnen doen wliegen.

3) Nu zal ik alleenlyk een forte be20 fchrywinge angaande de form vau de 2, opening zelfs doen. De garpinge van , de mond zoude men konner vergely"2 ken by een ronde, enige roeden groot "zynde, afgeftekene plats, welkers "bovengrond tot onder de mard toe, "t'enemal uitgeholt is, hebbende in ,2, zyn geheele rondte eer gelylie diepte 2) van ecnige vadens, nlwarr hict dan be, gint re raawwen, en t'zamen te trek, Ken, latende beryden den sand, dic wallernante de grond is, cen fehums af , loopende uitited van atade werblywen. 5. Dusdanig is her mede in den mond 2, Nan den Vuurberg geftelt, dat men uit , het na folgende eeniger mate zal , konnen begrypen.

3. Het is werwonderens wardig te be"fohouwen, hoc helder en klate alles , in den mond gezien word; zynde wath "binnen vier uitgeholde hoeken, die "zich, in vergelyking wan de buiten, rondte van den rand, ook allenkskens , ma binnen ondrajen, ftande met de , vier wiuden ook meeft regelrechtegen , ower malkanderen. De binnenkant is 2, 200 mbegrypelyk nitgeholt, dac bet , gechzins te begrypen is, hoe dien rand 7, dat fterk gedavel wan die krakende , uitbertinge heet lonnen verdragen, y, en uiritann, mat dit is zeer nemmer"kelyk, dac de vitfpringende en wlic- w gende fteenen tegen den fwakken rand, "nict, dan by een zeer onbedenkely k "gevil, konnen febieten, al zoo zy hew " anders al overlang zouden verbroken , en ingellages hebben; de reden is, om "dat die twee afgronden, de ecrac gele"gen atan de $O$. en de andere ann de $Z$. "kant, indiervoegen onder de holte van " den wand des Bergs geplatif $z y$, dat " "er regens de zelwe aan zekere tware , rots opgchate is, die als cen rchutzel "s voor dien uitgehaalden wal, die seche , over dezen afgrond that, werticlit, 3) zyode rondon zewer vademen liger dan s. den boven rand wan den Berg. Hier , tufichen door nu moeten de ftcenen 9. vliegen, endedọgr dien de buitenhoek n van de W. kant zecr wyd uitgezet flant, "zoo komnen de fteenen, die un den af" grond was de Z. en O. zyde wliegen, , Dadenal zy over zoo een hoogverhe"ven ftaketzel in de Jucht opgan, by "gevolge ook den kant niet belchnder?. "Zoodinis is het mede gelegen met den "afgrond tufichen de $N$. en 0 . zyde, nwant terwyl een verlieven rots voor "hem ftat, die na gifling tot op cen wafitant wan ticn waden met het bovenfte " an den rand gelyk komt, zoo kan by nden uilgeholden rand wan de Z. cn W. 3) zyde almede wiel ralken, hoewel het te "s verwodideren is, dat hy, nict tegen"ftarnde dit alles, doou den wal wan "fehrikkelyke thecnen, warr wan wel 2, cenige op den kutit nederkomen, nief wneerltort; en al gcbeurden "t ("tgeen "God nogtans verhoeden will) dar den "Berg een diepte wat 30 wademen, door ybinnen woorwarts over te ftorten, 3) quytgeraakre, zoo kan hier door, nog 3. Watervlocjinge, nog ardichuddingc "gefchieden. Het ecrite niet, ond dat ") die weinige en geringe inftortinge de nzee niet lan werhoogen. Hee tweede 3niet, om dat die ltoffe door de kieel "wan de middentte afgrond nier dun hee s cene voor, en her andere na pafteren, so wharom hy ook, wegerss zyn crigte, 9, niet alles t'effeus infwelgen lan. De , bovenmond is zuiver en fchoon. Hier , heeft men ma de Weltkant, tultchen y cen fchume afdalende rots, en tuftehen 3 de middelfte afgrond, een wierkantig "s wit lilipic, niet ongelyk zynde cen "groote linge zarlefteen. Het vertootit nzich mede als een fomal zandplantje, vodoch is te gelooven, dat het een witte "Atentigtige rots (op klip) ran cen on"verbekelyke lardigheid $\mathrm{zy}$, hoedanig , wy wel eenige dergelyke witte Acens, tjes nan den top ynden Berg, die kryt"agtig, doch onverbryzelyk hand wat "sen, opnamen. De mond vertoont 2) ich boven met teen cyrondheid, zyncie , den thed over al ewen hoog, uitge- 
3) zovdert twee klcine afch heuwelen tus, ichen den $\mathrm{N}$. en $\mathrm{O}$. kant, die hier mede ggelyl als twee hoeken vitmalien, "3 wat tulfehen een datende en dan we, derom ryzende mondsand, twifhen de "2 25 en 30 fchroder lang zynde, wain , deze twee hoeken gelegen is ; matr , dit alles vertoone zich van Neira veel , grooter, dan it cigentlyk is. Voorts , is de gatulche rand, uitgezondert "dat hy hier en daar een weinig uirge"icheurt is, wan een gelyke verhevene ,rondte. If was zecr nienwsgierig, , Om van bowen een ftecen in den mid. , denlten afgrond te finyten; mar myn "Reisbrocder Bufton, wyzelyk bewreelt , zynde, dux zyn nederkoming by gewal , ecnige beweginge atan de brandende , Itoltie mochte veroorzaken ontried, , my in ' $\mathrm{r}$ eerlt dat te beginnen, doch "hy dar op naderhand newens nuy zeer , begeriy geworden zynde, om te we, ten, hoedanigen geluid door deze in9) werpinge zoude gelioort wordel, zoo , Damen wy dan cen fwnaren fteen, dic " langs den uitgeholden inand al frim"gende en kerzende in den middeniten , afgrond wiel, wan op wy zeer clierp , tocluifterden, vernemende cen geluid , nls wan een heeten en ziedenden [wave], Atroom. Ik hemde vyf of zesmal not , een fterke ftem, ende hoorde daar op geen ftureszen echo. Eenige lwavel, dampjes zagen wy uit dien grooten oven ,3 vas de kanten oproóken, die als zout g, dat in 't vuur word gefmeten, knapten. "Men zag een gedururig gefebilfer wn , de rotzen door den Fwavel na beneden s, vallen; ende hicr mede gingen wy we, der benedenwarts", lovende God met , , cel korte dinkzegginge voor zyn ge, natde. Her afgar koltec niee weinig 3, moeite, terayly den Berg zcer fty] is, ydat echter aan die zyde vecl verlchec], de; matr ziende van de kant, die wy 3) waten opgeklommen, zoo gingen wy , zitten, en ftieten ons met de handen , "ras boven an, alzoo over die dikke alch beeneu fehuivende. Bencien komen"de, rot by nat 'tondet fte datu' den Berg ,begint, rolsen wy een peltige ftank , van een verrot licham, whir op ons ,yantonts in gedagten viel, hoe den , $22^{\text {Vien }}$ twee karels dow de lteenen 3, doodgeflagen waret. Een weinig toc ,tredende, ontdekten wy bet licham, "'t geen nhet drie gaten gewond was, y, zynde het eene, in de buik, zno groot als , een bollevan cen hoed. De kilederen g, waren hen tot het middenlyf wan de , gezengde tteenen afgebrand, hy lig , met zyn angezigte in het ftof gedon"pelt ; warlyk bequaam, om yemane , tot medelyden te bewegen. Op Neira y komende, gingen wy tot den $\Lambda$ chtb:

"Heer Prefident, die ons zeer beleefe ,ontfing, en hocwel zyn Ed uit wyze ${ }_{3} \mathrm{cn}$ zecr verreziende gedngten her ant3) merkte voon cen onderneminge wul ten ygeweldig gewar, zoo had zyn E. "nogutus een bezondere goedheid, om 9) door cen zeer beleeft onthal zich in , onze gelukkige uirkomft te verheugen. „2W Wyders befchonken zyn E. met cenige , ralpeter en fwavellteenen, die wy neet " alle boren op den rand, en ook ceni"gen onder den rand hadden opgerapt, ", ende ndien den Ed. Achtb. Heer Pre, fident beleefdelyk verzogt hier van een ng Fhriftelyk bericht te zien, om het atun , zyn beroemtie an wootreffelyke Edcl„3 heid, bencvens de reet anzienelyke ,Randen wan India mede te declen, zoo "heb ik zulte en billyk verzoek, met s, onderdanigheid gehoonzame, ook "roude ik my onderwonden hebben die "nh zyn Edelheid, benevens de Ed. ", Heeren Raden wat India op te dragen; w mat wegens de dringende kortheid, "zoo heefe dit papierekind, zyn vol, make geboorte niet komen ontfins gen, hoewel ik hoop uit grond myns ", harcen, dar het zyo ledelheid nevens , de Rataden van India niee onangenanm , zat wezen, nardien ik beneficns den , Voandrig Buffos, het niet hebben on= , dernomen uir inzigte van eenige beloo"ninge, matr ecnlyk on her te doen , cloorgacn, woor een zigtbar bewys "vid onze onverbielelylic cerbiedig, heid. Wan mede wy, ons werhal, , atbrekende, zoo wenfehen wy, indien "lica by gewil in $\mathrm{U}$ w Edelheids ende der , aunzienelyke Raden ván India har , handen yorfchynt, dat God Almagtig , met u athen $z y$. A M EN. Onderftont "Uw Ed. onderdanigfte Diensas, was ,geteckent, Auraban Fotlingries. Ter „Zyden, den $2 y^{\text {then }}$ Mey 1696.

\section{Gecollaticent Accordect Banda,

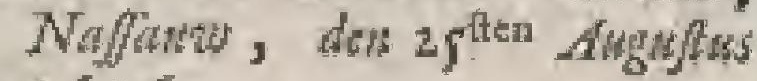 1696.}

\section{H. DEGENAARS.}

vt.

\section{JAN MARMER.}

Den $14^{\text {déa }}$ April des jatrs 17 ro. kregen wy in Amboina tyding, dat die van Neira, volgens fchrywen van den 10 dea dito van daar, wyf weken te vooren, een Iwarder andbeving, dan dievan "t jar" 4683 . geroelt, en 7.ich genoodzaalke gevondien hadden ' $\mathrm{K}$ Kattecl te verlaten. Doch valdezentyd af, tot 't jar 1712. was de Berg weder getied itilmar in dat juar den r oden Atrguftus kreeg 
men op Batavia bericht, dat by weder 7 of 8 digen gebrand had, en na dien tyd mat imeulde.

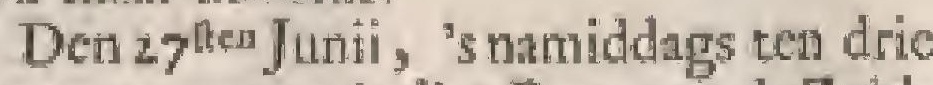
uuren zag men uit dien Berg ato de ZuidWeltzydezec fware dumpen, en fwarten took, opvliegen, die zomtyds met eenige wlam gemengt wos, en die men, wegens het flormend en regenagtig weder, niet al te wel onderf́cheiden kon.

Den 284 en dito was thet met her anbreken van den dag nog al cren eens. Men zag geen wlam; matr twarte rook, en vuurige fteentjens en affche; ook hoorde men een groor gedtuis, achter den Berg; doch dic op Neist waten, vemamen "er niets van, alzoo de fterke Zuidooften wind dit al om de NoordWeftant, en zecwart benen, wocrde. Men zag nogtans "s avonds ten 7 uuren ann de Zuidweftkant, na Lon hoir toe, niet als liche, en "t fitkkerea wan de vlan, dic door den fwaren regen dan eens wot minder, dan weer eens wat fterker whs. En even zoo dede het ools den $2 g^{\text {teten }}$ dito; doch den 3 ofien diro den ganfichen dag zag men weinig dampen of te rook, hoewel men die voor des zons ondergang tegen den avond beide weder pernam; mair na zons ondergang was de top des Bergs de ganche nacht door aan de ZuidWeftkant, na Lonthoil toe, mer vuur en wlan bezec.

Den t tea Juli vernmm men den ganfehen dag byna geen damp of rook, en na 'tondergnan van de zon zomtyds muat' een weinig flikkering, zonder reche te weren, of dit vai den Berg, of van de ftarren, wis. Even zoo whs het ools

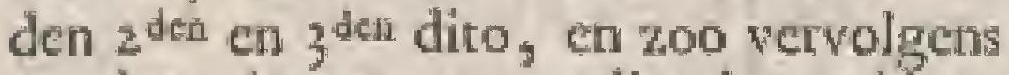
tot den gder toe, op welke de werlkbas met de feliuit den Berg rondvarende, das ongelyk meer rook en damp, met affche vermengt, die wan ecis rwalagrige reak was, werram. Ookeng by, dat vericheide boomen and die kut door 't wallen der affche dor, en als dood, en dat ook de klipfteenen an den yoct van den Berg doorganns met aflehe bedeke waren.

Na dien tyd hobbe ik wan geen verder branden van dien Berg; dan dat hy toen nog imeulde, vernomen.

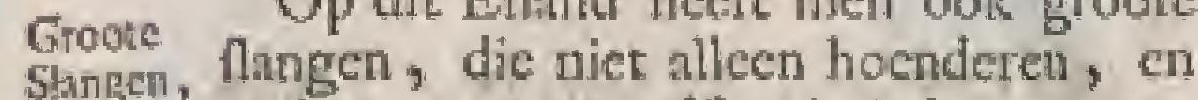

Op die Eiland heeft men ook groore eni op verkens, mair acti ools kalweren, en ditciland, menichen infwelgen, am hoedanige brokken zy ook wel komen te flikker, of dan zeer ligr doodgellagen worden, vernits $2 y$, datar door zee' belemmert zynde, zoo nies wontsonnen. De bete vas deze flangen fehyn it zich zelven urel niet groot,genocg on rulke brokken in te fwelgen; matr de natuur heef hat ondertec kakebecn zoodanig geichilkt, dat zy her zelve als een wajes konnen uitzetten, en daar door batren bek 200danig verbreeden, dae zy al eenvy grooten brok 'er doorzetten konne!s. Indien zulk een flang een menfch kome that te doen, of op hem hier of dant uit zyn hol toefchiet, zoo is zy gewoon hem eerlt een bogt of twee om 't ly te llingeren, hatren ftart an cen wortel wan ect boom vaft te zetten, en hem zoo dood te wringen, ten ware dat dic menlch gelegentheid heeft, of $\mathrm{kryge}$, on dien bogt met cen houwer, of inynes, doar te kappen, con dair door hate wingkrigt to breken.

Wen lieefe op dit Eiland ook veel wilde koebeetlen en verticus, die 'er vopr dezen, over honderder van jatren, eer de Bandaneezen nog Moorld waren, opgezer zyu, en 'cr al hed wel op arden, ichoon 'ef geen di up werlch water ep dit lind is, wat door zy genoodhake worden hici", gelyk ook op Neita, en op "teiland $A y$, hatren dorlt met zeewater te leftchen.

Dat men hicr ook een rchans hect, Deschans Kyk in de Pot germant, en regt tegen kyk inde over 't Waterpas van Lonchoir gelegen, Pot. licbben wy reets uic het eerfte bericht over dien toche boven an den Vurberg gezien. Datar lege een Sergeant mot ecnige folduten in, co is zoo wel wan gefchut worzien, dat $z y$ an alle weemdelingen her inkomen in her Lonthoirs gat, wanneet het wa "r Lonthoirs waterpis onderileunt word, volkomen beletren lean.

Men hectropdezen Berg, ande woet; thiet dan eenige Amwen van Inor, Solor, Tenimbar, Key, Aroc, Boeton, enz. woonen, om op de thuinen vith hunne Meetters te palfen, en oole wel verkens, of jonge knebeelten, te lehieten, dat $z y$ andters niet mogen doen, en hen wel itreng van hunne Mecters verboden word, alzoo datr niemant, dan de jager van den Heer Landvoogt, die dar toe in "tbyzonder gehouden word, jagen mag. In 't jar 1687. was 7whus Boveth do enige Vryborger, die op dit thand woonde.

Wat nu "t Vrouweneiland betreft, an 't Vnous de Noordzyde wan 't zonnegat gelegen, wend. dit is zoo klein, dat her, even als Poclo Kapal, geen belchrywing wardig is.

Men weet (om nog iets op dien togt Schrywers van de Heer Fethogias te zeggen) hoe ammer C. Pliviars Sectudus, de oom van C. Plinits king op Gecilws Secundus, doon zulken onvoor wan Plizigtigen dat, an zyo einde gerakt is: niwe, on want nadat hy was zyn zulter (in de tyd op t gedat hy te Mifenum als hoofd der vloot de Heer lag) in de maand November 's inorgens Fecilingius ontrent ten zcven utren verftan liad, by zym dat rich een wolk wa ech ongewoone togt ma 
foort en grootte wcrtoonde, ging hy, nicuwsgierig otn dit verder na te. vorfeten, wh een wartuig, en begaf zich mi den Berg (die men ontdekte den Vefuvius te zyn) zoo ticht datar an, dat de heete arch op 't watruig wloog, die, hoe by nader quan, hoe zy heeter en fwrturder wiert, ilzoo 'er ook eenige puimftecnen onder liepen.

Hy trit cindelyk te land en onthict zich ecrigen tyd in de werlatene en halfverbrande huizen, terwyl die Berg zoo tterk blaaktc, met uitwerping van zoo veel ftoffe, dat Pindis onmogelyli git die huizen zoude hebben konnen oncko: men, zoo hy dic nice tydig verlaten bad, hoewel net het uiterfte gevar, wegens de regerbui yan feenen, die (choon hunne hoofden omwonden waren) geduurig uit den wuar- en blikzembrankenden Berg rondon en ontrent hen nederitorte, zoo dat wich dan eens een heldere dag, dan weer eens een mare nacht wan buiten opdede.

Terwyl by nu bezig was om de boorder, dair de zec op afftuitce, wat nader te berchouwen, om te zien wat bolwer- ken der natuure dar nog overgebleven waren g quam 'er, pas nadat ly wat water tcgen de hectc luchtge eilcht en ingedronken had, ecn fchiclyke fwaveldimp, voor welke zy alle, vitgenomen Plhius (alzoo by geen quad wreede) de wligt namen; doch, dar toc nader verzogt, ftond hy wel op, maar zeeg, op twee faaven fleunende, weer neder, zynde waifchynelyk door dien heeten fwaveldamp gellikt, zonder anders eenigzins gequetit te zyn. Een verhnal, dat C. Plinus Cacihus Sewndus weleer wegens "t ongeval wan zyn oon aan Tartas dede; cn een onverwagte wyze win dood, dic by zich, buiten cenige noodzankelykheid, on rukkeloos, zelfs op den hals gehwale had, en aan welke (gelyk ook voor al an de dood van die twee mannen zoo kort te vooren voorgevallen) de Heer Fellingurs (myne oordecls) tich had behooren te fpiege len, anngezien dit ganfch beriche, en alles wat, zyn Eerw: dagt gezien heeft; immers wan dic watade en van dat belang niet is, on datrom zyn leven in zulken zigtbar gewat, als zyn Eerw: dede, te itclien.

\section{DER DE HOO F D T T K.}

$\mathrm{H}^{\mathrm{s}}$ Et Eiland Ay belobwern. " $\mathrm{Kaffel}$ Revenge. De Perken bier. Donderfteenet

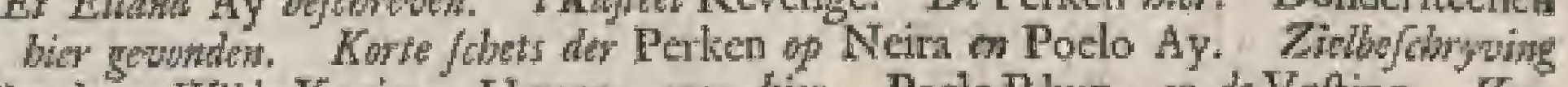
wa Banda. Wilde Koejen, Herten, enz. bier. Poelo Rhun, on de Vefting. Ver-

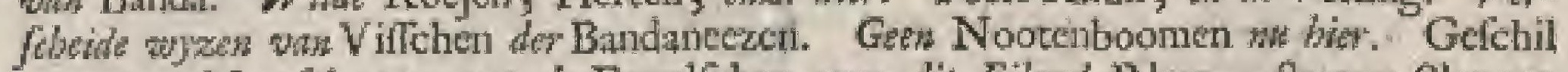
waw ons Matichappy wot de Engelfchen ovo dit Eilod Rloun. Swame Slangen bier.

Het Fi. $\mathrm{H}$ Et vicrdc Eiland, wax van ons nu te handelen finat, is het cilind Ay of Poclo Ay, zynde mar ecn kleine myl lang, en ontrent 4 uuren folyeppens in 'tond; doch des nict te min een van de vermakelykite, ja t fohoonte wan alle de Bandafiche eilanden, om dht het meel ower al whik hand is, hocwel het hier en dane in " $\mathrm{t}$ bofch nog wel ext klcin heuwelic heeft.

Het legt omtrent 3 mylen Weft tea Noorden wil Nein, zynde, by fchoon weder, cen frani rejsje om "er na toe te chepon, doch by quald weder kan dam cen vermantyke zee ftan, ca als men de rets nu al meind gednan te hebben, hecte men dicht by dit Filatid wan enige klippen, die "er hicr en darir an de Ooftzyde poor loggen, zuhken [xwinten brunding, en manting van de zco, dac "cr meenig martuig het onderfe boren geworpen is.

De Tenimberezen (zeker foor van welgeoeftende (choppers) ritoon 't onderite boven gellagen, keerch "t vartuig in de volle zec matr wecr om, hoozen 't uit, en. fcheppen weer voort; in welke handigheid ben niemint kin navolgen; doch als zy dit by nood doen, moet men ben woor 't bettellen van cen enkelden briéf wel 4 of 5 Ryksdandders geven. Dit omflaran der vartuigen gcbeurde verfcheide manlen in 't jant 1687 . en 1688. Wamnecr ik dar was; maar anmerkelyk pond ik toen zeker geval, by "t welke een Orembani yan een Perkenier, watar in niet dan haiven waren, dicht by "t Eiland omfloeg: twee, die fwemmen konden, begaven zich vaun ' $t$ vastruig af na land, maar $z y$ verdronken in de fwaure branding. Negen anderen, die niet fwermmen fonden, hielden zich alle by "t waartuig, en verdreven met de ftroom, zonder dat men taal of teeken van hen vernim, op "t eiland Ceram an, wan wanr ze den' OrangIsay van Gocli Gocli, na ben 6 weken wel gehandelt te hebbely, weer op Neira by den Heer Landvoogt wan Zyll bage, die hem woor deze belceftheid een frasi gefchenk van kikeden deed.

In 't Noorden heeft het cea regelmatig 
tr Rallecl kafleel, Revenge genatur, om reden, Revenge die wy by de verowering van dit filland zallen geven, In 'rzelwe beefecn Vaandrig 't gezag owet cenige foldaten, en tris wan alles wel voorzien.e Men is gewoon zcin[ehoten pan ' $t$ 'zelve pon' die that Neita re doen, bn then te verftendigeis, dat centchip, of rehepen zich "is zee herwalt ani ontdeken. Dool wie of whinneer dit gebouwer is, blykt al mede nier, manr wel, dat het er al woor 't jail Iofo' "nevens Nathurw, en 't andere Kafted, gewcelt is."

In dien zelver coord plast in wade tyden een Banduefche Wetting te flian; dic ann de zeckant cen muumgrie lind, doch na de landzyde open wats. Hier in hebben het de oude Brindaneezen, van cenige Juranen onder theunt; nivy lang; en tor in de mand Mey tós (wanteer zy wan den Hed' Oppertandwoogt Rew/ net ermit bezogt witerden) tegen.de onzen uitgethouden.

Dit ganfch Eiland doct zich met zya vlakkic Nootenbofichen, slzoo "er zeer" weinig heurelicen zyn, als de angenamite lufthof op, die nen zich wer= beelden kan ; angezien men "er op het hectle van den dag zelf onder de fehaduw der - Nootenmufchan- en anderc groote vrugtboomen (want in men veel Cacatocwas, loeris, groene rawens, en andere rogels, in groote menigten, 200 datt, als op de andere cilanden, wiegen zict) zeer yermakkelyk wandelen, en tich byzonder wol, dewyl het over al onder de boonen meet fechoon is, het zy te voet, het $z, y$ te paind, dat jk beide bezogt heb, verlutigen jan; "I geen ook de reden is, dat vele, die hier cenige tyd geweelt, en de fware koudelluche, die hier heestcht, vootnatnelyk ontrent her Hong Land vau Banda wegens de dunpen op dat hoog gebergt, gewoon geworden zyn, "er niet weder" van diatu willen, dat ook oorzak gegeven heeft, om deze Landwoogdy, en in 'tbyzonder dit Eiland, luet oudmanlunis te noemen.

Onder andere boomen zyn hier woor al; en ook elders, veel kapokboomen, die mode al emig cieriad, en veel nuttigheid, geven.

En watryle mag men dit Eiland wel als cen zeer diebbause paerel der $\mathrm{E}$ : Mitattchappy tanmerken, angexien het alleen zoo veel Nooren en Foelic, als'dc gallfche wereld (zoo men zegt) van nooden heeft, vitlevert, dat men darr an, al wits "er Nein of "c Hoog I and van Buind niet, genoeg zoude habben. Het fehynt zeer hol te zyn, flwoo men ontwortelde boomen, die omgevallen waten, gezien heefr, die met de zee ran onder gemeihchip bindden.
Ontent het kathed heef men cen groot wlek van Duittche en Miftifche Borgery, die hier mode lunne Specery- en Noorenperken hebben.

Ik kenue de: relve niet by hare naamen, en zal die derhalyen maar met de mamen van hume bezitters in dien tyd opgewen.

Het Perk yan $N$. wan den Broble is groot De Perroop roeden, lewerende 6000 pond Foelte, ken lies, cn 24000 pond Nooten. Her word geftek op 160 zielen, heeft is Alitwen, en wiert tocn gelichat 6 of $7000 \mathrm{R}$ ders witardig te $7 \mathrm{yn}^{\circ}$.

Gelyk er doorgans by de Perten groote ftecne lumizen ftati, die de flatwen, als zy ledigen tyd, en in "t bolch niet reel niet den oegit te doen hebben, wan zeefteen, volkomen opmaken (sangezien men in zulle een Perk allerlet ambagtslieden onder deze flataven, als timmerlicder, mexclarars, fnits, cnz. vry ruim hects) thond hicr op dit Perk een fohoon huis, vin 'c welles ik den bouwheer, den jongen wan den Brod, iers heb hooren zeggen, dat ik watdig oordeclo hier mede aan fe balen.

By "t leven wat zyn wader had ter plats, dan hy naderhand dit nieuw hus zere, een groote Mnnggasboom geftan, dic door ecn ewamen donderflug zoodtutg getrofien was, dat hy van zyn top tot banedea wan cen fcheuride, weshatwen men genoodzakr was den welven gelyks gronds weg te kippen. Zyn vader ondertulfihen overleden, en hy, beziter yan dit Perk geworden zynde, witer genegeh, ontrent 20 jaren ma "t f cheuten wan dien boom, om op die plits een fratü nicuxw huis te zetren; doch was genoodzalkt de wotel wan dezen boom, die hem in "t leggen wan do grond1ag verhinderde, eerit weg te doen grwen. Dit liet hy doen, matr vond, by 't vervolgen wan deze fcheure, an het onderfte Vau Donderden wortel twee donderlteenen (dic ik fteners, gezien heb) byeen leggen. Zy waren wornder ontrent een balve voet ling, en twoe duim breed, en cen halve duim dik. Hate gedante was even cens als econ tcherpen beitel aan de cene zyde; doch ann de andere zwde thomp; en de couleur als dic wala de Jeven, dar mer, - huizen mede dekt. Behalven deze donderftemen heb ite 'er nog een op Neira gezicn, die my te koop anngeboden wiert, doch wan een gebecle andere gedante, gelykende zeer wel na ecn bokkenlyorencje, el na gilthing ontrent twee en een half winger lang en oen duitn dits, wat kiom voor omgebogen, en wan een gilmmeade koperingtige coulen", it heb "er vod, doch noit dictgelylien neer, gerich.

- Ni deze korte butenfprong kecre its 


\section{B. A $\mathrm{N}$ D I A}

weder tot de hefchryving wan de verdere Perken allices.

Het Perk wan Antoni Melis was in 't jater 1688. (en ookk 1708.) 800 roeden groot, leverd 4500 pond Foelie; heeft 45 flat ven, Do zielen, en wicte gefchar $f$ of 6000 $\mathrm{R}$ dess watdig te syn.

Het Perk sath Huga de Ray wis groot gro roeden, leverde foos ponden Foelie, had 45 dhawen (gelyk hec onk op 4 o rielen ftood $) \mathrm{cn}$ wis roop $\mathbb{R}^{\text {dess }}$ wandig.

Matrits Mentridf luat een Perk, dat groot was 700 roeden. Het leverde 2500 ponden Foelic, hid 30 fluaven, flond ook op een getal win 30 tielen bekent, en was 3500 Reders watidig.

De gewezen krankbezoeker Kejzer had exn Perk vin I I oo roeden, dat 4500 ponden Foelie leverde. Her liad 60 1]anwen, hoewel het mats voor ro ziclen bekent ftont, en was $6000 \mathrm{R}$ dets walldig.

Deze zyn wel de voornamite en de bekentlle Perken, buiten welke nog verfcheide kleine, met de woorige eci getal van 31 uitmitien, 200 my bericht is, die zamen ontrent zoo veel fpeceryen als het comptoir Wayer, op r of 6000 ponden $\mathrm{kt}$, leweren konnen, 't geen op 30000 ponden Foclic, en Nooten maas mate van dien, witkomen zul.

De Perkeniers leefon hier in vootige tydeiz (alzoo zy nadethand onerent 't jagr I70ip. door den Landwoogt de Haze hier, en op de andere twee Eitunden, zeer gedrukt, cn datr door zeer werarme zyit) mede als kleme Prinçen, en dararon veel wetmankelyker, als op Neira, en op " Hoog Laus, on dat die Eiland in zich zelven ved vetmankelyker" en "vlakker" is en ofn dat zy hicr vry grooter erven, dan elders, by hunte huizen hebben, en allerlei vee weel gernakkelyker konnen aangueken.

Wy zullen hier ook eea lchets war de Perken op Neira, en op 't eiland Ay, cwen als vin dic op "t Hoog Land, by" woegen, om dus een gezigt win dezelve te hebben.

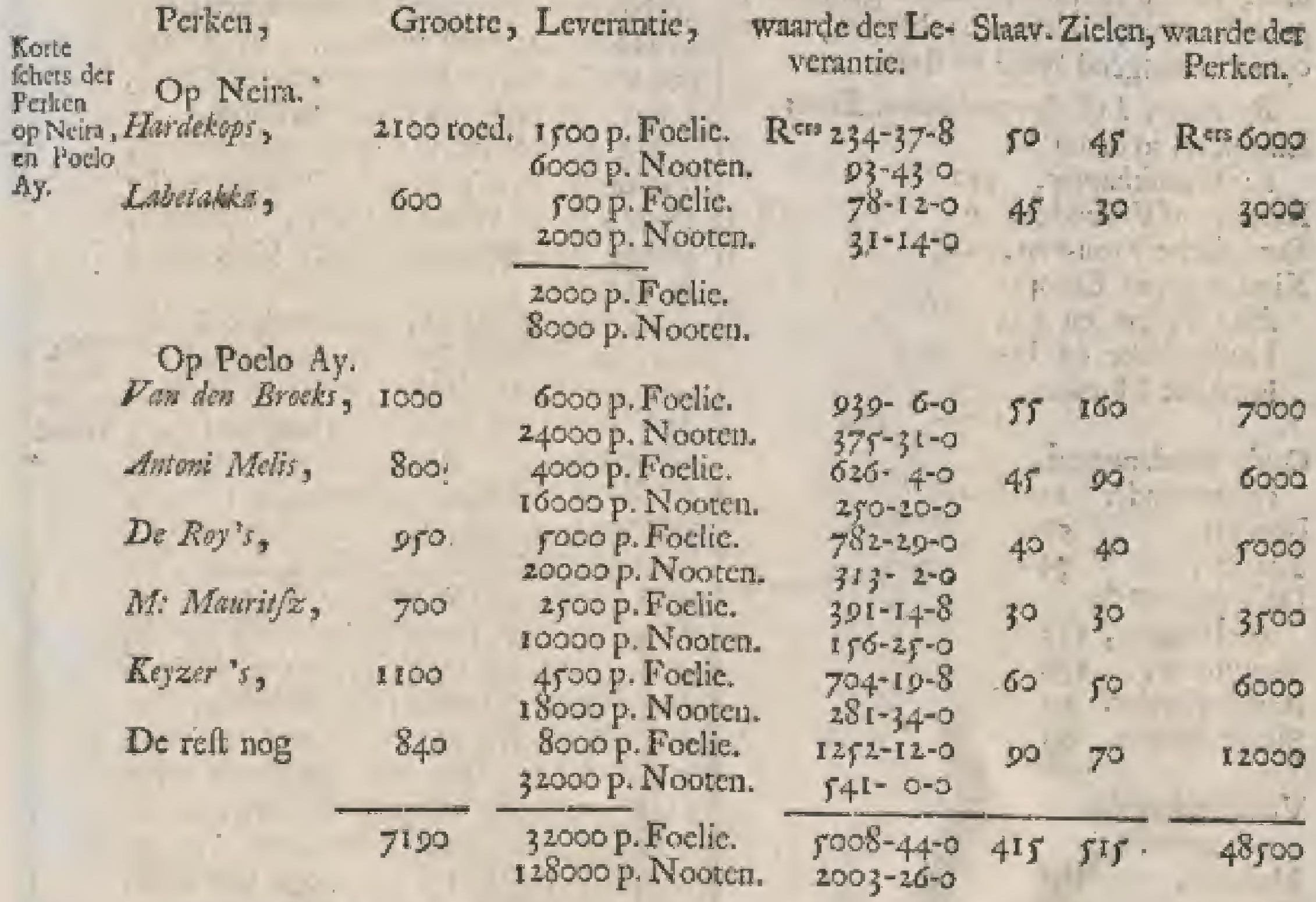

My blykt uit zeker Reiziger, dat 't eland Neirn in 't jart 1634. uitlewerde, Foelic 26631, Nooten 6t221 ponden; 't Hoog Land, Foclie 107074, Nooten 200750 ponden, Poelo Ay, Foelie 48465, Nooten 404773 ponden, 't welk zeer" veel wa 't hedendatgze verichilt.

Uit deze fohets, by de voorige wan 't Hoog Land gevoegt, blykt ons, ditt alle deze Perken op die dric cilanden wan Neirk, 't Hoog Land, en Poclo Ay, te zamen 34 in getal zynde, 41520 roeden of 6920 mergen lands uitimaken, die te zamen 289 roo Ryksdatders wardig, yan 2577 lataven woorzien 2 yn, ch in alles 4529 ziclen hier uitleveren, hocwel alle die Perken maar op $19{ }^{2}$ zielen geftelt zyn, dat weel te wcilig is; fchoon 't getal der zielen in verfeheide woorige jataren, als wan 't jaal' I632- tot 16 38. zoo' tuffchen de 38 en 3000 zielen (als uit dit opitel blykt) balicp. 
Ziellueftitryving vin Bana.t.
Zielleflorying der Ingezetenen

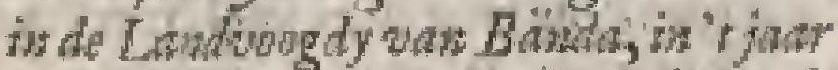
I6 33 . in Atg aftus gedsail; bedragende wein getal can 3842 pryounen, zonder dit, bestedess de 12 jwarks waten, medo to rekthis.

Op Neira Perfoonen

Open 'c Hoog Land van Banda,

Op Lonthoir, t ros Oerien, ror

Wajer, 244

Dender,

Sclama,

244

154

En op verfcheide Perken, 189

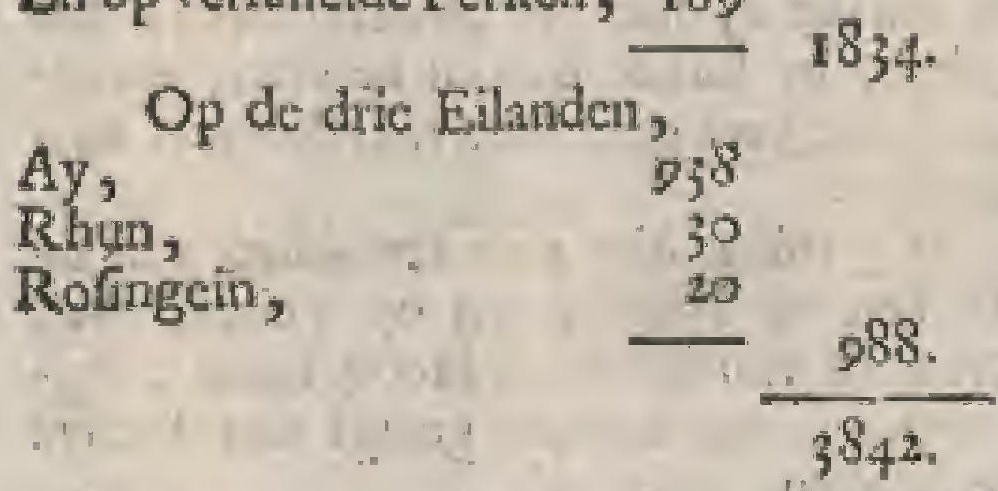

Om nu notg nader te zien, line vecl foorter "er, ' $\mathrm{t}$ zy wan Europecers of Inlanders, het zy van de byzondere geflagten, geweeft zyn, heeeft men lier oog marr op dit nawolgend lyftic te flan.

Byzondere Ly/f der voornoemde Zielon.

Europeers in dienft der

E: Maatchappy, $35 t$

Borgers of Viylieden, gt

Europifche Vrouwen, es

Kinderen van Europi-

fche Vaders en varn

Hollandiche en In-

landf he Moeders,

Oude Bandaneezen,

en daar onder mannen

Borgers, ro

Slanven, Vrouwen de- 33

De Vrouwen de-
zer Borgers, I3

Slavisinen, $45^{8}$

Borgerskinder. 97

Slaavenkinder. 69

Vericheidenerlei

vreenden

Mannich, $\quad$ 886

Slaaven, $\quad 7^{8 z}$

Vrouwen, 3 [9

Slazwinnen, 723

Borgerskinder. 328

Slaavenkinder. $4 \circ 5$

DusEuropeers, Yolwheffene, 462

$\begin{array}{lr}\text { Dito Kinderen, } & 77 \\ \text { Bandaneezen, } & 560 \\ \text { Vreemdelingen, } & \frac{2743}{3842}\end{array}$

Onder welk getal men ziet, dat 2190 flaten met hatue kinderen zyn, die, gelyk zy de grootite helfe der ingezerenen uxt maken, als zy wilden, dic Landwoogdy in groot geviar zouden konnen bjengen; swaur tegen, myns oordeels, op d'eene of d'andere wyze diende gezorgt te worden.

Ten anderen, zoo zien wy in " $\mathrm{rkorte}$ hier uilt , dat alle deze Perken 174000 ponden Foelie, die de E: Maatechappy maal 27236 R deas 2 ftuivers, en 696000 ponden Nooten, die latur mast 10800 Rden koften, jaralyks komen uit te leverent.

Men heeft op het eilind Ay kocjen, wilde en herten, die mitar in ' $t$ wild en in de Koefen, Nootenboftchen hier en daar lospen wei- Henten, den. Dezc kocjen gewen zeer goed vleefeh, enz. buch goede melk en boter, fchoon op dit Eilind al mede geen ver ich water is, walkon zy niet als zcewater drinken, gelyk zy getneenelyk tegenden avond naltrand loopen, om met die ziluge vogt haaren dorft te leffchen; alzoo al 'c werfch- of drink water met vaartuigen vas Conbir 'moet gehalt, en in martavannen, of regenbnklken, ten dientt der menfchen datar, cn elders, bewaart worden. By gebrek van werfch water behielpen zy zich weel, gelylk ook nog, met klappuswater.

Dit Eiland ladd $\operatorname{san}$ ouds twee fteden, Timor en Vrat genaame, van de welke Vrat weer in tween gedelt, "t hooge, en lage V rat genaamt wicrt. Ooli waren zy Oelilima s.

Het eiland Rhun, geneenclyk Poeleron, of eigentlyk Poclo Rhun, genitartint, Poelo

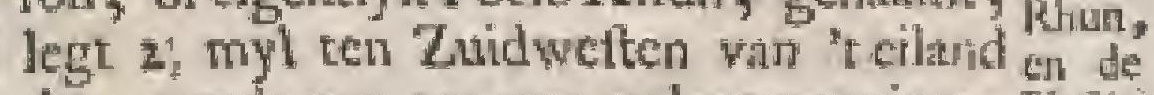
Ay, zynde wat grooter en langwerpiger, Vetling. dan het zelve. Als 't mooiwere is, gate de tocht derwaats gemakkelyk; maar zoo 't wat waid, is "t al wry gevarlyle, onr twee ondieptens, die men in zec, de eene ontrent den Welthoek wan Poelo Ay, $\mathrm{dc}$ andere wat Beooften ' $\mathrm{r}$ eiland Rhun, heefe, waar op by de mintte wind, een vervaarlyle water ftate; hoewel men, datar wat bekent zynde, en "er wat van af in zee ftekende, zoo weel nood nict hecff. Ik heb over die beiden, by therke wind, eens met ecu fehoone Orembay, in gezelichap van den Landvoogt van Zyll, en cencin Monfr. Eding 1687 . gevalen; masu het zag "er vry zutur uit, nlzoo "er nu en dan al een riem in ftukkea brak, en 't Opperhoofd van $A y$, dic wat in zee geftckent was, had geen nood ter wereld. Wy dagen het 'er niet afgebragt te hebben; doch quamen echter, na vecl uitgeftann gevar, dant nog gelukkig an.

Na de Weftzyde heeft het cen iteene Reduir, watr op eenig krygsvolk legt, gelyk het ook verder van noodig gefchur, woorrand van oorlog, enz, voorzeca is.

Het 


\section{B $\quad$ A $\quad$ N $\quad$ D $A$.}

Het hecf zect weinig inwoonders, en die zich dar nog al in hutjens behelpen, doen het meelt tegen dat het wit water voorby, en het tyd om data te willehen geworden is : want ontrent de mannd Oetober vangen zy daar, en ook op nndere phatzen, zoovel vilch (meef een foort by na als makreel) dat $z y$ lawne flawen datr van, en wan Sagoe, dic $z y$ van de Zuidoolter cilanden krygen, meeft konnen houden: want deze vifch plagten $z y$, op dat zy duuren zou, te vekken, of open te fpolwwen, die in de zon hard te droogen, en ze daw, als voorriad voor "t geheel jaat", te bewataren. Zy reluyn, als men 'er veel van eet, wht brandig te zyn, en zy noemenze ook Ikan Panas, dat is, brandige wifch: want men word "er rood van over "t geheele lyf, doch dat gat naderhand met hoofdpyn over" anders frntakt $2 y$ zeer wel.

Verfliej- Hunne wyzen van viffhen zyn dar de wyzen meeft tweederlei, en al wy geeftig. De yan wis- eene noemen zy met de Tali Sockey, de fcken der andere met de Tali Couwer te vifichen.

Bandanc- De ecrfte wyze Tali Soekey by de Bandanezen (doch by de Amboinezen Soki Soki, of Sofoki) genaime, word dus in 't werk geftelt. Mer het tumbreken wan den dag', rits men pas 't hair' op de hauden zien kan, en ook 'savonds pis na zons ondergang, gatan 10 of 20 kleine pratukens, oncrent ecn groote fnaphanslehoot, in een halve maan, wat wan den anderen afgerangeert, wan de wal in zee, even eens, gelyk men de zegen uitwerpt, leggen. Zy hebben by zich een zoer lang touw, an het welk eenige klappus- of gamoctobladeri 2 of 3 wocten van een valtgemalk zyn. Dit touw is zoo lang, dut het van het Ooftelylefte tot het Weltelykfte pramuwrje tocreilen kan. Dit nu werpen zy zoodanig uit, dat her man pis op de oppervlakte der zee ruft, envan yder pranuwken ook met een hatk zoo ftrek gehouden, en wat bewogen word. Dit doen zy, op dat de filappusbladen, die beneders in zee hatigen, en, door die beweging war alle dic hatken der praauwen mede bewegen, door der zelver vry dieper na de grond doorgande fchnduw, al de vifch, dic binnen die kring is, na de will toe jigen zouden. Op dat die vilich nu te fchuwer worden, en te nader an de wal konzen mogt, palmen zy, by zulk eet geltitdige beweging van dexe lyn, hoe langrs hoe meet 'c bot deszelfs in, malkanderen en de wall ook hoe langs hoe meer, cn tot zoo naby maderende, dat zy in Atat $z y n$, om al die vilch, die dan in cen zeet korte en ondicpe kuil by een is, door eenigê fero's, of fuiken, te beletten weer da zee te loopen, en die dus te vangen.

Ik hebbe dusterfebeide malen in ecne trek meer dan cen ganfch vartuig vilch, meelt makreel, zien binnen boord krygen; doch, wolgens hun and bygeloof, moet "er geen vouw by 't viffelsen komen, of de rangft is buiten hope.

De tweede wyze wan wiffchen gant dus toe. 'Zy liaten een toun, wath an op zekere afltand mede lilappusbladen waltgemaakt; en klcine hakjens met aas gedata zyn, eerjige tyd zeer diep op 30 of 40 vadem zinken, die zy dan nia ecnigen tyd met verlcheide viffehen te gelyk ophaten. Anders vifcht men ook wel met bobbers, of groote doorlugtige korwen ruct binnenfiviken, die zy op 100 of 200 vaden lataten zinken; en watr mede zeer fchoone zeekatpers, en andere viffehen, tyevangen worden. Bchalves de zelwe lebben zy ook groote en wyduitgebreide fuiken, even oens als hooge doorlugtige tuitten, met ecl firik wain binnen, zeet verre uitgezet, om de viffchen in te lokticn.

Op dit ciland Rhun plagten ook cenige weinige Nootenbomen te zyn, en ik Geoten heb de plats, dar zy (zoo men nuy boomen zeide) geftan hadden, toen de Engelzen aut hier. nog mectler hier wan waren, en whar over zoo vecl beweging in de wereld gemaalkt is, gezien, matar ik geloowe niee, dat 'cr joo thus boomen op hebben kontnein groejen; en men zei my, dut 'er op dut Eiland geen meer, mitr dat $z y$ alle, fchoon weinig in getnl, toen 'tde Erjgelecen werlicten, uitgeroeid when; gelyk men ook dezelve, zoo ris men 'er weer eenige wernam, die door de Nooteneters (zekere vogels, dic de Nooren infwelgen, en zich weer ontwallen laten, en dus als voortplanten) daar verwoejt mogken zyn, en eerften gewoor was uit te rocjen.

Dit Poclo Rhun is " $\mathrm{t}$, watr ower zoo Gefchilvecl [pel, veel jatren atn een, gelyk men let wat onllindig in Aituma, en anderen zien onte kan, tuffchen onze en de Engelfehe Ooft- Maatindifche Matichappy geweelt is. fenappy

Al welke gefchillen echerer ecrit in "t jaar FingelI667. den 10 Juli op de Bredalche vrede- tehe orez handeling niet alleen volkomen wierden dit eilanic afgediali, matar toen ook goedgewonden, Rlun dat de Engelfchen van ons, Nieuw Nederlind, tegen "t ciland Rhun, overnemen of" rerwifieten zouden, gelyls die dant of zoo gerolgt, en watr by dic Eilind zedert aun onze Comparuic gebleven is.

In oude ryden had men op dic Eiland twee fteden Vorat en Toeldar. Het hecft pis verich water genocg roor zyn volk, dur weinig is.

Zy waten wh ouds zec bygeloovig, fterk, gelylk de Bandanezen, wool de toovery, en ook Oclilima"s, en die van de cilatiden Ay can Rhun garen yoor, wan 
ouds al meefters over de 4 Ateden wan Neirat grweeft te zyn, om dat hume roorouders dir land yan Ay en Rhun eerlte bewont, mer allewei vragtbonmen beplant, cen zich datr 01 derwarts begever hobben, lantende matr zommige van hunne vrienden met eenige flawen hict blywen woonen, on labne zataken wath te nemen. Om welkereden zy ook nog in "t jast I 609. en eenige volgende jaturen, hun deel in "t balkkorragic- of anker- en andere gelden plagten te genieten, gelyk ools die vau Neira, buiten woorkennis van deze Ewee Eilanden, en wan al de Oelilimas"s, op verbeure tan een detde der goederen, geen koop wan ryt, kloeden, of van ecrige gelder, manken mogten, "t geen anders de Nederlanders gewoon waten in de tegenwootdigheid wath al de Odilima ${ }^{5}$ en al de Odifiwa"s, tot Orontale, onder dien grooten boom, te doen, en na zelkeren eiffh voor de Nooten en Foctic by den Intander, en een bod der onzen 'er op, gedaan, wel 4. of $g$ wethen dar mede bezig te wezen. Enzoo was het ool met het behandelen van alle andere fware landzanket, welke door die wan Neirn, of ecnige mdere fleden, buiten kennis der Oclilimes"s, niet behandelt mogen worden, ten wire dat zy mede in cen fware boete, of werbeuring yan ect derde der goederen, over welke by hen gehatudelt wicht, werwallen wilden.

Dit is 't voonam fte, dat if wath Poclo Swarc Rhun te zeggen heb, nict wetende, of Stharc men lier ecnig wild war berten, koc-jier. beeften, enz. maar wel dat men 'er flangen, zoo twant als ergens, en ook ecrige met pooten, heeft; watr wan ik zelf 2 pooten lang bewart helobe. Dk Fecr Landwoogt wan Z Wh, heeft my werhatit, dat er eens cen llang als exngroote bilk, die 8 matroozen matulys yoore honden trekken, dood gevouden is.

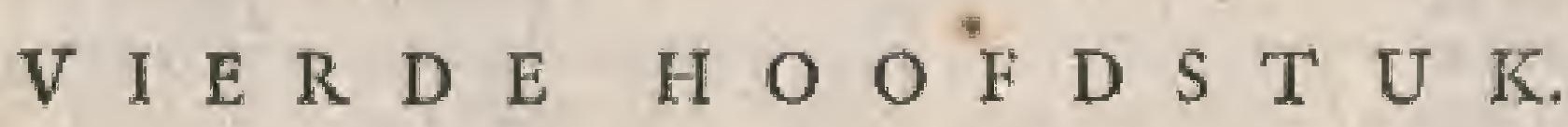

H Et Eiland Rofingein. Zechootenkens. Wilde Koejen. Een Reduit bier. Zeld1 zam Gras. Geen Nootenboomen nie bier. Poelo Sowamggi. Poclo Piefaing. Potlo Kapal. Onde zeaken van Banda. De Bandincezen verder befloweven. Aardbevingen. Tal ber gebruikelyle, De Zuidoofter en Zuidwefter Eflanden, Klein Kcy. Groot Key. Onffandig befchroen. De Aroëlche Eilander. Abcl Tasmans Tege na 't Zuidland, in 't jaare 1642 .'Vm Diemens Land. Frederik Hendriks Bant. Zien foby won Menflon NowaZedandia. Mer/chen gexien. De Moordenantrstati. Drie Koningen Eilland. Lange Merdchen gezier. Pylfturts Eiland. Di Eilanden Amfterdan en Middelburg. "I Eiland Rotecrdam. Prins Willems Eilarten, en Hecmskerks drogg-

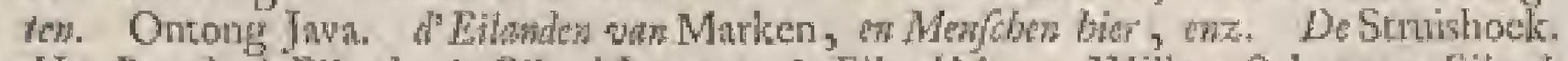

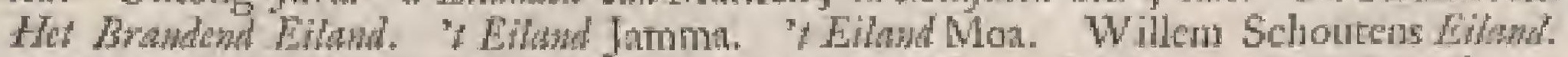

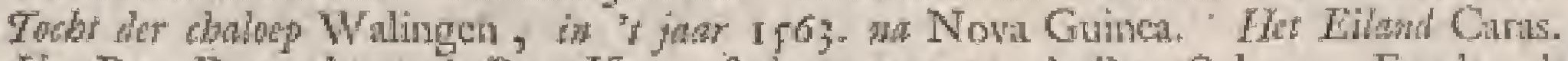

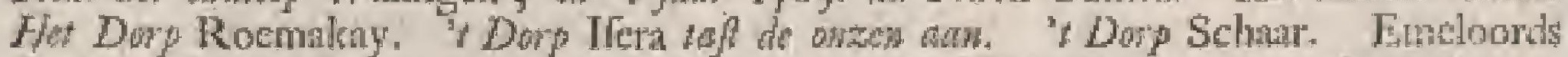

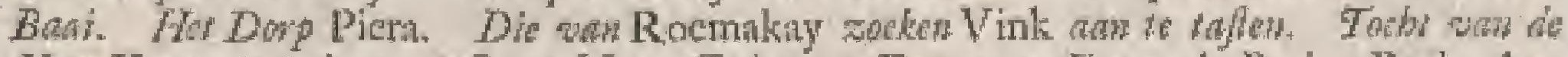
Hec Keyts in "/facer 1678. na Nova Guinen. Fataga en Roemali Bati. Pocho Aas.

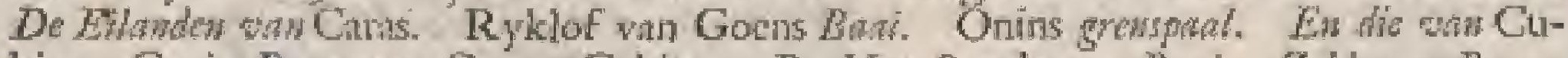
biay, Cani, Batoer m Carn. Cubiay. De Leer Speclmans Bato. Zeldeane Begra.

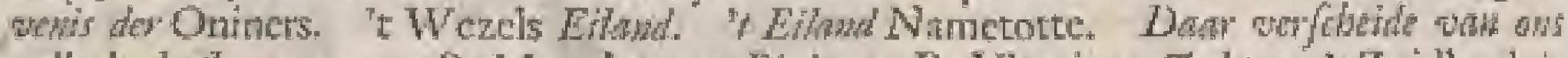

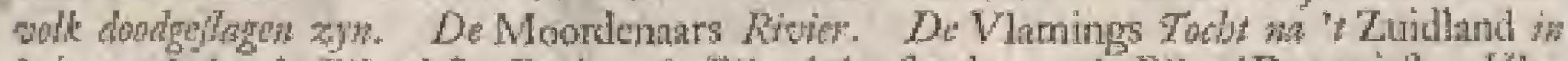

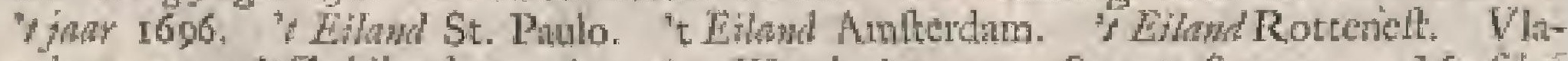

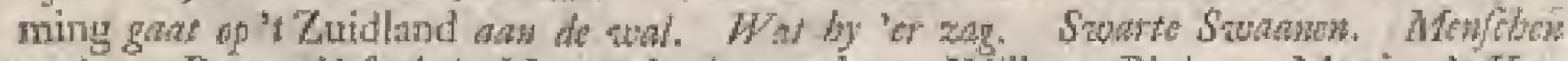
gezicy. De ozerblyfals in Hartogsbaai kevonden. Willems Rivier. Moni. 'c Ver-

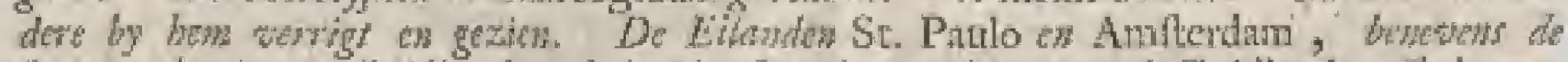

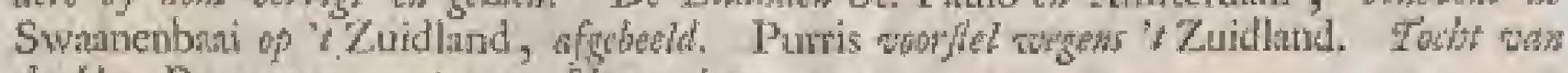

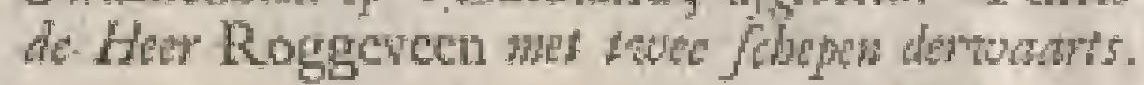

Het Fii-

land Ro
[T

Et zesde en lantfe der Bandanefohe eilatiden, dic bewoont

Het is vry klender als Poclo Rhun, of een des dric anderen, en legt ontrent 3 mylen ten Zuldoolten war Oerien, of wan her Hoog Land:

Het is ecn wild, woeft en bergngtis cilind, hoewel zoo hoog in verre nin niet, als hee Hoog. Land van Lonthoir.
Het dient meet on "er de Banditen, voonnamelyk van andere gewelfen, te phataen, én brandhout en inhouten voou de vartuigen door deze Banditen te Imten kappen, ats mede on kalk, dio van hen wan de zec-enkrwilteen, op de teven dar ontrent vallende, Gebrind word, wan daar te halen; doch den $23^{\text {nen Februati }}$ 604, verboden has Edelheden geen Baindirell, tor andere platzen 
reets behoorende, ofte wan dar na Ro* fingein, of ma Banda te zemden.

Ook vallen hicr finge en zeldzame zeegewafichen, woornamelyk wan die witte koratic zeebootnpkens met fwarte banden, die men ools als een geneesmiddel gebruiken kan; welke men opde reven fondom dic Ejhand zoo overvloedig heeft, dat geen tchiphier ontrent komen kiii.

Meu hect 'er weel ongemeene footen ZechoIำk horenkens, cwen alls in Amboina,

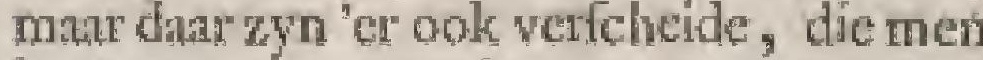
-in Ambon niet heeft, ats onder andere de fpierwitte kleine kruthorens, nnet Jwarte cakken, dieik nergens zoo, als hier, gezicn heb.

Ik heh ditar ook zuiver door de zon gewfineer zout gezien, vanzecwater in de holligheden dezer rotzen geflagen, dat zoo wit als hagel, en zeer goed was.

Men heef hier ook veel wilde kocjen,

Wilde

hocjen. eenige Deetren op dit Eiland gezet zotden zyn.

In 't jast 1687 . hebik, datar zynde-met den Heer Landwoogt, 'er twee wan gezicn, die door zyn Achtbds wildechut, of jtaget, in eene feluinze fohoot, met twee kogels byma op en en de zelve plants in 't woorhoofd, pas boven de oogen, getroffen witren. Zy zyn zoo kloek niec, als de Balifche, en fcheenen my Maosfrarfelve beetten te wezen. Of "er cenig ander wild, of gedierte valt, woet il nict.

Een Is- In to Noordwelten des Eilands heef duit hiser tmen een Reduir, die ik vertrouwe nien= wer te zyit, dan die, wan welke in "t jar 1627. in het Dngregilter, nevens dic wan Denner, Poelo Rhun en Wayer, gencle word, on dat if in de antedkengen war cen wriend, die her in "t jaar 1657 ; geweeft isf thlat nirgedrukt vind, dat zy nog niet lang geftuan had.

Behalwen de Banditon, die geen groot getal nimmaken, heeft men geen inwoonders op dic ciland, als de bezetting vat deze Reduit, zynde een Sergennt, en wat meer foldation, dan men gemeenlyk op zulk en Reduit legt; om de; Butititen, die de Sergeane en ayn rolk eens overwelclig heblon, en toen ontvluget ayn, war betef in toom te.honden. Il zag in die korten tyd, dat ik 'er was, math twee vrotwen, te wheten; die wan don Sergeantené een foldatien wyf, beide Mifticen, doch de hatite en buitengemeen klock thk: In oude tyden had her 200 inwwonders.

Zeldyan Het zeldzamite, dat ik hier vond, Gas was, dat vid het gras, ddat ik hicr zag; zich zoo hut, co lcherp, als doomen, vertoonde.

In de vifcheyd valt hier ook vel vifch, "L geen den Sergeant, door' de natftigheid wan zyn wouw, die 'er zect wel mede woet on te gani, veel foorded geefe.

Nooten- of andere viugtboonen heeft ${ }_{G e}$ then her uit de natuur geone, mat wel Noorem dic men 'er plant. If meine, dar ik, boomen daar een kitappabootr ontrent de Redur nu hiet, gezien heb. Bumboezen ziet men "er overvloedig.

Men heeft hier ook goede kJei gewonden, on efterikken, en andere ftemen, van te bakken; en 't is ook wel vath verfch witer velzicri.

Hien plagten in oude tyden wel de mintte mar ook de befte Nooten val Banda te vallen.

Op dit eiland Rolingein (van sndcro in oude fchritien ook wel Roflitngyn genaame ) plagteli van ouds drie ftedehens. of vlekken te zyn; Woctm, Tanamafí en Vali. Hee ciland heefi een groote droogte, een gooteling fchoot "cr vain gelegen. Ook was 'er in oude tyden een koning ran dit en wan de andere 'Eilitaden, wan welke men in Ridjali "s berchry ving van Hitoe's kuft gemele vind, alwar in de ighe Alkitra valn den koning wan Rofingeing gefprokets word.

Niet tegenftande men hier geen kaimatrs of krokodillen oit gehad heef, vernam men egtẹr, eenige jären voor 1687 een kniman' die er niet wel nnders, dán wan 't' piland Ceran, kan' gekomen, en zeketlyk door een form, of iet diengelyks, verwoer, en zco oferged wommen a d zyn, fetion het van Banda wel 15 of 16 mylen atgelegen is. Hy wioft ten ecriten ontdekt en gedood; doch yoor nog na dien tyd heett mes dafr, of ook op een dezer cilander, dit dien met vernomen.

Die nut is wel te genzen Bitoditch-ciland doch hice ha toe mogen, volgens ordre

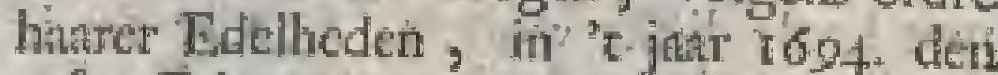
$23^{\text {ften }}$ Febrtari an die vith Anboina gezonden, gect gedoemden wan audere Landwoogdyen, dotil tha wor af verzoge verlof batrel Edelhedca, gezonden wort den. Ools heeft men wel Banditen op andere dezer cilanden (otreen wan de gunit des Land woogts med sithangt) geplitidt : want de oude Heer Cojert, gewezen Landwoogt wan Thyourn, heefe op Poelo Ay, jn en klein huisken, dat if nog gezicn hebbe, gewoont. Ik weet egter een getal van een dus begunfligden Bandiet, die zich op Louthoir onthicti, en die loak Edelheden, in "E juat 1688 . witdrukelyk na Rolingein ordonnecrden.

In deze zes van noids her bewoonde Fidandicn plagten wel ifooo zielen te we$z e n$, lioewel "er in alles nite boven de 4 of rooo weerbiture manten, met fohild en fward voorzien zyn, want onder dan nog

Fi

III. DEEL 


\section{B E S C H Y V I N G E V A N}

de flatwen getelt wierden. Nu gis its dat "cr op alle de Eilanden nier bover de 5000 zielen zyn.

Poclo Belyalven deze bewoonde Edtunden, Socwang-zyn 'er nog dric onbewoonde. Poclo

Swanggi of Sowanggi (dat in 't Maleits, het toowereiland, beteckent) is 'er een van. Het Yertoont zich als een groote klip, $f^{\prime} !$ myl ten Noordweiten wan den Goenong Api ; en is ganfeh woeft, en nergens wel nan te komcn. De inwoonders der andere Eilanden noemen het zoo, om dat zy gelooven, dat de Duivel 'cr' huishoud, en dat het daar fpookt, walaom zy met dat eiland ganich niet willen te doen hebben, en door ' $t$ vertoonen van weel fratzen en bygeloovige grillen (als zy 'er ontrent komen) hun beft doen, oin "cr voorby te geraaken.

Men heeft 'er vel' groote flangen, en men plagt 'er,ook eenige, weinige, vrugtboomen te hebbeir.

Podo Poelo Pieflang (dat is, het Picftang of

Pieffang. Bananas ciland, legt zeer digt by Neira's Oofthoek, wat Benoordes dien Oolthoek yan 't Hoog. Land. Het dient jegerswoordig alleen, on 'er een thuin voor den Hecr Landvooge atn te queeken, alzoo 'er de aardgewafichen zeer wel ticren. Dant woont ook matr een thuynier op, die om den tweeden of derden dag, en zomtyds wol mant cens.' Ts weeks, met groente aan zyn Achtbds huis komt. Daar is een klein Alege hasisje, waver in ik eens mee gezelfchap prolyk geweett ben, en met veel, werwondering zoo vecl vilch met de Tali Soekey watrgen zag, dat men dio in een fragi groot whartung niet wilt to bergen.

Men beeft.'er ook, hoe klein lot is (alzoo ment het met een: lange finaphatan byna zou konnen over(chieten), ecnige boomen, zommige wan welke ik met veel werwondering door de rotzen licenen, met harde dikke wortels, zonder dat ik de allerminfte arde dare ontrent lkon gewant worden, heb zien groejen,

Een weinig Benoorden dif eilandjc Poelo hecft men nog centikinder, zynde maw een barse rots in zee, Poelo Kapal, dar is, het fchip-ciland; genant, on dit bet zich vain virre in zee oven als een fchip opdoct:

In dezic eilanden is 't befte en meefe

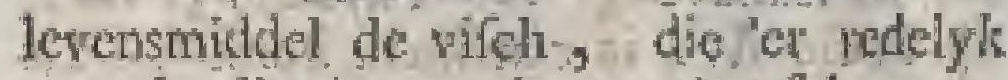
overwloedig is , ook zyn 'éc fcharpea, hoenderen, endrogels, cnz. Groente is 'er weinig : de geitoofde. Nootenbol fter is cen der befte, ichorels. Ry Ry en figroe, (dic zy van de Zuidoofter cilanden y en ook van Ccrusn en Amboing, wolgens laft

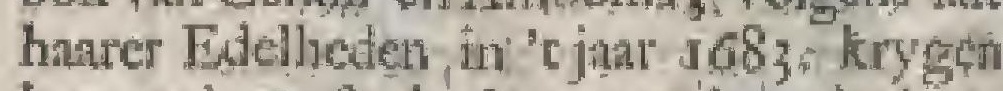
konnen) werthelet hen voor brogd, hocwel 'er dat zece fehoon, zob veel mpodig is, gebakket word; doch de digon is

cen groot voedzel voor hunne flaven: want fchoon "ert rys genoeg komt van de E. Matatchappy, cn van de Borgers, zoo weritonden echiter haar Edelheden, dar men de flaveu mant van figoe verzorgen, en dat geen Borgers humne rys aan $\mathrm{Cc}$ ranmers zouden mogen verkoopen.

In oude ryden phagen die zes bewoonde Bandanefehe eilanden yder byzondere onde woorscgen te hebben, eu yder byzonder Onde vek op zulk een ciland verdeclde die weer was Banmet de andere fteden en vickken. Een di. verdecling, uitgevonden, on malkanderen niet in de wey te zyn, en in ecrdragt zamen te lewen.

Labetaklsa land de groote viffehery, met zyn drie fteden; en zy waren het hoofd des Eilands, eer zy wain die van Neira afglcheiden zyn.

Neira, mee zyn drie fteden, matkte het koperdrand tót hoekcn, en zy mogten alleen matar op Thullelo on houwmeflen, en Iwatrden, vaten ; behalven eenige weinige, die zy dat echter niet, dan met 1o per cents te betalen, toelieten. Ook heeft de lconing van Thullelo (dien ik nergens wete te vinder, weshalven geloove dat het Tambocka zal moeten zyn) aan dic fan Neira cen zeil, als ees verkeerde bezati, en dat woortegt ier heveris gefchonken, om hét buirenite yan hunne krisfeheede boven ann, " ter brechte wan 4 wingeren, met goud te raogen beflan. Twee yoortegten, wan zoov veel belang, dat geen ander" Bandanees, zoo hy van hen niet beoórloge witl zyn, zich dic mag aanmatigen ten ware dit hen door die wan Neira by zekere gunth, die zy aun de vreemde Oelilimaze Orang Kaja's wel cens bewezen, toegeftan wiert.

Die van Louthoir hadden geen woor: regten wath eenig bolang; that wayer de magtiglten ter zee, in priauwencen joy* ken, met welke lantfte zy op-Micalfar, Java, Malacca; Patani, end woeren; en landel dreven, hoewel ay' dat in ' $\mathrm{x}$;hat I Gio. zoo fterk niet meer deden. Hier bequamen $2 y$, ook cenige biftoin, yoers, en itormhoeden, waar mede sy in Banda kornende, begeerden, als ceri voororegt hien eigen, de zolve ool te voeren; doch a|zoo 't ganfche land hicr tegen opptond, blect dat naserhand yder, want hen yry.

Dia van Hantuet, een zekerel oude Negry allier; geneerdon zich met Foclic en Nooter to plukken, en dare af Nootenolic to bminden, alzoozzy toen wel ode moetle! Nootenboomen hadderi. Zy soeteri jactlyks ook met' 5 of 6 groote pranaweri na ' 2 Zuidoofter eland Tenimbar y :ontrenti zo of 40 mylen wan Binda, alware zay flatwen, katrer, bokken, padi (of arytt net tzy boliter:) en boontjes, logien. 


\section{B A}

Op deze eilanden woeren ook die van Sammer en Orontates ; doch die vans Celatnme, Wijer, en Oudendenner, meeft op de cilunden Key en Aroe, danr zy hunne. groote jonken, en pratuwen deden mataken, wair mede, alzoo zy de befte boomen daar toe hebben, zy geheel Banda verzien.

Her eilnd Ay wart ook wel op Key en Aroc, doch meeft op Amboina, om fagoe. Hanr voorregt is, om fokkels c1 matten, aungezicn zy daar toe de meefte bladen hebben, te matken.

Die wan' het eiland Rlyury varen op de zelve platzen, als die van 't eiland Ay; tnar maken en verfelasfifen al de le lappessolie in Banda, atungezien zy de meette klappusboonien toen hadden. Ook maken $z y$ cenige foklsels en matten.

Dic van Rofingein yaaren meet op Key, en Goram, om fagoe, en plitgten allerlei ande potren voor Ceram, Gortm, $\mathrm{Key}$, Aroe, Banda en Amboina, 'cnz. alzoo zy feloone ande hier roe, en tot tichelfteenen, hebben, te bakken.

De Heer van Berkel, die zeer goede kennis van de Bandafche zatken had, zegt, dar de Bandancezen, ontrent 't jait I roo. nog van 4 koningen, te weten, die van Libenklka, Celamme, Wayer en Ràfingein, bettiert wierden, die zy daar ma verftooten hebben, ftellende zederr de regecring an de Ouditten des Lanids, die nevens de Moorlehe Priefters, die operal byna "I woornamitte bewnd hadden, over alles uidpratk deden ; doch zoodanig, dat deze uitfpratk echter, zoo de Boedjangs, of de gemeente, "er niet in bewilligden, geen voortgang had.

De geflagten, of mazaten, dezct vicr konisgen waren in 'c jaar 1610 . nog in Banda, en hadden hume naatincn, en "tregt van in 't gerigte te mogen zitten, op hunne byzondere plats, en om Sinhbandars te worden, toen nog behouden, hoewel zy in zich zelven geen meer maigt, dan de andere Orang Kajn's, hadden.

Het was, in zyn tyd, de gewoonte nog, dat die fteden, daar de koningen wel eer regecrden, in de algemecne landswergaderiting als koningen wierden angerproken, gelyk zy toen ook dien natm nog voerden. In die vergadering wiett de koning viln Labetaklea boven an, dant ma dic wan Cclamme, daar na die van Wayer, en din die yan Rofingein gezet. En Wayer voerde nu, by werfterf en door verhus welyking met die van Rofingein, beide deze lioningsnatmen allocn.

In alle vergaderingen wiert het voorftel coor de Ouiften, en de Sjabbandars, doch de uitfrank meeft door de laatiten gedaan; datar ra zci 'er yder zyn geroclen over, en datn de Papeu, elie volgens hunne wetten, na onderlinge Priefterlyle
A.

betanding, een tweede utifprak deden, die zy dan, zoo die hen bethagde, matinumen, of anders werwierpen: want de Boedjangs ( al eigentlyk de ongehuwder betcelketat , matr wan door zy de gemeente werftaan) gaven an alle be(luicen het fwathe gewigt, buiten welker tocftemming geen befluit ftant greep.

De Bandunetzen waren wath ouds her zeer hoognoedig, trots en opgeblazen; beromende zich yder niet alleen een edelman, en wan hoogen adel te zyo; mar dit gijg zoo verre, dae yder vau hen, na zyne wonderlylie uitrekening, ook de edelite, en in rang verre boven underen, zyn wilde.

On dit te bewyzen, halen zy op, hoe dat voor go of 100 jutten de groot: vader, bedtevader of owerowerbeltevant wan dezen, een rbure wan de averowetbeltevarir van cen anderen, dic zich zegt Fun hooger adel te zyn, geweeft is, en houten opdien grond verder ftatude, dat dierhalwen atle nakomelingen wan zulk eenen al mede tot fanaven ran dezen grooteren edelmin met al "t hunne, ter cyd toe, dat zy zich zelven vrykoopen, vervallen zyti.

Indien men hunnen Adel chter eens regt nafpeurt, zal men berinden, dat humne voorouders, of Bundicen, of weggeloopene flaven van hunne meefters, of wegloopers van hume ouders waren, en dat hunne voorouders of Caffers wan Mofmbile, of uit Anabien, Perfien en Cambaja, of ran Choromandel, Bengale en Muliacen, Pegu, Atsjin, Jatsa cn Mnnungeabo, ook veel Chinezen, Makaszauren, Molukkers, Amboinczen, doch meeft Gerammers, en weel Portugedche en Miftiçe hoerekinderen geweelt zyn; en zeer veel datacu wan Ceram, Key, Aroe, Timur, Solor, Bnetra, Teuinbar, enz. datronder liepen, die, met "er tyd door groote naarftigheid wat wetder gekomen zynde, met een Javanze, Malonftarze, Boctonze, Ternatnanze of Malcteze byzic huisgehouden, en dezelve, na "t teelen wan verfcheide kindercen, op hume wyze getrouwe hebben. Uit al het welke klatir genoeg blykt, dat het een mengelmoes en lauvengebroed uit: allerlei Natien is, van welke de meefte woortgekomen zyn.

Die by hen met een anders Gavin bocleerde, en 'er ect kind by kiregg, moelt, wilde hy "t kind hebben, de flate win wykoopen, en daa na voof het Ikind, wilde hy geen fpel 'cr over hobben, nog iets byzonder geven; want anders malkte die eerite meefter op zya onverziente net alleen op dat kind, maar ook op al het owergewonnene, $z y$ nen cifch.

De vrye wodiviven der Bundaneczen; E 2 geeth 


\section{-36 B E S C H R Y V I N G E VA N}

gect flawinnew wynde, mogten met hatr's: mans jonger broeder, doch de oudfte broeder mogt met de weduwe yan zyn -jonglten broeder niet hertrouwen

Dic by yemons Mham betript wient, moet antitomes, op "e ger thigenis velutwre lieden, doch wan geen fithen, fteren.

$V_{1}{ }^{\prime \prime}$ fere en Vryer liepen wan ands, en zel $\vec{f}$ in liner tyden, zonder cenige thaf by mallenderen; manr overipel wiert by hen met de dood geftraft.

Zy mogeț ook hatte vrouwen dricmat veruerpen, ea. ze weder atunemen; matit zondut yemane ten wierdental doen wrilde, moetten zy beide fterwen, of levendig, met 'thonfd "er bunter, begriмел, en zoo dood geltecrigt. worder, ten ware $z y$ in ftuat waren, on zich zoo dier , als de Prictiters prys op hen telden, wry te koopen.

Dievery wite in de twee cerfte reizen by hen nict; mant de dexdemat, als men 'el' yemint op betrapte, met een geloboete, of ook wel met oneffen flagen geitnft: want die zulk een dief met evere tlagen gettraft liad, moeft 'er zelf weer zoo yedl ontfungen, of zullks, volgens uitfpralk der Moorlche Putpen, arkoopen; orn 't welke te mydern, dant wonderlyk wel woor gezorgt word.

De oude Bandanezen plagten zich met. twee dingen arm te maken: de vrouwer met het geven wan maltyden wan hime Frienden, tetwuyl de mans op een tocht gingen, en on hen dus een bebouden rejze toe re wentchen; en de mans, weer behouden t'huis gekomen zynde, door "rwelkon biermin yan hunce vrienden, die niet vertrokken, woor dat de helft vin de on crwinit gevlogen wis.

Hax is wat ouds her een liardnekkig, De Ban- hoss, tinuwloos, verriaderfeh en wederdanecenth huig volk geweelt, op de welke geen befduge tha it ter wereld te maticen wis, waroms wen. zr ook meelt thicheroeid, of na de nabutrige ellanden, als Cerim, Gorm, Key, Aroe, Cailolo (dat meet' Bardanezen zyn) Soeli, enz in Amboina, en andere Landes verdreven, en gevlugt zy[n.

Iutur plagren 'ce ook op de kuft van Hitoc te woonen, aan welke in ' $\mathrm{c}$ jatr I6ro. cocgeftan is door hat Edeheden, volgens lehryven vam den $22^{\text {fteu }}$ December atn die van Amboina, on, volgens hun werzock, ma Batavia vervote te worden.

Het Ooftermoefon begint hier in Mey, en 't Weftermoelion in December, zynde April en November de kenterminden, in wilke de Oofter- of de Wefterwinden zoo nict doorwajen, matr ftil zyn, en wat uitrufter.

Het regent hier echter in "t Ooftermoeflon zoo larg; nog 200 fterk, of zoo waft, niet, als in Amboint, mitrik tieb gemerkt, dat het Weftemoston daat net fwarder nitberlting wan wind, din clders, en als by lwane whatgen, dic zontyds honderden van boones uit de aarde rakken, zyn aurang necmt,

Die hier eertl komen, ritalen enemeenelyle wan heete koortzen; doch die 'c laid gewoon, en dat door zyn, lewen ser gezond, en wry lang. Ik heb 'er zeer oude lieden, 211 onder andere ech vrouw op Celamme, gezien, die cen atukomende vтyfter was, toen de Hollanders in 't janr I6.2. "r Hoog Land innamen; ten bewyze bybrengende, dat zy veel mandelens met aurde angedngen, en zelf mede han beft gedinu liad, om bun wan 't dind af' te louden. Oof sug de ondereecrongt Hecmskerk met de zynen, in "t jatr s 509 , by hun komit in Banda, daxir dikwils een man wan 130 jutren.

In die tien manden, dat ik hicr geweett ben, heb ik dit land zecl: ongezond woor my bevonden; "t geen ill oordeclde door koude dikke dampen, die ile in "t Ooftesmoeffion' "s morgens op " $t \mathrm{ge}$ berguc wan "t Hoog Land, tegt cegen over myn kamer (geneenclyl vroeg op zynde) een tyd ling als rulten, en datr ma zoodanig nederditen zag, dat ik van tyd tot Eyd de koude ricer allieen op myn yoorhoof, en herzenen, gevolde, mat dat door van yder mand wel drie weten met den lwig gequeld wwas, watr uir dan koortzen outifonden, zoo dat ils datar ganch nier auden kon. Ook fterven veel tlaven of 't Hoog Land, dic deze koude en dirapige higt nict gewoon $2 \mathrm{yn}^{1}$

Andes hob ik het dat wonder wel ge= bat, whe ik had in al dien tyd de ecre van by der Heer Landwoogt wen $Z$ Wh in lius myn verblyf te houden.

Men heefe hicr zullien overvloed van vilch, of vleefly, en midere fpyen niet, als in Amboina, mar de zeelsarper is "er fchoon, efr hocwel men "er val meer, en beter felyapen, ditn in Amboina, en veel gelnedene en gemefte bokjens, heef, die diar op dic wyze juift nick gemeft worden, oordecl ik 'c ccheer in Amm boina ved beter koop, van levensmiddelen te $2 y n$; groente is 'er ook maar paffelyk; doch de turlaze boontjes antiden "er beter", als in Amboina. Vrugten zyn bien overwloedig, en byna de zelve als daal, uitgenomen dat ill "ct een wont, Pau, of de ltinkerd, genanme, dic in Ambon nice walt. $\mathrm{Zy}$ is als een Manggarugt, doch wateragtiger wan Imak.

Het heugt my, dat if in Mart 1686 . den Heer \& Herlog, opperkoopman en Hoofd tot Japara, en bevootens Hoofd 
B A D N D A. I 77 37

tot Lonthoir" , tegen Juffiouw Yosma Padbuge, Weduwe van de Heer vdy Fhet, over die Bunda, en den overvloed van allerlei eetwaren en werverchingen, die men datr had in st jat 1682 . (in welk jait $z y$, met Mejuffrouw hair Moeder, datir cenige dagen gewoeft was) zeer heb hoorer roemen, on 't wellec te bewyzen, lyy hat le. al vry trots afvangde, of zy dit by har anwezen ook nict bevonden hand Deze Juffrouw, van een vrolyken aurd, en genegen zynde, dezen rwetzer een fralje ftreels hict over te geven, zeide, ja, myn Heer, het is 200 , mat ik ho ook dat na, vertata, dat men te dice tyd is Bunda alles, wat men hiant by cet rapen kot, opzamekde, en datr door lang naderhand nog groot gebrek wan illies geleden heeft; watr ower" 't ganlche gerelrchap, uirgenomen myn Heer de Hortag, hertelyt begon te lacchen; on by Cpratk zedert noit meer wat Banda's overvloed.

Anthe-

Dere Eilanden $z y n$ ook byra 't ganfche joat door surdbevitigen, gelyk wy reets ecrigzins getoon thebben, indet'worpen, wata var de Vuurberg de voorntme oorzuth is, hocwel zich die meeft wan October tot April en Mey, "en ook wel in Augultus en September, voclen latater. En op die aardbevingen zyn 'er nu en dan ook twate watevoloeden gevolgt.

Dat men hicr zoncyds fwanten blikzem en donder hebben kan, is ons door de twee donderfteenen, in 't Perk van wan den Brok, gevonden, reets gebleken.

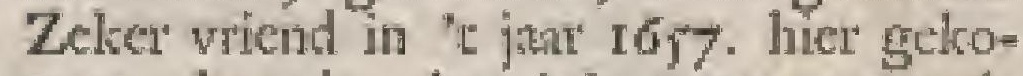
men, hoorde, hoe 's jasts te vooren de blikuen, in een fobip, dae op de reede voor Neira lag, ge0agen zynde, de "cheepskok al zyn hootdhair en batur, zoo zuiver, als of het afgefchooren was, weggenomen, doch hem ganfch niet gequerlt had, gelyk ly dit nict metkte, voor dat hy, by geval "er na tafte, el het toen met werbaltheid gewatr wiert. Men thont over deze zeldzuame werking des blitzems, zoer werwondert, en deze rchecpsleok had de ecre om danr over uitdrukkelyk by den Hecr Landwoogt $W_{y} w$ ontboden te wotden, die "er, inet zyn byhebbent gerelichap, zeer ofer werzet ftond.

Schoon de Bandanezen wan ouds hun Taial hier cigen tal hadden, 200 is de gemeene taal jyik, onder hen en met alle vreendelingen, zoo diar, als om de gaufche Ooft, ja door gan ich Indien (hoewel men op Batavia, Ceylon en elders ook de Portugeefche ved gebrukt) de Maleitfche, dat een cierlyke, ryke, en zeer angename tall is.

Daar zyn 'er, diemeinen, dat de Nootenboomen alleen iss Banda willen, doch dit is mis, gelyk wy toonen zullen, als wy van de Indifche boomen Tandelen; matar dic is whal, dat met "er deze landvoogdy alleen toe houd, om ze ant te queken, en dat men dic op alle andere plintzen uícroejd.

Tot de landvoogdy van Bindi behoo: ren werlcheide Filntaken, zoo om de Zuidooft, als on de Znidweft wan Bada gelegen, als mede de satut op Nora Guinet.

Deze Z. Ootter en Z. Wefter Eilanden zyn zeer veel in getal, die men mer hatre be Zuitnatuen, en in hitue thelking, in de katri zuter en C. zeer net vertoint zict.

Wy zullen eerlt deZ. Oofter, en dant Eifandert. na de andere, zoo vcre het noodig is, anwyzer en befisywen.

Deze nemen hat begiti ten $O$. wan "t groor ciland Cerm, ontrent I migl Beoolten Ceram Latoct.

Pas O. ten Z. wan 'é zelve ontmoet men ecrit rwee kleine eilandekens, wat wan het Oottelykit Tenimbur gename is.

Wancer men wan datu nu 4 mylen na 't N. O. zeilr, beeft men her ciland Goram, dat wol i 2 of 13 mylon $v_{j}$ Cetath Z. O. op legt. Het is wet 3 of 4 mylet louig, en wel 2 of 3 . inylen, breed, ea meet $\mathrm{N}$. W. en Z. O. geftrek leggende, whar na toc veel oude Bandineezen gevluge zyn, war mede de E. Mantichappy nu en dan nog al wat heeft te doen gehid. Het legt ook ontrent 4 myles O.ten N, wa Salowilki.

Twee mylen verder $Z$. O wan Tenimbar, hect mea 'iciland Sulowalki, dit byna meetl Z. ten $O$. en $N$. ter W. geftrekt legt, en digt by "t welke zich een rif, dat wan Ceram, l noee tot naby hex zelwe lope, opdoet. Het is 4 mylen ruim lang, 2 mylen bred (hocwel an beide de cuden imaller) en asti de $O$. kant wan cen baal voorzien, en 't heeft aan de Z. zyde cen klein rifje, dat na "t Z. W. ltiekt.

Het eiland Manbokka doet zich 4 mylen Z. Ooltelyker, met een Jilein rific ande N. W. lisnt, op. Her legt medt N. W. cn Z. O. geftickt, is ontrene 5 mykn lang, en fchats 2 mylen breed.

Drie mylen Z. Oottelyker leggen de twee cilandjes Matebello Z. O. ontrenit 2 mylen var malkanderen, en pas a myl ydes groot, val wara men 2 mylen $Z$. Ooltelyker by 't eiland Cocficvoey' homt, dite ontrene 3. mylen lang, en 2 mylen meeft brecd, en in " $\mathrm{t} \mathrm{O}$. en W. wan een bati voorzien is.

Anderhalf myl Z. Ooftelyker heefi mer ecn droogte wel van $z$ of 3 mylen ins 't langwerpig rond, mer een libein cilandjo tan de Z. O. zyde I myltje dar buiten, ten O. wan 't welke 6 mylen een droogte vau 2 of 3 mylen in "t rond, Poelo Floves genaant, legt.

E. 3

Twee

,

4 
Twee mylen ten $\mathrm{Z}, \mathrm{O}$. wan "t voornocme eilandje heeft men "t ciland Koercliofe, dat 3 of 4 mylen in "trond is, en "t geen pas tet N. O, ook cen likin cilandje leggen heet:

Even ten Z. O. van Koerchote heeft men her eilandje Tewer, dat 35 of 36 mylen ten O. wan Banda Jegt. Dit is zeer bergagtig, 2 mylen in "crond, en vol klappusboomen, die vecl olie geven. Ook is hier een hooge brandende Berg, die in "t jar loge. met groot geweld wan een berfte.

Twee of drie mylen Z. Ooftyker, en dan niet wel nog eens zoo werre, heeft men cwee kJeine cilandekens zonder nam, en dan nog 2: mylen Zuidelyker ziet men 't eiland Boen, dat cen drielioel verbeeld, en ontrent 3 of 4 mylen in 't rond is, hebbende in "t N. O. I myl wan de wal een klein eilandje, en in 't 0 . ten $Z_{3}$, pas buiten dat klein eilandje, een rif wan wel $f$ mylen in 'trond leggen, war' op zich nog twee kleine cilandekens vertoonen.

Twee mylen Cchars wak Bezuiden Boen legt het elland Caudar, meeft W. ten N. en O. ten Z. geitrekt, zynde 3 mylen hang, en I groote myl broed.

Drie mylen Zuidelyker (wel zoo Ooftelyk) ontmoet men teiland Cauwer, dat meelt $\mathrm{Z}$. ten $\mathrm{W}$. en $\mathrm{N}$. teil $\mathrm{O}$. geitrekt legt, "t geen ook zeer bergagtig, wel 3 mylen ling, en I of $1 \frac{1}{1}$ myl breed is. Zy bakken hier weel potten, die zy, nevens hare Atap in Bandiz te koop brengen.

Vyf of zes mylen Zutdelyker heeft men drie eilandekens, Noefta Telo (dat is de drie gebroeders, of eilanden, in "t Amboinees) in een drielprong, a st 3 fnylen van een, zoodatigg leggen, dat er een wan in " $t \mathrm{Z}$. komt, en de twee andere zich in " $\mathrm{N} . \mathrm{W}$, en in ' $t \mathrm{~N}, \mathrm{O}$. wertoos nen, zynde geen myl ydcr" groot.

In "t N. O., 8 of 9 mylen van ti Ooltelykfte der drie gebrocders, legt Tiando, cen groot rif, dat meelt W. ten N.en O. ten Z. wel I 3 of 14 mylen in 't tond geftrekt legt, en wais' op zich drie cilandekens, twee in " $t W$. en een in 't $O$., yder ontrent wan 2 mylen lengte, ca zeer" Iimal, vertooluen

Twee of drie mylen ten 0 . van dit rif legt cen ander ontrent vain de zelye groote, doch Z. en N. ftreklicende, en pas 2 of 3 mylen wan " $t$ ciland groot Key in "t O. (war win wy duar na, gelyk ook wa Aroe, breeder (preken zullen') gelcgen.

Vyf of zes mylen ten Z. O. van Noeft Telo leggen wwee kleine eilandekens meeft N. O. en Z. W. van cen geftrekt, van welk "t N. Ooftelykfto Toenjotokki genantht is.

Vier mylen Beooften Toenjotokki ver-

toont zich cen rif, dat wel ro mylen Z.en $N$, en wel 3 of 4 mylen O. en W. uititrekt. Het loopt in 't $\mathbb{N}$. met ecn boge on $\operatorname{van} 2$ of 3 mylen, en gaat daar dan na "t Z. zoodning om, dat het aiti 't eiland Key Watate in "t N. vaft legt, gefyk het in "it 0 . ook tot tegen klein Key loopt.

Op dir rifleggen wier cilandekeus, yder 2 of 3 myles ili t rond, alle Z. en $N$. geftrekt. De drie eerfe beginnen - in t $N$. digt by de zoom wan ' $t$ rif, en gitin zoo Z. ahn, dat zy ontrent 1 myl wa een leggen; en even buiten 't rif I nily1 van "t Luidelykte dezer dric eilandekens ziet men nog twee zeer kleine I mylO. en W. . wan een geftrekt; doch het Zuidelykfte van de wier, Moey gentamt, legt wel f mylen wa de drie Noordelyke, of wel wan 't Zuidelykft der zelve, zyode digt anu den Zuider zoom wan dit rif, ontrent I myl wat de N. W. hoek wat klein Key, gelegen.

Een myl Beoplten die drie Noordelylfte cilankekens, op dit rif leggende, en I myl Benoorden de N. hock wan 't eiland klein $\mathrm{K}_{e}$, lege her cilund $\mathrm{Key}$ Watala, dat is, klein Key, dat N. en Z. ann de W. en $O$. Kant ruim 4 mylen lung, en O. en W. wat fimaller is, zich zelve byna vierkant wertoonende, unitgenomen dat men in 't N. ecn bani met twee finalle hoeken, dic meel $\mathrm{N}$. W. Atrekken (gelyk ool de bati loopt) hect. Eth ila " $\mathrm{O}$, buigt de wall wat uit, gelyt $2 \mathrm{y}$ in 'tZ. weer wat' inloopt.

$B$ den $O$. hoet dezen' bah in ' $\mathrm{N}$. $W$. pass 'er Benoorden, lege cen cilandje op en klein rond rijje, diat an de wal yath Key Wualat vatt is, en 2 mylen Ooftely'ker" is "er" nog een, dat wat grooter, en, in "t O. ten Z. mede mer een klein rifje digt 'er' and bezet is.

Vyf mylen vandat eilandje, 't geen ten Z. W. van Toenjotoklti 2 mylen legt, ontmotet men "t cilandje Fadool, Eat ontrent $3 \mathrm{mylen}$ in "t rond is.

Een unyl Bezuiden Key Wuta legt her Wein ander deel var klein Key nuet zyn N. W. Key* hock, die root aan in "t N:W' 4 , doch wat Zuidelyker 4 of 5 mylen werre, mar 3 mylen breed is, zynde titn zyn $W$. zyde $Z$. en $N$, wel $D$, doch in st midden 5 of 6 , en an zyn 0 , kant ruim $z 00$ lang, alzoo zich die als in cen driehoek, met een punt ma "t N., een tia 'cO., en cen na ' $t Z$., met een eiliandje datar by, en pis 'er Bezuiden, vereonc.

In 't $\mathrm{N}$. heef het een groote ronde bat, die wel 4 naylen lang, cn ook wel zoo diep is, meeft N. N. O. ftrekkende. Ook zict men nog een klein baiken ant de Weflyde dezes cilands, ontrent 4 mylen van de Z. W. hoek gelegen. Her is wel 34 mylen in 't rond.

Twee 


\section{B $\mathrm{A}, \mathrm{N}$}

Twee of drie mylen ten $\mathrm{Z} . \mathrm{W}$. van des zelfs $Z$. W. hock legt cen rondagtig rif wel witn to of $\mathrm{t} z$ mylen in 'L rond, war op zich twee kleime cilinden war $z$ of 3 mylen in 'trond, meett $O$. en $W$. geftrekt, I myl van malkanderen vertoonen. Het Ooitelykf, zynde "c kileinite, is Ketember gentame, leggende byna aqn de Oofter- gelyk het ander tan den Wefer - zoom van die iff.

Een weinig Benoorden den 0 . hock wan Klein Key doet zich de Z. hoek valy 't eihind groot Key op, wata op de Negry Ekit bekent is.

Het zelwe ftrekt zich meef $N$. ten $O$. en Z. ten W. ter lengte van 19 of 20 mylen uit, en is in " $\mathrm{N}$ N. 4 of $r$, en tan "t midden af, en zoo verder" na " $\mathrm{tZ}$ ", 3 mylen breed.

Men zier duar matt cen klein buaiken in " $\mathrm{W}$. ontrent het midden des ellatids, ein een eilandeken er voór legger, hoedanige twee andere rich 4 of r mylen Noordelylier Z. en N. I myl wan cen vertoonen, zynde de wal dat, wan de vootnoemde bial tot pas Benoorden dit latate eilandje, wht ingebogen s en dari lege "er nog cen eilandeken in ' $\mathrm{N}$., p.s $I$ tonl wan de wal, op cen ritje van 2 of 3 mylen in 't rond, dae taln wederzyden thun de wal van dit Key waft is. Ook buige de Oofterwal in ' $\mathrm{TO}$., en zoo al verder tot het $\mathrm{O} . \mathrm{N} . \mathrm{O}$. (en dar wel "t meefte) zich uit, van war zy dan na 't N. ten W. weer wat met cen wakke bogt intruigt.

Dir ciland wort gegift on 50 mylen O. Z, O, van Banda te leggen, en beide deze eilanden groot en Jilein Key zyn hoog en bergagtig land, die vatn godatate, in opzigt val bare gebergera, niet vecl van Lerimor in Amboina verfichillett. Men heeft 'en ook vertcheide rivicwen, en 't is ontrent 40 mylen in "trond, zoo dat men wel drie dagen werk hed on die ciland rond te fcheppen.

Deze volkeren oorlogen dagelyks tegen malkanderen, matkende maltandess oor logsgerangenen tot hiswen, die zy dah atin de Bandancezen woor een geting geld, yan $10,12,15$ of 20 Rykisdanders ticn uiterster, retkobpen, hoowel zy dat wel ann bun eigen vrienden, buiten weten der zelve, even algodic wan Celebes en Bali, docin.

Whe nu deze Keyalen verder betreft, omtan- zy ftellen wit de averlevering humer voortheren. ouders valt, dat God hun land gefchinen heeft, ronder dat zy, dic zeer botte Heidenen zyn, dar iet verder vin weten te, zeggen, of icts wan zyn wezen op te geven. :

Wancer $x y$ "t ecri of 't ander ondernemen, of ther of datr na toe waten, zyn zy gewoon in zeker huts, warlchynelyk
A.

hunnes Tempel, te gata, en lien daar oin cen gocden uithag van hun werk, reize, enz. atin te bidden.

Eer zy zich tot dit gebed begeven, rigten zy een groote maliyd roor "t ganfch domp nan, en fligten ectige verkens, en bokken, waar van zy cen gedeclte atan hannen God, ftande op ecn itok, en op een vierkane verhevene plats wath fteen, ontrent twee voeten hoog, opofferen, en ra dat het zelve een halwen dag daar gethan heeft, kont zeker perfoor , watrfchynelyk hun Priefter, ce die dar wan leeti, dit ni zich neemen, aangezien de zelve geen ander irikomen, buicen een vrye wooming by dien Tempel, heeft.

Deze gebeden nu vangen deze inwoonders niet atan zonder een menigte van grillen, en grimatzen, die woor af gate, gewoon zynde dafi eens op hanne kapen te vallen, tan weer eens hut angezigt te trylken, en dan weet eens beide de hander boven 't liookd te houden, hoewel wy geen beelden hebben, yoor welke $x y$ die grillen eturicgten.

Zy wallen doorgans buin van wezen, hebben een goede lengte of evenmitigt heid wa lichaan, en zyu yan lang gekruld hoofdhair woorzien. Wan and zyo zy zeer gedienltig en goedaardig; dok niet dicfagtig; madr getrolw, en veilig om met hepr on te gatin.

Yder dorp beefe dric of wiet Oring Kat ja "s, enyder Orang Kaja weet, hoe vec ingezetenen onder herin ftin. In tyd tan hood than deere dorpen mallianderen by. Ook woet de Orang Kaja alle gerigtszatken onder hen uit, hoewel men anders, nog ain ayn gewitad, nog an zyne ttathouding, eenige wendaring of onderfeheid tuffehen ben ca ecti gemeenen Keyar, befpeuren kas, din alleen, datzommige onder hen negen of tien goude ringerjes in de ooren dragen. en een kikedje wan baften wàn bơmen. of ook wel een blaum badjoe annhebiben.

Hunne huizen zyn van Gabba Gabbn gemakt, net Atrp gedeke, en drie of vier voeten van de alarde op ftutten, ein zomtyds wel op klippen an de zeckint, of larigs fitrand, geciet.

De dorpen, қक mede de onzen in 'E jaal I624. -nl gehandele hebben, tyo Har (war voor zy toen gedrikert lagetr) Adcylar, Oerato, Soevat, Eli, onbotayl en Wayen, welke zeven te zamen wel 4000 koppen in tyden wain ootlog te veld konden biengen:

De hoofden dezer darpeni hebben gech inkomen, en zyn zoo wel als de gé meene man, genoodzinkt, han hoft met wiffchen, en van huntie boorien en landvragicn, dic Cillappus, Orangic- 
appeds, Piefling, Limoenen, en andere', rects gencld, te toeken, wair toc zy dagelyhs hunite flaven gebruiketi.

Deze woornoemde dorper atr de Ooftzyde gelegen, hadden wet fo motere dorpen op dit eiland, meer na 'r Zuiden, tot wyanden, tegen welke $z y$ vier jutren geoorlogt, en in dien cyd wel 400 koppen verlooren hadden.

Dezen oorlog is alleen darit uit ont ftun, on dat zy ydci hune byrondere voorregten (volg ons onde wetten wan hume voorouders) hebben, na welke zonmige bevoorregt $z, y n$, on alleen met bobbers (wifchkorven) andere mee fero's (fuiken) cenige andere weer met hocken, en wat dies meer is, te mogen vilftehen, en buiten welken regel zy, of andere, feliynen geganis ; cn daal door hun volk verlooren te hebben.

Het regt wort by hen ifi dewer wosgen bedient.

Die yemnt zonder reden dood, wort gekrift, of met pylen dooffchoten, dat er de dood na wolgt.

-Die owerfpel lredtyft, is dar cen man des doods; en zulk cen overfieeler, gelyk ook de overfpeelfter, word deil gehoonden mań, om zyn mode "er an te koclen, wolkonen overgegeven, en gemeenelyk mede, gekrift.

Een dief, die iets van watrde geftolen heef, worden de wier wingets whner regterhand afgefineden, of zonityds, ni dit de zanken ligr: of fwat zyn, matr van een oor berooft; docli oven kleinigheden, vmigten, of diergelyle dingen, wort hy in reen boete, gerige ni zyn vermogen, gedocmit, die dour lee gurlach dotp in vrolyliheid verteert word:

-De nans trouwen zoo ved wouwej als zy voeden konives, doch mannen, of vrouwen, zyn niet langer, din zy willen, atin malkanderen verbonden, en konnen, Dat de fohciding, weer cen ander nement. - By "t angana wan huwelyl bedingen de ouders zekere uitzeting voor de jonge litden, wam in milkinderen verftatan hebbende, wote er ecr maaltyd tan het dorp gegeven, ion door de gafter geondeelt, wic vath beiden, de bruidegon of bruid, het langft lewenzal, dat $z y$ wootgeveu te konnen zien an een Pinang, fie zy yder ceten, en diens urtgeltarude Pinang do blecklte is, die zal eerit fterwen. En daa by, is dan hun huwclyk bereftigt.

$\checkmark$ Indien hicr yenant ran atuzien tlerf, dic wort eerft met werlcheide oliellich kruiden gebalzemr; endan in een k ift tati "tdak opgehungen" war. onder ettelyke en zomtyds wel of of Iz manaden ( na

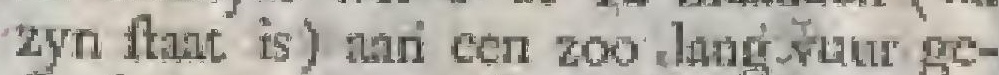
hookt wort, tor hy gehecl droog is,
Wath na zy hem is de ande begraven. Ook bebben zy de gewoonte, pas na de dood wan zulk cen perfoon, een feeft acti 't gamech dorp the geven, en een foorte van follemfpel tot een algemeene vreugde nan te regten. Ook geven zy cenigg goud, Jleederen, enz ath dezen en genen (yder Ta zyn vesmogen, om den dooden te helpen beweenen, welk gehuil wel een

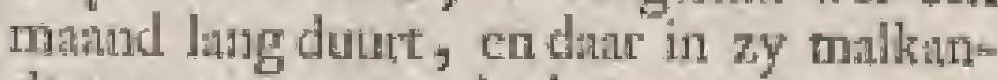
deren verwangen; doch ecn gemeen man wort aunitonits begrapen.

Ten tceken wan rouw lasten zy hun hoofdhair affcheeven, endragen dan ook tingen om de armen en beetien, en een gordel van rotang on " $\mathrm{l} l y f$, die "er zoo ling atin blytt, tot by "er afvalt. Zy onthouden zich dan ook eenigen tyd van zekere fpyze, en wagten zich te gelyk van litchen, of "t plegen wan eerige ydelheid.

Zy gaan mecft nakt, dekliende beide de gellagten alleen hunne fchmelheid. Zy hebben weing huistad. Hut lpyze is meelt figoc, pieflang, $\mathrm{cm}$ ocbis of wortelen. Hun drank towak, en puewater; hunne fchatten beltan in gond, olifuntstendet , en ecrige kleeden, hen wan de Macafiaten, "en anderen, gebragt, die zy tegen figoe, olie, enz. gerifile Jubben.

De ondte zoon verwangt hier zyn whder in de regecring; doch alle de kinderen erven anders gelyk.

Hui vee beftat in verkens, en bokken; doch paarden, bultels, kosjen, bullen, of dicrgelyke hoorndicren, zyn hier niet, dan zedert weinig jaaren.

Zy geven woor, dat $z y$, genegen $x y n d e$ te oorlogen, of yet sindis te ondernemon, eerft radplegen mec ecr vrouw, die vier oogen heeft, die zich man de Weftade des lands onthoud, wclke viouw, in hun bywezer, met zekeren goelt wegens hun geluk of ongeluk ratplegt, wax yan xy den galm wd hooren, doch bebben dien geelt noit gezicn; dat op een liftigen Priefter uitkomen $z a l$. Tweevan die oogen flam in 't voorhoold dezer, vrouwe, en twee in haren nek. $Z y$ boden ons wolk an, hen die wrouw te lanten zien, doch ry dorten zich zoo diep hndwant in nier begeten, alzoo het deertte maal was, dat $z y$ hier gekomen waren.

Deze wolkeren zyn zeer begeenig na Cayis Goelongs met rwarte hooften en roode velden, Petas met roode lroofden en een Jchoon weetchynend veld; wit Gunes linucin; Negroskleden; Rood Haket1., Tapissindos val vier Hafk, ook eenige Sarongs, roode Dronggangs Tsima Malajoc, als ook na yzere parangs, byiticns, oud yzer, mitsgaders! Paryswask, kralen, cicenige dege fruilteryen: 
B A N

Zy kemen ook restilen ; alle de voornocmde grooderen kan men hier verhindelen of tegen fugoe, olic, en andere waren, of met groobe wimit verrutien, endar mede Banda grooten dientt doess.

Allo deze zolaten zyn in "t jay" 1624 den Io Februar'i, door dic van 't jacht Gol, voor het dorp Hat ten anker leggende, zoonts wy die hier, uit een netre memorie getrakken, opgeven, van tyd tot ryd ondervonden.

Men hecf 'er nok boontjes, en buiten de rigoe (die 'er zeer weinig is) ook oebi en combili, een fourt wan worteler, ene. en veel goed hour, antigezien het land zeer bolchngtig is.

Dezo hicden wan Key (gelyle die wart Aroc) komen jatrlyks mat is of 20 klocke warturigen, met 80 tot too mannen bezer, na Banda, om handel te dryven.

Hume wapenen zyo cen fchild, wward, pyl en boog, en hazagayen, dic zy wonderlyk wel weten te gebruiken. Ook hebben zy eenige metalcbalten op hume coracoliss.

Vyftien of zestien mylen Beonlten De Aro- groot Key doen zich de eilanden wan Lilinden Aroe op.

Vierder zelve leggen meet $Z$. ren $W$. en N. ten O. als in een lyn, de Nooráte. Jyklte $1 .$, en de cwee Zuiltelydste 2 of mylen wan een gettrekt, en de andere zes doen zich 2, 3 of 4 mylen Ooltelyker op, van weike zich er een 3 mylen wan "t Noordelylsile der" vier voorige ineett in de lengte $O \cdot \operatorname{ten} N$. en $W$. ten $Z$. gethelkt, rer lengre van $r$, en ter breedre van 2 mylen, wertoont.

Het tweede der Ooltelyke doct zich pas wat Znidelyker ais het tweede der vier woorige, en 3 mylen 'er van gelegen, op, zynde ontrent $f$ mylen 0 . co W. ling, en 2 of 3 mylen breed. Her lege vin teerfte ooltelylite eiland wel 7 of 8 mylen.

Het derde der Ooftelylefte legt mede af en ian her derde dervier woorige $1:$ of 2 mylen Beoolten "t zelve, en 2 mylen wan "t lar it befchreven, hebbende ontrent de zelve lengte en brectie als het voor ge, gelyk zy beiden in "t Oolten ook ficherp uitloopen.

Twee mylen 'cr af na "t Zujden wan "t latefl befchreven eilind", en af en aan de Zuidhoek wan her derde der vier woorigc, ziet men $O$. en $W$, r myl van mallinadesen tuwee kiciner eilanden geltrekt leggen, zynde het Wettelykfte der zelve mar' 2 , en "t Ooftelylette wel r mylen lang; ch 'r cerfte $t$, en 't tweede 2 mylen breed, Bezuiden welk cerfte dezer twee 2 of 3 mylen zich nog ecn klein cilandje wan 2 of 3 mylen in 't rond, ontrent 3 mylen van 't Zuidelyke der viter vorige elladen, vercoont.

II I. DIEL,
D A.

Het Noordelylafe thu der vici Weltelykltc hroéze eilanden legt meelt $\mathrm{N}$. N. O. en Z. Z. W. F mylen, in de lengte, en 2 in de brecdte gedtrekt.

Het matte dart an, I! myl Zuidelyker gelegen, vertoon, zich als ean litar, die nee liee baveneinde wry war bred no 't W. ten $N$. en net de voet wat fmaller Ta ' 0 . ten Z. gelegen is, zynde in ' $t W$. ten $\mathrm{N}, 4$, en in ' 0 . ten $\mathrm{Z} 2$ of 3 mo. len breed; en $W$. $\operatorname{ten} N$ en $O$. een $Z$. ontrent 5 inylen lang. In to N.O. en in ' $\mathrm{t} Z$. ten $W$, heeft men twee kleinc batikens.

Her derde der Wrathelykite eilanden lege met zyn $\mathrm{N}$. cinde pis I myl, soch nuer zyn Oofterkwne wel 3 of 4 mylen Zuidelyker, alzoo zich dis byna als cen verkecit - ftandide latrs "er tegen wh tool]s.

Het flekt zich mede ten deele. W. ien $\mathrm{N}$. en 0 . ten $\mathrm{Z} .3$ of 4 mylen werte unt, doch 'rdrtait dan walk wan 't $\mathbb{N}$. dont "tO. ria ' $t$ Z wel 3 mylen verre (daar " 2 mylen, gelyk her anders 3 of a mylen, en in ' $W$. Wel 'tbreedite is on, znde wan het derde der Uottelykite cilanden entrent a mylen gelegen $A$ ande $Z W$. Lituc loopt de wal ann wederzyden leherp in, zich zelven alis cen batai vertoobictde.

Het lastíc der vier Weftelyle cilanden legt ontrent 4 mylen Bezuiden bet voorige, vertoonende rich tricest rond, 5 mylen lang en 4 bresd, doch an de N. en 7 . hock fmaller, en 't lege medt N. W. ten N. en Z: . , ten Z gelhekt. Of "cr" ma "t $\mathrm{O}$. nog meer' $z y n$, konnen wy niet zeggen, hocwel het zeer wiatfcliynely is is.

Deze eilanden leggen vat Bunda $6 r$, en wan Nova Guinea 18 of 20 mylen, beftunde meet in wlalike en bolchigrige Jabiten.

On van Banda na de zelve te zeilen, Tewer is men gewoon eerlt op "th ciland Tewer en

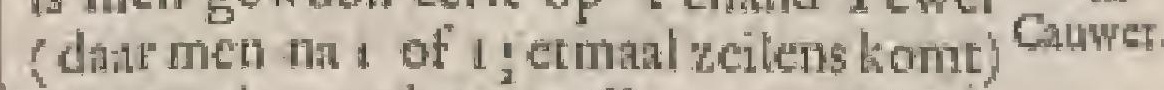
atr, en dan werder over Cautuer te gaar, watr tra men nog wel een grooten dag van nooden heett, om deze cilanden te belnopen.

Op de zelve heeft men veel dorpen, whar onder de bekentite zyo: Wokam, Wodjir, Workcy, Wamir, Toetewanang, Saguwading, Bocan, Guarnar, Bagimbel, Manycoor (dat op cen byzonder cilandje lege) Ratoc, Tafangan en meer anderen, die neeft gettadig icgen tratkanderen oorlogen, behalven dne de van Nova Gunién, en t Ruidliand, hen dibwils komen verneftelen i en deze oorlogsgevangenen zyn het, die zy man die wan Banda als flitwen in groor getal, en woor cen geringe prys, verkoopen. 


\section{B E S C H R Y V I NGE}

- Dit land in rich zelven is uces velkigls, doch "z volk nict te veftrouwen. Het is valu "t jatr 1623 . at onder de $\mathrm{E}$. Matefehappy geweelt ; gelyle wy nader uit eca Verdrag, tufichen hen en ons gemakt, mant dat wy nict nondig geoor dedir hebben hicr by te woegen, zouden Ironnen zies.

Een klare preupe wat den trouwloozen antind derer Inhaders zang men in " $\mathrm{t}$ jour 108 3. roen 'er kapitein Hyfeldeg, thet deis lientemane Roosenburg, en de wandrig

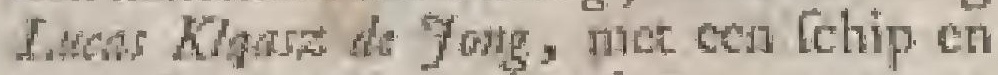
cenig krygswolk wa toeging : want zoo ras by diur gekomen was, verfchenen wol 200 gevipende mannen vool her dorp Workey, dat om de Z. hag.

Deze quamen $u r y$ ftout op hem af, cn chooten met pyl en hoog na-hem, en zyt wolle; matr toen $B y / f l d w g$ 'et eentige met her fichroot van zyn Princenftukjens wegmatide, gingen xy, niet gewoon op zulke heete boontjes te galt te gatil, ten eerlten door.

Naderhand tot de vrede uitgelolit, cu op een fteile doch velige plants by en gekomen zynde, wiert het verdng, dat $z y$ in drie pajen I8 flaten atn de E. Mathehappy-geven 'zonden, getroffen.

Volgens dit wetforek dagt men dat $x y$ de cerite zes zonden garu haalen, doch zy vetgaten weer te komen.

Men tirceg ook tyding, dat 'er geen ecin mentch meer in "tdorp wis, en dat 3 of 4 Hollanders hunne hoofden al quyt waren, hoedanig zy ook te Cabrono wocFen, een dag of twee reizens verder, wan opde onzen goedwonden nict nlleen Workey; mat nog 8 of 9 sudere dorpen te verwoctten.

Op. de zelve wyze waten de onzen dari in de jaran 1646 . en 1657 , ook onthath, wanneer zy eerlt met die van Goram, en duar na met die wan Ceram Lacet, onze ryonden, anlpanden, verficheide Hollanders vermootr, en enige Conteoras der Amboinezen genomen hebben; en geets wonder, altzoo de $B_{\text {anj- }}$ dancezen herwatts, en ma Key geviuge, deze lnlanders geduurig tegen ons ophititen.

Dop Dit Workey is en zeer groot dorp, Worky. en eet byzonder nette Negry, ftrek. kende zich wel cen kein half utu verre uit, gelyk het ook een der magtiglte Arocklye dorpen is.

Het hecte ook alleen ecu parlbank onder zich, wel it dag wan 't zelve geleger, want nit toe zy me jonken en groote wartuigen (hoedanige $2 y$ "cr wel 70 of 80 hebben) waren, war mede $2 y$ ook alle moleren de vant derwares belecten, of hen, 200 zy dur echter komen, beoorlogen.
De meefe, die hicr vallen, zyu matr ftofpariten; doch il heb 'er ook gezien, die nls ecn gratawe ere van groote, ja dic. grooter, en byzonder tehoonvan whtet waren.

De hoofdnegry is nu Wolam, anwant wy cen ferigeanc, cen corporit, co 10 of $\mathrm{I} 2$ foltantes in een velling van pritliszanden leggen hebben.

Hier wallen weel rerkens, hoenderen, sillerlei Indifche fintiten (doch weinig Tsjampeda"s) boontjes, oebi "s, fagoc, atap, paradys- cin koningsvogelyjes, coeflocoefos (zeler landuticr, dat wy onder Ambona's ftoffevertoonen) pilandoes (cen toor wan dieren als lionynen met horte voorpooten esnige zeldzame zehoorens) I_octi 's, ved vifch, en met diergelyke gocderen.

Ly weten dart zeer weinig (ujtgenomen nande hoofdplats, door de werkering net de Holhurders y vin gond, of zilver; mar hun befte lehatien zyu olilintstanden, en gongen.

Hunne doode kinderen, en ook de lyten der oude lieden, hangen $z y$ jJ gabba gabba kifter in den rook, en lanten die zoo hard, als mummie, uitdroogen, dic zy den werder onder hume lantey s, en zolderkens van gefpleten bamboezen, bewaaren.

Zoo hen vuat by ongeluk uitgant, zullen zy dat noit by hunnes tabutur, fchoon in een en 't zelve huis (alzooverfeheide hutshoudens ondet en dnk leven) zockcn; matar andtonts zelfs weder vitur matken, dat zy zeer beluerdig, met een zagt tegen cen hard houje in een latilije, dalu in genathe, zeer ftetk te wrypen, en met wat tontel vas drooge klappuse bolfter, of iers anders, daw by te leggen, weren te dotil.

Dic volk, wu en dan in Amboina verrchenen, gaven han Edctheden ast dic wan Ambon cn Banda, in "t jadr 1670 . den 26 Januaii, laft wel te bojegenen; doch in "t volgende jaur gaven $7 y$ weei bevel om hen wat Amboina en Java af te wecten.

Hier zyn geen riveres, weshalwen men zich lier mer reer flegt patwater, of met ecrige ftatade waters, moer behelpen, dat watechynclyk de oortals is, dater veelen fterven, en die "er nog van dan lcomen, 'er zecr ongezond nitzien.

Opdeze eilanden wan Arou, $\mathrm{Key}$, ent. mogen alleen de Bandancezen, watr onder zy cigentlyk fta: , en geen Ambo:neczen, dan alleen by vertof wan hat Edelheden, gelyk sy untrulkelyle den 6 Marr I69t. beveelen, vairen, by welk fehrywen zy 'c gewal wan Jacob was Condan, te dier tyd in Amboin woonende, uitzonderen. Ook werboden lyan 
Edelheden by fehryens Tha den 14 den Matat i681, an die van Amboina, dat geen Zuidoolter Aawen dat, moar alleen in Banda, zoudea mogen verkoft worden.

Ook gaven zy den $22^{\text {fen }}$ Februarii 1704. an die van Banda beyel, dat zy wel op 't gedrug der genen, die zy nadeze ZuidQotter ellanden zonden, zothlen leten, om, zoo veel ti nogelyls was, woort te komen, dat deze Inliuders geen ongelyk mogt worden angedati.

Gelyk nu de Bandanoezen op deze eilanden waren, en jarlyks wolk wat "wegen de E. Matechappy derwazts zenden, alzoo komen deze Zuidootherlingen jarlyks mee humne vartuigen, en warea, tegen Seprember, of in "t einde vam "t Oofterfadoen, is Bandis, om te handelen:

Deze wharen bettarn meeft in Alatwen, fagoe, dic Banda ginfch nict, en ectiter voot hunine flawen hoognoodig heef, toctombos (fraje dovecn van bladeren en zechoornikens, verfcheiden in een fluiende) paradys- en koningsvogelkens, katsjang, (zeker foort with boontjes) hout werk tot het bouwen wan varatuigen, cnz, pinang, gedroogde vilch, oude klappus, groote batattas, ch neer andere ectbase wortelen, en ook wat rylt en padi, doch wan weinig belang, en andere geringe waren win die foort:

Na deze cufichenitap kecren wy van

Ketem- Aroe weer na het eilindje Ketember, teh Z. klein Key, ditar wy het met de befehryving der voorige eilanden gelaten hadd der.

Beweften Ketember, of wel Beweften dat rif (wat op het legr) ro mylen, Jege het eiland Mote rondon op een rif, dut over al wel I myl bred is.

Die eilisd ftrekt zich medt $\mathrm{N}$. tén $\mathrm{O}$. en $Z . \operatorname{ten} W_{4}$, heeft man cen baaiken intu de $O$. kant; en is ontrent 5 mylen lang, en + my"st breed.

Pas Iezuiden "t zelve I myl legt een klein eilindekcn warr $z$ of 3 mylen in 't rond, mede londom op een rif, en medt $Z$. en $N$. geltuckt.

Een my Z. Ooltelyker heeft men een rif, dat ; of 4 mylen lang, in " $\mathrm{N}$. 3 ; en is ' $\mathrm{t} Z$ ' +2 myleri breed, endat in " $\mathrm{t}$ ' $\mathrm{N}$. wat in binnen inbuigende is: Op trelve leggen ryf cilandelects, twee in 't N. W, twee in " $\mathrm{N} . \mathrm{O}$. (cn nan beide de zyden ook $200^{\circ}$ gerltuelst) en een in ' $\mathrm{ZZ}$.

Bcooften dit rif 5 mylen is het ciland "Jenen- Tenember' "t geens rindom op een it, wel' Ler, z mylen breed, lege, dat in "r N. W. nog met con lpiewen hock titfolnict, ath de N. kirt an weerzyden goede ankergrond, th and de N. O. kant dige an 'teiland twee kiche eilaudekens $\mathrm{N}, \mathrm{W}$. geftrekt leggen heeft.
Dit eiland doet zich neef $\mathrm{N} . \mathrm{O}$, en Z. W.op, zynde zoo 6 mylen lang, en in 't $Z$. W. tot de helfe toe 3 , en in 't $Z$ mant 2 , en ook I myl bleced.

Een my] ten Z. W. vain 'e zelve is nog een groot rif, Z.O. en N.W. zich wel 4 , en $O$. en $W$. wel 3 mylen verre uitstrekkende, op welkers Noorderdeel een klein eiland, "t fichildpadsentend genamt,
legt.

Een myl Bezuiden Tenember 's Z. W Larat. hock legt het ciland Latat op cen rif, dat I inyl verte (en in " $\mathrm{ZZ}$. W. nog verder) Iond loope, itrekkendezich ool tot stht Timor Lanet "s 0 . en W. zyde uit. in

Dit Larat is onticne 5 of 6 mylen 0 . W. lang, en Z. en N. ontrent zoo breed, en wat gedsunte meeft rond, uitgenomen atan de Z. W. zyde.

Ook hceft mea an de N. zyde cen Heine bahi, en op 'tzelpe ontrent de $W$. hoek cen weinig Noorderlyker "e dore Lata, en in " $\mathrm{N} . \mathrm{O}$. byit "rdorp Co. cober legran, behahen ditt zich nog een cilandje 2 mylen ter $N$. W. vin 'tdorp Luth, en een zeer kldin deilindje, nie cen rifje 'er om, I myl wan de $Z$. hoed Anderhalf myl ten Z. W' de 7. W

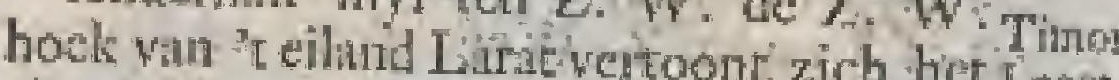
elland Timor Laoet met een finallen N L O. hock, die wel 6 ot 7 mylen lange, en in " $\mathrm{N} . \mathrm{O}$. pus 1 myl breed, doch na "t Z W vecl breeder is ? ? Ooch na

Deze bock vertoont zich ain de 0 . kant tulichent een fif, dar yan t cilnibd Lithat lings de 0 . kant vá T thot Liboe dige and de wal wel 6 injlen' $Z$. aht woortgaat, con dan weer wol s mylen na $t o$. ( daw ain "ceinde een kikin eltandje i myl buiten de wal is) draait, cir dan al yejderr 20 mylen verte var st $O$. allenskeits na 't $Z$. W. tot san de Z. O. hock' wat dic ciland loopt, diar zich 't rif wel yof 3 mylen in "trond verbreed, gelyk bok de wal wate uicloopt, en ditar zich oof drie tiskin eliandekens, en 3 of 4 nayfer Noonderlyker zich nog drie andere, beide in een driefprong, vertoonen.

Arn de W. kint vai dien N.O. hable van T mot Liout ziet men 2 of ' nulen van de wall dat zelve rit' ook wan 'wiland Larai," doch van des zelfs N. Jeint af buscen cen ellandje, in ' $\mathrm{N} . \mathrm{W}, \mathrm{i}^{\prime} \mathrm{myl}$ ? viti "t dorp Latrat geleget, omloopen, "t geen 200 tor tegen de N. W. kant waili dien hoek wan Timor Latoer wel of 6 ' mylen ver, doch atn 't cinde in ' $t$. W. met een fpitzen hoek (dié ha "r N. W. wel 2 mylea verte uitfeelat) loops, binnen of op welk rit drie cilanden $N . O_{\text {. }}$ I myl van ecin, langs de N. W. zyde van dezen hoek, en dus wel 3 of 4 inylen verre geftrelic leggen.

Dit ciland Timor Lnoet is buicen dezen $F_{2}$ 


\section{4 \\ B E S. C H R Y}

N. O. hoek (die atn "t zelwe als de gedante yan een harp geef, en ontrent 7 mylen hang is) 11 mylen aun de $N$. kane (te weren buiten of Beztiden dezen hoek) cr zoo nog al wat rerder een thuk weegs henen, breed, verfnalleade allenskens tot atu "t cinde ran "t eiland in " 7. ten 0 . rot op 2 of 3 mylen; en de lengte wan dit ciland van de $N_{*}$ lock af is, $2 \mathrm{I}, 22$ en 23 mylen, te weten de $\mathbb{N}$. hock "er niet by gerekent; want anders is 'r eiland in zyn gehol wel 28 of 29 rivlen lang.

De woornoende $\mathrm{N}$. O lioek loopt an de $N$. W. kint eerft 6 inglen verre, en dan nog wel $z$ of 3 mylen Z. aan, makkende data ecn fraje buta, die wel 3 of 4 mylen wyd is, en whal by $2 \mathrm{my}$ len ten N. W. wan de wal cen rif wan 3 of 4 mylen rond, cn fpits na "t $\mathrm{N}$. W. uicloopende, legt, watr op.zich in 'cO. ook cen cilandje wetoont, ook malkt dus de W. kant wan die baai cen felietpen $\mathbb{N}$. liock, die wetder wot het cinde toe gelyle henein. Joopt.

Op dit ciland wyn 3 of 4 dorpen bekent, een byat in th nidden 2 of 3 mylen van dien $\mathrm{N}$. hook, Joble Jorlo; cen ;" mylen Z. Oottelyker, en Wittlofi ; een 3 mylen Zuidelyker, en Elutey; eil en 7 of 8 mylen $Z$. Wettelyker, en Arelosfor gengami

Cena - Iu van dien, N hoek wan deze bai bopt weer est rif wat 4 of 5 myletserte tot atid de $\mathrm{N}, \mathrm{O}$. hock wan het ciland Ceta, dat 2 of 3 mylen ten $Z$. W. van dien hoele legt.

Dí Cen is byna vierkant, 3 ny] ling en breed tryte in " $t$ W. N. en Z. hice en diat wat minglogen.

Sikatoe Wlak Bengenden de N. W. hock wan Con 2 mylen N an legt het klein eilunde Silkevoe op en rif, dat rondom inelwe wat myl bred gar ; Bewelten th whlke cen rifi wel win Io of 12 mylen in th wienkant legh Gelyk men ten N. 0 . wh t $t$ alve 1 of 2 mylen dile zeer Whine dropten, ineen driefprong $\mathrm{N}$. W. thim en con eilindje da de Z. O. Kant, jeggen heelt

- Wat N. Ooftelylser, dan dit Noord-

Boeto. ontclydt ritic, legt 'er nog cen zoo met een ellandic en W. ten N, yan it zelve 6, mylen, leggen op cen rif, dewel 5 of 6 mvlen in 't rond is, twee cilanden, waar van igrootle in : . W. gelegen, Wherenatti dar onem Benoorden ankeren Jan,

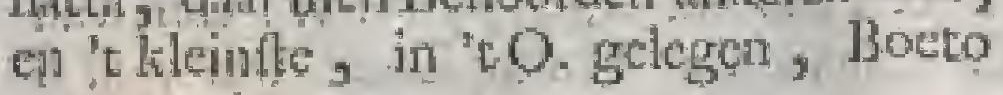
geparant is.

O. ten N wan Bocto $2 \frac{1}{2}$ myl legt 'c ciMele ladje Mele Kawoeter mede op oer rif, Kawos- dat wel I myl fond gate, ten O. wan 't welk I nuyl wet cen rif wel van $f$ of G. mylen in sond, en dat aan de Z.W. kant, wel 2 mylen als jingekeept en met cen thif is, $\operatorname{ten} N$. W. van "t welke meth

\section{$V I N G E$ E $N$}

een klein ellandie in "t Z. W. en nt "t N. O. ecin grooter, pis I myl van ecr, en Papenberg genant, ziet, gelyk men 'cr ook zoo twee N. O. en Z. W. geltrekr, man de Z. O. kank van die thif, en nog cen in 't $0 ., 1 \mathrm{myl}$ ' $\mathrm{cr}$ al', veruectint; tern O. wan welk laacte 2 mylen, men nog Iwce kleine cilandekens yder op een kleine droogte in 't rond, meelt $\mathrm{N}$. ven $\mathrm{W}$. ch $Z$. ten 0 . wan eetr gettrekt leggende beete ; buiten well $N$. Weftelyk entandje 2 mylen $\mathbf{N}$. Ooftelyker men weer twee kleine cilandjes 0 . en $W$. een halve myl van een op een rif, dit t myl rond gaat, leggen zier.

Ten W. wan de zelve 2 mylen legt nog ecnklein cilindje op zoo cen ritje, en nog NameI mal Weltelyker nog een eilandje, gang et Nammegang genamt, "r geen I myl ten Teng. Z. W.een rond klein rifie, an I myl ten N. O. van 't zelve hee eilandje Teng op een ritjc, dat roindom ontent a myl loopt, loggen heefr, zynde van dat eilandje, dacten Z. Wan 't eiland Móle legt, ontrent 4 mylen gelegen.

Negen nylen Bewerten "r ciland Cera legt het cilandje Mafide, dat 2 mylen N. Maffide. O. geftrekt, en ontient 3 mylen in "t rond is, op een iff rondom legt; en 2 mylen Babber. Weflelyker ontmoer men 't eiland Babber, dat ontrent g of Ia mylen in "t rond is, en een bani and de Z. W. kant, en id dorp. Welang, op de Z. W. zyde van dic bati hecf:

A) zedert 'e jar I67I. den $24^{\text {12en }}$ December hecf men belalt hier ect korpomal, fchoolmeelter, en 4 of $f$ foldmen te leggen, om andere, en woor al de roowerthe weendelingen, hicr varr darn te houden.

Bewelten Babber i myl legt nog een eiland wan 3 of 4 nyten in "e rond, meelt $\mathrm{Z}$. en N. geftrekt, en wan welkers N. W. hoek een rif 2 mylen buiten de wal tot des zelf's Z. W, hoels loopt.

Benoorden Babbers N, hock a mylea legt het eilandje Doctoe; dat jas I myl Doetoe. in "trond, en met ece rit, dat wel I of 2 mylen in st rond loopt, an $7 \mathrm{y}$ in $\mathrm{Z}$. Wunt bezct is.

Een grootemyl Beweften Doetbe, wel Kese?. zoo Noordelyk, legt "Ecilandje Keber, en i groote myl Beweften "t zelwe heeft jak men te cilandje Jjat.

Dexe latite cilandekens, by Bubler gelegen, Jeggen พm Bunda meelt Z. ten 0 .

Gelyt nu Ijat 2 mylen Jenoonden Bibbers W hook lest, atzoo lege her eilind Cenoewa 16 mylen N. ten W. wan I jat; doch eet men dan by kont, heete men o mylen ten N. W. van Jjak een rif; dat N.0. en Z. W. 3 mylen werte zich wifRicht, zynde 2 mylen meclt bred, doch in ' $\mathrm{Z}$. W. finaller. 


\section{B $\quad A \quad N \quad$ D $A$.}

Wat nu "t ciland Cerocwi betreft, dit legt op een rif, dat zich rondom her zelve wel I myl buiten de wal ftrekt. Het eiland is by na rond, 4 mylen breed, en ontrene ook zoo lang s doch $\mathrm{O}$. en $\mathrm{W}$. nog wel het langft. Aan de $\mathbb{N}$. lant van 't rif kai men ook ankeren, en ten W. van Ceroewa is nog een kiem eilandje of twee.

Zestien of I 8 mylen N. ten O. yan Ce-

wa lege het Vogets - ciland, ditt pas mylen in thond, en mede op een fmal rif gelegen is. Het zelve lege Z. Z. O. van 't Hoog Land wan Bincha, of wan Lonthoir, I8 mylen, zoo dat Geroewa ontrene 36 , en Babber, dat 19 mylen vati Ceroewa is, if mylen van Banda legt.

Twatlf of $\mathrm{L} 3$ mylen ten $\mathrm{N}$. W. wan Babber, en 3 nulen W. ten Z. dat rif, dat euflehen ljat en Ceroewa legt, hect men het eiland Nila, daar veel fwawel valt. Het is byna rond, en Z, en N. 4 mylen lang, en 0 . en $W$. 3: myl breat, hebbende in ' $t W$. een rif, dat $z$ mylen breed is, en wel 3 mylen verte $\mathrm{N}$. W. an loopt. Ten $W$. van dit rif 4 ! myl lege noy cen klein rilje, en een halve myl Weftelyker een rif, dat wel 4 mylen lang; en 2 myl bred, en meet $O_{\text {. }}$ en $W$. gefterekt is.

Met dit Nila beginnen de Z. Wefter Teuw, eilanden, wat van het cilandje Teuw, dat 5 of 6 mylen ten Z. W. vin Nilin op ecn rifje lege, het eerfte is, beflande in "c rond ontrent 4 mylen, en hebben een batiken na de $\mathrm{N}$. W. kant.

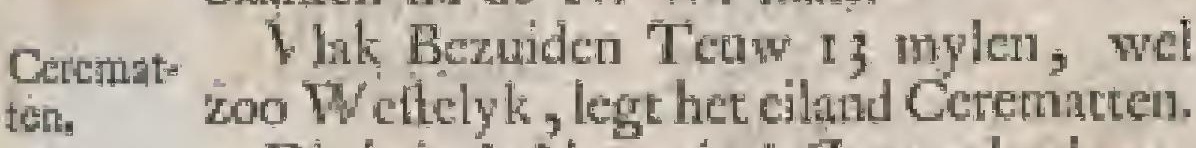

tin. Dit is in 't N. 5, in 't Z. 3 mylen lang, en O. ca, We mett 4 mylen breed; hebbende in " $\mathrm{C}$ W. een kilein eilandeken voor ecn wlake bail leggen. Beweften des zelfs N. W. hoek een halve myl is een klein cilandje, en Bewetten 't zelwe i myl nog een zoo, mec twee kleiner in 't midden, en ten 'Z wan de zelve nog twee zcer' lifeine I myl 'er af tegen een groot rif, ditt i myl Bewelten Cerematten lege, en dat vol katskoppen is. Her ftrelit zich als in een drichoek wel 7 of 8 mylen Z. O. en N. W., en wel s mylen $Z$. en $N$. unt, hebbende dric kifeine eilunden wail 1 myl in "t rond wan de $\mathrm{N}$. W. hock, t myl van ecn O. ann geltuckt leggen, fat welke het Ooftelykite wel

Nifenas- 't grootfte, con Niemalfe gename is s gefe. lyk ook bezuiden 'c zelve is myl hog een kloner', en I myl Zuidelyker nag een ander liggt, dat ontrent 3 mylen in zyn omitek is.

Vyf mylen $N$. ten $O$. van Nifemafte

Korlewe- legt een klein cilandje van 1 nyl in 'ctond; en 4 mylen N. Weltelyker "t eilatdje Korlewedan, dat maar' 2 mylen in 't rond is, op ecn Lmal rif, gelyk dat nog eelu kleiner cilandje If myl ten $\mathbf{N}$. W. van zich op zulk een fmal rif leggen heeft.

Twee mylen Bezuiden Katfewelan legt het eiland Damme op een rif, dat rond- Damne; om 'czelve wel i myl verre loopt.

Het is ontrent 5 of 6 mylen $Z_{4}$ en $\mathbf{N}$. lang, en doorganas 2: myl breed, vitgenomen dat het byna in "t $N$, met een breedien hock, die "t land darr wel is mylen breed malit, uirloopt, hoewel die ftreek in ' $\mathrm{t}$ midden matr $\mathrm{I} \mathrm{myl}$, en in "co. euffehen "t Z. en $\mathbf{N}$. maar 2 mylen breed is. Aan de N. kant is een kleitue goode ankerbaai, Wilhelmus-bai geratarnt ; mair an de 0. kint, wat tha "tZ. toc, is cen grooter bati, die wal 3 of 4 mylen in thond is, die de baai wan Koelewatte genamt word; cn in " $\mathrm{L}$. 4 mylen van dit ciland doen zich twee kleine eilandjes op een rifje op, wan van "t Z. Ooftelykite het kleinfte, en " $t \mathrm{~N}$. Ooltelykite het groofte is.

Dir ealand legt 56 mylen ruimo van Banda, en heft een fwaren Vuubers.

Wy hebben al voor secte jitiren op het zelve geviaren, en in "t jata 1646 . eent vedting datr op gebouwt,

Wannecr de onzen te dier tyd dar quamen, verklunden de itrandwolken hier zich onze vrienden, doch de berglieden onze vyanden te zyn, het welk toen de onzen al wate volk gekolt heefr; maar na dit $z y$ het bofch een kanonichoot werte omgekapt, en opgeruimt hadden, ging her vry beter, en men krtech de weking Wilhelmusburg, anders ook Natati ge-

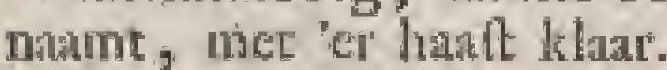

De ongezondheid dezes cithnds bleck dar atu; dat 'er in die 7 weken, die ry an 't bouwen der welting bezig waren, wel i 27 ftichen, 't welk ren grooten declen vas 'tbrak watel, dat zy drinken moelten, quam : waut fchoon "er landwatre in "sel good water wats, kon men, wegens der firoopenden vyand, 300 of 400 terk zynde, daur nier zeker by komen.

Na 'c voloogifen der wefting brage-men 'er 8 yzere ftukken op, en mon plitatte diatr ecn koopman, en een lieutenant met 7 foldater, met behoorlyke woomand woor cen jait", watr op de vloot in Julit weer na iBandit werctok.

De teden, warom de onzen herwarts quittien, en een velting datr gelege hadden, was woomamelyk, on dat men zeer ved vitn Nootemuulichatboomen, dat vallende, geroepen had.

Ook voeren de Maleyers, Macafianein en Javanen flerk, zoo hier, als op de andere Z. Wefter en Z. Oolter eilanden, Foo zy woorgaven, om 'er goud en maftoy te halien, matr buicen twyffel is 'e then vooinamentlyt on de Nooten, die daar viclen, of door de Nootenecters datar wet-

$$
\text { Fi } 3 \text { plant }
$$




\section{B E S C $14 \mathrm{R} Y \mathrm{Y} I \mathrm{~N} G \mathrm{E}$ V A N}

plant, of doon Lotrendrinjers "er gebragt tworden, te doen geweeft.

Om nu deze, en indere vreendelingen, hier wan daan te houden, en on de Nootenboomen, wit te roejen, had men goedgevonden deze wefting "er te leggen.

In 's jaar I664. zoguen de Engrilichen door een wa onze gewezene dienars,

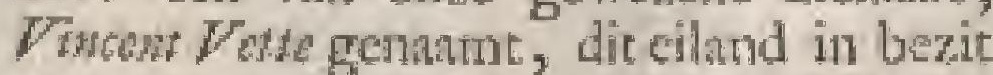
te remen; doch men zond 'er uit Banda volk ta toe, 't geen hen dar belerte, en then brige dezen Velte van daa" nat Bin* di, en verder ni Batavil, om datr zyn proces op te maken, al wat hy ons ook kennis gaf, dat prins Calchwha, broeder des konings wan Ternate, toen op MatEaflit woonende, na Eugeland gefchreven had, on die matic tot zelicren anflag op Ceram atu te zeten, weshalven voortain wat naauwer op fiem thont gelet te worden.

De quaddardige luge hier is echter oolzalakgeweelt, dat men maderhand ons volk, alzoo dat hier al te ftertk ftictf, wan daar geligt heeft; hoewel 'er nog wel opgevaren word.

Vyf of 36 nylen Bénoorden Damme; en 22 of 23 mylen Z. W. van Banda, leggen de twe 1childpadseilander $O$. en $W$. een halwe myl wan malteanderen.

Lolker. Twee mylen Beweften het groot rif, dat Bewelten Cetematen legt, doct zich tejlind Lokkens dat 6 myleri 0 . en W. lang f. en $z$ of 3 mylen biect is, en I myl Weltelyker 'teihnd Moa op.

Mon. - Dit is wel 8 mylen O. en W. lang, en 3 of 4 mylen breed, leggende in ' $t O$. net een dikken hock wat na "t $\mathrm{N}$. op, ca in " $\mathrm{s}$ W. met een rond klein hok je in to midden uit. Her legt ronton op een tonal rif, hoedanig ook 't ciland Leci 2 of. $;$ mylen Weftelyker zict yertoont, dat 4 of 5 mylen lang, $2 \frac{1}{3}$ myl breed, en 7 of 8 mylen in trond is.

Hier wallen veet verkens, en fehmen, die na Banda, cnook wel na Amboina gebragt worden; doch men heeft moeite on $z$ op te brengen, en in 'ceerfe ata 't geneen woedzel "dati' te gewemen.

Dit ciland fs zeer beigigtig, an de ingezetenen; die ik gezien en gefproken heb, fehynen van geen quaden imborlt te $7 y^{10}$.

Zeven of 8 mylen ten N. W. wan Leti legt "t eiland Kitler (dat ook wel Fetter genatamt wort) ' $\mathrm{c}$ geen ontrent 8 of $y$ mylen in 'c rond, en op cen frnal rif gelegen is, hebbende in " $\mathrm{N}$. aen flatawe bogt.

Agt groote mylen N. Weltelyker legt het cilind Eeter, dat meeft vicrkant, 0 . cn W. 4 mylen lang, en 3 ! nul breed is. De Hootdnegry, daar den konjug yan dat cilated woont, is Amagilli gemarme, die jo $t$ jar $\mathrm{I} 6 / 7 \mathrm{t}$. in groote wrece voor de. Pojtugeezen van Timor whs, die ben, en ook die van Kificr,
Aroe, enz dreigden, te overvallen, doch hatr Edeltheden gaven ant dic wan Bunda laft, om hen te onderltcumest

Negen of ro mylen Benoorden de $\mathbb{N}$. O. hoek wan Leti legt een klein ciland, ditt pas 2 of 3 mylen in "trond is, wau Teralta. $t$ welke het eiland Teralut pas 2 mylen Weltelyker legt, tufichen welker $\mathrm{Z}$. 0 . hock, en dat eiland, zich nog oen klein eilandje opdoet, grelyk 'cr tes Z Teralca if uyl nog ean wan 1 ' myl in "t rond is.

Dit Teralta is ook meeft wierkane $O$. en W. 4: myl hoewel na "o $\mathbb{N}$, wel mylen) lang, en 3 of 4 mylen breed. Ontrente de $\mathrm{Z}$. W. Loek legt her dorp Roman, en een half myl Beweften dis ciland, af en an dic dorp, een klein eiland, dat $\mathrm{I}$ ' $m y$ l in 't rond is.

Vyeiten mylen Benoondar de N. O. hock wan Teralda (wel zoo Ooftelyk) lees het brundend ciland met een rifje in ' $\mathrm{N}$, zyde "t cilant, en 't rif, yder omenen í myl in "t rond.

Zestien of I mylen Benoorden 't Brats- th Handend eiknd (wel zoo Ooftelyk) legt een dead fimal rit, het Zuidelyk vif genamt, dac eihnd. zich wel 2 of 3 mylen $\mathrm{Z}$. en $\mathrm{N}$. itrukt.

"Twee mylen ten $\mathrm{N}$. $O$. van 't zelve heeft men weer een rif, dat wel' 4 mylen N. W. tan ftrekr, en " $\mathrm{tgcen}$ wel z nyyIen breed is, whar op zeven kicine cilandekens $\mathrm{N}, \mathrm{W}, \mathrm{enZ}$. O. geltrekt, en digt by cen leggen; voerende den nuam van Nouffa NoefT Pinhos, en 2 of ; mylen N: Oolte- Pinhor. lyker leggen "er nog drie in een driefprong digt by en, zynde de dric Ooftelytie Noefla Pinhos genument.

Deze latite leggen ontent is mylen rnin N. O. wan de Schilpads eilanden, wiar mede wy dan alle de $\mathrm{Z} . \mathrm{O}$. en $\mathrm{Z}$. Wefter eilanden (zoo tils die gemerenelyk genomen worden), meench thangewezer te bebleit.

Doch hat Edelheden hebben deze want nitet alleen tot Killer en Etter, intar al zedert "t jatri 1683 ; oolk tot de kult van Barnwan of Balabon, atan de O en N. kut wan groot Timor, en Weftelyker, niet verder, dan tof Ade of Mancoetoe, bepale Op' wat brecdte 'nu alle deze Eilanden leggen, kan men in deze hare net: zien.

Zedert veele jutuen hebben de Bandanewen mies alleen op deze citatoden, miar Nova ook op Nowa Guinct, ats mede of de Gibinat Papoelche eldapden, en tot an lict Zuidland, of cen gededic van dien, gewaren.

Dir Nara Guiner is cen zecr groor land in zich zelven, crigentlyk it miede cen gedeclte van het Zuidland, zoo als het zich ngter Gilolo, en niet verre vath 'teulve, onbuigt, zyndevan de Aroéle he cilinden I 8 of 20 mylen $n a$ ' $t Z_{n}$ ', ei 83 of 84 mylen wan Banda gelegen.

Men 
B

A

Men zegt dat het wel 200 mylen verte bevalaen zou zyn; nuar wy moeten zeggen, dat men var die Lander, als ook van die der Papous, en van 'tZuidland, nog weinig kennis heft, en dicrhalven met weinig zekerheid dour van fpreken kati.

Papon- De Papartche cilanden leggen "ct" niet felie vere wal dan. Het cilland Meflowal, edanden, of cigentlyk Waygarna, legt ontrent I7 of 18 my len van Nowa Gutinea, en .'t ejland Suliwwati mar I myl "el' af ; en dir lantite legt ook zoer digt by "t eiland Sergile, dat het Noordelykfte decl wath Nowa Guinea is, en met econ lange fnuit Beootten Gilolo en de Papoefcluc eilanden cindigt.

Op dit land varen de Keflingers, Ceranlauwers, en Bandtuneczen meet on flaven, en on de Maftoy, zynde den batt wat een fpecerygeutige boom, als mede on pardysvogels wan verlcheide foorten, en Ironingsvogelkens, belsalven dax 'er' oole nu en din al wy groote paerlen vallen. Ook is 'er zeer goede Ainbre de gris ontdekt, wat wan men al zeer groote ftukker gezien heeft.

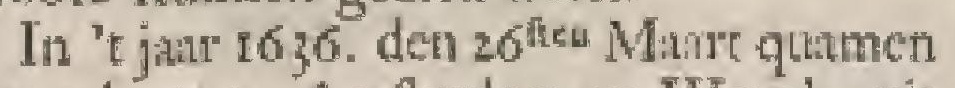
Tocht twee jagten, Amfterdam en Wezel, uit van Pool Amboina, met laft an den Heer Lindna 'Zuid- poogt Acoley, in Banda, orm an den be-
land. vellebber Gerdrd rbomasz Pool, hoolt dezer fechepen, zoodanig bericht wegens het Zuidland te geven, als by, om ecn togt voor de E. Matfichappy derwasts tc doen, van nooden hid.

Na dae meñ hern daar van de verejflite opening gegeven, en win noodige voorrasd voorzien lind, vertrok hy den $17^{\text {des }}$ April met deze boderns.

Den joflen Juni quamen die jagecn weer hier, en given te kennen, dar zy der 18den April ontreat op $4 \frac{1}{4}$ granden by deri whak ken hoek gekomen zynde, daar eenig volk tan land hadden gecet, on 'talleen van naby te belchouwen.

De bevelhebber $P_{\text {pol, }}$ genegen door zyn cigen oogen te zien, ging met zyn boekhouder, Andrigs Schiler, een Ncureiberger, zelfs mede; doch zy wutren 200 mis niet te land gekomen, of wonden zich var ecn groote troep wilde Zuidlanders, die zich eerft wiendelyk anthelden, doch hen naderhand wyundig aantafteden, zoodanig oncingelt en bezer, dat het hen niet mogelyk was dezen dus te ont/pringen. $D e$ berchlobber $P$ ow', dit klander, dau hesn lief was, zicnde; meinde het rog te ontloopen; doch lay wicrt cen waj de cerfte angetalt, en met een hazagai zoodanig getroficn, dat hy wooroverltertte. 'Terwy! hy nederwiel, en zyn boekhouder zich nog dapper weerde, ricp by hemi toc, dat hy her nuthr zout zica te ontloopen, alzoo 'er anders,
D

A.

47

om dat de troep hoe langs hoe meer nathgroeide, geen atkomen tan wis. Hy dede dit; matar wiert ook onder de voct geltooten.

De Zuidlanders, nu ziende, dar $z \%$ 't ftuk mefter wanen, rtukten de zabel wan Pod uit, en kapten deze twee mannen in ftukieen, die zy in "t bofch brtg" ten, zonder dat men verder weet, wat zy daar mede gedan hebber, of hoc 't werder met nog twee matroozen, die men mifte, gegan is:

Alleen wilten zy re zegget, dat deze Zuidlanders zeer lwart wan huid, bynd als de Katiers van Angola, doch ling en fwart wan hoofdhain, en veel langer en klocker van thatur, dan enig Europeetr. en, uirgenomen hume fohamelheid, ganlcl nealkt waren. Dat ook een wan ben, tchynende een overlte te zyn, een ruw vel van cenig wild diet om den hals geflagen had, en dat zy ten decle met hazngajen, en werppylen, met foherpe yzere punten, ten decle met pyl en boog gewapent whent.

Onu nu van dit onbehent Zutidland, Nova Guinen, en de werdere landen datr onerent eenige nader kemis te krygen, oordecten why bett eenige ontdekthingen, hice van tyd tok tyd, zoo door den bevelhebber Abd Taman, in 't jar $\mathbf{1} 6+2$. als doot de chaloep Walingen, in 'c jaat 1663., endoor den opperkoopman $700 \%$ the Kegti, in "t jatr 1678. gedan, met een letter shan te halen, ofm nul thet te fpreken wan de cogten van den Ridder Honptis Drake, Thomas Candich, Olwior sism Nowd, Spibcren, cumecr anderen, die mede dian', of datr ontrent: geweett, en dat land cerft ontdelst licbben, alzoo mendat in humse reizen zelf lezen kan.

Wat den togt wan Ald Tassan belangt, Abel

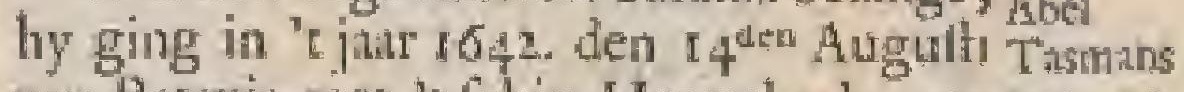
wan.Batavist met 't fehip Heemskcrk, en loge nâ de fluit de Zechann "i zcil, en liep eerft " $\mathrm{k}$ andna. "c ciland Mauritius, whis' wan 't Zuide" " $\mathrm{t}$ zar

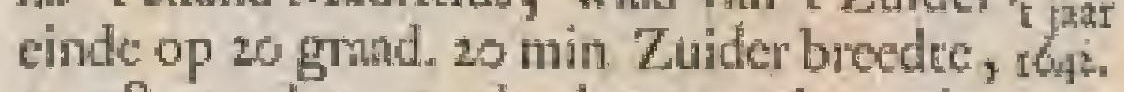
cn $7^{8}$ granden 47 milu. lengte gelegen is, bevindende, dat dit fo mylen Oolkelyker, dan hunne giffing, lag, "t welk 3 graden en 33 min. in de lengte bedmagt.

Den 811 en Oetober ging hy Zuiden nitn tot 40 of 41 grinden, alwati by de N. Wetterende niswyzing 23,24 en 25 grataden tor den $2 z^{\text {ten }}$ Oftober bevond te zyn.

Vun dar liep loy 0 . en wat Zuidelyker tot den $29^{\text {then }}$ op de Z breedte vin 45 graden 47 min. 85 griaden 44 min., cis bevond de $\mathrm{N}$. Wentering miswyzing hier 26 graden en 4.5 min.

Den 6fen dito had hy ecri ftorm met hagel en fineuw, mee groote koude ge-

hid, 


\section{B E S C H R Y V I N G E V A N}

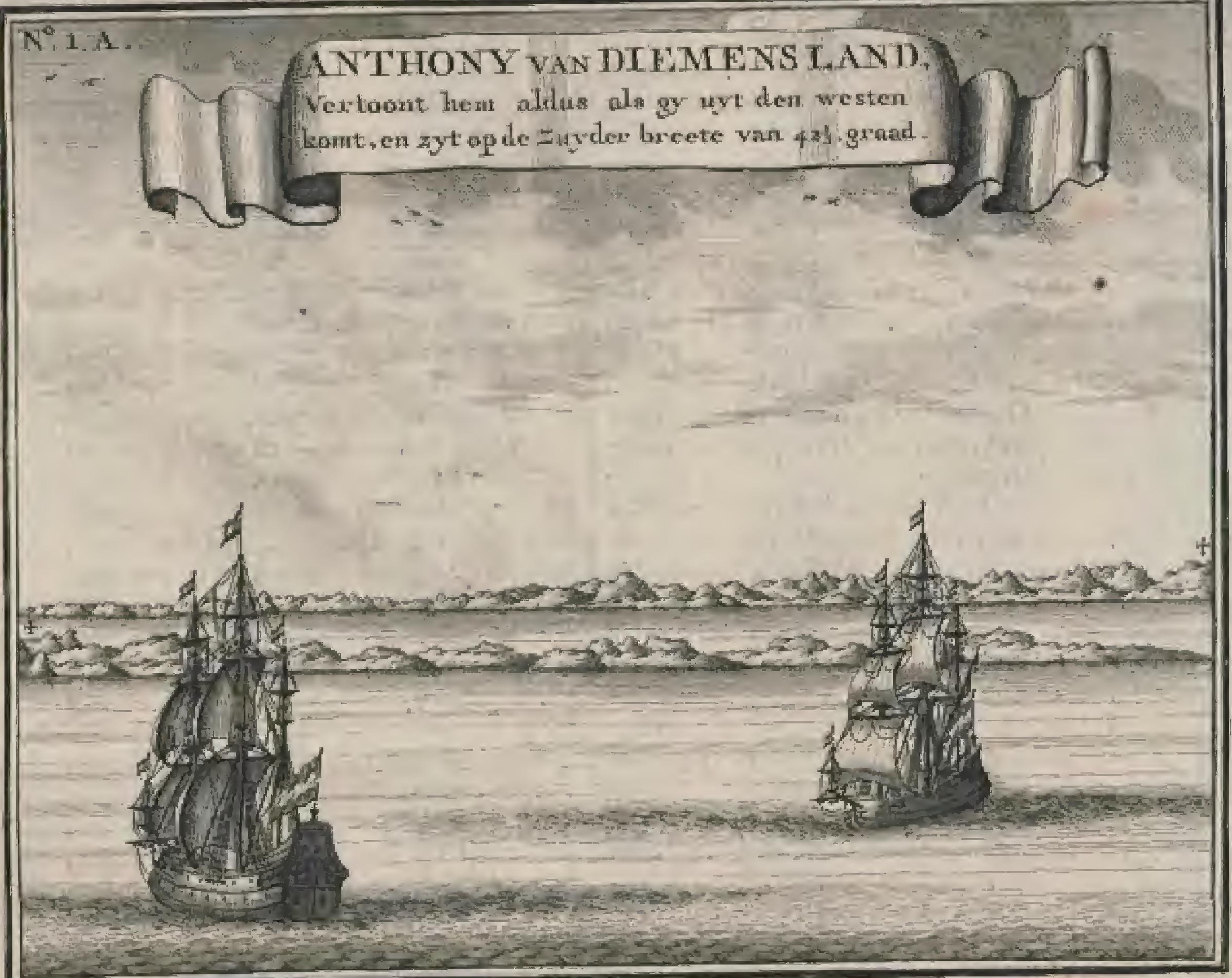

bad, op de gegifte breedte van 49 granden en 4 min., en op de lengte van 144 grtaden 56 min, ; en dit weder yan theeuw en lagel duurde den I den nog.

Den gten November hat by op 49 gratden en 4 min., en op de lengte wirn II gratden en 56 min., 26 graaden N.W. miswyzing, met zeer motrig en buyis weder, en holle dciningen uit den $\mathrm{Z}$. W. en Z., zoo dat op geen 3 ftreken land hier ontrent konden vermoeden re zyn.

Den $22^{\text {ten }}$ dito ftonden hunne kompaszen op geen 8 ftreken ftil, zoo dat zy hier gitten op ecnige zeilittenagtige mynen of gronden te zyn. Hy was un op 42 graaden en $5^{8}$ min., en vernam fwate deviningen uit den Z. W. zoo dat geen land on de Z. te gemoet zing.

Den $24^{\text {fiten }}$ dito, op de Z. breedte van Van $4^{2}$ gmaden en 25 minit., en op de lengte Lisd. wam 163 graten en so min. zynde, zag hy land $O$, ten $N$. Io mylen win zich, $t$ welk hy Antond van Diemens hand noemde, 't gecen wy in prent, No. I. A., zoo als "t zich opdoet op I myll werte pertoonen. Ontsent het zelve hadden $z y$ veel ftorm en onweder, liepen toen werder Z. tent 0 . artn, langs de kuft cot 44 granden, alwate 't land Ooftelyk en voores N. O. en N. loopt, en daar zy op 43 graden Frederik 10 min., en op de lengte vath I 67 graitHendrils den 55 min. in een baal, die zy Frederth

Howiks baai nocmden, tes anker quamen. Wy vertooneri dic, nevens ecuige andere cilanden 'er ontrent, zeer net in prent

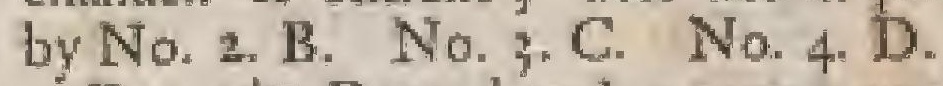

Den $2^{\text {den }}$ Decenuber 's morgens woeg

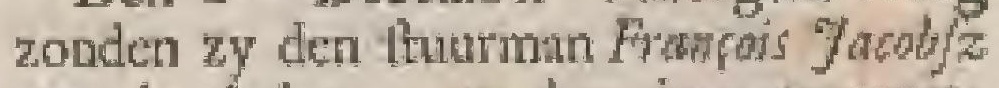
met de chaloep, en dant in 4 musquettiers, en 6 rocjers, yder met een pick en zydgeweer voorzien, nevens het prataken wan de Zeclatan, en hunne onderftuurlieden, nevens 6 musquetticrs, nanr cen inwyk of baa, welke N. W. Atyf $\mathbf{i}$ groote myl van hen lag, om te zien, War zy daar tot hun voordecl wan werfch water, werverfehing, timmerhout, of yet diergelylss, zouden mogen vinden.

Deze vartuigen quamen ontrent 3 utren voor den awond weder alu boord, en bragten vercheide foorten wan groente, die zy dar in overvloed gezicu hadden, in gredante niet veel van zekere groente, die men tan de kaap de Goede Hoope vind, ver[chillende, en dic zecr bequam tot warmocs was. Ook vonden ry nog een andere, die brak, lang, en byna als pieterzelic de Mar was.

Het verder bericht van den Piloot Major, en de andere fluurlieden, was, dat zy ruin I myl zekeren tock omgerocit waren, alwaar $z y^{\circ}$ hoog doch effen land, met groente, zoo als de mituur dit gaf, zeer vregtbar, en nies min van timmirer- 


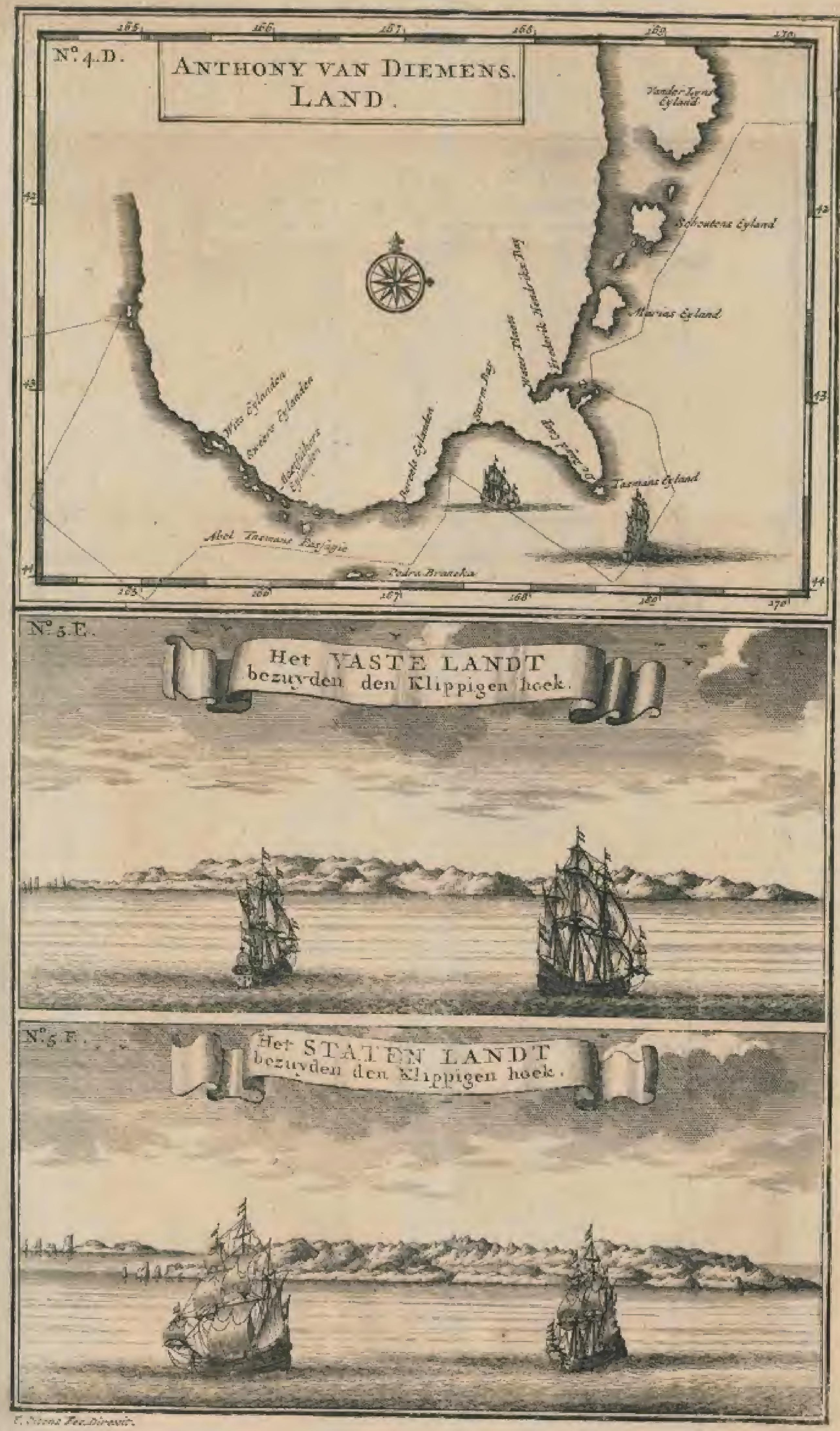




\section{B $\quad A \quad N \quad$ D $A$.}

hout in menigte foorzien, mitsgaders een afloopende waterplacts, wed ledige valeijen, ook wel goed watcr, maar zeer mocjelyk om to halen, en war wan weinig te bekomen was, alzoo 't uit een bak gefchept moelt worden, gevonden hadden.

Zy hadden hict ook wel geen menfehen gezicn ; mar egter cenig geluid wan menichen, en ook ecnig gefpecl, bynats van een tromp, of kleme gong, inet verte yan hen gehoort:

Ook haddden zy twee boomen, die 2 of 2 ; waden dik, en wel 60 of 65 voeten hoog waren, gezien, in welke met ecnige fteenen de baft hier en daur afgefchild, cn als een trap gematk was, om 'er op te konnen klimmen; doch de trappen ftonden wel, voeten van malkauderen, zoodat zy griten, dat hier ans menfchen wan een ongemeene lengte noetten bezis geweet $z y$. Ook tehenen de trappen atn den eenen boom nog verfely gemankt, ja zelfs nog groen te wezen, 200 dae diar nog onlangs, en zelf roor 3 of + dagen, manichen moctten geweelt syin.

Zy hadden ook her fpoor wan eenig wild

Zich

thyin

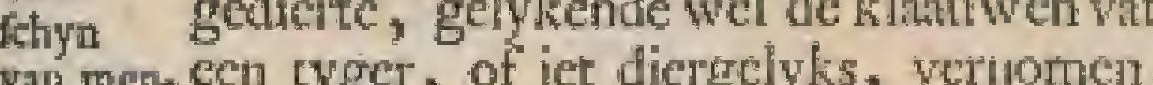
then en brigten ook eenigen drek van wietwoetig gedierte an boold.

Op de grond zatgen zy mede cenige, hoewel zeer weinig, gomme wan die boomen, byna als gommelak, leggen. On den hoek van deze bati hadden zy her hoogtte water I 3 of 14 vocten, en de ebbe en vloed hier ontrent mat 3 vocten, - en veel meeuwen dar bewonden, ats mede voel wilde enden en ganzen gezien. Hee geboomte, dat zy hier zagen, ftont wat ydel, zynde ook met ect dikkc bofchagie van kreupelbofch belemmert. Landwath in hadden $z y$ wel 't gerugt wan "t woorig gewonelre gehoort; doch niet gezien; matu veel boomen wetnomen, die door vaur te ftoken fehenen verbiand te zyn.

$\mathrm{Nu}$ en dan zagen zy hier ook in "t W. ten $N$, rook opgitan, en ecen bewys, dat "er menfehen win een ongetreene lengre waJeri, dat men ook klatr van boond gezien hatd. Ook zagen zy latogs dic diuft ved rooks.

Abd Tarnan lice hier den $3^{\text {den }}$ een pall opregten, wiats op liy "t merk der li. Mandchappy, en een ptincenvlatg ftelde, bevindende hué" 3 graden N. Ooltering. On dit te verrigten nam hy ma de Z. $O$. kant vat deze bani mee zich den Piloot Majoor Tancoss Jacobs, fchipper Gowit Zan/zoon, Janc Gil/omans, lcoopman wan de zeehitan, den onderkoopman Arabou Cowans, en den oppertimmermin Prerer "Yaldz; doch almoo zy dom de fwate bronding en wind nict ant koth den komen, wiere dit alleck door den tummerman, die na land fwom, verrigt, on die pal by 4 hooge boomen gezer; als by $N, 3$ C. te zien is.

Hy vertrok den, den December wan wot Diemens land $\mathrm{O}$. ann, met woornemen oni die ftreele van de lengte van 160 tor die van igs graten, on de cilanden valn Salomon te vinden, ce vervolgen, doch hy kon het nict langer lings de wal, alzoo de wind tegen was, houdest.

Denn gen dito hal liy op de $4^{2}$ gmaden 37 minuten Z. breedte, en 167 gmaden 29 min. lengte, 5 grataden N. O. miswyzing, vernemende cenige dagen datat na nog zeel holle deininge uit den $\mathrm{Z}$. W., zoo dat in ' $\mathrm{Z}$. of Z. W. geen land te vermoeden whs.

Den I $3^{\text {tea }}$ dito zag hy in * 2 . O. Is mylen var zig, op 4 g gatden en ro min, op de lengte $\operatorname{yan} 188$ graten en 28 min, zeer hoog en bergagtig lathd, "t geen tu Nora in de knarten Zeelandia Nowa gename word, fitwaar hy besonit de N. O. mis- dia. wyzing wan 7 graden en 30 min, 5 doch dit land noemde Tasman het Staken-land ( na de Herten Stanten) en oordedde, dit het zelwe land, 't geen zich zeer fchoon opdede, de wafte kult wan 's Zuidland was. Ook gaf hy and dezen doortogt den nam wan $A$ del Tomans doortogt, alzoo die eerft door hem ontdekt was. Een afbeelding van dit land zien wy No. T. E.

Langs dit land liep by N. O. ant , en ankende in een bata op 40 gratden, eri fo minn., en op de lengte vith Is gatadeu 41 min., met een N. O. miswyzing wan 9 gratden op deri $17^{\text {den }}$ en 18 sem December.

Hicr zag by, in een groote opene bah: wel 3 of 4 mylen wyd, Beoolten eeri finalle zandiunt, en nog wel I myl van. zelecren hoek, op de hoogte van 40 gma- Micide11 49 min., en op de lengte tan 9 fthin get graden 41 min., menfchen, die grof ratr jeth. item, en dik en fwatr van gebeente waren; soch zy guamen tot op geen gotelingfchoot na nitn boord. Ook bliezen zy dikwils op een fpectuig, dat wel na cen trompet geleck, wart tegen die ran de zechan mede cen matroos; woor trompetter uirgewaren, lieten bladzen.

$\mathrm{Zy}$ waten wan perwe tuffehen 'tbuin engocl, fwat en fwatr wan hail, dat op de kruirs op zya Japans op-, en valtgebonden was, en hadden cen grootedilike wite veder datr op ftran. Hunne kles. deren waren, zommige als wan matren, andere als van katoen; doch "t bowenlyt was nakkt.

Men revinde, of wuifde ecnige maten tegen hen, om hen asn boord te doen komen, coonende hen wit lywat, en

III. DEETL. 


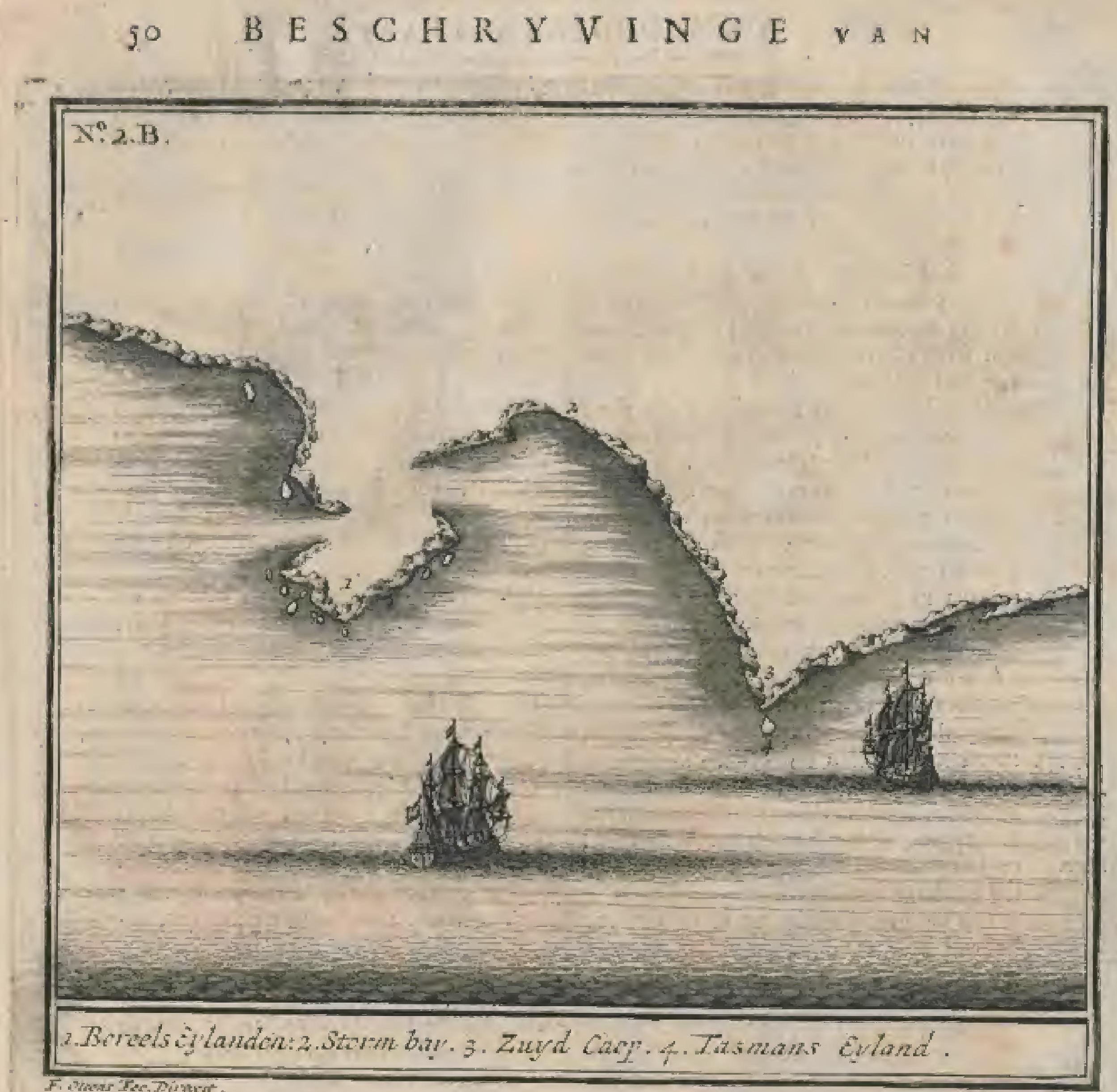

eerige meften, doch konden hen dar toe nict bewegen; gelyk zy ook eindelyk veer weglchepten.

- Daar op quamen de overheder van de zoehann, op Tasman ontbod, aan boord, als wanneer men befloot and de wal, zoo na nls "t mogelyk was, te loopen, alzoo daar goede ankergrond was, en tic wolk, zoo 'i feheen, genegen was om viiendfichap te matken.

Pus nat dit genomen befluit, zagen zy nog 7 vartuigen van land komen, watr vat 't cene (voor hoog en feherp opgande, en met 17 koppen bensand) aster den zeehtun omichepte, en "ttwecde (met 3 klocke koppen bezer) geen halve werp van Tasmans voorlchip quan, welke beide malkanderen in een woor hen onverftanbre taal (met de vocabular hec medegegeven niet overeenkomende, alzoo dic van de taal der eilanders op Salomons ejlanden was) ettelyke malen toeriepen.

Dana op wuifden zy hen weer met wit lywat, enz. toe, om hen anu boord te noodigen, doch zy bleven egter ftil leggen , wast op de ichipper yan dg zehan

zyn quarticrnicefter met en pratuwrje en 6 fcheppers na boond zond, on de onderfturticden te warehouwen, wan, zoo dit volk wan boord lkomen wilde, 'er niet te ved te lanten overkomen, en on verder wel op hun hoede te zyn.

Zoo als mu "t pratuwe je wan de zeelinan na boord chepte, ricpen en wriften zy met hunne panggajen, en wan de pratuw mede, die luet natite by eenvus de fchepen whs, tegen de anderen, die agter de zechan lagen, zonderdat on\$ volk egter hune meining kon begrypen.

Wannece" nu "t pranuken wat wan boord ttak, begonnen $2 \%$, die woor ons tutfich beide de lehepen ligen, zoo duffig dar op an we fchepper, dar zy ontrcine half wegen, wel zoo na $A b d$ Tarmans fchip, dic pratuwtje wan de zechan met humne fteven op de zyde :andeden, zoodat her zelve geweldig overiwalpte, watr op de voorfte in de praxuw dezer ichelmen den quartictmeeter, Cornelis foppes, met een lange ftompe piek zoo felverfcheide matlen in den nek ftict, dat hy over boord vallen moelt, gelyk daw op de andere van 


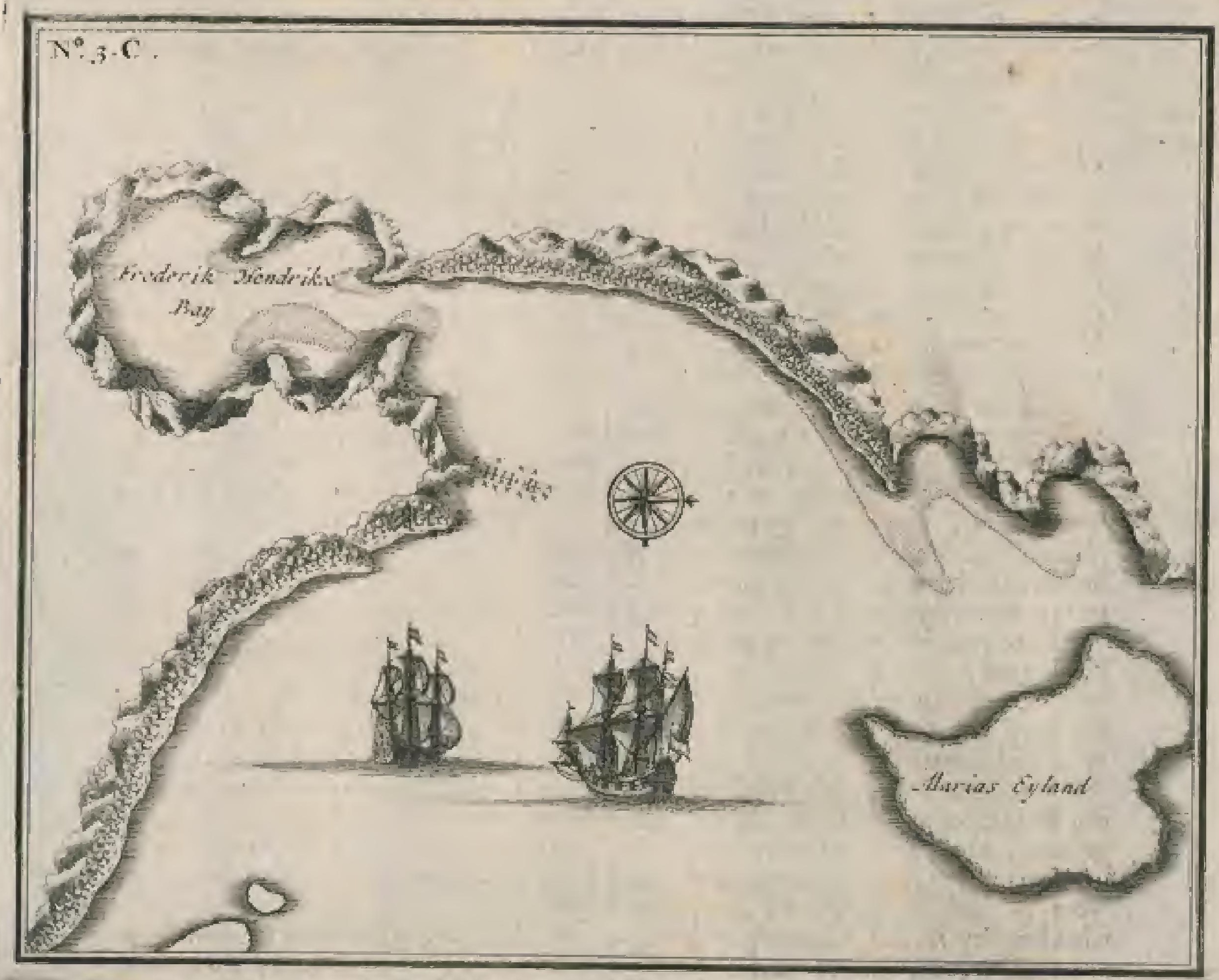

zyne"makkers met korte dikke houten (by ons in 't eerft yoor waare ltompe parangs angezien) en met hunne panggajen mode atnvielen, en "t pratauken overweldigden, in welken aanwal drie mannen wain "t wolk van de zeehana dood bleven, en cen vierde doodelyk gequert was.

De quaticrmecter, en 2 andere fwom-

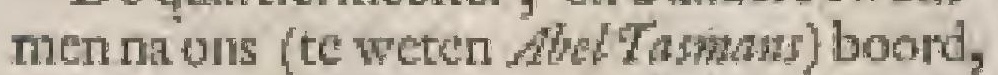
en wy zonden ben onze chaloep tegen, daar zy nog levendig inquatnen, cn dair op lieten die moordenats het pratuiken, tot eun groot geluk vout ons, dryver.

Zy hadden een van de dooden in bun pratuw gehate, en de andere verdronken, weshalwen wy fterts met musquetten en gelchut op hen, doch zonilcr te reften, folioren.

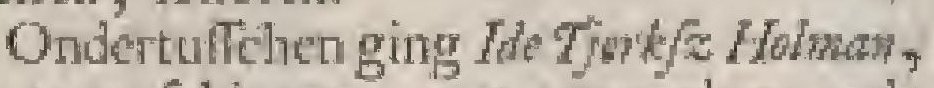
Tashas fohipper, met een welgenande eis gewapende chalocp ma "t praviutje van de zechata, wan mede hy teritone na boord keerde; vindende een dooden, en een daodelyk genuerfte dair in.

Wy vertoonen een van dieMoordenarswartuigen, met die moordenturs, hier zect finit, No.6. E. Gelyk ook 't land, zoo als zich dur vertoonde, N. 7. G.

Demoor Hicrom nomde Tasman dit de Mooritenatss- donars-baai, werecilendevan hicr, alzoo bna. liy hier werder-niets goeds te gemoet zag.

Zoo als zy mu van dara zeilden, quamen nog 22 vaartuigen van land op ben ata; watr op zy eenige reizen, doch te vergecfs, fchoten, doch die vari de zechari croffen "er een, met cen wit vanatje in de laund, dat by ter necrftorte, wair op $z y$ alle gerwind ta land keerden, wan de welke'er 2 zeilen van fatfoen als wan cen Tinggang hadden. Zy waren dar op $4 \circ$ granden 50 min. ten anker geweeft.

- Hier wan daan ging hy weer O, N, O. aan, das by rondom ook land vond, dat zecr goed en wrugtbaar, doch weel onweer, en $W$. winden onderworpen, fcheen, zoo dat hy weel moeite had, orn van dars te geraken.

Den $26^{\prime l t a}$ dito ging hy weer N., en wel zoo Weftetyk, han, komende den

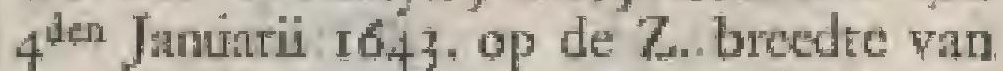
34 graden 35 min., en op de lengte van iot graden, g min., alwar' $2 y$ by de N.W. hoek wan dit land quamen, vernemende een zeer grooten ttroom, die hen om de W. zettede, cuacei holle deiningen mit den $\mathrm{N}, \mathrm{O}$, whar wit hy

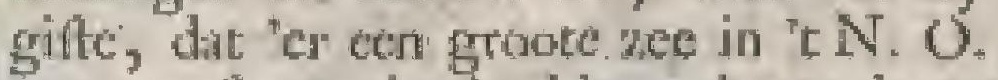
zyn disoelt, cndat hy hier ook oen doorgang vinden zou.

Hy ang datr ook cen eilind, dat by Drie ko"t drie Koninger ciland noemde (op 34 mingen griaden zs num. breethe, en 190 griaden eilank, 40 min. lengte gelegen) war na foe zyt

$$
G a^{2} \text { volk }
$$


woll ging, om zich te verterlehen, dar" zy ook verrch watej" gevonden fradden, en 3 o of 35 mentehen wh eel ongencene Latige lengte, voor zooverie $z y$, hog cen goed

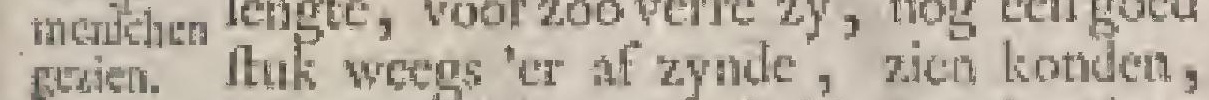
vernimen, die, net ftoktsen en knotizen gewatpend, hen met grove en luide ltemmen, zonder dat zy hen werftara konden, toeriepen, behalwendac $2 y$, een fnellen voortgang makerde, tijet geweldige groote itappen, ma hen torquamen. Wy vertoonen dit land N.8. H. en No. g. I. zoo als zich dat niterlyk opdoet.

In "t omroejen wan dit eiland zagen $z y$ ecrige menchen, en ook egr grooten man met ect lange ftok en piek, ha "t geleets, ook zagen zy zeer weinig of geen bebouw lind, dan alloen by cen werfeche rivier, dar de onge meinden water te haten, doch kouden "er niler ontente leomen; ook wertoonden zich datar over til vierkate perken, wan sroen en vernat kelyte land, even oens als it ons vaderhand, zonder dat zy de growtre belkennen konden, ook zagen zy daur 2 pristuwer op 't land gelualit.

Tasmow nam dam op het bellut wat met cen Oofterlioers tot de lengte wan 220 graden, en dan Noordwants tot de Z. breedte yan i7 gritiden te loopen, en den weer $W$. arn de Kokos en Hoarniche ellanden (by Wilem Sibowen gevonden) and te doen, on dar te werwerlehen.

Den gdea dito "s middigs zagen $7 y$ in 'tZ ontrent $;$ mylen van hen die eiland.

Den gen Tanuarii quam lyy op de 7 . breedte vatn 32 graden 25 . Imin, en de lengte wat 102 graden 20 min, wernemende dat men de $N .0$. miswyzing van o graden hier, en fwane deinitygen tis den Z. O. Iradde, zoo dat uit die ftreck geen land te:yentuoden wiss. Ook wits dit ech vatuwater wat op twell zect gemiak kelyle wan Batavia m Chili, alzoo rer niets in den.whg was, teilen kon.

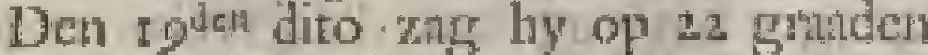

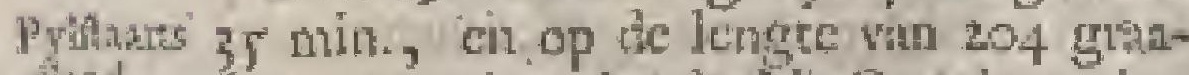
cistnd. den, is mis. (by de N: O. miswyzing vari 7 granden 30 min. ) een cilitnd, 2 of 3 mylen in 'E rand bellinde, t t geen hogg, Ateil en bat" whs, hee welk lyy "t hoog Prittarts ciland, on de menigte van. pylftarem, dic hy hicr zag , nocmde. Wy vertoonen 't welve, $1 . z 00$ als 't zich opdoe N. Io: K. Hy togt thar wel wat nader by te komen, doch 't wient hem door ate Z. O, on Z. Z. O. winden belet ; dages 'er an taig hy not $z$ andere cilander, en quatm den 21 tear dire antu het Noordelyit, dit op 21 grinden 20 min., en op de lengte van 205 granden ag min, De eilan lag, dare hy 7 graticn if min. N. O. den Am- miswyzing hid. Dic was net hoog. Hy flerdar noemile "ecene Amfterday, en 'tander an Mist Middelburg. Wy vertoonen die beide zoo ats zy zich val were opdom, No. I I. L. Hy wont op 't aerfte werkens, hocnders, en vecterlei fruiter, die de inwoonders, die zeer wriendelyk wren, hen coebratsten. Deze vieicn wat diefagtig ; doch fehenen anders geren guath in den zith te hebben, ook waren zy wan geen geweer voorzici.

Deze 2 cilinden leggen N. O.en Z. W wan malkanderen, en was her Z. Ooftelykfte wel het hoogite, en 't Noordelykfte her haggte, eren als Holland. Kregen "s middags een prausw met 3 thatkte byulne mamen an boord, die war langer dan geraecne lieden waren, van welke er eta kot gefchooren, en twee lang hair, en ecn licin kloedje voor bun fohanclineid hadden.

Hunne pratuw was froal, agter en voot cen groot ftuls weegs overdekt, ca hunne panggatjen war eer genteene leng* te; doch 't blida, datr zy mede lebepten, in "t midden breed.

Wy toouden en wierpen hen over boord cen Ituk lywat toe, wala na ben wat hen, die zer lang onder bleef, dook, doch hy quim dant mat met zelve weer bowen, en lei dit, ten tecken wan darkbatrlieid, nat dac hy it de prasuw getomen wu, verfeleide malen boven op zyo hoof.

Naderhand, alzoo zy met buñ pranw mister san ons boord quanen, wietp men hen een hout met 2 groote fiykers dant op gebonden, cnmen reikte hen en Chinees fpiegelken roe, en ooli wen keten Chaineeflue kraten, die zy met ect lange ftok na rich lyailden, wanr am $2 y$, tot vergelding , cenige wur hunne witchloeken, wan een foort wan parlemoer fchelpen gemake, met cen lyntje valtbonkten. Eenige wan lren lejden deze krailen, fpiegel, en keten, op hum boold, en de middelte bond de fpykers on zyn batls.

Ook reikten zy hen nog ecnander fpiegeltje tor, want in zy zien konden (alzoo 't oerfte deor een dichuifje bedekt was) da zy al meite op lun hoofd leides.

Zy toonden tien ook een klappus, co een hoen, ca wragden hem mee wootien wit hun medegenomen vocabulur na watter, werkens, ene. doch konden mialkntderen nier werftatus s matr zy weren de onzen al ha land, war op zy weer dilar vat toe, als of $z y$ iets halen wilden, fchepter.

" Namiddugs zang men veel menlchen langs flind loopen, zommige met witte wainkens, dat de onzen voor wedeteckens ntmen, die ook de witce vlug won agteren. licten wajen, dar op quandin 4 klocke mannen met cen prouken aur boord, welker lichum van de middel. tot de dyen fware gefchildert, gelyl hum 


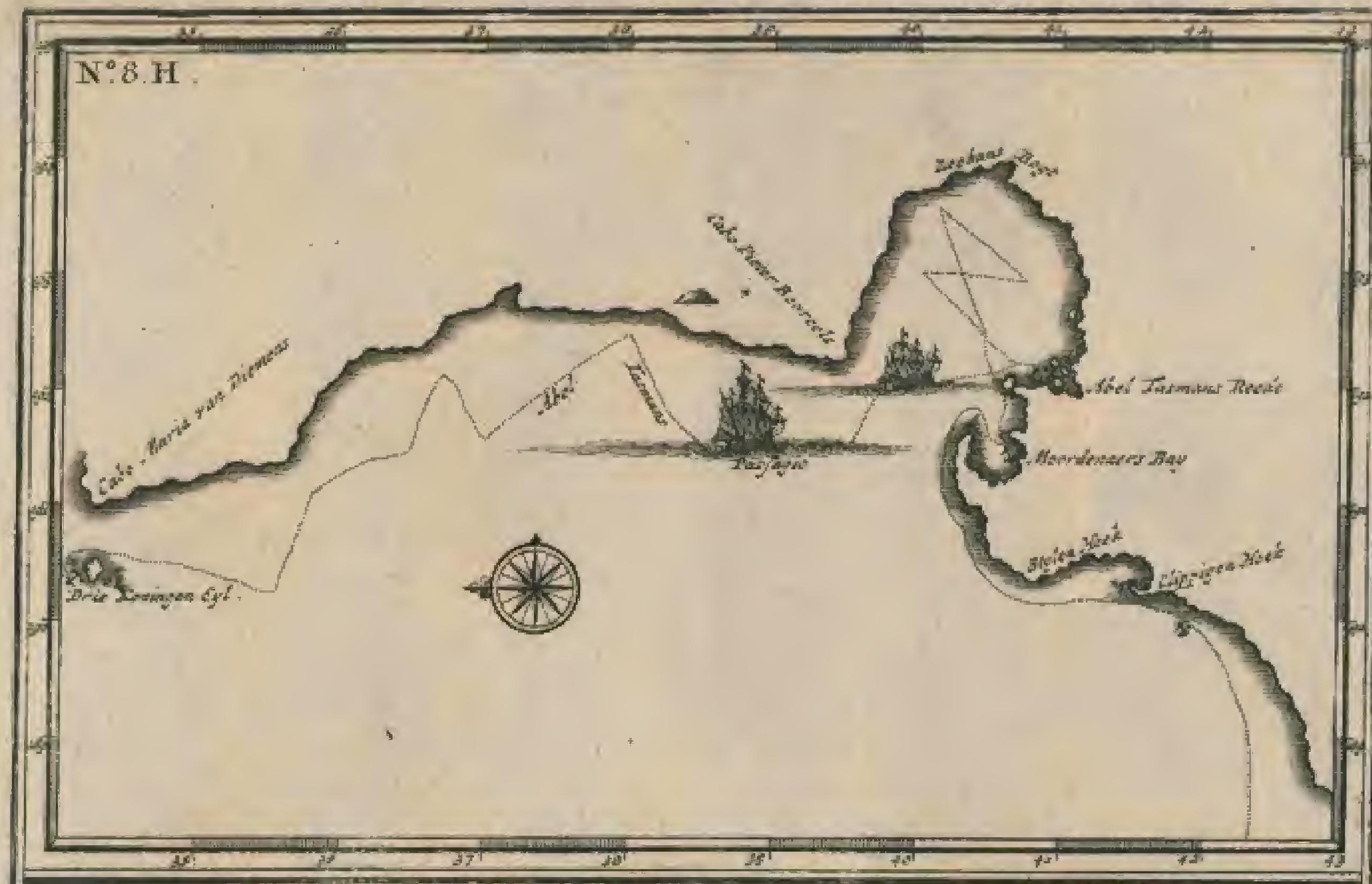

STAETEX LAFDT Bezyt en ontdolt met de scheepen Heensleerk ort de Zeehaen onder hot conmande pan den E. ABEL TA\&MAN. in den Tatre t6,

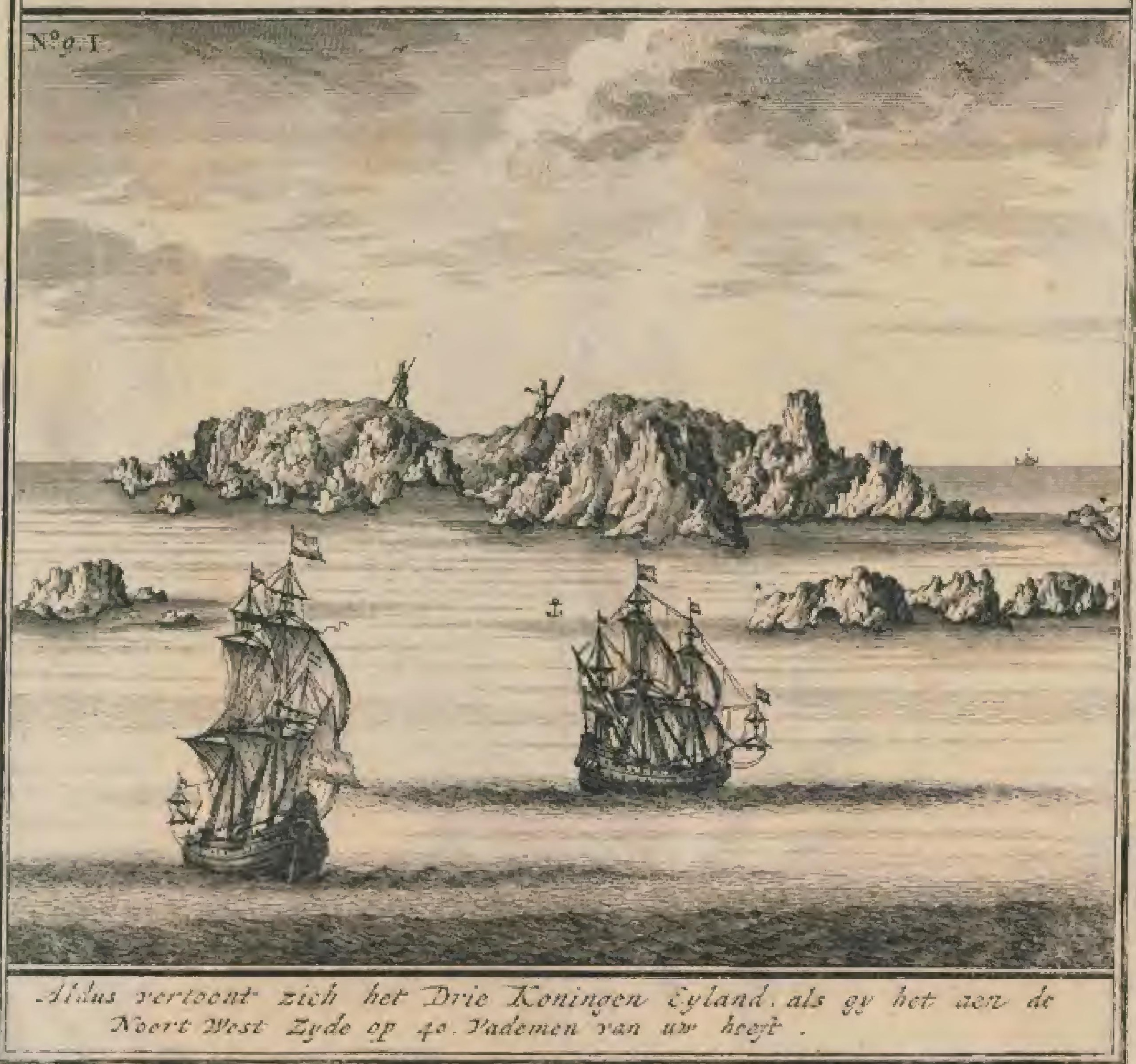




\section{B A N D A.}

hals met bladeren behngeis was. $\mathrm{Zy}$ bragten een wit wagget fe en een kleed wan balten wan bommen mede, welk whggetje zy op de plegs wan anze boot thelden.

Hunne pratum wiss and de ene vlerk met fchclpen en zcehommkens verferd, watarch $z y$ dit woor een prasuw van der koning of overlte des lands namen, om wellie reden zy hen een Chinees fpicgettje, een mes, een dongri, en exnige ipykets vereenden.

Zy dronken hen een glas wyo, tot hunne geruttheid, voor, en gaven hen toen een rocmer wyn, welke zy untgotén, en namen die mede na land.

Kort dair na quamen zeer weel pratuwen, zommige wan welke io of $12 \mathrm{klap}$ pus medebragten, die de onzen tegen ipykers ruilden, ook fwommen zommigen met linjpus na de feliepen.

Naderband quam een oud man, dien de andere cerden, an boord, die de onzen grooten eerbied, met 'tbuigen van zy'n hoofd tot zyn vocten, gelyk de onze hem weer cerbied betoonden, en verfelleide fivuitteryen an hem tebonken.

Eenigen wan hen gaven lier in "t weg: gatn preuven wan hun dievery, en tegen den wyond quamen wel 25 protuwen ontrent Taman fchip, makkten eerfe en gloot geroep watn wor, for, rwor, en bragten toen eeri verke日, cenige klippts en oebits, an boond, wanr voor men hen een fohatfchotel, en ecnig koperdriad weteerde; roilende maderhus nog ecnige klappus, pilang, oebis, een velken, enz. voor fpykers en kraten.

Wannecr 't nu donker where nertrok. ken, $x y$ alle weder, uirgenomen een, die an ons boord blecf flutper.

Den 2 ich dito quamets weder veel mhitnen en vrouwery, jonge en oude, met allertei ververfolung van diat land, an boord. De oudfe deter voutweis whes de pink der beider handen afgehouwen; doch dit zig men san gecn der jonge vrouwlieden, zonder dat de onzen de reden hiver van konder wirvinden.

Op dezen zelven digg quan die voorise onde man wer met ecis gefoljenk an boord, diet zy weer mee wen zattyn telest, een hoedyen eer hend belchonken 3 "s mid" dags quamen "er 32 kileine pratiuwen'g en een gronte met en zeil (eren als "t feen men in yacols to Motive "s journat zict) by heí, en wa dezelre ook cenige mannen en wouwen an boot, met hanace vrugten, ook eenige onbekende worte$1 e n$, en een batten - kleedje.

Tasmaw wercerde an den opperfteri wan 18 litoeke maned; en hunge vouwen een broek en hemd, whtar mede by zeer, na dat hy dic angedan had, verfierd Wals:

Onder deze liedon wh een groot Iyvig man met cence St. Thomns arn, en een vrouw menfeh, die naturrlyk ten weing baards had.

Wy doden woor hen eens lutitu op de trompet blazen, en op de viool fpelen, watr ower zy zich zeer vertonderden.

Datar op zond rasman zyn boot, en die wan de zeclytan, net eenige waterraten, om te zicn of diar nan dand water, alzoo die oude her hen met wyzen verzelert had, te krygen zou zyn.

Met yder boot ging een ftuturman, en rchipper the Tforizoen Holman, en de koopman Gilfomans togen met de chaloep mede nis land, en wist al ons volk wel van geweer, rehoon dit in opeige van der goeden and dezer menfchen onnoodig leheen, vooricu.

' $\mathrm{Na}$ dat ry nu cen fluk weegs verre pas de $\mathbf{N}, 0 . z y d e$ vitn dit land geroeit waren, quamen ' $y$ cindelyk by drie kleine waterputjens, watr uir men "I water met kappusdoppen licheppen moeft, bohalyen dat het oov in zich zelwen niet dogt.

Daty na bragten $x y$ ons wolk werder landewartit, op cen fraje remalelyke plitats, difir zy hen op een fientyke bidleoe, an op zeer nete fyne matjess necrzettedet, hen toen met 2 klappusnooten, cen voor hun overten, en cen woor onzen fohipper, enz. onthalende. Hier op keerde ons volk tegen den avond met een vetken, en met berigr, dat hier geen water te bekonen was, wetle"; doch itiilden dien dag nog wel 40 ver lsens, $7^{\circ}$ hoonteren, en werlcheide vrugten, voor zeer weing fylkers, zeildock, enz.

Dere lieden weten win geren tabak jonken, en hume vioutwen galan van de middel tot de knyer met matten wan bladen wan boomen gedekt, zyn woor de weft naki, en konterwan 'hain dan de mannen. Dew latite hebben cen band? wel 3 of + vingeren breed, doch an de kin bowen den mond redulyk getort, houdende hume Inevels ontrent 2 throobreed lang. Men zag by hem ook geen getweer, weshalwen men te minder voor ongemak wreesde.

Daigs 'er hatr wierden de onzen, weer atal land gekomen on puttert te delwen, voy beter wan hen net vitels, zoote melle', enz. onchalt, en in alleri deelen wriendelyk bejegend.

Ook vingrgen $z$ a an de obzen, wat zy wan dita quatmen, cn wat zy the tos wilden, watar op die zeiden, dit $z y$ reeds over de 100 dagen in 'zee' gewcelt waten, diar $z y$ zich zeer over verwonderden, webhalven klats blykt, dat zy malkatuderen (wartchynelykt door Maleifche of andere tolken) wel verftan hebben.

Zy ruilden hier nog vel werkens, hoenderen, enz. doch geratiten 's numiddags, 
54 B E S C H R Y

door de fteile grond, cndoor den pattuatwind, wan hunne ankers in zee, docli 's nichts weer behoorlyk ten anker.

On nu nog netter denkbeth van dit cilland Amfterdutm, en 't werdre dare ontreme asmerkelyk, te hebben, vertoonen wy her nog nader in a preticwerbeeldingen No. 12. M. I. No. 12. M. 2. alles juet een alphabeth, zoo ats mea hine verwolgens zier, aingewwezen.

A. Onae forepen on wa Diowens rede ten ahker.

B. Rleim pranwen van den konting dezes londs

C. Een zoilvaramig vas 2 prahaven newew5 dex anderen wet on zoldor wordekt.

D. Een wiflowante.

E. Hoe zy mot klapus, enz an bord fawming.

F. De boek, was de kowing wont.

G. De phats, dale ande bools hagen ow water to balem.

H. De plats, daar zy ans wolk to ganoe qudwen wet rutedendens.

1. De plasts, dhat ons wilt met grveer do wagt bidd.

K. Des koning bollow, inech pagger, datr by de onas onibals.

L. De ruglophats wow den homing, ch zywhe add.

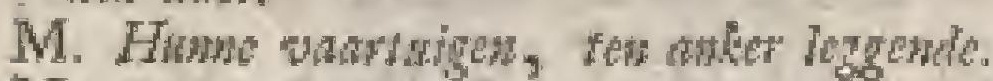

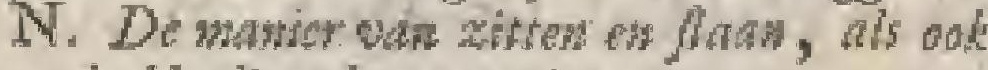
de lleeding desar nati?.

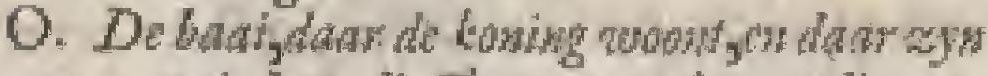
waartwe legt, die Tawan wa de gemlin was de Feer wh Ditwen, Marra's ban nowde.

De fraje teckening van deze cilhuden werdient zeet wel, nevens de andere diur by verbeelde zaakeu, dat wy die mede intafen. Danzy ten anker gelegen hadden, deder zich nog 2 hooge doch kleine cilaridekens $x$ of $i$ ' my! in 'er'ond, 7 of 8 myled van lien in " $t N$. ten $W$. op, en zagen toen nog cen camelyk grooe lag ciland io ' $\mathrm{LO}$. N. O., en th to. nog 3 indere zeer kleise, en in ${ }^{2} 2.0, \operatorname{nog} 2$, alle zeer lang.

Hict was gecn harde ftrom, en de cbbe liep 'er om de $\mathrm{N}$. $\mathrm{O}$, en de wloed om de Z. W., en "e vlocide hier 7 of 8 voeten op en neder, zynde het by een Z. Wefter Maan hier hoog wher. De wind liep geduarig Z. O, en Z. Z. O., Whar door 't jugt Heenskerle,zonder whiter in te konten wemen, yat dit eihnd afnukte.

Den 2 riten dito quan ly op de Z. breedte van 20 granden is min., en de lengte van $206 \mathrm{gta}$ den $19 \mathrm{~min}$, had cen miswyzing wan 6 gradien zo min, ook zag hy bicr verfectide kleine eilandekens,

t ERthd Uterdam cn Namokoki, Jie wy. No.

Rotter- 13. N. vertooncen; en gutarn by 't ciland

dakl. "Rotterdam, in de karecn bekent, alwar lyy (als beroorens) cen wriendelyk, doch ecer diefagrig volk vond, vernemende atm 't eiland veel kalappusbogmen, en nee - gelegde tuinen, dio zeer ordenclyk bephut, envan allerlei andyrugten woorzien waren, zynde de meetle fruitboomess lynegt als its wandelwegen wendecti, zeer" werminkelyk on door te gath. Vonden hiej ook ecn groot yerfeh binnenwater, wel $\frac{1}{3}$ myl in "trond, en wel If vadem boven luet zout water ithande.

Men lian niee, dás by hoog watter, hier ann lund komen, alzoo 't zelwe \& woeten op en neder loopt.

In dit woonosmde verich water waren weel wilde endvogels, die woor de menfchen niet fohtuw waren.

Deze inwoonders brigen werfeheide klappus, en kalbaten met werfch water, newens andere vrugten, werkens, doch weinige der latite, and boord.

War huno pratuwen waren ook zommigen war zciltuig voorzicn.

Hume klecting, fatfoen, en monieren, verlchilden aict tran die var 't woorig êland; doch de mans hadden doorganas zutken lang en dik hair thiet, als de andere. Ook watende wronwen immers zoo kloek var geftalee en leden als de mannen.

Ame dit eiland, by de inlanders Ammamokfin gename, hebben de onzen den narn yan Rotterdato gegeve:

Wy yertoonen die, nevens de verdere cilanden, "cr ontrent gelegen, en de inwoonders der zetwen, in de platen No. $\mathrm{I}_{3}$. N. en $\mathrm{No}^{-}$4. O. zeer net volgens die alphabetl afgebeet.

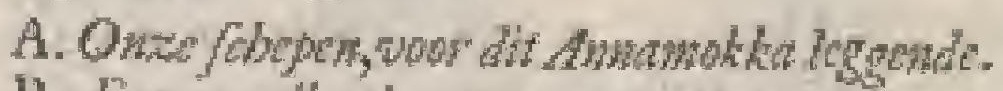
13. Een zandhad, wan watr zy wot butwe pranuwes an boord wooren.

C. De bat, datr de waze werbaldo

D. "f Ferfh bimenwater, dist onten de

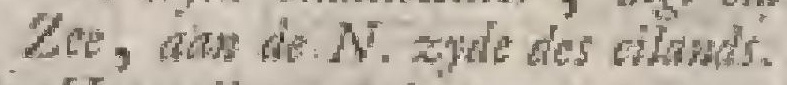

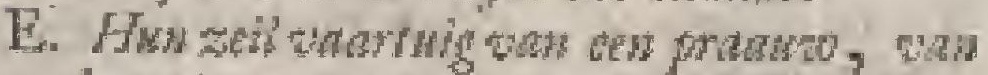
de andere cilandes wet on

F. De plants, waw whe baots lages on wenter to bastes.

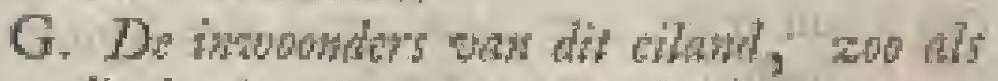

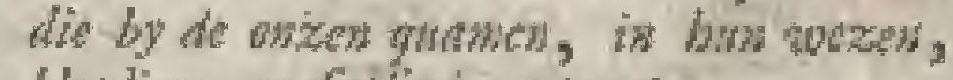
khodig, on fap/on wertomst.

Den $26^{10}$ dito bankden $2 y$ nog-2 boors watet voor yder fehip, con wertuilden nog ved verwerlching van vrugten, con. ook onteleten zy noterband, dae die volk mede op hun goed te ftecter, als "c maar' getegenbeid laad, zoet gezet wist.

Na dat zy zich nu hier overiloedis yar water en andere verweriching vootzion, ein een drienw befluti, om woor alles wel te zorgen en te watken, genomen hadden, gingen oenige wan onze woormatmfte tan land, om wan den lionisy afteheid te nemen; by wellse gelogenheid $z y$ die nctue beplantingen zangen.

Dit alles verigt zynde, hebben zy den I Hea Tebruati "s jurs 2643 , de' anliers 


\section{B A N D A.}

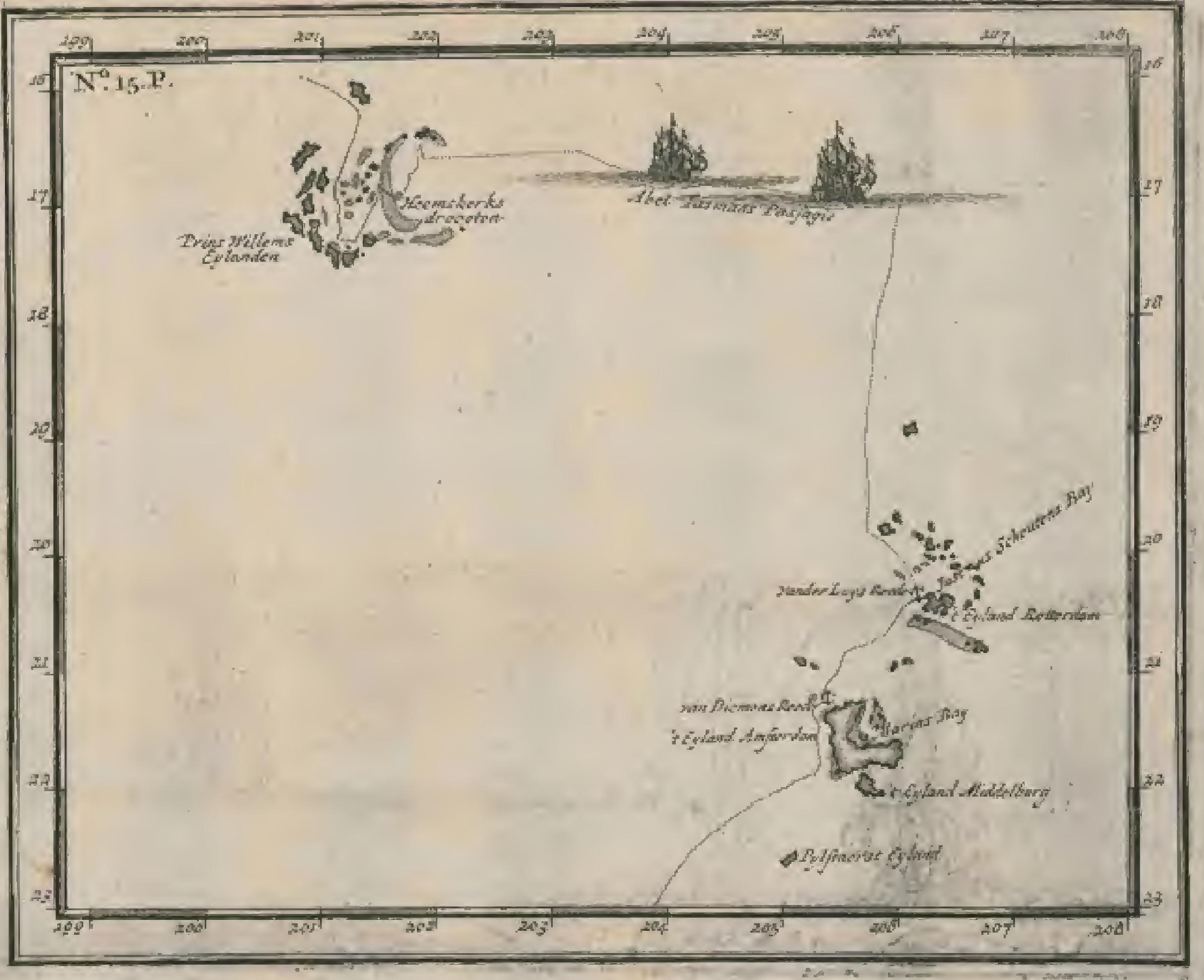

gelge, en zyn wan datr Noordelyker overgeloopen; en zagen nog cenige el handen, die in de kaart bekent zyr, zynde van voornemen, orm nu voorectit tot de I7 granden Z. breeder toe, N., en dan vorder W. מan te guin, ott de Verriders en Hoorniche cilanden niet voorby te vatren, witar op zy dan met een $\mathrm{Z} . \mathrm{O}$., en O. Z. O. koelte dooreeilden.

Hy ontmoette den $\sigma^{d e r}$ dito, op de brecdte PrinsWi]- wan 17 graaden ID min, en op de lengte lems Ei- wan 201 graden, en 35 min, weli 18 Heens- of 20 eilinden, die wol klippen, recwer, kerks- en droogtefi wiren, en die ia de. lasto

droggter met den now wan Prins Willems-eilander, en wan Heennskerls-droogrea, bekent zyn. Wy vertoonen de zelve $\mathrm{No}$. 1 r. P.

Twee dagen er ath had. hy op de if

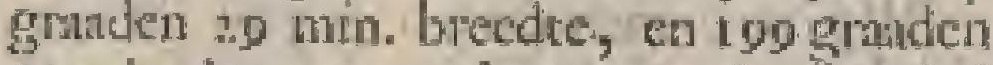
3 t min. lkngte, weel regen en harde wind uit des $\mathrm{N}, \mathrm{O}$. en $\mathrm{N}$. N, O. met dyzig cu donker weder, weshalven by befloot om N. ei N. O. tot de s of 6 granden ante gaan, ej am dan W. ant rot Nora Guinen te loopen.

Den $2^{\text {deth }}$ Matret was Jiy op 9 griaden 1 I min, breate, en I 92 gtaden $46 \mathrm{~min}$. lengte, das to graden N. O. mišwy-

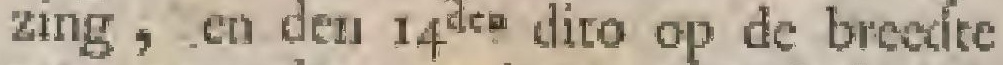
wan Io grituden $12 \mathrm{~min}$, en op de lenge van I86 grauden 14 min., net var 8 gratacn 45 mum. was, zonder dat hy in
I 2 etnaten hoogte hadden koninenty geil, alyoo "t zecr donker, mottig', en regengrgig weder walis.

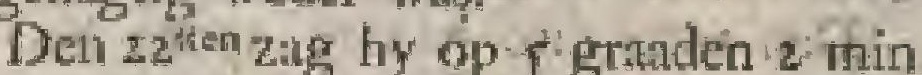
en op de lengte wan $1-8$ graden 32 mins, by ech $\mathrm{O}$; piffat, land 4 mylen $\mathrm{W}$. vito zich, alwalt zich wel zo klone cilunden Ontong apdeden, die door le Main in de Fratat gelegt, met det nuitm wain Ontong Java bekene $z y n$, en die ontrent go mylen with Nowa Guines leggen. Wy vertoonetide xelve in de platit $\mathrm{No}$ I6 $\mathrm{Q}$

Drio dagen 'er na quam hy by de ef-

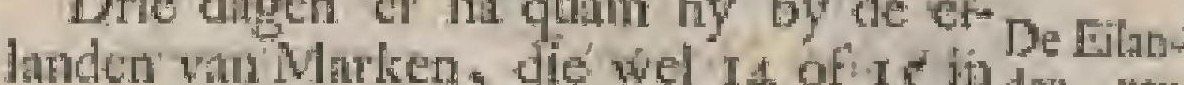
getal, en welker by nis gatich fridtre hatken,

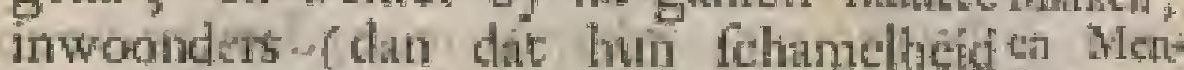

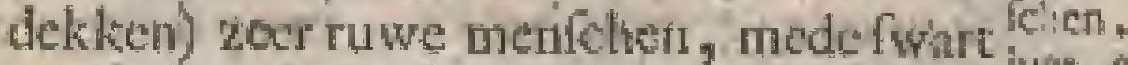

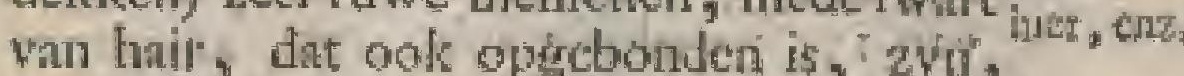
en wan de booswigten in'de mootdenatursbas nier verfetillen. W W wertoonen die eilinden $\mathrm{No}, \quad[\%, \mathrm{R}$.

Het thair dezer inwoonders is kort gefchoren, en eren zoo, his dat der booswigten in de noordenars-bani, opgebonden. Een wan hen brid 2 vecren thgt boven op zyu hooldkrtiti, ats of 'choor= nen waren, ftecken; andere hadden rin. gen door de neus. Hunne prousw was met ecn vlerti, ging fcherp toe; doch was niet nee gemakt: Ook voerden $z y$ pyl en boog, en zy malkten van onze knalen cin ipykets weinig werk. 


\section{B E S C H R Y V I N G E $\vee$ A N}

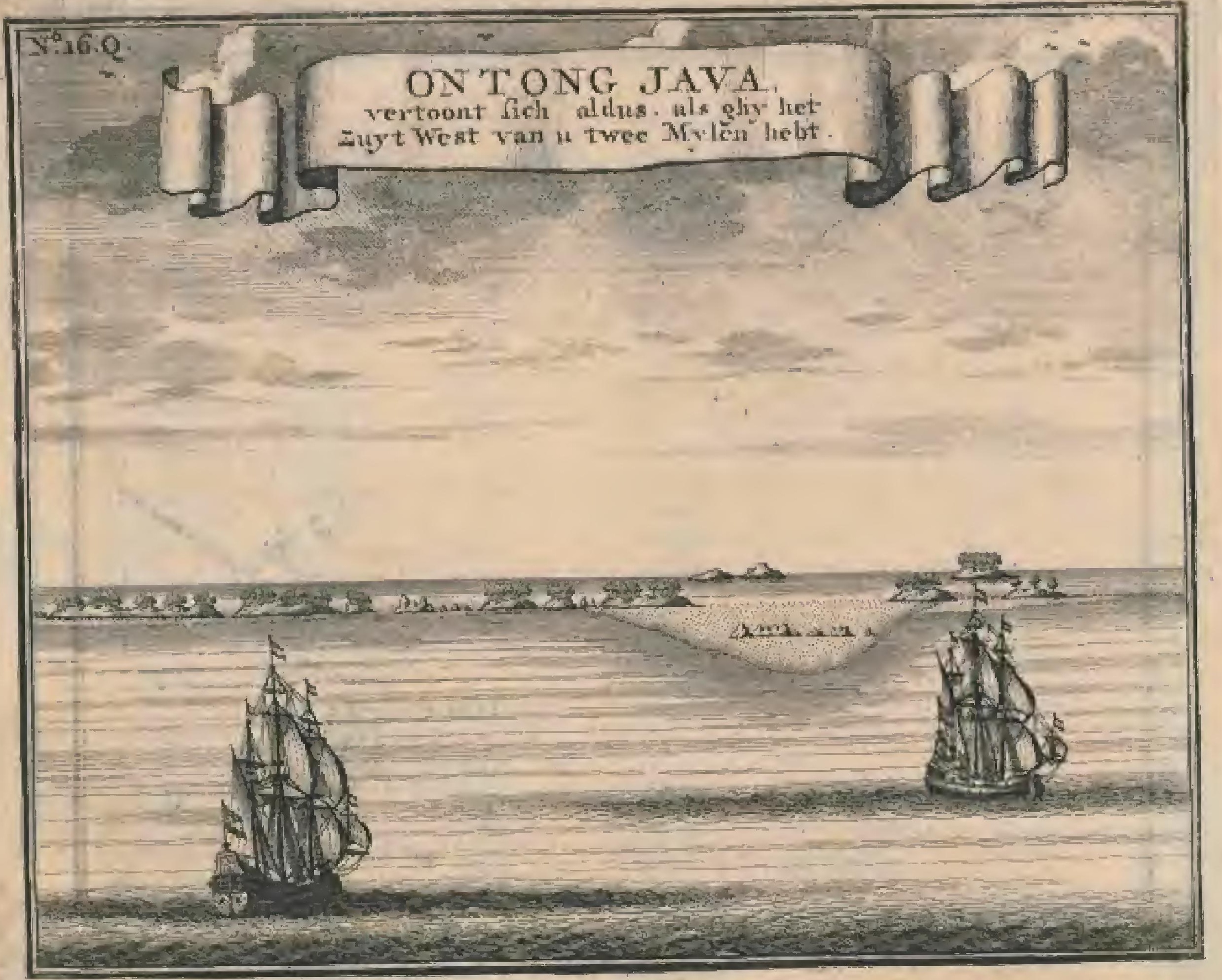

Dé omzen wataren lier in groote vrecte woot een rif , datar (zy nog zeer gelulklig door cen Z. wind afraakiten.

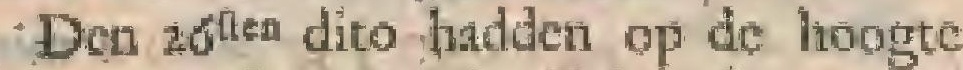
ran 4 graaden 33 min. $Z_{\text {, breedte en }} 774$ graaden 30 min. lengte, ecn hardo ftroom, en miswyzing 2 graden zo min. Noordooftering.

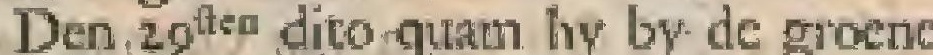
cilanden, welle wy No. 18. Si $_{i}$ vertoonen. Den zoten zagen zy St. Jans eiland (zoo als wy dat No. 10. T. albeclden) en den Iften April by Noya Guinea, dat Wev thicr No. 20. V. in prent gevent, z.oo wh sich dit and den hoek, Cabo St. Maria by de Spanjalds genanmt, opdoet, en dic op 4 graden zo min brecdté, en op de lengte

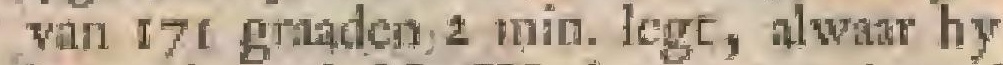
langs de wal N. W: henen tot Antoni Caans-ciland, ats mede vodrby Gerrit do De Stuns Nys, of Gurdenys en Viffchers-eilanden lowk: cnis tot wan den wittekenden Suruishock liep; merkendedat dare "r hand na " $\mathrm{Z}$. en Z. O. witlehoot. Wy vertoonen ook deze eilanden No. 21. W. De inwoonders wher notke, en zoer fwatr, en badden en wit boen onder de neus, een halve vinger dik.

Ben $12^{d e n}$ dito krecg by op 3 gmaden 45 min. breedre, ch op de lengre wat i67

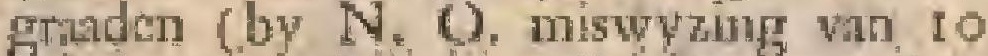
granden) een (watre mobering by nache, zoo dat al 't volk tuit zynen flatp zeer verbalt na boven quam, nict beter wetende, of "t fchip ftict op ect klip; doch vonden geen grand met het dieploot. De zelve dururde nog, al eenigen tyd; doch $z y$ wis noit zoo fterk, als op dien dag, zynde nu tot binnen den Struishoek reets gekomen, war op hy verder na do boge der Goede Hoope ftevende.

Den $14^{\text {den }}$ dito zag hy op 5 gratidet 27 min. breedte, op de lengte van 160 grader 57 min: (by N. O. miskryzing wan 9 granden $i$ ' m min.) het bad wan " 0 . en N.O., ea zoo werder na ir Z. tot het Z. Z. W. meenende hier cenen dongang, te windea, doch bevonden die vuft land tot in " $t$ W. toe te $z y n$, en liepderthalven $W$, aan laings deze, liutt.

Wy verionen deze bogt, ch dit verder hind van Now Guinea, met des zelfs wolkeren, No. 22. X. Eenigen van dic volk quamen ook an bootd, doch waren negre ongewapende licten.

Den $20^{\text {ter }}$ quatu hy san 't Brandend ei- Het land (dat hy op $r$ graden 4 min. breedte, Filand. op ate lengre vin $16+$ granden cu 27 min, by N. O. miswyzing van 8 graden en 30 min. bevond te leggen' en wermm uit dot gebergte ook een grooten brand. Wy tertoonen dit No. $23 . \mathbf{Y}$. zynde den Vulcanus van Willen Sobousn, in zyn dagregilker angehalt. 


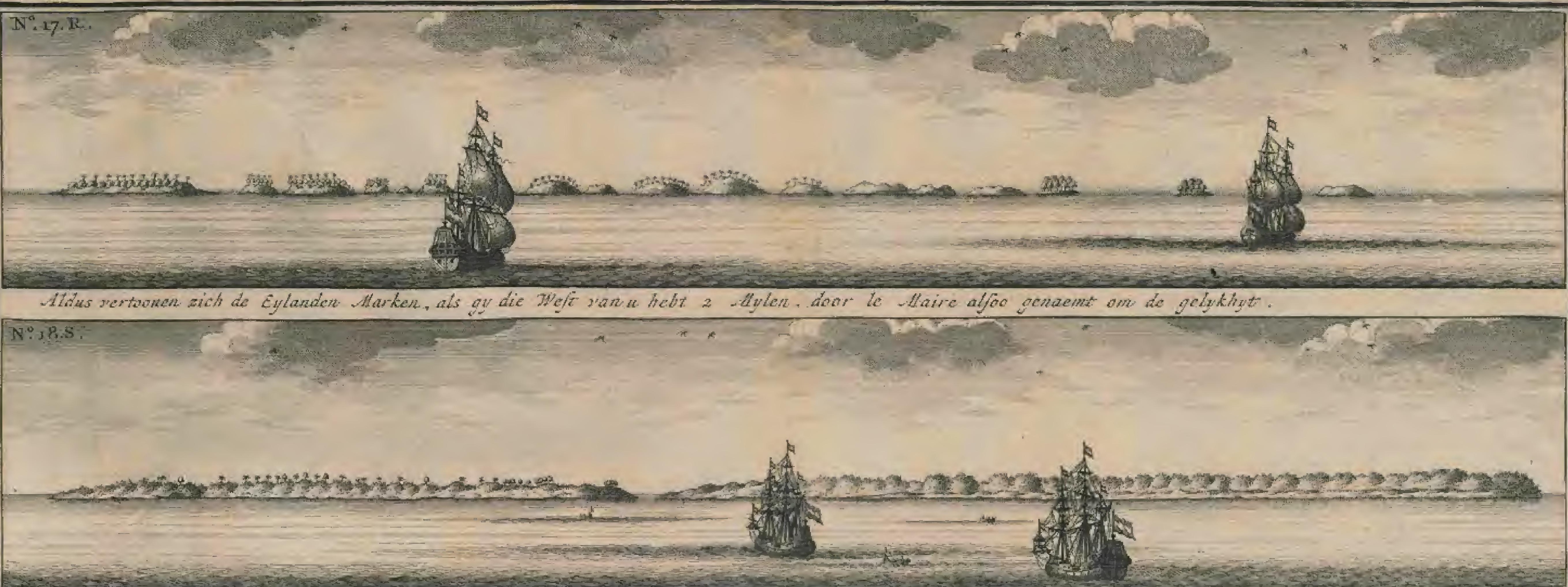

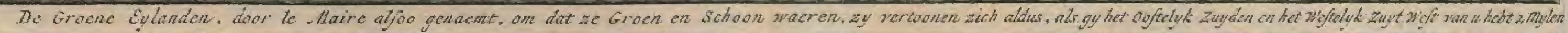

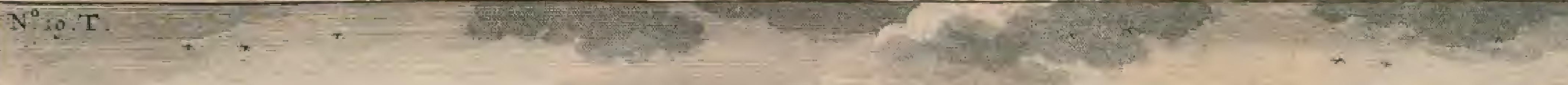

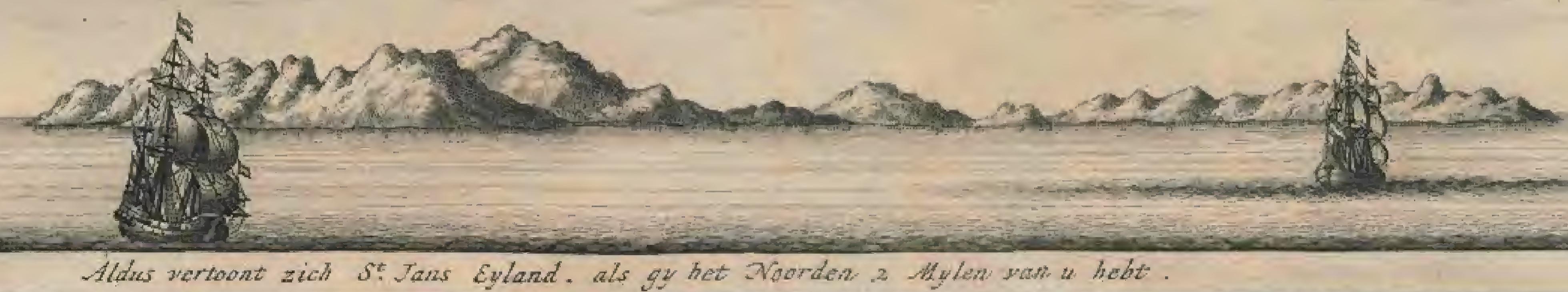
(2) Aldus wertoont zich St. Jans Eyland. als gy bet Foorden 2 Wy len wath u hobt

N.20.V

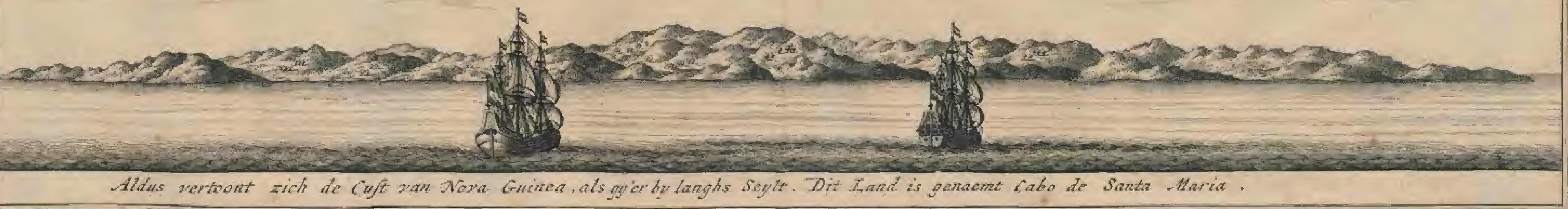


$+$

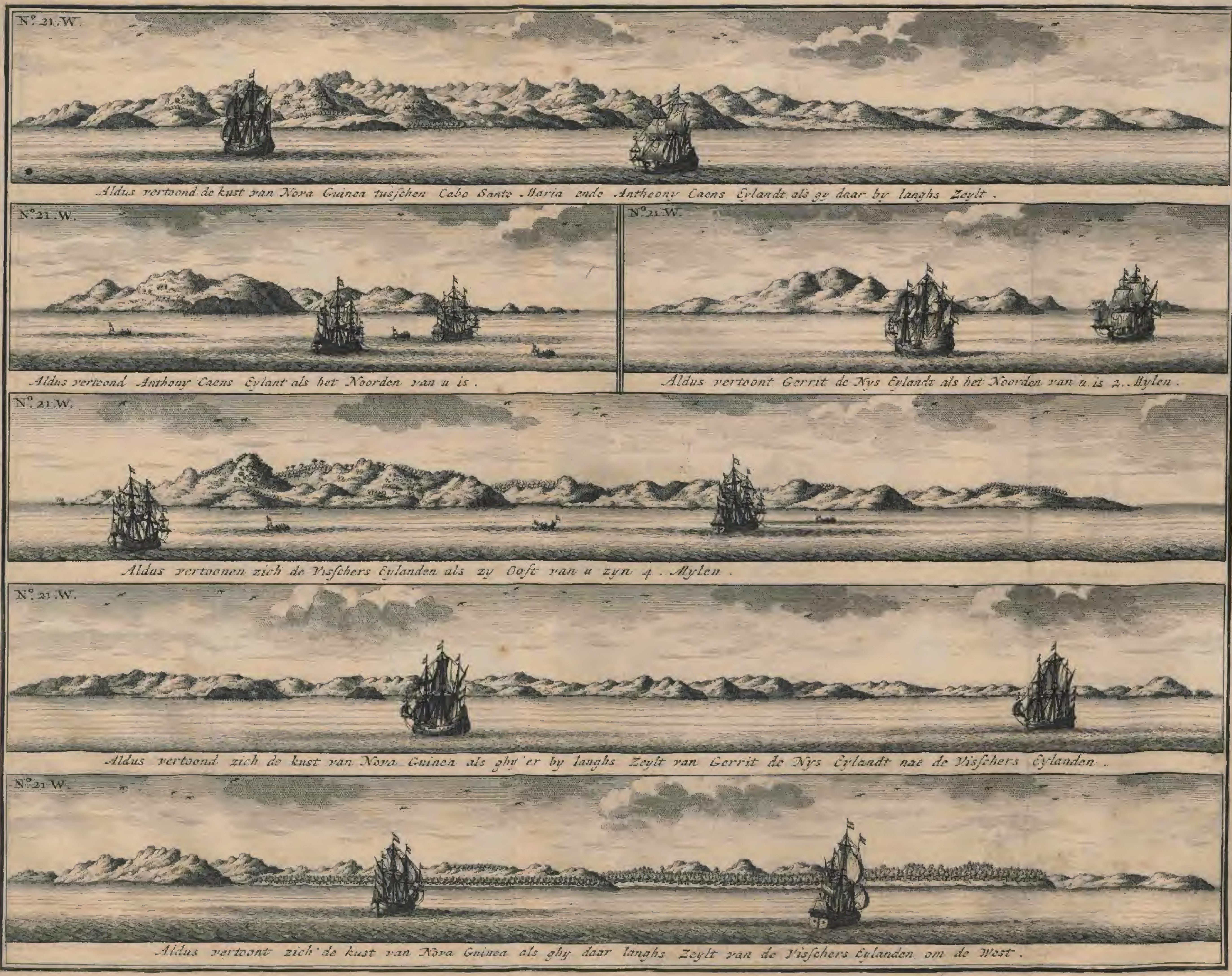




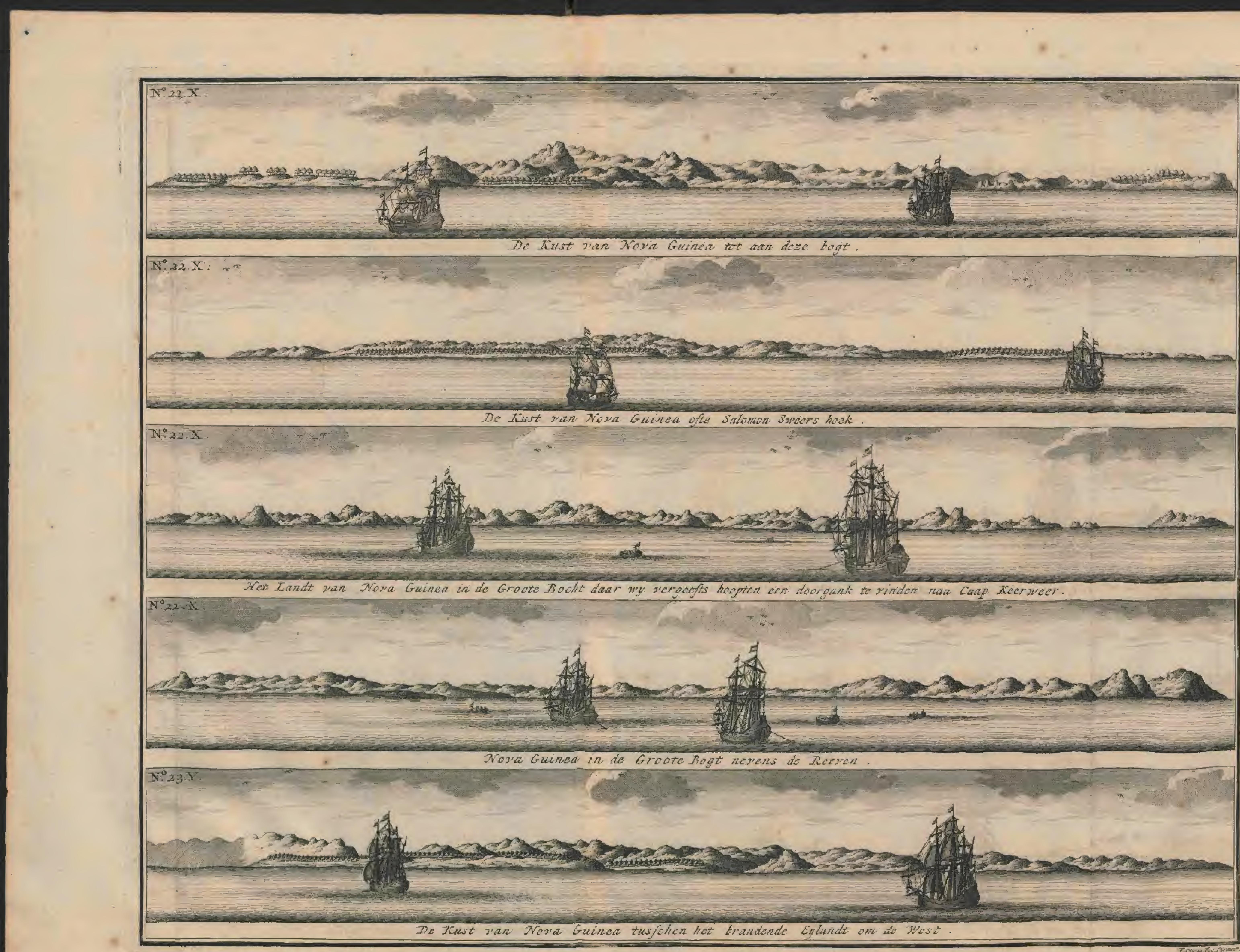




\section{B $\quad A \quad N \quad D \quad A$.}

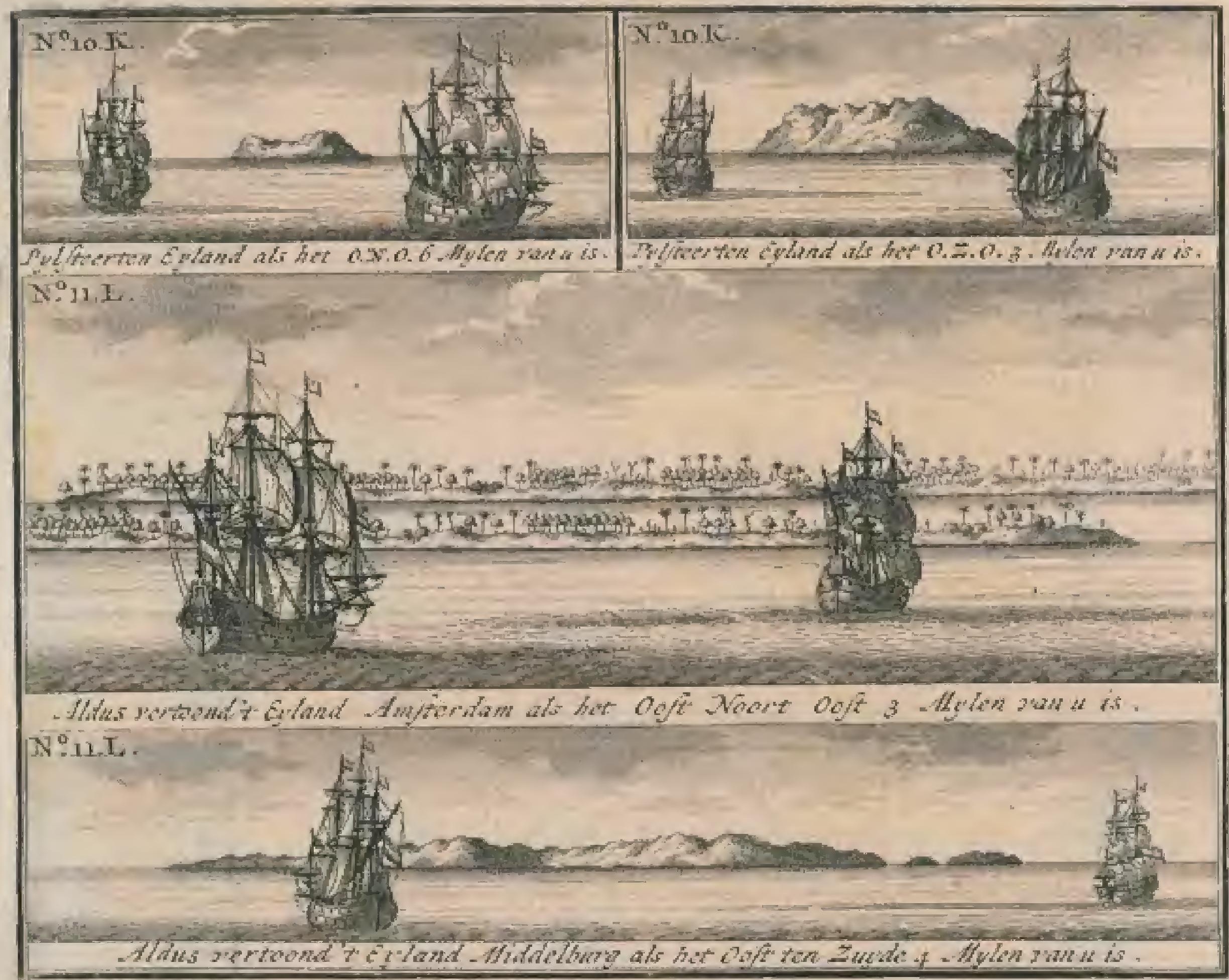

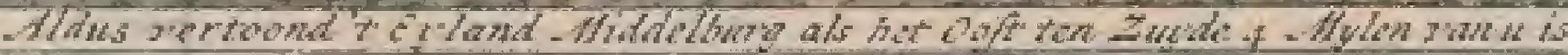

Tuffehen dit ciland, eri de valte wal, liep hy door, vernemende ook relf ditrt stan zee veel vunien, wat thit hy menkte, dat die een volkryk eiland was.

Langs Nowa Guinea liad by vecl thilte, zag dangs 'er aan dei hooger brandenden Berg, en liep W. N. W. langs de wal henen.

4 Eiltand Den z $7^{\text {ften }}$ dito quam hy by Jamma, Jamma, een ciland op 2 graden to min. brectte, en op de lengte van i 56 graden 47 min., (welkers kiut wy No. 24 Z neveris cenige eilinden vertootuen) gelyl wy "t eiland Jamma zelf No. is Z. Z. verbeclden, dat wat Ooftelykier als Moa, legt; alwar zyn wolk veel Inalippus, ca andere ververlehing, bequam.

Hy bevont den inlander hice zece fwat, en byzonder veetdig on zyn volk thit te fpretien; doch hume taal zelf zecr bitar, atzoo de letter R. data al zeer ditwils wan hen in gebruile wiet.

"t Eilatud Datgs "et an quam hy woor ti ciland Moa. Moa, duar hy, door tegenwind, tot den Gden Mey bleef leggen, ruilendic ondertuffehen wel 6000 kinlappus, en wel too boffen pieftang. Hoe zich de lauft hier vettoont zien wy No. 26. Y. Y. Itlat afgefchetf; doch 't cilind Moi zelf zict men No. 27. X. X. vettoont, gelyle mede des zelfs inwoonders, en die van Jamma mede zeer net na 'cleven afgemalt ftum.

II J, D HE L
Hicr vicl cenige moute voor, door dien cen inlandej" yemant van oths volls met cen Pyl geratak had; doch als zy zigen, dat Jaman net zyn fichepen digter thi de wal kortte, bagren de inlanders, zeer bevreent geworden, den fchuldigen zelfs by hem and boord, gewende dieln volkomen ath hem over, gelyle zy indien tyd ook wy berer te jpreken waren, mogelyl nog wel indigrig zynde, wat hiter 27 jatren te vooren (of it] 't jat 1626. den 16dea Juli) met $W / h$ lem Schorten voorgewallen was, dien $z y$ zeer yertatderlyk angetalt hadden, en die niet weinig op hen had los gebrand.

Den I 3 der dito zeilde hy op o graden 54 min. bredte; en op de lengte wan is 3 Willem granden i7 min. (by N. O. miswyzing schouwan 6 grataden 30 min.) lan wan Wrom Schoutems eiland, daar zecr rad volk, en welk eiland wel is of io mylen lang ficheen te wezen. Zes priat wen, yder met 20,24 of 25 man, wat groote ats een orembini, quanen om hein te bezien; doch dorften niet ana boord liomen. Tegenden avond liregen ay hier een byzondere itille en hoe linger hoe laugzamer rollende zee, zonder dat zy de reden dar wan konden uitvinden.

Den 18 den dito o graden 26 mils. breedte, en op de lengte wan 147 graden 55 min. 


\section{B E S C H R X V I N G E v A N}

- min. (by $\mathrm{N}_{0} \mathrm{O}$. misw yrug wan rgrtiden en 30 min.) gekomen zynde, merlste hy, dat hy nu al voor by de kutp de Goede Hoope gerialt was, watr op by dar atan den W. hock wan Nova Guinca quim, dat hy beront een gebroken hoek lands te zyn, zonder date ben verder ict antmerkenswandig voorguam; watr na ly zyn ftreets veorby Cerim, Bocto en Bocton, nair Batavia rooitsette, daur hy den I $y^{\text {ten }}$ I turi op de recle quam, hebbende dezen togt in 10 matanden volbrage. Togt der In 'e juar I 663 . den, den April heeft men chaloep met de chaloepen Walingen en de GarWilingen neel van Banda een togt ira Nova Gunch in "tja:a gedatan.

Now $Z y$ quanen dein $7^{\text {len }}$ dito by of ontrent

Ginea deze wal, zoo dat $z y$ "t lankl zeer klatr zagen, en den gove vernanen $z y$ pas 4

Het E⿺辶- tinylen van "t eilknd Cans te zyn.

hand $\quad \mathrm{y}$ vonden hier zer felle froomen en

Curas N. winden, die hen geduurig na de valte wal toe fleepten, en quimen den $g^{\text {den }}$ dito 's namiddags by dic eiland, darr zy een groote comeora met inlanders vernamen; doch liepen, ma dien nacht daar ontrent geankert te hebben, al werder na Nowa Guinen, dat zy met 'cr laalt opzeilden, Het Dore en quamen voot" hec dorp Roemalky op Roma- 2 wadem waters ten anker, latende de kay. witte vredevlas watajen, doch de intariders aldatr deden geen het alleminilte wederbewys, dat geen goed tecken wats, watr op den geheinfehrywer $/$ the den rad belei, on nader es bernatiligen, wat hen zou te doen ftum; doch ewdelyk werfelieen "er een priatuw met een vredevlaggetie, en tecken doende, dat men by hen komen wilde, 'twelle gedatr zynde, veEzogten zy (zoo de tolk zeidc) ons volls ann land te komen; doch men kon dat nict inwilligen, allzoo dit heis by hunne inftuctic verboden was; hoewel men eindelyk goedwond den tolk en een matroos aui hnd te zenden, nevens welke ook fink met twee appafters ging, krygende van hen de broeder wan den Orangkijia tot en oftigier.

7.y quamen hier meeft on flatuen, van welke de infanders "er matr" 12 of 15 fluks hadden, dic $z y$ a an Vipk, en ons rolk verkoopen witden.

De tolk, met her frekende, hooride dat cen wan de onderdannen des konings van Onin duan onlangs gewrelt was, dic zeide, dat zy wan dien koning gewage wierden, on wel follunen, die by had, ande onzen te verkoopen, at 't welk de onzen voor verdigtzelen hielden.

Zy kregen 's middugs cenige rieten thet ajer poetch, of fingweer, cenige kalappus, en een flate tot een felienlagie an boord, wala voot $W_{\text {filk }}$ een tegengetehenk dede.

Den $3^{\text {den }}$ zont by den boekhouder
Dretd Bolkol mee den tolk ma land, om te zien, of men den fantentandel dar zou komen berinnen. Kort na "ilanden der onzen gumen "c1, als in een oogenblik, wol 100 en meer vantuigen, met kalappus, figoe mutalh, knublon, gerookte vifch, werkens, en mee 2 of 3 lawen an boord; doch konden hen de Gawern niet athatudelen, alzoo zy 'er te vecl woon cifehten. Eindelyk nogtans tot is en Is Rylisdaniders voor 2 flaven lroop mukkende, beronden $2 y$ met de eene, atzoo het cen litmme neid wis, bedrogen te 7.yn, koopende toen nog een klein reskentje yoor, a Rylswhalders nat klecten.

"Tegen den avond quath hier een prasuz van 'edorp' Ifera mee cen flatwin by ben, welke $z y$ voor is Ryksdalders aan kleeden liogten:

Men wragde na meer faven, en de Orangkaja dede wel groote beloften; doch illes quam op nièt urit, en dit fehoenen matr vonden wan den koning van Onin te zyn, orn hen hicr langer op to houden.

Vink hier werder na "t land wan Onin, on des zelfs gefteltenis, vernemende, hoorde van den infander, dat het hoog en bergagtigr latnd wel ro of a mylen wan laier gelegen was, en dut dar niet anders, dan groote matritwathen, en gefchilderde potten met becltenifien, wan dan quamen, die zy nog niet vit de cerfte hand, mar wan andere volkeren, hooger de rivier op leggende, kregen. Ook fpraken zy wan een zecr dicpe bogt aldaw", en die ook zeer groot in den otntrek was, alwati $z y$ tan $\mathrm{t}$ cinde ecris moeraftig land zeiden te zyn, "t welk men pis oner geralit zynde, quam men (nit hum zeggen) nat de andere zyde dea zee uit, datr "y groote vartuigen met wite zeilen (als de onze) en blanke menfchen 'er op, hoewel mas yan verre, gezicn hadden ; doch dat de inwoonders vat dat land zeer wild, en ongemaniert water, en mata op "t ftrand en onder den blooten hemel huiswelteden, gencerende zich conkel met fildpadden ee hecren.

Wannect mu Fink zei, dat liy na deze bogt meende te gann, had dit den inlander geweldig mishangt, alzoo zy wau den roof, die zy date bequamen, leven moetten, weshiven lyy hen beloofde, dat niet te doen.

Datu op liep hy, zyn anker ligtende, 4 Dorp na "idorp liera, datar hy tegen den avond leusa voor quam, litatende dan mede de princeen vrede-vilg, zonder antwoond te lirygen, wajes.

Viak ging datir op zelf net cen orembatri na land, fprak met ben, verzockcnde cen gyzelair, dicn zy weirgenden te geพẹt. 


\section{B $\quad$ A $\quad$ N $\quad$ D $A$ A.}

Eindelyk quamen $2 y$ zelfs met vifel, ktabben, ganeclen, en mer werder koopmanfichap wan flaven, an boord. Her krioclde in die dorp van menlichen, die zich by duizenden, alle moedernakt, hier in en oogenblik opdeden, zynde meet zeer wel gewapend.

Zy beloofden an den tolk, Antomi Molfow, in 't korte weel tatwen by de onzen te zullen brengen; man daar quam al inede niet war. Ook bleck den onzen, dat deze roovers matit uititel en gelegenheid zogter, om heis an de wal te krygen, en dan hun flig wasr te nemen; want als $z y$ diggen ' $f$ anker te ligten, quan ben cen pratuw was Rocmakay met een vicde-wlaggerje watchouwen, dat die wan lera voorgenomen hadden alle de onzen, als zy atro land zouden geleomen hebben, gelyk zy $/ W_{k}$, en inderen, reets werzogt hadien te doen, certt zoo lang watt te houden, tot dat $2 y$ wark al het werdere volk win beide de clialocpen zouden meetter geworden zyn, en hen dan alle den hals te brecken; en fichoon dat gifteren mislukt was, dagen zy zulks beden uit te voeren, wan wetken vuilen wandtag dic Urmegkaja wat Roenakiny $\mathscr{V}_{h l}$ warlchouwen lice, verzockende, dat de onze hem wilden helpen, on dezen nathe Iferit af te loopen, what roe Wim niet koij overllar, alzoo hy merke dat die Ewee dorpen vyouden waren, en malkanderen man alle atbreuk zogten te doen, weshalven ook alles wel kon werzomten zydi watrom hy allech tor antwoord gaf, dat hy hem liet bedanken woot dezen dientt, en nnder datr ha vernemen, en zich wel wagten zoude.

Dati op vertoonden anch die van Ifera met een vredevits, am de onzen tot hem te lokken, die ook by her digt voor, max niet an de wal quamen; alwatr de tolk het woord stoende, men van arter de huizen etelyke duizenden var menflien, met pyl en boog, hatagatjen, enz. gewapent, niet alleen onttaft de tekte s. matit de onzen ook ten certten onze asth zoodanig gegroct wicten, dat $/$ hat zich genoodzata

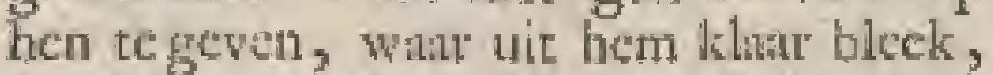
dar de Urunghij: wan Roemakay hen zeer tydig en wel gewaarchowwe had, endat des Orangkajit's vrouw (die "x uif de mond der feluemen zelf zeide verthan te hebben) hem niet misleid bud.

De onzen, diar op weder na land gegann zynde, hebben den wyand, die hen eerit dipper woderitane bood, waklier angetall, en op de wlugt gedrewen, wal op zy verder gelind zyonde, dit dorp is brand ftaken, "t welk door den vyand weder gelefcht wiert; watu nar Vimk ecn zein dede, dat all ons wolk na boord konen zoldie; doch de onderftutuman Abrabm 7acobf wan der \$faf, met nog ech dol voläant, tegen laft der onzen den wyand wat gevolge zynde, zyn mex de zelwe in zulfen herig grevegt gerakt, dat dic uit de Orembala genoodzilikt waren hen te hulp te komen, en ook beide de chitloepen zich gedrongen wonden met gefchut op hen te ichieten. Dit grevegt cen unir gedurt hebbende, kreeg men de ryand wel op de wlugt, mitur hy keerde wederom, en tafte de onzen zoo dapper atan, dat het ftumrizin euta der Staf, cen foldan, Cornelis Pierwe van Rypn, en nog ecn flutter, Dawid van den $B$ trg genamt, her keven koltte.

Danr ta quamen de onzent weer an boord, dic dit werls nog wel eens hervatten wilden; doch $F_{i n k}$ keunde dit af, en wond het beter, om dit dorp, op de ambieding van zeker quirejermeetter, in brand te ftedien, gelyk ook "t zelwe ten centen in Inoolen gelege is, watr" op by anditones van datar zelde; doch quam "s naches war van hatu" af ten anker".

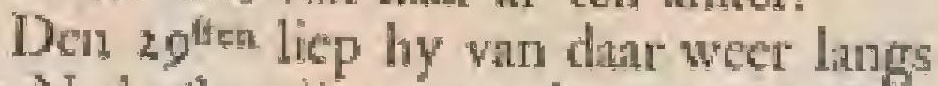
de $N$. listt, die nog al lang verdronken land was, en zag de overkilt Z. O. Wun zuch, belbende dat kanal ins 'c inkomen de wydte van 10 of 12 mylen, gelyk hy "s muniduags ook 2 rivieren vernan, daut de colk zeide wel met den koning van Onin, om datwen te koopen geweell te hebben; wal op Vtuh hier ten injer liep, zicnde dat die ftrekkng wan "t laris hier zich met weele en werfehendene houken opdate, behalwen dat $z y$ ook an de $Z$ : kuit zecr wakk lind atn de voet van "e hoog lind, "t geen dir gelyle was, en watt op 7y veel vuren verrimen, zigen leggen.

Den $20^{\text {ten }}$ dito "tanker higtende, liep by net cen $W$. wind, en O. en O. ten Z. koers lanigs de $\mathrm{N}$. wal, zicode "s awonds and de overkult, en voor uit, zoer hoog land, zoo dit hy meinde dit het cinde van deze boge (war in hy was, en die lier we zoo wyd als in "e inkomen is) hasitt te zutlen wezen, alzoo hy nu al 28 mylen ditar in vertierd had, weshalwen hy dat weer en anker quam.

Den $2 \mathrm{I}^{\text {then }}$ ' $\mathrm{n}$ anker weer ligtende, en langs de $N$. wal al $O$. cn $O$. ten $Z$. annzeilende, zag men mer zons opgang owet ial zeer hoog land; voor zommige wan welke gebergen ook lage voorlauden witren, en zich eenige eilanden opdeden; doch hy vervolgde zyn kocrs al langs de N. kust, om te zien, of hich of digr nier een doontogt was.

s Namiddags tem + uuren quam ty an "t cinde van die bogt, datr doorgntos lagg lired woor lag, meet in gebroliene eilanden beftamde, ter anker', doch alzoo hy geen opening weman, ligete hy "5 nvonds "tanker", metbetluie, on langs de O. kult te zcilen. Hy rond hicr wonH 2 der * 
derlyke ftoomen, en zag hitr nu en dan

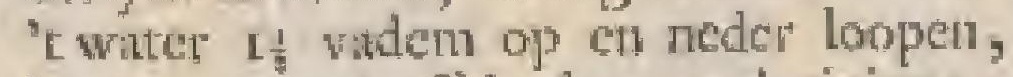
'r geen ongetwryfelt door veel rificren, die bicr leggen, weroorzatkt wiet $\mathrm{H} y$ had op dezc dog ontrue de chaloepen ook twee groote hooken gehad, die veel watter opurokken, en watr op veel regen volgde, komende 's machts, uie weeze wan ongenth, weer ten anker.

De lengte derel" bogt was ten minfte, พม⿱ Rocmakny af, fo mylen, en on die in de kante te leggen, zon men die wel op 45 mogen itelien.

Den $22^{\text {lest }}$ dito weer onder zeil gegaan zynde, om na cen goede biti te zoeken, ontmoettc hy niet, dan gebrokenc eifinden, zoo dat lyy wederom moefl keeren, zonder ecnige opening te zien, whatom by weer na de N. kult liep, al witur ly den $24^{\text {iken }}$ dito by 't cinde dezer eilanden - quam, dic har wah de $N$. tot de Z. kult tirftrekten, weshiven lyy zyn koers dant boven Z. Z. W. mantelde, om aur de $Z$. luft, nwaar by an de lage landen rook zag opgaan, te komen, datar hy ook ta toeliep, en 's' iwonds ten 7 uuren ten anker quam, ziende datr geen dorp, mat wel cenige fwarten, die op 't ftrand vusi matkter, ware op $D$ ink volk na lind zond; doch die zigen dar geen fwarten, berigtende alleen, dat $z y$ dir land zeer fehoon en vlak bevonden hiadden, zoo. dat "cr wel 1000 "kocjen zouden hebben konnen weiden.

Hy zond, op 'c zien wat eenige lwarten, weer volk ma de wal, die nus $r$ inlanders hadden gefiprolecen, dic heo natuwlyls te fpriak geftean, col by na zulk een tal, als die win Roemakny, hadien.

Deze hadden hem verzoge in hitar dorp tan laud te komen, ond lien flawen af te hindelen, awelk zy ondernomen licbbende, hadden $z y$ niec weinig op ons wolk net pyl en boog gelichotein, zoo date $2 y$ de vlugt moefter nemen.

Dhar op vond Fink goed "E plker te ligten, en werdex ryo geluk ander de hooge Z. kutt te zocken, dar hy "s rachts ook ten anker quam.

Den zoriten van dat zeilende, quam ly by ecrige eilanden in een zandbati ter anker", dan hy wel brandhout, doch geen warer, wond.

Onder de wral, dat hy den $27^{\text {flen }}$ na toe laveride, vond hy wel roo eilandekens, en guan 's middigs in een fchoone groote bani, dar men voor alle winden bewryd lag; doch zcilde na de wafte wal voort.

s Middugs zing hy colk verfeheide varartuigen, en cen met en frede-wag, gelpk ook kort " $\mathrm{er}$ ma den koning van Onin by otus quan met een Orembial, die een overdekte tent had, de welke an $V$ inh vertoge, dit hy op Orin cen cerften wilde komen, gelyle hy beloofte dangs 'er an te doen.

Her dorp, daar hy nu woor was, wiert

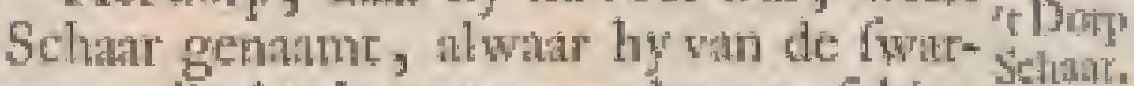
ten, die by hem met wed verwerfehing quamen, cen Anawnet je voot 13 i $\mathbf{R}$ ders zoge te hoopen, doch zy elichte 2 . Rders 'er voor, weshalwende koop agter bleef, getyk zy ook vict veel goeds inet hem in den zin ladden, dar 's miches nacter bleck, wanneer zeer veel vartuigen (Fehoon die van de chaloep de Gritneel hem toeriepeny op hem afquanes , bocwel zy op "t rospender onzen, zonder ant woord te geven, weer ftllekens athiclden, 'L gean Fink oordeclde door dien koning van Onta hem gebrouwen tezyn, en hy ponmum atm den zelwen, zoo ras hy weer by hem quam, te wredken.

Hy quam datr op net 2 vantaigen "s aronds ten f umea by Vink ann boord, v1ratgende, of wy ru gexint waren met hem na Onin te gatan, war op jir gczegt, en ly werzogt zynde ata boord te komen, 200 was hy daar toe nict te bewegen; weshatwen $P$ shk beft keude hem mat: ongenoeic te Jaten wederketen, om op cen andere byt zyn dlag war te nemen, onder belofte; dat hy hem na Onin ten cerften volgen zoude.

Hier op 'c anket ligtende g zeilde liy FrmeWren W. ten 2 . Jangs de watte wal, en loords quam den $29^{\text {ften }}$ dito, "s morgets ten $9 \mathrm{Bai}$ uuren, tin Eneloords-bani ten anker, duar zy hun drink watet himamen.

Tegers den awond quam een Orankaja met 's konings jongfte zoon, en ex gevolg wan ontrent so man, coceft Gorimmers, en Ceramnets, nan boord, zeggende, dat de koming na de Papoeze cilanden on diaven was ; doch diat lyy morgen weer by han zot zyn, en dat zy nu matr qumen, om $V_{\text {ink }}$ wan hunne guede gencigenheid te verzeketen, en te werzocken, dae hy voor hatre Negry gelicidere komen, belowende hen wan thaven in menigte te zullen voouzien; what op een zoopje ank gedronken wiert, terwyl ons wolk een wakent oog hielt.

Den lateften dito ging hy woor' 's kotings dorp, een gooreling foloot win de will, leggen.

'Mlidags quam dic Oranglayia met 2 zoonen des konings weer anu boord, cenige Aaven, en byni geen geweer, met zich brengende, wal was 'er Vhik cenige tegen 18,19 en $20 \mathrm{R}$ ders inruilde. Den ${ }^{\text {des }}$ Mey quam de koning met zyn wartuigen, wel 7 of 8 dterk, opdagen, die de onzen ata land verzoge, en eenige gyzeltars overgaf, war op Vink ecrige de anzen na lind zond, daitr zy zeer wriendelyk oukhinlt werden.

Ook ferzogt de koning, dar hy doch gecn quitud argendenkeo op ben hobben 


\section{B A $\quad \mathrm{N}$ D A. $6 \mathrm{r}$}

wilde, alzoo lyy eens bloed met ons gedrouken (dat is cenen eed gedan) en belooft had, de onzen getrouw te zyn.

HerDorp De koning was ook in "t dorp Piera Piela gewcelt, om fingoe mantah ce koopen, alwar hy zcide ontdekt re hebben, dat de Onsughaja van Roemakuy, en die van Ilera, vourgenomen hadden heos (Winte) on al zyon wolk, om halls te brengen, war voor by hem warfehouwde, nilzoo hun voornemen was on beide dere chatloepen te benagéigen, tot welken einde zy $f^{2}$ galejen daags "er" tun dar op zoudcin afienden, gelyk $z y$ aok, doch te valgeets, en te latt, in "t werk geltelt hadden, alfoo $/$ ind 's avonds van Ifen vetthokken, 'en nog dien eigen nacht worr Roemakay gekomen was, en dat die van Trera lyen wool die-genomene moeite een. Hollands afgetlagen hoofd vereerd hadden; woor welk berige men dien koning wel bedaken, mar te gelyk betuigen lict, dat hem dit geenzins van die wat Roenakay, masu wel van die wan Ifera gebleken, alzoo de eetfe zyne hulpe tegen den latitien verzogt, en by hem dat geweigert had. Ondertuffich verfchenen 'er geen meej flawen, gelyk de koning belooft bad, watr op dan Vomk hee anker ligtte, en van datr verzeilde.

Dien naclit zag ly een werwatlyk groot vuar in de luge, en cen ftreep wel so ellen hay, zoo rood als bloed, diezuch, als de butren ater zec, bewoog; doch dati na verdween; hoewel 'er" veel vuur dien nacht viel, dat de giniche chatoep ook betchadigde, rerwyl $x y$ den $\sigma^{\text {dea }}$ dito s morgens in thilte dreven.

Deb sten guam hy weer voor RocmaDie wan katy wen anker, om hunnen grond eens kay zoe-over "E voonoeme berige was den koning ken Vink van Onin te peilen, die hem beruigde a a tailen. quand regen hem woor te hebben; "tgeen zoo vetre van daar was, dat hy om $z y$ nen " $t$ wil bok den oerlog met die wa Iferi op zymen hals gehate, en gehoont had, dat die wan liera 6 dagen lang over de twee verthgene Hollanders, en Tumne afgekapte hootden, wrolyk geweet waren, en die tor het gebente toe afgekloofic balicter.

Ondertifehen qumen "er wanalle kxnten vatituigen, gepropt rol rolk, mi dit dorp, die zich dare tor 's nachts ftil hielden, wancer $V \mathrm{imk}$, dic op alles goede ordrę geftets bad, cen atgryftelyk gefclirectw en geklop van gong en tifi, en cen groot geblats op den hoorn, in "tdorp hoorice.

Nit dat mu 4 glazen in de cerite wagt wit whtect, bevont by 't zeggen des konings win Onin nice din al te watar, alroo onze tolk nu klare verltont, dat de wy ven de vlugt na 'i bofch nemen, crit $z y$, hem aianitents aantatten zonden, het welk hen wel door de vrouwer, alzoo het donker was, afgeranden wiert, doch te vergeefs; want op dan ook de vтotrwen Flugtten, en de wartuigen van de wal afgelyalt wierden, 't welk Fin bewoog atillonts het anker te ligen, enftil wcg te reilen, gevende hen nog + ecrichooten, die wel crettelyk rakten, tot een atfcheid.

Detar na is Wak mee deze chilocpen na Bandit te rug gekeert, komende der $10^{\text {deu }}$ dito nog eertt cens woon "t dorp wan den koning "ran Onin, wan wata by zye reire verworderende, den o I then dito 't land van Now Guinct nog kliar zien kon, en is, na weel zukkelets, eindelylk den $22^{\text {flea }}$ voor Banda met beide de chaloepen behouden of de recke gekomen.

Eenigg jaren ditu na is de opperfroopman de Heer Joams Krys, uit Togt wa Bandi mede na Nowa Guineat vererokfen. de Herr Hy ging den i $g^{\text {den }}$ Juli met de jugten de heyts in Roch en de Spiering, ecrt na Reffung, tiane zyade de clyiloep de Piellang den $4^{\text {den }}$ na 1678 . nora Gorith met den tolk Borr woot uit ge. Guimen. zeill. Hy quam den $22^{\text {flta }}$ dico voor Kefing, lintende de Spicring na Góman vomuitycilcn, vermits by op Keffing encri Lakoe, een Ceramlarwer, die hen voor gids dienen moelt, innemen zon, te meer, dewyl hy cen groot gezag op Onin voerde, en hen dare zeer veel dicont zou komen doen, behalwen dat de Kefingers en Ceramlawers, door hun langduurige want op Onin, dan immer'soo bekent, als in hun eigen hand, waren. Zelfs hidden zy "t danb zoo werre gebragr, dat $y$ der wan hen, die op Now Guinea hicr of duat, certh angelind was, zulk een landftreck voor zyn fololot, of handelen anker-phats, met uithluiting wan alle anderen, werklande; dat ook zoO verre ging, dat zy met dio islanders daar afgefproken waren, on alle anderen, die (buiten hun wextof) dats op hunnen tofolot kofven wilden, dood ie flan, welk verbond zy naminals ook door huwelyken bekizgtige hatden.

De Orangkayen alhier haduen te diec tyd weel twiften, en verzogten den Heer fiests de zelve te befliften, 't welk die Heer zcide riet te konnen doen, alzoo hy dan' too geen latt had.

Toen regeerde hice ovel die Cermhoetze Campans de volgende Onangkayot's: I. Coured/f, hootd van Keliwat m. 2. De kapitein wan Keleluno, zyndie de Ewe grodite en oudite Orangkayn"s van Keffing - 3. Manda, wan Kevitili. 4. Tawan, van Killeberoo. 5. OEnan, Yan Roenili Limeri. 6. Dromat, war Kilitay. 7. Solar, wan Rocmily Maroe, 8. Cado", wh Rocmah ËTi, 9. Mangay, van Roemh Toclis, 10. Soja, wankilitala: Ir. Ën Moy, vin Ewen.

$$
\mathrm{H}_{3} \mathrm{Vau}
$$


Var welke elf "er matr vier woor de heer Koys verfebeenen, weshalwerg hy hen nuadde, zoo lang, tot dat hy weer quam, en latt vin deli Hecr Landrooge in Banda lereeg, in vrede met den anderen te lewen.

Daar op quath de jonge koning yan Onin by hen an boord, voor eenige digen daa met een corncom atngekomen, $7 o f$ gename , die een jongeling wan 16 jarken was, en zeer begeerig on de Hollanders te zien, biedende syn land atin de E: Matichappy an, hoewel by riet beloven durfde mede na Bandat te gain.

Eer nu de Herr Keyts dezen Lako bewegen kon met hem the gids te reizen, moeft hy hem wel voor iro Rders an taleeden fchieten, om by 'Evertchenken der zelve ath zyn vrienden aldatr eerlt affcheid te nomen. Een zak, watr toc de Heer heys eenigzilus gedwongen was, alzoo hy zonder dezen Lake op Onin nicts zou hebben weten te vergigten.

Onk was hy (Lakod) doou den jongen koning way Onin wel uitdrukkely't werzoge, om daar te komen, en zyn owerleden vader op 2 yn Mohbmmedatus te helpen begraven.

Lven nu, gelyk de Heer Ireprsectit ettely ke kleeden an Lako moet geven, had hy, op Goram gekomen, ook voor Borr, en zyne vrienden iets moeten uitkeeren, $\mathrm{ch}$ dat voor al, om dat $L a k o$, die belooft had na 6 dagen te zullen volgen, nog niet dpdagde, en om dat hy ten miniten een win die twee diende by zich te hebben. Hy blecf hier nog tot den $3^{\text {fter }}$ Juli, alzoo Lakos niet quati, weshalven lyy wer. na Keffing zeilde, datr hem Lakou by Ceramboet ontinoette; zich dar mede verlchoonende, dat Calrefh, dic diever zelf mede gegama had, hem niec had willen laten vertrekken.

Ondertultehen lad de colk Bow f dagen to vooten cen valutuig met koopmandchappen na Onin geronden, ont daar de fehapen te fchecten, en de verkens voor den Hed $\tilde{H}_{\text {jyts }}$ over te Jaten.

En ahoo 'cr recds grooce jaloety tus: fchen dien toll en Lakar wis, zoo zont

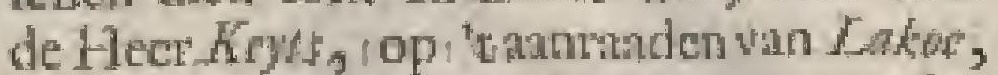
de Spriering met Bari na Carns vooruit, on lietr ditar in te wagten, envaft cen begin tnee den Manoi-handel te nuaken:

Den z $1^{\text {fleas }}$ 's morgens, mer het bver-

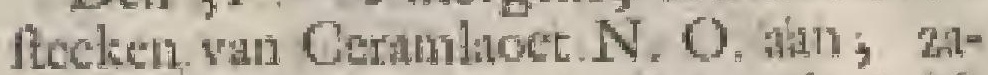
gen zy de kuft wan Nova Guined in "t $\mathrm{N}$. O. en in 'LO. N. O. rege voor uit, wan. noer zy Germis N.O. book in 'te W. ten $Z$, en Gorm angter wit in " $\mathrm{Z}$. ten $W$. haddes.

Datur op zaliden zy dien geheden dag al. N. $\odot$, ant, on quamen is savonds, op ontrent 4 mylets na, by dic wal; doch het jonk van Lakge liep hen, regt na de wal toe, worby, terwyl de Hecr $K e y t s$ "s nachts wht athicldy zoo dat de afttand wan Kefling tot de $W$. hoek vin Onis ontrent 22 mylen meeft regt $\mathbf{N}$. 0 . is.

Den itter Augufti zeilde hy nog al langs gé wal tan Onin, en quatr "saronds in een bati Benoorden ecn hoek ten anker. Dien nacht vodr lakoe ma de hoofddorper win Onin, Fataga en Roemalh Batí ge-Fataga ex

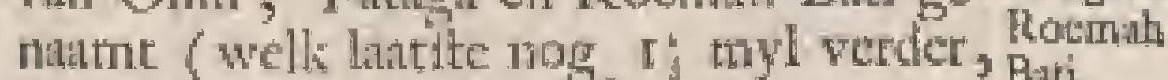
dan "t eerfte legt $)$ woor uit.

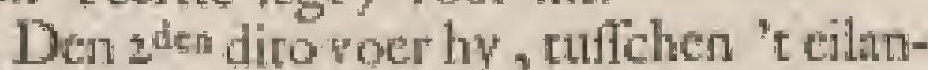
deker Poclo Ais doot, wlak op dit hoold- Poclo dorp Fathgit alti,

"s Mougrens wroeg quan de tolk Djaend zyo E. zcggen, dat Lakoe, ni den gaufehen nache met hen and land gefproken te helsber, lact cindelyk dara toe gebrigt had, dat de wede gemankt, en befloten wats, de onzen als vrienden te onthingen, gelyk die wan laud zyn $\mathrm{E}$ ook nuet alle hume contcola's zouden komen bezoeken; пиar dac zy dan ook alle met en vlagegeje moeften befichonken worden.

Kore datr, op werchenen ooli die watrtuigen vol menlchen, met een gooat gemats van fpeeltuigen, feheppende driential rondom het jagt wan den Heer Kogts, die dar op eenige ecrichooten lice doen, on lart gaf, dat mar enige der voornam te zouden overkomen, terwyl zyn wolk zecr wel op hun hoede wons.

Hy vereerde hen woor yder corri cora een wlagge, whar op zy tanboden "t jagc te boegzeeren, dar zyn F, alzoo de wind good was, atiloeg, lkomende tegen den wond dus te gelyk voor het dorp ten anker, terwyl de Pichang ondertulfehen de dáa ontreis leggende hocken en gronden peilen, en net belchrywen gings

Hy vond hici den poornoemden fof mede va11 Kefhug al mangeland, die zyn E. quan verwelkomea. Ools hoorde zyn $E_{\text {: }}$, dat het jonk, win Borri voor uix gezonden, in itukken geflugen, doch dat hee volk en goed nog geborgen was, wan over zyn E. niet weng ha zyn ruint lagte, alzoo die lorendrajier hem nu weinig telutude bybrengen zotide.

Hy wond dat ook een Ambonfch raattuig van Honimoa met cen pascedulle, zyind don towimole (die van Onu afhonftig was) na Nova Guinea gezonden; om hunne zatiken dar te verrigten, welke zyn $\mathrm{E}$, athgezicn hun cyd al veritrehen was, belathe te wertrelken, dat echter nog al cenge dagen anliep.

Dat. op ging de Hees Keys tegen den awond cens ann land, ahwat lyy door ' $7 e f$, en Maflasewa, zoon des averieden Folwa, koning war Rocmah Bati cn Kellibui, op een catil, of ruftoank, werwelkone, en tudichen deze twee yoornamfte landsyorten ingezet wite, ter- 
wyl tlle de Orangknyen op frand, met durzenden menfichen rondom zich, zaten.

Men begon voor af eenigzins een eifch van mafloy en flatyen te doen, die na de gedagten der onzen wry wit groor zynde, zoo wicrt "er dien arond mer verder it gerept, watar op de Heer hops weer na boord Fecnde.

Daags "er ann ging zyn E, weer ann land, zynde op de zelve wyze onffangen, en deden die wan Onin toen weder cenen eifch van $20 \mathrm{R}$ ders woor yder man-flawe, die in Tambockze fwatrden, Tinakki gename, en met Clymatze byltjens, moeften voldran worden, war wan de onzen nict vootzien warch; cehter wiert cindelyk het verdrag getroffen, en belloten, dat men voor yder manflutwe I 3 of I4 Rders, en woor yder duim, die hy korter, als de bedonge matr, wis, $4 \mathrm{R}$ de: minder geven zoude; hoewel toen de Heer $K$ oys nier weel flawer, dan voor zich in 'tbyzonder, bekomen heett, gelyk "er ook green byzonder beding over den Maffoy gemakt is, alzoo zy verkindrdende zelve op hua land nict te hebben, ca dat zy die van Carns, war mede zy nu in oorlog wiren, moeften doen komen.

Dit werdrag nu wient den 1 fitu $^{\text {Atugufti }}$ wel gemaakt; mur men vorderde, wat men then ook voor waten anbood, zeer weinig, zoo dit $z y$ wat dezen of genen tegen ons fcheenen opgerokkent te worden.

De voornumfte, wanr op de Hecr Kers quade gedagten liad, was Kakoc, en den Cermicbe tolk Pari Key, cen doortupten wos, welke beide wel zagen, dat hun gezag onder dien inlander merkelyk, zoo dit getroffen werdming thud greep, verminderen zou, om "t welk te belerten zy alles in de war hidpen.

Lako, en zyn broeder, wilden nat Onin Coweay, of Cubiay, niet medeyan, on de beloofde fmeckoolen anu te wyzer, woor en al eer de Heer Keyts hem nog foo Rets geliefde te leenen, cn dan nog 2 Hollatuders, als gyzelatars, yoo lang hy uit was, atn land liet, dat die Hew hem plat afiloeg.

Men warfehouwde den Heer $k$ eys ook, niet veel ann land te gaw, aizoo hom, en de onzen, ligen gelegt wierdou.

Eindelyk werfeheen de Spiering, en de Piellang, van Caris gekomen, den 2 ftem Auguifi by zyn E op de reede; doch met flegte cyding, alzoo zy, door Bar i's ichendige misleiding, daar niess ontent de Mafoy-handel liadden konneti uitsegten, rchoon de inlunders zich nict ongenegen cot de onzen betonnt hadden.

Vermits dall hicr op Faraga, en op Roemath Bati, voor de onzen niet meer reverigten was, is zyn E. den $23^{\text {then }}$ dito, nin nan yder dezer dopen mede cen vlag of wwee, met her muerk der E. MatFchappy, gelchonken te hebben, wan datr gercilt, hobbende hen ook cen pas verleent, on jartylis met a of 2 coracora 's in Bandil te mogen komen.

Lakoe gat de onzen ook ecn gerchrift, war in hy beloofde, en fwoer, ne "t iuitgatn wan hunne vallen, na Cocvely to zullen varen, en de angeweztne limeckoolen binnen 3 matanden te zullen at hat len; doch Boryt witert wegens zyne geplecgde valfcheid in de bocjen gellotem. en voor de inlanders werborgen gehonden.

Om nu met ecrig ondericheid van dic land volgeus zyne bevinding te fpreken, ootdelde de Hecr $\mathrm{hg}$, dat dit voorfte deel van Nowa Guinea, by de Ternitatinen Wonit, douh anders gemenelyk Onin genaame, ch matr een groote vi[hoek zynde, ecn cilasd op zich zelven, on var de valte wal afgezondert wis, hocwel ly date miet klane ondervonden, nog ook in cenige Kanten zoo gezien had.

Hy had alan de N, O. Kant een tamelylie openting, condut tegen over de wafte tiult, die men van de $Z_{+}$zyde ool betiennen kon, wetnotien, en kinar rulficher de Nooidelykile natte hock wa Batoe Pocteh, en de Z. W, hoek van Onin, cen byzondere groote inbogt, die wel mylen dicp, en 2 mylen wyd wats, ontdekt, on welke nauwer te onderzocken zyn E de Pieflang by zyn ainkonnt uritgezonden hiat; doch zoo mas die van $O$. nin, door de Kcffingers opgrezet, dit vertionten hadden, waren zy dat over zect misnoegt geweelt, weshalven dit agter woeg geblewen was, om hen geen werder argwand te geveri.

Men heeft hier orel al, tót wel $z$ of 3 mylea buiten de wal, zecr goede andiergrond, gelyk zyn E. an de O. kane van Poelo Aas, daar lyy gelegen had, ondervonden heett.

Voormiddags was "t dootgans hier mooj weder, doch suatmiddags wiert her land t'elketis mer lwate dampen en wolken, dat dan gemecoelyl op regen uirquth, bedekt.

Het land in zich zelven, voor zoo werre "t zich vath buiten vereoont, is woelt en wild, alzoo 't weinig of nier beziaid, thog betuint word, en op veet plaaczen Iteil en klippig, hebbende wan zich zelven zeer weing vтugudagende boomen.

De voonamente, die zyn $\mathrm{E}$. hica zag, waren zeker fig wan Nooten, die den Mulichantoon nuet ongelyk, doch die wat ling wan korl, dikiker van batk, en veel grooter vin bladen wiliten. Do folors gelykt nief na den gemeenen Nootenboom, Mlzoo zy zecr ruig, en 


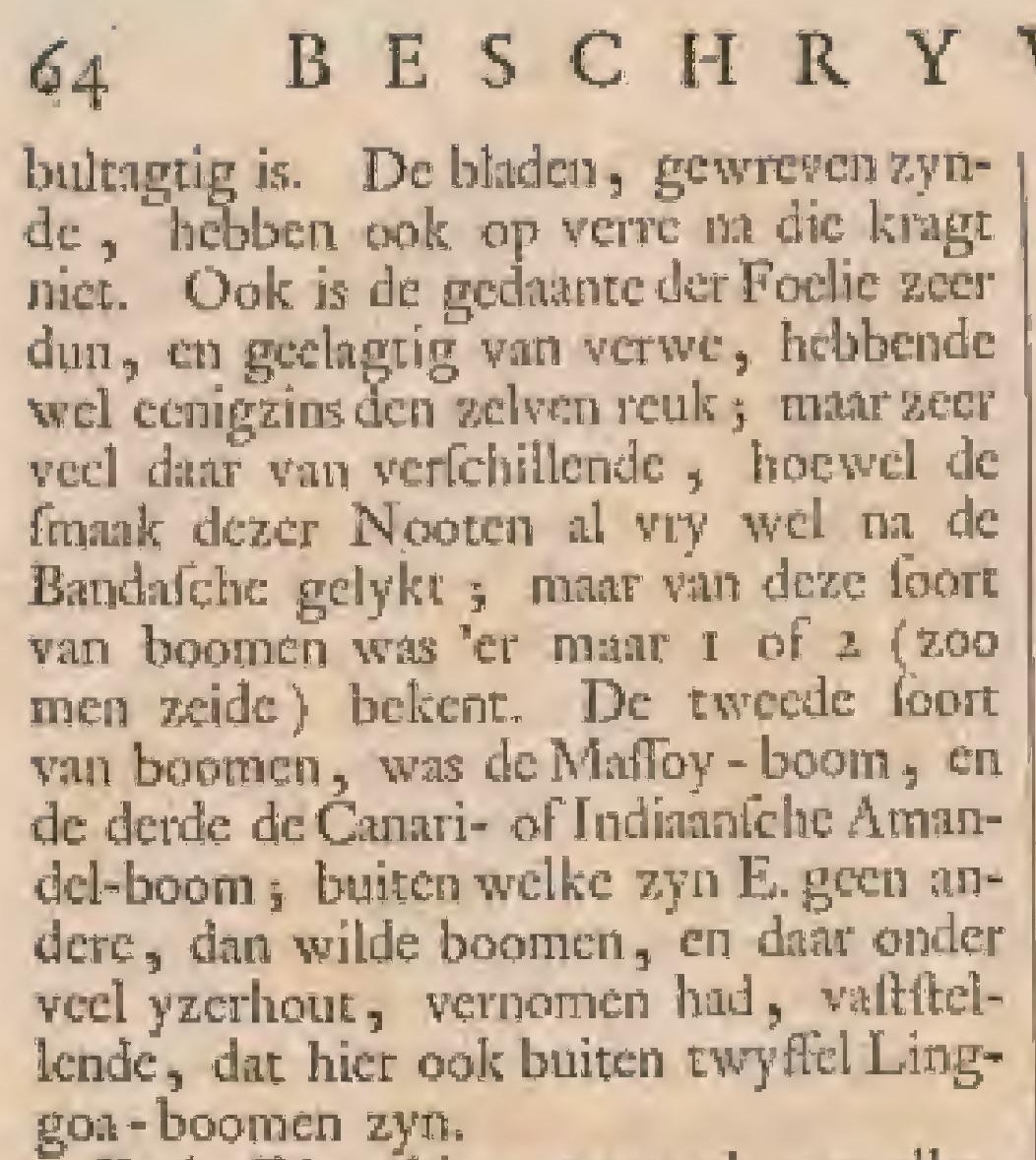

De boftchen hier waren ook met alleylei gevogelte verwult, die den ganfichen dag cen angenaame zang, of wonderlyk geluid, uitleveren; ook is hier over al zeer goed drinkwater, in owerwloed nan de ftranden te bekomen.

De lugtitreck is hier niet zeer gennantigt, mar vecltyds dyzig en dilupig, weshalwen men zich hier wel voor de nachtluge wagten moet.

De twee oppergebieders walu die land van Oniñ wates deze Mafalacwa, en Feef, wan welke d'eerfte (die wich in de Negry Kil, of Roemali Bati onthiclt) een der 7 zoonen van Radja Tabowan, wel de voornatufte was, diens vader, ontrent to jauren geleden, door die van Caras, nevens wel 3 of $400 \mathrm{~min}$, dood gellagen, en dat nog net bygelegt was.

$V$ an deze 7 zoonen lecfden "er toen nog 5, te weten, Malfalotwa, Baboe, Boban, Lueri/a, en Manakparin; en de 2 overleclene waren Manakaboya en Carof fa, - die voor den mderen its deerltgebooment gercgeert hebben.

Her volk is yan geftalte, atare, en ommegang (zoo veel men oondelen kin) nog tamelyk wel; mar men moet ben egter niet vel vertrouwen.

De tweede in gerag was de voornoemde 7eef, die in 't dorp Fataga, dac I myl Benoorden Racmah Bati legt, woonde, en welkers mocder cen zufter wan Radja Tobrewn was ; deze had toen een zulter van Mafialberva getrouwt; doch zyn vaders naim wort zeer zelden gemeld, om dat hy vas ect gering genlagt was, daar deze inlanders fterk op zien.

Vermits zy beide nu nog zeer jonts waren, wierden de landzanken nueel door de oudite Onungkayn's watrgenomen, watar ontrent die van Keffing (hocwel zeer bedekt) "t voomatmfte beftier ain zich hadden weten te houden.

Hun voon flnawen- en Madfoy-handel; doch de gemeene man moct viffehen, wil by ecten hebben.

\section{$V$ I N G E V A N}

Zy vatuen ook fterk op Goram, Keffing, en ook orn de Z. en om de N. heencen. Hun yeweer beftait in fivaarden whon verreheidenerlei foorren, in pylen, boogen, lancien, en pieker met korte wecthatketr.

De Heer Keys vemam ook uit 2 inlanders wan Teuw, dat dic wan Caras wel Mafioy nat ons hadden willen werhandelen; doch dat hen dit in alle manieren door Borri afgeraaden was; waar over deze 2 inlinders zeer verwondert hadden geftaran, niet konnende bezeffen, hoe men zich var zulken bedricger bedicnicn, en hem nog geld tocgeven kon.

Den $\sigma^{\text {den }}$ Augufti guam de Heer Kegts De Filanby de eilunden van Caras, dic wan Poeloden van Aas, daar zyn E. cerft ankerde, I2 my-Carss. len lagen.

Hiertegen over in ' $t N$. malkt dewafte wal een groote bana, met lag land, dat zich even eens, als Holland, wpdoct, en Ryklof waar jn wel 1000 febepen zothden kon-yanGoens nen leggen. Deza baai unemden de onzen baaj. Ryklof won Gocms baat.

Schoon dic valt land nu meeft lang is, zyn egter des zelfs 2 . en $\mathbb{N}$. hoek hoog land, watar by 'c ciland Goweay op 3 graden legt.

sVoormiddags zag zya E. cen wanttuig van 't cilland Caras na batoer overftecken, "rgeen lyy gifte her tweede jonk van Bow, doch dat hy bevont een wartuig yan Radja Moffon, van 're cilund Batoer, te zyn, dic geen wreeze voor ons volk betoonde te hebben, en ook verklaarde al ecn goede party Mantoy an ons te konnen leveren, zoo hen dit door Bomi niec afgeraaden was. Ook boden zy atur, in 15 of is dagen nog viy wat te befchilken, zoo men zoo hang wiide wagten, dat de Heer Keyts nier over zich nemen dorft; mar makkte egter verdrag, on die hen jnatlyks te komen athnalen, belovende hen woor yder drooge ro bofien 8 vadent linnen, $x$ lmal byltje, en I houwer te zullen geven.

Ook gif zyn E. ann yder wath deze 3 eilanden een whig, met liet merk der E. Marfchappy, waar mede deze inlanders weer wel in hun fchik waren.

Deze plats lege op de breedte tan 3 graglen eir 26 min., of, 200 wy met andere itellen, wel cen balve grand Noordelyker, hebbende niet alleendien fchoonen inbogt, maat tan de N. W. cn Z. O. hocken ook zeer hooge bergen.

Tot deze N. W. hoek nu fteckt zich Onins de gerigtsban war Onin uit, by hen grenspalal. Mengonan Sobolot genaamt, zoo dat "t gebied dezer cilanders tuftclen die rwee hoeken, en over deze bogt mede ging; doch Coveay, of Cubiay, nam zyn begin eerft alan den hock, dic in 't Z. tein O. Jag. 


\section{B A N D A.}

Cani, Ba* De eilanden nu, in deze bogt gelewer en gen, en bewoont, zyn Cani, Batoer, Caras. ct Caras, alwar men verfcheide eetbature vrugten, te weten, kahappus, canuri, ocbi, picftang, bontjens (die zecr goed zyn ) roode ryt, en overvloedig witch aun de ftranden, en veel timmerhout heeft, dat wan hunne groote vartuigen, die vecle uir een ftuk gemake zyn, te zien is Ook is "cr voornamently her yzerhout in grooten oweryloed.

Het fchecn hier nier ongezont te wezen, slzoo men "er een gocde zeewind, en wan de vafte kuft een lehoone en werquikkende landwind heefe.

De ingezerenen zyn in allen declen, als die ran Onin; maar zoo greflepen niet, angerien zy zoo vecl verkecring met ans, of anderen nier hebben.

Ook was 'er tuitchen hen, en die van Onin, nog een oud zeer wegens het dood. flann wan Radja Tabouan, en de zynen, want toe zw egter (volgens verhial wan Radja Moffon) nl groote reden hadden, altzo die Radja menignanl hunne wyven had gerwot, of geichonden, gelyk dit door hem zelf ans Mofrons eigen wyf, en door zyn faaf ook am Moftoms eigen dochter gedatn was, waar door zy dit alles zich zelven op den hals gehanl, en tan deze eilanders regtweerdige redenen, om dezen finad te wrecken, gegeven hadders.

Ander's is dic volk onder malkanderen, en omtrent ons zeer goed van vertrouwen, en niet belchroomt zonder eenige wapenen, of verzekering, wry poltig by ons re komen, om van 't welke ons to verzekeren, zy ook hunne wapenen, als zy die by zich hadden, in hunne pratuwen lieten leggen. Endus liep ons wolk al mede onbevreet by ben in 't bofch, on hout te hakken, of om vogels te fchieren.

Godgdient, of eenige teckenen dar van, had de Heer Koys zeer weinig, dan alleen cenige Teraphim, of kryitalyne fteentjens, die zy altyd by zich drocgen, onder heis wernomen.

Deze thenrjens hadden een groen en een rood itrecpie, ook waren 'er geele blinkende wan die foort, die zich byna, nls of 'er eenige erez mede vermengt was, vertoonden.

Voor develve had Radia Moffon cen groote cenbied, ch was gewoon dic ook alan te bidden.

De voornamfte Orangkayen althicr waren te dier tyd Bia/fe en Ratotil van "t eiland Can', Radja Moffor van "t eiland Batcer', en Goerowi en Cayitan wan 't étJatd Cirias ; doch Moffos fcheen onder hen wel de voornamite te $7, y n$.

Zy woeren (woo men merken lkon) nergens op, din op Cubiay, genererende zich enkelyk met menlchenroven, en met hunne plantagien en viffcheryen, die zy meefterlyk weren re theeken, al zoo geen wifchlynen by hen nog belient zyn.

Den I fteil September ging zyn E. vin Batoer tuffchen Caras en Canj door. trzeil, en quam daags "er aan by een hoogen hoek.

Gubiay begon zich hier regt op zyde cubiry. eert te ontdekken; mar hy kon hier zer weunig door de $\mathrm{Z}$. $\mathrm{O}$ winden, die hem tegenliepen, worderen, weshalven hy tuffechen 6 of 7 cilanden en de walte wal doonzeilde, dair hy zeer ongelyke gronden, wan ro tot 28 en 20 tridem, dic dan kilippig, en dan weer goed waren, wond.

Daar na zag zyn $\mathrm{E}$ in 't $\mathrm{N}$. cen diepe bogr, die veel mylen hang, en wel dric vierde myl brecd was, dar hy om zye lekken te ftoppen, wermis de chaloep de Picfang het nict langer gatnde houden kon, inliep.

Hier waren de inlanders wat fchow, roepende dat de onzen daar aan boord wilden komen, alzoo zy Maftoy en Tambaoco hadden

De Heer Keyts voer zelf mede ni de wal ; doch lier den tolk Djoesw mar atan laud gatan, die zich een weinig in de band querlte, en hen allen zyn bloed drinken liee, dat de voomamite onder hen ook deden, op hocdanigen wyze de vrede by hen gemaakt word, matu da virl eigentlyk geen handel op die tyd.

Deze bati legt ontrent iz mylen Z. en Z. Z. O. wan de Heer Ryllof bari, die De Heer zyn E. om hare lichoonhed, en on mans tgemak, dat hy er vond, de Heer baaki. Spentum ban noemde.

In 'E inkonen atn de linkethand is een zeld tame waterval, die wan 't gebergte kome aftorten, en die men wel \& mylen verre in zee, als een wit laken, zien kan.

Zyn $\mathrm{E}_{\mathrm{m}}$ meinde zich dar wat te gan vertrifien; maar 't was onmogelyk, om, of de afftanc wan een pylichoot na, dast' by te komen, nangezien zich 't gefpat wan dit water ils cen lware damp, of dikle milt, verroonde; doch hier ontrent wond zyn $\mathrm{E}$ nog werlcheide andere kleino beckjens, die onder de thenen quamen uitzyplen, cn waว aа men zyn dorft gemalkelyk leftich kon.

Gelieel binnen in die bogt legt een dorp by de rivier, en wat Ootlelyker heef men een berg, war agres een fchoon binnenwater wan een bequatre diepte is, watr in men veel groote felepen zou kommen bergen

Ann de Ooltzyde tran deze bogt, in den binnenften hock, ftone ecti klip.

II I. DEEL 
wast op de onzen veel dondshoofden zAgen, en een beeld, ren nuaften by als een zeldrame menfel tor nan de fehouders, en daar by Begrawe een wichild met enige andere gereednis der fehapen, en tegen dese klip ook dierOniners gelylic merken geteckent:

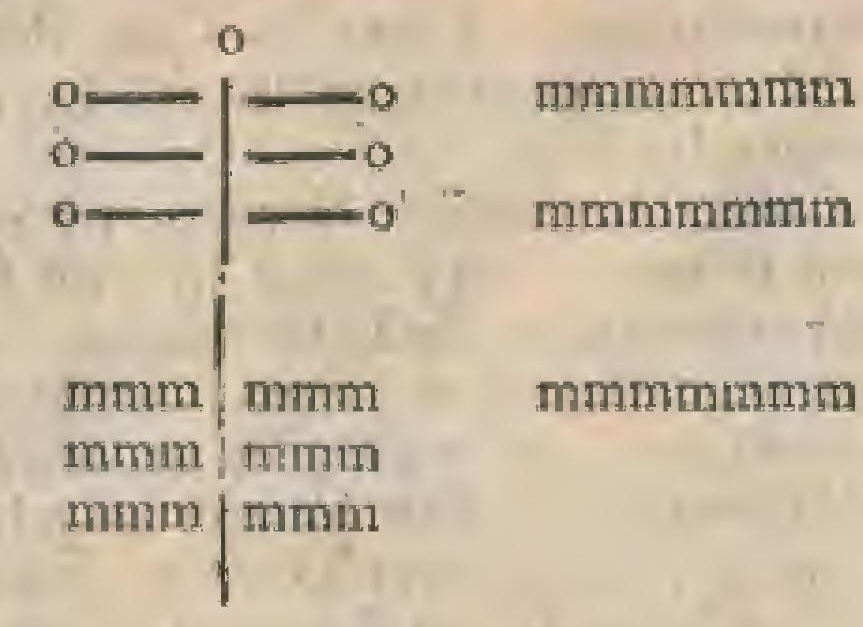

En dit was hume genecne begrate plats, en wyzewa begratven, gewoon zynde hunne dooden, niet ter warde te brengen, matr die op cen itrandlip in de regen cn zonnelchyn, am die duar zoo te lanten vergata, te platizen. En zalke begrafplantren ziet men hier doorgaaus langs deze Cubiay che kult.

Ant "t cinde dezer bogt in ' $\mathrm{O}$. heeft men weer dien hoogen hoek, zynde Cubiay's Z. W. Irock, an inger de zelve in de bai zagen de onzen een kanal, warar door zy gilten, dat men ann de andere zyde in zee weer uit zou konnen komen.

Den $7^{\text {den }}$ Seprember vertrok zwa E. uit deze boge, doch geralkte hier in groot gevatr, on, door de tegentroom, zyn lehip tegen de klippen te verliezen:

Hy bevont dat zy hicr 4 granden io min. N. Ooftering miswyzing hadden, en dat op de Z. breedte van $4 \mathrm{gr}_{2} 2 \mathrm{~min}$.

$\mathrm{Hy}$ lag nog 4 milen van Cubiays $\mathrm{O}$. 2. We hoek, die 6 mylen van de voorige $Z$. W. Eijand, hock lag, en o mylen van "E Wezels ciland, nan welkers W. hoek zyn E. den IIdes dito ten anker quim, doch wont, tan land gekomen zyode, geen volk, dan matr een mati, die fohielyk uic ecn hut fprong, en do wluge natm.

Den a $3^{\text {ien }}$ verzeilde zyo Ex van 'c Wezcls ciland, tuthluen de vatte wal en 3 cilandekens door, die ruceft ata een op ecrs vlakke droogte Jagen, wath welke 't Weltelyklle 2 mylen wan de wal, en 3 nulen vanden $\mathrm{N}$. W. boek van "t Wezcl ciliand lag.

Hier oncwicl hen de wafte wal N. N. O. en N., over al lase land zynde, wath by nog 3 andere cilanden lagen.

In 'E N. zisg de Heer key's een grooten inhasn, en ftak O.N.O. na de owerwal, I 4 mylen van ' $t$ Weels cilawd, en quam ;tur de W. $2 y$ de vari een eiland ten anker, legectide ontens I myl wan ecn liock, Lacwe genaimt, ngter welken hy, wol- gens de oude knurten, de Mondenantsrivier meinde te vinden, dat zyn E. dat toa anders vernitm.

Hier wond het velk weel Oefters, dic zeer wel na patrlemocrfchelpen getkker, whitryan zy "er ook cenige mede in Btrata gebrige hebben.

Den r gden Septerbber hier wan datn 'tankerligteride, ging zyn E, mę een 0. $\mathbb{N} .0$. wint onder zeil, vernemiende "s namiddags een groote corncora: Ool had de fterman yan de Pielling, dijge

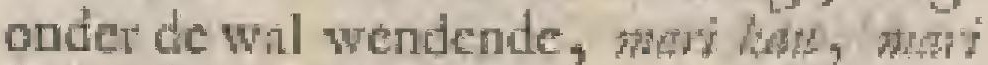
kan, dat is, kom bio" gy, kemt bion gy, hooteri rocpen; gelyk hy diar ook ecnuge huiskons gezien hall.

Dara na keerde de Her Keyls, op de Picflang overgande, na de patsis wa whtar dat geroep gehoor was; alwarde tolk met dic inlunders, wit he balch te voorlichyn en op de klippen gekornen $Z_{Y}^{y} 11$ de, lprak, zonder dat men hen efterregt, din nu co dan matre eens, zicn kon.

Zy tiepen zyn E. wolk dar ant land; dat de Heer hats ten eerflon niet bon toeltam; wapl op ztwerzogten, dazyn E. doch war verder op na hun dorp zou vatien, daar zy hem dan morgen nader Tpreken wilden, dac zyn E. beloofde, wat op die inlandes net hen wartuig dige onder de wal voor zyn F. heenen liepen; gelyle ook zyn E. dien swond mer dendonker digt onder de zelwe ten anker quam, en zich 's morgens datar an, den

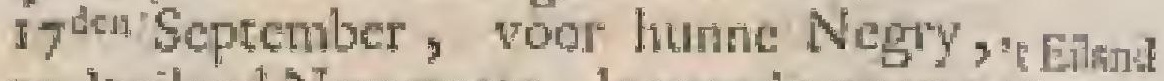
op 't ciland $\mathrm{N}$ metotte, leggende op wat Namemecr ats 4 graden Z. breedte, hader totte. onder de wal begaf.

Ondertufiches zeide de fturmman aan zyn E., dat hy weer water zon wan nooden hebben, en dat fiort hem verzekere luad, dat dilar een goede put ande wal was, dic by angeboden had hem thin te wyzen.

De Hecr Reys antwoordde, dhe hy wel lyden moge, dat dit gefehictle, nirs dat liy wel coezag, dat zy gecn ongennk Jkegen, dat hy sunntro wel te bezorgen; doch dat eon gelued ongelukligen untthe had

Dant op beguf deze thumban Gouses zich, tegen de vermanding vath de Cot-Dint weporat, zonder eenig rgewer ma land, Jiteride data $x y$ in 'ecert wel pricndelyk ont fun-wolk gen, en nadie put gelcid wicrden, mas dondgezy waren geen fo fehreeden vall Itrand thres gekomen, of zyn E. hoorde vrectelyk, pyo liclp, help, roepen; waar op lyy ataftonts nitzyn juge ctrelykeflukken loften liet, dat deze mootchenats de whugt deed nemen, die dus de overige, die reeds is 'c water gerlugt waren, vetietch, whar' op zyn $\mathbb{E}$. andtonts met het kifyguol that de chinlocp de Pieftung, en zooverdier digt onder de wat, en met de rchuit an 
B A I, N

land vocr, alwar $z y+\mathrm{E}$ nog 4 van de onzer dootelyk gequet ft na de le huit zag loopen' ; doch Goouen Danilffe de Roos, Joofl thesumz wan Komph, korponal,

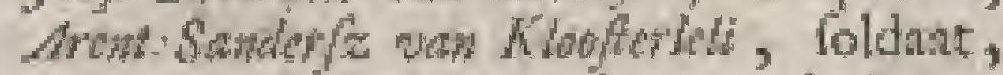
en, na xyn E. vermoeden, ook Berri, waren rects doodgefligen, de hoofden afigehakt, en makt uitgelkleed.

De fergeant trad met. 16 man (door ons gefelur gedelet zynde) nan de wal, en chargecrde brat her om, doende $z, y n$ 1: desgelyks uit de Piefling; en men bragt ondertuftchen ftumman Goo/fon, Mrent samerfa, beide zonder hookd, in de lchuit ; mata den korporal en Borri vernamen $z y$ niet, ziende een thuk weegs verre wel een lwart op Atrifd dood leg gen; doch kondon niet bekennen, of het Bmri, din of "teen ander was.

Daar op belafte $7 y n$ E. alle de viartuigen der" "yanden in den brand te fteken, dat in een oogenblik uitgevoere was, hocdanig $z y$ ook met lume indere vata' turigen en huizen tan de overzyde steser klip gsilegen, lecfden.

Ondertuficher rehoot de vyand van alle kenten uie het botch ook dapper met pylen, 't geen de onzen nict belette nog ettelyke prauwen wey te flepen, en tatn boord te brengel?.

Die was hier dus wel zeer qualyk uitgevallen; mat het kon nog ved erget uithag gehod hebben.

Daar op liget zyn E. 't anker, licp ; mylen buiten de wal, en zette onze dooden disi" in zee, tervyl ons "s awonds nog cen matroos, Jay od Dord genatut, afiticerf.

Dit ciltud Nametote legt op den WV.

De

Morete-

rivier. hoek wan de bekende Moordenats rivict, $\mathrm{cn}$ is tamelyle hoog lind, па gifling wel 8 mylen in "trond, bebbende zelfs atan de W. kant mede over al zecr goede ankergtond. Ook is hier wel de vootnitam te ftapel des Mnftoy - handels, 11waar de Cerammers jatrlyks vall Mey tot Augultus komen handelen, yan war $7 y$ ook zeer goed ebbenhout, en thatwen vervoeren, an de inwoonders duar voor nier veel anders, dan den buik vol ryift, en een deel groote kotaden, gevende.

Dit wolk is zeer fterk, en wry grooter wan gediante, dan cenige andere hics ontrent, en lpreckt, betwiven zyn cigcn, ook de Ceramze thal zeer vaudig; $;$ gann (uitgenomen dit $\mathrm{zy}$ hunne fchatmelheid met boombutten dekken) geheel thilakt. Hunne neusgaren zyn wol pricmen doortecken, en hun geweer beftatt inpylen, boogen, lancien en Tambockze fwanten. De wouwen hebben dikke komalfinocren om den hals, en de middelen, en zyn in has angezigt met fwarcel wan gefturnte fneckoolen zoo afgrylielyk toegemaaks, dat zyy ecr

bemorfte verticus, dan-menclien, gelyk zyn. Ook zyn zy zeer mbelchant, en, zoo veel men befpeuren kon, zondes cenigen Godstientt. Z Zy bataren huine kinderen in praturwen, op de ll randen, en in de bolkclicen, en liort dat" na werpen zy die in een zale, die hasr om den hals hatage, zyode in zich zelve onutute bectten, ot die ten mintten gelyk.

De W, hoek wan deze mochteniarsrivier lag $\mathrm{N}, \mathrm{O}$, teh $\mathrm{O}$, den $\mathrm{Z}$. O. hock van eiland Natmetotte, dat ons wolk wermoore was, N. O. ten N., th 't Ooftelykfte. wan 's Wezcis cilund Z., ontrent 3 mylen van ons. Zyn E. quatm datar op weer onder. "t Werels ciland en anker.

$V$ ermits nu hicr wod ons biet meer te doun wicl, terurde zyn E., nat nog $2 \mathrm{da}-$ gen vertoevers, belt, om, alzoo zy on "t Wezels ciland geen water tonden, ten cerflen wert na huis te keeren, hoewel hy, volgens pyne ondfingen list, nog eens op Aroc, wegetis de paarelbank aldair. an moct gienen, on cenige woormad voor ons volk data over te geven s mar 't zelve niet konnende krygen, liep $z y n$ E. mant ua Bondal, diutr hy den $26^{\text {den dito }}$ behouden ters anker quan.

Hier uir ru kan mest, ten minfeh ecuigermaten, zien, hoe het in die Nova Guinea geftelt, en wat land en wolk bet is.

Met een woond moeten wy Jier by voegen, dat, by "twetrek win de Hecr Commifteris Dik de Lldas uit Amboina mat Bativia, in "t jan" I60t, Kefting, en groot lundlchap op Ceram, ween one det" "Lbettieg van den Heer landwoge win Bandat gettele is; doch cgter wierden die wati Amboina, by fichrywens batrer Edel heden watr den $24^{\text {ftan }}$ Fobrurii r6gz. wel uitdrukkely belut, op hume fluikeryen van Nagelen wel te letten ; bocwel 't doel, dit onder Banda behoorde, zich, volgens forryvens van haar Edelhoden van der $26^{\text {then }}$ Jamaraj 168 o. anders tot de bogt van $H$ aja toe uittrekte, wande alJes Beweften dic bogt na die tyd onder Amboint; doch den $14^{\text {den }}$ Tebrunii 1602. en den $23^{\text {tles }}$ Febrtarii I 694. guwen latat Edelheden, by luw folvywens met het Huis te Spyk, berel, dat die wan Bundat met hunne chaloepen mast tot wufteh Keffing, en Werinuma, tot het beleten van "tiluiken der Nagelen, zonden behoeven te kruffen. Hoedanig zy 168r.

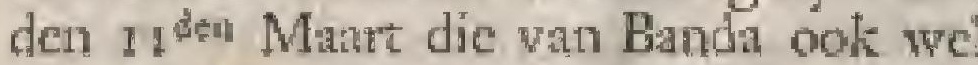
พan "t uitrocjen der fpeceryboomen tusrehen Sepia en Haja verleloont; man nan die regeering by hun felrywens tocn egter de thigt gelnaten frdden, om van Werinama tot Keffing toc alles te mogen doorzocken, zoo als zy 't noodig oordeclden. En 1695. den zon Januari roegden $x y$, by hum fcluywens met 't jugt: 
Bombali win die wan Amboina, " er by', dat $2 y$ egter begeerden, dat de Negryen op Ccrant, maler Banda ltande, nogeans de Amboafelie Hongivlon behoorIyke cere zouden moeren bemyzen; ook helsben har EAelheden de *art ma de $Z$. Oofter en $Z_{*}$ Wetter eilanden, by hun felryvens van den 280 tea Feturuat 1603. ann alle de Amboineczen vollagen geweigert, en "t.latife ook zell ath de Bandaneezen perboden, hoewel zy hen 'teerfte, alleen tor hun onderhoud, nog tocgeftan hinden. En, wolgens hunce ondre พan "L jati 1694. mognen die van Bandi ook gecn paltell ower Keffing verder , dan tot Goeli Goeli, Hatiahoi, Kiflahoet, Haje, er Rankie verleenen. Eet wy cgret val dic ftofte ran Nowa Guthen con wan het Zuidlaud geheel affehoiden, konnen wy rict maliaten hier nog iets atu te halen wutude reize, die in 'E jatr r696, om te ziten ('too men wil) of men iet yan de Heer Cocper of de zynen wernemen Jion, derwatts gedilith is.

Deze Heer is in "t jan" 1684 . of $168 \mathrm{~F}$. thit Holland met het folp de Ridderfohap mar Indién wertrokket, en behonden an de Kaap gekomen, alwatr zyn fchipper hoiognoodig oordeelde, ont liver een andere groote mait in te doen zetten, alzoo die, welke hy nu had, niet dogt, en hy net regt vreesde, dat $2 y$ hier mede de reis niè kiygen zouden.

De Heer Goper keurde dit vetanderen wan maft at, behiéle de oude, en ondermade teize ma Batavia hiet nuede; doch men heefe zedert noit tal of teeken wan die fchip, of van yenant wan dit volk gehoore, dan dat er cenige janten dar nat seu gerugt quam dat de zoon van den oudei Heer warler Sich, die met hem vertrokken was, op Madagascat nog leefde, doch alles quitr op niets uit. Zoo dat hy na willen ichyn met man en muis in de wolle zec geblever is. Of men 'er' cgter mog its wan ontdekken mogt op 't Zuidland, zoo wient in "t jut i 606 . deze volgende togt tondertionen.

De oude Vlictundiche fohipper Wham De Wa* de W Iwhing, ondernam de zelwe met 3

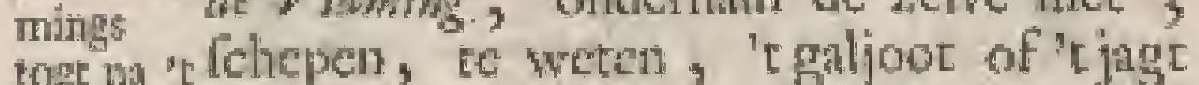
zuidiand de Geelvink (dnar hy lehipper op was) in "t juti de hotker de Nyptang, el "t Balijoot de icg. Wezel, wis het vadellind den 27 the $\mathrm{No}$ vember, beginnende die, na dat by wan dant reets wor by de Kanp der Goede Hoope op de Z. breedte wan 38 graden en 58 min., ai op de lengte van $2^{2}$ gratitden, cu 3 min. gekomen was.

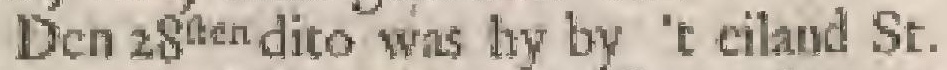
4 Eiland Patilo op de breedre van 38 granden en St. Ptulos 40 milu en op de lengte wan 91 grwaden 44 mitn, doch zas, alzoo het dyzig weder was, matr eten wakken hock "cr af. $\mathrm{Hy}$ bewond dit and de knten, of wan de W. too de Z. zyde, fohor, zonder cenig voct Itrand, en zonder yuilen, die men behoon te myden, zoo dac men tot op cen kinonfetroot na $\mathrm{cr}$ vlak op ain zeilen mag s matr wande W. kata thelk cen rif ontrent cen kanonfchoot in zee, , dar men kan zien brinden. Hy vond in 't andecilen, zoo als 't ciland $\mathrm{N}$, vatn hem wis gelegen, 40 vaden wuile grond, en hielt het datar op $0 . \operatorname{ten} \mathbb{N}$. Jings de wal, tot dat het ciland $W$. wan hem was, en zich pas cen musquet fohoot verte wan hem opdect, wat na hy hicr ten anker quam. Hy vond hier weel zecrobben, en nog een anitere loort, by wa als zecrobber , doch die wel 18 woet lang waren. Hy zag hier geen groente, dan eenig rietbofch, en hiér en darar túfichen de lilippen eenige groente als pictercelie, doch zecr weinig; ook weinig gevogelre; mant wing op de recile veel vilch, als groote fteenbratfem, en in 4 uuren tyds wel 436 groote vilfchen, als kleme kabbelgatawen, net de liok, en nevens de zelye veel lireeften. Brandhout whs "er niet, ook geen werfeh water, dan alleen op de hoogetens hier en darar in plafter, 'c geen zcel" moejelyk af te brengen zou zyn geweelti Ontrent de regte ree is cen bmk bintenwater, dat de robben wit zec over ecuige ftechen, die dic binnenwater, ontrent 20 treden verre van de zee atficheiden, inloopen. Anders lege dit lalve manns wyze in een befoten kom, zynde ontrent een piftoolfchoot lang, In "r zelwe vit te weel wilch, als fpanbants van gedanate, dic rood van werwe, en zerr lekther is.

Als men de W. kant van dit eiland matr nyd, zathen het over al zutiver vinden, en men mang "cre zonder fchroom op antoopen. Het is mooi hoog lund.

Den $2^{\text {den }}$ December wertrokken zynde, "t Eiana zals by den $3^{\text {den }}$ "t eiland Anfterdam. Hex AmilerJegt is of 131 myl tege $L$. en $\mathbf{N}$. wan St, dam. Paulo, op de Z. breedec van 37 grayden 48 min., en op de lengte van go granden $4+$ min. Het is ongelyk, doch gond ran grond hici:

Hy ging hicr atan de wal; doch vond het zoo dige wan bolch, dat men to cen dig geen 4 mylen "er op kon worderen, alzoo men door de feruiken Eruipen, cn orer de boomen klimmen moeft.

$\mathrm{Hy}$ vond "er al mede menfehen, nog beetten; mair alleen eenige vogels, muskens en zecrobben. Ook had cen van "t wolk (zoo hy meinde') ecs wierwoetig dier, als cen wezeltje, en eenals een wos, gezict, en darr was voel biesboich doot malkanderen gcuraflichen.

De grond if "er doorgans weengrond, die ontrent 3 roeten dile lege, en davi kny gt men theen als uitgebrunde puimiltecn. $\mathrm{Zy}$ is ook zeer mal, watrom do boomen 


\section{B A I N D A A. 15}

hier niet lioog waffehen, konnende geen ( was, en wonden ann dit ftrandje veel klatie genoegzatue wontels in de zelve, fehic- voettagen in "t $z$ and, zop yan bejaarde tent.

Hy. wirg op de recde bier ook wifch, en cen foort wan waderlandze kabbel fatuw, en ging. den $f^{d e n}$, dito tegen den swond na 't Zuridhnd t'zeil.

Hy wergoede den $\sigma^{\text {den }}$ hier de kompaficn op 20 graaden $\mathrm{N}$. Weftering, zynde nu op 37 granden 2 , mini, en:op de lengte van of graviden 45 min. $f 1$ cn 7olg hier fteenkroos drywen, 't gecn tot de 36 grataden 9 min. duurde.

Den I 2 defr dito zag hy op 35 griaden een zecrobbe, die hent al huilende quam nifwemmen.

Den $13^{\text {dea }}$ verlag lay ide kompaifen wedel op 36 granderi 9 muni, op de lengte witn 4 of flidden I I nith., wergoedende die vath 16. granden 49 min. N. Weftering. Den zollen dito dede hy dit weder op 35 graden 2 i mir., vergocdende de kompalferi wan 10 graden $\mathbb{N}$. Weltering; en hiet ftonden de zelve niet fril

Den $2 y^{\text {Aen }}$ December zag hy " $\mathrm{Zu}$ idland op de bevonden breedte van $3 \mathrm{I}$ gratiden 58 min., en op de lengte van 130 gratden 18 min.

Den 2 Siten dito bevond hy by 2 peilings hier de $N$. W. miswyzing vati 10 graaden 44 min, en win 10 granden 12 min. , werpende datr ook 48 raden wuile kraalgrond op 31 grataden 83 min. , en op de lengte van 533 ginaden 44 min., die dar nit op 25 waden liep, en bcterde.

"t Ettand Den $29^{\text {les }}$ dico quam hy onder 't ciland

Rotte- Rotteneft, 't geen op 31 gritalen fo min.

net. breedre, en op de lengte van i 34 graten 2f min. Itgt, ten anker, ging er den 3 otea tan tand, en wond cr een ftak Fuiurenhout, dat watrflynglykit wel eer in cen lehcepstek gefteken, doch al lang diar nan thrand gelegen bad, alzoo de fpykers meett vergan waren.

Hicre wis ook trandhou in overvloed, dhat hy zich dicrhalwen wel wan werzorgde.

Vlaming Den - $^{\text {den Janturi }}$ 697. ging hy met 88 Fant op gewapende mannen (tratroozen, folda' zuld- ten, co officieren) hier ann de wilte with

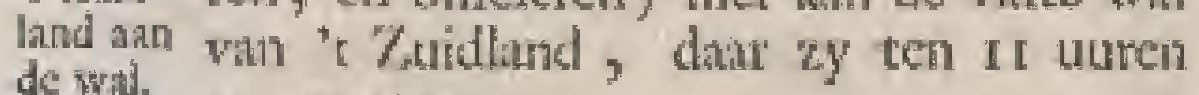
de wat. ranquamen.

Zy gingen cert 0. op, vernamen niets, datt tot voedzel dienen kon, en alleen matir eentge groote en kleine wilde boomen, uit wellke groote als een foort vitn lak of gomme droop, watr vall zy een moniter nedegebragt helbbeil. Ook von den zy hicr geen ander gevogelee, dan woel kleine kakatocha's, en groene tavens, of parkieten mee lange firese thatten, die zeer fichuw voor hen waren.

Wat lyy Ontrens 2 urien na de middag quamen er zaxg. zy by een bionenwater', date zecr zout lieden, als watn kinderen, zagen geen merichen, miar egrer ther en dat gropten rook opgan, dar zy ook mi toe trokiten, zendende 3 man, on $z$ fwarten wook uit, om do menchen, zoo zy "er waren, niet te serjagen; doch vermamen, by die plats geliomen, geen - monichen, $7 y$ bleven dien macht daki compecten, en vonden hicr eens een, en ditar has nog twee hutjens; dic meeft onder de woet lighen, zynde in zich zelve -nog thegrer, als dic der Hoctentotten, van geboliw.

Den 6 den dito verdeclden $2 y$ zich, en trokken in drie byzondere troepen, de eene $Z$., ve andere $N$, en de derde $\mathrm{O}$. op, I myl tandwatrd in ; doch quamen datr na by dic binnenwatet; om yder zyne bevinding op te geven ; weder by ectn ; dochl hadden niets dar i of 2 verwalle hutjeis, doch geen verfch water, dat hes meelt ontbrik, gezien; weshalven $x y$ een kuil by dit binnenwater grotwen, watr in zy redelyk goed water vonden, way mede zy zich in die groote hite, die ay hier gevolden, belielpen moeften. Zy vernatien by fume wederkomft ook, dat dit binnenwater wel I voet was gewallen, een tecken dat her eTgens in zee' $z y^{\prime}$ uistoge, of gemeenfchap hebben moeft.

Zy vonden deze uirwatring ool kort "er hat wat Bezuiden 't zelve. Twee wen hune fichuiten voetcn dit uirwaterend $Z$ wate gat in, en vonden daar eerft 2 , en dant Zwader, nth nog theer zwate zwannen, van welke $z y$ 'ct 4 ma Bativin medegenomen, en 2 er levend gebrage hebben, als ook veel vifch, zonder toe nog toe eenig ongedierte, klein of groot, te vernemen, blywende dre nache nog ats de wat, en gingen den $7^{\text {den }}$ dito weer rita boord, zeilinde dien zelven dig, ende andere fcheepjens ook op den ioden dito nader ma de wal toe, daar zy weer ten anker quimen. Zy peildien ook "t eiland Rottethett $\mathrm{Z}$, en eto de riwier $\mathrm{Z}, 0$. ten $\mathrm{O}$. van hen, wellie de Plaming na de middag met 3 lchuiten, om te zien, of lyy geen mentchen darer ondekken zoude, opvoer. Zy vingen hier fpiering met den hoel, doch werbumen anders nict, fchoon zy dit binnenwater, of die zoute riwier, wel ro of 12 mylen op geweeft waren. $\mathrm{Zy}$ bevonden hier klaar op de Z breedte van jt grasden 43 min, te zyn, zy ontdekten hicr ook een rif van $\mathrm{r}$ myl, leggende I halve myl wan de wal, en verzeilden den $\mathrm{I}_{3}^{\text {dea dito }}$ van hier, zendende, terwyl zy net een $Z$. en Z. Z. W. wind N. ten W. langs de wal zeilden, de fehuiten an ondin cens na de zelwe; doch kregen den $15^{d n}$ de wind O. Z. O. en 
$0 . \operatorname{ten} \mathrm{Z}$, die din cens weet van het $\mathrm{Z}$. O. door 'e N. na 't W: liep. Ondertusfehen quamen de fohuiten weder ajn boord, mex tyding wan gecn mentchen, nog vec, en zeer weinig fetoonte; als mede een ftcene rif ontren it 't flmud met vecl klippen onder en boven a water op 30 granden i mia. vernomen te hebben, gelyk alle de ichepen ook den 16 $16^{\text {bes }}$ dico s nachts weel rusten ah lind gezien hidden.

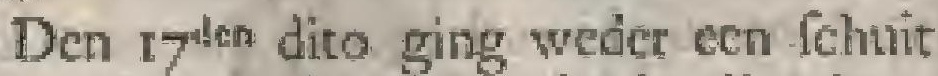
met gewarpend volk ann laud, dic nicts, dat eenige meewwen vitn de buiten- $\mathrm{cl}$ landjens en klispen, an boord bagten.

Den 18 den dito beronden, by een peiling, de N. W: niswyzing hier 9 gratader 21 min. (op de Z brendie vin 30 graden ' 30 min. ) te $\% y n$.

Den $20^{\text {then }}$ dico zagen zy eenige eilandekens, cn ant de will wite kreupelbofch.

Den $23^{\text {then }}$ dito op 28 ginaden 8 mim. peilden zy een fleilen hoogen. hoek yoor tuit, zonden de lehuir hier weder nal land, die tyding buagt hicr menclien gezien te foth ge- hebben, boch konden, wegens de fwate ricn. ftorting niet an de wal komens ziende ondertuficheri de menfichen op de dumen woor hen, doch wry verre war zich, hecnen loopen.

Deze waren mint van een gencene lengte, fwart con nalat wan huid.

Kort darr na de tchuit egtes ann land gerankt zynde, zagen $z y$ dati ook een zeer zout binnenwiter, et der $27^{\text {tken }}$ eerige hutjens, ook voet thippen wan menfehen, en eenig gevogelte matriden niets, dat woedzel geven kon, vernomen, dan alleen ecen plants darr (by nood) tedelyk drinkwiter, hoewel al te vere on naboord te brengen, whs. Al 't geboomte, dat hen bier ook ontmoete, whis mar kreupelbofch.

Deu $30^{\text {ffen }}$ dito zonden $z y$ de fchuiten na de wal, die dar 2 inhammen, watr wan "t Znidelykite we drie vierde myl wyd is, ontdekren, die ry bevonden op 26 granden If min. te leggen.

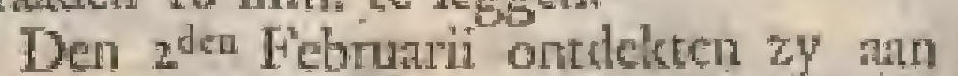
de wal 2 rivieren, tran welke de ecne van ' $Z$ Zuiden, cn de andere $O$. an zeer diep inliep. Ook waren zy eenen inham wel 8: inyl op geweett, en hadden bevonden, dat die inham in ' $N$. N. W. weer in zee ftortte.

Den $3^{\text {ter }}$ dito wer an land geweet zynde, bragen $x y$ nier alleen dit liarfte berige, mair voegden 'cr nog by, dne de opperiturrman wan de Gedvink otn platgeklopte tinnefchotel op de arde had vinden leggen, die met twee frykers thu ecn pallge valtgelpykert geweelt, en

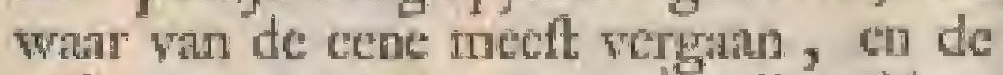
ander nog kenbenr was, op welken lchotel zy dit gefneden vonden.

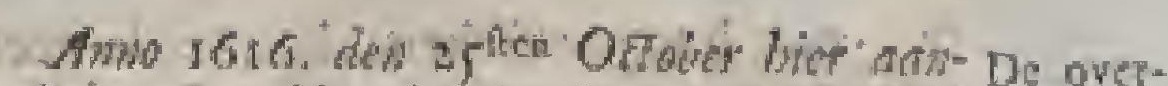

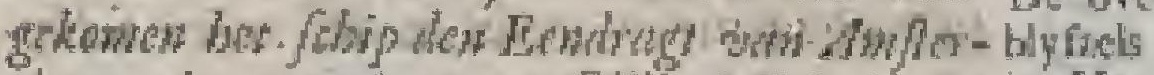
dam, den opperhoopshan Gillis Miebais vay in Har-

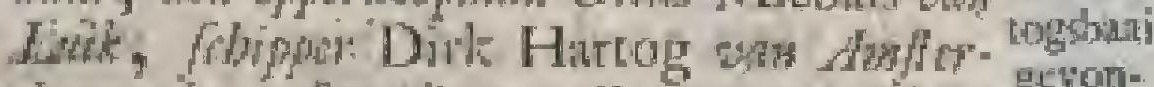

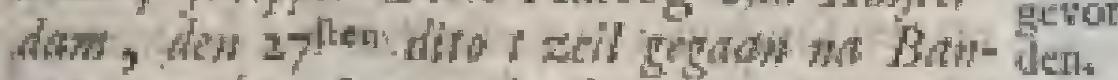
tam; $\mathrm{cr}$ wis het onderfte (roo mien niet anders zien kon ) met on mes aldus gefneden: Deionherkotpmon Jau Srins, de ghtherfhuwhan Pieter Dookus wan' Bily? AG. 1616 .

- Deze regte reede van Dirl Rhror batai (dant dic fichorel opgeregt geweelt wis) las op 25 graden 24 min, , data zy fht ook de N. W. miswyzing by een klatte pciling beronden 8 graden 34 min. to zym.

Den fien Februari woeren zw na de wal, hebbende zich woor 8 dagen wirp kaft en drank woonzien, te weren de comimandeur $V$ lawing net zyn folutit, ende bivelhebber van de Hoeker de Nyptang met de zyner, en fonden hict eca eiland.

Zy quamen ook in een rivier, die $7 y$ wel ; of 4 mylen opvoeren; wol lteenplatiten, en droogen, en zagon verder veel binnenwaters als vin wertronken land, matr geen menfehen, nog fers, dat voedzel geren kon; ook was te grond, wata zy ook grodren, zeir zilcig.

i Ly quamen tegen den arond nog in een andere rivier, die zy opvoeren, alzoo zy wel drie tiorde nol t ind inliep, en ditis een ronde kon, wwar by zy eindtgde, makite; doch altes wers tnatr zout water; en men rag geen menfchen nog becten, muta wel ecnige reluwe duikes; ook kregen zy' hot 'cr" na (wararen donder, werliche en een harde regenbut, die wel 2 uulen duurde, zoo dint $7 y$ den nache vry nege doorbmgten. Ook zifgen 2y. bicti foot nog stis.

- Den $10^{\text {den }}$ zeikten $z N$ deze rivier weer af, enontekten by cenige groote plaften van binnewateren woer cenige poettappen van volwafliche mentchen, cn van kinderen, dievan een gemeene lengte waten, en bevonden verder dezen hoek, welken zy hier ancmoten, zeer rool zathu te zivi.

Den I $2^{\text {ilen }}$ dico bevonden $z y$ de $N$. W. miswyzing 7 graten 25 min., en zagen

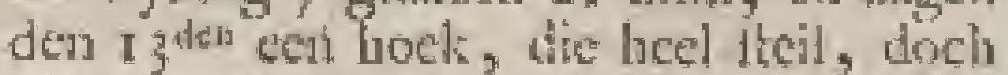
nict zeer hoog wits, alwar ook 3 klippen N. N.O. wat de wal thekteit, dic met reven an ecir gehegt waren; on de wal liep lier $Z$. $\operatorname{ten} O$. cn $N$. ten $W$, zynude mu op 24 gritiden 42 min.

Den I $6^{4}$ dito quimen $2 y$ onder de $O$. wal, en peilden den $Z$. hoek (dic $z y$ omliepen) $L . W$. wan hen, ctu zagen dir dir een cilind wis, zyrde an op de 7. bredtec van af gonden 54 mitn.

Den 17 den dito vergoeden $2 y$, op 43 graten go min, de lsonpulten van f 


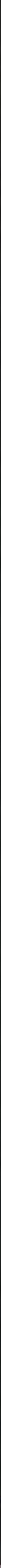


B

A

N

D

A.

$7 \mathrm{r}$

granden N.W. an zagen 2 mylen Bczuiden deze brecte een imbogt met een fchorre Z. hoek, en Benonden dic brecdie

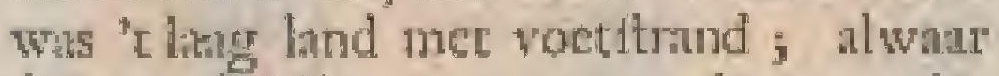
de itvondptiling van 7 gritiden 3 min. N. W. mistuyzing was.

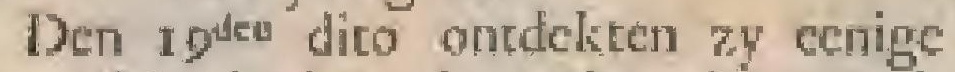
reven dije viende myl wan de wal, en ook een hook, wan welkeen sit een hatwe myl werre in zec N. N. W, an frekte, en Benoorden de zclwe was een imbogt, alwatar de Geclvink ten-anker quam, en wat werder zagen de zandcre fehcepjens, voortzcilende beneden dezen hock een opening, als een yivier, en die wel 3 mylen voor aan in de mond wyd was. $2 / Y$ zeilden "er wel in, doch vonden nergens nokergrond; en kregen tegen den noond wecrliche, en in de wind. Deze inhogt

willems- word Willems - rivier genaant, in wellic rivier. alle de fchepen naderhand nog ten anker quamen. Zy legt op $2 \mathrm{t}$ graden $28 \mathrm{~min}$.

Op deten zelven dag befloot men ook

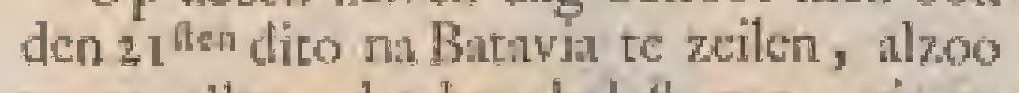
7y nut alles, dat hen belaft was, uitgevoert hadden; war op zy dan ook op dien dag de anlices ligten, en derwarts voortgereilt zyn.

Deri 2-iten dito makte de Geclvink wan hum af, en bewonden den $2^{\text {den Malat }} 4$ graten 23 min. N.W. miswyzing, en, by cen awondpeiling, madr 3 granden 33 min. N. W. miswyring; dic zy den fou dito bevonden op 5 ghanden if min. te 2yn.

Den zelsendag zagen zy 't ciland Moni Moni, op g gratudén go min. en den $\sigma^{\text {den }}$ dito was de N. W. miswyzing 4 grader 40 min., den gden dito 4 grikden 20 min., den toden 3 graden it miu., doch den I I tem op 3 graden $4 \mathrm{r}$ min., en quamen, zisende nog dien dag het land var Jiva, kort "er man behouden op Batavia.

Zy hebben hier en daut an land eerige twerdece crweten, gerft, en moftalatcand in gocwertige enden grond gezatid, en op zekeren dag gerien. ook I wezeltje en 2 gratuwe bazzen, ent cenige bostotten, als ook eenige pilandoks. (doch langer van pooten, dan de gencene, en fwat zynde) op dit land De cilat- getangen.

den St. Ook vertoonen wy hicr nevens de Panlo en cilatiden Amftedtim en Sr. Paulo, 200 dam, be-tls zich dic uicerlyk opdoen, mitsgaders natvens dic dien inlyam, datar zy dic fwarte wilde Swaner- fwanen gevingen hebben, met de lester" Zuidland, D. gemerkt.

afgetecth. De lantfe togt (myns wetens) 17i Paitys e $Z$. land gedasu, is op de rand win on woorltel Switzer, $\rho$. Purvy getchied, aa dat hy

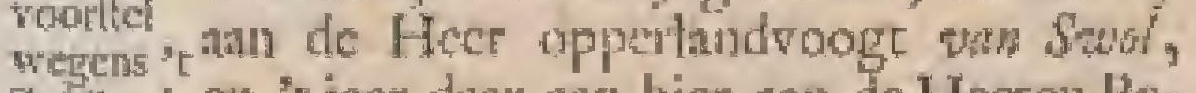

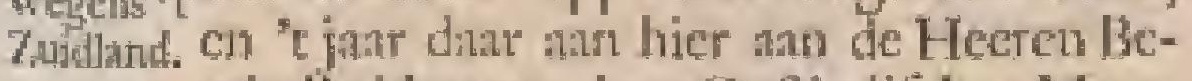
wiadhebberes der Ooftindifche Maatfcluppy, te vergecfs zynen diente angeboden had:
Hy wits wn oorded, dat men geet heerlyker land, on "er een wolkphiknting met weel voordecl te maken, woor d'E. Maticliappy ergers in Iindich, dou op 't Zuidland, ter plats datr 't hand wan $P$. Nuys legt, dat zich of 32 graden vertoone) yinden kon, en dat bnze Mantfehappy zich dar om verteneide redenen, die thy in cen boekje gecft, behoorde neder te zettent.

De Hecr won Swol wecs bem in "t latelt wath zyn leven met deze flelling, dat de E. Matichappy rects land te veel bad; af, en de Hecren Bewimdhebberen alhier zeiden iegen hem, radat by tot Amfterdan verlehencu wis, dat zynen voorllatg hen nict behaigde.

Diat ma heefe hy zich na de Hecnen Bewindhebberen der Wentindifche Matichappy begeren, cn die hebben Togt wata goedgevonden in "t jaar 172 I. dric de Hest ichepen, Thienhowen en den Arend ge- Roggenaamt, en cen Hocker, met de ken derHecr en Mr. Jacob Regresues, gewezen Rath fin Jufticic op Banyia (dic in 't jiat 17lat. na Holland vertrok) als Hoofd dezer enderneming, derwats te zenden, weltse cen gehel andere togt is, on de Z. wel tot 66 graden ondernoกาำ.

De hocker is op die togt gebleven, en zyo die 2 fehepen incen zeer clendige itate (zoo my gefchrewen is) den rodeu Seprember 1722 . voor Japara ten anker gekomen, dali na op de reede wan Butavia gcbsugt, en dan verder", 'L zy by anhating, of op een andere wyze, gebleven; gelyk ook de Heer Rugeven, en vecl hindere vat deze a felyepen, in "1 jat 1723 . met onze Ooftindifche wloot hicr weder angeiand zyn; doch nuderhand heb ik werftan, en ook cenigzins gezien, dac dcre togt door zWn E. en te gelyk doon fohipper Jath Kofter, woonende te Delfhawen, niet (Belyk ik in "tectrt meinde) ma " $\mathrm{t} Z$ unidland; mitit alleen ondersomen is, om nas zekere cilnuten, de gond-ciliunden gemuant, ch op jo graden Z. bredte gelegen, te zeilen, en dic op we zocken; marar die $z y$ (choon $z y$ nog wel rogralden vouder dut lan beltek of latt was, gereile bebben ) vice bebben kotmen vinden+ Ile meine dat devader vath de Heer Rogieven mede cens datu op tit-, hocwel hy chen ongeluktig, gewedt is wata dic niec te vinden. of die nu de zelwe goud en zilwer exlanden zyn, die (zon men wil) Beooften Japin leggen, can watar - ma coc has' Edelheden in ' $\mathrm{E}$ jiar 1643. fchipper Henrile Schato, en den onderkopunas Whow Byeded, met bet jage Breskens en Caftrikom gezonden heloben, en die te Nambo net hun twatwen geringen rakkten, weet ik niet; hocwel "t my reer watrichynelyk wool-

koinc. 


\section{2 B $\quad \mathrm{A} \quad \mathrm{N} \quad \mathrm{D}$}

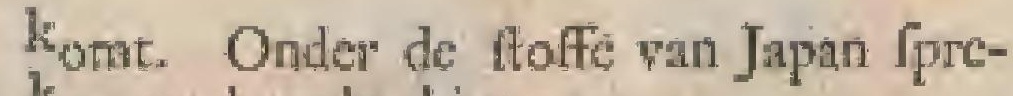
$k_{e n}$ wy breeder hier wan.

Ook heeft de Heer General Browerer zyneo wervanger iten Heer suin Diewen, by een brief, die zyn Edchcid wan de Kasp an zyn Ed. fehreef, al gevanden; om een togt na dezc goude eilanden, of wel nat ' $t$ goud en zilver eiland (7,00 by 't in zyn brief noemde) te lastetr doen, en was zyn raad, dat men dien toge den I fen Mey nict uit Japan, molar van Batavia beginnen, en dan verder Benoorden Borneo, Celebes, de Moluccos, de kuft van Moro, of Benoorden Gatnmacanorte, en zoo verder bovens winds in de Z. zee loopen, en dan om de N. Ateken, by ma zoo gelyk de Aquapulco's - vanders noen, on Beooften Japan de N. Weite winden te zoeken ; maar boe verTe doch oir de Hollanders by hunne vasten in "t Ooften geweeft zyn, noit is geen van hen zoo verre aldati, , dan de voornoende fehipper Kofler by dezen rogt, gezeilt. En daar alle, die derwatrts bevoorens gevatren hebben, wegens fware ftomen cn onweder, hunne reizen ftakkten, en wederleeren moeften, werlkharen dezc vrienden over al 't fchoonite weder van de wereld gehad te hebben, zoo ditl $z y$ een beter faifoen, dan de andere, moeten hebben waantgenomen.

Hoedanig nu dit Zuidland in opzigt van Banda, en de Aroe geftrelit legt, kan men al mede in dit kaartje van de Z. 0 . en Z. W. cilanden (hocwel matp thuks wyze voor zoo verre dir zig ruffchen de II en 12 granden vertoont) zien.

Wy geten in dit werk, op een andere plaats, nog ecuig berigt van groote meenfehen, cn reuzen, op "E Zuidland gevonden, door cen Ambons vryborger, die op 't Zuidland vervicl, en door cen ituurman, die zulk een genamte ma Batavia. van datr voerde, en die my dat beide zelf verbaale hebben; 't geen wy daarom hier niet berhalen.

Nu hebben wy hier nog by te woegen, dat zich ontrent 34 mylen Beooften Rarakit, of den O. hoek van Ceram, ecn groot ftulk lands, O. cn W. Atrekkende, Poclo groot $\mathrm{Co}$ genaamt, opdoct, ten W. With "t welke een klein eilandje legt, en ten $O$. vars welk cilandje $t$ of 2 mylen

\section{$\begin{array}{lllll}A & S & C & H & E\end{array}$}

zich nog 3 kleiner in en drieffrong, digt by de wal, pas Bezuideri de zelve, by een groote basi van $f$ of $a$ mylen in 't rond, chl stan des zelfs W. hock opdoen; gelyk men and des zelfș $O$. hưok nog cen gronter eilandje leggen ziet.

Twee mylen Oofielyker ziet men nog 2 zecr Heine en binnen de 5 mylen 0 . op digt lasigs de wal "er nog 7 leggen, van welke cerft I grooter, dap weer I kleipder, daur an weer a grooter eilanceeikens i myl waus cen, en dan nog 3 zeer kieme ontmoet, die voor een baaiken, meefl. Z. en N. I myl van een, geftrekt liwgen.

Ten Z. O. van den $O$. hoek wan dit Prelo groot Co legt een eiland, het Weacis eiland (een ander dan watr wan wy bevourens. (pruken) gentemat, dat ontrent $r$ mylen lang, en meeft 2 of 24 myl breed, hoewel het in ' $\mathrm{X} . \mathrm{O} 0 . \mathrm{nog}$ wel zoo breed is, en met cen huek oa 't N,O nitloepr.

In 's N. N. O, wan 'r zelwe leggen 3 kleine eilandjes dige by een met eer nifje an de Z. kant, en in ' $k$ W. Z. W , is nog I klein cilinatje dige by de wal, en I myl van des zelfs $Z$. hoek lege her yogelciland, dat meeft $\mathrm{N}$, ten $W$, to $Z$. ren O. geftrekt legt, en pas s nyyl in 't wond is, hebbende ann de Z. kam een rif, dat zich wel I myl rerre in zec Arekt. Waar mede wy dau, en van de befchryving war die Z. O. en Z. Wefter - eilanden, mitsgnders wan 't gene wy wegens het $Z$. land te zeggen hadden, affcheiden ; zyude het ons genoeg het weorInaninfte atugehaalt, co datr by, als met de vinger, anngewezen te hebben, dat die landen yan tyd tot tyd door deze en gene byzondere perfoonen by flukken en brokken (gelyk zy nog zoo manr belkens, itan) ontelekt xyn, tor welke ontdekkingen gelyk ook die van Nicuw Holland of Nova Guinea (een ftreek lands, die meer dan soo mylen, wan den so tot den 33 gralad Z. breedte beflaat) wy meelt aan Frelcrit Fontman, an dic van

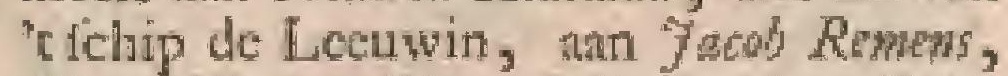
Pieter Novis, Pieter de Carpentier, Frassgois Pelfart, Antoni wan Diemen, en neer andere (buiten de bevootens reets van ons gemelde) verpligt en fehuldig zyth.

\section{$\mathrm{V}$ Y F D E H O O F D S T U K.}

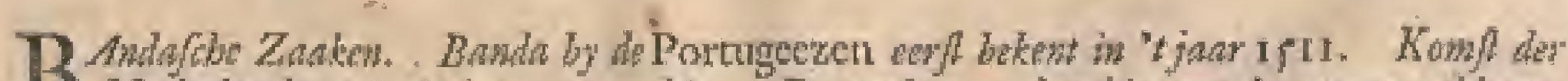

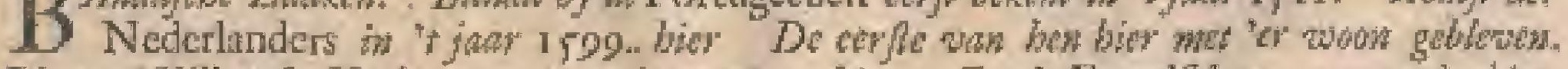

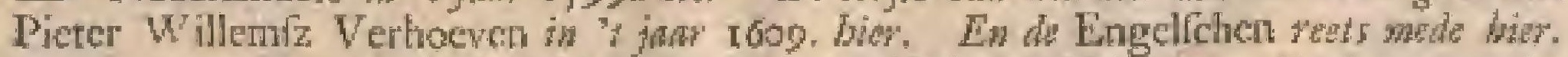

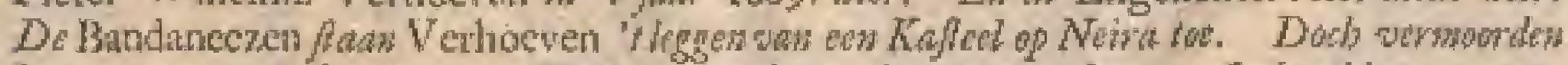

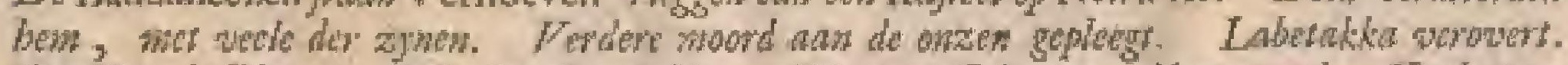

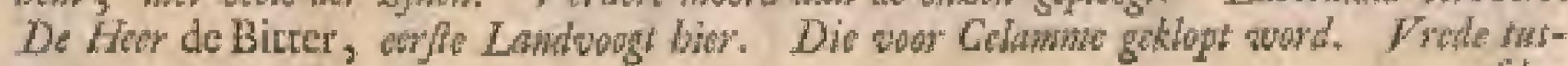




\section{Z A A K E N.}

folen de Bandaneezen en ons. Dood des Londvougts. Henrik watn Bergel revede Landwoogt. De srede tromoloos door de Bandaneezen gebroken. De Her Reynft 1615 . in

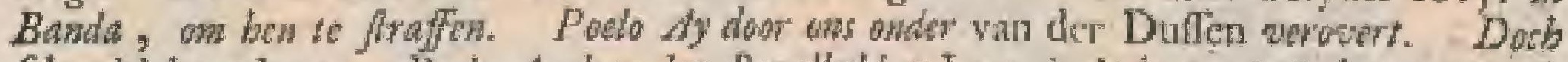

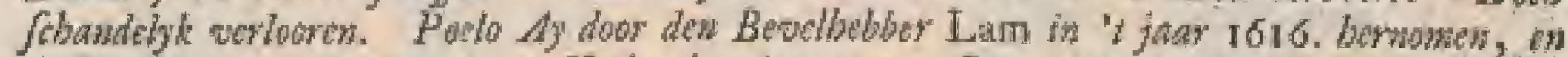
de Bandancezen tot en niense Verbond gedwangen. Dat ay soeder breken. Lomboin in

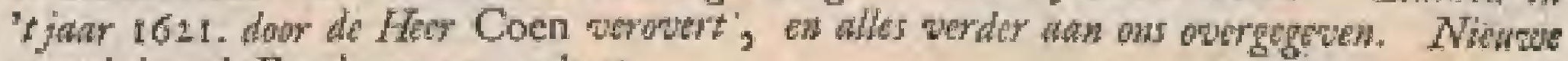
nooord door de Bandaneezen geplezgt.

Bandafehe
kehl
$\mathrm{N}$

A dat wy bevorens de eilanden van Banda, en 't verdere, daar' ontrent anntnerkenswatardig, befehreven hebben; zoo zal het nu niet ongevocgelyk $z y n$, dat wy beginnen nat te fpeuren, wanneer bet zelve aan de Europeërs begon bekent te worden, en wie het ecrit ontdekt heeft; ook walnnoer, en op wat Mre, de Nederlanders het verovert hebben.

By de Ouden vind ilk daur niets wan, en fchoon zy cenige kennis wan de Nootenmurchat, of van de Foelie, gehad hebben, wiften zy egter niets wan " $\mathrm{Eland}$ daar zy vicl.

Onder den Molukzen konting Marbboen $x y n$ in 't jaar $146 \%$. wel wericheide Bandancezen in Ternate geweelt, gelyk die eilanden ook wel van cenige Oofterze volken bevaasen wierden; doch wan de Banda by hedendiagze Europeèrs komen ons als de de Portu- oudite volken, die de Bandafche eilanden eerth be-gekend heblien, de Portugeezen woos: kent in In die tyden wierden de Bandancezen nog "s jaas door koningen beftierd, om 't welke te bewyzen, wy maarde 24 Alkit/a of hiltorie van den Hitoečchen fchrywer Ridjali hebben na te lezcn, die daat in zegt dat de koning vian Rolingein met een yloot der Bandaneezen mede na Hitoe ģuam.

In 't jant I ro6. zie ils, dat de Ridder Ludobyt di Baythema, een Italiaan wain Bononien, hier geweeft zy, die ecthter zoo belachelyk van Banda fchryft, dait men zou moeten oordeelen, dat hy deze cilanden noit gezien had.

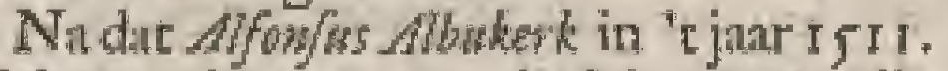
Malacer ingenomen had, zour dic groote man Antoni Abrews in December mer drie fchepen nate Oolt, ons de Moluccos te gaan ontelelket.

Gelyk uu by dezen togt wan hem werFcheide plaatzen anrigednan wierden, alzoo gierde hy in den beginne des jaars if $\mathrm{f} 2$. ook de cilanden van Banda allereerft atur, de roem hebbende van die 'tecrtt ontdeler te hebben, alzoo 'er (myns wetens) voor hem noit cenig Europecer, dan de voor noemde di Barbewa, geweett is.

Hy malkte te dier tyd een verbond met de Bandaneezen, rigtte op 't ftrand (wanrehynclyk van Coinbir, datar zy hun verblyf hadden) een ftecne zuil op, met de wapenen van lening Emantrl, en de tyd wan zyn komitt aldatar, daar op uitgehouwen, nani cen lading Nooten muskaten in, en zéilde, belet doot fware ftormen on de Moluccos in dat 1522 , jaar te konnen bezcilen, weet na Malacca, by zich hebbende Tranfoir Serratan, die, dic van hem afgedwalt zynde, ondertufichen gelegenheid kreg om zeer gevallig Amboina te ontdelketr.

$\mathrm{Na}$ dezen ceriten ontdekler van Banda blylst my nergens, dat de Porrugeczen hier in etcelyke jaaren weet quamen.

De naften an hem waren Garkas Hewrik, en ANtomi Brit, welke latite als eerfte Landroogt na de Moluccos gande, en in 't jaar 1522. in 't einde van Februarii hicr angierende, dezen Garfas themik, die pas voor hem van Grefic, op 'ecihnd Java, vertrokken was, al ten anker leggen vond.

In dezein tyd, wanneet de Molaceos en ook Amboina, twee tchoone landvongdyen, ecrit door de Portugeezen ontdekr warén, lag hen ook zeei veel atan Banda, als cen land, darr zy zedert zcer ved plagten aan te giereil, gelegen; " $\mathrm{g}$ geen Brir ook bewoog, of hier voor zyil veitrek mede cen zuil op te rigten dat egter zoo gemaklkclyk, als mer die eerife (die my toefehynt door de Banda* ncezen om werre gehaalt, en 'er toen niet meer gewcelt te zyn) geenzins toeging: wint de Bandaneczen, zich hier tegen, met hevige woórden, en daar na mer distdelylkheden aankantende; wilden dit in 't eerit ganfch niet toeftaun, maar naderhand, overreed zynde, dat 'er die met een heel ander oogmerk, : als $\mathrm{zy}$ zich verbeeld hadden, gezet wicrd, hébben zy het eindelyk toegelate.

Hy vertrok in Mey van dar met een wloot van 7 fchepen na Ternate, en in dat zelve jasu verfelicenen ook eenige Bandaneczen aldaar om nagelen in te kotopen.

Na dezen tyd fchymen de Portugeezen zich hier in Banda als kooplieden, die daar een wafte verblyfplats hindden?, opgehouden te hebben, te meer, dewyl ik zie, dat Martyn Alfonfo de Melo in 'i jaur 1524. wan daar 2 jonken na Termate zont, om Antoni Brit, met Alwanfor, kaning van Tidore, in ourlog zynde, te onderlicunen.

Ook gierde in "t jaat If 25 . Garjass Hewrik, vervanger van Awoni Brit in de Moluccos, hier an, dic Marty Alfonilo de Mrlo, van Brit na Malaklia gezonden, doch hier angeloopen, mee de Bandaneczen in oorlog vond, weshalven hy, zich by hicm roegende; hen tot zyn on-

II I. DEEL 

quet fuiur nog entigen tyd, en kon hict voor de inatud Mey na Ternate vertickken.

In "t jaar I s"26. zie ik, dat Garfas Hon rik, de tweede landvoogt der Molucecos, Martys Correa om ontzet ma Banda zont, alwat hy, na vecl thorm gekomen zyn* de, Awtogi Brit nog vont, en ook $\mathrm{Ma}$ wiel Fancon, zeker hootdman, daar met cenige waaren wan Makaklat, ten anker komen zag.

In 't hatit wan "t jutr 1528 . quan Gosfalvo D'sizevodo, een vermand Portugeefch hoofdman, hicr wan Malakka over Java ook aan, om den landvoogt der Moluccos, Menefes, te helpen. Hy wont hier nog Gayfias Elemik, den woorigen landvooge, en kotr daat na quam her vit Ternate Vincem de. Fonsead, met alle de ftukken en bevyzen ten latten van Garfos 'Henrits, wellects vatroig darom wan Gonflowo D', Azevedo genomen wiert:

In "t jar i 520 . zond de landwoogt $M e$ nefes ecnen Georga de Caltro na Banda om volk, en andere behotfen; doch te wergeefs.

Daar zyo 'er, die meinen, dat Banda onder den Portugeefchen Landwoogt der Moluecos al zedert 't jaar ifz5. en zoo vervolgeris, geftan zou hebben; doch dat is my al zoo weinig gebleken, als dat, Wolgens "t voorgever wan zommige, de komingen der Moluccos ook over deze cllanden geheer fcht zouden hebben. Beide deze zankenzyn zonder eenige de minfte grond verdigt; en hoewel de Iefuit 7 os -

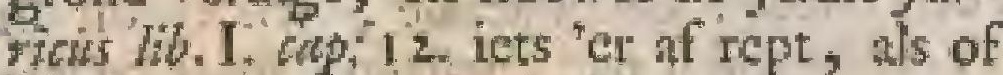
Banda wel eer onder de Moluccos geftan zou hebben, gaat dit by uxy in "c miniten riset door.

De Portugetzen hebben fier nu en dan allecn gebandelt, en wel een fortres, miar, woor zoo verte ik wecte, geen oppermat gehd, ook phaten zy hier wel oni te ververfchen, en water te halen, aan te giercin, cn ontrent Combir, en Orontattc (by Oforins Dalustatan genaant) gemeenely ks ten anker to komen. Een blyk hier af 15 , nog lang dar na geweett een overblyfzel van een Portugeefehe krank, hiter ontrét gewonder , buiten het welke men boven klein Walingen cen ouder gederklteen ontdekt heeft, dien de Heer Bioswanger, tocn liy zoder it jaar r7oo. bezitice van dat Perk was, wat ander tan ftrand heef lateen brengen, en datr na doen zuweren yan de atide en vuiligheid, war mode die bedekt was. Men vond 'er wel letters op, doch die onlesbar, en niet wel te onderfcheiden waren, hoewel men dit foor

een gedenkiteen der Porraygeczen gehou- 199 den hedt. It heb cgter yeman gelproInen, die my naderhind zeide, dasir op uifgedrukt gerien te hebben, dat zeker Porkugecs overte wan een vloot dar begravel geweett wats.

Het is ook zoo verte fan dant, dat de Portugeczen meetters valn deze eilinden geweelt zonden hebibes, dat zy zelf niet cens (volgens een bricf der Hoeren xvu. wan den $23^{\text {then }}$ Otober i623.) wilten, hoe vect de retve in getal geweet $n$, gelyk uit de angehalde platats van 7 arrices, ecn wan hunac bette feliny ves over de Indifche zaken, te zien is, daar hy zegt, dat "er f waren; "t geen, met one voorige belchrywing vergleten, zynde, bevonden zal worden een gropte mistag te zyn.

Hoe lang 2 hier naderhand zich nog ophiclden, blykt my niet; doch "t is zeker, dat de Bandaneezen hen op zekeren tyd, om zich ower hune geweldenaryen te wrecken, eensfchielyk overyallen, en alle dood gelligen hebben, zoinder dat $z y$, dan lang nin tic tyd, hier weerander wolk hebben duiven zerden; hoewel "er dat In, en zele in onze tyd, wecr cengezyn gekomen.

Dit berigt van de zaaken der Portugeczen un Banda geeft ons zoo, wed liche nice vati deze landen, als wy wel uir de bedryven der Nederbanders aletar belomèn zullen.

Na dat de whkkerc zocheld, Jacob Gomelis qan Net, mec \& tehepen, war kom Ne mede by in "t jat 1 ros, uitvoer", in $\mathrm{No}$ - der $\mathrm{Ne}$ venber eerft met 3 . feheper voor Ban- ders in tam, en in de rolgende mand ook de 5 "t jat andere datr ter reede gekomen yaren, 590 . vertrok hy met 4 fehepen den I deng Jamuiri If po, weer ma hece vaderland; likitende zynen onderdectoogt, Wymand was Waroyk met de 4 andere, om de reize nu de Moluceos te ondernemel, dar hy den goen Jenuari; als roevooge onct de fchepen Amiterdim, Zeeland, Geldedand cil Utrecht, newens zynen onderacevoogt Jack wan flowskes, ook uitwoerde.

Hy quam met de zelve den 3 der Matt trop. in Amboint, van wair den of dru dce zelver mand 's namiddigg de lehepen Zeeland, en Gelderland, na Banda onder

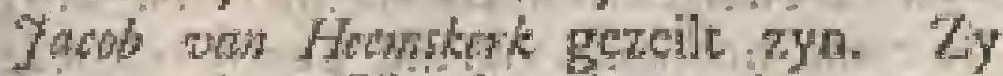

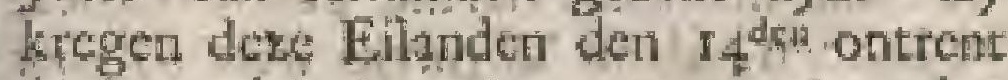
den avond in "s geaigt, quamen 's paches by Poelo Soewanggi, by lien Poelo Scithan, dat is, if D piwels ciland genatont. De loots die zy by zich hadden, had hen berige gegeven, dar niemant hice op durfe komen, on dat, nil hun voorgeFen, de Duirel hier woonde, warom $2 y$, hier ontrent komende, mar lus bett doen, om 'er voorby te geraken. Tendien eigde nam ook die loots ecr bootshank, 


\section{Z A A K $\quad$ E $N$.}

1509. en ging voor in "t fichip op de bak ftan, hatende dat eiland mee de hatk in fehyn als na hem toe, om 'cr dus te eer (zoo hy zich inbeelde) voorby te zyn. Als hy moede was, lag hy die wel neder, doch niemane moge dalu atrin matken, woor dat zy voorby waren. Indien het wat ftil wiert, fuitte en fchuiffelde dit manneken met zyoen mond, on de Duivel wan datr te lokken, en hem 'er als uit te fuiten.

Den is ${ }^{\text {den }}$ zagen zy de eilanden Rhun en $\mathrm{Ay}$, en quamen 's avonds op de ondinaine Reede wan Banda, tulfichen Neira en her Hoog Land, tein anker, alwar zy ten eerften werrcheide praukens met monfters van Nooten, Foeli en Nageler, an boord kregen.

Den If den dito qun "er een Sjahbandar (of tollenar) an bond, om met den onderzevooge over tol- en ankergeld te fpreken, "c welk ter wirde van 4 bhataren Foelie bedongen zynde, zoo is de Nederlanders hier niec alleen de handel, maar ook een huis, om hunne goederen te bergen, deor de Bandaneezen tocgeitaan, war na zy den $23^{\text {flen }}$ dito hun cerlte koopmanfchap in 't itedeken Oitattin, of Orontatte, and land gebrigt hebben.

Den 2 fiten dito voer Hermskerk na Neira, daar hy ook cen luis huurde, on de koopnanfehmpen in te bergen, thangezien datr meer trek en wertier der goederen, dan wel op Ortattan, was, om dit daar veel Javanuche kooplieden, die grooten handel dreven, woonden.

De verdere dagen van deze mand wienden by de onzen met koopen en verkoopen en 'x inladen wan Nooten en Foclie belteed; mant den ten April namen die van Neira hen han gewigt af, om dat $z y$, volgens 's lands yewoonte, "tordinair gefchenk an de Orangkaja "s nog niet gegeven, en dus buiten hun verlof datr gehandelt hadden. Dierhalwen zonden de onzen den Commies van 't fchip Zeeland na hen toe, on dic af te makiten, "t geen met een werceting van 60 ponden Foelic gedaan wiend. 2 y waren deze geheele mand, en een gedeelte wan de volgende, bezig met bunne witren, beftande neeft in kuttkleederets, fyit, porcelynen, fluweclen, damaften, amozynen, roode latenet, enz. tegen Nooten, Foclie en Nagelen, te verruilen, betalende woor een bahara Foelie, wegende 100 catei Banda, of $5+\mathrm{Hol}-$ landze ponden yder, 60 , voor cen bahara Nooten 6, en voor een bahara Nagelen $4 r^{\mathrm{R} d e r}$, tot 48 thivers yder.

Die wan Neira waren te dier tyd met die wan hee ftedeken Labetakka, op dit zelwe cilind tan de Noordkant gelegen, in oorlor, cen gerchil zedert cenige jarrell ontitatn, om dar dic van Laberalkka wel ecr verfcheide boomen in het gebied 1599. van dic wan Neira on verre gehate hadden.

Den fea Junj quamen die vatu Labetakka met 4 Coracom's op de Reede roor Nein, alwaar zy tegen hen cen richermutzeling begonnen, en eenigen gedood en gequetit hebbei.

Lit blecf niet lang ongewroken, alzoo die van Neita, Poclo Ay en Lonthoir, den $17^{\text {deu }}$ dito na Wiyer, een vin de Bondgenooten der Labetakkers, met vyf Coracora's, juilt op cen tyd, dat die wan Wayer te Labetakk waren, en "s nachits blywen moeften, gevaren zyn, watr door die van Neira gelegenheid hadden, om de neefter, die in her Aledeken nog gebleven waren, deerlyk te vermoorden; en aldus met weel koppen, wan een touw zamera gercgen, in zegenprital tha huis te keeren. Na dat $z y$ humen moed dus tan ecn meenigte Wayereczen gekoele hadden, rigtten $2 y$ nog een ander prociltuk vats wrecdlieid ann tegen een weertoos vrouw menfich, door hen als een lirygsgewangene mede gebrigt, krppende de zclve zeer onmenichelyk midden door, ẹn prono kende etelyke dagen ain een wel trots met hunne beblocie zabels, om te toos nen, hoe dapper zy zich in den ftryd tegen hume vyanden grdmagen hadden.

Not dis zy lang genoeg met deze of gekapte hoofden grepronkt hadden, wier. den die eindelyli an een fok goregen; voor 'c buis des Sjahbandars gebrage, en op eer groote iteen, Atande onder cen groote boom, niet zonder weel bygeloove ontrent die fteen, ten toon geftel, , en, na cen uur daar te pryk geltan te hebben, weer afgenomen, in een witwe kattoene doek gew onden, in cen fchotel gelegt, ter ande befteld, en over de zelwe, wol? gens hume wyze, veel wicraok gebrand.

Na dar de onderzectoogr Heowskork met de Orangliaji's wan Banda hee noodige aldatr verrigt, en den $2^{\text {den Juli alles }}$ De eerte met hen befproken had, heef hy. wan de wan hent zelve in wriendichap afleheid genomen en hicr mek 20 yan zyn rolk, met cenigo koopman- "er woon fehapen en geld, by de Bandaneezen ge- gebiexeth. laten, om ondertusfichen duar Foclie en Nooten, tegen dat 'er. weer lichepen uit Holland komen zouden., op te koopen. Deze heett by an de zelpe niet allecn zeer emoftig anibevolen; maar an deze Orangkaja's iook cenige frajigheden vereert, op dat zy hen te becen mogten handelen, gelyk zy belootden te doen. waar op by met zyn $z$ fehepen den 5 Iuli wan daar verzeilise, en in 't vaderland in April 1600 . angeland is.

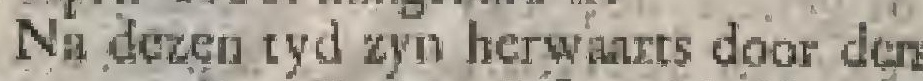
zecropgt Gormelis Matelif vericheide enkele fchepen, ats Delft, in Mart 1607 net den opperloopman Pawar oda Solt, 


\section{$\square 6$} B

$\AA$

165.

de Vetecnigde Provintien, Etastion, Cerfon, Tetwere, en meer undeteri, th t zelve jaur gezonden; matr geheel andere voorwhen hebter de onzen lier twee jaren diat ina gehidid.

De zecwoogt Puth Whews J trbot-

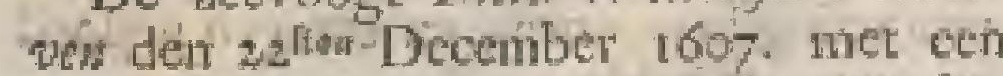
vloot wan 13 fehepen uitgezeilt, en den

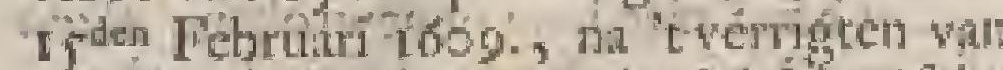
verlebeide zatken op de Malabititethe Fiut, ic Djahor, Arspicn, cur.., woor Binkin, met de fehepen Hollandia, Middelburg, de Geuniecte Prowintien, Dell, Rotterdim; Amfterdam, Hoorn, Zeesindia, 't jugt de Pilaw, esi en veroverde fiys gerehenen zynde, is hy met een getdecte wan deze ryloot (terwyl de onderzevoogt, a Fidhous What, met de . Eheperi Middelbutry , Amtlendun, de Pierer Pantw ende Hoope, nat de Moliceos

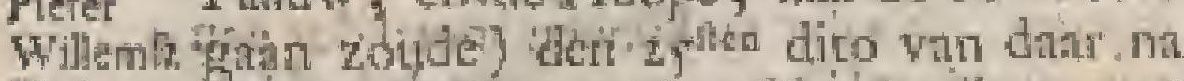

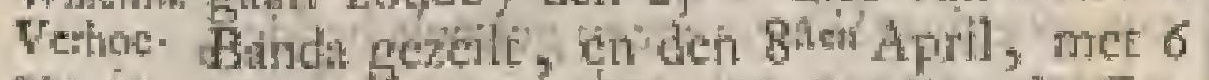
*en in feliepsn', te weter, Hollandia, ide Ge"togne uniterde Pronititici, Delf, Zeclandia, 'Rotterdam, Hoorn, voor Neirn ten anker gekomén, vindeive daat ook 3 fohepen Wan deji zecvongtwan Canden, to weteri, Binda, Pittant, en 't jagt do EenEn de drigt, newens een felip der Engelfechen, Engel- Hebtor 'genasnit, (dié er toch al begonSchen nert te kinent oj-de Reede' wrelk latifte alede bie Ichip deri onzdu in :e doopen der fpeceryeit wel nabidel ded, altoo zy yoor een

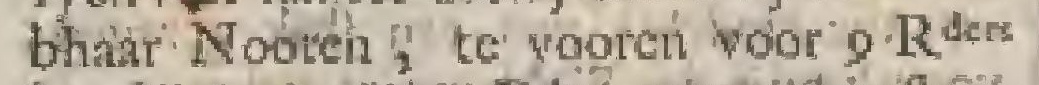

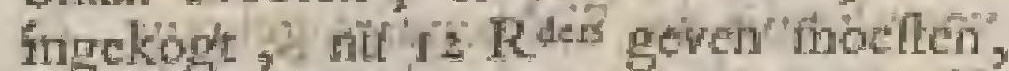
weslyalwen Fithoeven goedwond tegens de-

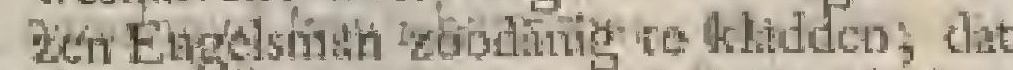
try hei onnogelyle tegen then gande kon houden! shotisy

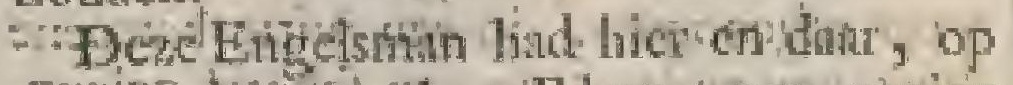

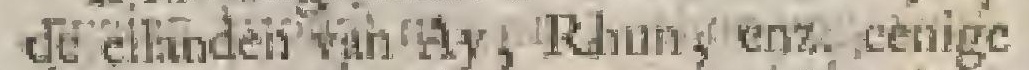
wan $z$ yin volk gelegt ; w wat wiert door

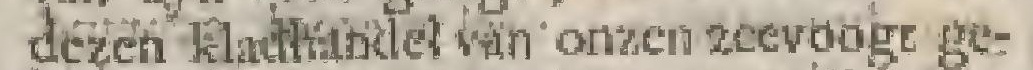

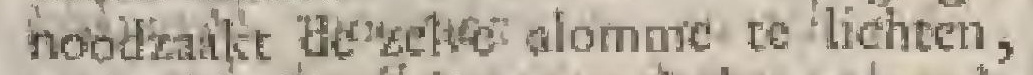
vetoedcenderw ters zyue luntpe tegen de

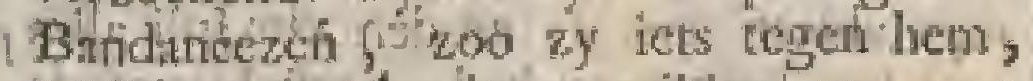
of Ac'zprist soghinnen wilden.

" De Bitidaneco kil buitengewoone zoo

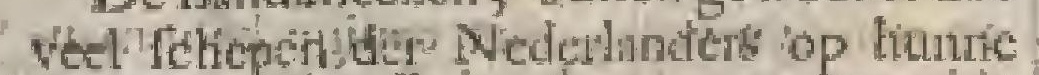
Redezieibes honden ten certen wel bertypen ' tobleg geftitede; en wambel: zy-by den

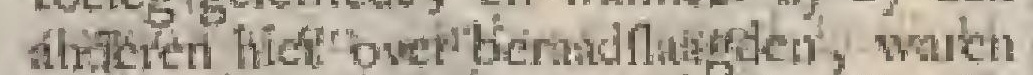
die wh Lorithoir than atwes, dnt dit geFehode of the cef hiven The Noin te

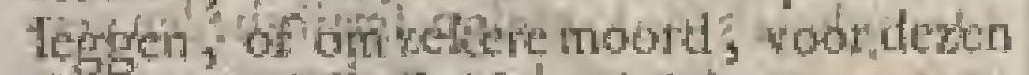

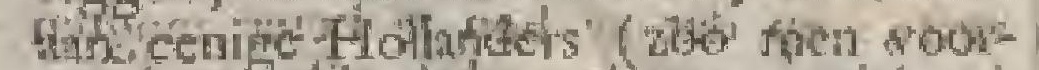

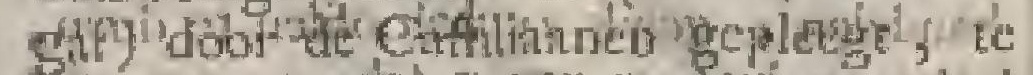

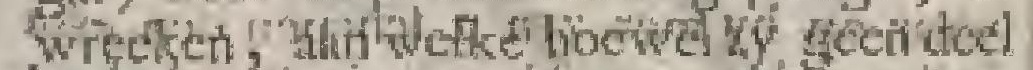
Widden' of gene, zyde? tzy-vin de Sphuthatiden,

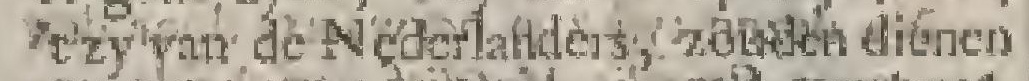

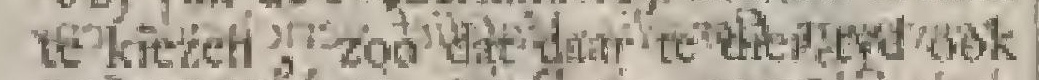

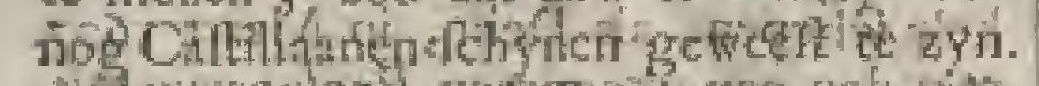

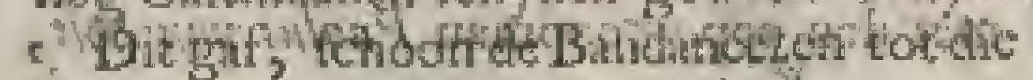
$+-$
A S C C H $\mathrm{H}$

tyd toe altyd in een zoer goed verftand I fogmet de Nederlanders, en, wolgens hunge eigene belentenis, in alle yriendfchap gelect hadden, onder hen geen kilene opfetudding, woo dat alle nacht mecr. als 2000 Batndaneczen rondom de Logie der Nederlanders watken, behahear dat hain heyloos voornemen, hen receds zoo vere gebrugt had, om wrowwen, kinderen, en gocderen', woor af nim "t gebergte te zenden, om diay mede, als liunnen atanlag tegen de Nedertuders cens uitbertten zok, nie belemmert ke zyn.

Terwyl dan $V_{\text {erbown bier ling, quam }}$ dęn $10^{\text {den }}$ April 't tehip de grotre Zon, en den $4^{\text {dem }}$ ook " $\mathrm{E}$ jagt den, trent, en de Volk met den koopman 7 abob de Bitter, wan' de kuft Clioromandel, hier. op de Reede.

Ondertuffehen maliten die ran Neira zich op de Z. Welthock yren 't eiland, acgen over do Gocnong hpi, ridar wel eur het Portugees kafted was, fterk, en 7ondun den i dera geranten natn den zeefoogt, met verontichuldiging, van dat $2 y$ zich met den andeten nog niet berandflange hadden, vermits huine bondgenooren, die zy tegens atultatide Woensdag verwagter, nog nies gekomen wivien, hoewel zy dit om geen andere roden roonwendden, dan on tyd te winneil, en zich ondertufichen nog fterker te matken, hoewel hutme veltingslens, ed paggers, vin weinig belang awith. - Zy wifter ook te zegen, dat zeker Dro, by hen als en Hoilig gewerd then woilzegr bad, dat in de latere tydeni cen wit solk mer veel fchepen by hen komen,

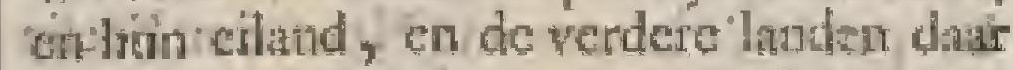
ontrent, vernitelteren zou, welke, tyd ay wredsiten nu gekonen, en dis dic varzegghis by hen kamit vervult te zayn; Whike tegen zy cgtes, zoo red mogelyk wils, matken owldum.

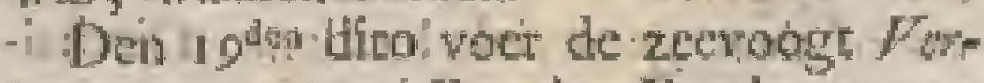
Woven met zy nen Breeden Rad y en aro Goldaren en Matrooien, ma Jonthoir', blwatery van alle de Ontrigkin's der tillanden wan Buda verwige wiete, on bieri het malken winn en katted op Neira te fprtan.

(") Wh dat hy inan land getreden wns, fteldehy eeritsymolk in ordre; en wien

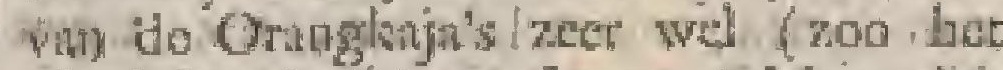
thitelyk gelecky iontfingen.. 'T Men ging daty op , volgons 's Lands wyze, ip cen

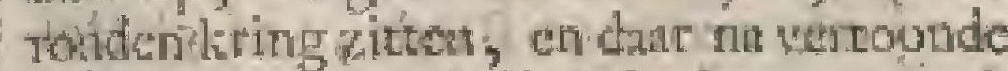
de zeevooge don waltbrief", hertwan zyh Howheis, dem Elecr Princen on ongie, en de' Hecren Bewindhebberen, tor he feggen rin ben latted op Neiril, mede-

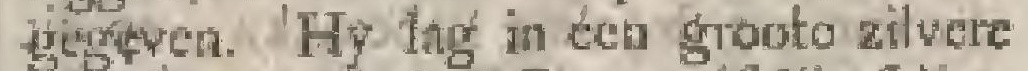

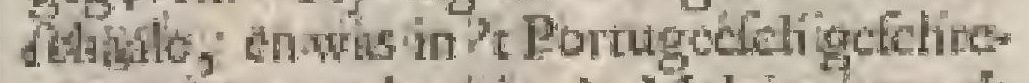

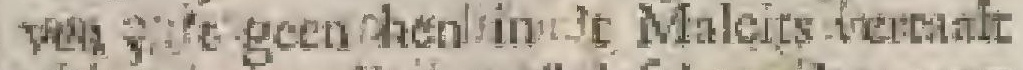
atherty mur dityobritel felecen hen zeet 



\section{$\begin{array}{lllll}78 & \text { B } & \text { A } & \text { N } & \text { D }\end{array}$}

3609

tel wereld vreezende, itond hun werzock gulherig toc, en ging met de Leden Wan zyon Rand zeer geruft en zonder geweer datr henen, latende zyn kirygssolk ter platze, dar zy in reijen en gelederen gefteli waren, blyvelt, te moer, alzoo zy belootden ook nonder geweer te komen; matr zoo mas hadden die fchelmen en verradderfiche Orangkajen hien dus, zonder eenig krygswolk, en zoo na by 't bolch, nict verromen, of $z y$ hebben hun geweer, dat met fteenen dara al wan 's nuchts te pooren bedekt lag, opgevat, en heis ten certten omcingeld.

De eerite van do Nedetlanders, die dit merkte, was eene 7 an de Brayn, die terftond riep, Hecr zecroogr, wy zүn verraden.

Doch Verbowendit mede, doch te lat, wervermot- nomen hebbende, riep ort zyn geweer, derihem, en volk ; doch dit woord wis naaulyks netvede uitgelproken, of had ook al 2 of 3 wonner ${ }^{2 y}=$ den, en wiert, nevens de meefte, die daur met hem gekomen waren, jammerlyk van die fchelmen vermoond.

De foldanten, die op 't itrand waren blywen ftam, een yfelvk gefchrecuw, dan cens van geweer, geweer, dan van moord, berwad, en manser belp, belp, hoorende, fchoten ten eerften wel toc, en bragten veel wan die fehelmen, tot den avond toe wegtende, ors hals; maar de meeften ontquimen het in 'c bofeh, en namer na zons ondergang de whyt na hunne valtigheden, die zy wan tyd tot tyd ontrens het tedeken Ratoe, daar digt by leggende, gemankt hadden.

Zoo ris men geen vyand meer vernam, ging men de dooden, ej gequetiten opzoeken. Men vont den zecroogt zonder hoofd, en met 29 wonden deerlyk atn zyn cinde gebragt.

Jakb van Grochergen, opperltompman op "r febip Delf, , was mede hoofdeloos, buten welken men ook $7 a w$ de $B r y$, Adraw Hevier, en nog 26 anderen, droevig vermoord fier en daur leggen wond, met welke ly ken de onzen, alzoo hier voor eerft niet anders te doen viel, weer na hum quarter trokken, dat zy dien nache wel bezitteden, om wity dic wermaders niet owervallen te worden.

Den $2 z^{\text {nen }}$ dico trokken de Nederlanders met vier compagnien foldaten door het eiliund, om turne verdere dooder alomme op te zocken.

Op "t trund gekomen zynde, vonden zy Tas de Molre, opperkospman op "t ichip de Geunieerde Provintien, en Niolnas de Vifher, hicwens twee joingens, en verfetherde anderen wan hun wolk, niet werre win dit itedeken Ratoe, mede vermoord leggen, die zy, om het fterk werpen net werplpiezen en liafigyen der Ban-

\section{A $\quad \mathrm{S} \quad \mathrm{C} \quad \mathrm{H} \quad \mathrm{E}$}

danezen, niet konden mede nemen, ge- $16 \% 9$. troodzaikt zynde met werlies win een foldath, die zich meetler wan dic lyken zogt te matacen, na hun quartier of te trekken, wry hadden hier 38 (of 200 andere willen 45) manen verlooren.

Men begroef den zeevoogt Frbown, Jatob wan Grocnewgen, en 7an de Broy, in een grat, voor hen in "t kafted Naflu gematkt, over welke, wolgens krygsnebruik, drie kanonlchooten van yder lchip, en drie chargien met musquettery, gcdaun wierden.

Men wont ook goed Simon Jay/e How, tot de woerkomft van den onderzecvoogt Franpois $W$ itrot, als zecwongt te er ketanen, enverfcheite andere veranderingen met ' $t$ mantellen vañ nieuwe bedienden te misken, onde opene plantzen op de rchepen, en in den Raad, te vervulleth.

Op dezen zelwen dag zonden die van Oroutate cen wan onze pofthouders, Woutrer wan den Endra genanis, tot de onzen op Neira, zich werontchuldigende vin an deze moord geen deel gehad te hebben. Dierhalwen verzogten zy met ons, gelyk bevoorens, in vrede re leven, belovende de onzen, die by hen wrets, tegen die van Neira te zullen befchermen.

Marr hoe onfchuldig zy waren, is uit een nadere boodfchap wan dezen wan des Exden, nog op dien zelven dag am de onzen op Neiat gedian, klat at te nemen, angezien $2 y$ lieten weten, dat de onzen her kafted andtonts atbreken, met hun krygswolk werrekken, en maar ecrige kooplieden, om met hen te handelen, en te koopmanfehapen, daur laten, of dat zy hen anders als vyanden mede anneatten, zich met de andere Bandanezen tegen hen vereenigen, en alle de Hollanders, op Orontatte, op Pocto Ay, en op Poelo Rhuin leggende, doodflan zouden, op at her welle de zeevooge $H_{0}$, met zy. nen breeden $\mathrm{R}$ and, geen snder antwoord gaf, din dat zv nier genegen waren zulks te doen, ecin boodlchíp, dic deze van des Enden hen niet brengen dort, om zich trelven, en de werdere Holtanders, dic $n o g$ by de Bandaivezen waren, in geen levensgeratar noedwillig te brengen.

Men vetnam in dezen nache tot drie malen toe een fwat geroep en getier, als of het onder de Bandanezen aham was; math dfar volgde niets op.

Den $24^{\text {ften }}$ Mey gutan ean den Enden, uit latt van die wan Oronttate, verzold valu twee Orangkaja"s, en cen Lonthoirze ftat, met geld en fchoone woorden hier toe bewogen, weder by de onzen op Nein in de Jogie, ntwar zy welkom gce - heeten wierden; mar men vont ondertuftchen goed, die Oranglonja's met 


\section{Z A A K E N.}

roo: hunnen dauf gewangen te houden; waar over zy zeer werwondert waren, alzoo tw. nict beter wiften, mogelyk door wath den Enden dit wys gemialkt, of wy hadden belloten her kaftecl te verlatiten, en met de fchepen, en "t krygsvolk, te vertrekken, laurende daar maar eenige lieden om den hindel met hen (gelyk $x y$ verzogt hadden) te drywen.

Men zont dezen diaf met een brief na Lonthoir, wat in verzoge wierd, dat zy ons volk in vryheid wilden ftellen, of dat men, indien $z y$ dit nalicten, hunne gevange twee Orangkaja"s ophangen zou.

Zy bequamen geen antwoord; mar ars de ding, dat de Lonthoirezen, onzen kooponzen ge-man aldaa", Dirk Pietery gentams, niet pletgt. tegenftande hy zirek was, en Cornelis was din Indes, adittent, jammelyk omgebragt hadden.

Bit foheindig bedryf wras oorzink, dat de zecwoige How, mer zynen Rad, goedvond de bloedwhg wan alle de fchepen te laaten wajen, en alle de Bandanezen den openbaaten oorlog dar by te verkliaren.

$\mathrm{Zy}$ befchoren darar op die win Lonthoir zeer fterk, en kregen een pranuw, watr of 'swolk overboord gefprongen, en het ont fwommen was.

Den zofter dito deed men een togt met boots en chilocpen iondom het eiland Neira, verbtatidende al de varreuigen der Bandanczen, die zy wonden, waar onderstwee mierwe jonken, die nog op ftapel flonden

Den $3^{\text {ftea }}$ dito befloot mien, de nienwe fterkten, die door den regen inftortem, tmer palwerk te omheyen, en te befchoejen.

Dén ifter Junif zolte ataen 't jage der Arent ran Amboina en Ternate, om kennis te geven van die bedroefde moord, door de Bandanezen atu zoo wed. wikkere mannen op zulken fchelmagtigen wyze bedruven.

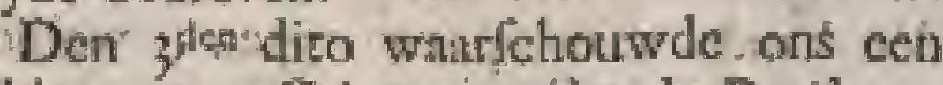
Chinece van Celamme, idat de Bandatezen cenen anntag op onze chalaepen en boots hadden, whar vood man zichider: hatweny zoo veel mogelyk was, wagtte.

Men was nog dagelyks met alle min bezig, otm thet weurige, dat nóg atan itkaftecl ontbrak, to woltoyen, net het aldas in een volkomen that van tegenweer te brongen f :.....

- De twee gevatigen Orangkaja's had men op te dip. Rollandin wel in de bocjen gezet, mant $z y$, middel gevonden hebbende, om die un fukken to breken, wanen overboord gefprongch, en sal land gerwomment:..

Den foler dito rang men cen jonk in zed, watr op men dric chaloepen; en cenige boots, uftzond, eca van welte de zelve onderhalde. Een der onzen I6og. overgefpronget zynde wiertainftonts met een kitis doodgeffeken, what op de onzen alles doodlloegon, en de reit der in landers, dic beneden geviugt, en niet genegen waren zich over te igeven, op is na, die om lyfigena badea, met vat tuig, en lading, in ryft, piporcelyn, conz. bethande, verbrand liebben; naderland bevindende, dat het eed vantuig wan Grefic, op Jawa, was. .....

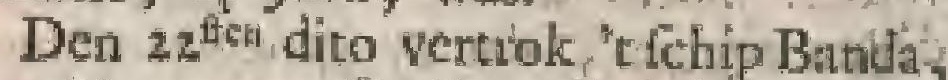
met Noocen ca Foelie vollader na ' $\mathrm{t}$ Wh. derland.

Den sen Juli hecft mén met alle de chaloepen, boots, en met de meefte fol- Labetalsdaten, het .ftedeken Lubetilkja ftomen- ka ver-" derhand ingenomen. De Bandanezca overt namen de vlugt in 't bofeh, en slicten alles voor ons volk ten,proy, ; die adi fragen burit, en onder anderen 14 bas zen, die men na 't kafted bragt , frvonden.

Dit had ons geen cein min gettof, miar de zeevoggt Hoes, en 3 s of 4 andes

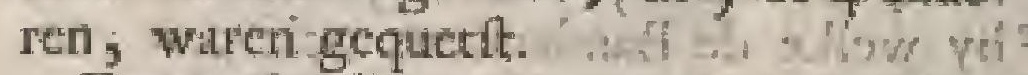

Den 26lendito wis nien nivet dientgelyt ken andigop Celamme bezig, om tunne vartuigen aldar ook te werniclen; doch

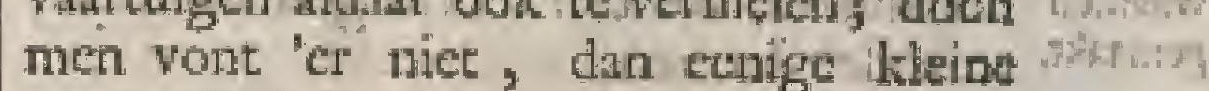

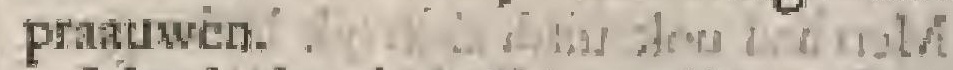

Men bid ondertufichen, altoo' 'v kafted nu voltooid wis' 'z' goedgewonden om 'de De Meet Hecr Yacob de Bütht, wir Harlem con de Biter, mies op 't ifchip Hollandia, s ds reerfton Land-

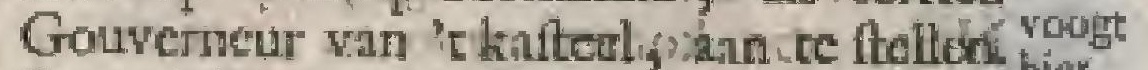
Dezen Hect nu, bewelhebber was that hier. volk, date tra Celamme gegan was meinde, dat men het dar by nief laatent,

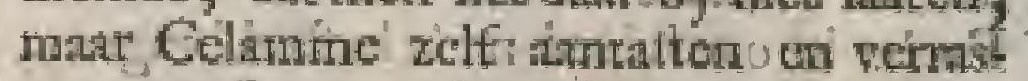

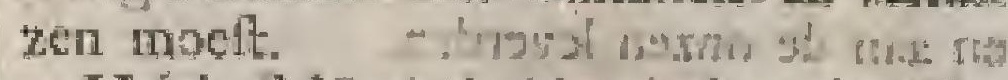

Hy decd het ook, thocwel met eonige w tont

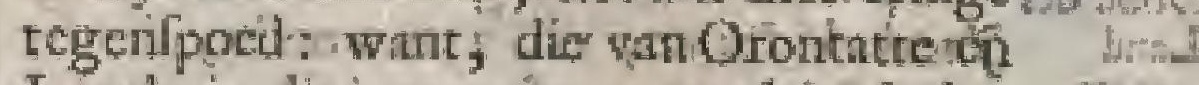

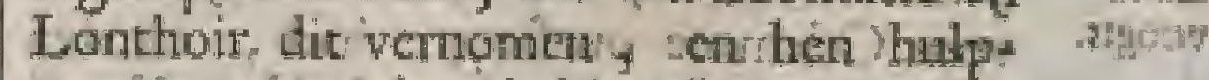

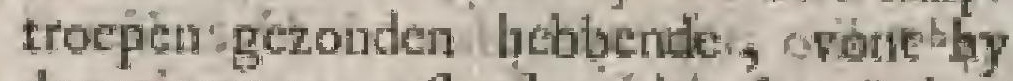

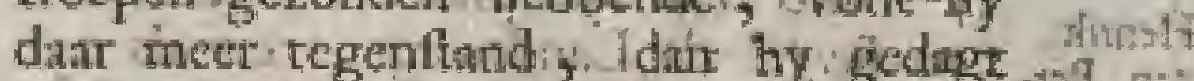
had, zoo dat hy, whoo hetidat overad

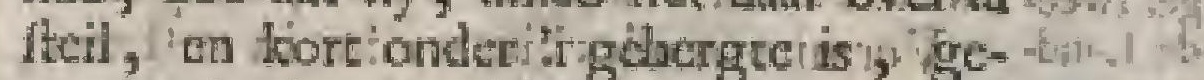
noodzake aras met' de zysen 'na dendhat locpen en boots , met' verlies vani g matr nen', en 70 gequetiten; (? af te trelkken. Hy zelf, wis mede door het dik wan zyb Die noor been gelchoten, beholwen dat zyn lieute: Gelanme jaut, ; wandrig; fergearic, en meet an- word, dere zoodanig roegettele waren, dar bet hen gerander was, zich weer na Nein Den 8 , क en rodes Auguti deden at Bandanezen, wel ziende, dar de Nederlanders befloten hadder zich date waft te maken, han utiterite bet, ; om vrede te bekónen, "t. geen door "t over eri weder gan wan zekere Macaliar, die weel bewind onder hen had, dindelyk zooverie gebragt wicrd, da Hewik wan Bergel,

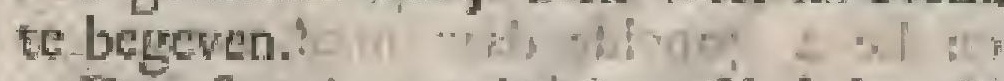


80

\section{B A N}

I 6

ie hier woor dezen als opperitoopman gelegen had, afgevardigt wient, oin met dien Macaflixar na "t fchip Zeclandia, dat voor Lonthoir op do brandwagt lag, tc Fairen, "om wan daar ter halver wegen nader met die van Loathoir te ipreken.

Den I I den dito wickt dit zoo verre beyordert, dat de zeevoogt Hoen, met de Leden van den Ruad, alzoo hen geen verdere moeite diende, den Bandanezen deden'zegggen, dat zy genegen waren, vrede met hen te matken, wast toe hy Hewrik wan Bergal, en Adrians vander Dusfas is nevens dien Macaflast na Lonthoir gezonden heef, nuet latt wan dings dhar atu op. It fehip Zeelandia ten dien cinde tevomeni: is

- ir Den izug dito wertoegde zich de Heel" How met zynen Rand ata dat fehip, laatende derwitte wlig. waijen, watit op do Macafany, then dat hy cens na lond gewaren was, ook cenige Orangkajats Vteds tan boord verehener, hoewal de viede

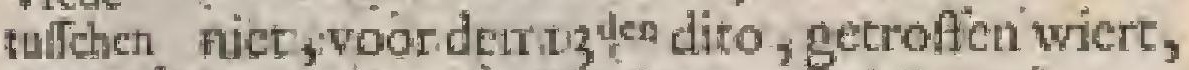
ons en de by welke de Bandanezen zich ook werBandane- bonden hadden de Foclic en de Nooten zen op an igeen andere; dan alleen an de Newasden derlanders, tot een zekere gettelde prys, gemnakt. te zidlen leveren:

Men hid ook uitdrukjelyk bedongen, dat' lalle" jonken r, htap buiten komende, gelrouden zonderitzyn onder hee kafted

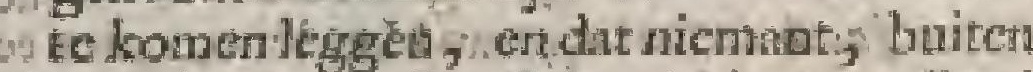

me uchlof van den Landwbogt, op 't ciland

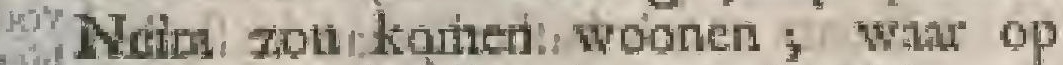
dath den 14 det dito de vrye handel; als beyoorens, zyact wódzgang nam, 200 dat de Bandariczen nud weer ? Nooten en Foelie in overwlood nin " 'c kafted biagten, en an de onzen leverden.

Dood des :Op dezenlzelveri dpg (tierf do Laindwogt

Land- Faco de Bhtor; win zyn wonde, die hy voogts, voorl Oelamme onefnngen thid, ch den veder dito is in $2 y+$ plants de Hear Hon it Henrils wat Berel als Landrougt, en als zyn

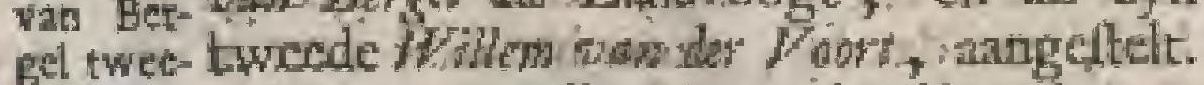
de Land- - yermits nuatles li ier weder ig ruit, Nwas, rongt, bofleot men den if drai adat de zoevoogr met de: fcheper Hollindia, de Geuniecre Pronintienen Delfe, den r gten dito, natar Amboin en Teinatévertrelcker, en Zee-

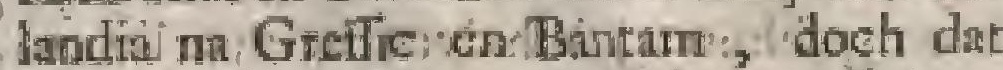
Rotterdatn en, Hoom diturblyven zouden, on hanrelading in te nemen sioo: ?t Ni dat mu deze thepen vertroktien, en die 2 gemelde dan mar.waremigebleven - warta' de trouwlooze Batidar nezen weder touicr geworden, en hadDe vede deń zich imeeft doot cen I Btigelstrint

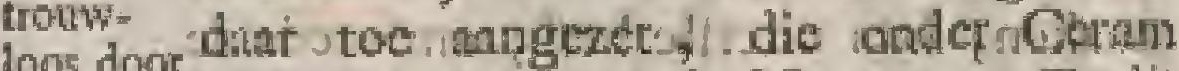
de Banda- ton anker has, i' en de Nooten an Foelie nezen ge-ddar zy nollogr dat hy op. Poela aly en broken. Poelo Rlum hid, bpkoopen liet, ook

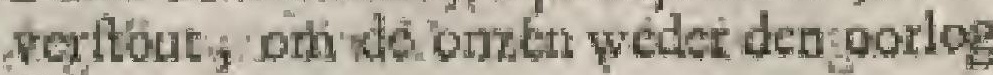

\section{A S C H E}

tan te doen, welke tyding de onze van ISIs; die 2 fchepen latift wan daar gekomen, tot hun leedwezen, in Julii r610. op Greflic, na dat zy daar al cen maand gelegen hadden, eerit wernamen.

Ook quan dit Engellch fchip, van fchipper Dawd Middelor, welk twee derde mer Foelie en etn derde met Nooten geladen was, den I 8 dea October in 't zelve jatr woor Bantam ten anker, beveftigende, even als het jagt de Griffioen den I dét September mede gedan had, dat de onzen met die wan Banda nog in oorlog waren, en dat de lanttle nu wel weer wrede zogten, mar dat de Nederlanders dat geenzins toe veritaan wilden.

Eer de Griftuen uit Banda vertrok, merke 't wolk wan die bodem, dat zeker fwart hun kabel tragtte af te hakken, welken zy gevangen kregen, en ain de bocgrpriet ophingen.

Zedert hadden de onzen geduurig oor* log met de Bandanczen, weshalwen zy. wan tyd tot tyd een walt befluit namen, om hẹ, zoo ras zy cen genoegzian getal Echepen uit 't waderkad bekomen zouden hebber, ecns met ernft an te ralten, en dat gunich nelt uit te roejen.

Dit diep egter nog al ecnige jaren atra, tot du eindelyk de tweede opperland- De Het voogt wan Indićn, de Heer Gerard Reysf, hont in met cen nuzienelyk wloot, in Junil i6r 3. "t jav uit T'exel in zec geloopen, en 1614 be- ifors in houden in Indien, ch voor Bantam geko- onda, men zynde, foed vond met de zelye in dart oves de mantid December nar Banda te ver-te that: trekken, om dit groote werk wan wrak fen. over zoo veel bedrewene trouwloosheden der Bundanezen net endt te gain uikroe$1 \mathrm{en}$.

Terwyl hy woor Japura op de Reede lag, quam dar het jehip Nalfau met den opperkoopman Piefer. wan den Broek, wan Antwerpet, die met hem uitgezcilt, mair ondertufichen na 't Roode Meir, en 't gelukkig Arabien geweelt was, on den handel diar op: te regcen, welker tyn Ed: ha den koning wan Boeton zon, met lalt on wan dna in Amboina, of Baida, ineder by hem te komen.

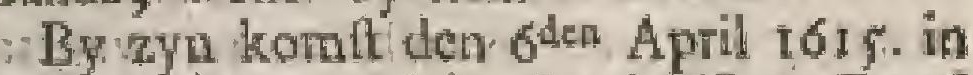
Amboin bevont hy, dat de Heet Regy/f atl nat Bandat vertrokken was; weshalver hy zyn Edelhd den $7^{\text {den }}$ dito wolgde, en nog diezelve dag voor. Neira op de Reate gekomen is, alwarr hy den oppertandroogt met een vloot wa it fchepen vone, die nu met 't fohip Natau nog verfterkt swierd

- Den 14tem Mey zont de opperlatedwoogt:'t lehup Naftu', nevens 3 , jegen, Eolus, Neptunus en de Morgeniftar; initsgaders a fregatten, I chaloep, ch 10 welgemontecerde boots; na Poelo $\mathrm{Ay}$, meritt an den Heer wo der Dufen, en den 


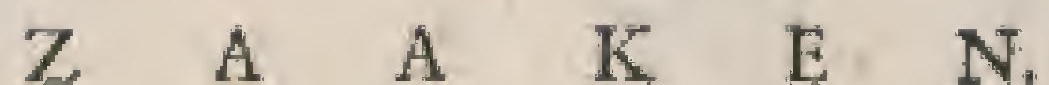

I6i5. den opperkoopmain van den Breet , om dat cillund in te nemen, hen poo foldaten, of matroozen, ten decle Hollanders, ten deele Japanders, medegevende.

Nid dar de Heer Adrian van der Dwffen, die 't opperbevel over deze onderneming hand, ontrent Poclo Ay gekomen wits, zecte by thet dige onder hee fort der Bandimezen, deed $\mathrm{z}$ \% wolk ten eerften landen, en met zoo weel dapperbeid op de velting antwallen, dat $z Y$, no een half uur wegtens, ecus bolwerk aan de waterkint inkregen, na dat zy de Bandanezen bevoorens al uit de loopgraven hadden Poelo $A y$ doen wyken. De Japanders wiren 'er door ons met hunne vandels eerft bowen op gekoonder wat men, en datr na de onzen, die hen der ver- dwongen de vefting te verlanten, en ma ovelt, 'tlatag gebergte (hoewel 'er maar weinig heuvelkens zyn) en in het bofch de whuge te nemen.

De Hollanders, op deze fpoedige verovering nu meinende alles hict meefler te zyn, begaven zich wat te fchiclyk tot rult, 'e geen de Bandanezen wartrnessende, zynzy mee een nieuwen moed weder tangevallen, en bebben de vefting wan de landzyde, daar zy open ling (hebbende

Doth

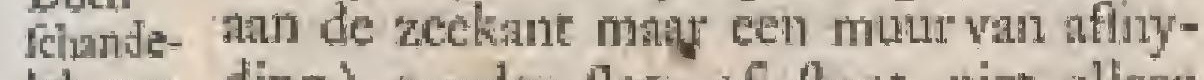
lyk ves-ding) zomder llag of thoot niet illeets looren. weder ingenomen, mati', door 'e in brandAteken van de pakhuizen, vol fpeceyen, ryit en likeden, en dọor hun fterk fehicten met roers, de onzen ook genoodzaakt het eilind mer verlics van weel wolks, en nog meer gequetilen op den derden alag fchandelyk te verlaten.

De onzen wonden hier een hecke en lalve Engelfehe chaker, (een foort van gefchut) met veel langc vogelroers, die zy voor af met 60 fockcls Foclie, voor alle onkoften, na boord zonden.

Onder humne getangenen, was cen Moorfehe Prictter, en een Javalanfeche fehoolmeefter, uie welken zy veriltonden, dat de Bandanezen mede vry wat fehade geleden, veimis zy wel 30 Orangkaja's, of Grooten, veiloren hadden.

Van de Hollander's waren "er, by "teinnemen wan die zeepurt, $p$ dood gebleven, co is of I g gequedt; matar in het aftrekken hadden $z y=27$ thoden, en $170 \mathrm{decr}^{2}$ lyk gequertten bekomen.

Oolk waten 'er 2 yin de onzen by de Bandanezch overgeloopen, vath welke de een , Oogien was Hadten genaumt, de onzen, met wit een. boom te fchieten, weel quatad gedias had, trefftende cens met een roer z perfoonen, die nasft de Hecr vas der Brotek ftenden, dit zy dood ncdervielen, behalven dat 'er nog een door gequetif wiert.

Dezé fleste tyding, te gelyle met al dit gequetlt volk, op Neira gelkomen zynde, was den Heer Reyrf ganich niet aunge- natm, en bragt ook cen algemeine ver- 5646 . fligentheid onder zyn wolk, "r geen onget wy ffelt van ecn beteren uit ling geweelt Fou hebben; indien de Heer Revnla (gelyk de Heer wan den Brock zyn Edelh geraaden had, zeggende voor zyn vertrek, dat liet in den Raad zyn vriendero nict waren, die hen dit atricden) zelfs in perfoon mede gegaan was, alzoo men op alles din wel berer en fpoediger ondre had konnen ftellen, daar men iu eert wolk na Neira, om zyn nader advys in te nemen, witar mede weel tyd vergeefs verliep, zenden noelt.

De ongehukkige uit1ag van deze onwoorzigtis behandelde en in "t eerft zoo wel gelukte onderneming was oorziak, dat "er in dit jalr niets verder hier vernige wiert; doch in ' $\mathrm{t}$ jar $16 \mathrm{ro}$. is de bevel Poclo Ay bebber 7 an Dirkf $z$ Lam met I a dehepen, door den en vect wolk, naar Bunda gezonden, watir ber Lain mede hy op den $10^{\text {den }}$ April Poelo Ay in 't jaar op deze wyze ingenomen heeft. A serf her-

Men had de voostroep nan den licute- nomeli, numtcolonel Gyben wan Vydsen, van Utrecht, verzelt van de hooffmannen Henrik Seedr van Sommelsdyly, Hrwik Gesdly, Willem Jachusan van Ter Vere, toebetrouwt, en hem 240 man, behalven enige Jipanders, medkgegeven.

Ower de middeltroep had de hoofdman Lambert Adamzan" gezcgt Lankhair, ceti Akenatr, het bevel, onderiteune door de hoofdnannen Pieter Backer van Antwers pen, Yan $V_{e}$ boeven yan Thiel, en $\gamma_{\text {shomad }}$ Corneliszoon vand dmitterdam, crizy bettokit in 't geheel uir 250 foldanten boven dezc officieren.

$D e$ agtertrocp wiert aangevoere door den hooldman Hewrik Beverying van Gouda, die de hoofdnamen Ahraham Halling van 's Gravenhage, en Hewrik Hetentads, nevens 230 foldatren, behalwen een grout getal matroozen, en Icheepswolk, by zich had.

Buiten deze hadden nog twee byzondere Zeeufche hoofdlieden her bevel ower al het ander feliecpswolk, dat hat had, om 't gefchur, en 't vordere tor dien rrein noodig, te verzorgen:

De Sergeant Majoor ever al deze manTchap wals de hootdman fadridan san utor Diffen, zoo my toefclyyn, de zelve, diens volk lier tegen zyne welgegevene ordre tis to voorleden far zoo illegt daar had taten leggen.

Deze deden nu hunne zaaken zoo wicl, dat zy niet alleen die vefting herworner, cn nú Revenge nocmden, malar veroverden ook het ganfch eiland $w y$, endwon-en de gen de inwoonders zsib van dat, als van Bandancede verdere omleggende cilanden, om mer ten tot de onzen in Mey 1616 . een nicuw wer enneuw bond tor groor vaordel der Ooftindilche gedwounMaarfeliappy, zoo zy her maar nugeko" gen. men warn, ann te gaan.

I.

Mants

III. DEEL, 
82

\section{B A N}

D

t655.

Mar wat ftant 'er op deze trouwlooze fichelmen te malken was, heeft men zoo in "t vervolg, als te vooren, gezien.

Zy hadden al zedert den Ioden Auguftus 1609 . een zeer nataw werbond met de Nederlanders atngegaan, watar by zy zich onder de belcherming wan hat Hoog Mog: geftelt, en belooft hadden geen fpeceryen aan icmant dan alleen tan de Nederlanders tegen een gezette prys, te leveren, wits dat die hen tegen de Portugezen, hun beider vyanden, belchermen zoudien.

Deze beloften quamen zy zoo lang na,

als " $t$ in hunne kranm diende, en hebben zich nive getchame, dit werbond trouwloos te breken, hunne fpeccryen aan anderen te werkoopen, onze comptoiren fichelmagtig af te looper, ons rolk, zoo $2 \mathrm{y}$ niet Moorlch worden wilden, jummerlyk te vermoorden, en aldus al= les, it geen wollage ichelmen en verbondbrekers palte, te bedryven.

Zy overtraden, en braken nict allecn weder dit verbond, maar zelf ook een niecow, in 't jaar I617. met den dereten opperlandvoogt, de Heer Lawros Reanh, fungegann, lantende zich gedurig door de Engelfchen opruyen, die de eilanden van Banda, tegen ons in oorlog zynde, van levensmiddelen, gefrhut, oorlogsvoorrad, volk, cn fichepen, verzagen, en hen de behulpzame hand boden.

In deze moerwil hielden de Bandanezen nog aian, tof dar in Junii 1620 . te Jalsatra op de Engelfche, en op de Nederlandiche wloot, aldant ter recde leggende, het tratant, van Julii i6I9. te Londen zulfichen den koning wan Engeland, en bat Hoog Mog:, tor vereeniging der Engeliche en Nederlandlche Oottindiche Martichappyen gelloren, afgekondigt wiert.

Dit tractate hielt in, dat de handel in de Moluccos, in Amboina en Banda ook ann de Engelfche Natic wiert toegeftan, en daar by dan alle gefchillen tuffchen de Engelfche en onze Opftindifche Mantfehappy volkomen weggenomen wierden. Als mede, dat men vootan met een gemeene magt van oorlogichepen, tot befcherming van den handel wan beide deze Martchappyen, alle die hen hier in eenigzins benadecten wilden, zou tegengatan.

De onizen hadden wel getragt de trouwlooze Bandnezen al eer te ftraften; doch :t was hun belet, zoo door feitelylsheden van de Engelfchen zedert "t jas' 1616. in Banda aangerege, als door weel mocjelykheden, den onzen door de Javaanen en Engelfchen in de jaaren I 6 18. en $161 \%$. op Java, ontrent Jikatra, Bantam, en ter zee, aangedann; geduurende welken tyd de Bandanezen zeer ftout geworden
$\begin{array}{lllll}\mathrm{A} & \mathrm{C} & \mathrm{H} & \mathrm{E}\end{array}$

waren, en zich van onder "t kafhed stist. Naflu zoo onbevreeft ontrokken hadden, dat zy nu niet alleen aan de Engelichen, en an ver fcheide Indiarifche $\mathrm{N}_{\text {at- }}$ tien, maar zelf ook an de Portugeezen, hunne en onze vyanden, ondertaan hadden fpeceryen te verkoopen, en zich met die laatte weder te bevredigen, waar op rceds al fo ol 60 Portugeezen op 'i Hooge Land waren gekomen, die by meerder hulp 'i rege tot deze fpeceryen wolfiagen, en zonder hoope van herftelling, ano de Engelichen, en ann ons, zouden hebben konnen bewemen.

On dit quand dan verder te ftuiten, vont de vierde opperlandvoogt van Nederlands Indien, de dappare Heer fan Piefersaon Cón goed, om in den gemeenen Riad wan Defenfie, uir Engelfehen en Nederlanders beftande, de teductie van Banda, als mede de herftelling, en de verzekcring van die quarticen, en wan den handel in Anvoina en de Moluccos, voor te ftellen, toonende, hoe beide de Maatfchappyen volgens dit tractate $\mathrm{ge}$ houden waren yder hagre gemeene magt en middelen zamen tevocgen, anngezien de behoudenis van alle deze platazen. zoo verte den handel betreft, beide deze Compugnien even vể raakte.

Op dit voorzigtig voortel van dezen Heer verklarden de Engelfiche Gevol. magtigden tot deze vergadering op den $1^{\text {ftem }}$ Januari $161 \mathrm{t}$. (gelyk by een Aete, van 't gene toen verhandelt is, blykt) dat hen de nood der zaaken wel bekent was, en dat zy wel genegen waren iet in het gemeen nevens ons ic ondernemer; doch dat zy, wegens gebrek wan tagt, fchepen, volk, cnz. niet in ftagt waren, om dara toe iets by te brengen; war op deHeer Coon verklaande, dat hy dan nuer de byzondere magt der Nederlandfehe Mastichappy die zaak gan bevorderen, en zien zou, wat zegen God Almagtig hem dars op zou gelieven te verlecnen.

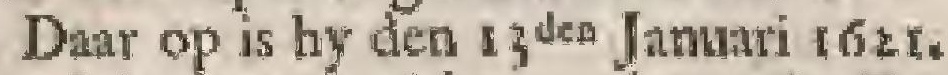
van Jakatra vertrokken, den I $4^{\text {dea }} \mathrm{Fe}$ bruari in Amboina, en vervolgens den

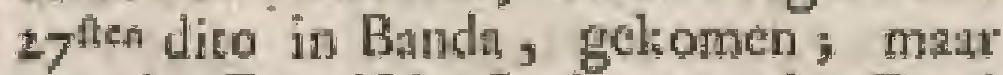
een der Engelfehe Leden van den Rata van Defentic, Jie den 1 lten Januari mede in die wergadering gezeten had, en in Amboina lag, als de Heer Coen van dant vertrok, had met onze fchepen bricven aan de Engclichen, op Poelo Rhun, mede gegeven, war in $z y$ hen onzen gnnfehen antidng tegen 't Hoog Lasd wan Banda, en die dat weer an de Bandanezern, bekent makten; war door zy dan ook gelegenheid hadden, on zich dar tegen klaar te maaken.

De opperlandroogt wan Indiën werftont ook, by zyn aankomt voor "t kattee Natfu, date de Engelichen van Toelo 


\section{Z A A}

4tit. Rbun die van Lonthoir 4 ftulken bygezer, en hendus in ftwnt gebrige hadden, om, by aldien hen mar war meer tyd overig was geweett, her inkomen ini "t gat vatu Lorthoir woon hem vry gevatulyk te maken, en mogelyk wel gehcel te beletten.

Ook hoorde zyn Edelhd, hoc cenige Engelfehen, op Lonthoir, de Bandanezen, onze en, uit kragte van "t woor" noemde tractaat van Defenfie, ook hume vyanden, met rnad en diatd byttonden, en ammoedigden, en nier tegenftande zyn Edelhd hen om bovengemelde redenen verzogt van Lonthoir te werticklen, zyn zy cgter by de Ban= danezen gebleven; wat op dic Heer tegen hen opentlyk betuigde, geen deel 'er an te hebben, nog fchuldig te zyn, zoo ben cenige lohade, of ongemak, bicr door averquant

De Heer Coen had voorgenomen eerth wan deZuidzyde wan het Hoog Land, op cen plats, Luchuy genaant, te landen, watrom hy hee tehip het Here, daar ontrent deed ten anker komen; mas 't had 'er niet lang gelegen, of "c wiert met een thtk det lingelichen 200 getrotfen, dat de onzen genoodzakt wierden het met een Coracora van de wal af te roejen, en twee ankers met twee couwen te laaten ftan, of "c zou gevan geloopen hebbea, om te zinken, of te wer" verbianden, Ookverklariden de onzen, dat $z y$ duidelyk gezien hadden, dat die fchoot door een Engelfchen konttapel gedann was; hoewel de Engelfehen dit wel ftyf loochenden.

Aangeziendic hier dan niet wel gelukt was, belloot de Heer Con met zyn geheel leger ande birmenkant, of Noordayde dezes eilands, te landen, aldata 't gebergte op te klimmen, en zyn gerchut te planten.

Daar op trokken de onzen den 8 den Mart met 17 vandels, uffchen Combir en Orontartan geland, langs ftrand, binnen lehoots van 3 ttukken geichut, die de Engelfichen ann de Bandanezen geleent, end die zy kort te vooren diar geplau hadden, want door de onzen genoodratak wierden weder tricheep to gata, on niet al hun wolk te verliczen, behalven dat ook de weg, dara ry drie jaren te vooren op waren, over al doot de vyand mee borltweringen bezer was.

Zy trokken derhalwen, zonder van de Bandabezen vervolge te worden, hoewel zy hen zecr befporten, weer nia de fehepan, want na de wyand, denkende dat wy het daar na by laten zouden, de meette vrouwen en kinderen weer in de ftndt Lonthoir bringt.

$\mathrm{Na}$ "r misluk ken dezer twee anthyen, cnkelyk door' 't gelchut der Eogelichen
K E N.

verooralkt, vond de Heer Con goed, I dat de onzen een algemeinen aanvial an beide zyden van 'r Hoog Land doen zouden, te weten, atn de binnerskut met 6 , en ann de Zuidkant met ro vaindels, zoodanig, dat dic ant de bimenkant een uur voor de andere landen zotuden, on den vyoud dar ma toe te lokken, endus asn de andere gelegenheyd tegeven, on zoo weel te gemalkelyke!" ann de Zuidkant telanden, en op 't gebergte te geraken, ten welken eindc ool een wandel VTywilligen, uitgelezen volk, aan de Noord7yde voor af gain zou, om 't gebergte wan die knt te beklimmen, geIyk neer anderen zulks op verlcheide platzen wan dit eiland doen zonden.

Dric hondert derrig hoppen, wast onder 150 musquettiers, waren tor be= manning en verzekering van 30 Tinggangs (zekere vaartuigen) geftelt, on die 10 vandels an de Zuidzyde des eilands te brengen.

Na dat de Hect Goen dan alles tot dete onderneming wel betteit had, zyn op den $11^{\text {den }}$ Matr de 6 vandels met het atrbreken van den dag tuffchen Combir en Urontatan geland, gaande hicr de wakkere hootdman, Maraten Jomsoon Vogel, van welken wy hier na neer iprekeu, met een deel uitgelezene foldaten voor uit, thwar hy, in 't opklimmen wan 'r gebergte, meer tegenftant wont, dan hy gedagt had, zoo dat hy, en afle de zynen, vermits al hun kruic werichoten was, in groot gevnar waren; matr angezien hy van verch volk zeer wel gevolgr, en onderfteunt wier, moelt de vyand eindelyle hand over hand wylken.

Terw yl men hier met deze 6 vitandels bezig was , hadden die Io vandels an de Zuidzyde fraje gelegenheid, nitet alloen om uit de Tinggangs gelukkig in een klein baiken te landen; mara" ook eenige met, sndere zonder, ladders, op het woorgebergte tegen de klippen op, en zoo werder tot boten toe te klimmen; watr nazy van agreren de ftadt Lonthoir, zonder ecnigen regenftant, dan var een verloorentroep, introklen, werliezende door eene chargic, wan ro of 20 musquetricrs, uit de vootnoende troep gedan, mak cen man, whar by zy nog 4 of i gequet ften kregen.

Lonthoir was door deze 10 vandels al Inng ingenomen, terwyl die 6 andere Lonthon wan de Noordzyde nog wakker mee de in 't jats' Bandanczen Itreden, doch dit cindelyk $162 \mathrm{t}$. doon lien eemerke zynde, verlieren die Her de van Madinngi, Luchui, Orontactarn en Coen Sammer, ook adnitonts hume Negr'yen, werowert, op dit zelve eiland Zy hadilen gedigt, en werter dat de 30 Tinggangs, her eilathd nu ann ons weer rond waren zouden, gelyk zy reets overgedricmal hadden zien doen; wajon zy beven.

$$
\text { L } 2 \text { deze }
$$


16it. deze lattfe reis "er zoo naauw nict oppelet, en toen te latar bewonden hadden, by fehoonery en lichtendagdoor deonzen misleid, en wur agteren wermicht te zyn, watr door $z y$ genoodzanke wierden zich op ende en ongenade over te geven.

Zoo hatit wy Lonthoir, nevens de atudere voornoemde plawen, werovere hadden, hebben die van Conbir, Celamme, Ouden Denner, Wayer, en die van de cilanden Rofingetn en Rhum, de vrede verzogt, die hen toegeltan is, mits, dat sy al hume fterkten afbreken, cn al hum grfchur, geweer, perdere krygswoortad, en ook hun land, an ons zouden overleveren, erkennende hat Hoog Mog: voor hume Opperhecren.

Eindely quamen die wn Lonthoir, met hurinen anhang, mede om wede verzoeken, die hen op de zelve voonwataden rocgeftan wiert; matr vermits zy dit zoo vecrdig, als het behoorde, wict naquamen, en onder de hand nieuwen opltant zogien te verwekken, gebood de Heer Com, dat zy wamflonts am itrand werfehyner zouden, oni dear, als borgers, in alle wrybeid, en zonder eving werlies van hunne goederen te woonen.

Eenigen wan hen gehoorzander, doch Nieuwe de meeften $\mathrm{z} y \mathrm{n}$ na "t hoog gebergte gemónd wuge, alwwar die wañ wercheide andere doot de, fleden zich by hen gevoegt, een NederBandwe lands onderkoopman, cen aflitent, en pleerg een jongen, doodgefagen hebber.

$\mathrm{Zy}$ hiclden zich langen tyd in dat gebergte, dat hende onzen alles atfineden, walt door zy genoodzankt wrierden, met eenige valutuigen nu en dan, ten decle nit Cerati, en woormmelyk ma Keffing, ten doele na Goram, of deze en gene Z. Oofter, en Z. Wefter eilanden, de vlugt te nemen, 'c geen egrer eenige jaren datar na, ha dat 'er welen vari doz hardiekkigen, onder onze eerfe Landwoogden van Banda gefneuvelt waren, gelchied is. Dutr wierden "er ook wel 800 op de felwepen perdect, en $\mathrm{n}$ Batawia werzonden.

Op deze wyze zyn dewerdere eiliaden vin Bunda, te weten, "c Hoog Land, Poelo Rhuin, en Rofingein, zynde "t laatfte, dat wy nog te weroveren hadden, door het groot beleid wan dien dapperen Hecr GDE, ingenomen, en werzeker. Welk latitie egter ontrent Poclo Rlium niet geflehied is, ondat hen die inwoonders fit gehouden hadden. Ook hadden Ae Engelichen tot bulp van die wan Poclo Rhun, op een kbin eilandje, digt by "tzelve gelegen, negen ftukken gelchut geplant, datr zy hen in lutten, agter róss: cen borftwering behielpen. Hoewel un die wan Poclo Rhun, volgens belofte, al hun geweer, gefolutr, enz overga veth, hebben de onzen egrer wan dat gefchut, op dat cilandehen, niet getprohen, op dat de Engelfhen niet zouden konnen zeggen, dat wy hanne wattigheid, volk, of gefchut, mangeralt hadden.

De Engeliche bevelhebber, Ondrey Afls Herbor, met zyn fohip de Exchange in Amboina voor het kafted Vietoria leggende, en wan deze onze verowering berigt betsomen hebbende, fchoot is eerfhoten, om ons met de zelve vecl geluk te wenfichen ; en deze verovering van Banda word datr ook jarlyks op den. I I wea Mare nog geviert.

Na dar nu dit land wolkomen in onze handen getiomen, en op de vootroemde wyze doot "r fwatrd perovert was, hebber de onzen "tzelve van de meefle dezer hartnckkige en trouwlooze fchelmen, whar van 'er reel na Micatlar vlugreden, geztiver, mant egter vetlcheide overgeblevene kinderen der zelven na zich ge nomen, in een feboole beftete, en die de Duitche tat, en lezen en feliryen latten lecten, gelyls ik zelf wit de mond van een oude Poclo Rhunze vrouw, welkers moeder dus door de onzen opgewoed was; gehoort hebbe:

Die doodelyle hat egter der gevlugte Bandanezen tegen ons is by hen zoo onverzetelyk gebleven, dim het nog velen van ons her leven gelooft hect. Dit hebben de Cerammers, in 't jaar 1630. op de Bandanezen fterk roovende, en die wan Tobo, in 't jarr 163 I. en ook die wan Rarakir (dau" "er weel wan hen na toe gevlugt, en zich nog onthoudende waren) doen blyken, wrameer $2 y$ in "t jall 1634" den koopman Belibgetor Wejwes, nat Banda gande, en den onderkoopmin Abrabam wan der Plas, ch ook die ran Gom, wannecrzy in "t jaat I6r8. den koopmin en Fiscanl Jacob Bowe, 200 janmerlyk vetmoort, behalven dat $2 y$, en de Ooft Cenmmers, ook geduurig hume bitterheid, en rooral in 'x jair 165 . en op meet andere jiaren, zoo an de Amboincerche, als ande Bandaneciche handelares, getoont hebben, wiet tegenifande $z y$ in " $\mathrm{t}$ anr 1637 . door" den Landwooge Acoley weer in vrede aangenomen waren II "t jaar 1649. die van Rarakit ook wel ernftig door de Heer de Vhaning (gelyk wy onder de flofte wan Amboina zien) angetift zyn.

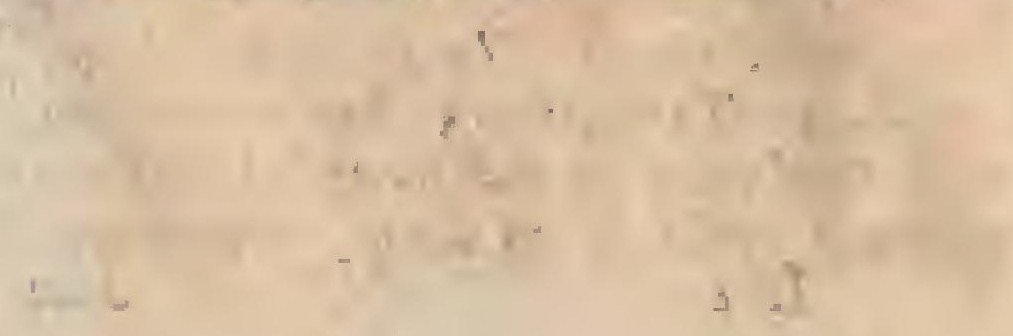


161.

\section{Z A A K E N.}
Z E S D E
$\mathrm{H} O \mathrm{O} F$
$S T$
K.

RAnda's ayze ran Beflering door de Nederlanders. De Ratd wan State. Megt des 1 Landroogts in dew zele. En de andere Leden in dex Rand. Stratroering des Landroogts. Zw inkomen. De Capitein. " Opperhoofe wam Lonthoir. $D_{e}$ Fiscial. De Soldy-boekhouder. De Geheinichrywer. De Opperhoofden wan Poclo Ay, en Wayer. De Rind des Gerigts. De Weeskames, De Vergadering der Kleine en Huwelykszaken. De Wondheetders, De Wertbans, Lylt der Landvoogden. De Heer Sonks gedrag. De Her Admiraals womdentw Jeven. De Her V Jak

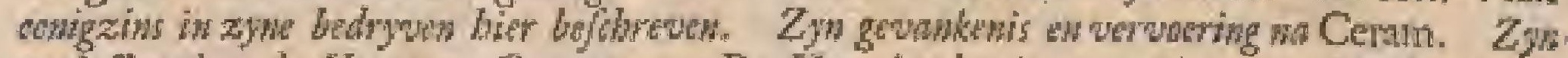
verlofing door de Her wan Gorcom. De Heer Acoley's verighingen. De Her van

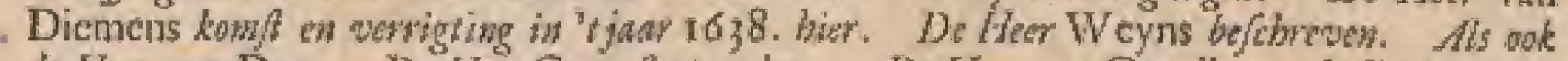
de Heer yan Dan. De Heer Cops flegt gedrag. De Her van Qunalbergs beflering bier.

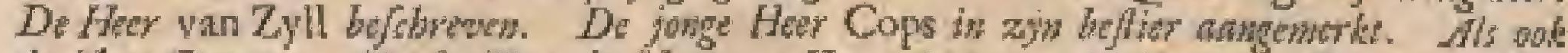
de Her Coyev. Ende Hor de Hazc. Het gedrag wan de heer van Eps in zon be Bier.

Baxk's wyze vall beticring door de Noder

Neder
landers. lle andere Landen in 't Ooften, hen eygen, c1 van hen bemagtigt, doon Lindvoogden beftiert, dic door eenen Rand wat Politic, als een Rand wan Stane, het opptbewind over deze ganfehe Landvoogdy hebben.

Deze Rand wergndert, nt het believen De Raad wan den Landwooge, of wel na dezaten van Stat, wan den Lulks vercifdsen, cens of tweemal ter week, ch dient, orn alles, "t geen tot Magt des wclfant dezer Landwoogdy behoort, niet Land- ma den zin ran den Landrooge, mar vongs in volgens de byrondere an ben voorgede selve fehewen ordre wh den Opperlandwoogt en de Raden wan Indien te Batayia, ecrlt te belluiten, en dhat nat te doen uitvosEndean- ren, van al het welke de Lndvooge defe Le- utvocrder, gelyk datiom zyn titel ook Raad. Landroogt en Befterder wan Banda is.

Vele egter dezer Landvoogden hebben getoont, dat zy dien Rand, nict tegersftande deze ordres, volkomeiz ma hun eigen zin, en zoodanig wifter te beftieren, als of zy 'er maat alleen met mage พลan te ftemmen, en hunne medeleden 'er maar als ftomme perfoonen gezeten hadden, iwetende zich zelven altyd of met dien Raad, of met deze zelve ordres een anderen draai te geven, te dekken.

De Leden wan dezen Rat zyn gemeenelyk de navolgende, en zitten in dezen raing: de Landvoogt, de Opperlroopman, de Capitcin, het Hoot op Lonthoir, de Fiscal, de Soldy - boekhouder, en de Geheimfehryver, die alleen dient, on de befluiten op te manken, ordentelyk te boeken, en dan door alle de Leden te doen teekenen, waar mede hy ook de eenige Notaris is. Het zou koinen zyn, dat heE Hoofd van Poelo Ay mede cen Lid was; doch wy weten dat niet regt.

In ' $\mathrm{t}$ jatr $168 \mathrm{z}$. ordonnerden hat Edel- heden, dat de Winkelier, nog Caffier, niet in den Rand zitten zouden, ted wite de Fisctal ook Caffier was.

Het Ampt van den Landrooge is hier, getyk op alle andere plataen, dar de E. Matutchaypy Lajutheer is, zeer atnzienlyk. Zyn magt, fchoor maar zyne or* dre volgende, dic egter veeltyds overticden word, gant zeer werre, en die hem tot wyand heeft, is half (zoo rjec geheel) bedowen; dair zyne vriendfechap in tegendecl yemant in weinig jaaren zeer gelukkig matken kan.

Het ftart in zyn mage alle mindere bedieningen met kennis pan zynen Raad, dic hem zeer zelden, dan tot haar nadeel, lier in tegenftaan zal, te wergeven; matr de hooger Bedieningen blywen meett ter believen van harar Hoog Edellheden op Ba* tavia; en fehoon 'er yin den Landwoogt, en zynen Rand, al cenige der bequanite nu of dar mogren aangeftelt zyn (' $\mathrm{tgcen}$ by atn de pen riet hooger dan tor Boekhouder, en an her krygswolk nict hooger, dan tot Sergeant, doen mag) zoo heeft, nog ' $\mathrm{t}$ zelve, nog ecrige andere aanitelling der minderen, ecuige vattigheid, ten zy het door de Hooge Regecring van Indien ecrit goedgekeurt is.

Hy heeft, gelyls alle andere Lindvoogden, cen byzonderelyfwagt, uit en Stutroofergente, corporal, en is of 20 gewal ring des pende foldaten beftande, van welle vandhem gemeenclyk over al, de fergeant, of comporal, met Io man volgen, gaande mer 4 mannen voor, de Landroogt in 't midden, en de 6 anderc agter bem.

Zyn inkomen (gelyk dat der Landvoogden van $A$ mboina en Ternate) be-Zpa in. ftata in 200 gutd. foldye ter motand, in komen. $24 \mathrm{R}^{\text {ders }}$ looftgeld, en $20 \mathrm{R}$ ders voor hiet onthaulen der" gande en lsomende buitenopperhoofder ( wamneer zy aan 't kaftecl vercilchr worden) (chippers, en andere licden val butiten, dic ly gewoon is, zoo L 3 
561. lang zy dar zyn, zyn tafel ann te bieden, en hen urtdrutkelyle door cen oppaffer to lataten noodigen, zonder dae $z y$ 'er anders komen zouden.

Hy mogt ook voot 75 R der telecden uit de winkel der E. Matefiappy tegen ro per cento wintt trekken, doch het tafelgoed, dat na 't jar 1680 . niet meet byzonder getrokken mogt worden, "ct" onder gerekent.

Buiten het zelwe zyn hem 2 leggers Rlyofche, Franclie, of Smunlehe whr ( tot 400 kan yder) tot zyner keure, foo zy maar in 'e magayy dat jar gekomen zyn, 3 vaten Moist, $f$ katlien (yder wan ontrent zo ftoop drank) Perlinatiche wyd, 2! vaten boter, yder wat 310 pond; 2 aamen Hollandiche azrn, i tand olywerrolie, (welke twee polten, by 't mazicn der jarlykze vertecringen der Luadvoogden ganfch Indičn dool", volgetes anthfchryven hatrer Edelheden var den r 7 dea Februari 1680. uit de bepalide lyt gelige zyn, en hem zoo weel, als hy wan yder noodig hud, cocgeftat , en 't noodig gebruik wat zout en fpeceryen toegevoegt is) 2 latten 1 ytt, I laft tarw, mitsgaders wafchkanrzen en lampolic to noodig gebruik, valgens aunfehryving Wan Bitivia den 2 den Februari 1679 . toegelegt. Hy heeft van ouds ook 288 R ders voor het onthaten win de Randen des Gerichts getrokten; doch in "t ja11" 1680 . belafte men ook ontrent dit, zoo veel mogelyk was, zuinig te zyn.

Ook plage de Landwooge hier fo flatven in gettiudigen dientt der L. Miarlichappy te hebben, en alle matad 3 R wer wan yder, en dus 15o Rders ter maind hier van alloen te trelken; ( $\mathrm{j}$ in woorige ty. den plagten 'er nog al meer te zyn, in zoo verre dat has Eaclheden by hun felarywens watn den $20^{\text {ten }}$ Febutari 1685, on de groote fomme der 17ater - loonen, ook weren wilden, whar toc men die at gebruikte) mat deze poft, wel de woormamite van lym inkomen geweel, duurde niet langer, dan tor te Heer Lindwooge de $M a z e$, in " $\mathrm{r}$ jar 1706 , die gehed en al atichafte, meinende, ver-

- mits hy gelds genoeg . op de kutt vall Choromanded, en elders, gewonnen had, dat zyn verwager het genoeg mec zyn verder inkomen ftellen kon, en dat de E. Matrchappy geen fluwen wan anderen meer in har dicnt, dan die zy doar rects bezat, wannooden had, wantom ly buiten twyffel, zoo wel wan alle zyne op= volgers, atls over andere talien van de meedte ingezetenen vitn Busda, als ecn verwodter wan die Landvoogdy, verwoekt, en doodelyli grehat is. Hy deed dit wel on een roole letter in den Almanach der E: Marleliappy te kygen, dewyl by de relve hice mede dit woor-

deel dede, matr zyn wonderlyk leven, ign. zoo daar, als elders, heeft hem by vervolg vin tyd zoo fwart gemalit, dat hem nog al zyn geld, nog zyne dint op $\mathrm{BC}^{-}$ volgde verhettingen tor excrordinat, en ordinal Rand wan Indién, geen bair meer agring, dan te wooren, by exlyke lieden gegeven hebben.

De opperloopman, die de tweede des Landvoogdy, en opperbehandelar is wan perkoopalies, wat den handel betreft, hoeft de mani fier rang, magt, ch spting mitaft den Land-beikhre: vooge, locwel dic zcer weel dar wan ven. verlehile.

Hy doec ref(treklking van allerlei watredn aer $\mathrm{E}$. Marechappy in "tgros ann allerlei andere minder bedienden, ofte vecmde kooplieden, en gelyk hy die alle, 200 als $7 y$ wan Battwia komen, ontfingt, alzoo moer hy alleen ook alle de zelve weder man her algemein comproir tot Batavia, even als de mindere, "t yy opperhootden, of andere bedienden in Bandat 'c ontfrogene weder aan hem, wer* antwoorden.

Zys inkomen beftant in 80, of ool wol $7 \mathrm{ym}$ inroo guld. Gisit" (dac het hoogite is dac ly tromen. wint Io Riler koftgeld, ter mand, in zeker getal van kumen wyn, en ponden walchkeerzen (als in Amboin) 2 kannen olywenolic, ecnige lampolic ter mand, cen wye woonims, en 1 ro pond Holhandlche boter in " $\mathrm{t}$ jar. Ool zit "er nu en dan een voordecltje, dat al vTy groot wallen lan, in 't veritandig handelen mee deze of gene meeft getrokikene kleeden, die hy dan ftil, als witsen het de zyue, met een fraje wintt weet tc verkoopen, gevende den Lamivoogt, alzoo 't anders nict gan zou, zyoe geregrigheid hier van.

Dol heets hy nog zeliere vate woordeclen, nice allecn van de leklsugie, en den afflag op vericheide goederen in de puthuizen, onder zyne vertintwoording berultende, als de dranken, terw, rytt, $\mathrm{cnz}_{*}$ mat trekt ook wan de leveruntic wan wlle de fpeceryen, die by hen ontfingen worden, wegens dawen, dar toe noodig, een fchelling dargs, cn ook wan de overwige der fpeceryer, die hem goed gedan word, een traje ltuiver. Een legger van 400 kunen verantwoond hy mintr tegen $3 r^{\circ}$, en zoo met de ret der goederen, die lekkigic onderworpen tyn.

De Capitein, de derde in rang, witre De Capl80 guld. ter nuand, heeft $10 ! \mathrm{R}$ ders koltgelo, 7 kanien wyn, 7 pond kaarzen, en nog cenige kleinigheden, hebbende in "t kniteel oojs een zeer goede wooning.

Hy is het hoofd der krygsmagt, en zonder ben, ths ly ten guadditer wil, kan de Landwooge, daar ontrene geen verindering, noggeen toldat corponint, 


\section{Z A A K E N.}

361. makken, hoewel het den Capitein, wil hy das eenige fille woondelen trekken, bett is, zich veel liever na "t goeddunken wan den Landwoogt te febiliken, angevien die al zyne ongeoorloofde voordeelen beletten kan, die hy anders door de vingeren zier, woor al als hy 'er mede van trekt, gelylk zontyds in deze cn gene Landwoogdyen wel gefchied is.

Hy heet ook 'topzige in 't byzonder over 't ziekenhuis, en de zieken aldinar, datr hy op zekere tyden "t gezigt wan gat nemen, om te weter, hoe zy gehandelt worden. Ook moet hy alle awond het woord by den Landvoogt haten, en dat wan de minder hoofden wan 't kafteel Naftau uitdeclen; doch die wan "t kaftecl Belgica, en de borgers, krygen ecn ander woord.

Het Opperhoofd wan Lonthoir, cen "topper- koopman in bediening, is de vierde in van Lon-rang, Hy heett op Lonthoir in de lothois. gic een fchoon huis tot zyn woonting, en alcyd, als hy uitgat, 2 oppatiers, en zyn vrouw cenco agker zich. $\mathrm{Hy}$ trekt 65 of 70 guld. 's miands aan foldy, hect $8 \mathrm{R}$ deri koftgeld, 7 knnen wyn, een zeker tutum van karzen en olie, en. buiten bet zelwe arekt hy nog (gelyk ook de verdere Buitenopperhoofden wan Poelo Ay en Wayer) de overwigt der fpeceryen, en voor 10 of 12 farwen I tchelling, voor den Marinjo, dic by tot het behandelen der fpeceryen wan nooden heeft, i Rder dags, immers zoo plagt het te wezen.

Den Fis Na hem volgt de Fiscal, diens nupt caly. het zelve met dat wan een Hoofifchout, dic derthalwen onk eyfficher in 'c Gericht, uitwoerder der befotene gerichtszanken, en weerder van alle openbarate onordentelykheden is, wat toe hy not een geweldiger, of onderichout, cn r of 6 kaffers heeft, met houwers en waklicte ftokken gewarpent, on de quandwilligen af te kecren, en des noods gevangen te nemen.

Hy word op die bediening gemeenlyk Koopman.

Zyn inkonen beftat in yo guld. Foldy ter maand, zonder meer, moerende het verdere uit boetens, cnz. vinden; doch tot een andere bediening overgande, wind by 60 guld, en heeft koopmans buiten - woordeelen. Een groot deel van zyn inkomen beltat mede dnar in, na hy wel of quallyl: by den Landroogt ftat, die hem, en in den Raad van Juftitie, en by indere voorvallen, met hec toeleggen wan veel, of " $t$ naau befnoejen der boetens, enz., zeer veel bevoordeden of benadeclen katri.

DeSoldy- De Soldy - boekhouder, zynde en Botkhou-onderkoopman, heett 40 guld., $5 \div \mathbf{R}$ ders det* koftgeld, en 4 kannen wyn "s mands: cen fober inkomen; doch darom, ne- $1 \sigma_{k} x_{1}$ vens den Geheinfehrywer (dat metle wan des Landyoogts gunft, en woor chtyvens na Batawia meet athangt) de natife tot een der mindere buitencomptoiren, als dat wan Poelo Ay, en Wayer.

De Geheimlichrywer, die onderkoop- De Gs man is, trekt zoo veet als de foldy-heimboekhouder"; doch heete duar en boven felarywer. een fatai inkomen wan alle uiterfte willen, getuiglehrifen, en alle andere openthare ftukken, dic hy maar alleen maken mag, watr' toc hy ook een byzonder comptoil' in 't kafted, of ontrent het huis van den Landvoogt, en ook den ceriten klerk, en zeker getal wan affiltenten tor ayn dienft heeft.

De Opperhoofden van Poclo Ay en De OpWryer zyn geneenelyk onderkooplieden. perhootDeze hebben mandelyks 'e zelye inko- podo men, als de foldyhoekhouder; doch $M y$ en trekken ook cenig licht, van kairzen en Wyyer. olie, hebben yder ecn finaje wooning; de certte in 'c talteel Revengie, de nindere in de logie op Wayer, en rerder. genieten zy. 't owerwigt der fpeceryen, nevens cen zeker tantum daags voor eenige lawen, die zy dan toe leveren.

Behalwen den Raad wan Politie heeft Dem Rasd men bicr ook een Rand wan Jultitic, woor des Gewelken alle borgetlyke en traffelyke zat- richts. ken alle week, of wel alle $1_{4}$ dagen, na de zatien vereiftchen, afgedun worden. Zy betiat nic de Leden wan den Politycquen Rand, die door een Lieutenant der borgery (de hoogtte borgerbediening hier, atzoó men 'er geen Capiticin heeft) en cenige andere van de roomaamite der zelwe, veriterkt, en by welke over alls de voornoemde zakken geoordeelt wotd, zoodanig nogtans, dat men van een wonris in 'cborgetlyke, of wan een proces, ria Batavit op den Rand van Jultitic aldaan zich berocpen kato.

Deze 3 Randen uit de borgery plagten Mo Rders "s jars an mantelgeld te trekketr.

Men hecte 'er ook een Weeskamer, Deweesdoor welke de zalken der weezen, by kamer. lieden wan cerag fatfoen en anzien nagelaten, en die middelen hebben, om van te beftan, op zekeren vaften dag behandelt . worden : want de kinderen der behoeftigen, en hunne ouders, worden of in "t Armenhuis aldaar ondefhouden, of de oudets kifgen miandelyles zoo veel wan de Diakony, als zy in redelykheid noodig hebberi.

Buiten dien is 'er ook een vergadering De Verwan klente en luwelykszaken, woor gadenis welte alle lieden, welker twiftzante der bleine minder dan $\mathrm{s} o 0$ Ruen bedragt, en ook en huwcnllen, die genegen zyn ondererouw te kyer doet, werfehymen, wan welke latefte alle dienasen der E. Matfichippy een verlof- 
IG t. "briefje, door den Landvoogt geteekent, medebrenger moeren, of $x y$ zouden gecnzins by die Vergaderiug tocgelanten worden.

De Men leeft hier ook cen Opper-en verWond- feheide Onderwondheders, zoo ten diente heelets. van het zickenhuis, 't kaftecl, en de feheepswerf, als wan alle andere bedienden der E. Maatichappy, en wan de borgery, doch buiten den Landwoogt, denT weeden, en nog eenige weinigen, moeten alle anderen hun jarlyks betalen. Ook lyeeft men Wondhexlers of Onderchirurgyns op Lonthoir, poelo $A y$, en andere pliatzen , daar bezctuing legt. Een Opperwondhecler" varn "t kafted luecte po, en, by "teindigen van zyn werband, 60 guld. s mands, en geniet koopmatns koftgeld en randioen 40 guld. wint.

De Men heeft bier een feliecpswerf ana

We there Welteinde van. Neira, digt by de Goo-

bans nong Api, wat op rich de febeeps- en andere timmerlieden, metzelnars, cnz. net hunne, baraen, onthouden, over welke cen opperfturuman wertbans is, die ook wel equipagiemeefter genannt wood, en die bezorgt, dat dar alles, volgens ordre wan den Landwoogt, werrigt word, whar wan hy "sarouds anden zelven, nevens andere baazen, berige doet, en dan weer vicuwen laft woor den polgenden dag ontfangt.

De Landwoogden, die men wan den beginne af hier gehad beef, nevens den tyd wan bunte regeting, wertoonen wy in deze newensgatude Lylt, uitgenomen vain den twoeden en derderi, welker regeertyd niet net angetcekent, of niet te winden is.

Eer wy van dese Land woogden aficheiden, moeten wy van dezen en gener rog iets zeggen.

De Heer De Landroogt Martyn Sond felynt Sonks ge-zich in Banda nict al te wel gedragen te drag. hebben, andigerien de Hees. Commifaris Herman wan Spoult in "t jaal 1623 . uitdrukFelyk dats na to uir Amboina gezonden wiert, met den Fiscalal yan de Brein, om nades zelfs gedrag natheurig onderzoek te doen. Doch uit etr brief det

- Heeren zeventienen wan den $1 y^{d e s}$ April I626. blykt ny klam, dat zy yaguas \$pecn, en Dotor Matimas Sonk thuis ontboden, om watn den ftant wan Japan en China mondeling berigt tan hath Ed: te geven. - ther:

De Hear De Heer When Yanstom Alwhad is Admis, cer amiterdatmze vothdeling, en in zyin ranls ganfch leven ect koddige han geweet. wonder. Hy wis voor flegt natr Indiën gevaasen; lyk leven, mas bragt het door zyne verdienten zoo yerre, dat hycert Schipper, en, nit verfelreide optredingen, Extraotinat Rad en Landrooge wan Janda, et in 't jatr

1626. ook Ordinaris Rand van Indičn 1523: wiend. Zyn gewoone wyze wan tpreken, als hy ier vooutbrengen zou, was, vooraf altyd, ik $z \mathrm{gg}$, it zeg, watrom hy ook reclryds it zerg, if zag, gemamt wierd. Opzeteren ayd hat hy zich zeer koltelyk gekleed, en werzogt ayn woornamite Riaden, dic mede wel uitgedoft waren, on met hem cen fpetresje na een der cilanden redoen. Dahgs te wooren had by den wertbatas. belatt de lichuit, die hy gebruiken wilde, en al de banken, wel te tecren; doch dit zei hy hen niet. Hy 't hootd, datar de lehuit lig, war in toen nog geels quarticrmeetter on te ftuturen, nog matrooxen, on te rocjen, พ:1

Hy makte niet veel uiterlylse belectheden, on an hen te wagten, of ze te doen roepen; matr ly fprong "er ten eerflen in, ging, hoe natt ook de banken nog vatide tect waten, ann 'b roe ziten, en zei tot hen: if zeg, if zop, datr cer Laudwooge an "t roer gant zitren, dati mag de Opperkopman, Fischl, en be andere Rautsperfoonen, yder wel een ricm in de hand nemen, en rocjen. ' $\angle y$ zagen wel op hun neus, geen gedagten hebbende wan dar gekomen te zon, on te roejen, en nog vet meer norden $\mathrm{zy}$ tegen die teerige banken; that of $\mathrm{zy}$ 'ct dit of dat tegen in bragten, zy moeticn mer die finije klecdercn op die bukkn gatan zitren, en nog brat rocjen toc; doch hen lougde dir phifiertje zoo (retwyl hy on hum bedorve klecren, en bebladerde banden in zys wuilt hachte) dat zy geen lult meer hadden, on met hem op en Tpeclicisje te gan.

In de tyd dat hy Banda beftiende, heef hyonog lang op Poeto Ay ecnige Mardyliers met 20 pratuwen gehouden, om op de gevlugte Buthanezen te palfen, en dus weele der zelve gewangen gekregen, die by ten eerlten, zonder eenig pleidoi, deed ophangen, of onthoofden, w. wat win nog weol hooften in zekere put op" Poelo Ay te vinden $2 y n$.

Dit malike hen voor dezen, ik teg, if zg, zoo bang, dat $z y$ dar, endders, zich op "it gebergte nict langer wetende te werfehuilen, tha dien tyd woommelyk woedvonden Banda te werlatent en pa de ellanden var groot ea klein Kev, Aroe, Gorar, Ooft-Ceran, Macular, enz. te wlugten.

Wanneer by uit Indich na "t Viderhat varen, en ha zyn rodip gatn zou, zeide hy-tegen en decl volk, die dat ontreme op de wal ftonden, monmen, ikzg, it

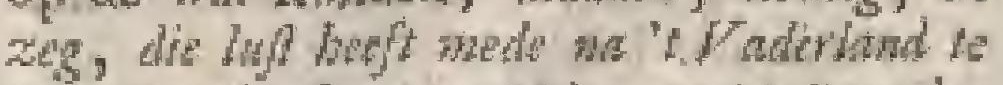

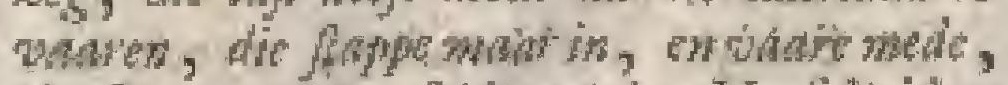

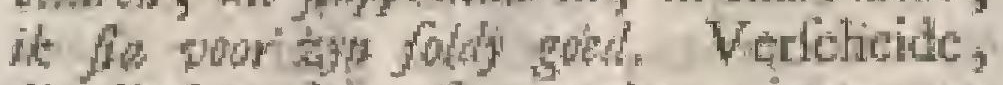
die dit hoorden's ftapten in, voerer met. 


\section{L \\ Y \\ S \\ $\mathrm{T}$ \\ Van de Landvoogden, Voorzitters, en Gezaghebbers van Banda, mitsgaders op wat tyd en tot hoe lang dezelve geregeert hebben.}

Lyft der Yacot do Bitter, eerte Landvoogt, regecrde wan Juni I6os. tot den 14 Augufti dat ftierf.

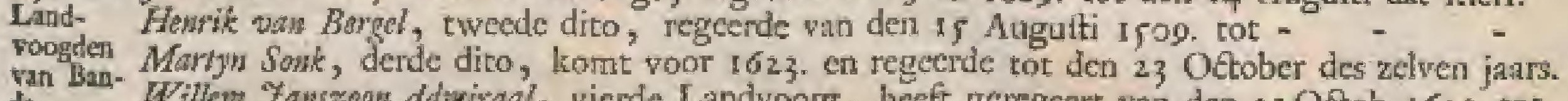

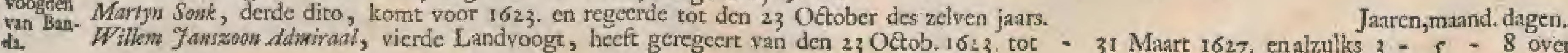

Dodtor Pieter Vhak, vylde Landroogt,

7an Janf Pt/feber, prowifionecl Vooritter, Arem Gardenys, als boven,

Kiyn van Ragmberg, zesde Landwoogt,

Fais simonzoos, provifioned Voorzitcer,

fais Simonzon, provifioned Voorzit

Fan Simouzons, provilioned Voorzitter,

Cornelis wan Otiboorn, negende Landyoogt, Abraban Weyss, provifioneel Voorzitrer,

Leonard vas Sorgen, voor cerft matas Gezanghebber,

Antoni Hurdt,
Emylt Sax,

Antosit wan Voorff, Hoofd,

Foames van $D$ wrm, elfde Landvoogt,

Jasob Kops, twaalfde Landvoogr,

Antow Hurdt, dertiende Landroogt,

Mawten Ross, provifioncel Gezaghebber,

Andries Bogard, vyfriende Landvoogt,

Cormils wan 2ualberg, zestiende Landroogt.

Willem van $Z$ Ill, Oppergezaghebber,

Willem Bafing, - provifioned Geztahicbber,

Cornelis Stul, provifionecl Gezaghebber,

Foamses Kops, agticnde Landwoogt

Baltbar Cortt, prowifionecl Gezighebber,

- - - - - negenticnde

en 23 Octob. $16: 3$, tot - 31 Maart 1627. en alzulks 3 $=5-8$ over Amboina na Batavia vertrokken.

Comilis Stul, twintigfte I

Andries wan Eps, provifioneel Gezaghcble

Gacob Classoon, provifioned Gezaghebicr;

Andries was Eps, ondertufichen Gezaghebber,

Theodoras de Hanze, ecnentwintiglte Landwoogt,

Matthens Schenkenheng, tweechtwintigfte Landvoogt,

Andries wan Eps, provifioneel Gezaghebber,

Philp Dowid vas Ucheles, vicrentwintigfte Landwoog

Pietcr Gabry, wy fentwintigfte Landwoogt,

Ball harar do Brovent zesentingitte Landvoogt,

Antow Hevafius, zevenentwintigfte Landwoogt,

Adriasn van Tets, agtentwintigtte Landvoogt,

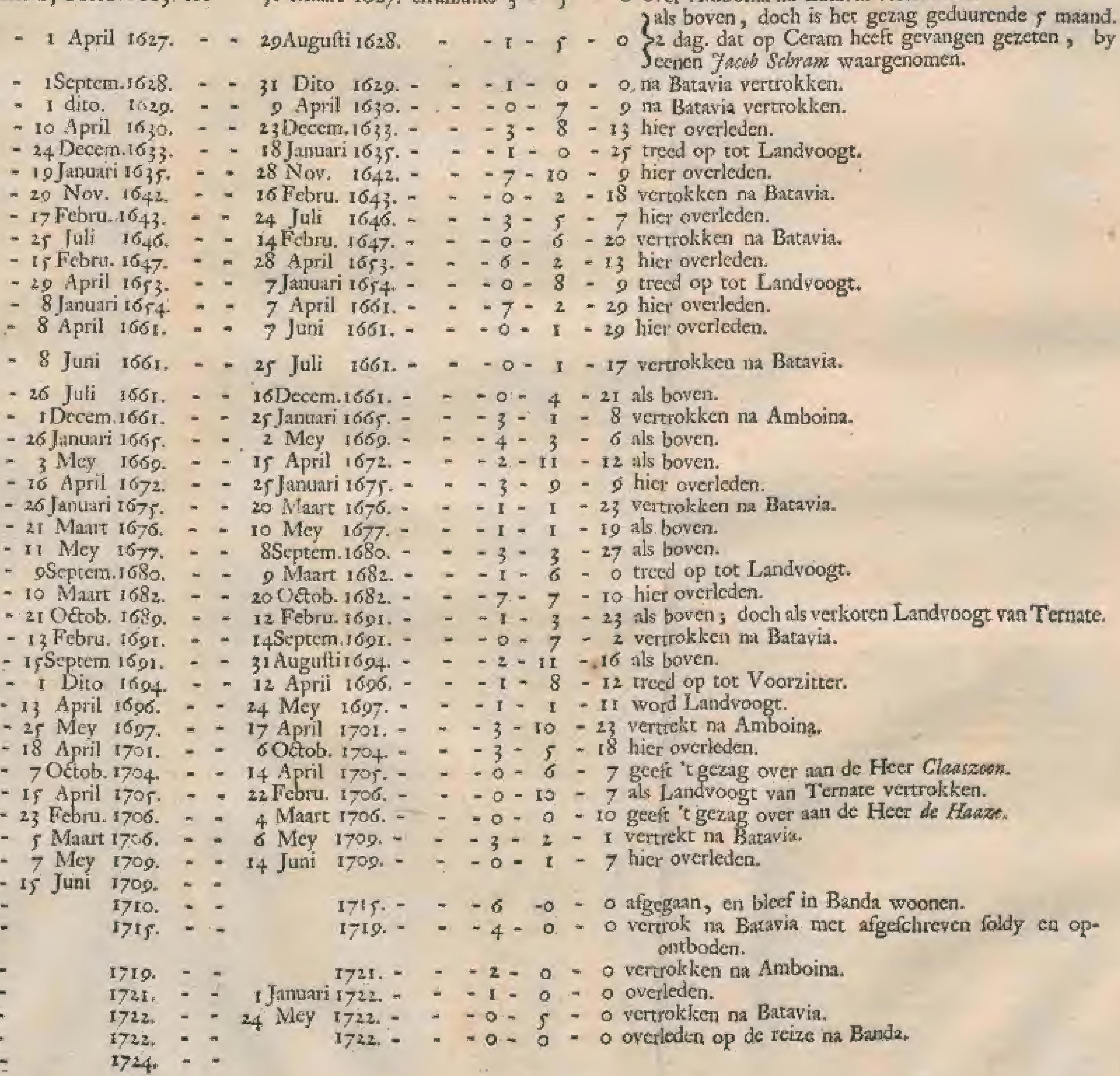




\section{Z A A}

I627. hem ni 'twaçerland, enty heefe ook bezorgt, dat zy lan foldy bekomen hebbeil.

Toen lyy cot Amiterdum quam, ontmoetce by twee vrouwen, de ene, die vootgat $\mathrm{z}$ yn moeder, en de andere, die zeide zyn minnemoen" of zooglter geweef te zyn. Tegen de eerlte zei hy: : ${ }^{2}$ zeg,

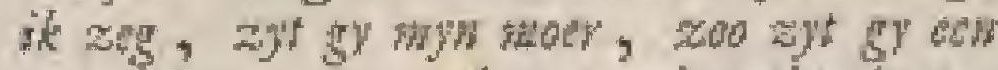
gropte baer, wh wed zetr onbarmbertig ste tweef, wn wy madr op de frant ("t geen hy wel wilt, ndergelget te beblen; on

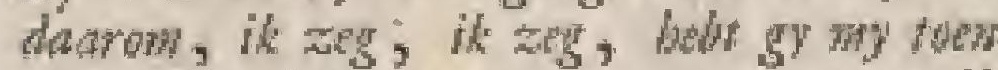

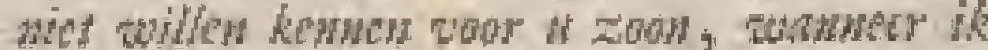
aitgenarch ben, en niets bal, zoo keme

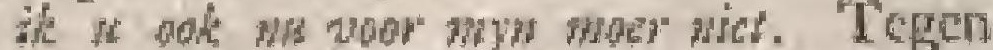
de nndere zeide $\mathrm{hy}$, it $z \mathrm{gg}$, it zeg, bebt

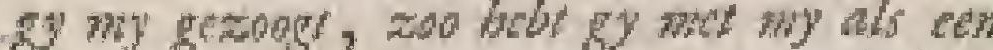
brave moder gedan, en gy zull bevindes,

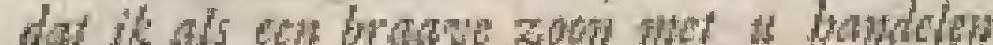

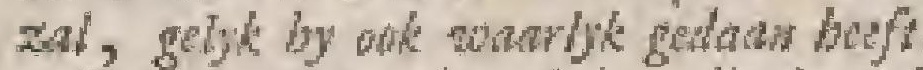

Ditarzwn "er ook weinig, die de Ireduit van den ouden Dernter (die men wil dar hy bouwde ) pool by gan, die rict het cen of "tander koddig verlual uit her levensbedryf wan dezen Fillen Fansolon (watn zoo wient ly doorgans genocme) mocten hooren. In zyo tyd was alles in De Heer Banda nog zeer woeft en wild; mat de ecnigzins Heer Pieter $\not{V}$ lak, dic onk een Ares was, in zytie heefe het hict behoorlyk in ordre gehedrywen brats

hier tore Hy is 't geweelt, die allerect de Perken, of ftukken lands, by kleine perceclen, uitgedect, de ltwaten afgeroyd, de Rind des Gerichts ingeftelr, tan het voornatume tot het ordentelyk beftier van deze nieuwe Landwoogdy verzorgt heet.

Deze Heen, den $28^{\text {hen }}$ Juli 1627, met cen orembati de viliee of ${ }^{5} \mathrm{r}$ bezoek agter "t Hoon Land zullende gath doen, nam den Upperkoopman Jagus Senear, zymen Capitein Nichas Colf, zymen Geheinjlchrywer Joac wat do pood, cu zekere fufrouw Maria Re/crs, mede; Z⿰氵 ge-mikt zyn foljeppers, ofte roejers, rankenis, Podo-1Rhunders zynde, voerden hem en ser- met zyn ganfch gezelfchap na Kellibon, vocting een doep op "t cilind Ceram, ats ith flatna Cerstis verny.

De Cerammers, zoo goeden bute hebbende, wilden ma geen woorwarden vin lostating of tatidoenering hooren, dan dut men eer'th alle Poelo-Rhunders op vrye vocten flellen modt, cen onmogelyke voorwiatde voor dic wan Banda om tha te lionen.

Ondertufchen vont de Ladudwoogt wan Zmm ver- Amboina, de Heer 'Jan wan Grom, poed, loiting a zich met i a Coricorit's den I then Oetober Heer wan derwarts te begeven; doch onderweeg Gotconn. hard wedea lingende, en weer te rug geratkt zyncle, is liy niet woor den $23^{\text {den }}$ dito thet 9 Corncorn"s in Banda ge-
K E N.

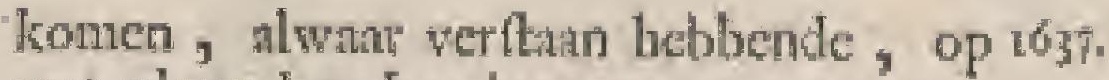
wat platits hun Landvoogt gevangen zat, is hy datr na toe gefehept, en den $2^{\text {dea }}$ November nangelind.

Dan vielen in 'tecrft werlcheide hevige woorden, en dreigementen, tan wederzyden; mar die wan Kellibon, wel ziende, dat hen de vrede beft geleek, gawen den Landwoogt $V / d k$, mer zyn gezelfchap iutgenotuen den Heer Semongdr, die al lang te vooren, na Banda willende overtteken, weggeraakte, zonder dit men oit meet wh hem hoorde, en die aldus warfchynelyk verdronken is ) zonder eenig randwoen te vorderen, atn de Heer vas Gonkon over, dic zynen Ampegenoot den roden November zeer ziekelyk in Amboina bragt, wan wat by, wat bekomen zynde, den $22^{\text {lita }}$ December met 2 fehepen weer na Banda wertrok.

Hy vereerde ecrige goude penmingen nan eevige Radja's en Urangkinen, die henis met hume Coracort's waren komen verloften, onder welle ooli de Ridja"s of koningen wan Soja en Hoetoemoeri, bevevens de Gnatohoedi geweelt, in welker fumilien diergelyke penzingen

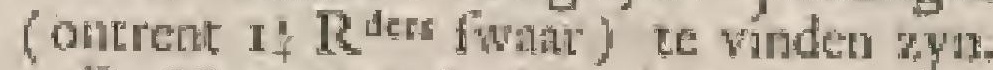

De Heer Cornelis Acoloy is cen man van groote verdientte, en vin weel ngting by de Bandanezen, geweett.

Hy ntm in 's par" 1634 . die van 't ge- De Heet fpalchap Cottarocwa (beftande in de Acolcyts dorpen Gelor, Kellemoeri, Kellibon, vertigurinAffin, Diwan, Amoclit, Whatcloni gen Onder, en Banmer) als ook die wan "t eiland Goram, wreezende ${ }^{3}$ Compignies gnteche magt op hun dalk te krygen, tha vect biddens en frneekens, weer in genude atu, natikende met hen diț nawolgende gefchrit wan werzoeing.

\section{W}

$Y$ Comelis Acolcy, Landinogr on Beflerder wegens des Nederlandfon

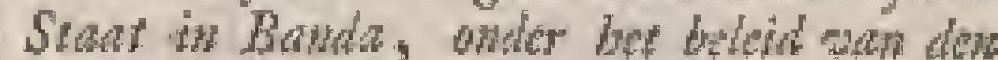
Edelev $H_{c} r^{2}$ Antoni van Diemen, Opperlandoudg wah gan/d Nedolends Indin, doch re waten, bo dat op 't cri/tig bidden en oolmoedig werzok for extreffe dow toe

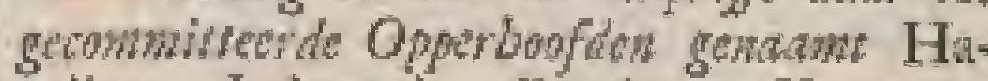
talima, Labicuda, Comboret Kaywan, Marika, Tibo, Labi, Malcyo, en Tittollo, van de reforiwe Dorpen Gatelowe, Awner, Duy, Ondei, Ainchor, Kelacket, Miern, Minda, en Reloftror, alle geleren of "I ciland Goran, na gow berigt ch oudobawling, tot difnte reizen gebouden, whar in de wow desen bedrewe fouten to vendig zy entoont, Hworgen ma fonddb-

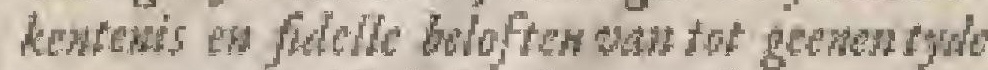
its tegen do Nedelanders, of der zelwer Sint, wa, wogte nimmermeer, in "telew of 1 groot te zallon attenteren, wed min is dulder, de gering fe onlafen on wan ben wiet 
te versorgen, dat ons vin bes ale bulp en

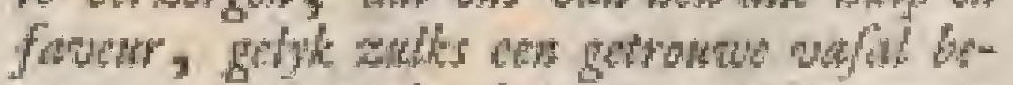
tuom, zall wordes betoont, cel dat wy in allos worden rebooraant, wata op zy don wis de Nederland/de Geoployerde Oogindifle Compagres en des zelfs Regenten in dit wedeverbond wecr atugenonen worden, fueshatwen ben on werforide insigten, ons doar toe mawernde, buar worig bolw yf met allect vergeven is, madr wat of wy ook nade" wet aldys wan onzen Rade we" ben in whwic on con cowig werdng gotredes ayn, en lsen als onze bondgenoten en ge-

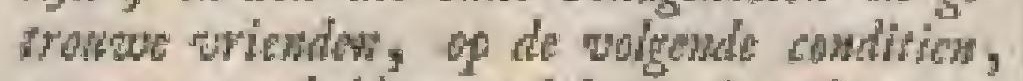
acngevones babon, gelyk wy de zitic aanwemen, w dad wor crkenen wis dexen; dienvolgende blowen, en foum de gemelde Orangkata's man Catelowe, Atumer, Day, Onde, Ainckor, Lelecker, Mieren, Minda,

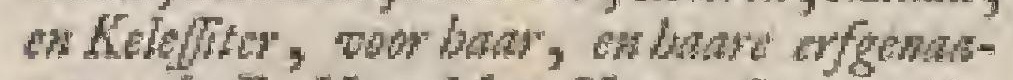
wes, de E. Howg Mog: Heren Srater Gewerad der Ferecuigde Nederlawin, zy Forfelyke Genade, don Prime wan Orangie,

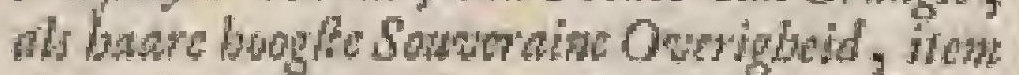
der zelver General, en des Gownernter der guarieren Bawla, gebow en gerown te zelles zyo tot don lat/fen adem lot, onder wolken ed de gendle Oranglafa's roezgggen,

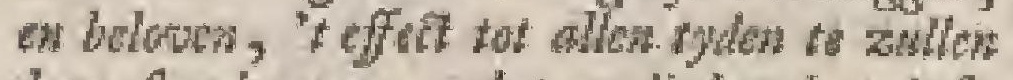
den fandgrpen; dat zy lielen de minto correfpondente mot geche wanden ean den Stan', boedang, van wat condite, natit, of suruse, de zelwe ad sondes mogen weszon, wimant uitgezondent, bouden, en wel min ben wame baven, of shecden rot fowit plastan veriecnew, of de minfle forterex

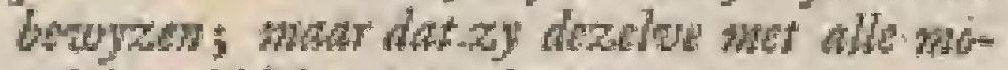
golyke middelen wan dart weeren, en zulls der Hoe Gowewnem wan Banda wa do befe gelegerbid to kamors gewon zallen. How, dat, by werlop wan plawen, enandere, de zhlon onder ordinatir berglaon en werterdis kofen, in redolybeh befaande, zonder enige friwle oxtenfen, in banden wan gewelien Her Gonverwedr loweren, en banr bof, zoo wed ben wogelyt is, zulles zockn to beworderen, gellk zy bew ook sen boggfon werbonden bouden op bot bowd wan weer gewelde Her Gwownew (dob wist dan by den wherfer nood) batw Coracora's in 'touater af se badon, en ben, bueffens zindeds magt, in alle getrowibed, zonder Tgentegsen, theden; an dit alle op pene

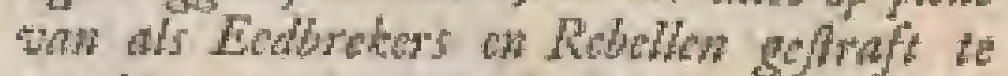
worden; wor "to tulke de nuergemilde Orang-

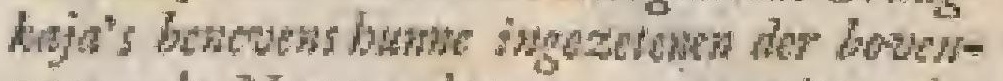

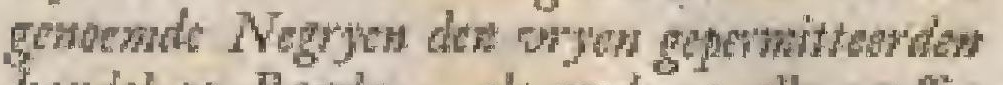
bandel of Basda, als mode op alle geafocaterde Nederlandfbs plantzen, ondar en behorlyke falfi, geneten, gelyk wy bew bok ale wiendlcbos zollew dow jmakew, en bo onder ange beflerwinge nemen, 200 als dal en setrow Heer, en goddrticren Vorfl benam, en met onge confintion

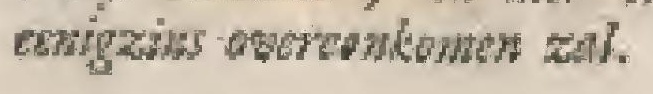

\section{A $S$ C $\mathrm{H}$ E}

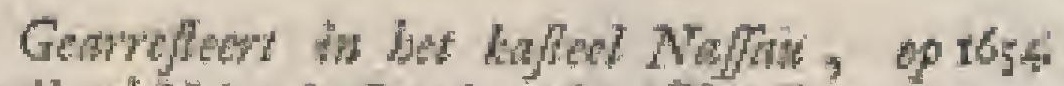
"I ciland Newa in Benda, dess 28 insa Decomber 'sjanars 1637. Was geteekent Cornclis Acolcy. Thy zyder Rositen cengre Ara

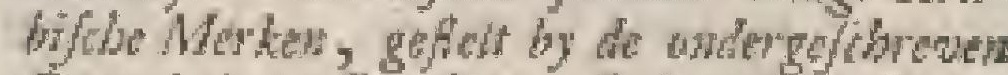
Orangknje"s Batalima. Lubacuda. Combowet. Ciyswan. Maritka. Tibo. Labi Libi. Maleyo. Tuxollo.

Onder dezen Heer Landvoogt Comehs Aculey, glam in "t juar 1638 . den $27^{\text {flem }}$ Februari, hier uit Amboina, met "t fohip Froderik Henrik, werzeld van het fehip Bommel, de Opperlandwooge van Indiên, de Ed: Heer Antowi wan Dicmer Hy bragt met zich Mewroww zyue Gemalin, den Ed: Heer Antomi Cann, Rand Wan Jndien, nevens zyn lyfwage wat belbaandiers, en drie vaandels foldaten.

De voorname reden van zyn Edelheids komit was, dat zyn Ed:, den koning van Ternate niet tyds genoeg in Amboina mangetroffen hebbende, met zyne tegenwoordigheid ondertuftchen hies nog cenigen dienft meinde te dont].

De Herr Landwoogt zone $2 \%$ Edelh. twee zyner voomatrite bedtienden, te weten, den Heer Gerayd Dewmer, oppejkooptnan en tweede Pertoon, ner ens de Heer Nicolas de Wild, Fiscual slfier, on zyn Ed. te verwelkonen, cin ann land ta geleiden.

Den I itm Mare vertrok zyn Edelheid rua 't Hoog Land wan Bunda, bezas darar de comptoiren Lonthoir, Oerien, Wajer, den Ouden Denner, en Cehama, welkers Iratite Reduit zyn Ld. Kuilenburg, na zyn geboorteplants, noemde. Ook bezng zyn Edelheid de Perken, of borgerhuizen en plantagien man de overzyde, mitsgaders Poelo Pieflang, digt by den hoek van Neira gelegen, en by zommige fpotsgewyze Poelo Parampoewan, dat is 't vrouwen ciland (om dat zy' 'er gatifh niec op wallen) genamt.

Ook ging dé Opperlandwoogt den r $g^{\text {den }}$ dito na de eilanden Ay en Rhura, hoorde onderweeg, chat "er een Engelfch ichip, de George genaant, voor Poclo Rhun lag, 't geen 'tyn Ed. 's anderen datgs nader' bleek, wanneer de Hect Jobor $1 \mathrm{~h}$ ver, Fietoor der Engelfohe Natic op Macallar, by zyn Ed. quam, verzoekende op dic Eiland weer bezitring te mogen nemen, ren welken einde hy (dic zcide dit niet eer te hebben konnen doen) ook cenig volk mede gebrage had; matr de Heer Opperlandwoogt gaf zeer bondige redienen, wairom zyn Ed. hem dit nu, alzoo' de tyd, datar toe geltclt, al hang voorby wis, niet kon toeftaan. Een zank, die onder Poclo Rhup reets behaudele is.

Dus quam dan de Heer wan Dicmes, en dezo Engelman met zya fchip, detr 


\section{Z A A K E N.}

1653. 220ten dito vain Poclo Rhum woor Nein ann en de lantite wertrok deu $26^{\text {iten }}$ dito met zynen boden mal" Macaliur.

Den 27 then dieo gaf de Heer win Dienen hict een pragtig affcheidsural nan I 2 r perfoonen, ging den 28 lee dito na boord en vertrok den $29^{\text {then }}$ dito met de reheperi Frederik Henrik, Bommel, Wallrnond, en nog een ander, weer natr Amboiliat,

Metecn letter moet ik hiet by wocgen, dat in 'r jatr' 6 636. den I lles Maart ook het Engeffel Iclip, de Paerl, noor" het dorp Lochum, op "c eiland Rhwir, verfcheenen zynde, de Hecr Acolg zich in perfoon derwatsts begat." Daags "cre atan tonte xyn Ed. de twee opperliooplieden, de Hecren Gerard Denwer en Piere WFinson, en den lieutenunt forfendong derwatats, ofn der Engetfehen koopman, Rendor 'Jofow, vandat cilitad met zyn folip te daen vertrekken, alroo de gantche bezetzing aldat toen masr in 12 foldater en 15 flaten beitons. Hyweigerde dit, zeggende, van zynen Heer. Voorzitter op Buntan mata gezonder te zyn, ora dat: ciland te bezicin, verzoekende, dat dic. vefting niet met meer volk bezet mogt workln voon inader ordre zyner Heeren Principalen; whir op hy den I dea Mante vertiok. Doch de woornoemde Huter fohyne op zyn berigt nederland herwarts gekomen te zyil, on icts van gewigt op dit eiland (dat de Heet wam Diowen door zyt atuwezen verhindert hecf) te ondetnemen.

De Hecr $A$ rolam $W$ ews is hier en De Hear zect loffelyk Litulwoogt, en cels man gebefchre- woeth, die zyn ecre itelde, in de menven fehen ten beite, cn tot vrede niet alleen te suden, watu ook buten pleydotjen te bouden, 't geen ook de reden whs, dat by zeer weming vergadermg van de Ratd des Gericlits hick, alzoo "cr by nim nicts wins, "tgeen hy niee in der minne deed afmatken, of zelt' buiten ecuig pleydoi ten cinde bragt; Joewel ik 'er wel gekent heb, die on de 4 of $r$ mandes eens vergaldering beleidet, on de pleidoijers te langer te doen dusten, en om de menfoben, dic dint na wagten moeften, te bederven. Hy wien in 't jatr 1660 . Exentordinar Rant van Indién. Als nok De Heer fodan wan Dam, uiggekomen
de Heer als vy Doetor, wien naderhand om cen van Datn. wakkere datd, die wy elders werhalen zullen, tor Sergeant Majoor van Batavia; cn I $66 \mathrm{r}$. tor Landwoogt hicr gewordert, alwatis tot 't jour ro6r. geblewen isnde. wertrok hy in dar zelwe juar in Februnrii ruar Amboilia, om de zralken aldar, als de watle Bundwoogt an Amboina gelcgen, by 't overlyden tan den Hecr Latndvoogt Simon Cor, wan naby te befchouwen. Wat mislyk vooryal hy datr, en verder op Batavia mee de Weduwe van $16 \mathrm{~L}$ : dien Heer, zyn trouwlooke bruid, en mee den Opperlindvooge, de Heer Johen Mata/nike, had, hebben wy rects onder de floffe vin Amboina en de Moluccos werhatalt.

Hy was cen korzelig man, wiert gemeenelyk, Jan wat de lowe Brock, om dat lyy weel met een lnnge Misquitenbroek ging, of ook wel de Lange $7 \mathrm{fu}$ genamt. Met zyn tweeden, den Hecr 2 wioni Hich die anders een briaf man was; kon by ganfchelyk niet oweren komen, watrom die ook in 't jatr' I664. ma Bacavia wertrekken moelt; cn door den Heer Anowde vervangen wiert. Hy was anders een dipper man voor zyn wyind, waar van hy verfchide deftige blyken gegeven hecf.

De Heer Jacol Cops, die hem in 't jau De Heer 665. verving, lag nice minder met zy- colstes nen oppertoopman, de Heer Amowde, nog in dar zdwe jar, overhoop, zettende hem gevangen, ma dat hy hem met 4 foldatien wan de Sectecary, terwyl hy felyoef (altoo hy roen ook geheinfeluryver was) met geweld had fatiten afharinlen; zoo dat hat Hoog Edelheden, die dit zeer qualyt mamen, hem na Bativia onbieden moetten, otdonnerende hem in 't zelfde jiat, al whs "tmet een huuchatoep over Amban te stenden, datu by in November annquam, vertrektende in to jal 1666. wan detir na Biltuvia.

Deze Heer beefe daa ats Lntndvoogt zeer fors geregeert, en by die ingezetenen ten llegten buim gehat, on dat by zeer inhalende en baatzugtíg was ; dat hy over al, dat hy geweett is, getoont heeft; ook was hy zed eigerzinnig, ganfch niec infchiktsende, willende ditt alles woor hem zou opdrajen; "t gech hen, gelyk wy onder Ambotion zieid, zecr quatily opgebroken is. Ondertusfehen is 'er" in 't jair 1670. cen verbond, in de tyd war de Heer forrdt, met dio wan Keffing en Rarakir gentalit.

De Hecr Conth wal Quallor, een De Heet zect. Forzelig man, wel een goed foldut van: (gelyk by 1673 . in Auguttus toonde, Quatroes hy uls Commandeur aver I 3 fche- heres bepen der E: Matafchappy regen to Engel- hier. Iche fel hepen flocg, cn, nit 4 umen vegtens, humnen Onderzeevoogt met 4 f itulden, den. Prefident genatmo, humen Schoutbynache, de Samfon net jo ftukken, en de Entilope met 34 ftukken, veroverde, doch een al te hulatig, en zeer ongemakkelyk Beflecter, die by na over al, zoo ann de Kup (vun wat hy ter ordre der Hecten zeventienen in st flat 1668 , tchoon dur Commateur zynile, iffigezer nat Butavia gezonden wiert) als op Malackn, en dau lyy gelegen heef, met de vooname Bedienden mocjelyleheden, en $\mathrm{M}_{2}$ 
$\begin{array}{lllll}92 & B & A & N & D\end{array}$ Perioon, den Opperkoopman Martes Roos, gehad heeft. Hy zettc hem ook ecoigen tyd gerangen, en zont hem met zya proces nai Batavia, 't geen Roos dant won.

Onder dezen Landwoogt is 'er door werfeheide perloonen een toge ma de top wath de Goenong Api gedaan, onder welke, zoo my zyne Gemilin in 't jiar 1686. op Batavia gezegt heeft, een Keizer, Koning, Hertog , en Graaf (dat is, perroonen, dien naim vocwende) geweeft $z y n$.

Hy is vervangen dow den Heer Willem De Heer

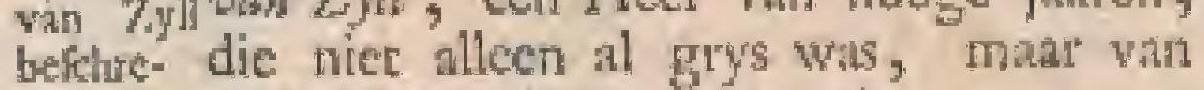
ven. ouderdon ook vry krom ging.

Van dezen Heer bebben de Bandarche borgers menigmaal zeer verigtelyk gefproken, om dac by nu en daur dé dronken bazzen, dic han werk niet wel reprige, en zich vol gedronken hadden, wel een ftreck met wyn dilken rorting met een zilvere knop (dicn zy de fes met de zilvere fehroef noemden gegewen hand; maar zy hebben hem (hoewel hy dat flagn wel kon gelaten, en ben op een andere wyze geltraft hebben) groot ongelyk nangedain, en vaderhand dar weel berouw wan gechad, toen zy andaren kregen, die hen ten uiterfte geplangt hésben

Hy was warrlyk, en buicen ecnige drift gefproken, ecn vroom, eerlyk man, en ecn zeer getrouw dienaar val de E: Mantfchappy; cen Hees, dieatgting voor braste, bequame en natartige lieden; miar ook en doodelyke hate tegen luinards en dronkarats had. De ecrtten licip hy woort, mar de anderen ftrifte en vervolgde hy. Hy was nict alloen nict bantagtig, of inharatende (een gebick van weel Landvoogden) mant in tegended zeer milddardig, en gulherrig ontrent die geen, die dit werdienden. Van zyne mildandigheid heeft lyy een groot bewysgegeven, warneer hy (celioon by de aurdbeying in Amboin in 't jan 1674 , zyn vroim, kinderen, en huis, wee alle zyn goederen, die beneden, en nier boven indevelting waren, weg(troomden) wcl 20 jairen lang zyne jawlykze foldyc, zoo lang als hy Upperkoopman, af Landroogt geweelt is (dat in II jarren wegrens zyn eerfte bodiening Izroo guld, wegens g junten wan zyn tweede bediening 21600 , en dus te zamert 33700 guld.' bedrangt) atin zyn zufters. kinderen in " $t$, waderland (dic het egter nict al to zeer war nooden hadden, alzoo hat zom, N: Roodenberg's Predikant op ecn dorp in Zeeknd was, d daar hys 't zeer wel had) zeorigulhertig heof thaten trekken, whar' varh ik, nog in Indien, 'noge in "t wadehtand, ecnig diergelyk vootbeeld wan anilhdandigheid oit meer gehoort- hebber - that;

\section{A $\quad \mathrm{S} \quad \mathrm{C} \quad \mathrm{H} \quad \mathrm{E}$}

Noit was by gewoon te parard ecn tur teso. of anderhalf uit te ryden, of by deed zyne oppthers, die hem te woet gevolge hadder, altyd 2, endendergeane, of corportal, 3 glazen Tranfelae of Rhynfelie Wyo, ni due ly dar zelf dronk, atatonis na zyn wederkomt, dat ik menigmasl zelf gezien heb, en in zyn bywezen, op dat zyn fharen hem hier in riet bedrieger zouden, felwenken.

Non heb ik, die cenige manden by hen gewoont heb, en zeer belexif en gullhereig van zyn Ed, onthale ben, eenig gerchit mer bem, dhat illeer daitr over gehnd, dur it hem noit 't een of "tander voor my zelven werzoge, hoewel hy my wie zich zelven zoo weel diente poutant? en $700 \mathrm{reel}$ belectiheden bewezen Ind, dat ik wel ondankbar geweet moeft $2 y \pi$, indien ik zoo een milddadig Heer roge ergens om voor my lidd willen ver zocken.

Noit deed its zyn Ed, voor ect ander eenig billyk verzoek, dnt al zomtyds gefetricd is, of zyo Ed, heeft het my tocgattan.

Met zyn ' $T$ weeden, en andene Rnadsperfornes, beefe hy in veel wrede en ruft toe zya dood toc geleelt; en pan zyoc wroomheid en cerlyketh is by myn anh wezen nog cen blyk, die ik hier rocde tot zyn lof wheckenen moer, roorgewalien. Zeker Perkenier, op een was zyn medeperkeniers, on dan 2 yn Ed. hem gowtlig was, zeer rydig zynde, quan den zelven op zekeren motgen, als ecm man, dio qualyk van den Lindwooge fohk, by ayn Ed. anbrengen, war over lay een=gren tyd wat onchute was, alzoo by geloofle, dat die man hem de wasthed gezege had. Zyn Ed deed my de cer wat my dir geval mede te deelen, wrangende, hoe my dit van een man, die hy zoo menigmal beguntige had, woorquan; its wi, dat il let nier geloofde, th dat ik zyn Ed., om dit rege te weten, randde, acen befchuldigden en dew befchuldiger op eenen tyd zamen woor hesm te ontbieden: want dir anderstzyn fyiaden in ftiac. watea, om altyd zyobelte vrienden by hem werdige te matien. De Heor worn $Z y h$ phecs die, en ricp: ze beiden vor hem. De befchuldiger was 'er ecrlt; mar coen hy den befohutdigden binnen komen zag, beftierf hy doodciyls. De Landwoogr deed ana den belichuldigden ect roorthel war deibefehuldigring; ; mane eer by zich dutr-ower eens reche verintwoord, en zyan alide atrigewezen had, vicl de muder aldectiyle door de minde, co bid am vergiffenis. Uit dit geval blykt ook Hint, dne by een - Heer was edic zich in Fatakt, die dat Joden konden, zeer geeme na de goeder rand van anderen richen-wilde.

$\mathrm{Z} y \mathrm{n}$ 


\section{Z A A K $\quad$ E N}

I694 Zyn Ed. is "wervangen door den Heer Jounser Cobs, zoon wan de Hecr Jacob Cops, De jonge diens meefte werk danr geweeft is, om Cops in zich and de Perlieniets, die zyn Wader nict zWn be- genoeg ingerolge, en de Hect Hord, thier an-zyn opsolger, noee andgehangen hadgemerit. den, op her bitterfle te wreeken, wat w over hy ools Aarl Antontsan Pener (alias Ant Haw Ho gendamt) zoo lang vervolge hect, tot hy genootaakt geweelt is, mec zyn huisgezis op to bieken, en na Batavita te gatn woonen.

Hy was een llegtBeltierder, een man van zeer weing werttand, en die weinis werk wan zyo dientt makte. Hy is egter naderhand (fehoon tyy, zonder ordentelyk door han Edelheden werloft te zyo, op zyn eigen gezng mar uit Band: op Bacavis quans Rand wan Indien, en zelf nog Ondinair Rand gewordens miar by makte her duar van tyd tot tyd, met byn noit in Vergadering te komes, 200 dlegt, dat hy op de klagte van den Opperlandwoogt, de Hect 'Gan wan Hoom, dat over wir het Vaderland bedaskt wiert.

Alo ook De Heer Cojot werwing hen, zynde de Heer met "er tyd Landwoogt geworden in wen Copets. plitats, dar ayn wakkere Vader als Bandiet (hoewel onfchuldig, zoo men meinde, en nileendoon de bitrere hate wan de Hecr Nicoldas $V$ crbtrg) gelect had.

Deze Heer had hier mede den beften retk niet. Een preuwe das yan was een geval, in "t jatr 1697 of 1698 . aldat gebente. Zeker Perkenier, in de Lnoctan, Yon Panlwszón (zoó my dooe zcken Hecr verlatalt is) van zyn fichoonzoon, Card Harder, belchuldigt zynde, dat zyn Aaraven een lokkel Foeli by cen derden, Barent de Bakker genaunt, gebragt hadden, on die an vremdelingen, tegen 't placcat, te verkoopen, 200 wient hiter nog by sevoege, dat des cerfte 's vrouw, cen zeer jiloers wyf, dit alles mede wel wilt.

Hier op ontbood de Hacr Cojett deze rouw, dic tit hem alles zect om thandig zei; what op $z y$, cn hatr min, en ools die, tot wicn de fokkel gebrage was, exigen ryd ling gevangen gehouden, hoewel zy en hatr man, no cenigen tyd ontlagen wierden. Maar augesten dic mun hem mogelylk voor die guntt nict na zynzin, of wel gaulch niee, bcloonde (velmits hy zeer bantzagtig was, 't geen hy niddagktar in Amboina getoont heeft, vone hy good het Petk, de Latoetang, den eerften Perkenier, zondet een proces "er over to maken, if te nemen, en antr Carel Harder, by fchatting (guntswys) woor $6000 \mathbf{R}^{\text {dens }}$, dhat het wel ecus zoo vecl wardig was, over te doen gever; watrin de eigenait, gitlieh misnocgt, goed wont ditar frut atith hath Hoog Edelheden kennis te 170 . geven.

De Hooge Regering wan Indien be* wont dit tuk in allen declen zect flordig, en ten uiseriten onsechtreerdig; dar men een man, zelf zonder" het corpus drith eens geronden te hebben, mat op een enkele befchuldiging, en zonder eenige geregrelyke aniprank, of onderzock, met geweld uit zyn goed zetrede. $\mathrm{Zy}$ Ichreven "cr atan hem, collen Rnad, wel zecr feherp over; mand de man heeft zyn Perk niet woder gekregen, flowg hier over ath den dronk, en is vitn droctheid het beftorwen. Hy nim, by zyn vertrek uit Banda natr Amboina, Jounes Lawotitus, gewezen Hooft wan Mauritius, en onk cenige fwate misbedryven noringein gebunnen, mee zich, hebbende op Mauritius by zyn uittoge wan hem betcetheid genoten; doch hatr Edellacden ordonneerden hem don zelven weer nat Banda te zenden.

Noit hebben de Bandaneezen een erger fen de Lntwoogt, als den Hoer Theodors de Heer do Hase, geluad.

Zy zeggen, dat lyy garfeh landa, matr Poclo Ay wooral, bedorven, en weel ingezetenen allhier zeer arm gemankt heeft. $\mathrm{Hy}$, die gelds genoeg bid, wilde walf 'er geen geld winnen, om te toonen, dac hy cen goed dional der E. Maut fchappy,

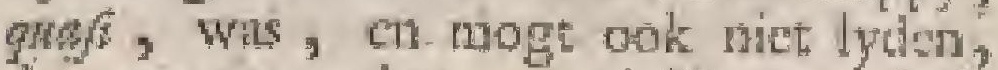
dar yemane suders, jot zelfs zyn eigen Tweede, en fwager, de Heer ran $\mathrm{Lph}_{\mathrm{p}}$ want mede hy ook geduuaig aver hoop hag, het sllerainite won; on wellice reden hy hen ook van tyd toi tyd de garifche vart zogrt te bestetten, on ze lus, als rotzen in de wil, geheel te doen titAterven; weshalwen de Heer do Hoze date ower wel ernitig an har Edelheden bheef; hoewel her juif den uitflag, dien by verwagte, nict lisd.

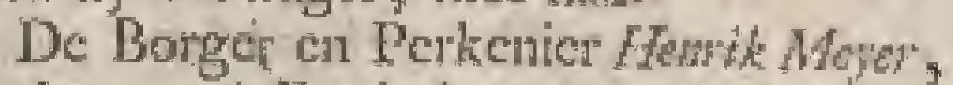
die hy woor 't Roche betrokken batd, wilde lyy atr de gitg, of ten minften op het fchavot hebben, watom by hen in d'ene. week zyn proses tegenwes ; mitar dic man dasar wan zichs na Batawia beroepende, en lyy, door ex reisje na Poelo Piefling, hem de getegenheid, rot mureckening: wan dit appel, zockende at te fiyden, wicre juit,, als hy op "c hoole quam, duarom verzoge. Hy trigte het wel te ontgann; doch velonits die man hom dreigde, alzoo de tyd wor zyn weder" komit voorby zou zyn, dari teycen te zullen protelteren, zcide hy cindelyk, nu, wy zullén zien, hoe wy het ftelken, en u genoegen geven. En datr op wees die zelve Landrooge me zynen Riad des Gerichs: (denlit cens hoe die Rad van een Landwooge athangen moet) een en de zelwe zank, die Meyr de weck te $\mathrm{M}_{3}$ 
A S C $\mathrm{H}$ E

ifog: Fooren verlooren had, in de solgende week tot zyn voordecl hit. Een dubbelt vounis, "t geen zelier Procureur op Batiavia, om de zeldzambeid, in twee bordekens, in 't net gefchreven, matt den anderen, als cen wan $x y$ befte folvilderyen, in zyn voorthuis ophing.

Hy zont ook op wekeren tyd dezen

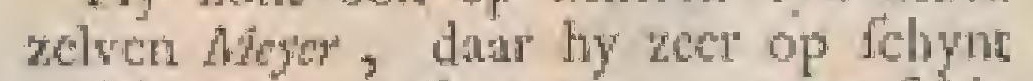
verbittert geweeft we zy, ract cen felip na Batavia, en wilde, dat lyy 'er geboeid na toe gan zor, hoewel dit niet gelchied is. De Perkenter, Whilen Hergé, was derwares wertroken, doch by had zich onder de beftelgoederen in de Konttapels lamer mocken verlteken. Fu hoewel Carl Hoder met zyn chaloep, en ect pascedul, naweel nobeite, derwarts wertrokken was, had by egter in de papiejen der E. Matulchippy vin dat jasi geen beter nam, din de anderen.

$\mathrm{Hy}$ befchuldigde dese dric, houdende

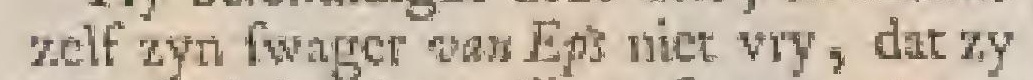
"t kafteel hadden willen afloopen, " zoo my cenige wa deze lioden welf gezegt luebben; mar lmat Edelheden wonden dezc belchuliging al zoo zot, als ouwanrgtig.

Hy malkte het hier eindelyk zoo grof met alle oyne tymaniche zottigheden, dat de Borgers en Perkeniers, en vooral Corl Harder, het niet lunger konnende brirden, en vreezende, dat hy hen nog de keel Eocbinden zol, goedwonden gezamentlyk over hen mil Thavia te kligen; will op batar Edelheden den Heer Scbenkenberg hier gezonden, en hem geordonnecer hebben ma Batavia te komen,

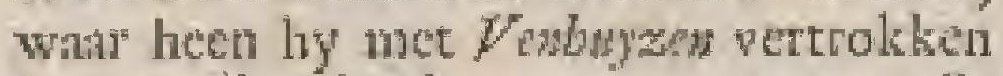
is, zonder dat hem cgrer wegens alle dic zottigheden, en geweldenaryen, datr over hem de Fischal behoove angelproken te hebben, het mintte leed geleinet is. Zoo dat het ect Latudvoogt, als lyy gunit wan Hoogertitnd heefe, wry1hat atan de ingezetericn alles, wat ly mast wil, thrnfteloos te doen; drut men by andere gevalled (als atu den Ouden Hect Coret, en de Hecr Jacob Copr, toen hy uit Amboina vertrok, als oole taț de Heer Hof waw, en whderen, bleck) wanneer men de gunlt van" "t Hoogerhuis niet heet, een Litudvoogt zoo wel, als een funder, doot den Fischili doen atnfpreket, alzetten, ch zelf op 'e fichur heeft woten te brengen.

Wat hier de reden van geweeft is, weer it niet; matr zeg allecen, dat zyue zottigheden en geweldenatryen zoo litar gebleken zyn, dat men heri wu duar heef moeten ontbieden, en dat hy over al die valfehe belchuldigingen, oprendingen, en over "t pligeñ wan zoo wed menfelien nict ecns gemocit, veel min iet gelecte is; wat her welke men hec nate

oordecles moet, dat hy vicr witte ipeg. voeten gehad heef, en dat het den 115 call, die hem anders wel gevonden zou hebben, wartfelsynelyk wel verboden geweet is. Ja zyn portigheden en hutsgeweldenatryen waten matt weinig weeken na zyn trodwen net een brave vrous, dic hy nict wandig was, 200 groot, dat ly de zelve, die by buar voorigen mus tyd, ats zeer veritudig alles beltierd had, zeer geerue ( $200 \mathrm{zy}$ matr zoo zot, als hy, gewedt was onder 'e beftier wan wy Aawen zon getteli hebberr, all2oo dic de fleutels van alles landder, wall door zy duidelyk zig, dat zy 'cr op die wyze volkomen thus lag, matr deze Mewouw, zulk eun lewen wiet gewoon, en niet genegen zynde dir langes op te volgen, min dast na haren flarg (wasmeer by zelf zei, niet genegen te zyt om by laar te blywen, om dhat $z y$, dic ontrent 100000 Rders bezat, 200 reel nint bad, als hy wel gedaut, of $2 y$ opgegeven had, en on dat er esrigge uititstande felulden onder wiren, die zoo atuftonss op zytren cilch nist inquanen) zoo wel whar, dat zy hem met bedtartheid vragde, wuth by don culde, dat zy does gou? med al bet wate, zei de gok, man ten eerfen becten gaan, als gy m,

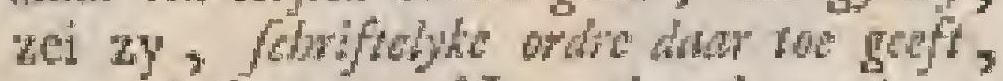
$z 00 \mathrm{z}$ ik gan. Hy outbood nankons een Notaris om zoo een getchrife wat fcheiding op te ftellen; doch als die zeide, dan toe niet buvocgete zyn, verzogt by hate neef, de Hecr Piter Habfor, die diar mede in huss woonde, dit te doen, die dit mede, als en zak, hem niet vocgende, weigende, en toesi lehreef hy ('t geen ook beft voor zyn wrotnw wris) dit zelf, want opzy nog dien eigeln nyond met al het hare, zeer vredzana, en wef dubbelt bly, dat zy op zulken bondige wyze wan dezen quadandigen gek verlout wis, uic den heis ging.

Naderhand ztg hy wel, niec door zyn eigen oogen, matr door die war twee andere Hecren Randen, dat by, dien 't nu boroude, en die rrigte hat weer by nich tehebben, zeer dwais gedan had; mati zy, die by haar deuk bleef, hecef het dast toe gebragt, dat $2 y$, nict laigg daar m, ook geregrclyk, en by klokkegenag, gelcheiden Lyn. En ma dien tyd heoft men zulk ecn man, die uje de Landvoogdy wan Banda eerlt met zulken thuk, en met nog weel wunzer reuk van zyn vrouw gecheiden wis (alzon by klat bewees zyn eigen buis nict te konnen beAticren) nog Urdivair Rad var Indien genarkt, en magt gegeren, om, newers zoo veel verthandige Hecren, ganlch Indien met ecabellunisende fern te regeeren.

Dit ftintje alleen (deok ik) zal bequam genog zya om dezen gierigen 


\section{Z A A}

r7o9. Vick, die op het alleminfe inzyn huishouding zelf zats, en dat geeme bedilde (felioon hy ecri man whs, die then zci, dat meer dan roosoo Rdess wan zich zelven bezat) te leeren kennen; en men verwondert zich nergens moer over, als hoe lyy; die fchandaleus gierig leefde, van zich heeft komilen verkerygen, om dat flatwenloon in Bunda, wasr wan hy mundelyks zoo veel trekken kon, af te feluafficin ; man de hoope vast hier door hooger te zullen ftygen, en dan vecl meer te zullen winnen, beeft hem dic hardé polk, met al de vlocken dast op gevolge, en nog dngelyks volgende, als de grootite fchynheilig, nict zonder vecl neepen van zyn gewille (die vy wonderlyls geftele was) doen overftappen.

Indien dit ons wan ons beftek niet te werre afleide, wy zouden hier van nog meer konnen zegien's inar zullen het bier by linten.

De Heer Schenlenberg, zyn vervanger, die hier in Mant 1709. quitm; fterf in Juni, des zelven jars, eij dicrhatven toonnen wy wan hem niet anders zeggen, dari dat hy datr met atte de ftatic, ontrent een Landwooge gebruikelyk, begrawen is.

Kort ma zyn owerfyden quam hiet de Ambonfche Landvoogt, de Hecr Adriam win der Stel, hoewel ongeroepen, én buiten ecnige noodzatkelykheid, gelyk wy nader onder Amboina zien. Wat hy egten hier verrigt heft zouden wy konnen toonen; doch ons te verte dair over mocten witbreiden, daar wy ons zocken; zoo weel mogelyk is, te bekorten.

Het ge- De latite Bandalche Lindvoogt dar drag wan wy nog iets van te zeggen hadden, is de de. Heer Heer Awtres wan Eps. Hy was de voorwan Eps'zoon van een wrouw, die met den Perin zyu kenics en Borgerlicutenant $N$. Hardoko is getrouwt geweet, Deze Heer Hardekop, met cen dochter van de Hecr wan Brugel getrouwt, en eenige jarren 'er na naar Batavia met zyn huisgezin pertrokken, en ook dati overleden zyode, is die juffrouw naderhand met de Hoer Donglas hertrouwt, dic cindelyk Rand Excraordinair, daut na Ordinair, en ook Directeur Gencranl win Indiën geworden zynde, dezen vam Eps, waarlchynelyk op de voorfpratk van zyn huswrouw, van tyd tot tyd zoo verre voortgeholpen heeft, dat hy, die anders dat toe geen bequatmhoden ter wereld, en noit eenig ander dan zyr geboorteland, Banda, gezien had, dar eindelyk egter Landroogt geworden is.

Zoo lang "er geen bittere en uitberfende gefehillen cuffehen den Heer Oppertandvooge Abrabam wan Rideck, en den Hecr Direterir Doughs, voorvieles, wicut hy door den Heer Douglas, en uit vreeze vain
K E N:

zoo grooten Chriftoffel ath "t Hooger- sjis; huis, in veel van zyn dwaaze quintert, van de Bindanezen verdingen, zotder dat men "er veel tuders, Gan dat hy de lnedigfte nitet wits, van hoorde.

Mair tna dat bet viur tuffelien die twice Hoeren soo openbahir en zoo ftetk tan 't vlammen geradkt wits, dat de bittere Heet wits Ritbeek den Heer Dosiglas Zaodanig in wolle Vergadering gehelkelt, en gcllingert had, dit ty "er Ty druen van te bed ligg, zoo moeften ook wan de weerftuit alle de vrienden van laièn Heer, en vooral de Heer wall Eps, muthouden, en ook cen Afrikaanfche houw over den nevis hebben.

Hier toe had nict weinig annleding gegeven, dat de Heer Landvoogt wis $E p s$ yemant had hooren zeggen, dat er een pasquil op hem was gemaikt, dat van heta gevallig in den openitainde leflemar vah zeker Affiftent Mattbets Caffella gezien, en ook warffebynclyjk door dien Cagletha bedagt was.

Hy had dit zoo mas niet vernomen, of hy zont Gecommitrceraten, on die leftenair te doen openein, en, alzoo cafolta dit niet doen wilde, gaf hy last vals die te doen opbreken, liet "er dat pasquitil, zonder maam, uithaulen, by hem brengen, en dezen Caffella diar over, zonder eenig vender bewys, dat hy het gemalat had, mat om dat hy 't bezat, zonder dat hy hat tan yemant gezegt, of jets daar van, verbreid had, nier alleen gevangen zetten, maar ook, ma hein dalu over in rechten betrokken te hebben, geefelen, brandmerken, en in de keten flaan.

Deze onordentclyke handeling, ontrerit "t juar $17 \mathrm{~L} 2$. voorgevailen, waaide ten eerften naar Batasia over, en gat diar, te meet, dewýl zy zoo wondeilyk in de kraam van den noitwergevenden Hecr wah Riebeck diende, zulken rocp, ditt hast Edeltheden dair over een zeer icherpen brief antin hem en den Rat in Banda fehreven, en Caffella, met zyn ttuklien, zoo als liy nog in de keten was, ma Batavin ontboden, on dar zyne Aetic tescen die genen, dic hem zoo onregrweendig mishandeld badden, zoo als hy te raicte worden zou, in te ftellen.

De Heer wan Eps, die dit noit werwagt had, en nu egter alles tot zwn nadecl, en de fpillen op Batavia ginfeh verdratid vond, was hier door nier weinig benart, ja zoodarig, dat hy Cafolla, toen hy yertrok, aumbood buiren de liecen ni Batavia te laaten gaan, even of dit verandering an zyn grove misilag gever kor; doch Caffella, die weigerende, zei, dat, had hy 'er nu zoo lattg in sezeten, hy "er ook nog wel tor Bataylia tós in blyven kon, en 'er ook in blyven zou, om daiar zoo te komen, en te zien, wat haar 
$9^{6} \quad$ B $\quad$ A $\quad \mathrm{N} \quad \mathrm{D}$

1j13. Edelheden hier overwerạ́er zouden goedvinden.

Dir intiftelde den Heer van Lós zoo. danig, dit het liem byna an de zimen ging, te mecr, alzoo hanr Edelheden wan hem ook cen omitandig berigt wegens dit ganlech geval, dalar by weinig raad toe wilt, afworderden.

Cafilla quam ontrent in 't midden wan Mey 1713 . in de keten op Batavis, en wicrt in 't Ambagtsquartier geplatall. $\mathrm{Hy}$ had gedage, dat hy ten ecrften uit de Keten geraken zou ; mar de behandeling van zyn zals, die cerft een mauleenrig onderzock door den Rand van Jufticie wereifchte, liet dit nog niet toe.

Den $14^{\text {den }}$ Oetolyer des zelwen jaras quan 'er tyding op Batavia, dat de Landyoogt was Fips 4 borgers tain Banda, zoo als $z y$ in 't fort quamen, had lasten valt houden, cul hatrzen, om dac zy orwillig waren geweeft tot nog toe to betalen zekere penningeth, dic hen opgelegt waren wegens buttengewoone vernieuwingen tan de Kerk, (dat gehecl buitein gewoonte was) om 't welk te ontwylken, de borger Catper, nu deze zelve matand Oetober mes zyn ganfeh huisgezin op Batavia gekomen was.

In deze mand vernam men ook, dat zeker Predikmt, ganfch niet cerbiedig, nog eerwandig van dezen en genen in Banda, behandelt was; volgens zyn eigen fchrywen aan zeker Heer op Batavia, die "t my voorlas.

Her Opperhoof van Poelo $A y$, Jatobus Valenty, had hem, kort na zyn aankomft op dat ciland, eca brave oorweeg (zoo zommige zeiden) gegeven; doch hy had dit Opperhooft zoo detrig bettailt, dat lyy 'er eer wan lad, hoewel zich een Predikant noit mer zyn handen, moat met zyn tong en pen, werwoeren moet.

Niet lang daar ma was die zelwe Pater op de voorbruiloft van de dochter vatn de Heer wan $E_{p s}$ ten huze vin dien Landvongr genoodigt. Hy quam 'er' doch wict hanftonts door zeker Heer nic alleen zeer qualyk, over cenc Theologiche ftoffe Iprekende, bejegend, mar lkreeg ook (dat vecl hooger licp) een brave finflet, 't geen hy nier wel kannende veelen, z,oo meinde hy dien Heer by de kop te krygen, (dat hy, myens oordecls nier moeft gedlarh, maar liever weggegatan, en maderhand hicr over geklatige hebben) maar deze Heer, war kort zynde, ontdook zyo handen, hatende, zoo ik meyne, egter nog zyn pruils in de loop. 'Zoo ras hy 't ontdoken was, flectde zich zeker Onderkoopmian yoor hem in de bres, maar hy pacte dicil onvoorzigtigen jongeling zeer onyenadig an, en werp hem zoodtinig tegen de grond, dat
A $S$ C. H E

hy, niet weer ontrent hem komendurfde, 17 13. De Fiscarl de Groot, die al mede het tcgen hern had, wraigde, wat be ac zeg* gen Juas, dat by dien Onderkoophas zoo basilde, en wilde hem daar op'mede anpakken ; matar lay guf hem van ditt zelve laken ecu rok en brock. De Capitén, die 'er mode byftont, en, die zoo mea zei, met al dic nndere oppeftemt had, om dien Piter eens te degen pal te zetten, en een vuile Atheiftilehic tal tegen hem uit te flan, quam zich het Jartife $m$ in de bres flellen, meinende door zyn lervgsklundige agtbaarheid, en grove handen (alzoo hy hem ook anr" taifte) dezen Puter niet wleen te overfnuiven, manr oolk wakker af te roliens doch dit ontichoor hen wolkomen : want de Predikant greep dit ongezonten en ltinkend ftuk veesch in zyn ruggellseng, cu wierp hem zoodanig, dat hy quat fte: tegen de mutr.

Geduurende deze bataille in 't douis Fan den Landwoogt waren de kaarzen onk uitgeraakt, want op de Heer was Lps; nier wetende, wat er te doen was, in die kamer gekomen, en, by ongeluk ontrent dezen Pater gctakt, dien by ook, zonder hem te kennen als vyand, matre tot zyn ongcluk, zantaftcc, anngezien by hemi,cen groor getal muilpect ren gaf, wartom lyy zich eindelyk bekent mankse. De Puter, hoorende date hy den Landwoogt onder zyn Eluiven had, zeide met bedhartheid : myn Heer, tyt gy bet, ik had bet of uzoo nies gement; man dagt, dat bet en ander was, the wy als qyand anstafte, eit dewalsen as my dat leet; en dus liet hy hem, nerens de vier anderen, met alle de gekregene tlagen daar, en ging, on verdere mocite te myden, nia huis-

Het bleef datr egter nict by : want dangs daur ant tot den avond zich in huis gehouden hebbende, ging twy mee zya Calbyy, of dunne Japonze rok, om eer arondlugtje; doch had een klein houwercje daar onder verborgen, of zomtyds cen van deze avondwolven en toeleg, gelyk hy vreesde, op hem gemaakt mogr hebben. En waarlyk zyn voonzorge was niet te vergeefs: want, in zekete itrant gekomen zynde, wiert hy door cen van deze vier gatten, verzelt wan ecnige flatven met dikke ftokken, zeer fchiclyk overvallen, maar had hy zich wel in des Landvooges buis geweert, by deed bee hier niet muder, rukte andtonts wan leer, "t welk de llawen zoo ras nier zigen, of zy lieten haar mecter in de peleel, welken hy dwong op ltran al kniclende hem om vergiftenis van zyne dwansheid te bidden.

De Landroogt vaf Eps, die dir alles hoorde, fchreef wan al deze gevallen 


\section{Z A A K E N.}

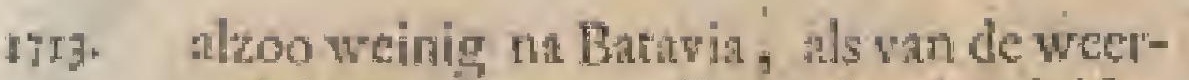
gadelooze flagen, die lyy by dae duifter "twondjpel zoo onverwigt lreeg, mar" verzoge alleen, dat bat Eatelheden hem in plants van de dric Prodikatuen tocn aldiar, (die ook om hunthe opliomt, zonder ergens verder af te fprcken, verzogten) drie voome, cetlyke, en godvrugeger Pefoonen geliefilen toc te zenden; whit uit wecken op Bataven geloofden, dat of die Landwoort gek was, of dat liy teir miulten raftidde, dat de drie, dic on hunne verloling verzogtes, niet vroom, cerlyk, nog godvrugtig waren ; doch de eyd heef geleert, dar het eertte matr al te wate was.

Nog bucte zertwe matrd quam 'er tyding, dat de Acer wan Eps, geen tuad met de zaak van Goldelle, watr op has Edelhatew zeer ityt flonden, wetende, tice alleen mymerde, mar, niet vecl beter als gek en beroerd was; wat dooi hy ook genoodzankt geweet is, on in 'I fatr' 1714 . Ortiligy vas zye bediening, mits verblywende datr, te verzoklen, "Egeen hem beide, mits affehrywing van gigle,

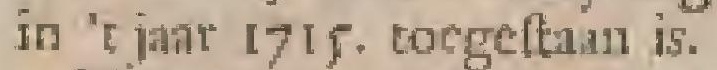

Hoe "t nu verier met de zals van Cojflld, en hem gegan is, weet ik nice neE, dan allecen, diat hant Edelhaden in "t jant 1766 . 't werblyf wan den Hecr wa $j_{\text {ps }}$ in Bunda ingerokken, en hem geordonncert hebbea wegens de zatk war Cofflat op Batayia te moeten komen, antugesicn hy huar nog ganfch geen verantwoording daar ontrent gedan hadde.

Ik gelool egter, 'the die zath zulken varat jike meer, als in 'teerll, geloopen heaft, om das de Heet with R beck in "ejunt 1713 . onderuffechen is komen to overlyden, en Ehoon de Heer Dongla, 1713 . pation vain de Heer an $L_{p}$, nict lang "cr ald mas "t vaderland wertioklen is, heeft Jy egter dant in ay'a plare den Heet Caffelow, zynen wriend, cuook den Hecr "von Swol, gelaten, met wien, toct Opperlandwoogt zynde, lyy in een goed. vertand flont, en nleyd gettan heef, ten ware dar in door de Eyd eenige verandering ("tgen nise geloove, nag my gebleken is) gekonen wh.

In zyn plates quan in "t jar I7ty. de zontyds waslfeja fprekende Heer Phipo David sun Uechlon, dic in 't jar 1719 . in 't begin met zyu 'Tweeden 7 os de Croce, en den Fiscal Lasis Bartwakert, ower hun flegt luishnuden aldat, opontbodeth is met afgefehreven foldye, un door de Hetr Picter Gabry, Tweede wat Amboina, in 't jatr 16 ig. wervangen.

Deac Hed Gaby blof 'et tot "t jar 1721. cn wice door den Hecr Salomon Storn verwingen ; doch deze in 't jant 1722 . $1^{\text {ften }}$ Januari overleten zynde, is ingn fehoomzon de Heer Brhluar de Braysue hier 5 maanden Gezighebber geweef.

Uit deze weiuge thaltjens kan men zien, hoe "t in zutk cen Landwoogdy $y$ en dats taegat, en hoc zoo veel brave ตาarnien, en huisgezionen, dikwils wan de zotte capriçe en hoofilige grillen van een dwazer gek, cu aweregtzen Lindvoogt, geheel en al afhangen moeten, zoo $2 y$ niet t'oentmal bedorven willen worden, "E geen ber, hoe yoorziging $2 y$ ook rouden mogen $x y$, dikwils cgier te beurc valt, ajs $2 y$ mart 'c ongeluk hebben van by hem in 't oof te loopen, en in "t quade blindje te flian.

\section{ZEVENDE HOOFDSTUK.}

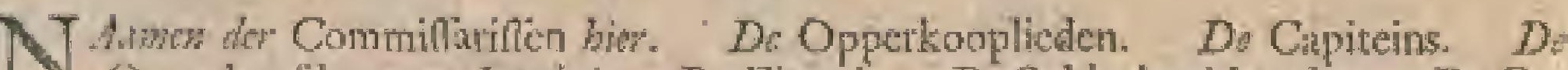
Opperhoofuen van Lombor. De liscals. De Soldyeboekhouders. De Ge-

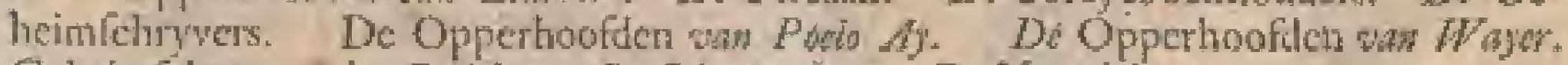
Geheimflaryversies Goridts. De Lieutenants, De Vandrigs.

D At men wu en ditn hier, en in andere Oofterche Provintien, wel een Conmitiaris, of Gevolmagtigden tib. mana van har Edelheden, gezondwn heoft, om alles dair wan naby 1h- en door te zicn, is wel war, matr dat getchicte meer, als men oordeclde, dat bet belang der E. Matchappy dit vereiflute, dan wel om eenige onordentelykheden, door cen Latudrooge began, na te fpeuren, of te ftraffen; behalven dat 'er matr zeer weituige geweelt zyn, die al mede na hunne dififen, en veeltyds rice zonder groote zugt, de zaken bebandelden. 
$\begin{array}{lllllllllll}9^{8} & \text { B } & \text { A } & \text { N } & \text { D } & \text { A } & \text { S } & \text { C } & \text { H } & \text { E }\end{array}$

Namen der Commi/fari/fen der drie Oofterfhe Landvoogdyen, Amboina, Banda, en Ternate.

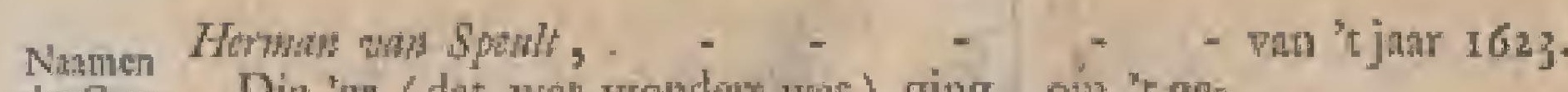

der Cont* Die 'er (dat wal' wonders was) ging, oju "Ege-

imiliaris- dtag wath den Lilndwooge Sonk te onderzocken.

zen liel: Gils Sole, - - - - - - - 1627

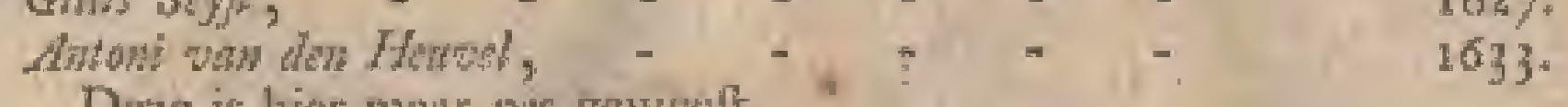

Deze is hier natur pis geweett.

Aris Gifis

Die hier in Juni 1635. quan, en in September vertrok, mee "L fehip deaz Arend.

Anton mon Diemen, Oppenlandwogr, - - -

Die hicr uit Amboinat voor ten tpringtogi overqutu, on dat de koning vath Ternate disir nog niet verfchenen was, on met hem alle zatken te vejefferien.

Antohi Can,

Superintendent, Overter, en Zecroogr over de drie Oofterfote Prowintien.

Anold de Vlaming was Oudbow,

Superintendene, Velduherte, Commitits, Zcevoogt, enz.

Sinton Cor,

Corsels Speloun, - - - _ - - -

Superintendent, Commilitris, Zacwoogt, cri. was hier den 14 den Mey 1667.

Antoni Hurdt,

Ook quam hy in " $\mathrm{j}$ jan $167 \mathrm{r}$. by 'towerlyden wan

den Landwoogt, hier voor een fpringtoge.

Roburt Padingere,

Deze is in alle drie de Landvoogdyen geweelt

Disk de Haas,

1633. cn 1635

$16,8$.

Deze ook.

1643.

I6go. tot "t har 16,6.

I 66.2.

1607.

1672, en nog 1676 .

1682

L689.

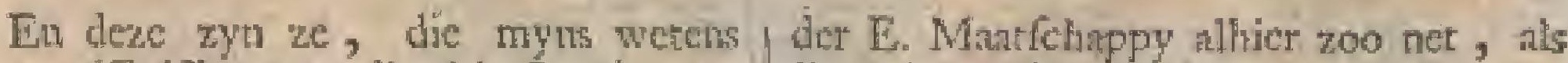
Commiffritien over die drie Landwooge dyen, hoewel ik niet weet, of $2 y$ alle wel in alle de zelve geweelt zyn.

Schoon it bevoorens eer nette Jyin var de Lindvoogden optelewert heb, lieb ikegter, wat moeite ile diar toe gedan heb, die van de verdere Bedienden

ik wel wente, niet konmen bekomen, ik tal egter, "t gene ik "er af wete opgeven, op dat een ander, die "er beter gelegenheid, dan ik, tot gehad mogt hebben, de reft diar thit, zoo 't hem luft, byvocge, of mydic opgeve. Hocwel ik het myne al vry the gerage hobbe.

\section{Opperkooplieder, en Ttoede Perfoonen van Banda.}

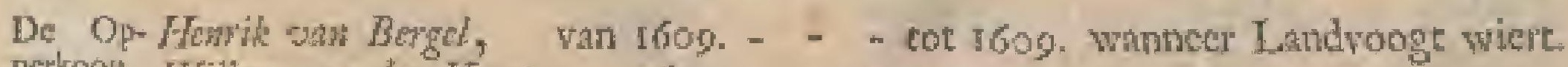

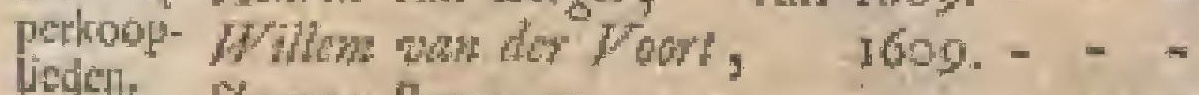

Yagues Serepant, - - - - - I627. wanteer vertronk.

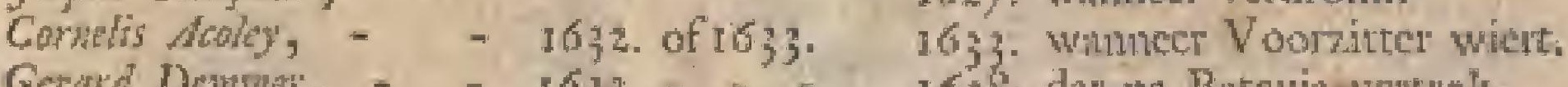

Gerd Demar, = - 163 \%. - - 1636 dat nataviavertok.

Pierer Willemzan, - $16 \mathrm{~g}$.

Ahrobm Wiys, - - - - - 1653. als Voorzitter wiert.

Irane Topander, = 1660 - -

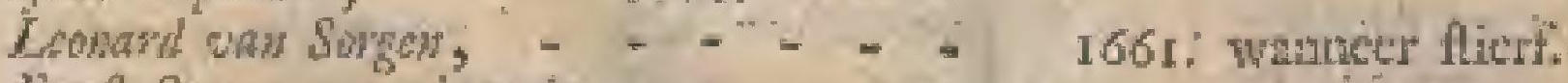

Linf $S_{a}, \quad>$ perinterim

en $\{$ te zatien $166 \mathrm{t} .=-\cdots$

1662

Awom Hard, $1665_{1-2}=$

Joham wan Amonde, - t66r. - - -

1669. vertrok mit Batakis, wiet Commifliris yan de W eftsult.

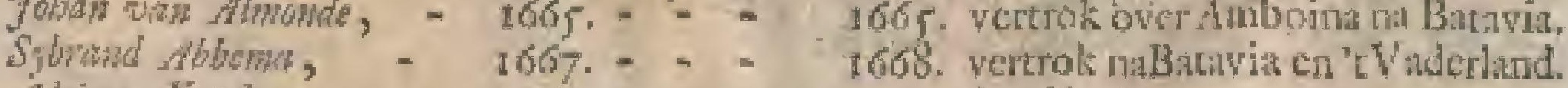

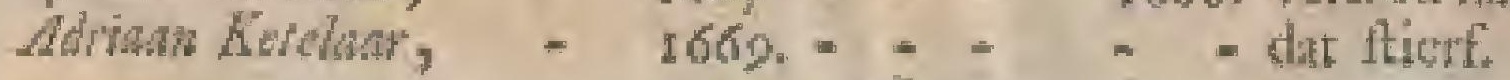




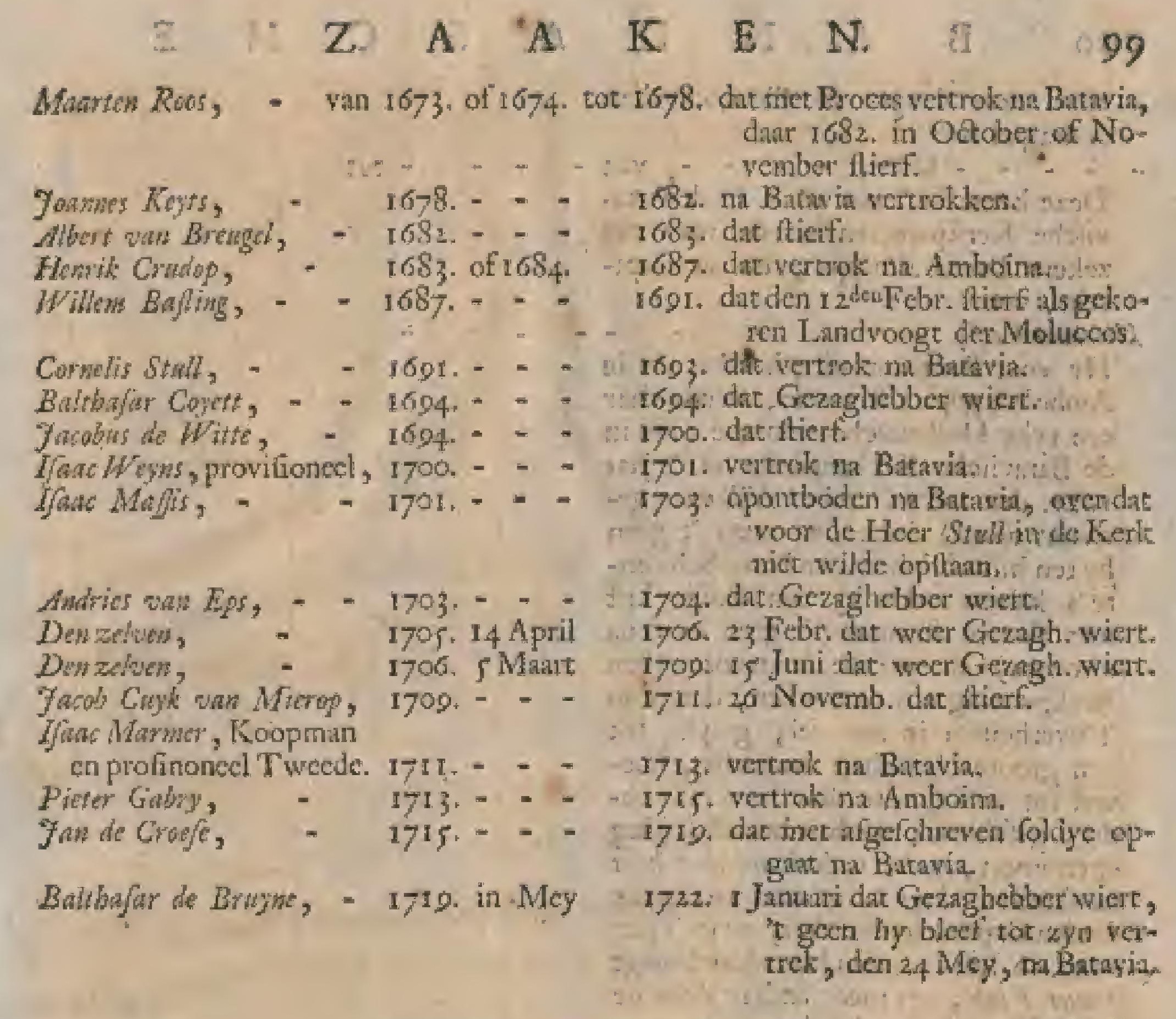

\section{Capiteynen van Banda.}

De Gaj-Howik Bevewing, wat Gouda, - man i6i6.

teinefi. Hy kome in to jar 1616. hier voor als commanderende over Nafla en Belgicith

Adrian van de Diffor, commanderende.

Jas Ferbowen, vat sop Poclo Ay over io 16.

Tiel, Sit Fott Revenge.

ILarik Stess, yan Sommelsdyk, - -
Deze nam Poclo Ay indit far mede in.

Matrten Janszon Fond,

Deze heeft den I I deu Mant "s jatrs I 621 . 't Hoigg Ialnd helpen innemen, en was een dapper man. Hy was getrouwe met en inhndze Amboinedche Mixtize docher wan Noefla Lnoce, Britis Pien* tas gename, wa cen Portugecflie vater en Noeflaloeze moeder geteclt,

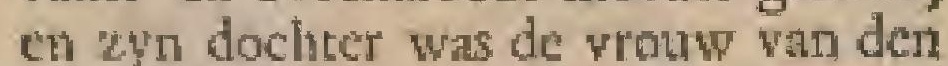
ouden Heer Laseres Pit, wan Bremen, dic I-andwoogt wan de kult wa Choromandel, on Ordinar Rand wan Indien geweet is.

Men zegt dat hy ook Poclo Ay heeft helpen inuence en dar over met een groote goude keten befchonken is doch ik vinde zyn natur othder de Hoodlieden yan dic veldrogt nict anageteckent. Igter wil it her wel gelooven, on ditt my dit yan een zeer oud dienar van de E. Marrchappy, dic allerlei oude papieren der Secretary doathuffels had, en die zelf ook cen Inlander wan looge affiomlt was, gezegt is; doch dit wete ik, dat by zich

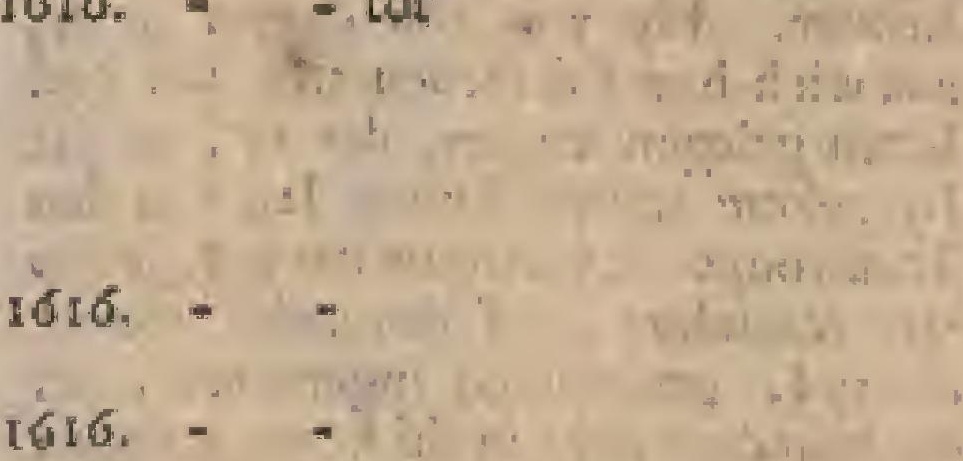

5


aliyd zecr dapper in alle voorvallen sedragen hectr:

Deze komt in 'c jakr note in de Butravifche Kerkpapieren als de man watn zekere Dond Pbilipas, en als Cipiteint, wool:

Wicolda colf,

Hy voer Sergeant uitgekonen en in Amboina:geplarit zymde, vryde dtar een ryke Hollind che wouderwe (die in de Batavifche Kerkpapieren in 'te jar

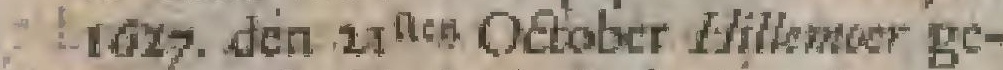
- ndame word) doch had niets 't geen hy ten huwelyk brengen kon. Schamte"s halven wulde thy $x y n$ ledige $k$ int met of uzare itecten' ( $\mathrm{t}$ goen ditar na - vitcuiany en gaf ade matroozen cen fteckpenuing om. temaken, datyy in "t overheiffer in zee viel, gelyk, to zyn groote blydlchap inwendig, hocwet tot zyn grosote droctheid uituendig; gerchicde, doch. 'c huwelyle ging egter voort, en hy wderhand met has na Barda, diat hy ina wed tucficlyke - diaden Capitein getvorden s' en in "t jar r627. in Juli met den Heer Landvooge Pieter Fiak, en meer andere doon de Poclorhunders, die hen feliepten. gevangen genomen, enthelibongevoert is, gelylewy te vooren getoont hebben. Hy was ecily -dapper man; an wien hat lidsheden aikl zoo reel lieten gelegen leggen, dut $z y$, mat by zekere werting buiten latt vin den Landwoogt lik wertrouw dat het 2 why van Rasmburg, of ecrn ander ontrent. die tyd, geweelt is) ingenomen, en die hem duar over in de lieten geflagen had, goedwonden hetn, na Bativis zoo opgezonden zynde, nier atleen zecr te pryzen, en udt dien keten te ontinan, maar ook een fwalre goude keten on den hals te hangen, en dezen dapperen held daar mede onder cen Quighol van Stant getheel Batavin rond te doen leiden ; en om hem nog meer te eeren, en te regtweerdigen, zonden zy hem "t jas" daur' atr mee den yzeren keten thin zyn been, en met de goude keten in een doos 'er by, weer na Banda, met vitdrukleclylic latt an den Landwooge, dat, had hy hem zoo onvegtveerdig in de keteo doen than, hy zelf in perfoon met hem na de Sint zou gatn, th hem wan de ketor doers verlohicn, en hem dun zelt dien gouden leten, als cen man, die de. zen, en niet den yzeren door zyn dapperheid verdient hat, on den hals te hangen, of doen hangen, hem in "t weekomende ordonnerconde de behandeling der krygszakken allecr aan den Capitein, tot wien die cigentlyk behoorden, on die ze ook beter, dun
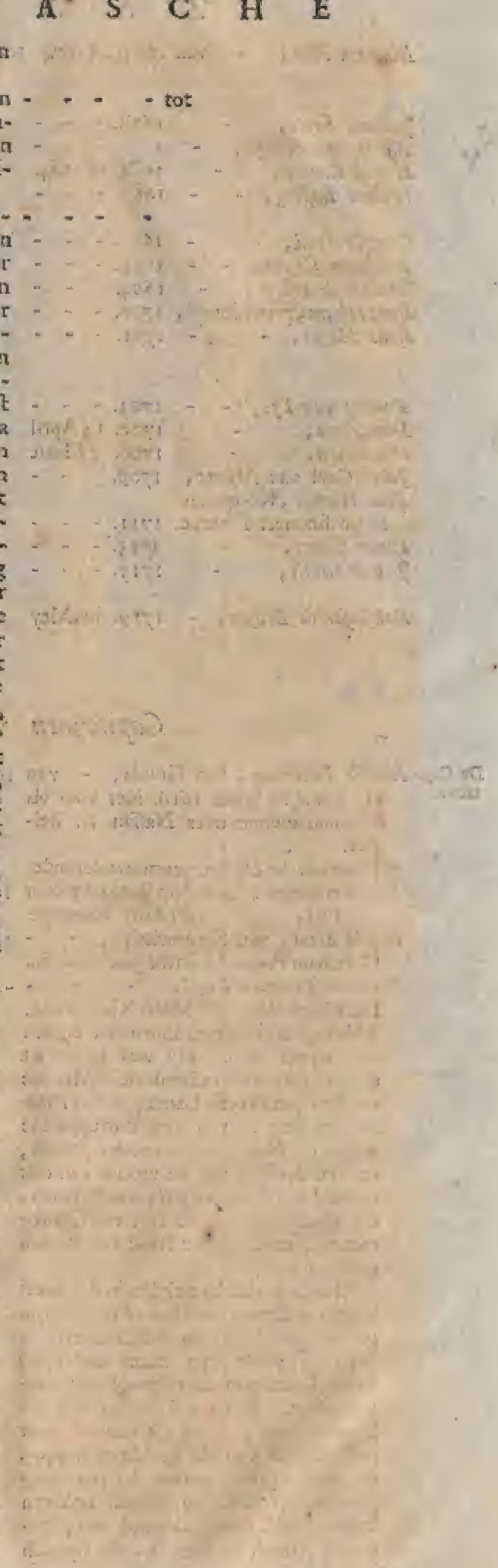


\title{
I Z A A K E N.
}

by, verfont, te laten, cti zich dasr

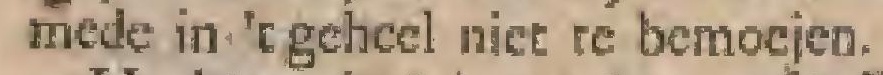

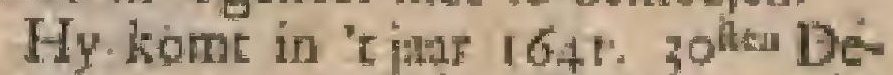
cember, in de Bacav. Kerkpapiereñ, in Banda nog woor.

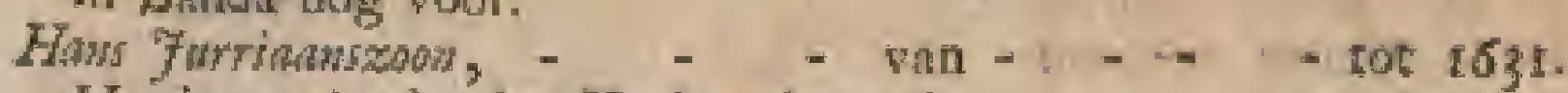

Hy kont it dezclve Kerlipapieren in

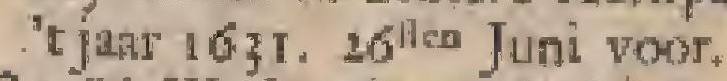

Donid Wuffen kome in " $\mathrm{k}$ lat 1633 . by de Heer Ramiargs dood, "voor.

Fredtrik Gownctsolop, - -

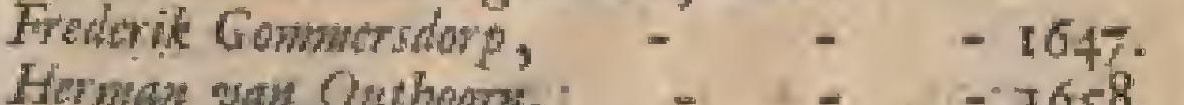

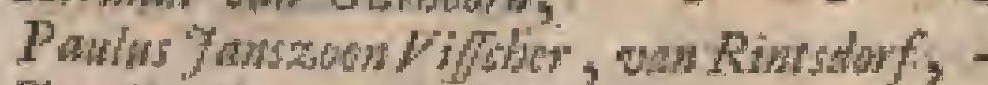

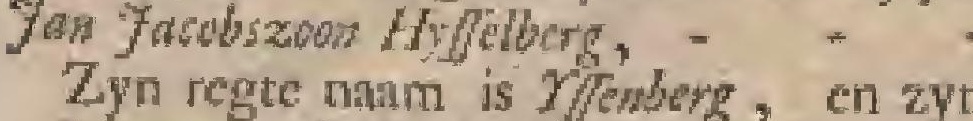
bynatm, Capitein $a d$, om dae hy in ecn werfanl zeer diswils dic woorden, fchoon zy ier nice te pas quamen, ge* bruilite.

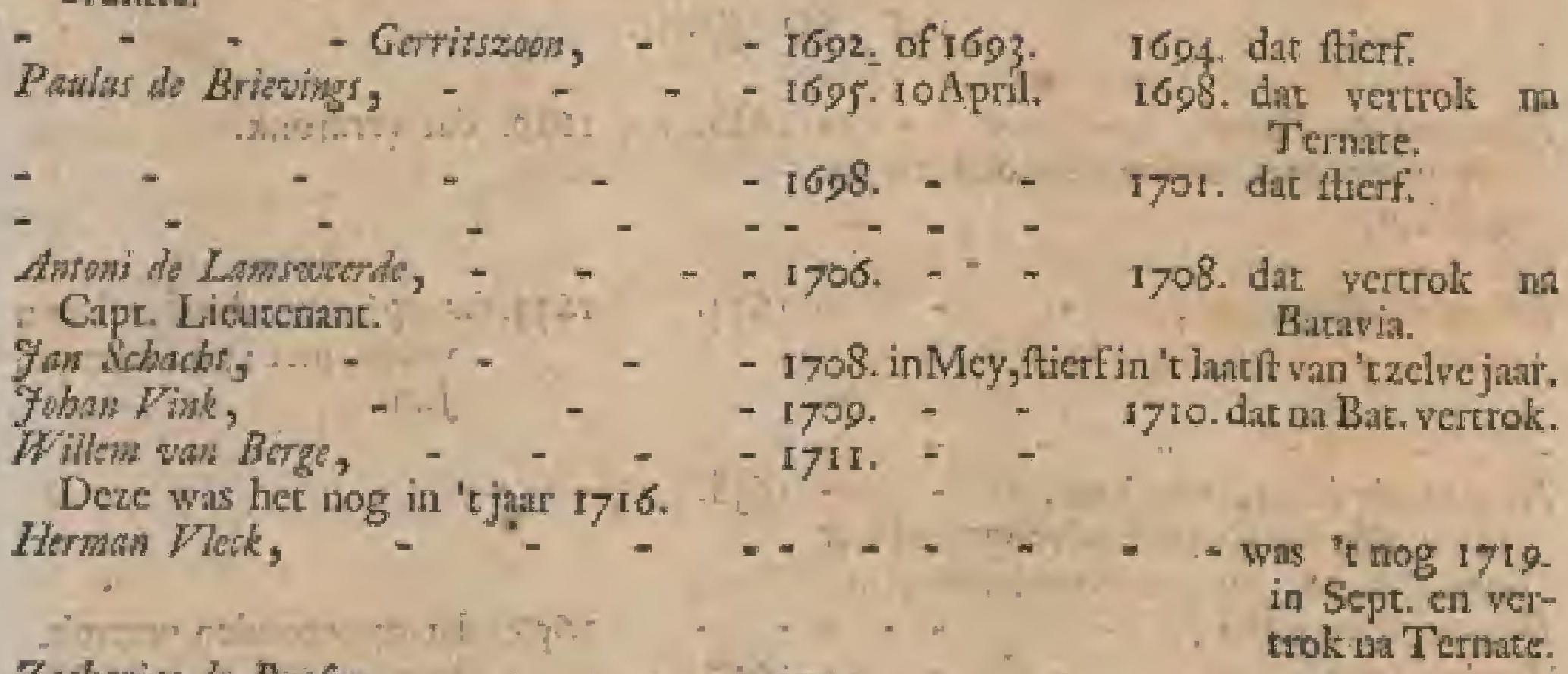

Zacharias de Benin, - + - . - i iziz.

1662. of 1663 .

$1668:--$
$1683^{-}-1682$, wanneer ftierf.

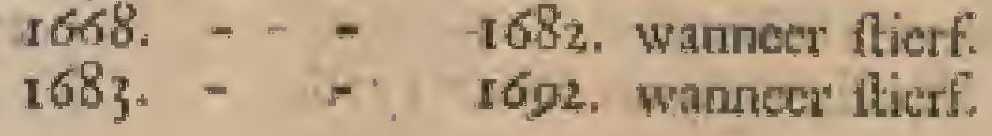

\author{
-
}




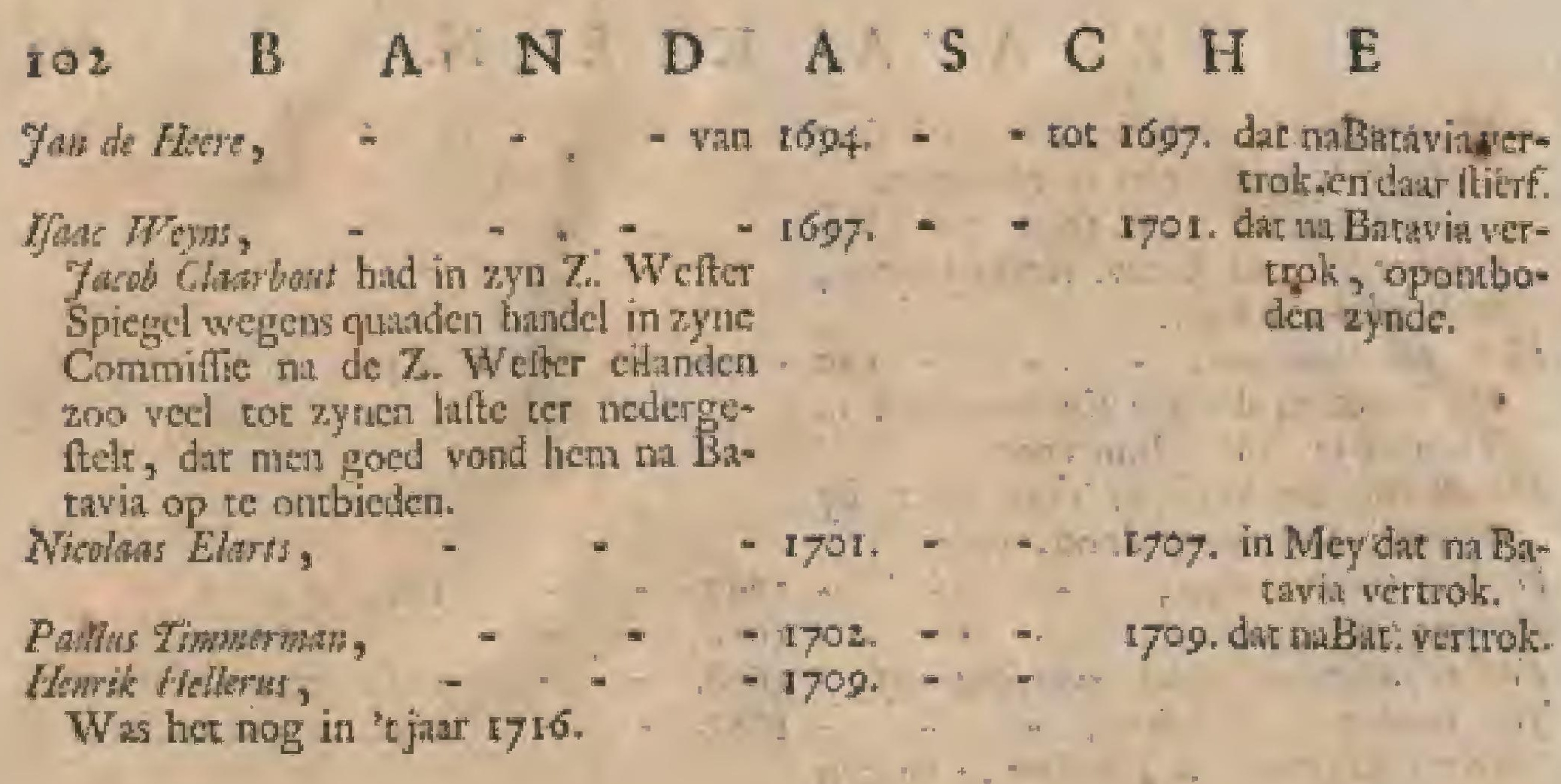

\section{Fiscaaten van Banda, zynde Kooplieden tot $5 \circ$ guid.}

Fiseasle Iface wan der Dood, - - - van 1628. tot 1629 . dat verdronk.

Hy wiert met een whterwloed in zee geीecpt.
Balbajar Wojwgen, - - - -1633.
Nicolad d ${ }^{-}$Wid, was hier, $=-1638$.
Hy latalde den Opperlandwooge de Heer
wan Dienen, by zyn komft hier, in.
Willow Manzwiker, -
Jacob Rowet,
Voor zeer korten tyd.
Ermp Sat, - - - - - 1677
Jocmucs Roberti, = - + - - 1663.

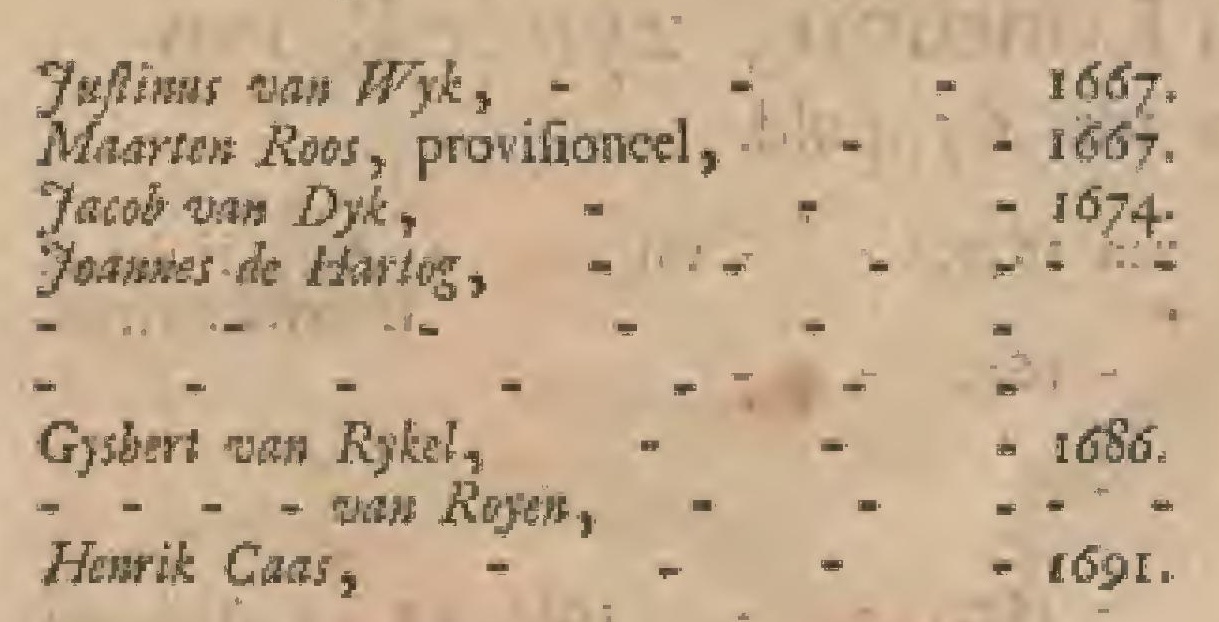
Pieler van dis Pont, - + =- -
Jhat lloys,
facol Ched,

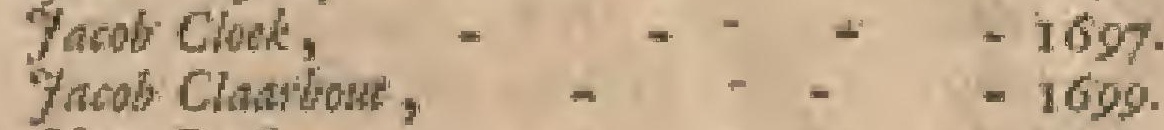

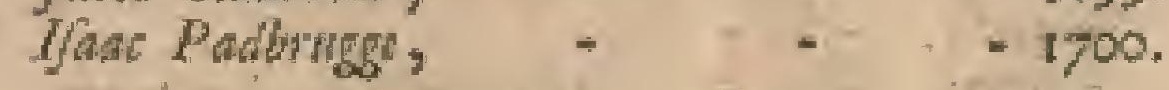
Hewik Sreenkop, = - - - $=170 \mathrm{r}$.
Faob Botlesdorp, - - - - -1702
Jacob Crok wan Mirog, - - - -1798.

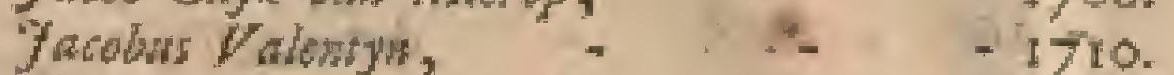
Hewik do Groot, + - - - - - 7711 .
Lowis Bammaker, ... - . - - -1715 .
Dezt: was 't nog in 't jar $17 \mathrm{c} 6$. ging
op met afgefcheven-gagic w I 9 .
N. Latcur$$
171 \text {. }
$$ - witrt, mee 15 anderen, in Juni.
1633. dat op Cerm doodgeflagen
165. dit opgezonden vertrok.
- - dere is 16,8 . van de $\mathbf{G}$
rammers vermowd.
166 , dat Hoof op Lonthoir wiert 1664 dat, door don Lindwooge van Dan gegyzoli zyoue, 1667.
16ro. dat dic vaft wiert, tot 1671 . I676. dat Hooft opLonthois wier
- als boven.
- - da fterf.
- $=\operatorname{det}$ ktiēif.
- - dit als Twoede na Macas far'ging.
$160 \mathrm{r}$ dat Hert.
[697. dat Hoolt ip Lonthoir wiert 1699. dat vertrol na Butavia.
1700. dat ma Poelo $A y$ gat.
17or. zynde tuffehen 1701, en 170 1 , buiten vatte bedis- ming seweett.
I $70 z^{2}$
1708. vertiok na Amboina.
1710. dat Tweede wiert.
171. dat an Poclo Ay gat.
$1715:$
1719. 


\section{Z A A K E N \\ Soldye-Bockhouders van Banda, zynde Onder- kooplieden.}

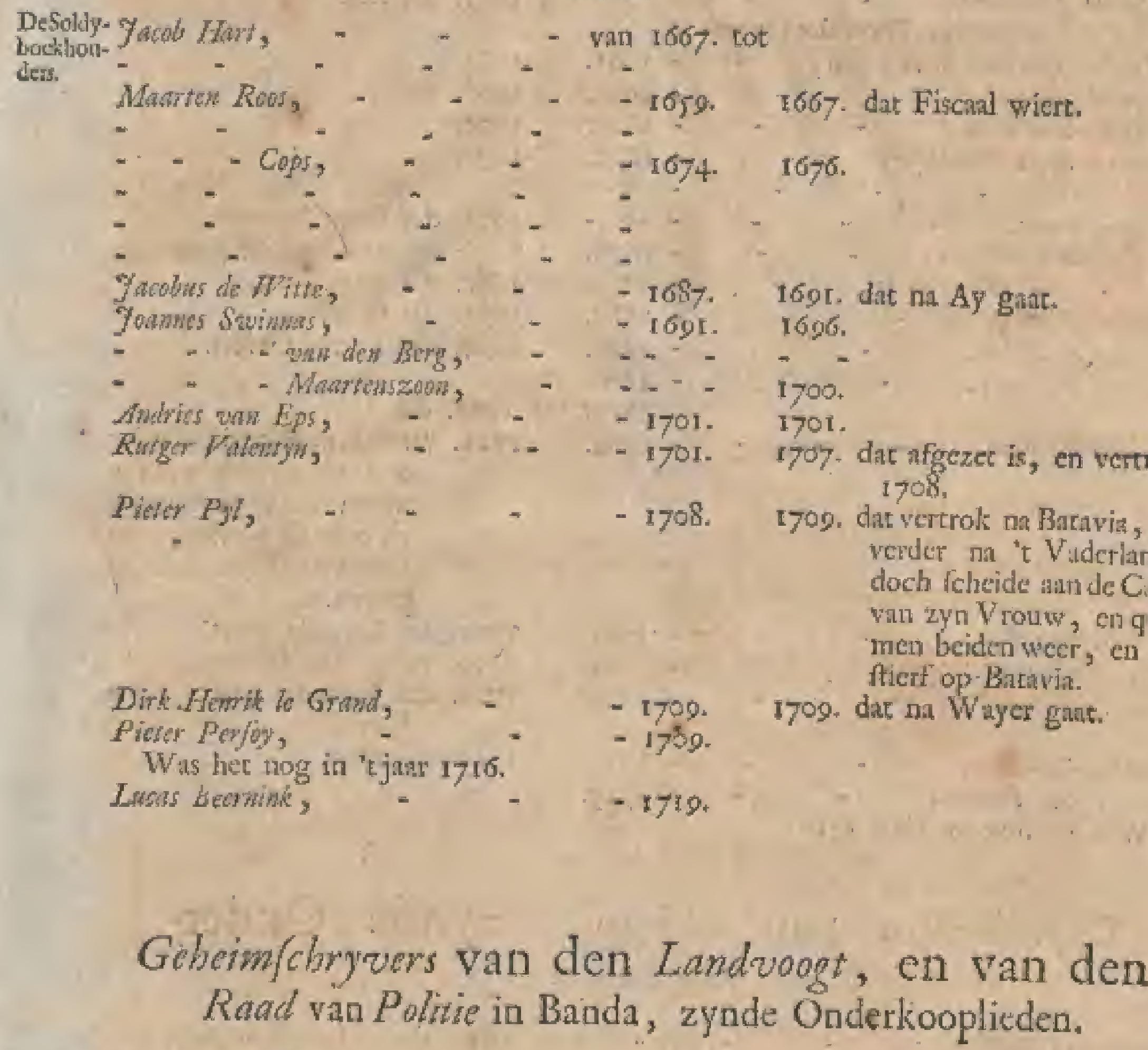

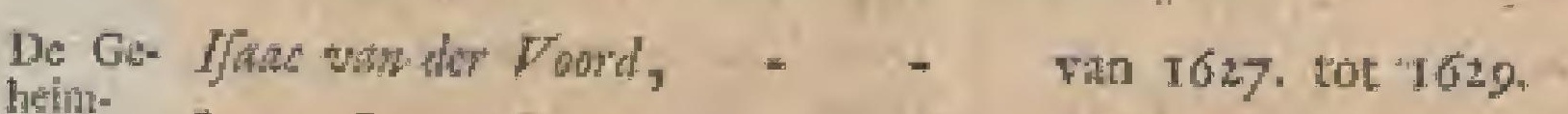

Ichrywers:

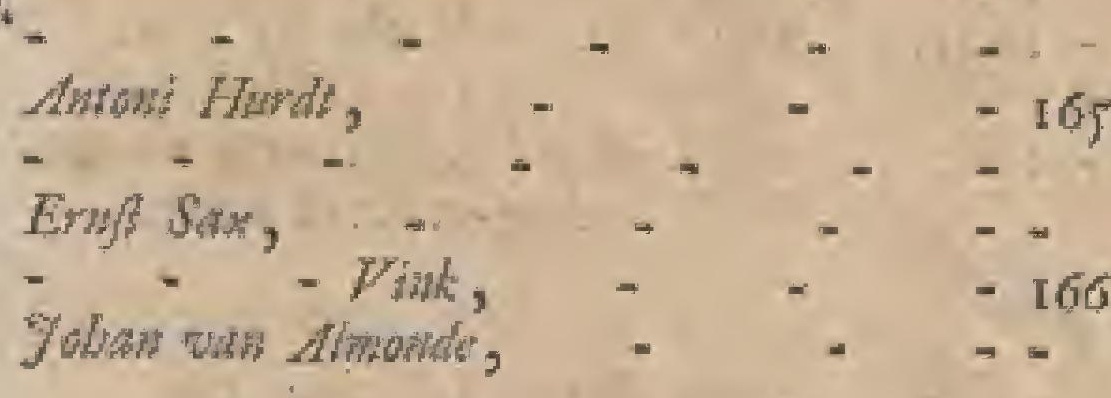

1657 dat Hooft op Lonthoil wiert . - $\quad 1657$. dat Fiscal wicut.

1665. datover Aubon na Batwia. vertok, - zyate te celyk ook Opperkoopman, ea

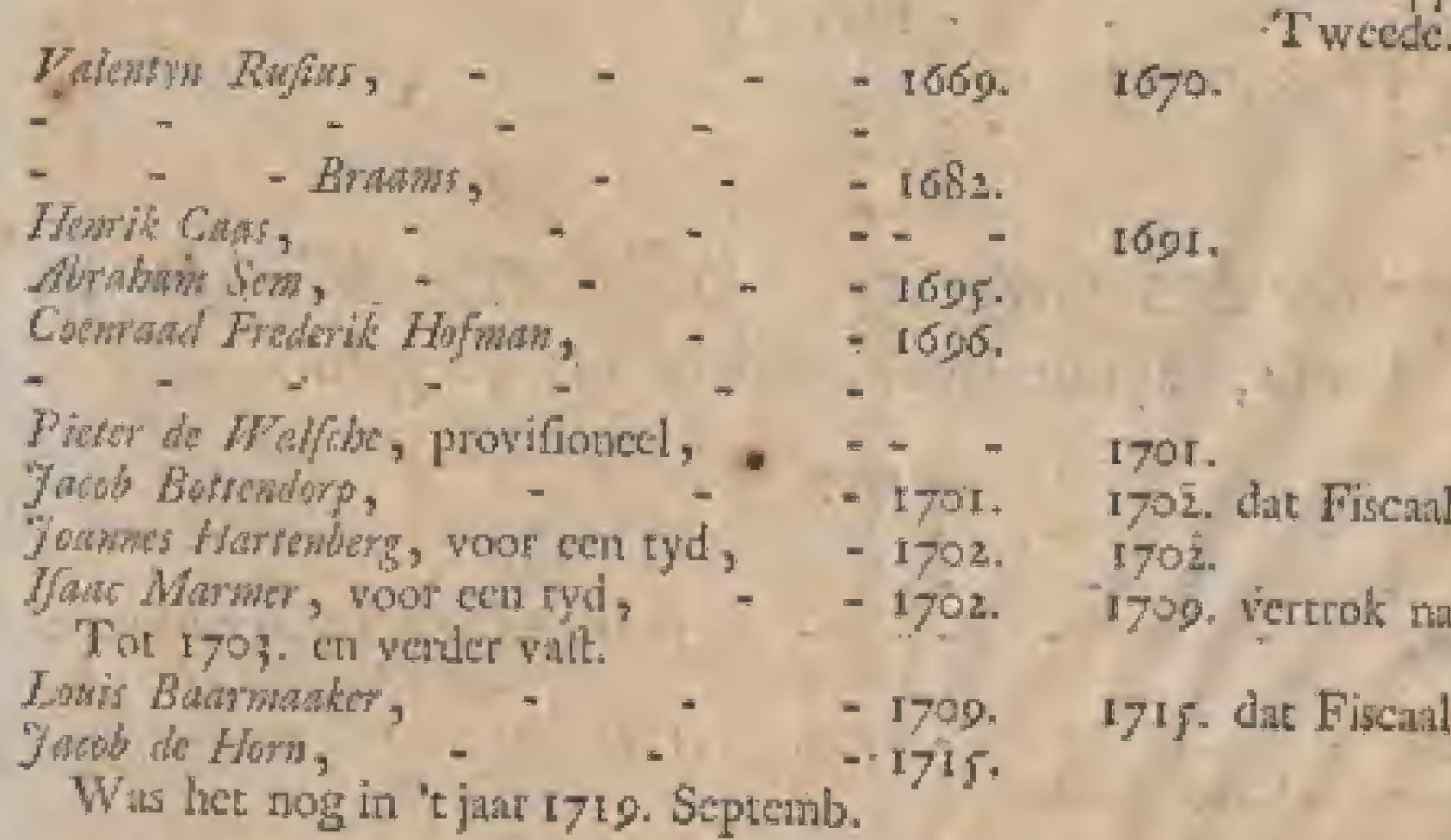

Wus het nog in "t jatr t719. Stptemb. 


\section{B A N D $\quad$ D $\quad S=C=H \quad$ E}

Opperboofden van het eiland Ay, anders Poclo Ay, genaamt, zynde ook Kooplieden tot $\sigma_{5}$ guld.

Opper. Melbior Mombat, - - van = - tot $166 \mathrm{I}$, dat dierf.

houtsen Pbilp de Carpentior, Zoon des Opper-

van Poclo landwongts wan dien niam, - - I667. 166\%

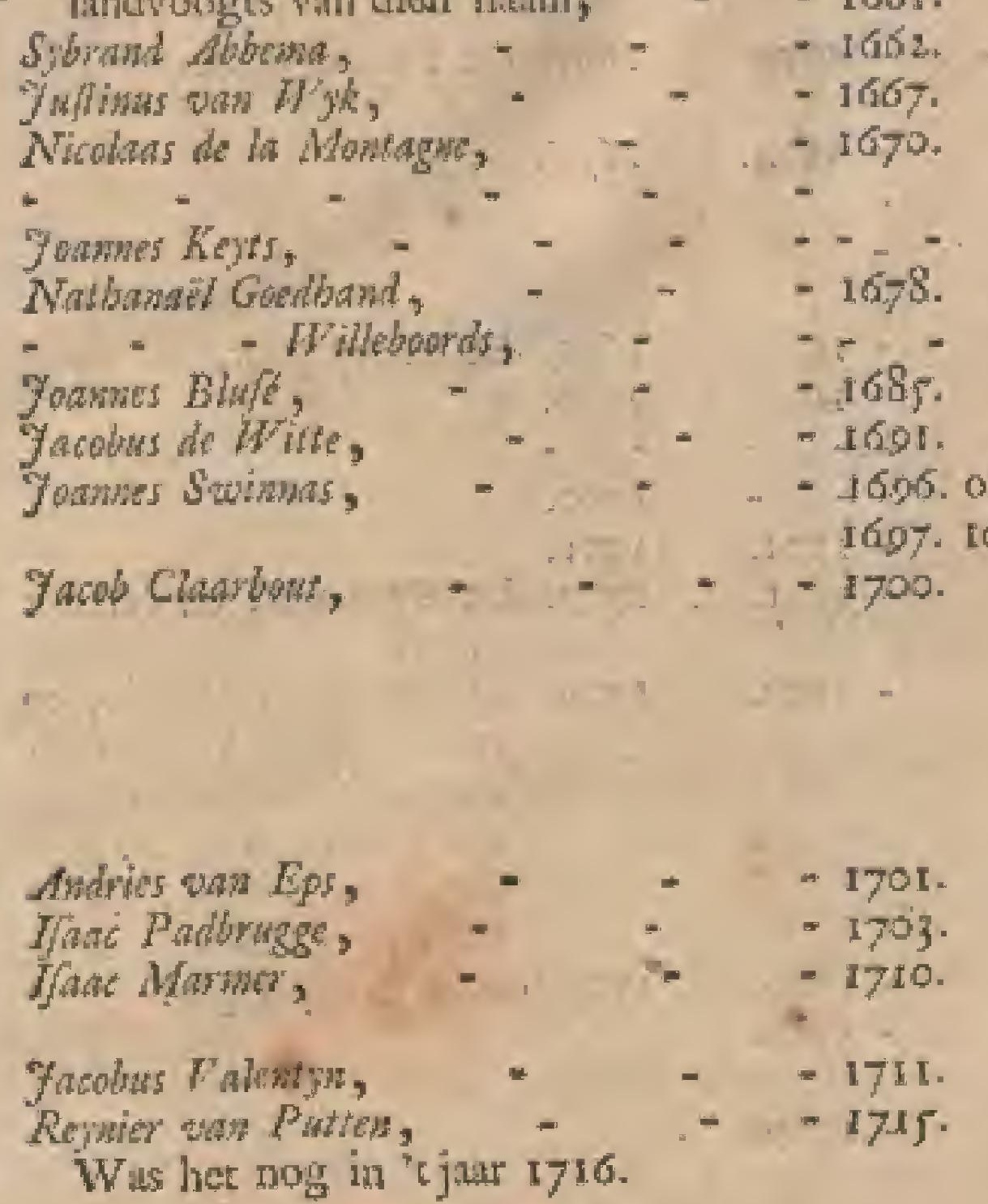

I.6\%7.

1670.

167

1678. dat Tweode wiert.

- dat ma Lonthoir ging.

I685. dat ltierf.

169t. dat terf.

169: dae Twede wiert.

Gacolus de $W$

1607. Iot 17\%0. dat thict

I7ol. vertrok ria Batawir, daar onboden zynde wegens zynen 2. Wefteripiegel en over de zatakets, ten lafte yn $W$ gy dnar in geftelt.

1703. dat 'Tweede wiert.

17to. wertioli the Batavia.

1711. dat Tweede wict provilionecl.

Wis het nog in "e jar 1716.

\section{Opperboofden van Wayer, kooplieden.}

\section{zynde Onder-}

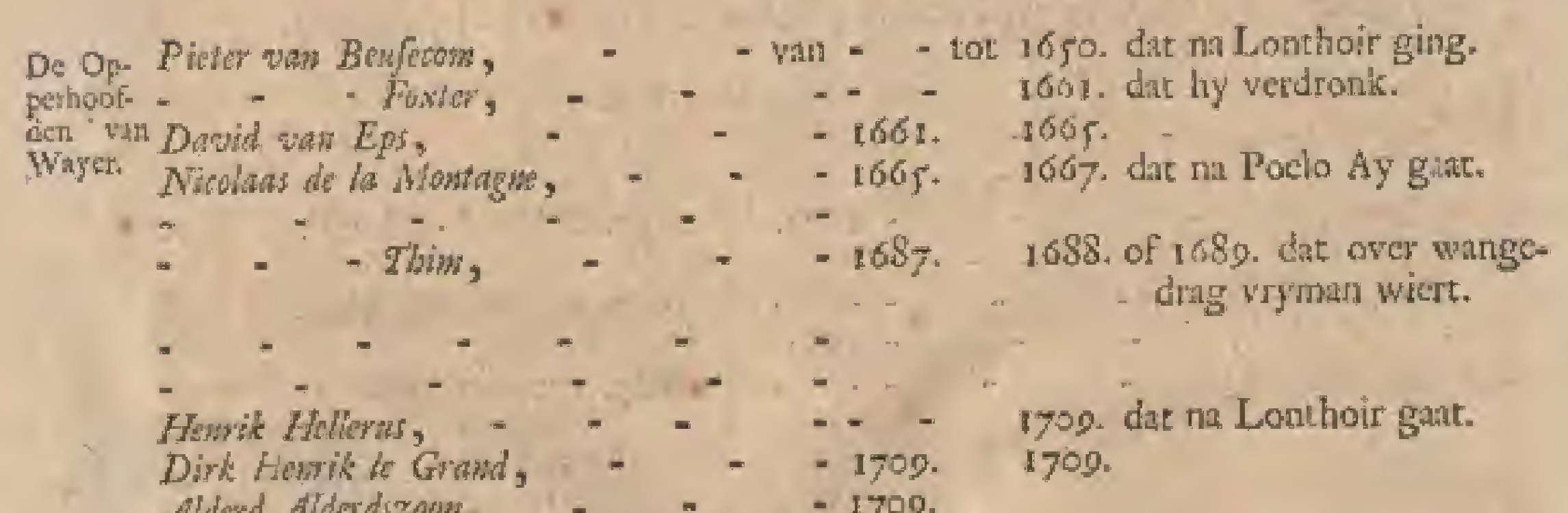

Alderd Aldedizoon, = " - 1709

Hy was her nog in 'c jaar 1714 , en

mogulyk later.

Gebeimfchrywers des Gerechts, of eerfte Klerken in in Banda, zynde Boekhouders tot $3^{\circ}$ guld.

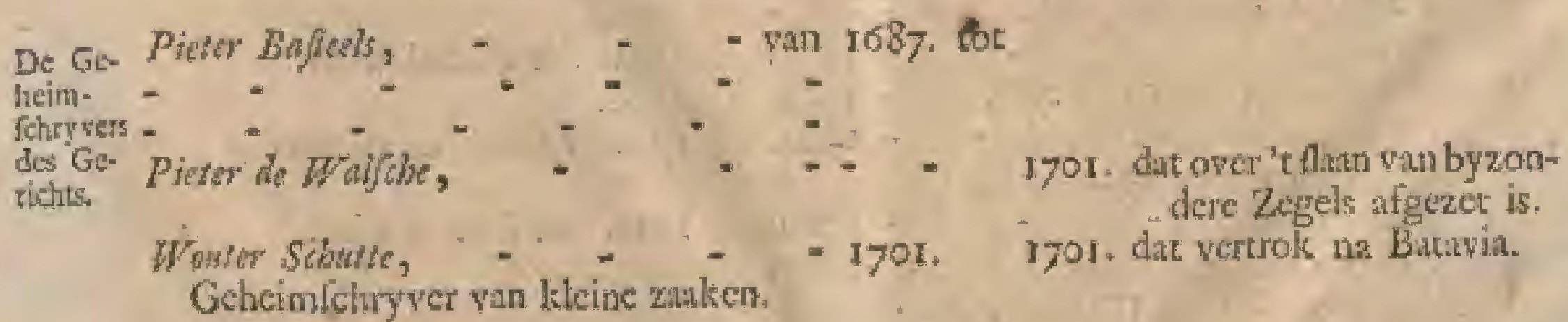




\section{Z A A K E N. $\quad$ rog.}

Louis Badwakker, - = Yan 1701. tot 1709 .

Geheimlchrywer van kieine zaken.

Fan Yacobsoon, als boven, - $\quad$ - I709. I7 IO. dat na Bataya vertrok.

Henrik Proof, als boven, = -1710

Hewh Lrenkman, -. $\quad$ - I759.

\section{Licutenants in Banda.}

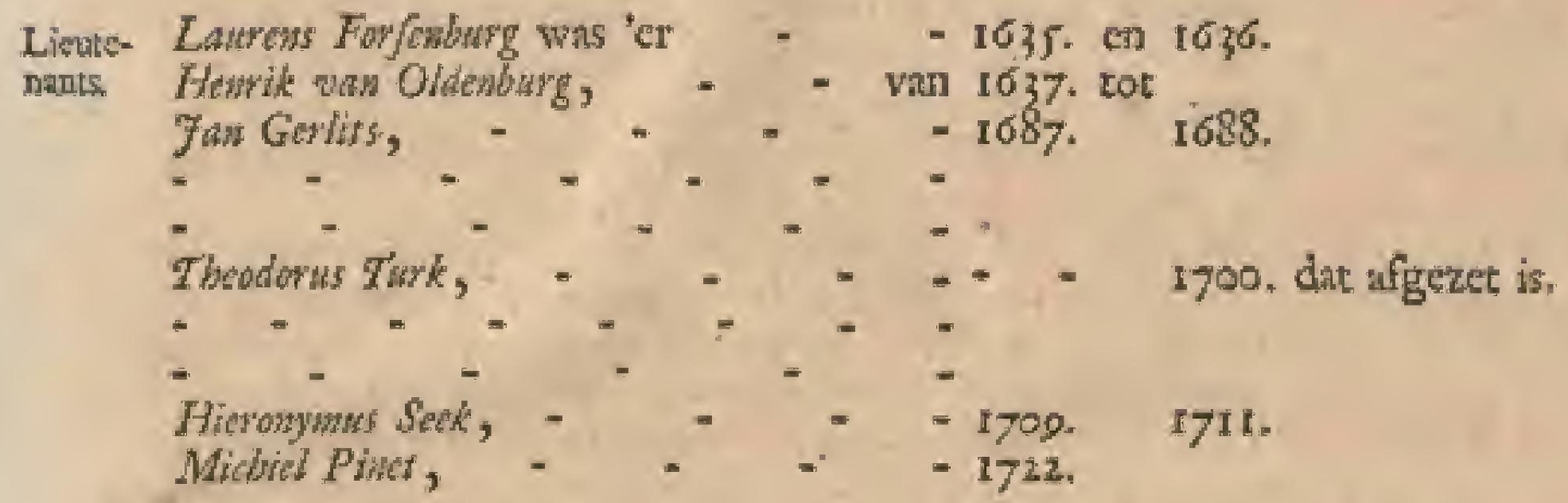

\section{Vaandrigs in Banda.}

Vast-

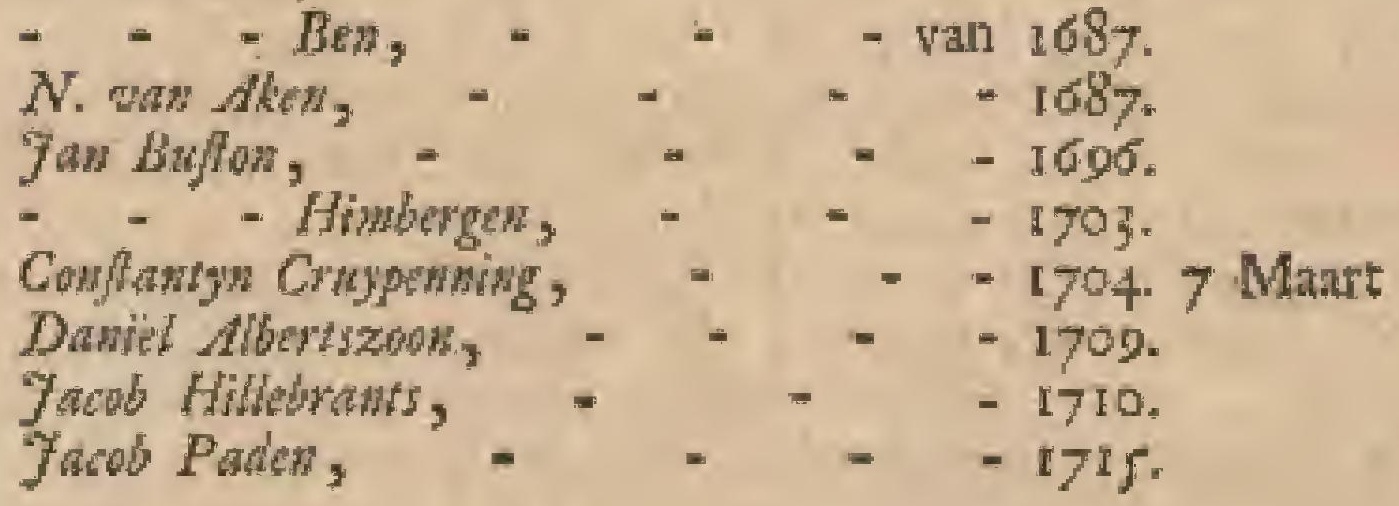

tot

I704, oflingos, dat ftierf.

\section{A CH TSTE HOOFDST U K.}

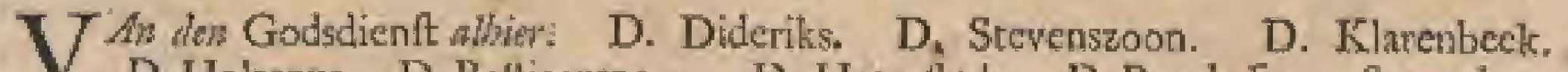
D. Holtenus. D. Baltiatnszoon. D. Heemitede. D. Pontkaten. Stant dezer

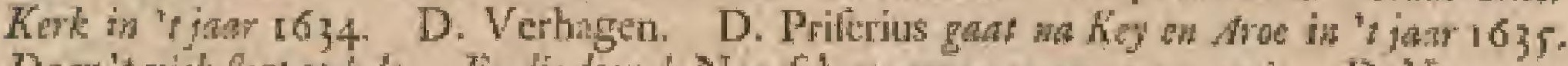

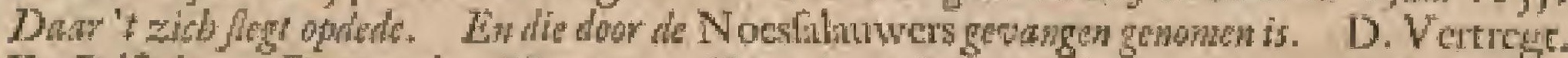
D. Priferius. D vin den Houten. Slegte bevinding in 'r jaar 1646 og de $Z$. Onfercilanden. D. Ritzius. D. D. Pantherus, en Lippius. D. D. Geesdorpius, en Ringius. D. Brouxwerius. D. Molanus. D. Spiljardus: D. à Warmetoo. D. Brougbron. D. D. Malius, ende Moor. D. D. Callier, en Sibelius. D. de Grafe. D. de Birect. D. Manteius. D. Rliyndyk. In " iant 1670, een Krankbezocker os Aroe gelogt. D. Rhynsdyk. D. Carpius. D. de Large, D. van der Linden. D. Manceau. D. de Bois. D. Brakel' die ma Batawia vertrok, en 't jaar daar aan aver bitr gutw. De Schryver kom hier. D. Gobius. D. van Simey. D. de Witte. D. de Graf. D. Loderus. D. Feylingius. D. Bierman. Aroe's Kerkfaat in 'f jaar $160 \%$. D. Stampioen, D. Boterkooper, D. Cammiga. D. Hoyer. D. Noot. D. Sertuss. D. van Schic, D. Boekeoberg. D. D. Ens, en Pars. D. Cramer: D. D. Hurtog, en Moller. D. Loyal, Lyit der Bandatiche Predikanten. Neirafche Prediksmes. Louthouriche Prodikanten. Poelo Aycche Predikanten.

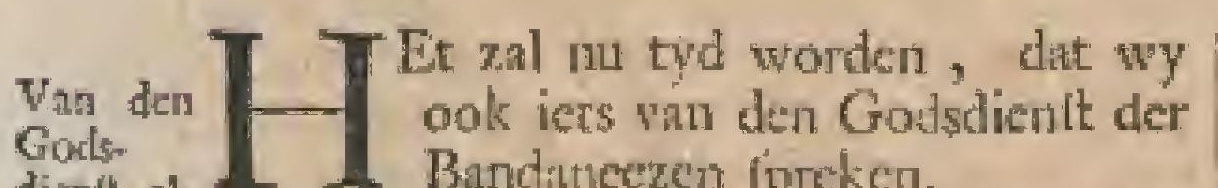
dicnitl hiser. wan te bepalen is een onmogelyke zatk, vermits geen nette anteckeningen dar af vinde.

By de komlt der onzen in "t juar 1590 . den $15^{\text {den }}$ Matart watren $2 y$ al Mohhammedatinfch, cen wy wat bitter, hocwel zy van de gronden wan dezen Godslientt zeer weinig kenuis hebben, hocdanig het met de meetle Moluhammedumen on de geweelt; makar in de laater is de Moorfehe, of Mohhammed anfelac Religie door den oingang esi luandel der Javannes met de Bandineezen hier al mede allengsleens ingedrongen. De nette tyd hier 
Oolt geltelt is. De Gemeinte onter hen is nict in that om de Anbilehe ictter te Lezen of te teloryven, en dichtaluen weten zy wan den Coran, of hum Werbock, en des zels inhoud, niet sunders, dan 't geen de Priefters en Moorlche Patapea hen daar van reggen, die in 'r lezen en fchrywen wath die letter allect erwaren, en 'el' ook maar zeet weinig zyn.

Het grootle deel wan humen Goulsdientt beftont toen is 't doen wan gebeden vyfmaldes dangs, "c zy in hume Maftigit (eigentlyk de Mesdjid gentame) of tempel, 't ry' ook wel elüers, in welke zy niet gewoon when te komen, ten $z y$ dy hare voeten met water, "t geen dial ontrent gemeenelyte in ecr aade watervat that, eerlt gewaflehen en zich gereinigt hebben. Tot "t zamenroepen der Gumeinte gebruiliten zy zeluere groote thande of ook wel hangende tronnmeis, of groote - kopere Gongen.

Zy maakten ook groot werk yat hunne Valten in de intand Ramiktath, cen gathfche mand lang wan zon's op tot des zelfs'

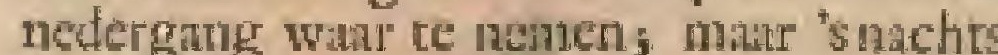
finulden zy dan heldes.

Hun geloove wis regt eun geloove, als dir der anclite Pafilten, die gerult zyn, op "r geen de Prietters, of, zoo als zy 'tnocmen, de H. Kerk geloof, en soo ftont "et hicr mede met lhen.

Nit de konut der Nederlanders is deze Godsdienlt, gelyk ook de ganlche Ban dancefelhe thatic, door "t fward des oorlogs, doch meet door hunne onwerzettelyke bandnekkiglyeid, wit deze gutche Landwoogdy coodung verdrevell, ditt men "er nu befwarlyk een Moor, of Molihammedam vinden zou.

Eer men hier egrer Predikanen an toe zont, hecft men zich in de eerfte tyden maar wan Krankbezockers bodicut.

Om nogtans net te konnen zien, hoc het hier van den beginne af nee de Kerke gegan heef, athen wy het zelve volgens de jarren, zoo ats de zanken hier nalkanderen volgen, opgeven.

In 'c pant' I $6 \geq 1$.

Den 28 acul oftober wiere in Kekenragde op Batavia wörgellagen, on $\mathrm{Ca} / \mathrm{p}$ *

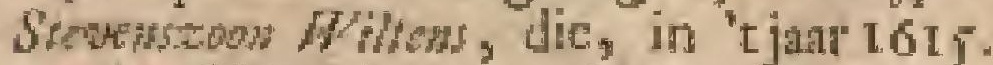
met het fehip Terveere uitgewntren, door de Gedepureerden yan 't Cladtis van Walcheren in Oetober 1620. fturk anbevolen whs, nat Banda, angezien hy reeds op Poclo Ay gelegen had, als Predikant te zenden, wata toe hem 8 dagen tyd, on zich te bedenken, gegewen zyn, doch by weigerde dit, en ging nit 't Vaderliknd.

Den I $3^{\text {dea }}$ November bieck, dar Bewik vanSarf coen op Poclo Av lag, zonder dar blykt, of hy Proponent, or Krinkbezocker, hoowel "l luatte hec warichyndykit wis.

Ook blykt by die zelve belluit, dat op Neira toen tag de Kankbezoker Wuter Mcldiorsaon ; en op Lonthoin Adrian Porwa ; dic in 't jar' 16z2. met D. How Folu, 200. als 2y den inham vis Amboina inieren, verdronk.

$$
\text { In "L jat I } 625 \text {. }
$$

Qtuan ats certle Predicitat hier D. $M n-$

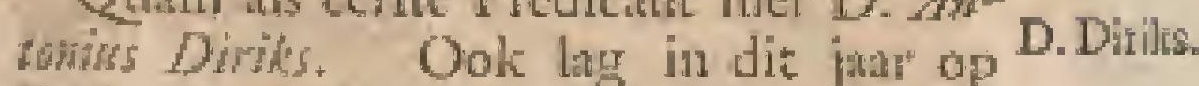
Foclo My de Krankbezouler Adridna de Karraminder, en op Rofingein zou 'cr ook cen geicht worden.

Hier was nu ook ecn foloole onden op. zige van $N$. Figh

Moutcr Melbionzoun wer fcheen dit juar wit Banda op Batnvia, zonder dat blykt, of hy Proponent, dan of liy nog Krankbezoeker was, des zou men made ftuter Kerke alhier, als mede na $/$ inor ${ }^{*}$ lctrool, en ra de raaken, den Landroogt Which Jowsoon berteffende, vernemen.

D. Carpon Sravascon, den zoden $\mathrm{No}$ vember by de Hoge Regering wan Indiên D. Sie goodgekcurt, om lictwarts ils Predikane Netosoon. te gaan, wertrok wan Batavia.

$$
\text { In "t jeth" } 1626 \text {. }
$$

D. Stovenzow quam hicr in "o bogin dezes jarrs.

De Kramlbezocket de $K$ ar $/ e m a d k$ vertrok-van hier na Butavia, virs waj den $5^{\text {den }}$ November Ger, it Gerrirzoon in zya plats herwats gezonden is.

$$
1629 \text {. }
$$

In dit jaar fchyne D. Dinks, die op Lonthoir geleges hat, overieden te zyn. eo ook D. Stcomsnoon.

Die wan Bandit hauden gelchreven na Batava, dat tie van Key en Aroc on een Chriften-Leasur verzogt hadden; soch men had daar goedgevonden ecrlt te vernemen, hoe zy mee den Krankbezocker

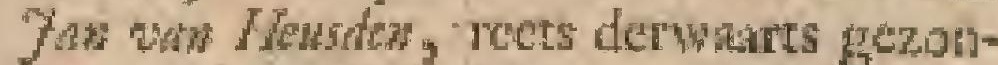
den, gehindelt hadden.

D. Mabal Charewhed vercheen hict in D. Lia Februari, en is geplatil op Lonthoir, D. Cisdoch van D. Wiltews, dic op Neira lags. licp thicr een quand gerugt.

In dit jut is de Kranthetoeker $7 a n$ Pietrozoon herwats gezontien, en in Mey de Lonthorize Kranbezoter Jan wan Hersden wan hicr na Batavia vertrok-

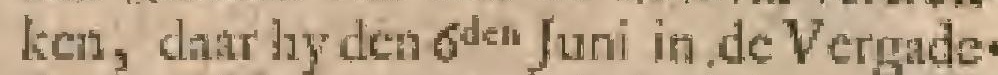
ring verfeheen, gevende beriche, wat de Landwoogt, de Hcer Qwirn rin Rambog , den Kerkenratid athier had willen opdringen, on twee Politique Comm iflatrifen in base Vergadering te ontfingen, dat de zelye gewcigert, en by daar op den Kerkentand verboden had Vergadering te houdert, hocwel zy egter, tor zyn vertek toc, hare Vergaderingen (doch woor ext korten tyd) wervolgt badden. Ook hat die Heer den Kerhennat opgelegt, om, by forme wan dwang, 
1 Z A A

hatife Kerkelyke brieven an liam te noeten overleveren, on die telis tha Batawin te zerden. Doch de Kerkentand had gezegt hict ower met andere Kerken ecrlt te willen thatplegen. Dus. wient hen "t vergaderen ner alleen verboden; muar ook hang geftremt.

D. Hol D. Gulieimas Hotewes was in to begin temus dezes jars buer ook verichenen.

Den if den Decenbet had D. Hewnius (diens tyd uit was) op Batavia verzoge, on na Key, Aroc, Timor en Solor te gan, zonder dac dit egterwontgang had.

In "r jaar" 1631 .

D. Bne. Is her gekomen D. Geghort Bafiains-

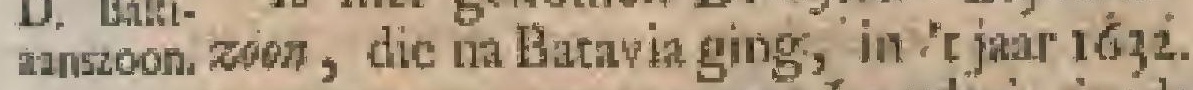
weerquam, en toen.ep Lonchoir in de phass wan D. Clavenbeck (die ni Poelo Ay ging, en den $I 7^{\text {den }}$ Decenber "cl fticrf', gelege is.

$$
\text { Tn. 'te jatar i } 633 \text {. }
$$

Deh rgden Matt feicf hier Gribert Baftianszaon, Predikant op Lonthoir, ook vertrok wan hier met "t rchip de Goude Leeuw na Bativia de Krankbzocker Hows britizen, en den $3^{\text {den }}$ Novembej zou van dart herwates komen de Kratikbezoeker Coridis Cormiszon van Hiarlem.

\section{- In t jast 1634.}

Den-ride Oetober verzogt de Krankbezocker Cormh Ditkzon Heonflede op Batavia, om herwates gezonden te worden, 't geen hem is totgettans.

D. Hotenes was in September wa hier na Bitavia vertrokken, en den I zén Oetober ditar gekomen; : war tegen in dit zelve jaar weer hich in Augufus uit AmD.Heem-boina gekomen was D. Jounes Hemplede ftedc, van Rotrerdan, the den 27 ften dito op Neirn, gelyk de Proponent D. Kewrik D. Iront- Ponkinfes op Poelo Ay, geplantit was, kiters. zonder dat van dien lateften blykt, wannecr, of van watr, hy hirr gekomen $z y$.

Mwoni Amoniszoon wan Utrecht, Krankbezoeler lag op Wayer, en Pieter Janizoon wan Groningen (die om zyne verlofing verzogt) hg op Cchamme, en M. Onterwans, mede Krankbezocker, op Lonthoir.

Sint de- Ook berigte D. Holtems nog verder ser kerk op Batcivia, dat in de cilanden vau Banda in "t jat toen waren roo Inlundfche, en 600 1634 Duitfiche Chrittenen, de kinderen en lyfeigunet mede gerelcent, als mede $70 \mathrm{Le}$ dematen, en dat 'er 5 fchoolen aldatu', te weten, op Nein een met $3 \circ$, op Lonthoir een met fo, op Poclo Ay cen met 5o, op Wayer een met 16 , el op Cefamne een met is fichoolkinderen wareh, die te zamen 162 uitmalksen; on welke te betcr voort te zetten, zy on 2 Nederduitche, en on 3 Inlandiche Meefters verzogten, gelyk ook om nog cen Predikant, en cen Krankbezocker:
IS E N.

In 't jaar I 635 .

Is bier mat 't lchip den Arent gekomenD. VosD. Amonias Verbagen, van Utreche, en hagen. in D. Cloreweeks plats op Poclo Ay ge: legt.

De Heer Prelident, Gurwib' Acolcy, in Seprember 1634 ann den. Opperlandvooge on cen Atigrelyk Predikn, om nis Key en Aroe te gan, gefchicren hebbende, quam nu dit jar ten dien einde henwads D. Ifan fowsow Priferio, D. Prilewan Enktuizen, dic voor eertt op Poelo nus gant Ay, gelyk D. Terbagen nu op Lonthoir Aroc it geplaat th was, anugezien by cerft den"r jasr - do Den December an de Z. Ooften - eilan-1635. den, Key en Aroe is gegan, oni dwar mec een Adfilten, 4 foldaten en 2 rchoolmeetters cenigen, tyd re Jeggen; in welke mand hier op Netra ook de Orangkaya wan Key, Nawathis gedoop, en Joowses genanut is. Ook verrogica zy wan hice om een Predikant en een Kralcberocker, om D. Heen/fede, en den Krwnkberoeker Anont Amoniszon, te verlofien.

En eindelyk droeg de Bardafche $\mathrm{Ker}$. kenrad D. Pomkefin, nu nog als Proponene op Poelo Ay leggende, aan die fan Baravia woor, ou bem, als zynde in de Maleitiche tnal erwaten, tor Predilkatot te yorderen.

$$
\text { In "t jaar } 1636 \text {. }
$$

Den $22^{\text {ften }}$ Jemuari itier $\mathrm{D}$ Yoshas

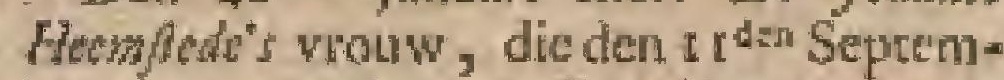
ber weer troude mee Zara Yansze Rorih for, een van de zes Compagnies docticers in ' jaar 1630. hier in Bandu tan Batavia gekomen.

D. Abrabam Rutalu, Proponest, zou in I'cbruari na Banda gan, on D. Pontkafen, zoo hy na Batawia quan, te verw loflen, ca den dient op Poclo ay wate te nemer ; gelyk hy, en de Krankberoc-

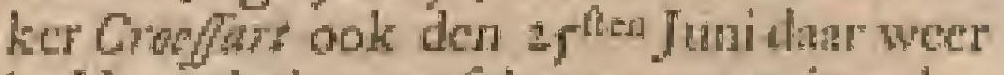
in Vergadering verfectenen, getuigende, dar zy in Banda nolt yoor den Kerkenrand geroepen, en in "tecrft zeer vreemt wan den Landroogt, de Heer Aclyy, bejegend waren.

By fchryvens van D. Pricriws wan den Das "t $27^{\text {len }} \mathrm{Mey}$ dezos jatrs uir Key atan de Hecr zich llegt Landvoogr Acoley bleck, dat hy darar nog opciede niets opgedan, matr zeer dikwils gew inr wan zyn leven geloopen, en dat by geen hoope ter wereld had, wan hier cenige varige te zullendoen. Hy quan dethalyen wan diar, doch wiet in Augultus dowr ran die dic van Noeffa Laco, woot 't dorp Amet door de genomen, en is doutr na in Amboina geko-Noethmen. Oot verzogten de Batulafche Blice- latwess ders an die van Bustaria, dac D. Ponkafongevangen dar by hen cot Predikant moge gevordert, gen en ten dien einde onderzogt worden.

Zy makiten ook bekent, dat D. Forbager den gdest Septernber op Lonkhoir operteden, ca hee dierbalpen noodig was,

$$
\mathrm{U}_{2}
$$




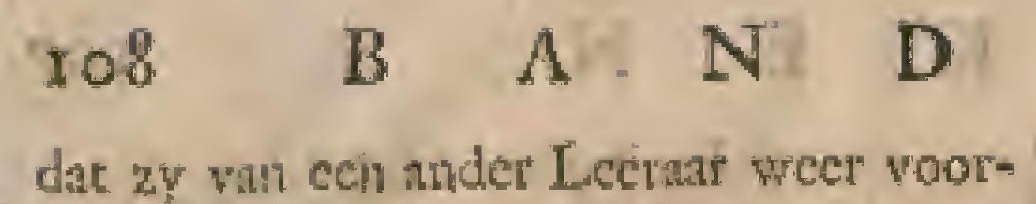
zien wilerden.

Burbard Loblowsogn wan Alkmat vertrok nut mede, met "tchip Bueren, na Batavia.

Den roden Noventer hat mer op Batuvia D. Jecolu Fotrgy herwarts beroe-pen, en deri ig den diro goedgevonden, dat D. Ponkajes hicr blywen zon', on in Balud anderwhat te worden, mangezien

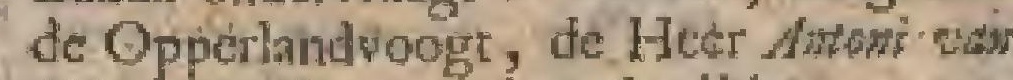
Diemen, by zpri komft alliet, cwe Predikanten medebrengenty en op syth zank letcen, of anders hem na Bativia mede nemen zot, on dar beveltigt te worden, wermits de Bandalche Broederén th gelchrevene by die van Bitawia niet wel in atgt genomen hadden.?

$$
\text { in 't fant i } 637 \text {." }
$$

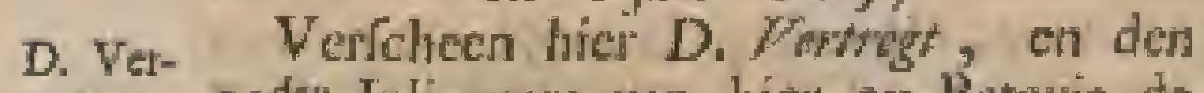

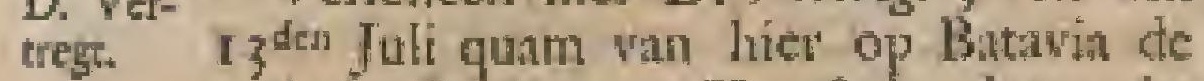

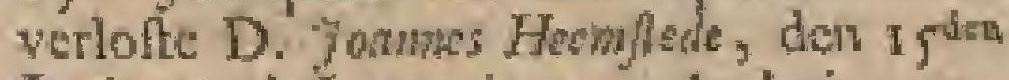
Tuni net de Leenwin over Amboina vertrokken, berige brengende van den goeden flant der fchoolen hier, en dat D.

D. Prije- Verthtgt op Neira, en D. Priferius, die rius, tait Amboina weder hier gekomen was, nu op Lonthoir lag. Die van Amet lindden hem nal den Teruatannzen Kimelaha, toen onzen doodvyand, oveigegeren. Men bad hem it zyn boeken en goederen afgenomen, vecl ongenak doen.uititan, en hem, om guantzuis nog cerrige Clriftelyke hiefide met een half Heidenich en half Mooufch hart te betoonen, alleen op "r ftrand van Papero, op 'c ciland How nimon, nedergezer, otn hem zoo gelcgenheid te geven wan by de onzen op dite eiland aun de Hoofdplates te komen; maar zyn Coracora, en twee foldaten, bleven dat by hen nog.

$$
4638 \text {. }
$$

Volgens befluit desBatawifchen Kerken ratads, van den 28 ten December des voorleden jarrs, quam hiej" weder Glan Brits wan Antwerpen, als. Krankbezocker; ook verzogten die van Banda or en derde Predilarus en "t is wariclynelyl, dac D. Pontkafes toen ook hict by 'taninezen wan den Heer Opperlandwooge sum Dionen Predikant gemaakt is.

$$
\text { I } 639 \text {. }
$$

D. Pr/criss vertrok van hick wa Amboina, zoo dat I ftont, weshlyen $z y$ ook hier een inder Predikint verzogiten.

$$
\text { I } 64 \mathrm{t} \text {. }
$$

Den $27^{\text {then }}$ Mcy verfichen de Krankbezocker Jon Dble van hier op Bataria.

$$
\text { I } 64 \mathrm{z} \text {. }
$$

Dej 6den Oetobej was D. Marian Gi * diconsoon wan den Honten herwarts berocpen, otr D. Poukajen te verlofien, doch fiy droeg tich ondertufichon ontrent het Kerkenboek roo otwoortigtig, dat by

\section{A S C H E}

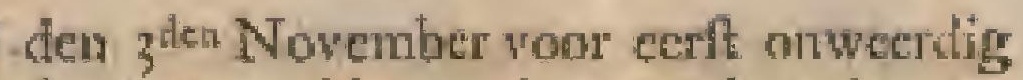
daur toe werklaat wiert ; alzoo ${ }^{7} \mathrm{er} \mathrm{eco}$ blad uitgefeheurt was.

$$
\text { I } 643 \text {. }
$$

D. wan Houten, na zich by cede ge- D. wa zuiwert te hebbem, verfchen het dic jant', den Houen witer op Poelo Ay in plates wan D. Postkdangelegt, die ven hier na Amboina vertrok:

Men verzogt wan hier na Batavia dit juar ook om bocken, alzoo zy hier if firen geen boek, nog blad papier, ontfungen liadden.

$$
\text { I } 6.44 \text {. }
$$

D. Vortrege wengogt erntig zyte ver lofling, weshalven zy om een ander in zyn plants, en ook on nog cen ahder op Louthoit, verzogten, klagende zecr over gebrck wan fchoolbehocfen. Men had hicr" nu 6 fchoolen, 2ommige ven 20 tot 30,40 en po fétholierco.

De Ktankbezocker Yan Pietorzosn, in Mey van hier vertroklien, verfliecen den apten Juni op Baturia, niwar de Broedeten, op "t werzock van hier, goodvonden den 22 Aeu Augufti de Vaderlandze brieven tet lezing anu de Bandarehe Broederen te zenden. Ook fehueven dic way

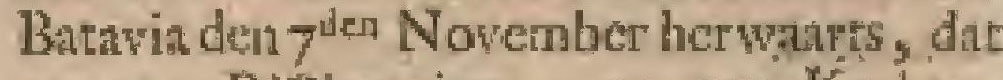
zy cen Didionarim, en eer Kerkenordre, beft met de gefteltenis wan hare Kerk overeenkomende, opltellen, en rá Batavia zenden wilden, om dan dat ees fte werder tot ecn algemein Dikianimm in 's Portugerleh, Zinkntms, en Maleits, te doen dienen.

$$
164 \pi
$$

De Krankezocker Siman Jacolszom komt die jar hics.

D. Vorrest bood zyn dienft man, om op zeker biland hier ontrent, dari nog noit gepredikt wis, het Eungelium te gan prediken, veitzockende, dat men datr toe de goedkearing pan Batavia geliefde te verzocken, of dat har Edclideden, arngexicn zyn tyd uit, en hy ongenegen was langer hier te blyven, hem anders zyne verlofing geliefden toe te ftan. Dezen yweit wan zyn Eerw. wiete den zden Oetober door den Batavifehen Kerkenrand wel gepsezen, en ook van zyn Edelhcid wel getrocmi doch die zag vecl fwarigheid in de middelen yan bevordeling.

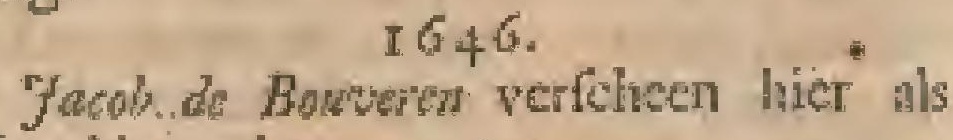
Krankbezoeker.

D. oan den Howten wis zick, en D. Protreg' thone hanft te vertrelken, weshinlwent zy hier om een Prediknth, en een Proponetse, verzogten.

stegre bi:-

D. Vorreg bad de cilanden wan Aroc, vinding "Tentrmbat, en Damne bezogt; doch deze ins "5 jast wolkeren zeer brutat in leven, en zon-da 7 der ecnis ordentcly bettier ol Hoot, Oofer 


\section{Z A A K E N.}

alzoo yder duar meetter zyn wilde, geyonden. Ook hid by gezien, dat zy groote vriendrchap en ommegang met de Mooren, Macafiatren, en Javaanen, door dea handel ( 200 ik vertrouwe net en on de fpeceryen, dar vallende) hiclden, en ath de zelve zich in vecl zatiken gedrocgen. Daar nu nog al cenige Orangkyje's waren, thar wierden de Ingezecenem, meeft Moorich, lediggangers, en zeer jalocis, over hume wyven, en dierhalven bang voor zoo veel fehepen, als zy vernamen, dat in Banda cocn waren, zynde door hunne Hoofden opgerokkent, om na "tbofch devlugt te nemen, gelyk zy ook gedan haddern. Ecn fegt gevolg op "t werzoek, 't jant te vooren by die vin Aroc, om Chritten te willen worden, gedonr; max zy wiren door de oude Bandanezen, die hier in menigte na toe geviugt zyn, alkeerig gemalkt, en tegen de onzen opgezet. Ja zy waren zoo bitter, dat zy, op zekejen tyd, hum kans klaar ziende, Ichielyk uit her bofch op eersige van ons wolk ranviclen, twee bootsgezellen "t hoofit nitloegen, en eenige der onzen mee vergiftige pylen querfteu, whar wan 'er' ook zommige itierven, hoewel ecrigre, door ten eerften warme meram. fchen-drek in te nemen, nog bebouden. wierden.

$$
\text { I } 647
$$

D. Nicolan Rotwins quam dit jan hier, on D. Fortrgt, die nu na Batavia wertrok, te werwangen, en D. Gerordus Velhbufws quam hier nu mede in plants wan D. wan den Hown, die hier niet linger dienflig, mat fchadelyk geoordecle wictt. Ook. quam de Krinkbezocker, yob de Lange, van hier op Baravia, alwar den i 2 den Mey ook D. Fentegt in de Vergadering verlcheen. Ook verzogren $z y$ van hier on cen derde Predikant, en on de verlofling wan den Krakbezocker Clats Beck.

\section{In 't jaar 5648 .}

Den 8ten Juni quam de Krankbezoeker Moblel Claredede van hier op Batawia, nlwar des r $0^{\text {den }}$ Augutti de tyding quam, dat D. Riszius hier overleden wiss ; wes-

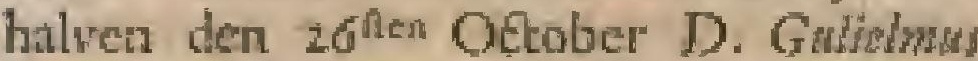
Pawherus beroepen is, on herwats te wertrekken ; en atangezien D. Velboyy/on dit jatr cok owerleden fchyne te zyn, zoo is nevens den zelven den 30 ften $N$ ovember nog berocpen D. Arnoldus Lippits, grelyte die in December, en mee hen de Krankbezockers, Pintr Srals en Johas Stal, herwarts vertrokken zyn, met belofte wan ook 150 Plilmboeken, 3 riemen Papier, en joo pennen te zullen zenden.

$$
\text { In "t jair I } 649 \text {. }
$$

D. D. Verfehenen hier D. D. Pantbors, en Panthe- Lipsins, wellce lazile dit jar fehynt overFus, en leden te $a y n$, alyoo by niet meer woortsont.
Den II den Ottober" quam wan hier de Krankbezoeker, Howik Carlass, op Batavia, alwan men den Bhas Nowember D. Contias Gecslorpus herwatre bericp. I. 650 .

D. Gecdorpis hier pis verfchenen zyn- D, D. de, is lromt "er an overleder. Gersdor.

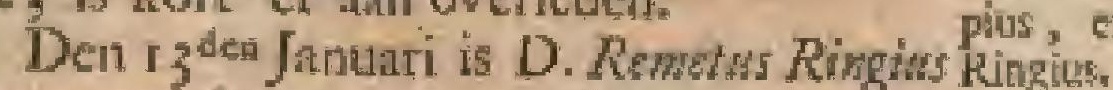
herwarts beroepen, en kort 'er na biet gekomen.

$$
\text { In "t jant I } 6 \% 2 \text {. }
$$

Qunm hier de Proponent, Fowbin Pieferizon, en den $3^{\text {den }}$ Tunî verfeheen op Batavia de verlofte D. Panhorws.

$$
\text { In "t jaar } 1654 \text {. }
$$

Den ziten September wiert D. Damill Bromazins herwarts berocpen; en D. Ringits is yan hict ma Amboina vertrokkert.

$$
\text { In it jatr i } 6.5 \% \text {. }
$$

Quam D. Browwerins lier, doch kreeg D. Brow in dit zelve fon in October zyne verlos-werius. zing, die hem war Batryia ook toegeftan wiert; howwel hy toen nog niet vertrok. In 't jaar 16,56 .

Quam hier, volgens zyn Beroep, den gien Oetober op Bacavia hem a D. Jachws Wolame, weleer Predikant op de Wall con "O Oolteinde "op "t el Texel, en wiert op Neir geplast.

Ook quan dit jaas hier D. Johas spik jardus, die op Poclo Ay gelege is, matr D. Spith D. Browoweriws vertiok van hier als werrior Predikant, zoo nader in de Acte wan den Kerkenrand van Banda van den 3 often $^{\text {fte }}$ Augulti blykt, foi quam den $6^{\text {den }}$ Oetober op Batavia in Kerkentade te verfebyuch.

\section{In 't jaar 1657 .}

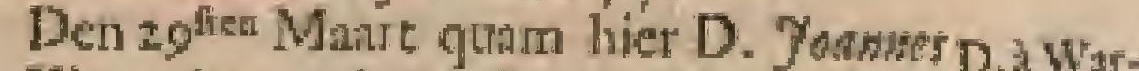
a Warmelos, volgens Beroep van den Bfea meloo. December, tor Batawia op zyn Eerw. gewallen, zynde te vooren in Ternate Predikant geweet, en 't jatr te vooren dit Batavia vertrokken. Hy wiert op Lonthoir gelegt.

$$
\text { In "t jatr } 16 \mathrm{~g} 8 .
$$

Den 1 dirn November verzogten die van Amboina om den Thalkundigen D. Spiljartus; war op zy den I 8 den vati de zelve mand antwoondden, dat $z y$ dan thiet, dan den ouden D. Molants hielden, ook berifpten $2 y$ die wan Amboina, over 't fchryen buiten kennis wan D. Bh"orgbrow, als ook datar over, dat zy in laaren brief zeiden, zich na den Landrooge te fchikken, datr 'e Kerkentecht medebrigt, dat hy zich na hake fuhik ken, en lasine befluiten, billyk zyade, goedkeuren moett; en eindelyk zeiden $z y$, ditt het ganlch onbillyk wis, dat zy nu (gelyk $z y$ it) 'E jatir $1655.200 \mathrm{zy}$. hen verweten, nog eens gednan laddeny weer oen Piedikant, even als of die ma hare ftonc, 'cr uitpiktea. 
$110 \quad$ B $A$
En was deze bricf door 7. Molams, 7. Spilfiordos, Henrik le Gramd, Pbilip was der Eyken, cn Barcm Hobsin, Ouderlingen. Dirk Marrtenszont , Yachim Piearizbon, en Fac. Dowrgang, Diaconen, geteckent.

Egter vertmak D. Spiljawdus (volgens "t befluit des Kerkcurads, om gewigtige redenen, en op 't voordmger var den Commiffaris Politycq op den $20^{\text {nten }} \mathrm{No}^{-}$ vember) nog in December dezes jaats na Amboina.

Endus moet D. Wrameion ook dit jpar, of 't woorigge, van lieer (zonder dat iny' blyke whtte nit toe, alzoo dat Adteboek gebrekkelyk wats) wertrokken zyn.

$$
1659 \text {. }
$$

D. Molanus verzogt (zoo den $27^{\text {net }}$ Oetober op Batavin bleck ) by 'I cindigen van zyn vytjarig verband te mogen na "E Vaderland vertrekken.

$$
\text { I } 660 \text {. }
$$

Dit jarr was D. Molanus hier allecta.

$$
\text { In ' } \mathrm{t} \text { jast } 166 \mathrm{i} \text {. }
$$

Komt D. Berwardus Brouglow hier van D. Brougt Batavia, nam den aden Mart feflie in Vergadering, en wiert op Poelo $A y$ geplantit.

D. Molanus had cenige Predikatien, volgens otdre desCatechismus, in " $\mathrm{t}$ Hoog Maleits opgeftelt, ower welke rnen hier Gabricl Nache, voor dezen Krankbezocker, en een Inlands Schoolmeefter tot Revifores gefteit had, welke men den $20^{\text {ten }}$ Juli na Amboina zont, mee verzoek, dat men die dasr ook eens thzien, en hen wan das met echige Pfalmen op rym voorrien zou, welke zy den $5^{\text {uen }}$ Augufti litegen; doch over dezc Predikaticn antwoordden die van Amboina den $7^{\text {dea }}$ September, dat de zelve wel goed; doch voor' 't gemeen wolk wat te fwat, en te hoog oin te verittan waren.

In 't jait 1662.

D. D. Den $4^{\text {den }}$ April verfchenen hier in Ver-

Mafris, gadering D. D. Marews Miffuts, en Fownes

ch de de Moor, de eerthe wiert op Poelo Ay;

Moor. en de andere op Lonthoir gephat ft; doch om ook Neira, zoo lang D. Molswus nict vertrok, mede war te nemen. Van welke hatifle anngetcelient ttaut, dat hy den fien September na Batavia vertrok; docli dat is niet gelehicd, en hy nog hier geblevent. Ook vertrok D. Broughron ower wangedrag na Batawia.

$$
\text { In "c joar } 4665 \text {. }
$$

Den I sten Juni kreeg men van Batawia tyding van her overlyden yan D. Molanus en D. de Moos, en D. Mafus is toen op Neira, na bun dood, geplaart. De netre cyd var 't owerlyden dezer. Heeren biykt nict, alzoo dar Actebock gebrekkelyk is. In 't jar 1664 .

D. D. Den 4 de Masr quam D. Pewn Cofer, Gilier, en die op Podo Ay gelege wiert; en den
A $S: C D O H \quad E$

I $y^{\text {der A }}$ A wil wercheen licr nok D. Parws Sibclius, die, door fohipbrenk in Tcrnto, eert in Amboin, en dar un hier, doch zeer lam en roak, gekomen is. $\mathrm{Hy}$ wiert wel voor eerlt op Lonthoir gelegt, doch, wegens ryne twakheid, vertok by in de zelve miand weer mi Batavia.

In 'e jatis 1665 .

Geralkte D.D. Mafw, cn Caks, met den Landvoogt Cops overhoos, nlzoo die den Kerkenraad de behandeling der $A v^{-}$ mentwiditelen ontreleken, en als oppermagtig (dat noit te vooren gefchied was ) hicr in handelen wilde. De eerlte wiet hies over voor een tyd afgezet, en opgezonden, hoedating hy met cen vertoog wan de droevige fant der Kerke, op Batavia refleheen. Ool foheen D. Calor al mede afgezer, en de ganfche Kerkenratd allser door dezen Limdwoogt weer mishandele te zyn: want D. Mofiss dar met een zeer loffelyke utfelieids-

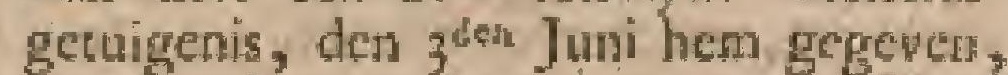
en met volkomen bewys van zyn onfchth (gelyk ook wan die van de ganichea KeTkenrad) aldar bimen ftont. De Kerkenroal var Butavia, haur aller onfchule zecr Vhar ziende, vont goed twec Gecom mitteerden tan de Hecten der Hooge Regeering den zuten Nortmber te zenden, zoo om de onfchuld van D. Marus, D. Cajor, en wan den Kerkeimad alhier, te wertooners, als om hunne volkonen herftelling, zoo in opzige van hum Ampt, als in opzigt wan hun vertreden Kerkentecht, te verzocken.

De Heer Opperlandqooge, en de Hecren Randen zagen mede wel klar, dat de Landvoogt alleen fchuldig whs; maar $z y$ behandelden de zante egter zoo niet, afs de Kerkennat van Basivin die gecme, en miar in billykheid, gezien had. D. D. Mofits, eu Cafor, wierden wel herftelt, $c$ dat neters wiert door hat Edelheden wel belooft, dat zy an den Landwoogt Chryvenzonden wan de Kerkzalien op den ouden voer, en die tanden Kerkeninat te laten; matr D. Majph moett egter van de cyd wan zyme afzering tot zyn wertek na Burayfa, en D. Cafier 3 manden var hunne lơldye en buitenvordecten miflen, om dat zy zich het onbillyk belluit des Landrooges, en zyne geweldemary ovet "t Kerkelylie, dic tegen alle voorige voorbelden ftreed, tot mader ancwoord op zyn fehrywens nat Bacavia, niet onderworpen hadden; en de Landroogt, die alleen de fehuld van whe dete onordentelykheden hath, wiert nicts ter wereld geleer, veel min, gelyk by alleen wel klaar werdient had, geltraft.

De Kerkenrand vas Butawit over de gebrekiclyke en now onbillytie herftclling van deze twee od chuldige Heeref ganleh nice revrete, heeft zich wel hoo- 


\section{Z A A K $\quad$ E N.}

I I t

gelyk hicr over bedroeft, en naderhind vecl pogingen gedan, on tir by haar Edelhodea heritelt te krygen; masr nille haare annge wende moeiten, gely t by hatae Aete vanden I den November blyke, zyo te vergeefs geweett.

$$
\text { In 't inar } 1666 \text {. }
$$

Quam hicr wa Batawia de Krankbezocker, Dawid Nowakerk; an dea 2 dea Maart verfcheen hier in Vergadering de Propo-

D. de venen, 1D. Yanmes de Grasf, die uir Amboinat quim. Hy wiert op Poeto $A y$ gelegt, mat ftierf den isder Mey.

$$
1667
$$

D. de D. Gulethms de Biter verfoheen hier Bitter. den I zuen Mcy in Vergadering, en by die zelve AEe blykt, dat de Superintendert, Zeevoogt en Commifaris der drie Oolterfehe Provintien, de Heer Corsalis Speiman, D. Gafrer, op zyn toche ma Macatiar, als Leger- of Treynspredikutue met zich nam; war op dan D. de E Diter in zyn plates op Neira gelege is. I 669 .

D. Man- D. Garolus Manteas, den $27^{\text {ften Decenn- }}$ teal. ber 1668 . herwaits baopert, verfoteen hier den 26ten Februari, en is op Poelo Ay geplatit. Ook quanj den $7^{\text {den }}$ Mcy

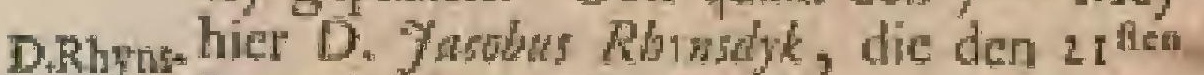

dyk. Jametari door zyn Edellheid iwat zeldzams, alzon dat te vooren altyd door den Kerkelrand, onder goedkeuring der Hooge Regeering, plag te getchjeden) herwalts berocpen was, en op Lonthoir gelegt is.

In dit zelpe jaar zonden dic was Banda de Predileaticn wan D. Movan, in "thoog Maleits opgeltele, weder ni Amboina over, en verzogten, by hun fehryvens van den 28 hen Februari, dar D. Caron die in 't gemeen en lang Maleits overzetten wilde; doch de Kerkedrand wan Amboina fehreet dae den I $2^{\text {den }}$ April af, als zynde cen te verdrictige zak , en D. Garon wats veel liever genegen zelfs iess in 't gemoen Maleits tot dienft der Indifche Kerken op te ftellen.

$$
\text { In " } T \text { jatr } 1670 \text {. }
$$

In 4 jal Is de Krinkbezocker Niew Krantabe- Aroe gelegt.

\section{zoek op op I $67 \mathrm{I}$.}

Mrot ge- Vertrok D. Rbystyk in September na Buavia on zyne gerondheid, en om te स'ouwen.

$$
\text { I. } 672
$$

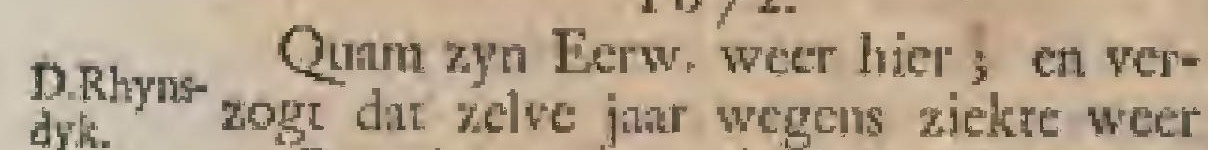
n. Batavia te gian; doch hy bleef cgter nog, hoewel hem vryheid gegewen wiert, on over al in de ganfche Lindroogdy, dar het zyn Ecrw. ton verkryging yan zyn gezondheid butt digt, te konnen gan.

$$
\text { In "t jaxt } 1673 \text { - }
$$

D. Car- Den 16 den Mey quam hier de Propopiss " nent D. Alewander Campas. D. Mantean

wiert toen op Lonthoir, de eerit angekomen 1. Carpiss op Podo Ay geplatift, en' D. Rlyasdyk vertok na Batavilit.

OnerentaD. Carpist wont men den $27^{\text {then }}$ November op Battivia goed, zyne verdere bevordering cot Predikant an de Hooge Regecringe te verzocken.

$$
1674
$$

De Proponent, D. Simes de Large, D. de quam hiee den $23^{\text {gen Jancent. }}$

$$
I_{17}+\mathrm{t} \text { jiat } 167 \% \text {. }
$$

Den todea November is hicr D. de Buver overtederi, en D. de Large nu op Neiri, om datir den dientt in "I Malciss war te nemen, geplatetl. Die van Butava hadden (zoo by een Acte ran den $2^{\text {dan }}$ December blykt) belloten, hem nat Ternate te zenden, doch dewyl ik piet vinde, dat hy derwares vertrokken is, en il niets meer hier wan bem leze, fehynt het my toc, dat hy dic jair hier geltorven is.

Dit fitt fetynt D. Carpiws ook tot Pre* dilatnt hier gevordert te zyo, anigezien zyn Ecrw. (zoo by de Batavifche Acte vath den $2^{\text {des }}$ December blykt) aldatar wan 60 tor 80 guld. ter manit nu in foldye werbetere was.

In dit jatr is de Krankbezocker, $D a-$ wiel Nicwiklerk, op Aroe gelegen hebbende, seltorven.

\section{a 1676}

"De Krankizezocken" Hemrik Whow" soon, verfcheen wan bicr den $22^{\text {fren Juji, }}$ cn Abraban wan der Her, den $27^{n}$ Juli op Batavia ; en den zongu Juai wertrok hier tha toe de Krinlibezoeker Lodesyk Lawbinon.

$$
\text { In "L juat } I 677 \text {. }
$$

Giag D. Mareas van hice na Batavi in Seprember, afgeter zynde, khitigde

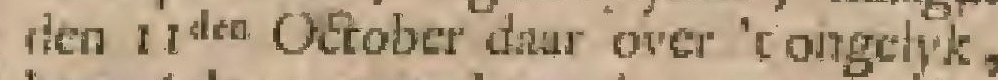
hem (alzoo men lyem dar foen reder ter wercld van gegeven had), aungedand. Den 27 tien J becemb. bleek, dit sinmon, de voornazmite oppufici van Radga Salomo

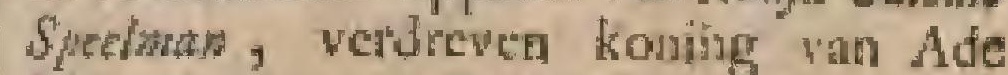
Mancoetec, een. Ooftelyk Lindlehap op "c ciland Timor, den $26^{\text {ikn }}$ dito op zyne Belydenis gedoopt was.

Op Bativia was D. Jacolus Maxwel her-

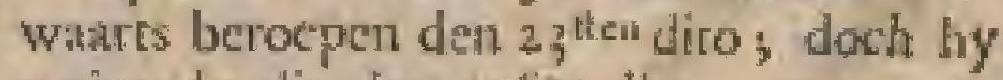
weigerde dit den $27^{\text {tien }}$ dito wan te remen.

$$
\text { In 't juar } 1678 \text {. }
$$

Komi D. Hwich Antoliges vas der D, war Linder ( wolgens zyn berwep, deis zollen der Lith December des voorleden jours tor Butavin den. op hem gevallen) hier, en is op Lonthoir geplatif.

Ook whs hier unt Amboint gekomen D. Stede Proponene, 10. Jaumes Clyiflogharas vens. Stavens, dic eert op Poelo Ay Belegt is. 


\section{I 2}

B

A

$\mathrm{N}$

D

In t jat 1679 .

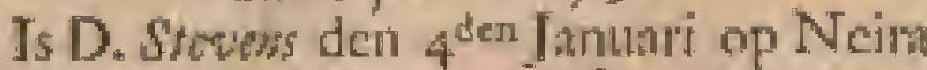
(alzoo D. Carpins wegens rick re zyndiendt niet watnemen kon geplateft; gelyk dan op D. Garpins wolgent zyth verzoek, den r $\mathrm{r}^{\text {den }}$ Aprih hem toegeftan, in Mey ra Batavia wertrokken, en den 2 flas Juni dat in Vergadering verfchenen is. Ook was den g $^{\text {den }}$ Febrenti rocgeftan door hatr Edelhedein, D. Wyetens de handen op te leggen.

In "t jaar 1680.

D. Mane Ouan D. Corohes Montens den $27^{\text {den }}$ reau. Febr. van Batawa weer hier in Vergadering, cn wiert op Neira geplantit.

Radja Salowo Speelma, koning van Ade Mantoctoc, flont wan hicr (zoo det $y^{\text {der }}$ Febr. blykt) in 't kotre weer na 'tcilind Timor met een Meefter te vertreliten. Hy verzogt nok, dat cen Predikint zyo Eiland wilde komen bezoket.

Dit zelwe jar kreeg D. Mantegn moeite, zoo dac het hem in zyn ketir gegeres wiert, hicr te blywer , of met afgelchrewen foldye na Baravia te gutan, hoewel hy* hiter blect.

Den $27^{\text {iten }}$ December ftont ook angeteckent, dat D. von dor Linten overleden was.

$$
\text { I } 6 \mathrm{~g} \mathrm{I} \text {, }
$$

D. de D. Tacoliss du Bois (den 26hen Decembos. ber 1680 . herwarts beroepen $)$ verfechen hier den $17^{\text {der }}$ April, en widt op Poclo Ay gelegt.

$$
168 z
$$

D. Intel Den I4 den Mey quin hier D. Girbertus Bralet, die op Poelo Ay, gelyk D. du Bois op Lonthoir gelegt is. D. Mantat had zyne verlohing wel bekomen; doch bleef egter nog hier.

Den gen Februari zont men wan hier cen Meefer ma "t eilind Tenimbat" ook

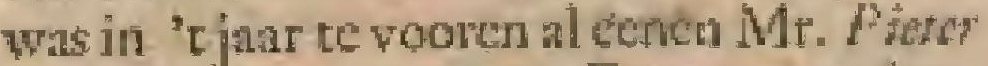
Antoriszow na 't ciland Eucr gezonden, die 'er dit, en "twolgende jant lay s en "t jazr daar ant op hee elland Kiffer geplaat? is.

$$
\text { In *t jiatr I } 484 \text {. }
$$

Dienas- Ging D. Brakel voor ecn lipringtogt nat tavia ver-Bacivis.

trok, en In t tatar 168 F

" jas Ouan zyn Eerw. weer hier den $12^{\text {uen }}$ dair àn Februari

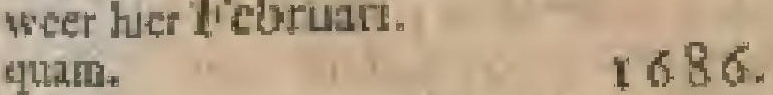

Den then Oetober is D. Bratel overleders.

$$
\text { In "t jast I } 687 \text {. }
$$

Is D. Jacobus du Bois den $22^{\text {then Mant }}$ met de chaloep de biefiang van hier ter Bezocking ma Aroe gezeilts doch quam, ziek geworden, en den $22^{\text {then } A \text { pril wat }}$ dat wertrokken, dend 4 der Mey voor Latrike, en zoo vender den. I I ditan dito voor "I Kufted Wietoria in Amboina (met zyn vartuig door Itroom en ftilte verdreved)

\section{A $\quad S \quad C \quad H \quad$ E}

ant te landen, alwar Jay den affen dito in myn huis overteden is; by weil over-

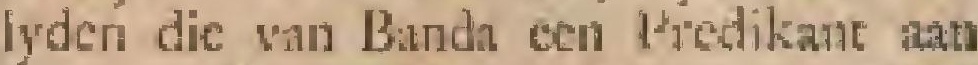
die var Ambain ter leen verzogten, war toe ik verkooren, en den $t 7^{\text {deul Juli }}$ met "t foheepje Niturdermeer veriokken,

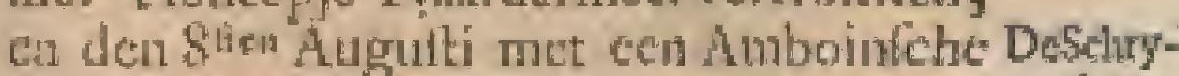
bricf wan den $14^{4}$ ten Juli lien gekomen ver kothe ben.

D. Momeas vertiok met ifgefehreven foldye, enopontboden, om a pa Vaterland te moeten veruekken in Seprember (vermits geweigere land na Ambotin te gang) ma Batavis, 200 dut it, in dere tufichen tyd Ncirn, Lonthoir, en Poclo Ay, alliecn warrixemen, en on de 3 weken op yder ciland eens prediken, moeft. Ik vont hict twee Krankberoekers, $N$. Key/er, en zownes de Graf, welke latiIte, bevoorens Jieng op droe gelegen hebbende, nu als doprinter is 'o Armenhuis op Nera gepliatl, en bezig was zich in "I Mithers ke otfienen. d"Eertie

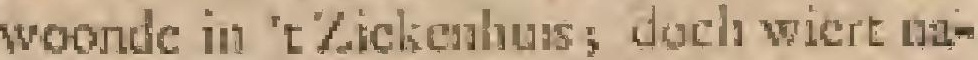
derthand Perkenier op Poelo Ay.

D. Mantean quan den $17^{\text {ieu }}$ Ostuber op Batriria. Hy had relclyke stgeing by de Germecnte in Bunda, doch was getuat van den Landvoogt, en wicrt (z00 men zei) elendig wan zvn wouw "geplange, die hem veel quand in zyil gooden wath dede.

$$
\text { I } 688 \text {. }
$$

Quaru den 8 ten Apil hier man Butavia D. Go D. Fredericus Gobus, en wiert op Neira bias. geplatidl; war op ile den ígden Mey weer na Amboina vertrol.

$$
1689
$$

D. Fbomas why Simey (den $20^{\text {ter }}$ De- D. war cember hier beroepen ) verlehen hier dit simey. jotit den $7^{\text {ted }}$ Mey, ea is op Lonthoir Belegt.

$$
1600 .
$$

D. Ermefar de Whe verfohecn hier den $\mathrm{D}$. de If A A pril, dic op Lonthoir geplatit is Wite. den $20^{\text {tisn }}$ Juli, Simey op Neita, en Gobius op Poido Ay.

$$
\text { - In 't jatr I 6. I. }
$$

Den 2 tea Mart quan his it Vergi- D. de deritug den Predikant D. fod wim de Grad Ganf. cdie den gleu October op Barawdit verzogt hin, aro Proponene worden; cendate toe den $18^{\text {ten }}$ Januari, en den $1^{\text {tan }}$ Februari tot Predikant ondervatage, en den $5^{\text {lex }}$ diro dezes jairs herwianis beroepen was ) met cen foldye van 80 guld. Hy wiert op Poch Ay, Grobis weer of Ncira, gelegt, en wan Simer acbeltitu, on eet ifrugtogt na Batawid te town, die in September vertrok, en 'cr Liek. en lati anan hand gitum.

$$
1692 .
$$

Is D. Jodwnes de Grasf by D. Gobits, om zyne onpafilykheid, op Neira gelegt. 


\section{Z A A K E N.}

In "t jatis I 692 .

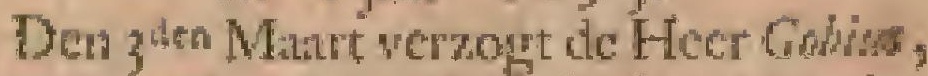
aatigezien hy zich 't belluir den' Vergadering nice onderwcrpen ton, en zich op de Hooge Regeering bericp, om zich voor has Edelbeden te verdedigen, wala op de Kerkenaad lier goedgevonden heef zyn Ecrw. den t8tan Mey na Batawia to zendert.

Ook is itan D. de Whte deh $3^{\text {den } A u-~}$ gufti roegethitn, on (gelyk in Septcmber ook gelchich is) na Banvia te vertrekken.

\section{In "t jistr 1694 .}

Den $7^{\text {dea }}$ Aprit verfelues hier in VerD. Lo. gadering D. Andros Lamberils Lodevis, volgens t $\mathrm{t}$ Beroep, den zilea Nowember op hen gewallers, die op Neirt geplaneft is.

En den 1 deden September quans thir Am-

D. Feg. boina, en vali Honimon, hier D. Ahr-

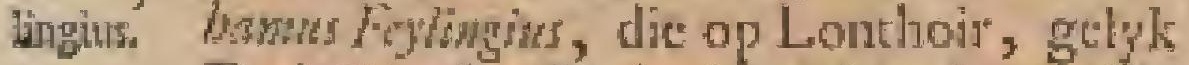
D. de Gragf op Podo $\mathrm{hy}$ gelegt is, welke

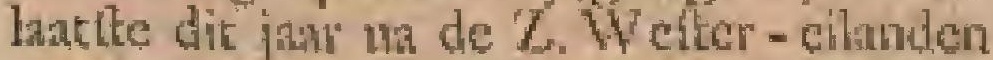
geween was, en nu na de Z. Ooflercilanden thont te gatnn.

$$
\text { In 'f jait } 1695 \text {. }
$$

Den I fodu Mey makte de Regering hier by Extract ont den Kerkenrihd bokeme, dat D. Laderas tha Batavia wertekken zou, die ook mee een zeer gocde getuigenis. en aficheids - fchrife vertiols; en toen felynt D. de Groff weer op Neirat gelegt te zyn. D. Feylingins was tin de Z. Wefter-eilanden geweet, $e^{\prime}$ 'et ziek พan dans gekomen.

$$
\text { In 't just } 1698 \text {. }
$$

Is D. Feyllygins ni Batavia in Juli vertrokken; D. de Gridt, zoo den I $3^{\text {ten }}$ Naat bleck, oserleden, en D. Broman, Anboina ter leen verzogt, en in Oetober D. Bier- Aicrgetsomen, door welken ook, fhoon hier alleen zynde, een togt wa Aroe gedan is, dar te wooren alryd cen Kuankbezocker plingt te leggen, gelyk is, de Grotf, nog Krankbezocker zynite, Jing op Wokam, de Hoofd-Negry, gelegen hectr. Buiter welle er nog 2, Wamir, en Maycootr, nog half Heidens en half Chriften waren; anders waren "cr nog weel Heidenlehe dorpert. Ook lad men 'et 3 of 4 Inlandiche Metters. Op

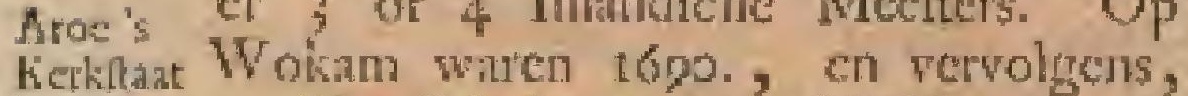
in "t jar 40 rchoolkinderen, 30 Chriftenen, en rog8. op Maycoor zo Chriftenen, en 40 leetlingen in de rehool.

$$
\text { In 't jaxr } 1690 \text {. }
$$

D. Strm- Quarn dep Iotes Jumi hien uit Temate piosn D. Jarmes Stampiorn, en D. Jitrman wertrok in deze matand wan hier weer ma Amboinin.

De fluat der Ketken on de 7. Ooftet* en Z. Wefter-Eilinden was elendig, en zy de nuam wan cen Kerle taict watirdig. Ook was dit jark hiet geen buitenberoek der Kerlicen gedam, wasrom zy te meer bier oen Piedikat, en twee

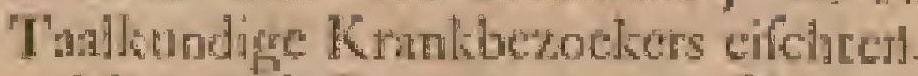
Meti had D. Stampros op Neint geplasitit.

$$
\text { In t } t \text { jats. I } 700 .
$$

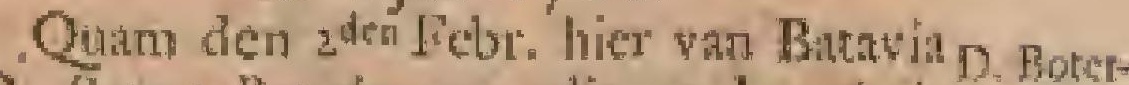
D. Perms Botereoper, die op Lourtioni koort. gelegt is. D. Strompiom had dic jatr de ¿. Wefter-cilanden berogt; doch die zeer clendig bevonden. Opde cilanden Kifler, Wertert, Leti, en Danne lagen vier Meefters, op yder ecr, ook wiwen ?er door zyn Eerw. 139 tchoolieren, en 267 Nantuchritenen, dach die niets wan "C Chriftendon, of Godshlicnlt wiften, gevonden; en geon wonder: watut men. deze Eilanden op zyn beft on de wwee jaren mar cens bezocken; on dat rian "I cene juar na de Z. Oolter-cilindea ging.

It "t joat I 70 .

D. 24 fin Febt- gum hich wan Batawit D. Gelhus Cammina, die op Poelo Ay ye- D. Cunplatit, en nice hang dari nat "er" overleden maga. is, hebbende mar sen belluit der Vergadering geteckent.

$$
\text { In 't jatar } 170 z \text {. }
$$

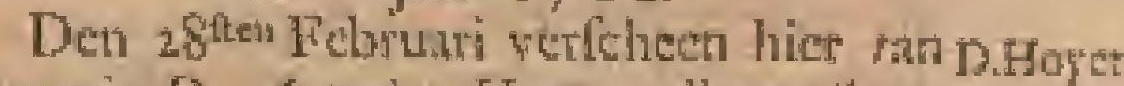
Batavia D. Anowint $H$ byer, die ecrit op Hoclo Ay, doch ecnige matnden 'cr ma op Neira, gelyk roen D. Shmidon op Podo Ay gelegt is ; hoewel D. Hojer muat yoor cerft op Nein litg.

$$
1703
$$

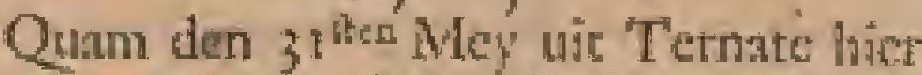
D. Perns Nart, alic op Podo Hog. toen D. Lower ook valt of Nein geplatit is.

D. Shathowers vertrok in Mey of Jun tha Bitavial.

In een der volgende jaunen blykt my uit een Kerkbezock vian D. Boteritopor, op deZ. Yolter - eilunder gethist, dat cr OD Aroe, cnz. 220 Chriftencu, cvigo fchoolkinderen, doch datt zy ater thege warers.

Deze drue Itredikusten, D. D. Boterkopper ; Hoyer, cn Nout, zyn hier zoodanig, en zonder eenige verandering in

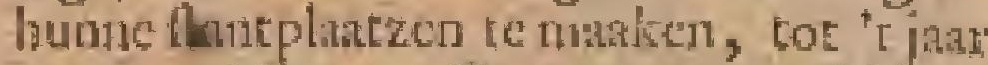
171 1. gebleven. En toen waren hier in alles 1576 Chriftenen, en dat ondel" $2 k_{4}$ Lederjaten. Ook waren 'st door D. Borerkoper op de Z. W. Eilimulen 94, en door D. Boyer op Aroe en de Z. 0 . Eilanden 44 gedoopt; doch die Kerk zeer negt gefteit.

In dic jar quan de Orangkaj:i wan

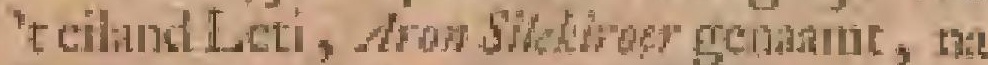
Bndal, om zich te litaten doopen; doch by trundde ontent "c dorp Rocton in Anboira in Augulti, ga wict in $\mathrm{Nom}$ vember met de chaloep de kratnvogel, गa zecr onbillye, an onbatmhertig in Amboina gehandett te zyo, пa Banda Beroert.

II I. DEEL, 


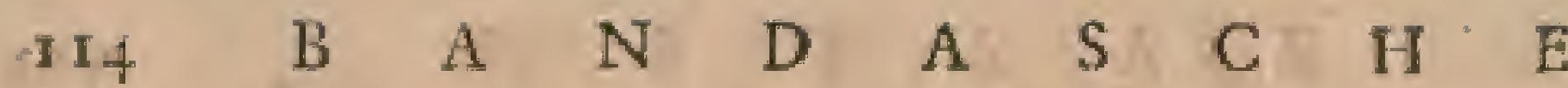

In $t$ jast 1712 .

Is D. Carolus Geongus Serrats hier wan

D. Set- Batiaria den 28 nen Febr. gekontin, 200 dat er toen 4 Predikanten (dar zelden gebeure) waren.

In dic jatr is D. Boterkmper door de Hooge Regering belaft, om na Ternate te gasin, en ook wertholiken.

$$
\text { I } 7 \text { I } 3 \text { : }
$$

1s D. Now op Lonthoir, en D. Semus op Poelo Ay gelegt.

In 't begin dezts jars quam hicr van

D. van Bataria D. Nedoss van Scbie, en in dit Schie. zelve jar nog vich die zcldzame worfleling vor, tuffichen een der Predikanten met die 4 perfoonen, en den Landwoogt wan $E_{p s}$, volgens ous voorig berigt.

$$
\text { In ' } \mathrm{T} \text { jat } 17 \mathrm{l} 4 \text {. }
$$

Vertrok D. wan Sebie van hier in Mey Da Bataria, alzoo syn Lerw. thet de Regoering moeite hid, dat egter nict belette. (alzoo men wel wift, wat een llegt Hooft Banda bettierde) dat zyn Lerw. kort па z.yn komft dan den $4^{\text {nem }}$ Juni met de Weduwe van den Macafianzen Landroogt, de Heer sdn Tol, trouwde, doch quam ontrent vier matnden icr na der $20^{\text {flén }}$ Oetober aldat te lterven: gelyk in dit zelve jatr nog in de miand October hicr D. Noo overteden is.

\section{In 't jast 1715 .}

Vertrok D. Serroth van hier na Amboina, en in 't begin wan dit jaar quam

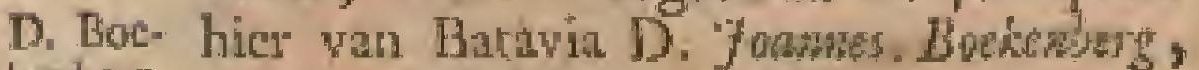
kenbers. die op loolo Ay gelegt is.
In "t jat $17 \mathrm{I} 6$.

- Vertrole van hier na Batavin D. Hecr, en toen quasmen ool in 's begin des jars $D$. D.

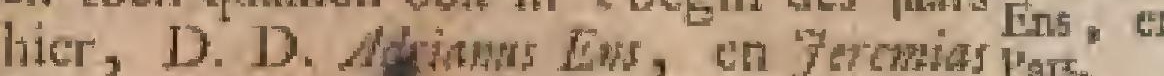
Jonnses Pars. En is toen D. Bockenberg op Lonthoir, D. Lims op Neira, en D. Pay op Poelo Ay, gcplintt. D. Hover dec nog cen kort bezock na Jawn "s Ooft. kult, ta zyn komit op Batavia, en is, kore na zyn weiterkomft wal daut, op Batavia overleden.

$$
\text { In 't jart } 1717 \text {. }
$$

Stont (wolgens de berigten van Batavia) D. Pars thatawia onboden te worden om Portuges re loeren; dic ook in 'f jutar I718. derwaris wertrokken, en beroepen is,

$$
\text { In } 1 \text { jar } 172 \mathrm{I} \text {. }
$$

Is D. Nicolas Cramer hier gekomen; D. Ca2doch in "t jais 1722 owerheden.

$$
\text { In "t jaur } 1722 \text {. }
$$

Zyn D. D. Framiscas Harlog, en Bar-D. D. Wbold Philip Mollor hier werlichenen , en Harto in dir zelye janr is D. Lrs liner overleden, enMolet.

$$
\text { It 't jiar } 1724 \text {. }
$$

Qum her D. Foames Guilichus D. Loyal Loyal.

Toi mecter gemak hebben wy hiet nog bygeroegt ecn Lqfl van alle de Predikanten, die hier gelegen, benevens de cyd, en de netre jaaren, die zy hiet Dienlt gedan hebben ; en dan daar op latten wolgen nog een drievoudige Lyt, adsuwyzende de nete tyd, op weike yder der zelve op decilanden Neir, Lonthoir, of Poclo Ay gelegen hicbben.

\section{Bandafche Predikanten.}

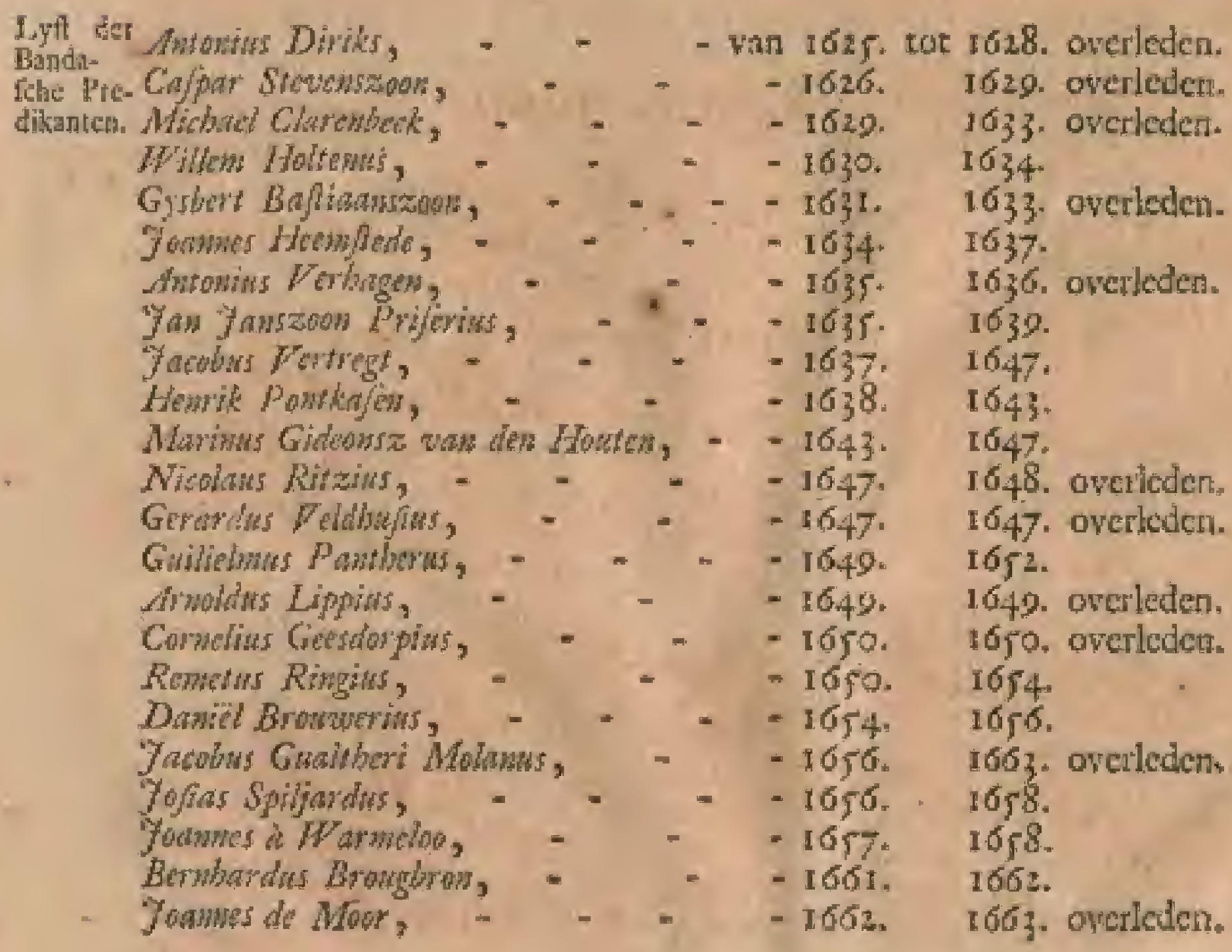




\section{Z A A K E N.}

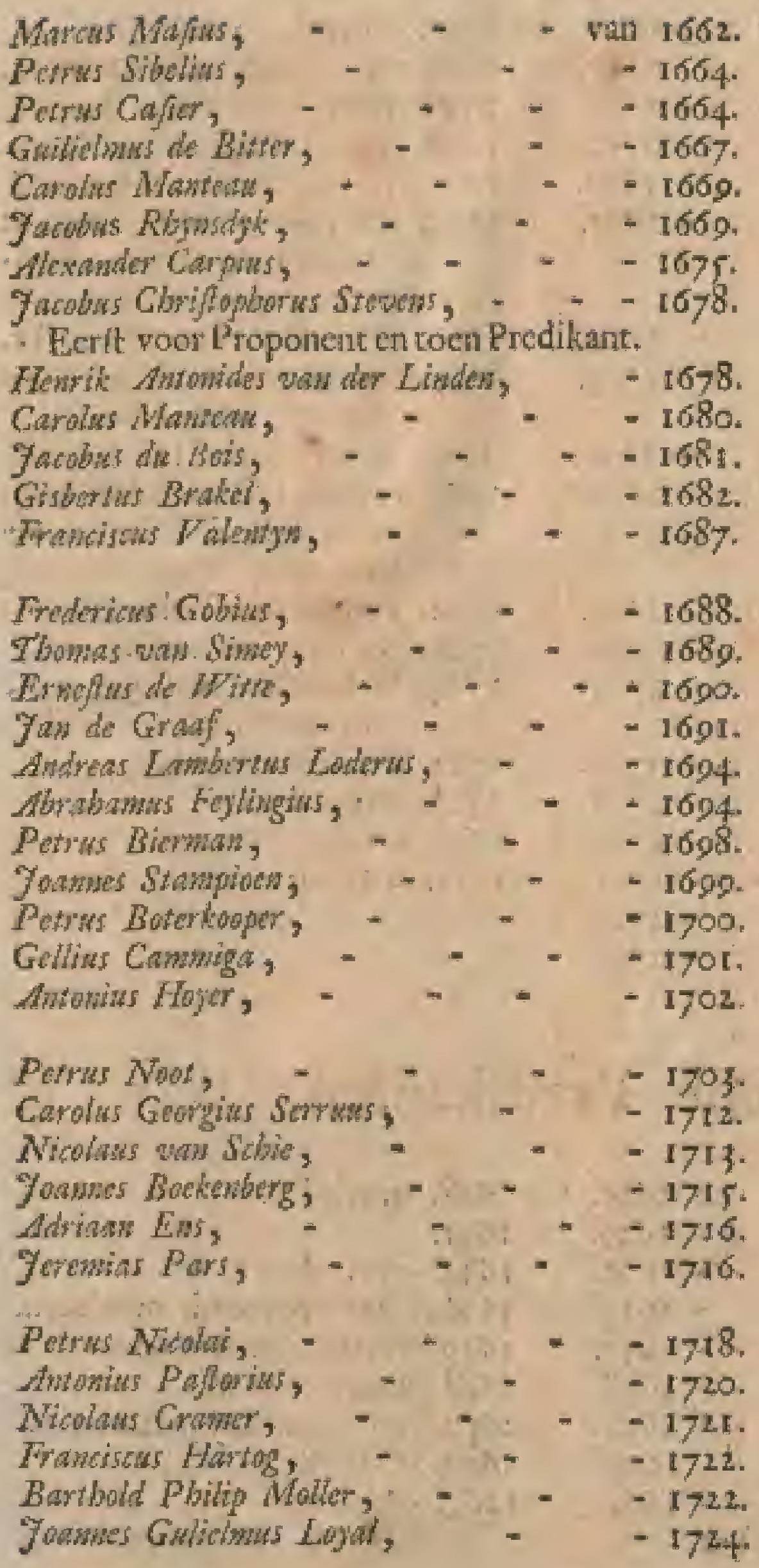

1005

1664.

1667.

167\%: overleden.

1677 .

1673 .

1679 .

1679. overleden.

1680. arerleden.

1687.

1687.

1686. overleden.

1688. nam alle de Eilanden hict alleen war.

I693.

I69.

1693 .

1608. overleden.

1695.

1098.

1609.

1703 .

1712 .

I70 . overleden.

1716. wannect ha Batavia gat, en un "c zelwe jaar tierf. 1714. oyerleden.

175. Wanteer na Amboina ging. 171.4. opgezonden.

I722, overteden.

17ı8. als na Batavia wertrok om Portugees te leeren.

1719. oferleden.

1720. overledeti.

1722. overleden,

\section{Neirafche Predikanten.}

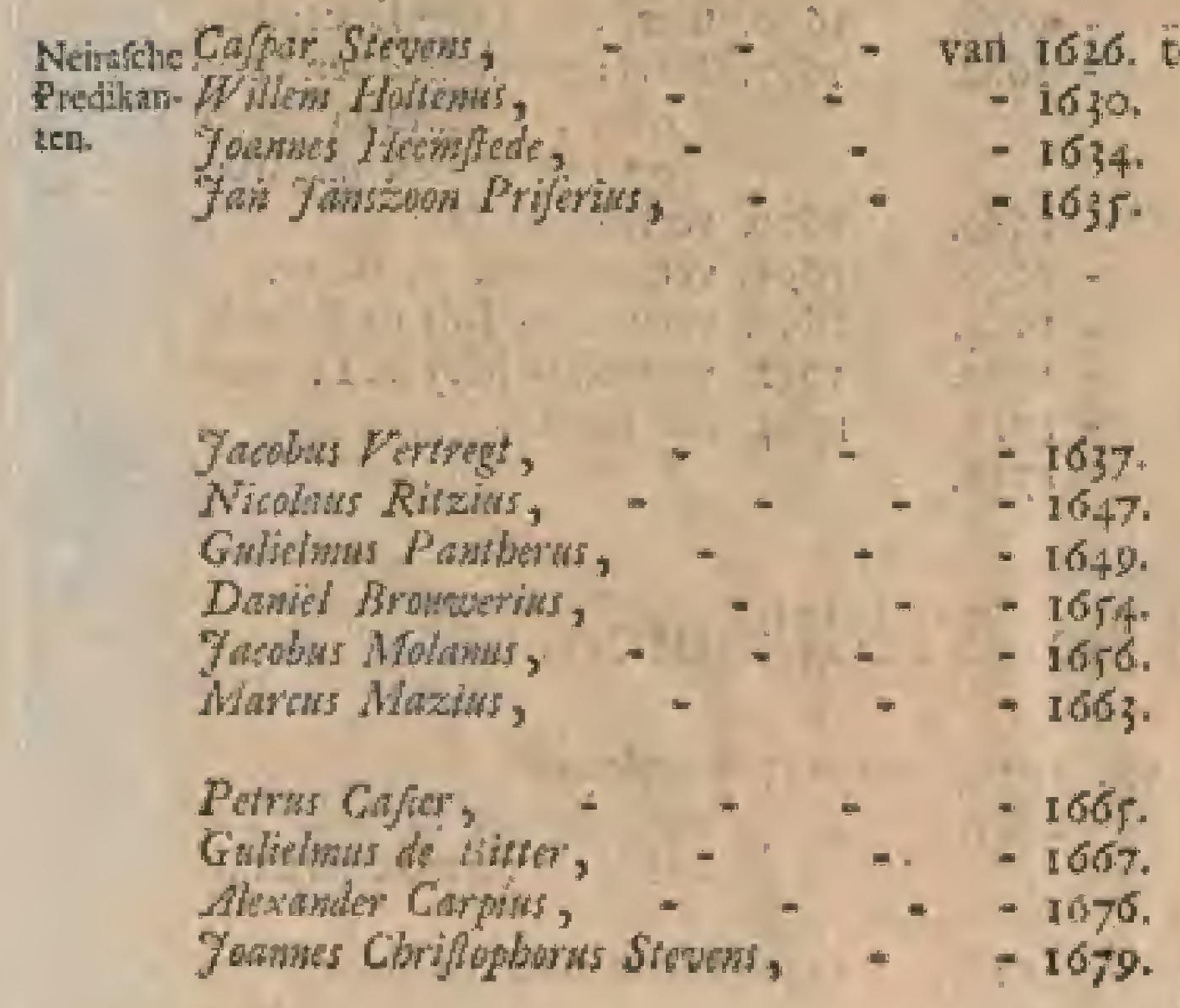

1640. overleden.

1634. vertrok in Sept tha Bataviz. 1637 . als boven.

opAroe tot 1639. in Atguti voor Amet genomien; quam 1637 . weer hier, en wertrok ma Lonthoir, blecf ficr tot 1639 .

1647. Fertrok na Batawia.

1648. overleden.

1652. vertrok th Batavid.

16r6. vertrok na Bacavia.

1663. ovérleden.

I605. vertrok onwettig en on: fchuldig afgezet.

1667. vertrok met deHr.Spcinan. 1675. overleden den $10^{d e n}$ Now. 1679. vertrok na Batavia. $\mathrm{P} 2$

Cas 


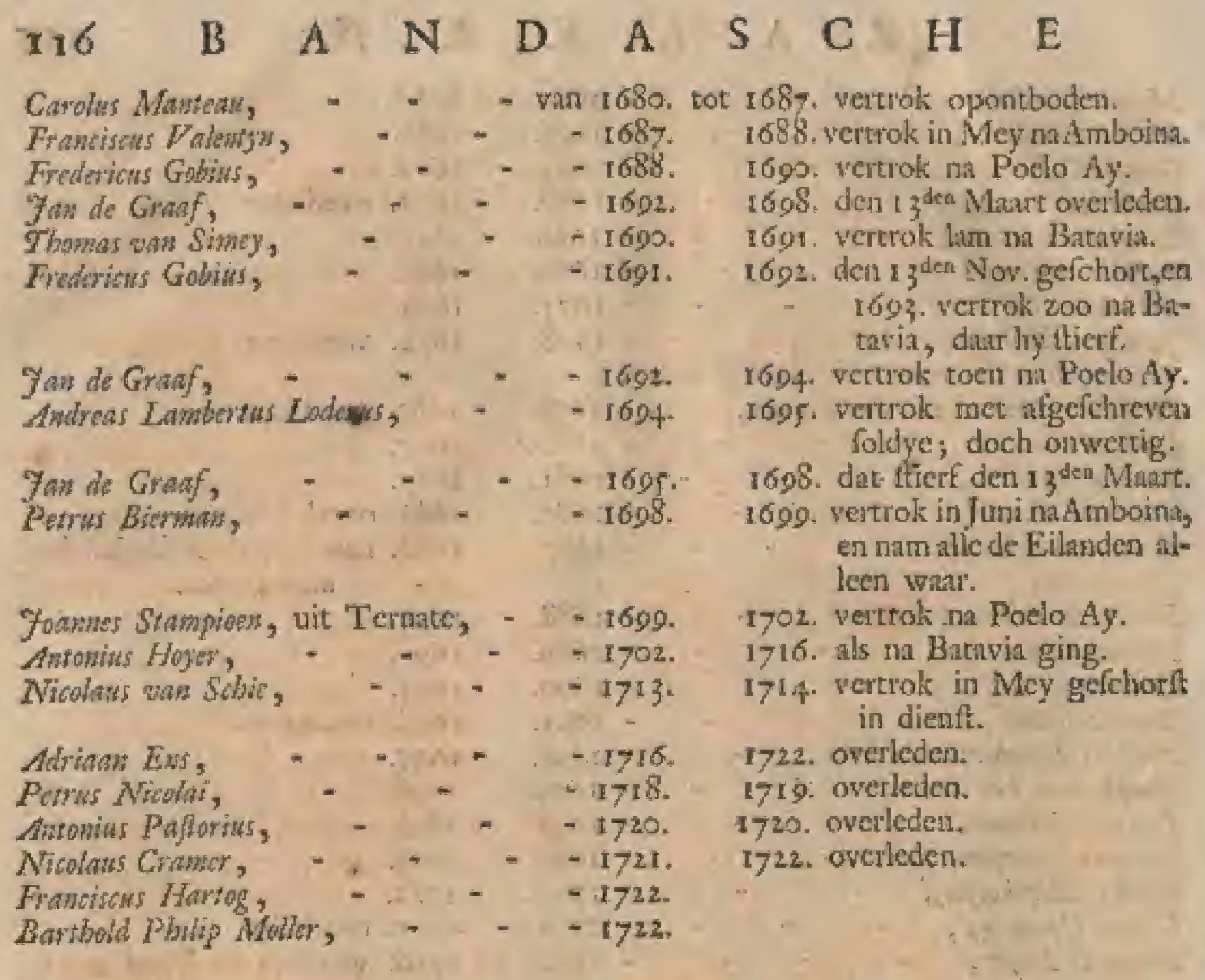

\section{Lonthoirfche Predikanten.}

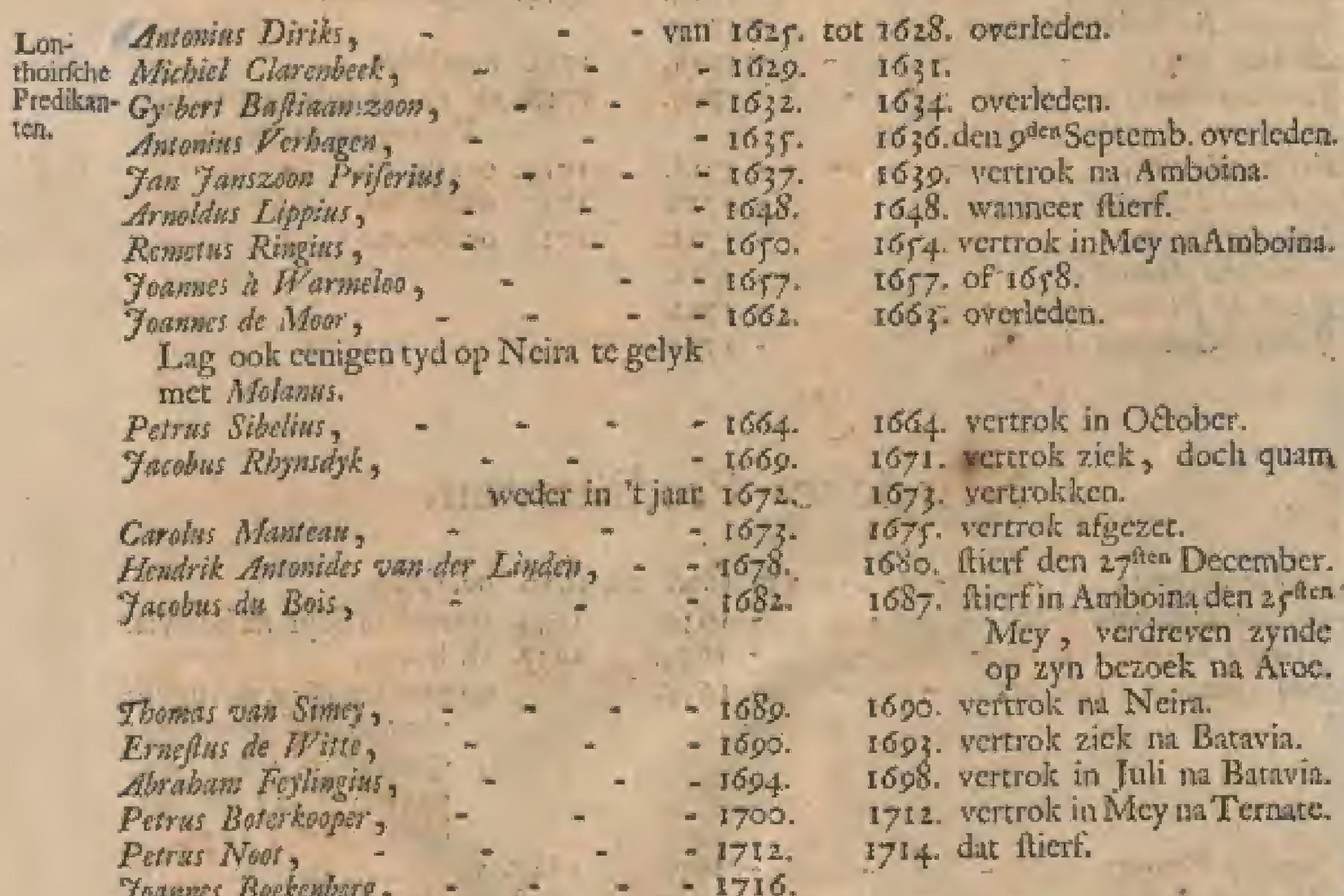

\section{Poelo Ayfche Predikanten.}

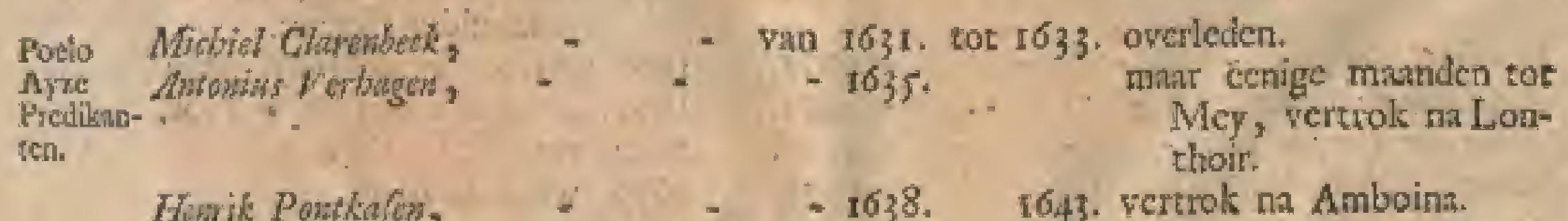

Henvil Pouthafon, \& = 1638. 1643. wertrok na Amboina. Mart. 


\section{Z A A K E N.}

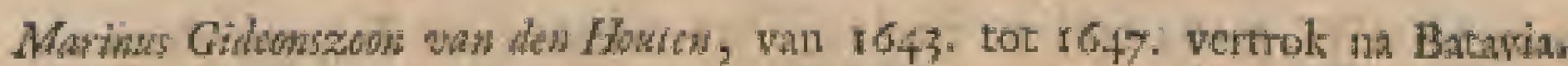

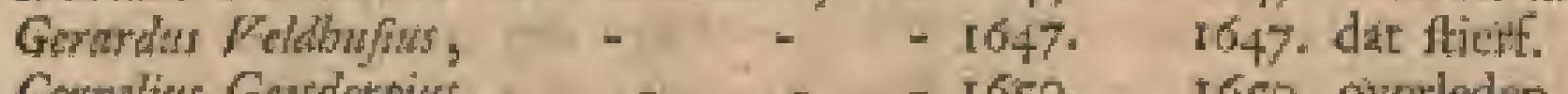

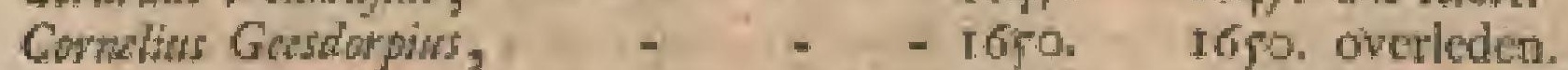

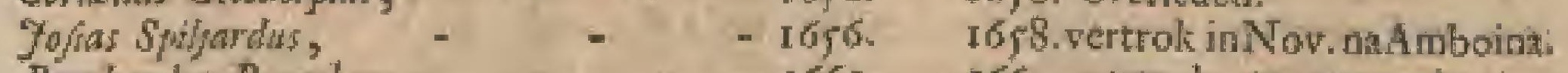
Bernbardar Brougbron, - - - $160 \mathrm{t}$. I604. wetrok on wangedtag.

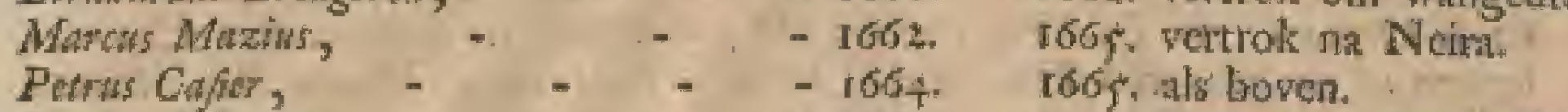

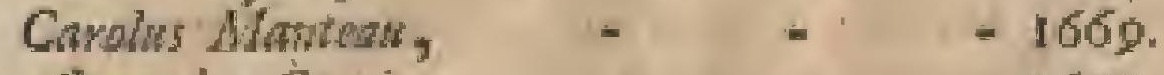
Alewander Carpins, - $\quad$ - $-167 \%$. Joanwes Cbrifophoris Stewew, Proponent, 1678. Taiolus de Bois, - - - - 1081 . Gibertur Brabl, - - - -1682.

weder wan Batavia, 1685 -

1673. rertrok na Lonthoir: 167\%, wertok na Neir.

1079. als bowen.

1082. watuok nat Lonthoir.

I.684. vertok inOctober en quam I686. overieden $\mathrm{t}$ obtober.

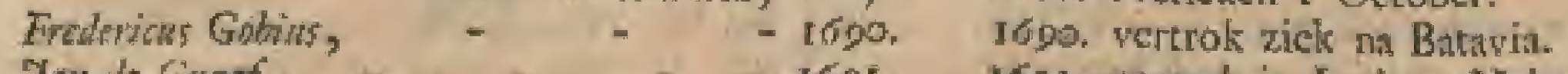
Fon de Grasf, - - - I691. 1692. vertrok in Juni na Neira.

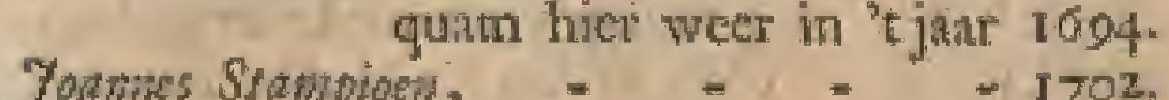
169) - veitrok ha Neira.

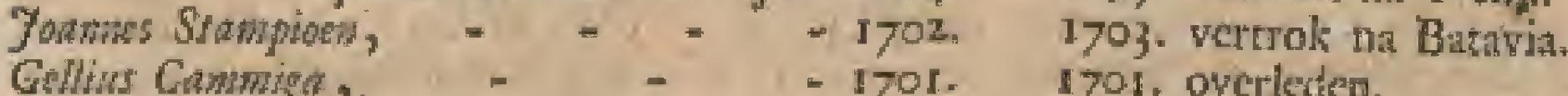
Guling Cammiga, - - $\quad$ - 1701. 1701. overleden.

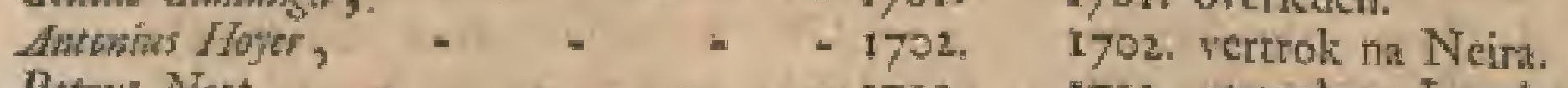

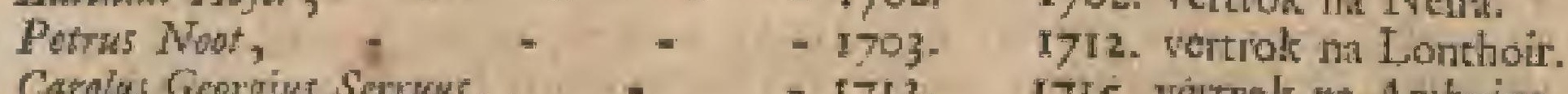

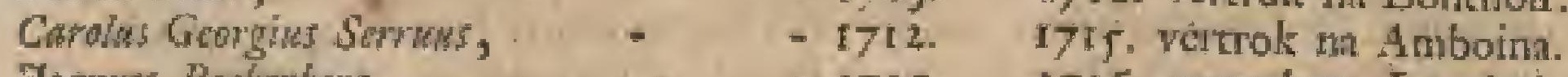

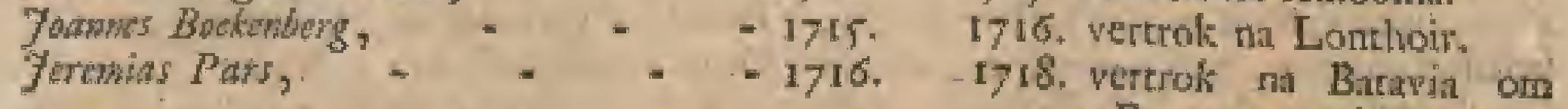
Potcugees te lecren.

Wrat nede wy dar "t roormainfte, dit / den, on nu tot de Befehryving van Solor "er wan Banda te zeggen valt, aangehate cn Timor, als zypde her muth dati an hebbende, van deze Landroogdy aflehei- gelegen, over te gath.

\section{NEGENDE HOOFDST UK.}

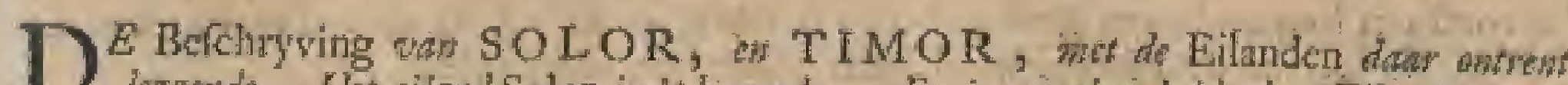

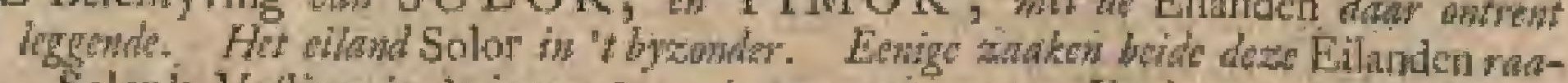

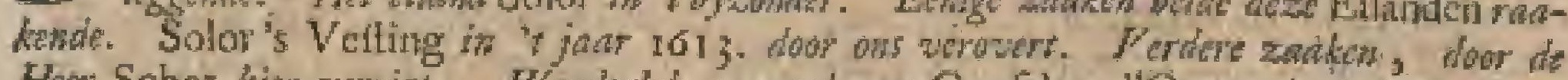

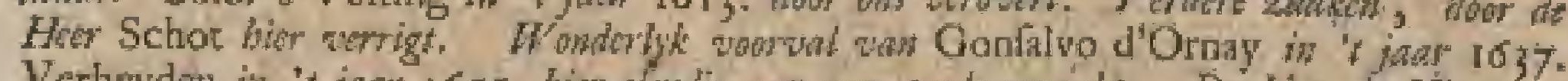

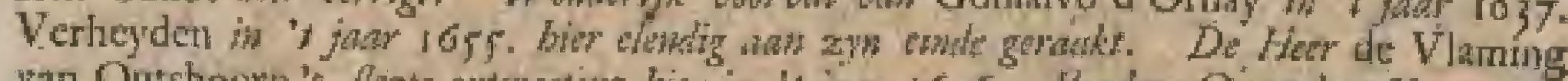

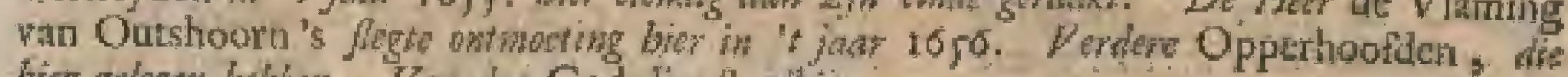

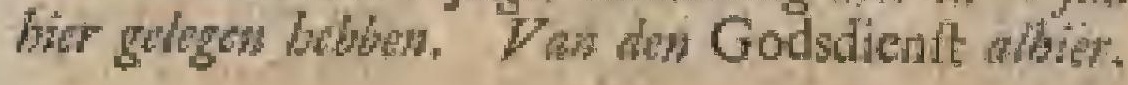

Beflutyving voln SOLOR,

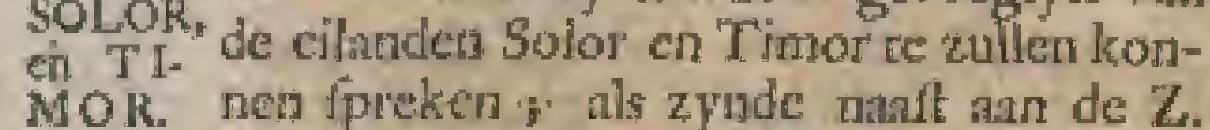
Werter - cilanden, die onder Banda ftan, geleget.

Wy zullen date nict secl van zeggen, mal dezelve too net, als 'tons mogelyk is, kortellyk befchrywen, en on datar se netter begrip af te hebben, zullen woy rolgens de Kart, wotar "in wy Solor en T'mor mede vertoonen, voor af eerft een korte befchryving wan alle de Eilanden, dan ontrent gelegen, geven.

Wy begimen dari dic beitels van "t ejland Saleyer, "s geen in " $\mathrm{N}$. W., of anders dig by de eilandekers Boegcroenes, of wel by de Z. W. hoek van de Boge uan Boni gelegen is; cen eiland, dat i3 of 14 mylen, Z. en N. meett gethekt leggende, hing, en ontrent 3 mylen in 't midden breed is, lodpende na ' $\mathrm{Z}$ Z. en N. hoe langet hoe fpitzct toe. Langs de Wellkane loopr exen fmal rifje, dat zich op de eene plats wit verder, als op de andete, tititrok.

Ook ziet uxen diu die kant valk in 't middencea klein eilandje, i myl warn de wal, het Bajer-clabd gendame, "L geen byna rondon, nitgenomen de $O$. zyde, in cen rif lege, dat van teiland saleyer $z y n$ begin neent, en tot des zelf Z. O. hoek voutloopt. Her is ontrene 2 triylen Z. en N. indelengec, en $\mathbf{I}$ myl O. en W. In de brectite, hebbende zuylen N, AV eftelyker nog een byzonder rif op zich zelve, dat onteres 2 inylen in 'r rond is's en meet N. O. en Z. W. geitretit, in f of $6 \mathrm{my}$ Jew W.N. W. van 't relwe leggen tenige rotzen, "Zoutelands Rotz" n" getiatme.

Bezuiden 'c Bajon - ciland ot 2 mylen, ziec men ook op dar rif, duc langs silleyer loopt, zeilandekens opeen phats dar dar 


\section{I18 B E S G H R Y V I N G E y A N}

rif zich in mo ' $\mathrm{W}$. wel $t \mathrm{myl}$ of 2 nta th. ats ook na 't Z. en N. breecter uitzet; en wan de Z. hoek van Saleyer, I myl' er Bewreften, ziet ajen Z. en N. myl vars malkanderen dric kleine Eilandekens, en de twee wel zoo Zuidelyk, gefrekt leggen ; die yder een kleine anyl in "trond pyn.

Natt an Sulcyer doee zich het ciland Calauro in $\mathrm{t} Z \mathrm{Z} .0$. op, zyode ontrent 2 mylei met ayn $\mathrm{N}$. W. hoek (was by een klein cilandic legt) en wel 3 mylen met zyn $Z_{\text {. }} \mathrm{W}$. hoel "er af gelegen. Men zice ook tuffehen 't midden van dit eiland, en tuffehen de Z. bock van Saleyer, $\frac{i}{2}$ mylvan Catauro, nog cen klein cilandje, cu ath de N.O. kant vin ecn rivice, die zich dut ontent in "t midden vertoont, Z. O an nog tric diergelyke I myl wan mallinderen zoo geltrekt leg: gen, dat ber Z. Ooftelykfte af en wan de N. O. hock wan dit eiland zich vertoont, behalyen dat men nog zoo een eilandeken (doch wel zoo groot) in de voonoende rivier zict.

Het ciland Calauts is 7 of 8 mylen N. W. en Z. O. Jutg, en $r$ mylen N. tet 0 . en Z. ten W. breed.

Het hect pas binnen zym Z. W. thoek een kleine bata, die wel 2 of 3 mylen is "trond is ; en ten $\mathrm{N}, 0$. wan de N. 0 . hock des zelfs zict men een ciland, "t Hoog Eiland genamt, dat zicl meeft N. N.W. en Z.Z. O. op ecn-rif, dit "er tond on loope, henen ftreks.

Ten N. O. van dit Hoog Elland heeft men wel is of 16 mylen in "t vierkant, meet $\mathrm{N}$. ten W. en Z. ten $O$. een ganfohe rift wan wel 20 eilanden endrongtens leggen, de Tygers.eilanden genanem, vin welke "er drie in ' $\mathrm{L}$. meet $\mathrm{N}$. $\mathrm{W}$. en Z. O. gefteke leggen, die darom de drie Zuidelyke Tygers - cilatden genamt worden. Rondom de zelwe zym zeer ve: tevet, ch in t.N. O. is nog cent klein cilindchen, het Slangen - ciland geпุaมm.

Veertien mylen Bcooften deze Tygerscilinden, of wel van 't Slangen - ciland, leigt een groot rif dat rich wel 6 of 7 myler $\mathrm{N}$. O c $\mathrm{Z}$. W. in de lengte, en meelt 2 of 3 mylen in de breedte uitItrckt.

Vyf mylen Beoolten "t zelwe lege een eiland ie Grocnwond gentamt, aynde 2 mylen O. cn W. Inng, en i myl ruim bred, cri 2 of 3 mylen Bezuiden "t zelve legt in $t 0$. cen tif yen 2 of 3 myten in 'crond meett $\mathrm{N}$. W. en Z. O geltrekt, co cen cilindic in te W. I noyl 'er af, zynde $z$ mylen in 't jond, het Hagedisellind genarme, en pas Bezuiden dit hatfte nog 2 kleine eilindekens $N$. W. cri $\angle$. O. 1, mys var een leggende, welle

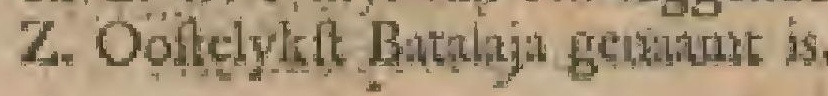

Vha Bezuiden da Tygers = eilanden of of 6 mylen legt een droogte, de Heillogt getlamt, die 3 of 4 pylen in te rond, en vol katshoppen is.

Negen mylen Beweften dit rif (wrel zoo Zuidely 5 ) en 4 mylen Bewuiden Ca latro 's. Z. hock, lengen de eilianden Schicelam gename, zynde yder pas 2 mylen in 'i rond.

Het N, Ooltclyleft legt maar 4 mylen wan Calauro, doch de 2 Zuidelyk fte wel 6. of 7 mylen. Deze twee latte legget O. ci W. I myl van milknderen, en van het Weltelyktte loope en rif, dat zicli W. ath wel 11 mylen en $Z$. en $N$. wel 3 of 4 mylen were uitltrekt, loopende in " $t$ W. War nat ' $t N$. W. om.

Zes of agr mylen teu $Z$. $O$. wan het Ooflelykfte dezer cwee cilnden doet zich cen eilandje op, dat o, en W. 2 of 3 mylen lang, 2 myl breed, en "tgeen Batue Pandjaug genatme is, hebbende in ' $\mathrm{Z}$. O. een klein rifje ant zich walt.

Twee mylen O ten $\mathrm{N}$. was 't zelve legt her ellandje Bata Cariman, dat ontsent 3 mylen in t rond is, en a mylen Oottely. ker rog z eilandeliens $\mathrm{Z}$. en $\mathrm{N}$. zeer dige by cen leggen heets; ton $Z$. W. wan

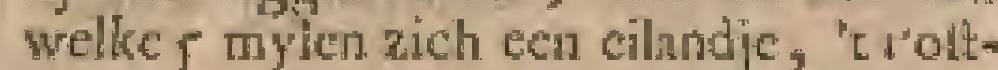
pard gename, op een ril, dat er rond loopt, vertoont, zyode mer rif met al ontrent 3 mylen in den omtrek.

$Z$, ten $W$. van is Poftpaard $f$ mylen legt het eilandje Rollit Gooroc, dat pus I myl in "t rond is, en ten O. wan 't welk nog een kJeintje lege.

Zeven of agt mylen mecr na ' $\mathrm{Z}$. W. doet zich her ciland Loch Radjit, dat pas 2 mylon in " $t$ rond is, op. Beweften 'c welke f mylen een onbelient cilandje van 1 myl in trond, I myl van 't groot eiland Ende lege, gelyk men 7 of 8 myJen Beooften Loefa Radja nog 3 kleine eilandjés, meet $O$. en $W$. dige by een geltekt, pas $t$ of a mylen wan de wal wan dat groot viland leggen zict.

Eer wy serder vin 'teiland Ende (mders ook 't lind val Floris genamt) ipreleen, moeten wy poor - if zeggen dat 6 of 7 mylen Bewelten "c zelve zich de O. hock van "t eiland Sumbawa, en dat zich die $Z$ en $N$ : wel 7 of 3 mylen lang, en wel f.mylen 0 , en $W$, breed vertoont.

In 't N. van dit deel wan Sumbawa lege cen dorpken, Sapi genumt, ten N. van "t xwelke I mylieen eilandje wan I myl in 't rond lege, en 3 mylen O. ten Z. Sapi legt nog een eiland, dat wel zoo klein is, en theen nog 8 of 9 kilciner eilande* kens ten $L$. van zich meeft $O$. en W. geAtreke leggen herfe ans de $\mathrm{N}$. zyde wain die Arrat, die an dir dorp de truat ván' Sipi genamt, en die wel 7 of 8 mylen $N$. en $Z$ u lang, ta wel 4 mylen $O$. on $W$. 


\section{S O L O R E N T I M O R.}

breed is. En gelyk men die cilindekens in " $\mathrm{N}$. dus heeft, alfoo vertoonen 'er ricl nog 4 andere digt by Sumbitw 's O. kant, een pas woorby cen rivier die ontrent 2 mylen Beruiden 't dorp Supi zich opdoet, en drie I myl Bezuiden dat eilandeken ; myl wan cen Z. en N, 1 myl wan de wal in de $\mathrm{Z}$. mond wan deze ftrute geltreke, hoedanig cen meen "sт nog zeel digt by Sumbiwa' 's Z. O. hoek ziet.

Vier mylen Beooften Sumbawa, wat Zuidelyket als "t midden wan des zelfs 0 . hock, doet zich eec ciland op, dur Z. en $\mathrm{N}$. wel 4 mylen lang, en $\mathrm{O}$. en $\mathrm{W}$. in ' $\mathrm{Z} .3$, doch in ' $\mathrm{N}$. matr' 2 mylen. breed is, nan welkels $Z$. $O$. Jant men cen, gelyk men by de N. O. hock nog dric, en verder Beooften bet zelve nog drie kicine eilandekens $\mathrm{Z}$. $\mathrm{cn} N \mathrm{~N}$. geftrekt leggen ziet; van welk Zuidelyk it der drie laitite, myl ooftelyker, men weer vier eilandekens 3 of 4 mylen werre nil "tN. met cen kromme bogt, die wat na " $\mathrm{O} O$. loopt, thekken ziet, tegen over de welke zich 2 myten Ooftelyker digt man de wit var "E ciland Ende veel katskoppen pas Bezuiden een ander cilandeken vertoonen, tuffehen welk cilandje en de $\mathrm{O}$. wal een rif wan I myl breed, 2 of 3 mylen $\mathrm{N}_{\text {. }}$ an, en wan dar dan $O$. nan wel 2 of 3 mylen breed is, wel ro of 2 mylen verte tot tegen de $\mathbf{N}$. hoek van "t eiland Ende zoodanig loopt, dat het allenskens tot op I tryl breedte ver Imald, "tan welkers ende in " 0 . mendrie kine cilandekens meeft O. cu W. (wel zoo Z. W.) * myl wan een geftrelat leggen zier, watr Fan "r Ooftelykit "t Wlak cilnd, 't nailt 'er ant her Zukerbrood, en 't Weftelykit het Groot ciland (zynde ont 'egrootile) gename is. En of en nan de N.W. hock vas "t ciland Ende, dan" dit rif op zyn breedite is, ziet men nog zoo een eiland, wan groote als dat, datr dit rif beginc; tufichen 't welke en de watte wal zich nog twoe ksleiner eilandelens, $N$. O. en \%. W. gellrekt, wertoonen.

Vyf mylen wan de W. hock wan 't land ran Flores lege nog een eiland, dat wy newens noy 2 andereil, ahoorens het zelve. te befolurywen, gecrne cerft af zouden doen.

Het ecffe is Nomba genamt, rynde W. N. W. en O. Z. O. onerent 6 of 7 mylen lang, en meelt z mylen bied.

Vyf mylen van des zelfs N. W. hoek, en 2 mylen wau des zelles Z. O. hock, lege Poclo Tsjindana of het Sandelbolcheiland. Dit is een zeer groot en woeft eiland, dat zich al mede meett W. N.W. en $\mathrm{O}, \mathrm{Z}, \mathrm{O}$. 30 mylen ruim in de lengte, en Z. en N. 14 of 15 mylen in de breedte uifftrekt; doch ann de N. W. hock is 't pas 4 of 5 , en atan de Z. O. hoek mar
3 of 4 myleti breed. Ool loopt 'er cen (nval rif, dil pas 2 of 3 mylen Beoolten de N. W. hoek begint, en zoo I inyl buiteth de wal zich uartirektende, dus langs de wal meet (uitgenomen by den W. hoek) gelylk doorgatat tot aan de $\mathrm{N}$. $O$. hock, wh watr het dan tor de Z. $O$. hock wel werder vervolgt; mar het word diat wel 2,3 en 4 mylen breeder toe op de helft (dar in 't midden ook cen klein ciland je legt) wats watr het allengslens na de Z. O. hoek toe tot op I myl werfinales daar het anders langs de $N$. wate dootgatos moar I myl breed was.

Men wil dat op dit eilatrd geheele bosfehen met Samilelhour zyn.

In Z. Z. O. heets dit eiland een diepe inbogr, what voor de wethe 2 of 3 mith wan de wal her cilandje Suuvo lege. Dit is Z. en N. 4 mylen lang, en O. cn W. 3' mylen bred; doch in " $\mathrm{CO}$. is "twed zoo hang, ca in "c N. wel zoo breed, zynde ande $\mathrm{O}$. zyde wat ingebogen. Ook ziee men een klein cilandje ande Z. O. kant zeer digt "er anu leggen.

Nu keeren wy ween tot her land wat Floris, of 't eiland Ende, ch zeggen, dat hee zelve wan ' $c 0$. tor her $W$. (drajende in ' 0.6 of 7 mylen wate na ' $\mathrm{N}$. on onerent 42 of 43 mylen lang, en Z. en N. in. "t midden wel $\mathrm{t}$, , in ' $\mathrm{L} \mathrm{W} .5$ en ook 3 , en in "e N. O.5, hoewel het 4 of 6 mylen Bewellen de N. O. hoek initar Is myl breed is.

Het Noordelykfte deel wan de N. O. hock word Karp Flores gename, en Io mylen Bewelten de zelve, 2 nylen Bewelten dien mauwen bals, die ' $\mathrm{t}$ land dait' makt, lueefr men ecn plaats, Crocwi genaumt. Tulthen dic Crocwi en Katp Floris heeft dit eiland ana de Z. O. kane twee bayen, wilit wat de nanfe atul de N. O. Loek 'cr pas 2 mylen Bewelten gelegen, 2 mylen diep, en I nyy] wyd is; matr I myl Wettelyker lent "er ecr, die wel 5 of 6 mylen diep, en wel 3 of 4 mylen breed is, en rich meeft $\mathrm{N}$. W. en Z. O. Atrekt, hebbende ngter an by na regen de wal een kleis cilandje wan $\mathbf{t}$ myl in' 't rond leggen.

Wlat Benoorden Croewi leggen digt by de wal ook cenige katskoppen, ten N. O. van wellke de drie eilanden ton 0 . van Loefa Radja zich opdoen, en Beweften die karstappen of wel van Croswi (datar de wal wel 2 mylen na "t $Z$. inbuigt) loopt cen rif byna van enkel katskoppen wel 2 mylen busten de wal; die daat na $W$. añ na "t $\mathrm{N}$. weer allengskens $\mathrm{N}$. $\mathrm{W}$. uitfichet, en dan $f$ of 6 mylen tor and de $\mathbf{N}$. hoek $W$. nistoops, welke $\mathbf{N}$. hoek de Yzere hoek gentaine word.

By dezen Yzuren hock is "c land op zyn breedfte; doch an de Z. kant buigt die wal van de Z. boele ma "N. W. wets 
mylen in, diar de wal by cen flein eilandje, "t geen mern dant digt regen de zelve an zice, dar vlak W. anin met een final rif (diat ontrent I myl breed is) tot au des zelfs Z. W. lyock byta woortloopt, terwyl men hier en dhar onderweeg een kleir cilandelicen ontmoct. In "t N, O. wan dic eilund, I myl wan de wal, doet zich nog cen eiland wall inyl in , trond op.

Vlak ten O, war den Z. O. hoek yan 'teilhnd Ende, in 't midden tuficheis dat ciland van I myl, en tulfichen "t ciland Solor (hoewd wel zoo Z., en wel zoo Da an Solor) legt het eiland Serbite.

Dit is ecin zeer hoog en bergagtig ciland, dar botchryli en luttig zich zelven vertoout, zynde ontreit 7 mylen 0 . cia W. lang, cri 3 of 4 mylen $Z_{s}$ en $\mathrm{N}$. breed; doch in ' $\mathrm{WW}$. wel op zya breatite.

Op de N. W. hoek legt Adenare, op de W. hoek Labetau, in ' $t Z$ e na de W' katut ziet men Toctang; a myl Ooftelyker Limafe, nog I myl Ooltelyker Carmit, of Curming, ch nog I myl Ooftelyker byna an de $O$. hock heeft men Latshale ; dar men ook een fchoone riviel" heett.

Tufthen die elland, en "t land wan Frlo-

Met de Filnders is cen ftrant wan I of 2 mylen breed, dar en dic wel 3 mylen lang is, en die das ontrent nog wel 7 of 8 mylen tuflehen "c land lesgende van Ende, en tufichen Solor Z. W. man wervolgt; gelyk "er ook zulken Atrant tuffehen Solor en "reilant Serbite is, die zich weh mylen in de lengte O. en W. en 2 of 3 mylen in de breedte uitttrekr, zynde Solor's N. W. hotk en Subite "s $Z$. W. hock 2 mylen en der zelver $O$. hocken 3 of 4 mylen wan een gelegen.

Nu zouden wy wel diencen van Solor te fprcken; doch wy zullen dau mede wagten, tot dat wy nog 2 of 3 cilanden die wat Ooftelyker legren woor af $z$ ulleu hebben afgchindiclt.

Ten 0 . van Solor 2 of 3 mylen wertoontzich de W. hoek wan "t cilund Lombattu, en I myl Bcoolten 't cilland Serbite, fertoont zich de $N$. Enoek van 't zelve, dic ook met cen $W$. hoek 'er na toe dmind, mankende dus yon des zelfs W. na des zelts $\mathbf{N}$. hock een diepe inbogt, die, met cen half rond, wel 7 of 8 my. len verre loopt.

Aan de Z. W. hoek wan dit ciland legt een zeer klein eitundje, het Doorlugtig ciland genanut; en 5 mylen Benoorden de $\mathrm{N}$. hoek legt bet cilandje Batoetata, dat pas I. myl in trond is

Aam de Z. kant is dit Lombatta zcer bergagtig ; en I myl Beoolten "E zelve zict men het ciland Pontare, tuflehen beide welk elland een that is wel 5 ing lin lang, en mar $I$ of $\mathrm{I}$ : myl biecd. Aan de N. kane, nant and Pontare legr
V I N G E y A N

cen ellandic van I 13y] in "trond, en een

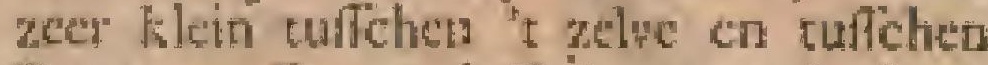
Pontare. En ald de Z. kant wan de ftrat Icggen "er voor de mond vist, de rwee kleinlte digt an Pontare N. W. en Z.O. en de cuec groot te 0 . en W. geftrelet, zynde "s Weltelyk th ontrent 2 cn 'tOoftelykt ontrent I myt in "trond.

Het ciland Pontanc is meet $\mathrm{N}$. W. cal Z. O. gelticks, en alchus oncent f" - mylen lang, cn 3. mylen bred, doch in "EN. W. kan de breedte wel is mylen hitalen, ath des zelfs $Z_{\mathrm{s}} W$. kant buigt de wal met en diepe batai na "t W ons cr an de 0 . kant zyn ook twee kleine bitityen.

Tegen orer dir eiland 1 myl of 2 tha 't 0 . Jegt het eilad Ombo; tulfchen "t welke en Pontate wedert cence ftrat is, die N. W. en Z. O. wel 6 of 7 mylen litng en 2 of $z$ mylen wyd is. In "t midden wan die itrat legt een eilundje digt ann Unbo, gelwk nen 'er nog twee nali een, N. W. cin Z.O. geltrek, wlak voor de $N . W$, hock vin dat cilaud op een rif, d.t rich wel 3 mylen in 't rond urit* ftrekt, leggen heeft.

Dit cland Unbo (ook wel Emmer gemanac) is O. co W. r4 mylen lang, en 7 en $N$, in 't W. 5, en in " 0.6 mylen breed, zynde over an! meel cen gelyke yierkante wal, uitgenonien dit men atan de $\mathrm{N}$. kant twee kikne baven zice, die yder 3 of 4 mylem in "trond, hoewel de Ooftelyltic de groorlte is. Ook is 'er tutu de W. kint nog een lilcir inbogtic.

De N. O. hoek var Umbo lege r. my! wan 'teiland Etrer, en de Z. O. hoek of mylen van Thmor's N. O. hock, en 8 of 9 mylen wan te eiland Kifler of Feter, dat vilk Beoolten "ezelve leyt.

Wat nu het eiland Solor satsgant, dit Het Filegt 3 of 4 mylen ten 0 . van de groote land Solor

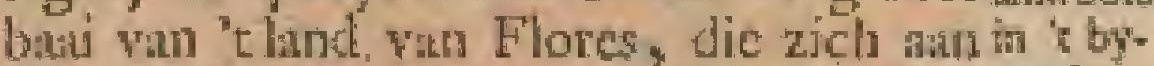
des zelfs O. knnt vertoont, en ontrent is zonder. myl wan bet ciland Scrbite.

Het lest mect N.O. en Z. W. 6 myten in de lengte geftrekt, en 't is ontrent 4 mylen in ' $\mathrm{Z}$. W. cus mylen in " $\mathrm{N}$. O. breed. Aan de 7. O. kant is een groote bai wel wan 3 of 4 mylen lengte. alwat ons Fort Hemrikus legt.

Lên my] buiten de Z . W. hock zat men wer kileine cilundekens wool de mond wan cen ftritat, dic tuffichen 'e land war Ende, en anfichen Solor is, en die zoo wel 8 of ro mylen verte $N$. nam tultehen die twe wallen, en tuftchen die ran Ende en Serbite, loope.

Pas Benoorden de $Z$. W. hock zict men Lefauw, en wat Noordely her vertoont zich Larentocke, twee platem dic onder de Portugeczen thin.

Ten $Z$, de cilunden Solor, Lombatta, Pontate, en Ombo (te wecen wan Solor 


\section{SO L O R E}

en Pontare if of 16 , wan Lombattin 9 , en van Ombo matr 4 nylen) doet zich het fchoon ciland 'Timer' zecr luftig op.

Dit Eiland legt meclt O. N.U. cn WW. En Ti $Z$. W. geftrekt. Het vertoont zich is deze Katare (en ook dongans in de atidere) matr fó mylen, mant het is wel 80

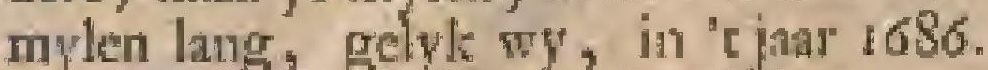
"er langs zeilende, bevonden hebben.

De breedte is zeer ongelyls, zynde in 't midden 17 of $\mathrm{x} 8$ (marr ganale allengskens rit " $\mathrm{Z}$. W', doch voor al tha " $\mathrm{c} Z$. O. af, en dan ma 'r N.O. weer een weinig verbreetende) in "t N. O.by Sillevan co Matavay 5 , en in " $\mathrm{Z}$. W. mede 4 of 5 mylen breed, doch in 't N. O., wan Sillevan al N.O. nangande, word de wal allengskens breeder, konnende 8 of $p$ mylen wan gemelde plats wel to of II mylen hatlen; doch van damr verlmalt zy weet zoodinig, dat de N.O. boek matu" 1 of 2 mylen breed is.

On dit Eiland nu verder te beiclsywen, zullen wy vir de $\mathrm{N}$. $\mathrm{O}$. hoek af beginhen, en ecrit de N. kane langs gaun.

Een myl of 2 Beweften dezen hoek is cen batiken, dint tsen ankeren kan, alwhat zich een plats, Hon genthitne, vertoont:

Een myl Weltelyker, dar de wal wat na 't $N$. W. ontrent g mylen verre uitloopt, ontmoet men Marenti, en 2 mylen $N$. Weftelyker Laber, tulfchen beide welke platefen de wal wat inbutigt.

Pas voorby Laber ichiet de zelve met ecn klein rond hockje na ' $\mathrm{N}$. W. (watar voor een klein rifje zich a myl nis "t $\mathbb{N}$. W, uitltrekt) uit, matkende een kitcin fmal, doch lang baiken. Hier lege het konindary van Ade Mantoeroe, diens konitig de Portugeezen verdreven hebben, en die ook in "t jarr 4680. in Ainboina en Banda geweeft, Chriften geworden, en Salowon Spulman (17a de Heer Commifaris Speelmuth) gedoope is. Het voornoemde batiken is manr I myl biced; maar wel 3 mylen lang. Wan de W. hock vin dic baiken (daar zich weer een fmal ritje wel 3 miylen $W$. an vertoont, en dahr men eerft Bato, 1: myl bath Ade Mantoetre, heft ) buigt de wal wat in, makende een whkke bogt vin 3 of 4 mylen. Twee mylen van Bato na t $t$ W. legt Mateto. Twee mylen N. Weftelyker (darir de wal wat 't N. dranit) Jegt Butenclo.

Diar na loopt de wal wat na "t W. en makl by Turjer (dat 2 mylen Weftelyker legt) weer cen klein wlak bogrje, dit wat na 't N. W., ontrent 2 mylen, uitloopt, alwar vlak yoor de $\mathbb{N}$. W. hoek (duar dit N. Ooftelyk ftukje linds op ayn breedite is) het dorpken Toetobabe legt.

Hier wan daan dratit de wal 9 of to

mylen ma "t Z. Z. W. in, daar zich 2 of 3 mylen van de $\mathrm{N}$. W. hoek (dic pas I nyl breed, etl 2 mylen lang is ) cen baaiFen, dat ontrest 3 mylen lang is, wertoont, van watr de wal al Z.Z. W. en den weer wae Weftelyker vitloopt. Ontrent 5 mylen van deze bati, of 8 mylen war dic N. W. hock, legt Bilaboa woer an ex klein baaiken, alwaar zich het land turitchen deze plase en de Z. O. whl wat Bezuiden Loemani zerr bergagtig vertoont.

Twee mylen ten Z. Z. W. van Balaboa ontmoet men cen klein rivierken, en pas ten Z. Z. W. van "t zelve legt Batocgoede, van war nog 4 mylen $Z$. Z.W. angande (dait zich de dieptte inbuiging der wal watn den $\mathrm{N}$. W hock af zoo wan die als mede wan de Weltkant vertoont) ontmoer men Sillewan, pas Beweften 't welke zich $\frac{\bullet}{3}$ myl wan de wal een zeer klein rifje vertoont.

Van sillevan loopt de wal weder i4 of 15 mylen N. W. an, en van desc plats 5 mylen $N$. Weftelytier onumoet men cerft een rivertjc, en dan Atipopon $V$ an die riviet loopt 3 mylen $W$. ana cen final rifje, yoor 't wike twee cillandakens meeft 0. ci $W+\frac{1}{3}$ myl val-een, en een weintg verier wan de wal leggen.

Vier mylen van Atipopon, N. W.ath. legt Batoepoetch, en 2 mylen verter, by cen kleine rivier, ziet men Afen leggen; van war 4 of 5 mylen Mecna (cen magrig koniakryk) by cen rivier legt, pas Bewelten walke zich een $\mathbb{N}$. hoekje vertoont. Als men vari daar na "Z. O. 21t, doet zich eenig geberge op.

Hier van dian loopt de wal wel ro of I2 mylen nueelt W, ten Z.

Twee mylen van Meem legt Liffetat. Nog 4 mylen varder is een licin whak bogtje; war tha de wall weer wat $N$. W. buigt, en din whe W. 3 mylen tot an cen rivientje loopt, wan war de wal $W$. ten Z tor by twee kleine eilandekens, pass 1 myl buiren de wal gelegen, en elle op en byzonder klein ritje leggende, loope, wanthe reven 't Uoftelylitt wel t myi O. en W. ding, en 'c ander rond, gelyk ook het Weltolykt eilandelsen Poclo Buto gentamt, co dat van Liffetatu ontrent io of II mylen W. ter Z. that gelegen is.

Tuffolien Liffetnu en Poelo Bato is dit Eiland wel op zyn breedte, en witn dater loope de wal I4 of is mylen verre allengskens nat " $\mathrm{t} \cdot \mathrm{W}, \mathrm{Z}$. W en nat 't Z. W. zonder dat men van Poelo Bato ontrent 9 mylen $W, Z$. W. ath iets ontmoct, dan ecrlt eenig gebergte ontient het ltrand, en ook landward in 4 of 5 mylen ran Poclo Bato, welk gebergre langs ftrand zich wel 7 of 8 mylen werre 


\section{B E S C H R Y V I N G E Y A N}

wertoont, en i of z myleriendes, of ontretat to mylco van Poedo Bato wertoont. zich Latoe Boeton, wan watr nog 4 ot 5 myler dit hatid met ecu frnallen hoek, die pas 1 myl breed, ch wel 3 mylen Jang is, nu t $Z$. W. uitloopt, en en zeer groote baal makt, dic wel 10 of 12 mylen in 't rond is, zyode mede N. 0 . ecr Z. W. geftrekt; $2 y$ is ontrent $6 \mathrm{my}$ len $\mathrm{N}$. en $Z$. breed, ch 6 mylen $\mathrm{O}$. en W. diep, hoewcl zy the ' $\mathrm{Z}$. W. nog al verder uirloopt, zynde veot man in den nond wel s mylen wyd. Pas beoolten dezen $\mathrm{Z}$. W hoek a myl, vertoon zich cen klein rond ritice wat i tnyl difit by de wal; dje eerfl 3 mylen N. O. oplebiec, datr zy cen klein bogrje makt, en dan nog 3 inylen O. anloopt, dau" men Selvian heeft, vali waat, 3 of 4 myber na. 't Z. onbugigende, zich Amabitu opdoes.

Vindate dratie de wal 6 of 7 mylen na "t W. ten Z., zonder" dat men jets, dan in "E midden man do wal raft cen ritic, 2 of 3 mylen in den ontrek, umenoer, want sa men by Coupang (dat outrent 7 mylen vati Amabien, en f mylentran den Z. W. legt donst.

Dit is de hoofd plates, dar wy ecen velting hebben, en dart het Oppettiontd, zyade gempenelyk een Onderkoopman, hoewel cr ook wel cens een Capicin hag, doorgates zyn verblyf toet exige bezeting heeft.

Het lege ath een rivier, datr cen zecr goede ankerplats, en 1 mylen Benoorden welke een kein eilandje nee een riljo in " $t \mathrm{~N}$., "cr atr valt zynde, gelegen is. Vin Coepang loopt de wal nog $1 \mathrm{myl}$ W. atn, cn dan bungt ty ontrene 2 my$\operatorname{len} Z$. inth in, en loopt din weer W. ten 2. 3 mylen nit, makende datr ats een - vliklie bogt, van war de wal weer ! my]

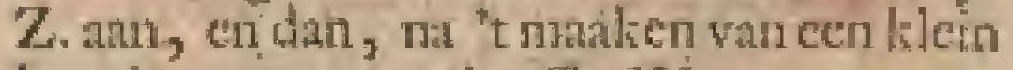
boytje, nog 2 mylen Z. W. an tot atn het cinde van de Z. W. hoek loopt.

iTwee mylen Beweften deze dikle hoek des lands van Cocpang, tot de Z. W. hock Yan Tinor, legt cen eilund, Roti gename, dat meett $\mathrm{N}, \mathrm{O} . \mathrm{cn} \mathrm{Z} . \mathrm{W} .4$ of 5 mylen lang, $c n$ y of 4 mylco brecte 0 . en W. geftrekt legt, aan welkers N. kant zich een fraai wak batiken met een frati dik hockje in 't N. W., N: an uidteIkende, en in 't N. O. opdoet, pas Bezuiden welke thatfe meir nog exen kitein braiken, en I nyll Z. Weitelykej men nog een groote, met een kilcin cilandje dast woot, I myl van de uxil, en rog 1 myl Z. Weltelyker weer zoo een klen buaken, endun het $Z$. hoolge verneemt, who "I welke W. ath een fmal rifje wel 2 of 3 mylen verte W. nath loopt, dar zich weerecn klein batiken opdoet; want ua incriby de Z. W. hoek wan Roti kont, pas Beodten welken, I myl buiten de wal, vier klcine eilanulekens leggen, "zynde de $\mathbf{N}$. W. wal glid en relyk, zonder dat zich dinar iers opdoet.

Dre of vier nylen vlak. Beztiden Roti, en 3 myler. ten Z. W. van 'limoss $Z_{\text {* }}$ W. hoek legt her eiland bemiu, dat meeft Z. en N. 5 en 6 mylen lang, en O. en W. 4 of 1 mylen breat, an de W: knate wat rond na "c N. O. gebogen, en an de $\mathrm{O}$. kant van 2 bajen roorzien, san welke de Zudidelykite de grootile en 2 of 3 mylen an xyin omrect is, an wel kers pitze Z. O. hoek zich pas buiten de wal cen klcin cilandje opdoet, gelyk men 'er wlali voor die buai, 3 of a mylen wan de wal nog een zoo op ecal kilein rond tifje leggen zict.

Wu Timors Z. W. hoek nu, des zelfs Z. $z y d e$ langs, en 3 of 4 mylesio. ten Z. ata gaande, ontmoet men zeer dige by de wal een klein eilandje, wan wan de wal nog 4 of 5 mylen 0 . an met cen kleine bogr loopt, endan na "tO. N.O. cerlt 3 mylen (duit men Amudif legren ziet) en dar hog 2 mylen verder 200 at mandraic, vart watr $2 y$ dan 2 of 3 mylem verre $O$. ant met ecn kleine bogr of ewee, en dan wer mes cen kleine uitpuiling na " 2 . van ontrene 3 of 4 mylen werre tot 'atn cen klcin biailken loopt, welker Weftelyke wakle hoek de witte hoek gename word:

Van dezen whaken hock bope de wal meef gelyk wel to Inylen O. N. O a an, zonder dat men daut ficts, dan alleen 2 unylen Beoolten den-zulven Barapoeteh en 5 of 6 myl lanuward in nat " $\mathrm{N}$. toe cen fwat gebergte ontmoet.

Thies mylen van dien witten hoek, en S ten O.N. O. van Batapocteh diet men by een lklein bogtje, darar de wal I myleje na ${ }^{\prime} \mathrm{N}$. in buigr, Anenosbur, warr wate de wal ontrent 26 mylen werte tot Tolocke toe meeft $O$. N. O. weer auloopt.

Vier mylen wan Amenocban ontmoet men cen riviertje, en I moll N. Ooflelyfrer Batoctain, 4 of 5 mylen rerder 0 . N. O. pp Liemale; en nog 3 of 4 mylen Ferder Fiale, datr de wal taree cen zeet frol hockje myl na $t \mathrm{Z}$. O. witfehet.

Vin Fiale Atrekt $2 y$ weet doorgans 0 . N. O. mus, buigende hiet en dax zeer Amuw wh in.

Vier mylen wan Fiale (Benoorden "t welke zich dat gebergh, "t geen rulfeben Afen legt, 0 . en $W$ geltrekt vertoone) legt Voetere, 3 mylen verder O. N. O. an Sown, z mylen verder Cuminate, nog 4 mylen verder Boero (daar "t land tegen ower sillewar pus 5 of 6 mylem breed is) en nog 4 of 5 mylen meer O. N. O. op Matavay; pas ter N. O. van 'e welke een rivierte is , watr na menz of 3 nilyIen venler cerft by 'Tieres; en 3 inylen 


\section{S O L O R E N T I M O R.}

1612: O. N. Ooftelyker by Serit, en nog 2 mylen verder by Tolocke kom 5 , van with de wal nee 5 mylen verse viak nok "t $N$. ten 0 ., endan nog 5 mylen vlak na ' $t \mathbf{N}$. dratit.

Tuffich Tolodke en Lamoenyy (dac

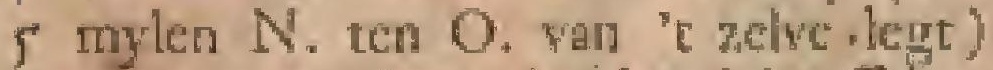
ontmoct men niets, daridat zich tuftchen beiden een geberste vertoon, dat van deze wal af $\mathrm{N}$. $W$. en $\mathrm{Z}$. $O$. gettrelkt legt; co diat zich tot digt by Babboa tan de N. W. zrde vertoont.

Van Locmagi tot an de N. O. hock van dit eiland ontmot men nicts "meer, dun alleen 2 mylen Bezuiden den zelven ontrent : myl buiten de wal ma ' $t$ O. cos, een klein eiliandje pan a myl in 't rond, wat mede wy dandit geluel ciland rond gewandet, cn hee voormanithe dar van (voor: zoo werte dic belchlyving betrefr) gezegt heblen.

Op dit Solor en Timor na zyn de Por-

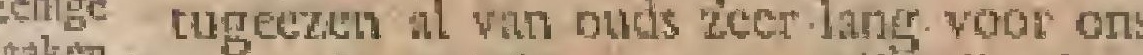
bede dc.geweet, gelyk zy nu nog dic eilinden, 20 Eilan-ot altoos het Grootfe ded van dien beden rain= zitten, op "L cerite voomamentyls of kende. Isefuww, en Lititentoeke; doch op Timor byna dat gehoel eilind over zich onthoudende, alzoo wy matr cen zeer kleine ftreek lands in " $\mathrm{L}$. W. W. ontrent Coepagg dat van onder ons hebben.

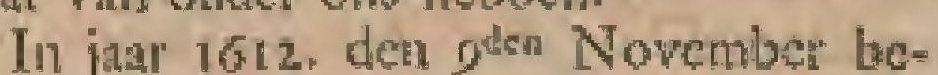
floot de Opperlandvooge wan Indien, om ide Hed Apulorios Schot nee her telip Tervecr eerit na Boeton te zenden, om met dien koning een valt werbond ie maken, gelyk hy den $7^{\text {der }}$ en $18^{\text {den Des }}$ comber gedarn, en Gregorits Comolizon darat ais Koopman en Hoofd gelegt hecf.

Den odea Jathati 1613 , vertrol by met het woomoende felip, en 'c jagt de halwe Manz, en nog cen Tematuatche Cort corit, van dati na Solor, dan lyy vich vlak woor 'c Portutes kaltel op den 17 ten dito vertoonde, en 'tzelve befchoot, daar door cen butery, dic zy 'er ludder, bedervende, gelyk hy op dien zelven dag nog een ded wan her vele in brind thik.

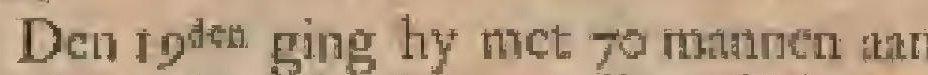
de 0 . zyde te land, atu die wefting war agteren re belchowwen, en den. wyand dar, too veel het mogelyli wis, te benanwen, en de huizen in brand te ftecken, warr mede by den 21 den wervolgak, nemende nong een galjoot.

Onderculfichen gatende Portugeezen na Timor watn deze kontt def Noderlinders kemus, werzoskende, ditt men hea ten certten ontzetten wilde, dat de onzen, zoo veel mogelyk was, rogten te beletten ; Latudende on sn das op "t land van Solor, etr den vyand diar alle bedenkelyke stureuk doendic.

Hy had ook Willew /acebroon met het

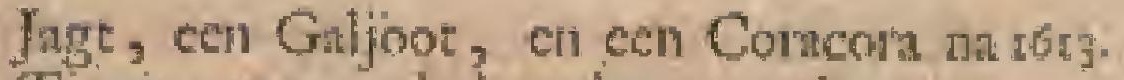
Timor, on op de brandwagr te lergen, yezonden, die den I tien April van daar na Solor heerde met een verterte feluecpken der Portugecen, wast in hy 250 bharen Sundelhout (docrade yder hicr 200 katti) en I 3 lortugeesen vont, en onder dezelween Copiten, nerens cenige Miltiçen en Swarten, hebbende ontrent Timor nog en galjoot werbeand, uit bee welk de Portugeezen zcer verftrooit tha dat ciland gevinge wircin, op 't welk zy vur dic op hen werbitterde ingezeteten zect vervolgt wierders.

De onzen, toen op Timor gekomen zynde, hadden daur met verfcheide koningen, die hen zeer vriendelyk, bejegenden, gefproken, de welke toen doot den koming van Coepang, tot de onzen afgezonden, tocgettam hebuen, dir $2 y$ ditar, gelyk kort daa magelchied is, een veftung zonden bouwen, belowende ogk Chriften te zullen worden; gelyk $z y$ bevoorens an de Portugeczen toegezert hacden, "t welk de onzen nit cen verarterde brict, wan, den Parco Wicaris ann den koning van Portugal gebleken was.

- Te dier tyd hebber de onzen; met soo. hurne zaiken op. Solor ondertuflchen Vefing voortvarende, uit vreeze $w_{m}$ door de in " $\mathrm{t}$ jat Portugeczen van Timor in hun voorne- ror 3 . -men beler.te worden, én de lehependoor oba Patani an Zeeland by zich gekregen heb- Feroverth bende, "Tarteci nognuals, net bedrei-ging win anders nicks te fouren, opgeeitche, watr op de Portugeczen her zelve den zotten April zonder fling of ftoot an de Heer sebot overgegeren liebben.

$\mathrm{Hy}$ wont vecl koopmanlchtappen, en eetige voor fand van oorlog, in het zclve, tan welk eerte $z y$ de helfe, en alles wath het latetle turn de onzen overgawen, want onder 4 vaten kruit, I yzer ftuls, 1 metale wydmonder, en 8 gronte metalle Falconetten met eenige bafen. De voornamite man, bier by de onze verlooren, wats Ahabsan Cloaszoun, felipper op 't frhip Zecland.

De Heer Scbot had dit accoord zecr ftert doorgezct, cп mari anngenomen, on dat ly hoorde, dat het ontzen van Timor naby was, het welk by niet zou hebben kommen belettesi, date te landen, et is "t Fort by hen te lromen.

Uit dere refting troklsen wel 1000 wielen, wans onder 2 go Swarten en Millicen, ontrent 30 Portugeezen, en 7 Domirikaner Monnilen; dic meeft mi MaJakkat, 2 of 3 uitgezondert, die nevers alle de Swarten by de onzen bieven, vertroklećn zyn.

Eer de onzen deze velting weroverder, hebben. $y^{4}$ 'er Soo-kanonfinooten op.geidnatr. Hee hegt op ecen hoonte, is $z e c{ }^{3}$ Q2 


\section{B E S C H R Y V I N G E v A N}

1613. fterk, en wel gelegen, hegt en wel van merzelfteenen opgebouwt. Men ziet an Vendere - weerzyden twee diepe valeycn, van welke zatiela, de Ooltelykite zeer diep cin fteil is, wat door de in zich de Portugeezen con Inkanders agter Heer een gemetzelde muur nog lang verdedigt Schot hicer ver- hebben.

rigt. Hier ontrent hadden de Portigesezen verfheide dorpen, die onder hen ttonden, en reets Chriften waren; te weren Tsjerebate, dat 40 huisgerionen, Pamincaye, dat 'er ontrent 8o, en Loewolaing, "tgeen "ev" 30 had, hoedarig op een elland dar ontrent, Carmang, dat byna 1005, Loewococol, diar 'er' 300 , Loewonmang 300 , Loewoongin Ioo, Mimba, ontrent 300 , ap "teiland in de Sika 200 , en in Larentocke ontuent roo huisgezinnen onder bunne gehoorzanmheid waten, die alle zeer wel van pyl en boog, wan fchilden, fwa roets voorzich, en in ftatt warem, om zich nog vry lafig tegen de onzen te konnen verweeren.

Ook waren tot de onzer op Solor nog deze Moorfche dorpeng te weten, LAmalice, Lamale, Toelon, Ademare, en Prinoloti (onder welke oot vel Heiden(che boeren ttonden) en meer andere platzen yan Serbite, onder Solor ftande, overgekomen.

Daar by badden zich die van Aude en Sillelauwo, dic zeiden eigently onderdatnen van den koning van Ternate te zyn, mede woor ons verklaart.

Terwyl de onzen nu hier wren, hoor dẹn $7 y$ van den koning van Amenosban op Timor, dac datu zeer veel Sundelhout viel, dat in China een zeer grooten halndel gaf.

Dit alles nu hier afgehafpelt hebbende, wertiok de Heer $\$$ choi den $26^{\text {ten }}$ Mey met 't fehip Patani, en 't ingt de halwe Marn, benerens her Galjoor, nim Timor, om met de koningen, die azn de bimnenkant wan dit ciland zich onthouden, een verbond te matken, nemende eenige wasren, die daar getroklsen wicrden, en den koopmar Fon Gybrtszon de Vrye met zich, on darir den handel voor ons waar te nement.

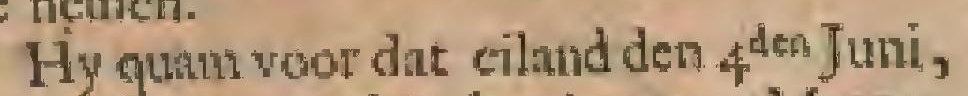
cn werfoge met den koning wan Meena, en der magtigiten op Timor, te fpreken, die alaftonts by hem qum, en zeer minnelyk atu ons toeltont daar te handeIen, cn ecr Vefting op hun land te bouwen, belowende dat met wh volk te heipen malken, en 't jagt de halwe Mhan met Sandelhour, de womatimite wasue dezes linds, af te batiden.

Het wale antrent Mecna, en Coeparig, too orervloedig, dat de Portugeczen parlyls van "t zelve over de 1000 bhatem, behalyen 'tgeen de Chineezen, en andere. wolkeren nog wertlecpten, pan hicr na rorts China en Choromantel vervoerden.

Ook kon deze handel van "t Sandelhouk ons by oce Chineteen byzonder wel dienen, on her wat gernakkelylier, in 't toeftatan van den handel op China, te matict.

Buiten den koning von Meena quam de koning van Altem de onzen als cen der voommanite op dit eiland voor, dien ede beloofite, al 'c Sandelhout, op zүn hand vallende, an de oneen te zullen leveren.

Na dar de Heer Śby nu net deze vorften, als ook mer ecnige Moorfche koningen of Solor (hoewel hicr weinig voorded te doen was) cen walt verbond

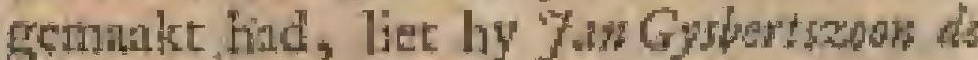
Vige met Krya Yacobsoon wan Rawalurg, om den landel datar zamely wata to ncmen, Tan welke de ecrlte moeft de zahken op Timor, en de ander die op Solor gade dhan zoude.

Ook lier try op Timot Capisein ots de $V_{\text {Adte }}$ als hoord vari 't krygswolk, to der cyd de Opperlandroogt een ander hier zender zoude.

Hy bewont onk, dut hiet allerlei Cho-

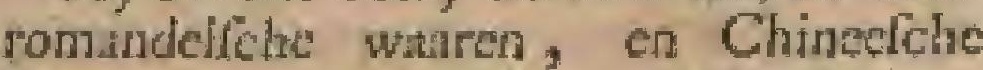
krameryen, wan kmalen, emu. zeer gerrokken waren, hoswe] "er niets beter en meer gewild wats dan fyn goud, wat tusede nuen hier allerbeft ec rege komen kan.

In "x jar 1616. vonden de onzen in Juli goed de Vefting, die wy op Solor en "Timor badden, te verlaten, en hadden "er de lehepen den Arend en de Sturre na toe gezonden, om een niveuw verbond met de koningen daar te makaken.

In 'e jart I 6L9. 7ont de Heel Coen wa voor Jakatm "t fehip de fager uit $x, y$ n vloot na Solor, orn na woornad van rytt te zien, zoo dat wy 'er toen nog op handedden.

Na dezen hebben wy ons wan tyd tot tyd hiter wel wather gremakt, ett onze verdere Opperhoofden op Timor gehad. doch winde de namen der zelve, voor at wan de cerfte tyden, zoo net niet, als 't wel bchoorde, mangeteckicnt.

De certle, die my woorkomt, is geweeft Gonfalvo dorasy, de whder witr ecron Amton d'Omay.

Dewe, ninder hand Yoban d"Orny genatant Wonder(hocwel hy bewoorens een anderen matn lyk voosvoude) was onze Bevelhebber in 't jarr' Gonitile

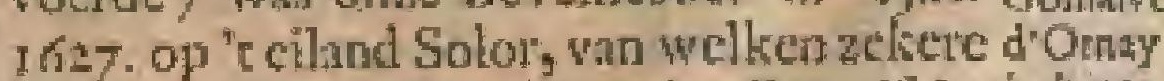

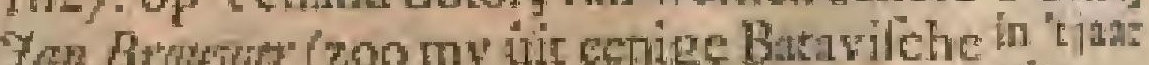
Kericpapictur gobleken is) berigt and de ${ }^{16 \%}$ onzen gaf, dac 2 of 3 Hollanders befloten hadden hem inverzekering te nemen, alzon zy verftan hadden, dat lyy wats voorncmen was, on die Vefting an de Portugecren ovej te leveren; doot welk berigt deze Bromoter ook in groot levens: gevaat gormkt was. 


\section{S O L O R E}

16.6. dOmay, dast op niet lang fammetende, was ten eerften na de Portugeczen overgeloopen, en van de zelve, voomamelyk om dat-hy Roonich Catholyls wiert, zoo gunftig ontfingen, dat zy kote dat na zyn zoon, Ahrouk dOmbi, Bewelhebber wan Larentocke, en over alles, dat de Portugeczen op Timor bezaren; makter.

In "t jane I 646 , betloten ham Edelheden den zen Januari 't fort Henticas, ch die inwoonders, onder hunne betcheroning te nemen, dat zy beroolens, en ook toen eerigen tyd felyonen nugelaten te hebben; alzoo zy in "t jaar 1650 . den 260 in A pril fchreven, dac zy den handel op Solor, bevoorens geftalit, om goede redenen nu hervat, en "i fort Henricus weer in bezit genomen hadden, on tr roomenen der Portugezzen te teutetn.

Na die tyd kome my in 't jut 1648 . de Heer Majoor Whilm van der Besk als Hooft op 'Timor voor, die mer een koningin van Solor trouwde, dat de Hecren der Hooge Regecring riec zeer wel beviel, die hee nog al eerigen tyd datr na geweet is, en in " $\mathrm{t}$ jar 1659 . doon den Majoor Jacob Verboders, als Hooft wan Vertey- Timor en Solor, vervangen wict, docl detr in die het niet lang geblewen is, aangezien "t jar he by in dat zelve juar in de belegering van

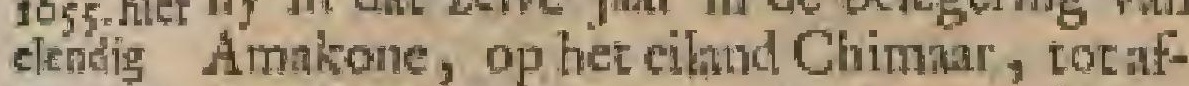
atr zyn break der Portageezen by hen ondernoeinde ge- inen, zeer fehendig ras de zimen werla-

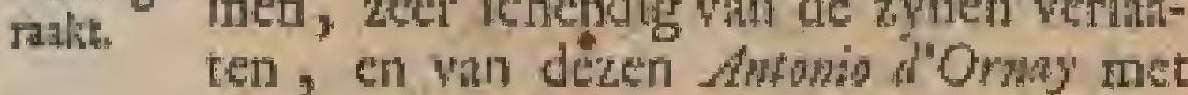
een Gigfward ter nedergekapt is.

In 't jaw' 1 6r6. ging de Hect Amoll do De Heer Vlaming wath Onthoorn, me dat by de de Vla- Zlawhis wa Amboin en in de Moluccos ming van volliomen lierftelt had, nee een nagt Outs- volliomen lierfelt had, nee een magt 1legte toe. Hy was wat den Capitcin Radfa, timg hier benewens in de 60 koppen, die onder in "t jall hem ftonden, en war Capicein Johker,

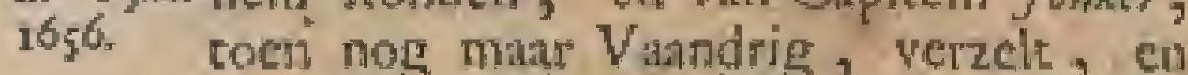
gutum den aten Jamuari vool het kaftecl Henricus ren anker, vindende datat alles th ecil redelyke todtant.

Het cerlte ongeval, dat dezen Hoer hier onemoete, was, date het pratuber, wat in Ae Onderzecvooge Roos. wiss, zoo ats hy vin boord na Timor vertrok, digt by onze vefting Concondia, omflocg, alwar by met nog 4 anderen den 25 -lte Februari verdionk, watr by de E. Mantrehappy cen wilk ker dienat verloor.

De Heer de Vlawing vyt dagen op Solor, on datr alles te bezorgen, geweert zynde, ftak na Timor over, en roeteerde den $17^{\text {den }}$ der wolgende mannd un liet wek Amarafia, dair des vyands hooldplants wvas, hebbende zym volk voot een wetk wan her noodige wortivin.

Hy quam, tot op 4 mylen naby 't woomoende vlek, dait hern cen fwate
' I $\mathrm{M} O \mathrm{R}$,

dagregen zeer fehielyk overvicl, watat 16,6 door hy genoodzankt was na de voorige halteplants te rug te keeren, alzoo deze reger zoo ligt niet fcheen op te zullen houden, en hy geen de mintte gelegenheid vond, om op dic kital en bultig gebergte te konmen fchuilen. De Swarten, die hy by zich had; hem ziende te rug ketren, wn zich inbteldende, dat by doot don wyand op de vJuge gedreven wiert, wierpen alles, wac zy. by zich hadden, wite een werkeerde vrecze tegen de grond, en namen (gelyk $s y$ in zulken geval gewoon $2 y n$ ) alts bloode guilen de vlagt.

Dit was ooraak, dat deze togt tocn niet voortging, en tot een nader twd uitgeltelt wier, alzoo hy ontrent alles hior vemt, en onkundig was.

Na ryp ovelleg hervate ly den $27^{\text {ftel }}$ dito die togt, en ging her geberge na Amilti te voer ops komende, $y_{3} 3 \mathrm{da}=$ gen yosteerens ontrent de legerplats der Portugeezen, die onder den vootnoenden Anowo "Onay hun beft deden, on de onzen den verderen togt door alletei beJetzelen af te foyden.

De Heer de Vlaming, dit ziende, zond 'er den Capitein - Licutenant kicler' met 6 vandels op uit, on des vratids doen ea lasen wel at ue kyken, en hen allen afbreuk te doen, "t geen hy met al zyowermoger naguatr, hoewel met weinig vootdecl, alzoo de vyand wel op zyth hoede was, mar cen weinig dan ma licp hicr alles tegen, alzoo 4 vaiundels, op cen averegts geruge agt gethagen hebbende, zich na een verkeerde plants begaven, om "r gemeen gebrek, dat zy zicli dar' ingeboeld hadden, te helpen herftellen.

Hier door overdrongen $z y$ malkinderen zoodanig, dat den Superintendent laft tot den afroge geven moelt, zoo hy ze nier alle wilde aien in de basrs whegen, efa elçndig frueuvejen.

Hy kreeg daar 8 dooden en 48 gequetfteri, onder welke de Vandrigs Kletold en Han 7 wrian $W_{e b}$ waren; hocwel de wyatid "er ook al cenige werlooren had.

By angeluk witr hier ook in "t midden van de nacht de Licutenant Dawid de Coning door een wan ons volk dood geCcholem, war an wy een wakker foldant quyt ralaten.

Men had den Heer de Vlaming, gelyk lyy nu an "r gunfch beflag zag, de zaiken hier geheel verkectr opgegewen, zoo dac hy geen maandes, mar jauren, wan nooden gehad rou hebben, om alle de poiten in te nemen, en, als by die al verovert hiud, alan was her fop nog de kool nict watrdig, itmigezien alle de voor deelen vin T'imor en Solor die onkolten niet zonden hebben konnen goedmatken.

Het verfichilde lier ook niet weel, of de Cipitein-Licutenant Kriler zou 't leven Q3 


\section{B E S C H R Y V I NG E V A N}

165.' door een wan ons ejgen volk verlogien hebben, zoo men dat in tyds niec beles had.

Eindely bertten de wyanden, ziende dat ons wolk hun geweer niet it re wel gebruiken kwh, zecr onwerwige op de onzen los, en ontnamera zecr veeles humne wapencn, ja zy ruket den VaandrigGerad Gerardsoon met geweld, met waatdel met al, wit zynen troep, en ontnamen een tronmelfiager op de zelve wyze zynen trommel, dat un tectift cen groote werflagenheid onder ons wolk grat, hoewel zy zich maderhand wat heritelden. Zy kregen toen egter 37 dooden, en rtgequeilen, "r geen den Veldhect befluiten tede wan alle vertere ondencmitmer op "Bimor af te zici, en geen volk hier nuect, on de roornocmde redenen, te wagen.

Mendad ook zeer teel yan den over. vloed vin leefogt hier gefolsrecuwt, en ondertufletren niots ter woreld gevonder. Nier minder had men hoog wan de magt wath den Sonnebayer (cen wortt landwitatd in, die men voorgaf dat wel t5000 gewapende mannen te veld brengen kan) opgegewen, en den Heer de Vhaning ook wan zyne hulprerekert doch by heeft ngg dezen vorlt, nog cen cenigen man vanthem, vernomen.

Derhalwen is by, na dat hy bier in 't geheel ipoblanke koppen verlooren, en zecr dapperen regenftanc witn dezen Astomia d"Ormy geleden had, owverigter znation val Timor na Solor weder overgethoken, en met zyn wolk den ghem Jule voor ic fort Henricus ten anker gekomen; bec welk by 200 nege vone, dar het zeer noodig etr ecrlte diende herftele te worden, howel hy berer oordedde dat men 't zelve flegten, en en ander Velting op 't cilland Roti maken zoude; itzoo men van dat ciland mede zeer wel een watkene oog op het doen an lataten der Portugeezen houden kon. Zelt wikie hy de velting Concorditit op Coepang geheel ingetrokken bebben, dat egter geen voontgang grehd hect, alzoo, mo zyn komil op Batavia, alles "er nat gefebilit is, on de velting Concurdia merkelyls te verbeteren, met voornemen oth dae voor ons Hoofitcomptoin alhier, nelyk het zedert geweelt is, te houden.

Hy zogt wel met den Portugees dar in onderhandeling wegens be Sandelhout, op Solor vallende, te treden, en hem te bewegen, om dat jurlyks tegen kleederen en geld an de E. Matelchapy re leverten; doch al asne antugewende mosite wis vergeds.

Hy liet derhalwen op Solor i I Inlandze yatraigen met 436 mat , met lift ata! "t Opperhoofd die, zoo riss het Mocfion date toeliet, nan Amboina te xenden.
Dian na wertrok by over Bima na Bin- 4 67. tavia, en dede an har Edelheden verflag van "t gene by op. Timor en Solor" verrigr, en hoe verkeer hy alles dats, in opzige van 't berige dat hem "cr alfegeven was, bevonden had.

Hoe de koningifi van Solnt in "r jut 1660. by de Heeren wan Dam en Traymass an boord quam, komen wy by Wowler Sibouten pag. 8o. zicn.

Wie "er in dic ryd Oppetheofd was; Werdere

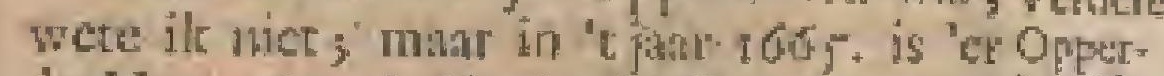
de Heer Anowi Herd als Koopmin en hoofden, Hoold an tocrezonten, dic "er bot "t be- dis hez

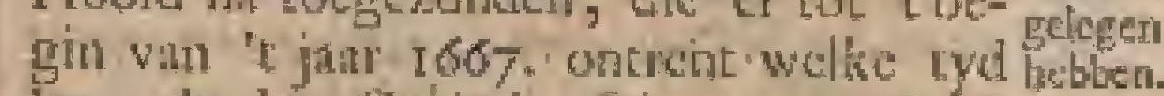
'er ook den Cipien-Liememn Farb Pichrsoni de Copper als Hoold getegen bect.

Wie 'er ith de tulichentyd tot 't jar 1677 ing, is thy ook onbekent doeh in of enevent dat jata is "er de Heer Yobur wan fedon', behint vader van de Heer Alyban whin Ribeck, en flitwader van zyn Ed: Beminde, Nevrouy Moria Elfabel wan Bosgem, geplatalt.

Hoe lang 'ec deze Heer lag, blylut uty netgens; math in 't jiar 5680 . en echitye volgende jurien, is de Heer yas 7 Wherfoot lier Hootd geweel.

Lange baven daw ba heef er ecnen ow der End of wan der. Inde als Hoofd grategen, die in 'e jarr 1701 . of 1704 . door de Hect Cipiceiti N. Pocams vervargen, en die "er tot "t jar 1705 gebleven is.

In zyn plats quan cotn de Onderkoopman Joanes on Alfen, die dar Hootd tot "t jat i 706 . blect.

In zyn tyd is de Herr Gerard $\mathrm{Bu}$ bet bofo, Opjerlioopman, hier als Common-

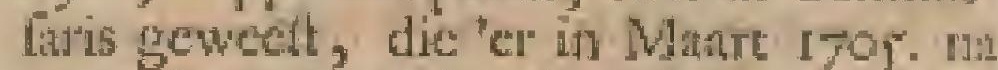
eoe ging, en in Augultus wa dizn quam.

:In 't janr 1706 . is "er Capitein Dulof Alad gelegt, die 'er tot ' $\mathrm{j}$ jathr $17 \mathrm{r} \mathrm{L}_{\mathrm{r}}$ als Opperhookit geweed hectit.

Hy wier roen doon den Onderkoop-

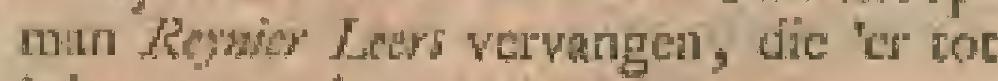
'c jaลr" 17 I 4 . ling.

In zyn plats is in dut zelve jar de

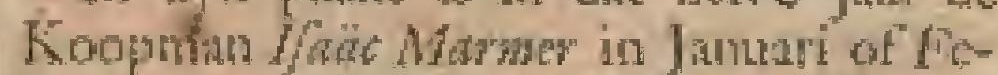
bratari angeltete, en detar tot "t I7/5. gebleren.

In zyn plats quam hier dit zelve jatr de Kooptran Whom was Purs, dic in

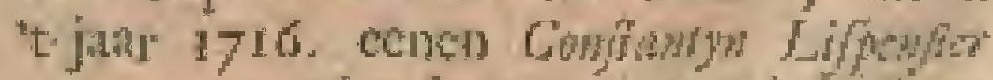
tot zyn cureden leweeg; hoewel die hen thet verving; alzoo, in thar 1717 - Baren wan der $S w a m$ ha $z y$ pliats gevordere is, die zich tin 't jaar i 78 . of 1710 . met echi piftool dood ichoor, zonder dat ik wete, wat hem dare toe beworgen heeft.

Wie hem verving is thy onbekent; nfutr' zedert 't jam 1721 . heeft hier do Onderkonpman Hom ik Eingelber' gelcgen, die tar hee volgende jur nog lag. 
S. O L O R I

Dit is ket alles, dat wy, in oprigt way. "t Werddlyle, wan Solor" en Timor weted te zeggen; theoo dic land in zyn binnenfte ons nug zeer weinig bekent is, din dat wy uiterly hebben komneh zien, dit het zeer bofch-en bergagrig, en meell over al langs des zelfs itranden bewoont, en zeer volktyle is.

\section{Van deZaken des GODSDIENST"} allict:

Wat nu de zatken yan den Godshojle Van den hicr berreft, 'uit ons woorig verhal is dichit it-reets yebleken, dat men op solor ver-

hier. fcheiden Mohthammedanen, voor al in de dorpen Lamakene, Lamoeic, Toelon, Adenate en Pratololi, en mogelykelders, ca ook of 'T'mot zeer warlehynelyk, had, behalyen dat 'er veel Heidenen, en liver en dar ook door de l'ortugeczent teets ectige Chriltenen gertuale waren; die, zodere de komft der Nederlanders, trog al merleclyk toegeromen zyn, zoo dat men lue witn dat gewige geagt heeft, oin bicr niet allect cen K mal bezocker, en cen Inlandze Schooimeetter te leggen; matar ook om de 3 of 4 jaxers, of langer, 11a dat de Doopelingen zalles eer of litater vereifeliten, cen l'redikane" herwates te zenden, on er de $\mathrm{H}$. Sacramenten te bedicnen.

In 't jatr 1670. vertok D. Cormlins heyerskind na Tinor, on 'cr watt te Jeg-

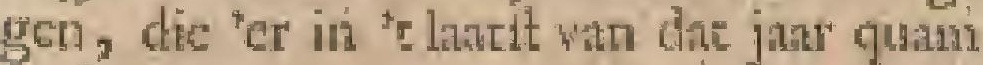
te tetren.

- In 't jair i673. ging derwartes D. Diowyfots, en et volgende jar D. Jacobs Rbyshly, om die Kerk te bezocken. Nit dezen tyd is D. Aaxondop Carpins "er

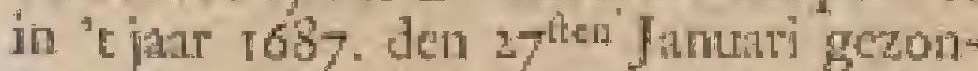
den, on 'er' valt te Jeggen; doch " $\mathrm{c}$ jant darer itan overleden, en na zyn tyd heeft 'er noit Predikatut meer vaft gelegen; matr deze Kerk is nlleen door een blyvende Kratikbezoelicr watgenomen.

Men zond 'ef ten dien elinde in 't jat 1689. den Krinkbezocker Yam Dinkrow na toe; doch hy liep in 't janin' i Gor, tot de Portugeczen mitrentoske over, en omhelsde, als en atrallige, humen Godsdientt.

In 't juar I69t. wient hen $31^{\text {hta }}$ Decenber bether on 'er den Ir rumbezoeker Gybort Theffers na toe te zendens' die 'or tot "r jur 1702. gelegen heeft, taen verlof, es in 't jall 170 , of 1704 . in 't begin door den Krankbezotker Urbws Meddeg verwangen is.

In de tyd van Frofless zyn "er nu en dan Predikanten na Timos, on deze Kerk te bezoeken, geweelt.
T.I M O R.

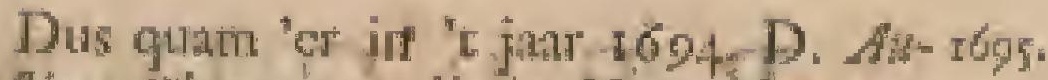

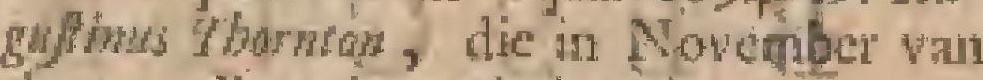
dat op Batawa wederkectde.

Zyn Ecrw. vond "er tocn Pawe Coepark, endezen Treffor, beide in "t Maleyts redelyk ervalten, en als Knunkbezockers thiel den Dielut wationemende.

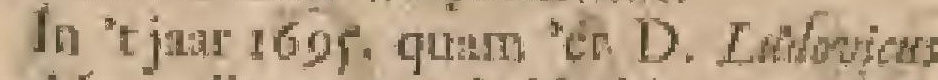
Is Mey, diczeriog beide hier, en oole 27 Ledemateti rond, doch 1699. was 'er cerk Lidmat' mech", en tocn lig 'cr Triffors mat alleen, dio zich byzonder in "Malcits beyverde.

In 't jar' 170r. was hier en fohool wan 22 kinderen opgerege $;$ doch dwat waten Ithas 27 Ledemaaren.

In "t jatr I702. quarm D. Gajhs Andrd, on die Kerk te bezocken, en yont toen hier-33 Ledenaten, onder oprige wir I Oudering, i Diaken, en den Krinkbezocker 1 rofhes; ch dar wagen nog wel 12 of 14 ongedoopte kinderen, en 8 bejatrden, dic rich tot het doen yan furne Belydenis bequan mankten ; en 6 Heidentche kinderen die fehool gingen.

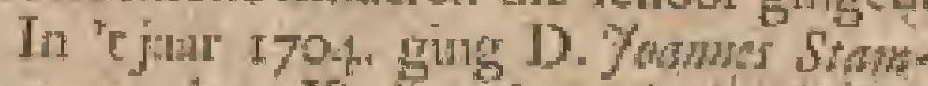
noen om deze Therk te bezocken, dic "ct 34. Ledenthten vont.

In 'c.jaal 1716. bezoge D. Godefridts 't Hoon Hogsworn deze Kerk, en bumge ct toen een wan myne Leerlingen, thos Pieversobon Thene als Inlands Lecrneeltet na toe, die "er nog ass Krankbezocket lege, komende, dat wat zeldzann voor een Inlaider is, de Dutifiche tal zeer wel Ipreken, en 't Maleirs met een fintije Ambifche leter ongemeen net fclurywen, hoewel "t my wel heagt, dat hy her nog zecr llegt fehref. Hy quinh in pluas van den woomounden Parhs wan Coenors.

De Hea Hongendorp had datr cenige Ouderlingen en Diakenon met de Karkenrad gekoren, doch "tOpperhoofd had doze verticzing afgekeurt, en op zyn cigen gezag anderun angeltelo ; dat hat lidelheden, dan van berigt door den in

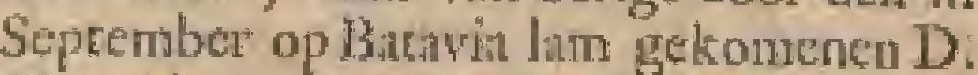
Hoogenturp, zeer weent voorquam, en die naderhand date ordte in ftclden, ten cinde zullis aiket meer gelchieden zoude.

Na den Kritnkbezocker Meddig hg hier yaob de cuyfer, die in "t jant 1717 overledera, en in Jantati door Merma Thenkins verwangen ; mat die zeer loore na $x y n$ komit ( des zilven jaurs berigt wiert) gellorven. en "r jatar dant an dow Lender" wan Dyo vervangen is ; war mode wy ook cen cinde wat het Kerlielylie vin Timor en Solor" rataken; zullende nu tor de Bes febryving wall Macalat ow crysur. 


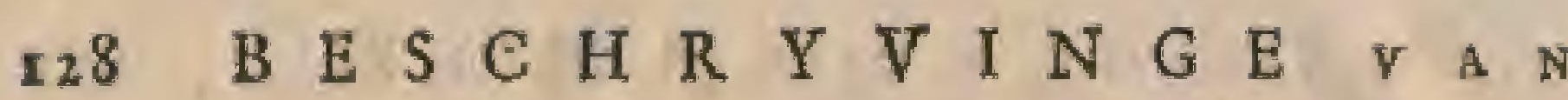

\section{B E S C H R Y V I N G E}

\section{A N \\ $\begin{array}{lllllllll}M & A & C & A & S & S & A & R\end{array}$}

\section{T W E E D E B O E K,}

\section{E E R S T E H O O F D S T U K.}

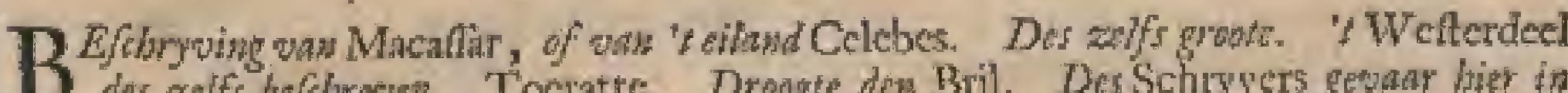
B des zelfs befchresen. Tocratte. Droogte den Bril. Des Schityers gevar hier in sjagr 1707. Tranee, enTanahkcke. Gelifon. Panakoke. Samboepo. Oedjong Pandang, of 't KaffeelRotterdam. Tello. Maros. Tanctta. Badjoekike. Mandar. De Boge van Boni. Loeboe. Soping. 't Meir Tempe. Tsjiurana. Boni. Tanjoli. Boelocomba. Saleyer. De Bocgerones. Bonteyr. Wawoni. Pangafane. Cambayna in 't werflchiet. Boeton. De Toecan-befi's. Calauro. De Tygers-cilunden. En verfcheids andere Eilanden. Welke Ryken tot Macafiar, en welke toi Ternste beboo-

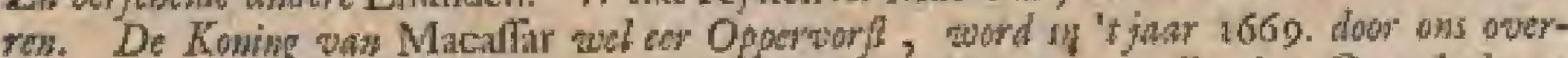
wormen. Eenige nlemeene zalken. Ere, die men de Koningen wen Boni en Goa, by bunne

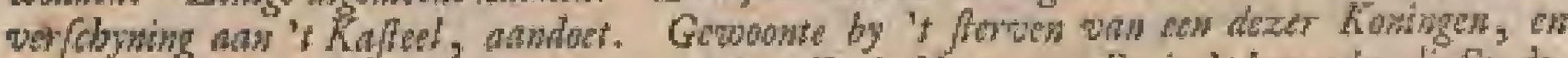

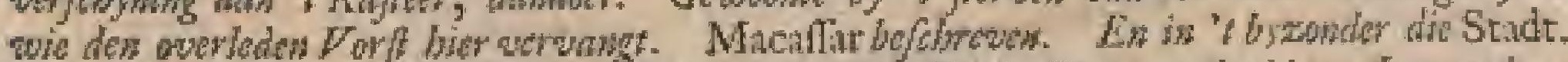
De Veffing Oedjong Pandang, of Rotterdam. En in Pren werbeeld. Thwoosders. De Macaliaren bef dreven. Husme Vrouwen. De Boegis, enz. Ons Conproir bier Wat de Landroogt bier te bezorten beeft. Scboonc Rytt. Wataren bier getroklen, of ook bier sullemice. De laften en winften won de joaren 1708. en 17og. Droogre enirent

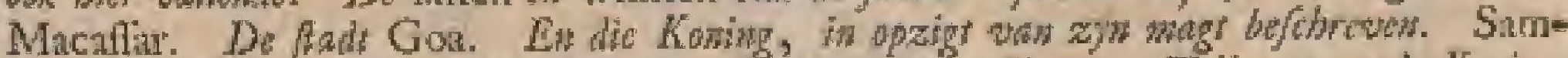
bocpo. Tello, Boni. Bontualac. De Boegize wolkeren. Tsjinrana. 's Konings brizen dadr. Hoe dio Koning do Gevolmagtigden der E: Mattchappy dadr onthash. De everdere Komingen. Bima, enz. en onzs Logie daar. Derdere byzanderbedeu vas "teiland Sumbawa.

Brthry-

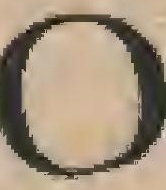

$M$ eén net berigt yan deze onze Landroogdy in " $\mathrm{O}$ Oolten, onder de Eilinden van lodiën, te geven, zill het, volgens ons gewoonclyls beltek, voor af noodig zyn het Land zelfs, en daat na de zakken, daar in voorgerallen, te befehryven.

Het ciland Celcbes ( wwatr op Macathr legt) is, zoo verre dat by ons belecent is, in de Kaart der Moluccos, waar ant wy ong gedragen, teets vertoont.

of wh Macat Tar legt op een groot ciland, $\mathrm{Cc}$ -

't ciland lebes genaame, "t geets in "r Ooften de

Celebes. Moluceos, en Amboina, in "Étuiden de eilanden van Surnbawa, Flores, Onbo, Teralta, ontrent 't cilind Timor, en in 't Welten het groot eilind Borneo 'tallernatif leggen liceft.

Het is een van die drie eilanden, die Prolonews onder de Sinder, of Menfchenceters eilanden, ftels.

Het legt ten decle Benoorden, en ten decle Bezuiden den Evenaar. Her kleinite, of het Noorder-einde, legt op 1 grad en 30 min. Benoonden, en het grootfte, of "t Zuider - einde legt, op s granden en 30 min., zoo dat het 7 graaden Z. en N. (gelyk her rich ook meett wertoont w witgeitickt legt, terwyl het O. en $W$, of in de brectre, 3 graaden beflatr; doch de fimatler ftrook lands van de kuft van Maundo, tegen over Ternate, flitek zich ontrent , o mylen werre $\mathbb{N}, 0$. uit, Yan 'tuiterte van welke hock, $O$. ain, twen het groot ciland Gilolo, of Hilamahern ontedekt.

Hex word gehouden 300 mylen in Des zels 'trond te beflan ; hoewel het nog wel groots. iets minder in zich z.chen is; mair die matr 6 artanden woor de lengre, en 3 roor de breedte ftellen, mialien her veel te klein.

Om tm dit deel wan Celebes, zoo net, en zoo kort, als 't ons mogelyk is, te be- 


\section{$\begin{array}{lllllllll}\text { M } & \text { A } & \text { C } & \text { A } & \text { S } & \text { S } & \text { A } & \text { R. } & 129\end{array}$}

fehrywen, zullen wy woor af zeggen, dat | als wy deze noly mat twat-Nowdlyker zich hier twee ftreken lands, met cen fevenes, in welk zeggen de fticmarn, groote bati of inhan 'er tulTehen beiden, die hier zeer bevaren was; en met weel zoodanig vertoonen, dar men de eche ftreek in " $\mathrm{O} \mathrm{O}$, en de andere in "t $\mathrm{W}$. leggen ziet, terwyl men in "t midden de groote bogt wan Bont heeft.

Wefer- Wy zullet ons nict werder hier ower

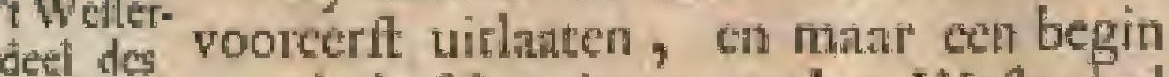
aels be- met de befelrywinge wan het Wefterdeel

[elurevej. mastien, atovingende met de ftadt of vlek Tocritte, in het Z. W. op dien hock metrent cen binnenbai van 1 myt of 2 in zyn omtrek zoodanig gelegen, dat men ontrent : myl wan de wal een Jizin eilandje zonder nam ziet. Ook fehiet die baxi mee de $\mathrm{N}$. W. hoek wel een myl diep ma "c N. W. toe, gelyk men ook buiten dien hoek cen kicin ritje werneent.

Dir Tocrate is al een migtig lentints-

Toeratte ryl, welkers koning in fant is om een frail leger te weld te brengen, gelyk hy ook al mede onder de vermogenden dezes eilands gerekent word.

Zeven of agt mylen ten $\mathrm{Z}$. W. van Drongte Toeratte legt gie bekende en gewarlylic den Bril, droogte den Bril, zysde ech rif wan ontrent 2 mylen in "t rond, medt $\mathrm{N}$. W. en $Z$. $O$. gettrekt leggende, en wast op de E. Mantichappy ook ved fehepen verJooren beefe, dat men egter zeer gemakkelyk tydig tegen zorgen kan, als men, ontrent Toerate, of "c eilandje Tamakeke komende, zich ten eeriten digt onter de wal, daar men aukergrond hoeft, beygert, en liever too ling ten anker blytt leggen, tor dat men een goede wind treft, alzoo men anders gemakelyk zyn fchip in zeer korten tyd verliezen Fan, otn dat, zoo ras men buiten de ankergrond geratkt is, de ftroom zullt cen fchip neelter word, en zoo finel na die droogte trekt, dat 'er onmogelyk met een bocgzerfchuit tegen an te rocjen, en nier dan een elendige fchipbreuk te wigten is, ten ware men "r geluk had, on undertuficher een goede wind, die "er" 'a zelwe afbrengen kan, te krygen.

lk kan met ondervinding datr var fpreken, alzoo ik in 't jatr n 707 . พan Batacia na Amboina zeilende, en Tanahkete in "r gezigt gekomen zynde, den oppertlieman $N$. Surmdonk tegen onzen fchipper Ceen Gerriszow hoorde zeggen: Sibpper, wy wocten bier digier ma de wal van Coletos looph, en goede zorg dragen dat wy ankergiond kighta, of anders zullen wy op den Bril raakin, wronits do flroon dan zeer flow is, en de wind in zoe boe langer boe wer ver/lappen zal, daar wy zaker on gerugh met de lawdowind bet langs de wal gatade bouden, of anders zao lang ren anker lownen blywen legeren, tot dat wy eon goeds ch ferke zeewind kyges. Dit konher wy, sei de dierman, seter gowaktely doen,

1II. DEEL. grond rpmk, wolkomen gelyk hind, Des doch de fchipper, die hier noit geweft, geryar en een botte dwarsdryver was wilde hice in zich met zyn onwerzetelyk hoofd na een' $t$ jast Journal, of Dugregitter, dat hy van spot. zeker vriend gekregen had, gedragen, en diethalwen nog meer om de Z loopen, dan wy nu rects zeilden, watar op de op= perftiermasz (alzoo de twee onderitieslieden hier ook noit geweef waren, en den fchipper dierhalwen niet dorften tegenfpreken) regen hem zeide, dan zullen wy morgen ogtent op den Bril zitten.

De onverzettelyke fohipper kreunde zich hier nict cens ain, Jehoon de opperltierman zeide, dae wy "cy zelfs met deze cours, zoo als wy nu zeilden, nog zeer lige konden op ratken. Schipper Coen gaf egter in de eerite wagt 's avonds aan de onderitierlieden, die deze en de hondewngt moeften wairnemen, klare laft, dat zy nog Zuidelylier, dan wy mu zeilden, en Z. O., of eet Atreek datr onterent, zouden zeilen, dut dan niet miszen kon van op den Bril te vervallen; doch de oppertierman belafte hen, in myne tegenwoordigheid, nog Noordely= ker dim wy nu deden, of wel voltelykei" te zcilen, "tgeen zy ook deden; en egter zagen wy 's morgens net 't atmbreken van den dig deze gevtarlylke droogte niet hed verre voor uit leggen, cn wernamen (dat ons meeft ontzertede) dat de wind hoe langer hoo meer ging leggen, en dat de throom ons vogeswlugt 'er na toe zette, wate door wy geen athdere-gedigten hadden, dan dit wy binner een klein hall' uur "er boven op zouden zitken, en rot [pranderen gerauken.

De opperifiesman riep datar op den chipper, dic, dit niet groote werbalifheid ziende, met de handen in 't hair on ten uiterfte verlegen ftont, vervloekende dien genen, die hen dat Journatal gcgeven had al "c welk ons nier helpen kon, en wy zouden er elendig toegezeten hebben, zoo God de Hecr ons nier zeer onwerwagt een Zuidelyle wind gegewen had, watr door wy onder de will wan Celebes, en ten eerfict ten mker geralkten, endus uit alle dic fwarrigheden gered wicrden. Ook luilterde de fchipper in "t vervolg wat meer na dey opperftierman, en ftont noit zoo flyf weer op zyn Journial, alzoo hem dat zoo fehetidig misleid had.

Vam Toeratte nu N, W. 2 mylen man- Tanat: gande, komt men by den Z. W hock en Tawan Tanalikelie, die in rynen ontrek mathethe, wel een myl of aderhalf bedat, en I myl Noordelyker (nhoo de liut hier 


\section{I30 B E S C H R Y V I N G E v A N}

ontrent tot Macaflar toe meed $\mathbf{N}$. an draaid) beeft men "c dorp Tanaë, en I myl Bewetten den bock wan Tanaë het ciland Tanalikeke, dat ontrent $2 \mathrm{my}$ in "t rond loopt, met cen rif rondom, witgenomen aan de Ooftzyde, bezet, en meelt onbewoent is.

Gelilon. Een myl Noondelyker dan Tanaé legt hec dorp, of Prinstom, Gelifion, zynde ratur ecen open wek van weing beling;

F'antike- en een myl Noodelyker ontmoce men ke. eerft het fterk katteel Pamboke, datr ma, surboe al arn diezelve zyde, de findt, en 't lanpo. theel Sambocpo, en nog war Noordely= ket 't Kafteel Oedjong Pandang (dat is,

Oedjong den Kykhoek) hedensdntgs met den nakm Pandang van 't kaftecl Rotterdam bekent, wan

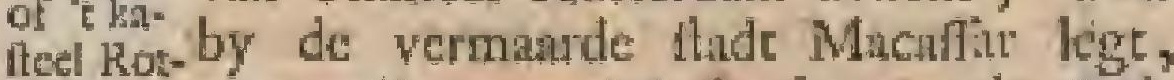
tridmi. win welke, gelyk fncde wan de ftadt Sambotpo, wy untwoerig in "t velvolg Pprelicis.

Bewelten Macafiar 2 mylen wertoonen zich een of twee kleine rifjer, en nog 2 mylen Weltelyker een groot fif, en een onbekent cilind, dat zich wel imylen $Z$. en $\mathrm{N}$. in de lengte, en ontrent $\mathrm{a}$ myl in de breedte $\mathrm{O}$. en $\mathrm{W}$. uitftelit.

Een groote ny] Bcnoorden Macafhar lege de ftidt, of het wlek Tello, de hoof:plats van een koninkryk van dien nam, al wati" sich de wal al tineer the "i $\mathrm{N}$, ten O. dratit.

Beweften Tello, en ten N. yath "t zelve, 2 of 3 mylen verre, vertoonen zich verfcheide reven, terwyl men van deze plats O. anu nict dan fchoone gebergten, ry ftwelden data op, en hice en dasar fware boffchen heeft die zich byna tot de Oofterwal, en tot aan "t Meir Tempe, ontrene Tsjunine ust trekken.

Vyt mylen $N$. N. O. vàn Macafiè

Maros. ontmoer tren de fladt Maros, ten W. wat de wellke (gelyk ook ten $\mathbb{N}$, tufficen de zelve, en Tanetta) zich 2 of 3 mylen buiten de wat reel reven en kleipe ciliardekeus, wel ten getalle van 8 of 9 ftuks, vertoonen, zyide alle onbekent en zonder nanm, uirgenomen een, dat Bewelten Tanettat op cen groot rif legt, dar zich N. O. en Z. W. uitttrekt, en 't geess Spharm Mundi, wattchyelyk thi oen felip, wat dan op werzeily is, gentamt word. Dit Maros is ecn fchoon rysgewelt, war uit de E. Mintichappy alleen wegens hare Thiende van die ryft groote voordeelen heef, die zy door een fergeant, die hicr mer 7 of 8 man in een Pagger leit, doct inzamelcn.

Zes tnylen Benoorden Maros legt de

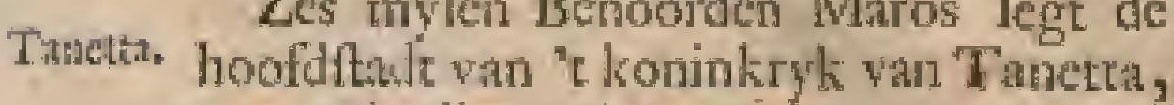
voerende dien zclyen niam.

Hier loopt de wal ter lewgeven I myl N. W., en dan weer $N$. O. nal, matkende datr een grooten en zecr diepen imbogt, die de bogt van Badjoekike ge- namt word. Deze bogt ftrekt zith by Badjoena van Tanetia af tor aan "t land wan kike. Mandar zoodanig uit, dat zy voor aan wel wat na:uw, mal wan binner zeer wydt is, zoo dat 'er wel 100 forcpen in komen leggen, die datr zeer goede anlergrond winden; doch binnen in atan de bukboordswal doet zich een groore lwatte klip boven water op, die den Olifint genalane word.

Vun Taneeci, daar zich cen zeer vermogent koning onthoud, tot Badjoekike, of tot het midden dezer bogt, die wel 7 of 8 mylen Z. en N. whn Tanetta tot an de itadt Mandar in de lengte belluat, Mandar. heet men 4; mylen, en var dala, dhar de wal ua t $\mathbf{N}$. W. draait, lieeft men nog wel byna 6 mylen wan nooden, eer men atan de flede Mandar, de hoofdplatis van cen lconinharyk wan dien zelwen nam, komt. Dit is cen witnemende groote landturcek, en cen koninkryk, dat zich tot asn de bogt van Cajeli, de viterfte grensplates tufichern de kominkryken wan Temate en Macalar, vititrekt.

"T'ot dus perre, en werder niet, gat our bettek wan "te ciland in 't $\mathbf{N}$., hebbende ons gebrage op de zelve breedte man de groote boge wan Boni, die in "t N. hier begint, en die Beoolten de bogt van Budjolike 4 of 5 mylen legt.

Tuffchen Tanetta en 't dorp Badjoe- De Bogt kilie dout zich in "r $O$. min de overwal, van Bont. nat de kant van de groote bogt wan Boni, her koninktyk en des zelfs hoofdftadt Locboe op; danr zich cen zecr magrig Loeboe koning zecr digt by deze boge onthoud, in weike bogt, als atsen wan 't N. 5 of 6 mylen na " $\mathrm{Z}$. afzali, zich een menigte wan reven, newens verfeheide narmlooze cilmdekens vertoonen, wau welke zommige digt an de Wefter- cn andere weer digt ontrent de Oofterwal dezcr bogt, dic in ' $E N$. $f$, doch in "tmidden wel 6 , 7 en 8 mylen wyd, en wel 17 of $18 \mathrm{my}=$ len $\mathrm{Z}$. en $\mathrm{N}$, lang is, gelegen $x y n$.

Elf mylen Bezuiden Lorboo lieef men de ftade Soping, de hoofdplats wan her Soping. koninkryk van dren mam, tulfehen de welke co de ftadt Boni (dic invlen Zuidelyker legr) zieh mede verfcheide reven, en eenige cilandeken zonder mam, vertoonen.

Bezuiden Soping komt men in "t land der Boegineezen, die den koning yan Boni tot opperheer hebbets.

Drie mylen ten $\mathrm{Z}$. W. wan Soping , Meji hecft men, 4 of 5 mylen landwante im, Tempe. 't meit" Tempe, dat eenige mylen in zynen omerek bellate, en uit het welke de rivier van Tsjinrana hinaren oorfipronle heefe, en die van daitr tot aan de boyt van Boni 3 mylen verre ulftoomt, dar $z y$ in zec ftorc.

Een halve myl Zuidelyker, 1 myl 


\section{A C A}

$S \quad S \quad A \quad R$

I 3 T

Tsjintana landwate in van de bogt van Boni, legt de thadt Tsjinana, die wy in 'i werwolg breeder befchryven.

Een myl Zuidelyker lege Boni,de hoofd-

Boni. ftade vin dat koninkryk, diens koning de magtiglte van alle de Celebifehe volfercm, en die engentlyk de koning der Bocgincezen is, var welken wy elders breater fpreken; doch by houd zpu hof gremenelyk op Tsjinina.

Twee en een halwe ayl Zuidel yker legt

Tamoli. Taujoli op de fcherpe Z. O. bock wall deze Wettelyke landitreek wan Celcbes, pas Beoolten welken lrock men het kicin

Boelo- cilandjo Boclocomba hoeft, nier verte

combis van it nanuw of de engte, die tultchen de eilanden Celebes en Saleyer is.

Het is zeer opmerkenswandig, dat wanneer de padi (of rylt in de boliter) op Maros ingeocget word, men dan de zelve op dic eiland Boclocomba certt begint te planten, gelyk men die weder op Maros plant, als men the hicr inzanelt, dhar deze landen nogtans zoo digt by den anderen leggen, zyoude alleen matar door cen bers, die egter niet al te hoog is, van den anderen gelcheiden; even byna gelyk het op de kuften van Choromandel en Malabar mede 700 gelegen is, dar d'eene van diandere kuft matr door "t gebergewan Ballagature watn een gefcheiden, en wat doot hier made diergelyke verandering wall filfoenen is.

Ontrent I myl Bezuiden den Z. O. hoek:

Sateyer. dezer linditicek, of Bezuiden 'Tutioli, zict men 't eiland Saleyer', dar zich Z. cT N. 8 of $g$ mylen in de lengte, $e n$ in 'tmidden ontrene 2 mylen breede, doch tan beide de cinde icherp uitpuilende vertoont, zynde an de W. zyde mee een fmal rifje bezec. Ook ziet men ontrent "t midden des zelfs in ' $t$ W. een halwe myl watn Saleyer nogeen klcin cilind, "r Bajenellatad gename, war by nog ecnige De Bos-klippen bowen water, Zoutelands rotzen geropes gendant, zich vertoonen; behalwen dat men aan ' $\mathrm{t} Z$. einde van Saleyer ook nog z cilhndelens zonder nann, pas Beweften Silleyers Z hoek Z. en N,; ontrent een halwe myl van een, geftrekr leggen ziet; en dan vertoonen "er zich nog. 2 tuffichen Saleyer en Calauro, dat a myl Bezuiden Saleyer legt.

Dit eiland Snleyer flat mede onder de koningen wn Goa of Macaflar, gelyk ik colk geloove tat 't eiland Caluuro, mitsgaders de Tygers - cilanden, cn CambayMa, onder hem al mede thann.

Tulfchen dir eiland Saleyer en Cclebes vertoonen zicli ook 3 kleine cilundekens, de Boegerones genatme, tufthen welke ner gewonn is door te loopers.

Als men 2 mylen voorby de zelwe na it W. is, koms men woor een boai, dic wel 2 mylen $Z$. en $N$. diep, en it myl. bred, en an welkers $\mathbf{N}$, zyde Bonteyn, Bonley: ecn ftadt wan rermak des lionings wan Boni, gelegen is.

Deze Badi madke hier atu de W. kant een breeden hoek, wel van 1 myl; en dan loope men wel 3 of 4 mylen. W. aan, dair weet als cen whkle boti is, eu dur vertonst zich dan een breede hoek met 4 takiken, dic te zamen wel 2 mylen beAlan, el1 \pm mylen N. W. (wint zoo dritit de wall hier) beete men de ltadt of 't wlek Toentte, wan wiat wy begonnen badden, en wan by wy dan dic Wedterdeel van Celebes rond gewandele liebben.

De lnidttreck nu Beooften de Bogt van Boni ftrekt rich Z. en $\mathrm{N}_{\text {. ontrent iz of }}$ I8 mylen in de lengre, en $O$. en $W$. in de breedte ontrent iz mylen in 't $N_{\text {. }}$, wel if of 16 mylen in 'r midden (datr' 't ook met cenen hils of hock wel wan 5 mylen na 'to. loopt) en 8 of ro mylen in 't $Z$. uit, zonder dat wy werder ice van de landen dar op gelegen weten te zeggen ; dan alleen dae mes Benoorden dies hisls in 't midden niet verte van die wal cenige droogten co cilandekens hecte; daur zich ook ecnige witte lsormalftecn wertoone, ten $\mathrm{Z} . \mathrm{O}_{\text {. wh }}$ welke hec eiland Wawoni (dat 4 of $f$ myler in. "t rond is") zich, met cen kortaldroogte een myl Z Wawobi Ooftelyker opdoet.

Everi zoo vertonen zich pas Bezudien dien hats, en ereetyke mylen Zuidelyker; mede verficheide eilandekens en reven tusIchen de eidanden Cambayina, Celebes, en tufichen Pangafine, dat 3 of 4 mivlen Beooften de 0 . hock wan Celeties Z. en N. Pangaraontrent 9 mylen' in de Jengte, en in de breedtc, $O$. en $W$. meet 2 mylen uitgeftrelst, en nict boven I myl of 2 vith 't ciland Boeton, dat zich Beootten 't zelve vertoont, atlegt, en op welleers $\mathrm{N}$. hock men hẹt vel- Tiboroluecte, dar de hootdplants vin dat rylk is.

Ain deZ. kant van Celeber, ontrent. T myl buticen de wal, ziee men 't eiland Caminy. Cambayna, dat 5 of 6 mylen in 't rond na in "t is, en dat cen ciland e pas Beweiten, en verdehict. "er nog en in 't Z. O. even buiten de wal beeft. Wy vertoonen dic in 't verfehiet. by No. 2y. O. cn No. 23, P. ook, liet ciland Solombo, "igecn zicli tufichen Java en Colebes, bymit in 't nidden van die reire, of pas Beweften 'r eiland Lomboc, 7.cer hoog opdoct.

Het cilind Boeton, dat zich nen O. wat 't ciland Pangarane opdoer, is I5 of 16 mylen $Z$, en $N$. lang, en $O$, en $W .3$ of 4. mylen, hacpel aa de Z. bock wet 6 of 7 mylen, doch by de Dwalbail (dic zich pas Benoorden de $Z$. O. hoek vertoont) man 2 of 3 myles breedt.

Pas binnen de Z. W. hoek, zoo als men in de ftratt: van Bocton, tufichen dit eitand en Pingafitie komt, peroont zicle $\mathrm{R}, 2$ "tile- 


\section{B E S C H R Y V I I N G E V v A N}

Boeron. "t fledeken Bocton, ch t myl Noordely" ker heeft men de eerfte engte, die pas myl breed is, dar die wal i bati make, dic $Z$ en $N$. wel $3 \mathrm{f}_{4}$ mylen lang, $\mathrm{cn}$ wat" whik ingebogen is, alwar zich een hooge doch Imalle uithoek, en een Berg na ' $\mathrm{t} W$, vertoont, de Pjek vars Bocton gentame. . Twee noylen Noondely ker legr Scherpenk, 3 mylem Noordelyker de groenc Hock, en nog 3 of 4 mylen Noordelyker Coroni, xyode de laitute plats atan die kant, en die nog wel 3 of 4 movlen van de $\mathrm{N}$. hoek afgelegen is: van de welke tot atn de $\mathrm{N}$, boek vatu de Dwalbaai (dat wel ro of if mylen van cen legt) men gen eene plats ontmoct, dan dar. zich op dien hock de ttadr Coclonglocloe vertoont, hoedanig eene zommigen ook pis binnen de ectite engre der thrat op eenen heuvel platizen, en dair de koning wan Boeton ook zyn hof houd; doch myins oondecls is dit lant lte Coe. longforfoc, "t zelwe met de ftath Boetor, dic rommige zoo, en andere weet Cotlongfoefoe noemen.

De Dwailbani, an de O. zyde van Boeton $11 a$ des zelfs Z hoek gekgen, en ontrent' I. myl Benoorden dien haels beginnende, ftrekt zich wel 5 of 6 myieh

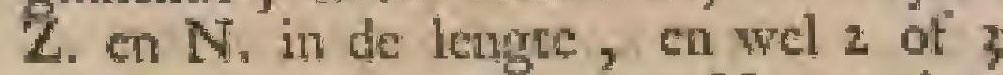
mylen in de breedte; thit. Het verdte, dat var dit ciland te reggen valt, kan men onder de ftoffe war Temate (alzoo 'tonder dien koning tatat, en die koning door den leoning wan Temate gekoten word) breeder zien.

De Toe Beoolten 't eiland Bocton 5 of 6 mylen can-bel's leggen de Toccau-befi 's cilanden, dic 'er wel 8 af 10 in getal zyn, en die ook verfelueide mamen hobben, die men in de Kant wan Ternate uitgodrukt ziet.

Het Noondelylifte word Poelo Wangi Wangi genaant, dat 1 of I mylen in "trond, en op cen rif dus grtggen is, to zamen, met ecnige kleine eilandekens 'cr" op, wel 4 of 4 mylen beltande.

Een toyl Z. Ooftelyker volgt "t cilandje Cayloepr, dat Benonten en Bezuiden een

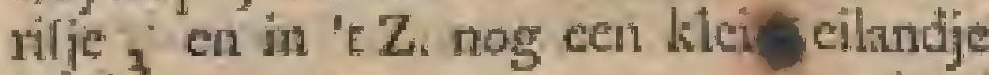
becter.

Een my $Z$. Weftelyker doet zich een rif op dac $N$. W. en $Z$. O. wel 8 of $g$ mylen in de lesigte, en 2 of $;$ mylen in de breedre bellas, hocwel "t in "t N.W. fonaller is; ook wertoonen zich hier en dar eenige kleive cilandekens 'er op.

Teget des aelfs $Z$. O. kant homt een rif, win 2 of $;$ mylen in 'crond, zyonde meel $O$. en W. gettrekt, doch fpits ma 't c r. ujitloopende, tegen welkers $\mathrm{O}$. haek zich "r wiflehers-eiland (dat zeer klein' is) vertoont.

Twee of drie mylen ten 7.0 . Tan treilund Cayloepn, en I myl Benoorden "L Viffehers-cilund, legt Poelo Tamea, dat $\mathbf{z}$ of 3 mylen in "t tond, en ande $Z$. O. kant met een rif is, "dat zich am die zyde wel I myl buiten de wal, en ook nog ecruigzins wat na "tN. $W$, aมn wcderzyden uidtrekt.

Een myl Z. Ooltelyker legt een klein rifice, "Boomkensrif, ch nog I groote myl Z. Ooftelyker nog een grwat rif, de Zandplants - tif gennam, the wet 2 of 3 mylen is 't rond beflat, en dat ontrent 2 mylen Beooften 'c Viffchers eilandje licgt.

Ontrent r mylen ten N, O. wan "t eiland Tamea legren 2 eilandekens, de St. Matrheus eilanden gename, op cean rif, dat ontent I myl in "trond is. $\mathrm{Zy}$ leggen N. W. en Z. O. geftrelit, cen balwe nyl van malkanderen.

Tegende zelwe, of tegen ditt tif, ben ik, ren tyde dat ik de cerftemal uit Amboima na Bataviz in "t foat 1604. vertrok, cens "s nachts ren half twatif, by heldere matuelchyn, zoodanig door de flroom by doodltil weder gedres en, dit ilk een uur dair na de klippen ter $7 y d e$ olb folocepie dindromeda all wry hoog zag uitfelien, 700 din ik nice anders dagt dan diar te vergan. It zal er hicr niet breder wan fpreken, om dar ik dar elders doe.

"Twee of drie naglen ten $Z$. O van de Zandpliats - rit doen zich nog $\mathbf{2}$ cilaradekens op, "t eene "t Veldhoens-cildnd, ch 't ander 't Aapen-ciland, Gename, vats welke 't litalte wel-I my IV. Uofteiyker als "r cerfte lege.

Drie of vier mylen Z. ten 0 wa Poelo Tamer, en 3 mylen ten Z W. van de Zandplats-rif lege Poelo Pinocka, zynde pis 1 myl in "t rond op een rif", dat zich N. W. en 2.0 . ontrene myl werte uititickt.

Zes of zeven mylen Bezuiden Boetons Z. hoek yertoont wich een groot rif, dat meelt N. O. en Z. W. getlrekt legt; zynde wet s mylen lang, en in "t midden 2 mylen breed, doch na beide de cinden finaller.

Een myl Bezuiden dat rif, wel zoo Weitelyk, legt her Hagedis-ciland, dx geen myl in " $\mathrm{L}$ tond is, met nog cen ander, das wat Z. Ualtely ker leot, en Bitalaji genamme is, 'er by, doch Bezuiden het eerlte ziet men nog a kleine cilandekens zonder nam, en $0 . \mathrm{N}$. O. wan dBatalaja o mylen het Groenwoud, ecn eiland, das ontrent mede een myl in st rond is

Alle deze eilanden wordeq de Toecanbefi's, dat is Smids - chilander, genaami, om dat de zee net de minlte wind zoo tterk op de zelwe anabisul, dat het aan yemant, die wan verte dare na toe komt, nice anders toetchyof, dan of hy doar cerige Sunids met lume huners mite 


\section{$M$ A C. A S S A R. 133}

malkanderen op "t ambeeld hoorde klop- is, en i myl Z. Weftclyker "t eiland Baroe petis.

Vyf mylen Beootten "t eilund Saicyer

Cahuro. ziet men hee eiland Nicodenus, dat 2 mylen in "t rond is, grelylk men 6 of 7 mylen Znidelyker een diergelyk eiland heeft, 't Hoog eiland genatme, en pas 1 myl Beoolten "t eiland Calauro (dat 6 mylen lang en, mylen breedt is) gelegen.

Die twee voorgande eilanden behooDe ren mede tot de Tygers=cilanden, dic Trgers- zich ten 0 . van de zelve; of 4 inylen eifinden. vertoonen.

Een groote my 10 . ten Z. van 'te eiknd Nicodemus doet zich 't Harders eilatid op, dat zoer klein if; by oen drickastig rifje, dat "er in "t Z atr walt legt, met nog cen kleinder in " $t O$., cen quatr myl 'er' if.

- Pus Beoalten dat latute rifje legt her Spans eiland, en a myl ten N. W. wan dit Spatans cilard het Rotren-ciland, beide zeer klein, en yder op een klein ritje gelegen zynde.

Een halwe myl Zuidelyker legt het Harten-ciland, dat mede zeer kiein is, ten N. O. who "t welke een halve myl zich een rif wel wan 2 of 3 mylen in 'trond na ' $\mathrm{O} \mathrm{O}$. vertoont.

Een myl ten Z. O. wan " Harten-eiland legt het Slangen-eilund, dat een halve myl in " $\mathrm{t}$ rond is.

Een balwe myl ten Z. W. wan "t Haxten-cilind legt cen droogre, Hiverlum (warlchynelyk na een Jchip, dat dar op gebleven is) geniamt.

$\checkmark$ un th Harten-eiland verder $Z$. ann is "t wel 7 of 8 mylen verte vol reven, en din kome men by drie eilanden, van welke de 2 wat na 't $W . Z$. en $N$. een myl wan een geftrekt leggen, en 't derde legt een groote myl van die twee anderen, hebbende in "t 0 ., een rif dat zicli wel 2 mylęn 0. arn uithrekt. Deze dric eilandekens zyn yder I myl groot, en worden de drie Zuidelyke Tygers-eilanden gennant, cuffchen welke, en 't Harderseiland, nog 4 of 5 andere kleine cilandehens, en ook eenige tewen leggen.

In ver- Dric mylen Beztiulen deze Zuidelyke fohede Tygors-cilanden lege ecn drouge vol ancere hatskoppen, de Heibot genamin, 6 my-

Euraden, les van welke 4 ellanden ty cen, 2 of 3 mylen wan malkaderen leggen, dic alle Schiedan gename worden, zynde mata

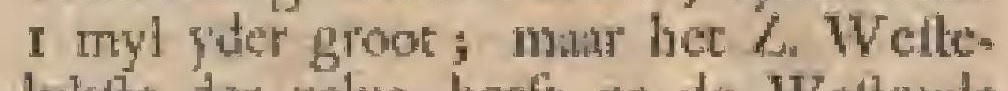
byklte der zelve beeft na de Weltayde een lwatr yif, dat wel 6 of 8 myleu W. aati zich nittrekt, en dat ontrent $2 \mathrm{my}$ len breed is.

Tultuch steze eilanden en de Heilbot als in can driefprong legt o mylen Bezuiden do Heilhot (wel zoo Weftelyk) het ciland Batoe Cariman, dat a myl in 'crond Pandjang, date ontrent $I /$ myl $O$. en $W$. lang, en ! myl breed is.

Vyt mylen ten $Z$. O. wan Batoe Cariman, lege het ciland het Poltpaard, dat zeer klen is, en 4 mylen Z. L. W. wan "t Poltpard zict men 'r ciland Roflagoerot, dat geen myl groot is, en war by nog een groote klip atn de O. katu legt. Vye mylen Z. W. wan Rofigoerot legt "t eilandeken Loelaradja, war na men ain "t land wan Floris (anders " $x$ land wan Ende gentamt) komr, "t geen onder de thoffe wan Banda jeets belcheven is. Het that, nevens de meelte cilanden daar ontrent gelegen, onder de koningen wan Goa (of Macaflar) of onder dic wan Boni.

Wy zoudon hicr nog werlcheide zatien komen byvoegen, die wy nu met opzet vootly gatan, om dar wy in, "t vervolig van dezelve zullen lpreken.

Op 't celand Sumbawa, dat wat Beweften "t land win Ende of Floris legt, heeft men verleheide koningen dis eenig" zins watatlen wan Macatlar in oude tydes plugten te zyn; dach die nu onder d'E. Maatlchappy belıooren, hoedanige die wan Tambora, Domps, enz, zyn.

Na dat wy nu dus verre over dit ciland in "tralgemein gelproken, ex dat in "t korte met de char ontrent leggende cibandea befchrewen hebben, zullen wy poortgann om over andere zaalien, "t zelve in 'tbyzonder rakende, te fpreken.

Up dit groot eiland leggen veel magtige koningryken, van de welke zom. injge onder de Macaftatro koningen (zoo men die in " $\mathrm{rgemeen}$ malar noent, on dat hare ryken mede op het zelve eiland met Macaffar leggen) en eenige onder den koning van "Teruke ftano.

Wat nu de ryken der Macaflarze vorften betreft, die zyn werfeheider, ery Welke weel in getal, te weren, dae wn Boni, Machllar, wau Macalfit, of tu eigentlyk wan Gon, wan Locboe, wan Tello, yan Soping, wan Wadjoc, Tanute, van Layo, Binkiala, Tocnta, Budjing, Pamna, Bacca, Mandhar, darar men- noy de koningen van Bellenipa, Tsjinrana, Binoung, Tampalang, den regent Arwoelijoe woor zyn koningir, de koningin Dain Mamell, de koning vali Majernte, en meer andere vorlien heeft behalveri dat de koninkryken van "Tambon, Dompo, en meer andere ryken, op "c ciland Sumbawa gelegen, dar medo onder gerekent wotden:

Onder den koning wan Ternate futan on welke wlle de koninkryken en landen wande kuft tot Tervan Manado at, tot de bogt van Caicli nate betoe, nader hier na in 't $V$ redens-verbond hooren. tuffelien ons en den Macadiat Art. 17 te zicn.

Wy hebber in "tbreedediar van ondel" R 3

de 


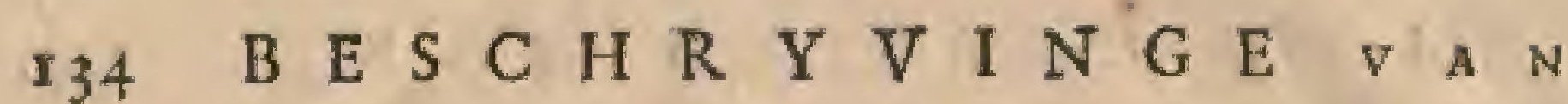

de ftoffe wa Ternate gefproken; doch zullen ter in "t korte hier af zeggen, "t geen. wy oordeelen tot de betchryving var $\mathrm{Cc}$ lebes te behooren, en dat wy menen voor den Lezer ook genoeg te zyn, om 'er een aet denkbeeld at te kirygen.

Als men, in "tN. O., vatin Manado 5 mylen $Z$. W. opgant, konat mien by de bogt wan $A$ moen, die wel r mylen diep iss.

Wanncer men to mylen Weftelyker gat, komt men by "t konisliryk Boelan, war var Boelar de Hoofdplats is.

Bewelten Boelin 4 mylen onmoet men het dorp Auwn, of Aja, wan war nog 17 mylen $W$, op gande, kome men in 't koninkryk wan Caudipun, da in twee hoofddorper, Dauw, en Boelan Itam Bcnaamt, verdect word.

Nog 40 mylen $O$. en $W$, van het dorp Dauw, anders 2 etmanien fcheppens van duar, heet men hee dorp Bwool, of Bool, in cen bogr leggen, van watr nog 20 mylen verder $W$. an zeilende, komt men by de rivier van het magtig dorp Tontoli, dae in cen bogt wol rever lege.

- Nog a mylen Beweften Tontoli heet men het dorp Dondo, dat nict zeer verre van het kounkryk Mandar legt, 'Tgeen onder den koning van Bani behoort, $\mathrm{cn}$ dat door de Mandarezen verwoelt is.

Hicr yan datan kan mejo over land na de boge wan Tomini (aan de overyde leggende) en zoo verder tot Silenfit, en Balaifan komen, welke weg by Dincoeloe en Tolcbugi (twee dorpen, pas I myl van cen in dien grooten binuenboczem leggnde) uhtkomt, matr tot het voleindigen wat welke toge men wel f digen wan nooden heef.

Digt hier by legt eendorp, Dumpelas genatmi, with by ook een rivier, pis I myl var ftrand, is.

In ' $\mathrm{Z} .0 .4$ of 5 mylen landward in van danr legt hee dorp Cool, en agter Balaiftin is ecn groot binnenmeir, en nict verre vin dat het dorp Cotra.

De Welthoek nu wan Tontoli, Caydang gewannt, is ook met cen groot rif bezet.

A Is men nu var Dondo, of wel wan "t cilandje Tomtom, nog i f of 12 mylen verder gaat, koinc men tot Silenlak, Balaifan, en Dimpelis, $;$ dorpen, die nict werte van ees leggen, en rufichen welk Dondo en Dampelas men 4 cilandekens beeft.

Wanmecr men nu nog $\mathrm{I}_{\frac{1}{3}}$ myl $\mathrm{Z}$. WefteIyker, wel zoo Zuideyl, witn de Z. W. kant wan deze hoek, anngat, ziet men weder cen rif, en als meri dan dien hoek even omloopt, komt men by de groote bogt en by "t dorp Cajeli, dair eigentlyk de icheidspali is tuftchen de landen, die de koningen wan Mlaciflar en van Ternate toebehooren.
Wammer men nu alle deze mylen eens te zamen trelit, zal men bevinden, dat van Minnado tot de bogt wa Cajeli een uithtsekking wan 107 of 108 , inylen lands in de lengte (zonder de breedie, die in zeer fwam geberge beftant, te rekeneu) onder den koning wan Ternate Itaat.

Men $z a 1$ ons niet wesren, dic Landen vervolgens hicr weder te belchryven, vermits wy onder de foffe wan Ternite rects alles, tgeen ons bekent is, daar van gezegt hebben, weslualven wy den Lezer met reden dar m toe wyzen, alzoo die Landen ook eigentlyk tot dat $\mathrm{ryk}$ behooren.

Wae nu de ryken onder de koningen war Macafiar angant, wy zullen allics, dac ons vat de zelve bekent is, opgeven.

Om dain weer net en onderlcheiden vin te fpreken, zoo moet men de landen onder deze Vorften, en de landen onder de E. Matichappy ftandc, byzonder aunnerken.

In de oudfte tyden pling 'er matir ect De Ko. opperiort te zyn, onder welken de an- ning wo derc koninkjens, als zyne vafallen, ftonder]. Macallar

Dit is toen den foning wan Mncallin opertgeweelt; dach, deze fin 'r juar 1667, en vori, voor al ten tweedemal i 669 , overwon- word in nen zynde, zyn wy mecter pan "t $z c l w c$ "t jazar geworden; en vernits de E. Mart-door ons fehappy de opperlte en de cerlice bond-orergenoot in rang hier te lande is, zonder wonnen. de welke de Inlandze koningen, hoe magrig ook anderzins in zich zelven, niets mogen onderisemen, gelgk zy ook buiten des Gouverneuts weten nat hume landen miet vertek ken mogen, en op zyn ontbod ook an "t kalteel mocten komen, oin te hooren, wat zyn Ed, hen te zeggen heef, zoo zullen wy eerft van de ftadr Maciffar, en wan it vermogen der E. Matfliappy alhier, fpreken, na dat wy onige zaaken, de koningen in 'Egemein becreffende, zullen hebben liares voor af gunn.

Onder alle de Inlandze koningen zyn die wan Boni en Gon de magtiglte; doch Funtige de koning van Misenfiar, of van Gon, is ne vasonze oudte; hoewel van ouds her een ken. zeer trouwlouze bondgenoot geweelt.

Als "er over cenige ziaken in "t gemein gehandelt zal moeten worden, geet onze Landwogt kennis dar af aan de lronile gen tan Boni, en Gox, win welke dur de ectite de Rylswergadering beroept, en belegr, en waar toc de Landrooge gemeenclyl swee Gevolmagrigden thic zyner Rand wend; zonder welker ken. nis en toeitefnmigng "er nicts in de zclye mag befloten worden; dat in the lintelte jaaren (gelyk men hier ma in "E verthal der Macaffirze zaken zien zalj) juílt zoo net niet magekomen is, 


\section{A C A}

Als deze Vor ften atan "t kalteel, on Eere, die deze Wergadering by te woonen, of wel konipg om ecrige undere reden, verfchynen, van Boni worden zy doot rwee Leden wan den Raad en Got, wan de Heer Landwoogt ingehnalt, doot andoct. een batrilion foldaten in 'c geweer, en onder 't wliegend watndel opgewagt, en by liun vertek met 3 charges der fnapbannen, en ol kanonfichooten wan de velting Rotterdan vereerd. Ool gaat hen de Gouvctnentr zelf tot digt ontrent de puy, of tor in de voorzal, te gemoet.

In oude tyden pligt men 2 ttukken getchur meer woor den koning van Botai te loffer ; doch nu gefchieden "er poot beide evenved fchooren.

- Als cen yan deze twee kouingen komt Gewoon- te fterven, word 't arnittelien wath cen te by ander aier door de E. Matichappy, Fan ech matal" volgess 's lands wetzen gedan, de dezer ko- welke eiffchen, dat die vertiezing door aingell, 7 . Pitos (zynde byna als de Kearworlter in "t Duiteche Ryk, hocwel zoo magtig viet) binnen den tyd van 6 of 7 uuren na 's konings dood (binnen welken tyd hy ook moer begriven zyn'. gefehieden moet, alzoo het ryk nier langen zonder koning zyn mig.

Ook word nict de zoot, matr doorden were gans, ren wayce by wyze wan geweld, leden de troeder (hoewel juift niet atryd, $\mathrm{gc}^{-}$ Vorthies lyk wy zien zullen ) ale wewanger vas den vervangt. overleden vorlt.

Indien hier yemant de dood, of ecn minder Atraf, vendient heefe, iterit hy onder 's reche dezer koningen, dat hen de E. Matichappy wry Jati ; doch ten overtaun vata twee Gecommittecrderi der velve.

Na deze tammerkingen voor af, zullen wy tot de liorte befchryvinge wan $\mathrm{Ma}$ catiat overgatin.

Macafer Macaldar (by de Inlanders in hunto

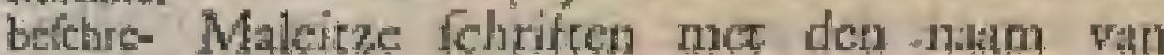
ven - Mantedfa bekene) is een wa de oudite cn magtigfte koninkryken op "E ciland Celcbes, wan 't welke de ftudt Macaftar de hoofdplants is.

In oude tyden plagt men niet als van deze flade, en geen woord wande ftadt, of van "tryk wan Goa, te hooren fpreken; doch wordendeze twee fteden, en ryken, onderfolisiden.

Wat nu het koninkryle wan Macaftar was onds, en nu angant, dat verfechile zoer ved; want wut ouds behoorden dalar de meefte bekende ryken onder, en fehoon men bier en duar deze en gene korwingen had, die fonden al te zamen onder dien Opperwortt vall dat ryk, diar nu de latrden, tot het fyk van "r jegenwoondig Macallit behoorende, eigentlyk onder de Nederlandze Marfehappy ftan. Wat dit voor landeri zyn zallen wy uaderhand breeder zeggen.

\section{S S A R. I}

Wat nu dit ryk, en wel de fadt Mto En in caflar in zich zelwen, angat, zy legr to byzonpas binnen den Z. W' hoel. wa Celcbes, der die doch eigentlyk in 't Wefterdeel wan dit Stadt. ciland, zoo als nern van 't $Z$. na 't $N$. wil getrgatu.

De itadt is mar een open vlek, dat ook anders vel de Negry Vla rdingen getanant word, en wair in men muar een groote ongeplaveide ftmat (zoo meine de Chinesiche) en dan nog 2 of 3 kleine ftriten heeft, want in de Nederlandze Borgers, echige Chinezen, onder hunnen Capitein, en cenige Macalliaren, en sndere Inlanders, woonen, en dic ook afgefloten, : en door de Chineefche en de Borgerwagt bewalkt worden.

De bedienden der E. Maatichappy woonen alle in de weiting; doich de Fiscanl woont buiten; onn te beter xyla ampe te kounen oeffenen.

Men heeft hict verlcheide zeer goede buizen, die cen zeer frat uilzige op de rheode hebben, alzoo men, wannecr men op de rheede bomt, als in ecnen inham inzeild, data men de ltade mo wederzyden leggen heeft, doch de wertooning door Woatr bhostow dast wan gedian, als of tmen in "tNoorden, of ter linker. hand, de velting Oedjong Pandang, doch 't geen gemeenelyk Jocpandaug gena:ame woid, en is "t 7.uiden de verting Pamiat koke Jeggen zier, is gehel en al buiten it fpoor, alzoo die wervolgens zoo langs de kuft jeggen, gelyk wy dic bevoorens befchreven hebber.

Buiten de ftadt gaat men ter regterhand op, wan de lindpoort van Oedjong Pandang, (waar van wy hier ma onder Boni breoder fpreken ) en ter linkerhand opgnande hefe men wed fraje chuinen.

De vefting, Oediong Pandang, of de De Kykhoek, genazme, om dat zy ran de Velting. N. zyde als op der aitkyk wan de buti, Oedjong

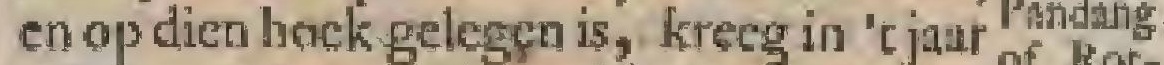
1667. , even na des zells overgave dev terdar. naam van Rotterdati, oin dat de dappere veldhecer en overwinthar van Macaftat, de Heer Cornelis Spelman, een Rotterdammer vin geboorte was.

Van de oudfe tyden af heeft zy onder de kroon van Tello gettan ; doch de koning van Macarfar, groorvader vais Sombantko, of van Iffonodden (dic 't ian. ons overgat) heeft dat, als een onderdrukker, wan-dien konitig, na zich getroklen, on dat het Juem zeer gelegen woorquam, heewel het, wit notar van de koningen van Micaliar, en wan Tello, an ons overgezeren is.

"Het whs te dier" tyd zeer onregehnatidg; en toen wy " $\mathrm{k}$ kegere, Joor' dien het wed geleden lad, zeer vervallen, watrom Wy het ten eerften ook in beter ftat meinden te brengen; doch het wicrt ons, 


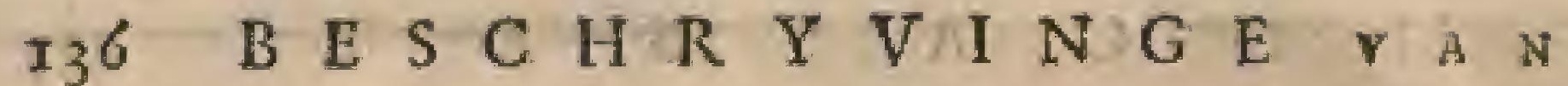

door de wecr opborlende trouwloosheden det Macaffarer, die ten ceriten de wrede braken, en "t beloofde ann ons niet geven wilden, belet, en men heefe' 'er, tot het fluiten pan een andere wrede, den i 5 den Juli I660., medie nocter wagten, wanneer men "s jaars "er ath, dit hoognondig werk hervate, en van tyd tot tyd daar atan gearbeid heefe, tot dat men bet in "t jaa" 1677 in dien Aast, warr in het nu is, volrooid heeft.

En in Wy vertoonen het zelwe by de letrers Prent P. V. zeer net afgeteekent."

vetbecht. Het is fraal groot, en is met of bolwerken, die Mandarsith (of Mandar(aha) Amboina, Batsjan, Boeton, es Boni genant zyn, werterkt, buiten de weike het ook een water- en cen landpoort, en een foott wan cen ravelyn heeft, die in "t jaur 1679 . aan de lanupoort gehege is, na dat 's jitas te wooren de reduit Magdarsjah, die ontrent 2 jo treden Beooften dexe vefting lege, Bezniden het Hoog Pad, dat na Bontewal (cigentlyh Bontuwalac genaant) loops, van vierkante ftenen opgetrokken, en mee een gragt omringt was, hoedanig die $110 \mathrm{~g}$ met cen bezetrigg van i 『crgeans, 2 corporals; I boftchieter of konitzpelsmat, en 3 o of 35 fehildergaften, in wezen is.

In deze vefting woont de Nederlandze Heer Landvoogt wan Macalatr, de $\mathrm{Op}_{\mathrm{p}}$ perkoopman en Tweede vas die I-audvoogdy, de Capitcin, de Predikast, ain de eene $z y d e$, by de Kerk, en de verdere Bedienden ats de Soldybockhouder, Sjahtsandar, Winkeluer an Geheimfetryoer an de andere zyde, hoewel zonity ds wel ientige Bedienden mede buiter woonen. Ook is de Kerk bowen ven gewelf; en beneden hetf men eenige pakhuizen.

Het verdere, dac men wan deze vefting zou konnen zeggen, dkat men in de teckening, uirgedrukt zien, watr by wy niet anders te voegen hebluen, dan dat dezelve geneenelyk zces wol, zoo van geflbut en verder Ammunicie van oorlog, , als, wan ecn. fterke bezetting, vootzicn is, om dat Macaflit root de feutel van de Ooft gehouden word, be halwen dat geen wollieren zoo zeer, dan de Macufturen, te vrezen $z y n$, weshalven daxi tegen goede zorge moet gedrigen worden.

De sudere veltingen ayn, volgeiss het Io Are wam bee: Vredeverbond in 't jarer a669. tufichen ons en deze vorlten gemakt, af fyebroken, cen geflegt.

Op Macatiar is geendrink - of rivierwhice, das al wry vere gehale moes worden; doch'men becte cr overvloedig putwater, dat groed is.

Men heef "er verletheide Baffats en Markten g:- what op orewloed vas rytt

(alzoo dit het regte, en 't felowite ry thland is, dat men wenflien kan' hoenderen, ganen, enden, dinding, of gedrooge hertenvlecteh, en alles zecr overwloedig, verkogt word; maar op de markt der Boegis (onder de koning van Boni ftande) is 't niet zeer pluis ; alzoo then dour ligt een ongemak krygen kin, vin gekrit, of qualyly gehudedt te worden.

Men kan hier in wrede's tyden ecn laft ryit van 3000 pander yonr is of I 6 R $\mathrm{R}$ ers een fehoonen endvogel roor cen dubbeltje, cen groote gans woor een fchelling, een kocbeeft woot 2 of $3 \mathrm{R}^{\text {dés }}$, ca dus ook het yordere zeer goed koop lisygen.

Hier is overvlocd wan wilch, wlecteh, en wildbrand. In cene jagt der koningen worden 'er 2 of 3000 hercen gelyk gepangen, welk vleclch zy in de zon liaten droogen, en dan by Pikols tegen 4,5 of 6 Ruers verkoopen.

Groente is 'er mederedelyk, en men vind "er zelt, hoewel niet overwlocdig, afpergies. Buiten de Hollanders ays hier nu geen andere Europeèrs, hoewel "er in voorige Inwoontyden de Engelzen en Deenen medehurne ders comptoiren gelnd, gelyk ook de Portu-

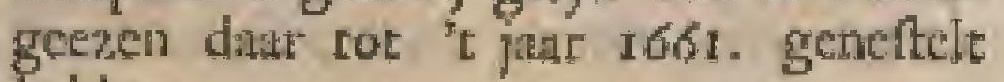
bebben.

Benevens de zelve woonen hier ook Maciflaren, Bocgis, Tocatters, cnz.

Men vind in " $\mathrm{C}$ Oolter geen trotzer, rernuftiger, oorlogskundiger, nog dap* perder volkeren, als de Mitcaltaren, gè woon zynde, als zy ten ootlog treklen (gelyk ik wel gezien, en gehoort hob) al woortrekkende de dappere danden van burne voorouderen op re zingen, on malkanderen tor klocismocdighed op te wekken.

Zy zyn zoo vernuftig, dat zy byma De Maalles, it $2 y$ van Inaphatinew, en arlerici caftarengower, tzy vatu gerchut (dat zy onge- burche neen frail en cierlyk gieten) kruit, cin what dies meer is, zoo wed, als wy zelfs, weten te makkeo; mar' zy tyn ook zeer troa wloos en wratagierig, komende niet den minten hoon of froad angewroken lasten doorgan, zoodat $z y$, in daverny vervallenzynde, ools woor de gevartykifte daven geliouden worden, hoewel $z y$ de Fchanderfte, mooilte, blanille, zedigIte, mocdigite, arbeidzanile, en cerfieriglte zyo, op welke men wel gerult kan wezen, als men hen maar niet hoond, en voor al, als snen (ii) opaige vau de mans) zich wagt, om nice by hunne wyven te loopen, alzoo een Nederlanter, of wie 't zy, diedit doet, al was ly nog zoo groot, met zyn leven fpecld, watr af verfehcide voorbeelden zyn, gelyk 200 de opperkoopman alhier, Pawhs de Bok, na 't just 1678 ., 700 ats hy in zyn ftoep nhet cemige vrienden zat te jraten, door 

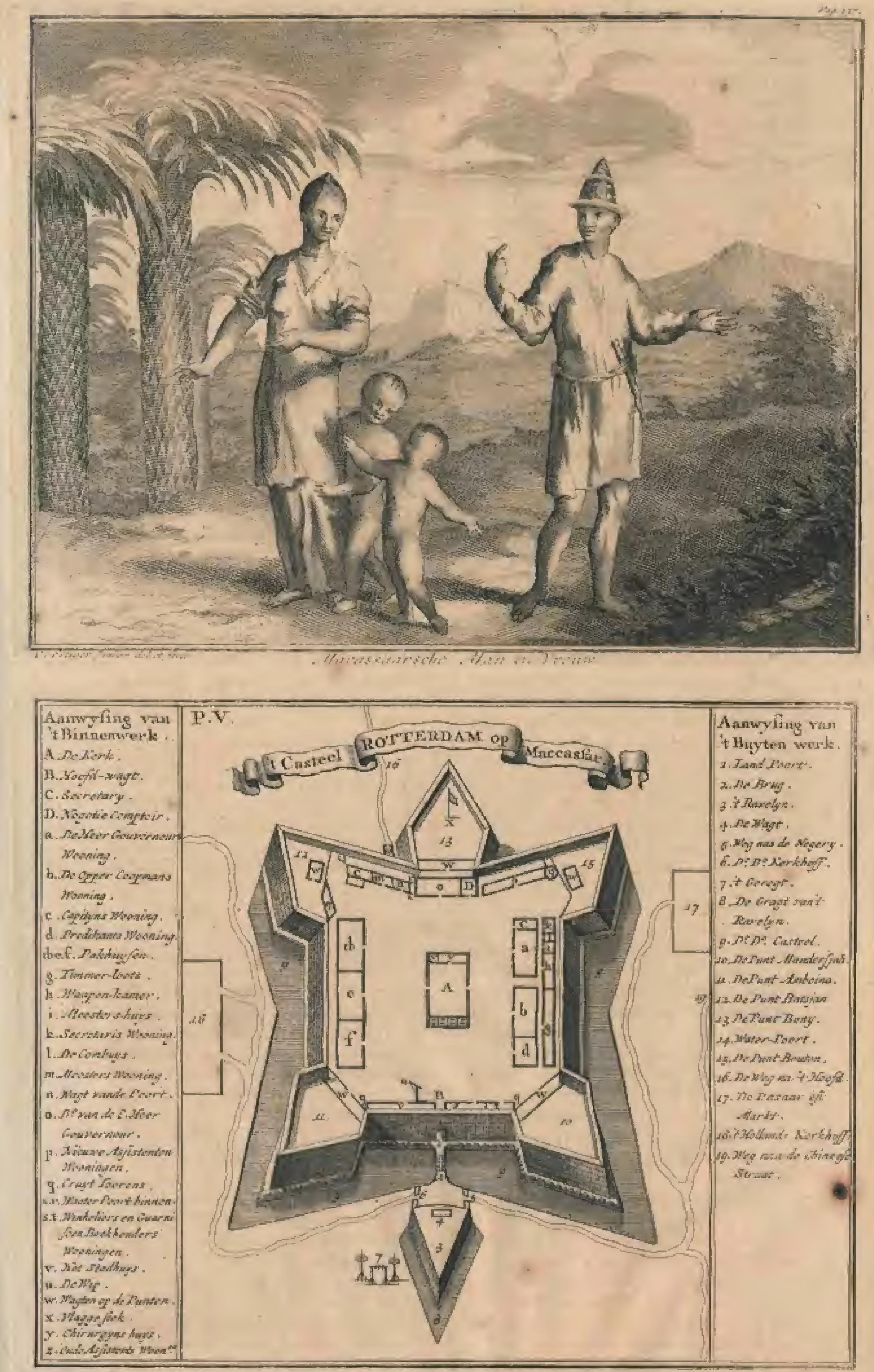
M

A

C

A

S

S A

R.

137

eten van zyne fhavels, by welkers wye lyy 't hich, inee een kis van agteren doorftooten is.

Hunne diagt is byna ots die vatrs de Malcyers, dragende cen badjoe, of een keel, over 'e lyt met een gordel "er am, cn dan nog een boven-badjoc; mat hutu fmal pits oploopend mutsje, met ruirjens, onderfeheid hen merlielyk wan Fidere volkeren op dit land. Ools hect dar mussje onder en boven een breede satnd.

Zy.zyn blank al welgenalkt wan angezige, wat bredt en eenigzins ingebogen พan neus, Iwart en lang wan bair, dar $z y$ gencenelyk opwinden; want als zy dat los fmakken, din is 'teen tecken, dat "er wat gande is.

Zy drigen geen batd, mas trelken dien uit, en gatu gemeenlyk bloots voess.

Een van de grootile cieraaden ftellen

Hone $z y$ in litirne canden te fypen, die git Youwen fwith re houden, of die zoo te makicon, en zommige trekken "er goute kiften, ni de tander gemalk, overbeenen, dut soomamelyk een cientid der groote wouwen hier is.

- Ook heef men onder then allerlei anbagtslieclen, die alles, whe ry ons woor ziendoen, zeer net en kontig weten na te matken.

- De vrouwen zyn door de bati weel fchooner, necter befheden van wezen, en veel blas kel, dar alle andeje fndinanze vrotwen, en ditur zyn 'cr ondes', die al zece nat ant onze Caftiçen komen, en dic men zegged kin fial en fohoon re zyn, watron $z y$ by de metle Hollanders voor alle aintere flatininen gezogt wor:den, te meer, dewyl zy zeer frzai van cogen, mooi, doch wa plat van weten, zeer v riendelyk, Jieftallig, en doorgatiss zeer beleeft ca weh opyevaed zyn, whar doos zalke fmavinen buate juffers en heeren ten eerlten wel weten te believen. Ik lieb 'er gezien, dat 550,200 Rees, en meer woot gegeven was, datar men anders voor 80 of 95 , en ten witerften voof 100

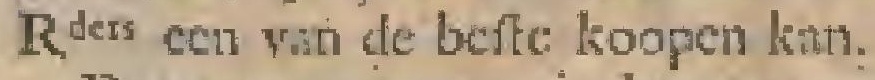

Doze wouwen zyn in hase eygen land ook zeer moedig, entrots, en weter haar furloen zoo wel, als de befle Hollitndze juflrouw, te houden. Zy zyn ook zecr fehrinder cn vernutig in alles, dat ecn jufrous beloost te weten, mitur zy vallen wry wat hoeragtig, wetende zea wel dic gene, dic bara minnitus zyn, en dic daur na by anderen loopers, voor hun ontrouw te flitfen, alzoo zy hen beluendig iess ingeren, watr door $z y$ niet in itiat zyn om ect wouw te beirennen; wan welke zielite, de Mactliarze zickte genams, zy ook yemine ten cerften weten te genezen.

Zy zyn-doosgans, ns zy जatat with

III. D正L,

cenig fat loon zyn, in lyatr land, en el. aler's, zecr net en cierlyk gekleed, hoes wel zy anders meett mar met cen kiled ic orkder, en mee een lange Mateitze lied, of badjoe, dar hen eot wan de lnyen komt, geklecd zyn, ftroopende de mowen wat hoog op, op dat men hare blanke arnen. zich zoll.

Zy dragen gemeenlyk onder hatre kleedjes ecen broek, in platis wan ecn onderklecdje (clas andere Indianstelie vonwen meert drigen) en nemen dic vecliyds rate fraje zyde, of ander ltof, watr ower dan hisa likedje over "t benedernlyt, en dan een badjoe ower "t bovenlyt kont; doch de groone volwen, dritgen 'er cen tsjole, of aniuw hemdrokje, Thet goude tanoopjens (ats de çicrlykite Mifticen, die zy na-apen, gewoon yn) onder, en dan cen lyo betilis badjoe, of half henadje, watr doon ment by niten geheclen opgedrongen bouzem ziet, dat over homen.

Het liain, dat zy in "t rond om hat hookd winden, is geneenlyk, gelyk dat der mannen, pek-twart, en zoo ver en glad met ecnige welriekende olic bettreken, dar hict glimt, wat op zy moedig, * en zeel gezer zyn.

Zy hublyen ook hate cieruden van gonde ringen net getteenten, goude, zilvere, cen andere arminigen, gonde liallen over de thinder, hathe oorciertaden, en mecr andere, gelyk men by de Oolterze volkcren heeft.

Fawe bovenkeedjors, die zy over hane broeken dragen, ryn dikwils tyf vai "c goud. Deze lated zy hier wath hatr eiger volk weren, en tik heb 'er gezien, die $100 \mathrm{R}$ ders, en mect, gelsolt findelen.

De Boegis en 'Tordjit's zyn wolkeren, De Boeonder den koning wan Boni ftande, engis, erri. die mede zeer verntuftig, dipper, moedig, Atrydtratr, trots, moordithadig, en zeer wrankgicrig zyn, gelyk de voorige; doch niet wel zoo blands, als de Micutharen.

Verder becti men hiet ook eenige Chimotzen onder hutnen Capitein, die hica mede zeer veel leven gever, en den handel merkelyk yoortzetten.

Dar wy hien su ouds her gehandele, ons co esen comptoir gehnd hebben, zal hicr Conptor isa broder gezegt worden; doch zedert hiest 't jar I 669 , wanneer wy den troczen Macafliarzen koning chder onze migt, en woor once wapenen buigen deden, is onze Matchappy meefter van deze fadt. en velting geworden, de zetel wan Innnen Landroogt, en it hootd-comptoir geplatit, zonder dat ill weete, dat, buiten de ftade Macintur, eenige andere bedienden, dinn allecn fergeancen, hier of dutu op enige buitenpolten leggen.

De voormamfle reden, watom wy

5

hiter

औरम 


\section{${ }_{13}^{8}$ B E S C H R Y V I N G E Y A N}

hier cenen Landroogt houden, is, om deze koningen, die ons in woorige ayden in Amboinit zect geplatge hebben, in toom te houden, alzoo Macallar de fleutel wan de ganiche Oolt is.

Buiten den Landwoogt heelt men hier ook diergelyke verdere Bedienden, alle zulke Vergaderingen, en diergelyke verdere Regcering, als wy reets in $A_{\mathrm{In}}$ boina, en in andere Latudvoogdyen, of landen, ons toebehoorende, en door "t fward overwonnen, getoont hebben.

En angezien by 'r weroveren wan Mi* culfit, en wan alle deszelfs koningen, verficheide landen onder ons gebleven $z y n$ (gelyli men him na onder de artikelen wan Vrede, itt. XIV, $\mathrm{xx}$ en $\mathrm{XNI}$ tien kiti) too is de E. Mictichappy hict gewoon de thienden dezer Janden, die al try weel, on groot $z y n$, en wall op men zect beerlyke ryltwelden in menigte ziet, te [jekkea, dat al ven groot getal wal Liften is de errfte tyden plagt te matien; mat dat nu, datr van zeer reel rerchild, zedere dat dere en gene Landvoogden, om matr hun eigen beurs (zoo geloowe) te matien, hata Edelheden gersaden Jieblen, zoo wecl fehoone landen ande koningen van Macallat van tyd cot ayd weder te geven.

Wat die Hee roornatimfte, dat hier do LandLind- woogt te docn heeft, is matr, on de vont' ry It, die hant Edelheden wan hict wordelutur tr be- ren, ic verzorgen, hume thienden in te zoigen zamelen, een walkend oog op bet doen hectit. en laten wan de Inlandze lioningen te houder, en yoor al on te beletten, dat "er tuffchen de koningen wa Boni en Gon geen al tc nauw verband komen mag, zoo dat de matregel van Stati hicr de zelve is, als die de Lindvooge in Ternate tuflchen de Molukze vorten te bezorgen cn wat te nemen heeft: want do handel, buten dic van de ryft, is hier van geen groot bolang.

De rylthaidel, en verkomp van dicn, phet, eoen Dan Tabolihe, die veritandige Bonize konjigin, weduwe van Radjo Palacka, nog ieefoc, wit anmerking wan haate dienten wel sin brar allecr geliaten te worden, wath mede dith zekerlyk vecl geld over te wirnen was; doch zedert is dat weder te niet geloopen, en yder brengt zyn ryft zoth mat ter markt.

Schoofie Deze Macatfatrze ryft is zeer wit, Rylt. lieffelyk, engeurig, zoodat hee een luft is, om de zelve te zien, te ecten, cn mati te rieken, nlzoo $\mathrm{zy}$, gekooke op de rafel ftaande, haren greur door een geheel vertrek verfpreid, doch $z y$ word voor zoo duurzam nict, als de Jnvatote, gehouden, wamomzy ook doorgans minder geld.
De wharen, hier getrokken, zyn deze: Waraen Readen van agens.

Verfoheidenerlei klecden.

hiser ye-

Rood koper.

Peper.

Suratze Zeep.

ATi-fatidis, of Duivelsdrele

Yzer.

De watren, hier wallende, ayn dere: of hie: Rytt.

Goud; doch flegt van alloi.

pallicadia,

Vel Sappanhoue, en weing Sandelhout, op Bims.

Kocbeefter.

Patrden, woor al Bimancefche, dat fchoone Telgangers, en Bergklimmers zyn.

De fpeceryen, dic hier en daar zouden mogen vallen, mocten volgens "t versdreg, voor cen gefchenk wan 1500 $\mathrm{R}$ ues juarlyks, untgerocit worden.

Goude en andere koltelyke kleedjens, die de Macaflaren zelf wewen.

Allerki kopere huistaad, die zy maken. Endvogels, Gunzen, Kocjen, Buffels, enz.

De laften wan 't jaar 5700.

beliepen hicr I8912-15-0

En พan "t jutr" to vooren

mar $\mathrm{I} / \$ 327-17=0$

Dus toenmeer, dan $1708, \overline{30784-18-0}$

De winfen en inkomiten

belicpen in "t jas 1709. $63407=1=0$ In 't voorleden jair $52763-17-0$

Endus dit jar t709. meer $10633 \sim 4-0$

Ontrent het land พันก Mineaftar hecft men werfohedde droogten, die ons nu en Droogte dar at cen fehip gekolk hebben, als by ontrent de Walvifch, en de Jecuswin in "c juar I 665 , cr an Zilwerltein geblckicn is, dat op den Bril bleet.

Ontrene 2 mylen Benoorden de fadt De nas Micalfar heeft men de fladt Goa, die mu Goa. ook mati een open vlek is, watr by men niet atleen mede een foort war cen welling heeft, nodat welke by naderhand hecit beginnen te verterken; doch welkers wnilen die koming, yolgens ordre harer Edelheden weet heef moeren af* breken, dat ons bier na nader blyken zant.

In de zelve plagt deze vorfle wan "t jax 1660. at tot 1606 . toe zyn hof te houden, doch wegens gefchilleri, toan eufichen hem en den koning wa Boni roorgerallen, rakte hy 'er uir.

De ftade is mase cen gering open neft, beltande uit cenige flegue Macafliarze huizen, dic gemeenelyk op Atanken, eerige vocten van de gtond, of in de hoogte verhewen, ftan. Men heefe 'er ook ecrige fride gebouwen wan teze ch 


\section{A C A}

gene Grooten en Howelingen, doch voor de relt is 't nier veet.

Over dere ftadt, en 'r lioninkryk wan den zelven natm, heerfela een koning oppermatig. Hoewel de koningskinderen (zynde Macaflataen van koninklyken bloede) jegenwoordig al mede zeer veel in te brengen hebben, gelyk zy zomtyds wel alles daar na hun zin plagten tedrajen. Deze plage in oude tyden opperwatt van "t ciland Celebes te zyn, es [choon de koning van Boni nu magtiger, dan hy, is, zoo is "tegter math redert die gemakte vrede in "t fiat 1669 dat de koning van Gon of Macaftar, volgens het xwit Art, afftund van dit koninkryls der Bocgis, als mede wan dat Fan Loebue, en wan meer andere rylicn, gedano heefi, en dat hy den kosing van Boni van onder zyne magt onthagen, ed hem als een wry konink op zich zelven erkent heeft.

Zyn mage ging niet alleen over deze en gene koningen en landen, op dir ciland gelegen (war van die van Tello, Locboc, Soping, Palacka, Boegis, Toratta, Tonidji, Mandar, Matros, cn de ganlehe liult wan Mailado de voornam fte waren) mati zelfs ook over 'teiInd Zumbawa, of over de ryken van Bima, Tumbora, Dompo, Snngarra, en mee: andere latiden, daar op leggende ; ja relf Aonden de dorpen Patlir en Koethe, of Coeti, plarren op Bonneo, van ouds mede onder dezen magrigen en trarzen vorft; belatvendat hy ook 'c koninktyk vat Bocton voor "t jar 1669. onder zyn geweld gebragt had.

Die nograns de befte licfunifle wan de Macattauze zaaken meinen te hebben, oordeclen, dat de oppermigt van dezen vorft riet bowen de roo javien gedururt heeft; doch wy zullen hier wa toonen, dat deze vorfen al in vecl auder tyden in de fchriften der Malejers bekent zyn, als worften van cen vry groote magt, en die toen hun ryk al vry verder hebben zocken uit te breiden; hoewel ik wel geloover wil, dat by de landen van Mandar niec zecr lang bozeten hedt, dic men wil, dit door den grootwader van Fonitug Smbangho (die in 't jar 1653 . overieden is) cerft verowert zyn.

Ecn tan zyne voom nme vettingen is Sumboe- Sumboepo, met een wlek wan dien zelven po. natm, dat ecnige mylen van Macaftar Jegr. By wat gelogenheid dezc velting zoo genamut en wanneer zy gebouwe zy, zullen wy in 't verhalal der Maçallarze matien onder 't jant 1 f 80. zien. Wy vertownen de zelve hier zeer net in profil by $\mathrm{No}_{0} 22_{\text {. }}$ ch in platie grond by $\mathrm{No}+23$.

Wht migt deze vorft wel eer gehnd heeft, hoc groote vlooten hy na Bocton,
S S A R.

I39

en Amboinn, in oude tyden geronden, en hoe by ons in die Landwoogdy veel jutren an cen geplage heeft, hebbea wy onder de zitaken van Amboina al vertoont, belulwen dat wy darr wan in "cretvolg, om het op zyn plaats mar an te halalet, fprelen zullen.

Noordelyker op, fint de W. kant dezes cilands, is "t koningryk wn Tello gele- Tello. gen, getyle men dalar ook een ftade of wlek var dien zelwen nath zice. Deze itadt, en koning, is al in de cerite tyden bekent, en altyd mede een van de vermogenfte vortten geweelt, met welken in 't jaar 1660 . te gelyk met den koning wan Macafin', of Gon, 't werbond gemankt is.

Nog Noordctyker leggen de landen van Mandir en Maros, watr na men by die konimkrylen en landen komt, die onder den koning yan Ternate behooren.

Aan de Oollkanc des cilands (daar 't lind zich tendele als een bolchagie, en ten decle met zyne vituenyende fehoone ryltwelden tegen 't gebergte ă, cir zelfs rot boven toe and der zelwer toppen zoo vertoont) en lindward in, lieefe men bet koninikryle van Boni, en de ftade wan dicn zelven nam.

Dere koning, nu de magtigfte op dit gelved ciland, is mat vm 'c jar 1667. of ecil weinig te vooren, bekent geworden, gelyk de ecrite vorfk aldaal coen nog miar als Radju Patacka, of koning van Pancki, belient was.

Naderhand heefe hy zich koning wan Bowi Boni docn noemen, gelyl; hy ook in de ftadt Boni (dic, zoo men will, wel 8 . dagen reizens van de ftadt Macafiar lege) gemeenelyls zym hof houd.

Radja Palacke heef dic viek niet allecn zeer verflerth, matr ook in ${ }^{*} \mathrm{t}$, ninkryk Tsjinma (3 dagreizens wan Macallar ) Mandar, enelders, vericheide volkingen gennat, en die wan alles, "t geen dant toe wan nooden was, voorzien. Hy wis de cerlte onder zyn wolk, die zelf Jecrde litsphanen, en allerle ichietgeweer, net, en inmers zoo lehoon als $x y$, te niaken, "c gecon by dar na ook zyn volli leerde, zoo dat dit by hen mu cen gencenc konlt geworden is.

Zyn wapenkaner was waadig om bezicn te worden, alzoo hy in zyn leven in flat was, om 60000 wel gew mannen in karten tyd te weld te bren= gen.

Deze koning van Boni, genegenzynde an 't Isaltecl Roterdam, of by den Hecr Landwooge op Macallar te komen, is gewoon dant af ann den zelven ecrit kennif te geven, om hem met die flatie, en cere, die men gewoon is, in te haslen, by wolk geval hy dan gewoonelylk Bontw? op Bonguwalit, dat cen groote halve walat

$$
52 \text { myl }
$$




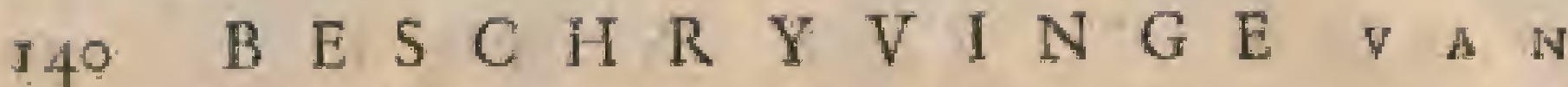

myl wan Maciftur legt, zyn werblye houd. Men gant dat na toc, zoo als men de landpoort derwefting uirgant, en de weg ter regterhund, die wy hoog ch fehoon wan groote ftcenen opgezet is, cn regt tuit loopt, tithluat.

Zyn hoofuplants op Boni is Tclio genatimt, wat ma dezen vorth oole wel Aroe Teko, de koning wan Teko, gename word:

Zyn koninkryk is eigentlyk het land De Eoe- der Bocgis, zynde ecn byzondere Natie krea. op dit eiland, die mede zecr vernafig, en dapper, hoewel door de bank by de Macalituren niet te vergelylen is; doch de dapperhed wan Radiu Palacka beefi, door dien liy met de zymen lang ofder ons gedient, en, zoo op Sumatra, als op Java, verfehetde fwate weldtogten bygewoont, en daar zeer veel gezicn, en geteerd heeft, dit volk veel dipperder en beroender, dan beveotens, gemalkt, zoo dat $x y$ jegenwoordig fohreyeling over die van Gos henen zouden zitten, by aldien wy dezen vorlt dit niet door hooger gezag belecteden.

De woomoende verbly fpluats wan dezen Jeoning, Boneuwalak gename, was wel. eer de verblyfplats pan cenen Crain Gromgrong; een tan de voornamile Macutauze worften, anthezer wan dien koming tegen ons, voor de verovering van dit wolk, en Foor 't maaken wan de vrode. Hy bouwdo te dier ryd dar een zeer frajien fteenen Moorze Tempel, wath mede hy ergter, alioo by yry Hatuw in "t warnemen van zynen Godsdicnlt whas, al zeer lang is bezig geweef, en mat dat zy nl renankt was, verfeheen hy dar weer zelden in, om te Sombthyong, of om zynen Godsdienft whtr te nemen. In nuwolging van dien luecf 'er de koning vin Boeton ook een gemalis ; doch de koning vin Gon heet "er geen.

Tikina Een wan de fralle veltingen wat deze foning is in "t koninkryk won Tsjontia, Schoon Radia Bom hier oppervort wall ganfch Boni, en dus mede wan Tsjinutua (een koninkryk op zich zelven) is, zoo heeft men lier ook een byzonder koning. Voor 'o juar 1677, was hier eenen Daik Hoelo koning, die tocn zyn jyk an zyn oom, Crain Baroworo, overgat, die lang dar na hier geregeert heeft.

Wat nu hee wlek $\mathrm{I}$ sjinrana verder betrefe, men heeft 3, en, ma het gelukt, ook wel f etman wan nooden, on hier te liomen. Men zeild 'er na toc langs de Oollkuft, data men in ' $\mathrm{L}$. O eerit een vlek, Bonteyn geniame, dat al mede onder hem ftark, on dax hy wich ook veel onthoud, wn dar an werfeheide reven ontmoct, om welke men "s nachrs genoodzunter is ten anker te komen, 200 dat men, ect męn in de bai van Pndavg-

Padang gentaken kun, wel 80 mylen, yar Mlacalar tot dars toe, wan nooden heefr. Darar na moet men nog wel cen ctmal landward in te puard ryden, wate na nien aan ecr groot meir komt, over het welke, alzoo het vol riet en liesboleh is, men zonder ecr triaje locke niet ni re wel gesadien kan, en daw hect men nog wel een exhal wan nooden, cer men op Tsjingra kome. In het drooge moctlon lege lact ( 700 nls het zich in de lengte wertoont) ten grooten deele droog, lloewel 'er altyd nog een diepe en bevartbare kreck ofte guil in is, on dat alle de rivieren van "t gebergte daar ontrene zich "er in ontlaften, wht waar alle deze wateren min dit meir weer in de rivier van Tsjinrana ftorten, en dan verder in zoe vallen.

Dit meir, Tempe gtnamt, legt midden in en tuficher her gebergte, en 't gatat dar ook cen weinig' op, ca datr ontient zyn ook zeer fchoone ryftwelden, wial na toc de Veldheer des konings พan Boni, die (grelyk wy hier na zulten zien) in "t jant 1709. of 1710 . met ded prisis var Boni, zynen fehoonzoon, de wugt nam, zich begaf, on dat by verzekert was, dat hy lace dare met zyo volk zor wel zou konnen gande houden; hoewel hy, zoo rits liy vertam, dac de koning wan Boni in dir meir nu en dan met de zynen wiflen quam, ten eeriten hooger op na "e gebergte wedk, dar hy zich zoo verfterkt had, dac hy in thar was, on ecen leger vas zo of 30000 manuen met ltetmen dood te werpen.

Van dir meit nu, of na dat men 'er over gernakt is, mout men, nog wel cen ctmal verte de rivier van Tsjoranih thet een vartuig opfcheppen (zoo dat deze planes ontrent 5 of 6 etmanl ruim van Macaftur legt, als men alles rekenen zou) en dan komt men eerfl an 's konings's konings groote Bamboeze huizen, onder een der huiken welke on boonch, yder als dric kecrels dade. in hunne midelen, than.

Deze buizen zyn buitengencen groot: ch breedt, thee idaken, cu een goot in to midden, en met 70 of 80 digt by een thande trapper, on ser voor op te klimsफen, voorzicil.

In cen wan deze 2 huizen onthond hy zich doorgatns, als hy op "Tsjinrana is, diar hy allerlei nmbagsliedan, *ats goudfinids, zilwerfuids, roumalkers, gefchutgieters, krisıankers, piekmankers, en konlige inleggers der zelve, kruitmankets, keurlyke wevers var koftelyke goude thoffer, en wat dis meer is, by zich lueft, en alleen tot ayn vermalk onderlioud.

De Prineen; en werdere howelingen, onthouden zich in cendorp, dgit outrent gectegur. 


\section{$M \quad A \quad C \quad A \quad S \quad S \quad A \quad R . \quad I+T$}

Hy wott gemeenelyk wan wouwen gedient, hoedunig zich de koning van Goa, cur zeer reel andere Oofterze vorlten, gelyk wy op Java, Bustar, Atsjiten, cnz. miede getpen hebben, ook litaten dicnen.

Het koninklyk merktecken wad onderfeheid tuffehen de andere huizen, it $2 y$ der hovelingen, "t $z y$ der gencene lícten op Tsjinran, is, ditt men een oflentiop, of offerhooitis, san wederbyde wan de Sevel ziet, dat geen onderdan zoll durven nadoen, of voeren, ten wate hy met zyn leven fpelen wijde, alioo dat zou worden opgenomen, als of hy na de kroon, of den vorlt na "t Jeren ftout.

De huizen der princen zyn door twoe klampen, wat op atto wederzyden twee Twatre batiboezen rtufter, dic "er voor gelpykert zyn, wan andere gemeene huizen onderlehclden.

Wamecr nu en dan Gevolmatigden Hoe die van den Hecr Landyoogt nit dien vorlt Gerol- op Tsjintana gezonden worden, is hy miguge gewoon de zelve koninglyk met alles, den der wae hy hecrlyks in zyo ryk heeft, tc T. Mant- wathaten, by hoedinige gevallen hy dar ont-dau ter ecre vat hen wel een hertenjige thalk, andtelt, dair $z y$ op dic tyd troepen wan will roos, 1200 , en meer herten zigen, van welke "er veclen, zoo vetre mei die zien kontie, na de zceloute van Tsjinrana, dar ' $t$ whlk is, gejongt, on tite wellke dnu 60 of 70 ftuks boklicn (want de lihaden verfelioonen zy zoo ved als 'c mogelyk is) door zoo vecl Galerans, Crains, of indere hovelingen, en prineen, zoo lang gejangt, en afgethat worden, tot dat $z y$ woor de planes, dat zich de koning met zyn gezelichap dan in een borchluis onthoud, doodmoede blywen ftan, das yder ridder zyn beeft, dat hy gejange heeft, dan een itrop om den hals werpt, die altyd ano 't paard walt is, op dather hem, weder beliomende, niet ontloopen moge; doch zoo ras die ftrop toegchalt is, werpt zich 't beett op zyde tegen de grond neder.

Uit deze beeften worden aunltonts dan de vetite voor de Hecren Gevolmagtigden, door zekere dar toe medegebrage vrouwen, die een gehecle kombuis, met gercedichap, dian toe noodig, met zich vocren, zcer lekker toebereid, en hen danveel cere en wermats, met alles, wat hy mar bedenken kan, nangedan,

Datar is geen dorp in zyn gebied, dar hy niet diergelyken huis, met cen net thuintje dair agter, en unet de noodige opzieners, heeft, en die ran zoo ecn dotp mocter wel goede zorge dragen, on zulke Gevolgmagrigden, ewen of hy dara rclfs tegenwoordig was, zen wel te onthalen, en was alles, dat $z y$ noodig hebben, rykclyk te voortien, noo

zy, zulks werwatrloozende, niet in zyn uirerfte ongunft rervallen willen.

Als deze worft, of de koning van Goa, cenige gefehenken arr hatr Edellacder zend, en eenige der zelve wan batr Edelheden ontfingt, worden die gemeenelyk met veel ftitic, en niet zonder ettelyke charges, en 3 lianonichoten, die verder tot in toc wel verwolge worden, it de vefting ingehnalt, en by de uittogt, als men die verzend; worden "er " weer 3 charges, en 5 limonflioter, ge-

By "tzenden dezer fchenkagien, van wegen haar Edelheden, word in " $\mathrm{E} g \mathrm{gc}$ meen and de wortt wan Boni, als zynde den oudiften bondgenoot, wat meer, dan ana den koning wan $\mathrm{Goa}$, gezonden. Na de koningen var Boni en Goa volgt De rer-
de koning wan Loeboc, dant na die van dere koTello (bevoorens at by ons angelaalt) ningen. en dari de koningen wan Soping, wan Wadjoc, van Tancte, van Layd, van Bancala, Pana, Bacca, en meer andere, wan welker ryker, alzoo die klem, en ons meedt nog onbekent $\mathrm{zyn}$, ik weinig of niets wa belang wete te zcggen, dan dat zy te zanmen, als onze bondge noorea, door den koning wan Boni by den aniteren getoepen zynde, Leden wan den grooten Rand des cilinds Celebes zyu, war in alle de gemeene Lnudzatken verhandelt worden.

Gelyk nu onder Macaflat ook de ryken Bina: yan Bima, Dompo, Tambora, cuz. op anz en 't cilind Sumbawa, ftatn, alzoo hebben onze Lowy duar ook ennige Logien, of Paggers, gie datr. en pofthouders leggen.

Deze lieden vati Sumbawa zyn niet heel veel te vertrouwen, gelyk men klan verdere gerien heef, wanneer zy in 't jar 1686. byzomtoen wy die arocjelyheden op Jara we-dentedent gens de dood wan de Heer Tak, cnz. wan ' $t$ cjhidden, zich werfouthebben, tegen het sumba Contrace in "t jar' 1677 .gematkt ('t geer wa. hen verbied cenige gezauten wan weemde vorften buiken onze kennis by hen te lataten komen ) ecn brief, cen viig, en eenig water, wan den koning war Blicon, of Radja Sacti (anders bett met den natm van den keizer wan Majugingabo bekent) met cenige gebeden belezen, nict alleen te ontfangen, mant de zelwe ook een otigemeene cere an te doen, hoedanigen bijef dic van Bima wan hem bekomeis, en nevens welken de brenger, Towsidh Bong/o, cen Malcyer, fehimpswyze togen Ridja Tambora gezege hid, dac by, inet de Compagnie zoo gerrouw te blywer, dood krank was, cn nu wel hate, alzoo 'er iets op til was, de geeft geven zoti.

In otwe tyden waren alle de koninkryken op Sumbawa op zich zelven; doch dit eiland naderhand (uitgenomen Tans: 


\section{M A C A S S A A R S C H E}

bort, die den Macaftar o manden tegenftont, doch eindelyk al mede buigen moedt) door den koning vat Micalä overwonnen zymde, zoo geraken zy alle onder en vorit, hoewel die dezclwe niec langer, dan tot jast 't 1667 en 1669. behich, wanneer zy onder de E. Maatfchappy gerakt zyn.

De oude koning yan Tambora heeft cen contrat met ons in "t jart 1677. gemake, doch die worlt is in "t jar 1687 . overleden, en door de hader van den jegenwoordigen koning verwangen." Op Tambona heef nen veel dorpen, te weten, Cndinding, Cutliecloe, Barabon,

Wawo, Lawala, Papocnti, Lalcekat, Salepe, Sakeewy, Lrewong, Waro, Tanga, Sockon, Cutopat, Touwy, Tompo, Calomon, enz.

De num des konings van Tambort in "t jan 1688. was Sultban Ningoneddien, Ablal Bazot, zyn overleden vader was Djawalddicm, en $\mathrm{z} Y \mathrm{n}$ zoon, die hem volgen zal, Abdal Djalid genaamit.

De Grooten en Rykshaden hier worden Djeweli's en "Toerili's, en de grootite Mantri (of Rylisma) word Makandiri Hohnu genamt.

Hier yale weel Sappanhour, Warch, Rylt, Parder, enz.

\section{T W E E D E H O O F D S T U K.}

\section{MACASSAARSCHE ZAAKEN.}

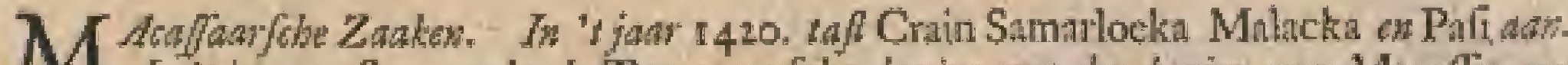

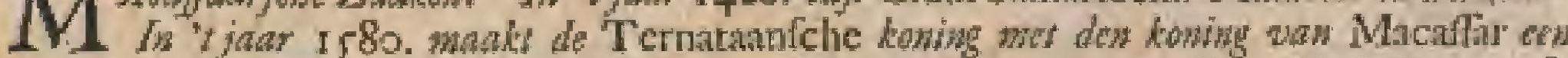
worbond. Redenen wan Samboepo's benawing. De Portugeeten hier al in 't jan 1538 . en Ir 45 . De Deenen bier I632, De onzen konen bier in tjan 16\%7. Matelief, war Solt, en l'Heremite. On Comptoir bier. Hus gefor mit den honing wan Tello.

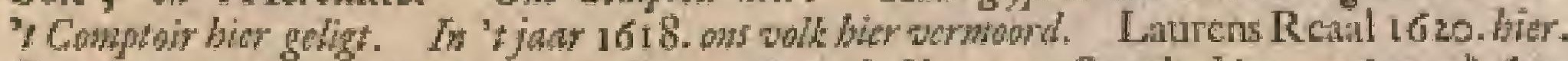

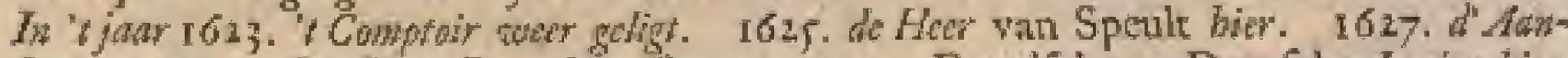
Aat tegen ons. De Her Can bier Gezane 1632. Engreliche ow Decufche Logien bier.

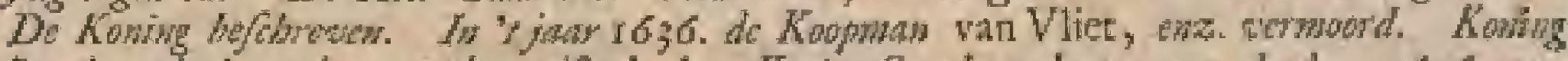
Sombunglto's vader, en des zelfs dod. Koning Sombangko en zy dod. 1646. wan

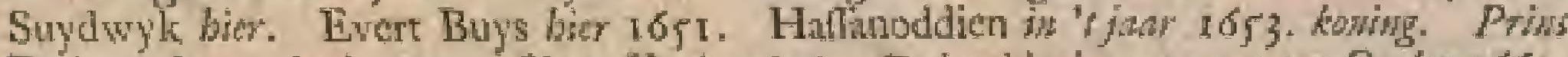
Patinggaleans dood 1654 . Slegre Vrede 1656 . Toubredzelen wan ons tan Oorlog 1660.

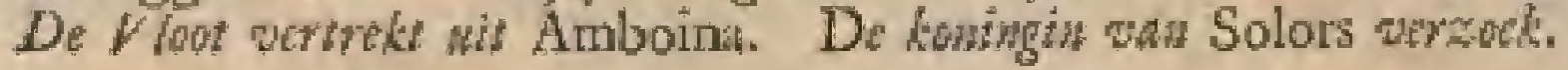

I 4 ?0.<smiles>c1ccccc1</smiles>
At de koningen wan Macafir wan ouds her al bekent, vermogend, en als zoodanige vorften onder In "t jaw de koningen wan "t Ooiten beroemt was IAto. taft ren, blykt ons in 't jatr 1420. dati Grain marlocka Sowarlocke, koping van Macalial', voor Malacka komt, met 200 vitutuigen ma Malacka en Part gande, om dien koning te beoorlogens ath.

doch by wiere door den Lacfarmatu, of Zecroogt des konings wan Malacka zoo dapper angetaft, dat hy genoodziakt was na de ftade Pafi, op it eiland Sumatra, te wyken, alwar hy die ftadt geen theine felacide, door 't verwochen van hature landeryen, tocbragt.

In t $\mathrm{t}$ jar . In 't jaar 1580 . nam de magtige koning I580. wan Ternate, Bad Ullab (dite is de Powt manalkt de Gods) of unders in "t gemeen mar" Bable Terna* genaamt, voor, on met een migtige tankiche genaame, yloot een togt ma "t eiland Celebes te met dendoen, alwari by zich in voorby konink felueppen meefter wah "t eiland Bangry, caffs cer en andere dar ontrent gelegen eilanden, weromd. als mede wan de koninlyylken Tumbosko, Tiboro, en neer landen, makte.

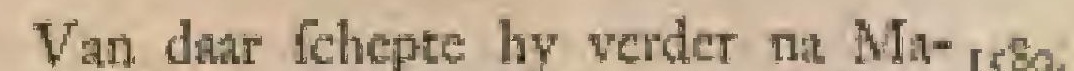
caffar ontrent Tanahkeke, de Zuridhoek van Celebes, dati de koning van Ma* calat , Crain Pating glaw, of unders Crain Caroet, genamit, voor de gevreesde magt dezes konings, dic met zyn wloot zoo na by zyn hootuplats was, verichrite, hen te gemoet voer.

Terwyl nu deze Macafituren an quamen feheppen (of rocjen) zongen zy zeker fchep- of roeilied (onder " $\mathrm{t}$ welke $z y$, volgens zekere nete munflag op de Tifa of Gong, feheppen) war in onder atsdere deze woorden wan Sowhab Oroc, Somblh, dat is, wy enter athere, of, ay eren $u$, o Her koning, nede quamen, nat de beteckenis ran wellse woorden de Ternatanze worlt zyn wolk, angexicn hy de zelve nier weritont, gerragt, en Reden verftan hebbende, wat die beteckenden, boepos en dat $2 y$ enkelyk gerigt wumen, om de beparicerbied en aguing, dic de Mactifaren minge woor hem hadden, te betuigen, bevielen de zelve hem zoo wonder wet, dut hy datr op met dien vortt na Macrfin 


\section{Z A A}

I539. voost gefehept zynde, dur miet alleen een verbond met hem opregte; matr hern naneindde wat verder van das een vefting ontrent de ftrand te bouwen, en die, nat de woonden van dit feheplied, Sombali Uecoe te noemen, war wan met 'er tyd, door verdrajing, en resbuftering, cerft 't woond Somb.h oxpos, en dar na Sambocpo, gegrocit is.

Wat deze worlt hier te dier tyd ontrent de verandering ran den Godsdientt gedatan heeft, zullen wy breeder zeggen, als wy vin deze zanken hicr na in 'tby" zonder fpreken.

Na dezen tyd hebben de Ternatanze koningen al meet vefoweringen op dit eiJand Celebes, en woot at ontrent de diult wan Mando, en "t Noorder deel des zelfs, gedaling wy atr wan de dappere koning van Macalfar hem nu en dam 'teen en 't ander' weder, gelyk anu 't eiland Bocton bleek (dat ook onder bem thont) albanding gemakt beeft, mat at her wellic by in "t fitur 1660 . an dien wort heet moeten weder uftuan, gelyk men dat hicr na is het Viedewerbond, Art. XV. cn XYI. zicr kan.

De Por Van de Europecfoche Natien zyo de tugeczen Portugeezen bier al mede de eerfte, en bier al in al in of ontrent de tyden wan den Ternii jas tranzen Portugeezen Landwoogr Antom 1538. en Gahas, in 'c jan IF 38. en ook ten tyde

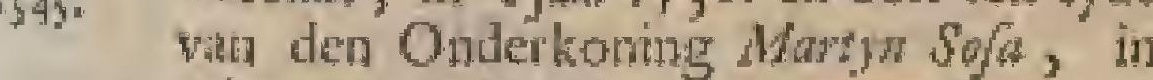

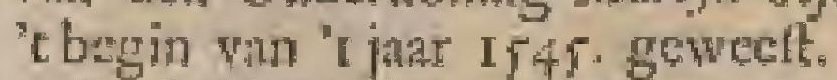

Zy hebben liet een wath comptoir gehad; doch wanneer dit zya begin genotmen heef, blykt-my nergens. Eyter is dit een zekere zatk, gelyk hun hoofd Franciso Wiera, een byzonder ryk nuat, op Macufar ecn recks wa jalren ato cen 2 zon vaft verbly f gchad, en tot "r jar i 601 . behouden heeft, zonder dat ik war hume zalaken iets, dan 't geen ons albier onder' "x jall 1660 . voorkomen zal, te zeggen weet, dat wy op zyn plates in 't vertolg breeder zallen atunhalen.

De Dee- De Deenen hebben hier eenigen tyd sen hiver atan een ook een comptoir gehnd. WithI6j2. Deel zy eerit hici gelsomen, of hoe lang zy bier gebleven zyn, is my onbekent; hoewel ons biyken zal, diat in 't jaur 1632 . by de komlt wan den Hecr Caan, de Heer Roland Carpe als Generat, of algemein Overte, uit nam des konings wan $\mathrm{D}_{\mathrm{c}-}$ nemarker, hier lag, en dat zy toen hier cen Logic, gelyk de Engelzen al ecr "er mede een hadden. Ook is dit zeker, dat hier, nit 't jatr 1660., geen andere wolkeren, dan wy, hebben mogen Jomen, of handelen, "gelyk in bet $\mathrm{Y}^{\prime}$. en vit. Art. van 't woorlz verbond te zien Deconem is. is.

Wonten Wat nu onze konft hier angat, it hier in "t zic, dat de Hecr Cormels Matelsy in 't juar Mareice 1607 . den 2 den Mart allerecrit ontrent
K E N.

143

de Zuidkant van Celebes by 'tdorp Ra-1607: leekt (dut nog wel 7 digen reizens vali Tello, dat verder on de N. lag, gelegen wis) ten anker gekomen is. $7 \mathrm{ym}$ volk fprak eerlt met eenige wiftchers, die hen riet wiften te regt te helper, Datat m, weer te land gevarten zynde, Lpraken zy mer een Orang Kaja, en met en Maleyer, welke laitite ani boord quan, de henj zejden, watr Tello lag. Warr op by van daa", bevindende dat "t land yan Macaflar een fohoon land wis, nat Amboinin is gezeild

Niet lang "et na is de opperkoopman wu Solt Pardus was Solt, in 't zelwe jutr, in ge. con lith-

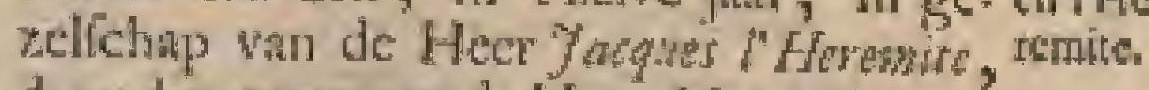
door den zecvoogr de Heer. Matelisf, met het fichjp Medenblik den $4^{\text {ten Mey wit }}$ Amboina macafiar gezonden, dart zy den I5 dem dito op de rheede gekomen 2yt1.

Wy hatdon toen hicr al een foopman Ons van wegen onzes MarfohilpPy, zonder Conptoif dit my blykt, wic, en wancet die hier hict. gelegt, of wanneer dit ons comptoit hice opgerigt is, ook blykt my rice, dat de Engelichen of Deenen toen hier al ect contuptoir fridden.

Deze koppman quam "s namiddags by heth aten boord, en bragt hendien zelwen arond hog aan land, al war zy dien rache in "t huris, "t geen de onzen toen liser al hadden, blever.

Den $16^{\text {ten }}$ dito quan de koring van Tello, vergezelichapt met den koning van Buttergon (dir zal mogelyk de koming van Goa zyth) en cenige howelingen, by hen in ons huis, klagende geweldig aower eenige [chadedie de fehepen yan dw zee* voogr, Cormals Mateliof, art euvige van zythe yratuwen in zee, wauncer hy na Amboina zeilde, toegebigt, en hoe hy wel 4 minnen yan zyo wolk gedood, en 2 prauwen in de grond gefehoten had.

Zy fehikren mer dien koning deze zakk in de bette vouw, in zoo veric, dat hy zich endelyk volkomen dar over bs:tootide voldan te zyn.

Ook gaf de Heer wan Sol an dien worft Hun ge-

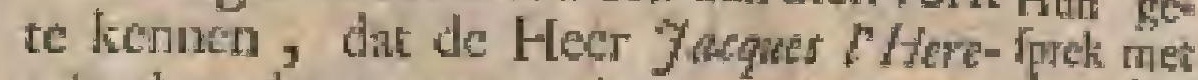
wite door den woolnoemden. zecvoogt uit- dem thodrukhelyk met cen geloofsbriet an hem nims wan gezonden was, welken brief ly zyn Hoogheid ook ter hand lelude, dam by voegende, dat deze Heer lalt had, on nader met zyn Hoogheid ower alles te fpreken.

Hier op belatte hen die vorf, dat $z y$ of dezen avond by hen zouden willea verfchynen, gelyk $2 y$ deden.

Zy given 2yn Hooghrid te kennen, hoe de Heer Mathief wriendelyk, wit man des konings van Djohor, verzogt, dat zyn Hoogheid doch geen rytt ma Malactar geliefuc te zenden, om de Por- 


\section{I44 M A C A S S A A R $S^{*} \mathrm{C}$ H}

t6op tugeczen, orre vymden, te fpyrigen. Hy' wangde hen datr op, of zy voorgenomen hadden, met der ontog tegen de Pontugeren woort te warein, zoo neet, zonder oy hem by de Porengecen zoer gehat maticis, el hem een gerantyken wyand op den hals haten, diar hy anders beft keurde, zyn land voor alle vrecmde Natien open te zetten, en geen zyde te kiezen.

Egter brigten zy het by dezen worft zoo verte, dar ly hen beloafde, van dic far geen oyft na Malackat te zullen zenden, gelyk hy dit anuttonts over al in zyn bud werbieder lier.

Naderlhand is ons egter het tegendecl gebleken, en men ontdekte klar, dat liy dit wel beloofá, doch niet gemeend had, dit de Micafliaren, zoo wel, als de allergrootfe veinzers vat Stat, wcten te doen, es diar in den beften Italiaan niet behoeven te wylken.

Zy quanen, volgens 's konings nader latt, den $17^{\text {den }}$ dito weder voor liem, en wierden deftig met ppyze en drank, op

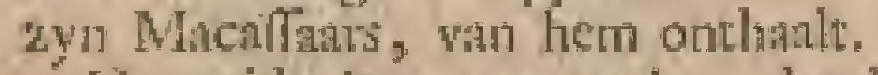

Hy zeide hen toen ook, dat hy de Spantyitarden, die met acen feheepleti yata Tente na Malacka wilden, en die op de eilatrden ontrent Bocton' 't zelve ves" looren haden, voor hinne komft in zyne befclorting getomit, en tan de zelve, op hun verock, ecri praaw gefohonken, en dierhaluen aton hen te verioeken had, dac zy doch hen op zyn rheode nier quatlyk handelen, nog "t regt der zelwe Ichenden, of zyo koninlwyls woord nice bieken wildet, welk billyk rerzoek $x y$ hem geerne inwilligden.

Het wuilfe, dat deze Hecren hier ontdekiten, whs, dat onze Joopman hicr nict alleen met deze Spanjatuden, onze vyander, heulde, (hocwel lyy nu, by

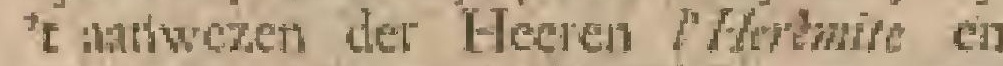
was Sols, hein werboden had, nan zyr huis te tomej) mar zich ook zes" ontronw en lesgengtig in 't werk wath zyme bedicuing gectroctr.

Den $10^{d e n}$ "en zoren dito hebben deze Hecten 38 buhar Fodie, door dezen koopman hice ingekogr, gelader, gewende te gelyk, volgens Jilt van de Hecr Mathof, zyne tekening nan de Heer I"Fremite over, dic, feloon by in de zelve over al zynen bedricgelyken handet klan ontektc, egter den Heor was Sol verzogt, hem in "t nazien vandeze bedricgelyke rekening we willen behtipram zyn, dewyl hy dezen koopman op zeer weel lengens betrapte, ont welke te beter na te peruren, $x y$ te zamen befloten, dat de Heer wim Solt cen togt landware in doen zot na eenige koningen, op welke hy hem gewezen, en die hy hen wysgenatikt bat, dae hen nog veel folvuldig whron.

Dall op dat is de Hect wow Solt 's nta- 1607 . middags, wat 7 norters de Mulder en Yocob yousoos verzeld, landewart in geteden, dair zy 'swonds cerft anyquamen, en dear hy hen op extige fehulden van zeer weinig belang gewesu had; $z y$ fliepen daat dien nache, eyfchende var cenige Portugeczer hee geld, als mete de ryth en foclic, die hy hen, tegen $z y^{*}$ nen eed, geleverd hat.

Den $23^{\text {hen }}$ dito vertrokken $2 y$ na verficheide Inlandze koningen, te weten, die van Cangila, Rocpo, en Mangalyn (platzen, dic ik hicr niet kenne, en dierhalva zolkcrlyle verkewt opgegevan zyn) doch dezelwe zeiden, dat zy der koopman niets fclutcig waaren, en by aldicu het walk in wich zelwen niet goodiatrig en deugdzan geweed was, zouder $z y$ zonder gewate hier riet wan dan geriakt zyn, te meer, dewyl deze koningen miet wiften, wat dic zesgen wilde, dat men her quan manen over een verdigte fehuld, oordeclende, dat hicr wel iot anders, tot nivded wits han land, onder verborgen kon zyn.

- Tegen den donkeren avond quamen $7 \mathrm{y}$ in Samboepo, dar zy weder beune nikchruft namen.

Dangs "er ant manden zy hicr ook alle de fchulden in, die zy al mede niet half 7oo recl, als zy wan den loopman opgegeven wiren, bewonden te zym.

Hy guan den then dito weer in Tello, gat and de Heet ll Itwowitc een net berigt Fan zyne ferrigting op dezen togt, cu feden die tier in getchift, doende verder den koopmin dit alles ondertekenen, en hy wiert dant op als cen bedrieger na boord gebrigt, con hem na 't yaderland te zenden, alwana by zyn doen zou mocten vernowouden.

Ook wient toen dit comptoir, tot "t Compgroote drothecid des fanings, geligt, toit hist zonder hier cer ander in zy plitats te gellgk. leggen, alzoo zy zeer befrant over 'r gedrag was dezen koopman waten. $\mathrm{Zg}$ beloofden egter man dezen loning, dat de Heer Matdiff ten eerlten ecn ander koop* man in platts war dewen aenden zoude.

's Namiddags ontbood déze yortt hen: weer, onthalate hen zeer wel, en bihd hen andermal, dat $z y$ zyo land doch nier. verlaten, mian footgian wildes ons. hier te batuden, hizoo ly foelie win. Banda ontbieden, en dia silleen and hen. leveren you.

Dant op zyn $z y$ den $2 y^{\text {fhen }}$ dito wan Tello nat boord gevanen, daar zy tegen den midalng aanquamen, hebloen ter 2 turea hume ankers geligt, en zyn das na Grefic vontgezelle.

Dit Macalfar had de Heer Mately in Juni dezes jaras ook als de fpyskamer wata Malacka belithreven, rahdende de onzen 


\section{Z A A I E E N:}

46is. verder, on Banda mer 3 feliepen en 200 man voor den Matulfiar in te nenen, mits due dium nictnatne, dan wy, fpeceryen zouden mogen laten; en dat wy bem alle de selue tegen een vafte prys zotoden afremen.

Den zoten Augultus licp het tetip de fwarte Lecus, win Amboinin nantam vertrokken zyde, op Mncaltar on ryltann.

In December ging "t felip Gelderland ria Micalfar ook om rytt, on met cest gedoelte wan dien Ambonn te Eyrigen, en het verdere in Ternate te brengen.

Of wy nt indezen tuffehen-tyd weet cen comptoir hicr opgeregt hebben, weet if niet; doch "t tchyne my als een zekere ziak, dat zulks gefchicd is, alzoo do bedriegelyke koning vin Macathar al ons In s jast wolk hier in " jun 1618 . heeft doen doodIfrs. ons latan, en onze Logie afloopen; weshal-

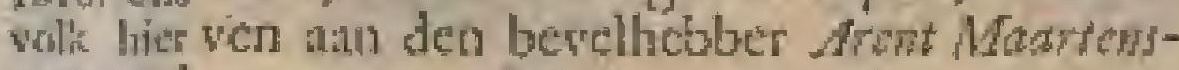
wemoond zoos toen ooli lift gegeren is, om met 3 fehepen, na de Ooll gande, ten ectften op Macalfir an te lopen, en deze mootd te wrecken.

In dit zelwe jiar den $13^{\text {dea }}$ December reluteren de Heeren xittuen, dat 't Iehip den Orizont wir Denemarken sai Indien gezcilt, endat hat voornemen was 'er in "t kore nog + to laten volgen; wharfchymelyk, om hum comptair hier, en elders, datr mede te verlterken.

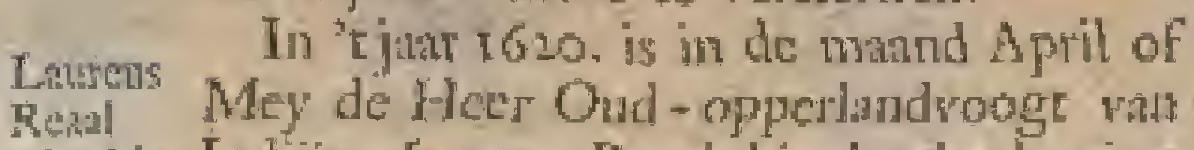

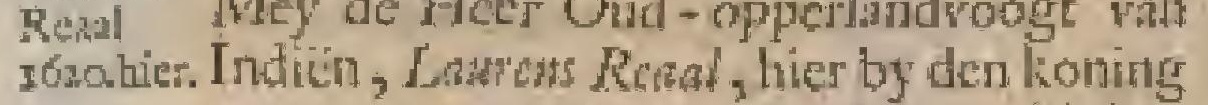
weer atigeweelt, zouder dat my blykt, dat 'er ict vyandelyls som'gevallen is.

" Comp la 't jaar 1623 . gaven de Hecreo xvinen wir weer laft dir comptoir te ligten, zoo dit wy seligir toen al weder cenige bedienden, die hier lager, gehad hebben.

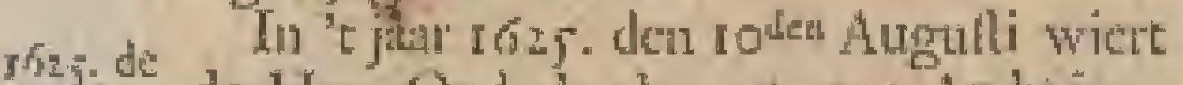
Heer wan de Hecr Oud - landwoogt van Amboina,

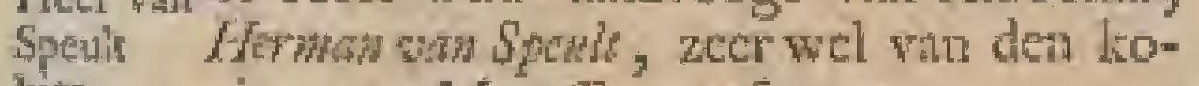
luer. ning vitn Macartir ontfangen.

Engelecthe In dit zelve jar den 18 dea September en Deen-hidden de Engelzen hier ook cen comptoir Tethe Lo en liar Opperthoofd wis tocin ecren Mr. gien hier siont.

De Logic der Engelzen hecfe mas cen musquetlichoot Benoorden 't kalted Oedjong Pandang gettati.

T61.7. In "t jull I627. ontdekte men, dat "er Anidag tuftehendezen koning en den kaning vin tegenons Tidore cen atrig ag tegen ons whs.

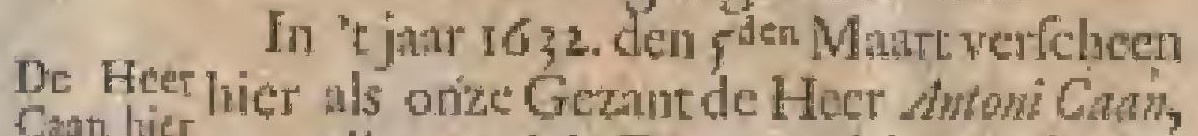
Gutuant op welken tyd de Decticn, hier mede ecn

so:33. comptoir en Jogie hudden, gelyk zich allbier van wegen den koning ran Denematken de Heer Rociand Carpe (die in "I jatr i 23 . al op den 14 ten October by

ade Naritaze vloot verfelecen ) als General en Overfte wan zyo Natic met 2 tchepen onthiclt.

I I I. DEEL.

Het was te dier tyd tuffelsen ons en de 16 in $^{2}$ - to Macenfataren, wegens den hirdel der $N_{\text {in- }}$ geten in Ambotna, niet helder.

Na dat deze Gozant al zyn gefchut geloft lad, de wittevlag lict watjen, en na dat by een uur op de reede geweelt was; quanuen "cl a Princen, en 6 of 7 Hoyclingen, met een gelehenk an boord, on hem re verwelkomen.

Zy wierden ran zyn Ed. zeer wel onst hatt, warl op hy tegen den avond mee 8 pafoonen tha land voer, lantende de gemelde Princen zoo lang als gyzelares witn boord.

Zoo ris lay tan land quan, wiend $z y n$ Ed. zeer belect van den woomoenden Hecr Gatpe anhalt, gelyk onte 40 gevangenen uit Mneno, en 2 uir Malackin zoo litng in de Decilalche Logie geweefl waren, on hier nu an zyu Ed, na een gevankeris wan 15 manden, dic $z y$ in Chisa in lecteneda tingeterat badden, overgelevert, en in wryheid volgens 't gemake werdrag geftelt te worden.

Nog dienzelven wond wiere zyn Fd, in "s konngs patcis gebngt, dat exn fchoon groot, byzonder konftig gefneders en "f geen verguld gebouw van hour wats: heerlyk op 46 hooge piluaren ftonc, dic wel 3 valch hoog waren.

Hy volt den koning op een yeen holtelyke nant, met 2 of 3 hutwcele leunkufens hgtel zich, zirten, zynde wan errelyke honderd perfoonen verzeld, ten decle howelinger, tchidecle dienatrs, doch alle met krifien op zyde, welker getelten of hnndyateen zommige van goud, andere vin ivoir, en zommige zeer konltig gefncden, of gewroge waren. Ook zaten "er 20 of 22 wan zyne bywyven natalt hem, die niet anders deden, dan them geduurig taibak en pinang te gever.

Zy zaren alle, als de [uyders met de beenen ondej" "r lyf, op eet wloce van gefpletenc bamboczen, diestoorlugtig was, zoo dat "cr geets vuiligheid op kon biysen leggen.

De toning, cen dik fwastlyvig mat, $\mathrm{De}$ Ko: jo of 60 jagren ond, en ghd van bind, ne hing

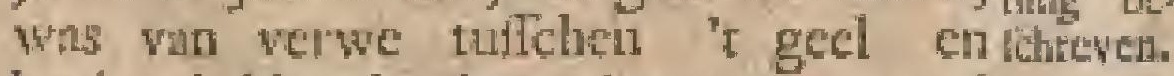
lyuin, hebbende nicts, din een met goud doorwroge kledjen om zyr benedenJyt, terwyl zyn bovenlyt bloot, cn zyn hoofd met een wit mutsje bedelet whts. Ools wis ly zeer vriendelyk en minzam wan talal, zoo teren ders Heer Coran, en den Heer Cante, uls tegen anderen dic dagr tegenwoordig waren; en zy wierden net tabal , pinang, jonge klippusiooten, couz. onthatr.

$\mathrm{N}_{a}$ dat ly met den koning over deze en gene tatuken gulproken, en dangs 'er atn onze gevangencon mán regen mian tegen die der Portugeezen, die onder ons waren, nitgewifleld bad, is hy hicr want dith tha "cciland Bocton gezcilt. 


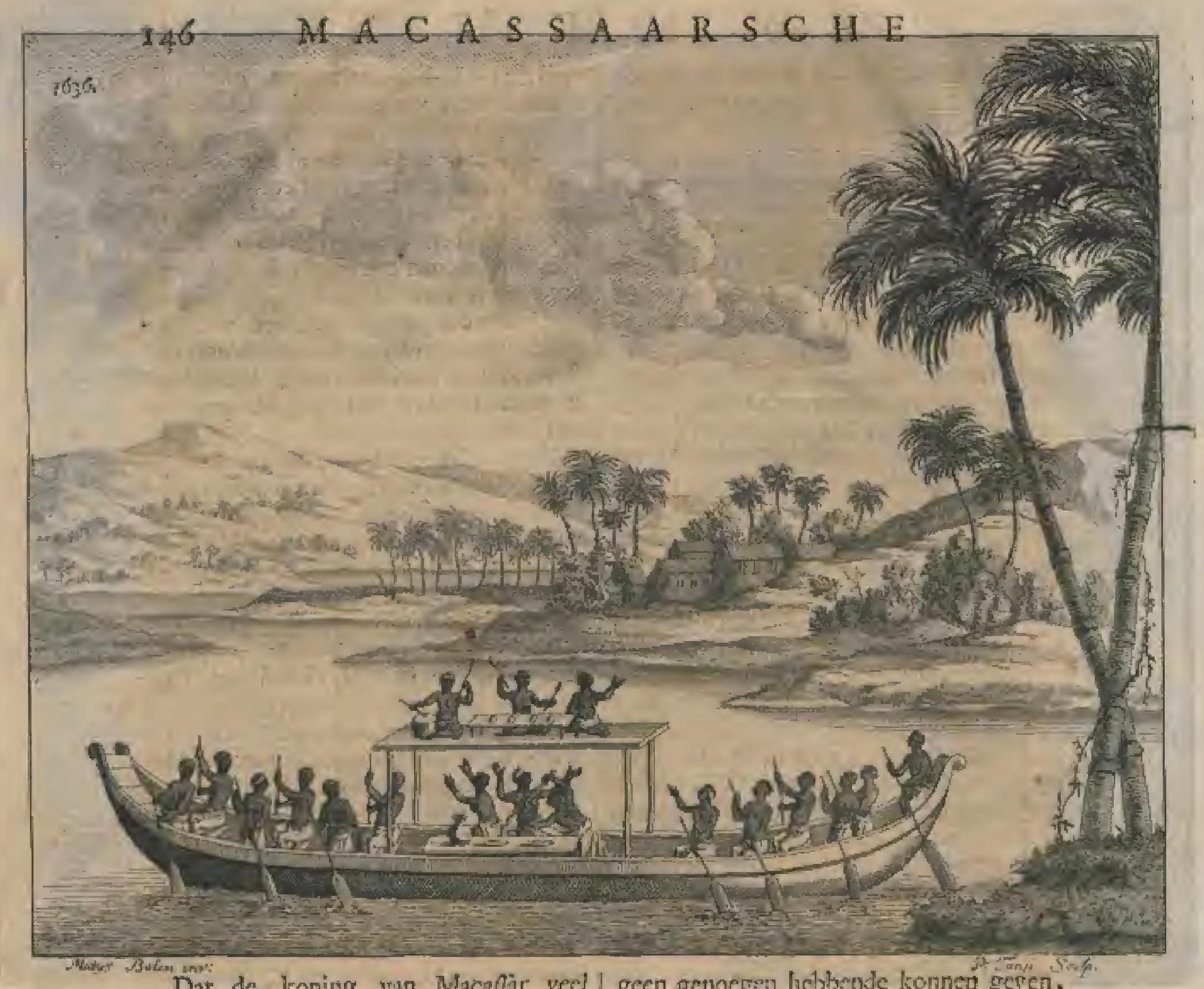

Dat de lroning viln Mlacafor veel phatzen van den koning van Terrate op Celebes verovert, en in 't jast I6 34 " ingenomen heef, hebben wy onder dat frar in de llofte van Tenate al geroont.

In "tjaar In 't laxte wan ' $\mathrm{c}$ jarr 1635 , of in 't be1636. de gin wat "c jaur 16j6. was onze koopunat lioop- wan Fliet hiter met 4 of $r$ Nederlanders

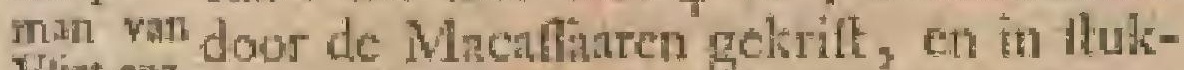
Vhert, enzi ken gehukt, en op Boeton was de on-

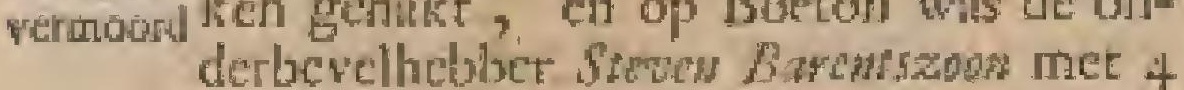
of i Hollanders doodgelagen, dat door den bevelhebber Pool an cenige Boctonders, die in zyo fchip door zekere lift gelokt waren, en dic hy wan gelyken dede ombrengen, ten decle gewroken wiert.

In 't jur 1637 . makke de Heer vow Disan ther dezen konims weer cen nieuw verbond.

"t Jiar char wan verlchecen in Banda voot den Hecr Opperbindwoogt waw Dimen, het Engets Hoofd op Macaftit, $M_{r}$ John Hwher, on Poelo Rhun weer in bexit te nemen, cen klarar teeleen, dat zy toen nog een Logic op Celcbes hadden.

Koning Oncrent dezen tyd regecte hicr een Son- magrig Koning, die niet lang bevoorens banglo's de landen van Mandar en Maros had zoc-

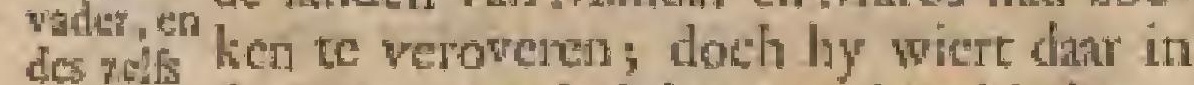
doot. door een wonderlyk voorval verhindert.

Al zyne wyen en fraije byzitsen hem

geen genoegen liebbende konner geren, om zyn vule en verteerde lusten te matigen, zoo had foy tot zyn ongeluk zyn oog op een wan de wryen zyner Hovelingen lasen wallen, en de zelve ool: 11 k zyn hof laten yocret. Haar nom, doodelyle hier over geraalit, en nant golegenheid zockende, om zich anj den koning te wrecken, krecy datr toe de fehoonlte, die ly watchen kon, alzoo de koning net zy siicuwe meelteres, dic hy eerig byzonder verninak wilde athdoen, ergens ltont wit vifchen te gads. Deze gebounde man, wich behendig. onder de yedante ran ecn rocjer, of rchepper, mede in dat viartuig begeven hebbende, nam, zoo ras zy wat wan land waven, zyn flag zcer wel watr, ging in de tent, en teak hem met zyne verborgene kris mee is of 6 theken onder de voet, en fprong toen in zee, zonder dat men hens geleregen, of oit met van hen gehoort becf; doch zym gantch gefligt, en alle zync nuatbeftiander, wicrden hier over in zicdend water elen. dig an hus einde gebrage, on mnderen ecn affichule van zulken konings - moord te gevert.

Hy liet twee zoonen ma, Cresas Som- Kon!9 bongk, ci Crom Whblla, wan welke de Sumprins Sombangle, nu zz jutren oud, op tongko pyns vaders bhoon fterg: " . dood 


\section{Z A A K E N N . T}

1645. Het corfe dat hy dede, wats, dat hy die van Mindar, de Boeginecen, en meer andere Celebize wolkeren, atu zyne heerlehappy onderwiesp. Hy had ap den zelwer tyd ook de Totaljers wel lonnei overwinnen (wolkeren byna onder den Evenas gelegen) dech vermits lyy zieh, even als zyn vader, te reel atu zync weilithen net zyne wyven overgaf, bleef dic iguer weeg.

Hy is in "rjar 16 t2 of 16,3 . averleden, en zyn toon Hhforodith, tegens de gewoonte, in zyn plats gekomen,

alzoo anders zyn broeder Gram Mablia hem moeft gevolgt heblen.

Onder koning Sombagke heeft van 1546. war wegen onze Maatelutppy de opperkoopSuydwgt min, yoban wimn Snydquk, hier als Hootd hier. gelegen, the in 'c juir 1646. in Amboiria verchenen is.

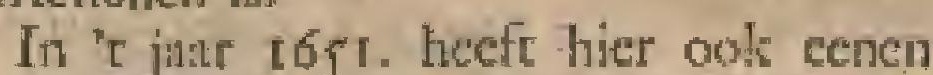
Frent Evon Bajs, koopmin, als ons Hoofd tot

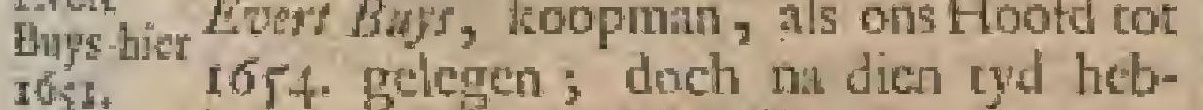
I0j. ben wy net de Mocaltarea, voornilmelyk in Amboirn, in koning Sombangke's tyd, en onder den prins Poring galons nils lRyksbeftierder allier, veel noeite gehad, geisk in "tbrede onder de ftoffe wam Amboina getoont is, een fpel, thit Fiafo- $n$ koning Sonbonglo's cyd wan dei ko-

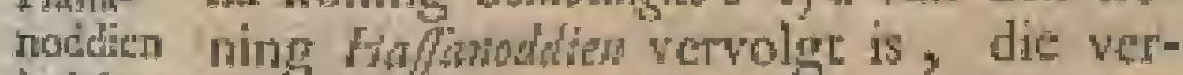
in 'tjatr fcheide wlooten na Boero, onder' zyuc

1653. ko- weldheerco Dain Bodean, en Gran Boe-

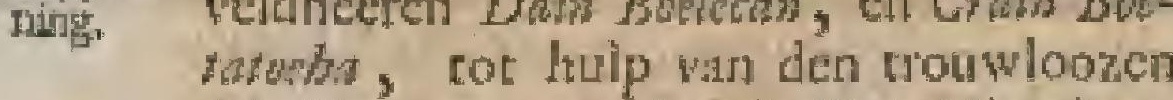
Mallira, en van de afwillige Hitocézen in Amboina, gezonden hect.

De grootite bettiender van alle deze zanken was de prins Patrgotom, ecn vorth, die in verfcheide tialen, en zelf to de Latyniche, zeer crvaren was. $\mathrm{Hy}$ had ook kennis van veel konften, en won "t behandelen der Globen, gelyle de Hecren Bewindhebberen hein cen heeslyke arajkloot vin lioper gezonden hebben; watr op de Hecr Jouf ran den Fondel (bem Panagowlo noemende) dit gedicht, Pag. 582: in zyn Mengeldichen te zien, gemaakt beft:

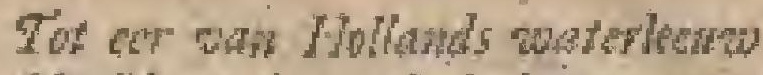

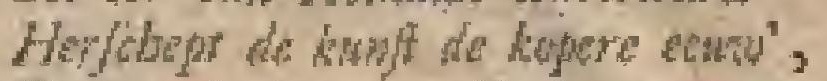

Eca rowde dater con kiake wom,

En Pallas, wel in foriswen sou.

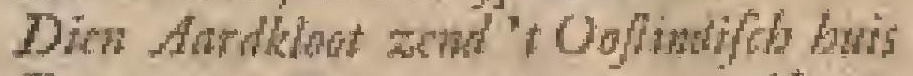

Den grooren P A N T A GOU LE ThWis,

Wen aldourhuffelonde bein,

Ien ganflo wereld od te klorm.

Men wenche dat zyn forter wh,

Bergike decho en diandere as,

En cer bet Aten wan de tyd

Dit koper han ons wiewdlohap fot".

Alle deze roor ons langer ondrigelyke bedrywen wan den koning wan Maculfar fchenen onder dea nicuwen koung Hot- froddin, en voor al na de dood van den ruso fchranderen prins Patingrabosn (die sam

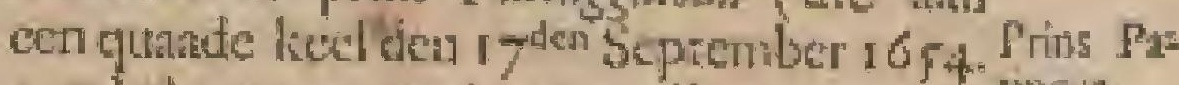
operleden was, en met wellien wy over thest-

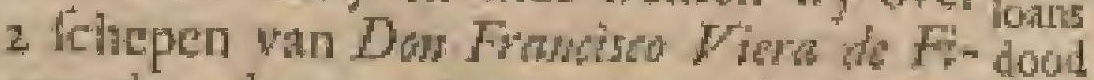

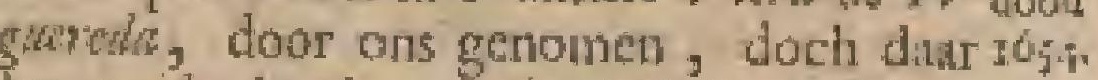
hy en de koning mede decl in hadden, groote mocite hadden gekregen) cen einde te zullen nemen, gelyk 'ol ook eindelyk in ' $\mathrm{c}$ jar $16 g 6$ een $V_{\text {rede, }}$ by den Heer

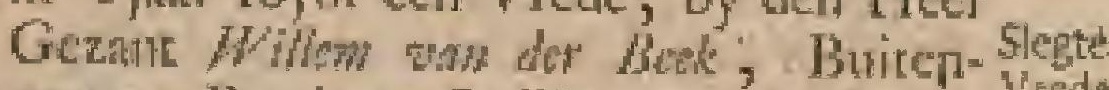
gencen Raud van Inditu, en oud Land wede vooge wan Amboinal mee den liorjing wata Macuftar angegan, op quam tc volgen, how wel $z y$ voor der Macuifar reel te woordeclig, en ganteh niter van de froank wan dew weldher se Vhanis in A mboina, was, te meci, altoomen toegeltuth had, hem alle zyne gevatigens, in een tyd, dat wy in Amboiln, en elders, ovet hetr zegepralden, weder over te leveren. Ook wiet dit zoo gualyk genomen, diec hy dasi op wan zyne bedieningen ( $z_{0}$, niec beter wete ) van Buitengemeen Ratd ent Mijoor atgeter wiert.

Ook was ian de Mnenfataren by deze Wrede luetwanen op de cilanden van Goram, Ceramelatoct, en Coram (daw egter zoo veel sha gelegen ha ) biet cens verboden, gelyk 'er leot nade getroffene vrede, z Macaflarze welgernande viajtuiger op Cemm - Janet overgekonen warein, war over mon. ljem nu hiet antiTpreken, nog dit verbieden lion.

Aldus wis deze vrede dan mate cen goede delinantel, on ons fut vecl meer, dan bevorens, te plagen, gelyk hy zulk's niet naliet, date by man cenigzins kon, dat cindelyk zoo hoog liep, dat wy de trotwwlonze behandelingen pan dezen croten en hoognnoedigen vort nier langer konnende, nog willende dulden, hasr Edelheden op Bativia goedvonden dexen oorlogszugtigen koning eens door de wapenen tot reden te brengen.

Zy zonden dierhalven, on geen rehyn Toebetér wereld van dezen toeleg te geven, een readmen fraje vloot in der ftilce na Amboina, va ors om aldan by den anderen te verzamelen, ten Dot

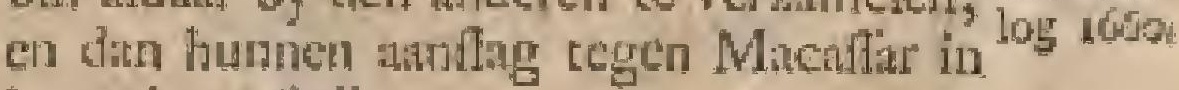
"t werl: te dellen.

Na dat nu alles hier toe gefchilit was, vond men in A toboing goed, in alle de geweften, en op alle des zelds butencomptoiten, een algemeenen en plegtelyken Vaft- en Rededig te houden, on den zegen des Heeren over deze onderneming op het ootmoediglte af te bidden.

Daar na wierden de Heren johom wa Dow, en Yoban Trwyman als Opperhoofden vast deze vloot, doon" de Heer 'wowob Hof a or, Landwoogt alhier, woorgettelt, walr an ay alle onder cede verbonder, en wath na alle ftuken wan de velting Victorit in "E rond afgetchoten wierden.

$$
\text { T } 2
$$


t66o:- As nu alles dis verre klar gemake en yder ia zyn boord geordonneert was, liepen de gredagten vali dexe en gene herwatts en derwatrts, overwegende whit na toe doch wol dea toeleg zoude mogen wezen, en wie bet zou mogen folden.

Zommige lpralsca yan Solor en Timor, en was de Portugeezen alduar, te meer, alzon "t telap Atnemuiden derwants woor af gezonden wicre, hoowel dit inat dicmde, om hen, alsome vriender, re wath= fchouwen, dat wy hen niet mender, en dat zy dienalven niets to wreezen hadden?.

De woot Men verliet dar op in Mley I600, the werteke ciland Amboin, en de Opperlootden vit Alt- vercrokket val datr met een vloot van boint, 22 fcheper, 3 gatjoots, cu 8 chalocpen,

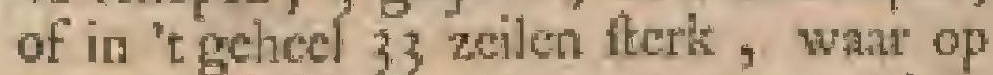
24 vaandels bianke koppen, tot fo yder, en 400 koppen wan de lnisuders, mecht Anboideren, wancer, alle welke met her verdere feheepswolk ontent $2790 \mathrm{~mm}$ uitmatkten.

Men fchokte met de zelwe vontby het hemellhoog gebergte wan Bocro, cn mecr andere cilinden, woort, tot dit men bet kiein cilandje Batatarm, en dam na de hooge bergen wan de cilanden Lombatte cu Serbite, in 'toog kreeg, alwar' nu de Opperbootden geraaden wonden, aan de wertere foliecpshooften, kennis te geven, watr ta toe de toge aangelegt, en dat het op Macaltar genunt wrs, doch dat men de vloot cert ecrige digen an de eilanden Serbite en Solor zou lasten ververiclsen, on dan na Macallat over te fteken, cen tal, die zommige bevressde volkeren in deze vloot wonderlyk in de oores klonti, zoo dat zy wel wenfehten in Amboina geblewen te $z y n$.

Men Jiep tuffehen Lombritte en Serbite mer cen holle zee, en cen lterke ttroom, woorby den brandenden hoogen berg op te6e. 't certe cilund, dont de engre fan Lotnbatte henen, tot dat de vhoot, nimt zonder gevalar, alizoo de grond niet heel goed was, yoor' 'teiland Solor ten anker quam, alwar men de koningin van So* lor, met cen groot getal wan hare Grooten, onder f gerammel van een groot getal wan Gongen cn Tifa's, an boord Jieeg, ter ecre wan welk 'er witkker gefchoten wierd.

Zy vertogt, dat men wilde tanhouden met hat in vrede en vriendfolap te leven, De toen dat mon weer een wetting op hat land vahsolors bouwen wilde, on hat tegen de Portu- versotis geczen, hare en onze vyanden, te betchermen.

Men zei har dir toe, met verdere beloftera, dat men, naten Macafiar bereugelt te hebben, hier weer met cenige folsepen komen zoude, on de Portugoczen op Timos aok te bezocken; wat op die verheugde Yorlin met batac mageve Edelieden zeer vergenoege na land vertok.

Mervond deze ankerplats zoo genarlyk, dat men bell keurde ta ankes te ligten, en na de overwall tan 'tefland Serbite wer te fteken, atwar zy thigt by land ten anker qumon, meivende hicr verfoh water re vinden, doet vergeets; en-nnoetten wan dar m Lamhale"s engte, tutichen Solor en Serbite, verzcilen, en

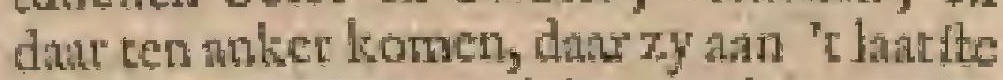
ciland cen fechoone riwice wonden, niet were wan 't vlek Lambale in zec ftortende; doch mogter van de fehepen niet anti land konten, hoewel de Soloreezen, en eenige andere Eilanders golegenheid genoeg gaven, om allerlei verwerlehing voor geringe beuzelingen en finuilteryen tot hun volkonen genoegen in te ruilen.

\title{
DER DE H O O F D T T K.
}

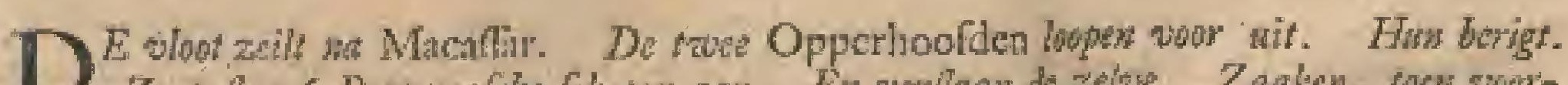

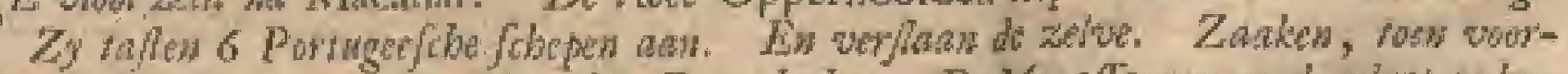

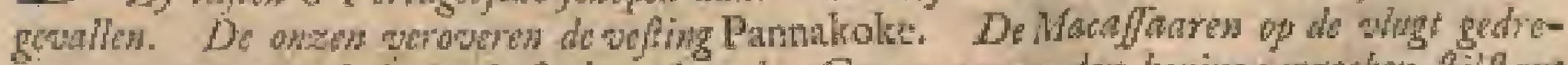

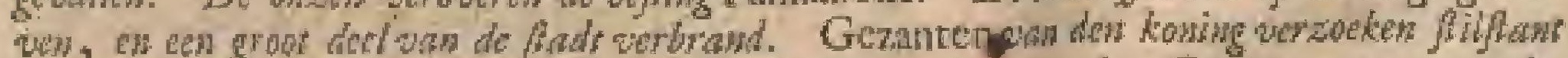

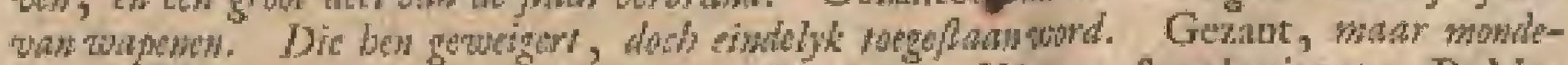

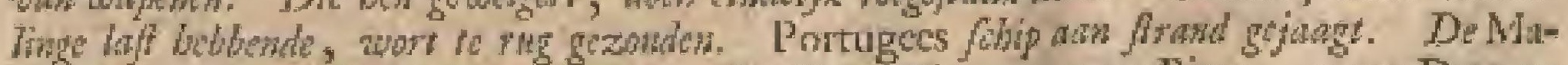

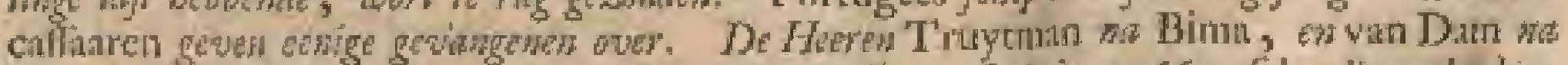

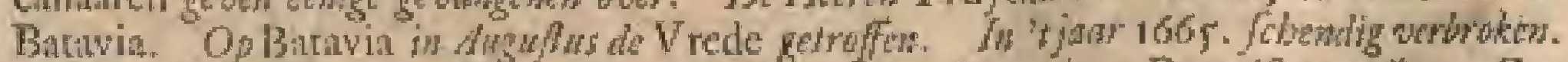

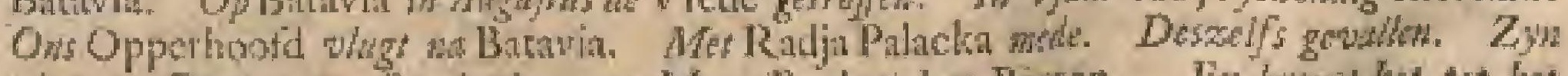

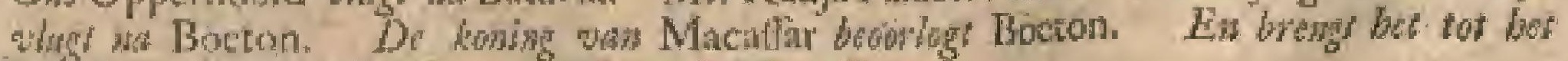
witerfte. De Her Spechnan werfatt de Macalataten.
\end{abstract}

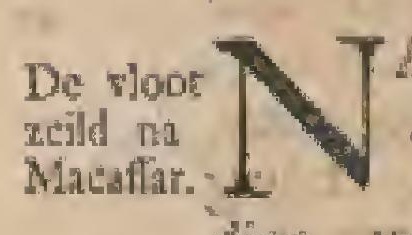

A dat nu de ganklye wloot zich , wan genoegzilatinc ververfésjog, drinlwwiter', en 't verdere noodige, wel roorzien had, verrok decelve den 2 gin Mey wan hier, zeilende weer tufichen de engte ran Lommahale en Lombatte, voorby den Lombutzen vuurbers, doox , tot dat $2 y$ in de ruime zce 


\section{$\begin{array}{lllllll}\text { Z } & \mathrm{A} & \mathrm{A} & \mathrm{K} & \mathrm{E} & \mathrm{N} & \mathrm{I} \\ & & \end{array}$}

I66. Geterneu zynde, met 34 zeilen liugs teiland Ende: na Macalfar voostzeilden.

Na dat de wloot ontrent "t ciland CeleDe twee bes geliomen was, wier in den Vlootshoofden rad betlotest, dat de Hecren wam Dam loopen en Tws mom met 2 fohepen, de juars on voor ast Breukelen, na Macufar voor uit loopen, en een proeve nemen zouden, of door minnelyke werzocken deze hardnetkige vorlt nu hog nice tot teden te brejgen, en net hem cen wrede zou te ruaken zyn, wat op men zich wate valter, dan op alle de woorige vrede-verbonder, zou konnen verlaten f ca terwyl zy dit onderftan zouden, zou de vloot nog twee dagen ower en weder blywen zeilen.

Na dat men dir in 'e werk gettele had, liep de yloot by Tumahkeke ten anker, om zich voitkomen flagvadidg te matien, en ten eerlter de weltingen der Macallaven met cen dapperen moed alan to calten.

Tersvyl onze vloot hice nog lag, zaGen, zy den I aden Juni wan verre een Macallitats santuig in 't verlchict, 'c gaen $z y$ dagten dat hen de blyde tyding van een aangename vrede brengen, en van alle volgende moeite verlaften zoude; doch na dat deze galten de vloot ter degen berien en werfpied hadden, zeilden ZY te rug. Ondertuftchen zag men de $z$ woor uit geloopene fchepen Mars en Bresliclen te rug komen, die mocite hadden om by de vloot te geraiken, weshlalwen men befe keurde digt by hen te komen ankeren. Hin be- $7 y$ brigten tot berigt, dat zy op de
reede van Macaltir 6 Portugeclehe fchepen voor der zelver verblypluats, zeer ryk gehden nu pus van Macoo gekomen, hadder zier Teggen, dic voornemens waren ten cerfien na Goi te vertrekken; matr om ben de pas das toc af te foyden, vond men goed, and de Macaftatren, by "tantaften wain deze Portugeczen jn 't gezigt, en oniter den rook van hun kaftelen, ecos blyken van onze dipperheid te gever, en heti te coonen, dat wy zoo zoer niet te verigten water, als hen de Portugezen, met ons voor bloode zeeroovers, en ecr volk zonder Pring, of Regecring te felobden, batden wys ge(milikt.

7y tates "Men wagtte nicte langer nis den mor6 Pottl- gen diarr asis, en talte hen, ma "t uitgetche florten van cen zecr ernftig gebed tor ahityp God, on zynen zegen over deze onze - onderneming, met her aabbreken wan den dag door a fehepen mee de witerite dapperheid ann, begroetende hecr certt met en wolke lang.

De Pormgeczen, die mede op hun hoede waren, en hier voot wel gevrect hadden, deden in "teerft geen kilewe togenftant; matr verbath ftond de koning van Maciffir, als hy deze 6 Portugetelic fchepen door 2 Hollandebe (een zeer on- 1660 . gelyk getal, en dat nat 't werk wiri geen bloodatards, gelyk zy alcyd vooryegeven lindden, gelcek ) terwyl de ganfelwe woot dit Jpel maar anzag, zoodanig zag havcuen, dat $z y$ niet wilten, watar $z y$ zich kecren of wenden zouden, wit al bee welke hens nu te late bleek, dat hy zich reel te onroorzigtig door deze Pontugeze fnorkeryen had latacn nuisleicien, en dat het hem in 't korte wel berouwen moge, dat lay de zrede, hem zoo edelmoedig van de Hollanders angeboden, niec angenomen had.

Terwyl dic de koning met zyne horelingen wan zyne velting, benewens een Ichatr Far duizenden Macafaren, die "t ftrand wervulden, aanzag, fjoonk tot hunne uiecrite ontiteltenis de Porrugeefche zeeroogt net al zyn wolk an duizend fpanderen in de lagt, by ougeluk een fchoot, of cenig wuli", in zyn kruitkamer, dic in vollen brand gernatite, gekregen hebbende, Hier door geralkten ook nog $z$ andere was hunne felepen in brand, dic tot aan 't water srereerden, hoewri 't meefte volk, na de wall fwcmmende, zich zelven borg.

T'wee andere fchepen wierden door En wer onye 2 cegen thrund gejaigt, cn 'tlatite, flatan

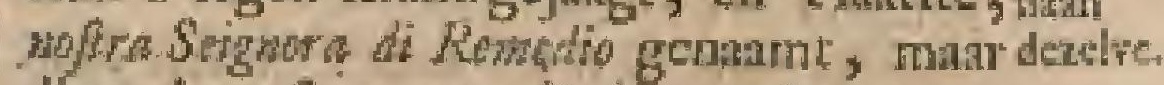
die wrel een llegt remodic botonde re $z y n$, wiert doof de Auic Breuleten an boord geklampe, en in aller geangt werowert, en woortan de Hollandre remedic gcname. Men vond et weel zyde ftoften, Sindelhour, en veel Chinecze warten ir.

Men had ook veel Portugeczen gevangen belwimen; doch men gaf her vryheid, onj weer na Jand te ganu, on daur te verhalen, date dit mat een voorlpel whs, en dat het nu ecrit regt de Ma* cafaren, daar zy eigently on gekomen waren, gelden, en dat men ben eens lecren zou, wat onderfcheid 'er wis tus. fehen tt fhorken der Portugeczer, en tuffehen de dapperheiat der Batavieren, die zy nog nier regt kenden.

Alle de fchade, by de, onzen in die gevegt beliomen, bethont in 4 dooden, en 8 getwonden; max" "tfeheelde weing of onze zeevoogs was met den Potugeefchen in de lugr gefprongen, vas woornemen geweell zynde, om hem tan boord te klampen, wate door hy vry digr by hem genader, en in groot gerant geralk Wis.

Het verlies der Portugeczen hidd men voor ons wel verborger; mair het is lige te denken, dat zy veel Jooden, en nier minder gewonden hadden; zoo ditt $z y$ nict in that waren, om den bentrden Macafianzen koning ecnige hulp soc re brengen.

Hot was dar in de veftingen, en in de

$$
\text { T } 3 \text { " itadt, }
$$




\section{I5o $M A C A S S A A R S A$}

Itadt, alles in roeren, en duizenden wath Macafatate, die dir gevegt mafchouwt hadders, en su als de mierer door malkinderen liepen, wiflen niec warr zy zich wan benanulacid keeren of wenden zouden, terwyl $L y$ vin hume opperhoofden, en de heefehgefchreenwde Macattiwze prineen, yder tot han wandel geroepen wierden, on mede atm dien doodendans te geriaken.

Be oever weergalnde vin 't ge: Verdere fohreeuw der menfchen, en wan 't gerain= zoaken, melder Grongen en oorlogstrommels, die Yoorge- een viy naten toon alonime foegen; en

vallen. men zaf eindelyli wan de veltingen der Macaflauren de bloeduliggen opltecken, wata uit men moelt aficinen, dat zy geneger waren zich dapper te vendedigen, en nier ongewraken te therven.

Daags 'er atan belloot men den vyind, zonder tyd te geven, weder inn te talter, wath op de voot, 35 zeilen fterk, op den Macalliar anttonts los girg, hocwel zy 't ongeluk had, dat het itil wiert; docl tegen de middag weder een frati koelrje bekomentle, wat op zy tocn at kanonuecreade en weder met fehroor lidende, al zagkens tha we wal fichokten', "t geen in den pyand geen kleine verlagenheid veroorzake.

Niet liag diat ata quam 'er cen vatetuig met een wrederan tan boord, met cenige Edelen, in haft hebbenice, om de Opperhoolden dezer vloot uit "s konings nam na de reden wan hume konft ontrente zyn hand te vingen. Zy wilten die zeer wel ; doch zogken de onzen matr op re houden; die, veel te wyys datar tos, hea muar loot en goed befcheid gaven, en zeiden om geein andcre redeis dar gekomen te zyu, als on den trouw loozen droning wan Machlar eens te degen over alle zyne an ons bewezene trouwlooshedem te ftraffen, en om hem te lecren, dae wy zulken blooden wolk niet witen, als - hy zich van de laffartige Portugeezen had laticen wys mialten; mardat wy, al te lang en te vecl wan bem geterge zynde, hem nu cens rege toonen zonden, wat woor een foote van volk de Hollanders waren.

Met deze bedroefde tyding keerden $z y$ weder na land, en bragen humnen benatden vorft, die gement had door zyje lifigewlegeryen ons nog alcy wel tot de vrede te zulles brengen, in cen wry jammerlyken ftat, alsoo by nu wel te gemoet zag, dat "er geen niddel was, om dic gitawelyk onweder te konnen ontgalan, werl minder, on zulken mage wan volk, en Chepen te woderftaln.

Den inde Juni by de ecrfte welting der Macafiaren ten anker gelomen zynde, blewen zy dau", alzoo "t ftil was, leggeh, zonder ant wederzyden eenen kanondchoot te doers; doch wat na 9 naren "s morgens $x 66$. rukter i der klockefte fehepen de mikers wit de frrond, fchooken wikker eerlt op de vefting Pitniakoke, loopende zoo al verter na de vefting Simboepo, om 't gros der Macaflaten dar na toe to lokken, en ap die wyze door een krygslift Pannakolie door een troep volks wan ons te doen verinflelien.

Hier was nu "tblad wonderlyk omgeJecer, darar de Hollinders dat zelve kafted, vou' "t wethe zy zoo menigmal geltreken latklen, on Cram Crusuron, prins van de velting Greflic, den grouthen anthitzer van dets lioning tegen ons, te eerbieden, mu zoodapper dorlfen aantaften; on de volle liatg man "t zche ycyen.

Na dat or zulke groote blanwe booner vlogen,en zy ze langs "t ltrand hoorden balderen, zag men wan alledic dujzenien meratichen, dikat "c ftrand bevoorens van krovelde, "er su geen cen; mar anftumes wierden wy uit humie veltingen mededipper, doch in de hooge lugt, beantwoord, alzoo al hum gefchut fehen geftelt te $2 y n$, om de vogels in de lugt, en niet om mentchen te fchicten. Wy hiepen eindelyli de bogt in, befchaten de ftade mee ernlt, en hielpen datr olles wrakker in rocren.

Na dat nu de onzen ondertuficher tot woor de refting Sambocpo genndert waren, brundden zyn met hur i I fchepen gelykerhand ine zulken geweld dat op Pos, dat allo in die vefling daverde en dreunds.

Zy guwen hier ap weder goed ant woots, te neer, alzoo de Portugeczen loun oond verlaten, en zicly by ten koning tor hulp in de velting begewen hidden, wardoor zy onze ichepen al zeer groote felaute met huune fwrate kogels van 18 en 24 pond toebragten.

Een wan s lonings liefle wyven was met een fwaratroget, als zy nevens hem zat, in flurden gelchoren, zoo dat hem het ingewand om de ooren gevlogois was; door it welke belenneringen doze rorlt, half rnadeloos geworden, orode gegever had, dat ecnig rolk, dat in de velting Pnnnakoke lag, daif wit trekken, en fpocdig totzyn hulp na dic wan Samboepo liomen zoude.

Dit wriert volgens "s konings latt in "t werk geftelt, tc meer, om dir zy geen syand by de velting lantrakolse meer vernanen ; doch de onzen van de lcheper, nu liumen tlig weh warnemende, begaven zich te Jand, en namen die meeftverlantene velting, mer weirig moeite veroned in, alzoo de geringe mantchap, die "er vero de in gebleven wis, zich niet in itaa be- vefting rond, on hen te wederfan, weshalwen Pannatozy reces "er alles ma gefchikt hadden, om the. de Land- en Waterpoort uit na de ltade 


\section{Z A A K E N. I5I}

165. te vlugten i doch " $\mathrm{w}$ wiert hen door onze piekeniers belet, en alles, dat men vone, In de pan gelualit.

Veel Macaflitien lieten hicr hę leven, en veelen, die geen luft hadden on an een pick geregen te worders, fprongen zich liever van boven neder te bariten, terwyl de onzen alles in deze velting in wolkonen ftat wan vendediging bragten, porzicnde de zelve var genorguame mantchap, con anomunicic van ootlog, en batende, tot fipt der Macaftaren, de Princevlingen dare all" wiajen. De Ma- Zoo ms hidden de Maciffiaren dit niet
affaren vernomen, of zy quatzen, met duizenop de den vam dis wefting Samboepo weer na dic wuge ge-van Pantrkoke, wallende met ecn atgrysdreven, zelyk gefichreuw op ons wolk man, megroot deel nende zoo bloots voets er weer in te geyan de raken; math zy wienden 200 jammerlyk fladt wer-door een yfdy $k$ gebriak wan een menigte brand. memale fukken, en door het doodeiyk gekrys der door de lighe liuilende en ziszeode domiterballen, en kumppets, en der wh cen beritende hadigranaten, begroer, dat zy nict wiften, waar zy zich Penen drajen zouden, hocwel dat vecten Yan hen benomen wier, atzoo $z y$ op de plats doed bleven leggen.

Dant mu togren de mzen in zeer goede ordre uit de welling op den vyand an, en dreven hiem tein eerlten verter op de vlugt, jugrende hum rullichen de grone rivier, tuffchet die 2 weltinger, ma.

Dant na trokken de Hecren wan D D w

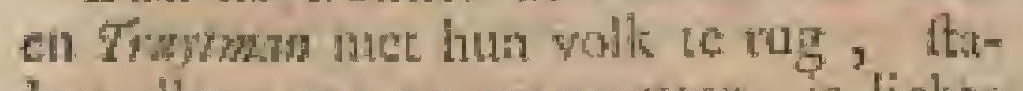
ken ulles, wat zy onemoeten, in lichte whan , want door $2 y$ een groot gedecte van dece trotze thutit in koolen leiden, en nun de vlam opofterden, na welke dippere data $2 y$ weder ba hune velting keeröen.

Ondertulfehen befohoten de onzer wan de voornoende it fehepen Sambocpo nog ill wakker, tot dat $z y$ de vlam wan de itadt Macaflin ziende ten heincl fteigen, en de onzen reets op Parmakoke zegempraten, het nu tyo oordeclden Simboepo wat te thaten ruften, cu na "t Pottrigecteh oord at" te zaliken, getyli $z y$, zonder de Logie der Fingellehen te noejer, tor hut genotgen ordentelyle dexleti.

Nadat $z$ p mut woor de fterlkteri der Portugeezen gekomen waren, donderden zy, zeet digt ter hngs loopende, niet weing dat op los, gevende tan hen rato de if fetepen te gelyk de volle latg net zuhken algrylcelyk gekrak en gebulder, dat de Partigeczen meinden, dat het in, 18 ponders, co kmuppels, in haren oord regende:

$\mathrm{Zy}$ liepen dus woorby hun hecnen tot fiet Koordely k kattecl, Oedjong Pandang, doch koerden fpocdig te rigg, om de Por-

tugcezen nog ecns ter degen te grocten g roto dari zy tocn ketels vol blanuwe boonch in hunene yeflingen zagen wiegen, endic. wy hen diar geftadig zagen ontduiken, en in "t einde nog ocos langs hunne fterkten loopende, en met econ verichrikkelyls gebalder alles op hitate reets ver wheflede bateryen losbrandende, wenichtende on$7 \mathrm{Cn}$, il koo het donker begon te worden, ben goiden awond, komende by onze andere fehepen ondent de vedting Pamakoke ten anker, alwitat zy beronden weinig volk verlworen te hebben.

Den $13^{\text {teta }}$ dito zont de koning wank Gegnten Micafiar, die geen luft meer in zulken wen den fpel hat, cenige Afgeranten ma het fohip koning wan den zeevooge, verzockende de Heeren werzeswan. Daw en Trwyman on ecn ftultand ken [tjit= van wapenen, beruigende vetder, dar de wapenth koning ower de dapperheid der Hollanders zich ten uiteriter yerwondert had, en dat hy door middel varn dere dtilitand verider tot een goederride hoopte te tomen.

Onze wakkere Opperhoofiden wel ziende, dat de liftige Mheadtazze koning door deze vleyeryen niet dan tydwinning pie hen beoogde, en nier genegen , ich am der gewethuin te lanten leiden, zciden vlak uit, dat zy dien mouwloozen leoning nergens it meet geloof, of het alleminite viticl wilden geven; mal dat vegen hier de boodfolie, con dat alles, "L geen $x y$ dus werre gezien hatden, matar een begin wis. Ja dat zy wan dara rict meinden te fcheiden, zoo ling 'er mant ists van geheel Macifar overeind ftont, almoozy bedloter hadden inl zyne veitingen tot de grond toe te Alegter, en hen met alle de zyuen of ant "t Fatard op te offeren, of na " $t$ bolcl te jugred, op dat hy das" door lecren mogit, de Hollander's wat mece te agten, ch hidata" met bedartheid zyne menigyuldige trouwlogsheden met berouw na te deioken.

Dit antwoord ontitelde deze Gozanten nict weinig, zynde de ecrite Princen van doch

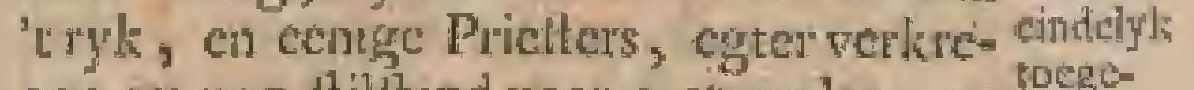
gen zy nog ltititad woon' 2 etmalen, cu foegelanger nier, mits dir de koning binnen work dien tyd conige gevolmagtigde Gezanten zoude afzender, die met ons na Batavia zouden gara, on datat met has Edelheden een valte yrede te fluiten.

Datr op voeren deze Gezanten wolyk na land, die hunnen koning ner berige gaven, die in 'tectle over de woigcting der ftilfand zeer ontelde, matr dat na verlatude, dat zy egter voor. 2 ermalen toggeltan, en diar op gegrond was, date hy binum dien tyd Gezinten. met volle migt ma den Zevooge zou moeten zenden, om met ons na Batavia te gaan, en darir een vafte viede te matken, dyam hy die voorwarde zeet verblyd aas, en zont 


\section{\$2 M A C A S S A A R S C H E}

76o. binnen dien bepalden tyd Crata Paposan, thet volle magt na de onzen af, onn, van Gezant, ved Macalharze Grooten verzeld, met matr hen na Beavia te fevenem.

monde Men wragde bem aunltonts na zyn

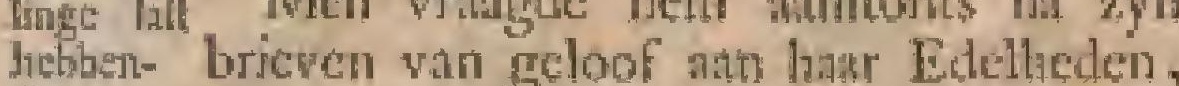
de, lyzeide, dat by zelf debrief, en dat zyne thit, die ly wa den koning bat, mondeling was; doch men rei hem, dat wy ons tan geen woorden zouden houden, Word te dat 'er bricveti door 's konings hand gerul ge- teckene, en wel antitonts, moeften zyn, zonden. of dat wy bem terlont weder zouden nantalten.

Terwyl Grain Papowa na land ging, Portugecs om den koning liennis hicr af te geven, arand gac jangden de onzen nogr eco Pon tugees fochip jage wan ftrand, zynde cess dier 2 roorige, 't gecn na Gon ftillekeris meinde te loopen, doch dat zy ru zelf op ftrand in de grond boorden, on in thiklien knpten.

De Ma- De Micaftauren, wy luandelbatadet caftagen dan te vooren geworden, gaven ons nu, geven op onswerzock, ten eerfien onze gewhenige genen ower, die zy wan ecn fehecpien gewnige oret. gerooft, landwatd in gevoert, en zeer mishandeld hadden, zoo dat het duizend tegen een was, dac deze menichen zoo lang in 't lewen gebtewen waren, dewyl zy hen het noodig voedzel onthouden hadden.

Men belloot ondertuffehen in de vloot, De Heer dat de Heer Frotwan mee cenige ficheTruyt- dat de Bima om ryit, end din verder na Bima, en Solor en Timor gannzou, on de Portude Heer geezen daar ann te taften, cu op Solon een wan Dam gerang te bouwen. Ook wond men goed vin. Pannekoke met cen noodige bezetring te vootzien, en dit de Heer was Daw met de andere fchepen, en de Micaftirze Ge7anteri na Batavia zou loopero.

Eindelyli hadden dic Macaflarze Princen als Gezanten zich lifat gemaikt, on met 4 vartuigen mede derwates te gan; en van dic alles na Butavia liennis en van de bevagte zeege op de Macafiaren door 2 fchecpkens gegeren zynde, wierd, zoo op de vloot, als in de vefting PanntFoke, cerft een algemeene Dankdig gehouden.

Vier fchepen bleven hict tot dekking der vefting, cn wan onze bezeting, en om op de l'ortugeczen, en hunne fchepen te palfen; en de andere wertrokken, na dat ze dezen van wees gelirompen koning hofyk met hun gelchut gegroet hadden, onder 't geklank van trompetteri, en 't geroer der wommelen, wn dar, en zeilden tor Tamahkeke voort, alwial de Heer Truybur na Bima, en de Heer wan Dam met de vloot, en met de Macaftarze Gezanten, na Bataria licp, alwanil men de Gezmen defig inbinide, on in Auguftús cen goede en bil- lyke vrede getrofien wient, hocwel 'cr I66on. op Macatfar nog tot den $16^{\text {dea }}$ November mede getalmt is. De Hoes con Dam zot In Muweer na Macaftit gegnan hebben, toch yultiss de witde alleen gan, en Jei, om dat mentroficin,

hem dat miet Loeftont, zyn dienft als Mijoot neder, en toer giarg de Hect Gatuw met de Hoer Wagenar.

Doch wat hiclp ons dere vrede, alloo 't den Maciftar onmogeryli we zyole fehelmitukken en trouwloosheden thit te latden, wazr van deze lioning ons verfcheide nicuwe protven gaf, met onze verongelukne fchepen nan te tiften, "t wolk te vermoonden, en ale roederen wed te soowen, gelyk an "t felup de Watwich,

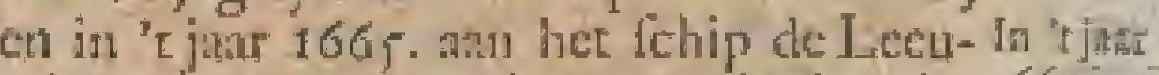
win, of den Bril gebleven, gebleken is, 1606 .

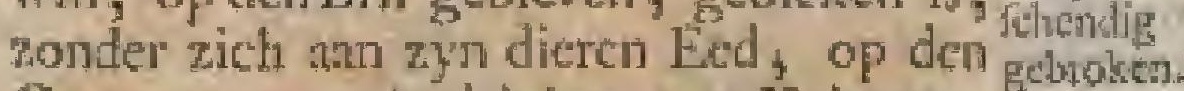
Corants, met "I drinken wan Kriswater" gedaan, eenigzins te kretenen; ja zelf liad een Macaliarich prins de thoutheid, om ons Opperhoofd, toen op Macaffar leggende, en 'slionirgs hulp wat crnitig, ontren dien lantifen bodem, tot berging wan ons volk en goederen verzockende; een fuffer te gever, weshtwen hee ons' Ons OpOpperhoofd beft dagt, en ectiten zy biezen te pakken, en tich met een wan Batavia. onze reluepen, dan nog Jeggende, na Bataria te begeven.

Die vorlt toonde dit nog al zoo wel in dat relve jatr, wannecr hy ropoo gewaxpende mannen na "t ciland Bocton zout, en de ftoutheid had, om aluas onte veltingen itut te taften, en ons volk te misltardelen, zonder zich man onzen Gezant Pierer do Buthr te gedragen.

In dien tyd nu, dat 't yootroemt Ma- Merdia cafliars Opperhoofd, na dit hy zoo on- pahecha behoorlyk gefutterteert wis, wertrok, mede. ging met hen in dilte mede cen Boegis Edeling, Radja Palack gcinamt.

Deze Jongeling, zeer misnocgt op den koning Itaflowodrith, hat dubbelde redenen, on zyn koning te ontwhgten; want zwn grootwader was door dcn koning wan Goa, fonbongko, levendig in een ry ltblok Des zels te pletrem gentampt, en zyn vader, peralem. certe Bodicnatr wats that, col al eens begenadige, was, on dat hy ten tweedemanl nat sleonitigs leven gethar had, gekrift. Van dezen koning nu whs Radja Palaka Pinangdoos-dmger; mat, follon jong, egtcr zoo vol wrakzugt, dat by mant werfchte gelegenheid te hebben, an zyn grootwalers ch vaders dond tc mogen wreeker, en by deze getteltenis

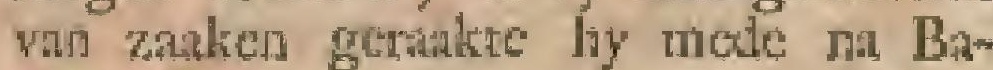
tavia.

Zoo rits liy dand gekonen was, klagde hy zyn leed an harar Edelheder, vetzogt hume hulp, en woses hen te gelyls ano, hoe $z y$ hun leed zouden konnen weeken, en wat middel'cr was, om meefters 


\section{$\begin{array}{lllllll}Z & A & A & K & E & \text { N. } & 153\end{array}$}

2665. van Macufar te worden, onder toezegging, dit hy hate Edelheden merkelyke onderthant doen zou.

Dain op hobben har Edelheden alles met hem rypelyk overlegt, en belloten een anzienclyke vloot derwarts te tenden, War welke de Hect Connels Sirelwan zecroogt zoude zyn; doch men vont ook goed Radja Palacka, van wienswluge men op Macaftar nog niets wilt, woor af oa Macaflar te zcuden, niwa by geko= men zynde, om zyne volkeren by der studeren te verzamelen, dic zoo bot en onvoorziguig begon, dat hy, zoo hy het niet ontweken was, in ongemak geraalt, z Za lowe ben; doct hy ylugte nog tydig na Boeton, ton. yan war de koning yan Goil hem door Gezaneer opeillchen dede; doch die rotft zei, dat hy hers als cen wricnd in ayne bejcherming genomen had, en niet genegen was. hem over te geren.

De ka- Datar op zone de koning wan Mactlitur ning wan cen yloot wan 25000 man in "t jatt" 1606. Macaliar na Bucton, cilclite Radia Palnckin weder, beoonlogt of dreigde anders dezen koning, en zya Botol. land, te zullen werderven.

Den koning wan Boezon, dus dhor dien wan MacelTir gepert, en an de andere kant door Radja Palacha verzekert, chat er mat weinig dugen oncbraken, in welke de Heer zecoogr Spedman met cen atuzicnlylie vloot tot zyn hulp bier wezen moelt, flocg dit op deze verzekering weder at:

Enbengt Datr op belegerde de koning wan Mahet tat het calfur Boeton, en dwong dien koning in titerle. "t gebergte tevlugtem, alwatr liy hem zoo fterk vervolgde, dar hy her datr nier lang zon hebben konnen hurden; doch de looze Radla Palicka, wreecende dat hy' befluiten mogt hem andien koning over te geven, zcide valt tyding te hebben, dat de Heer Spelman naby was, en dat ly binnen 6 of 7 dager op Bocton zou zyn.

Hier op werzogt de konimg van Boeton manr deze weinge dagen uitfel, wootgevende, dat hy de bergrolkeren zoo fehielyk tor dezc overgowe niet bewegen kon; mat dat hy anders gehed en al darr toe gereed was.

De koning wan Macaldat ftont hem deze weinige dagen tot, oordeclende, dat by dien ryd lige wit wagten kon; doch de Heer Spelwah verlelieen net op den 6deu dag, of der $21^{\text {ften }}$ December met 14 fchepen woor Bocton.

Hy cafte deMaciffiren ten eerften met De Heer veel dapperheid an, werflocg dam humen Spelriman belten $\mathrm{Adel}$, en de uitgelezenltetrocpen, deMacas zoo dat 'er matr zeer weinig Hovelingen farchn ontquamen, om de tyding te komen brengen, en dic "er niet dood bleven, kreeg de Heet Stodman gevangen, en

Fecte hen op een eijotnd, daar geen meil- $166 \mathrm{j}$. fchen waren, on dats var houger te fterven; wat na ly na Macaltu is gettewend, dain hy allereerlt door die var Turatie (dat de onzen moders nog weel mocite gegeven zou hebben) onderffeunt zecr mel onthingen, en zod render tot Micarlar doorgethongen is.

Na dat deze Heer det $24^{\text {ften }}$ Nouctober I606. net i zellen van Batava gezeild was, joo Nedatlanders en 300 InJanders by zich hebbende, nevens teel bootsgezellen, quam by den $1 g^{\text {den }}$ in her gezigt van den Macaffar, die aantonts rog6 goude Marlen tot roldonning der vermoorde Nederlatudess, en nog $\mathrm{I} 435$ $R$ ders, uit hee wrak van 't verongelutice Ichip de Lecuwin geviliche, an boord zone; mat de Macaltanten cindelyk tot niess verier willende verltath, zciluen de onzen met bloedvliggen ( ha dat hen den ourlog angezege was) voorby de ftade Macalia, witar nat $2 y$ in de bogt wa Turate alle de Negeryed verbrandiden.

"Dangs dar an oumenze voot Bont teyn, veruiclende zo dorpen, en roo 5 vastuigen, benefens 3000 lalten rys en "pradi. In "t jata 1667 , zeilden ay voor "Bocton, en hoewel "z zelwe een mand " lithg mer 4 ro reheepies en roooo Indi2, anten was belegert geweeft, triden de "Hollinders "s morgens anm land, flekcnde $n, 60$ val deze vartuigen in brand; whar , over de Macaftar zich in zyn yoorin nemen verydele ziende, te meer alzoo , ved vin tyn voll begroft weg te loo"pen, ftak zelfs zyn legertenten in brand, , ch, wrezende vin 0linmer, toog op de

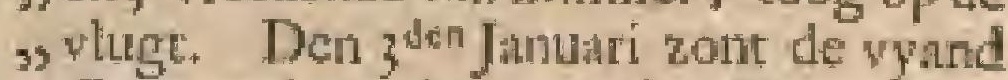
3) Gecommittecrden atan den Heer Sipeds, wan, mar de zelve wierden tos driemal , te rug gezonden, om dat ze te gering 23 van anzien water y des anderen dartgs " quamen de drie voornamite Hoofden "van "t Macaflatrze leges, en gaven zich "op genade en ongenade an de Com"pignic over, jrooklocke mannen zyn, $\mathrm{de}$, wierden op een eiland tuffelien , Boeton en Pantliama te lande gezet, en ,400 to[ flatwes es l]arinnen gennakt, y, zynde onderwylen jooo Bocgis met 86 ") praauwen wan den vyand by hadf $P d$ "haka overgekonen, en 200 gerooften ,2 Weder atn den koning T:tn Bocton ge, reltizueelt, 200 dat nier min als I 1000 , menfeken in 's Compaguies handen wa9, ren komen te vervaller, als mede wel 3) 4000 latten ryft, co waren wel 300 3) Priauwen allecen fo de bua wan Boeton "in de grond gehakt, behalwen nog zo ," viartuigen an den koming en grooten " van Boeton, en 10 van de befte ain "Radfa Palacka uitgedeelc. Twee fchoone , Oothogsjonken mam de Heer Sprowas , mede in de wloot, en behiet ook alle

V. , de

I I I. DEEL, 


\section{I54 M A C A S S A A R S C H E}

\pm 6 7. , de voomaanfte Macalfiarze Bevelheb"bers als gevangens by zich; beltaude 7) de buit, op Boeton bekomen, voor "t mee, Icndel in goude en andere knitien, een s, party fehiet- en fteckgeweer, poonts , eenig gemunt en angemunt goud, be3, netrens 195 randels en wimpels.

, Van dat is de Admitat Spotmon ver, trokken na de Oolterfche Prowintien, , $\mathrm{cn}$ aldhar alles verrige hebbende, is den , gren Juni uit Amboina gercheiden, en , na Boecon voortgezcid met 16 lehepen y, en jugten, mitsgaders I4 chalocpen en 2) Jugren, dax onder 4 wan den koning कvar Ternate; deze vloor, in "t over" , fteken wan Bocton na de Boegetoenes, 29 Lad zoodanig hard weer beloopen, dat ") de Inlandze varurtuigen wan Radja Pa"Wack, onder gelcide van Capitein Pole, wan mede van Amboint vertrokken, , meeft waren werftroit, doch Capicein 93 Polman was maderhand met de Chaloep 3) de Eendragt by den Admiranl gekomen, , met tyding, dat by Radja Palack ook , in nood en verlegentheid had gezien, ,2onder bem te tonnen belpen, en war" "om gemelde Cipitein Polewom mat 2 w) Chaloepen weder wient uitgezonden, on "den voornoemden Radja op te zoeken, s, en by den Admilaal te brengen, die na "veele moeiten mer hem te rade gewor9) den is, om door het land van Boni door , te breken, en zich alzoo met de magt " Fan den Admiral te vereenigen, dat met "geen minder moed en yver, als mannc5) lyke dapperheid, is volvocrt, verbran,g dende meer als ioo Negeryen, en onक) tallyke menigte yan jys en pardi, de 2. Admimal ondercufichen ont rent Bontcyn "(de befcheide vergaderplats) konen${ }_{2}$ de, wont het drar, en ook langs hees. 2, zoo met pallizantwerken als met marde , fortjes, zeer werfterkt, an wel met 6000 , Macalfater bezct, watom de Heer 2) Spedmon genoodzaakt is gewoett den 3, vyand van daar te laan, dat na rercheide ,hicete ontmoetingen welgelukt, en , voorts alles in de aflche gelegt is, zon,y der eenige merkelyke fchade wan de on, zen; wast na de Hollandiche wloot ratar 3) Macaftar is woortgezeilt, dart ze den , vyand gereet tot tegenwer vonden, n doch wert uit hune kalteclea, als uit , onze wloot, op den snderen niet gefcho, ten, blywende darr zoo lang ttil leggen, , tot ant 'er' nader kondfchap wan de com,. Ite vam Rarya Palacka, en de inlandze 3) magt gekomen was, De Macaliaren wry , ie wancrouweti, felvorea den $1 g^{\text {den Juli }}$

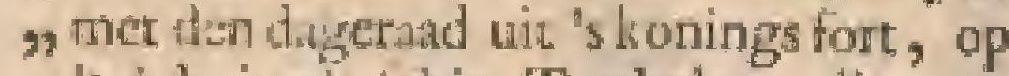
", Admi"kals Ichip Tertholer, die men , rot 's avonds met gelyke mune betaalde; "zeilden van huer op Panodkoka, alwat 2, dangs te vooreti dic Buetonders met 24 2) Vartuigen al 1000 ma verichecnen;

" "E klein ratruig Jindde aan "t dorp Batta $\mathbf{1 6 6 7 .}$ "Batta, dac ze verbrandden, en Fanonsnecrden dien dag voor Borrambon, "quamen den 28 aess voor Glifion, daar "Jonher Sloot, net I 4 andere dood blecf, , egerer den vyand fpacre "twelat in; on"dertufichen was det Admirat berigt, 9 dat den yyand valn meeninge was Rodjo "Palacka, co Capitein Polchwn, met hatr , byhebbende magr, komende wan Bon, teyn, te land te ftuten, warom zyn "Ed zich mee de geheelc mage derwairts j) begif, vindende oncerwagr Ragh $P$ a, Wake en Copitein Polema ontene $\mathrm{Pa}$. " lembean, die mee den wyand een liecte , ontmocenge hadden gehad, en overwin, ners waren geblewen. Datr op keerde w gemelte Heer Spodman met de wlooe we"der ma Glifon, en handde aldatat zonder , verhindering den 2 wen Augutti ; dien dag कs wieken 'er harde fehermutzelingen tegens , den vyand voor, dari de onzen 56 ge, quetiten bequamion; de vyand week , veldwarts in, zynde hunne principallet " voorvegters gefneuvele; dair witerd ver3 zekere dat de vyand in de a wee onrmoe, tingen over de roop doopen gehad bud" de, en was Crain Mont chowano wan ons 7. weder ma Maenflĩr gevlogr, latatende $z$ y sy oudte zoon en zufter in onze hander. 3. Onze magt beflond (buiten de 1nlan, ders) indezen tyd in nice mer als or , militaires en 778 zecrarende perloonen. , "t Jagt Nuifenburg was op den 7 den $\mathrm{Au-}$ ,gulti, zynde des anderen dangs nil hun "wertrek wan Macathr, in groot perykel "donr 4 - Macaftarze fiamen, en 15 ge" vangens van hooge gelligten, her voot „Mncaftar overgegeven. Deze waren by "nache uit de bloks los gerakt, en bat s den de wagt met feherp gemaakte Bam"boeren atgemat en aniok gelpeelt, ja ," "L was zoo terte gekomen, dacze de brand "in den bak-gettigt, en de deuren open "geranc hadden, matalizoo de onzen by "tyds mee een katron vol [chroot dar "onder Fehoten, triwan de Goude Leeuw "Ontze kregen, waren $z y$. alle in die "furic om 'Lleven gebragt; "r Bonize ic. " ger" beftont in 6000 gewaipende man, nen, waren wan T"uratia met onye fichespen voor Glifton anugekomen, en ann ,h hand gezer, Ralja Palake bid op Tus. rataden eeriten micht al ecn uitval go"datin, en den vyand thit 3 bezetringen s gejangt. Deonnen waren nu op Glifion , lterk 7000 Bocgis, cn ruim 3000 Ters Maranen en Boetonneczen, bebatwen 5)'t rolk wan Capitein Jouker en Sirjker, en "hadden 4 halve kartouwen nan land " gebragt 5 's konings mugt wiert begroot 20 20000 koppen. Den 184 Augulti 3, had den Admiral Sperhaw en den Raad , met Radja Palata gocdgevonder, doot "100 welyewapude iculingen, encen , OVGr. 


\section{Z A A $\quad$ A $\quad$ E $\quad$ N. $155^{\circ}$}

1067. woverlooper tot wegwyzer, "s vyands 2) vefting op Glifion by nacht te averom"pelen, "t gene geluklkig uitriel, kry"gendeden Admiral ten 3 uturen 's mor" gens de tyding, dat Radja Palacka "Glifton in had, en bulp terzogr, die "ten dien cinde al gereer tonden, en "wel te pas quamen, watit de vyand "deed wan 's morgens ten 6 tot "s mid"dags tet I 2 uren defperate anyallen, "matr wierden E'elkens mimbafrig $n$ fge"Magen, zoo dat $z e$ afwelien tot y uwen "in den agtermiddag, wwhtyeer ze nog "zulken woeften uninal deden, dat de "kans twyffeligtig zoude gellan heb"ben, indien de onzen niet volkomen op "hun hoede haduen geweert. Door de "werking van z vuupotten, en zoo veel "handgrathaden, wert den wytnd eerit ,gettut, daar op cen uitual van 5 of 6 , van des Admirals oppaflers, dic door "Rarla en cen groot getal vatu de zyne ,gevolgt wierden gedain, en den vyand ," voorby hun ectfe Pagger gedreven, die , ze door dwarg yan vuurpoten en gia, Manden raide moefen verlaten; .deze ". Pagger wiert wegens zyn ferkte nevens "Glifon geconfidereer, en beronden ,s dat de vyand zeer voordeelig in beide , deze Paggers had gelegen, wan watr de ss wyand ook wat meeninge wils geweeft s de fehepen en Inlandze martugen te "bedchieten, das" "E gelchut wel opgesifteld was; volgens des overloopers zeg"gen, had de whnd groot getril dooder, " dar onder den koning van Mandhar, "met den oudlen zoon wan Crain Limques, "en veel vañ den voonamiten Adel; " han onze zyde waren 6 Boegis doodge"gebleven, en ro gequetiten, en wan 4 ss gequetlle bolfchietess een geltorven. In "de befchanfingert op Glifion wiett een "Nederlandze wagt bencvens de Boegis " onder Capitein Polewan beftelt ; 's nachits "rukten de Bonifchen met \& Atukjes onder "s "skonings leger, en ftelden " $\mathrm{c}$ in atlitrm. "Devyand bragt 's morgens met den dag "alles t'zamen, makkie een omkring orn

" de Pagner tot Gliftor, cu deed dar op " cen hefrige florm, matr ons gefchut " dara binnen, en de Boegis dar buiter, "fcheurden hunner omtrek; in de namid"dag verlice de vyand het weld, en "san"deren dangs ontrent 8 uturen de Zuide"lykitevefting, datar de Boegis been lic, pen, den brand in de huizen taken, en "digt onder "s konings ferkte met ganiche ," troupen ell met een dragt padi ic rugge , kecrden, danr de wyand 't gros op uit , heef gezet, ch an wedcrzyden heftig "gevogten wicrd, hebbende, zonder roem "Viude cen of deander, ontrent ma 2 of , 3 uuren vegtens wederzyds 't verlanten. ,Zoo verlietén dan ook de wyanden hun "Werken, fteliende die zelfs in bont, en

"On te toonen, dat zy ordentelyk aftrok- 164 . " ken, deden zy een genernale chargic w wal musketren, en darar na eenige zware 3, basfeplooten, en begrepen hurneti orn3) Mag een groot liatwonlchoot verder in " "t land, buiten onze Pagger ; dar op " den $26^{\text {llen }}$ "s nachts Radja Palacka twee " veifcheide paryen uitgeltuurd hecft, " watar wan de toorlooper's door een wage " wan ro man ontdekt wierden, welke "wagten vlogen on de hunne te waltr"felsouwen, mat wierden wall de onzen "zoo ras op de hiclen gevolgt, dat ze met " hen te gelyk binnen quamen, zoo dat ") " $\mathrm{e}$ in "t donker luftig op een doodfteken "ging, en den wyand on cen goed heen "komen zag, agrerlatende 30 dooden, "en voorts hee leger ten belten, 't welk "de onzen lecdig makten, en mei een "party rys, kieederen, 4 hootden, I I "vandels, 30 kriflen en houwers, 60 "picken en 20 fpatten te rug gekeert zyn, "3ebbende de onzen 2 uuren verre na "Mncartar en Zuidwaturs alle dorpen ea "huizen in koolen getet. De Admiral 2. Spechan, otze Piggers en valtigheden „3 op Glifion verlitaten en gellegt hebben "de; was des nachts Bezuiden de riwier ". Ayen werzeild, alwar by zyn mage dan ", land tuffchen fchantskorven dede plat"zen, van waar Radga Palocka "sinchts "den Ioter naderde tot win "s wyands , werk, en fehoon de vyand een hevi"ven uitwal op hem deed, moeft hy door nhulp wan des Admirals oppatlets wyken. "Zeder zyn de Macafiers over al in het "onderlpit geraakt in vefcheide ontmoestingen. Zy waren wreed on de Neders, lander's te vermoorden, men zag wan de "hurine ook verlcheide van manzien in "battaljes atflepen. De koning Palates, "op den $3^{\text {dea }}$ October weder mee een " magtig gros om Adap uitgegan zynde, " kreeg berigt, dat zeker wolk wan Pat"trubite, niet verte wan daar een vefting "manlite, des rulite by derwarts, en "vicl by maanlicht op den vyand, ver"dreefrze uit hune werken, en ftak "er " den brand in, leerende wederon met "G hoofder, 5 vaandels, ecri party krilten, "rys, kleedugen, en andere dingen, en "waren de Macuflataren wa meininge ". met 32 pratuwen en 1000 voorvegters " in het Jand der Bocgis cen togt te doetr, "en om die te ftuten zyn door den Ad", miranl Spromon dorwanrts afgevandigt "de fchepen Domburg, Vlicland, Lie"rikzec, en de chalocpen d'Eendrage ea "den Dolfyn. Go Sopingers tot de onzen "overisopende, verhatider, dat hunnes. , ouden koving ran Soping na 't geborgte "w was gevoett. Radja Palacka, werwittigt , dat in "t dorp Sumangen veel.wan zyn ${ }^{2}$ blocdverwanten en andere byeen gekowasn waren, ging "s nachts met joo mat

$$
V_{2} \text {, det- }
$$




\section{MA C A S S A A R S C H E}

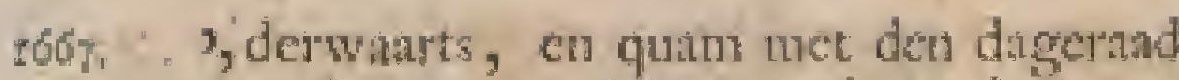
2, wederom, medebrengerde tot buie 237 1, wrouwen, dochters, en tinderen, net, fens tyf i go mannen en jongens ; dit 3, was den $y^{\text {jen }}$ Oetober: Matar Rodja als , overfte loog den 12 deu "s naches weder , met goo maln ait, thak ecn dorp by Sa9, Anangen attn, en bragt ten 3 uuren 125 o 700 wrotu wen, jongens, als meisjens me"de \& Rodja verloor hicr door "t fpatcen 33 der zyoer, wientzels gequedt, egter ndoor tegengifr with de fenytugheden be, houden a din behich inwendig de lroosts. ${ }_{93}$ Zedert is Beywiden "E botch Butta Batta s) met de Macafar ecr bitailje geweet, , diar ly, als een anbertecsde zyn volk ngedurirganuoctende, ververte. Zoo nging ook Ralja Paraks, onderteurie , zynde van de oppaffers van den Admi53 thal, en 8 of to matroozen met handw) granaten on vaupotten, tufichen den , $22 \mathrm{~cm} 23^{\text {tar }}$ October des nachts, roor ;) de derdemal na des vyands Bagger, dje "hy overweldigde; de-vyand liet aldar 2, 3 odnoden, deberetting betbone in 300 , of 400 koppen, dast wert in gevondeu 2) if fandard, 2 vandels, I felouone nea tarle bits, 2 kleine metale flutititukjes, , 10 pond kruit, 20 fparter, en fpatios) kers, 20 biskogels, chz. met i vrouw 9 cn I jongen, en waren datar 2 Bocgis „2doodgebleven, 7 gequetlt van lpatten, , , en I mer cen toris; hat deze Pagger 1) was een mudet met fehanskorwen valt"gematak, daw zich Radie Palacka tus3 , Fethen den 23 en $24^{\text {iten }}$ "s nachis mede „, meefter wan makte; de wytud had al5) datr 5 dooden, dan in wierden gevousyden 2 metalc karnerlfuklien; I groot , metal falconnet, 1 vilandel, jo fpattert, 5, 6 musquecten, core. De ryand was "dant in wel zoo man fterk, en onder "'t gezag van' eench Dain Martitso ge3) weeft, dic behalven de rooder nog wel 9.30 gequetfen hadden afgevoert, die 3) Thee ft geltorven zyn, doch an deze zy de 9) Was thitir i man wan Radja Supigg volk, ,en I takndrig van Polkek gefneuveld, y, mitsgaders $R$ adfa $u c l v e$, en nog wel zo

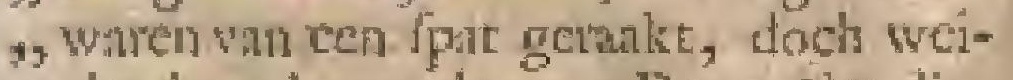
gnig datar door geleni. Den $26^{\mathrm{k} k \mathrm{H}}$ dito ") Maderten 30 of 40 voorvegtess tor in yatan Batta, wata op de onzen in atra3togt quamen, en hen begaven na de "lante Pagger, dar de vyand oole $\mathrm{ma}$ ,3 toe trak, en onder befcherming vina y't gefchur ftand hield, war op de onzell , weder te ring trokkci, met verlies vat , 2 foldaten en 1 timboer, en komende ", buiten 't geboomte, wonden $2 y 5$ ryands "Yandels, met ecnig volk daar by, die ; zeer fel líchoten, doch van de onzen op y, de vlugt gedrewen wierden, niet tegen"Atande de andere wan onder de Pugger is tot.hulp quamen, dis ook het eigen

,pad moelten kiezch. In "t aftrekken wer-16\%" "banden de onzen in "t voorbygan twe "legerplatzen, en trokken voors over "de rivier onder "s yyands tterkte, cu "s "sonings eigen verblyfpliats; dit ver, oorzakkte zoo groote verbonaltheid, dat s den wyand met heck trocpen tot in $\mathrm{Mat}^{-}$ , callar liep. De jonglt gemakte lterkte "Brauiden Batra Barti gelégen, wiere "door Radja Palacke in kolen gezct, de , bezetrilkr aldurar gelegen hebbende, be${ }^{3}$ ftont in 6.50 knppen, dar onder do , Loon van Crah Peppor, die met pak en $\rightarrow$ zalk waren doorgegan, en daty in ge") hiten 3 gemeene en 1 groote bis. In 9" 't teld bequanen de onzen nog a dub-

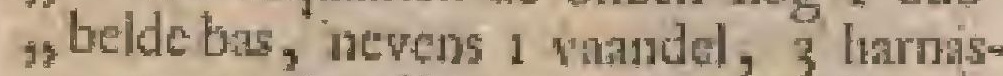
, zen en $f$ hoofden, dan onder dat van "Gran Tarromasts ; volgens de berigten "waren vin den wyand fo of 60 , mat 3) Fan onze Boggis niet meer als 4 dood"gebleven, en: 13 gequett. Gende "Boegis hebtwen van den wyand nog af"genomen 400 buffels, zoo dur 'er een 3, roor 6 of 8 fellethingen ani lywat ce ,bekomen was; war op de Ieer Acl"miral ca Veldovertle, Conselis Sped", Mas, den $2 g^{\text {ften }}$ dito two Banize Gew ,2 connmitteerden met een brief ann den "koning van Macalfir afzond, Met ann, rading on wan het bloctvergieten een "cinde te nitaken, welke Gecommit, teerden by iden koning en Grooten met , vect cere wieden ont fingen; den bricf sgelezen $2 y n d e$, wiend 3 digen cititel, , 0 tuflehen dien tyd ftildint wan was:"penen velzoge. Dit rooven en branm dela, mink Een zoo grooren fchyik onder 3, den Maciffatr, dae hy den I llen Novem, ber cen Gezant met cen brief am den 12 Admiral Spelanan afzond; 't foheen "gedwongen werk, want deze Macas"ratuze Gezane wis wan over de 200 zic3) lea gevolgt, en $\mathrm{zy}$ bleven hem by, , troen hy in een tene op 't veld zyn bret yoverleverde, met werzok vallititant "wan wapehos, en 'i zenden wan z Ge, commitecrden; de ftilftant wien hem , tot "s avonds ken 6 unuren, en langer , wict, tocgeftan. Menzont 2 Gecon3, mitcenden, dic datadelyk in "s konings "Lagger ter gehoor gebrugt, in tegen= 2) woordiglied zyther meette beampen , der Nedcrlanders brief hacn , mitat "ftonden werfteld, en vrangden of gecr s, andere mondelinge lalt hadden; men , gaf goed anewoord, ilzoo die lroning 3) al wry loos is, doch niemant fprit meet, , Als zy R Rad sheer Cyongrow; die op deze "handeling lachende zeide, "thooft na , den koning draitende : Wr bebowat "gecn gelyh? avat wah bier eet berad?

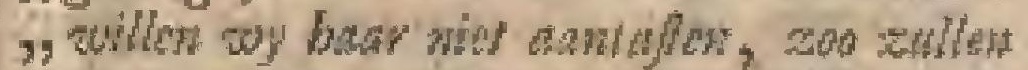
3, z) " $t$ ans dow $;$ en zoo vertiokken de , Gecommitecten. De Crabs Layo en 


\section{Z A A $\quad$ K $\quad$ E - N. 157}

I6\% , \#atwale vertoonden hun over de rivier, y, met voonenten, om zich ran de'Mt:$\Rightarrow$ cratharen te onthith, what op de Ad, miral Radio Palake derwatris afrone, , met 2 goude kiflen, en 2 fohoone , goude alegilas, om and die. Hecren te 5, verecrcin; docn zy Radja zagen, traden , $29 \mathrm{y}$ zelfs door de rivicr, itlecen werzel 5 met de zoon vin Grain Lajo. Na korte y, Zimenfirank wituen $z y$ genclde ge,2 fchenken dankbuntlyk aan, en feluciden; ngenclde Croins waten tzamen anbe3, volen te bewataren een Paggertjen, ag, ter de Hockpagger wan ayen, voor, noende Iockpagger was atr eenelw "Cram Layrm berolen, die om redenen "giet goed wis geronden fiet ran ope-

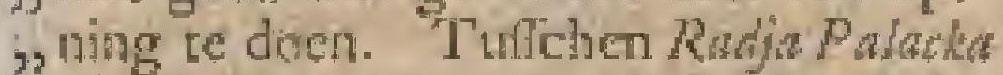
, en genselde Crairs was belprolicn, dat 2, de onzen tufichen den 2 en $3^{\text {des }} \mathrm{No}_{0-}$ 2) venber hunet Pagger zouden nantalten,

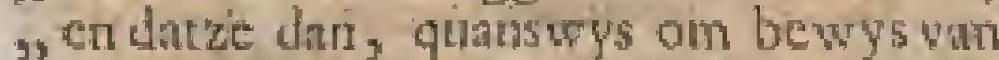
5. vetdediging te toonen, hun volk in de , hpogte zoutuen Jitaten ichieten, en, the , eenige chargies dant uit, regt 17 huis "Whigen, on hun volk te reizamelen, "en hurac gebuturen te vermanten, zich , ra hun voorbecld by de Compagnie te "begewen, that makende met 5000 man, nen van wapenen weder by de onzen , te komen, gelyk dan zullis ter beftery"der tyd wolerokten wiert, mal die yatr 3yen deder hum beft om zich te wer"dedigen, dach de onzen hudien des "morgers al 6 ftuken katron by de wer, tien, on op Ayen te fchiecen, maar de "Berelhebuer Gran Layfan zich gequet,f, " cn zy hun buiten hoop wat onzet wirl 3) dende, verlicten tultehen 5 of 6 uuren "de Pagger, 2 yzere 3 ponders, ch 2 , metale baflen wierden "er in gevonden; "buiten deze Paggers hadden de onzen , nog 2 P'sgrers in "t borch gevonden, , Jie an de liche tham wienden overge3) grevent. Den 4 Nowember wiert Rada "Cajo met or vartuigen nu Turata gezon" den, mede nemende cen wereeringe nu "hare Hoogheden aldaitu. Al dic voor",gevallene had den ryandezcer ontltelt, "Els willente Crain thlo de onzen met , 3000 man milagen, wiert het zetve door „3den loning wan Macitfar belet. Onder "den voorliz ftilftant van wapenen had, den verfcheide overgetromen Xulanezen , stan de onzen berige gegeven, dat de "prins Colawat genegen wits om met "d'Ed. Matehappy weder in wricndfchap "tre leven, en wat op de onzen twee 2. Ternatuanen met cen brief na hem toey.zonder, en zoo zont ook gemelte $\mathrm{Ca}$ "Irwatla een Afgezant tan Magde, om "hem op zekere plats te frueken, die , ook by Calmana in 't veld qum, ", medebrengende een bricf en gefohenk "Wau den Admiral gezonden : die ge-

9. fohiede in 1 bywcten wan wel 10001607 „, zoo Malcyers nis T cratananen, tooncode , alic grootc blydichap, zont ook cen , tolk atin den Admiral met zyne groete, 3, die hem weder met den zelyen liet we, ten, dat th hem angenam zonde wezer, "dac by zich mer de Mlatebappy en zyn "broeder den koning wan Teriate ver"2 zoende; en indien hy genegen was on s zyn E. zelve te foreken, dat by daide"lyk buizen 'tbofeh moeft komen, al"Wata de Admiranl tuet Rudga Palacka "zich ook retrogede; dus quam oot 5. Motude en andere voomanc 'Tematn, men net den tolk zamen tii , matr zy "Hoogheid Coloman, bercid zyode ons ", thit te tomen, wicrt door twee Macas"fattrer ten howe geroepen, des by de , gonzen hun afiched gaf, met belófeo , de zanken wyders wel to bettieren, tot , voordecl van de Matelchappy. Op den "Oever van de rivier wiert ook ecn Pag3. ger door den wyand zelwe vertaten, en 3, aool de onder gellegt, ook was de ,s groote Pagger in 't Ooften wan de onnzen, aver de rivier gelegen, al meet ", tet neder geworpen, en weltig bezeris ting danr in , noch en anderc Piagger; is zynde des konangs eigen verblyfplats, "ging ook toe niet, en feheen de vyatud "2 "r hoofdquatier int den ocwer wan de " rivier Greflic te willen begrypen s an 7) teindevat " $\mathrm{t}$ bofch lag nog een Hoofd"Pagger, onder de bewainge valu Crats क) Linexs, rege agter Borrambon, nat "t trinon was "ct al uitgeligt. Weshat. "op den $7^{\text {den }}$ Novenber en de volgende " machr det Adminal, newens Radg $P_{s-}$ , labr, en Ctpitcin du Pon, met 200 "Nederlindze foldaten, ook de Amboin neczen onder Capitein Jonker, dur hen "ginger, ftckende voor ecrit het dorp "Bon:ye in brand, zynde doevoonts wan "meening cren an 'teinde wian "tbofch soen hilve gellegte Pagger op te nuawken, om op de weiting wh Lingus toe , te leggen, om by goode voontgang op "Borrambont toe te leggen. De koning , en de gemeente rehenen zeer geneyen , tor wrede, milr Grain Tello was hari, nekikig en als defperatat, willende de , onzen op "t lyf vallen. Cram Grefe was , ook in Wadjo aningekanch, zonder dat "hy ceinig merkelyk toeval wiln wolk had s gelcregera; zoo wis ool: Radje Pana, y, neef van Redja Palecks, ath onse zy. inde tan Beron Dan Soping opgebroken, , daar hy in goeden thant wis , Dain "Pabik, nls ook mede dic vin Loeboe, "w Wren in verfeheide ontmoetingen met " لic van Wadjo geweet, co ain de is overhand gebleven, en wareo gemelde "Wadjo's door 't Fetbranden vau de om"gelegen dorpen ontrene hunne hoofd, negerye gedreven; "t voll ani deze zyde 


\section{M A C A S S A A R S C HE}

160\%. "der riwiere waren de oncen voor een ge3 deelte toc gerallen, en de andere na der "Macultaren zyde gewelien; ook had23 der de Lamocrezen 's Compignies , hulpe verzogt, mits de quelling van "Din Matume han ondragelyle was. De "Bimaneezen wilden wel anu de beganc , Tchelmitukken en moord, door hunnen ", koning gedan, niet fchuldig zyn, doch ,y ladden egter niemant ato den Admiranl 3, gezonden om "t werbond te vernieuwen, \%) nog ook de gecifichte bioeders wan den "Bimazen moordenatu derwarts go* "2 Fhilkt. Den $7^{\text {den Nowernber waren wan }}$ , den Koning en Grooten wan Macaftar 5, by de onzen cenige afgezondene ver3, fchenen ; deze bristen een brief, en 2y dat newens 7 zalken geld, das in be9, wonden wierdeu $3394 \mathrm{R}^{\text {ders }}$; dat ook "s tegens, dex awond ten $f$ uuren in ge,Ichrife wiert geftelt, en door de onzen 2, ufgezonden, dic met den clonker in de "legresplats des honinge verichenen, al, wharze met goede ordre wicrden ont,Fanger, en hun door Crain Jer emica auns, gedient, dat den koning by zyo rufte " was, endat zy den Admiral wan "s lo2, things wegen de groetenifie wilden doen, , en "s anderen dangs 's morgens zoo vToce, 5, ths "t harr geliefle, weder zouden kog, then, zoo darae met den brief te rug פ, keerden. Middelerwyle de onzen kenniffe bekomende door een owerlooper, 3) dat de Craws Layo en Bancalo al op de , been waren, en de negeryen Palingen, , onderhoorig an den koning, in koolen ", hadden gelegt, en voorts humen marich , Min Linques gemonen, ook dat Cran "Lingwes met 300 koppen derwarts was 3. Vertrokken, on "t walk (zoo men ge"loofde) weden tot afval wan den koning , te vermanen; war op den Admiral 3. met de chaloep den Dolphyn een bood"Chapper derwates folikte, om hen , tot klockmoedighcid atn te zetten, en "s Compagnies goede meeninge belent "te makten. Zoowierden oole den 8n "November woor dag onze bricftragers , weder na den koning van Macuflar ge, zonden, en quamen nar de middag , met 3 Macafiarze boden te rugge, be, rigt gevende, dat ze aldair wel ont, fingen, en vour den Isoning ter gehoor ,2 gebragt when, en was der konings wer, zoek, dat hen mogte vergunt worden " 10 dagen ftilfand van wapenen, isict y3 alleen daar, matr door 't ganfche land, , omme over de vrede behoorlyk te mad, flagen, en als dan Hecren wan atrzien , af te zenden, om mec ons te bandelen, 3 was op hen 3 dagen ftiltand vergunt " is , zynde ondertulfichen de onzen bezig , om de Turatze Bontgenooten by een te , krygen. Tello was ziekelyk uit "t leger , in een rosbar nate zyn verblyfplates

, ontrent Joepindan gedmgen, gande ross. n Calawatio mede tue hem derwants; क) zoo lad ook de koning an de rivies 3, wat Grefte "r dorp Bonte Birtyn begon", non te verfterken ; 2 pratuwen met "Boegis waren ook den 8 the November „, wit Mariton gevlugt, en by de mzen 3, verfeheenen, die berigteden, dat 'er 9, geen 10 Matcafituren in bezetting lagen, 3, en ganich Maciflizar om wrede vep.

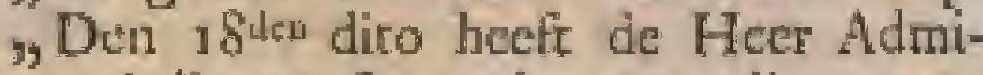
, ral die woelte en hoogmoedige vyan${ }_{3}$, den (de Macullitaren) zoodanig ver3, ootmoedigd, dat by ontrent Bosmbon

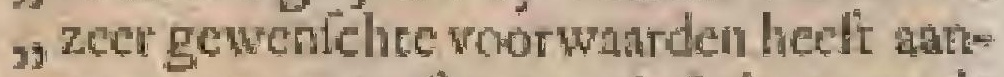
„B gegan, en teritont na "t fluites van de ") vrede het Noorderfort Jocpandas in be3, zir overgenomen, en het welve den nam "van Rotterdam gegeven, zynde cen zaer "Aterk katteel, wan goed drink wrater woor"zien, en op ecr gezonde plants gelegen, "heblyende bequame reede, datr onde "Fluepen yoor alle winden beichue kon,2 nein leggen, en over zulks wel matg "genocimt worden cen voorburg wath de "koltelyke Ooftere Provintien. Over "leze hecrlyle overwinumg, en datr op "g gevolgde wrode, zyn tot Bataria den "I $4^{\mathrm{d} \text { tn }}$ Maat 1608 . tegen den awond 25 w kanonfchoten van "t kaftecl geloft, en

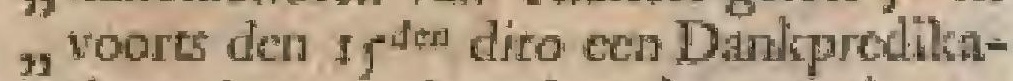
"tic gedan, mitsgaders des avonds wan " tkaltecl rondon de ftadt, en butten"forten 't gefehut gelaft, en vreugde, , rutren nangefteken; doch dewyl de w vreagd zontyds geen diepe wortelen , Ichict, hebben ook gemelde Macadat", ren "t verbond in April 1668 . weder "trouwlooslyk gebroken, hobbende " voor ecrft 2 onzer foheepsboots, yter , gemant met 8 Nederlanders en 6 Boes, gis, vermeettert, en al het volk dood,gellagen, war onder de lehippets Ma*

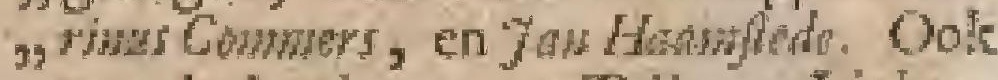
"2yn de lominget van Twlo en Linties, 3, die zich door eco nuder werbond atn de , Compagnic hadden verpligt, wweder wat

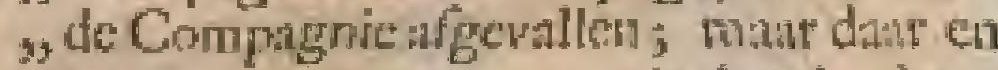

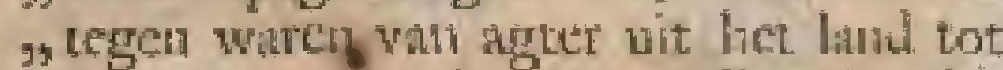
"de onmen overgekonen roo Boegis, dat s, al vry wat moer bial wetoorzakt, doch , de ziche en fterfe nim zoodatig toe monder de Nederlanders, Hat 'er in de s mind Mley over de 100 waren tel ande "gebrigt, eis de reft meeft alle thet э koortzen gequele, en wan welloke zielute , den Heer Adminal zoodanig mede whis ,getrofien, dat zyn $\mathrm{E}$. (onn verandering 7, van luet) gich voor eenige tyd net het , jagt Hoogenlande in zee lad begeren; ,2 niet tegenftande alle deze ongemat: , leen, ichecn "er goede hoope te zya, , otn de zaak door den oorlog tot oen ge, wenflicht cinde te brenger, too matr

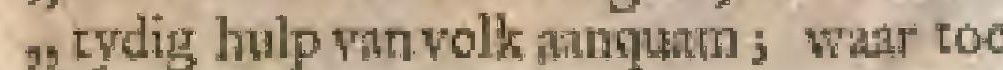




\section{Z A A K E N. $\quad 159$}

I6r8. ; onze Pagger Batta Barth, wan de N, zyde 9) Fan Sambocpo, door den Atruiral Spet,Way weder wicrt ingenomen, on data , doon de wolkeren vin Tuna gelegent"heid te geven tot on orer te lemen, , als dar toe reets geneg nynde. Orze "Bocgis hadden den I Iden dugultus 1668. yonten Maros een anmerlienswaruige 3s overwinting tegen den wyand te evogen, , hum garlch ut het velu geflugen, en 6 , 2, a/getapre koppen betkomen, watr onder n) Het hoofd van Paye Lingen, convoorniarn "Macaffers weldhecr, het joge Purmes, land, bezig pynde newens andere fichepen , op "c furt Sumboepo te knonnereo, 32 forong door zyn eigen kruit. hwly "Lobor, die tót dien tyd onze zyde gehou, den had, wa as met so koppen na den wyand 9, overgeloopen. Tot vertterkinge vaw , ons leget wierden mer de fehepen Da, miaten, 'R Raidhuis, en Wiltenburg, 375 ,foldatea vati Battavia milar Miculfier ge, zonden, dicaldatr ook wel annqumen, 3) Whar mede de Hecr Adtsisal zon digt , onder" 's wyands wer'ken was gevordert, \% dat ze inalkander de band londen toe, reiken. Onder wylen gingen de bricven 3, van wredchandeling walt ower weter. "Zoo hadden ook de koningen Grain, "Goa en Tillo den $18^{\text {den Seprember door }}$ " ecrige Macifarze briefdrugers cen brief y aan zyn E. den Heer Gouverneur Ge, nerat, en de E. E. Raten wan Indiët "gezonden, die nier voor den I 8uan Mare "1669. tor Batavin wertcheen, behelzenic ", cenige verontehuldigingen wegens hut , verbreken des nerbonds, en fichuivende " daar wan de foluuld gehoel op den Heer "Admiral Speolwa, watr uit men konde "bemerken; dat hun het vulu al vry na , an de voeten lig. Onze Boegis heb"ben op den $2^{\text {uen }}$ October des wyands , valtighed of Barres ftormenderhand in". genomen, dair in bekomen 300 gevan"senen, zoo wrouwen als kiuderen, be"Palwen 36 a Egeliakte hootden. Ook wns ", den $12^{\text {ten }}$ Oetober, op den helderen , middag, ftormenderloand ingenomen "zeker wyands werk of lterke Pagger, , tulichen de zeckant en Simboepo gele"gen, en was de wyand bezig om weter" , een nieuwe aflinding, in phats wan ", hume verlootene, te maken. Onze "Boegis waren wan onze vefting Maros , tot in de negerye Pamadingan gendert, " en hun aldata met 3000 tioppen in 2 "Paggers wertlerke hebbende, tullichen is wegen alles in de koolen gelegt, wat ,9 hur wath den wyand woorquam. In $\mathrm{Mey}$ 2. waren onze werken alreede tot ontrent 2. I roede na anu de muur wa des vyands. "Aerkte Samboepo genudert, en genoeg, zatm in ftate van verdediging, om een , hardr Itorm af te keeren, doch Crain ,yerwide, een beroemt krygsman van

\# van den vyand, was met een hulptroep 1660 . "Wan 2 of 3005 manen tot onczer van ") den Macaflat uit het lind gekomen, 3) met welke en perdere thagt de onzen 9) dagelyks wierden gedreigt, miar was " ditur op nog niets gevolgt, dan dat tus, IChen den 13 en I $4^{\text {ten }}$ Mey "s nachts het "jagt de Schelwis van io of It vaatuis" Ben, vol wolk, befprongen, matr man* sn nely af athigen was, lowewel niet troet 3dan 17 of 18 gezondtu mannen datr op 9. wenen. Wolgens de berigen der ge, tringens, en andere owerkomende. pers. „foonen, in 't begin van Juni Bedan, "was onder het gemeene volk van denis vyand groote dende en hongersnond " doeth de Hoaldbeltierders toonden geen inde mintte neiging on vrede te verzoe, ken; terwyl waren de onzen fterk , bezig net een myne te graten, was , mede $z y$ den gulia Juni tọt onder de 1) muuren yan Simboepo zyo geraake, , met voornemen on de zelve te doca "Pringen, gelyk gevolgelyk ook get

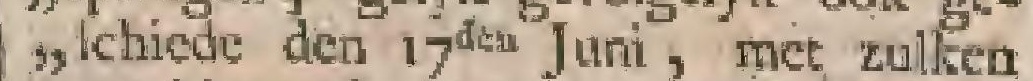
3) werking, dut er cen groot futk wan de " Inutr is de lage fprong, doch de breffe "wan de wyanden weder" met fohanskor"ven en anders geitope wiert. De onzen, "daar op den ftorm verfebcidemal her" "wattende, quinen zoo verre, ditte de , velting belilommen, maar egter zoom , dauigen tegenttant wonden, ditze niet , Eer its den $24^{\text {the }}$ Junii het groot kos , ninglyke hof en hooflk lleel, cn de "thad Samboepo hebben ingekregen, en ;watr wit de vyand landwate in vluge$\%$ te, hun voomamely onthoudende in "het kafteel Goa, hebbende vin alles ge"brek. Over deze heerlyke overwinting "hebbeñ de E. E. Hect Gouverneur Go, neral en de E. Heeren Raaden wan In"dien goedgevonden, een openbaaren "Dankdag re houden op den $24^{\text {then }}$ Juli "1669. en des aronds wreagdeteckenen 2, an ce rigten, als men gewoon is in , zoodanige gelegentheid te doen gelyk "2ulks ook verrigt is, en des awonds de "gewoone vreugdevieren angefloken ,2 2yn, mitsgaders wan "t kalteel 30 kanon"f fehoten geduan, en de Filuic Buswaker"ke, die dezc anngename tyding had "gebrage, brande rondom zyn getchut " los, dala op door den Adminal wán de " reede mer g fehoten wier genntwoord; "w war op dan gevolgt is met het jagt de "Cabbeljaw, op den is $5^{\text {den }}$ Augulti atal" gekomen met der E. Mawimilian de "Yong, gewezen Voorzitter in Ternate. "Het nuder felorywen van de Heer Sped„2, Mas, wan den latiften Juii, behelzende " de ildere voorwarden mee de Koningen " cn Grooten wan Micalfar getrakt, war "by blykt de gewenfte en voordeclige " rrede yoor onze Natic, die deze hoog* 


\section{0}

$M A C A S S$

¿66, w, moedige yyanden heblon mosten inwil") ligen; nls namentyk, dat de gemelte 3) Koningen en Graten beloven opregitenyk te zullen houder en ralsomien de $x$ voorwarden in 't par 1667 . den ister 2. Novenber met hatr te Bonaye gemalst, y en vorders op nieuw, dat zy man de. "Compagnie zullen overgeven al hum gg kmon en baffen; da zy ten believe n wan de Compagnie zullen on werre wer, Penalle hunne fterkien, zonder oit, als nmet bewilliging vin gemelde Con2 Pagnic, cenige andere to moget man${ }_{3} \mathrm{ken}$; dat $\mathrm{zy}$, tot verzelcering vath deze 3) nicuwc verecning, of zelve, of yemant "van de Grooten, ter kicure ran de "Compigitie, by en onder ons zullen

\section{A A R C H E}

, komen woonen. De koningen Cran 166 , ,Gox, Grain Telto, en Cram Linder, nhebber ook by hume brieven yder in ", het byzonder", ant den Heer Gouver"netr Genteral en Rinden viñ Indičn "gezonden, hume rohuld, tegen de "Compangnic begants wegens het verbond"breken, bekent, en wergiffenis verzogt. „Alzoo is deze hoogmoetige Nitic (die 3, zoo ved jatten de Molukze cilanden ;) door invallen heeft beroert, en tehier 3, van al de wercld woor cer dwingeland ", wiert gehouden / onder des Compagnies 3, magt gebrugt, waar xoor de Heere , der Heirfhatren geloof en Beprezen , $7 y$ pan ceuwigheid tot ceuwighed. ,A M EN.

\section{E R D E HOO F D S T U K.}

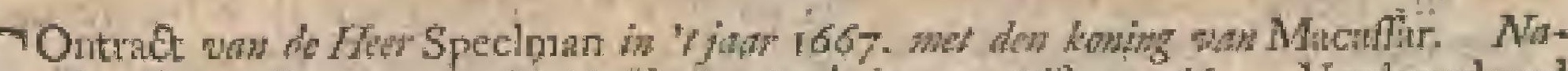

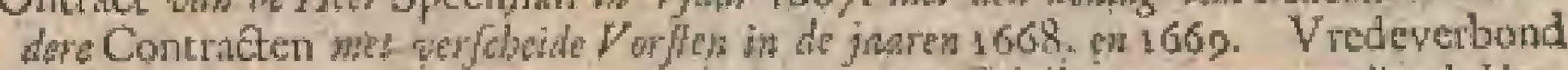

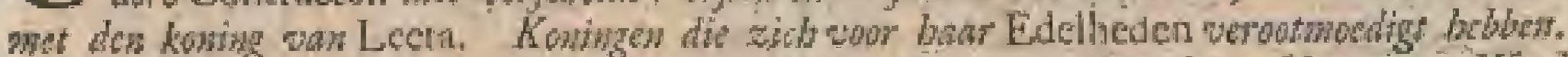

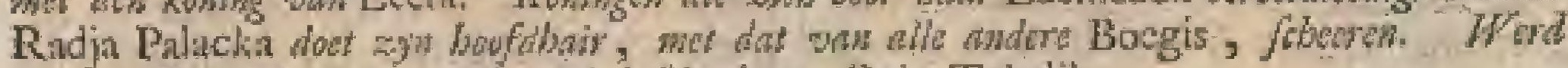
W zyw Ryken befled, on berblk befomkn. Dain Thatile.

Articulen, wara op tuffchien den Grootmogenden. Paducha Sirt Stlkan Lafor Oddy, Koning en vondere Regeering vat Macuffir, ter ecrier, en den Ed. Hecre Gamelis Sfolman, oud Gouwerncur vain dé kutt Choromandel, Superintendent en Commilitis over de Oolterfehe Provincien, Admiral en Krygsoverfte over de feheeps-an ktygsmigt, in den naame fin den Ed. Heere Youm Meitraiker, Gouverneut Gencral, en de Hecren Randeri van Indièn, ieprefenterende de Hooge Regecringe en Oppermagr wegens de Generale VercenigdeNederlanducGeoctroyecrdé Ooftindilehe Compunie in Indiën, ter andere zyde, is gemalkt, geAloten en valtgeltele cen ecuwigdutrende wate en goode wiendfehap en bondgenootichap.

\section{I.}

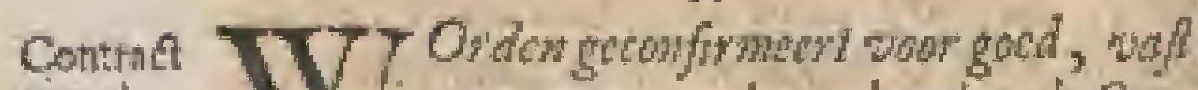
van de $\quad$ en con wadorden gebouden de ConHe्sT Spechnan 1660. op Laravis, in thaferl, wulfow Traten, in doto i $\mathrm{g}^{\mathrm{dew}} \mathrm{Amghh}$

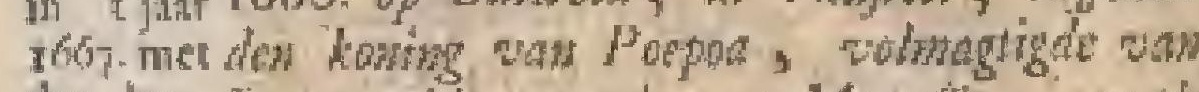
den ko- houegemeld negering op Mada/gar, en de

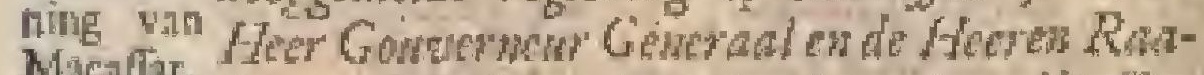

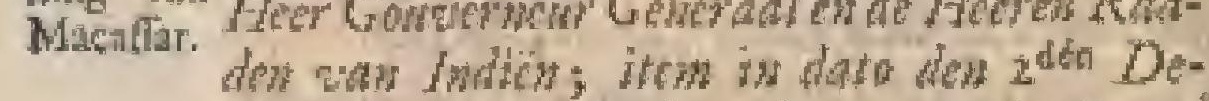
cowper 1660. raffben de vonzaide Regrering, en Jimob Chusw, ais Commiforis wan gedagte har Ed. gomak w gefoten, zhk

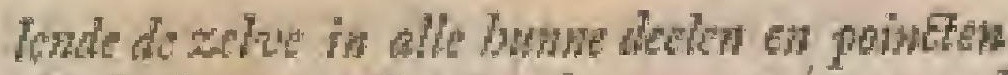

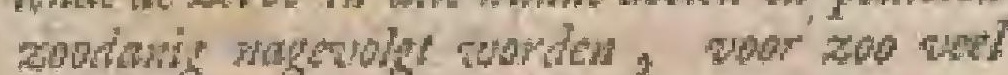

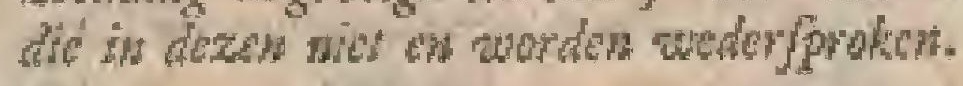

\section{Zouder cesto ${ }^{2}$}

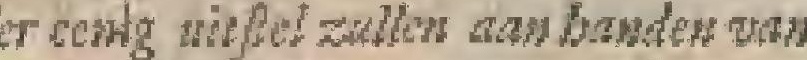
den Admiral overgezewen en getranfportert

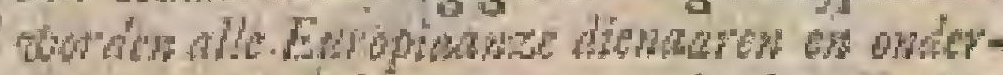

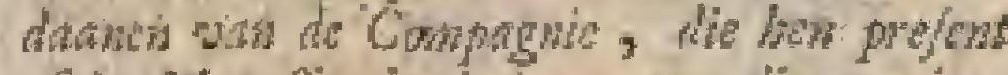
of in Macafin bevinh, zoo die su ntow-

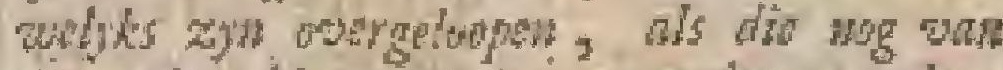

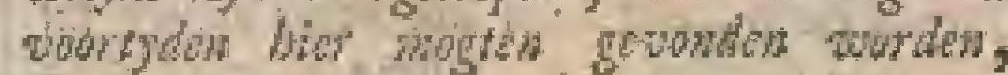
geche wirgezowert.

$$
3 .
$$

Dat an buten wast de Costpagnie ant

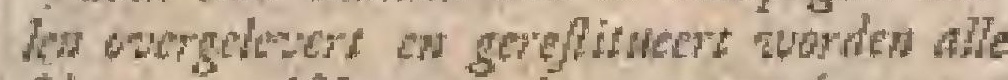
fobcepgeredfohappen, konomen, cóntanten, en andere gocderen, geen witgezonder, whike wit "fobip de Wolojh, op Saley, en 'jagi de Leenam, op Polo Doh Donange

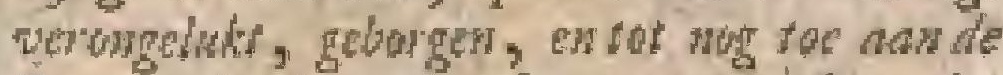
Compague boonden kom te worden sit

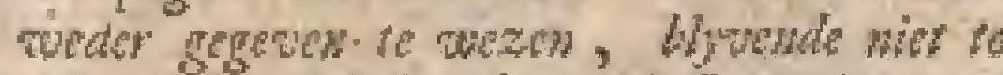
win aigen an do hoghgewd de Regerringe wa Macn/hur zoolanige 8 fukken yzer kanom, als von de Wnolfob bier borafen, indien blyke dat de Compagnit dan wan met 4000 ryders, ten jonghen adrousen wan den Conmilfaris Catuw is woldaran.

Dat ats nog ad gifbicden prompe on

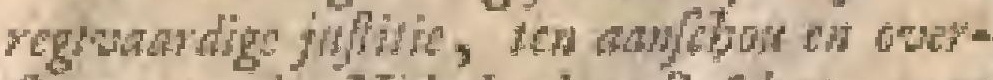
Mans van dow Nederiandzen Rejolen', over zoodange porfowen, als wen bervinden zal

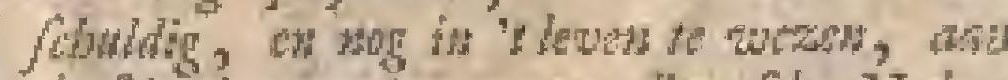

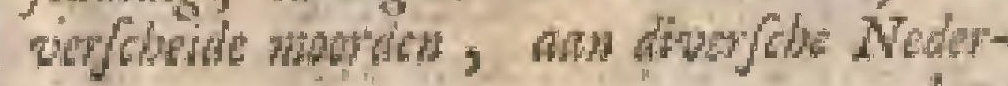




\section{Z A A K $\quad$ E N. I $\quad$ I}

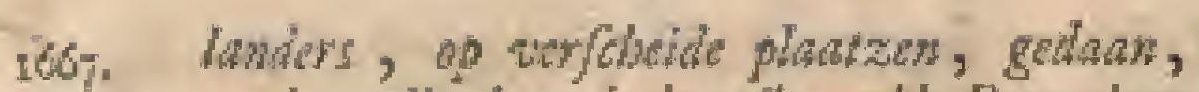
es de welle door de bongtgemede Regecrimge wat alle narfigbod zullen wacten worden opgeragt, for afforik wen zodanige lpasdaden in "t lockomende:

\section{5 .}

De Koming en wordere Grooten was Macoffor , zullen bezorgen dat we tem wren des Compdgnies debireurcu kanon to waldoen, ch te betalen alle 't gene an do conmenio

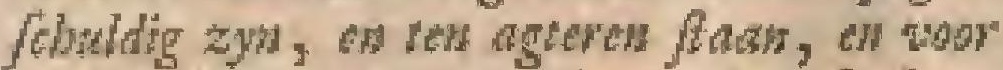
zoa wed dow ads mogte lowen te onbreken, dat zelve opregtelye aat de E. Compagwe te owgoeden, it 't niet dit fajfocn, dan ven

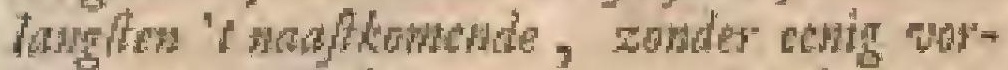

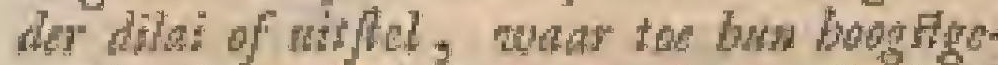
welde Regering door don dezen foroinly verbind.

6.

Znllen als neg doen wotrethen, in cos-

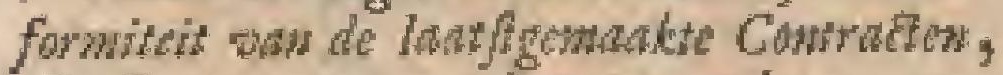
alle Portugezen wet bonten dawbang, gew witgezondert, waar die onder de Regueringe wanden Machalfar avordes govonden: Endewyle do Englzen gebouden wacten worden wor grootc anfolet's en verooriallers wan

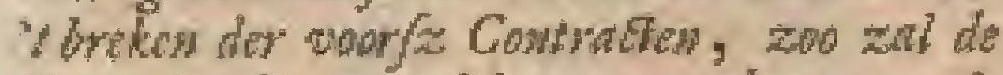
Regering die met al bunnen danbang wet do allereerfe gelesendbeid wede wan onder basme Jurisdile doen werg gat, zonder dat yemant wan we worlz Natich of bum Greatwen oit of oit wet dezen in entige plastze, ondep der Macaffarten gebied weder ter Negotie of anders geadwitter zullen nogen rvorden; ook win net langer mogen werblywen als wittorlyk tor dow laatfon

tos: Zoo on zd bog neer ergens ondtr baur gebred w of na dezm ter Aegotie of anders wogen imalaten, ad-

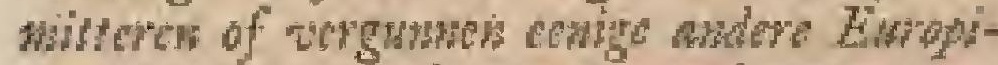

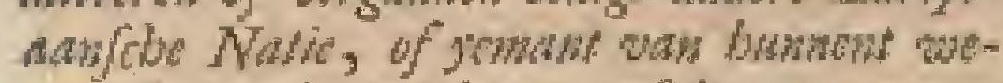
gen, 'f zy ruie ze ook zyn, of boe ze genomt suorden, geen witgezondert.

Ent word de Compggite allen, wet sit-

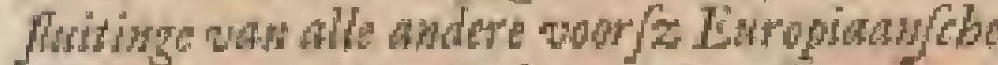
Nalics, onder 't gebied wan Magabor, over. gegewn dan wyen bandel on maghie, zonder dat wok cenige awelere Indianude Natras, "izy Moren, Jawanen, Malcyers, Aasjinders, Siamars, geen wiguzonden, bier ter mark of te kocp zallon mogen brengen cenire Cormandelze, Surarz, Perhanec, Bengadac kecden of kopman/choppen, wog ank geen

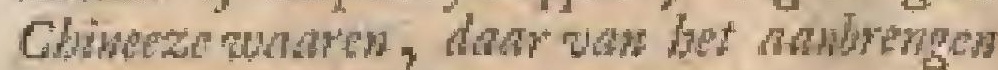

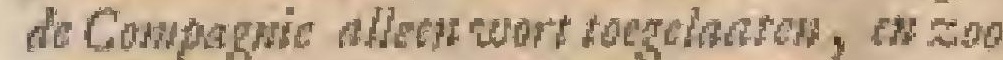

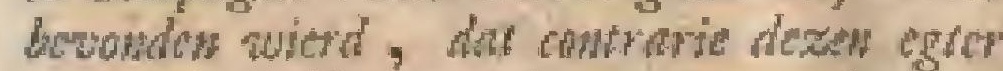

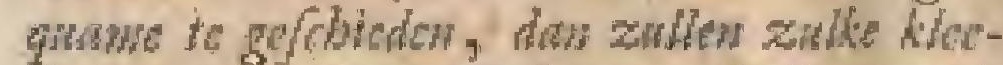

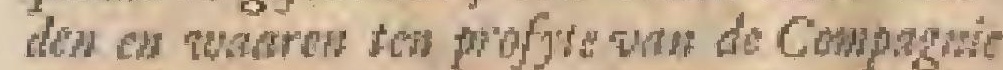
gecoufsquert, en de overtreders dan en bo-

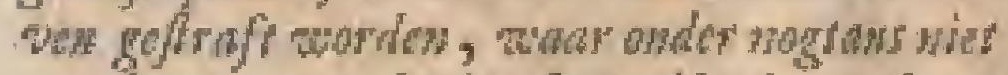
zym begepen aodanige fegte klecten, wh op de Oghkn wo Jow zelf worden geweven. 8.

De Comprgnto wurd by dezen wy gekent ch onthigen waw alle follen en forestigheden, 1667 zoo wan de goederen de ze kom and lo bugen, of wacg te weren, gectw witgezondert.

9 :

De regering of ondetaanen wan Macas

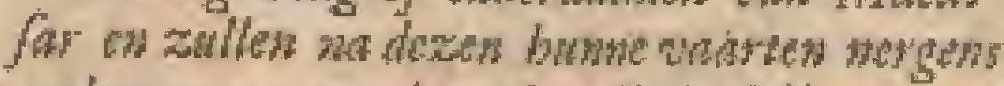
anders mogen maken, als op Buly, do yavananz knf, Yacatra, Bandan, Yambs, Palimbons, Jobor, Bowe, en gehouden quewe dan toe wan des Commandast wan deze

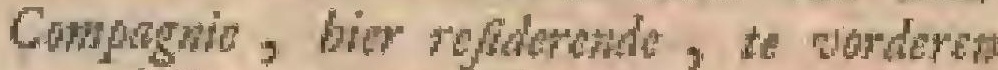
pascedolen, op pane dat wie wen zonder de zelch in zice of te elders and kumen te winden, vor vyandch angezicn, en auggenomon zulIn worden, zohdor da wowtan op Bina, Solor, Timor, enz. cerige ratartigen zenden, of aok Brogfen den boek wan La/fen, zymde de Oojkan wa de Jrat Zaloer, lonen mogen, ook wor ads de ando zydo Beworden of Begaften Bome, wa Mindando. of de cilanden dar ontrent, of werberto wan bf en gord dor gerer, die dat elders kont geronden te worlen.

10.

En devyl alle de Fontificaticn longs den

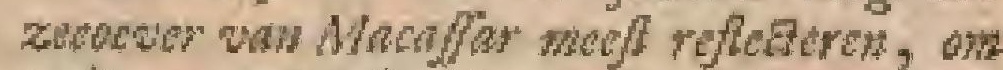

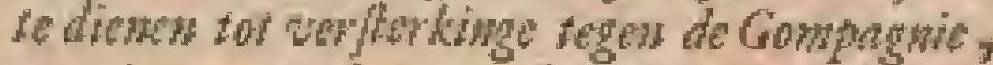
zao is geccordwor, dat de zelve in a r promptinde zathen gellggt en weggenonat worden, als Borrambors, Panndeke, Greffe. Marifon, Borrebos, of andere: Zullende

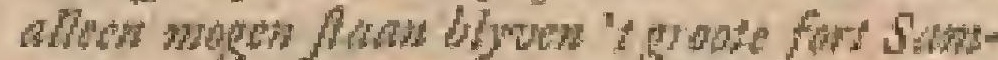
toepo vour de homing, zonds dat ha dezen ectige nientue dad tat pinatze, of elders,

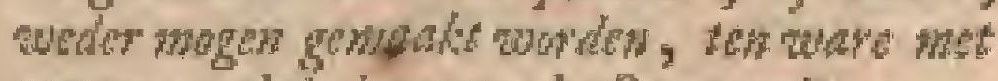
gewen gocloindw won de Compagie.

II.

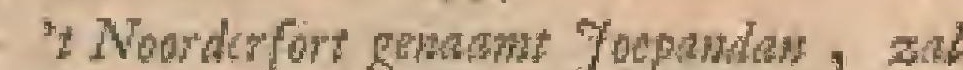

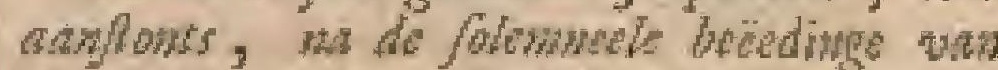
deson Contran, wan Manafars guawilow worden geledigt, en aan da Compagre in

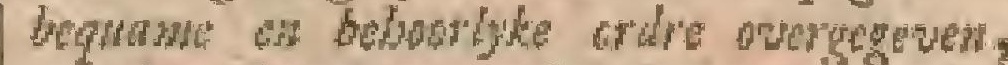

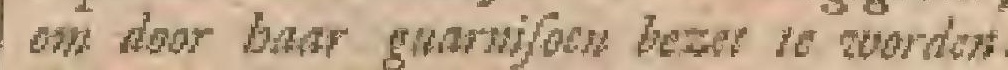
Blywhto bor dorp en land dant onder bebooronde, geivle woor dozen, zonder dat de Re-

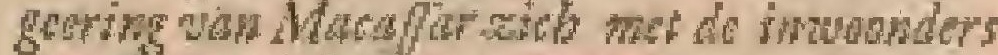
van dien zal bebou ic bemogen, des zullen de hoophiden vaor ham negalie an do bo=

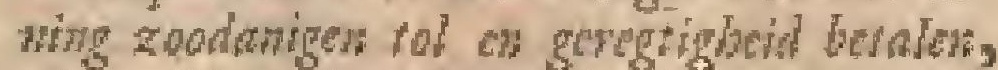
als theber hoogigemedale Regerning en do Compagme no bedongen fans to warden,

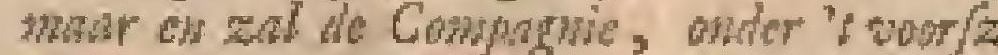

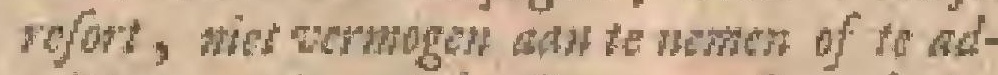
wittern enige misdadigers, of zeodstige als an de kowing of de Grootin cont geld folukig atw, the ware aloorews wilded, en zal Compagmi 's lagéce ad tan ecrilen in zoodonige ordre als dir gelatch is door dow koopman Verlprect, 't zy bimuen of buiten "t fort, ter kewre van de Compdgite, wedor wordly opgeregt:

De Hollandas Monte, zondang ds dis of

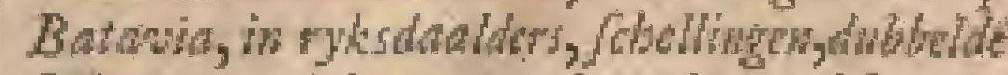
Ahwors witjess, gandoar is, zal bier op

II J. DEEL. 


\section{2 \\ $M A C A S S A A R S C H E$}

166\% Maaffor in argener watarde male cows beblow, en woor zoo vel wogte bevonden wonden, dat bet de geneente regendon, new te Regering an, wet all wermoges

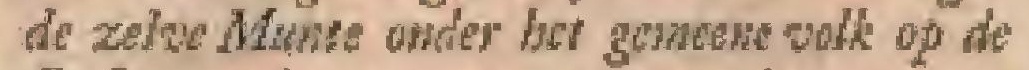
Bajar wede almenam is mader.

I3.

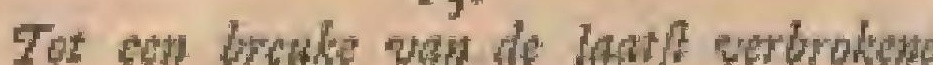
vrede, beloven de Koning en de Grootem atan de Compagnie op te bromen 1000 hatach $n$

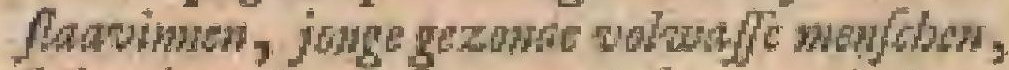
bibandems dat ben wry zal Naw, de hetalinge of met fauven zelue, of met kanon, gosd, of met zilver to doen, wurdende, is conforniteit vas do Macoffarac gevooute, in walken geval erchen op $\mathrm{z}_{2}^{\prime}$. Tey, of 40 Marafabrae goude Mazen yder, mits dat bigr wan ten mishen de belft met de te doenc bezending in Jum anfarada natawia, en de gan/abe refe ten langfen 't wolgende faijoen woldan wourde.

14

Dar des Koning on Gronton wan Macafar wortan bwn riel zillen werwogen te bewoyen wet "t land was Bioma, ex 'brefort, mar de Compagme dan' mat laten gevorden mar bun welgewalls, zonder. de selve we of oit mar dezen, os deen of d'andere wyze, direalyk of mdiredclyk, wet rand of wet daad, te bulp to kamen tegens de Conpoggie.

$$
15 \text {. }
$$

De bougfigendte Regecring bekent gedtan wezende, di growwlye maord, an johlmJuk, war an zich de koning van Biens, zyn Choonzoon, Crain Dompo, Radj Tambora, Raja Sangalec, en lron wolgers, ferk te zomest is Pojoonen, wafl Biwanezm, in burne foric tegens de Compagrie beblen wergrepen s nemes arn den zeluen Rad ja Biema, en zao vel was zy medeplighen als "er pewondes worden, in bander oud do Compagnale

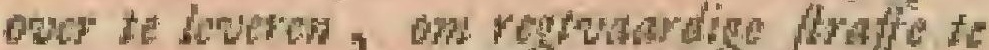
ouffongen, ingelyles Clain Montemalano, op dat by zine was wisdad in allo ootmod wargifenis weratek.

$$
\text { I6. }
$$

Zullen adn da koning wan Boton ten etr Aten revgadon, en repinueren, alle zoodanige

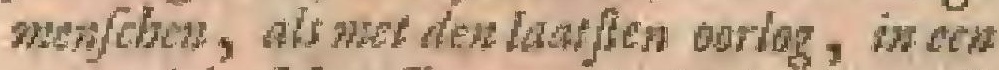
oocrual der Mackfaren, in dat land reroof

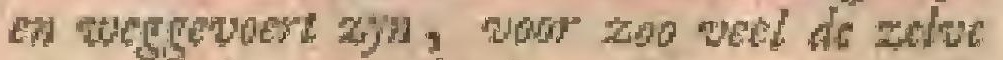

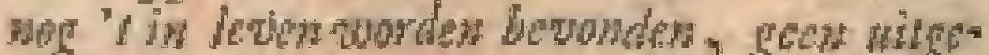

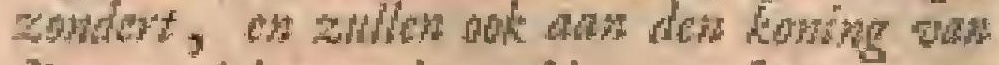
Boeson wiskeren bet getd, ontfangen woor xoodange Bowoncrs, als zedlot denverhap

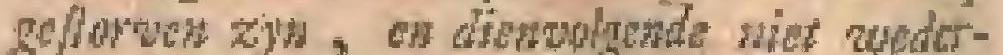
gereven konney rewden, zonder nu of ait,

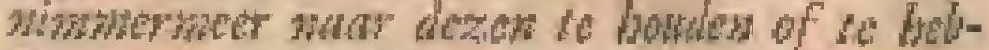

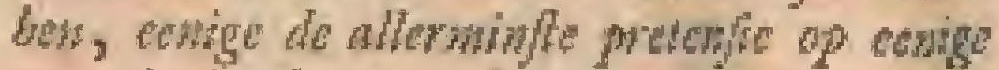
wen de landen way Bocton, dar wan by dezen wud oxpres renunciante.

$$
17
$$

Ook zwhen an den kongra van Trmat wedergewen, in eyrent wyze als an bet 16 art., de genofle mowlow wan de Xwhs,

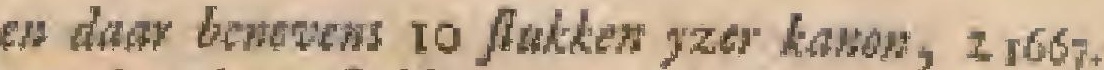

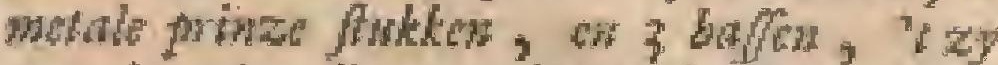
met de zelve de wan daar gebaalt zyn, of ander in de pladze, werkarende op de zelve cillodon geeme pretenfe te bebhen, of te

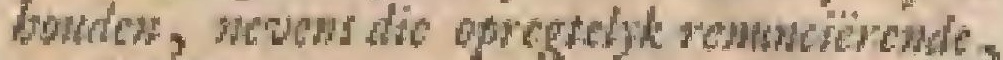
ten beboeve wan gemelde koning, wan alle geprotenderde esgendon op de eilowdensaleyer, ch Pantrano, als made of do ganfobe Ooflkof van Celobes, to rekenen wan Manado of tot adn Pawjfano ree, de cilarden Bangay en Gapy, als andere dp de zelwe kuf gelegen, daar onder wede begrepen: Mandbar, Monadu, de londen wan Lawbagy. Candipan, Buol, Towedi, Dampellar, Ballis-

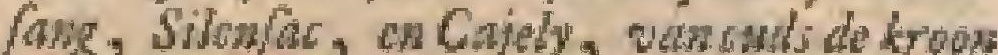
wan Ternate in gyendom compterende, wh de sulke de bouggemeldo Regering wan Macajor opregrebliffiat, belowende wimmermeer wa dezch de honing wan Ternate daor whe te turberen. 18.

Voorts rewherient de bogg g gcmelde Retee ring wan alle beerfobapye der boaris en Locboe, de zelve Landberes erkeninde wor wrygetooren koningew, princes, en beeren, daar by geen de alderwinge pretemie op is beldewde, blovende witsdien, zonder enis withe, den ouden kowing wan Soping, wet alle gywe landen, vrourven, kisderes, buisgenoten, goederen, nicts wifgezonder, in polle wryclow te flalew, ch can onate banden over te geven, benevens apk zoodanige andere beren Hoegis als elders onder bet Macafjarts gebied in gevangenis en balling folop op belen mogten zajs: itch alle wrowwen on kinderen der boegis, welke nog onder de magt wan bogghtredagte Majeflul wogten gewonden worden gene witgezondert, op dat aboo de grond gelegt worde lat en opregte vrede in wriend jabap.

19.

Zoo verklaren ook de koningen van Lajo es Baweala, met bet ganlese land van Thrata en Badjing, en al wat daa onder boort. floande dew oorlug, tot de Compagnie owergekomen, te er kennes voor wrye kowiggow, berch, en landen, dacrac niet ter wereld op an beblen nog on basden te pretendecren, dezelwe ondlaande wan alle wourgande berfebappy on gebued, wa en allwos.

$$
20 .
$$

Ale lawden door de Compaguie en butre Bongenuoten, faande den worlog gtwomnon en werovert, grekent van Bolle-Boloe of, tot an de dandon wan Torala toe, wowrs weder wan ginder ton bier aan Bowgay, zWlen zyn en byuen als oy gen gewoinch landen, cubuare Bantgenosten, volgens rgt van worlog, wadar op wits dies konisg niet weer beboud eenig reg! of eygendom, wog ook niet op de inowonderen van dess, blyoende alkes tor dijpolitic wan do Comprenie, ommo dar

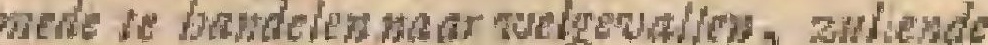
by overkinfo wan de komingen wan Panat 


\section{Z A A}

166. ch Bace konen alogenuzen wordon, wat ons in kragte woor/z Bemorden Matafhr is computeresce.

\section{$2 I$.}

De isaden van Wado, Boeloc - Boloc en Mandbier, als zymde misdadig aan de Com pagnie in baare Bontgenowen, werhart de

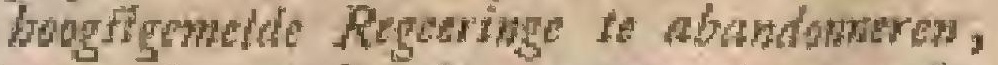
en onsdaur wede te loals geworden, zowder dezche diellel of indiredelyk wa of ait na dezen, te zuldew feconderen met wall, wa-

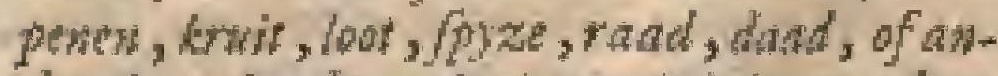
dowins; be her opk genoemt thigte worden, ter goder trowere.

$$
22 .
$$

Zyude anderling ver,fan chavereen gekomen, das do Botgis en Toeraders dib ate $M N$ ca/fasza, on woder Maca/faren die Boegtis of Toratze vrowuen beblen, elk de zine anl werngen $n$ a zill te nemen, 'tzynes beiteve, getyl als dat belanm, en voorts dat wu woorian de Macafiaren, sibl begevende onder de Boggis en Toeraters, ook weder de Boggis on Toeraters onder de Monafianch, niet zullen quermogen anmgebouden of ingelaasentewrden, ais wet toglfoming en hemis van yechls wetrig Her on Koming, in zonder dis woden worden afgewezen, ch weder ha buis gezonden.

$$
23 .
$$

De boogetremalte Regering belooft, in

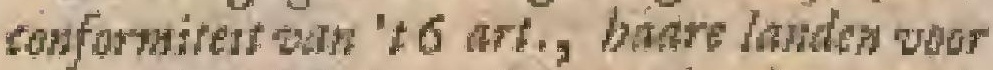
alle andere $N$ atien gefoten le boudon, en in

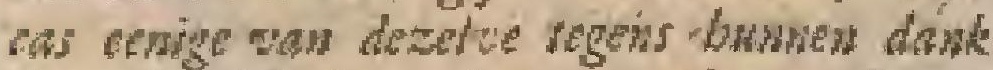
dear in zith begeerden ter neder re Man, Rezelwo met alle verwogen ca magt tet awlich

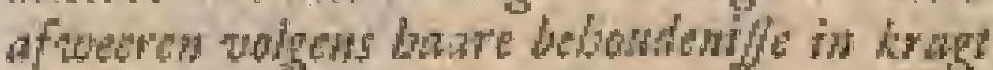
wh dezen Comtano, dach in gevalle an doar toe niet wormogent waren, en onder de band te jowak vilen, als das de Compague, ats bumen fobr-en foldermet, rit buth zouden werzochen, alzoo ay veritaren de

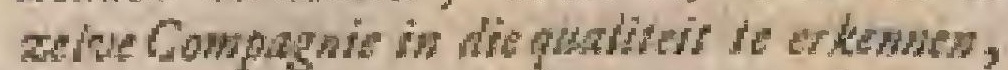
des zulen zy ow gebonden wezen, daat toe geropten wezende, de E. Compagste te a/ffrom wet alle vermogen, tegen zoodanige vandwals busber, by of ontrent Macajar, tegen de Compagme mogten openbiaren, wat whbintenife, dat zy ingen onderbandeling ton erede of anderzins wenten athen men cenige Natie, dakr mede de Compagnie in oorlog is.

$$
24 .
$$

Op alle welke worf contrater, en van

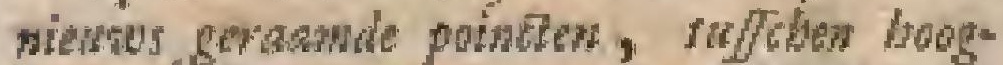
gedagte Koming en Grooten wan Madfar is

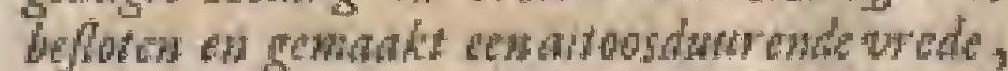
wiend-en bontgenoufbap, in de wilke ook worden berepen do growmogende koningen wan Ternate, Tidor, Batson, Boelon, de koMingen wan Bocgy, Sophs, Ladoe, Toerata, Luay, Bading, mel alle basie landen en orderdacnen; irem ood Biema, en nog zoodange andere Landberen en Vorfen als mar derats, zullen nuerzoden mode in dit bantgenotic bap te mogen treden.

\section{K E N.}

163

25.

Of bet gevile dat thebch de bontgenooten en de refpelive kowngen, door bet cton of "I ander wistorfand, cenigediferente quime te ontfats, zoo zmilen paryen mise fraks walkanderen dagrom enig whemat of owrog

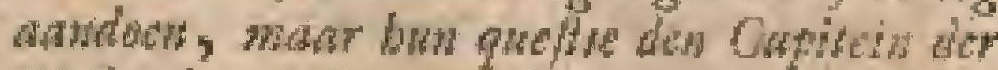
Hollanders bekent masken, wane (zod bet mogelyk is) door bemidteling vis dexelce.

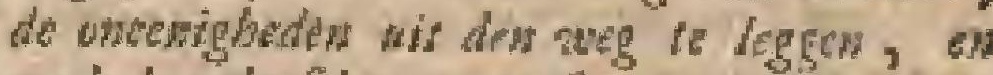

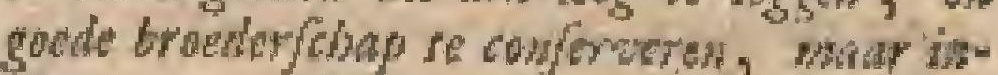
dien oen wan de pownen na gen bemiddeling hijlenen en bortuklig byow whis, zomder zich na de reden ite wegen, whtan zullen de gensene bontgenowtes de onderes, whar wor-

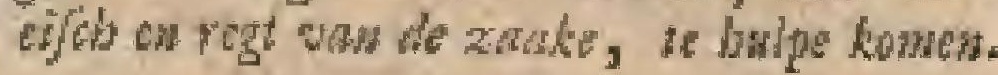
26.

Wannew the dit wredewerband onderterkent, betedigt en werzegeld zal aotzen, zal de Koning en Grootes von Macafar yelowdew zy, meves den Admiral, han Buthwia te commineeren towe vooname Konisgen wit bet midden wan den Rat, " sy Crin Tello, Linclies, Poppoc, Crongron, Greffe, Catapar, of ves whinen rue wit

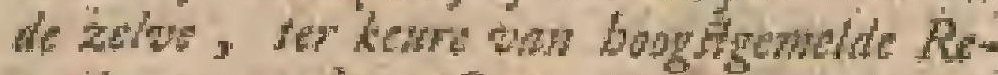
geringe, an dezen Connale wan wrede dan de Ed. Heer Gorvenuetr Gentral, en de Gerren Ravidon wan Indien to prefenteren, an bw Ed. gocdkewringe dadr op te veruesken, onler werzekering, dat gemelde Hecren

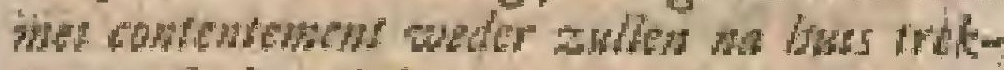
kon, doch zal bei dew Heer General wry

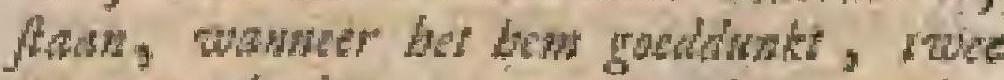

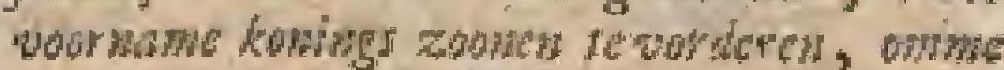

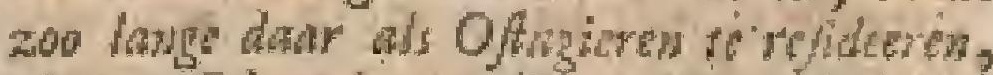
als zys Ed. meint noodig to zin, dho zal dok roted den köning wan Machlar 'f zymon believe, by langer ocrbilf wan tan jaur, de zeloe door andere mogen doen terwuigen, en de Compagrate gehorden ajn zoodatise Princen ic confervercm in compatiled repa an eere, zonder qun yenam do allowinge over. lapte boden.

\section{7}

Tor anpliate wan "t 6 art. word wergin dat de Compagnis de Enzelf ben to bunn goederen alhier athen wernugen te ligren, $\mathrm{cm}$ nat Bataria te voeren, zonder dat bet den koming zal wermosen tegen te flakn. 28.

Fem, fot amplatie on 't 15 6r'. is be loof, da indien do koningen van Bitma ch Montcmarano, tevende of dood, in 10 dagen wiet ruarden gewonden, als dax rot borge in banden was de Compagnic te whilen Relich de zoon wan Bicha, en de zoow van Montewarano.

De Regeringe blogft atw de Compagnie wil te keeren, in vergoedisg wan baste onkoftew ten oorloge, $250000 R^{4 t}, i n$ wy

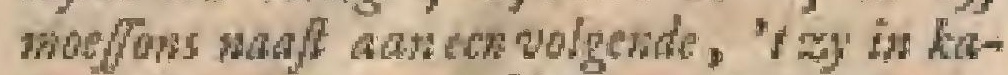
now, 't zyinkopasifchappen, "i zy in gout, zilver of juweles, el war an waste.

$\mathrm{X} z$

En 
30.

En op dat alle de bovenhande Ponden des te teliging wagers wowdth whderbowden,

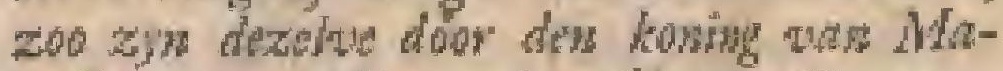

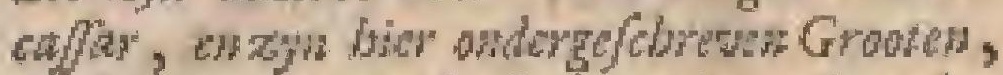
en by tugen wan de Comparsis, door den Admiral, novens ool de Konimen en Prin-

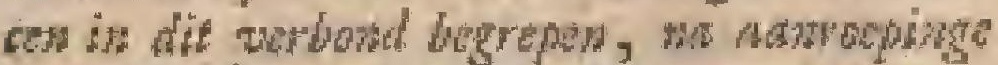
war des Learen Heiligen Name, beedig', getchent, en verzegelt, alk op zyn wyze,

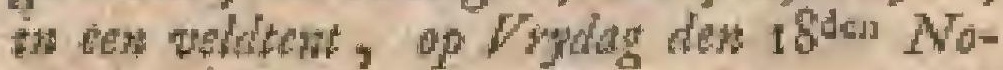

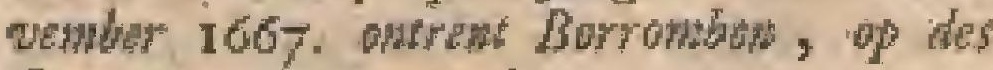
Compagme eygen groud,

\section{Naarder Contraden, gemaakt net Radju 'Tello en Crain Lunckes.}

Den $9^{\text {den }}$ w I $5^{\text {den }}$ Mant "sjaws 1668 .

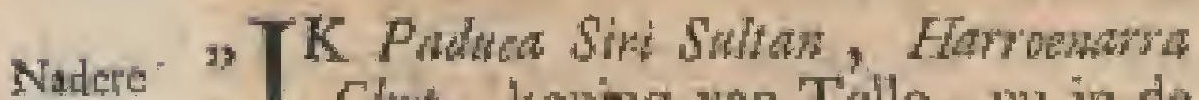
Contra- "I Cbyt, koving van Tello, mu in de ten met " latuftgendakte vrede met Macaflitr geFerfelyei- "wotden zynde Compagnies yrund en de Wor" "bondgenoot, gelyk dar wan het gefen in de , malkte en door ons beédigde Concract jaren, ens, in " $\mathrm{t}$ breede fprecke, my erimerende de

166\%. - "getrouwheid en waderlyke zotge, waar " inede de Compagnie doorgans en altoos " is angednat ower" hatate verbonde vrun"den en bondgenooten, verklatre door "dezen, nate ingenomen advys van mync "Landshecren, broeders en onderdanen "te raade zyn geworden, my ende mynen "ook nevens dien myn ganche ryk en " jurisdictie nog nader" en in 't byzonder "met de zelwe Compagnic te verbinden, "en t"evens te verzoeken; dat ik niet al"leen in har befcherminge particulier"lyk angenomen, neen nuat ook myne "kinderen, zoo by myn lewen, als ook " nat myn dood, met my anngezien "mogteh worden, als vranden en wer"wancen van de E. Ooftindifche Com"Prgnie, dieze houd ch neene in hintre „2, vaderlyke bewaring, op dat ons van "nicmant tet wereld ecrig leed of onregt 3, moste overkomen, e gun den Heere , Cortelis Spedman, Admiral pan ' Com"pagnies magten alhier, reprefenterende , door kngt wan zyne conmilite de "Hooge Overigheid wan den Gouveris neur Genernal en Rataden van Indiën op "Bativia, te mynen begecren door ${ }_{3}$ Paduea Sint Swlta Mandarlaba, koning , wan Ternec, en Mamalyang, koning , wan Linckes woorgedragen, en teeke, nen gegeven wezende, heelt het goe, dertictentlyken en in een oprege herie "believer tan re nemen: Mirs welke1s , ik my, myne kinderen, broeders en 3, zulters, woonts alle myne Rykshecren ,en onderdatinen verbinde tot alle op= 3) regtegetrouwheid, ons geheelyk over3) gevenule an de goede voorzorge van de
"Compagiase, alzoo dat hitre vyanden re6\%, , en virienden de myne en on'ze, en wy , alcyd bereid zullen wexen, met on ne, wens hatar, darze ons komen te rocpen, , ter corlog te treklen; gelyk din ook ", myne kinderen en kindskinderen, ir ,2 Cas vin myn overlyder, zullen ftath en , blyven onder haue vaderlyke woogdye, "en zoo 'er op myn afterven geen by ") levea waren, of dat zy lieden lterven3, de, geene narlieten, zullen myne "Landsheeren, broeders en vrienden, "geenen koning in mylu plattre mogen , verkiezen, als ten overtana en met ", goedivinden wan de Compugnie. Ja jim") gevalle ook zulke myme kinderen hen ", nict ma behooren quamen te gedragen, ,2 2 al de genelde Onthindiche Compngrie " ten goede wan myn hind en onderdad, nen, ook yennur anders van de natale ") in hun plares mogen ftellen, 't gecne , ik alles nit opregte herte de Compangie " toencrtrouwe; en op dat hier pan yoor , de ganfche wereld blyken moge, zoo "heb ik dezen door myn Ryksegel ver"zegeld, en door Dain Margagon, myn "broeder, en Carre Moulle, mee Gale-" "rn Care Pap, laten onderteikenen: "Uok de gctrouwe onderhoudinge van "dien op den Alcoran, Da onze wyze, "ten bywezen wan Mr Daneker wan der

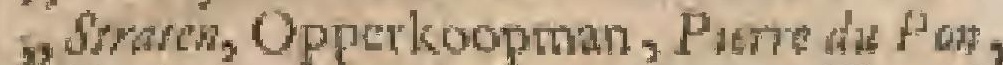
"Capiceil, en $A b$ abow Gabbria, Fiscant, is betworen, zullende als her des Admi3x'als begeeten en goedvinden zal wewzen, dezen in myn fand en plancze "a door openbane Gomllag worden ver"kondigr. Aldus gedani, befworen en , werzegeld in myn fort genanme 'Tello, , op den 2 folter var de matand Ramelâ, "des jantrs ro78. zynde, volgens de $\mathrm{Ne}$ "derlindze ftyl, den glen Masr 1668. "wezende hica over tor getuige beroepen " dea hoorthgebooren grootmogenden "Mandar/aba, leoning wan Temate, en , mynen bloedwerwaine Momalyare, ko, ning ran Linckes, dic to beceilseninge "van dicn, medo hun zegal hier onder "s geftele hebben.

"Wy zyode geweeft exprefie gecom. y, mitteere dool den Hoene Admiral Cor"nelis Spelmon, verklaaren dat in onze , , prefentic, ter plantze voornoemt, al "zoodanig desen Contrate is folemee "lyk, zelts ook door den koning en ge,t tuigen op den Alcoran becedigd ende "werzegeld, het zelve al te vooren duis, delyk begrepen, en grondelyk verttañin, "gelyk wy her dan ook an welgemelte ", $2 y n \mathrm{E}$. in dierwogen gerapporecre heb"ben, en overulks geordonnecrs $z y$ 25. Compannies acrel thier nevens te ftel, len, met onderdehrywing van den Se, eretaris, ten Dage en Jare als boven ,3 in 's kafted Rotterdan op Mncalàr, 


\section{Z A A}

1668

9, was geteikent $D$. wan der Sraten, "Pieme dis Pon, A. Galdawa, ter zyde ") ftont Compagnies zegel gedrukt in "rooden lakke, wate onder geflicheren "Atont, ter Ordonnancie van de Heer "Admiraal voorthoeme, ten dage en "plattze gemelt, en was getcikent

Hendrik Louf, Secretaris.

9 TK Mandyong, crtkoning wan Tsjin"I rame Linckes, enz. Wryheer in "t koniokryls wan Macatar, met rype , andage wel en ter degen opgemerkt, 2, gelezen, en begrepen hebbende het ge,3annexeerde Contrict, wath mede te „, mynen eygen overtam mynen broeder "s den koning wan Tello zich am de Com21 Pagnie fueet verbonden; verk late voor w, my en alle myne zoonen en dochteren, "hiriggenoten, landen en volken, my 9s niet alleen mede zoodanig te verbinden, " mar ook in "r geheel te ftellen onder ") de gehoorzamieid en befeherminge „ toan de E. Compugnie, die ik belove , in alle hatre bevelens, dienften en or, donnatiotio nu en altoos in der ecuwigs) heid gehouw en getrouw te wezen, z, overzulks tot betcekeninge van watar, agtige warheid en myne fincere goede " meenilige, luebbe it dezen, houdende , het Conerid van Fello, hier in geinfes reert, met mynen zoon, genannt Tantara Crawi wa Patsa, in handen van 9, den Admiral befworen, verzegeld, en ") anderteikene, mede ren bywezen wan "Dancker eas der Sraten, Opperkoop", man, Prerre du Pon, Capitein, Abasham Gabbeswa, Fiscal, zynde hicr over s,getuigen the Bondgenooter Koningen 3. Van wiens wegen hen zegels en hath9, reikeningen hier onder geftelt hebben; , den grootmigtigen koning wan Ternate, „2 de koning wan Palacla, en de prisce 5. Galeman, en den koning var Layo,

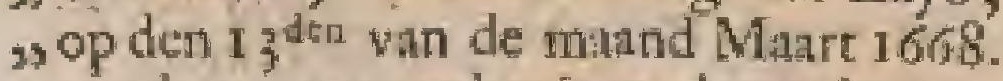
3, zynde ra onze rekeninge den $2 g^{t}$ er wan y, de mand Ramelầt, des jaars to 78 . in 37 "r lanted Rotterdam, onder Macaflar, w, onderltonden de zegels van de ltoningen , van Ternate en Plicka, in rooden , Jakice gedrukt; lagerftont, Nota: "Deze bezegelinge en onderteikeninge 3. va 't bovenftiande is eerft in wollen

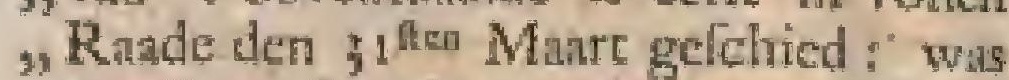
,geteikent Dancker van der Siraten, Picrie "dve Pon, Abrobasm Gobbema, in margine ,2 Atont Compagnies zegel in rootien lak , gedrukt, diar onder Itont, ter Ordon") niutie wan de E. Heer Admimatl, ten ${ }_{2}$ dage en plaarze voornoent, en was ge, teikent

Hewdrik Louf, Sccretaris.
K E N.

165

Naardere Poincten.

I668.

"W TAar op den Konitig en de Gale. "W rans, voorts de geheele regecy, ringe wan Tello, iten ook Cran "Lincke, nas woorgande verootmoedi"ginge, weder tor warde Bondgenoo2, ten wan de Ganerate Compagnie, en "Van wegen de zelve uit den nam wan "de Ed. Hecr Foan Maraliker, Gou9, vernent Generaal, en de Hecren Randen "wan Indièn, aangenomen en imgeliaten „zyn door de Heer Corwelis Sprelman, w, Superintendene en Commit]aris ower de , Oolteriche Provincien, Admiral ca "Krygsoverte ower de fcheeps- en krygs= „) mage hier op en ontrent Mucallar.

I.

"Dat welgemelte Hecren, Koningen, " cn de ganfche Regeeringe heiliglyk on"derhouden en getrouwelyk natkomen "2ullen, nu en altoos, ecuwiglyk en on"werumetlyk : liet Contritet en ceuwig 3) Verbond tulichen de Regeering van , Macaltar, en de generaale Nederlindze "Compignie gemialst, wederzyds vér, zegeld, cu rolemneclyk beeedige op , den I gea November I 667. tot Bonaye; "irem nog en nader Contrat unffich 3, den Koning en de Regeering wan Tello, s, en Crain Lincker, met welgenelde Com"pagnie aitngegatn, beforen, verzeyeld „ en beécdigr op den gdea Mare des 3, volgenden jaurs 1668 . verkharende dat "het aftreden van het zelwe, door guat, den en verkeerden radd, hat was ten 5, allerhoogiten leedt, enderhatwen datze 3) hun kendel grootelyks verpligt, wam , datar over by de generale Companie "op hnar oomoedige bode, gemade te "hebben ontfangen, an de welker gocn, derterentheid $z y$ lum mitsdien in bet "geheel owergawen, onder verzoek, dite "ze in 't reguard wan de geldiommen by "t Bonayze werbond beproken, voor " zoo veel dat in hum andeel annging, ", nixe boven hunne magr befwate mug,s ten worden, protelteerende grootelyks " onvermogens re wezen tot het voldoen „wan dien, zulks is hun onk wetzeker, „3 dat ze ongetwyftel op hurne vertoot muinge door de hooge Receringe van "Indien, dezen angagande, net nille , billyke en betantinelyke ciwititei ge"tritetert zouden worden.$$
2 .
$$

7. Hebben zy verkliture woot een groote "gunfte en weldad an te nemen, dat " de Compagrie her beliefde te laaten , behouden hame handgewearer en mus, quetten, en dat ten opzige zy har vata "de vondere regeringe van Micallar af, gebroken haduen; en de eerlte uitqui"men on har te verootmoedigen, thet , beloften, datze zonder eenige vertchui$x 3$

nling 


\section{M A C A S S A A R S C H E}

1668. , ling zouden atnwyzen, en anftonts 2, overgeven, alle zoodanig lige kanon, y en baflen (fwata kanon hiadden ze niet , meer) als de koning en regeering van 2 Tello en Crain Linder nog cocbehoor3) dern, "t zy dau dar het wis beruftende „2 in Tello, in Goa, in Sadrebone, of el", ders, zonder daal woor iets te preten, deren, mar bedantuen de welgenelte "Compagnie grootelylss, datze het zelfde 3belietden am te nemen, tot afmindewringe van opgenelde fohuld woor de s) walarde.

3.

, Beloven $z y$ tot reperitie en te inecr3 der beveftiging van " $\mathrm{r}$ Bonayze Contrat, n zoo het de Comprgnie zal believen te g, ordonneren, de wallen van Tello rond, on neder te werpen, en noit an, dere fortification te matken, fils ma " woorgande todtenming en bewilliging „, van de Conpagnie, direetelyk nog inw) divectelyk.

Ingevalle de koning en de regecritug ", van Goa, hat op de overgezonde acte 3, van Pardon, niet mede quamen san de "Compagnie te verootmoedigen, dat $z y$ 23 alsdan als goede en getrouwe Bondgeक) nooten wan de Compagnic, newens de 3, vordere Geallieerde Wrienden, de zelwe 3x zouden houden woot hunne openbante s vyanden, en mirsdien dezelve nar ver", mogen helpen doen alle mogelyke fcluade „2 en atbreuke; doch zoo al lichoon den ") koning van Goa wederhoorig blect, zoo "ch zullen darrom andere koningen en "konings - kinderen yan Macaflar, nog , ook geene van de onderdanen, die , haar veroótmoedigen en om gentude wer, zoeken, niet afgeweren, matar nige, nomen worden, mits due de koning en , regecring van Tello, voornamentlyk ") geenc luiden var Stant en conditie zul, len inlanten, zonder dar van t'elkens "prompte advertentic te haten doen.

5.

"Dat ingevalle Crongron, ats putre oor" Zalke van het verbroket Bonyze wer, bond, zich in 't byzonder nict l'eenc: , maal ongewapent komt vernederen, "en bidden oti genade, zich itellende "ter volle dipolitie van de hooge Regec"ring op Batavia (onder verzekering, "doch ongevergt, dat den zelwen aan , lyf en leves onbefeliadigt $x a l$ blywers o dat $z y$ hem alsdan, in zulken gevalle, , zullen helpen vervolgen, vangei " of dooden, ntar gelegentheid, en ratle goederen, welke wan hem gelre, gen worden, ftellen in hidien van s de Compagnic, tot atkortinge van ", 't geen ara te Compotgnie, wolgens "'c Contract voorfy, betwalt moet wor, den:
, Dat de hoogftgemelde konifg, ter , begecre van de Compagtie, zal ge. ,houden zyn, tot verzekering van deze , nieuwe wereeniging, of zelve of yemant , van zyne Grootes, welke de Compag, nie kome re vorderen, het $\mathrm{zy}$ dan voor 3) altyd, ofte yoor ectigen tyd, by en , onder ons, op een bequane platze te , komen wooner.

\section{7.}

, Ten latiten belooff de hoogfge, melde Regecring en Crats Linther, om , alle quame bedenkingen, difidentien , en mistrouwen weg te nemen, datze "har volgens de colkimen, onder de "Nedcrlithders allerwegen gebruikelyk, ${ }_{3}$ noit bintren Compagnies valtighejen , 2ullan komen; als net weinig rezel"Flhap, doch dezelwe ongewapent. ", moetende "c verdere gevolg buiter bly "ven, ten wate om by zondere voorvil, lende redenen anders. wiert toggelaa. ys ten.

,Tot folemnecle beveftiging van dit "alles, zoo hebben Dan Mangeppa, halwe "broeder van den koning van Tello, de क. Gallerus, of Ryksmaten van wegen , hooggemelde koning, wermagen hun 3, credential an dezen origineelen ge, anmexeert. Item Grain Linhes voor zich „zelven, en wederom de bovengenoende "D Din Mangappa, de Ryksmaden Man", chis-Jove, cn de Patto, yder voor zich "zclven, dezen op den Alcoran foletn"neel belworen, en tot te meerder be"kristinge van dien, nog gedronken " het water, over hunne criffen gegoten, , betekenende natr des lauds wyze, dat , indien zy her werbond quamen te ver"breken, zy alsdin wan hun eigen ge"weeren mocten verniele worden. Al"dus gedaan en befworen in "t quartier "Jicatra, op denzoom wan de velt, wan " "E veroverde kafted Sambocpo, tor pre"Fentic van de newenttande Bondrenoo"ten, die dezen zoo werzegeld, als on"derteikent hebben, zoo wel als de gee, ne, welke als Leden wan cien Ruad, by ") deze negotiatic zyn tegenwoordig ge"weef, op den I $\gamma^{\text {ten }}$ juli i 660 . binuen shet logement vatn den Admiran!

, De boventiande nadere Poineten zan " gefchrewea tan d'een zyde in 't Neder$\rightarrow$ lands, en ara de andere zyde in 't Ma"leits, en waren gretcikent onder 't Ne"derlands, by Maximilian de Jong,

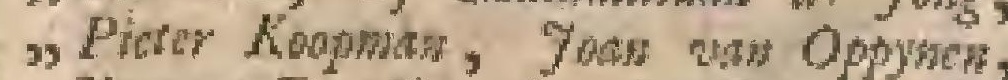
"7ounes Frangen, Lendert Rus: Onder "t Maleits, lyee zegel wan Crain Lindes,

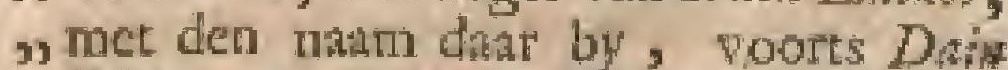
, Mangapar; Galeran Mantilo, Galeran , Gare Paro en Din Telolo. "s Vol"gende zyn de Bondgenooten, die pre, Ient waren, 't acgel van de koning van
1.669. 


\section{Z A A}

I668, "Ternate, wat onder ftat Majula Yw"rotulls; "t zegel wan den koning vats , Soping, en zyn nam daa by, Radj ,Palack ; Aroe Varque, Pal/a Poia, ", Radja Cajo, Palimpa Dan Sinabe, Aroe is Pite Toefara en Aroe Pite Lampo.

"Den koning van'Tello, op heden ter , zclwer platze verfeheenen, en verge"zelfchapt zynde mer Croin Liwhes, Dain "Mangapp, Galeras de Patto, Dain Tulolo, 35 en anderen, zoo heeft zyo Hoogheid " in eigener perfoon, den Eed op den Alw corm folmnel geprelteer, en werpol"gens tot te meerder beyeltiging, zyn " zegel hier onder doen drukken, bene"vens ook dar van Grath Liscker, en de " handteitening wan de vordere Grooten," "op den 2 I fien Julii dar an volgende, " "Bondgenooten, hebbende ook ingevolge "van dien tot vergenoegen wan de koning "va Tello, zvn Excellentie Colamata, "wegens zyn broeder den kaning van "Ternate; iten zyn Hoogheid den ko"ving van Palucka, insgelylis op den Al. "coran gerecollecrd den woorgaanden gedamen Eed, op het $V$ redererbond tot "Bonaye: Was in 't Nederlands getei"kent by Maximilan do Jong, Piwer "Koopnan, Jobannes Franden, Leendert "Rus. En in "s Maleits, "t zegel wan de , koning van Tello, met zyn naam dax ,by, Din Mangapa, Galeran Mantfitoe, ${ }_{3}$ Galeran Carre do Pano, Dain Selolo: ${ }_{23}$ De volgende zyn de Bondgenooten die , anwezig waren, 't zegel wan den ko, ning van Soping Radja Palacka, Pa/h

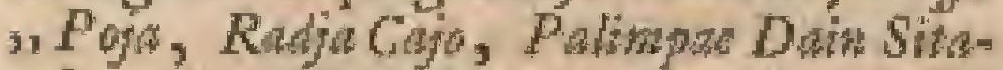
"be, Aro Fite Tofawa, Aroc Pite Lamwpo.

"Op heden verfchenen wederomme "Den Macuele Sabanbar, Crain Ma"woet, en Crain Rapoesjina, genthitect " met Dain Wandaliqu, Dain Telolo, nog "wyf Soroeins, met naamen, Carro $\mathrm{Kl} / \mathrm{g}$ " gename Imama, Garre Tucca, Ltewa, "Cawe Tadjon Imat, Care Telolo Lwan" to ; de Tolken, Carra Ropa Natoo, "Carra Gappa fjono, en den Schryver "Amien, vertoonende opgemelte drie "Perlongies een half vel fchoon papier, "dar met Macaflaurze letreren op ge"Ichreven ltont, door de hand des fro" "nings, hume maumen, met bywoeving "van 't groote Zegel, dienende woor Cre", dential, en tor meerder bekragtiging , zoo wiert ook by hun owerlegt des kom , nitigs zegel zelve, verk liatende door de , ziekte des lenings gezonden te wezen, , orm alhier zynen cigenen Perfoone te ", reprefenteren, en van wegen de zelve „ongcwapent te bidden om genade tan s) de Compagnie, met oomoedig verzoek,
K E N.

, datre zoodanig als den koning wan Tello rGo, , mogken authenomer, cn. tor Compag,nies Bondgenonten herdtele worden, , mits welter de voorgemelte verbinte, silfe batarluiden te wooren gelezen, en " tot nader verlihating, in de Mineaffarze ,, tale overgezet wezende, hebbenze de , zelwe zoo in zyt gelieel gesceeptect, w zonder de allermintte temenfprask, ca wh fpecial ook her Contriet op den odea , Maart 1668, in 't byzonder met den ko, ning wan Tello gemaike zyndc, voorts ' geamplieert.

"Eeritelyk dat hier vooren gezegt is , var Tello, ook nu door de koningen , en het wolk van Goa, en Sadrcbone, , ter eerfter begecrte wan de Compagnie , zullen neder geworpen en gefoopt wor, den alle de willen, musen, en forti, ficatien van de iteden Goa, en Sadrew, bone, zonder dezelve, nogte ecnige 3, andere, weder te mogot opmaken, als "Met de wille wan de Compagmie.

nitem dat de koningen zich niet zul") len mogen bemocyen met de Maleyers, " Moorer, of enige andere uitlanderen, "hoe zy ook getraimt zym welke op " heden in Tello, Goa, of Sadrebone, " of nog elders onder de Jurisdiatie mog" ten gevonden worden, mar daar mede "de Compagive lasten began, na hat "welgevitlen, en fpeciad Mapulle, zoti"der ook nut dezen weder ecnjge van "die of djergelyle Natien in hun Nege"ryon te mogen atnomen, als met wille "en begeerte van de Compagnie; gelyk "har ools vry zal ftann zoo tot Tello, Goa, "Sadrebone, te mogen houden en leggen, "Zoo weel wolk als $\mathrm{c}$ har gelieve cot toe"zigters, zonder dat op of jó de rivieren , พan Tullo, Sadrebone, en ook alle an"dere tuffichen die beide in gelegen, zoo , ze de Compagnic quane af te fatro, „ cenige vaarcuigen, gehiwend of mtfan12 gen mogen worden als alleen zulke, 1, welke Lascedullen van de Compaguie "konnen vertoonen.

'W Want op de voorenftande Gedepu, tecrden, ecrit voor, en van wegen bat , koning, er diar na voor hun zelveg " geprelteert hebben den Fed van ge. "rrouwe Bondgenoolichap, zoo op den , Alcoran als met ber drinken wan het , crifle water, even nee de zelve folen= , niteiten, als by het Telloze Verbond " ftaxn uitgedrakr, ter prefente van de " ondervolgende Bundgenooten, en Or, dinaire Raaden wan den Admirat tet w. vooriz plateze, en op den $27^{\text {ther }}$ van de w maand Juli 1669 .

"Was in 'c Nederlands geteikent, by ,Danker vas der Siraten, Pieter Koupman,

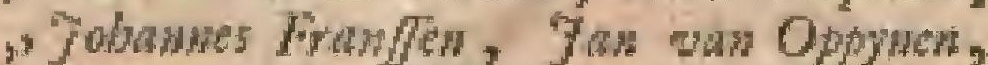
"Leavicot Rus En in "t Maleits, Dith , Macede Subarader, Manowdjimgan, Crain 


\section{M A C A S S A A R S C H E}

r66- 9. Mamos, Gram Rapoetsini, en als "Bondgenoot, Radja Palacha, mecr , Bondgenooten zynder niet pretent $\mathrm{gc}-$ s weeft.

,Op heden compareren ter wooren* "semelte platze, in het logenent van "3 den Admiral, den ouden Toning van "Goa, syade den jongen lowing Mapa" "Jombo ziek, Grats Grongron, Crain Oedjon, "Crain Ropersjim, Crain Tompo Ballang, "Came Manse, Gran Baban, en Dan 1) Mavilope, bebben in eigener peroone, , ook op een Alcoran, geprefteert den "Eed 5 en vervolgens tot meerder benveltiging wan tir alles, hume zegels 3, hier op gedrukt, met hablteileninge ") " el mede ten overftan zoo van de ne2, venilaande Bondgenooten, als Radssperfoonen.

"In "t Nederlands geteikent by Maxi-

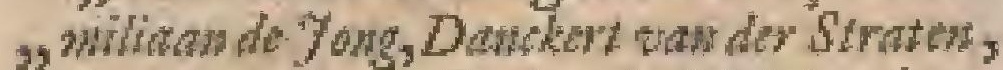
"Lendert Rus. Onde" 't Maleits ftont "' 'tegel wan de oude koning van Got, "en data by gefchrewen, Graw Riblod, ") voorts Aldh Lamy Crongron, Datn $\mathrm{Ma}^{-}$ "mou, Crain Hodfou, Crain Rapoetsjini, "Hinaligongan Crain Tompobdlarg, Dain 3) Menwing, Crain Bobabon, Carre Mo"wou, Menon Djosgang, Dain Montyly, wen als Bondgenooter, "r zegel dar nef-

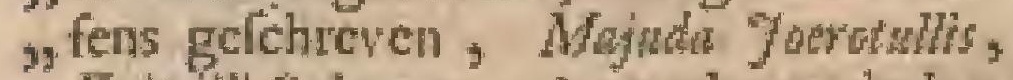
"Farsjhi Calawaria, "t regel wan de ko, ning van Soping, daar zyn num by "2taat, Radja Paldolos" "t zegel van den , Foning van Tello, en doon liem dar , by gelchreven Crain Teis.

Drie Trandaabrieven, wit bet Maleits, geclbrewen door Radja Goa, Crain Tello en Linckes, kowingen of " Hand won Macaljar, ann den Ed. Fleer Gowoment Gereranl Joan Mantzuiker, en de E. E. Howch Radden van Indien, ontfongen den $\mathrm{I}_{4}^{\mathrm{den}}$ Atrguli $\mathrm{1669}$. met 'i jagt de Colbolinaw.

MHINo van Grain Goa.

"C

Efchreven wit alle opregtigheid en "U zuiverlueid des gemoeds van $P_{6-}$ "duca Siry Sultan Crain Goos, uit weder"z zydze genegentheid ath den Gouwerneur "Gcuernal "oan Madtzuile", de Raaden "Yan Indien, en alle de groote Perloo", then in de ttadt Batavia, die wys, en 2, zeer veritandig, en een fehcidsman in "'r uitfpreken en voorezetten wan Verbonoy den met alle konngen op der aarden "benedens winds is, vorders zynde zeer "3 medogent en liberaal, by al zyn Vrien"den en Bondgenooten, dic van een ge"negentheid zyn, zoo dat zyn opregrig-

, heid altoos en over al doet blyken, $26 \mathrm{Cg}_{\text {: }}$ : "2, nevens zyn affiftentie en onderhouditige , ontrent al die geene die ongelyle nam"gedatan worden; want hy is de winkel "van alle veriftand en kennis, in "ton* "derhouden van zyn beloften, en zeer "opregt in zyne Refolutien en Juftitic, "Whar door hy zeer befaumt is in alle " ${ }_{3}$ theden bovens winds, komende tot be"3 nedens winds, alwaar wan zyne mage ${ }_{3}$ en ftoutmoedighéid in 't veld des oor" "logs verhate word, ook van de ken"ris in de handelinge wan ' $\mathrm{rgew}$ ger, zoo "te water ath te land, waan woor alle "zyne vyaniden berreet zyo, en wien yden hoogen God in al zyo doen wil "2 zegenen mer gezontheid op deze wereld. "Vorders man dit verklaaren wy uit „2en opregt en zuiver gemoed in dit pat* "pier, hoo wy alle bekemen opregte "wrienden te wezen wan de Compagnie, sen te blywen zoo lang zon en maan "f fchynzel geven zuilen zonder werande,ring, vorders alzoo wy donr vergele"genthcid en onverftandige onwetenheid "quaalyk by deCompagnie gedian heb"ben, dat verzoeken wy, dat ons veel", Fondig mag vergeven, en gepardon"ncelt worden door de Compngnie en "Gouverneur General; ook zoo wer"zocken alle koninklyke linderen, "ca ,a alle de Groote Perfoonen, gezanentlyle " om pardon, alzos wy uit ons zelven, "3 met alle konings kinderen enville Grootc "Perfoonen gerefolveer hebben, by den "grooten perfoon war de Compagrice, "s den magtigen Veldowerften Cornclis "Speelmas, Adnitat, Commiffaris en "Superintendent om de Ooft, te gaan, "en pierdon te verzosken, die ons ook , anngenomen en gepardonneert heeft, " "met een opregt cin zuiver gemoed on "te vereenigen, nevens alle andere Bond "genooten, met het verbond dat nu op "nicuws gemaake is, dan onder begre"spen te worden, en befworen is op den "Alcoran, op dat het kragtig en taft "zonder cenige verandering zy ; dit mata"ken wy mus den Gouverneur General ", bekent, wegens de viede die wy met "den Admiraal gemaakt hebben, doch „3 zoo wannece den Admirnal na Batavia , keert, zullen wy konings lkinderen in 3 des Admira:ls gevolg mede zenden, tot "ecn tecken, dat wy pardon verzoeken, "ter ecren van den Gouverneur General, "doch wy en komnen nog nier uitvinden "de namen van dic loonings kinderen, ", alzoo onder de mentch veeliyds ziektest 3, komen en fterfter, darrom zoo manke 3) dit an den Gouverneur General be", kent: Vorders na dit, zoo hebben wy "twee brieven voor dezen geronden, en " of die den Gouverneur Genemal beiteld ", zyn of nict, is ons onbelent, alzoo 
Z

A

A

K

E

N.

169

1069. "wy in die brieven oote on pardon very, zogt, en onze ganiche gelegentheid 3. bekene gentakt hebben ; wegens her "gepafiecrde: Nier hebben wy tot gec "2 Icbenk an den Gouwerneur Genertal nte zenden, door martquenente var ge"legentheid, man zal God meke en dag 2) voov't welvaren van den Gotverneur s. General bidden.

Mhowe wan Crain Tello: grflowen

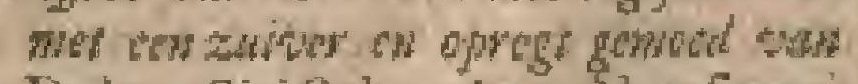

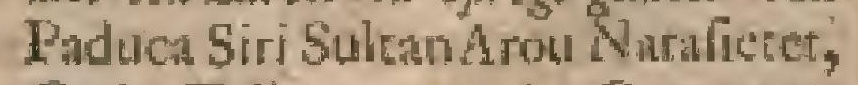
Crain Tello, aan den Gawormenr Geworal Jon Matzuilier, en whe de Rawlen wan Andire.

"T Orders mar dit, zoo bekennen wy ") van ons zelveri, dat wy qualyk "by de Compagnic gedan hebben, al, zoo wy "t Contrat op Bothye gemalk, "zetwer hebben verbroken, als mete het "Verbond, dat wy allecen in Oedjong3) pandan genaake hodden, dintron zoo "hebben wy ons zelwen by de Cumpagnie "óvergegeven, en pardoa verzogt, en „h hebben wy dar nevens ons groor ge"weer, dac wy hadden, overgegeren; "en zoo den hoogen God oris in t teven "Wat, en den cyd wan des Admirals ver"trel gekomen is; zullen wy nevens des 23 Admital op Batawin komen, of anders "zal Crain Linder in onze platts komen, , ofte onze oudfte broester Dain Ma gap"Ak, of een ander groot Perfoon, gelyk , ten tyde, wanneer met den Aduirat "vereenigt zyn, heeft zelve willen nat , Batavia gan, on dat ik royn cigen 2 misdand swift, en dat om pardon ran , den Gouverneur General op Batsvia " te verzocken: Nicts en heb ik tot ge"Fchenk te zenden, anders, als cen zuj2 ver en opregt genoed, en anders nict: "Dezen briet is gefchreven in "t huis y"an " det koning, in de ftadt Teilo, op den $p^{2} 5^{\text {dew }}$ van de mand Juli, in "t jant I 660.

Mhow tan Cnin Linclacs: gefore-

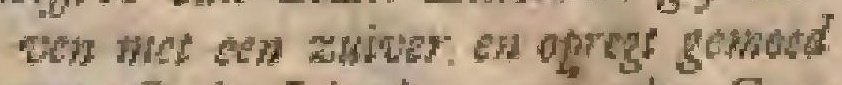
wh Crain Linckes, an den Gowverwes Geweral Joun Mastzuker, en al de Raden wan Indien.

"TOrders, na dit UE: dienan be"V kent van hem zelven, dat by tew gens de Compagnie misdant hect, , iti 3' trerbicken wan ' $t$ Contract op Bonaye, , en " $\mathrm{t}$ Verbond dat UE. dienat alleen in ,Oedjongpandan gemake had, daaron "zoo heett UE. dicnar hem zelver by , de Compagnie overgeseven, co pardon ", werwogr, en heef U E. dienar dar ne„veris al zyn groot geweer dat hy had,
9, overgelevert: En zoo den Hoogen God 106 . , my in 't lewen laki, en den cyd van des "Admimals vertek gekomen zal zyn, "zoo z.ll UE dienar mer den A Imiral „, op Batavin komen, om dat by zys eigen , misdiand weet, en tom op Batuvia van "s den Gouverneur Generaal pardon te ver"Zoeken. Niers en heeft UE. dienalar , tot gefohent te zenden, anders ats een "zzuiver en opregt gemoed, en unders "niet. Deze briet is gelehreven in " $t$ hutis

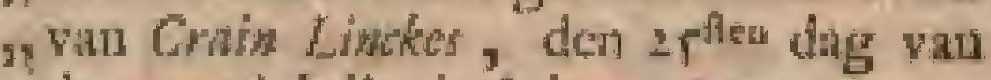
" de mand Juli, in tijar 1669 .

Uit het omitandig werhal war al die yoorgewallene ziet men hicr latar met hoe veel dipperhed de Nederlanders rich van Mucafar medler, eh met hoe ved befchcidenteid zy alle deze hoogmoedige en trorze koringen wernedert, en gedwongen hebben, om zich op Batavia voor hatar Edelheden te moesen komen verontmoedigen.

Dhar op zyn met de Heer Sptedmon, nog in dit zelve jat" (zoo zym Ed. an Koningen "topperhoofd van J para den zzíti No- die zich vember" I66g. (chreet') deze nawolgende Foor has koningen en princen, met hus voritelyls den vergevolg, ook na Battavia gegan. ootmoe-

De koningen van Tello en viu Linckes, digt heds met hunne vrouwen ca gevolg, 350 of 400 zielen llesk.

Crain Birby zoon des kogings wan Macaftar. Crain Mandd/i, zoon van Crain (dac is Prins) Crongron.

Care Mawor, i twee der Grootfe van Grain Wello, $\xi$ "t Macaftars Hof,

Galera Mand/a, San wegen den koning Goleran Timbl, Svalg wan 4 o menfechen. Prins Calamatta, en xyn wrouw, en de zurter des konings wan "Iello, die wel cen fleep wan i jo mentchen by zich hadden.

Alle de welke, behalven hunce wernotmoediging voor den Heer ( pperlandvoogt Moatzisiler, en de Heeren Ruaden van Indién, inu ook derwarts gingen, om de goedkeuring win has Edelheden op de gematkte vrede te werzoeken.

Behalven deze Vorften troliken ook mede de koning wan Palacka, en de prins wan Boni, newens meer indere Ge: volmagtigde Celebize Landvorlten, en Bondgenonten, met een gerolg van 800 koppen, die een groot leven en gekrioel op Batavia en ook al ecnige belemmering an har Edelheden gaven, en vonrmmentlyk het volk van Radja Palacka, wast onder zeer ved dar tele galten whren, die by nache en ontyde zeer veel ongebondenheden aanregreen, hoewel harar Edelheden een middel vityouden, om zich nict lang dant na van dit volk te ontilan, en de zelve nuet humnen

ko-

III. DEELE. 


\section{M A C A S S A A R S C H E}

I665. koning in zekere veldeoge te gebrui= ken

$\mathrm{Na}_{\mathrm{a}}$ dat nu de koning van Palacka, Ratjis zyonde te gelyti de honing onder welken Palicha de Bocgis, en die van Boni ftonden, de hoofluibiond wan zyn grootyader en vader na met dat zwo gedisten gewroken had, wolbragt van alle hy ook zive belofte, ee weten, dat hy andere, zyn hooldhair, tot een erkentenis van fcherch deze verkregen zeege, zee plegrelyk (dair anderans de Macaffairen en Boegincezen zoo grooten werk van hun lang hitir maaken, en dagelyss benig zyn, on dat inet allertei geurige, vooml met welriekende klappusolie, dar zy bloemen in doen, te beftryken) liet affiny* dest.

Hy ftelde dar toe ecn witdrukkelyken dig, ri p zyne belle vriendet, cn weele van de volkerein onder hem Aaride, alas wellic ty te dier tyd een koninklyt motal gaf, zynde dic genen, die hem hich in navolgden, wel 30000 mat iterk geweeft, 200 ditt een Bocginees, nog op dezen dag, zeer lint an esu Macalar, wegens zyn kore has, te onderleheiden is.

De E. Martichappy over dezen lioning, Word in en zyne dappere dadern, zeer voldan, zyne $\mathrm{Py}$ - herftelde hem nise alleen is zyne ryken fteld, en wan Palackit, Boni, Soping, en meer ainheerlyk dere; mant rehonk hem ook ecn hecrlyke berchor- goude keven, met een penning dat atur, die hen met zeer veel thatie thuis gebuige, en met veel lofusting omgelsingen wier, wall over deze vortt zeer verblyd was.

Ook hebben has Edelheden ma dien

Disis Ta- tyd, een groote a ating vool zyn gemal-

halite Hume, Doiv Tabillite, getoont, behalven dat die verttandige konimgin zich de gunft, en prigtige gelchenkelu hares Edeliheden nu en datw, in vericheide gevillen, by welke zy hun fill wegens deze en gene quade armiagen wan den koning har gemaal gewardelouwt, en dus groote ongevallen roorgekomen bect, wel dubbel wandig heett weter te maken, zynde dit allecen hatr gebrek, dat zy op deze gunft haver tidelheden zeer moedig en gewoon was nu en dan al viy fterk datr op te roemen, en by zulken gelegenlueid als eenigzins vervocti, ook wel zalaken, die beter gefwegen wares, te zeggen; watoun men hat ook geen geheimen $16 \%$... vertouwers kon, fchoon men weet dat zy deze fwaklieid meer uit gewonte, dan uir quatalardigheid, oeffende.

Her was ook een groot bewys wan Warter Edelheden agting voot Rndya Palacka, dat $7 y$ hem minndelyks $200 \mathrm{R}$ Jers, zoo lang hy leefde, gaven, war door lyy dan ook den meelken yd op Boneuwalac wis, en ditr eet grooten blosi in alles door zyr bywezen werwekte, dat nu zoo nict wolgde, an dat Aree Poxi, die dit niet trok, en die daar over nu cit dan wel ecro fchimper, wich meet op Tsjinrana onthiclt.

Hocwel nu Radja Palack groote deugden liad, alzoo lad hy ook zyne gebreken : wine "t was zeer ondankbant dat by zyn gezag bowen dat der E Martchappy, die hem groot gemakt hat, zoge re wertheffen. Daar ben ven die hem ecus op de keen getrapt hadden,

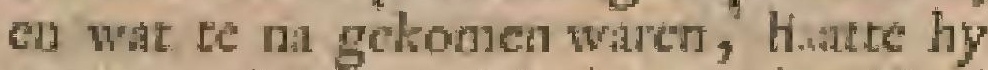
olwerzetrelyk, gelyk dut nas den. Heer Ptha, over "t beltier der zaken wegens de moord der koningin van Dompo, en regen den Sabundaur firims, gebleken is, dien hy nagat by de Heer serenkenderg, dat zy zys verderf gezogt hadden; riete willende dewen Jwains meer onder zyn oogen zien, om welke reden hy ook werklande nier weer op Bontuwalac (zoo lang 7 uniss "an "t kafteel was) to willen kamen. Dat zoa weul zegigen wilde, als dat men hem na Butwia zenden moeft; dat juitt altyd nier te pas quam on de bequaamite perfoonen (hoedanig deze Jwhis was) ten govalle wan zutk cen worlt te verplatimen; behalven dat by een zeer lchrandei navorfcher yan weel geheimen was, en nies misdann had, dan mer zyn Hees en Meelter is tannbrengen was zulke zaaken trouw te dienen, dehoon zy Radia Palaka nict andtonden. Ook was lyy op de Heer youns zoo moejelyk, die by de Bondgenouten niet wilde by een roepen, nog den brief vin hat Edelheden onthangen, of hooren lezen, bedloten hebbende to de komlt wat een ander Voorziter op Boni te blywen, alzoo deze hen tot cen leugenate gemalat liad, by ays ichrya wen an har Etellseden.

\section{Y F D E H O O F D S T U K.}

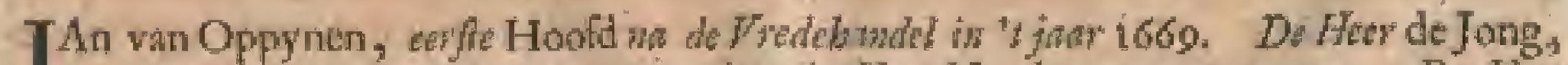

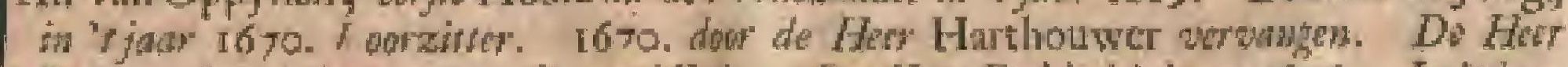

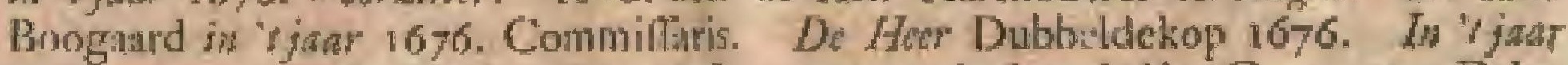

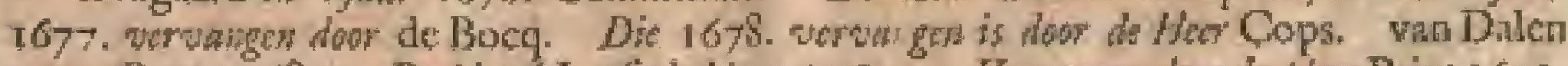

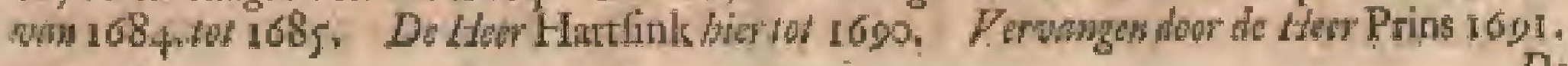




\section{Z A A $\quad$ A E N. I I}

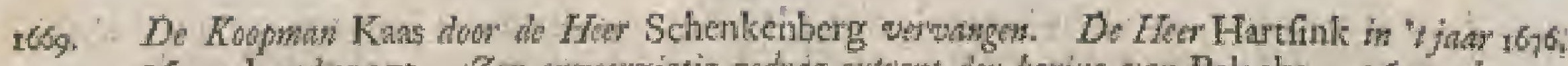

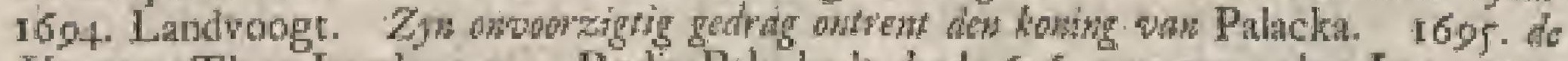
Her van Tlyye Landwoogt. Radja Palacke "s dood I606. wervongen door Lapatauw. De mopd wan Dain Mabani dopr Aroc Teko. Derdere redenen dadr van. De dood wat de Heer var Thye i70o. De Heer Beornink Landwoogt. Berigt batrer Edelheden an de Her Beernink wegens de vorige zanken albier. En bate bevien owerem

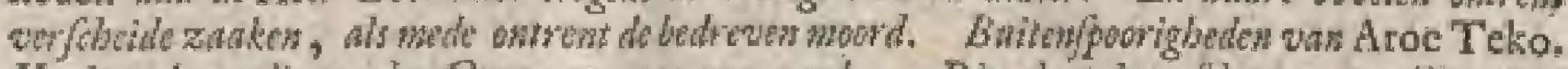

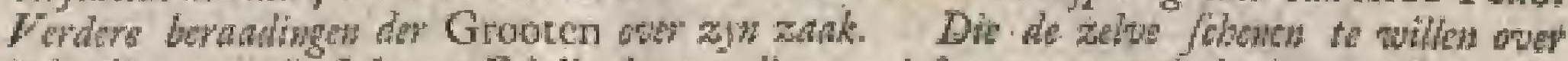
"i boofd sion. Laft batre Edelheden on die moord freng en mat de dood te fraffes. En kort 'er an, on, zoo de boledigde prityen de zak wier acnlonden, dan fil parton woor

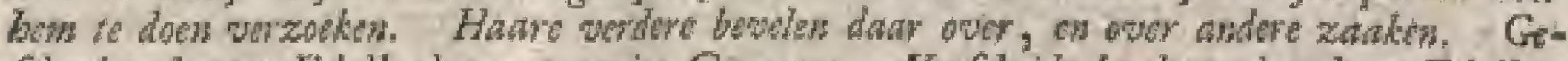

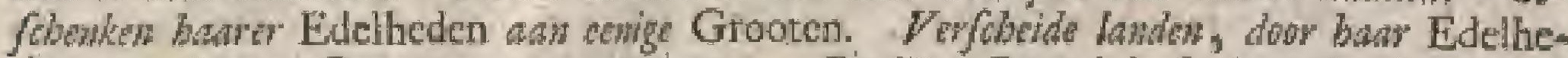
den an de wan Gou, onz., wergegeven, De. Her Beernink fondent den koning was Lotboe ower dic noord. Wat Aroe Telo dater van in apzigt wan de Hed wat Thye, en Radja Boni, zet. Nader fonderrigg was anderw bier over. Magt, dis zich de ko-

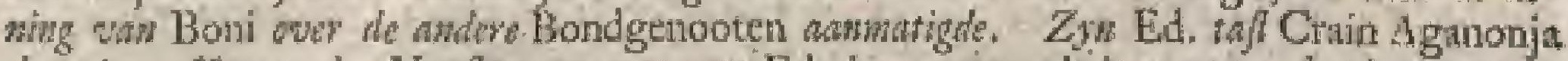

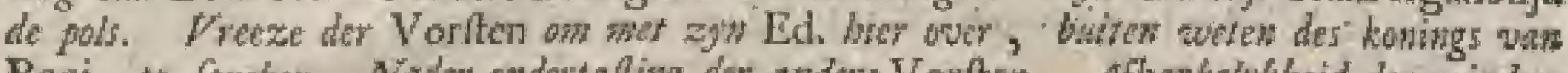
Boni, te fpreken. Nades ondertaling der andere Vorften. Afbankelylbeid wer windere Votfien was den koming wan Boni. Engelzen op Buijts Mafin, en bown poging.

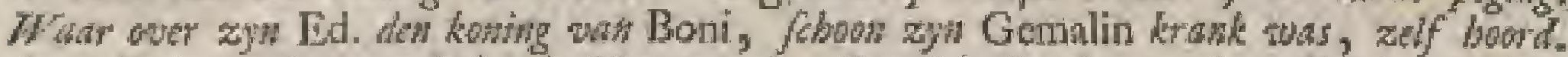

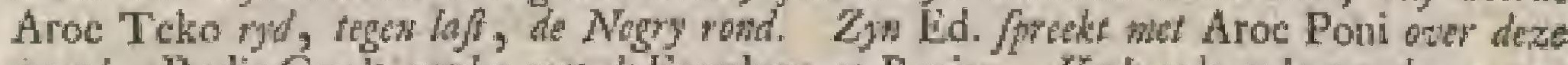
wowd. Radja Goa's anteg we de Engelzen op Banjar. Yokkerde gedagten der onzen van de Bondgenonten. Dic alle vour Rampafién zyw. Dat om vocl redenes ook beft,

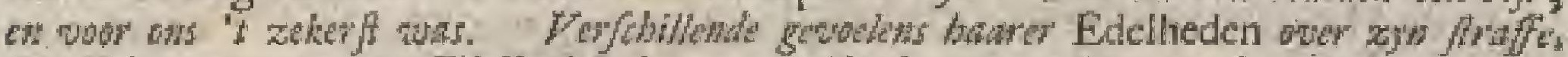
Zjn Ed. toont an bar Edelheden de onmogelykbed, wh pardon woor ben te kohnen wer: towen. Tocmemende ziekte, en dood van Mevrow Becrnink.

Jair พan Opproc certie handel in Danker von der Straten, wolgens de ordie "tjar van har Escllieden, te laren, doch alizoo 169. deze Heer nog voor zyn Ed. vertrek is komen te ferven; wiert by door latt van de Heer Zeevoogt verwangen door Yobaw wall Oppynen, onderkoopman, die het beftier hier tot den-29 pen Mart 1670 . waargenomen heeft.

De Heer In zyn plats quan hier, met den eerde Jong nam van Voorziter, de Heer Maxhi-

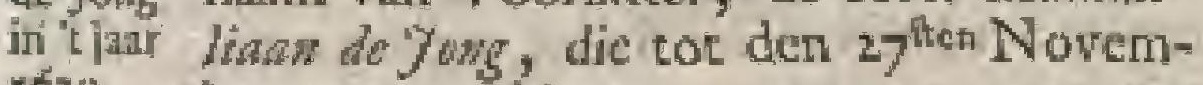
thoo ber 1672 gebleven, en roen voor een ter. foringtogt na Batawia vertrokken is, het gezag in handen van zyn Tweeden, den Heer opperkoopman David Hanbowder zoo lang hatende; doch de $\%$ ong (wiens becltenis nog in de gemecne $\mathrm{R}$ andkamer op Macallat te zien is ) quam dit zelve janr op Batavia te owerlyden.

I The. Hy wiert den $26^{\text {then }}$ December $167^{2}$ : door de door de Heer David Bhwlyawer, met Hoer de titel van Voorzitter, werwangen.

Harthour- Hy kreeg eenige gefchillen met Radja wer wer- Paldka, wieshlwen has Edelheden De Hecr Boedvonden de Heer Andries Bangand; De Hecr gekoren Landvoogt van Bandi, als Comin 'riar miffaris, of Gevolmagtigde, herwants in is 'to. 't jaar i 676 . te zenden, zoo, om de ver-

Commis fchillen tuffehen deze twee by te legger,

faris, als om andere zaaken met deze rorlt te werhandelen, welken Heer den I den Januarii hicr met 't fehip Butren angeland zynde, na een kort verblyf wan maar een masad, op den trien Februari ma Banda vertrokken is, terwyl de Heer Harhowwer in zyn dienft hier vervolgde tot den fen Maurt dezes juar's, op welken tyd zyn Ed. als Landwoogt, met 't jagt de Geregtigheid, na. Ternite vertrols.

Hy gaf het gezag, ter ordre harrer De Hee

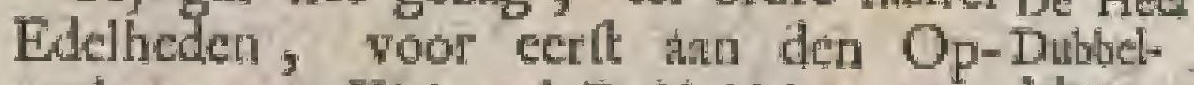
perkoopman Wybrad Dubbidakop over, delop die by brieven van den zuen December 1676 . 1676. door hitar Edelheden als Wootzitter in zyn dienft beveftigt wier, doch hy quam den 18 tem Mey 1677 . te awcrly. den.

De Koopman, en Tweede, Paulw In 't jatar de Bocg quam in zyn plats, ton nam het ranger gezag op dit comptoir tot den $12^{\text {den }} J a$ - door de nuan 1678. waar, wancer de Hecr $7 a=$ Boeq. cob Cops als Voorzitter werleheen, die hier Die r 69. blecf tot "t jaar I684, den Ioden Nowem verwar-. ber, op wellien cyd zyn Fid. als Buiten-gen is gemeen Raad vas Indien hier overleden Hoor is.

Onder dezen Heer keurden haar Edelheden in 't jar 1679. den $24^{\text {flen }}$ Jatnuari goed, dat Cajeli de feheiding, en uiterfte gienspal tuflehen de koningen van Ternate en Machlar zyn zoude.

De Koopmain, Adramwan Dalen, nam van $\mathrm{D}$ toen ${ }^{t}$ gezag hier tot den zoten Juli I 68 r. Jen val watr, en wiett vervangen door den Heer I684, tot Voorzitter Willew Hart/min, welke Hecr ${ }^{168} 5$. tot "t jair 1600. den $13^{\text {den }}$ Oetober hier Hutings gebleven is; maxr niet weel wermant ge- hier tor durende zyin beflier geliad heeft, dewyl ${ }^{1690}$ in geduarige mocite en onrult met Radja Palacka leetde, die zeer ftout begon te woiden, en dion by daron geenzins 


\section{I72 M A C A S S A A R S C H E}

16gr. dort vertrouwen, gelyk hy hem ook niet toeftant wilde, met exnig gevolg in de velting te komen.

$\mathrm{Hy}$ vertrok toen voor een fpringtoge met het folip de Leilt, met tooftemming harer Edetheden, ma Batavia, en liet Veryan- "t gezag atar den Opperkoopnian en gen door Tweede, de Hecl fromsus Prins, die dar de Heer eenigen ryd watinam.

1601. In plats Fan na Macafiar weder te keeren, bleef de Hecr. Harbigg op Batavia, alzoo hy er nict weer henen wilde, of hy verzogt meer wolk; en ammuritic, way op coen de Heer Pris door latar Edelhoden (nict on dac de Heer Hartfint op Batavia overleden was, gelyk de Macaftarze lyft der Landwoogden meld, alzoo ik dien' Heer in 't jnar 1694. zelfs meer dan cens op Batawia ten zynen huize bezogt hebbe) nls Voorziteer in zyn platits, in 't begin wan 't jat 1601 . wiert angeftelt.

Ditar op yerficheen hier den fen Juni 1601. de Hect. Dirk de Hars * Genieen Rand van Indicin, en oud Landwooge van Amboint, als Commifiris met tefoip Henrik Maurits uit Amboina, blecf er tot den I $3^{\text {dea }}$ dito; en vertrol toen na: Batavih Wat die Hece hier toen vere rigt heeft, zullew wy hier na ecrigzins, zien.

Zyo Ed. hie "t gerag bier verders ann de Herr Prins, dic tat zyn dood, dis den $4^{\text {den }}$ Mitrt 1694 , woorwicl, in de regeering geblewen, en rotin ropt een tyd; Defroop-door dech Koopman en Tweede, Hentide mankings, Kan, die dat cot den zzlem Juni bleaf; Hear en dic tom als Tweede doos de Heer

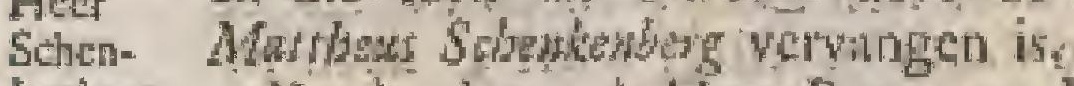

lenbers De dood wan de Hecr Prom, ea de geverwat rugten van Radja Palake "s voornemen, gea, on het hier in de war te werpen, alzoo men zejde, dat hy well 60000 matnen by De Heer eer zameldo, gaven op Batavia zulken Hartfink bekommering, dat hair Edellneden goedin "ijar wonden den Heer" Hawhore, by dit voor-

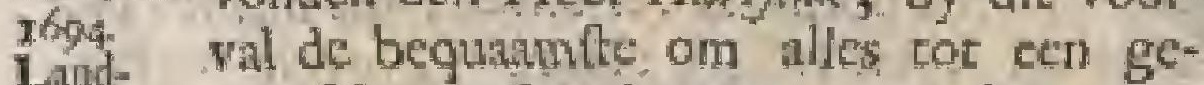
roost, wenfohte rufte te brengen, to doen aanzoeken, ont hem de reize na Macallin weder fmakkelyk te makken; doch die Heer betuigde in het eerft ganfcli geen genegenheid hier toe; maar eindelyk liet hy zich, op atmbieding van daar, Land: vongt (dae cen krulleje- nieer was) te zullen zyn, nog bewegen; doch, tom nog ziek zynde, en zyot ziekte hoe langet hoe meer cocnemende; is hy in 't,begin wan " $t$ fatr $160 \mathrm{~g}$ (200 meine) op Batriat komen te fterwen.

$2 y n$ on Deze Heer was in 't eert al te gevortig menzan mot Radja Patocka gewect,

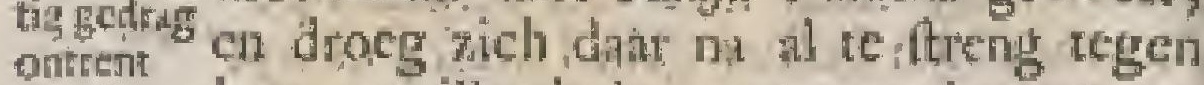
den ho hem, willende hem nergens in vertroujing van wen; dat vecl quand ged ano heefo.

Paliek, DG Hocr Shbohemerg ondertufichen

"rgezag van den $22^{\text {ften }}$ Jusi tot den roden 1606 . Fobuari $469 \%$. gevoert, eri ontdekt hebbende, dar Radfa Polacka nie's tegen ons, math alleen tegen den Sabandar ' J wiws, en andere, die by niet gairne zag, hadde, gaf 'er' hitr Edelheden kennis af, die hier op de Heer $1 / a$, wan Tbye, ecrfte Opperknopman des kaftels tor Batavia, herwirts. als Woonzitter wilden zenden; doch die Heer, niet genegen te gan, dan als Landroogt, vertrok derhalven met dezen titel, en quam den $10^{\text {der }}$ dito met het lehip Zion hier.

$\mathrm{Hy}$, die een fyn, en een zecr net man 1605. de in alle zyne zarken was, witt her met Heer wan Radya Palack zoodanig te bediffelen, en Thye hen 200 te believen, dat de bekomme. Landringen, dar over gerezen, geheel en wobt. al verdwenen, mar men was jog veel RadjaPagerufter, wanneer by in April 1606, lucka"s yiarir té fterven. Hy wierc door dood zynen neef, Laporaur gemamt, ver- 1696 veryangen; doon Lat

De Heer oan The bleef hier regeeren patomw. tot den $\sigma^{\text {thll }}$ Juni $\mathrm{7} 720$. wanneer hy orelled.n is, hebbente zoo lang nier mogen lewen, tor dat de tyding var zyne ato Athing cot Buitengemeen Rind van In dięz bict quim.

Dus was zpuc tegecting in der beginne zoch gelukkig, en dals deden zich ondze dezelwe geun donkere wolken op, dan dar er kort voor zyn dond eti zalk voorviel; die naderhand zoo nan hatr Edelbeden, als an zynen vervatiger, groote moeite en ved bekommering lieeft gegeven. 'Die wry derhalwen van de grond at mocten opthalen, om cen net begrip en doorgezigt daat van te hebben.

Het was de verfocifelyke moord, die De door Aroe Teka, esn der woomaamfte prin- waord cen aan "t hof van Boni, of eigenlyk op Maburi. zyn laft, en door zyme bedienden, atridoorAtos Dain Wlabani, altis Aroe Beloc/oe of $B a$ * Telo. Jisfoe, een der voornanatte princen airs

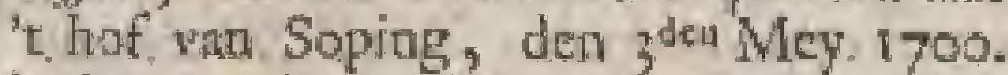
bedreven, wiert. Een zank, die mogelyk noir zou voorgerallen hebben indien zyne gemalin, Saena, of $\$ a \cdot c y s$, , (een nige zoo men zegr van den koung van Goa, hoewel, Aroe Felo dat in "t vervolg anders toont) zich zelven maar ffil gehouden, of niets wan de minneryen van dien Sopingzen prins gerept, of atan hotaren man (dic, "er niers af wilt) bekent gematk had Een dhe darom te vuiler, om dat hy by samatetelyke, en wel zyne gelictite kinderen (war onder $A m a$, met de dochter yan. Datoe Locha op Sumbawa getrouwt, een der vootnamite was ) verwekt had Teze. Anoe Trko was niet alleen een van. de doorligugiglte Bonize princen, maar by de dood des konings ool de riante tor de kroon.

Dit werk nu had ayn begin al ettelyke 


\section{Z A A}

Ino:

fanten te wooren genomen, waut Aro Teka wis ontrest 'i jatr logy., nevens

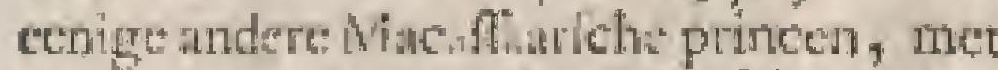
ecuge resepes der E. Matichappy ma 't aland Sumbatwa vertokkn, om Raigh Tandria, wit" de koningen yan Bima, Dumpo, caz * op dic zelve eikand beoorlogde, te onde'teunen, gelyk zy ook "t geluk haduen win deze koningen te overwinnen, en der zelver landen onder hunne magt te brengen; doch fethoon de andere troepen der Bondgenooten, rit dieñ oorlog selulkig ten cinde gebragt te heblen, weer nu Macalfar wettrok ken, waren eger Aroe Teko, mer cenige Botgineezen, en Craik Jormica, een Macaffars prins, en den roover Pomelsean, die al $t i$ of 12 jarten Fan Celebes gerlugt was, daur nog geblewen, zich zelwen met het rooven valu menchen en vee bezig houdende, wait over Aroo Pow, of de koning wain Boni, op Aroe Tho zecr werbiltent was, de welke dit cindelyk mede vernomen hebbende, en voor dien youtt bevreeft, wel ten eerten na huis quam, doch ildar vertehenen zynde, begat" hy zich terftont onder de bercherming des $E$. Matfehappy, om voor de woede des konings yan Boni nite bloot te ftan; maire wat nu Grain Jerewick angat, dic blecf op Sumbawa met de roover Poniliaw rooven, zoo op dat ciland, als op "t eiland Mangray, belalven dat hy zich niet ontzag, zulks ook op Java en Bali te doen, daur hy cindelyk zyn einde op een elendige wyze bekomen heeft.

Aros $T$ C $k 0$, nu t'huis gekomen zynde, hoorde nog in langen tyd niets wan de zatik, tuftchen zyne gemaalin en Dow Mabini voorgevalden.

Alleenlyk befpeurde by aan haar cen foott wan wildheid, ongebondenheid, en een atker van hem, die al vry werre ging, niet tegenitande $z y$, om de kinderen by hem geteelt; dit wel anders mogt gerchilkt hebben.

Ja tiet ging eindelyk žoo verre, dat $z y$, zonder eenige reden and hem te geven, van hem wegliep, verzockende te gelyk win hem gefchiden re worden, warichynelyk, om dac $z y$, den ard van har gethatal, en ook de gewoonte der Macaftafen by voorval vitn cenig overfpel, niet dan al re wel kennende, niet anders, by "t uileleken watn liaren hardel met Dats Maban', dan een zekere dood voor hen beiden, te gemoet gezien heeft, het welke $z y$ door deze vlugt nit den koning van Goa heeft willen voorkomen: want men moet weten; dat de weten der Mohliammedazten medebrengen, ditt, zoo cen getroude wouw, hare trouw en eer vergetende, zich met ecn ander, buiten basen man, komt in
K E N.

173

tè haten, cen rrouw des doods is, be-r7on balien dat ook de man het regt op zulken overfpeclder heeft, om hem na die zelve wer mede zoo te doen ftraffen, of om hem zelf (woor al zoo de gehoonde cen prins is) op heterer dand op een andere wyze te behandelen, hoewel dat latite meer een uirwerking van den algemeenen tard der Macalâaren, dan een gettatit regt, is, hlzoo zy zulk ecn overipeelfter onmogelyk; en even zoo weinig een overfpeclder, behoudens hun cere. in 't leven konnen laten, al wiften $x y$ dat zy daar over anultons op etn fehawot zouden moten iterven. En om hunne wrakle hier over regr te offenen, is zulk een gehoont man doorgnans niet getult, voor dat hy zulk een overfpeclfter, na hatr eert alles op 't bitterfte werweten te hebben, zelfs gekrift, en het zelve even zoo aan die gene, die zyn vroww onceren dorft, uitgewoert heeft.

Dit was dan de ware reden ran Sacha 's vluge, en wan hate billyke vrecze voor de woste van haten man, wanneer hy cens agter deze zank komcn mogr; manr by, dat rice af werende, en geene de minite reden hebbende, om wan haar, die hy zeer toeder bemínde, té felieiden, wilde hat dit verzoek geenzins toeftan.

Hy ging dierhalven dant zy was, en bragt hau door minntlyke redenen zoo werre, dat zy zich liet ter nederzetten. doch als hy op zekeren tyd zyn Padivelden op Tan-Ginalla wilde gaan zien, bad' $z y$ hem 's awonds te wooren wel be loofil mede te gann' miar zeide "s mor" gens zickelyk, en daar' tóc nict in ftat te zyo, weshalwe hy met zyrie kinderen alleen derwares toog. Terwyl hy

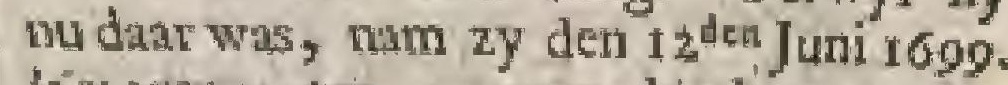
smorgens ten 4 uuren de vlugt na den kowing van Goa, fonder de allerminte redenen hucr toie te hobben.

Oritrent dezen tyd kregg men op $\mathrm{Ma}$ cullit ook tyding, dat Cram jorenta de Baliers net zyn rooven van menichen en beeften, zoodanig verbiticlt had, dat zy hem op "teiland Salamparin, onder hej thatude, gedood, gelyk zy het noornemen gelnad hadden, om den roover Powelican'mede de reft te geven; doch dic was dicn dans onthapt:

Vermits "el nu van iyd tot tyd" ook getchillen tufchen verfcheide princen, zoo van 't Bonich als liet' Sopings hof, gerezen warch, wat over zy zich genoodzalkt gevonden haduen, on zich onder de becherming der E. Maatfichappy te begeven, wierden har Edelheden gedrongen zich dan medé té bemocjen, die 't, door hut voorfchryvens ato den koning wan Boni, en aan de loninginne Regente van Soping, eindelyle zoo werre in ' $\mathrm{t}$ jat 1609 . bragtets, dat alle deze Y 3

prin- 
s7oo princen (war onder Aros Tetho een der voornatmite wh) by ons in onze beFeherming genomen, door dien koning en koningin begenadigt, en inalle hune ftraten en goederen herltelt wictden, by welke gelegentucid ook tultchen de konitugen vau Boni en Gou (dic, fehoon de eerlte met des lantitens dochter getrouwt was, op de fprong ftonden, an met malkanderen te breken) weder beviedigt wierden, dit een heerlyke zank voor ons, en yoor de Heer wan Tbe was; die 'er de fwardte lift wan zou hebben moeten dragen.

Wat nu de vlugt wan Sä̈ma venter betrof, de koning van Goa liet dit Aros Tok met een briefic, door zekere Macallatzevroww, pintagentaint, weten. Zy ontmoetede hem, by zyne te rugkomit, ontrent de rivier Mangafia, en liy ftont, op to lezen win dicn brick, niet weinig verzet, en begon bekomutert te worden, of 'cr ook :all zyn wrouws kant jiet wel deze of gene verborgene Jeden wezen mogt, alizoo hy man bar bevoorens' noit iet diergelyks befpeurt had. Daar beneven raadide hem de koning yan Got mete zeer therk in dit briefje, om van baar te fcheiden, "t gene liy, by Aro Tho"s komit te Gou, hem doon cenen $D$ din Thom nög cens kanraden dcde, doch 't geen hy dezen boodichapper volkomen allioeg, alzoo hy zeide geen reden ter wereld te weten, warrom by wan z rne gemetilin feheider zoude. Ook vrahgde hy hem, wat reden Saèma dar toe had, wermits by hat", gelyk yder ecn wift, zeer beminde, betuigende tegen $D$ in Thom zeer werwondert te $2 y n$, wayom zy wan hem, dat by geenzins van hatr, wilde fchiden.

'Zy was toen al 27 dágen by der koning wan Goa geweef, en Dan Thon quam ljog verflacide malen met dic zelve boodfchippen wan te feheiden by hem, "doch hy zont hem geduurig met het zelve antwootd, dit hy dar toe ongenegen was, en 'er geen reden toe hivi, te rug. Wat reden Radja God had om zich hier mede zoo te bemocjen, fichynt cenigzins, Cchoon men zei, dat zy zym nigt wis, duifter : want zoo men Aroc Teko"s zeggen gelooven tal, was har mocder, cen flakin van 'zyn oom, vit Latyoe oorfpronkelyk, endus gecnzins in Goa (gelyk men zeide) gebooren, of van dien wortt zyn magghlhap.

Kort dar" an ging liy na den koning van Goa, on zyn pligt wat wernedering by den zelweis a te leggen, en te gelyli om Saina, was "t'mogelyk, weer by hem te krygen.

Hy dede dar groote moeite toc; en $\mathrm{zy}$ liet hein tot s nachits ten 3 uuren te vergeefs, zonder dat hy iet op har ver- werven kon, wagten, want op hy dail 1700 " onverrigter zatke, en moejclyk, weer fol huis, els na zyn roftplats ging.

Terwyl hy datr gerult las en fliep, wict $z y$, Yan 'skonings huis, hem door eenen Fobam Rapora, zynde cen blinde Hoogenprielter, t'hus gebngt. Hy bleef tot 's morgens leggen, wameer hy, eindelyle wernemende, dat Saba ftil thuis gekomen wass, by lutar -ging, en has Wrangde, wat 'er nan fcheelde, on watrom $z y$ hem alle die mocite an dede, dant by voegende : foreck doch "bert tegen wy wit, fli zogt $m y$, wat er nan ba. pert, alow it th noit te voorch zoo af kecrig van wy befont bebe.

Darr op wiel $z y$. hen al Fohrejende te Redenen voct, omlieisde zvn beenen, en: zeide, dur wan, if beble alleen de jobud, en ik bobe my ontrent w miet awe gedragen, weshalurs if wy gehel an al daw N gordwindes onderwerpe, gereed zyold alles, da gy wy didt over zallt wilk andocm, to ondergan.

Hy, dit gehoort hebbende met de uitert te verbaltheid, zei datr op nict anders, dan, il zal u wiens doen, devol gy zelfs wive wis/lag beken; mar werbent dic wor wy wiet, "I zy ton goode, "tzy ton quadle, dangezicn dit bot rgte midd is, on wy bait gernfl te Mollen, en ow allor goed woor. wzolwen to briwerlen. Dit zeide hy, on wat meer uic haaf te krygen, hocwel hem reets ved zaaken bekent waren, die hy van $D$ ain Malaba (broeder van Dain Mabani) Dain Majanang (Säna 's fuiter) Trahon Rapad, en mecr anderen, al vernomen had.

It beble, zeide zy data op, my me Ditit Mabani to bahes gegane, die wy werlabide mimebrieven gezonden bed die it angewomen, maar weef werbrand bebb, ch wonas toc by zokere disn/mangt, Sibonde gebruikt, die haser ook werindngtipt. bad, dat 'or wag 1 of 2 was dic bricuen owergebleven, con hindar weder bur in de jagp.

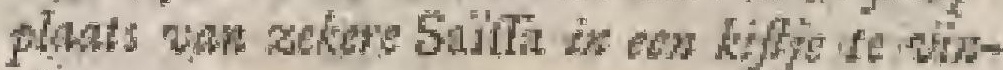
den wonitu.

Zy gaf datr op ook an $S \pi i / /$ laft on ze te halen, die zc aniftonts by hem bragt, welkc hy met vell opmerkig en ontzetting lis, verbrandende den cenen, hocwel by den anderen hield, en wel, alzoo zy van weel belang was, bewnarde. Hy zeide daur op tegen Salm, dat zy

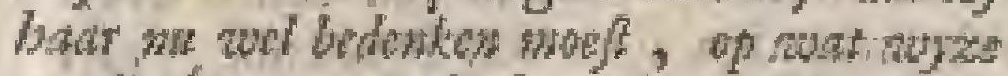
zy dit baa wishdyf zorted goed waaken. want of $z y$ hem antwoorde, dat $z y$ beredd teas, on bole bet allewille dat by bade zon willow weggen, ts ondrengas,

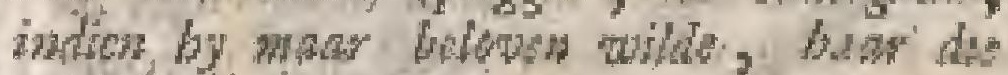
mishan ic vergentr.

Hy zeide, "is and, en it belowe ato

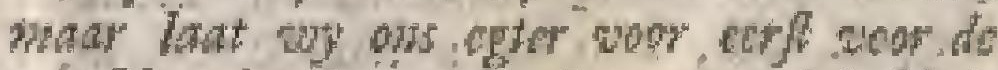

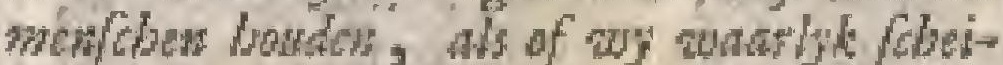
Acn wowden. Zy nat dit, ook zelf onder 


\section{Z A A K E N}

xoo ede, op den $15^{\text {dea }}$ Juli 1609 , aum, en datar op zeide hy, dat by woor corlt wan bata zowde fohiden; datar by voegende, ik zat in "t Campon Bbaros onterst bot

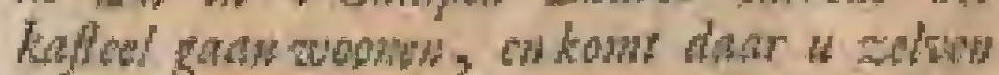
in feby als an wy owergever, en dan $\approx 0 l$

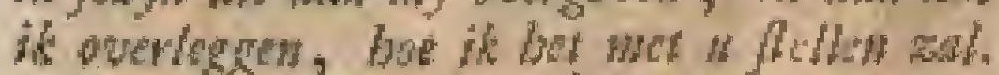

Zy werzogt hem, dat hy haar ten eerften na "c Campon Bhatoe miar medenemen zou, en dat zy dan datar van cen feheiden zouden; doch, alzoo hy dit infkeunde, onderwierp zy zich gehoel aan zyn welgevallen ; waur op hy dic alleen nag zeide (vermits $2 y$ "er by vocgde van dan zoo haalt daar nog niet by hem te

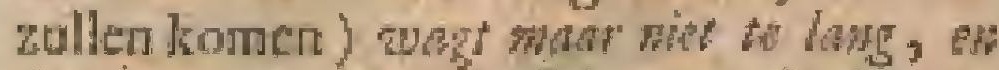
drategt zorge, dat de Eda, zynde de gezetre tyd van wagten om te willen felociden by de Mohhamedaanen, te weten, van 3 maanden en 3 dagen, wiet werlopt : want zoo ms die vootby zyys, valt er over 'I Icheiden (dat dan vaft volgen moet) geen bedenker meer, daar men anders in dien ruffichentyd (fechoon al geficheider zynde) weer by malkanderen komen mag.

$\mathrm{Zy}$ narm atn datr wel woos te zullen zorgen, en beveltigde dit weder mee een ecd.

Aroe Telo ondertuffchen gebruikte dit gewaund icheiden alleen, als een middel om te berer ngter de gehede zaak te komen.

Hy zonr has diun wẹder nat 't paleịs van den koning yan Goa, en ging dangs "er ann merter woon na 's Campon Bharoe over, doch bevoorens quam Dain Thom hem weder vrangen, of hy dan waarlyk van zyn wrouw gelchieiden was, by zeide ja, doch voegde datar by, ik zal den koning van Goil nader dar over fpreken.

Zoo ats hy mu in "r Campon Bharoe werhuift was, liee de koning van Boni deren prins op Bontuwalac roepen, met welken hy over deze gaufehe zaals in "t breede fprats.

Daar op begaf hy zich na den Hecr Landrongt wen $T$ bye, die hy mede van al dit voorgevallene met Saema, in 't bywezen van Capitein Rawis, kennis gaf; die hem ratide nog wat te wagten, doch nier te hastig te zyn, en die zaak met Are Pani (dai, is, den koning vari Boni) verraits hy mair pas met hem verzocnt was, eerit wel te oyerleggen, otn dar in verder na zynen raad te handelen. Dit nam by anj; en wan daar weer thuis gekomen zynde, quam daags er aan Down Mangimba, de zoon van Aroe Tanetia Mafoecta, hem uit zyn vaders naam aаnzeggen, of hy eens geliefde by hem te kromen.

Hy ging "er ma toe, en verhatde hem toen ook de ganiche zaak, turlichen Saema en Dain Mabami voorgevallen, die dit ftuk ten uitertte verfocide.

Agt dagen ditar ma begaf hy zich na
Goa, on zyne andere gemalio, fowiola, noo. nuet Aroe Marosing wan daar te liatlen, alzoo hy har by zyne verhuizing nog niet well had kgnnen modenemen.

Hy ontmoete toen juitt nok gersillig: den kouing van Goa ten huize van zyn. moeder, vindende aldarar cok den afgezetten koning van Soping, To-lifjong, met zyn genalin, Crain Lomgelong, de zufter des lionings, van Goa, by zya hoogheid zitten.

Hy ging char op met den koning para Goa alleen, enverklante hem nier alleen alles, wat 'et tuliehen Saina en Laing Mat bani vodrgevallen was, maar vocgded diar ook by, dat hy zyu genualin daarom cgter geenzins verworpen hath, maar dat dit alleen in lehyn, en mer hun beider goedvinden gelchiede, lantende hare ciarrom aillcen nu nog in Goa blywen, orm ondertuffchen eerit regt agter die geheele zaak vat haar en Mabani tc: komen, cD om dus alles in zyneri grond klaur te ontidekken.

Ook zeide by tegen zyn Hoogheid, dar zy daar na in 'e Campon Bharoe woer by bem komen, en zich an hem, volgens luu onderling verfprek, onderwerpenz zou, on met harar dal na zyou goedvinden te handelen. Is dat zoo, zei de koning yan Goil, dita zal ik my maar houden; als of ik van die gehecle zaak niets wete.

Dev $9^{\text {den }}$ Augufti onderzoge liy de zanke

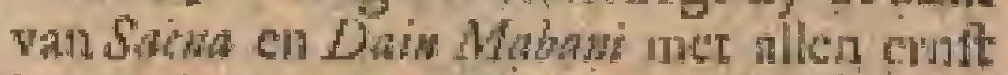
by $\$ i-b a n d s$, de welke getuigde dit Ditin Mabsini wel valt in zyn huis, en by Saèma een ganiche nache gewceft, ea dat zy hem zelf 's morgens uicucluaten had, waaron zy ook nier gelooven koth, dat Sä̈ma oit weer by hers, hace dier $z y$ hem dat ools gefworen mogt hẹbbern, komen zoud:.

Den $20^{\text {fleu }}$ dito zont lyy zekere $P_{\text {aturt }}$ na Goa by Torbas Rappass, oun hem tce 7eggen, dat by geheel en al ann hems itelde, on dezaik tufichen Sareng en hem. te verefficned, alzoo hy hal gecnzins verhated, en aun der koning van Goa daar van̈ ook kennis gegeven ladí ; wayr op dar Toehan Rappan antum 't goede beft tuffehen hen te bewerken.

Eenigen tyd heroorens had Aree Trko, Duin hiakbs, den ouder brocder van Datian Mabuin, by zeh geroepen, den welken hy, ma mer hern over de zald van zya broeder gefpraken te hebben, na Dan Malbani zont, met bclofic, dat by hem, zoo hy de warthcid zcide, en onn vergiffenis verzo 35 , alles vergeven zou, verzockende exnelyk te mogen weten, wat woor brieven ty gewiffele, en wat zy verder te zamen gedatan hadden.

Hicr op zei Dain Mrbani, dat by in die zalak geen Ichuld ter wereld, en dar

ร 


\section{M A C A S S A A R S C H E}

5700,- hy gecminos hat, mat zy heni, gezogt, gelyls hy ook, "t gene zy bem zone, thiet gehouden, mar geweigere had, dit mader hier mede beveltigende, dae by verfcheide wan diedingen an zekere vrouw, Siffe genathe, te bewitater gegeven had.

Drie dagen dant na liet Mro Toka an Dain Mabani door Dan Moitula zegeen, dat try hem rond uit de warthet belyden, of dat hy anders die tank door de wapenem met hem vereffenen zoude, antgezien by (Aroc Teko) gen ring, en die neusdoet, hem door sarena gezonden, en die hy nog dagelyks droeg, zeer wel kiende.

Dinis Mabni dic gehoor, en geen lult hebbende on te vegect, gaf kort daar

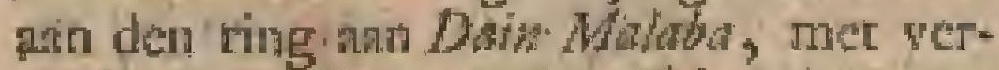
zock, om die an Aroe Teko te geven, doch de neusiloek zeide lyy anm zyo noeder gegeren te hebben:

Ditar op gaf Dowh Malaba den ring nan Aroe Teko over, doch verzoge, diu hy hem verder buiten die zonk wilde lanaten, alzoo by de zelve, fchoon doon zyn broeder gedarn, ten uiterfter mispryzen, en hem in alles ongelyk gewen moeft; wat op dan Aroe Tulk belootde, hem datit over nict meer te zullen aampreken, hem alleen nog verzockende, om van zyo broeder eens te hooren, of ly geen brieven van Säma bad, met bedreiging, dat lyy die doch voor hem niee wilde verbergen. Hy zcide ook nog, dar, zoo Daw $M A-$ boin die 2 meiden, Sije en Sowting, die tuffchen beiden gegann hadden, wan hem overgeven, en hem on sergiffenis bidden wilde, Jy dan met Detin Malabe by hem komen kon, en dat hy hen dan alles sergeven zou.

Datr op ging Dain Mahb by Aroe Cejoc, ecrn wan 2 toe Teko"s broeders, en gaf hem kennis van dit voorgewallene, wala op Aroe Cojoe gezegt had : 'tis avel, weil mw broder dis and wa broder wergewch, it mg bot wel bacn; doch late ons licwer watem tor dat Aroe Mawah, hoe Belo (Mabar s halve broedces) en Arae Mampo (broeder van Aroe Telo) wan Mandlar zulden gekomen zyn, on din te zamen die zak cerft rypelyk te overweger.

Aroe Teto, van dit onderling overlers. tultithen dere twe princen mede kennis gekrcgen hebbende, keurde dit ook goed, en zerde zich zeer garne in die zalk wh "t oordeel en goedwinden wan zyn brocders te willen gedragen.

Hy wagte dierhalven tok hon te rugkomitt van Mandhar, of rot den $13^{\text {den }}$ Oetober; mat dan wiert van hen over dic mak niet gefproken, nog getepe, zoo dut dit zoo heen neurde, zelf tot den $4^{\text {ders }}$ April 1700. wannecr Aroe $\mathrm{Ma}^{\circ}$ whil na Boni wercrok, om de guude
Quitufol (ofte zomiefchetm) in Boni te 170 : brengen.

Aroe The, hoe ongedudig onk over dit onbehoorlyk wirittel van een zaak, wala an hem 200 vecl gelegen was, wagte na Aro Mamal's vertrek nog 8 dagen; mitr ziende, dae "et al weder niets wan quarn, fchoon hem ondertusfchen van den eenen en den anderen groote beloften gedatn warch, ging diar op deze ganfche zulak den koning var Boni bekent matken, dar byvocgende, date by ook de Heer wan Thy van nlles kennis gegevei, en dat hen die genaden had dit met zyo hoogheid eerit wel te overleggen, en zich an zyoen rade te gealngen.

1) itar op gaf de koning wan Boni (zoo Aro Tho and de Heer Bremink naderhand verhaside) ann froe 7 tok den $2^{\text {dea }}$ Mey, op Paring - Loung zynde, roe antwoond: is dat za geleger , en becf Dain Mabani

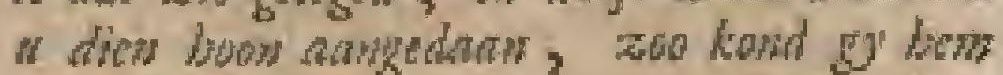
madr doodes: want wat etor en wanger-

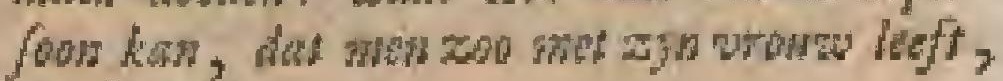
secrdraten:

Da: $\mathrm{cn}$ bowen hat Aro Pom op zekeren awond (gelylk wy in 's verwolg na* der mahalen) Asoe Teko, zoo als by coen zelf met $D$ ain Mabani w en en te zelve rafelbord gegeren bid, en "t gezelfhap nu fheiden zou, by zich getoefen, en tegen hen gezege: Fader, zoo wexig-

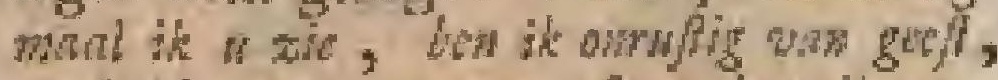

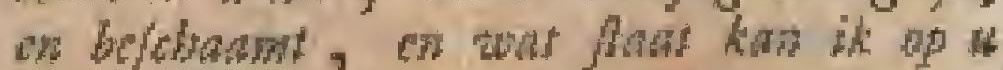
manken, dat gy wyne ordres wat aitwown

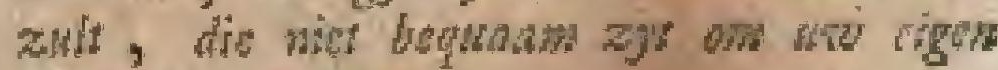
Chande to wrehen.

Are Teko, dezen dondelyken ftek des konings van Boni woelende, en ten eerften wol beerypende, war zyn Hoogheid heen wilde, zei tegen dien torlt: Aroe

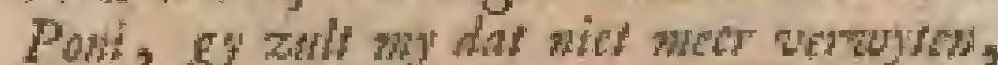
en it werzekere a by bavdrafing, dat Dain Mabaui morgen, of dat it anders zelf, ach byt zyn zal.

Doch eer zy van ecn feheidden, beloofde de koning van Boni am Aroe Teko, dat hy hem, alzoo 'er daags 'er an een hatnengevegt befproken was, zot laten weter, sls Daw Mabnwi dat verlchenen wiss, en dat het tecken wan zelserheid tulfelyen ben wezen zon, dat by dan Aret Teko's groote kamphann zou liaten verzoeken, on welke reden ook Aros Teko, dic toen by dac hanenvegten niet werfoheen, in zyu huis op de nader tyding, en "E euffehen van dient hatu, blecf wagter.

Zoo ras was er de dag en tyd wat it lunnengeregt niet, of Dain Maban: verfcheen daar nevens veel sndere Micaftarze princen; en de koning van Bont had "er 200 ras geen kennis af, of hy liet de groote Eamphan wan Aror Tiko eifichen. 


\section{Z A A $\quad$ K $E$ E}

1700.

Zoo rits had Aroe Felo dit niet gehoort, gaf ann zyo wolk latt, on op Dasn Maban wel te paten, en hem, wanneer hy wan ditar ging, onder de woet te ftooten. Dit mamen zy den $3^{\text {den }}$ Mey 1700. 200 wel wall, dat $2 y$ hem, zoo rats hy van dant vertrok, zeer behendig, niek verse wan het kaflect, het leven benamen, dat itantlonts ecr grooten kreet ganfel Macaffar over gaf, alzoo dit ecn fchandelyke moord win een der grootte Sopingze princen, en die men ten eerfen ook wift dar door Arae Toto's laft bedreven was, en die nog zyne magkige vrienden, water onder de regerende koninginnc van Soping, nog de E. Martfchappy, ongewroken zouden, nog knonden laten.

Op den zelwen dag van "t bediyven dezer moord gaf de Heer Landwoogt wein $76 y e$ san hatat Edelheden kcmis darir wan mer werzoek, om haten lalt bier ontrent. Ook werbood hy Aroe pelo wel in "that fled, of de negry Viandingen (s'aar door men de tade Alucaliat verftan moct) te vericlyonen, mor hy hecte toen in dit ftuk rier gedtitn, "t geen hy als cen wakker en onberreelt Landwoogt gehouden, en wemogens was te doen: vant had toen Aroe Teko gevingen genomen, zoo bad by hem, volgens de wetten der Macaflaren en der Boniers, zeer genaklkclyk ter dood konnen doemen, war in bem toen alle de koningen en princen ten ecrften zouden tocgevallen hebben, te meer, alzoo Aroe Pohi, en die van zyn ftreng, die de magtiglte is, nier anders zogten, dafi heuis ath cen kant te hebben. Ja ik thelle valt, dat beide deze princen, Dan Mabani et Arok Teko, den koning vani Boni even zeer is de weg wiren, en dat hy geen beter middel wift, on zich wan hen beide te gelyk te ontlan, dan Aroc Feho tegen Daja Malomi op te hitzen, en henj an te rasden den zelven te vermoorden, Faftellende, dat lyy dar als moordenatar van Dain Mabani ook ter dood zou moeten gevonnilt worden, als de zaken volgens "s lands" wetten mar behandelt wierdeo. Dit, zeg ik, zou de Heer ran Thye toen zeer gemakkelyk in dezen that bebben konnen brengen; matr vermits hy den tyd en gelegenheid liet voorby loopen, is hy oorzak geweeft, ditt har Edelheden, benevens zyn wervinger, en de regecriog wan Macaffir, daar over zeer groore bekommeringen gehad hebben, en, door te lang te dralen, busten ftate geratke zyn om hem and "t leven te komen.

Indien hy dit onder de regeering van de Heer Beerwink gedian badde, zoo was hy zekerlyk in korten tyd ta dic moord, zoo my ait feluyvens van zyn Ed. ge- bleken is, een man des doods geweeft. 1700;

Doch indicn men het zeggen van Aroe Toko, en de gedngten vau suderen, eenig geloof geren mist, zou niet alleen de loning yan Boni, matr ook de Heer won Thye (dat ik niet gelonven kno) hem geraden hebben, on tich op deze wyze an Dain Maloni te wrteken; ja daar zyo "er, die meinen, dat de Heer wan $T$ bye met opzet, om Aro Tekp te behouden, zoo godralt, endie zank niet alieen uitgettelt ; mas dac hy ook nict weinig geld (dat ik al mede zoo niet annemern lian) daa" woor getrokken zoude hebben.

Waar by dan nog deze zaaken gumen, dat de beledigde purty, te weten, $D_{\text {an }}$, Maban's broeders, en rooral de regeerende koninginne wa Soping, zelf de 7.akl nict al te iterk anbonden, nog regt over dien moord worderden, gelyk an de indere zyde de koning wan Boni, rchoon ricts ter wereld mect, dits Aroe Feke's dood, wenfchende, en de koning van $\mathrm{Goa}$, by geen van beiden gectne voor den quaden man wilden dongatn, watr door tregt, wallem ter dood te honnen doemen, metter tyd quata te veriallen. Daar hy, een yial de gevarlykfte princen op ganfch Celebes, en woor welken nu co datu zelt de koning van Boni gevteet heef, nu wel ens wan dit eiland na onze ryanden had kounen vlugten, war van de E. Matichappy wel zeet droevige linerten zou heober konnen gevoclen.

Dit alles egter, om my hier op rondborftig te werklamen, had de Hecr wan fbye ('t zy fchuldig, 't, zy onnoozel) buiten alle tegenlprank wel konnen voorkotnen, minar wie zal my verzekeren dat hatar Edelheden zyn bedryf, van wulk ent prins buiten haren laft te dooden, wel zouden opgenomen hebben, war. voor it valtilelle dat de Heer van Tbye gevreeft heef, wetende, wat fterke itrengen haur Edelheden, voor al in zaaken van zoo veel gewigt, altyd om den arm howden. Dies is bet zeker, dat hy niet dan om zeer goede redenen, alzoo by en zeer voorzigtig man was, zulks gedaan heeft; en lchoon by ata $A$ roe Teko werboden had, in de itade of ontrene het kaftecl te komen, dat hem ook uit den rianm van den loning van Boni angezegt was, heeft hy zich egter geenzins ontzicn, om dit verbod, "t zy des Landvoogts, "tzy des konings van Boni, te overtreden, en vercheide males in de negry Vhardingen, en in deze en gene ftraten met cen grooten ftoet te verfohymen, en zelf by deze en gene Bedienden der E. Mantchappy (gelyk ons nog wel mater biyken zal) aan te gaan, zonder dae dati over mede iets, "t zy door de Heer wan Tlye, 'tzy door dien koning,

teret

II I. DEEL, 


\section{M A C A S S A A R S C H E}

noo, tegen Are Teko gedann is, what vit dan by zommigen te meer valtgeftele word, dat fro Teko deze moord niet, dan mee voorkerunis en goedvinden, 200 ran de Heer wh Thye, wis wain den koning with Boni, bedreven, of thit men ten minften zeer grooten fehyn tot zulke gedigten gegeren becft, hoe fterk ook de koning wan Boni dit datr na (gelyk ons in 'Evervolg nader voorkomen atl) loochenen mogt.

De dood Ondertuffchen quam de Heer wat The van de niet lang na deze bedreven moond (dar Heer wan wel meeft tot zyne werlchooning is ) in Thye Juni te fterven, waar van de Regecring 17co. Wan Macafar den I $4^{\text {dea }}$ dito atn has Edelheden kennis gaf, dic rees nier dan te veel met dic moord van Are Tuk belemmert, zich niet minder doof "t onwer wagt afficrven wan dien Heer werlegen vouden; doch om zich hier door te redden, wonDe Heet den hatr Edelheden goed de Hecr CormeBeernink hs Berwhk (dic zy al beroorens in de Lasd- Heer wan Thye "s platits gelooren hadden) woggt. met hun fchrywens van den 21 ter Juli, na Macaftar, raar met zulke wonderlyke bevelen over 't geval wan Are Teko, af te zenden, dat men nu en dan mocite hebben zal on te raden, wat zy in deze netelige zauk beliefden gedhan to hicbben, alzon zy dan ecns belaften, dat men hem ftreng ter dood vonnifen, cn de agting der $\mathrm{E}$. Mitutichappy in dezen wel bewaren, en dan weer, dat men zien zou door de Grooten in der ftilte op allerlei bedekte middelen pardon voor hem by hat Edelheden te doen wer zoeken.

By "t vertrele van de Heer Beowink hadden har Edelheden ook (gelyle al in "t jasr 1698. vaftgeftelt was) befloten een tweeden Capitein nevens 7 an Pieterizow Weffelbrg (namelyk Ditlof Blad, die ower cenige digen met het feheepje de Hartloop volgen zou) ma Macaffar te zenden, en den Heer Hewik Collaset wan Lynden, te dier ryd Gezaghebber hier, nade Heer wan Tbye"s dood, te verlofien, en zyn E. met de Hartoop, of ecnig ander watruig, op Bitavia te verwagten, ftande als 'Tweede hier dan de Heer 'Jacob Khaszoon, en de Fiscoal Eemik Sicenkop (dic zoo na Banda ging) door den onderkoop= man 7 ocobus $\nu_{05}$ vervangen te worden, gelyk zy nu Arent wan dor Myl als Sabindaar goedkeurden.

Aangezien nu de nieuwe Heer Land. toogt Bermink by zyn lomft op Macaftat (volgens gewoonte) gecn memorie wegens den ftat ran "t Macafiums gouvernement, dewyl de Heer wa Thye dood was, te verwagten had, zoo hadden hase Edelheden hem allebricven, zedert 't jatr' 1693. over en weder gewillelt, mede gegeten, on die op de reize re doorlezen, en dana door en grondige kennis ran de Maculfurze zalken te krygen, waftitellende, dat de Heer Coldewt, en de Rand, zyn Ed., by zyn kontt, wel nader wan alles, "i.geen vedert mogt voorgevallen zyn, onderigten zonden.

boch eer wy hier mede voortgan moeten wy tuffehen beiden inlafen zeker berigt, dat haar Edelheden an de Heer Bornink voor zyn wertrck gaven.

Zy vertoonden an ryu Ed., dat Micaffar de fleutel yan de Ooft, en dat deze Berigt Landwoggdy hen, tentyde, toen de Ma- haarer Ecalfaren nog in lunnen bloci wasen, detheden zeer groote belemmeringen en mocjelyk-Her heden, voor al in Amboina gegeven had-Bemink de; mat dat $2 y$ in de jarren 1667 . en wegens

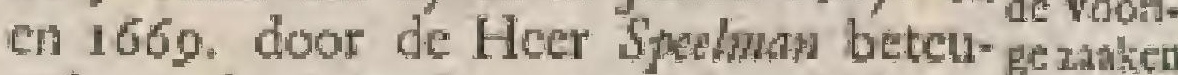
gelt zynde, men har nu ook wel ftreng âluier. in dien band houden moct, warr toe de E. Maatchappy nu de magt in handen hide, door 'E Contrate wan Bonaye, en 't xxy. Art. van diens stzoo zy by dat Art. gemagtigt was, on over humne gefchillen, ils eerfte Bondgenoot, in billykheid, en volgens 's lands regten te vornilfen.

Matr gelyls nu, met dit te doen, de regte bahnce onder de Bondgentaten gellouden word, aizoo is dit cen zatak wan de uiterfte omzigtigheid, cn wan zoo wed mocite voor de Hecren Landwoogden zedert dien tyd geweet, dat hat Edelheden bekennen moeften, dat men dit, by "t Jeven wan den voorigen kowing wan Pa. lacka, noit na den eifch vara dien Art had konnen utvoeren, antgezien dic koning, bewoorens mede door de Macaffiatren t'ondergebringt zynde, en zedert onze wapenen onder de Heer Spelman gevolgt, en door zyn groote dienfter, weel ver: mogen by ons bekomen hebbende, die gelegenhid en genegenheid wat hat Edelibeden wan tyd tot tyd had zocken war te nemen, onn zich aan de Macaftat ren, op welke hy treer verbittere was, te wreeken, en hen, daw by mal kon, te werkleinen, gelyk ook hich uit cen belegering in "t jur 1677 . door Ralia Palatha gevolgt, en war door cen grobt getal Macalfitaren wan 'tciland Cetebes gevtuge was, die dair op hunne rooveryen, en andere voornemens op Java's Ooltkult, Tsjeribon, Bantam, Sumbawa, Palimbagg, Jambi, Siam, Borneo, en elders, zeer fout in 't wwerk geftelt, en de E. Mattfchappy op alle die eilanden, en kuften, veel moejelykheden verwekt; en tor groote onkoften genoodzalkt hadden, alzoo zy beu dwongen na alle dic platzen, dar zy de pypen ttelden, van tyd tot tyd veel krygsvolk te zenden.

Door dezen analeg had de overleden" Radja Palacka metter tyd op Celebes de volftrekte oppermage over able de andere 


\section{Z A A}

moo. koningen wan dat ciland zoo verre rets an zich weten te trek lien, dat nice alleen die wan "konitkryk Soping, en andere, die bevoorens onder 'c jok der Macaflisren ftonden, zedert volfingen wan hem athingen, en al hume magt an hen opgedragen hadden, maa dat ook den lioning wan Gor zelf ricla niet ontzag dit by cen bricf zeer lafherig an hat Lidelheden te kenten te geven, "hocwel deze briet nier buiten kennis van Radja Palacka afcegair, en ecrlt van hem doorlezen was.

Ja zelf had Radia Polacha dic bepalde magt zoodanig metrea tyd beginnen te misbruiken, dat hy in toon de Grootlte des lands nict verfehoonde, ef hen maar nederzabelde, dar egter mecr de feluuld der Bondgenooten, dic dit leder, datr zy teftucten lionden, dan wel van $R$ aldo Palitekt, wis.

Ondertulitchen was hy 'took, die de Bondgenooten certh verzameld, die wrygevogten, en ze alle by de E. Martichappy als een wader (hoedanig men hem annmerkte) gebtage, whrom hy ook zcer weel by de zyne; en by ons, noor uit had. Ook dede by zyn zituen zoo ftraf, en zoofehiclyk at, on dat by witt,

dat zyn wolk zoo moeft beltiert worden, en ain te beletten, dat wy door onze verkeerde voorleratk dit niet verhinderen mogten.

Dit bedryf na wan Radja Palacka, wai ziclf de grootite konimgen a:th den hals te komen, en dezelve, zonder ze eens te hooren, on te brengen, ftont har Edelheden wel geweldig tegen de borft, maar aangezien zy hem zelf zoo groot gemaak hadden, konden zy hem nu niet voor "thoofd ftooten, te meet; thoo teden nam bad, dat by dit alles ten belte wan de E. Maatchappy dede. Hoewel by niet anders zogt, dan zich zelwen, tor nndeel der E. Matudchappy, meetler van alles re maken.

Ondertufelen gaven har Edelheden aha de volgende Lindwoogden laft, om die door grewcha nu onbepantit gewordene oppermitrt wan Radja Palacka too woor'= zigtig en zagt, als 't mogelyls was, allenskens te bepalen, dat ook de Heeren Cops, cn Harshim, wel met weel owericg hadden zocken te doen; doch zy waren hier in zeer weel door de lathertigheid van den koning wat Goi verhindert geworden; gelyk hier doof in 't verwolg, yoor al door de flatuw heid van de Heer Prims, hat erenwigt geheel en al in 't voexzand geraakt was, zoodanig, dat de E. Mattfchappy toen geheel wan hat ftuk icheen verzet te $2 y^{n}$, voormanentlyk ook, nim de moord der koningin wan Dompo, in welke tyd batr Edelheden, by hare in-

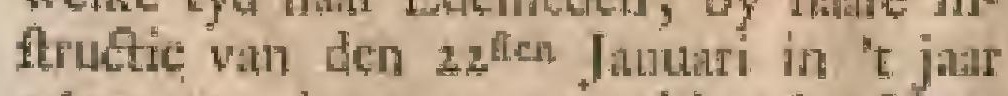
4695. ant den tocn veitrekkenden $\mathrm{Hecr}$
K E N.

Landrooge san TH; zoodanigen laft ge- 17os geven hidden, als zy in opzigt der indeve Bondgenooten meinden yan nooden te $2 y+1$.

By zyn leven had Ralja Palack zyn neef Lapotawo wel als zyn wervanger verklatr, docli hem dar" na weer verworpen, alzoo hy verwatrlooft had den Heer can The, volgenszynlaft, op te wagten, en 200 Aroe 7 ko toen niet op Sumbawa gewrelt was, zou hy zekerlyk dien koring gevolge hebben; mata dewyl hy no afwezig wits, wift Ralfi Gar het egter

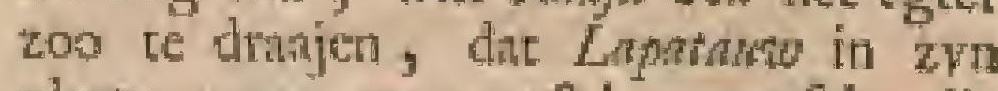
pliuts gun; cen woeft bot mench, die yan nicmaus wil geradei zyn, ga zyn hoofd leefe, en zeer hatitig is.

Na dat ru Rodja Palacka it jaar dati ath overleden, en Crats Lapatanv in zyn plates, als loning wan Boni, angeftelt was, was "er een groote vetandering ontrent het houden wan die ftreng gekom men, alzoo die prins in zich zelwen zeer los en ruw van keven, en met veel andere onvolmaktheden bezet was, behalwen daf 'er ook wufichen hem, en ryn fchoonvader, Radfin Goa (gelyk ons later blyken zal) cen doodelyke verbittering outfont, war by nog de voorige koning van Soping, Toydsjang, door den voorigen koming win l’alucka afgezer, in en over Soping ats lionjug weer alangeltelt wis, cen zatk, watr in de koning ward Gon nice weing de hand gehad hadde, ca die de jegenwoondige koning was boni door cenig krygsvolk, rects na Soping gezonden, zoge te beleten, waar door hy dan ook weel princen genoodzatkt had, zich onder de betcherming der E. Matfchappy te begeren, al het welke iju atth de $\mathbf{E}$. Mantichappy meer roct gegereta had, ons den koning van Boni in zyoe oppermagt over de andere Bondgenooten, die by zich even zoo tterk als zyn oom amleanen lice, wat meet, dan te vooren, te beteugelen, Egter dorte Rndja Lobos, cven na Ralja Pracka"s dood, by dé aanftelling yan den nierwen Radja Boni, wel zecj Hout an de Heer wan 'Tby vraagen, of de jiggenwoordtge loning was Bon bet rik nu con zoo, als de voorige koning, en mot do zalve magt over de Bowdgenooten, hebben zou; datr nog by durvende woegen, dat, soo bet met die zedoe magt wiot wos, din ook de wrede en engig-

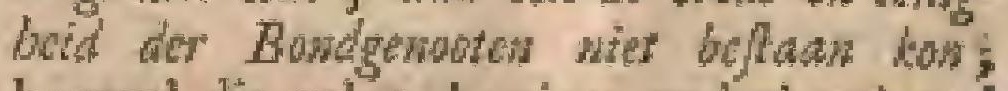
hoewel die zelve koning naderhasd wel heel andere tal gewoest heef. Egter moer men beternen, dat, fehoon wel de E. Mnatchappy de eerltc der Bondyenooten is, zy watulyle dar rege niet wel oeffenen kail, ten zy zy door een tweede medehelper, dic ma alles venteent, en dat cerft in dea hate brengt, geholpen, en onderfteune word, watrom ook de 
Hect Spamm, dit zeer wiel voorziconde, die hooger mirt in 't bywezen wan alle de Grooten, onder ons hooger gezag, ann Radja Palack opgedragen trad.

Hier op was verder den oorleg van dea trosing wan Thmbon met die van Bima, Dompo, cme. in "t jal 1690. (dogr ator Thk en Crain Jerewira mede onder "t hoogen gezig der l. Mantchappy bygewoont) gely. mede de vrede ruffchen ino Pont ea den regerender koning van Spping, en alle de princen, whar op ty misnocge waren, ja zolf een onverwatg vergelyk tuftehen de koningen van Boni en Gou, gerolgt.

Uit dic berigt nu meinden hat Edelheden dat de Heer Berrim veel lich Irreeg, om wel ce bezeften, dat, hoc reel moejelyke beradthagingen har Edelheden hier ower in de voorige tyden, zoo, over "t houden wan "tcvengewige, als in "t bewarea man 't gezag der E. Matheliappy onder de Bondigenooten, om bier alles weer in den thak te krygen, ook mogten gehad heblen, de algemecne zalk na cgter een geheel andere gedante, an ha:tr geasg alliel zulk cen neuwe luitter gekregen had, dat zy den Heer beomink hier by vooreerft genocg meinden in ftat gettelt te hebben, om te weten, wat hem, tot het ordentelyk houden der balance wan 't evengewige onder de Bondgenooten, verder van nooden was, watr ontrent bem "t doorbladeren der medegegevene brieven nog wy meer' en klatder opening Dtont te geven, alzoo zyn Ed. dat uir nador blyken zou, van wat atatd de jegenwoordige koning wan Bonit was, co hos woorzigtig men zyn Hoogheid binnen de pulen van zyn pligt houden, en wat zya Ed. ontrent den Koning en Grooten van Goa, mitsgaders ontrent alle de andere Bondgenooten, doen moclt.

Voor nl gawen hat Edelheden dien Heer in late, woo'cr feitelytheden mogten woorvallen, die men nier ftuiten kon, dat hee das altyd beft was de E. Mandchappy buiten 't ipd, en onzydig te houden; mits dat hy dan ook voorzigtig beletten moeft, dat de eene party de andere uiet bedicrf, dat alles op zyn tyd weer tot een goed wergelyk gebrigt, en de werongelykte doot ' $\mathrm{I}$ gezag der E. Maatchappy in zyn voorigen ltant herftelt wierd.

Ondertulichen moeten wy hien zeggen, dat gelyk do oude Radja Palacita een uit lteck onder de Boniers was, alzoo zy dootgans doffer en botter pan geelt, dan de Macafitaten, zyn, de zaaken na zyn dood cen wonderlyke keet famen, wat wan zich 't Hof wan Gon ook wonderlyls hect weten ce dienen, iargezicn die hooghertigen iets angebooren bebben, waat mede zy de orerige Celdbize volkeren now. weten te lokken, en tot hun gevoclen over te brengen, komende hume polixike voornemens doot een geraffinee:den Tarpel zoo fyn door elkanderen drajen, dat de botteriken wan Boegineeren niet eens konnen merken, wat ter agter lteeks. Ook zal men niet fyns nog geedigs onder de Boegineczen yinden, dat thit geen Macaliztre herzenen getiomen is.

Mea belalte zynkd, ook, dat alle de En hase koningen wan Sumbiwa (als die vin Bima, bevelua Dompo, Tambora, Core, Pelrar, en ontrent. Sumbawa) dala de Celobiche vorften verfeneifchreyeling zogten ower heenen te ziluen, de watnict meet, als bevoorens, gedrukt, miar mede in hunne regten gehandhanit, en dac zoo ontiense weele wan diar gevluge volleren, op de badrewelke wen vuile rooweryen, geplecg had, moor?. in "thunne hertteld, en door ons gezng eens weder opgebeurt mogten worden, waar door het anzien, en de ngting der E. Matichappy niet weinig by alle deze wolkeren toenemen zoude,

Het fchyir ook dat de brief, door den Heer van Thye zalr. enden R and wan Macalfir, over de moort wan Dan Mabant an haar Edelheden gefcheven, zoo lzort en verward opgeitele was, dat hen dar. in alles nog re duifter voortqunm, om ecinge vate ordre te gewen, te meer, alzoo $2 y$ zedert geen nader ichrywens datat over wan Macullar bekomen hadden 3 warrom zy dan eerit cen nader en een omftandiger berige van do Hecr Beerninh, nit dar zyn Ed, dom zou angeland zyn, verwagteden.

Ondertufichen hadden haar Edetheden ook germerkt, dat die van Goa zich nog wel meelt daze zatak antroklien, wes= hatwenzy den Heer bewnhh in laft gaven, om voor al doch te beletren, dat die van Soping zich met die van Gon nie: tegen die wan Boni verfterlien mogten, sizoo din de fpil van "t gezag der E. Matafchappy getuel en al in de aftche legren, en zy buiten alle tegeniprak ten eerlten in "tonderfpit weaen zoude, angexien de woorige tyden ben geleerd hadten, dat de overwinning van den koning van Soping an de Macaliaten "t grooflte gougg coegebrigt had, on hunne heerfehapy oper gaukh Celebes uit te breidon, on wellee veden die van Boni zich ook altyd van dien wian Soping aan hunne zyde laadden tragten te werzekeren, gelyk das de E. Matitebuppy ook bef diend, en "t van hatar altyd, zoo wed 't mogely na grefchilkt is, om dus te beter in ftat te xyu de bilane tuffehen de Bondgenooten in erengewigce te houden 3 mar hec zelve moet by on's zoo werre niet getrokken worden, als de koning wan Boni das wel garme zoude hebben, te werch, 


\section{Z A A K E N. $\quad 18 \mathrm{r}$}

t7os om over die wan Soping als Opperheer 't gezag te vocren, alzoo dit geenzins de meining harer Edelheden, mat in tegendeel hare faft en bevel was, on de regten wan yder Bondgenoot in "tbyzonder in alle billykheid te handbavell, en mar te beletten, din geenwan die twee magtigtte partyen een all te grooten ambang tot nideel van ofss gezing kreeg.

Har Edeheden hadden ook wel berigt gekregen witn de dood wan Cran 7 eramca, en yan den buit, die men dear by bekomen had, beftande in veel geweeren van goud en zilver, enz., gelyk zy data by ook zagen, dat de zelwe ano de Heer wan Thye reets door Radia Gos, in 'tcles ven wan dien Landvoogt, waren owergelevert; mat alles quam hen dien anngaande mede nog zoo duifter voor, dat zy meer liehe dienden te hebben, eer $z y$ in ftat waren, om nader berclen hier oren' te geven.

Aangezien nu die wath Butha au hat Edcheden beloot hadden, zoo veel Sappanhoue te zuller leveren, als 'c fehip de Peperthuin, na deszelfs komift war Timor, zou komen laden, zoo zouden hat Edelheden dit ook by de ecrite ge= legenheid te gemoet zien.

Hier nu mede vertrok de Hoc Berrink in 't midden van Juli met het fehip de Matroos na Macaliat.

Ook gingen nu te gelyk an de Regecring wa Macallar eenige brieven wan hatr Edclheden, wata by zy ant hat Agtoden

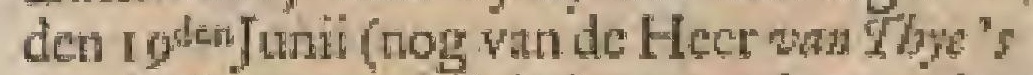
dood niec wetende) bekent makreis, du zyn Ed. door de Heeren Xwit. in "t taderland den jotter Oetober r69g. Butitengemecn Rad van Indièn gemalke was, en dat hat Edelheden daat op goedgewonden hadden zyn Ed, tha Batiwit te onbieden, en hern door de Hecr Becrink te doen vervalugen, doch onderallichen "toverlyden wath dezen Heer, by hau" Edelheden vernomen zynde, hadden zy

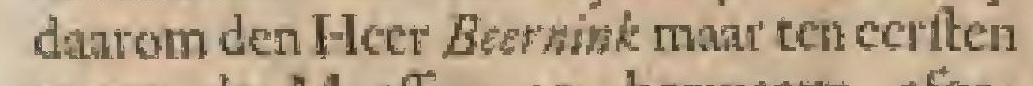
tegen de Moefton op herwarts afgeveerdigt.

Zy hadden by hun fchrywens anth den loming van Bon, en an dé lonitgin van Soping ook emfig atubcvolen, on dic noond van Dain Maban arm Aroe Teko llreng te ftraffen, hoewel de tyd ons leeren zal, dat hatar Edelheden by die latt niet zullen voltharden. Zy gaven ook bevel om wat meer fchildpads hoorn, dan bewootens, at was het tegen 70,80 ja 90 Rders 's picol, voor d'E. Maarichappy in te koopen, mits dat dit deugdzam in zyn fuotc zyn moef.

Hen bevel was ook, uit lafe der Hecren xw1., om allezins hier tegens het liftig inbooren der Engelzen, en wan allen die onzen handel tragten te bendelen, ywe- now rig te waken, als mede onj de jatrlykze remen var opgenomene penningen vun 5 tot 4 ten 100 . te rerminderen dat wan den Itea September by allen, die hum geld op dien woet by de E. Mantichappy liaten wilden, ingann zou, en dic dit ongenegen was, kon men zyo geld maar wedergeven.

Voor" "t lant makten ry nog bekent, dit "er" volgens de Nieuwe; of Gregorianoze ftyl, in "t jar I 700. geen fehrikikeljaar wezen, en das dierhalven Fobrumi man' 18 digen (whar op men in 't mataken wan alle ichriften wel letten moeft) hebben zoude; dati by rocgende, dat in "t jar 1600 , en verwolgens alle 4 jar, wel cen fchrikkcljar geweelt was; maar dat "er in de jotaren 1700 , I 800 . en 1900. geen, doch weer in 't janr 2000. eer pehrikheljar wezen zoude.

Zoo ras nu was ayn Ed, niet hicr, of hy nun de Regeefing wan de Heer Col-

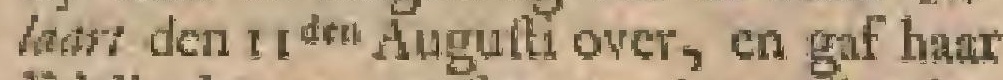
Edeheden ten eertten van ' $\mathrm{c}$ noodige be rigt.

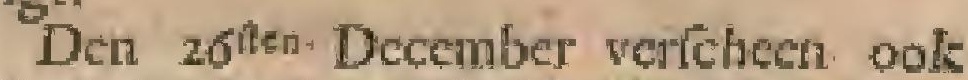
Capitein Bhal met de Hartloop, nevens cen lading van $f \mathrm{I} 68 \mathrm{gI}-5=8$. in verle heide watuen beftakde, en den $31^{\text {tien Decem- }}$ ber 1700. zonden hat Edelheticn, met 'r fehip den Yfel, den Fiscal Pos met Ioo krygsheden herwarts, behalven welle $2 y$ in 't begin des jarrs "er nog 80 gezonden hadden, die met de verdere, hier in beztting leggende, 646 loppen uitmakten, in tyden van vrede overgenoeg, on alle polten te konnen bezetten $;$ doch in oorlogstyden tion men tea eerlten meer volk en lpoedig ontzet krygen.

De Heer Bewnik nu op Macaftar verfehenen zynde, had Ralif Bom (zoo uit hat Edelheden rehryweis wan den 31 fen Februari i 70 . bleckj met ved ywer zich van Tsjinatan ma 't kalted begeren, on den nieuwen Heer Landroogt ordentelyk tecontlangen, en om den brief van har Edeheden volgens gewoonte zoct ftantelyt te doen inlialen.

Nadat nu zyn Ed. cenigen tyd dar mat Fan alles, en inzonderheid over de zak

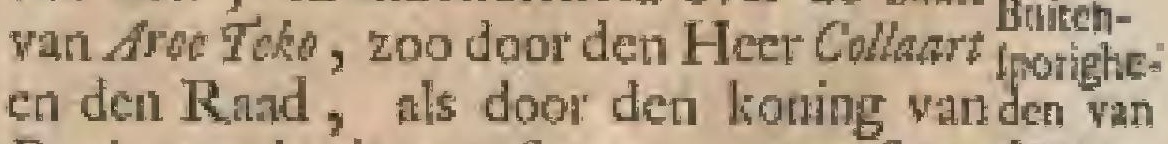
Boni, net berige oncfangen, en verftam Aroe had, hoednnige buitenfpoorigheden Aroe Tekon Teko nog bowen die moord, zoo by "t leven wan de Heer wan Glyo, als vooral daar na, by dexe en gene onzer bedienden bedrewen had, alleen on dar hem door dien overleden Landwoogt de ingang in 't kaftect vetboden was, en hoc

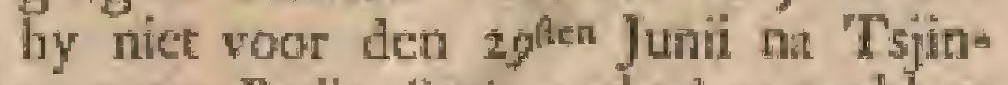
rina op Ralja Boris ontbod vertrokken was, wadat bicr over ant zyn Hoogheids 


\section{MA C A S A A R S C H E}

roo: Studihouder of Rylssbeftiender Aroe THwire Mutaesa, door de onzen zeel therk geklangt was a gaf zyn Ed. danar with :an laa Edelheden behoomlyke kenuis, dati by voegencle, dae" te kaning wan Bont, zoo 't icheen, neer meenltrenge traf oner die moond, den wel tot enige incluikling, overhellen zoude, hoewel

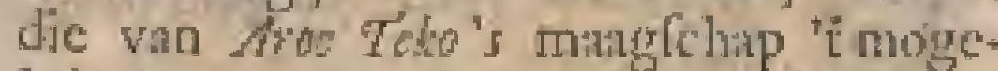
verdere lyk dan tae zouden zoeken te brengen, gen der ook blykt nyy wit werelicide brieven onct Grooten en veder gewiffele, dat, hoc zeer de over syn koning wau Boni na de dool van Aros ank. Tok in zyo hert hakte, hy cger, om zyn ware mening te ontreinzers, nevens die van Soping (dien 't voot' il walke) gezegt Jüd, dat deze zank hen nict nat1ging, zonder cgter dat by te woegen,

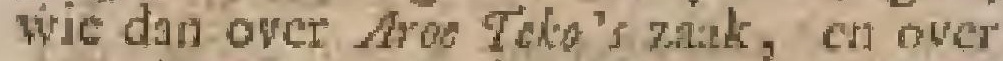
zoo vilien moord, ils Regter zitten zou. Ia zelfs had Gordefong, tolls des konings van Boni, deri zuen December $17 \% 0$, den Heer Becrust, nit Radja Roun"s nathm geregt, dat die twee Hoven het oorded ower die zatk an de E. Mitutchappy berolea Jieten. Welk zeggen nogasis matr woor een beleof complimene op te nemen whis', alzoo die zelwe Garelefous kort bevoorens qit manto van Dato Rinuato, koningin ran Soping (de gchoonde en klagende party) dalar nit gesegt had, dat, vermits Dav Mabmi au wa kane het ook beft whs; dat men liet daar by lier, en

Die de dat het meter ryd wel dood blocden zou.

zelve, Ools quam "t befluit wan den konikg van

se wren Boni, curan de koningin wan Soping,

owet dasa op wit, dat zy hen nit, "alzoo 'er,

"t Jootid volgens de Macafiantze wetten, reets te

ulen. veel tyd' verlooper was, niet konden wonniffen, watr uie dan de Hoer Berrinde niet qualyk - belloot, dat fehoon men, om 'Lregt en 't gezag der E. Mardchappy in ecre te housen, al goed wont het voninis des doods over Aho Zho te wellem, ly egter met wed grond vreesde, dae het zelve vier zou uitgevoert worden, waar by dan de E. Natitchippy in opeige van hatr gezag en futoen te wed zoude wh: gen; weshatren hee daur nit toe felyeen te hellen, dut het (gelyk uie latuer fehrywan de Heer Berwist van den $20^{\text {then }}$ April I701 . bleck ) bett zyir woude Aro Fek, om zyne groote trienden, en on van de IE. Mant fehappy" "s wegen niets te wagen, matar te begenadigen.

Hatr Edelheden ondertuftehen meinden Lath has-wolliomen hanen pligt in dezen betrage ter Edel. te hebben, fnet ans de Hoven wan Boni heden en Soping in allen ernlt te bereleth, om on dile doch zoo vuilen moord ftrenge, en zonfinceng ther tamzien win perfoon, ten fpiectel yan met de anderen te thaffen. Wilde ondertusdood te ichen de koning wa Boni dit niet doen, trafter, en was dagr zelf de beledigde toninerion wan Soping anede te wrede, zoo konden joo ool geeal van de asdere Bondgenonteri zich dittr male bemoejch, of ${ }^{z}$ er jers togeu inbrengen, altoos met die hoope niet. dat "er iers goeds op volgen zonde, in hoedarigen gewa het woor de E. Mantfchappy liet allerminfe vocgen zon, har futloen dant alit te wagen, en cenis gen grond te geven, on her vonnis, dat zy dill over mot alle reden ook vellen Lion, te zienbefpotcen; cn woor zoo verte En kort

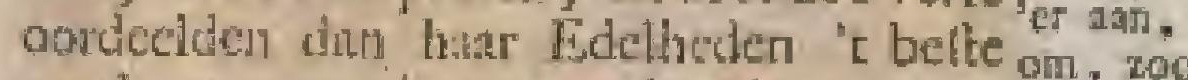
om harar gezas in ecre te houden', wan- de beleneer de lowen wan Boni en Soping ge- digde pust heir daar toe ifrbragr wievden, on Groe tyitn de Teko"s.zalk weer ex sanwanden, dat $z y$, aanbonin plats wa hem te vomififen, voor liem den, , than by fian" Edelheden wilden foreken, en $z y$ a titil pardon pardon verzocken, watr door hat gezf voor bant

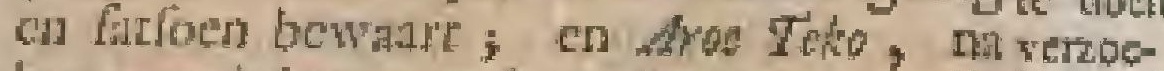
bare meinilg, se kiugtiger en nam die ken. Hoven, $\mathrm{ch}$ dan de E. Midichappy, zou verbanden worden.

Indien nu de zask ondertuffehen van noture veranderen mogt, dun moeft de Hect Eewank weer zulke matregels nemen, als de tyd hem toonen zoude woor de E. Mantlchappy bett gemaden, en voor de gemerene rult dienitugtt te zyn, al "twelle zy zyo Ed, en der Kand vern dej bevolen lieten.

Dit waren zoo de namerthingen en bevelen van hat Eliclheden in dientyd, die hier na wonderlyk na 'eloopen dezer za:k zullew repindereu.

In dir zcluc jur t70o, niet lang na zym lcomit, had de Heer Brenht, woor in op den 28 ita September han Edetheden getwanfehouwt, dat, nangezien de $\mathrm{Ma}^{-}$ calliarct nu zedert ; jatren vecl verzocken over deze en gene zanalien gedann hidden, het nu tyd poor de E Mantfchappy begon te worden, on han milde hatd rood hen te fluiten, om zoodarigge redenen, als zyn Ed. dar toen by gewoegt bad.

Aro Fek had zelt ool over zNn zank in dir ache jar een brief an de Heer Directeur Generital wan Hoorn gefohreven; matt" dic verfotitlde in "t verhal zoo wonderlyk veel wan Radja Bon's fchryven ann bar Edelheden, dat zy niet wiftcn, wat zy day" van zonden oordeclen, watrom zy by dere verfehillende verbatalen nergens meer na verlangden (zno zy den woies Februari i7ot. Ichreven! als mard te hooven, wat wonnis dat over tot "Tśfinrana zou gevele worden.

Verder zeiden batar Edelheden coen, op des Hocren Landrooghts yoorig Coluywen: indien de Howen wan Boni en Soping dit feit indeluikfen, zoo konten wy, op UE. vrange by UE. Mifive wo den $2 y^{\text {tra }}$ Oetober, nog niet zeggen, of UI dat van gelyken, als hy onderdanig by UE. 


\section{Z A A}

trot

quam, zou mogen laten doorgan; mar wy werftatu in tegendecl, dat, zoo "er een vonisis oyer Aro 7 7 bo, niet overeenkomende met de atrociteic van die verradelyke moord an den Sopingen prins, inogt geveld worden, UE. dan niet anders tegen de Bonize en Sopingze Gecommittecrden zeggen zal, dan dat gy dat voor gecommuniceert houd, zonder UE. egter daur over te verkliaren, mar dat UE dar an ons fohryven en onze nadere laft dara over cerft afwagten 7 al. Ondercuffchen zal UE. Radja Bani recommandeten te bezorgen, dat Aroe Teko bimen Boni zoo lang, of altoos buiter 't bereik wan ons kaftecl nier allecn blyve, maar dat hy niet vat Bontuwalac, of uit Goa, om verdere mocjelykheden woor to komen, zal hebben te gaan.

Ook moet UE ons hicr ofer de gevocverdere lens der Hoven aldatr bekent makken, bevelen war na men met lift on ftil zal moeten daraver" vernemen. 'Zoo 'cr' nu gelehil zufichen andere die wan Boni on Goa ower Se-cyna mogt zakken. gerceen zyn, en zoo die wat Boni dic yoor hun regtbank eifichen, en Radja Gou dit niet opwolgen wilde (dat volgens zyn Hooghcids bricf an ons apparent is ) zoo zal UE dat al mede tragken tot onze nander ordre in ltat te houden, en ons onderturichen van UE. iantinerkingen dienen.

Wegens den buit van Jerenica gaven hat Edelheden by dir hun fehrywen ook laft, on, alzoo de E. Mateluappy danr door veel onkoften had, tan de zelve wel 'e groothe gedeclte datr af toe te wyzen, en om derlalwen an de Intanders of Milcaffaren de geweeren en Danten, doch de buffen, en andere Neder landze felictgewceren and de E. Matichappy te geven; en de 2 krifien (watr op die wan Goa ftonden) kon men a an Crain Bontua lanten tockomen, mits dat men ecrft werneme, wat regt dic van Sumbawa op deze goederen zouden mogen heblien.

In "t begin wan dit jail" $170 \mathrm{~s}$. hadden Gerchen- hatat Edelheden ook deze gefchenlien an rer Edel- de Celebize vorlten gezonden.

hedesala

cenige

Grooter

\section{Aan den Koning van Bant.}

I ftuk goud Perzinans.

$y_{+}^{\prime}$ ellen Hollands Fluwel Aurorit.

I goude Alegia.

1 zilfere dito.

I goude Tats.

10 tyne Chirzen.

10 ps Saralat"s.

6 ps Moeriften.

6 ps Caffa Bengala.

6 Mallemollens.

6 Mdathays.

2 Japaniche verlikte Schilden.

2 vergulde Snaphatnen,
K E N.

I fyn Roer met 3 lesopen.

1 par vergulde Piftoolen.

2 kalien mer Roozewater.

s?o:

An Datn Tahalile, koninginn Weduw wow Radja Palacka.

2 fyne Chitzen.

$6=-$ Saraliats.

2 ps Mocriften.

2 ps. Caffa Bengala.

2 Mallemollens.

2 Adathays.

2 fyne witteBaftas met goude hoofden.

2 kaffen met Roozewater.

\section{An Dito Riwnto kominginne Regento was Soping.}

2 fyne gefchitderde Chizzen*

2. ps Citta Bengatí.

2 ps Mocrinter.

2 fyne witec Buftas met goude hoofden.

2 Gefchilderde Sariffa s,

1 kas toce Roozewater.

En aangezien haar Edellieden an den Vercheikoniting van $\mathrm{Goa}$, nog al by de Heer wan vercheiThye "s keven, belooft hradden, de landen den, door van Polong Bangkit op Laylan, te haarEdelfcherken, beloofden $z y$, by hun felsry- hedenatin

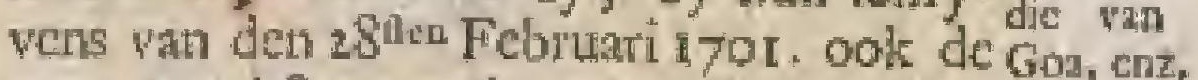
verzogte Aete van de overyift der zelve weargeeerlang in een zilvere doos te zullen over- geven. zenden.

Op diergelylen wyze waren ontrent de jaaren 1697,1668 , en I699. ools de landen van Muros en Sodiang, neverns des zell's hooge en lage landen and die van Goa, en tha thecr andere vorften van $\mathrm{Cc}-$ lebes, op het fnaakelyls voordagen van de Landrooge van dien tyd, mede gefchonlen, dat hat Edelheden wel cens zou konnen berouwen, en oin welke landen te verkrygen te veel Nederlands bloed geftort was, om die zoo ligtveerdif weer weg te geven, daar het by hatar Edellhoden (myos bedunkens) eet valte regel yan flant zyn moett, die voriten zoo klein, als 't mogelyk was, te houden, wel verre wan hen zoo veel handen weder, en hen diss de magt, on ons te wedcritain, zelfs in handen te gever, verzekert zynde, dat wy de zelve nu zoo gemakkelyk, als in de Heer Speehnane tyd, niet zouden weder krygen, alzoo "er een groor onderficheiul tufeliende Micaltaren nu, en tocn, is, on dat zy nu yecl civaatrender, dan te dier tyd, in de krygszalken, en yeel geflepener in alles geworden zyn.

Te mecr was het te verwonderen, dat haar Edelheden dit deden, dwar zy den $22^{\text {fitia }}$ 


\section{4 \\ $M A C A S S A$ \\ ijoT: \\ Februari, of 6 dagen wan te wooren, hem een Ade van quytichelding, wegens al- les, dat by ons nog thit lrage wan 't Con- tract wan Bonsye fehuldig gebleven was, zoo gunitig roegezonden hadden, dair by alleen bedingende, dat dic ontling geen fand grypen zou, zoo zyo Hoogheid zyn werbond met de E. Matichippy t'eeniger tyd verbreken of overtreden} mogt.

Men moet ook, als een zagk wan zonderlinge opmerking, niet vergeten, dat hant Edelheden den Heer Berfink wel ernftig in laft gaven, om allenthalwen doch de andere Bondgenoaten wel voor te houden, dat xy geenzins onder den koning wan Boni ltonden, of wan hem, gelylk veele meinden, athingen; matr dat zy vrye Bondgenooten waren, en datr woor wan ons ook gehiouden wierden. Dit haalen wy am, om dat het dat: na te pas komen zal.

De Heat Om nu de latt haarer Edetheden, weBeerrink gens het fonderen der Bondgenooten over fondert Aro Teke's zaak, na te komen, had de den ko- Heer Becrwink Datorwa $L i-L$ obbe, of think wan den konink wan Loeboe, den $9^{\text {den Juli }}$ over die ntil by zich ontboden, dic daar na op mootd zekeren dag, zonder' den tolk van den koning van Boni, wolgetrs 's lands gebruik, te watrfehouwen (dat ten ecrfte in dien koning nagedagten en argwaan verwekte) by zyn Ed. in 'r kafteel zonder ecnig gevolg quam. Hy wiere van de landpoort tot aan "t huis van zyn Ed. geleid door den Sabandare van der $M y$; ten dien einde gecotnmitteerd, en tan een tafel in de voorzal geplatuf. Hy quam (zoo her den natm had) alleen, on dera Heer Landwooge in zyn nieuw gezag alle heil te wenfehen, en wond by zyn Ed. den Hees Capitein Wefulburg, en den onderkoopman Joantes Hockart zitters.

Zyn Ed. dede zyn Hoogheid eertt een kopje thee, endaar na ook frilh pinang, mitsgaders Inuiftabalk, dar die voriten zeer lterk op gezet zyn, ambieden, en hen cindelyk een droog collation voorzetten.

Ondertuffechen fprak de Hecr Betratul omftandsg met zyn Hoogheid over de zaak warn Aroe Feko, van Sacma, en van Dahis Malrani ca by oordeelde, dat Saina zich zeer vergrepen, en dat Aroe Yeko cen zeer groot rege tegen hast, en tegen Dain Mabasi had, on wan de Bondgenooten vonnis over has te verzocken; doch aris gaande de moord, aan Dain Mabani zoo driftig geplectgt, oondcelde hy, dat zich Aroe teko zeer misgrepen, zyn goede zails verbrod, en zich wolgens 's linds wetten zonder etenige werfehonung feluildig gemailtet hald, alizoo dic zegyen, dat geen konings kinit, of hoe hoog ook vant afliomit, zyors gely ken, buiten woorgande /

\section{A A R S C H E}

vonnis van oen wettige vergadering, het $\mathrm{n}$, leven benemen mat.

Hy oordeclde ook, dat het Radja Boni,

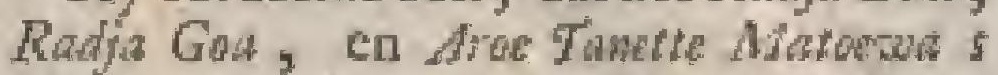
fchuld was, dat nen met de zaali dus lang gedraalt had, waar duor men nu den tyd, om hem ain 't leven te komen, volgers 'slands werten, matr ook mogelyk wel met opzet, had lanten voorby gain.

Aroe Teko, zeide de Heer Beernink daar watAro op, zegt opentlyk uit, dat hy deze moond Tetho met woork unnis wan de Heer wan Tbye, en daar van yan den konstg wan Boni (hocwel die dirin oprigh nu lonelhent) bedreven heeft; wanr op yon de zyn Ed den koning van Losboe verder Hecr van wrangue, of zyn Hoogheid ook iets daar Radja van wilt; waar op Radja Loeboe zeide, Boni, zel. dat lay niet veel van de Heer van Tbye's medekennis hice van wift te zeggen; maar dar egter Aroe Telo"s gemecnzanine oninegang en tocgang tor zya Ed, zeer grooten fchyn gaven, on daar ies van te mogen giffen ; doch belangende Radja Lowi's voorkennific hier at, daar wan kan ik by myn gryze haiten ( Fattende saar op by zyn gryzen band) wel betuigen, dat ilk her zelf geweeft ben, die Aroe Pow (dat is dezen loning) op Aroe Teko"s tmeeking ben gaan aanzeggen, dat hy (Teko) . ziende, dat men nog geen begin van zyn proces mankte, van ongeduld nier langer feheen te zulten wagten met zich zelven, zoo "t regt geen woortgang nam, aan Dain Mabani ie wreeken ; waar op by (Radja Loeboe) van Aroe Puaigeca antwoord kreeg, hoewel by uit de gebecrden van dicn koning wel zien kon, dat by tegen deze wraali nict veel had; doch hy (Radja Loeboe) had dit noit tegen Arue Teko gezept; ook verzogt Radja Laebor, dat de Heer Landwoogr dit geliefde by zich te houden, op dat hy voor de oploopenheid van Aroe Poni, dic hern over deze tanal fwatr ftraffen zou, nict bloot moge itan.

Angaande de werdere behandeling dezer zatak oordeelde Radfa Locber, dat Aroe Teko, zoo wegens 't fatioen der E. Mautichappy, als om door dien hoon de princen lindercen van Soping (dic van fturn die yin Boni nier behoetden to wyken nuaar veel ecr overtroffen) tot geen murmu ering te brengen, onmogclyk ongeftrit blywen kon; doch alzoo na 's linds wetten de cyd, om hem an 'r leven te komen, te verre verloopejl was, was 'er njer niders overig, dwn hem, na een depe onderwerpming voor de Bondgenooten, een fware boete, die hemn niet weinig kor wieken zou, en die nog hy, nog yemant van de princen qualyk zou konnen keuren, op te Jeggen, watr mede deze vorft zyn reden belloot, zyn.Ed. bedankte, en woder vertsolk.

Den in den Julii bringt Marcus Sandbeek 


\section{Z A A K E N N 185}

I7ox: (door den Heer Landwooge uitgeronden, onj deze en gene Grooten in der ftilte Nader over die zask re fondecten) berigt, dat

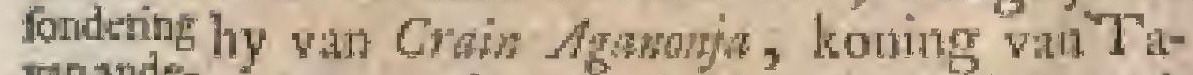
van ande- neta, verthan had, dat stroe Toh's zate oper. eu rege in 'ecerite teer goed was, docla ditt hy dic door de bedreven moord verbrod, ton, volgens 'slands werten, at Intgg werdicat liad dat over gettraft te worden, en dite her hoogtyd wis, on hem nog te ftuffen, of dat hy anders vreesde, dat hy door argwitan, of mismoegen, wel lige de vlagt nenten, en, zoo hun allen, als ools de E. Waatchappy nog wel cens veel mocice audoen mogt.

De Heer Landwoogr liet ben weten, dat by hem zelf dats over wel eens wenlche te fpreken, wratr op hy tot antwoord gif, dat hy by zyn Ed. niet komen dorit, ten zy by dur door den tolk des komiags tran Boni begeleid wicrt, Magt, dic alzoo geen der Grooten, onuer dien kozidh de ring thande, dat buten zyn kemis, con koning buireri begelerding van zynen tolk, zou van Boni durven ondernemen. Dat, ingevalle ly andere dit buiren zyo Hoogheids weren dede, Bondge dit anilouss of nar $z y n$ Hoogheid, of nowten aan Dith Tabahe, de koninginne weduanjita- we, verklike zou worden, gelyk men tigde. datr nu teets al wilt, dat Radja Lowbe in der llite, en butren begeleiung van den tolk Garefefeng, by den Hecr Landvoogt geweel wats, zonder dat hy Aros Pont tot nog toe keming daar van gegeven had; een dand, ftrekkende tor krenking viun de regeten en wan "t gezag wan 't Bonilich Hot, ca watr over Dan gabablo zelfs rees tegen hem ( $A$ gantonia) gezegu had, dat men den konuys vatu Boni geen grooter hoots dan deze sundoen, en have agting in 't by zonder nergens mede meer, diun mee zulli ecn daid, als met voeten teden kon, vermuss bair overleden Gemall die gene was, dic allereert de gronden ditur toe gelege, en alle de onderhoorige koningen altyd zeet ltreng in dien band gehouder, en hen geleert had hem in alles te kemmen.

Dit was dau de reden, wamom Crabs Monowia ootmochig ain zyn Ed. verzoc-

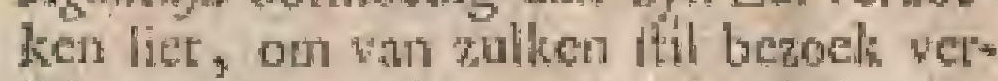
fehoont te worden, vermits de koning Van Buni dit thict alleen zeer quatyle nemen, malit hem dit ook zekerlyk betatit zetten zoude.

Sombled ging hem nogmatis perzoeken, onder verzekering, dat de Heer Landroogt hem deklen en befchermen zoude; doch Crains Agonowia, met die belofe eens dichende, zei thak uir, wat

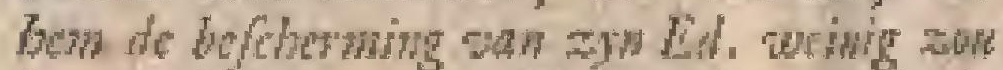
kowwh belpen, als by 't waft wer bad; doch, teu desdemat hicr toe iangemant,

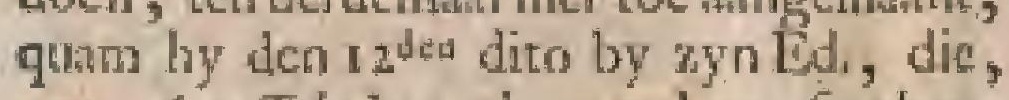
over Aroc Tebo's anak met hem Spreken- de, weder byn 'tzelve van hem, alswin 17ot: den loning wat Loeboe, dat' over vernam.

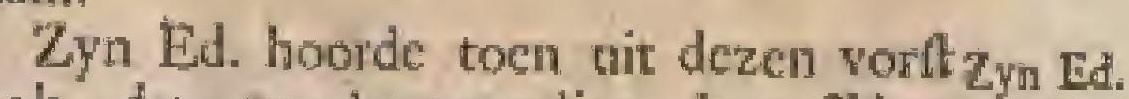
ook, dar, zoo 'r geruge liep, "cr tuffehen talt Crain Sorion en Wabani nog geen vlcefeluelyke Aganonja gencenfohip geweelt whs, dit al eenirs de pols. zins, doch niex volkomen, rot werontfchuldiging Fan Dain Mabari dienen kon, boewel hy mede oordeclde, dat Sacma en Mabani zich zeer fchuldig gemalkt, en an Woe Teko cen groot regt tegen hen gegevei hadden, om hen wolgens de wetten te doen ftraffen, mat dat hy door de moord wan Dain Mabni zyn goede zank ganlch bedorwen, en zich zelven doodichuldig gemalet had, doch dat de tyd, ori hem re Itraftera, verloopen zynde, men ut geen andere ftraf wolgens de wet ten ath hen oeftenen kon, dan echelyk van hem te rampufen, dat is, wan zyne goederen verbeute te werkluatei, en hem buiten alle zyne waudigheden te ftellen, of wel van hem te bannen s doch dic bannen hicld hy, uit inzigren wan that, nut als ondicntig, alzoo dic zeer quade gevolgen na zich zou konner lepen; zoo dat nit zyne gedagten het bett was, zyne goederen miar verbent, of hem van alle zyne waradigheden vervallen, te verklareni mits dat men darar mede dan ten berlten voortging, co 'cr nuer lang mede Wagte; war op din die vortt zyn afTcheid nam.

Niet regenfatade de Hecr Beerwink nu Vreete hoe langs hoe meer in alle de Bond genoo- der Vor ten der Celebifche vorlten een algemeene foten on beweefthed befpeurde, om buiten yoor- Ed. hier weten wan Aroe Pow met hen over deze over, butzaak te komen fpreken, lict zyn Ed ten weten

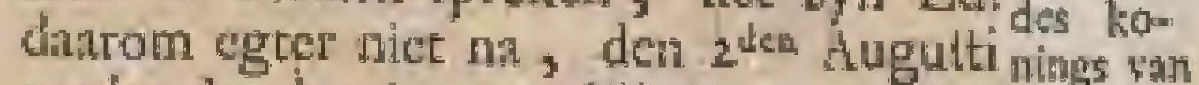
weder den lonting van Wadjoe, en Aroc Boni, te Bto (verbecldende thans de honingin) Jpreken. als ook den ouden Aroc Tamerc Marowa, eeriten ryksbeltierder vau het Bopilich Hof, dooj zy hen likerk, Marcus Sundbek, Nader zeer behendig de pols over dit werk te onter taften, "e geen deze borlt, als zeer erwat taiting ren in de Maleitze en Bocgize taal, cot der andeweel genoegen wan zyn Ed. bestelde.

De koning wit Wadjoe, anders aroe Matowa genant, zeide: Dain Mohot is nu dood, en hy kan zich niet revantwoorden; doch 't is zeker, dat Aroe Teko, en prins wan "t Bonilelt ryls, bem wemoord heeft, watur toe by wolgens onze wetten geenzins geregtige, gelyk hy in tegendecl gehouden was dalar over "tregt van zyn koning, die alle de om= thandigheden dezcr zinal wilt, Beduldig af te wagten.

Ik heb gedagt, dat het rylk wan Boni, door dit zammelen, en "t nier afdoen dezer zaals, genegen was een fchuldenaser der Sopitigers te blywen, om naderhand $A$ der 
jow"- als "en cens iet diergelyls woorvicl, en als de beledigde parcy een Bonifch jrins wis, zulken diad dan mede ongettraft te laaten doorfichieten; doch zie nu, dat de Heer Landvoogt atan die zatak begint we tillen, en 't zou cen groote laft van onzen hads zyn, zoo men die tot wederryds genoegen wan die twee Hooge huizen matr Ppoedig aftnen kon.

Hnd men Aro Tek op heeter diad met de dood geftraft, dat was wel verre it befte geweeit ; doch, dic tyd woorby synde, kon men niet anders dan hem zoo mimpalten, en kortwieken, dat hy geen vlerken hicle, om meet quaad te doen, hoewel by anders door zyn groote matg fchap zech te viezen wis.

Aroe Belo, brouder van Darw Maban, was van oordech, dat $A$ re Triko de dood buiten alle tegenfpratk verdient had, ook zoude ik, zeide by, myn brocders dood al op de dasd gewroken hebben, zoo de koning van Boni my niet zeer ernitig had doen bevelen, my itil te houden, en datr over 't rege van de Ed. Mastichappy af te wagteri , doch dewyl ik zic, dit 'er niets af komt, weet ik niet, wat ik doen zou, zoo Are Tcho, moordenala van mynen geliefden broeder, my zonder gevolg regenquam, alzoo myn bloed dan wel lige aan "t zieden zou konnen ralken, on my aar zulken werrader, die 't hate niet gehad zou hebben van myn broeder voor de vuift an te raften, en dic ' $r$ derarom op een vermaderlyke wyze door andere liet doen, te wrekken.

Dat nu, zeide hy, onze leningin (te weten, de Sopingze) nitet fterker op har regt is blywen ltaan, is, om dat wy, en voor al $z y$, hara te ranuw reets als ant hun beider belang verbonden heeft, en dautrom zeide zy ook tegen froc Powi: Nef, al wat gy in atze sabt doet, dat zal ik voor welgedan asnzicn, on goedkewnon; daw zy anders wel wilten, dnt de dood war zulken prins, als myn broeder, niet dan met de dood van den moordenatr, kon geboet worden: Lierhalwen moet ilk bekennen thu niet langer te weten, wat it wan die ganflue zaak oordecien zall. Radja Ban wil wel hebben, dat ik hem alle belectiheid bewyze; mat by denkt niet, on my in de zakk votr myn zoo fchendig vermoorden broeder cenige voldoening te geven.

De itokoude Aro Tanetto Matwous wws mer den koning wan Wadjoe wan cell cn 't relwe gevoeden, dat "er niet anders overig wis, dan on trot Teko"s goedexen werbeute re wetklaren's doch dat dit ook, op dae by "er de finut niet af in de news kygen mogt, ten eerlten diende te getchieden, zoo men hern niet na Banjar Malin, of clders, ni onze ryatiden, wilde zien vlugten.
Ook voegde de latifte vorlt hier by : mo: Non is 'er bevezen, dat Dain Mibani wet

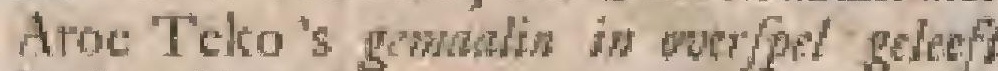
beel, foloon 'izender wan zyne minnelve. wen acw Saèna kldar, ch rolgcos whe wet frafbor is; matr froe Teke was nier bewocge zich zelwe te wreeken, die wel tot zyos vertchooning zegt, dat hy my, en den koning van Boni, datr wan woor af kenus gegewen heeft; matar, in opzige van my, is dat onwair. Zulk een dand nu, dair leggende, mont volgens onze wetten geltratt worden, "t $2 \mathrm{y}$ met de dood, "t zy met zyn gocderen tic mompaszen, 't $z$ y met hem te bunnen.

Warom nu deze ftruffen nog nict geoffent $\mathrm{zy} 17$, is zecr ligt te denken. Aroe Pons, om de quadic pier niet re zym, had lichlt, dat de $\mathrm{E}$. Maarichappy, die hicr door mede gehoont, en de certte der Bondgerrooten is, daat "t vomis ower uițpok, op dat $A$ ro Teko's broeders geen quaad bloed tegen hem mogten zett n. Om hem mer de dood te ttraffen, datr toe is de tyd te verre verloopen; dierhalwen oordecle ik, dat hy moer grampatt, en van alle zyne wandighedeir afgezet worden, zonder hem oit weer in eenig anzien te brengen, on zyn wrak nier onderhevig te zyn; doch zoo men dic ten eerften uiet doet, en hy lont rickt, zal ons die rogel zekerlyk ontwliegen, en ons datar na vecl moeite and de hand geven. En dic was in 'rgemein 't gevoelen dezer voriten over deze zatk.

Den 8ten Augufti liet de Heer Berwint den koning van Gon, en Crath trowlofongo (zynen ryksbefticrder) de pols door Sandbel mede hier over taften, die beide van oordeel waren, dat frot Telo een van deze twee ftraffen, of dedood, of "r rampaffen, ondergana moeft, en dat de E. Matfohappy or een wan deze twee behoorde te verkiezen.

Den Ioden dito hoorde zyn Ed, dat de koning wan Tello (dic in alles meelt mer Crow Aganowja overenttende) van oordecl was, dat roveripel tuffchen Saim en Dain Mabani noit bewczen of geblem ken, en dat Aroe Telo des zoo veê minder tot zulken vuilen moord geregtige, en diethalwen te doodfchuldiger was, te meer, alzoo "er pas te wooren cen verzocning eufichen hem en zyne Gemalin, met Dan Madani, getroften was.

Schoon hy nu hier door de dood verdient had, kou egter de E. Matefchappy dat vonnis, alzoo die tyd te veresereroopen was, wel wat verzagter, mits dat de Macalfarze wetten ongefchonden bleven, dic in zulken geval dam van "r rampatten, of wan 't barnen fpraken, wiar door alle misnoegen onder de beledigde partyen zou weggenomen worden, die nu byra nict weres, hoe zy 't met do 


\section{Z A A K E E N I 187}

ner. tak hebben. Ook whs hy van gedagten, dat de Heer Landwogt, als zynde 't Hooft aller Bondgenooten, hem, nog niemarar der Mticaftiatze vorften, in zyn gevoelen behoorde te vrager, alzoo hy ten wollen getegtigr en gevolmagtige was, om ten eer'ken tot de uitwoering te treden, dat hen alle de andere Bondgenooten zeketlyk wel zouden daten gevallen, wanneer "er matr wolgens hume wetten (daar niemant an [wy/felde) getandelt wierd. Hee rampalten, of bannen, oordcelde hy, moeft cen van beiden ten ecrften an hen in "t werk geftelt worden, "hoewel hy 't cerite 'r bette, en voor "r minil gevarilyk keurde Ook flelde hy walt, dat dit $A$ roc Pont, hoe hy zich ook houden mogt, van die zath, uit inzigr van Aro Teko's magtige broeders, te willen laten dood bloeden, mede zect wel gevallen, en zekerlyk ook "t.'yne dat toe doen zou' de, zoo ras hy zag, dat de Heer Landvoogt met die zuk begon, en "twatrd voor hem man begon op te varten. bin die wiss 't alles, dar de koning wan Tello hiter over zeide

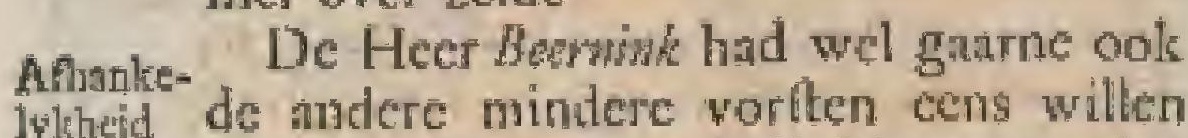
der min- doen fondecten; doch die hingen wan den dere Vor- koning van Boni met zulten flatagtige fteil wa weete af, dat zyn Ed, daar atn niet illning van len dorft; dierhalyen keurde hy bell hatr Bond. Edelheden, op haticen late var den I tem Janutri, dezes jatrs, om de Grooten hier over te fonderen, mat cen ner berigt 7an de gevoelens dicr vorlten, die zich ditat over gethe hadden, te geven, en har Edellieden verder te verzoelen, on hem looedig latt tot het uitwocren wat "t wonnis te geven; dat hy haar Edelhe-

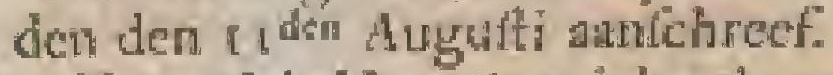

Terwylde Heer berwinh zucl met deze fware zaik Yan buiten belenmert von, wiert zyn Ed ook door een andere vas binnen, die hem nader ter haten ging, zeer gevoelig angetat, alzoo Mevrouw zyoe Gemal hnt, nu al enigen tyd zick geweeft, hoe langer hoe erger begon te worden.

Onderfufleben lies Radjo Boni zich don Marres Sendbet den i $9^{\text {den }}$ Augulli by zyn Ed. vetrntchuldigen, en zeggen, dat zyn binedek 't niet quanlyk nemen moet', dat by un eenigen tyd nici by liem gekomen wis, alzoo hy dat alleen on de zickte van zyn Ed Gemalinne, en om door zyn bezock dikwils geen nanleiding tor hat Est. verergering te geven, nagelatien had; doch alswo lwar Ed. niec bererde, en zyn Hoogheid dierhalven zyn Ed. nog niet preken kan, fehoon dne wel noodig was, liee hy nu zyn Fid. door bem (Samdbak) weten, dat de Engellehen zich op Banjar Mafin nice alleen nedergetlagen, on dar reets ryet. cene valtigheid opgerigt, maar dat $z y$ "t voornement hadden, om een mecenigre Engelzen der Celebize volkeren; 't zy met goede Mpathing woorden, "t zy mee dreigementen, tot en hunge zich te lokken, doende door hunne poging. kruilters de Boniers, die uit Tsjinnta, Wadjoe, Locboe, cnz na Paffur, Laoet Poelo, enzi ten hindel vaten, aanzeg= gen, dat zy, des genegen zynde, zich masr onbefehroome na Banjar by hen lionden begeven, endat zy door den Engelen Generial dat gehandhafd zouden worden tegen allen, dic hunc rufte datr zouden willen verthoren; ia zelfs dat zay de Hollanders niet behoefden te veezen, als zy zich man in dienft der: Engelzen widen begeven, biedende an yder foldant 5 , en aan yder fergeant wan hen 8 Rders ter mitand, door welk lokaas zy, volgens zeggen wan zyn Hoogheid, reets zoo misnoegde Macaliatarze en Boegineeze koppen in hus dicent gekregen a en wart over $z y$, na die in ver feheide vandels verdeclt te hebben , den gevlugteu en belienden $B$ amblang als hoofd gettelt hadden, "I gecn een wan zyn Hoog. heids fpions wan Bambang zells verittan hat, en noodig oordeclde den Her Landwooge te doen weten, en warr over by zyn Ed. nog meer zankelu van andere, die daar mede an fohuldig waren, en buiten zyn Ed weten in der thile met de Engelichen heulden, te zeggen hadde, die hy aan andere niet vertrouwen kon, en ware in egter tydig diende voorzien te worden, om alle Europeers buten onzen gerichtsban re houden, en on te beletten, dar die koningen van Mandhar, dic ay mede ieer therk anngezogr hadden, nict mogten waggelen.

De Heer Berwisk, deze zatk was te wat veel gewige ingende, vont goed, vier over zyn

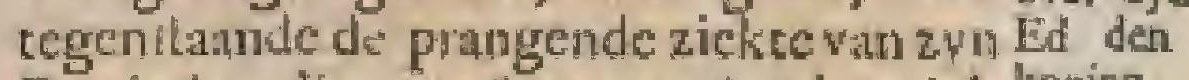
Beninde, dien vorft ten ecriten by zich koning te ontlieden, die den zotia dito ook by fan Boni hem quars, en wan alles een omttandig zyn Go berigt gat", en hoewel de Heer. Bermink mantin "er incer af witl, dan zyn Hoogheid wel lowals dagt, liet zyn Ed. dic zoo weinig, als boord. 't mogelyk was, blyken, on dair door nog meer uir zyn Hoogheid te hrygen. Hy zeide egrer gehoort te hebben, dat "t Engelich opperhaofa op Banjar' Mantin rwee kleme monttervarjens met buskruic, yder wan 2 pond, aan voomame lieden op Macallar ten gefchenk gezonden had; doch Radja Bowi zejde: neen, myn Broeder wil zeggen, a klethe, en 2 groote vaten; de lanite, die in der Itilre geligt zyn, ten gelehenk, en de certle, om er wat anders mede uit te beelden. De belteider der zelve, zei Ragja Bays, kenne ik zeer wel, en weet ook, dat er brieven by geweelt zyn, A 22

4hant 


\section{M A C A S S A A R S C H E}

nok. wasr yun ik U Ed. op myn koninklyk woord verzelecien kan, gelyls its ook reden beb, ors te gelooven, dae 'er, om vrienden te makken, wel zelserlyk op zal geantwoond zyn.

De Heer Betrinhl, die dit rog niet geweten tud, en diar zeer ower verget ffont, gaf dar op den koning van Boni eten fnuifje, in hoope, van dat "er wel meer uit komen zonde, dar zyte Ed, niet in mitte, alzoo zyp tong nut wat los begon ce worden: want, vocgde hy "erby, IIog mas' onlangs zyn "cr ailktei fing var Engelae hakenen op de Bafars geweeft. Doet men dar hier, what zal er das njet wel op Mandhar, dat zoo verre van de hand legt, getchied $z y m$

Schoon nu de koning van Boni den Hecr Landwoogt wericheide dingen $z \mathrm{ei}$, die zyn Ed, nict wilt, ferklairde $z y n$ Hoogheid egter den z24ta dito an zeker vriend (die "eden Gauverncur weierom zeide) dat hy verbaatl gettion had, dat de Heer Landvooge witt, dat "t En= gelfeh opperhonfd op Banjar gerehenken, niet alleen and den koning wan Groa, mats ook tan Crain Bomplongo (nu ontrent 2 of 3 manden goleden ) gezonden had. Hy zcide nog wel jet meer dar van te weten, mand dat hy, alzoo zyn Ed. hem 'er nice verder na wragde, het dartr toen by gelaten lind, on geen foliyn te geven, dat hy "t Macithers hof by zyn Ed. zoge fuare te rpaken, te meer, daur by, en de koning var Goa, zyn lchoonwader, door $\%$ y Ed. certh verzoch watem ; doch zoo de Gonverneur, zci by verder, my, als cen Bondgejoot, in allen ernit datr nat vinage, kin ile nict malaten zyo Id. dit te zegren. Dok is dit de cerite nall niet, dat do Macnfararen de gedagten hebben laten gatan, on met vrcemde Nation buiten de E. Minarlchappy an te fpanthen, on datar door sweer tot hunne oude heerrehappy te geraken.

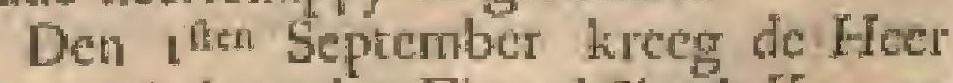

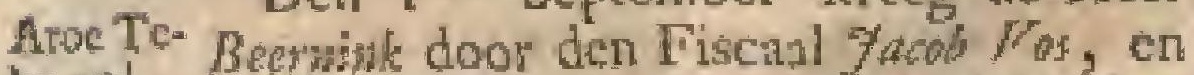

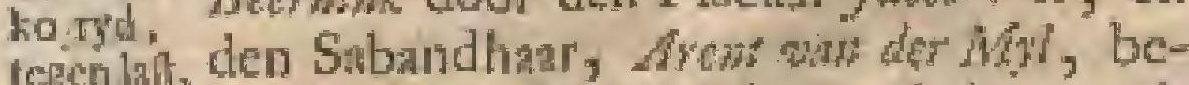
de Nergy rige, dat Aroe Toko in de voorleden week rond. de negry Whatdingen niet allecn dootkruitt en rond gefeden, maar tot bun grooter verwondering (loewel $2 y$ hem dat nict lieten blyken) uich ook verftout had by hen in huis om een pratice te tre den, weshalwen zy twy fielden, of Radg $B$ wi hem dit omlwerven ook wel uit zyn Id. natm verboden mogt hebben, lconrende anders niet wel bezeffen, hoe by zoo flout zou durven zyn.

Om dit nu net te weten, liet de Heer Beming hici oycr Aro Teko thillekens door Maras Sondlock ondertalten, die by hem ging, onder voorgeven van zyu fchone jamphanen, en moje posarden, ecns te rien
Na ectige onverichillige redenen be-rjex: kende Arot Telo man Somblek, dar hetn uit ordre wan den koning vas Bont, en van den Gouverneur verboulen was in de negry by de Hollanders, of digr onder "r kalteel te komen; en dat hem al voor twee maanden gelaft was, dat rond y den na te latten, en in zyn campon, of crl, te blywen; doch, nit dat Sandhed hem "t gefehenl mares ledeflyeden uit lait van den Gouveneur gebrigt had, was hy wan oordeal geworden, die hy nog zoo qualyk by hare Edeltueden, als men wet voorgat, nier lthan moeft, flwoory hem anders geen gefelienli zouden zenden. Weshalwen hy ook geoordect had, met cens fond te ryden, fchoon tegen Arow Pon's laathe ordre, zoowed niet vezalJen misdoen, wat op hy zich ditn, njet altyd in $7 y n$ huis opgelloten konnende blyoen, ouk werltour hild, om nu en dan een lugrje te gaan fcheppen.

Op dezen zelwen dag fprak de Herz Lindvongt ook met den koning van Boni fpreekt in "t breede over de moord, dpor Aree nivet Aroe

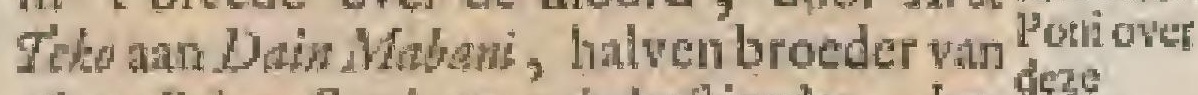
Aro Belo, Sopings rylisbeftierder, be-moord dreven, en zeide dat hy weh zien kon, dat zyn Hooghein, en de koninginne Regente van Soping, nier anders zogten, dan die geheele zalak mant wan hun halzen te fehuiwen, en de aitprats an de E. Mathehappy te verblywen, mar dat hy nu verzoge zyn Hoogheids gevoelen ower de that, die men hem zou behooren aan te doen, om, als men daar ovel vonmiffen zou, ten nanften by to konnen gilTer, war het me dic zatk heenen loopen zoude.

Ano Poni zeide dar ap: dat ik hice ower lwarigheid genakt heb, kan ik niet ontveinzen. Men bad bier zeer lige een ejude uf́ konnen maken, zoo Dain Maban' brocders die moord op heeter dand gewroken hadden mer de wet var vergelding, en dan was her, valgens onze werten, uit geweelt, zonder dat dien wreeker wan zym brosders dood iet datr over had behoevea re lyder, mat tha dat my $A$ roe Beto zegger deede, dat zyn broeder zoo veraaderlyk vermoond was, dat hy gereed ftont on zyu dood opentlyk te gaan wreekert, was nyo pligt lien dat it te ragden, en te beJaften, dat hy "t vonthis der' Bondgenooten, en der E. Matlchappy, datr ower afwagten zoude. Drar op nu is diezak al fepende geblewen, ten decle door de ruffehen beide gekomen dood wan de Heer wan Thye, ten decle on dat die wan Goa niet cerft dar an wilden tillen, en zich Atil hiclden, on ik heb, vit inzige wari Are Telo "s vrienden, mede de quande man niet willen wezen; want op ik dan weder, na de Heer wan The "s dood, tha 


\section{Z A A $\quad$ K $\quad$ E $\quad$ N. 189}

17or. Tyinrana gegan ben, zonder dat owcr die zatk zedert iets gedhan is.

Wat de zatk nu zelis betreft, th is buiten alle tegenipratk, dat Seotho en $D$ a Mabani, beiden; zich leclyte misgrepen, en dat by an Aroe Teko groote icdenen gegeren, hebber, om thit na onze wettendar over te volderen; te meer, alzoo men grond heeft, om vaft te itellen, dat op die minnebricten ook de converlatic, en weefhelyke gemeenfchap, wel gevolgt is, cen zitak, voor Rron Tho te fnertelylicr, ondat Dah Malawi friopelyk eên 's prinsaten zoon, en zyn moeder matr een gemeene Mulcitze vrouw was, daar Aro Tcko wanvaders en mocders kadi zyn adelwhe ltam onbefproken uitrekenen kan; wil het welke hem egter geen regt Buf, om cen prins es vermoorden. $\mathrm{Hy}$ had voorzigtig gedian, mer zich by dat rege mar te houden; mat al dut yoorrege heef lyy door zyn bedreven moord onwedertprekelyk verlooren, car ditu door, by aldien de ryd niet te verre was verloopen, na onze werten de doot verdient ; doch nu kan men hem, nuyns oordecls, niet anders doen (ten ware men de grootfe oprichudding ter wered onder alle de princen wilde zien, die niet zouder cochaten hem nu te dooden ) dan hem te rampiaften, of te bannen. Tot bet latite zal ik noit myth ftem geven, agngezien dat wan 'E uiterlte gevar is, on on dut Bujar, daar de Engellehen neftelen, hicu te dige by legt. Dierkalwen is "t beft, hen wan zyn goederen en witrdigheden te berooven. Een ftraffe, dic heri, en alle de Bondgenooten bett gelykt, en dar geen van allen iets tegen bebben zal; man" tor for watn zyne reder zeade hy wede, dot men dant mede nict ling wagten, en zya Ed. wel bezorgen moeft, dat de datader nict ongeftraft bleef, zoo hy atan de vrienden wan $D$ ais M/Wbai, en ara de werdre princen, eenig genoegen wilde geven. Indien ik, zei die vort, den nam nier bad, yan sil te hotatig to zyo, Ahoe Teko bad al lang wit de wereld geweeft; mant ik heb licver willen afwagten, wat myn broeder (de Heer Gouverneur ) en alle de princen daur af zouden oondeelen.

Radja De Hecr Bermink, verblyd, wan dit Goa's uit zyn Hoogheid verftan re hebben, ankeg bedante hem voor dit berigt, en hoorde Enetren toen nog wan hem, dat de brief, door de oflanjar. Engelfehen van Bunjar op Borneo ain Radja oa gezonden, its 't begin der voorleden mand doon hem beantword, en door een vertuouwden Micntliar zonder pass derwarts getragt was, zynde da: ook Anac Bromi's, of cenige wan 's konings lyfwigt, die men zuo niet wegzend, by geweeft, zonder dat zyn Hoogheid iet yerder wan den inhoud wan

die brirf des lonings wan Goa wilt te ryot: zcigen.

Wit het voorig zeggen dan, zoo wan wertecerRadja hon, als van alle de andere onder- Verkecttalte princer, bleck klatr, dat, fchooriten der men in 'c eerit gemeent had, dut men al-onten les mar de $E$. Matffiappy zoge op den van de hals te tehuiven, en 'er zich buiten te Bonderehouden, om danr na met han vonnis, 200 zy Arue Telo cens ter dood geronuilt had, den fpot te dryven, het zecr werre van diar, maar dat het vecl ocr can mistha wan de Her wan thye, of wel van de E. Martichappy geweell was, vin ten eerfen nier eendoodvonnis over hem geveld, en de zalk dus ruftig con onbeveeft ten cinde gebrigt te heblen.

Na het zich nu lict anzicn, was te denlien, dat die van Goa wel tegen luce Atrufien van Aroe Teko, uix andere inzig. teti van Itrat, weren, endat de ko= ning van Tallo dezen vorf, als zynen vriend, op 't fpoor valgenzou; mat" " $t$ is ook zeker, dat alte de andere bondgenooten den koning valn Boni medo zouden volgen, dewellie mede voor een vonuis, Diç alle om hem te rampaften, zynde, 200 kon foor st. zyn Ed, verzelier wezen, wat ook die zen zyn. wan Goa daar tegen mogten ftemmen, dat de meette Bondgenooten woor deze ftraf zyo, en dat dierhalven de E. Matechnppy, hat item dar toe mede gevende, ftal maken kon, dat zy geenzins be: fpot, mar hot gezag in zyn wolle kragt behouden, behalven dat ano de Bondge nooten en misnocgde party daar mede gront gennegen gegeven zoude worder.

Ook fneduren dan voor het tocko-Dat on mende ande Grooten, by diergelyle woor wecl redewal, alle quande voorbeelden en de ge- nefr ook volgen wan dien af, alzoo zy dat uit ze- roor on

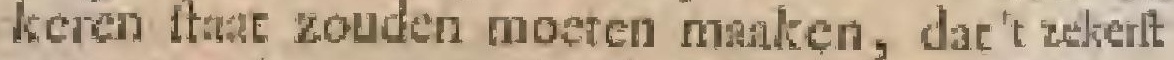
men over hen zoo wel, als over de min- Wras. ften, rege doen, en hea om hunne hooge geboonte geenzins werlchoonen zou, dut hen zokerlyk itcrk betengelen, en de E. Mantichappy by hen ook ved anzien en ontang geven zoule.

Uit her bevoorens angehanlde is orss Vetrhilwel gebletien, dat hair Edelheden cerat lende gebett oordectden moe Teka itreng en met yotens de dood te traffen, hoewel zy daar ratdelleder weer an de Heer bermink Lid guten, ower zph om in der ftilice door de woorfprank en llaffe. 't talfichenkomen der Hoven van Boni ca Soping pardon te docn verzocken; mat $z_{y n}$ Ed. als men de zinak eens in zyner grond toont as belchoude, was her onmogcly $k^{3}$ om hatlidelhier wan ier goeds te hoopen, en det-theden do halver zoo ongeraden on diar an ie pnithegesillen, dat "er ecer middel was on den he- on parmel en de arde te vertenigen, dan om don roor Aroe Pow data toe te brengen, alzoo "cr hem te

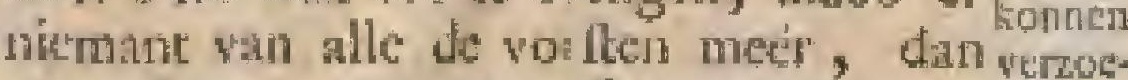
Ared Pont, woor Aro Ticko wreesde, en lieft.

$$
A+3 \text { oper }
$$




\section{0}

$M A C A S S A$

17or ovetzulks ook meer na zyn dood werlangde, wan al het welke tyn Ed. hat Edelheden, zoo rus hy kon, kennis gaf.

Toene Eer wy nu komen voortgan, om over mendo deverdere gevolgen van deze zalk te fpreziskte, en ken, moeten wy woor if , nls tulfichen dood wati beiden voorgevallen, nu eerfl wan de hoe Mevrout langs hoc meer verergerende zickte, ch Beenink dood, wan de Heer Bormils brawe en lofwatrdige Gemalinne fpreken, die ik datom lotwardig noeme, om dat ik de eere gehad hebbe, wan har Ed. in Amboina ecrige jaren te wooren te kennen, en te dier tyd te ondervinden, dint zy een vrotw wis, dic zeer' wel opgevoed, en wan een byzonder gulhertigen omaneging met al have wrienden was, in zoo verte dit hare Ed. zich daar door by allen te dier" tyd al zeer bemind makre, 'c geen naderhand by har Ed, komit op de Weftkuft van Sumatra, datat wy har
Genual als Opperhoofd ontmoeten, en ifot: by hate verfehyuing op Macaflit, 200 verje toggenomen was, dat alle de Joningen, princen en worftimen sim Celebes by alle voorvallen een zonderlinge agting voor har Ed. getoont, en een zeet voordeclige getuigenis van har Ed. vriendelyken, nimzatmen, en zeer edelmoedigen atrd en ommegang hadden gegevers, gelyk zy dan door byna aller gemoederen vooringenomen, en de genegenheid wan grooten en kleinen gewonnen had.

Zy was de dochter wan den Heer SypReyo, in zyn leven Med. Doẗar, en Borgernietted der fladt Utrecht, en quam wath cen ziekte, datar in men metter tyd hoe langs hoe meer hitare dood te gemoet zag, den rader Scptember te fterven, waar na wy zeer fatardyk volgens hurem rang, gelyk men omftandig in "t volgende Hoofdtut san wen, begraven wiert.

\section{Z ESDE HOO F D S T U K.}

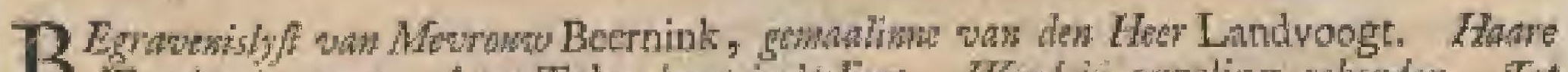

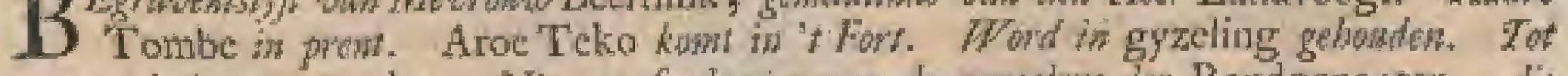

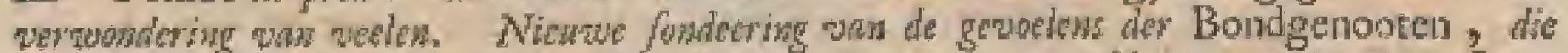

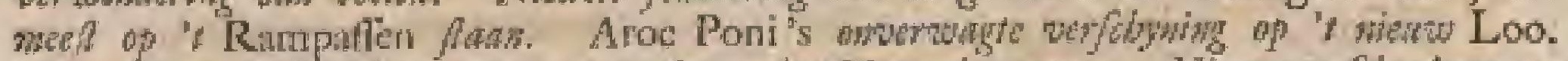

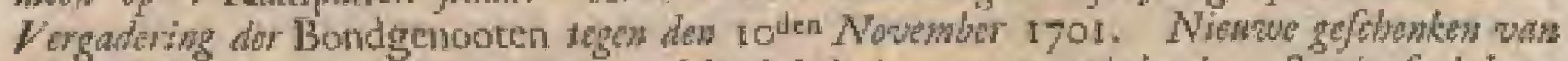

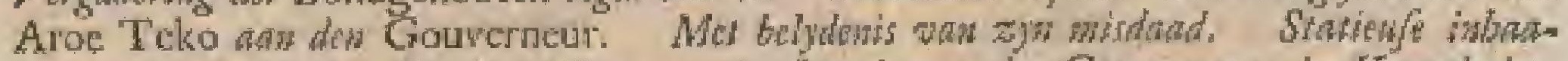

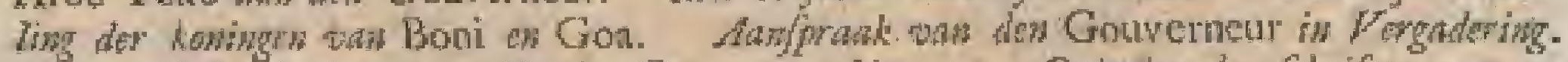
Antwoond der komingen was Boni, Gon, orz. bier op. Oplezing der folfiften wor an tegen den wisdadigen. Atroe Poni loublend Aroe Teko laft to deze moud gogeven te

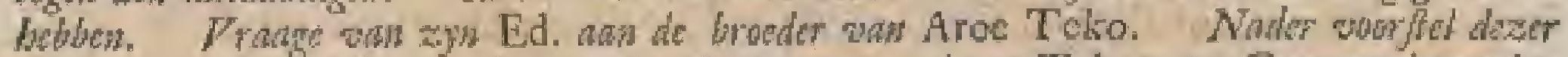

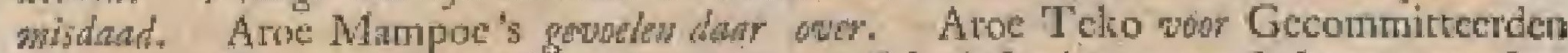

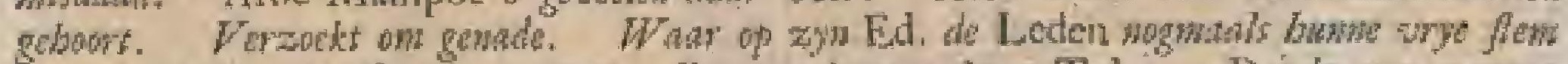
wrindatigde. De Boidgenonten whlow wawis wer Aroe Teko. Dat by zon geram-

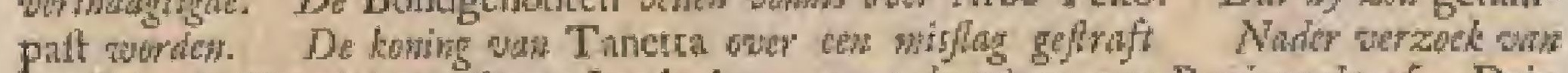

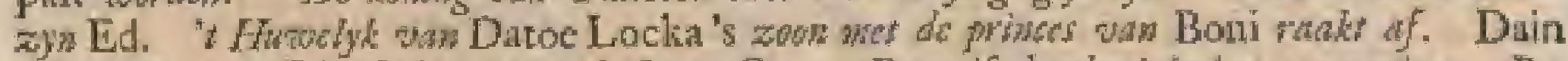

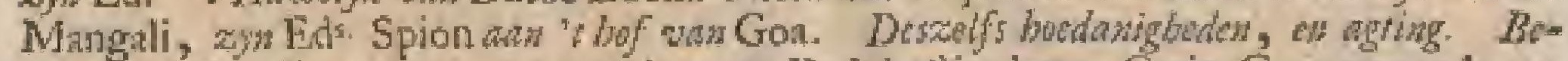

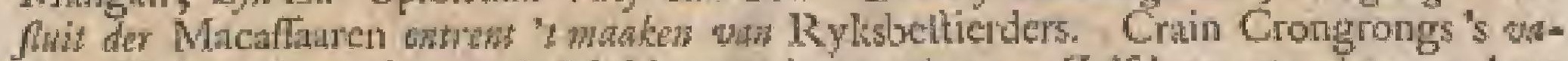

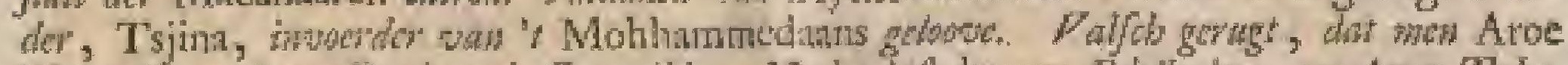

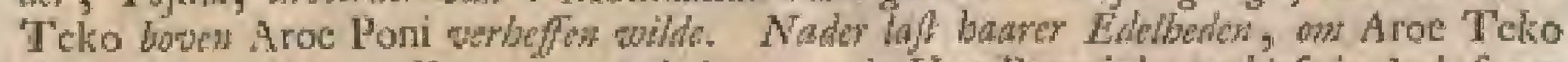

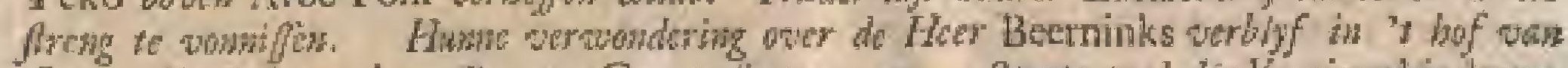

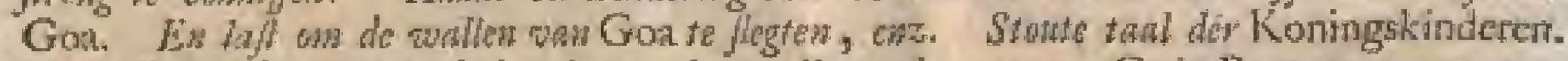
Crtin Bontolongo deloft bet flgeren Ler wallen fo hezorgen. Crain Bontoewa wan wer-

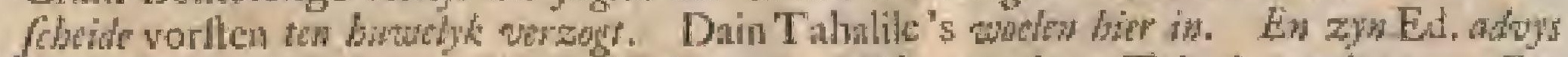

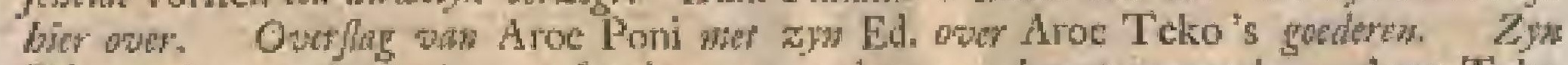

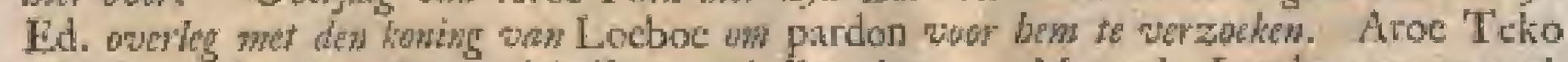
fobryf cen bref wa Bujar Mallin ahs de Engelzen. Magt des Landvoogrs over de

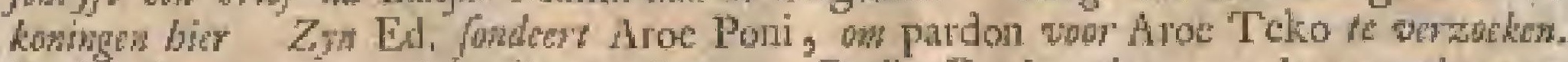

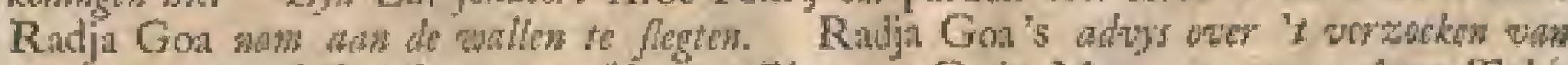
pardon. Sjech Jofets zotre verfobyt of Bima. Crain Manampang. Aroc Teko

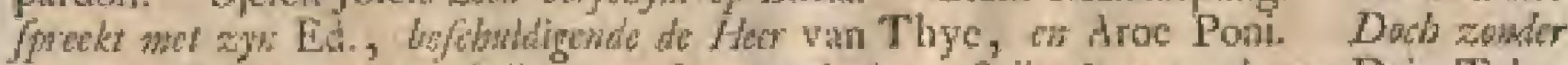

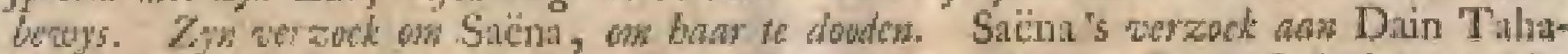

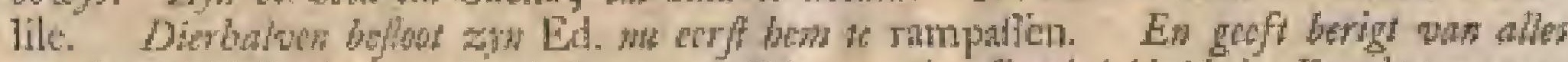

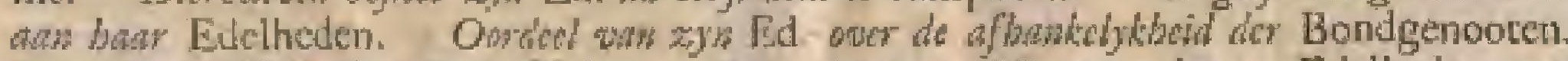

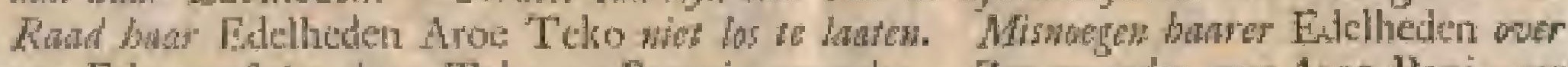

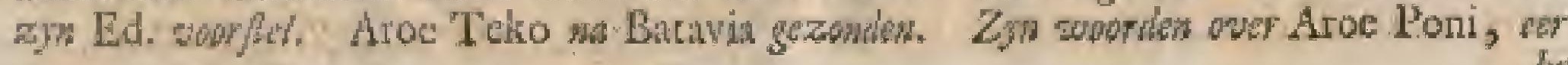




\section{Z A A K E N N N}

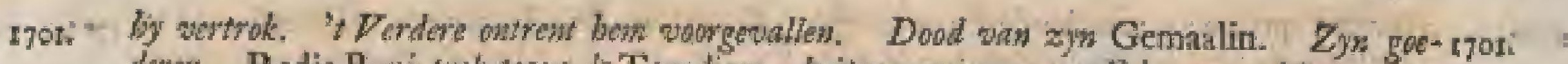
deren, Radja Boni trok vegon de Tonadjers, buiten weten was zyn Ed., op. Nader aan. werking outer zen perjoon. De wailen wan Goi gellegt.

Extradt wit de daaglyze anteekeninge geboudden ters kaffecle Rotrerdam, op Macafar, in de maand September des jaar's $170 \mathrm{I}$.

Sateriag den roden dito.

Begrave- $"$ Ezen avond ontrent quartier voor मithly

1.

van $M e-$ 2) to uuren is de huisyrouwe van den Ed Heer Gouwerneur Beenink, "Corndis Beethinh, gename Cormlia yan

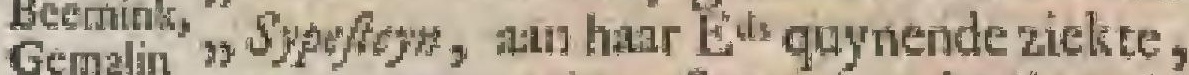
van don , waar aan ontreut 8 weeken boullegerig Heer ,geweft is, ten overthan wan de mecte

Lind-

voogt. Radsperoonen, en andere gequalifi, cerde vrouwer, Godfiliglyk in den Hecre onthlapen, tut groote droctheid , Fan zyn Ed., als ook wan groote en kleine "hier op Mucaffar ; wan welk overlyden "aanftonts, door den boekhouder Marows ,Sandbek, an den koning van Boni, en de ${ }_{3}$ koninginne Wed. Dain Taballe en Grain "Laykan; en door den tolk Jak Ferdi. " mandus, den koning van Goa de weet „ogedan is; wordende hat Ed lyk anais itonts afgelegt door de Juff:" "Flackart, en "t Hooft, ten overitaati , van Juffi. $W_{b / f l b o r g}$, en daar na-in de 3 ordinare bezock kamer op 'i bedde vati , cerc gelegt, zynde ondertuifchen door " den Heere Gouverneur 't bezorgen, of 3) de preparatien tot de begmeniffe ай , den E. Jacob Classzon, opperkoopman " en Tweede dezés Gouwernemerts, den "Capitein faw Pieterszan Wefflbarg, en , den Eerw. Predikant Gerafdas Hey, op, gedragen; die din ook, ten cerlten band , itan 'L werd flocgen, de gemelde kamer, "item de voorzaale van ' $t$ huis wan boven , toe beneden in den rouw hehangen, als "ook de agter galdery in die ordre ge"brigt hobben.

\section{Sondag dens $\mathrm{I}^{\text {den }}$ dito.}

3' morgens voor "t arrgath wan den , Godsdiente , quam den koning van Boni, "zonder eenig gevolg en in "t purciculier, "zonder ma gewoonte ingelanale, of ons, Fangen tc worden, zyn pligt van con${ }_{3}$ dolentie met de utiterfe beweghinge , ontrent den Hecre Gouverneur affeg"gen, zynde, ontrent na 2 uuren wer"toevens, in gelyke maniere weder ver, trokken.

, "s Agtermiddags ten 3 uuren, zyn de ,onderkoplieden Moll, en vander $M$ hl, 25 als Gecommittecrden gereden na de " koningen yan Boni en Goil, zoo om , haar Hoogheden 't affiterven van des
, Gouvemeurs Gemalinne. bekent te " maken, als om hall, nevens hare "voorname Grooten, te verzoeken tot "hat bywoonen der begravenis wan ge, mele lyk, tegens morgen agrermiddag "ten 3 unren; welke boodfchap dezelve "Gecommirteerden den koning vin Goa , verzogten, dat ook manden koning war 3ello beliefide te lanten doen.

, Nit den agtermiddags Godsdicnft ging " de geregtsbode Jacob rior, nevens den "Rotter Aart Thomaswon, werield mer "vier oppaffers van den Gouverneur, $m$ alle in den rouw gekleed, als rouw "beklagers, alle de Leden van den Raad "met hume vrouwen, item de Militarire "Officierer, en alle de.ingezetenen van " "c quarcier Vlatrdingen noodigen, on , de begravenis tegens morgen agtermid2) dag ten 4 uuren by te woonen, gelyk "ook de Chineczen, Maleyers, enz. „2 zynde dezen dag de groote klok, drie"maten geluid, te weren, "s morgens $\eta$ พaว 6 tot 7 uuren, en "s middags wan "I 2 tor I uar, en "swronds wan 6 tot 7 y) uuren.

\section{Marindag den $\mathrm{I} 2^{\text {dea }}$ dite.}

"Wiert de klok wederom 's morg. ten "6 unuren tot 7 uaren gelund, ook "s mid"dags cen $\mathrm{t} 2$ cot half een uur, en wederom "vareen uur tot half twee, wan twee tor "silli drie, en zoo veryolgens alle uwen , een half utr, tot den tyd der begrawe, niffe toe; "s agtermiddags ontrent w uuren de Militie in a Compugnien, doch " met opgerolde vaandels, in 'r geweer n, gebragt zyt1de, quitm meett te gelyk, "doch d"een de waterpoort, en dinder " de landpoort binnen; ook quamen toen " de koningen van Boni, Goa, Loeboe, " cn 'Tello, yder by hun hebbende ect "sroot geral hunner woornuantte Groo* , ten, welke door den Capitein $7 a n$ Pig"tersaon WeJforg, den Fiscal facouss "For, en de Onuerkooplieden Moll en

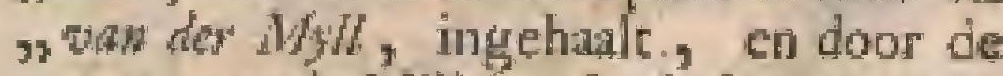
s gerangeerde Militie (doch de trom nict s, anders, ats mer ecin roffel, geroent worndende) binnen gebragt, en door den "Hecre Gouvernetur in de woortalle ver"welliont zynde, beconden de zelve "Koningen en Gronten, yder apart nhune overgroote droctheid over taf"Iterwen wan des Gouverneurs Gemantin* "he, zittende alzoo nog cenigen tyd, "onder "t drinken vin ecn kopje thee te 3) discoureren, tot dat anderufifhen de "Ferzogte vrienden en wriendinnen mede 


\section{I92 M.A C A S S A A R S C H E}

notr, ", binnow quamen; wortende de rerzogte „) Jufrouwets (die alle in den rouw ver${ }_{2}$ fincenen) in de kamer zitplatec nan"Bewezen, en beftonden dezelve in deze:

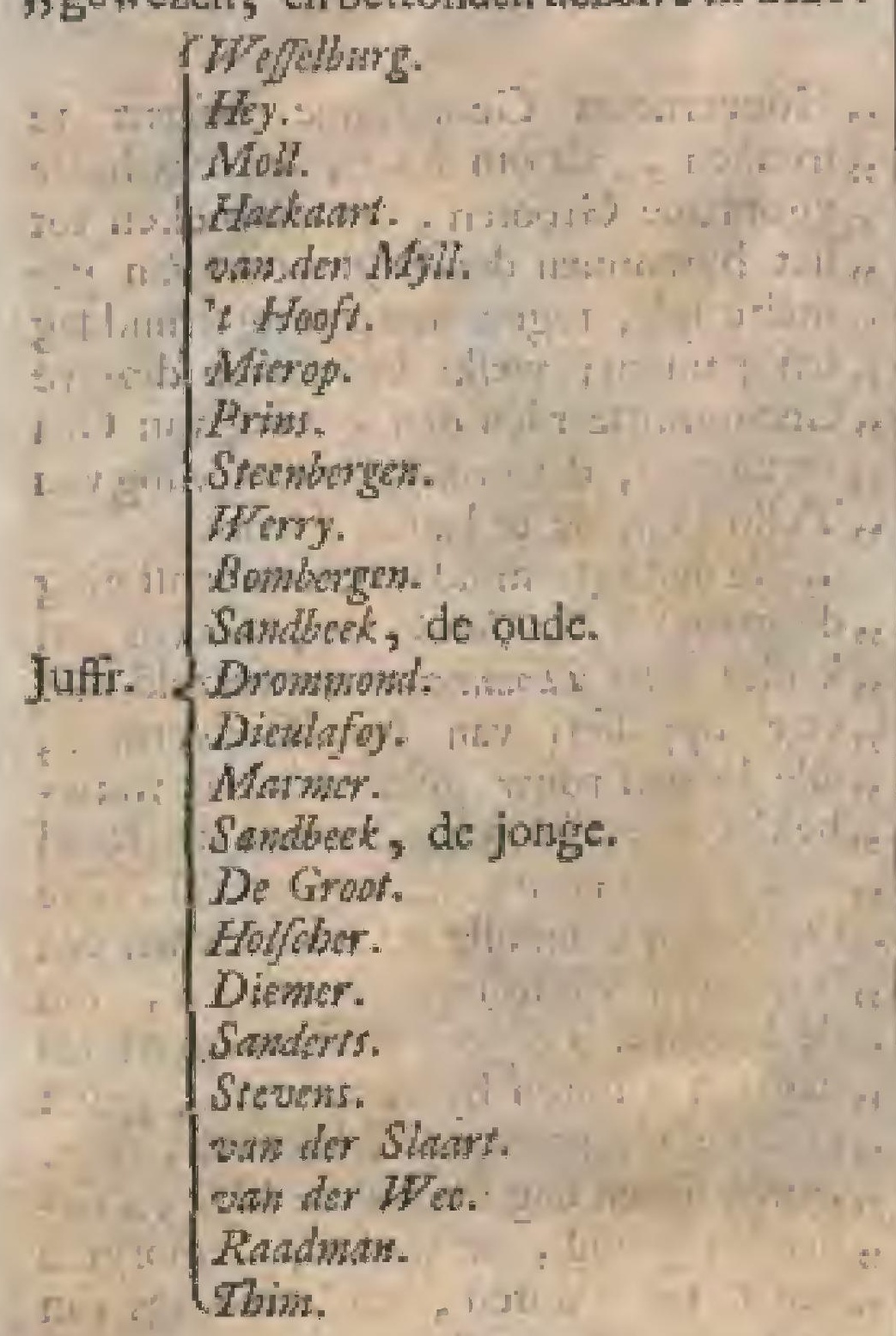

"Den tyd alzoo tot orer 4 utren $\mathrm{ge}$ "pafeert wezende, wiert het blk door s) de dragers uit de kamer gehale, er op "de bar gezet, Bande poor het zelvedes "Gouverneurs ordinare lyfcompignic, , beftatnde uit 48 koppen, opgevoert 3, door den Vandrager, lfaAe Aexarders9, zoons hier nu volgde de Geregtsbode, 2 met den kolter $A a r$ T bowaswan, als ${ }_{3}$ Bidder. Exen wool het lyk volgde "hat Eds wapen, gedragen wordende , door den Opperituman en Werkbans 3. Barbolonear de Groote gande op beide 3) zyden wan de baar om de flippen wan , 't doodikleed te houdeŕ:

Den Onder hoopman Atrites $W_{\text {cryy. }}$

Den Opperchinutgyn dezes Kalfecls Cbrifian Bomber.

Den Vandrager Martrits Dromsasd.

Den Opperchirtirgyn ' vas - Holpical Pierre Diendafoy.

Den Boekhouder Cad Gallors.

- - - - Z Zachaias va Rye.

, Werdende voorts het lyk gedragen , door de volgende:

Dẹ Adfiltent Thinamis Moldews.

$-{ }_{-}-{ }_{-}$Asdrie de Larchto.

- - - - Somat Gallois.

Den prow. AdGltene fon Hapon.

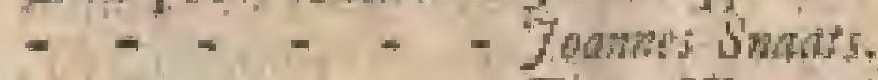

- +. - - Frans Wagmavis.

- - - - - Adrianava der Rat

Den Bass smit Han Palwer.
Den prov. Bas Timmermn Combis $K$ nanp. ner.

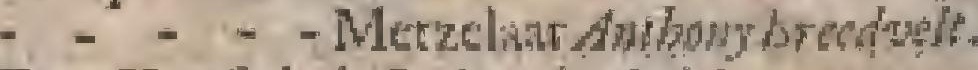
Den Kontabel Lodewh Andricsaon.

Den Sergeint Howber Y daszow was Bredo. - - - - Fald Fermans.

- - - Ginil Jamzonn de Lic.

- - - Lodewje van Ronge.

- - - Harmen Mojer.

Den Chirurgyn Clas de With.

$-"-.-$ Jan Marce.

Det Ondorchinugy Midiel de Clerg.

- - - " - - - - Pifter Tirion.

Agter het Lyk rolgde:

Den EE. Hecre Gouvencur en Dirceteur Contis Bermind, met ecn lange 1lepende rouwnantel.

Montr Lacas Beeringh, en

Scignt. Wilfow de Runte.

Zyi Hoggheid, Aroe Pon, "lioning vat Bonit.

Den E. Opperkoopman cu Tweede Chaszour.

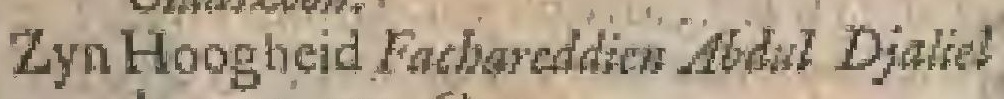
konung van Goa.

De Mantante Capitein Jan Paterszoms Whdibws.

De koning vatu Loeboe.

Den Eerw. Predikant Gerawh Hay.

De koning yan Tello.

Den Koupman en Fiscaal Yacolos de Fos,

De Sopingze Prins, Aroe Bele, RyksbeAticrider.

De Onderkoopman en Guarnifoen Boekhouder Larsout Moll.

Aro Masapoe, koning van Wadjoe.

De Onderkoopman en Winkelier Jounos Hackatrit.

Crain Aganowa koning wall Taretre.

De Onderkoopman en Sabandaat Arent vas der MH.

Crain Mangali, broeder van den koning van Got.

De Onderlioopmatn en Secretaris Yace Caver was Mierop.

De Boekhouder Marat Sandhek.

De Adiftent Wh Wh Bawholsonon Marchier.

De Chirurgyn Jacol Ments; alle de voorentlatinde in den souw, en de drie Latligenoemde als Domeftiques gereken, naft mallkanderen gande, on dea rouw te luiten.

Des Compugnics Tolk Jan Ferdinawas, met de reltecrende, zoo Bonize als Macaltarze Grooten.

De Erankbezocker Dirk Stevenszoon.

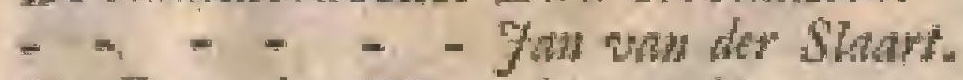

De Bats der Wapenkaner Jacouns van der $W_{c e}$.

DeCipt, der Chineezen, Ongruatho, met 7.yn gevolg-

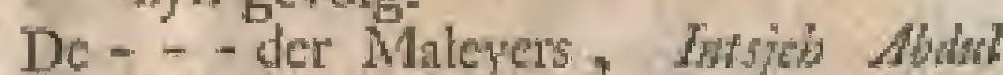
Ragfol, met zyn gevolg.

De koning valu Tambora, met eenige Gropten wan het eiland Sumbawa.

Voorts 


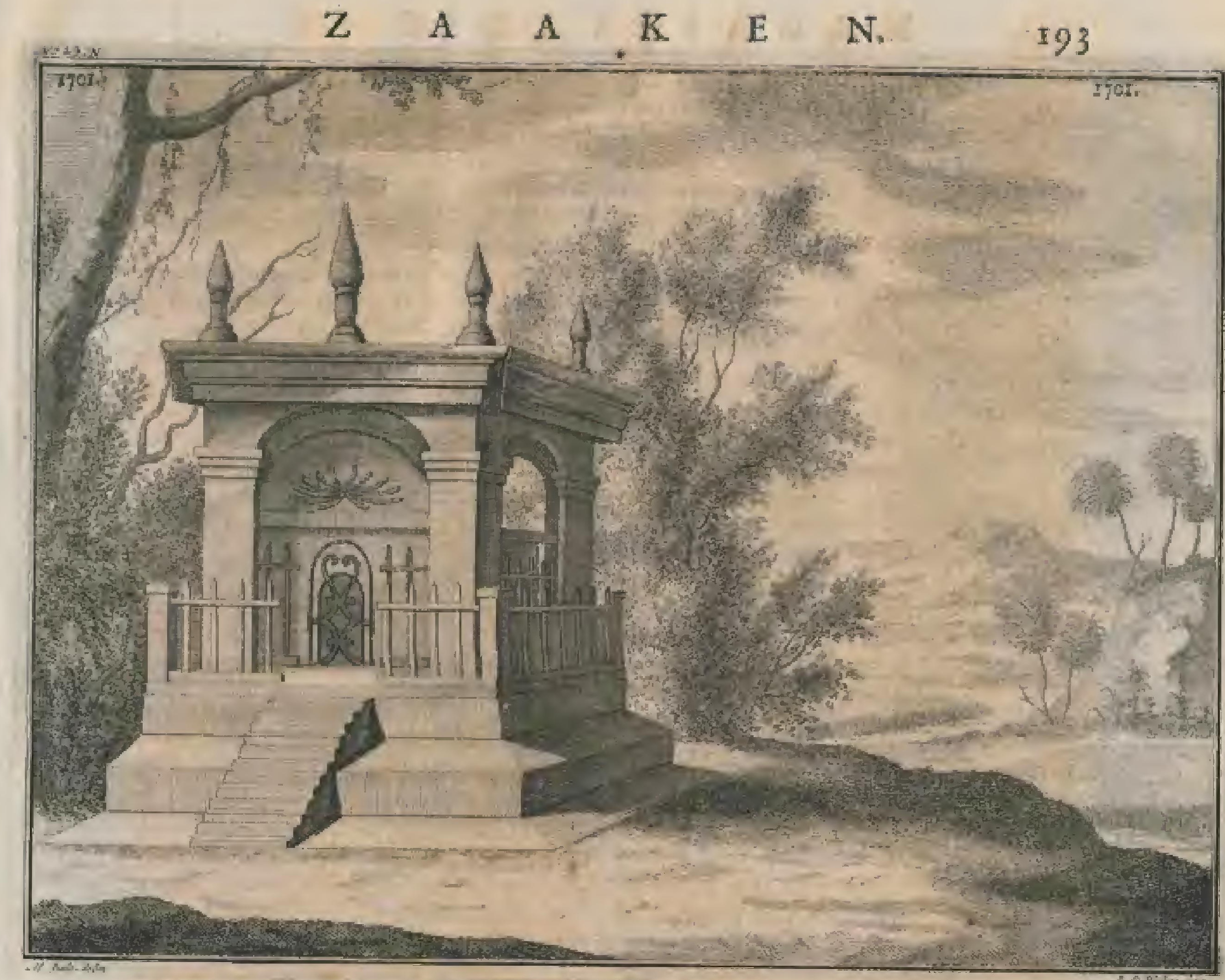

"Voorts alle Afiftenten, Chirurgyns, "Sergeanten, Burgers, en verdere inge"zetenen van 't quartier Vlaatdingen. "Nevens den Hecre Gouverneur en den "Raad gingen zyn $\mathrm{E}^{\mathrm{ds}}$ oppaffers, waar 3, van den Sergent, en 4 man, die altyd " met hatr E. zyu vitgegatan, wan "t hoofd "tot de voeten in den lakkenzen rouw, ;; cn de refterende met rouwbanden voor"zien wareng wordende bet lyk in ma"r riere als vooten uit zpn $\mathrm{E}^{\mathrm{ds}}$ wooninge "de kerk om, de waterpoort, en de ${ }_{3}$ Noordlant dezes kafteels om, na de " ordinaare begrafplants onder het geluy , der klokken gebragt, en aldarr in een g, daar toe gemetzelt feenen graf by pro"vilie grezet, xynde alle de vrienden on"der her geluy der klokken alzoo weder "binnen getomen, en in zyn $\mathrm{E}^{\mathrm{d}}$ w woo"ninge mier een rouwcollation outhtalt, "en de dragers in des E. Compagnies "kleine thuin met eca braave malityd "getracteert ; walar na met den donker ") alle de vrienden hun aftcheid uamen, "en weder vertrokken zyn.

Ontrent cen maand naderhand is hatr Ed. vit "t woomoende graf (dat even bur" ten het kaflcel op het dant toe beftelt kerkhof was) door lieden van fatfoen 's morgens heel wroeg (eer de Hecr Beerwink ung by de hand was) na bet nicurw

III. D是至

Loo, piats van vermak door syn Ed. niet verre van 't kafteel Rotterdarn aangclegt, gebragt, $\mathrm{cn}$ in cen zeet prigtig grat, dat in "t vierkant onterent 20 woeren liad, onder cen zeer deftige Tombe begraven.

Wy vertoonen de zelve hict by $\mathrm{No}_{0} 23$. $\mathrm{N}$, in prent, zoo als har Ed kift d Hate in op cen yzere roofter ftome. " in prctit.

Voor de zelve ftonden deze twee Latynfche verzen, waar by de overledene tot de voorbygangers ats zegt:

Vos quilranfitis, wemores, vos advoco, fitis. Quod fun, buc critis, furmu gandioge, grod efts:

dat is:

Gy die voor by gat, 'k bid, gedenk to dexertyd:

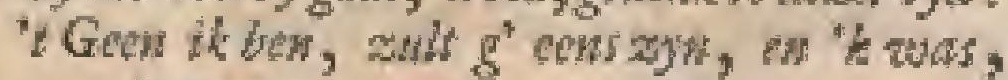

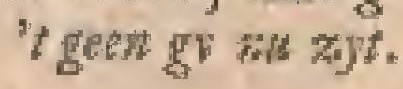

$\mathrm{Na}$ deze zeer deftige Vrouwe deze latifte ecre anngedaan te hebben, kecren wy nu wederom tot de zisk van Aroe Thk.

Ondertufichen deed zich een gewentchte en ganfeh onverwagte gelegenbeid woon đen Hecr Bewnink op, on Arec Teko zecr gemalkkelyks gevaungen te krygen.

Hy had al lang tegen den Lieutenant Riddll, en anderen gereget, dat hy wel B b wersichte 


\section{$194 \mathrm{M}$ A C A S S A A R S C H E}

not. wenfehte den Heer Gouverneur zelf cens te fpreken, niet twyffelende, of de zaitIsen zouden zich dan ten eerften wel anders fchikken. Darr op lier hy zulks den $14^{\text {den }}$ Oftober dezes jatrs werzocken, war op zyn Ed. zeggen liet, dar hy komen kon, als hy wilde, en dat by hem al over jiar en dag by zich werlangt had te zien, zoo hy genegen was zich tan "t oordeel en de gerigrshandel der E Maatfehappy te onderwerpen, en de zailent, das toe vereifcht, in age te nement.

Daags ${ }^{\mathrm{e}}$ er ann quam zyn boodichapper zeggen, dat zyn Ed. voorlag Aroe Teko zeer wel beviel, dat hy die in alle onderdanigheid ombelsde, en bereid was om zich op genade cn ongenade ann zyn Ed. over te geven, mits dat by woor af wan dit $z y n$ voornemen ann Radfa Boni kennis geven moge, walar toe verlof verzogr, en dat hem toegeftan wiert. De Tolk, deze toeftemning hoorende, opende zyn gordel (wan uir ons blykr, dat de Oofterlingen hum geld, volgens Masth: 10: 9 . Marc: 6: 8, in hunne gordels bewaren) en haalde daar een bundelken yan $4 \frac{1}{4}$ thay] (yder 8 Rders op Macathar doende) geraeen goud uit, dar by uit zyon Moetters nalm verzogt, dat de Heer Gouverncur voor een dathon firils (dat is, een frribbisd, of gering gelchenk) van $z y n$ dienaar wilde annenencon.

De Heer Beevinink hind dit, on te toonen, dat lyy nict goudgierig was, en dat dit noit minder, als nu, re pas quam, wel konnen sam de hand wyzen ; tmat on de vogel (dic zelfs wel gezege had, dat hy de Hollanders, als hy maar wilde, met goud gemaklielyk lokken kon) te ligter in de knip te krygen, en on hem ten miniten Ichyn te geven, dat hy daar mede by zyn Ed. ook wel te regt geriken kon, nam zyn Ed, dit aan, watr over die tolk zoo werblyd was, dat hy verfcheide mailen des Gouverneurs handen en woeten kufte, en aldus zeer voldann vertrok.

Aroe Te- Arou Teko, meinende dat zyn ban nu ko komt heel klaar wiss, vertoonde zich ditar op in 't Forts nog dien zelven avond met een klein gevolg van 5 of 6 perfoonen byzonder welgenooed op de voorzal yan "c kaftect, alwar de Leden van den Polityken Rand zaten.

Hy ontbond in de deur zyn kris, trad met de zelve in zyn hand den Gouvetneur te gemoet; en gaf hem die met cen laandkus over, verzoekende, dat zyn proces, of pleitzaak, door ons en de Bondgenooten asnvaand, en fpocdig afgedhan mogt worden, " $t z y$ dan dat wy hem doodfchuldig houden, of vry kennen mogten, alzoo hy verlangde, wan die zatk cens af te zyn, matikende datar op cen zeer nederig ecrbewrys woot zyn $\mathrm{E}_{\text {. }}$ en den Raad.

Men wees hem, ten opzigt wan zyn hot. hoogadelyk gellagt, een thocl buiten af nal de linker zyde der tafel, terwyl hy bezig was, on honderderlei rodomontidos, drajjer, en fwieren, te maken.

Dit was de etriftemal, dae zyn Ed. dezen Aro Tolo zag, an welken hy tor antwoord gaf, dat de E. Maticlappy niet gewoon was zaken, die in hata hand quamen, lang dralende te houden, cr dac men sict nalaten zou op zyn zatak wel te letten, "t zy om hem ten flrenglte te ftraffen, "t zy on hem zyne buitenpoorigheden, na dax "s lands weten zulks cifichen zouden, te vergeven, en hern pardon te verlecenen.

Om dit nu af te wagten, zou lay zich macten getrooftet 200 lang liver in Word in I kaltecl, tot dat dax over ordentelyk tyehougeronnilt was, in gyzeling te blyven; den, en ondertuftehen zou hem een plats, diar by zyn verblyf hebben zon, worden angewezen.

Die eertte woorden waren wonderlyk goed, en klonken zect wel in Aroe Teko's onren, manr dic latatle, van in her kafted te blyven, alsocondonderflag, en hy was "er zoo bedwelme cn veraet wan, dat hy den waren zin, Ichoon "er goed Malcits gelproken wier, $n o g$ niet wel fcheen vertan te lubben, weshalven by det tolk wal zyn Ed, Jaw Fordhandus, verzogt, dat hy hem de woorden wan zyn Ed. nog eens in "E Macafiats herhanlen wilde, het welk gefchied zynde, was die moedige Ane 7 rko met alle zyne nodomontados zoo verzet, dat hy ecn man zonder geeft, en geheel buiten zyn ftuls feheen te zyn, "I klam fweet brak hem oyer deze woorden and nille kanten uit, voornamently als hy verftont, dat men zyn kris, die lyy met zoo veel beleefdheid overgegewen, en welke hy verwagt had, dat men hem ten cerften zou wedergeren (alzoo by valffelde, dat zyn goud cenige uitwerking geditan bad) zoo ling, tot zyn zatk ten cinde was, bewarcn zoude, tnet wentch, dat men hem dic met zoo voel fatfoen mogt wedergeven, als hy die ann zyn Ed. overhandige hand.

Op deze woorden man den Gouwernear witer Aroe Teko's tong zoo beklent, dat hy geen goluid meer geren kon, wait na zyn Ed, en den Rad, opitond, dat zoo veel gezcgt was, gy belt gedad, en kond als esn grwangent anet der Liewtenant van de wage (die al op hem pafte) $n \pi$ wove befheden flasts gacm, wat op hy door dien Licutentant na twee gyzelkamers, naatt de Kerk, gebragt, en dant door hem, of zynen wervanger", wan cyd tot tyd bewalte wicrt.

De Heer Beewink gaf nog dien zelven atwond aan de Hoven van Boni en Goz val 


\section{$\begin{array}{lllllll}\text { Z } & \text { A } & \text { A } & \text { K } & \text { E } & \text { N. } & 195\end{array}$}

7por. van deze wathouding en gevankenis vat Aroe Teko kentris, mer lat, om dit ant de verdere Bondgenooten mede bekent te maken.

Radja Bowi lict weten, dut by "twoor bekent gemankt hield; en on te toonen, dat hem dic ten triterften angenanm was (alzoo hy dat in "t bywezen van froc Mampoe, Aroe Tolo"s broeder, en ande. ren, zoo niet zeggen dortl) drukte by de hand wan Sewdeek, die lien die tyding bragt, al wry hatrelyk, als of hyzeggen wilde, dat gant wel, en die manter van behandeling is goed.

Radjo Gos, dit hoorende, was dar Tot ver- over (geiyli ook anderen) als opgetogen, wond le- foeg een gat in de lugt, en riep uit: tine van boe is "t mogebl, dat men Aroe Telo, vesten. zorlken lifigen wor, zoo gentakedyk in 'i not gekresen beft! Hy lier den Gouverneur voordat berigt bedanken, en zeide, dat by gen andore gedagyen tans ben badde, don das zyn Ed. allecs womemens was an bwa wetren te bowdldwew.

Zooras dit vooraf gegant was, gaf zyn Ed. by de certe gelegenticid kentis liner van, daar by vocgende, dac hy voorne* men was alle de Bondgenooten eerltdangs in 'r kafteel by een te roepen, om verder' over diezak te hindelen, vaftellende, dat yder by hen advys, dat hy reets an zyo Ed. data over gegeren had, blywen zoude. Schoon er nu cenigen Ppraken van hem na de Katap der goede Hope, of elders, te bamen, makke zyn Ed. cgter ftat, dat het op 't rampaflen wan zyne goederen uit zou loopen, war toe by hav Edelheden den $2 o^{\text {ftén }}$ Oetober 170 I $_{4}$ ichreef mede over te zullen hellen; doch zoo "t op een wonnis ter dood uitkomen mogt (dat hy egter nier te gemoet zag s zot by de uitvoering van dien tor har Ed. Ed. nader ordre ophouden, verzoekende lpoedig ant woord hier op te bekomen, en dait by ook te overwegen, of men een man, als Aro Feko, met ecr linpel rampaffen geftrate hebbende, het dan wel geraden swas hem weel op vrye vocten te ftellen.

Duar op fondeerde zyn Ed wanden 1 flen Nienwe tot den 8 then November de algemene ring kan Bondgenooten nog eers, ondertaltende de gero- wooral de koningen wan Boni, Goa, Solens der ping, Locboc, Tanette, cn meer andenooren, ren, mirgaders de ryksbeftieders van Boni en Gon, met zoo weinig beweging, als "t mogelyk was, om zeker" te konnen weten, waar heenen deze zank zynen loop nenenzoude, en war zy oordeelden dat Aroe Teho, zoo over đe moord, als over zyne bakdadigheid, van tegen de lall van twee Landroogden, en tegen een dubbel verbod des konings vala Boni, door de ftadt zoo ltout, en met zoo red veragling wan ons gezag, hier en

daar omgefworven te hebben, verdient r pot. had.

Daar op rerltont zyn Ed, dat hunaller gevoclen (airgenomen tilleen die van So- die meef ping, door droe Belo werbectd ) eenpana op op uitquam, om hem te rampaften en te patfen bannen ; alle ook zeer fterk daar op ann- thash. dringende, dat $z y n$ Ed doch ten cerlten mee die zalk en 'c ronnis wilde voortgnan, gelyk zy ook, op 'r eerfte ontbod van zym Ed., beloofden te zullen komen, on de zaak af re doen.

Dhar op zei hen de Gouwerneur nog, dax, als zy nu in Vergadering waren, $z y$ dan niet voor den goeden min fpelen, de Vergadering of hem befpotelyls maken, of wal dezen en gienen der Gronten ma de ongen zien, matar als Bondgenooten, die yder cen vrye en onalthankelyke flem hadden, en onder niemint ftonden, na laun getnoed, en zoo onrdecten moetten, als zy meinden voor fod en de wereld te konnen verarit woorden, en meeft met het Itgt, en met de agting der $\mathrm{L}$. Mitatflippy, die zich in dezen geenzins zou latacen befpotten, over cen te komen.

Radja Boni bezogt ondertuffehen den Goumerneur den 27 lien Oetober zeer on- Aroe Poverwage met ecn trein wel van tooo man ni 's onop 't Nicuw Loo, anders ook wel het werwagte ronde Bosje, of Marigepe genaams, een ning op dand, by Aroe Poni uit groote vieeze on- "Lnicuw dernomen, on dit men zyo Honglieid Loòwysgemalkt had, dat zyn Ed., eenige dagen geleden, met deze cn gene Bondgenooser butiten zyn woorweten (Aat tegen "slands werten en de gewoonte was) in der ltilte gefproken had, dat zekerlyk voor hem nier veel goets beduiden kon, en wan uit men hem verder had doen begrypen, dat zyn Ed. voornenen, wel verre war Arge Reko te itraften, allecs matr was, om hem wy te fp:ekert, den zelve van langzaner band ook boven hem te verheffers, en de kroon wan Boni oṕ 't hook tezetten; al 't welke, alzoo men in zullken zate niet omzighig genoeg zyn kor, hy ten grooten deekn aingenomen, en dat hem zoodanig ontlelt had, dar hy"er mog nier wan hiad konnen bedavens doch de Heer Bernink deed al die donkere wolken wan zyn Hoogheid anftonts verdwynen, ftelde hem wolkomen geruft, en verzekerde hem, dat hy mer de zath ren cerften zou voortgan.

Daar op liet ayn Ed. de Vergadering vergadeder Bondgenooten tegen den lodé $\mathrm{Nu}$ - ríng der vember $170 \mathrm{l}$. "s morgens ten 9 uuren be- bondgeleggen, om dan dic zak van Aroe Teko nooten volkomen af te doen, met verzock, dal iegen dea
Io Nodoch alle de koningen en wartten met een wember kicingevolgran 8 of $t 0$ musket- en fpies-rjor. drigers, volgens hun voorige effprati, in " $\mathrm{t}$ kafteel gelietden te komien, de deze

$$
\mathrm{B} \mathrm{b} z \text { vet= }
$$




\section{M A C A S A A R S C H E}

Frot: vermindering vàn bun gevolg (alzoo de plats niet grooter lyden kon) nict quas. lyk te nemen.

Van deże Bondgenooten is de E. Matfe: happy de cerfte, en Radja Boni de i weede, wart na Radya Goa, mitsgaders de Radja's van Leeboe, Tello, Tanetta, Datoewa Ri-Sawite, Datoewa Ri-Socpa, Crain Barroe, Grain Binawo, Cran Bangkala, Toerongan, Crain Pannma, Crass Baclacombe, de Mandareclche, en meer sindere koningen, volgdei.

Ondertufficher nam Aro Teko de viyNieuwe heid yal den Her Gouwerneur eens te Gen yan bezoeken, en bood tan den zelven ( in Arot hoope dat dit hem merkelylk in zyn zaak

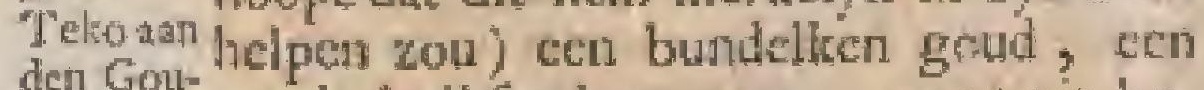
den Gout- goude buikfnyder, enz., rond uit be-

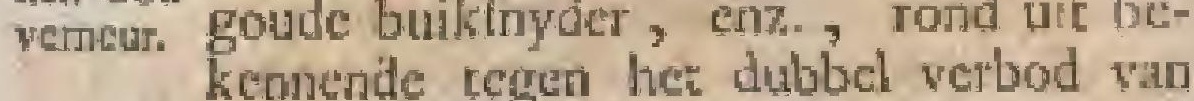
Methely-Aroe Poni in de Negry omgelworven te denis van hebben, biddende, zelf met een voetwal zyn miss voor zyn Ed, om vergiffenis, en belydaad. dende, daar mede meer, dno nuet alle zyo andere miscladen, misdaan te hebben; waar op zyn Ed. hem alleen dede weten, dat men zien zou, wat in zyn zank gedaan kon worden.

Den roden November 1701 . dun rag men de krygslieden in Lwee vanadels op 't plein in ringuetten, vas de land - en watespoort af tor des Gouverneurs wooning, verdeelt Itaan, daar zyn Ed. lyhisagt alles met een dubbelde vleugch tochloot, en mar opening voon den ingang liet.

Ditur op lict de kuning vir Goa zich door zyn tolk atandienen, dat by naby was, waar op de gewoone GeconmitStatieufe weerde Lederr van den Polityken Rand,

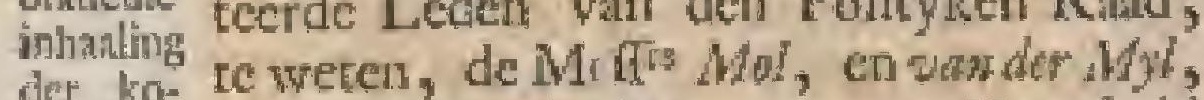
der ko- te wezen, den wierden, om zyn Hoogheid vin Boni voor den ingang van de peort te ontfanen Gos, gen, die dan ook met dien koning, onder' 't flatan van de trom, en een wliegend vaandel, weer binnen traden tot de wooning wan den Gouverneur, alwaar zyn Ed: zyn Hoogheid zeer ttatieus ontfing, en den zelve verder tot in de voorzal leide, beleeft verwelkonde, en daar zy zamen ann cen lange tafel gingen zitten, ann welkers reger zyde de Rutsperfoonen, na 'c oud gebruik, geplaatlt waren, en de Gonze ryksbeltierder de hooger hand wan Rarlja Goa zoo lang nam, tot

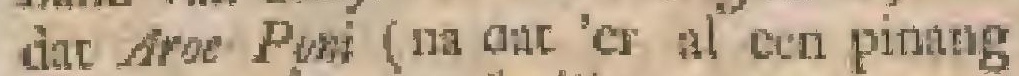
gegeten, en een fruitje genomen was) zich mede lict andiener, dic op de zelve wyze, als Radju Gou door Gecommitteetden (terwyl de Hect Clanszaon, en cenige andere Leden, zoo lang den kouing wan Goi, eaz. onterhiclden) ingehanlt, door den Gouvemeur, als woorens, atur de deur wan zyn wooning ontangen, verwelkont, en op de hooglte plauts naalt hum gezet wicre, die zyn Hooghew nim, terwy l'er cufichen die twee koningen nog cenige hoflykheden gepleegt wierden, I7ta wat na ook an alle de andere Bondgenonten, die ondertufichen mede daar werfohener waren, yder zyil plants angewezen wiert; toch men bevont dar veelen den rang an anderen, "I zy om bunne hoager faren, of uir verwnteflap, of wel uie ceniye andere inaigten, owergaven, dial de Heer Gouverneur ongemerke liet dootfochieten, ondar zy "t zclis zoo liefit hadden, en on alle verdere talmery daar over af te finglen.

Her overige volls, dat men nier buiten houden kon, en dat meeft uit mindere Grooten, Koningskinderen (war door men of wate kinderen varn koningen, of ouk wel zoonen der ryksbeltierders, weritat) Galerans, en nudere Edelen beftont, lireeg hun plats op de agterbanken.

Na dat nu, ma "t drinken van cen kopie Aan. thec, het oerte flentian vernomei was, fprate deed zyn Ed. een zeet gematigde en te Gan den gelyk dekige nantprak tot alle de konin- neur in gen, Datoewa "s, en de verdere bondge- Vengadeneoten, zeer net op de zak , warom ring. xy te zamen gekomen waren, gepaft, en wanl by by hen nls zyne broeders nu verzogt, om nevens hem een cinde wan de zatk van Afor Tedu, wegens de manlarg alan den Sapingzen prins Dain Wabaw, anders Avo Balocfoo genastm, in Mey des voorleden jaars bedreven, te makken, als zynde hoognoodig tor handhaving der wetren mu Celebes, en tot veilighath en geruftelting der konings - kinderen, behalwen dat "t ontzag det E. Maatchappy, en 't regt der zelve, vorderde, dat then de fchuldigen hooren, en de pnoordenars wel thifen, mat hen nitt anders, dan na bevinding van zalken, of wry ficken, of doemen moeft.

Behalven deze moord, zeide zyn Ed. heett hy zich ook veritout tegen myn verbod, en regen de uitdrukkelyke laft wat zynen koning, zeer baldadig, tot onzer beider hoon en veragting, foor de Negry te fwerven, watr na its hein op een gemikkelyke wyze hior in "t kalted gewangen gekregen, cn tot nog toe gehoudicn heb, om nu gezamentlyk mider en rypelyk te owerleggen, wat ftraffe men oordecle, dac hy over deze misduaAen verdient heett.

Hy toonde aan den Rand, dat menalles tot eyn taa- cen voordeel op 't papier bad dotri ftelien, op dat de t'zamgeroepene Bondgenooten re rege in flant ayn mogten, om datr over te konner oordcelen, en wrala op tierhalven ook nu yder zyn advys zoodunig te geven had, als hy oor declde, zouder anzien van perfonen, of zonder zich an cen anders gevoeien te verlarven, voor God en de menichen te konnen Yetanitwoorden. 


\section{Z A A}

I7.t:

Oolk vriagde zys Ld, of 'er, thi de gedigten del Bondgenonten, nog iers was, dat lon hindende om met de zatk voort te gaan, en, zoo nict, dat lyydas den miscladigen voor hen wilde doen homen, om opentlyk gehoort te wor" den, watr op zyn Ed. hun aller adwys verzogt-

Na dat die tweental zeer luid in 't Maleits en Mncaftats getegt, en pertaale was, was 'er eesfl cendiep ftilfwygen en ftarongen op malkanderen, war op roen een ftille mompeling en bycentteking der hoofderi wolgde, doch cen half quar"-

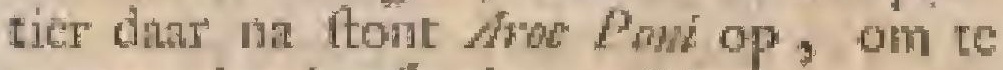
toonen dat by fpreken wilde, en wejklaarde zich roen, na dat alwoovens weer Ant- was gaan ziten, op deze wyze: Aroe woord Teke"s misdatd is ons allen bekenr, en ik der ko weet, nevens de n Hec Golwernetr, wakr ningen in lay, buiten die moord van Dain MaGoa, enz. bami, thoge in "tbyzonder zeer twast gebicr op. zondigt hect, doch zoul eerft moeren hooren, wht bydar tegen tot zyne verfchooning heeft in te brengen, "I geen verlange to mogen weten. Dit fiende Radja Gue mede toe, en alle de andere Bondgenooten gedroegen zich in dezen wan "coordeel dezer twee koningen, en an dat der E. Martichappy, of wan zyn Ed.; doch de Het Gounerneur vertoonde an de Bondgenooten, hat men zaaken wan zulken gewigt rice aan 't oordeel wan 2 of 3 mentehen verblyven, en die zoo nier afdoen; matrat yder van hen die ma zyn gemoed behandelen, en elk dar over als een vry worl, zonder vin yenant anders af te hangen, of zonder zich and een anders gevolen te verflanen, oordeelen, en dat ook docn mocit, zonter yemant tet wercld datir in te vyeezen, of na de oogen te ricu, alzoo dic een zask was, dic God van cen yders hand vorderen, en wast ith ons geen worft nog koning eenige hulpe znu tonnen bew'yzen; dat bet niet hun, Jnat Gods gerigt wns, en dat men 't gerigte derhilwen Gode, en nice den mentchen, houden, en hem daar als een kenner wan herten, en dongronder det nieren, voot oogen hebben moclt.

Hy vertoonde her, dar $z y$ indeze Vergadering, om hun them te gewen, alle even veel te $7 \mathrm{eggen}$, en yder cen vrye cn onathankelyke fteni hadden, in zoo verte dat de minfte ftem hier wan "t zelve gegewigt, alsde zyne, fchoon wan de cerite Bondgenoot, w5; ook voegde hy hicr nog by, dat yder van hen niet alleen zyn advys cn vonnis over deze zalat by monde zoude mocten geven, mitar da ook onOple zing derteckeuen.

derichrif Das op lis men de fchriften was Aroe en tegen Tok de Vergadering woor, en zyn Ed. deti miss- warlchoude de koningen van Boni en Goa daadigen.
K E $=$ N.

vooraf, dat zy nict zouden gelieven $r$ ot, mocjelyk te worden, zoo har Hoogheden in "toplezen der zelve deze en gene anathoorclyke zanken voorquanen.

Nat dat alles gelezen was, watagde zyo Ed. atat atle de Bondgenooten, of $z y$ den inhoud dezer febriteen wel verltaan hadden, 't welk met ja beintwoord zyrde, vraggde zyn Ed, verder, of $x y$ nu gertegen waren Aroe Telo zelf hicr over nader te hooren. Zy zeiden, neen; doch op het fterk dringen des Lethdwogts thonderi zy tos, dat men. hem in een bvzondere leamej doot anzienly ke Gecommisrechden uit dic Vergadering nog cens zon doen hooren, om dast op dan regt te does].

Terwyl "er ordegeltel wiert, on hen in ecn byzondere zydekamer door den AmePoni Licutenant Riddel te doen brengen lookend wangde de Heer Gouverneur an Aroe Teko taf Powi, of liy atre Teko (gelyd 'er klarar tot deze in dit gelchirift ftons) ook laft tot die moord moord gegeven had; doch zyn Hoog teheloben. beid untwoorde tor drie byzondere reizen, op nadere conlige vragen valn zyn $\mathrm{Ed}$. dat by noit eenige laft dar toe gegcven hiad, en dant in door Aror Telo belogen. wiert, werzockende das op wel te letcen; wat het inhad, als een minder hem, zyn cigen loning, ecn leugen in 't anngezige wiyvendorlt, en of her, met dat zoo te zcggen, maar genoeg was.

Ever zoo ofucluuldigde zich de konitug yan Goa, wegens "t gene "er in dat fchrift over "t verwerpea wan Saena gezegt wert, zeggende, dut hy van geen andere, dan wan een wetxige verwerping en vergering van alles, dat "er voorgewatlen was, wift, ch dat men ook darom Socha aan dro follo met voorweten van de Hecr wan The geweigert had.

Na dat rude Gouverneur den nard wan Vrage Noe quk "s misdaten knar en in biar vrage wolle kngt woorgeftelt, en. nict alleen Ed an alles, war men tor $z y n$ verlchooning $z g-d e$ broegen.kon, bygebrugt, maar han Aree der wan Manyoc, onditen browier wan Ara Telo Troko. gevriage had, of hy wegens zyn broeder nog ier te verzoeken, ult tot zyn verfchooning in tc brengen, en de zelve ecn wy mificlyk antwoord, dat liy zich met de zatk var zyn broeder nict mocide, gegeven. had, ftelde de Heer bewhint deze zatak (op dar "er daar na geen uitvlugen plats grypen mogren) in dezer voegen in zyoc byzondere ledea:

I. Dat Aroc Tcko Dain Mabani Lefpron- Nader gen, en vermoerd bad. wootth II. Dat by, wa dit wigevoen to bebles, deret wg zoo bognedig on whejchant geweepl abas, on zulks den Hecr van Thyc te laden woten, dat zowed wat, alt of by zetde bowen allew waten te zyo.

B b 3

111. Dat 


\section{8}

M.A C A S S A

Inot. III. Dat by ook, flown bem datw op doo"

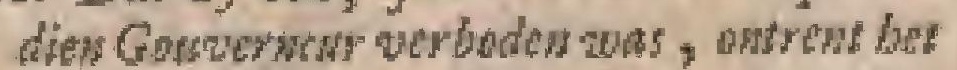

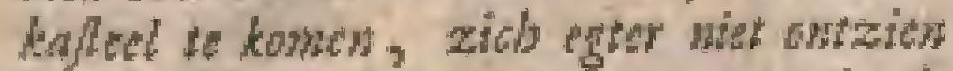
bad, wet vel getuapende mamen in de Negy Dlaardingen onder 'i hafect to komo rond forven, en aan onse Hoof $\mathrm{d}$ of therenal formpende of ite tragen, waraom wen bem beletten wilde bimen is kowen, en wat by midada bad? dat zym misdad mor buten verisf was ate Gowvornew, Radia Boni, en wan zyn Ryksbeftiorder, gaplegh ruas, enz, boned de

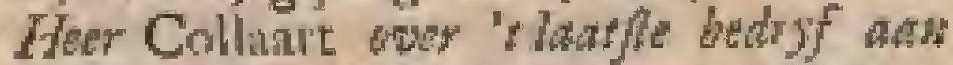
Aroc Tanetre Matotewa nor geklagt, on verzagt beft, dat dide in orde magt geflelt worder.

IV. Dat de Her Gorwersedr, op de erge tyding wan Dain Mabanu's dood, na "J hands waten, gorgtigt wat, om als cerflo Bomdrenou Aroe Teko bien bet te doen Arafen Ha verdienfe, tot vabording wan andere quade gevolgen, en tot voldowing val ate blod werwaten des verNagenen,

V. Dat Aroe Pon bier toe gelyke magt gehad beef, duch dat dit on rederen, dady men matr wa gifon kon, moglt gelanten zyw.

VI. Dat man Aroc Belo, Din Mabani "s brooder, zalls wede wier kon berwiften, zoo by, zumder vragen, op beter daad wet zyn work mar woothegan awas.

VIL. Dar man (febon andes cen diep inzin: bad) nog met ens morff rekenew, boe by (Aroc Teko) zyn 's kanings berieleninds wind flande, onlbefonam 2 of 3 wanden

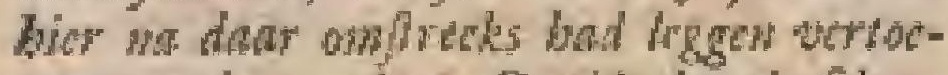
wes, cer by, op Aroc Poni 's bewd, foboun foucds onboden, M Thimana opgegadn whs.

VIII. Dat by dar na, als of zye orb"fobanibeid nog niet grout genorg tods, ho dat de niowe Gowvermear zith al 13 mandes bier ombosden bad, en by ( Aroe Teko) wet Aroc Poni van Tojuran afgeknen was, zicb niet onsten beft, deses mewon Gountwens bevelen we derdm wet vocich te tredes, en zouder

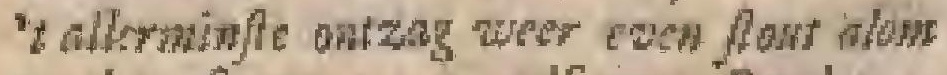
rond te fuerven, on zelf orse Rasdsperfoowen te bezoken, daar bem zalks wederom door Aroc Poni, es wit mann von dezen Gourtrueur, werbaden was.

IX. Dat by micters, man werlebide reizen, Jegen dat werbad des Governews, en wam droe Poni, angegsaw bad.

X. War ontrent wy ordre zowden gefflt beblew, zoo Radja Boni ons wier bad doen veraeken, ngg een af te wagten, of $\mathrm{by}$ dat ten derdemal wertreden zon.

XI. Dat de Goworisen gevallig wa 't grat wen tan do Panmpang, of to oyver, op Mamper, gaande zitn, bomegter, fobon met geen gevols, en balf onkenbur lougetaleh, wan agreren oplopende, al wil-

\section{A R S C H E}

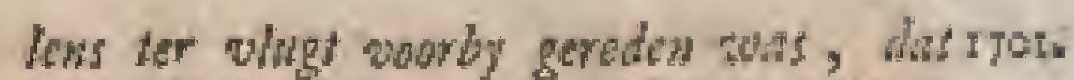
bew (Teko) ron dede wedrom kecren, op woike tyd zyn Ed. dit wet opzet gedaun bad, on die vegel dear no zoo weel te gewahkelyker in de knip to krygen.

XII. Dai by ook (Jboon'er man tayffelagtig wan is zome jebrifren geforoks word) wor evige dapen wat groute onderdanielbid wor den Gousement bekent bad, dat ben dat omf werven door Aroc Poni, woo ait zyn Ed., als atit Aroe Pond "s nam, cerboden was.

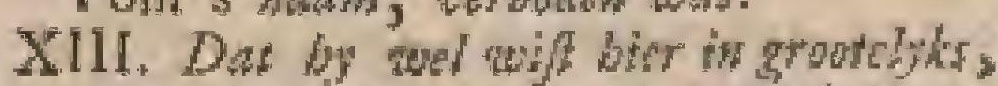
ex zelf in zoo verre misdant ic belpen,

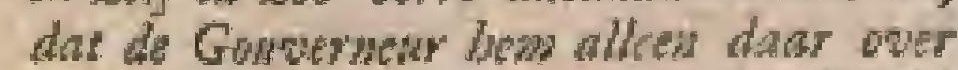
wat de dood Fraffer kon, fa dat by dit woor zys grootfe misdand bieh, on dar ow genale " $r$ over verzagh.

XIV. Dat "er nog enel weer tot zusnen lafe te zeggen za vallen, waar over, door varlop wan tyd, malgras gewd/ben was.

$\mathrm{XV}$. Dat nets, fobon bet de boofdzondt nel wegrem, tepen alle deze befund ringen tot zy nodel, dit to zyn woorderl zeggen kon.

I. Dat by sry lang gezammelt beft, en by bier door ouverduldig wor denkon, dat wen zyu zonk, ower "rbehen wan Dini Mabani met zy urow, up zyn matrmaden godacw werzed, niet er begonn beeft.

11. Dar ber en man, zoodong van ach prins, dien by dagehls wor bew gaas ale, ge-

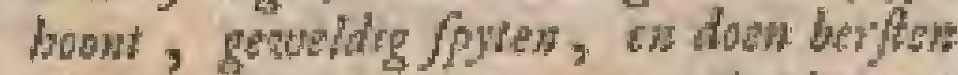
wow, dat egtor nan ayn zank whens getily ward.

111. Ex dat by gedwtyig wata met woorden gepaait, en aonder eang vervols op do zank wigefle word.

IV. En lat by (datr bencon boogmoed ig en wh boggen buize zynde) befl gedagt

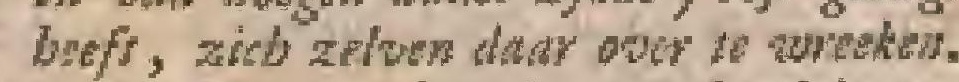
V. Om aldus zyn boonder wier dagelyles neven bem, en ongeflraft, als on bem neg re zarres, ren Lowe io zisn wer fobym.

VI. Dat by wol mogel wh wet gece quad voormenes zoo ongerwstum, ch dit misJebirn weer door monodigheid, en wor een onbezons drift, dis mat opzet tegen zw koming, of tegen den Gowernenr, of an ean der zeive to roctur, gedan befi.

V1:. Geifk by dat laath ode bokent, engenade dat Gever werzogt bad, wedke ondor-

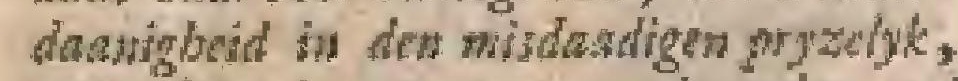
vedtyds we' wat near genzde, don wol barnektigheid, werdiewde

VIII. Darby de dodfrafe, daderzins bier toe hande, nier meer under batig, alwo 'er te oed tyd's na de smoord veriopen nus,

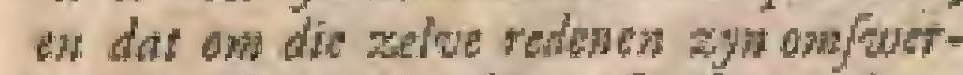
wen zow fortig nin kow geflraft worden.

IX. Dat men agt op zys bong ge/dagt, on worfelyke blodwerwantes, goven math, 


\section{$\begin{array}{lllllll}\text { Z } & \text { A } & \text { A } & \text { K } & \text { E } & \text { N. } & 199\end{array}$}

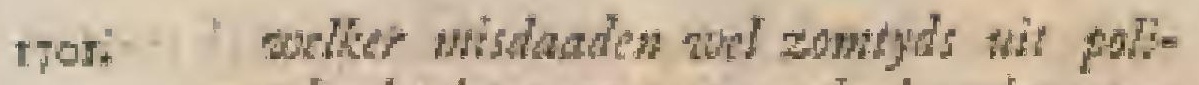

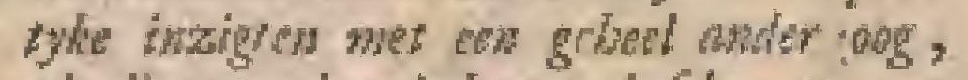
dis die wan de windonen, beflownt, the daaron zonbids zoo $/ \mathrm{hrag}$ sied gefraft wierden.

Dit, zeide zyn Ed, zyn myne anmerikingen over deze zati, zoo ecgen, als voor den misdadigen, wal by de medebondgenooten de hunne konden woegen, zoo zy dar nog iets by te doctn hadden.

Hoewel men hicr tegen nog dit zou konnen zegges:

I. Dit al die biantute blowkens den and wat de mourd niet weranderes, rog de

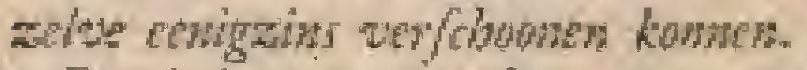

II. Dat "t lang wagion bew geen rogt gaf, on ayn expen riger te ayn.

III. Dat men zy Righos gen wotten kon Aellen, on ech metelige zaak, als deze; wor de with af to doen.

IV. Dat die befluldigde zoo oel cen prins

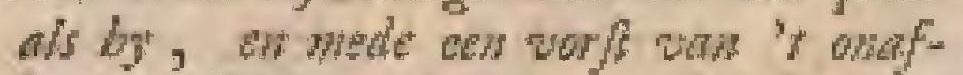

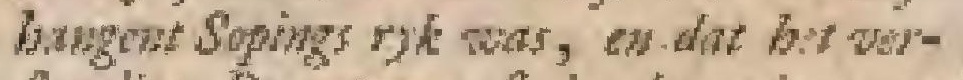
fandige Regerten papt in ate mine en twiten ontafien alle gefobilen of te dow.

V. Dat de blyken kinar leggens, bae Aroe Poni, dow wiflbryen, co malyden, bet dat toe beeft zocken to brengen.

VI. Dot men ook mesdo bet rets werre genorg golvagt to beblen, wernits de prinew, weraend zonde, wer als broders wer walkader on werkerdon.

VII. En dat Aroc Balocfioc zelf gen andre gedagten gebad had, dah dat alles wo gedan was, terwyl do misdadigge op

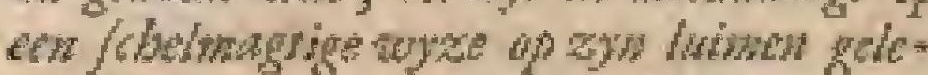
gen bad, om by de erile gelgenbetd ben wh the wereld te belpen.

VIII. Dat zym groote gebuarte bew bies in wet werchowen kon, ten wark men zalden boven de avetien flellen wille, in wielk gewal das mimanit wat ben, of woor bus-

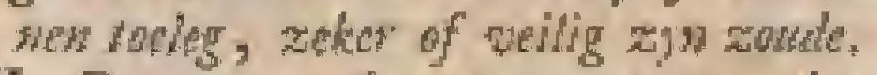

IX. Dot wen wed mont owinugen, dat de ter Nedergeflagen mot allen zoo wel en

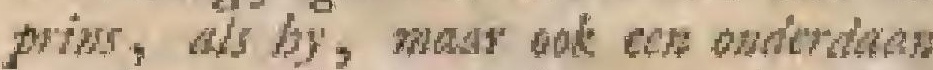
won bom, of zy ver/l is, en dat dierbatentyn blocd on wrad lat God rogp, op dat ook whdere llaning - kinderen wan

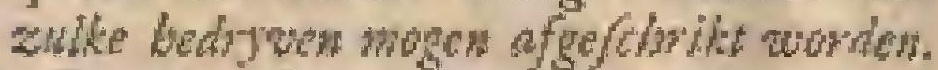

$\mathrm{X}$. Dat de redenen wan worklooming wegens żn onfwernen, tegen een dubled werbod aan, wat bhawwe dockjons zyn, abob dat wiet wit mismoditbord, madr mot opat en zeer Mow door bew getaen is, en woord dit in ben ongefraft gedwh, wat zal men don in 't wervolg wan alle anderch wiet ve ruagten beldew.

$\mathrm{XI}$. Ood is zywe foludbehentents gees aitwerling wan browe; Mar wan vreze, on dat by we in de kions it, endar door ic ert bopt bos te rathere.

Na dat nu dit alles omfandig door zyn spot. Ed. in 'L Maleits voorgeftel, en dare en boven (terwyl men een kopje thee dronlty in "t Macaffats vertolkt, en nog eens her'hulte was, zeide zyn Fd. tegen Aroe

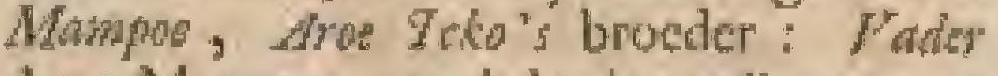
Aroe Mampoe, gy bobt daw alles wor es

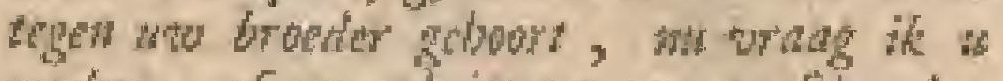
weder, of gy ode tet tor syn serfobonimg wece in te brenges. Hy gat hict op tot

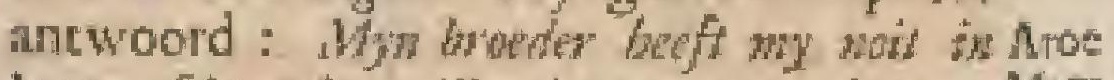
"I cen of "tander ruillen kenser, en dawow Man-

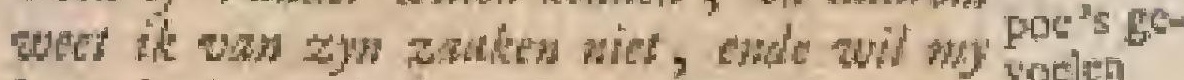

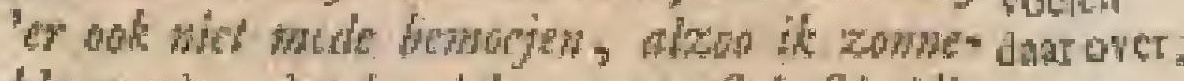
klas zie, dat by zicb wretgegfort folsuldig bicft gemadk, zelf wot zyn unfwerwen,

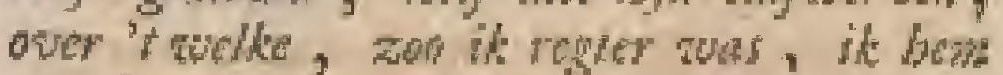
zoo fwatar, als over 'tallewerfoyedy/l be-

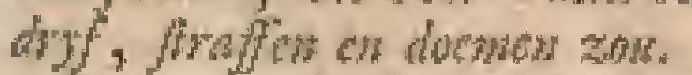

Diatr op fprak de Gouwerneur de verdere Leden an, en woatgde, wat or nu werder in deze zak, wolgens hune gewoonte, cn na bun oordeel, diende gedann te worden; wat op men meinde, dat het nu Lyd wiss, om Aroc Tho voot Gecommiteceden te hooren, cu bem te "itagen, of hy buiten zyo fohrifen nog iat te zegeren had.

Diar op wienden de Meftrs Hakagn, Aroe Tewan der Myd, en den Gelicinfchryver hoe te Polityken Rad, en, uir dewerdere Bond-minteergenooten, de koningen wan Tello en Loe- den ge* boe, nerens de twee dy ksbetierders wan hout. Bonl en Gon, te weten, Aroe qanette Marowa, cn Grain Bontorongo, als Gecommittecrden aangeftelt, on bem, ten overtann van den Heer Gouvernetr, dic in een zydekaner blyven zou; te hooren.

Deze viatigde hem, of alles, in zyne fehriften werwat, watir was, das of hy nog iers tor zyne verfchooning te zeggen had. Hy zeide kortelyk, jus on dut hy er nices meer by te wogen had.

Din is, zeiden $z y$, onze commiftic uit, dan dae "er nog te valagen walt, of Aroe Pon hem rite, tot twemal toe, op groote ongenade, vit zyu, en des Gouveneurs maam, angezegt had, wan in de Negry Vhardingen alon niet rond te arden; war op hy, watverlegen, ja zeide.

Men whagde hen, of lay dit woor cen geringe zaak hielt, dan of hy wel wilt, dat zulken dad, na 'slands wetten, de wictertte ftraf verdiende. Hy bekende, dat het een hooldmisuand was, endat hy. Wenoelat dartom den Landvooge om zyne genade om genaverzogt land, gelyli hy die nog van zwn Ed., en den Rand verzogr, dewyl hy dit geduan had, door de fehenkagic, dice hy dit jaar van Batava gekregen had, van vreugde verwocrt zynde, war door by zich vergeten had.

Dast 
17os. Daar op groetten zy hem, en Eraden met den Heer Gouverneur weder bianen, terwyl hy na zyi gyzelkaner gebringt wict.

Na "t gedant berige dexer Gecommittecrden ant de Vergadering wegens $A$ roo Teko's antwond op hunne vinagen, ftelde zyn Ed. woor, of "ter wolgens des linds wetten, nog verder iet in deze zatk, alwoorens over hem te vonnificen, vereilche wierd; zy zeiden, neen, alzoo 'er de doodlag klase legt, en de omwerwing klat door hem beleden, war by de zanak dan nu ook in that wan wyzen is.

Dais op herhalde de Heer Bermink "Wast op (om hier in de laft hater Edetheders wel de Leden na te komen) wederom, dat een regeer nognaals nict op zyn bloote bevating vin een $z$ atak , lunine of met zich uit een verkecrde vreeze en vereftern' ontzag an "t gevoclen van andere Leden

tigder te werflawer, cen vonnis wyzen; matr voor al owerdentien moeft, dat hy ecr vye en onathangende ltem had, en dat de ftem wan het allerminte en lintfe lid dezer Vergadering zoo weel gelden zou, en moct, als die van 't eerte en woormatathe lid, weshalven zyn Ed. hen ais voor Gods anigezigt verzogt, doch niet wit hate of gunit, en nite wit annzicn of vreeze van dezen of genen, matr alleen na hunne gewifle, en na 's lands wetten, in dezen te wonniffen, zonder daar' in bet $z y$ de E. Maarfhappy, het zy cenige koningen, hooger m rang dar $2 y$, te ontzien, verzockende eindelyk nog to mogen weten, of yemant duar jets regen had, en, zoo neen, dat dan Aroe Powi zyn gewocicn maar fchriftelyk geliefde te geven, om dan azoo van de andere Lcden gevolge te worden.

Nadat thu de Tolken cenigen tyd rond geloopen hadden, en zich een tuffchenmompeling der Grooten over de zaak opgedhan hand, zeide Aroe Poni vit aller naani: Wy hebben den Heer Gouwerneur zeer wel begrepen, hebben dur niets tegen in te.brengen, alzoo 'er zeer - Jegtrinuig, en na circh dexer zatk, gefproken is, want woor wy zyn Ed. bedarken; doch wy vmagen voor af, of er, als wy orts gevoclen geuit, en onderteckent hobben, na de wet ten zal regt gedan worden, en of het den Gouverneur ernt is, dat wy ons, zonder wanzien van yemant, that ftipt aan zullen houden, on ar de meerderleid war ftemmen te vontiffen, en dat wonits na 't gewystle uit te woeren.

Hiev op wiett, na een berading van zyn Ed, met den Politykea Rand, door zyu Ld. ji gezegt, wat op toen de honing van Boni opitont, en zcide vatrdig te zyn; doch vertogr, dar de minderen eert mogten ftemmen, ware over lange gefchilen wicken, tot dat mea "t cindelyk dante toe brigt, dat Aro Pom (gelyk ryor. ook belsoortle) voorgan, en zyn gevoelen in cen zydektmer op een vel papict, ten overkaan van 7 w Ed. cn conige Loden nit den Polityken Rand opftellen zoude, om dus te beleten, dar de byzondere femmen en didyen wan dezen en genen nier openbast morten worden.

Na dat dit in 't by wezen wan de Hecr

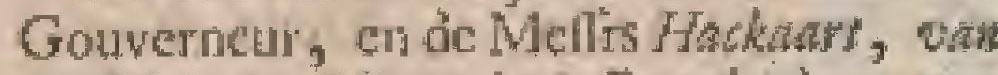
der. My, cn Mher in 't Bocgis door zyn Hoogheid opgeftele, en vertalt was, zoo wolgde bem de koning van Gon datr in, na dat Aroe Poribuiten getreden whis, hotdanig naderthand alle de andere Bondgenooten volgden, en bunne ftemmen gaven, hocwel de meefte her door hunne fchryvers man deden anntedkenen s doch De Bond"t was zeer opmerkelyk, dat ria de ftem-genooten ming en onderteckenimg der wicr cerltc vellem Bondgenooten de overige opitonden, en over prot hen eenpanig werklatden met Ane Poni Tekon en den Gowerncur, when geroelen te zyn, en dat zy zich verder an alles, dat zy 'er byzetten wilden, zouden gedragen; wan op zyn Ed. hen weer toonde, dat zy nog met her, nog met Aroc Pons, tc doen hadden, mas dar yder wan hen roor zich zelwen, na zyn gemoed, en wolgens "slands wetren, themmen, en dat wor God veratitwoorden moeft, zonder dat het ant hen ftont, om eenige Hoogheid wan menfelaen aan, of dezelve conigzins na de oogen te zien.

Hier op dar, na dat zy $A$ ro Poni (dio dit niet gatme loorde) nog eens saugezien hadden, traden $2 y$ toc, en quamen "c verzoels wan ayn led na.

Duar op nu zeile de Hocr Betmink, dat by hun aller gevolen gezien lad, en zich daar mede byrocgde, tchoon by gedagt badde, dat men de misdanden hooget gehouden en fwander gellentt zoude hebben, wat ma de Vergadering, na zeer defrig mes een collation onthalt te zyn, reheide.

Het vonuis, tegen hem geveld, quam Dit hy by meerderheid whr ftemen daar op uit, zou gedat by zoo zou germipurt worden, dat rampat juen geen reden zou hebben, on meer wordts. voor hem te vreezen. Men meinde hem dari en bowen in "tectl ook na de Katip der Goede Hoope te zenden, doch ment hecfe naderhand beter gewonden, hem na Geylon te rocien.

Van dir geveld romis over de moord en verdere misdaden wan Ano Tako, gat zyn Ed. ten cerite her vereifche berigt ann hat Edellueden, verblyd zynde dat liy 't reets dus verre gebrage had.

Den I $y^{\text {den }}$ November was er in dede kogroote thuin der E. Maticlanpy een ning vit vergadering des Bondgenowes, om eca 'Tanatia

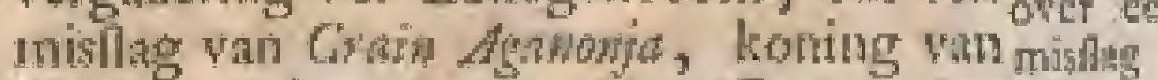
Tuneta (atzoo hy oen Hecr Gouvenent get rist 


\section{Z A A}

t7or. vall belegen, en woorgegeven hud, ats of $240 \mathrm{Ed}$. mec het brzonder gefpek in der ftile onlangs mer hem iet oubehoorlyks in den zin zou gehad bebben, wats op een groote opfchudding gerolgt was ) te vonndest, el ben te wakrichouwen van zich in to tockomende voor zulke Atrecken te wigten.

$\mathrm{Hy}$ wiert ditur en boven in ten boete van elf thith goud gedoemt, die den r gden dito, in "e by wezen wan allen, wiggenomen vat Aganoyia, door Rafla Bon woldatt, en auiv den Gouperneur overgegeven wicte; doch die lioning had Agnoma verboden, om daval, 200 . hy zich niet dubbelfchuldig tnaken wilde, te verfchynen, gelyk by daderhand ook klan blyken dede.

Voor de overgave yan die boete bedaniste zyn Ed. den koning wan Boni, en ook alle de Bondgenooren, wegens de agting in dezen voor hem, en zyn goeden mam betoont, betwigdu woluante zyn, dat dir by den Rath zoo virgewezen, en dat die boetc voor cen oogenblik in zym hand geweed wais, en gat dic nu weter an Aroe Pon, om die ten dientle var] deze enigene behoeftigen, tha hun aller welgevallen te verdeclen; voor welke heusheid ryn Hoogheid, en alledeandere Bondgehooten, , zyn Ed: bedankten, en dar geld wel weder ataniamen, doch onder verzekering, dat $z y$ dit nict anders, dan nat zyn Ed goedvinden, zonden aunleggen.

Dar op vragge de Gouwerneur tan Aroe Pom na Agawas, wemzende hen nog wet remift te het bed, doch Aroe Pow zejde, dat hy hen dit, om zicly niet weder fchuldig te maken, verboden had, mant de Gouverncur coonde hem het tegendtel, alzoo zyne verfelyning datur gedien wot hebben, niet om hem dini in onderdanigheid te doen komen, of on heir zyon mishay opentyk te werwyen; mat atleen om ec toonen, dhe hy mer voldoening van 'e gewrysde de misdand ook rergeter was, en dat de Gouverneur, on dic te bewastheden, hem zyn wootige rang en plats onder de Bondgenopoten zoude :tutn wyzen.

Op deze woorder lton Aroe Poni op, bedinkte den Gouverneur inet een bewys, als of by hem (vorvoert over die beleeftheid) de hand litfen wilde, dat zyn Ed, zoo weel mogely] was, belette, endar-op dele Aroe Pont den knning Yan 'T anette roepen, die cen lhilf urar dant na quam, willende, volgens gcbruik, op ecrn onderduanige wyze zyn handen op zyn hoofil legegen; doch de Gouverneur belete hem die mes een werle, en belafte hem op zyne openftande plants en ttocl te gaun zitten, alwaar de Gotwerneur, geen tien tellens 'cr ng, hem cen finuifje (cen ongemeene
K $\mathrm{E}, \mathrm{N}$.

gunit in zullien gelegenlueid) toezond, rza: en mer genegentieid (ren bewyze, dat hy any 't poorige, en atn zynen misllag, niter meer dagt) dat anbood, voor welke ongemeene en onverwagte heusheid alle de Bondgenooten zyn Ed. nogmaals bedankten.

$\mathrm{Na}$ dar nu alles vergeven en wergeten wis, hette zyn Ed. cen ander gefprel op. Nader en verzogr de Bandgencoten, groutern en veruek kleinen, dat $z y$ doch wel gelielden te Ld. overwegen, dat het woor ons omnogelyk was, omt 't xvili. en XIx. Art. van 't Bonayich Contrat in zyn kragt te houden, zoo zy de een van den anderen, en de minder yan den meetderen, -1adigtig wilden athangen, en dat hy derhatwen ook hoopte, dat de Hoven vin Boni en Goit zich geenzios eenige oppermigt ovel hunse broderen, de andere Bondgenooten, zouden haten ainleunen; man dat zy woortan alle zulke Bondgenooten, die zich an hume Howen wilden komen yercooner, om van hen af et hangen, belect zouden af wyzen.

Hier by was wel de latt qan laar Edelheden opgevolgt; doch dik was woor die kwee troningen vel fnvertelyker, din of hen. een frude-in "t aungeage gegeven wierd, alzoo men ben clate by in hum anzien en gezitg niet allech veragtelyk kortwicke; melar nog dats en howen wille, dat zy dat zelf goodkcuren en verder uitwoeren zouden.

Terwyl zya Ed. dit nog zeide, kikte Dienun, en Arat Pow keels zecr ltemmig wool zich neder, Feinzende dit niet exps vertuan te hebben, hoewel de wertcheide pothuren, wilu in hy zich draaide, het [ergended, en dite hem zulk ecn vettoog zeer mishangde, niet dan al te vecl toonden.

Eindelyli woegde de Gouverneur hier nog by, dar dit zyn zeggen geenzins lot ktcinagring war hor Poni of Radja Gora, maar alleendiende, om ana alle de andere Bondgenooten te toonen, wie zy waren, ofte wan voor zy by ons te boek ittonden, en in wae agting wy her, volgens 't Bonayfch Contride, hielden, enverder wilden houden, alzoo wy datr by met anders, dandic gewentelice endrige on der hun allen ( $g$ elyk zyn Ed, nog Jatit जuet het wrzoenen wan die twee cerite koningen, met zoo ved hutrelykheid en opregtheid betoone had) beorghen.

Zoo ris hidden de koungen van Boui en Goa dit njet gehoort, of sy fprongen wan vieugue van hustie ftoclen op, en bedankten den Gowverneur voor den dient, dan by an hon betden beween (hoedanig oole alle de andere Bondyenooten zyn Fd bedankten) war na deze vergadering, wa dae zy diali een trital collation op gehad hadden, teheidde. $\mathrm{C}$

Den

II L. DEEI: 
sher: Den 3 then December 1701. werlialde de oude koning rari Sumbawa, hoe 't by't Huwe-gekomen was, dat hy (Datos Locka) nog lyk van fong zynde, zyn 1 k atro zyn zoon, Amás; Datoe overgegeven liad, te weten, om dat Look met 't Bonize hof, en Dain Tobahle voor al, de printes zeer verlangden te zicn, dat deze zyo van Bonizoon met droe Pox"'s dochter, Foudga, takt mil zynde de oudite dochters dochter van Kadja Loobe, wolgens 's betlorne net Rada Palack, trouwde.

Deze Datoe Loka was getrouwt met een halve ouder rufter van Rorlat Thlo, welke princes Tamifange gendime was. Dic deed Radja Palakis, om de kleine vorften wan hem te doen athangen, en dic tot zyo melkkoejer te manken, en orn deze vorltin Tawilang (dat een ko: ningin, zoo zuiver en syk van gefligt, dit zy nier behoeft gerafinecre te wol:den, beteekent) an 't ryk van Boni fware geflonenken tedoen geven.

Nu hid hy Daroe Locke in "t juth e 695 . an den ziek leggenden Radja Palaba belooft, dat, zoo zyn vrouw een zoon, en Lapatat zyn neefs wrouw een dochter kreeg, dan die twee an een zouden trouwen, en dit hydan ook, onder zyn hooger gezag, dic ryk and zyneu zoon opdrigen zou, al 't welk by ann Radin Palak a uit ontzag toegezegt, gelyk ook Lapatan zyn rockomende dochrer an zyn (Datoe Lock"s) toekomende zoon beloot lind.

Hier op was zyn vrouw wan een zoon, cn Lapatan "s vrouw van een dochter, Toudja genmamt, bevallen, ca dus was dic huwelyk gematkt, en fehiken datar op dit zoonje, als humen cockomenden koning al voorgeftelt, na Boni, on de bruid datr mede eer ntin te doen, en dat verblyf duarde, tot dat Radja Palacka quam te fterven.

Daar na bad Datoe Lokew met zyn Ryksraden over de fwarrigheden, die hy in dit liowelyk zigs, gefproken, dat zy ten atlerminten woor een handbloen of gelehenk ata de bruid zouden moeten geven 70 of 80 flatyen, behalven de goude armingen, cu andere vereifchte koltelyklieden, na marte van dien, die men nict woorby kon. Dat hy ook op den 7 of 8 dag, wanncer de nicuwgetrouwden zich reingen, ria "s lands wetten, weer op nieuw, fattoens halwẹ, wel 40 dlaaven zou moeten geven; ten derden, dat 7er onder "t gevolg vin den bruidegon, terwyl hy ging, on die plegtlykheid te wolbiengen, niet min dan 4 of zonden moeten zyn, om hem te gelciden, en dan tog wel half zoa veel, om die koningin, uic natm พnก 'E Sumbawa's ryk, te gazm opwagten, en dat die alle aan "t Bonize hof, terwyl men zyn cigen volk fararde; fware dicniten zonder loon. zonden moeten doen, en door die vain $\mathrm{Ijor}$. Sunbawa buiten 's linds onderhouden worden. Dat zy oolk huinten koning ydear reis, op "t wenken van Ralla Boni, zouden moeten miffen; en dat deze by zyn fchoonvader noir met ledige handen zou konnen komen, want doof hun syk onherftelbar zou gedrukt en uitgeput worden. Dar $z y$ wel wilten, hoe veel $z y$ ian de Ed. Compagnic wegens hunne bekomene wryeid verpligt waren.

Dat zy Rykstanden ook wel wiften, hoe nadeelig alle huwelyken, met 'c huj van Tello of Gon ingegarn, woor 'cryk var Sumbawa geweelt waren, en dat men zich dierhalven an to woorige fpiegelen modt, behalven daz 'er, om zoo veel mentchen by een te liryen, wel cen op: thint op wolgen kon, en dar deze, om wry te zyn, dan de vluge zouden nemen. Ook dat men alle Mactudatren, en Boegi 's, op Sumbawa komende, als princen en heeren van den linde, zou moeten ontbalen, behalvea dat zy alles maar, dat zy konden, wegtoopen zouden, zonder dat men over hen zou durven klagen.

Bar op befloten de Rylsiraden poor eerit hume jarlyke homagie in te houden, om te zien, whar dite heenen wilde; war op den oorlog en de overkoming van de Craims feremica en Pomelicay gevolgt was, die hen fchriklkelyk berouft. hadden, dat men zien kan in Lieutenant Riddels atceftatie, onder de geheime papieren wan $A r o c$ Fiko te winden zynde.

Derhalwen nu verzoge lyy hice in des Gouverneuss ratd, on die huwelyk te ontgan, te mecr, alzoo Dain Thando dit lutwelyk zoo fterk wootzetre, en liem 'er geftidis toe annmande.

De Gouverneur zei belt te zyn, zich te veronkfohuldigen op de onnilgt der Sumbawers, om hunnen koning ann zulk een anziendyke princes uit te huwelyker, en die na har fatfoen te onderhoudens te meer, vermits 'er door de onde vouw, Dain Fabalil/, al werfcheide pretendenten onv deze Toodja afgetlagen zyn, en dat Radja Tello's zoon daar om oole hanft werzoken zou.

Om van alle de gcheimen in "t hof wan Goa, envan alle hunnen toeleg, godtu- Dain rig nete keanis te hebben, bediende ztch de Heer Beewinh al wroeg wan de vriend- Spion añ feluap, dic hy zeer bedektelyk met Dain"thof yan Mangli, broeder dezes konings wan Goa, Goa. hiche.

De koning had dezen rynen broeder als zynen vervanger woorly gegitan, en den prins Sampurenti, zyn dochters en Aroe Poni oudite zoon (aizoo by 'er nog ecr, Padang genwant, beeft, diens nitam een prins, die tot beide de rylen even mi geregtigt is, in 't Macaftiars betekent) 
Z

A

A

$170 \%$

tor zynen navolger opentlyk verkiant. Hier ower was Dah Mangali zeer misnoegr, en een man wan veel meer verftand, dan den koning Faboweddies Abdul Djalit, zynen broeder, zynde, liet derhalwen niet na den zelven Ail en onder de band alle atbreuk Ec docn, zonder an de koning ecns te lasten blyken, dat hy dit voorby gann hem cenigzins qualyk nan, watom de koning, die hem egter zeer beminde, en om zyn verltand hoog agre, niet maliet hem alle de geheimen mede te vertrouwen.

Deszelfs Dewyl nu de Heer Beemind "theimehoeda- lyk misnoegen van dich prins witt, en nigheden, egter zyn groot aanzien by den koning cn agting kende; gebruikte hy, om te ecr agter alle gehemen ftil te geraken, deze lift, wan hem in der ftilte san te houden; en hoope te geven, dat, fchoon hy doot zyn broeder voorby gegan was, by verandering van zaken, dit wel cus cen anderen keer ten zynen voordecle nemen kon.

Niemant kou qualde gedagten op hem hebben, alzoo de koning zelt", die "er meelt aan gelegen was, bem alles vermouxde, behalven dar niemant van zyn geheimen ommegang mer de Hecr Gouvernetr wilt, en, zoo "er' al yematre onder de Grooten iet af rook, was hy, zoo on zyn bonge geboorte, en de agting by zyn browder, als ook door zyn axinzienelyk luswelyk met Cran Paege, zulter des konings wan Tello, en on zyn groot verftand, vanyder con zoo gewecit; dat niemant een woord daar wan reppen dorft, alwoo dit de konings-kindisen meer, dan eens, gebleken was, dat by door de ongemeenc folu riusderheid wan zyn geeft (want in by boven alle Macafiaren uititale) zulken cicilyken drati and een zaak wilt te geven, dat zy allen, die jets teger hen wilden inbrengen, datr voor ten eerlten opdrajen, en betuigen noeften, het zoo niet begrepen, matr nu nteer liche datr in gekregen te beblben. En fchools die konings-kinderen (die "t land dar", nevens de koningen, mede ats Raten helpen bettieren\} dit dan zoo zeiden, lieten zy ondertufiehen nict na hem by hun zelwen te haten, on dar, loo vecl quald hy heri ook doen moge, zy tooit in flate waten hem dar wan te overtuigen. Dus gat' 't hem geen klein annzier, dat zyn kindskind, Mapotal, regerende konding wan Bima was.

Hy was ondertuhthen zeer gengt by Gran bonolongo, zy brodes eerften Befuit dicnant waristat, die ook altyd tragte der Ma- hem in zyn plates, als rylisbeftierden (aleaffasen zoo nienatit dara toe zoo bequatr was) in maken te docn volgen; hoewel liet te bezien yal tylis-zy, of ditzoo gelukken zal, wermis 'el befick by de Macalfaren een beluht legt, om
K

E

N.

203

geen andere ryksbeltierders, than wit het tyow ged lige wan Crato Grongrong, dic een nuder bracder pan Grasn Bontofongo gewedl is, re kiches.

Dit befluit is eigentlyk genomen, on cenige dankbarbeid anj deu vader wian de-Crain zen Crongrong, fstima genatm, te bewy- Grong s zen ; en dat wel poomamelyk, om dint veder. deze 7 stina de errlte gewcet is, die den "Tsjinis, Mohhmmedandehen Godsdicnet hien invereser heelt belpen invoeren, en een der eerfle Moh-" Tempels geflige, water in hy de roctlap- hammepen van zyn wader, Whban Mobamised da aris (die nog onder her als een Propheet en gelouve. Tolk Gods geeerd wient) gevolge heet. Ja de cerbied, die $z$ y voor dezen Tsjima hebben, gan zelf zoo werre, dat zy, een Tsjinees andforekende, ofte was hen iets zeggende, hem geen Tyma, mar Sam gofle (dat 't zolve in hatr' tal beteekent) nocnien.

Doch on weder tot Grain Mangals te keeren, deze had oulungs den Heer BecrWhit gezegt, dat Radja Goa zyn Ed. cens onder vier ongen vraggen wilde, waarom men daar zoo regen was, dat Lqpatan w, koning wan Boni, de hecrfolnpy, Belyle de voorige konjug van Boni, over de Bondgenooten acfinde, jadar de koning wan Gon zelf hem die ecre wel geven wilde, als men, de Macafitaren mant cea klein voonegtje $g a f$, en her ook niet te veelatin 't Bonitch hof verftatude. Hocwel 't Radja Goa anders al nier veel verrchillen kon, alzoo "c zeer witafchyntyk was, dat beide zyne dochners z ronen, Sumpuwali en Padong, met "er tyd beide de ryken van Gon en Boni als koningen belticuen zullen. Ondertultich ligg er den Gouverneur zeer ved angelegen, on te weten, dit Radja wa cen toeles had, on hen hier over an te fpreken.

Terwyl nu Aroe Telo, dus gevonnift zynde, nog al gerangen zat, deden zich twee zeet sirectnde zatiken op.

Het ecrlte was, dat de dochters wa vatich

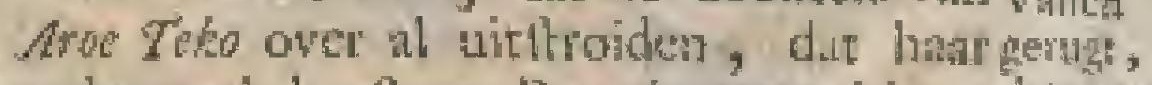
vader wel hath pa Bativia sertrekficn, dat inen manc dat hy kore datr ath mer veel meer Tek ho* cere en hifter te rug laceren zoude, om sen Aroc in een verbefener stal, dan oit te vooren, Poni reten als hood bowen alle de Bondgenoo- hiffen ten gettelc te worden; teo dat $z y$ der-wilde halven na dien ding verlingden, on bern sa boord uitgelej re doen.

Dic had nict alleen Radja Lodioe (die 'r den Her Berwink den 18 dea Matrt 1702. quitur te kennen geven) gehoors; malar' wiert, als hy by cran rontoronga in Goa, volgens zyn Ed. lat, dan ua vernim, bier in niet alleen verfterkt, maur ook verzckert, dat dit geruge door ganich Goa licp, zonder dat men daar eenuge andere redenen aff geven kon, datr dar dit 200 de gedagten van do gemecue man, en $\mathrm{C} \times 2$

dat 


\section{4 \\ M A C A S S A A R S C H E}

17os. dat die, zoo "them todeheen, car ust opgenaakt warela, om dat $z y$ inden brief harer Edelheden, jonglt angebragt, en wolgens gewoonee in de wouraal des konings openbar gelezen, 200 "f een en 'tander, vall Arod Felo das' in voorkomende, angchoort, en mogely k das' uit ict wan zyne aanltande verbefting gegift hadden.

Dit zelve geragt qum ook thos Pon ter ooren, dic dar op den $12^{\text {deis }}$ April by zyn Ed. gekonem wats, en met de tratnen in de ongen hier over k bangde, dar by rocgende, dat Aroe foko rict ulleen boven zyn hoofd ftone werheven, edy hy verfehopt ic wordens man dat by

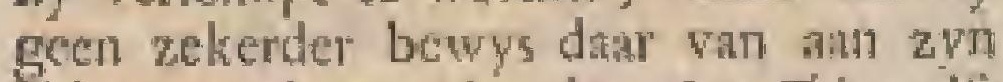
Ed. geven koin, dan dat Mro Toko zells dit tegen een wan zyme ( $A$ not Pas 's) lerygsowerten, To-Mangewolt, gezege, en hem verzekest had, dat hy in thorte met zyn wrouw en kinderen to Butwin gatn, doch als hooft der Bondgenooten, en malte nan den Gouverneur, ten eerften weerkomen, en dat by datn hetn (To-Morgewali) ook thelpen zoude; al "t welke de lening zeide wan To-Mangwali zelf weritan te hebben. Hierdoor, zei Radya Boni tegen zyn Ed. weten de Bondgenooren vice hoe $\mathrm{zy}$ "t hebben; jth ite zells wete niet wat ik 'er wan denken zal. Zommige geloowen her, en hoewel ik, my op UEd. woord vertatende, er niets af geloove, 200 wentehte ik cgret wel, dat hy at weg was, atlzoo hy, bos komende, in ftat is, om dic ganlch eiland in rep en roeten te ftellen.

Van veel meer opmerking was de tweede zatk, bicr in beitande, dat ham Edelheden den gden Januari 1702 . ann de Heer Becrniak en den Rad fcheven, vit zyn geheimbrictje wat den zolten Oetober gezien te hebben, dat de Heer Beerwink zich ontrent her by laar geordonnecte verzock van pardon vour Arae Tho, doot Mre Ponr, of wel cenige andere Grooten, te doen werzoeken, zich zeer werlegen vont, en geen doorkomen "er aan'zag', ondat, bethilven Radja Goo, niemant mees, dah Ravlia sosw, verlangde, on dien belhamel an en kant te ticbiben.

Noderlat . Des niect te min fchreven hatr Edelhe. Noderatit den coen weder, dat $2 y$ togg by die latt Esclhe volhardden, hien in beitande, dat hy, der, on zonder aanzien wa $A$ roe Tide "s groote en Aroe wermogende broeders, Arom Mampoes en flenge te Whor Cojo, mer de zatk, alzon die nu wenullem. in onze handen was, mer alle gettrengheid wootrgatan, en dio volyens de werten maar afdoen; doch dar hy onderwsfehen onder de band, en in 't geheim, buiten wetefr der Bondgenboten bezorgen moelt, dat et pardon woor hem, door Aroe pow , Dann Tobalite, of andere,

Grooten, verzogt wiert, om "t zelve daat noz. na an hein, onder gocdkeuring liatrer Edelhedes, teverkenen, valgens de ge-

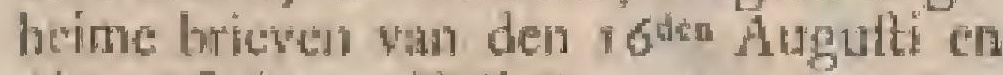
6den Oetober. Wil dan Aro Poni hee niet does, 200 mote nen atudere dars toe zoeken, om thoe Jtho en zyn vrienden aan ben te verpligten; ook zoulen har Edeltweden dan een lechip zenden, am Aroe Jeko, nevens zyn vrouw, kinderen, en 3 of 4 dienaten (zonder meer gewolg) af te halen; doch zoo hy mecer volk mede wilde voeren, dair zou liy zelfs warkuigen toe moeten athuturen; en den $12^{\text {dea }}$ Februari felireven ay nader, dat zy de Pepcrthuin ten dien cinde zouden afzenden, dar by vocgende, dat zy tret groote verwandering gezicn hadden, dat de Heer Bewninh zyn middigruft, Hune 'r bezigtigen der fterkten wan God, in derring "t Hof van dien honing genomen lyad over do cen raak wan "I uiterlte gevala" (zoo 'c hatal Heer Edelheder rodicheen ) weshatven zy latt Bestinings thits dezen gawca, dat dic noir meer zou "t hol wan mogen gelchecen, whoo de Macaffisren Goa. noil te vertfouwen, eli niet te goed zyn, on alle onze zalaken op Celcbes, door zulk cer geral, an de moorden das op konnende volgen, in de war to lyelper, alleen matr om hun graor opysir te bereiken, en dus weer volkoners meelter vin hun land ce worden, ot, met cen wooyd, on er ons weder vlak uic te bonfen.

De Heer tum Thy was ook dus echs in Gon geweet, doch zy verboden 13u wel wirdrukliclyk, dat geen Gouwemeur dac voutan meer zou hebben te doin, alzoo datr by te vecl gewage wiert; dewyl op zullke galtmialen, jigten, wiffeheryen, enz. quintzuis ter cere wan cen Gouwernewr angeregt, de grootite cri meefte vermanderyen gplegt, en de onzen dus, in 't midden van de vrengd, van die verraiders altyd vermoond warén, gelyk men mer vericheide folurikkelyke voorbeelden zou konnen bewyzen.

Even zoo wilden han Edelheden, dat de Gouverueut dit ontrent den koming van Boni, zoo veel als "t mogelylk was, myder zoude, om dar men in zulke zatken niet te voorzigtig kan zyn.

Het gerugt liep ouls, dat huar Edelloden, by dic hen fochyven and den koning lin last en de Grooten vas Gran, belalt hadden, waller om de wallen yan Goa (volgens den in- wan Goa houd wan 't Bonaylch contrast) te flegter, te degent, en tot de grond toe te lloopen, ills mede ent. dat de koning wan Gow wan de andere worlten in Goa, of onder de Maciftaren zich onthoudende, en alle hume onderhoorigen aun lunne regec meelters wederpeven zou, dat Radja Lueboe regen den Heer Gubverneur"zende al mede gehoort te hebben. 


\section{Z A A K E N. 205}

57e2. Na dit nu die koning by Crain Bortofongo geweelt was, nm na deze en gene zaraken wate nader, volgens laut wan den Heet Gouvemeur, te vernemen, quam Stoute der by den 27 then diso weer by zyn Ed. met thonings- berigt : dat alle de koningskinderen onverkinderen. dragelyk ftout tegen de Grain bontojongo gefproken hadden, en van den koning hun patr yan de gelelonkene landen warn Polongbanking nice alleen dorften eiftichen, matr ook nirt alle geweld 'cr mede door' wilden, ori weer tot hun oude hegrfchappy tekomen. Dut homofongo (dic daur mede wel na verlangde, doch wel zien kon, dat het nu nog geen tyd was ) hen dit wollagea afgeraden, en tot her gezegt had, dat de Macaffizren, wildeó zy zich nu niet ten uiterften verdagt miaken, volgens "t Bonays contract (alzoo nu alle gefchillen tuffehen de koningen wan Goa en Boni ophielden, en 'er geen weftingen of flerkten meer noodig feheenen) buiten alle tegenfprata verplige waren om hunue wallen te $17 \mathrm{cg}$ ten, te meer, alzoo hatr Edelheden ten tyde wat oorhog die ommanteling wel gunflig tocgeitian, doch date by bepalt hadden, dat dit niet langer dan de gefchillen duuren, en, by verzoening der vorften, anftonts ophouden mocft.

Eenigen tyd geleden hal de koning van Goa verlof vat zyn Ed. verzogt, en verkregen, om ma Paloe te gaan, dat zyo Ed. an hatr Edelliedton had bekent gemakt, doch has' Edelheden gaven zwn Ed. latt wel na te vorlchen, of dic reisje peen ander verborge quade reden hid, gelyk men dit ook naderhand ontdekt heeft.

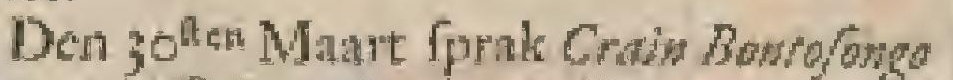
Bomo- met zyn Ed. nader over dit negten der fonge be-wallen, ingevolge var hat Edelheders looft het ordre, en hy rian ande zullen bezorgen, degen wal- dat de zelve zouten gellegt worden.

lea ie be- Den a den April quam er cen andere zorgen. perfontagie voor den dag, om weer een nieuwe figutr op Macador te flatn. Het was Cran Bunrows, nugehatene rueduwe van Cran frombike, , die met zyn vader,

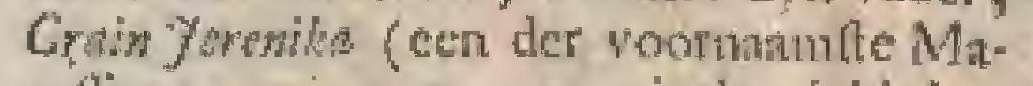
cuffatre prinszen, an uic koninklyken btoede gelproten) in 't jatr 160 r. Joor de Baliers, met ift wan de zymen, wolgens de lalt van den koning van Bali,

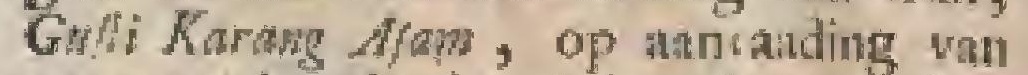
onze goede wriender (atzon hy mis Sorrapar, en ouze vyanden, tegen ous anfpitude) om hals gebrige wis.

Dit wecuwtje, een der bewilligfte, bankte, co rykdte Macallarze princefen 2ronde, had rich by Dan 7 abalite wonderlyk geage, en by her hof wan Boni zoo benine weten te maken, dat 'er, by na wan geen andere, dan va han, gerept wiert.

Ook zoge men don allerlei middelen Ijez, aath dat hat, om hatar an Dato Loke, den ouden linoning van Sumbawa, uit te loppelen, tor wellen $z y$ groote gencgenheid had, en dat al zeer verte gekomen was; doch Radja Tello, dic halar bevoorens al bemine had, zoge nu dit halfbakken huwelyk on verre te frooteln, en verkliarde whk uit aan kindja Goa, due hy haa begeerde te hebben, wanl coc dien lioning, als ty valgens zyne mage, ch na "slands wetten, handeled wilde, hatar wal dwingen lon, mans" men oorm declite her warachyndyleft, dar hy, om Crain Jcrenika's amazienelyk gellagt, dir liever op een andere wyze zou zoeken te fchikkern.

Om egter and den koning wan Tello Crain cenig genoegen te geven, antbood hy bunter Crain bontorwa ren Hove, en itclde hatr wa wat 't verzock des konings van Tello, otn met devorlen hat te trouwen, woor; doch zy werk harde tes hu dwar op, dit $z y$ den koning van Tellowelyk Banfch niet zetten mogt, en dat $z y, z 00$ perrogt. zy ten tweedenatil trouwen moeth, noir cen ander, dan Dextor Locha, nemen zoude, watr by $z y$, hoe ltraf hat de koning wan Goa ter gunfte des konings van Tello anfprak, onwerzetielyk volhardde.

Terwyl men nu aan "t Hof wan Goa Aerk voor den koning wat Tello in op- Dain Tazige van dit huwelyk werke, woclde woden Dain Tobahl niet weing ann "t Hot van biet is. Boni woor Datwe Lorka, nict allecn, on dat $z y$ hem zeer wel lyder nog ; mat on dar zy hoopte en garne zag, dat

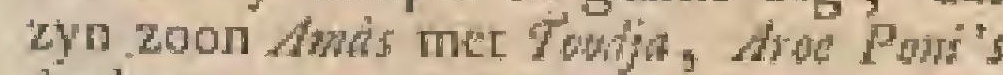
dochter, Erouwen moge, war toe zy ook meinde geen beter grond, dan dezen, te konnen leggen.

De Heer Sermink nu en dan ook over En zyn her buwelyk van deze princes met ecn kd adys
van deze vorften, en wegens zyn oorderl hicr over. 'er over, ungefproken zynde, was wir gevoclen, dac men hasr liever an Radja Tello, dan and Datoe Locka, behoorde te geten, om datr door de overzydze kothingen en Grooten te minder met "t Mas calfare Hof te vereenigen, bebalwen dut onk zulke huwelyken wotr die kleine koningen alsyd nadeclig, en maar zorgelyke middelen waren, on hen wan zoo een gevarlyk Hof (dat rects to ved anhing had ) te doen athangen; daw "tnograns exn onwrikbare regel van Stata is, dat mer de Macallaten noit grooter, intate wel kieiner, maken moet. Ool behoorde zich Daroe Lacka te fehaimen, van de weduwe wan dien gener, die zoo opentlyk en fehelmagtig zyo had beroort had, ece trotuwert.

Den $t z^{\text {eta }}$ April vervolgde Radia Bon ook, om nader met de Hetr bewwink over Aroe Teso's goederen, tha "slands wettea perbeurt verklater, te fpreken.

$$
\text { C } 3
$$




\section{M A C A S S A A R S C H E}

17on. Zyn Hoogheid meinde, dat men die goederen, die Aroc Tho in den oorlog Overflag van Tambora bekomen hiad, nan de E. yan Aroe Mantlchappy, on hase gredaine onPowi met kolten, rocwoegen moelt, en dat men

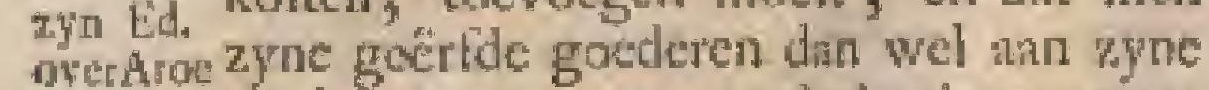
Teko"s kinderen en mangen verdeten lion; man Boederen. dat men ook die goederen, die hem varn tyd tot tyd door "thuis wan Boni middelyk gegeven waren, stan Ahe Tomeite Matowa behoorde over te geven, op dat de Bondgenooten, zoo Aroe Tek" "s gocderen woor eert nog in fequeltratie of verzekering blewen (dat de Hecer Bewwink vooreerf meinde belt te zyn niet denken mogten, dat by zekerlyk in "t korte weer in hooger ftant (gelyk 't gerugt liep, en daar Are Pow zoo fterk medce voor vreesde) hier komen zou, whar toe dat bewaren war zyn goederen (dat andens nice noodig was) grooten rehyn geleek te geven, am "t welke dan wolkomen af te finden, Aroe Poni belt keurle die ten eerften te verdeelen, war uit de Bondgenooten dan klagr zien zouder, dat men hee met hem meende, dar zy anders altyd nog man zouden cwy ffelers, gelyk hy (dic nog altyd vreesde, dat men iet tot zpn nided met Aroe Tek, en met dit bewatren van zyne goederen, voorhad) vry meer, din yemant, zoo lang by die verdeeling nice volgen zag, daar an rwyffelde.

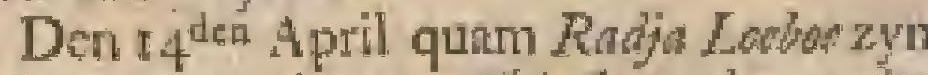
Ed. zeggen, dit Arat Fto hem den soden dito een Bonięr, To-Angko genamt (een Priefter, dien by had laren venosken, om een kapitel wit den Coraan voor hem is zync gyzelkamer te doen lezes) met een brietje gezonden, en hem daw by had doen zeggen, dat zeker man van anzicn bert (Aros Toka) in 't geheiri gercge had, dat by ycmant opmanken moet, on pardon voor hem te verzocken, war toe hy hem, Datoe Ri-Loobe, nu zeer emflig gebeden had.

Zyn Ed. llont hier ower verzet, hoe Aro Tek mogt te weten gekomen zyn, dat hart Edetheden die middel (met zoo ved omrigtigheid by harr angelegt) tot zyne behoudenis wilden gebruilien, dat nict wel anders, dan door een varn bize cerfte Bedienden, lion witgelekt zyia; ech zatk, die har Edelheden zeer zoude mishagen, alzoo die wel uitdrukkelyk belaft hadden, on dat zoo geheim, als "r mogelyk was, te doen, op dat geen der Bondgenooten hier kennis af krygen, en dutir by zien mogeen, hoe tegendtydige bevelen har Edelheden op een en den zelven tyd, ontrent dit tuk gaven, alzoo zy an de koningen, en den Gous verneur, eerlt fehreven, om dic zank met alle geftrengheid, zonder faluzien der perfoonen, en ha thewigt wan de vul- heid dezer moord te behandelen, en op ryoz een en den zelwen tyd in "t gehein weer latt gaven, om zyn pardon, by die retwe, datr atan zy zoo zeer, on hem ftreng te behandelen gefchreven hadden, to bewerken, dat gatulch niet ower een to brengen was, wat by men niet anders feloen te beoogen, din om zich door zalke bevelen buixen alle fwarigheden, too 't eens qualyk afloopen mige, to houden, en om alle de fohuld datr at op den Gourctieur (alroo hy zoo wel ele latt tot "t ecne, itls rot liet andere, hid) of op yemast anders te fchutven.

Op dit briefje had den konisg vala Loeboe an Aroe Teko doen antwoorden, dac by dit ntet vergeten, on 'er over Spreken zou; doch hy wocgde nu tegen zyn Ed. nanltonts dase by, dat, zoo /roe Telo los genakte, "er dui buiten alle tegenfprats grooten oproer op volgen zoude.

Daan op nu nam de Heer Bemm fot $z_{y}$ Ed opwolging wan de latt harer Edelheden, avefes oin parton woor hem te bewerken) het met ven met cene war, om me Radjo Lobo koning nader over zyne begenadiging te fprcken, boe on hem vangende, of hy Aroe Povi nict pardon zon durver vooritellen, om pardon voor vor hem Aroe Teko te verzockes ; witar op Rakja pererLoebor antworde: Are Poniltelt wat, dat $A$ oe Telo na zyn kroon that, $\mathrm{cr}$ is ter uiterften bewreeft, dat hy dar toe nog wel eens moge verhewet, en hy verthooten worden, en dierhalven is daur wan by lien niets te hoopen, alzoo hy niets zoo zecr wenlelite, dan dat hy maar van kane was, weshalven Rodja Lados bete oordeelde, zoo on 't gewant", dat datt in itak, te ontwylicn, ths om Radja Bon alle vieere te benemen, dat 'er nuet hom matr ten cerlten wolgens her geveld wonnis gelandele wiert.

Dant op zcide zyn Ed.; wcl, zoo Radja Goa, Ana (dia is, motiler, of eigentlyk cen minnemoeder ) Dais Finblis, of Datoesua $R i-S o p i n g$, an my eens pardon woor hear verzogten, wat dan? Deze, zeide Radja Loblwe, mogen zyn naam niet mee hooren nocmen; wint Dain T'abaWhe heeft hy al over etcelyke juaren fohendig gehoont, hitir noit by hist regten matr altyd met een vuilen fehimpmantan noemende, en de koningin van Soping werleht hem wel atu de gailg.

Datr op vinagde de Hecr bermoth of "er dan gech ander middel wris, om Aroe Teko te behouten. Ja, zei Rofo Lowe', de E. Maufchappy heefe dat is hatre band, en die kan hem, als zy nitar wil, op den throon zetten; mas dan moer ic Aroe Pord, nry, en allen, die her wel met de E. Matichappy meenen, eert kriffen, on dan ie zicn, hoc gy naderhand net hem waten zult. Weshalien 


\section{Z A A K E N}

707

27o1, hy de Heer Becrniat nogmanls rade, witde liy zeker zyn, om Aroc Teko's goederen, volgens 'E wonnis dat 'er' lig, tot genoegen wan alle de Bondgenooten, dic data op zatgen, en niet anders van zyn. ld., valgens zyn gegeven woord verwagteden, mita ten ecrften te verdelen. Wil nu, zeide lry, Aree Poni utit alle die goederen, die de E. Matatchappy en 't Hof wan Boni toekomen, an de rrouw en kinderen cen brok "er af uitkeeren, dat koin hy uit nildatigheid, en uit medoogen ourer de onnoonele kinderen, doen, volgens de gewoonte der lioningen, dic zulks wel meer pligten in 't werk te ftcllen, ar te toonen, dat ay welde fchuldigen volgens de wecten, mar geenzins die genen, die dur tegen nier gezondigt licbben, gewoon zyn te ftraffen.

Anote- Den istea April makte Radja Boni korchryt den Gouverncur belent, dit Aroe Tiko en brief uit zyne gevankenis (cen itoute en zeer

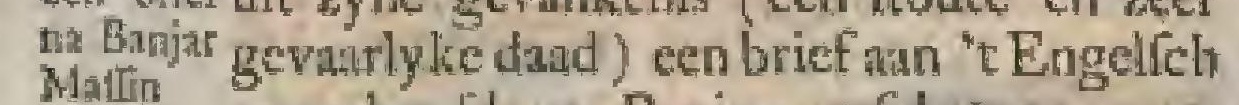
Matlin opperhoold op Banjar gefchreven, en Ingelzen. datr in gedreige liad, om, als lyy matr los quatm (diar ziet men al, of Radjo Lodoe, . en anderen, de warlocid van zy nen gevarityken aard voor (pelt hadden) añ allea, 'tzy bier, 't zV op Batavia, te doen zien, op wat wyze men met hem dagt te thandelen, en zoo men hem data Geen rege dede, en na zyo zin handelde, zou ly ten ecften op Baniar met vecl volk komen, om de Eugelichen te helpen.

$\mathrm{Z} y$ n Ed. hoorde dit met veel verwon: dering an, en tont werzet 'er over, hoe by zulken brief had weten ce rehryven, cn nog meer, hoe by die, dadr "er zoo rianuw op hotn gepaft wiert, wilt weg te krygen. Hy betaloke dezen work voor dit berigt, en zei', dat hy har Edelheden dit ten eerlten (gelyle by dede) bekent maken zoude.

Wy zouden hier wan deze zanken der Eirgelfeluen meer konnen zeggen, doch svy zullen dat voor Borneo, daur 't beter Jomen zil, over houden.

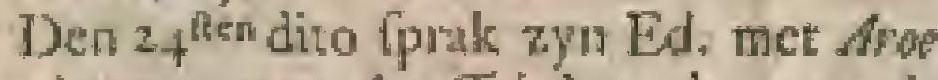
Mage des Pon weer over Aoe Telo's zank, zoo als vond-s hy wan zyn Ed. verbof yerzogt (zier cens over de wat mage hier een Gouverneur heeft, lioninger en hoe do magtigfte koning zelf nier na hit. zyn eigen land buiten zyn verlof perciekken mag) om weder na "Tsjinrtna te 'gan, en fondeende toen zyn Hoogheid midecens, hoedanig hy "c opnemen zou, Zyn Ed. alsmen hein woorhiele, of lyy wel pardon fondeert voot Ara: Teko zou willen verzocken; ntoe Po- wal op de koning van Boni antwoordde:

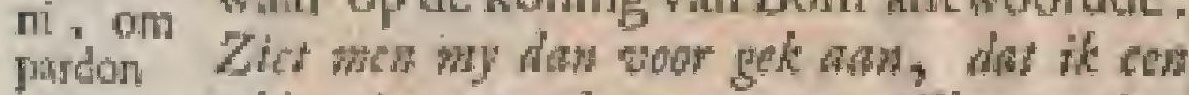
woor adder in myn boczem zork willes voden. Arne Nern dock niet, en ik zeg rowd wit, loat "Teko te dif yemon, dit matr woll, dow, maar die

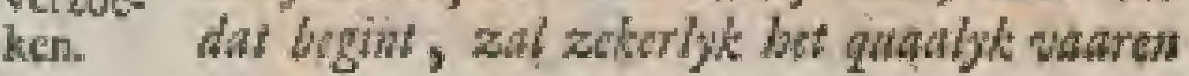

zoo wan mys wh, als wan't gebol eiland, 1702, zacken, en zyn Hoggheid, over dit voorflel ten uiteriten ontroet, verzogt dat men danr af niet meer preken mogt, en man̆, na " genieten van cen collation, $z_{4} \mathrm{y}$ a affeheid, vertrckkende met entelyle pratawen ord de Zuid.

Den $29^{\text {fes }}$ dico fprak zyn Ed. met Grist Radja Bonfyomg weder over t flegren wa de Gad nam wallen van Goa, de welke belcheid asu de brigt, dat de koning van Goi, weten- wallen te $\mathrm{de}$, op wat grond hem dic ommanteling lagteh van de E. Matfchappy toegettann was (te weten, om zyn buffels, vec, crąz. die by den oorlog cufichen de Boniers en zyn Hoogheid veel gevar liepen, dar in te belluiten, dat nu, by hunne verzoening nier meer wan nooden was) bereid was, om die af te breken ch te flegten, te meer, alzoo hy hier tegen niets inbrens. gen kon, en zeer wel wilt, dac het de pligt der E. Matifchappy was, te bezorgen, dat de een Bondgenoot over den anderen niee heerfchen mogt; dierhalven was die bereidwillighcid van Radjo Goa den Heer Gouverneur zecr angenatam; doch zyn Ed. wenlchte ool -wel te weten, wasneer zyn Hoogheid een begin. daar mede maken zou y vragende verder, of bet in de ranttande mand niot zout konnen getehieden, thoo de padt nu geplant, en alles uit de weg was, Crath Bonthosgo zei neen, vermits de padi dan baar halmen fehicen, en 'e volls dan te vecl te doen hebben zou, en dat het beter was die dan ecrift te laaten in: oegfen, war voor hy 3 mainden ftelde, otm het dan gelykerhand af te doen; hoewel hy werzoge, dut 'er dan egter weuce een ompaggering voor "t vee wrezen mogt, watar over zyn Ed. naderhand beloofde te Ipreken, als men nu de vafte tyd wan " $\mathrm{t}$ degten der' wallen mar wift, om dat an hat Lidelheden re konnen bekent maken; wast op de gryzc Grain bowtugngo tegen zyn Ed. zeide: Myn wder, mak, op my woord, wry wajten flaar dat bat jegzen dan zekctlyk zyn voorgang bobben, en dat ik daar voor zorg dragen zat; wast mede de Gouverneur zeer wel te vrede was.

Onderturtehen was zyn Ed, ook gebleken, dat de Macaftaren eenige zalaken ant haal Edelheden verzogten, war vat zy zyu Ed. geen woord guzgt, ea weet min eenig werzock gedaan hadden.

Hier over was de Heer Beeming (die door haar Edelhoden van alles berigt gekreggen had) zeer moejelyk, en dede Crain Bomtojonga begrypen, hoe qualyt de Mineifamen deden, mee iets van haa Edelheden, buiten zyne kennis, te verzocken, behalwen dat, dit latatlit verzogte een zatuk zynde, die hen de Gouverneur toeftanh kon, zulk een verzock ann has 


\section{8}

$M$ A C A S S A

เ pow "Edelheden nier anders, idan met veragting van'syn Fid, gerchieden kon, nider toonende, dat $2 y^{2}$ thar in not hun oogwir bereiken' "vermits thar Edelheden nicts atu hen, wonder vooraf des Gouverbeurs ootdeel te wicten, toeftan zollden, welken gehoonden Gourcrnem $2 y$. dan wel ftud tmaken konden, dat an har' Edelhedeh -geenzins tot hun voordeel lehrywen zoude: Gy bebr gely, ' $\mathrm{Bapa}$ (of weder) zerde Crain Bontofongo, en geWh is dar alles ater wal wed, alsol beb ik bet bu khat genct gezegt" "en gewararflowest; doch mer had isa hem niet willes luifteren, en him in tyn cigen hoofd gevolgt, wiarom hy ook werzogt, dtat

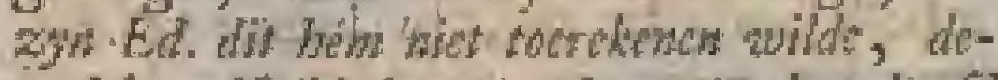

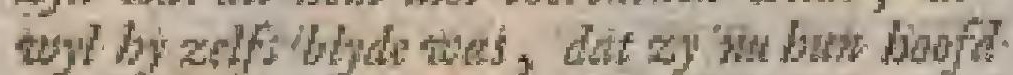
zoo leclyt gefooten bodden, endat dit geval

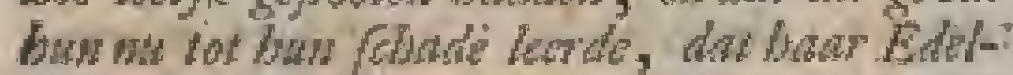

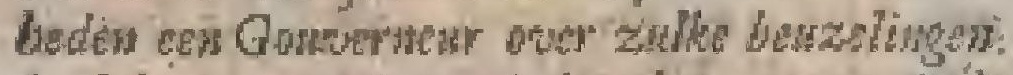
(gelyk zy mghtain woinden boter te wates) Hoit zon namer-bepaslder.

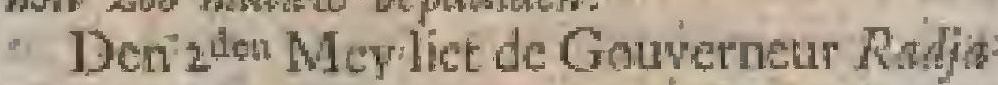
Radia Gos weten, dat Ato Icho, Radjo Loboe Goas ad- by cen brictic had Jaten vratgen, om vys owe pardon woor hem te verzoekef, en liet

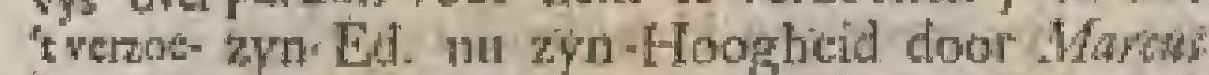
ken var Sandock fondecten, hoe hemedie voolpandon. quim, tn ytagde an zyn Hoogheis verder, of er geen midul kezen zou, om door voomatime perfoonen pardon voor hem by han Edeilieden te doen werzockeis.

Dite op had de koning tuffehen beiden am hem gertagt, of Aroe Telon nivet hath (zoo hy gehoort had) met cen Fohip na Batavia vertrekken zou. Sandect zei, dat hy dit niet wift, en het nict geloofde, alzoo hy hoorde, als of dit wel een arderen kece wou konnen nemen, zoo Radja God, of eenig ander groot Prins (wolgens zyn verzoch, an Rodja Lodio gedan) pardon voot hem belielde te yerzokkon.

Hicr op gaf de koning vall Gol tot antwoord: Ik gelarve nict, ida Radja Locboe, of enig ander kowng, at doen zal, en wog minder alalk. Wy bicr toe inlawes, alsob ik, wallo anderen met wy,

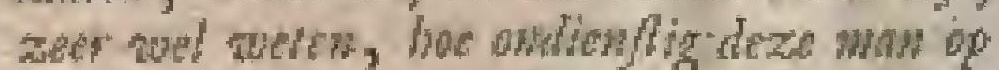
dit eilund Celdes is. Zou ik; dis.ted ower hew gerownif bel, pardon wow bens werzother? Nect doch wist ; dit agt in bed

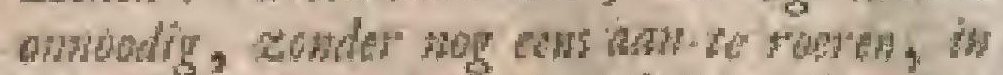
suat wor cen oproer gebes Gedebs bir.dow geraken zon, indien dezo lloute gaf matr eevs los quan. Moet wiet de E. Murt-

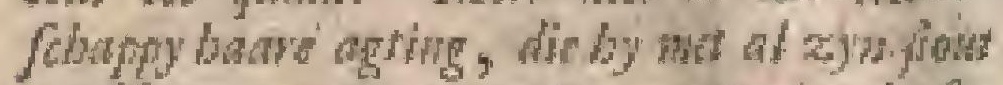

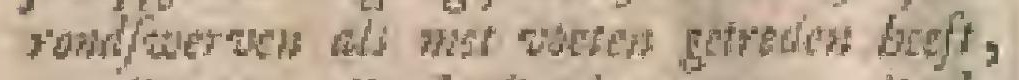
cis fite wan alle de Bunderooten, die by

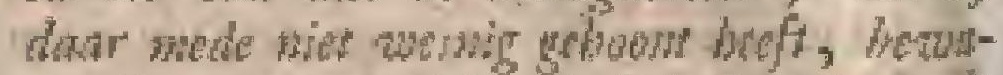

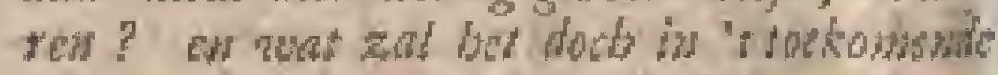

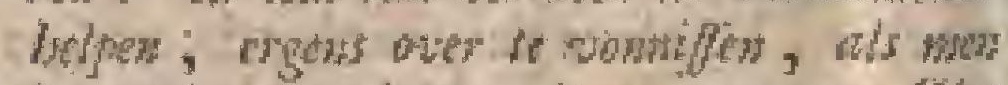

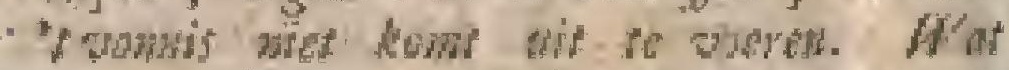
wat wen dow wh anders leren, das in

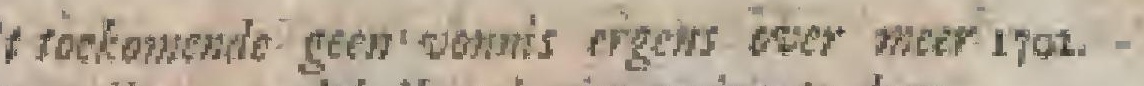
fe wellen, gelye it ook wier meine te doen,

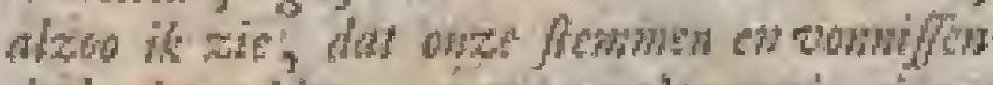

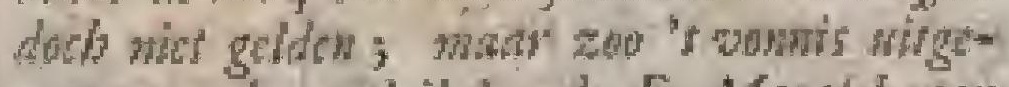

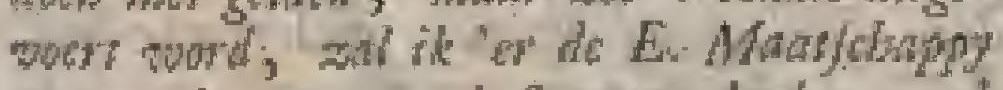
wegens "t gemene befl' woor danken; al 't welke Radja Goa met een zecr Juide ca' werheren ftem (on te toonen, dat het hem crntt was.) gezegt had.

Sandbell zede hier op, de Gouncrwewr zegt wit, dat a Hogbeid puton vos ben Derzoken zal, maw by omage alken, bo a dat verzot wan Aroe Telio as din konis wan Loeboe woorkomt. Uit bet gete ate daw ters gezest beble, zé Radja Goa,

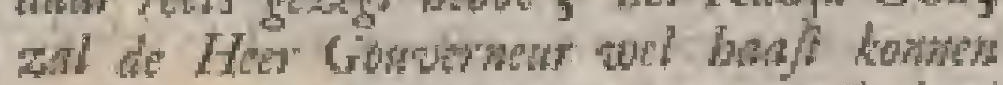
zim, boe my datoowhomt, en auat is dact of dow, ch"t was god gerwed, dat mo fen cerfen mad do weg wan Dain Mabeni

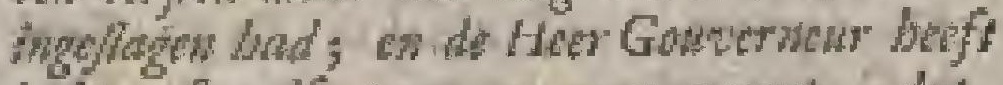
in' zoo die moord an zon tyd noorgeculles wasi, by in 24 mow fyds ma Din Mabian' s doot Aroc Teko's proces woldangen ros belbeat, te neer, om dat de miocrdenatr nog zon ylow geweel was, win de moord an de Her van Thye bekent re dwone maken.

Onder de nieuwe tydingen, die de Heer Sietc Gouverneur door Dain Whagh verno- Jjefets men had, werdiende hat zyne opmes-zoon werking, dat de zoon van den bieragten (en (chynt op na de Kaip der Goede Hope gebannen) Bima. Hobgenpriclter, Sjeich Joff den $13^{\text {den }}$ Juni dezes jears met een vhartuig op $B$ ien gekomen was, om bem de eere, die men atn den zoon wan zoo grooten Heilig fenuldig was, te bewyzon. Deze ecte zei Dain Manghi in een voetkus te be1tam, die zy allen aan bem dus moctten bewyzen, en dat de grootfe koningen op Macalfar, zoo hy dutir werfcheen, zich niet zonden konnen ontrekken. Deze was pas 20 jaren oud, en de zoon war cen Macalfirze moeder, in "t dorp Paralowe, cwen Benoorien Tello, gebooren; doch ware hy een Anat Sanate - mate (dat is cen, die wan vader en moeders wegen wan Macafiars bloed was) gewect, hy zou nog wy meer agting by de Macaflinien, din nt, alzoo hy mar ecn half-1 lag was, geluad hebben. Hy was egter hoog genogg wan geboorte, ahroo by de zoon was van de zufter des konings van Bantam, dic in 't jarar 1702. regeerde, met welke zyn vader wettig getrouwt geweeft is. Hy had ook den nam wan in den Mohhammedanichen Godsdient (dat herr vel anzion by alle Grooten gaf) zeer ervararen te ayn, zoo dat yder , die zyn - nam mar hoorde noemen, zich wolgens de Prophutiche wetien, ten opzigt wan zynen zoo zeer aungebeden vader, wer. plige agtte cen byni Gouldelyke cetbied - an hem te bewyzen. Indien de ahachoda (fehipper) Care Todjom her langs Sar- 


\section{Z A A K E N.}

47or lamparang (cen ciland, onder de Batiers ftande) buicn eenige vecze voor Crain Pomelian (welk Groin in "t Macalliars enprins beteckent) bad liaten door (tan, dist orer moer men zich niet werwonderen, alzoo 't cen hoofdzonde in de Mohliammedame Leere is, zoo yemant, groot of klein, zoo ftout wis, om, cen varitug, wat in de zoon wan zulk cen vermaarden Heiljg was, an te taften. Egter ftclde Dain Alungeli walt, dat, fchoon deze borft nog wat op Bima blyven mogt, hy egter binnen ect hàlve mand wel hice op Macaftir wezen zon.

Dit verftone zyn Ed. met ved verwondering, niet konnende geloowen, dat hau Edetheden kents van dezes jongelings wertrek hadden, weshalwen by an. nam dit hat ten eeriten te fehryen.

Deze Sjeich Joff was een Gitcran, of groot Macalitu's Eddman, en zelf ook, behalwen zyn vermatagh lapping ano " $\mathrm{k}$ koninklyk huis van Bantam, yun 't Maagfclrip des konings wan Got, that ook de reden was, watron die worlt zoo ernftig, zoo on hem, als oot om zyn wrouw en kinderen, toen by an de Katp nog als balling leefde, verzoge had; doch alwoo hy in 'i jar $170 \mathrm{I}$. overleden was, verzogten $x y$ hath Edelheden thu om zyn gebecrte, om dat op Macufar (20o zy yoorgaven) tc begrawen; doch hat Edelheden vreezende, dat zy afgodery daar mede zouden plegen, hebben belt gcondeclt 's mans gebonte dar geruft op dien uithoed vin Afica te haten blywen, op dat lyy, die har in zyn leven zoo weel ondicnit gedarn, ben na zyn dood doos ayu gebeente niet meer verontruften mogt.

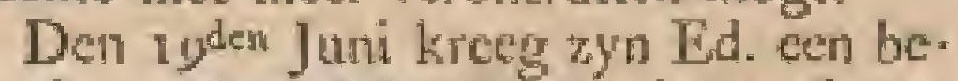

pang. der vin den viugtigen Crain Pomelion, cen konings find, endus wit den blocde var "t koninklyk huis wan Goa.

Hy was cen Hecr var zonderlinge zedigheid, seer perftandig na zyn jiaren, en die de roem had wan eenezeer goed en dapper krygsheld te zyn. Nab dat hy met zyn Ed. over werfcheide zalken zect net gefproken liad, viel 'e gefprek op den $\mathrm{Bo}-$ nizen prins Sampuraha, zoon des jegenwoordigen konings, en toctsomenden erfgenaam van de kroon wan Goa, wan den welken hy met korte woorden zeide, by is zeer dof von ped, onds/ig en onbequadm on jets th leren, en groote jhapert, en west

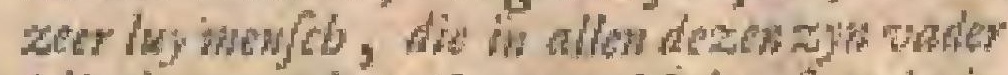
(die dạa mede nok geen kleine fncede in 't annzigt kreeg) nog zeer werre owariteft,

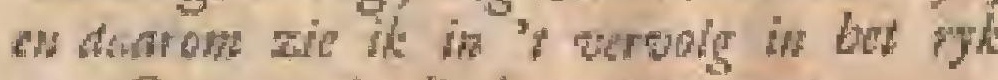
wan Gu en elendig leven te genus.

Den $24^{\text {ten }}$ dito dede de Goupernar den koning wan Boni door Careldfang weten, dat hy, na 't wegzenden van $A r o t$ Teko (dat hy zỵa Hoogheid nu verzeke- rer dede, wel harft te zullen gefchie- 1 ?es, den) bezorgen zoude, dat 'er een ordentelyke rampuffing wn zyne gocderen tou worden in "t werk geftelt.

Den $29^{\text {ftein }}$ dico deed Aroe Teko werzoc- Aroe Telien, orn den Gouwerneur eens te fpre-Aroe Teken, by welke gelegenheid hy zyn Ed. mot zym zece onstandig her ganlich geval wan zyne Ed, bedreven moord, en van de verdere zaaken, culfichen hem en Saèna voorgevallen, als ook tuflchen hem en de Hecl oun Thy, mitsgaders tufichen hem en Aro Pont, verhalilde.

Hy toonute, hoc by dit buiten voor-

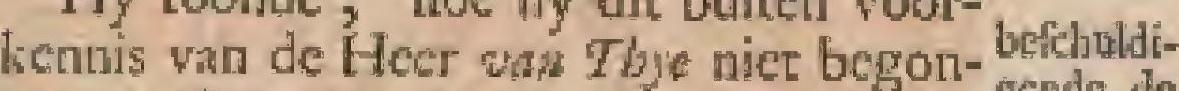
aen, en hoe Aroe Pori hem in allen deelen acede te tot deze wyze van zich ye wrecken man- Thye, geraadea, en hoe hy in "c cerfl nog dar en Aros op gezege had: Nem zon Hooberi, zoo Ponis fhilyk nid, it zal dact na myn far wol

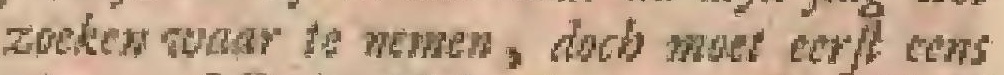
ziten, of Datin Mabani geen nider fould bekemen, on intggen zal Dis alles, zei hy tegen zyn Ed., blef nog al zoo flependit for dat wy, kowngskinderen, by Aroe P'oni werzogt zymde, Dain Mabitis wede dow guan, zonder dar 'er echig gefobl the-

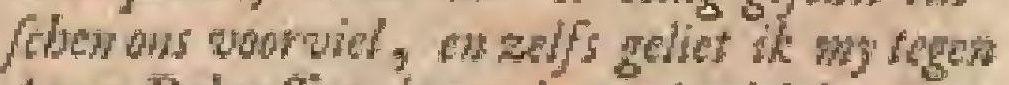
Atoc Belocfloc byzonder wriendelyk, zeo dat wy ron te zawnen wan een en bet atwe hord ates, wat it mat dede, on bon te beter fo doeken, gelgh ith bew door dion aveg zoo wer kregr, dul if in flat ratkte, ow bew de refl if geven, with nevens hy zyn Ed.doen alle de bandelingen wan die twee Gelieven zeer omttandig verhaalde. Ahe dese zakw, zeide hy, zsw wolldagen zipo .

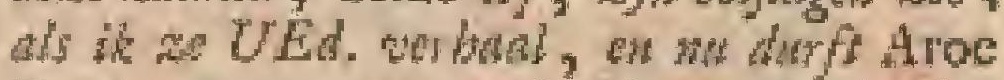
Poni, on wy watr te drukbes, alles loobsnen. De Heer Bermink wagde hem, belt gy ceng berwy birr way, dan is 'er midde on of be ben, mar zeggen zowder zoch bewys han u by den Rigzer niey brtpen, an bewy. zin loorben zal wed woer hygng, dan al ww zeegen, buben. Ith even, zeide hy, dat ULd dar in groot gelle beeft; dod egter is 't de zuivere warabed, die ther wer UEd. belde, of durft by dit alles loobenen, daar by nat naderiand ook die

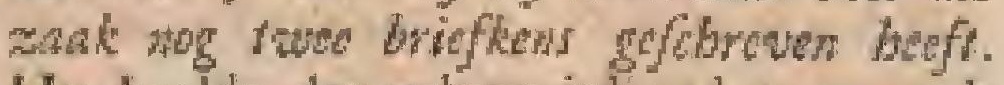
Hy halde der zelver inthoud toen ook wan , doch $z y$ behelsdem geen zaken, wata by men iets tot zyn naddeel bewyzen kon. It bod deze, en wel andere dinges, zei hy, wel ac kowen zegen; dob it beb allo zoo al wit ageng wor wys kowng oggekropt, en me zre ik, dat it elendig, $m$ zonder eeng bewis, bier zit en lyt. Datr op zeide ly verder, dewyl ber doch wict

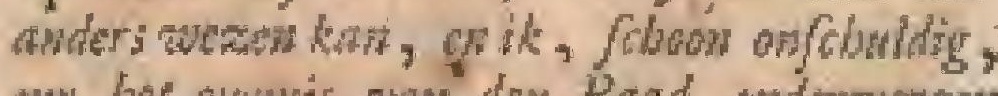
wy bor consts way den Raad ondorwerpen woer, daar the wiers tegen beb, febow it perven medf, zoo everzod it dan endelyk 7 yn qeimont allew usn UEd, om Saëna by myzoek on te hotben, en dow zal ik gen ferantighud Sacha,

II I. DEEL. 


\section{0}

Ijot.

moaken, on adnhonts do dood wer bynotdig te byder.

Zyn Ed., der antd der Macalfiaren rects zeer wel hobbende loren liennen. Fragde hem dam op, en mat toe zon dit dacb dienen, of wat zoud gy bart doen, wh

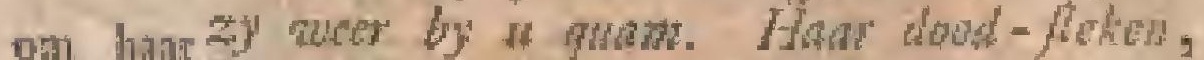
te doe- Hew Gowwerveur, zeide hy, reat zon it den. bavr anders dery? worm dat beefo an werdicw. Zoud gy zedker, zei zyn Eid, ja wyon Her, zech hy, zy woel Dain Malsani wolgen, dow is gor hidden ter word twa",

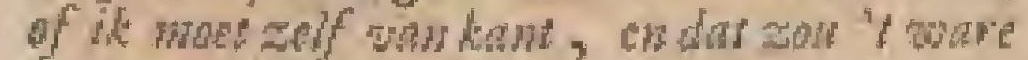
regt zyn. $W_{i}$, mest $y$ dam, zeide zyu Ed, dh" "er, over " perfou gevomifl zy" de, gech regt gefched is, dagr zid de fag-

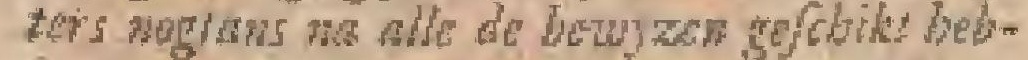
ben, bo ole mis anders, dewy Aloe poni alle bocbend, lonten zuzen; mocfen zy

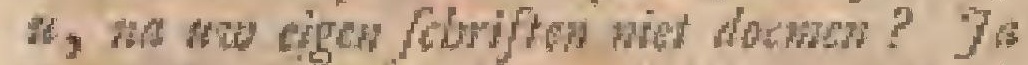
myw Her, weide by, dob sper bde ik onf buldis.

Dit alles zeide hy zyn Lid tow in 't by wezer van de Heeren Ghasson, Hackan', cth Ifä́ demanders.

Vermits men nu al vry opentlyk vin Aroe telo's vertek begon te fpreken,

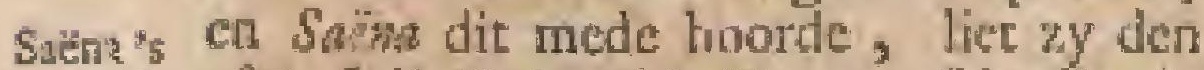

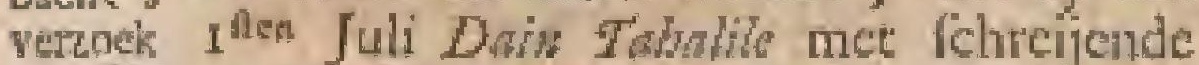
nan Duin oogen verzocken re bewerken, dat doch, Tahalite als hat man ta Baciwin veutrol, loate dochter, die $z y$ by hem had, niet mede derwatus gan moge, watr over Dain Tabalile hatr belooft had den Heer Gotsverneur.te zullen fpreken. Zy ging by zyo Ed. in de thuin der E. Marifelsappy, dhar hy die vorltin op hate belcwratging had doen verzocken, en hoorde doen, hoc atroe Teko's wouw, en hatr noeder, net weing by har waren homen klagen; doch zyo Ed. zci, dat dit alles au ontydig, en dat hier nict meer in te doen was ; doch hy vrangde hatr, of 't niet beter was, dat $z y$ (Tahalle) zelf pardon voor hem was komen verzocken, nagezien Aroe Trko, en alle zyne vrienden, hier door grootelyks atn har verpligt zouden zyn. Zy gat datr op zeer fcherp tot antwoord, zon ik, Hecr Gouverneur, woor zalle en wan forken, die gees drep deredzadm bloed in zgh ly beet , en die zich nergens mode bemosit, als met de fouthie Waiten/fnorighedon te budrow, en met mant alles, wat bos voor de mow' kom, "cr wat

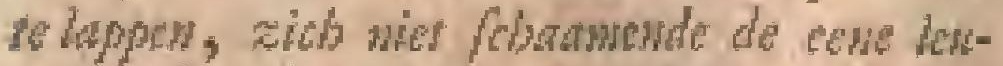
gen op de andore re Raplen? Necr docb nit, da zy vore, dat ik myn gonden wasto dat wede belladden zon, wet te forchen woor ech man, die zidh niet febanen zou my, ch UEd, gelegenbid te enen wan ben dan by

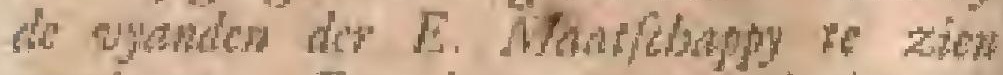
owtwhopon. En wic zou mos, als dat zoo cens thivid, daar anders, das my, de fobth

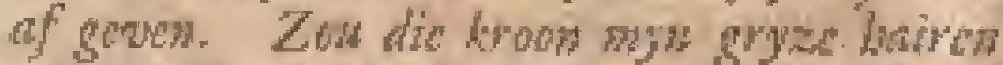

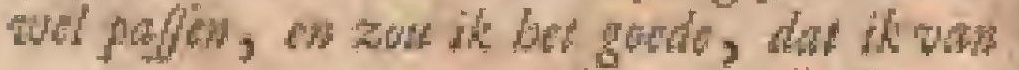

\section{A A R S C H E}

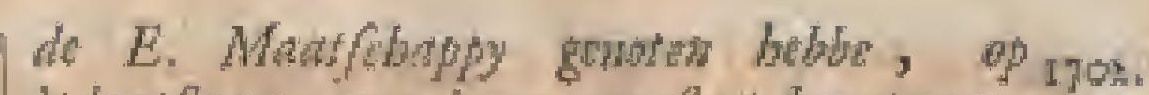

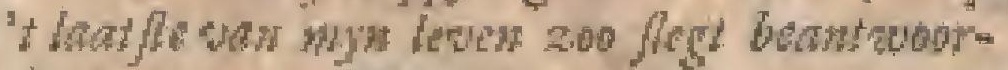
den? O neas, Heer Gouperneur, geem en wen/cb ran trephond zal my da" konnen

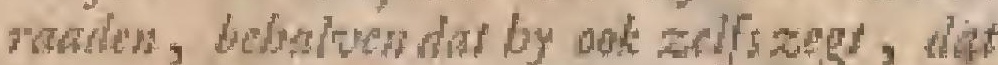

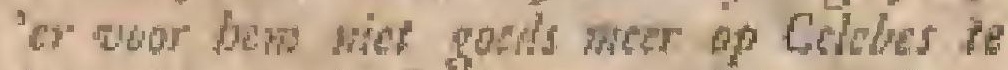

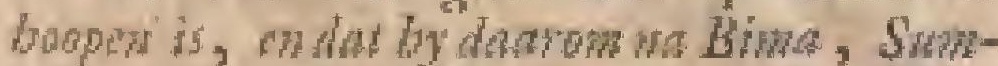
basea, Jawa, of Bayjar mot. Ook beft by zicb nits unzicn wy ca Aroc Poni febendig to budregen: ruant mat by belopt bul zyn doclter adm Aroc Poni fe geven, en die zeff in Tsinwana te brangen, is by in tegendel toen ma Gos gewht, laarowale ons allen zer leclyk zimen kyken; ja zilf owlzag by zich doch ook siet, om zecr whagely, zoo waw Radja, als wan de Hol-

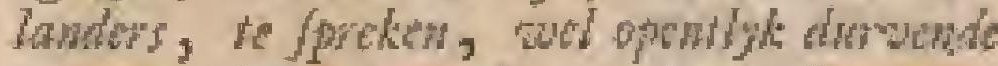
zeggen, dat mon mat ban, els men hen matr goid te ceten geefi, docnkan, wat wen ail. Sprat dar, Heer Gourerneur, wilt gy voorzintig zyn, nois wer sidn, wath ontbotal wel, dat by nit wargten $\mathrm{z} h$, dat by in 'a kepel geongen gernen beft. Op th 'e welke zyn $\mathrm{Ed}$. eindelyk dic vorftin zeide, dat zy dit war als cem pratrit, ton verder nict, opwemes moefl, angeribs by

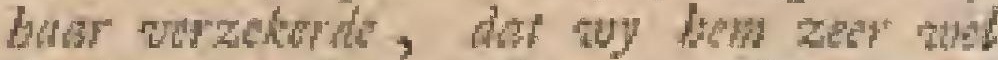

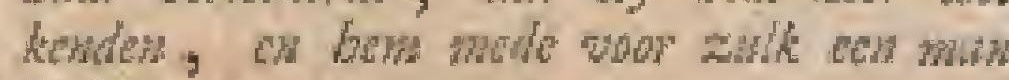
bidlen.

Onderuftehen was men, zitende niets Diem: voor hem uit te werken, wa befluic ju ven bezoo verre vertudere, dac "er reets goed-flow zyn gevonden was, zyne goederen te ram- Ed mu patfen en te verdeelen, watr ontrent de te ramkoning van Boni an zy onderylspe-pollen. Aticrder, Afoe Fojmoctudi, reets laft gegeven had, on 'er mede woort te gatan; doch de Heen Betrinh gif den zelven, in 'c bywezen yan de Heeren Chas:omen den Subiadatar em der $M J l$ latt, dat hy, Tia Aroc Telo"s vertrck, dat binnen drie dagen flont te wolgen, mer beztadigdheid ontrent dieverdeciing handelen, en doch wol berorgen wilde, dat de yrouw en kinderen wice alleen woor allen overlatt bewryd wickder, matar dat by har, als uxit een foon wan agteloosheid, ook die thingen zou taten behousien, die wel is waardigfte waren, al was her den ganfchen imbocl, ats "t mat cenigzins door den beugel kon.

Ontenc decen tyd antwoondde zya Ed. Fin geef hat Edelhedes cok op hate brieven van berige wan der $\sigma^{\text {deu }}$ Oetober i7on, Gdem Junuart en alles ata i $7^{\text {den }}$ Februati over drie zakicn wan be-harkdellang, yoor cerlt over Aroe Tello, ton ain heden. deren over' 't nettelen der Engelzen op Banjar Maflin, en tenderden oper 'e wesbod aan den Gouwerneur, wan niet meer in Goa 's vefting, nog op mialtyden, jagten, viffcheryen, enz, door deze of gene koningen aangeregt, te ganti, on danr doon in geen gevar te raiken.

Over Aro Teko celtreef hy, dac hy hem zeer gemakkclyk in gyzeling gekregen 


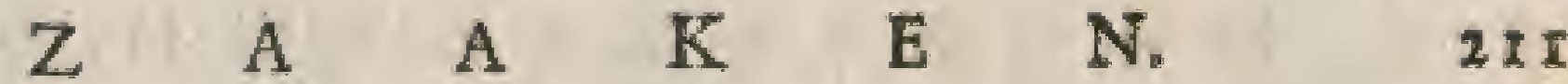

17or,

hebbende, vin hem ondertulfeheri ook ontrent i oọ R Russ aan goud, en cen netie inventaris wan zyn godderen bekomen had, gelyk hy verder zeide, dat hy den rolen Noveribet 17or. (en dierhalwen zoo lang voor "t ontfangen van harer Edelheden brief, hoewel die, al was hy tydig gekomen, de zak geenzins werandert zou hebben) door den Riad der Bontgenooten gevonnilt was, om geram= patt te worden, en dat het volflagen onw mogelyk, en ook ongertaden wiss, om door yemant der Grooten (volgens hat Edelheden fehrywen wanden $16^{\text {ten }}$ Augulti en Gden Oetober ) pardon woor hem te doen werzocken, alzoo zy alle er flipt op ftonden, om "t wonnis, over bem gevelt, te doen itantgrypen, of dat zy " $\mathrm{t}$ anders als cen zata, waar mede men de fpot dreef, zouden anzien, weshalyen by belloten had dit met de komft wan "t fehip de Peperthuin te doen uitwocren, zullende een derde van zyne goederen voor de E. Matichappy, als hat regt, trekken. Tulfchen bejufen wees hy har Edelheden ook klaar aan, dat de Inlander door geen bewyzen wan goederticrenheid te wimnen, en dat dit in tegendeel een middel was, on al hatar agting by de zelve te verliezen, alzoo $\mathrm{ZY}$ niet zagt, mar ftreng, moeten geregeert worden. Ook had zyn Ed. an Aroe Pon wertoont, hoe werre een $y$ ders regt kon getrokken, en in wat gevallen 'er al wolgens "t Bontyrch Contwat gehandele moeft worden, zoo men der Bondgenooten regt bewaaren zoude, 't geen zyn Ed. meinde voor die tyd al pry veel gezegt tc.zyn, eu dat men het nu datr by mar behoorde te latiten, om Aroe Pon' "s gemoed, dat nu rects genoeg an 't opwellen was, niet meer gaande Oordeel te maken. Egter oordeelde zyn Ed. van zyn beft, om by oogluiking nu zan Aroe Poni dc ahan. de magt ower de mindere Bondgenooten kelykheid toe te itant, vermits zy doch nu al in die de Bond- pewoonte waren, en dit zoo niet te begenooten. Petren was.

Hy warichoude harr Edelheden van Rasd haar dezen gatt, die nu liaglt na Batavia flont den Aroe te gaan, wel gade te flaar, alzoo men Teko zulke gevreesde vorften nier gevangen nist loste neemt, on ze weer los te laaten, ten laten, ware hitar Edelheden met 200 o lchelmen, in zyn kampon zynde, en ten eeriten door nog grooter getal ftannde gevolgt te worder., op Bitiwia, daar zy zich wel fpoedig zouden down kennen, gedient waren, dat egter niet te geloowen was, alzoo die in that waren, om dic fade in vutur en vlam te zetten. Voor alle welle Menoe- trouwe warlchouwingen zyn Ed. dar rer Edel na tot zyn loon had, dae hair Edelheden heden hem te laft lyden, dat zy hem wel belaft over $25 n$ hadden, on te beletten, dat de Bondficl. genooten doch zoo niet van Aroe Pom mogten athangen, maat dat hy dar mede 17 ch. nog zoo hatitig nice moeft doorgegaan hebben

Over de tweede zak, de Engelzen op Bunjar betreffende, gat zyn Ed. by een geheim berigt haur Edelheden kennis wan alles, wat dien angande nader ingekomen was.

En wat het desde, of des Gouverneurs verblyf in de wefting des konings van Goa, betrof, daar op zedde hy, dat hy de ordre halarer Edelheden ftipt nakomen zous toonende nogtans dat hy weel minder in dezen, dan wel de Heer Hart/chk, gedaan had. Hier benevens zont by ook de advyzen van yder Lid van den Polityken Raad fchriftelyk wegens Ano Tolo ann har Edelheden over, die alle daar op uit: quamen, dat het niet geraaden was pardon yoor hem te verzoeken. Ook had zyn Ed, alle de byzondere fclariftelyle gevoelens der Bondgenooten bier by gevocgt. Eindelyk fohrect zyn Ed, dat zy nu Aro Teko niet met de Peperthuin, om dat dic nog nice verlcheenen was, 'mast mer het fchecpje de Matroos na Batavia zonden, om tgeduld der vorlten, die na zyn wertrek reikhalsden, niet langer te tergen.

Hy had ook, op den voomocmden tyd, "s nacht Aroe Tcko in cen befloten drang- Anoc ltoel, omde minite opichudding te heb-Telo na ben, met een ordonnantie, in Rnade Batavia goedgekeurt, en and fchipper Jas Boers genonovergegewen, ma boord doen dragen, met den. latt on hem in de kajuit te huisvelten, en wel op hem te padfen, ten cinde by hem niet ontvlugten mogt; hoewel zyn Ed. hem wooral stubbevolen hadde and den fergeant Dirk wan Niewwer/hys, on bem wel te bewarel1, ten dien cinde hem nog cen korporanl, en 12 brane keerels, die twee en twee altyd voor de kajuit waaken zouden, medegewende.

Daur beneven zont zyn Ed. zyn kris an hatr Edelheden, met die hoope, dac hy die noit weer dragen zoude.

Ook wiert den lergenur, en de verdere, belait, on de ordre van den Ratd, by woorwal van fchipbreuk, of andere fware ongelegenheden, die hen beletren mogten dezen gevangen an har Edellieden over te geven, volgens cen verzegelt bricfe, hem mede gegeven, en dat alleen dan, en anders niet, geopent mogt worden, uit te voeven, wall brictie hy (lergeant) anders zoo werzegelt ann haar Edelheden overieveren moelt.

Dit brictje hield in om hem, in zulken voorwal anniltonts met ecn degen te doorftooter, of op een andere wyze rer dood te brengen, om hem de gelegenheid van te ontvlugren te benemen, en darr door alle vendere mórite, die dar uit ryzen kon, woor te komen.

$\mathrm{D} d \mathrm{~d}$

Ec: 
212

$\mathrm{M} A \mathrm{C}$ A S S A

1702.

Eer ly nog na Batctwat wertrok, zei lyy, op zyn tamden bytende, tegen den lieuZyn tenant Ridld, fat by fin centigbed, $n$

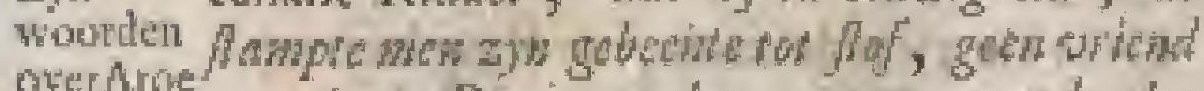

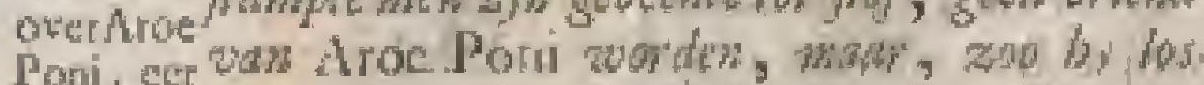

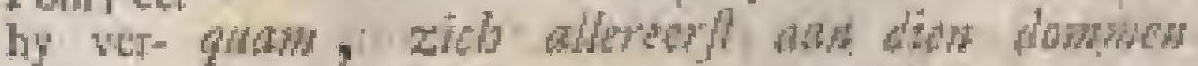

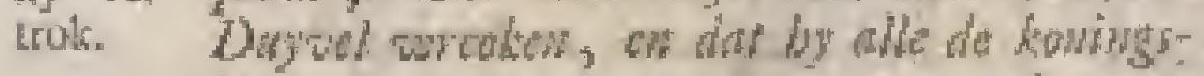
kinderen, die das me rengten, dan sen

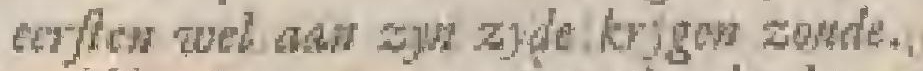

"Verdere Nied lang nat ayserrek wietden zyme ontrent goedevenverdeclt, en den $7^{\text {then }}$ Septenber

Hent

vootge.

vilutert

Dood

yan zyn

Gemalīn. is zyn vrouw, Sakn, overleden; doch, na zyn komft of Butnvia, vonden hiaj" Edelheden, dic hea cerit ba de kwap dagren gezonden te licbben, volgens hun chrveh van den $15^{\text {der }}$ \$:ptember 1702. goed hem ma Ceylon te felukken, daar hy nier veel kromane fprongen maken kon.

\section{Ly/2 der Goderonvan den Boni- son Prins Aroe Teko.}

Iu con Bortans Kifle.

I Stormmuts, met cenig goud overtroktked.

Zyn gotdxtern.

1 Knop tot een Kitalol met goud owerblazen:

27 Goutle Armringen, gefortecrite, $\mathrm{cr}$ diar onder 2 grooic gedrovene, meet allen met hilpuis gevult.

27 Zoo halve Arm- en Beenringen, ats. itukjens der zelve.

7 Slegre goude Vingerringen.

7 Stukjens goude en zilvere banden.

14 Goude z Krabben, of Ootcierader, 3 Zilvere 3 met lnoverkens.

Ettelyke ttukken gellagen en gedreven goud, [wath 2 pond 5 thinl, tot 8 Riders yder.

Een party allerlei flag van gevalt gond, twat 13 thail.

Iuen party allerlei zilver werk, war 6 thail.

Her onderlte wan een Machaftarze Gondel wan gefligen en, gevlogen goud.

2. Phate gellagene goude Keters tot Badjos.

2. Bondels Boclo Boelo's (of vierkante platgellagene platejens) toteen klecdje.

I Stuk van een gerlogte goude band, tot ben Buikgorde].

3 Krifencheden met goud owertrokken.

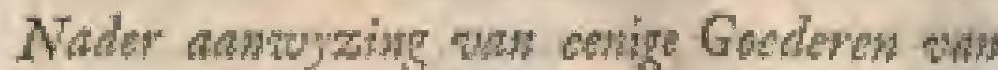
descm Prins op Oedjurg 7ahab, wolgens

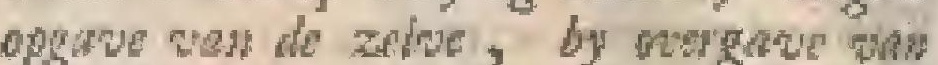

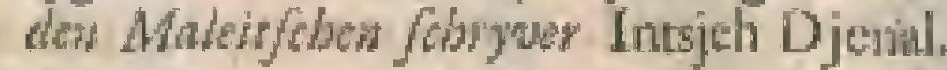

404 Zoo wrye mentchen, als krygsgevangenen, als tataren on flawinen, fertuande in volgende perloonen:

106 Stuts t1-taven en havinner, alle by natur opgegeven, en verder nog

\section{A R S C H E}

eerige andere Dathen door hem als i 7̧o krygsigevangenen bekomen, cn door de Hecs asu The hen Logerewen.

it Tumboereezen, onder Aris Pankien.

37 Dornponecter.

4o Viye, die geld op hune lyven genomen hebben.

170 Vlye, of weilker felutulden by (Aroe 7cko) betalt heeft, alle de welle uitmakien de cerflugemelde 40,4 koppen.

$5+$ Sruks gemalite rolijens of lorte knliters; diergelyken loort, wolgens "b lunds wyze, als wan welke men I Sam: I: p. lectt.

6 Regte gemalide rokjens van yoer.

42 Snaplananen.

2 Japaniche rocrs,

6 Muskcten.

20 Balden, groor en kleen.

I Mlentitulicic.

I Lage fraphian.

so Spaten met hare gifpylkein, en: kolkers.

40 Hafuganen.

2 Goude Stormhoedent

3 - - krillen.

2 - - Buikfinyders,

30 Thail gotd.

5 - - gefmolte gond.

27 Draadwerlize goude knoopen to: ecr Batjoc.

Si Stuks platte goude knoopeu.

I Plate gande keten : Befúc door koop hen tot eco. Badjoe. toekomende, hoewel.

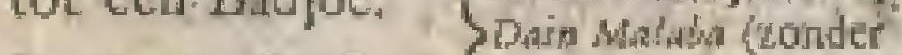
I - - - - - bew Ms dic uge mazi tot een Kleedje, Jeries is hebben.

- Sted dito Boclo Boclo rot een Tulband.

1 Platte zilwere kéten.

46 Zilvere knoppen tot 2 Badjos. Ios Sparme Rylisdalders.

I25 Musketter, of Stuphaturen, en Japurtche roers, wile eenigzins onbeGนดมบ?

2. Kopere-Donderbufien.

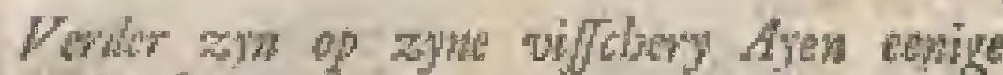
Pofousen, rag wre, als /awen, bepaonde in

I fo Wrye mans, wrouwen, en kinderen, en in 79 flaven, en flutinuen, te zitusen 229 koppen.

5o Bulfels.

20 Parden.

Op. Maros awark nos,

38 Shawei of flavingen.

io Vrye lieden, mans, rotuwen, en kinderen.

20. Buffels.

Io Koppen.

$$
\text { Op Padaris Padag nog, }
$$

30 Buffels. 


\section{Z A A A K E N. H}

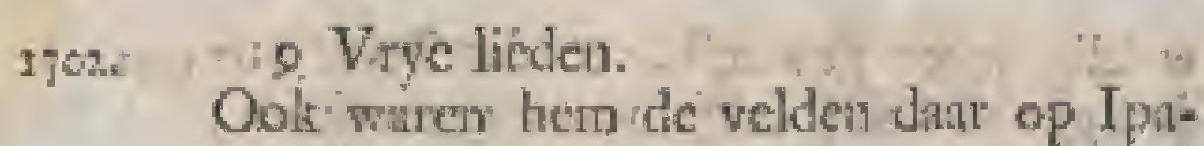

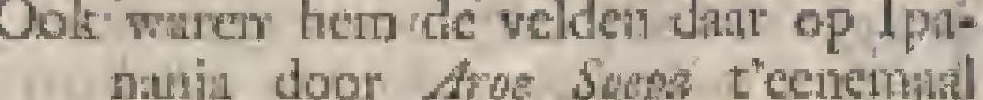
gegeven.

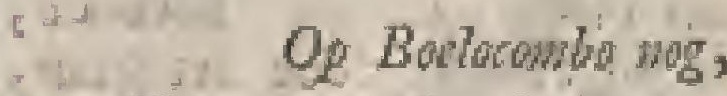

-10 Slataven en Danyinnen.

\section{if.uty : OP Caloronking,}

80 Mans en vrouwen, hetr door den ckoniog wan Bour als cen forb prowg getchonken; doch de Negy Tcho (uit-welke $z y$ waren) heeft do koning werr na zicls genomen; lattende de volkeren onder ben (Ais Taho blywen.

\section{Koppen.}

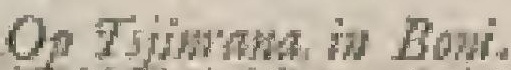

Op Labo, getgon ontut Boncyn; 26. Paidden.

Oolk had de koning van Boni hem gerchonken de Padivelden ontrent "T'ं. no, zynde die relder Poncondo genamint.

$$
\text { Op Magdray, , }
$$

45 Stuks mantaen, wit eemige Bonters en Mangariyers lom door de oude koningen wan Boni gefehonken, en dic nu en din na Mangaray geloopen, - en dar vooitgeteélt zym.

6 Gontings, of inlandze.groote vartoigen.

4. Groote Prahoe, Binawa?

$x=----$ Pagcy $\}$ gsename

$$
\text { (n) }
$$

Al-1 welke by den anderet geriokken zynde, in oprigt van de mentehen 490 vrye lieden, en 337 fiawen uirmisat.

Teweren, mive Anaven

Aanzyn bus + $210 . \quad 106$

Tamboreczen Fon on

Domponeczen then 37

$\begin{array}{lll}\mathrm{Op} \text { Mpen } & 150 & 79\end{array}$

Maros ro 18

4. Padang Padang 9 ro.

Boclocombar

Caloconkong 80 utit Teko.

Tsjintuana

Mangany

$\frac{40}{490}+\frac{10}{337}$

In "t becin van Stptember wiss Radfa

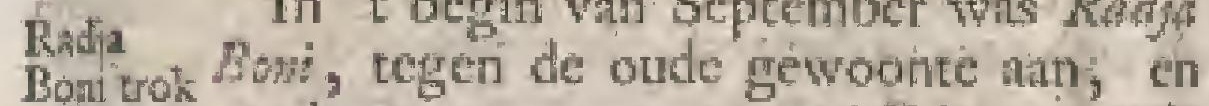
tefer de zonder voorweren var zyri Ed, met de Tou: bveen geroepene Bondgenooten (dat wel djers, bui- wiet wezen tmogt, miar dat niemast der ten weten zelve nalaten dorlt, nlzoo zy zyne ladFd, op, Atgheid kenden, tegen de Bonizc Toradjers opgertokiken. Hier mede had hy "tfafoch der E Mantfolapy zeer gehoont, en wol werdient over deze zyne loshoofdigheid, zoo het andere träen 1701. geweelt waicn, eens eroftig berifat if worden; doch men moeit dit yir latit= lisnde na maar door de vingeren zien, on dat op zyn tyd, en eens tuflichen wier oggen te docn, by hoedanigen gelegenfied (dat nog al bett in licm is) hy zich nog al wry wel leiden lait.

De Bondgenooren wetent, dat hy die mage niet uin zich zelven heef, on hen te zamen te rocpen, alzoo bet as den ecrlten Bondgenoot fiatr, om 'er Litt Ioc te geven, cu wast op hy dan gewoon is die by een re roepen. Mark komen zy op zyn opontbod nice, zoo wreezen zy ongemak te zutlen lyden, eer wy hen konnen dekken (dat wel vedryds war is) en liomen zy zyn bewcl na, zoo toonen zy (ditt ook niet wezen ming wolgeris 'Bonayfoh, Contract) dac zy gehed en al van hem athangen.

Hy is wel zces loshoofdig; max niet quadardig; doch zonder beteid is by Nader gewoon 200 that toe te haken. Ool tanmeto had hy, yolgens "tzeggen yan Crain Bi- king over

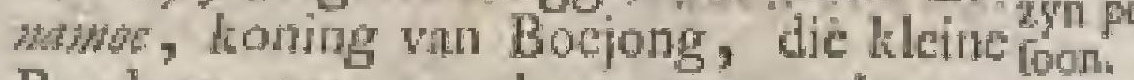
Bondgenooten nu alzoo verie gebrage, dit $h y$ 'er mede omfprong, zoo hy wilde, zondanig dac 'er geen een der zelwe "E hart had, om buten zyn woorwecen in "t kalteel te grau; en geen een yan ben had her har, on tegen hem an te ftenmen: Want vermits $7 y$, zoo werre om Jiag zittende, onmogelyk cenig voorltel Yan de Heer Gouveneur hooren konden; en de tolken hen wad "t woortel pat ech zank nier.meer zeiden, dan Radya has babben wilde dat zy zoteden weters, waren zy niet in ltate; om die vryheid in 't ltenomer, en die onathankely letred yan eenige Hoven, die de E. Marelchappy hen werzorge had, zoo als 't wel behoordo te konuen gebruiken; by welk geval die kowing antu Marcas Sisdled ook verhatde, hae Rafia Bon zich niet ontzien hadde verfcheide onderzaaten rah hem Fan goed en leven te berowen, zonder dat days een han ma lefthide, of dat datr ycmint wan reppen dort. Wharm, zei

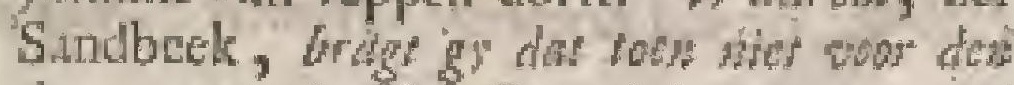
dag, top de Her Becmink mat zoo wet crist $n$ allen dismmanden on wan whment, alros gyleden vollhgen viry award, af ie

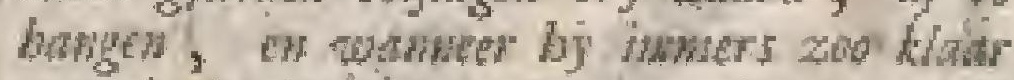

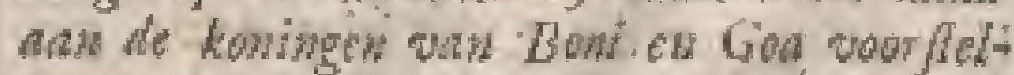
$d e$, on wich doch noit renigr magt owes de bondgenooten, en bunne wheddroeders, fo Ratcr adnlowen.

Itwil, zei hy, wel gelowed, dat fle $E$. Compagnie on hilpen, warb gelore ool te gebl, dat dit vel to that lomen, en dat, Als ay on ean luglo waren, men trgen Radja Boni allew zegen zou, dat by dat wit weer don moef, dat wis inners wa onze

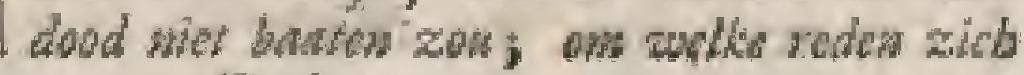
D d 3 
17o2. geen voorzigig man dar an wagen, cn hever wuat lydes wil.

Wy hebben bevootens gezien, dat hatar Edelheden au den koning wan Gou belatt hadden de wallen van Goil te flegten, en dit Crain Boutofongo na 2 of 3 matanden aangenomen lad dar woor te zorgen. Matr behalwen dae de koning wan het toegezegde dat ontrent (als ben zaak, die al hate agting by de werels werminderen zou) al berouw had, zoo manken de koningskinderen dat over in "t ecrit zoo weel beweging tegen Grain Bowh/ongo, dat er met hen tot geen befluir te komen was, te meer, dewyl hy ook den koning tor geen zeker beltuic brengen kon; doch eindelyk liet de koning en Crain Bontoforgo (na die de Heer Bermink zya Hoogheid de latt van has Edelheden den $2^{\text {dda }}$ September weer had laten verindagtigen) nate zyn Ed. weten, dat den $21^{\text {then }}$ Oetober valtgeitcle was, om Dewallen dan met het flegten -der wallen te beginFath Goa nen, gelyk het toen ook zyn begin gegeflegt, nen, gelyk hoewel 't Hof wan Goa dar ge- weldig tegen geweeft, en dat liever an-17sa ders gehad had; doch nadat zy merliten, dat de Gouverneur, volgens latt harer Edelheder, datr onverzerclyk op ftont, zich an hun misnoegen niet kreunde, en alles maa" ongemerkt door liet gan, moeften zy "et cindelyk toe fromen, gelyk zy or nu al aan bezig waren; doch loet zou na allen lchyn mar alleen de fteene borltwecring, en nict de geheele wallen gelden, om de puin na binnen té werpen, en om "er dan weer een Pagger om te treklen, dat zyr Ed. beft oordeclde mat door te latien lichieten, alzoo die wallen niet zoo zeer ons, dan wel de Boniers, in "toog geloopen lodden.

Eti dit zyn wel de voornamitte zarken, die geduurende de regeering yan den Heer Berrwiw hier voorgevallen zyn, hoedanig awn Ed. tot den if den December 1703 . 'i befticr hier wargenomen; en tocn zyn ontflag op zyn verzock van Batavia bekomen lieef, cn ook deriwats vertrokken is.

\section{ZEVENDE HOOFDSTUK.}

T $N$ ' jaar 1703. de Heer de Roo in de Her Beerninks plats. Zyn wertrel in 't jaar 17o5.

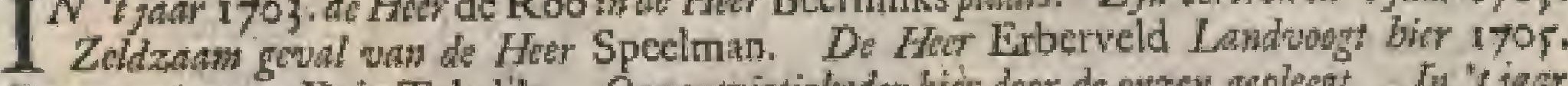

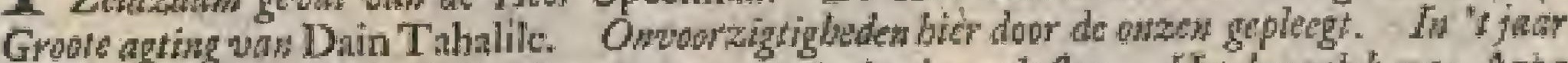

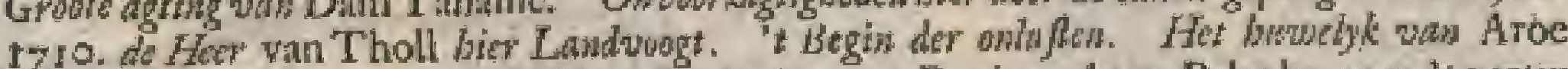

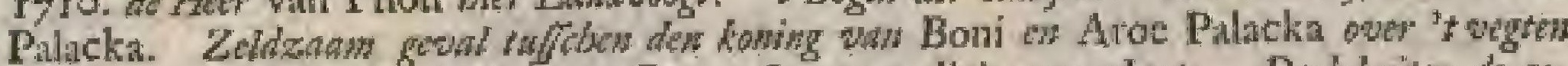
wan banen. Dood dos konimg wan Gon. Sampowali in aym plants. Dech buten de ge-

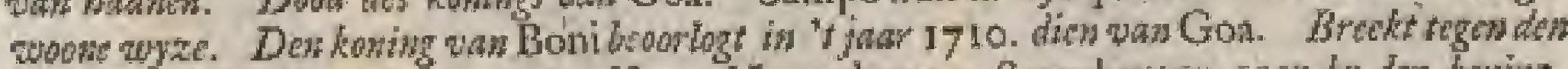
rawd was al zy wienden op. Do Heeren Hartenberg en Steenbergen gaw by den kowing.

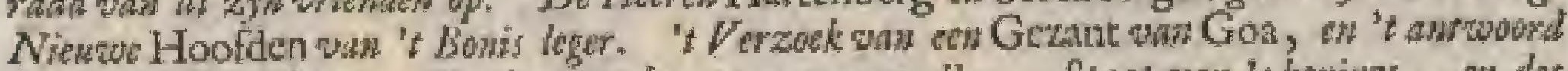
des donitigs wan Boni. Verdere zadaken toen woorgewalkn. Stan wan 's kowiggs, en des princm wonde. De onzen geraaken weer an den wyand. Twede trefling. De koning wan Goa gequelf. Verdere zaaken toen worgerallen. Aroc Palicka's overgawe doot de Landroogden aln den koning vas Goa wirzegt. Slegt antword "w op" Radja Boni "s

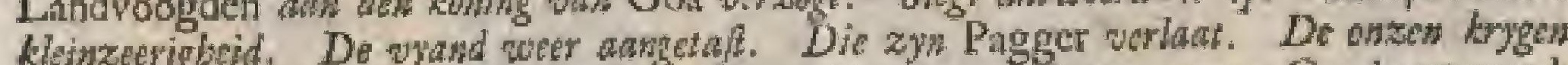

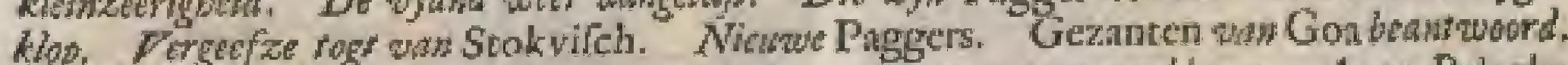
Fowflel aan den kowing van Goa van zich dexen dag fe moven werklaren. Aroe Palack kow tot ons over. Zakken toen woorgevallen. 't Leger foheid. De koning ow Goa wer-

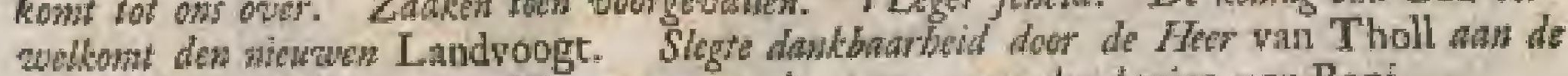
Her Etberveld bevezen. Nitwe wreze der onzen reor den koning van Boni.

to Heer Bewwid wient hier verIn "t jat Heer de $1 \int R o$ in ' $x$ jas 1703 , die hier als Roo in Landwoogt tor den $3^{\text {Ites Mey }} 1705$. gede Hect bleven, en door har Edelheden toen na Beer- blewen, en doon han Edelheden toen na ninks Bataria ontboden is, om in Riade wan plants. Indiër, als rangenomen Lid, die Hooge Vergadering mede by te wonnen; hocwel ik dara wel andere redenen van hebbe Vetrek wel in "t jaar hooren geven, dic Heer op Batavia zoo noodig, wallon dan hem kort dar an na Bengale als Dircticur, dat veel minder in ting dan een Gouvernement was, gezonden. Men zegt dat hy weel geld aan zeker groot Heer fchuldig wiss, en dat dit moctl betals zyn.

En dic was byna ceri diergelyk geval, 7ejdram als zich eens in den tyd, dit de Heri Speel* geval wan man General van Indien was, opdede. de Heer

Hy zont een zeker Heer als Directeur speet(zoo men zegt) na zekere Directic, met iuan. belafting wan datr voor an hem een briefje wan to000 $\mathrm{R}$ ders te teckenen.

Deze Heer zoo vel in de wereld riet bezittende, en 'c werftand niet hebbende om hes te wisnen, hand wel zin in de bedic- 


\section{Z A A. K E $\quad$ N.}

575. bedienings mar gecnzins in dat onderteckenen; diethalven "retale hy an zyn Eudelheid, th ben for die bedrening wiet begraw, en ik wet wics on tum onot $\mathrm{ecm}$ tuyze it wibo ved geld wownen tow, on zyn Edhbrid to lownet betalen. Wrat op de Heer Sperban zeide : Fent, ik geve u

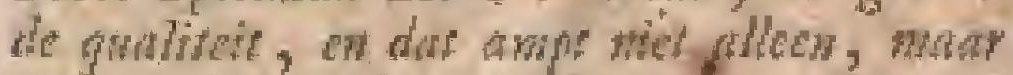
zad $n$ ook th weffand 'er by geven. Gat gy mar benen, ik zal a noit dahom madnen, bebolen dat ik wercekre, dat gy over

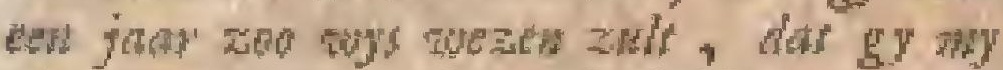
wier mer war moden anlt loblen, en my ool wiets mer folddis awh cym. Zyn Edelheid, zei de ander, dan zal it of u aegen was gerif bewn gan; en by bewond binten "thalf jaat al, dat hy zyn Edelheids goeder raid nict meer van nooden that.

De Hecr De Hecr Foldan Facob Erderedd, den Frberveld $21^{\text {fle }}$ Februari 1705 . hier met den EenLand- hoorn verfchenen, nam 't gezig wan bem vougt over.

Dah Tahatie, wedwwe wan Ragla $P a$ Groote hacka, en koningin ran Boni, was by de agrug volkeren van Boni, de Boegiueezen; en Tah bain meer andere Celebize inwoonders, volgens 't berigt dat if in " $\mathrm{c}$ jar 1704 . in Oetober dant of kreeg, nog in zeer groute ngting, watrom lriar Edetheden jatrlyls, on te toonen hoe yeel genegenheid $x y$ voor huar tot nog toe findden, nier nalicten yeel anvienclyke en koltelyke gerchenken aun hat te zenden, verzekere zynde, dar $x y$, zoo lang zy lectule, wel bezorgen zoude, ditt men of Mncallà geen moeice of optant hebhen zon.

Men had egter bevoovens ann onzen Onoor- kant hict emige zaken gedtath, wat tejignighe- gren har Edelheden wel uirdrukkelyke door de bereles gegeven hadder, nier begeculonzenge- de, dat de koningen wan Boni, of Gon,

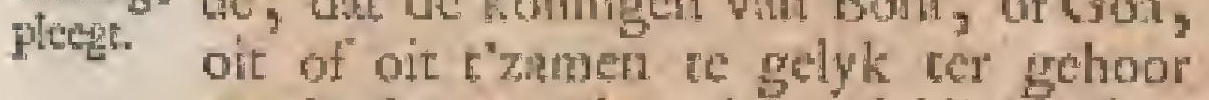
zouden komen, alzoo dax anleiding, of tot grooter gefchillen, en wel tor ecn beter veritand rafichen dic twee koningen, als met her belang der E. Matichappy over ecn quam, geven koll.

Ook heett men ditur na veel hegte gevolgen daar af, en cindelyk ook gexien, dat deze koningen malkanderen nier alleen wel verltaun, en hun oud hoofd. ge[cljil bygelegt hebben, maar ook vervolgens $A$ wo Pow, mee de dochter van de koning van Goa getrouwt is, een hu* welyk, wat tegen alle goedie Staxkundigen zich op zeer goede gronden atngekant lucbben, 2.00 dat die gene, die dic rondanig befteticn, of het niee wel begrepen, of altoos zeer onvoortigtig gehandelt, hucwel de zaken met 'er syd weder een gehed anderen draxi tuftchen deze twee koningen kregen, gelyk wy dat teu declen nu en dan al gezien hebben, en in 't wcrvolg breeder zullen zico.

Ook was "er niderhand tuffehen deze rpro twee kaningen befloten, dat de prins Samprovali, oudfte zoon des konings wan Bori (hocwel de fnedigfte niet) nin de dood des konings van Goa in "ty k, gelyk wy beroorens al gezcgt hobben, en nuct Crains Masigali, volgen zou.

Onder de Het Erberwhs regeering feholite het met de Macafiaren en Boegibezen zoo nog al met horten en ftooten voort: want ' was zoo werre van daar", dat door 't voornoemt huwelyk de getroffene vriendfohap tufichen deze twee vorften in wollen ttane Lou gebleven zy", dite zy in tegendecl, tegen alle welgegronde faatkandige gedagten an, weder zoogroote vyanden geworden waren, dat de froning wan Boni niec anders wenfehte, dan matr verlot wan den Her Landrooge vien Micalfil: te belsomen, orn op dean honing wan Goa met zyne Boniérs eenss te mogen los gatan, hocwel hem die altyd belet wient.

Dat op wiert de Heer Jibrwh in De Heer

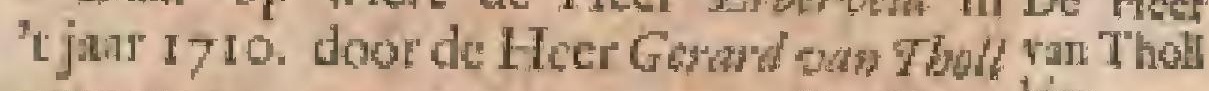
verwangen, en zoo tas was die Hecr hier niet in de regecring, of het begon, ook woogt. zelf al terwyl de Heer Er brodd nog hici was, niet weing te honmelen, dic darrom cerft mee her lanafte fehip wercrok.

On een net denlibeeld van dir voorval te hebben, moeten wy het wat hooger uit de prond oploalco.

De koning was Boni had buiten zynen oud lten zoon, Samprivali (dic tot der on. bet ryle van Gou, als verwanger wan zy-Julten. nen mocderlyken groutwadel gefchik was) nog een zoon, in 't gemeen Aroe Palatk, dat is, de koning van Palacka, doch anders Ave Parmy gentamt, die weel giauwer dan de oudté ('t geen dic van Goa te late verianen, alzoo hy arjders van dien vorlt tot zyn vervanger zou gekoren zyn) en darom van zynen wades" tot zynen erf-en kroomprins gefchilkt was; buiten welke den koning wan Boni nog een jonger zoon had, Aroe Mampor gename, dien by in veel latuer tyd kireg.

Dezc Aroe Palacka wu had zich ondertuffehen in luwelyk begever met de Huwdy docheer varn den weldheer wan Boni, een Paldetas man war weel dapperhejd, con wan zoer groote verdienften, gelyli hy "t door zyne heddagrige datuden ook zoo verre gebrigt land, dat by welsheer wan den koming zyn mectter geworden was; doch andiers gech math wan cenige, en ved min wan koninklyke geboorce, zoo dat de kinderen, die zyne dochter by Mroe Palacka reers gekregen had, geenzus, wolgens de. gewoonén der voriten wan Celébes in eenige anmmerling konden konen, om na de kroon pan Boni te ftan.

Dier- 


\section{M A C A S S A A R S C HE}

t7to Dicrhalven fprak de koning wan Boni dezen zymen zoon hier over op zekeren dig, hem voor zyn bed ontboden hebs bende, dus tan, dat, antgerien gecs vas de kindcren, die by by de debter wan zymen weldhey Dain Mangimba badke, volgew

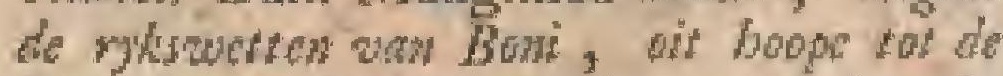
kroos konden boblen, ondat zy wit konintlyken blecte pefproren dionden te zyn, by

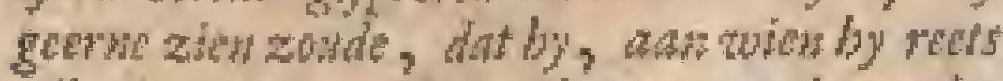
alle de rylscicrades, als zymon tolkontuden wervinger, whgegewn, en alle mektechwen von erre, witigenomen bet goude zonmefohm, dat by tot zyn food io voor zitb weinde te bowlen, overbowlig balde, wh

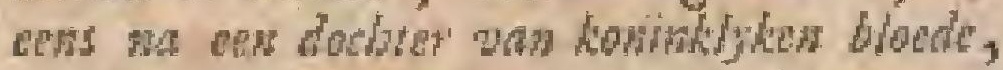
wedkprs kindern met regt wa de knon zon-

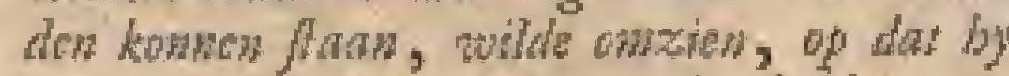
Wow zyn dood zyol knoon, whe by bom na lastan zoude, wog ans ( zoo by woor zym zoon of dite voor bas magt kown te owetbden) in boope mogt zill raften op bet boofl wan cen kwinkinke forat, die buiten alle twify de mathe daw toe roode geregtigh zy).

De prins Aroe Palacka, den koning zynen vader met veel andage over deze zalk gchoort hebbende, zeide, wat by bet wede zopdang begrep, en ook ten wollen gengen was bow te gebooramen, en, om te toonen, dat by het ook mecndic, zag by ten eeriten mi zulk een Bonize prityce om, wond 'er een volkomen na $2 y[1 \mathrm{zin}$, en na die wan den koning zynen vader, en ging dar op by der zelwe, nier negen (gelyk "s lands wetten vereifchten) maar alleen drie dagen tuishouden, hiep "er toen weter af, en liet ze zoo zitren, over welke dand de koning zyn vader zeer toonnig was, "t geen cgter bygelegt wiert, zoo dat de koning bet nu meinde weer whik na zyn zin te hebbea; doch de prins warrelynelyk wan zynen fichoonvader, Dais Mangana, ongezce, nam zeer [clsjelyls de whuge, zonder dat men in secerit wift, wair wa toe, of wat de reden van zyn vingt was.

Darr zyn "er, die zegen, dat de koZcestam ning wat Boni zynen butan tegen dien war geral uts- zynen zoon-wegten liet, en dat die vorth ichen den des han wan zynen zoon, die den han koting defl hatn wan aynen zoon, die den hasn en Aroe ten toon in duzend ftuktion lapte.

Palieka Dezoon, dit ziende, en dair ofer zer over misnoegt, Wragde, wat reden zyo wadts "twegrci misnocgt, viagde, wat reden zyn wadk nen. zus wertwoed en wred te dratgen ; watr op hem de koning belattec thil te fwygen,

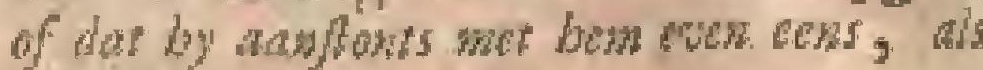
met dien varis, benter zow.

De prins hicr over nog meer onteld zynde, en zyns vaders wotde, dic hy lende, niet werder wiliende atwigken, is, zon on deze, nts on herr thdere Zakkcn, พan daar gevlugt.
Men ontdekte nogtans emdelyk, dat hy zich by zynen grootwades, den koning van Goa, ophick, terwyl zyn fchoonvader ma tr gebergte wan Mandar gevlugt wis.

Onderuffechen lice de koming van Boni zynen zoon พan den koning wha Gon wedereificherin, doch die lier met beleefheid an dên koning vatn Boni te rug zeggen, dat hy ecnen prins, hem zoo $1 \mathrm{a}$ in den blocde bettiande, als deze, geen Jysberging had konnen weigeren, en dat hy ook fwarigheid makie, on den zelven ann zynen wader, die nu op hem wertootne wis, over te leveren, verzoekende allecn matr cen weinig uittel, in boope dat zich onderwyl een middel wan verzoening, tuffehen den vader, en den zoon, opdoea mogt.

Day op nu lice de koning wan Goa 7an den Nederdandzen Landvoogt wan Macalfar vraggen, wat by zyn Hoogheid, zoo die prins by hem moge komen vlugten, indac geval, voornamelyk, zoo de koning zyn vader hem dan weuterom worderde, zou ruden te doen.

De Landroggt, en de Raad wan Macaffir, wiren wan oordecl, dat zyn Hoogheid niet betw doen kon, dan den prins tan den Heer Landvoogt over te geven, die dan verder annbieding dede van met zynen Ratd tufficher beiden te willen gatat, om te zien, of men deze zaak dan werder niet tot ecn gewentcht einde zou konthen brengeti.

Ondertuffchen quam de koning van Gon te fterven, en die van Gon namen Dood de

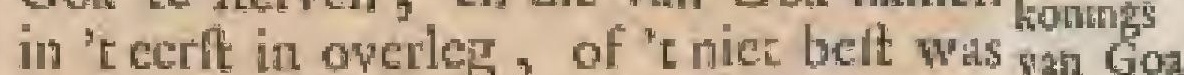
Aroe Palade tot kouing, in des overledens plats, ano te ftellen, angezien by veel fchranderer, dan de prins Sawporali, was ; man de veldheer, en de eerite Dienaar wan Staat van Gm, of wan 't koJinkryk vin Mnendat, Bontolango gematimt, een zeer oud, en byzonder [chrander Heer, voorftellende, dat des overleden konings uiterfte wil wis, dat de prins Somporoli hen vervangen zou, zoo wiert 'er woor al , op 't andringen van dien hatfen Ileer, die al in de oude Miverffiarze verbonden zeer bekent wis, goedgevonden, dac deze oudfte prins, yolgens "s lsonings wil, ook in zyn plants komen zot.

Deze tantelling van den prins Sampo-Smpowhil tot koniug wa Goa gefchicde nier walli in op de gewoone hadswyze, dat is, his eenzyplats. vergadering van alle de koningen van Celébes, Bondgenooten der $\mathrm{E}$. Mattfchappy, watir by dan ook de twee Gecommatrecrien van den Her I,andwoogt, en zyncn-Rnad, wan wegen de E. Martfchippy tegenwoordig $2 y n$, en datr ath tocttemining geven mosten 3 inar de Macaftaren deden dit maar wolgens cygen 


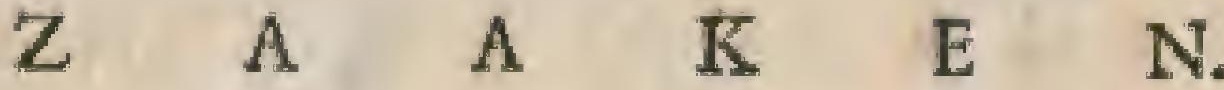

1710. gezag, en gaven 'er den Heer Landwoogt, en aynen Rand, mata kenris af, weike Doch zatk wel garlch nict in den hazk, en buiten de tegen de oude wyze wan watkiezing det

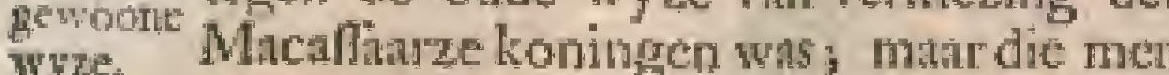
nu egter ltilfwygens uit andere inzigren doorllippen lict; hoewel men, myns oordeels, qualy lk dede, met zulke quatade gronden, wak tegen het gemalkt verbond, te leggen woor een wolk, 't geen gewoon is, tils men het denwinger geefr, de gehecle hand ftout na zich te nemen; behalwen dat zulke ftoutheden, zoo openbant gepleege, naderhand ook andere vorften anslejding gegewen hebhen, om dit quand voorbecld te volgen, gelyk onerent 2 jarten bevoorens den koning Yis Boni, by de dood des tronings van Soping, zich "er op die zelve wyze, buiten liennis ofte toeltemming wan eenige Gecommitterden van de E. Matfchappy, ingedrongen, en daar na and den Heer L.andwoogt, en zynen Ratd, "er" matr lkemis af gegeven heeft; watr over coca an har Eaclheden wel gefcheven; doch wata over nier getklage, en geen vertoog ter wereld tegen gedann wicer, warom het by de verkicung van dezen nieuwen koning vall Goa te ligter na gevolgt is.

De koning van Bori ondertulichen, ftampvoetende vant toorn, on dat men hem zynen gevlugten zoon geweigert had weder te geven, klaagde in den Rand der Bondgenooten over 't geweld, dat men hen in dezen opzigt aundede, trot zyn kris zeer verwoed (gelyk hy doch at te havefig in al zyn doen was) in den wollen Raad, en werzogt, dat de Bondgenooten tegen zyne wederfpandingen uituekken, en hem datr in behulpzan wilden zyn.

Zyu verzock wiert in den $R$ aad toegeftanis doch onder dic bepaling, dat men de koningen, data by zy gerluge waren, niet moejen, nog beledigen zoude.

De ho- Datr op geralkten de koningen wan ning vis Boni en Goa in een openbanen oorlog Boni be tegen malkanderen, en de E. Matfchappy ootlogt in hiele her mee den koning van Boni, zenryo dien dende in 't jaar 1710 . drie vaandels, wan Fan Goa. 48 man yder, onder den hoofdman facob Stcenboger, aan dien vorft tot hulp, on den koning van Goa, tot overgave van den prins, Aroe Palacka, te dwingen.

Deze Capitein vertrok, té ordre van den Landwoogt, en den Raad van Macaflar, in Juli met zyne 3 vandels mis jongay, om zich aldarr tnet her leger van den doldriftigen koning van Boni te vereenigen, alzoo de algemeene vergaderplats aldana was.

Zyn Hoogheid gaf dar op ten cerften ordre, om de artillery te vervoeren, en t leger te doen bewegen, onder belofte

III. DEEL wan darr ma, zoo ras "er man' een vaftigheid t pro' voor Gou gemakt was, voor genoegzanme levensmiddelen te zullen zorgen.

De hoofdnan Stcendergen had fiever gezien, dat de koning met alles zoo voorbaarig niet woortgegan, en met wat neer bedastheid gehandelt had, van Btedt welk oordecl zyn cerlte Bedienar wan tegen deb Stant, Cardeforg, mede wass, doch darar zyn was geen reden tegen zyn Hoogheid te rrienden gebrulken, dreigende, dathy, zoo men op. hem niet volgen wilde, atleen zou henen trekken, hocwel her elendig"mes hem zou afgeloopen hebben, zoo men hem niet tydig bygefprongen had.

Egter dwong by den Heer Steenbergen, fchoon nog alles zecr onklaar was, mede na Gou te trekken.

Men had op Jongay een vefting, of fterkte, gemarks, watr wan an den $\mathrm{Hect}$ Landwoogt den $14^{\text {den Juli liennis gegeven }}$ wiert.

Den If den dito brak de koning wan Boni met zyn leger, 5000 of 6000 man fterk, na Goa op, war op dan de Heer Stechbergen met zyne artil]erye, en volk, mede volgde. En niet lang diar na geralkter de legers van beide de koningen atr eer. Den koning wan Goa had in werre na zoo weel volk niet, its die van Boni; mati zeer veel en fction geweer.

Deze vorfen waren riec lang anden ntnderen geweelt, of die wan Böni namen de vlugst.

Dhar op fehoot Capitein Steonsergen ten eeriter toe, om de vlugtende te ftuiter, ell den vyand te rug tedryven; mair, tot zyne groote onfteltenis, zag hy, dat de koning wan Bont wegens een fwnire ontfinge wonde "L gevegt verlaten moeft, perzoekende, dut hy deo leoning van Loebox, die hem wan de dood bevryd, en her nu te gutad had, byfpringen wilde. Indien by nog man cen weingig langer in 't gevegt gebleven had, was hy wey geweeft., Ook was zyn ftandare, en trom wan Staat, met meer andere ryks= cieraden, ta se loop gebleven.

De Heer Stcesbegen dede dit; doch de koning van Locboe verzogt hem te rug te treklen, angezien alle de Boniers ats fchelmen de vluge namen, en zich niet fchatumden zelf al honne artillery te haten ftan; wan op dan deze Capitein belloot met den koning war Loeboe na hunne legerplats te kecren, gelyk die van Goa, zoo ras zy 't volk der E. Marfchappy zagen, mede na Goi troklicn.

In deze flag wiert de lioning van Bonf met 2 kogels an de linkerzyde door do lies van zyn been, en zyn jonglte zoon, Aro Mampe, door den buik gefinoten. Den. Tomillalang, Aroe Paloma, een groot overfle, wient het hoofd afgeflagen, en Aro Goeroe Tojoma, een van $\mathrm{E} e$ de 


\section{M A C A S S A A R S C H E}

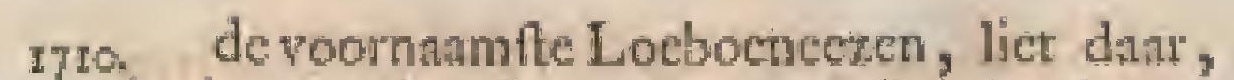
met veel anderen wan zyo volk, het lewen.

Na de midda quam de opperkoopman, de Hecr Havenberg, in "t leger, De Hec-die nevens den voomomiden Capiecin, ren Har- wls Gecommitteerden, uit na:m ran den tenherg Heer Lundvoogt, en den Ragd wan Mabergen Caflitr, na den koning wan Boni ging, gian by oni hunne droctheid ower zyne ontange den ko. wonde, en verdese gelede fchade, te nug. betuigen, te neer alzoo zyn twee befte overifen hier mete geblewen waren.

De opperkoopman zoge zyn Hoogheid te bewegen, om van Bontuwalac, war mat coe de zynen meeft gevlugt waren, en data" $L y$ "t niet lang houden konden, op te breken; doch dit was voor cen doof mans deur geklopt, en diende alleen om zyne wonde, door zyne geduarige dair op wolgende hattigheid, te werergeter, alzoo hy zeide, dae zyr leger weer in

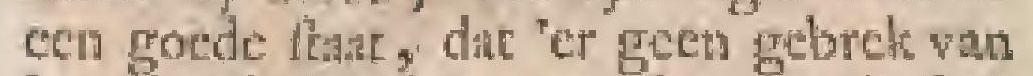
hoofden in "tzelve, en dar zyn belluit Whs, niet eer, voot dar hy zynen zonn in lianden had, van diar op te breken, bedankende te gelyk de E. Maaticliappy, en den Heer Lindroogt, voor den onderifand, die zy hen deden, watr medo dan de Hecr Hartenberg, zonder iets op dien worlt te konnen winnen, tegen zyn wil vertrekten moett.

"s.Avonds kreeg men tyding, dat de wond wan Mot Mampor zoo gevalulyk nict was, ats men in teerf gezegr had. Hy was met ech werplpies foltums in den rog geworpen. Ook wont zich de koning tegen den awond beter.

De hoofden van Aroe Palona, en Tom joewat, door die wan Bomi van de Macasfaren woor i cati en I thail gond verzogt zynde, wierd dien van Boni aan de poort Manufi tot antwoord gegeven, dat men de relve niet geven kon, "nzoo zy beiden, den Tomillalang, en Crain Psinkadjwe, de ecu door Moe Palake, en de an= der door zyn Rchoonzoon, die in Goa woonds, reets begraven waren.

Wy badden te dier tyd 100 dooden en gequecten betwomen; doch hoe vecle die var den vyand waren, kon men mer gecu zekerheid zoggen ${ }_{j}$; doch dit witt men, dat Aroe Palacks in "t been gefeloten, en dat te zoon van Grom Bomemenowpo dood geblevent was.

Op Woensdag den 16 den dito quam de koning van Tanetta, wit laft van den konimg van Boni, by Capitein Stendorgen, Nisuwe on hem kenns te gewer, dat, vermits van hy van wegen zyn wonde het opperbevel "t Bonis over 't leger niet meer voeren kon, den leger, koning wan Locboe als cerften of opperveldheer, en dat hy hens, ce weten, dien wan Tuneta, als tweede, en Aroc Belo als derde hoofd van zyn leger angeltelt; doch te gelyk ook goedgevonden had, dat $z y$ buiten dien Cipitein niets onder- ij to. nemen zouden, war voor deze Hoofiman den koning wan Boni door dien wan Tanet ta bedinken liet.

Ten guures wits 'er in 't hoofdquartier' een algemeene vergadering, wair toe de Heer Shenlerges mede verzogt wiert. Hy ging 'er na toe met den lietutenane Fonnas Stanbs, en den opperftiorman, Jacolsiokrifds, en men wone toen goed, on in tilles zeker te gaan, met Pagger, en kleine fterkten, Goa hoc langs hoe meen te ninderen.

Ten I I uuten quam 'et cen Gezant van 'p Feroek, Goa met cen teeken wan de halve matn, wan een by hen Karktako en Carkely gename. Geasnt Deze cifiche, woot cen zelcere fomme van Goa, gelds, het hoofd wan Daim Haroepa, war en "thit" op de koning wan Boni liet weten, dat des kohy geen kenhis tel wereld had, dat dit nings ras hoofd door yemant wa zWn wolk geno- Boni. men was; dech, 7oo hy it zelve gevonden had, hy het de zelve eer zoude amgedan hebben, diedoor dic van Gon than zyne overiedene overften bewezen wats, en dac hy dierhalsen waft felde, dat het nog op 't weld legget moet. Hy woegde hier nog by, dat hy niet gewoon wits menfchentiootden te werioopen, doch dat $z y$ "c zelf op "t dlagveld konden gann opzocken, en, daar 'then behughte, begrawen.

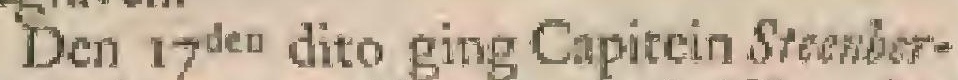
wen, bunewens ftiengan Stokvifo, den terdere kaning van Locboc, Crain Agamoma, cn toen Aloe Otdfong, na 't vorteren vin de Pug- vourgegers tien, alwara zy bevonden, dat de vallen. Bondgenooten ecn Pagger op " $\mathrm{x}$ cinde van Mancrocki begonnen op te werpen, dat ook Benoorden de rwier wan Goa, wat Weftelyler als de wooning wan Crath Bontolongo, twee vyandelyte Paggers flonden, en dat onze Pagger op dic verheid dar van gewerkt wient, als het buicengeregt van de Landpont op Macallit af gelegen is.

Ook modt 'er, na' 'e voltooljen van deze Pagger, nog een gematit worden.

Daur op liet by 't weld ma Gon ontedelken, wont op de plats, diar de koning wat Boni gewond was, wel 20 of 30 dooden, en cenige der zelwe met de hoofden rects afgelapt, leggen.

Te dezer tyd trokken ook 6 of 700 Macafiaren buiren de Bonilche poort van Gon, poltecrden zich tutchen deze poost en tulfchen humen Pugger, thwarr $\mathrm{zy}$ bleven leggen.

De koning van Boni, en syn zoon, bevonden zich nu redelyk, welkers Gezanten, door Socropojake als hoofd geleid, ten 4 turen tan die van Goa quamen ver" indagtigen, dac, eer die wan Boni en Goa Mohhumtredrans wierden, ecnen Lalere doeni koning y 


\section{Z $A \begin{array}{llllll} & \text { A } & K & \text { E } & \text { N. } & \text { z }\end{array}$}

5ito, Jroning wan Goa was, en dat beide dete koningen toen zeer goede wienden geweeft waren, welke vricudfchap nog onlangs, toen de lioning vin Goin, en Cram Bunorongo zich op Tijomana beronder, op her huis Latemojoe weer bereftigr was. Ook voegden $z y$ hier by, dat $z y$ tot onderhouding wan de zelve nu I cati en i thatil goud bmgten, alzoo "cr na reets bloeds genoeg, tot koeling wan de gramlchap des koungs yan Boni, over de vlugt war zyoco zoon, gettort wast lattende door Aroe Ofoug dant nog byvoegen, dat zy wergeten waren, dat de E. Mateliappy wan ouds der beider rylken wellaut atisd gezogt, en dat zy weel prewen dans af gehad badden.

En om te coonen, dar lay datr ontrent redelylitheid gebruiken wilde, zont hy har nu 2 cari, en 2 thal, goud, begecrende nice auders, dan 't geen 'c oud Mohhammedans yeloof medebragt ; doch dic zyn zoon tegen hem gezondige had, endat het billyk was, dac by voor hem ech voerval dede, en vergiffenis werzoge die, toen hem de relve angeboden was, datar niee ma bad willen luiftcsen, behalven dat hy oot de rermalistg wan de E. Matafchappy verworpen had, Stat va s konings zoon tiec anders, dun 't-blocdvergicten princen wan weele onlchuldigen, en te gelyk ool moedwillens zyn eygen dood zogt.

Datar op vertrothen die Gezanten, en de 2 cati, en 2 thail goud wierden nog dien zelwen awond te rug gebrigt, illooo dic wan Goa dir goud nier hadden willen annemen, dewyl dic wa Boni ook hume I cati goud te rug gezonden lindden, zonder dat zy hicm op ecnig ander nne woord gaven.

Op Vrydag den 18 ten dito geralkten beide de Paggers, de encep Maneroeke, en de andere, wat verder gelegen, voltoid, en zy wierden don hoo Sillkote, en door die wn Tanownas, bezet.

Van dezen morgen wiet "s lionings wond ook gefpuic, en was de opperwondhecler, Mr. Jacod de Ponter, war gedagten, dat de koning met 3 kogels getroffen wis, en dat er ecu agter in Ifpier van den bil, en de twee aladeren door de lies in "t hol geralut waten.

Wegers de prins, Aroe Mompoe, kreeg men berigt, dat zich die nt redelyk wel na ten ryd bevont.

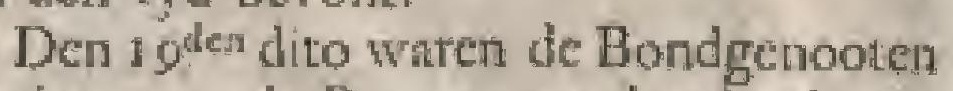
bezig, om de Paggers op den hoek van Pakedjence op te wespen; doch moeflen die, om den fterken annul, En 'Eothophoudelyk tebieten, ttaken.

Op Sondig den zoten dito werzogten he koningen wan Boni, Loeboe, en Tanetra, om 2 ftukken gelchur, zynde pothess, ondic tot zekere onderneming

te gebruiken, watr op men cerft "tant- nto woord van den Heer Laudvoogt afwagten moett.

Dexc morgen gerakcen dic wan Boni met die wan Goa, over "t matien van die Deonzen Pagger op Pakedjene, woder aan malkarn- weranger san deren, by wclk woorval de Bond tertooten den branf itand hielden, way door de onzen, wy and. in "t maken wan den voorigen Pagger belet, met een nieuw Paygerrje ten eerften in ftat wan verdediging geraliten; doch 7y verzogten nogmalis 2 dtukken gelchut te mogen hebben.

Men zeide, dar wy te dier tyd zodooden, en 25 gequetten, en dar die wan Goa "er nier veel minder hadden; ook bragt mejo de 2 hoofden tan Garretojo, Perankan ihalyoe (dat is, een Maleits inboorling) en van Dain Mamgat, zoon van deu koning van Bontein, by den ko* ning van Boni.

Het eerile wiert door Grain basklebt, en 'c laitile door' de Towadjos gekregen, en deze hoofiten zyt, op "Everzock der vrienden, atn de zelwe wedefgegewen.

Tegenden arond quam de koning der Towidjos aan Capicein Stenburyen zesgen, dat lyy op dezen dag 46 gequethen, en 4 dooden betomen hadd; ook hadden. die wan Tauette, vermits zy zeer dapper ftand hielden, neverns die wan Bankle al eenige folyade geleden.

Den $2 I^{\text {then }}$ dito trokken de Bondgenooten weder uit hun Isgerplasts, ralten de Tweedo Macatfaren met vecl dapperheid an, en retbuge. Atonden als manneu, ganfch onbeweeglyk, doch de koning van Locboe verzogt wedetoni 2 tetkken getchur, not hatr toebehooren, ea met de bofichieters, wat op de mader ordre van den Heer Landvoogt eenth moeft afgewagt worden.

De koning wan Gua was met den grooten findard tot voor ons Paggertje ge-De kokomen; matr zoo dapper atgellagen, dat ning was hy geen fult liad, om wedes te verlchy Gou ges nen: wath by wiert met 3 verlcheide quett. kogels gequeti, en was dari op met $z y-$ nen opgerolden ftandated ftil na Gon geweken. Daar" bencwer waren "es al elf voormame nffekapte hoofuen voor den loning van Bom gebruge, dat de Bondgenooect geen kleinen moed gaf, te meer, wanneer zy" "t werzoghte gekchut wan dep Heer Landroogt bequameth, water op $z y$ de Macilfitaren geheel verdreven, en de Pagger yoltoit rabkte.

Men had Aroe Palak op dezen digs, nog gifteren, rier buiten wernomen, wat wit zommigen giften, of hy uiet mede mogt gequerit zyn; wahr op egter niet de mintte ftart te maken was, anngezien men nict hooren kon, wat fingate de Bondgeooten hon angedan, of wat $z y$ zelf daar by geleden hadden.

Na dat nu de Pagger den zaten dito

$$
\mathrm{E} c \mathrm{z}
$$
vol- 
Ifro. voltoit was, wierden de koningen vau Locboe, Tanette, Toerate, Bangkle, verdere en van Salckette op de regter, en de kozaken ningen wan Soping, der 'Towadjos, dic toen van Mandar, en Tarnpuning, op de lin= wallen- ker vleugel geplatift, en men ftelde de Boegineczen wak voor de Pagger, terwyl de koning wan Boni op Jongay zyn ruft hielt, laatende het oppergezng over zyn leger nog an den kowng van Loeboe, die lyy wilde dat met den koning van Taneter over niles, alzoo dit een vor fl van ervarentheid was, ecrit rat-plegen zou.

Ordertufichen begeerde de koning van Boni, dac Crain Leforafing, en zyne Jyfwigt, muar by hem zouden biywen, om hem tegen exnig fchiclyk toeval te dekken; aungezien er belloten was, dat de Bondgenooren dings "er an opbreken zouden.

's Naniddags quamen "er' twee Geranten wir Gos, te weteli, Dain Matowing, cn Dain Karkd ; doch deze zeiden latt te hebben, wan niets, das in "t bywezen van den koning wan Loeboe, te zeggen; 't welt dan cindelyle gefohicdende, boftont hum gehcelc boodlehap daar in, the de koning van Locboe als Miudelatar usfchen de honingen wan Bonj en Goa zoude mogen haidelen; dat al zoo woel was, of zy niets verzogten, alzoo zy wel wilten, dat daar op niets volgen zou.

Op Woensdag den $23^{\text {fles }}$ dito bevont zich de kanisg wir Boni zect fromi, en men kreeg toen ook berigt, dat Cron Ponpamere in de lartite trofing doodgebleven, en dat Aroe Palacke in zyn been gequetlt was; wiar op de koning van Loeboe de gencene zalk nader met Crain Apanowia, Aroe Belo, en met den cerfter beltierder wan 't ryte wan Boni, Garlefing, owerleide, en in welle byeakondt by de Bondgenooten goedgevonden wiert, Aroo Pa-een minnclyken Mateizen bricf ust nam lackits der E. Mantehappy ano den koning vals overgave Goa, atn Crin Bontoforgo, en han de door de verdert Rylisgrooten win Macuthar to yoogden fehryer, en dar by nogmals de overdati den gave van Aroc Palacka an des zelfs Heer koning vader te verzockes, mer werzekering, พैan Goa dat dan den oorlog ten einde zyn zoude. verzogr. $\mathrm{Zy}$ wiere door ecnen Boew Parigi, verzeld zynde wan cen Hollandze wigge, die men voor uit droeg, gebragt, en met liet dezen vorlt oole werder anzeygen, diat hy hier mede de E. Wartchappy groot genocgen geven, doch dat hy, zullis niet diocnde, oorzakk wezen zou van al het onnoozel bloct, dar verder om zulken geringen $z a \mathrm{ak}$, die men zoo genalk ketyk byleggen kon, stont vergoten te wonten; beruigende din gecn deet in "tallermintte daw an to wilion hobben, en dat $2 y$ hem londen wertekeren, da hy nu voortand door de zelvevry ferker, ijo. din tot nog toc, ftont amigenalt te worden.

Den $24^{\text {flen }}$ dito quanten "er Gezanten was Gon, om op den brief wan de Heeren Siept antLandwoogden Lwewell en wo 7 hol/ te waond antwoorden; zy waren mer har dric, "eq op. te weten, Cram Bontepaja, den Sabindar" Crain Gre/h, en Glaratg Mando, benevens een tolk; doch zy brigten een zeer. befpotcelyk antwoord, weshalven hen vict toegelaten wiert ua 't kaftecl Rotterdian te gaan, en gelitt, on, zoo zy iets maders te zeggen hadden, dit in 't leger maar voor te ltellen, en aff te handelen.

Zy zeiden egrer, dat Crain Boworngo zyn uitertte beft gedan had, om Aroe Palska be bewegen, dat ty weder na dea koning zynen vader keeren wilde, doch alle zyne beweegredenen waren by tien prins verworpen, en men lund op den zalwen niets kohnen wirnci, zoo dat het an hem veel meer, dan azn den koningy, of de Grooten wa Goa, haperde.

Oole verzogten $z y$, dat de koning var Loeboe zelts eens in Goa geliefde te komen, om liem datar oxer nats te fpreken, alzoo zy oordeclfen, dat zyn gezag, en zpee beweegredenen, zoer veel by hem zouden gelden; doch dexe koning floeg dir wak af, alzoo by na de Heeren l-andvongdea, en wh zyner rader, nier had willen huitteren.

Den 2 flien dico quamen de Gezunten van Gon weder in "e leger"; doch men vont goed hen roor af te zeggen, dat, zoo zy met geen andete voon warden wa vrede quamen, zy matr weder wertrckken konden, alzoo, zy nier genegen waren, zich wan hen oin den thuin te daten leiden, en dat men belloten had, met hee mualen van de Paggurs zoodanigg woort te gann, dat men ten eerften onder Gon moge geraken.

Ondereafichen klatgde de opperwondhecler, Mr. Puorter, and dek Hecr Radja Landvooge van Tholl, dit hy, van we-kleipgen de kleinzerigheid en pynelyklueid des zuerigkonings van Boni, het nopdige tot het heid. geneezen van zynewonde nief doen kon, en dierhalwen bett ootuedic, dat de Heer Landwooge hem doch geliefle te doen begrypen, dat 'er getn inder middel was on hem fpoedig te genecten, dan ' $\mathrm{g}$ geen by hem reets an den koning wootgedagen; mas "t geen hy weragtelyk van de hand gewezen, behalven dat men ook groore vreeze woor en foluielyke verergering had, indien "er een cerften nier tegen woorzien wicst w war toc de honing meer geduld wan nooden had.

Ten 2 uuren ging Capitein Stce whergen na den Heer Land poogt, om over eevige 
Z

A

A

K

E

N.

$21 \mathrm{I}$

1710 zakken yan gewigt te fpreken, na wellec werrigting, en zyme te rugkomft in 't leger, men goed vont den vyand analtonts weder ann se talten.

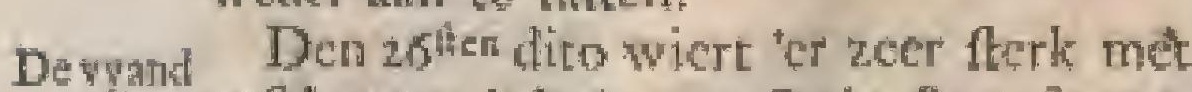
weeran-gefelut op "t huis wan Greis Bontoronge, getailt. en op nog cen Paggertjc, op "t hoog pad voor de poot vin Mitruta lannde, gefchoten, alwwar de obzen onk een Pagger met der hautt opwierpen, het welke zy weer op niew den $27^{\text {flen }}$ dito op de kant vats de rivier deden.

Den $28^{\text {the }}$ dito dede de wyand cen uitval 's isachts ten 1 uul' op de Pagger' det' Lozböneczen; doch zy wierden deftig te Iug gelagen. $\mathrm{Zy}$ wernieuwden dien uirFal nu en dan wel weder, met 6 of 700 mai te gelyk door de poort Crongrong op $A r C B d{ }^{2}$ "s volk; doch zy wierden even, als te vooren, dipper door diten vorft antfangen, te meer, alzoo Capitein Stendergen den vort Agamonga tot zyn hulp zont.

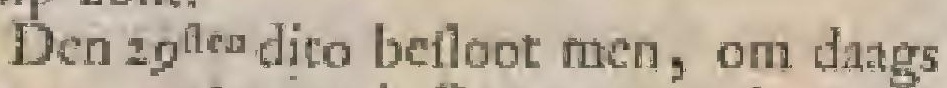
Die roph 'cr aan op "s vyands Pagger ecn nlgetricevertat, sen ftom te doen ma de middag, date de vyand zyn Weltelyke Pagger vethaten hild, cin nu al over de rivier getrokken was, reets bezig syade on dat een nieuwe Pagger te miaken, er poft te vatren.

Heden wis de koning van Boni viy beter, en wat geduktiger, dan te vooren; zoo dat 'er nu hoope wits, dat zyn wonde ipoediger zou genczen worden.

Den $3 \mathrm{~g}^{\text {flen }}$ dito vict "er' nicts van belang voor:

Den $3^{\text {fer }}$ dito taften de onzen cen De onten Paggertje van den vyamd, zonder gevolg, krygen alzoo 'tons wat tegentiep, aan. Ook hiof wiert hier con korporat met cen ipat gequeth, en ons kanon, met weel gevar vinh her te verliczen, te rug gebragc.

Verfoheide anderen wierder hier gewoud; mat dati en tegen hadden de volkeren yan 'T*imocrong, Saleketre, en de Towndjos, zich over de rivier in een fterke Pagger wan den wyand gepofteert, en by "t overkomen wan deze rivier' werfcheide andere Macalfatrze opgeworpene vaftigheden ontdek, war op men dan goedwond cen wergadering der Bondgenooten, in welke de Heer Landvoogt mede regenwoordig zyn zoude, dags "er aan te beleggeo, whur in den $1^{\text {then }}$ Auguali Wergeef- belloten wiert, dat de Bevelhebber $S_{\text {rol- }}$ Te togr wifh met eenige urtillery een anval op

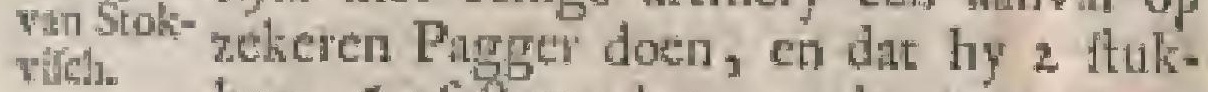
ken, 6 of 8 ponders, mede nemer zoude ; doch zyn togt was te verget's, alzoo de Bondgenooten niet eens hidden durven antatleni.

Nieure Den $2^{\text {uen }}$ wietpen de onzen op "t pad Paggess by jache eer Pagger, en de Macalfarien op 't cinde wau dit pid "er twecop, calten- de "s avonds een Pagger wari onis op de nzio. kant wan de rivier, wellie doch Aroe yalisg bezet was, ann. Mera mifte dien awond den grandier 7 an Lammekess, die dén

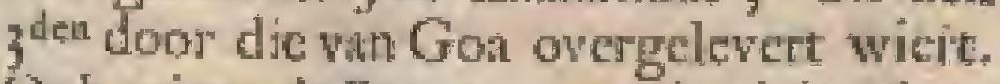
Ool wiert de Pagger ower de rivice door de onzen verovert, en op den $\sigma^{\text {den }}$ (alzoo "er den 4 en filen dito niers woorwiely wed een Pngger door 't volk tan Maros digt by Theyn gemadk, wir welke men mot handmortieren gemakkelyk vuur in de ftudt Goa werpen kon.

Ten $g$ uuren quanen cenige afgezondenen van Goi, te werch, Caryekalle, Geanteri en Carrotako, door den Koning en Groo- tan Go ecn van Goa gelaft, om an Radja Loebor woodd. te viagen, watrom hy een Pagger zoo digt voor 'Theyn dezen nache had laten mlaken, dara de koning wan Goa gifteTers arond al had lateren weten, dat by heden Gezanten zenden zoude, on een Itilftand wan wapenen te verzoeken.

Hicr op gat de koning van Loeboe cot antwoond, dat zulls gefchied was, om onze andere Paggers te verzekeren, en date die Pagger de goede voorthellingen van vrede nier wethiuderen zoude; behalwen dat die ran Goa den gaulehen Fache op den Pagger van ho Belo gefchoten hadden, weshativen lay zoer goede redenen bad, om mee dit syn werk yooit re gatu, dall by roegende, dae, 200 hun laning nog iets voon te dtellen had, hy dat dezen middig nolj doen moeft; of wht by re lat komen zoude.

Dinu op wiert ten eerlen ordre gegeven, om de Pagger woor Theyn nog grooter te mistalien, om met kitnon en morticren den vyand te konneo atutatten.

Pas nom de midulag quarinen die Gezanten yan Goa weer by deh koung yn Loeboe, verzockende uir fatain van huthnen koning uirflel cot morgen, om nadere voonflagen te doen; dach de koaning van Loeboe wees die van de hand, en zci, dat, zoo zy t goede in den zin hadden, zy dat nu volgens 't verzotk der E. Marafchappy dienden te doen. Egter vont men goed ben zoo ling te laiten wagten, tot dat Radia Loblo hiet ower met den koning war Bomi, en tont Capitein Srewbergen, eerlt zou gefproken hebben, die gow wronden dien eeren digg (alzoo dit rolgens de Celcbize grond- en landwetten het wel moge geweigert worden) ata den loning wa Goa toe te Atan, mits dat zy by cede op deri Coran dan morgen weer hier moeiten verfechynen, om hen werdig wan een watt belluit: des Konings en der Grooten te doen; doch voor af matkte nen hen ook bekent, dat $z y$, mer her gene de E. Maitfchappy cifchte, zouden mocten te vrede zyn, Hicr op nu was 'er zoo lang ltiltand. Teger den avond wicroen de

daken

QNFII ESTLIARARY 


\section{2. $M A$ A A S S A A R S C H E}

5ye. daken der huizen in Thein afgenonen, 't geen na geen wrede geleck.

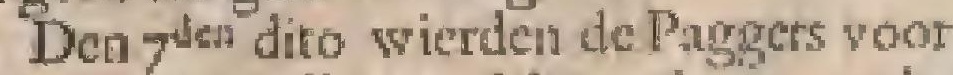
Theyn door die var Maros dezen macht al meer verfterlit. Daar op verfichenen. de Gezanten wan Gon ten io turen voor orje Pugger met een brief wan Aros Polacka in te Malcits, by welke dic prins verzogt, om met Cupiten Stendergen te mogen fprcken. Men nam den brief in, doch men moeft op 'c wetzogte ecrit lalle van den Heer Landvoogt hebben, die voof at and de Gezanken dede zergen, Voodtel dat, zoo Aroe Pelacka nee zyn vrouw añ den en kinderen in 'e kafted Rotterdan zich kowing zelwen begeven wilde, hy dan in volle van Goa zelcerheid wezen wou, wat' op nen nog dezendag dezen avond klar antwoord diende te te moe- hebben, of dat de Bondgenooter met ten ver bun werk anders voort zouden gaan.

kiaren. De Heer Srehberes herlatalde dir alles nog eens tegen de Hecren Gezanten in "t bywezen vah den koning var Locboc, जan Crain Aganowio, wan Aros Beloc, en van den Tomillaling Are Oedjong in de legerphats, op dar zy geen-reden mogten hebben van te loochenen, dat $z y$ behoorlyk en dubbeld orcer gewarfehouwt waren.

Ook makte dezo Capitein an den koning van Boni bekent, dat zyn zoon, de prins Aroe Palacka, cen brief an den Her I Andwooge wen Tholl gelcheven, en wat by aw zyn led. wegens zyn genomen belluit dair in iseder geftele had, het welk dezen wortt zeer wel behagde.

Ondertulichen verrchenen de Gczanten, te weten, Jomang Oent, en Sowde Patake, weer voor ontze Pagger, ah welke de Hecr Stenlargen kennis gaf, war ondre de Heer Landwooge antirent her athaten wanden pritus, thoe Palacka, gegeren, dat hy (Capitein) zelf latt on hem in "t kafteel te geleiden, en dat de Heer wa $T$ bo $/ /$ het verdere rerzod den prins mede toegeitann had, weshalven 'er geen langer uifitel to wagten viel.

Zy werzogten zec ernltig, dac, dewyl zy niet in ftiat waren, om dezen arond nog antwoord te brengen, men de goedhes hebben wilde, oni matar tot morgen vroeg te wagten; ook zciden de Gezanten, dat Aroe Palacka zcei genegen was, om by de E. Martchappy over te komen , doch dat hy bevreeft was, zoo lang als by "t leger der Bondgenooteri daw' nog zoo uitgeftrekt leggen zag; hy verzogt derhalven, dit zy eerft whlden opbreken, welk ougegrond werzock hem afgelagen wient; en dien prins geranden ten cerliten onbevreelt over ic Jwotien, onder verzeliering, dat de E. Mantfchapdy hen woor alles, wat hem ook ontmoeten kor, befchermen zou.

Dhar op keeg ly nog tot 9 turen uit- ftel, on dat rond uit te zoggen, of hy rto. geneen wis over te komen, of IJict.

De Gezanten gingen dicthalven om hen die af te trangen, en hy liet datr op weten, dat liy nu niet overkomen kon, atwoo "I hun dag win Godsctionft was; doch sat hy, zonder ecnig uittel morgeu tot ons overkomen zoude, verzoclende gedientig om eenige foldanen, die hem uir de poort van Boni ontmoeten, en ma zyn vatrtuig geleiden zotuden, als mede, dae wy Theya in bezerting wibien nemen, on het wan alken onerbate te bewryden.

Men ftont an deu prins dit verzock toe, en men gaf hetr verzelecring, dat eenige Emopianen hem konen athathleir, en zelicl na 't kafteel Rotterdarm geleiden zouten; wan al het welke behoodylie kennis an de koningen van Boni, Loeboe, Gran Mignomi, c1 Aroe Bela, tot hun volkomen jenocgen gegeven wiert.

Tegen der awond quam hice een ruiter met een brief, an Copitejn Steenbergen, met Jaft wan den Heer Landpongt, on werdagt te $z y m$, angezien den prins Aro Palack zyn kerzock, om door enige foldanten atgehalt te worden, was toce geftan, dir 'er cen trocp wan 36 man, onder I fergeane en 2 korporials hen diende cocgezonden te worden, wan welke ook enige roor cen korten ryd zonden dienen, orn Goa en Thern te bezetten.

Diar ma lier men Aroe falacka door den tolk Brogum viangen, wanneci hy zou buiten komen; doch de koning van Goa dede zeggen; dat by zelf morgen met zynen bioeder mede na "t kntteel garan, en hent pelcide zoude; doch de colk had Aroe Palacka zelf niet konnen ipreket, wermies hy heel agter in de fladt woonde. Ook lict de honing wan Goa verter zeggen, dac hy nog nice wilt, op wat uth, en of hy te water, dan te lande, komen zonde.

Den gten Augurti, "smorgens ten 9 Aroe H2curen, quamen $2 y$ ons andienen; dat de helat Eoning wan Goi, en de prins wan Pathelers, kotnt tor

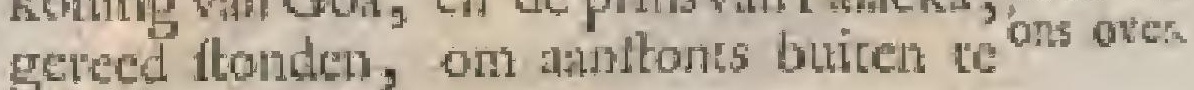
komatr.

Daa op zont Capitein Sicesbegres den troep, tot geleide van de prins gechilt, en men zag hen amitonts dati na mee hum hotftoet de Bonize poort uit, en laugs den hoogen weg over Maritjaja tha 't kafted trekken. Hun foer wits wel I 600 zielen therk, en dic overkomen Wan den prins duurde, eer alles in ordic wats, tot "s awonds ten $f$ uuten. Ools wilden de princen var 't gevolg des konings van. Goa, en Aroe Palacka, in "teerlt hume kriffen nier overgewen, dat zy dat ma egler alle ann den Landvonge deden, die hen dezlve toen wederguf. 


\section{Z A A}

De fergeant Gorndis wan Ogfen was met 24 min in Goa-getrolken, watr op zy door Cram Bono/ongo in Goit, en cen korporal met 6 man wis "Theyn gelegt wierden, om dan ontrent alles gocde orde te ftellew.

Die van Boni begonnen, zoo ras dc koning van Gou, ern de prits, voor by onze Pagger getrokiken waren, nict weinig met hume Hafiganyco te Tspatalile, ct te fohermutzeren, "t geen deze twee vorften zeer mislangde, angezien deze prins zich aru de E. Maleliappy, mar geenzins an die van Boni, overgaf.

Hy lict hier af ten cerflew kennis atan Capicin stembergen geven, met verlock, dat die moge getteit wordew, gelyk dic Heer dat ook asuitones dede beletten.

Zatien

Den rodea ging Capicein Btecrbegen met de Mefis wan der Stel en Happon na de verblyfplats des konings van Boni, om zekeren lalt by zin Hoogheid wit te voerch.

Crast Bontoforggo terzogt ook cenig wolk tot ayn geleide, aangezien by gegenegen was, morgen mede in "t katted Roterdan te komen; mato alzoo die Heer ondertulichen onpaftelyk wiert, liet hy her zelve op den $1 t^{\text {defl }}$ zeer belecti af weten.

Den 12 des dito vertrokken de Gecommitcerden, wot der Stel, en Hoppon, na dat zy humen lalt uitgevocert hadden; doch Crais Bontolongro liet weten, dat de Boegineezen een vantuig, hem toebehoorende, en wan hec cillond Sumbawa komende, angehouden hadden, 'twelk hy verzogt dete ondligen mogt worden, gelyk ter enften gelchiede. Ook wiel "er eoen miets ferder wan befang woor.

Den 1 odeu diro ging de koning wan Goa, met ecrige Grooten, vooby onfe Pagger nat 't kafteel, op welken tyd ook de verbonden vernicuwt, en alles " $t$ geen nog unodig was, wolkomen tultichen hatr' Hoogheder, en den Heer Landwooge, mee alle de Bondgenooten, gefloten; wait op Capitcin Stenbergess nog dien zelwen avond gelalk wice ondre te gewen, dat hee leger opbreken en feheiden zou, gelyk op Woensdag den iolles Auguiti de te raggetogt na Oedjong Pandan dar op gevolis is, zynde onze troepen "s morgens ten 8 uuren, stzoo zy met het anbreken vin den dag opgebroken warem, al in die vefting gekomen.

Men zegt dit aan de Macafturen by 't maken van deze vrede opgelegt is,

I. Ahe de lewanlen weor te gewen.

II. Allo de gerofde citrades wom do krom wan Boni werer wit ic kever. Dat gefchict is,

III. Lowge Chatezen, dir ved pdetangels gewalk budden, ons at bonder te gewen.
K E N.

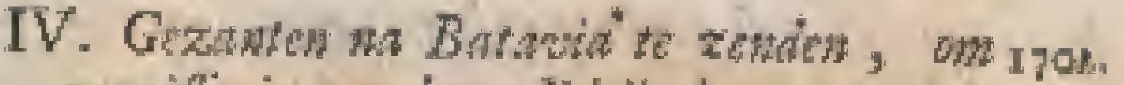
wergifferis wan bar Ldelheden te wezomhen; die den Ber Erberveld kon 'or wa gigralgt zjy.

V. Gox's maturen te fegrew.

Nuderhand is de koning van Got op De kia-

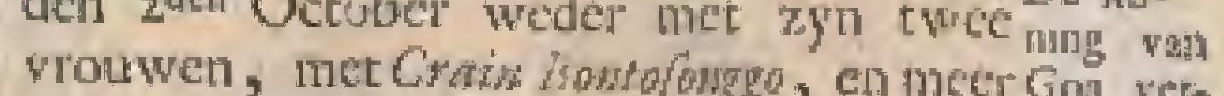
andere Grooten in ' 1 fort greweelt, dat" welkont zy op cen ver lchatp (het grootle, what den niedop men de koningen van Boni es Goil wandby hun komft in 't kitted, on hater roggt. kan, alzoo zy zeer dini op gezer zyn). zeer hecrlyk onthale witerden, ec meer", dewyl dit de eerlte molu was, dat $z$ den nicuwen Hecr Landvonge quamen begroctet. Oob fprite men ce dier tyd ower het gedocnec wan Craim Bonteromb (Crain betcelicut een prins, enool een princes) en dat wan hateen man, den knoning wan Conti tegen den koning wa Pulir, alzoo beide deze vorlten wan Borneo onder den koning wan Goa ftonden; doch dice zatak was win een linger ndem, en de zelve houft naderhand nog weel moejelykheden gegeven.

De koning van Boni was den $3^{\text {dem }}$ Oetober yan zyn wonde nog niet genezen; doch de opperwondheler, Mr. Bomberen, had er nu moed op; hoewel deze vortt zetr ongenalskelyls te belundelen was, wat toa zyne fwaty lygherd zeer veel dedle.

Ondertuflchen was de oude Landwoogt Slege alhier, de Hecr brberwl, na diar dankbaratles tot filite geraake wi:s, op den $7^{\text {dea hejd door }}$ Sepember na Batavia vertrokken ; de de Heer den Heer was Thol ir dieu betommerly- van The ket ryd zeer veel dientt gedtau hidHeer Li(want anders lon by, dewyl zyn tyd berwetd uic, en by vervangen was, mar na Ba- bewecone tawia vertokken hebben, stzoo nu alles woor rekening van de Hecr wan Tho/ liep) doch zyn Ed, beloonde dien Heor dit guilich niet wel, met ten ecrften na Baarvia tot zynen lafte ( 200 men my berigt heeft) te tolityven, dat hy das alles liad laten wervallon, en dat by dar no nieuwelings gekonen, al den latt, van it vervallene te vernjeuwen, zou moeten drigen.

Hast Edclheden, de nict begecren, dat men op de buitenlandvoogdyen cenige onnoodige onkolken doen zal, namen dit juitt zoo breed nict op, als de Heer wh Tholl wel had gemeint, behalven dat $z y$ wel witten, dat de Heer Er burwd, buten hitiren uitdrukkelyken latt, niet bevoege was cerifge onkotten van belang te maken; en datrom verwecrdigde de Heer Erberveld zich niet eens, om zich dase over by har Edelheden te vernatwoot den.

Men zeide in dezen tyd ook, dat "er 


\title{
224 M A C A S S A A R S C H E
}

I7I. cen geheel andere pot te wuur, en dac de Nimuse koning wan Boni, die doch niet ruften Nielwe kon, wan Foornemen was, om weer
vreeze der onzen nieuwe voorftellets en eifichen wegens de yoor den landen wan Lange Lange, Bontopanno, koning

van boni

\section{A G TSTE HOOFDSTUK.}

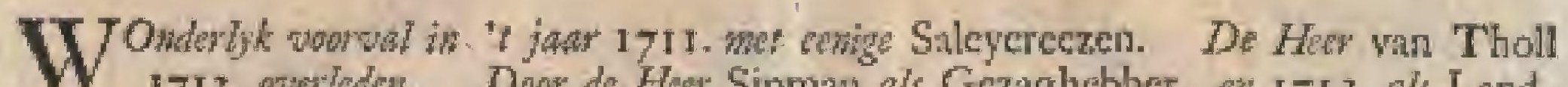
17 2. wollden, Door de Her Sipman als Gezaghebber, en I 75 3. als Landtoogt worwagen. Verdere zaden way Aroe Palacka. En van Radji Tambora.

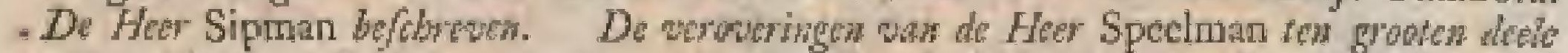

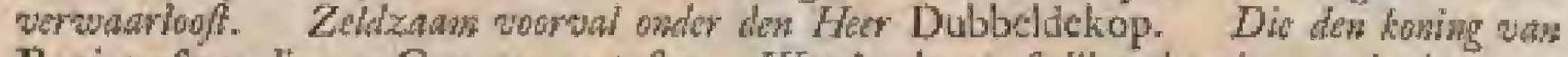

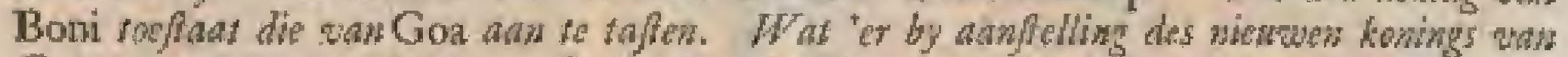

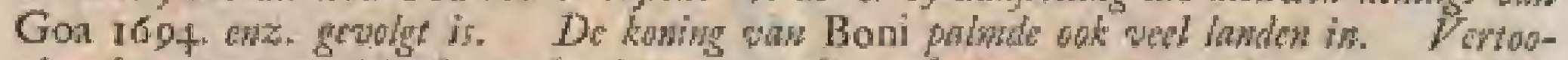

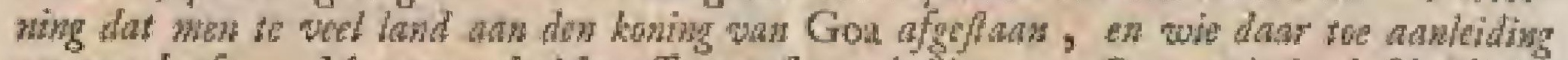

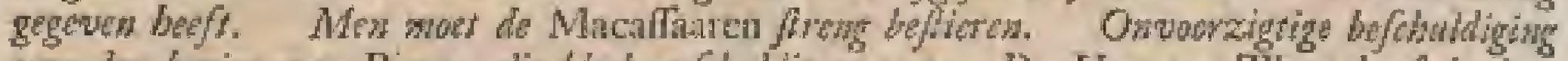

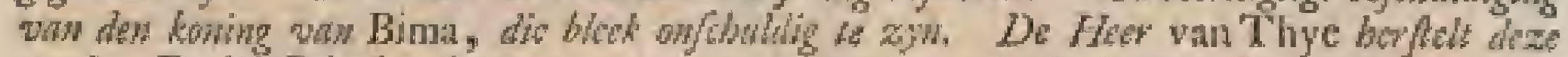

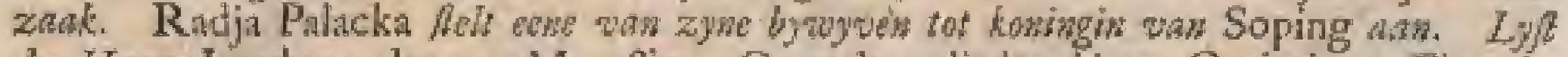
der Heren Landvoogden wan Macafir. Opperkooplieten bias Capiteins. Fiscals. Sfabandars. Winkeliers. Soldy-boekhouders. Geheinfolarywers vas Macalatr. Hoofden vam Bima.
\end{abstract}

Wonder- T $\mathrm{N}$ "t jaar I7I . den Iten Maat, viel lyk woor- 'er ect zecr droevige zuak in 'c kafteck val in "t 1 Rotterdatn voor. Eenage lieden vat

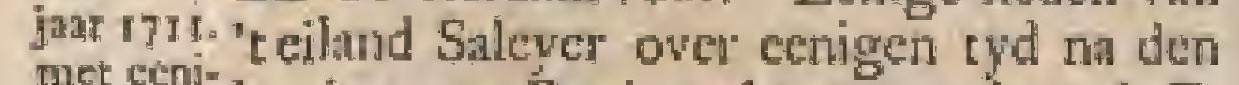
met ecenje-koning van Boni gevluge, en door de E. reezenl. Marfichupp vali dezen worlt geërfche zynde, om ze als wegloopers an de Heer Landvoogt over te gewen, wierden de zelve 40 in getil op zelieren dig door dezen koning aan dien Heer gezonden.

Zy quamen onder 't optigt wan een zeer oud man in de vefting, wiar op Capitein Stembergen hen, volgens gewoonte, hunne krifien afeilchte; 't wel]: $2 y$ niet gewoon, of wel foor ict quands bevreeft zynde, had die oude man, al ftampwoetende, zyn kris uitgerukt, it de grond geftoken, en de zelve 'er weer vitgehalt ; wat op alle de anderen ten ecrften umok fpeciden, en yder op zulk ecrien, dienzy mur met lin geweer began konden, annielen, onder welken $\mathrm{LV}$ toen ook Capitein Stembergen, en meer anderen, doodelyk gewond hadden, zynde het duizend tegen cen, dat de Hecr wa Tholl niet mede onder de woet geftooten was. De meefte wh deze wegloopers wierden met de trolwen der friphanen doodgeflagen, docla cenige wierden egter gevangen bekomen; ook waren 'er 7 of 8 Europianen dood gebleven.

Zy hadden Capitein Stendergen zoo wel geraakt, dat hy 3 dageo dahr na quam te fterven, en de Capitein Licutenant Stewhof volgde in zyn plates.

Hy wiert na zyn dood van onvoorzig. tigheid, in 't afeiffehen der kriften, ass of dac geen marier neer was, belchul. digt, en dus al de fchuld van dit ongeval op den dooten gelchoven, dant "timmers in "t geval van Aroe Palacke by zyn overkomft geblelcen is, dat 'topergeven der krifen wel ter degen de gewoonte tot nu toe is.

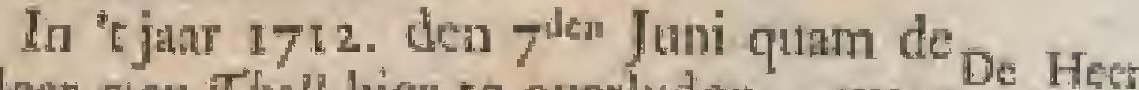
Heer van Tholl lier te overlyden, waar we Hect op de Heer Hartenlerg het gezig tot den in "t jar $9^{\text {den }}$ October warnan; doch inde mand I 72 . ran September hoorde men op Bativin, orertedat de R yksgrooten van Goa liunnen lo- det. ring op eigen gezng atgezer, en den ho= ning van Tello cot humen troning hadden angeftelt, twee quade zatien, tor geen vau welke zy de allerminfte magt hadden, veel min om dit buiten hennis van de regeering wan MacafTar te doen.

Men fchreef dit arn has Edelheden, Door den die darr tegen in het tockomende de Heer sipnoodige ordre ttelden, na dat de Heerigan als Jownes Pbiliphs Sipman, gewezen rweede hebler, in Amboina, op den gden Oetober de en $17 \mathrm{j}$. Landvoogdy wan Macatfar, en 'c gezag nis Lation Fan den Heer Wantenherg overgenomen vervahad. Hy was van dien tyd af manr Ge-gert. zaghebber"; doch wiert in "t jaar" I7 I3. Laindvoogd.

De prins Groe Paldke zat in "t jalli" 1713. nog in de velting Roterdim ge-verdete wangen; en, zoo het der nam hid, on=zatiten der onze beficherming, matr ondertuficher pas Mros moge hy "cr nier uiggatu, alzoo men din Palacks weer woor nieuwe mocite veesde, weTmits by niet pencgen was, zich woor als nog an den lroning zyneis vader over te

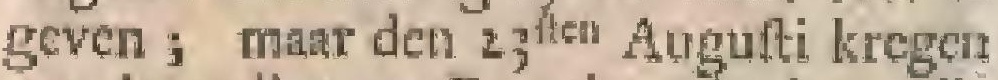
wy de tyding op Bat:tria, dat hy, dit lever moede, unt de refting gevluge, 


\section{Z A A $\quad$ K $E$ E}

1713. en genegen was zich op nieuw tegen den koning zynen rader in poltuur te thellen. Hoe dut nu afgeloopen is, kan ik nict zeggen, alzoo it zeder gen berige meer over dic ftuk bekomen het.

Den $27^{\text {Ren }}$ Augufar was 'er op Bima Fn wan weet eenige boskerte door beftel wint den Radja koning wan $\mathrm{T}$ anbora geweeft, dic ichoon Tambo- hy overzyne bewontens mangercge moord vin de konijgun uan Dompo op Biona, en over zyn ftout optrekken met 2000 mannen tegen ons rolk, zoo lang dan de Kap gerangen gezeten had (gelyk it hem diat in t jair 1705. op de woonity van de Her Landwoogr wan des Ste in Hottentots Holland mer zyr wouw ge2ien, en gelproken heb) nu nog nier ruften fion, en zich des nu weder in nieuwe moejelylabeden ingewikkelt had. Hy had bevoorens gerrage, om den kaning vatn Dompo zelf re vermoorden, doch, dien nier sindende, zich aan zync gemalin gewroken, en zyn voomemen was toen zich meefter wan Búmi, Dompo, en var de drie overige rylien op "tóland Sumbawa te makker, dat ben mislukte.

Hy was uic ayne gevankenis and de torap door de Hecr Joban wan Hown pss wetlott, en op Batavia gekomess; en wiert in "I jats" $1713 . \mathrm{om}$ 2ync nieuw werwekte beroerte op Bina, door zym felarpen en woelen; weer na de Katp na zyn oude gevankenis, duth hy nu wel blyren zal, gezonden.

De Heer "Wat ${ }^{*}$ er nu werdet by de regecring van Sipman de Heer Sipman (die in 't jalir $172 \mathrm{I}$. hier beichric- nog tegecrde) poorgevalleri $z y$, is my on* veh. bekent, dandat ik alleen tor lof vandien Heer zeggen moer, dat ili de cere hebbe, ous zyn Ed, woor een wakker en briaf Befticrder, en voor een zeer beleeft, mimnelyk, en gullertig Heer te kennet, zoo dat ik walt itclle, dat Macadtar onder zyn beltier zedert gelukkigr geweeft, gelyk 't geen geringe blyk 'er af is, dat zyn lid. in ' $\mathrm{c}$ jar 1722 . dar nog zynde, Buitengemeen Rnad wan Indièn geworden en 1723 . Yerwangen is door de Hecr 70 bu Fredarle Gobins, gewezen veldheer op Javn, doch hatf Geheimfchrywer wa har Edelheden.

Nu zoude it wath dere ftoffe wel konnen aflelueiden; mint moet hier nog icts byvoegen, "t geen ik oordecle voomamelyk tot de zaken wan Macaflar te behooren. De vero. Dat de Ed. Heer Sperhan door zyn wetingen hecolyke verowering van Macaftar con Wath de grooten fteen wan it herte der E. MathHecr frbappy geligt, es has ontrenc Amboiten geose nha en de verdere groote Ooft, (water ten decte door tnen Celebes, Amboina, Banda, verwar- en de Molukze eilanden verftiat) zeer $\log \sqrt{4}$.

geruft gettelt heeft, is tects bevoorens ita "r breede vertoont, maal wat heeft het ons ved konnen helpen; dat wy op Ma- caffar vecle landen daar by bekomen hebben, en door 't florten van zoo weel blocd meetters daur af geworden $z y n$, vermirs men dar no, doot 't plegen van deze en gene onworzigtigheden, en op verlcherde quaade bersgren wan batzoekende lieden an haar Edelheden, wan tyd tot tyd zoo veel landen and deze kieingennakte, ell zoo deftig gekortwiekte koningen weder gegeven heett conder voorgeven, $\mathrm{d} a \mathrm{t}$ het mat kleine ftukskens lind waren, dic dezc koningen van has Edelhedea vel zogten, mat dat zulke Landvoogden wel beter wilten, en daar try gewifrige redenen toe hadden, am egter andere getuigenis daar af te geven) dat de Hect iptehwn, too zyn Ed eens weder oprican moge, naawelyks cenig oveifchoe vañ die groote en menigvuldige landeryen, by zyn Ed. zoo dapper verower, meer vinden zou, alzoo deze koningeat, volgens hunne liftige gewoonte, "r cene woor en 'E andere na hice weer ingepalmt hebben, ftellende dit hun werzoek dan by hat Edelheden zeer gering woot, nat da zy zulk cen Landwooge voor af door gechenken, in der filte, hadden weten op hun zyde te krygen, om een gunitig berigt aan har Edelhedon te geven, op welk berige egre deze landen ( $200 \mathrm{my}$ wan aldan zeer kondige lieden berigr is ) van hat Edelheden noir aln die koningen gegewen zouden zyn, indicn zy een netre kiate van Celćbes (relyle dat behoorde) is hisen Raid getrad hadden, dewyl zy dan te grooten ondericheid tuffchen "E voorltel, en de grootheid van zulken ftuk lutuds, dat verzogt wict, ontdek zouden hebben.

Zeker Heer, dic lange jaren op Micaftar gelegen, en alle die zuaken zelfs bygewoont heef, heeft "er my cen net berigt wn gegeven, 't geen ik, zoo als "c my opgegeven is, hies" byvoege.

Een van de certe Heeren, die diat zeluzam over veel anwegribg (zoo die Heer zegt) zeoryal geleden hect, is de Hoer Onbidabon onder den gewcet. Host

Hy wier doot den koning wan Boni, Dubbiof toor Radja Pallocka, fterk angezogt, niet illeen on zeliere Aknden weder te hebben; man werzogt ook werlof wan op die vatin Goa los te mogen gain. Om zyn ougwit te bereiken, bond zyn Hoogherd hen zeer veel fraje geflhenken wan gotd tan, en relfón oole cen goud Pinangbekten met zyn toebehooren.

Hy fehrecf hier een brief aver aten de Hecr Hars bowwer, terwyl hy nog onitrent: Pannatioke dreef, die hem daar op een twyffelagtig antwoord gat, datar allech bywoegenúe, dat by dic konigen, geduh-

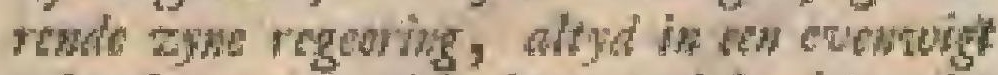

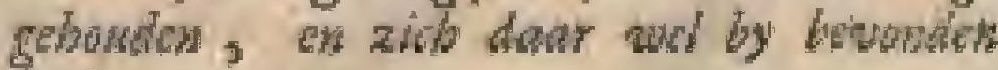
had.

Dant 


\section{M A C A S S A A R S H E}

Die den Daat op gaf eguer de Hect Dabbldeko koning (wetende op wat grond hy dat dede) ain wall Boni den koning wan Boni serlof, om den ko: toctiat ning van Gon wan te tafter; doch zoo Gron ran ras de Heer Dabbldebop wel overwoog, te talten. wat by gedaan luad, was lay dar over zeceverlegen, ging boven nazynkamer, en is vin groote droctheid kort dar na dit beftorwen.

Op dit gegeven verlof tafte de koning van Boni dicn wast Gow in 't jatr 1677 . aan, dat has Edelheden egter quand keurden, fchoon "tgoed in zich zelven was, dreef hem nit Gon, gelyle hy' 'er ook tot "t jan r 694 uit gebleren is, woonende in een dorp an itrud, on dat hy zyn leven in Goi voor de Bonièrs niet zeker hielt; weshalven zyn Hoogheid ook eenigen tyd zyn werblyf in 's kafteel Rotterdan gehouden heeft, cn naderthand natavia vertrokken, en dats overleden is.

Wat "er Zyn werwanger woonde, na dat hy in by an- 't jair 1604. mee Radja Bon' vereenigt felling. form- was, eet fl ann dtrand, en daar na geruit wen ko. weer in Goa, 'tgeen, met zy w wal van nirigs van kiei en doornen, de gedhante wan een Gourón. ftadt hebben wil.

emzere- Deze koning van Goa nu begon in 'c janr 1604, de itade Gon heimelyle te veriterken, watr tegen de koning van Boni mede verlof werzogt, om Bontuwalac te verlterken, en diar een wat om te hallen, "I geen hem de Heer won Tbje nfratade, doch da hy zeide te zullen, nalaten, als de koning var. Goa dat mede nahe, en "t gemakite afbrals. Dit wicrt dicrhalven door Gevolmagtigden onderzogt, en war bevonden, alzoo 'er wel il of 12 valtigheden ongemalit. waren, war na men dan "t zelye an den koning van Bont in opzige van Bontuwalac tocfton, in zoo verte, dac by ook 'topen veld mer een aftnyding werdeclen nogt.

De ho- Nis de dood wan Dan Tabalihe heet nime yan de konisg wan Boniook Bontcyn, en ved Bon landendan? onder behoorende, behalwen palme ked meer andere, wan har Edelheden verlunden in. zogt, endic niet alleen verkregen; max ging ook wat tyd tor tyd woort, on meer andere landen allenstiens in te palmers; dit hour tidelheden nog wel eens zat kantran berouwen

Bevoonens is rects getegt, dat de koming van Botil de magrougte der twee opperite lioningen op Ciclebs, of op Milcaffur is, die, hoc groot crontzigchebli hy ook zy, op zich zelven nangemerkt wan cen zee $t$ geding vermogen zy

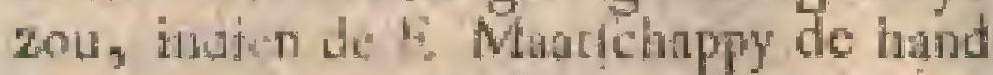
mas war thm strok, en ben dryves Jien: woth das zatuden de meette kwin.

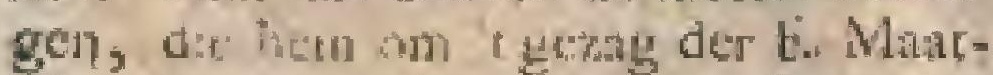
Ichappy mog amolnangew, amtonts tor den alleen laten zitten, daar hem alle dete volkeren nu met veel fchrik na de oggen zien.

Hier uic kan men dan zeer wel bezeffen, dat, gelyk men ann de cene zyde woor alle de andere koningen hier niets te wreezen heefe, zoo lang de E. MartIchappy hers matr aan haar fnoer houd (dat zyn eigen belang hem mede rawd) hetanj de andere zyde nogtans zeer noodig is tuffehen deze twee opperkoningen zoodarigen evenwigt te bouden, dat men werzekert $z y$, dat 'cr, wit cen fill te groote rriendfchap der zelven, geen quade of gevantyke gevolgen woor haar konnen woorkomen; te inter, om dat men wan cyd cot tyd an de liftige koningen wan Goa recrs njet alleen de velting l'amakoke, zoo dapper wan de onzen ingenomen, matr ook veel fohoone linnden afgettan heed

Hiter toe is wel de cerlte grond (zoo Vuroomen my berigt heete) door de Heer ning dat Franpois Prins gelegt, cen Heer, ann men te wien men (ichoon hy anders de belte "Fet land man des werelds wate) zulk een dierbare anoning Landroogdy, en wath zoo veel uiczigt, wan Goa als die van Macalfar, noit moelt toever- afgellaths, trouwt hebben, alleen om dat hy wan de da wie Roomiche Godsdient, en war don hy aanleiin ftate was, ou ofs darir veel nadeel te ding gedoen, behalwen dac dit tegen de grond. geven regering wan ons land $w$ lak aanliep, alzoo hefft. wy ons noit van t jok yall Spanjen wrygevogren hebben, om weer op nieuw Papze overheden in ons cigene tanden, met zoo wecl gevar als hier, atn te ftelJen. Een zask, dhar immers in opzige van "t wereldlyke, cn nogrueer in opzigt wan 't kerkelyke, op behoorde gelet te zyn, en dat op geen indere pluliss met meer gevaar, dan hier, kolk verwarloolt worden; en over welke cen l'apift zelf zal moeten bekennen, dat ik duarom gelyk hier in hob, om dat men in de Innden, dan $z y$ meefler zyw, geen andere Overheden, dan van humen Godsdientt (gelyk ook redelyk is) vinden zal: What vizoo zchitzan als "t luiden zou een Landwooge vass den Hervormden Gods: dientt tor Romen rc hebben, alzoo miszelyls heeft het op Macaftar geluid, een Paips Landvoogt over die van den Hervormden Godsdituth te gedogeir.

Die lieen" ru beete ecrth in "t jaar $160 \mathrm{r}$. den Heer Dirld de Hars, hier in Juri als Commifaris, of Gevolmagrigde van liar Edelheden, atagierende, den bequarr: lien Hecr, dien ic oir gekent heb, om gewigec zaken met de viterfte omzigtigheis te behandelen, weren te bewegen, on by has Edelheden door zyme vootpralk te bezorgen, dat zekere lunditreck, Sodinng genaamt, en als mar een klein thikje hands voorgedragen, 


\section{Z A A K E N.}

Dats den koning van Goa (zoo it meine) weder afgettaun, en gefchonken mogt worden

Hier in hecf de Heer be baas geen rchuld gehad, om dat met reden voor= onderftele wiert, dat de Heer Voorzitter Prias, die datr zeer landkundig was, hern zoo moctwillens niet zou misleid hebben, gelylk nogtans in dic ftuk gelchied is, alzoo Capitcin Sternberger als fergetro op Maros, daar dit latndechap aangrenft, lang gelegen hebbende, te dier tyd hicr wa cen geteel ander berigt na warheid am de Heer de Hacs geven, en an zyn Ed. wetroonen wilde, dat dir niet een klein brokje ugelyk de Heer Priws voorgaf) maar cen ftuk lands wel van 40 mylen in zynen ontrek was; marar de Heer Prins, die dit mede zoo wel, als de lergeant, will, gnf hem cen wakkere graus, en zei, dat hem dar niet na gewragt wiett, war mede by vertrelkien en lwygen moeft.

Op dit werdigt berigt wan den Heer Prats wiert, op voorlprak van den Ed. Heer de Hads, dit brokje lands aan den koning, eerit voor een gedeelte, on maderhand gehecl, gegeven.

$\mathbf{N a}$ dien tyd hebben zy weer om 't eiIand Cadjung, cri meer andere landen, langs de wal wan Celóbes gelegen, verzogr, die hen al mede of zulke lofie gronden tocgeltan $z \% n$, al het welke de E. Matrfchappy (zoo my die woorige landkundige Heer berige heeft) nog wel eens zeer zou donnen berouwen.

Radia Palacka zelf heet in zyn leven
Men mect de

Nacks

ditieng beliverin. menigmal over ons, nict, om dat wy al te theng, mala om dat wy over de inhanders veel te zage en te barmhertig - wareo, geklangt, willende fgelyk vec. goede Starktudigen met hern ftande houden) dat mers de Macafharen, Jatrat nen, en werdere Ooltertingen, zal men deeg wan hen hebben, flieng regeeren, en nergens in ontzien moet, dewyl zy datar anttonts te flour ap worden, behalven dac zy dic trengheid vin jongs af gewoon $2 y n$.

Deze vorft, het volk wan zyn land allerbeft kennende, gaf darar wan ecn door Gaande procve ten tyde van de Heer Hant/fuk, wannecr by den Rylsbeltierdervan Soping, ower een fpytig ancwoort aln hem gegeven, om anderen af te fchrikken, de lippen affnyden let, dat my egter al vry wreed, aan een man van die rang, voorkont.

Ten tyde van de Hecr Prins viel ook de zaak van den koning van Tambota, over de moord der koningitne van Dompo, voor:

Onvor Men had ande Heer Prins een zeer rigtige guad berige van deze zank gegeven, tyilag van watr op hy de Vergadering der Lands- grooten, en Bondgenooten, zamen rot- den kopendede, belchuldigende, op een walfch ming wat verleent berigt (dat dar na bleck) den bima, onlchuldigen koning van Bima in dien vollen Ritad, en hem nils een, die deze moord bedreven had, woordrigende.

Diar op gingen de Landsgrooten (aan welke de E. Mararichappy op de woorflig van den Heer Landwoogt of Prefident Fin Macaffar toeltuat, hun eigen misdaadigen volgens de Landswetten te rechten en te itraffen) met deze zatk voort. en vonnilten dezen koning, on gekrilt te worden.

De Heer Prims nogtans van oordecl zynde, dat men niet te roorbaanig hicr. mede voor moelt gan, angezien hy nu nog twyffelde, of dic vorit wel zoo rchuldig was, als volgens de ingekomene berigten geleet, wilt de zatk zoo ic drajen, dat zy eenigen tyd uitgeftele, en dat hy, op nader beragding, na Batavia gebannen wiert.

Nadertiand lirecg de Heer Prins, by die beek een netrer navorlching van den Sjahbarn- onfehuldaar Jounits, een vecl netter berigt, watar dis te by bleek, dat die koning onichuldig, $2 y^{n}$ en dat hy ontrent die ganfche zaak zeer quadaurdig belogen cratigeklangt was; wat op de Heer Prins het vonnis, oves dezen loning reats geveld, verautert wilde hebben.

Dit wilde de koning wan Boni geerzins coeftan, zeggende, dat by (Landwooge Prims) hem zelt als fichuldig an. geklagk, en dat zy, Grooten, diar op ecn vomnis, mee die anklagt overeenkomende, over den koning van Bima geveld hadden, zonder dat de wetten Fin "t land, die lyy (Heer Landvoogt) voor af kenkle, date in eenige verdere werandering konden lyden; en dat uit krigte van dien zys banniflement woortgang hobben moeft; max dat hy, genegen zynde hem dientt tedoen, wel by een brief am har Edelbeden verzoetken kon, dat hy van dit vontis ontheft mogt worden, te meer, alzoo men berigt wan zyn onfchuld, doch te hatt, belkomen hid.

De Hecr Prins, wel ziende, dat hy dis nict doen kon, zonder zich zelvet een finede in 't anngezigt te geven, alzoo dan zyn walfche andinktagt op cen walfch ingetomen berigt mede woor "t oog vin haar Edelheden komen moef, wilde geenzins tueltan, om dit vonnis te late uen uitwoeren; doch quam ondertufichen te iterven.

De koning wan Boni , zeer misnoegt over het ftutten wan de uitvocring van dit vonnis, terwyldeze koning van Bima nog gevangen 7at, tokdara op ren ecrften landwatd in, wiert veel volks, en makte op Macallar zoo grooten bewe-

$$
\mathrm{F} \text { is ging, }
$$




\section{M A C A S S A A R S C H E}

ging, dat hatr Edellheden op dit gerugt, na Batawia overgewanid, goedvonden den Heer Harlyas atum te zocken, on weer derwarts (gelyk hy cindelyk aunman ) als Landwongt te guan.

De Heer Wy hebben bevoorens reets getoont, van Thye dac die Hecr op Batavia in 'f jatr 169r. herlel geftorven, en dat de Heer wan The toen dede hier als Landvooge gekomen is.

Deze Heer, bevindende, dat de koning wan Palacka, volgens de behandeling dezer zatk na de wetren wan zyn land, vollagen sty gely had, bezorgde dat het bumilfenent wan den koting san Bima an Bativia foortging; hoewel 'er te gelyli zorg gedragen was, om liem mencer tyd weder in zyn ryk tedoen koman, doch die vortt quam in de gevankenis vat hartzer te flerven.

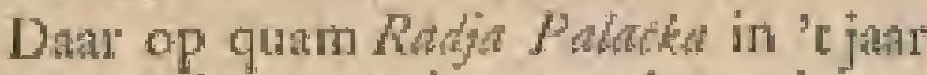
Radjapio 1606. mede te overlysen, het ryk van ene van Bonj an zynen neve overlatemde, doch wyne by-voor zyn dood had hy in "t rylk van Sowyen, ping cen wan zy wo bywywen, voor welke toikonin- hyg croote agting had, als koningin, in Sopins weerwil wan den koning van Goa, araऔan. geticlt.

Na Radja Palacks's dood ftclden die van Soping, op den koning van Gou fteunende, een andere loningin aal, war over de afgezette forftin and den nieuwen koning van Boni, ten tyde als ly zou angetteh worden, quan likgen; die daur op die was Soping well rwee of drie mal na de reden van deze werandeving vrutgen, cu hen verzocken liet, deze wortlin weer in har voorige plants te Atellen; mar vermits hy geduurig dwars ant woord wan hen kreeg, ficlde lyy zich in poltutur, on hen door de wapenen dar roe te dwingen; gevende hier van voor at an de Heer Landwoogt wa Tbye liennis, diens ratd hy hicr owes ook ver* zogt , doch deze Heer rade hen dit geheel af, duidelyke tedenen dom een berigt van Capirein Wefolwg gevende, warom her roor zyn Hoogheid belt wezen tou weer af te trekken.

Hy volgde dezen goeden rat, nevens alle de Bondgenooten, die gereed thonden om hem, op cen bloote wenk, to volgen; matr her had veel beter geweel, dat de Heer was Tbye dien koningl had laten begann, om den koning van Goa wat kleitier en ootmoediger te maken.

$\mathrm{Na}$ de Heer wa Tbye is de Heer Berminh gekomen, die rich, fehoon cen jong Landvoogt, met zeer recl omrigtigheid in die netelige zalk van Aroe Teko zocdanig gedragen heeft, dat de wonderlyke dubbelamnige bevelen win haar Edelheden, die (relyt wel meer voorgevaller is) doorgans net ecnen dag om den arm opgettelt, en, $200^{\circ}$ t quata lyk uitriel, 700 gefichiks waren, dac men hen daar van de fichuld zou hebben kpnnen gever, geenzins hebben konnen voldoen and de verwagting, die men 'er "tul had, on dut herquade, in de zitalvin Aro Teko opgefloten leggende, met goed beleid door dezen Hoer algehedicn, ess de geheele zocleg van dezen en genen dan door werydels wert.

Wy zouden nog veel andere zaaken, het bettier, cn "t voorgewallene op Macnflar l'akenule, konnen zeggen, die mogelyk an zommigen al iry wolvderlyk zouden woorkomen, mar wy mocten, onveel jedenen niet alles operibarren, alzoo ik my, z,00 sed "t mogelyle is, yoor alle feherpheden, en zanken, die mar cenige, asultoot an yemant konnen geren, zoeke te wagten ; hoewel 'er' zckere gevallen tyn, die my dart roc geperf bebber, om was "t mogelyk, in "t toekotnende, by die gene, ann welke dir ftut, cn die "e dikwils zoo nier weren gelegen te zyn, te bewerken, dat deze en gene misthgen mogren werbetert, en de quade zarken hertele worden.

Ools is ber zeleer, dat men mich dyd zeer khar ondekt hect, dat dic groote roegeracntheid wan hatr Edeiheden (z,0o geloove uir goede inzigten, om alles frich in fult te houden) in zoo veel landen than de koningen wan Goa en Boni af te 1taan, cokelyk mas gedicnt heeft om lien, en veet andere Macufarare Grooten, ten uiterlten ftout, ondankbas, cn baladadig te maken, "t geen ik oordeel dat noit zou sefchied zyn, zoo men in de voorige tyden den teugel wat ftrakker gehouden, en ben zoo weel nict ingewilligr had. 


\section{Z A A K E N. \\ L Y S T der Heeren Landvoogden van Macaffar, en de verdere Opperhoofden hier.}

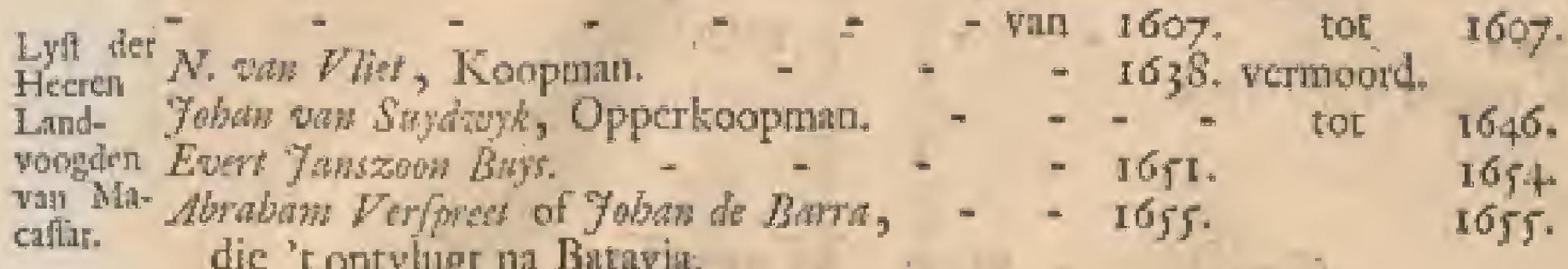

caflif: die 'tontyluge na Bittavia.

$\mathrm{Na}$ de verovering wan Macafier in "t jan 1669. door den Hecr Spelonian.

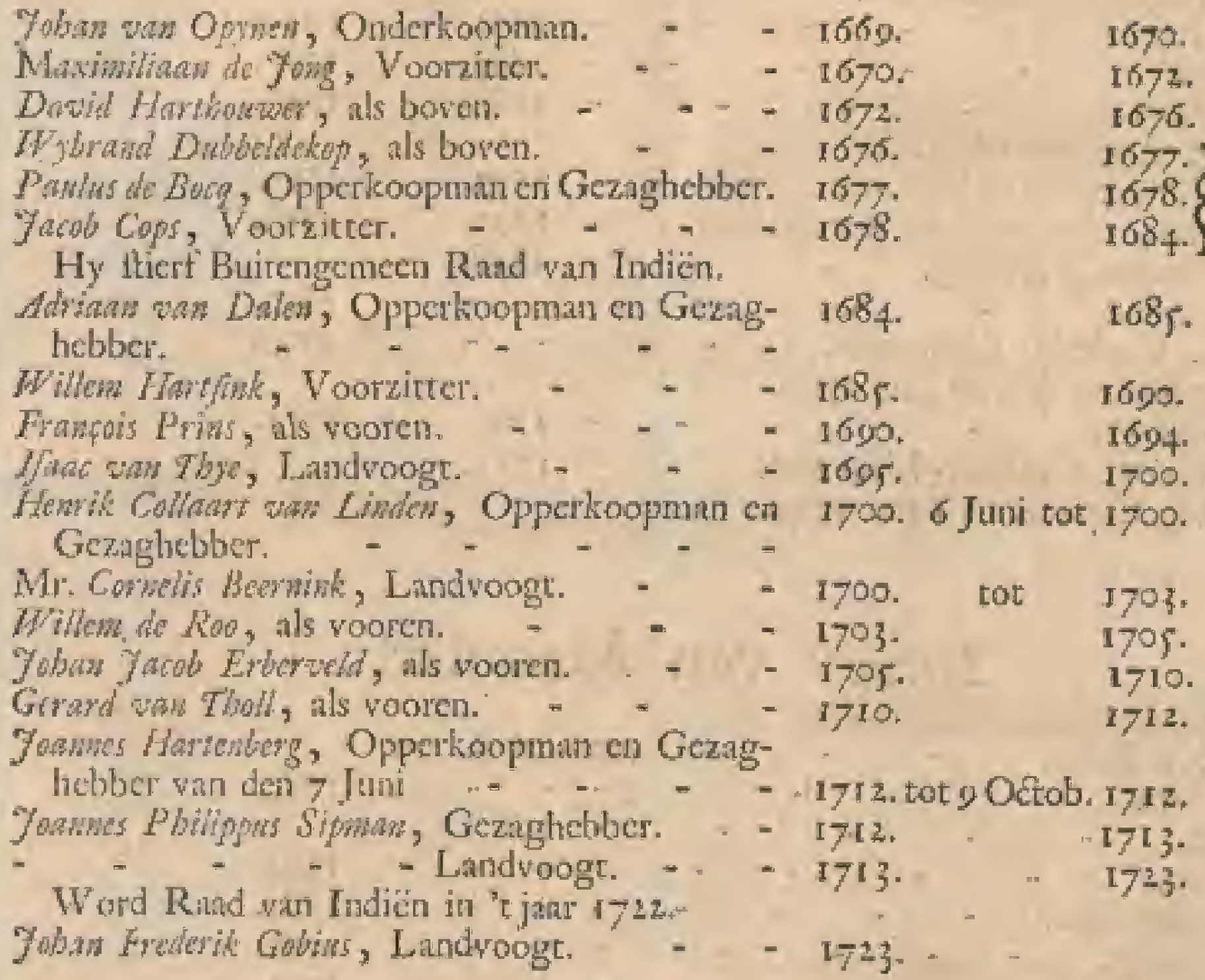

\section{Opperkooplieden of Tweede Perfoonen van Macaflar.}

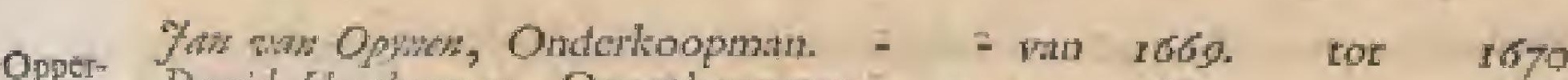
kophlie- Dawd Rarboutw, Opperkoopman. - = 1670. 1672. deti hier -

Wybrand Dubuldep, als vooren. $\quad$ - - $\quad 1675 .-1676$.

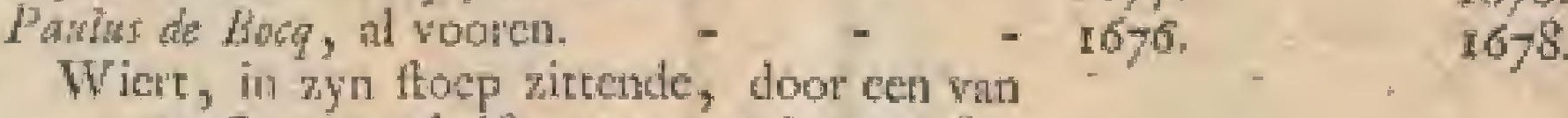
zyone Atuwen gekrilt, ontrent 't ja:t' 678 .

Aariany Datos, als vooner. $=1678 . \quad 1685$.

Stierf hier den $20^{\text {then Juli } 168 \% \text {. }}$

Finçois Prin, als vooret. - - - 1685 . 1600.

Hewik Collatit, als vootcis, of Capiticin. - 1600. 1694

Howil Caas, Koopman van Matt - = T694 tot 22 Juni I694

Mathlows Scbonkenberg, Opperlicopman. - I.694. tot. 1697.

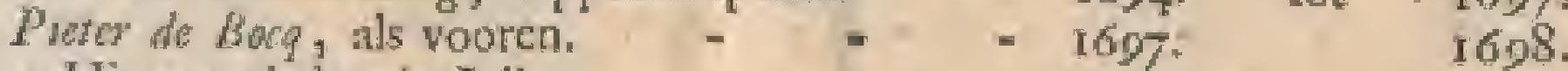

Hier overleden in Juli.

Harid Cullart won Linden, als vooren. - - I600. $\quad \mathbf{1 7 0 0 .}$

Tot dat den 6 Juni Gezaghebber wiert, dat

hy bleef tot den II Augulti.

Yacob Classamen, als vooren.

Jowhers Howtewher als yooren.

Gezaghcbber wan den - Juri tot den o Oto" bet: 
Joanmes Pbitipous Sipuan, als vooren, en Ge-

zaghebler. - - - wan I712. tot 1713.

Dideride vax Beerendrechl, Opperkoopman. - 1713. 1716.

Joban Happos. - - - - - - $=1710$.

Wrs dit nog in 't jatr 1724 .

\section{Capiteinen van Macaffar.}

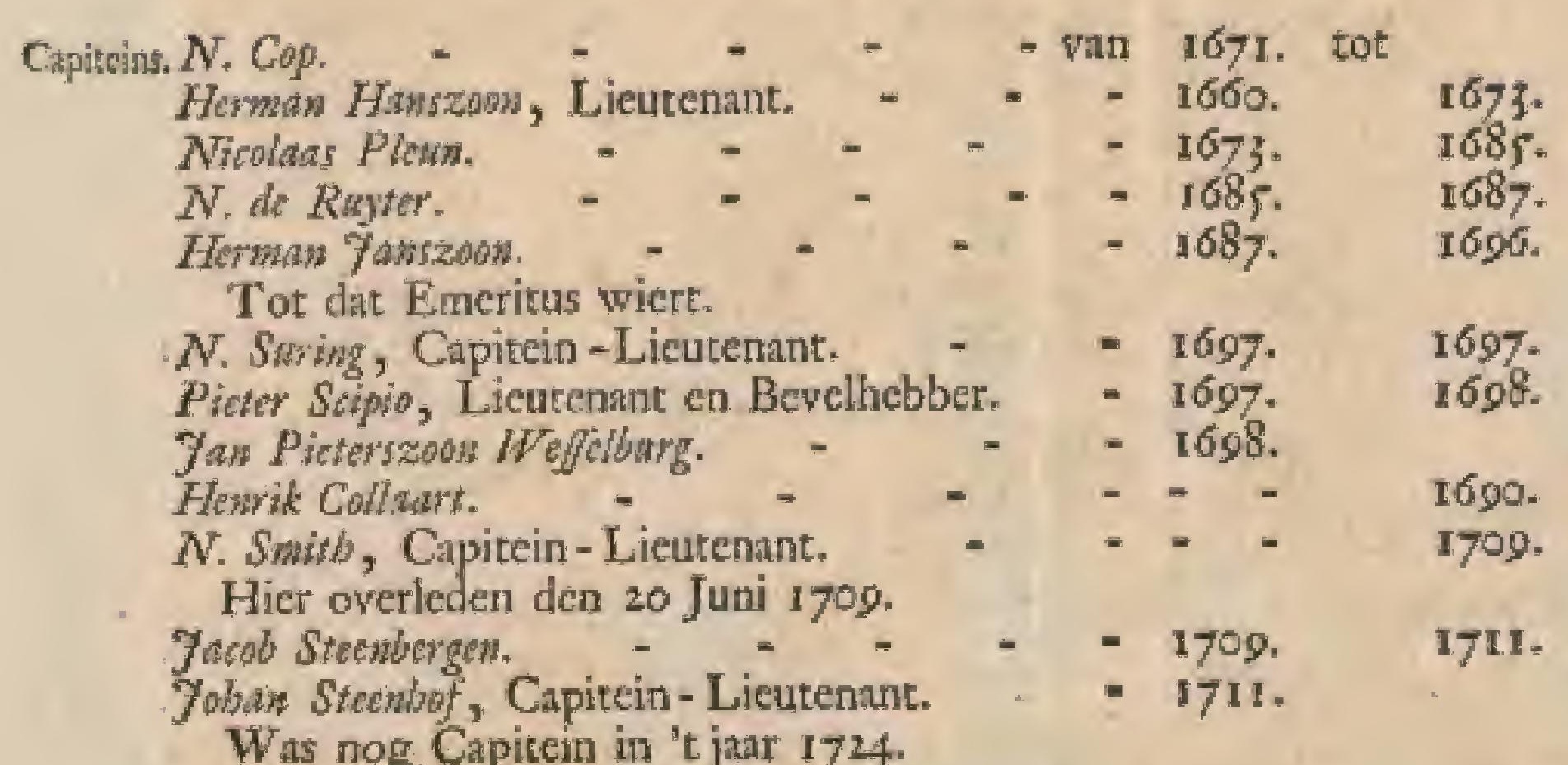

\section{Fiscaals van Macaffar.}

Fiscals, Alrian vatis Dales, = - = van 1678. tot

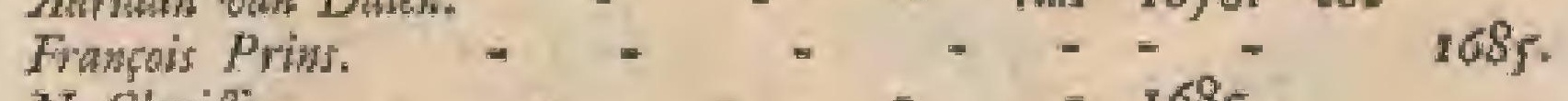
N.Charife. - $-\quad=-168 \mathrm{~s}$. Howik Caas+ - - - - - - - 1694. Acht was der My. - + - - - - - 170I. Howik Siterkop. - - - - - - - 1701.

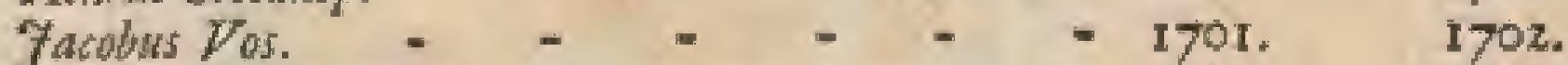
Fownes Hackant. - = - - 1702. i703. yacol Coyk wan Mierop, - - - - - $1704 . \quad 1704$.

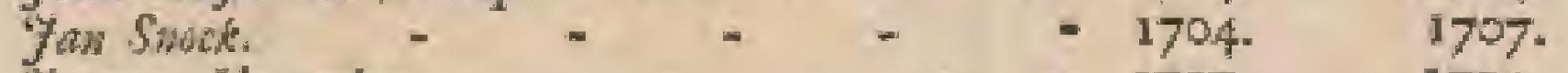
Yoanes Hartenherg. - - - - - - 1707. 1700. Diderik wom Becreadreds. - - - - 1709. 1713.

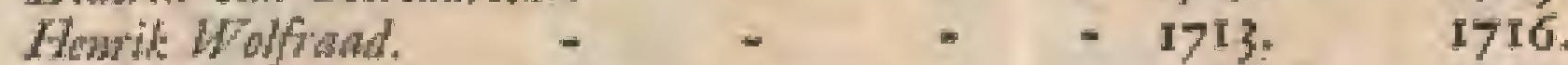
Fohan Hopow. - - - - - - 1716. 17ig. Abrabin vaw den Anker: - - = - I719. 1724 .

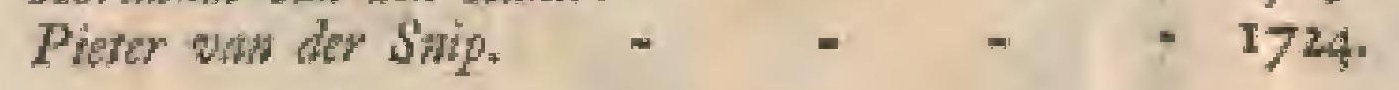

\section{Sjabbandaars van Macaffar.}

Sjahtath-Francois Prins - - - - van 1678. tot

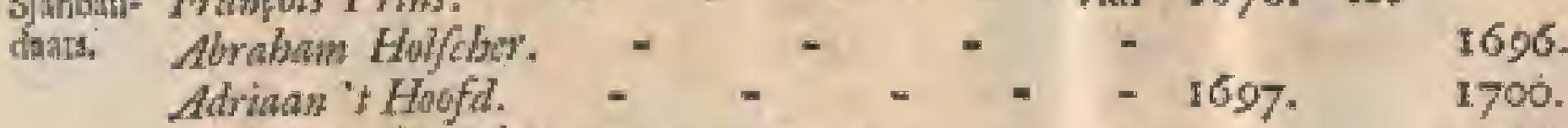

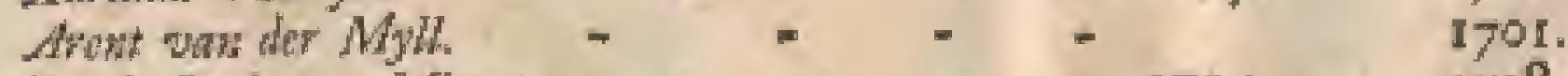
7ack Cugk wam Mirop. $\quad-\quad=\quad-1704 . \quad 1708$. Foumes Harianderg. - - - - $\quad 1708.1708$.

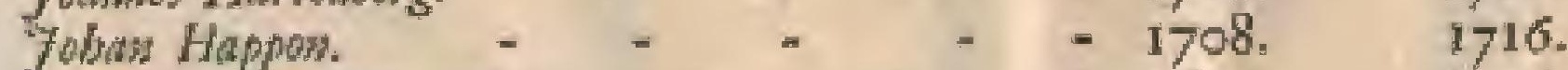

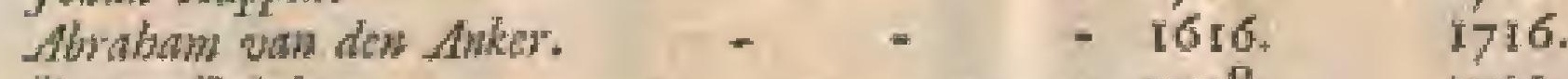
Rutger Erkelens. - - - - - $1718 . \quad 1723$. operledich.

En hect ook de Winkel cenigen tyd wal"genomen. 


\section{Z A $A$ K E N. $\quad$ N}

Winkcliers van Macaffar, die ook Caffers zyn.

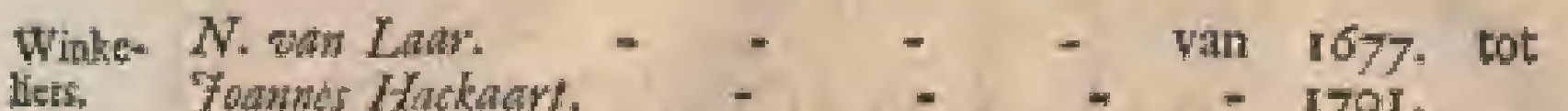

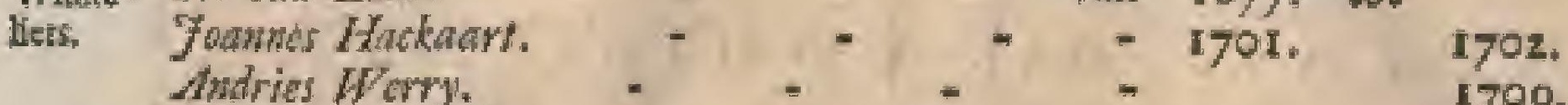

Andries Werry. - + - + $\quad$ - 1709.

Stierf toen hier.

Hemik wan det Stak al.

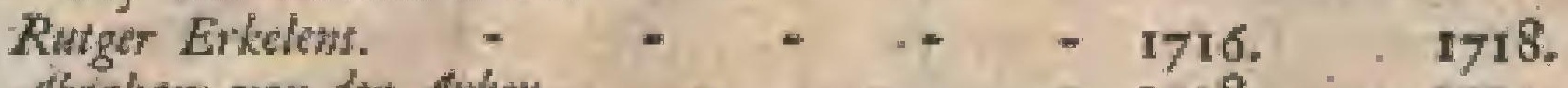

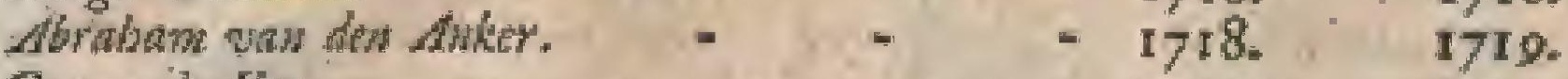

George de Pos. $\quad-\quad+\quad+\quad=\quad+1720 . \quad 1723$. overleden.

Yacd Rowaid, - + + - + +1744

\section{Soldy-Boekhouders van Macaffar.}

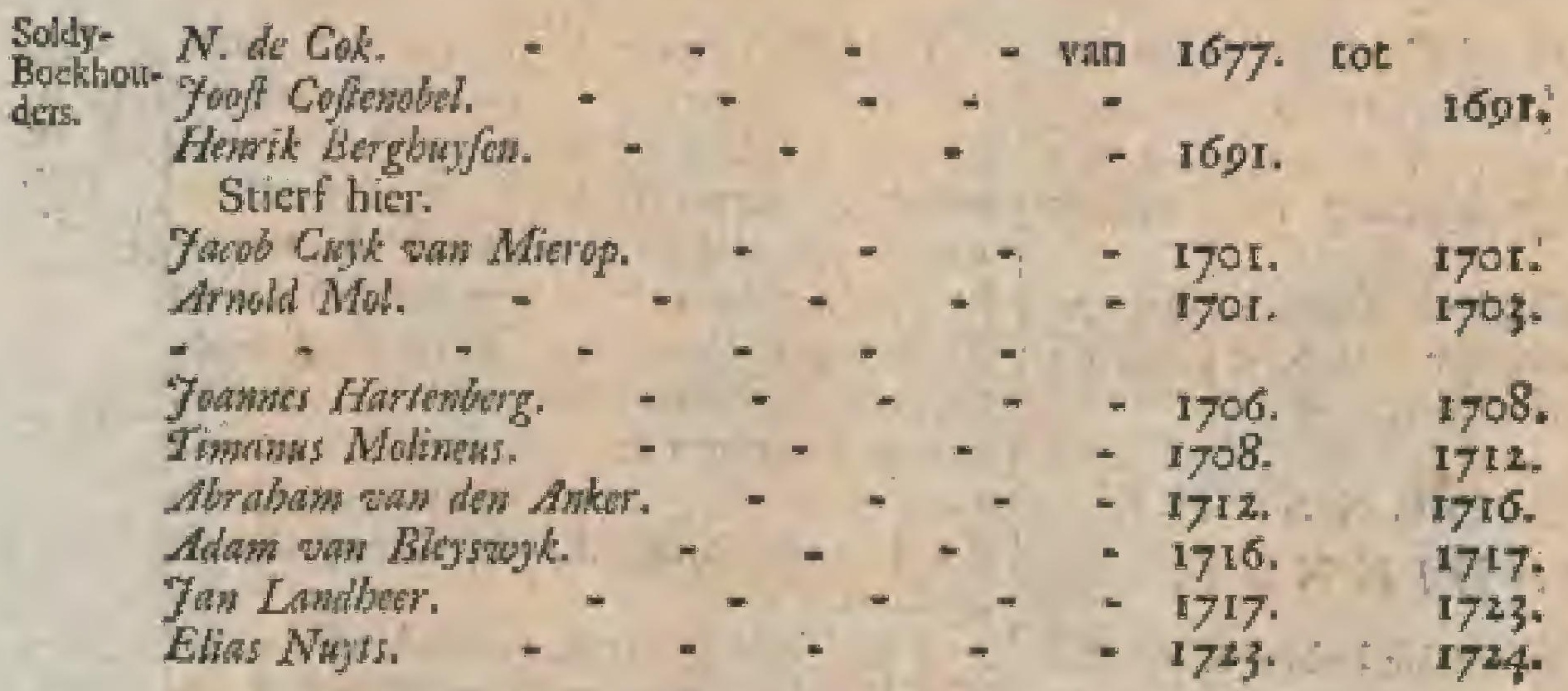

\section{Gebeimfchryvers van Macaffar.}

Gehima Abrabaw Holdow.

Schryvers $N$. Blom.

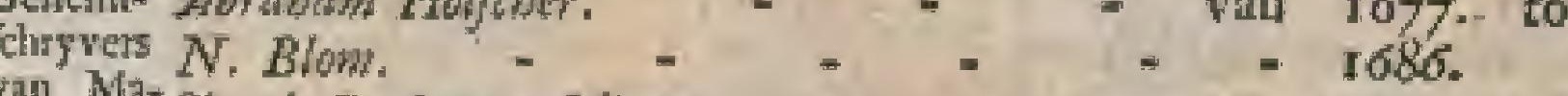

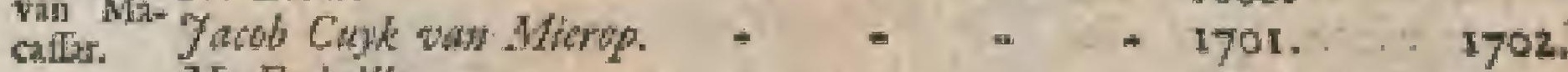

N. Frowlle
Willow Moors.

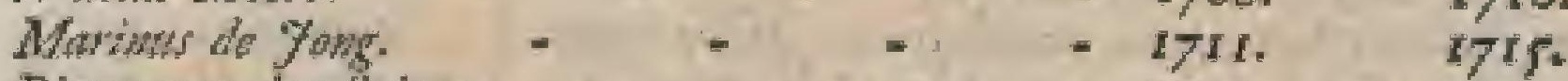

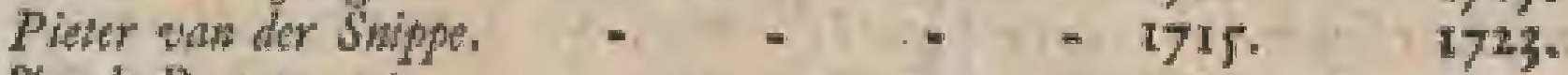

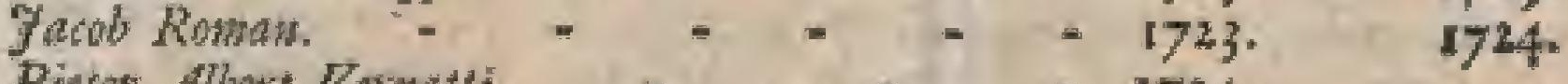

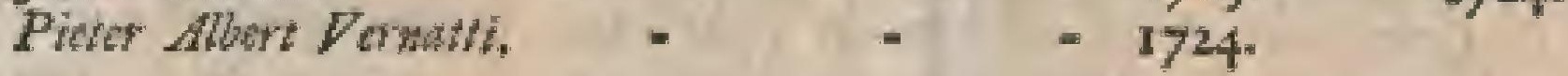

\section{Hoofden van Bima.}

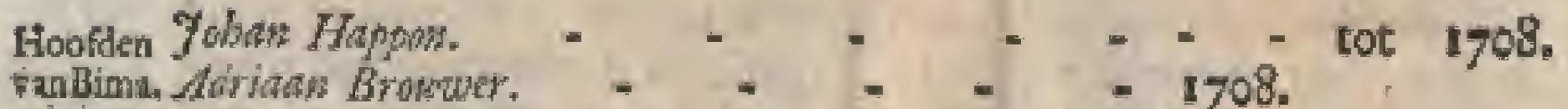

Hy lag 'er 1710. nog. 


\section{M A C A S S A A R S C H E}

I53.

\section{- MN EGENDE HOOFDST UK.}

\section{ZAAKEN VAN DEN GODSDIENST.}

$\mathrm{Z}$

Aakn won do Godedienlt op Maenfar. Derfohte Godsdienften of Celebes. $D_{c}$

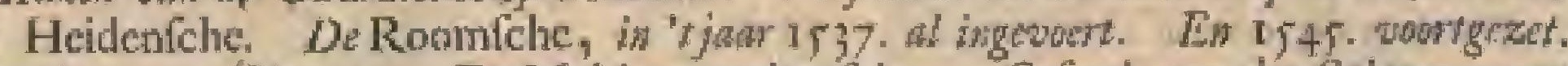

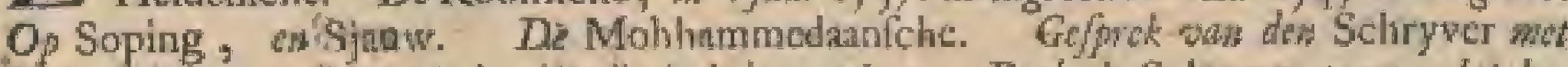

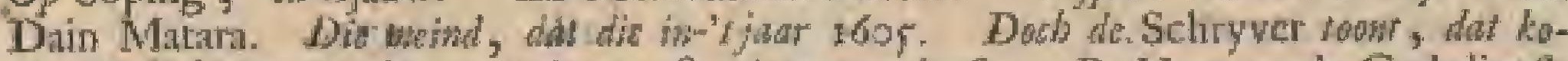

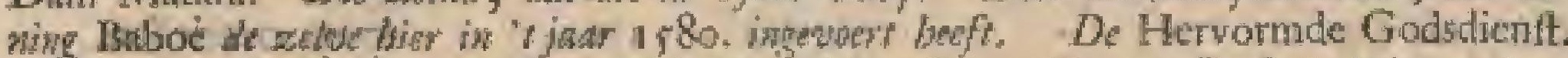
D. Berghuylen $167 j$ de cerfe. Predikant op Macaftar. Dr wan Beck in "joar 1672. D. Craynanger bier 160I. D. de Wirte I694. D. Hey 1696. D. Hooglander 1703.

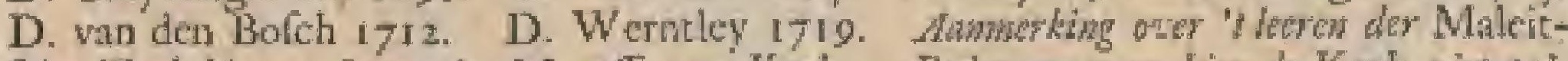

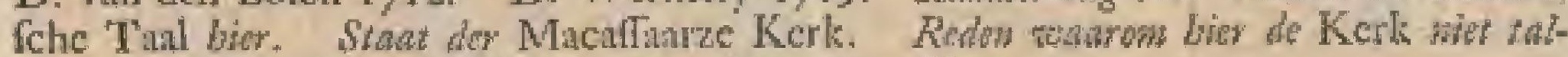
wyker is. D. Snock wun Clect. Machorzo Predilonten.

Zaakcen Fan de Gods dienlt op Macafiar weeft, of tegenwoordig nog bekent

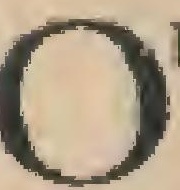
$P$ het eiland Cofbes tromen liny vietderki Jobrten van Godsdienth poor, die 'er of พar ouds ge-

Verfher- ${ }^{2}$ Deze "zyn, de Heidertifhe, de Roondicuftem fohe, de Molshammedaurfehe, en de op Cele-Herwormde Godsdient. bes

$$
\text { -. i il }
$$

\section{DE HEIDEN SCHE- GODSDIENST:}

De Hei- WJAt de Heidenfelue belangt, dere is de oudte, en men wint hier en dax in het gebergte nog overblyfzeler datr van, welke ons-doen zion, dat $z y$ in den grond, en thítwezcn der zalite, niess wau den Heidenichen Godsdient der Amboincezen, Ternateanon, - Javnaren en alle de Ootkerfehe volken diar om ftreeks, verfehild ; te welke in ecn anbidding wan den hemel, de surde, - en "c heir des herrels rde algenuene Goden wan " $t$ Heidendom) en in het ceres พar de beelden der zelee; of wel wan andere Afgoden, zelés van boomen, ea ftenen, die zy in de oudite tyden a anbaden, en in een menigte van bygeloovige plegtlykheden beltant, wan de welke zy jegrent+ woordig nog vol $z y n$, en dic $x y$, "tzy Molihammedanteh, "t $x y$ ? van cenigen anderen Godsdiendt synde, nog nier konnen alleggen, th gewogin $2 y n$-openbut, daar zy konnen, efr de meellet zyn, of in "theimelyk, datio zy door eenige wetten en ftralfen, bepaalt oyn, te plegen.

\section{E R $O O M \quad M \quad C H E$ G ODSDIENST.}

De Ropthfone
De Fefint Petrus Maffers teckent an, In 't jai des in "t jatr 1537 . , ten' tyde wan dent 53 \% al "Tetratantchen Portugecichet Land-ingeviert" woogt, Antoni Galvain, cenige licden Fin I sws. van it ciland Macalar (Celcbes, meind wert by, of let koninleryle win Macudjar ) in Ternate, op "i gerugr wath de Godsdienftigheid en-Godwugt wan dezen Heer, cr op "tberigt ran twec brocelers, dan - rects gedoupt, om voor veet underen, die zy mede bringren, den Doop te ver - Locken.

- Met hen wiert toen ook Francisus Gafrius (dic daar reets eenigen tyd geweelt was, na Getigath (dat ik niet kennen, nog randen kan ) te rug gezonden, die dar den koning, zyn brocders vrouw, zoon, en vel whdere Edeler, ten getale wan i 30 , doopte, van whal hy toen na it cilatid Mindanao wertioliken is ; man als ik myne gedagen over dit gewal uiten zal, cordecte ik wel, dat dis lieden wat ". $\mathrm{t}$ eiland Celubes konnen geweeft zyn; manr dit zy cigentlyk onder den lioning sarn Ternate, - Lindvanga Galatam, geftaan hebben, welke zalken men onder die van Macaflar niet verumarren noet, anigezien die van een geheel anderen ard $2 y n$, en tot de Moluccos behooren.

In 't jagr 1545 . quam wan Malak ka cen Portugecfel koopman, Anomi Paya genatne, op Macalfur, dic, zoo de Jeluit Zarions zege, by den kaning win Soep ${ }^{3}$ (dic zal Soping zya) firliomen is, en Op sdzich van dar na her ryk Sion (Sjaw 7 al ying, en by meenen) fo mylen van daat yeleger, begeven heft; al watr beude die konimren door den ywer van Paye gedoope zyn, gevende ann dien worll wat Soping den niam van Losids, gelyk by zyn koningin, en weel anderenatarat, mede gedoopt heeff ; doch den koning wan Sjaw hecht hy den nasm wan yan gegeren.

Zy vicrzogten beide, dat Payva, in bunnen nawn, een verbond met den die wel 30 of 40 jarren wont de Mohhammedatabine belent, hoewel dar van zecr weinig belang geweeft is. 2.1. $\mathrm{K}$ 


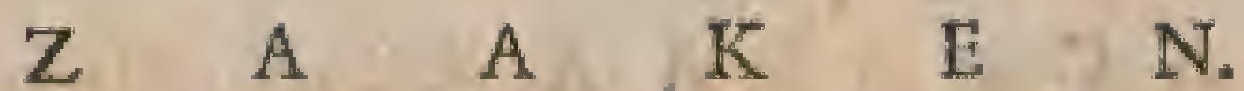

154. Koning wan Portugal malken, en hen Priefters zenden wilde.

Dewyl nu die Sjauw een ciland is, dac onder den koning van Ternare behoort, word dit hier weder zed quatlyk onder de zasken wan Macallar verwatd, ahtzoo her tot de zanken wan den Godsdientt der Molnccos, of wan Ternace, alwarar wy breeder duar af fprcken, behoort.

Het is zeker, dis de Portugeczen in de luarer tyden, watmeet $z y$ hier eed valt Comptoir tot 'r juil 1660. of 1661. gehad bebben, bunnen Godsalientt hier verder uitgebreid, en vect Heidenen of Mobhammedanen gedoopt heblow ; mar het is ook zeker, dhut deze Natmehrittenen, die die geloowe man wix wereld che inzigten anngenomen hebben, en geen genoegzaame gronden nog lemnis van dien hadden, het zelve ten ecriten weer verlanten, en naderhand zich, of tot den Mohbummedanfohen, of tot den Hepvotmden Godsdient, begeven hebben.

\section{DE MOHHAMMEDAANSCHE G O D S D I E S T.}

De Moh- T) E Mohtrammedantehe Gododienft hamme- 1) is wan de grootlte uitbreiding op danafine dic cilind, en byria alje de loningen mee hun onderdanen zyn Moors, en volgen de Leere $\operatorname{yan}$ Mobjammed, zoo als dic wat Abobekis, Omar en Oonnm angenomen is, die men gewoon is Sumber te nocmeit.

Wanneer deze Godsdienft hier cen begth 13: het niet nens, watas over mein zich nict ic verwonderen hect, alzoo zy geen nete antecleningen was hu cigen ziaken hebben, gewoon tynde de gedagtenis van hunne oudfte gevallen ia hune liederen, die $2 y$, ten oorlog trekkende, opringen, te bewaren.

Gefpels Ten tyde, dat ik Legerpredikint op

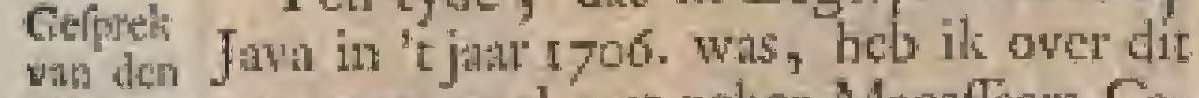
Stlisyer voorwerp wel met zeker Macnflats Ca-

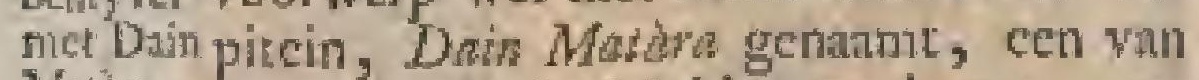
Matha, de wethandigfe Molahammedaunen, gefipoken, en op myn vmage, hoe oud hun Geloove, en op wat tyd en wyze het op Macaflit ingevoert was, tot antwoord bekomen, dat zelker Maleycr, wan Cotatengah, op Sumntri, Dato Bchdag genamt, in 't jan 1605. op Mactifin gefomen is op een cyd, dat de Macaflation nog meelt de boomen, en groote ltecnen, als hunne Goden manbades. $\mathrm{FH}$ wees hen atu, dat zulke Grilen hen onmogelyl in den nond konden helperi, en deed hen begrypen, dat "er cen God was, die alles geternpen had, en nog beftierde, wi die vericheide Propheter, als $N_{\text {ath }}$ Modis, of den Propheet Mo/s, Nols Dnod, of den Propheet Darid,

II 1. DEEL,

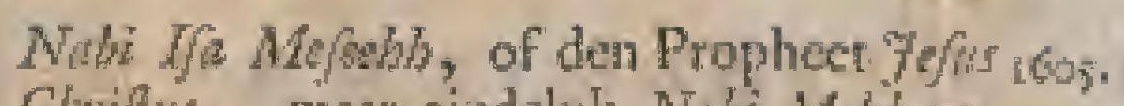

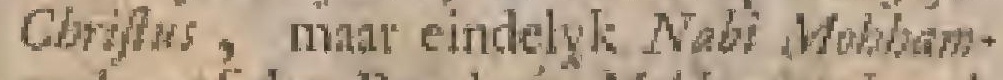
Had, of den Propheet Mobbamind, als den grootfen en that then der Propheten, Die gezonden had, om hen den regzen wegmeind, dat? det zaligheid atan te wyzen, op welken mera dis God zy dierhalven al hume hoope grond- ha 't jast veften, en by welken zy rich door de 1605 . voorfpralic van liobbamid motten zocken athgenam te mathen.

Dit viel, volgens zym zeggen in "t voornoemule jaur den oden Septenher op eenen Vydag woor, en de cerfte, by wen deze Letre op Maciflur ingang lad, en dic

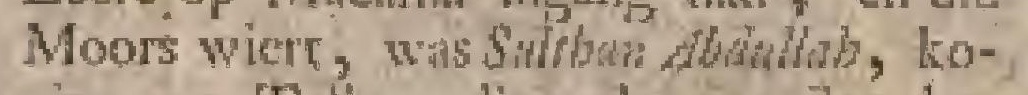
ning van Telio, die vadel van den beroenden en byzonder geleerden Prins,

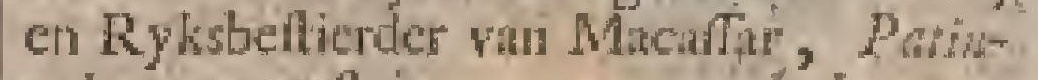
gallan geween is.

$\mathrm{Hy}$ wien lier in antlons vas Swlbm Fonnem Righkon, koning vilin Got, en in "t jar ífo. die wa Wadjoe, en de Boeginezen, den I len Mey gevolgr; dech die van $G$ on, en wan 'c ciland Binn, waren in "rjati 1617 , in April, en de. Bostonders, na dat de hening yan Goat hen overwounen hatd, in 't jair Ió26. hen. eerft in deze lecte nagevalgt. Naderhand is die Lecre op Matalitr ook zeer. Tterk door Swh bun Mobbanind, en door Crain Tjin, zynen zoon (die de valer vin Cran Crosgrong was) voortgezet.

It will wel gelooven, dit die verthat Doch ten

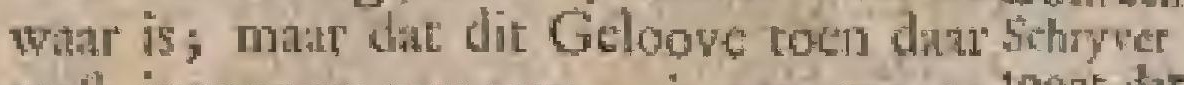
ecrtt ingevoert zou zyn, is een groote tonnt, dat

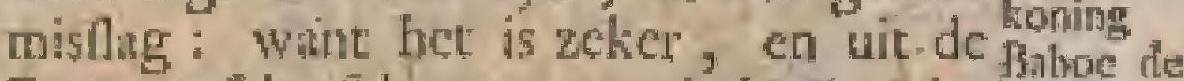
Portugeefche rehryvers ons bekent, dat telve has 7.y by hun komft hice lang voor dien syd in "rjalr Mooren gevonden hebben; matar om deze 15 Re. ist-

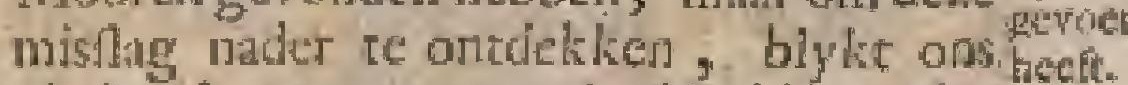
nit bet bevoorens angehathe fititr, dac. in "t jan" 1580 , by de komf van den Temataturehen koning Boboc; of Banb Uhah, met zyn vloot op Mucalar deze Godsdient door dezen vort hier ingevoct, en dat die Lecre allerecrlt dóor den koning van Mucattur, Crain Paingaloon, strder's Croto Caroet gentant, *angenomen, en zedert ditur doorgedrongen is.

Wy zullen van den inhoud ran dezen Godsdient hier nict wea fprelies, filzoo dit onder de thofte van Jown gedian is matr dit alleets 'er nog byroegen, dat deze Godsdiente zich hier onder deze blinde Teidenen zeer verre alonme uitgebreid heeft, zoo dit het grootfe ge* deelte van dit eiland Mohhimunedanchlo is, en Godsitient, die zecr gernalikelyle cri byzonder ligt door ben kan witurgemomen wordels, dote ook de reden is, watrom hice zcer weinig veugt by ons (gelyk in 't reryoly nader blyken zal) hecf tomen gedah worden.

$$
\mathrm{G} \cdot \mathrm{g}
$$




\section{M A C A S S A A R S C H E}

166. + DE HERVORM DE GODSDIENS T.

De Her- TA da de Heer Conels Spelwa in De Her- 1 "t jarr IG6o. Macaftar 200 dipper vomde enzecghatig verovert, en andezo trotz: dienth Celebilche koningen getoone had, dat her bloed der aloude Bativieren en Catren in 't Ooftem nog eren zoo kragtig, als van ouds, iv de aderen der gevreesde Nederlanders fwierde, (war door by zynen en onzen nam dant voor ceuwig geplane en ontzaglyk genaakt hecft) oordeclden hatr Edelheden op Batavit, als Oppervoeltephecren van de Ketken wan Indich, dat mon hier ook ten teriten voor de zatiken wan den Godsdicinfl behoorde te zorgen, en dat een valt Predikutur vain den Hervormden Godsdienft te legren.

D. Berg Dat op wiere D. Paras Bergbuyen als huyzen, eerlte Predikant den $8^{\text {heall Augulti }}$ I660. I6jo. de op Bativia herwarts beroepen, wertrok

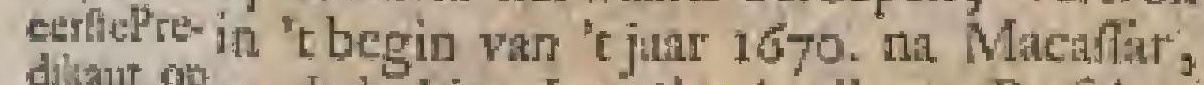

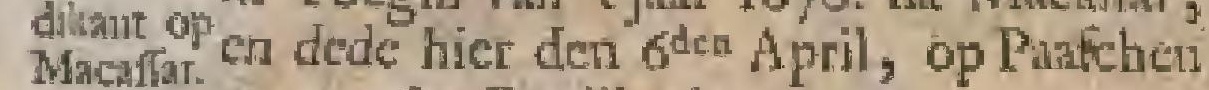
zyn eerite Predikatic.

Deze Heer heeft zich in dien korten tyd, dien by bier gettan heeft, nict it|lien in "euithreiden van hat Euangeliutr Chrifti ia de Nederduitche taal beywere; mar zoo uit zyn felayvens na Amboina gebleken is, zich ook in de Maleitfche tanl cenigen tyd geocffent, met tocleg om de Mooren aldara zoo veel te klaarder in hun eigen cual (of wel in deze Malcitfche, die daar immers zoo veritamiliat, nls 't Macaftars, is ) aan te fprelken, ev uit hum eigen gronden te overtuigen; maar deze goede en neertige Heer heeft dat niet lang konnen doen, alzoo zyn Eerw. 1671: zick geworden, en toen hier overleden, en onder de zinal in " $r$ kafted Rotterdam, in de Wondheelers winkel, begraven is.

In "t jatr 1671. deed D. Abertus Struts, by zyne komft wit Ternate hier angierende, en cenigen tyd hier gebleven

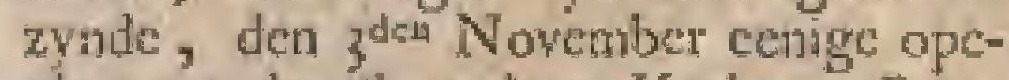
ning wan den ltatat dezer Kenke op Bativin whar opinen, de dood van D. Bergbryzen vernomen bebbende, goed vond,

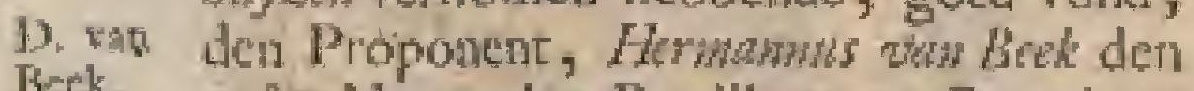
I672. 3often November Predilant op Butrawia te matken, gejyk $z y n$ Eerw. ook zoodinsig in 'c jar r 672 . na Macaffat' gezonden is.

Dit is cen mathig en yorig mon gcweelt, dic oot cenige heginzelen, on de Malcidche tanl te leeren, genalkt heeft ; mat het fchynt, dat zyo Eerw. "er niet hect konnen door geraken, om dat in zyn eigen letter te lecren. Egter hect hy 'er in gepredikt. Hy hoeft hic: 3 jaren, ca 3 of 4 manden geftan; doch ontrent her werk der bekecting onder de Mohbanmedinen (die zeet bitter, en hardnekkig hice zyn) weing konnen vitrigten, hocwel zym Erew. van 460 . alle zyne woor - en nizarcen nog wel her mecite roordel ofider ben gedian heef. Hy is den I $7^{\text {den }}$ Mey I $69 t$. hiner overteden.

In "t jalr 169r. wiere in zya Eerw.

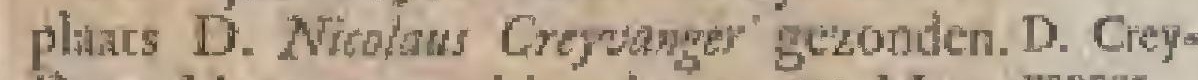
Deze Heer quarn hice den lover Mey, ranger heeft hier niet lang geftan, en is mer hier 169 . cerige mocjelykheden, die zyn lierw. met de Heet Collaws had, in 't lantet var 'c jar 1693, tha Batavia wercroklen, Watar door zyn Eerw. (dic dian op ma 't Waderland wortrole, alzoo hy niet genegen was ma Banda ie ganj nuer in Ltiac geweelt is, on hier veel dientit, dewyl mar 2 jaren hier geblewen is, te dotn. Zyn Eerw. is op de thuisteize $169 y^{-}$. in Augutti voor Ond Beyerlath overleden, en datar begraven.

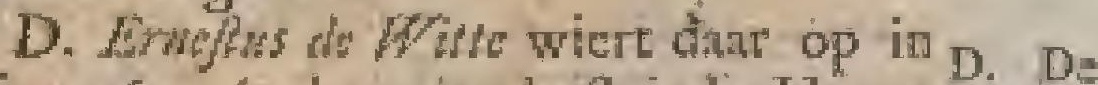

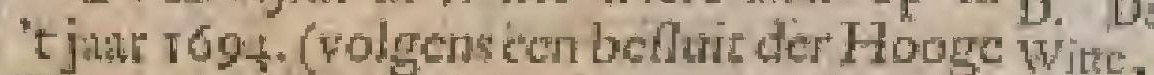

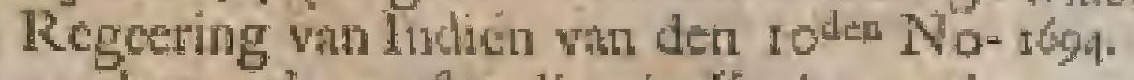
nember, den $23^{\text {ilea }}$ diso in Kerkenrade พan Batavia ingelevert) ma Mactafar gezonden; hoewel men bevoorens "t oug op de Heet. Perws Jachins Colkerus, die tuen in Tornate lag, geflagen had , matrer die Heer op Batarta gekomen, en wegens zickte nier in ftat zynde om clders gebruikt te worden, en dala op verder in 'c jaar a no4. na " $\mathrm{t}$ aderland gande, is $\mathrm{D}$. de Whe in dat zelve joir den zutsi Mey hier verfeheenen; doch deze Heer is hier ook niec lang in 't leven gebleven, en in her tweedie jiur datr an, of 1606 . den 3 den Febrwati overleden.

In dit zelwe janr quam hier D. Gerandis Hey den $19^{\text {den }}$ Marte, dic 'ef not 1703 . 1606 .

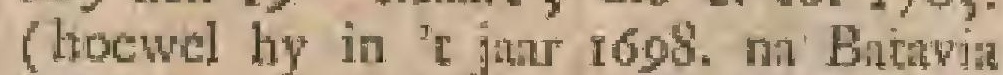
vertrok, on te trowwen, collier 1609. weder quam) gelegen heets, in welke 7 jatrer zyn Ecrw. wich alleen in den Nederduitichen dientt bezig gehouden heef, waar op zyn Lerw, wan hier na Barayia wertrokken, en dair zeder geblewen is.

D. Jacobus / Logland verwing zyn Eerw D. Hootin " $\mathrm{t}$ jar 1703 ., die den 13 ties Februari land,

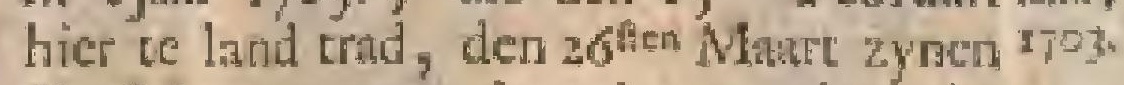
dienit begon, en de zelve toe den gusa Mart 1711. marltis wargenomen, doch zich in geen Oolterfolie ritalen geoeften heeft.

Men had op Bataria D. Yarolus vans Holdingen in zyn plats berospen; doeh zyn Eerw, ondereutichen getroww, en kore date na ziek geworden zynde, is

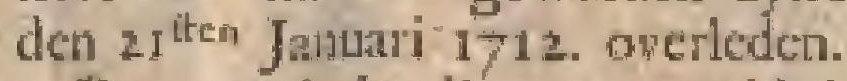

Datr op is in dit everigemeld jarr D. D. сап

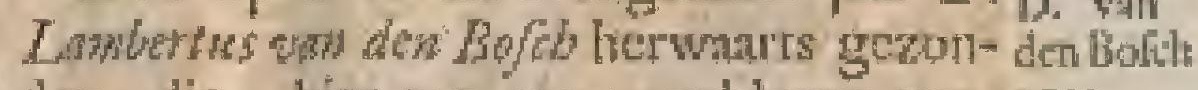
den, die, hier tor $1>\mathrm{L} 4$ - gebleven zym-17t2. de, ma Barvia vertrokken is, on te crouwer, gelyk dar zyn Eorw. mee cene Juff. wan Soin in den Egenituat getreden, weder herwatts gekomen, hier tot 17.9 . gebleren, en toen na Battria qeatrolken, 


\section{Z, A A I K E N}

179. nlwatr zyn Eerw, nu nog een yan de Predikanten buiten wate bedicring is. Zyn Eerw. heeft hier 7 paren geflaan, en heeft $2 y$ dicuft hicr in het Nederduitfeh, zonder dat its wete , dat $z y n$ Eerw. zich in 't Malcits geodfene heef, zeer wel wangenomen.

D. In 't parar 1759 . is hice D. Gergins HowWerntey tho hermiley gekomen, en deze Hecr 175\% heeft 'er tot 't jaar $[723$ - gelegen, wai]neer zyn Eerw, tha Batavia on onbeden is, on cen der Rerifores van den Malleilichen Bybel ran D. Leydeker te zyn, wanr thit men gifen-met, - dat-zyn Eerw onderturfehen Maleis gelecre heefe; hoewel ik niet kan oojdeclen, wat Maleiss zyn Eerw, weritąa, ofte wat woor begulmheid hy dar toe heef.

Ammer- Over geen zaak ber ik meer werwonfing over dert, dan dat nier eenigen van deze lan" lecten tere Hecren Predikanter nuet lalt, om de der Ma-Malcitche tial grondig te Jeeren, anthal hicr gezet geweetl zyл, te meer, alzoo darr mede hier reer veel dienft te doen was; natar mogelyk dat $z y$, gezien en gelwoort. hebbende, dat de Hecren Ferrira, Lyydekler, con ik, dari mede matr veel moeite, nyd, en ongunft, zonder eenige agting voor al bumen bloedigen anberd te beliomen, op den hads gehialt hebben, daar door gcheel en al afgetchrift zya. Ester moet ik nogmanls tot Jof van de Heer Bergbuzons zeggen, dat zyn Eerw. zich al zoo verre daar in geoeffent had, dat hy in that was, on icts in deze Tial met ecn Arabiche letter te Vehryvea; doch de Heer wan Beth was zoo verre gekvonen, that hy den Inlander in die tal fhigtẹ kon, gelyk zyn Ecrw. mecu als ecous openbatr in die tanal gepreStaat der dikt heeft.

Macas- Wa nu de fatat yan deze Kerk beftngt,

kuthe boegroot de zelwe, wat door deze 7 of
8. Predikanten in den tyd van $5 \mathrm{t}$ jaarent 170 . verrigt is, zulls is my door de Hecr Hogiand in 't juar 1709 . aldus anngefchreven, en was dezelve in dere mavolgende Leden toen beltande:

Ledematen - - - 207

Inlaudze bejarde Chriftenen ito $-\quad-$ Chriften-kinderen 138

Dit is wel een zeer klein getal; doch keden men moct weter, dat hier matar cen Pre-wanom dilatue in "t midden vin zeer harrock hige hier de. Mooren is, en dat die werks genoeg heet herk niet met zyn Kerkdienlt eens of rweenal, ralryket na de gelegenheid zulks vereifcht, on een Catechizitie datr by, wnar te nemen gemecnelyk wan 2 Ouderlingen en $x$ Bidienci verzelt, en onderftcunt zynde. Dar bencven moer men in opmerking nemen, dat het, hier wa'de natftigheid of triaglieid vin eem Prediknar, mant wollagen wan de neigitug der Mooren alhier afharigt, of zy zich tot hec Chriftendom begeven willen, of niet, alzoo zy volkomene wrybeid van Gewite hebben, en men noet hen nauwlyks dar over fpreken duife, om dat de Mooren dit teis eerften, als of men hume onderdamen tot het Chritendom zoge to perszen, vidkrysen zouden, zoo dae men genoodzatakt is te wagter, tot dat $x y$ zich zelven kometn angeven, cn verklatren genegen te zyn, om Chriften re worden, watr tim men heil digelyks in de groiden van den Godsdientt doet onderwyzen, tot dac $z y$, in Atant zynde Belydenis te doen, dair of dan gedoopt, as Ledematan erkent, en angenomen worden.

In " jaar 1623. is in de platuts wan D. D. Snock Wewly hucr D. N. Snot wa Klef go- vanKeer
zonden.

\section{Y S T der Macaflaarze Predikanten.}

Macas-

Garie

Fordi=

iauten.

Petrus Berghtyen.

Grwakshs wow Beok.

Nicolars Crejwanger.

Ertchas de Witc.

Gerardus Hoy.

7abous Boggiand.

Lamberist wan den Bo/ch.

Georghs Finricus Wermites.

Alrabun Snock van Kletf.

En dus meinen wy nu, by "tbefchryven wan 't gene door de Nederlanders, in te veroveren van Maciffur mee den tankleven wan dien, werrigt is, ook weder middagkinar vertoonte hebben, dat geen der oude nog der latere Befchryvers ofte wel beziters wan Indic n, of deze en gene decleu des zelts, het zy in oprigt van de

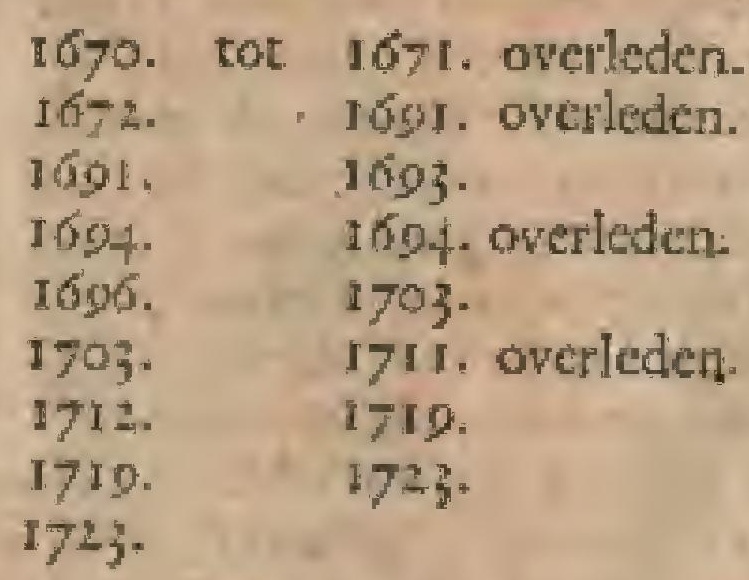

nete befiryving, luet zy in opzige ran het klockmoedig veroveren dezer landen, ecnigermanten by die dappene Batavieren konnen vergelekeo worden, wial medo wy dan ook aticheid was de zatken van Mieaflat, en fan 't eiland Celches nemen, om tot die wan de cilunden Borvề en Baly over te gam.

$$
\mathrm{G} B=\mathrm{BE}
$$




\section{B E S C H R Y I N G E $\vee$ A B E S C H R Y V I N GE}

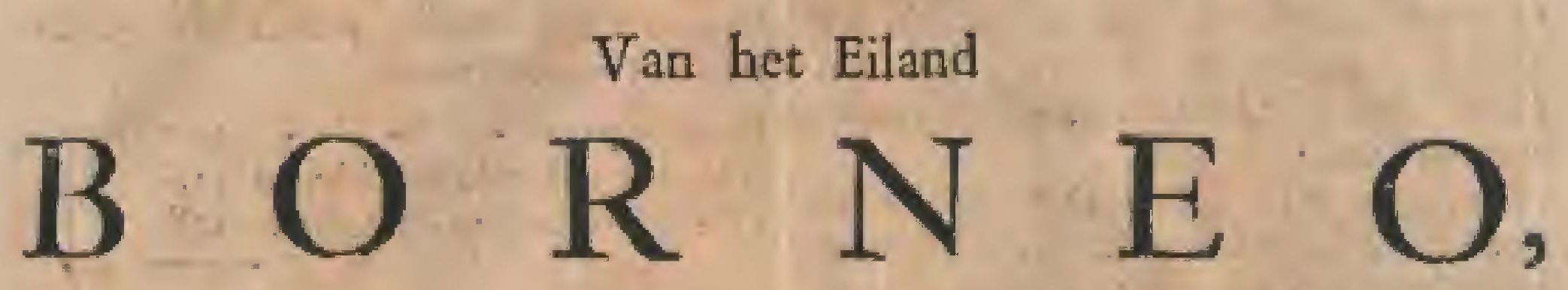

En onzen H A N D E L aldaar.

\section{E R D E B O E K,}

\section{E E R S T E H O O F D S T U K.}

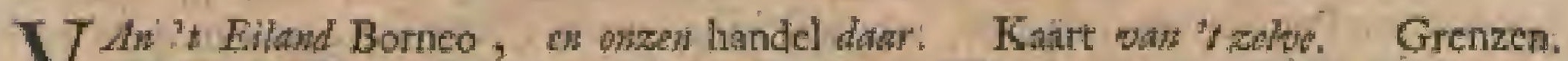
Banjar Mafin. Huizen. Ingezetenen. Watren, bier vallende, of bier gewokkes. Grenspal dezes yks. Krygsnagt des kowings va Banjar Maffin. Succadañ. Landa. Sambas. Bornco. St. Annebani. De Dwalbani. De Dorpow Coeti, Billipapan, en Paffr. Ferfbeide andere Dorpen cn Rivieren, Borneo van binsen. Mefl ondekent.

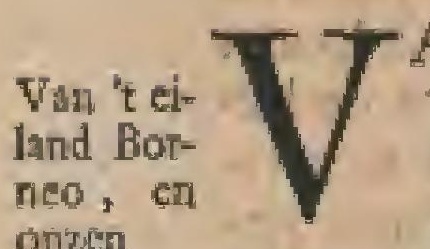

An de befehrywing van het eiland Celébes of 'c Gouvernement-wats Mnculfir gaas wy over tot het gene wy over het eiland Bornco oniten bandel datar:

\section{te zeggen hebben.}

Het is het grootlte, dat wy in Ooltindiên lennen.

Hoe groet het zelve net is, is ons onmogelyk te bepalen.

Kaart wan Wy geven hier, onder No. 37., een "relve. groote en vel berer Kalart wan "t zclwe dan de voorige, tit welke blykt, dat het zich Z. es N ruin tot of wat voorby den $4^{\text {den }}$ en een hatwen grad Bezuiden, en Benoorden den Evenas van den Iten tot den 8 ten grand, en aldus in de breedre r 2 , gratden, en in de lengte, of O. en W. wan den 1 ro cor den ifs grand zich witfreke, dat voot de breedie 187 i en woor de lengte I27! mylen uitlevert, en dat dan in 't rond ontrent 525 of 3 o miylen nitmatken zou thoc goed nu de onde Kant ook in zich zedven 2 , $7 \mathrm{nl}$ men wit decze nieuwe, en uit onze beichryving klar geweg zicn, dat het in opzige wan de platzen, dic tuftchen Banjar Mallin en Cotaringan leggen, ongelyk grooter wezen moer.

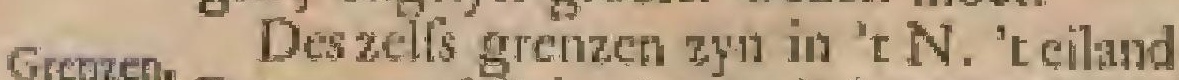
Parggoya of Calamines, in laet O. Mangundana en "teiland Celibes, in " $Z$. de cilanden Java, Bali, Sumbawa, enz in 't W. de Maleitze kurt, ci in 'e N. W. "t koninkryli Sian.

Het is een var de rykfte en hecrlytefe cilanden, die "er in de wereld $2 y$, doch in zyn binnerate nog niet regt bekent.

Men heefe mata 4 of $r$ treningen en hoofdphatzen op het wches, die tot nog toe met den nam der koningen van Banjar Maftin, Fan Succadana, van Landa, der Sambas, wan Hermata, Jathoe, en wan Borneo, bekent zyn, van alle do welke wy hier en daar zullen Freken.

Die van Bunjar Mallin fethwn wel de Baniar magtigfte te zyn, ook is by wel 't meeft Mallini belkent.

Dir Banjar Maftin is geen ftatt, gelyk men voorgeeft; man alleen een dorp. Het legt in it $Z$. ontrent op de breedte yan 4 , en op de lengte wan I 5 r granden. atn ecr groote breede rivier, die van hat ren mond tot aan Banjts Maffin zulken rck bellant, dat men wel ; dagens fcheppens werk hectt, onde rivier uit, en in wee thomer.

Men beeft hier en dane ecrige banken, doch egter wel 3 of 4 vadem waters tusfehen de zcive, en als men 'er binnen pekomen is, word het "er veddieper, 200 dat men datr ana wel 6 of 7 wadem diepte krygt, nwalar men op ecn zeer goede moddergrond ten anker kotnen kith.

In de zclve zyn doorgans wenig. droogten; doch hicr en daar doen zich wel ecnige booge cilanden 2 of 3 mylen ra boven, co ook 2 mylen van Banjar weer anderen, en voor al 3 ejlinden op, ewen beneden wellie, regt froor deze plats legigetde, zich een fware fpruic nu de hoofdrivieg onclaft, hangs welle de dorpen Tatas, en Cajoe Tengihli leggeis, gelyk Bamjar zich aan ecn kiein watertict wertoont, ha "t welke nen tuffehen twee wan die cilnndekens doorfart.

Hotwel dit poon de booldphats ran 


\section{B $\quad$ O R $\quad$ N $\quad$ E $: 0 . \quad 237$}

tr ry dezes konings gehouden word, Let dorp Borneo, en op Calca, Satihoud deze vortt egter doorgans zyn Hof in Tutas, en Cota Tengah, watr by nog 2 of 3 kleine dorpen leggen. Deze voornoemde fpruit ont lprings uit zeker kein gebergte digt an zee, in welke bergen ook flegt goud valt.

Hưzen, In Banjar Matio zelf zyn ved huizen, meeft van Bamboezen op zyn Indianfeh opgefingen, hoewel ook zommige wan plinken gemakt. Deze zyn doorgans zoo buiterngemeen groot, dac 'er wel Ioo huiggezinnen in een huis konnen huisvelten, war in ook yder huisgezin zyne byzondere verticklen heeft; doch in zulk een huts woonen gemeenelyk geen andere, din bloedvrienden. Zy zyn als de Macaflarze huizen, op thanken of palen gebouwe, onder welke zy dan ook gewoon zyn hun wee op te queken.

Ingezte- De ingetetenen alhier an ftrand zyn nan oorpronkelyke Jiwanen; Johorezen, Makyers, Maningcabers, of Palimbangers, Macaltaren, enz, van wat het cok komt, dat men hier Maleits, favants, Mitcaffars, en Sumatrans lpreekr. Men oordeelt egler, dat de meefte uitgeswekene Jnwanen zyn, die met cen Madurees Prins, cen bafturt wan zekeren Sotferbotacn, die zyn vaders toorn vroesde, herwatrs geweken zyn, en zich hier nedergezet hebben. Het zyn trous loose en moorddadige menfehen; 'doch landward in op 't gebergte heefe men cenige bergwoonders, die var een becer atard fchynen, en die, behalven dat $z y$ de grootlle ichatten watr dit land bezitten, onder hen ook zeer friti befiedenc, byzonder blanke, en zeet verltandige wouwlieden hebben, war mede de koningen en princen op dit land zelf zich in den echt begeven.

Hier is zeer grooten handel van verfcheide volkeren, dic op deze platas, en op andere domen wan dit eiland, waren, wat onder de Chincezen, Siammers, Johotecten, Jwataen, Palimbatngers, Portugezen, Engetzen, en de Nederlanders wel de voornamitte $z y n$; doch de Chincezen maken een groot deel var Banjar Maffins ingezerenen uit.

De Wanten, die bier, of elders op dit ciland, wallen, zyn deze:

Waren, Goud, in menigte, 'tzy lofgroud, 'tzy hier ₹al- by kloupen, doch 't ent llegter als lende, of "tander.

thive ge- Diamanten, woornamentlyk in "t ryk van Succadina, Lave, en elders.

Peper, meeft over al in "thand, cal ook op Banjat, in groote menigte.

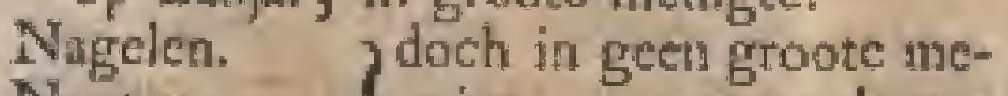

Nooten- $\{$ nigte, cn matr boven mulchaten. $\{$ in ' $\mathrm{k}$ geberrte.

Parien, op de Noordkuft allieen ontrent

bas, en Molanoege.

Camfer", in "tryk wan Succadana.

Benzoin.

Drakenbloed.

Rotrings.

Calambic. Sop Succadana.

Agelhous.

Yzer, op 'r ciland Crimataja by Succadana. Koper.

Tín.

Bczorr, Ampen- én Boklicnftecnen.

Pedra de Porco.

Toctombos, of doozen van fyne Rotang cn bladen gemitikt. Walch.

Hier tegen trekken zy wedct derk dere navolgende Waren:

Langwerpige Roode Agatifeencn.

Roode Agate Ríngeti.

Kopere Armringen,

Allerlei Corateri.

Porcelyn.

Ryit.

Amfinen.

Zout.

Ajuin.

Look.

Zuilker.

Tamarinde.

- Allerlei Lywaten, en Kleoderi.

Orin deze Waren tegen andere té verruilen, of tegen gercet geld te verwiftelen, komen hier wel io of I 2 Jonken jaarlyls uir China, Stam, en Johor, die wel tullichen de $z$ of 300 haften konnen voeren, welke weg hen door de portugeczen van Micas gewezen is, die hier alle just wel 4 of $f$ fchepen me Peper, en andere Waren, van dats halen.

Ook gebetute het nu en dan, dat "es", om den woordedigen handel hicr te wafter te makken, ook wel Gezaurten met zeer heerlyke gefolnenken vin den koning yan Sim, of var de Chineezen, Portugeezen, en andere volkeren, anden koning van Banjar Maflin gezonden worden, sizoo men bem als den voornamiten worft van dit ciland anmerkt.

Om dast nog meer fchym tan e geven, doet dit koninkje zich zelyen din eens keizer van 't eilind Botrnco, en dan cens Ponombaban, dat in "rJuaranfch den annbiddelyken beteekent, noemen, wanr is hy den Soefochocrats, of keizer van Jitra, febynt na te apen. Ondertuffehen is by niet minder, als een keizer wan dit tiland, dewyl hy over vecl andere koningen niets te zeggen heeft, howel by zyn beft nu. en dan wel gedan hoeft, om over den koning van Succudaria den meefter te fpelen.

G g 3

Hier 


\section{${ }^{2} 3^{8}$ B E S C H R. Y V I N G E A N}

Hitervalt veel Peper, en in de bintenen berglanden, onder deren worlt fhande, zcer weel goud in ' $\mathrm{g}$ gebergte, dat ook de rivier, die men eenige mylen verie opvaart, af kount ftroomen, en hier en daar in groote zandkujlen en poelen valt, uit welke het door den Inlander in fehotets opgezamel, en litgezoge word, zynde het eene wel wat beter wan alloi, als "tander.

Om in die hadfreke, dar 's konings goudmynen zyn, te komen, heefr men ertelyke dagen cerft te water, en dar na nog wel 8 of 10 ermat te land werk.

Men gat yañ Cajoe Tengali en Tatts (wat ontrent 2: mylen Beweften Pateri legt) met prauswen de rivier op, en na 4 of $\mathrm{f}$ dageil onderweeg geweelt te zyn komt men by "s koniogs Peperdorpen, Compay, Lulong, Borangbalia, Motanpijouw, Nagarrit, Alei, Nahari, Natstsa, Blatsja, Comenting en Bonuawa Tengal, watr na men, weer een togt wan 3 dagen doende, op Bonnawa Atam kome, daar 's konings Landwooge legt, die 't opzigt over zyne goudnynen wan Alei tot hich' toe heeft, en die alle jarar zyn tienden en regten ophaalt, wain wan hern juift de allemetle riskening niet doet, dat dien yorft, om dar hy die fwatare togt niet altyd zelfs ondernemen kan, wat door de vingeren zien moct, om dat hy niet verzekert is, dat een ander hem getrouwer handelern zal.

Als men ou nog 2 of 3 dagen verder gat, kome men by de dorpen Plajoejali Tengah, Coticl, en Paracle, datr luet koninkryk Jathoe een einde neent, tot hoe verre tou men te water gat.

Daur ma hapt men te land, cu word in hangmatten op 'tgebergte g of to etmaal verte gedragen, daar men verfeheide groote dorpen, zommige boven op ecin zeer hoog gebergte, en andere in th hangen des zelf, heeft.

Hicr walt niet alleen reel ftofgond; max dit minemal ook met groote ttukken, voornamentlyk in zekere poel, daar het doorde attroomende rivier in nederttort.

Ik weet, dat hier in ftukken van 10 . If, 20 en meer ponden gevonden zyn; doch het witer, in dexe poel ecrigigentyd geftan hebbende, is yskoud, watiom men den isalander berwarlyk 'er toe krygen kan, om het 'er uit re halen, en als zy dit nog al doen, zullenzy, wie een onnoozel bygeloof, noit an de groote klompen goud durwen taken, alzoo $z y$ die woor den wader en moeder wan $t \mathrm{t}$ minder goud houden, en vreezen, dat zy dan geen goud meer zouden konuen werzamelen; dat hen de tyd egter wel anders geleert heeft.

In dit geweft wale niet alleen goud; maur ook yzer, koper, en tin.

Vyf dagreizen werder of den $\mathrm{N}_{\text {in }}$ is een gebergte, dasr liryttal, in menige, $\mathrm{cm}$ wart onder nu etr dan wel cen fraaje din. mant walte, tuftchen welke on 't kryflal deze inlanders of bergboeren geen onderfchid weter.

Het rylk des konings van Bayjar Maflin thele zich wan dar meelt $\mathrm{N}$. wal 3 of Gicnspal granden Vetre, ch ma 't W. tot-man Cora-Rygs, tingar uit, alwowar de uiterfte grenspaal van dit rylis is.

Om nu ren naften by gifling te konnen maken, hoe serre zich die ryk wicftrekt, moet men weren, dat men 12 of $\mathrm{I}_{4} \mathrm{da}$ gen, mer een mantige lioelte langs de Wal zeilende, wan nooden hect, eermen by de rivier van Cotaringan komt, die men dan nog ecnige mylen opwaren moet, eer zich "i dorp Cotaringan opdoct. Schoon nu Cotaringan maar ontrent 45 amylen van Banjar Mafin legt, kna men wel 100 mylen, na gifing, in "E zeilets vertieren, vermits men bier door de tegenftroomen zeer dikwils lang zukkelen moct, dat egter, by een goede rekcning, matr op 45 mylen uitkont.

Na dat men ran Binjar" , Takas, en Cota Tengah $W$, an wertrokken is, ontmoer men de dorpen Campay, Lufong, Nigara, Alei, Enlavoemas, Conlohongi, Oelaing Djaki, Labeyer, Soengei Benatr, Soengei Camonti, en Caliong Compang, ontrent welke latete plants ook zeer yeel goud valt.

Wat Noordelyker heefe men de rivier en 't dorp Tabanjouw, dar meaft timmerlieden woomen, wau whar men wat verder by cen ongencene groote rivier, en by 't dorp Mandaway komt, alwatr veel goud, drakenbloed, walch, bezoarlteen, rotangs, en toctombos vallen.

Nant dar an grenft het dorp Symanauw, en dan nog ecnige nylen Weltelvker ontmote men de rivier Sumpit, diens mond $2 ! n y l$ breedt ; en voor welke zulk ecn grootebai is, dat "er wel rooo rehepen, voot alle wiuden belchut, tea anker konnen leggen. Inags dezen ftroom is mede grooten handel in gond, en :ulnderc wataren, alzoo hier ool Nagelcit ch Nootenmulchaten vallen, dic in deugd voor de Amboniche Nagelen en Bandache Nowten niet behocwen re wyken; doch zy zvn 'er in zulken overvloed niet, dat men "er hardel mede zou konnen dryuen, en zy wallen boven in "tgebergte, wan war de bergbocren die atbrengen, en voor geringe fnuifteryen tan de frandwoonderen, die dezelve weer met weel wint aan de Tsjincezen, en andeten verhandelen, overgeven.

Daar na ontmose men liet dorp Cotatinggi, met een verfche rivier Bewclten "t zelve, en nog ufin Weltelyker de Slyle hock, of Kypershock, en nog wat Welto- 

B
O
R
$\mathrm{N}$
E : O.

Weftelyker de rivier en 't dorp Ponboang, dan veel goud, en fchnone roteingen vallen, en dan kome men by 't darp Coturingan, daar het einde en de uiterfte grenspalal van 't Banjar Mafius ryk is, en alwar het regen dic wan den koning wan Sticcadnina ftoot.

Dit dorp lege ook atn ecen fehoone rivier, die in gondkykheid en otcrylood wan kottelyle witren alle do poorige dorpen zeer verre overtief.

Wan wat vermogen nu deze voomoemde Kryos dorpen zyo, en wat manclap zy in tate mangt des zyn om voor humen lioning op te brenyan Ban-gen, han men van yder in "t byzonder jackullin, zien.

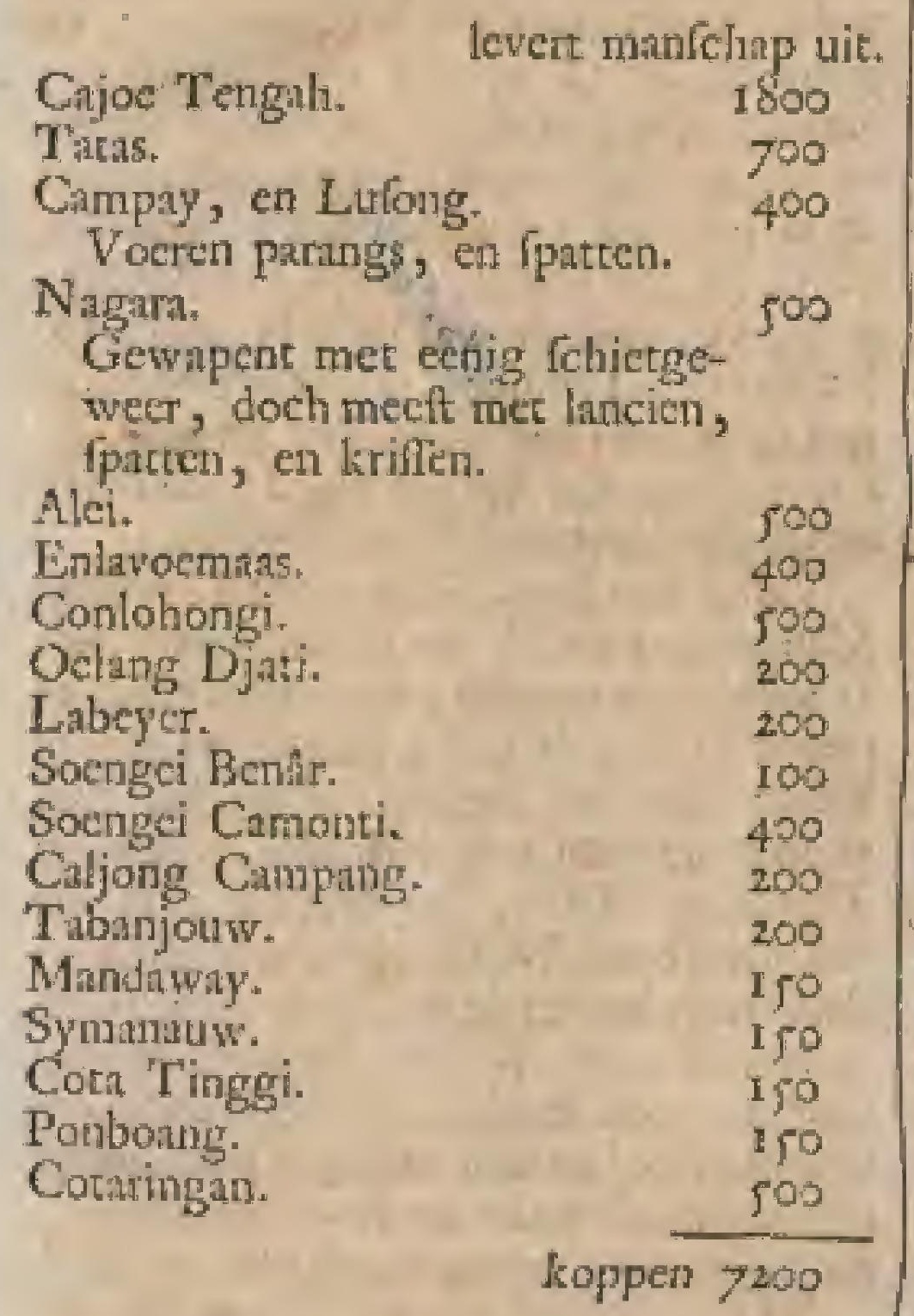

dast de wal ba ' $\mathrm{NN}$. W. drasit, alwan roendan ten $\mathrm{N}$. W. wan een klein fpranje 't hoog latid van Condawanga, en wat hooger op buiten de wal de cilanden Monkoedoc, en'Tockoeke, enwerfcheide indere platzen, hoeken, en rivieren tot Succidin toe heeft, dic in de lawal blyken.

Deze koting is in verre na 200 tringtig nict, als die van Banjat Matin, allzoo hy nier boven de 1000 gewapende manen onder zich hect, war onder 'er egter vecle zyn, die fehietgeweer gebrutiven, en vry wel dat" mede weren on te gan ? doch felboon hy zoo magtip ith wolk niec is, is by egter weel rylke", als de honing vin Banjar Matlin, zoo door zyn diamantmynen, als on den overvloed van lkamEct, die hy bezic, en de ander nict, ten zy hy dic hier, of elders van dian, kryge.

Het dorp Suecadana, dae ontrent in "t W.Z.W. ant een rivier, die men we! 40 njylen met chaloepen op varen kan; en op I! grad Z. breede legt, is in zich zelwen maar een geringe plats, dur nien ontrent $f$ of 600 buizen, op de zelwe wyze als die van Banjar gebouwt, heef. Schoon hier noit diamanten zoo groat nis een thalf hoender ei vallen (hocdanige de koning van Golconda uit zyne my nen gehad heeft) zyn "er hier egter als groote knikkers, en als kleine ftuiters, of als duiven eycren gezien.

On wan alle de zelve meeter te worden, is deze vorlt gewoon ecisige welgewapende vartuigen an de mond van zyn rivier re doen oppaten, on $x y^{2}$ ingezetenen tebeleten, wadic ath conige wreendelingen te verpalfen, en om ben dus te dwingen van ze alle by. hem te brengen, dar woor hy hendan wier meer geeft, als hy wil quyt zyn; doch dit belet nier, dar zy "er nu eindan-wel cens op uithuimen, wetende tegen wat tyd zeken Buntamze, Djuthotedche, cn andere vaturugen dar komen eillen, dic, zonder deze valaruigen des korings te ontzien, 'er de riviet' op inyiaten, en dus al zeer veel diamater weter te krygen, gelys ik "er verfcheide, doon de Bantammers op Baturia te koop gebiragt, พan gezien hebbe.

Wat Wettelyker als de rivict win Succadana, ecrige mylen buiten de wul, heete nen ocrige eilinden, en datar onder Lajuk, Crimaraja, en meer andcie, op welk liarlte zoer vecl yzer wilt, whar wa de Succadiners (onder welke de zelwe Itan ) hunne kritten, lancien, pieken, enz. maken; behalven dat "er door die vin Palimbang, Blicot, Banka, en Djahor, die jarlyks hier ta toe veel roofvintuigen in December zenden, zeer reel yzer hier wan daar gevoert word.

Pus Benoorden den Evenaar begint het. 


\section{B ESCHR YVINGE $\mathrm{N}$ A N}

Latuda. konivaryk wan Landa, en men ziet het dorp van dien natm and den grooten Aroom Lauwe al wry net leggen, nlwar die vorft $7 y$ n hof houd. Buncen deze rivier heeft men hier ook den froom Moim Sambas, Mampatu (die zeer otdiep is) ch meer anderen.

Dit ryle wan Landa plagt in oude tyden onder den koning yan Soerabajic, op Java, te Itaan; en ook ten grooteis declen, in de Heer Hownakns tyd, ran die van Succadana af te hanger, doch jegenwoordig is daar cen koning, dic met den zelven, nog ook met anderen, niets te doen heeft. De platizen Benootien Succadan, tot Lauda toes, ziet men in de lisuart uirgedrukr.

Al verden om de N., opden $2^{\text {dea }}$ grat Benoorden den Eventar, heeft men ecrlt Hermata (diur dat ganich koninkiryl na

subas, genamt word) en dan het land van den koning wat Strnbus, het welik ecnige mylen landward in legt, an ecn fpruit van ect fware rivier, die zich in drie groote taklem verdecht, Dit is cen matis konng, wat welken wy hier mi breeder fpreken zulles. In zyn liknd wallen ook fchoone diamanten, en meer andere diesbaure waren, die by van de wilden en bergboeren (dewyl men landwitard in fware gebergten, en zeer groote bosfchen heeft, woor deze en gene geringe finuifterven inhandelt. Tulfehendir Sambas en het dorp Borneo (wan na 't ciland zyn nam drage) heef men cenige rivieren, hocken, en zeer weinig dorpen, in de kart al mede net uitgedrukt, te zamen wel 40 mylen, en meer, beflatande.

What in " $\mathrm{N}$., of ontrent in het $\mathrm{N}$.

Bomeo. N. W onthoud wich de koning valt Borneo in het dorp van dien natm, dite al mede aan econ grooten fehoonen throom by een zeer groote baai legt, die aal wederzyden in " $\mathrm{O}$. en $W$. cen fwatr rif heeft, vlak voor welke zich 3 cilandeliens, die al wat bergagtig $z y n$, opdoen.

Men zte 'er' 2 by een, 12 ' nyl buiten de wal, Poclo Trja, cn nog een, Monpiacem genatmt, met mog een filcin zonder nasm; ook ziet men by de zalve eilanden een fwar rif $\mathrm{N} . \mathrm{O}$. en N. W. ftrekikende.

Hy word by zommigen wool den lioofd. troning en dit dorp woor de hootoplatias van het ganfeh ciland gehouden. Her legt fun cen groot moeras, con meet alt yd onter water, zoo dat men meclt met vantuigen ande huizen, die wel 2 of 3000 in getal, en secl rat planken zyn, varen noet. Ook heblen zy buiten de huizen, die hier by cen ftan, nog weel andere lithd = en thuinhuizen, dar zy zuch in een groot getal, altyd met pyl en boog en met fpatten gewapene, onthouden.

Die valu hunne patpyltjes getroffits word, is doorgans cen man des doods. Hee zyn klocke en ttoure, doch we gelyk ook trouwlooze mentchen, op de welke gect ftatat ter wercld te matken is, grely]: de onzen andervonden hebben.

N. O. van "r dorp Bornece op minoet men eerlt Quelle Copan een dorp, an een rivier: what verder $\mathbf{N}$. op is weer ecn tivice, daur de wal met een grooten hock, Tandjong Sibnon genamt, na "t $N$, W , uitdrate. War verder $O$. ata draie her land net cen bogt, en alwar men "tdorp Tangifier, ontrent 7 mylei van dien hock, leggen heeft.

Zes tnylen verder heefe men "t dorp Quinoni (war voor, 5 myler buiten de wal, weer 3 cilandekens (egers) en 4 of 5 mylen N. 0. op het dor p Bacarica; ontrent nog zon weel verder Bajer MorJa by een fprutie (dar men 3 mylen buitè de wal weder 2 eilanden heef $)$ waar na zich 2 mylen vender "tomp Api $A$ pi opdoee, wan wratr de wot! na "t N. en N.O. tot and den Tandiong ofte hock Satriton wel i 4 mylen verre ondratit, terwylzich 2 mylen van Api Api de vloed Saridanton zeer luftio vertoont.

Van deracn loek Sanfion tot Tatdjong Mater (die vlak $N$, an dranit) heeft men I I mylen van nooden, watur woor etcelyke mylen buiten de wal 4 groote en ecnige kikine eilanden leggen. Na dar men vootby de baai van Mirtudo, dige by Tandjong Mater, en onterent 8 mylen wan dien hock N. W. an, gelomen is, heeft men buiten de wil Pollo Avigo wat verder $\mathrm{N}$. W. op Punta Corpaon, datr men ook ettelyke kileine cilandekens tufichen deze en den voorigen hoek hecft; gelyk zich alverder op zoo lings de wal, als "er buiten, eenige reven wertoonen.

Wan der hoek Colpaon (2ynde een witnekende $\mathbb{N}$. Ooflelyke hoek) drait de wal met een groote bati, die wel if mylen wan den cenen tot deri sthderen hoek breede, en 17" myken diep is, nin "co. Deze baai word doorgans de St. Anne-se Aline bitil, en oncrenc des zelfs midden, datr Bua.

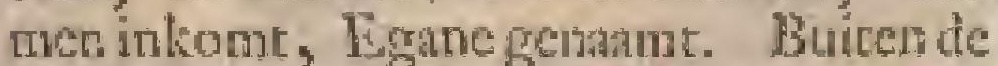
7. We ctitelyke mylen na ${ }^{*} \mathrm{~N}$. loge "i cilind St. Michicl, neverts nog or Fleine cilandelcens. Aan den Ooltkane van de St. Anne-bani lege Tandjong Matre, wata voor men ecn wathr yif, en ectelyke cilandekens dant buiten beefe.

Van Tandjong Marce r mylen heet men weer $O$. an een kinen hot, en Beoolten den zelven de rivier Sifor, wata na zich een klein baailken met 2 fpruiejens tot Chim Baligon (den natm van cen dorp) opdoen, gelyk men tufichen die vivier Sifor, etl dit dorp, O.N. O. op eilandekens eenige nyten buiten de wal zict.

Dant sa al O. an to de O. Hock ro 
B

R

E

o.

$24 \pi$

mylen roortgande, ontmoet men nog 3 riweren, en dan buigt de wal van dien O. hoek af hoe langs hoe meer ma ' $I$ W. datar zy de Dwalbiai, I mylen breed, en 8 mylen diep, en in 't midden wan welke een klein ritje is, makk ; van war zy door " $\mathrm{O} O$. whk Z $Z$. O. atn met cen zecr Hanuwe en lange boge, wel wan 53 niy. len, tot tan den hoel vau St. Antoni

DeDwaldrait. Turee mylen Z. atr van de Basi. Dwalbai ontmoe men hen dop Cavion, nog maal zoo yerte Zu ant Tandjong T"upe, data de kuft weer $W$. ant 2 of 3 mylen en dan weet $\mathrm{Z} .0$. an 2 mylen uitloopt, alwar zich Cofta Briva, of een woufte kuft, gelyk zich digt by Tandjong Tipe 'I eilind St. Augultinas, nerens 3 of 4 kleine enlandekens opdoec. Deze woefte kalt zoo Z.O. than al langs gaande, ontmoet men 10 mylen verder St. Luchin balai, 8 mylen verder 'c dorp Se. Añtonio, en 7 mylen verder de bua wan St. Wit; gelyls men 6 mylen verder het dotp Liton heef. Nog 14 mylen verder heeft men Porto Tube, zynde cen zeer goede haven, en nog 8 mylen verder liceft men den hoela wan St. Antoni, twiftehen welke en de baai rals St. Vit buiten de wal 24 of 25 mylen zich cttelyke reven of droogten met ecrige kleinc cilandekens, van welke 'er' zomnige in de kntrt met hare namen witgedrukt ftam, vertoonen.

Van den hock St. Antoni af, dat die flatuwe lnge bai eindige, en by welke dige arn de wal 4 cilundelicns leggen, drabitede kull woer $Z$. O. añ ro mylen verre tot an Aart Gynens ftompen houk, van waar de wal weder 6 of 7 mylen verte meeft W. an loopt, tulichen beide welke $O$. en $W$. hoeken men 2 riviejen heeft. Vin duar, of san de WVeftelylife rivier $Z_{\text {. }} \mathrm{O}$, ten $\mathrm{Z}$, an loopt men ontrent Io of 12 mylen vere tot Tandjong Brouw, of Deutckomshotk, dar men weer cen bala wan 3 of 4 mylen brectr en wel 5 mylen diep, met een groor eiland in t midden pas buiten de wal $\mathrm{Z}$. 0 . en $\mathrm{N}$. O. geftrekt leggende, by her dorp Cocti heet, dar zich oob ece rivier ten Z. van cen dikken hoek vertoont.

Van de rivier vati Coeti 4 of 5 mylen De Dor- $Z$. and heeft men her dorp en de rivier Milledpatis van Monta; datr ba buige de wal mee en Paffiecen diklen hoek van 5 of 6 nylen ling tot bee dorp en de rivier van Billipapar, en nog 3 mylen verder wertoont zich het dorp en de rivier van Pafir, met wellie lieden van PaAjir en Coeti die van Macalfat wel gewoon zty te handelen, dat men breeder onder de ttoffe wan Macafiur zien kan. Tuflichen Billipapan en Paflir hect men cen dorp, het Slangevangers Kerlkhof, alzoo men dialr vece en zeer vergiftige flangen heeft.

II I. DEEL.
Vier mylen wan Paftir, at $Z$. an, legtPaflis Briva, of hee Woett Paftr, meic tan en fchoone rivier, vals war de wall met fwee hocken 2 of 3 mylen verte na " Z Z. O. draic, tuffehen de welke zich oots ecn rivier vertoont, Ech weinig vender Z. tem W. op heefi men 'todorp Pammatan ant cen rehoone rivier, $2 m y$ len verder" 'c dorp' Apper by ecn riwier" dan 3 myles nester den ingen bock T'andjouw by centivier, tuferen welke,

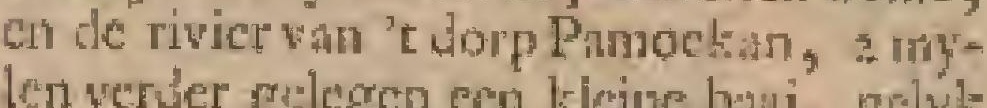
ten weruer gelegen een kiche bali, gelyle 'cr wat yerder nog eca rivierte is, $\mathrm{en} 4$ of 5 mylen yan Pamockin het dotp on de rivier vath Capocs, Atrckkende de whl allengsleens al hoe langer boe 7. W elleJylier wor Oedjong Selatin of den Z hoek toc, die zicls van Coeti wel 4 ? of $50 \mathrm{my}$ len verre uitilrekt, en meeft $Z . Z$. W. and dratic.

Var Cipoes z mylen werder gande, heeft men het dorp Carapja, wan welkers riviel men tot het dorp en de rivier yan Camla 5 of 6 mylen wan nooden; gelyk men witfinen beiden nog a rivieren heceft.

Van Camla tot hee dorp en de rivier vertheiFan Boekil hecfe men 4 mylen you noo- de andere den, en tuffeher beiden wertoont zich Doppen nog cen fehoone rivier in 't midden vas en Riro dien weg, gelyls men af en andic rupter pis buireu de wal 3 kina cilindekerss $\mathrm{Z}$. en $\mathrm{N}$. ontrem I. ayl van toulkàderen!

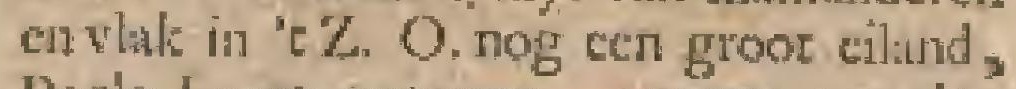
Pocto Lioet getament, ontent a mylen van de wal leggen heeft.

Dit ciland, dat Z. W. en N. O. wel comylen lang, na de Z. katu 3 of 4 , en nade $N$. Kant ontrcan 5 of 6 mylen breedt, can dari ook van cen fmaje bat en van yerfehcide riveres an de $\mathrm{N}$. W. kaje, doch marr van esne and de Z. 0 . kant voorzicn is, hecte ata de Z. O. kant ook ces lifuae balai, war in 3 ellandelens gelyk "er nog 8 win de Z. boek tan dit eiland leggen.

Vyf myler wan het dorp Botkil heeft men tan een fratic riwier het dorp Auter leggen ; buten welken ftroom men nog een stodere, die grooter is, tufteben beiden heefte. Var Auwer toe het dorpen. de rivicr wan Kintap heeft men 3 mylen vils watr de wal van ' $\mathrm{Z}$. all meer en meer nae $Z$. W. dratit. Twee nylem verder nat den Z hock doet rich "I doyp Afimattar, en die rivier, nog 3 myich verder het dorp en de rivier val Tape, en dail m nog 4 of 5 mylen werder de Z. hoek op, dic wel 6 mylen hagg, ed 2 of 3 mylen breedt is.

Vandezen hock buigt de wal, diedar vry revig is, whik na "t $N$. wel 7 of 8 mylen tot and Banjar Mintin 19 a binncas, zonder dat men ier anders, da diverfube $\mathrm{H} \mathrm{h}$

vivic- 


\section{B ESCHRYV I NGE $\mathrm{V}$ A N}

rivieren ontrenc $\mathrm{x}$ of 2 mylen van Banjar Maftin, tufichen beiden ontmoct. What by wy dit ganfch ciland omgewandelt Borneo licblende, 1 u nog mat weinig, van

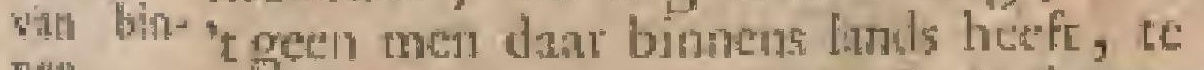

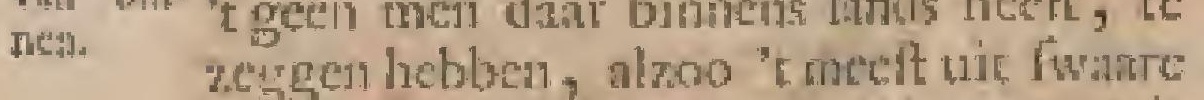
bosklhigien en gebergten, gelyk men wit deze onse tatut zien kan, beltadi.

By de fande en bani van Mlarudo, in "t $\mathrm{N}$., heeft men de St. Pieters berg.

Ontreat Succidama, en Beweften 't zelve, doenzich $f_{i[j d}$ wand in de koningry= ken Hermati, Lindo, en Lava, (daar vecl dinuaten en ook peetlen willen) thet hume groote dorpen op, zoo als Gich die ryken na 's $O$. wan "E W. flrand af uitikrekken; er Beruiden de rivict wau Stecsdant vertoont wich 't hoog dand wan Kondawanga ruffeben die sivier, en ensMeell. Folken die van Mandiway en wan Banjar onwelenti. Maflin, en Benoorden Cotaringan, als ech zeer groor en woet land, wan het welke, selyk mede van het zeer wort, groot, boftchagtig; en zeer bergagtig landfehap san Marudo, an de N. zyde van Thet land, niet veel, wermiss die landeri nog weinig bekent zyn, te zeggen walt; hoedatig her al mede mee ' $t$ lnthfchap der Sambins, Benoorden Hermata, gelegen is.

Men houd devolkeren van her dorp of wlek Barneo woot de rykite wan "r geheel eiland, niet alleer art dur 'er mede zeer veel ftofgoud walt; mant otrdat die foost van goud yed zuiverder, hooger, en beter varn alloj is, dan 't gene men op alle die andere phatzen vint. Dar beneven heef men hiet ook veel en zeer goede ja (zoo men wil) de befte liamfer van geheel Indién, en meer andere fraje waren, dic hier met groote wint gezogt, en tegen kleeden ferk geruilt worden.

Deze Borneers hebben ools ongeneene lehoone, hegse, en groote prtatuwen, want. wa 'er zommige wel 8 of 10 vosten wyt, wel 40 of yo votten Jang, met cen gronte tent in 'rmidden, en wan 70 of to licheppers woorzicu zyn; hoedanige men laier an weel vind, alzoo zy wat handwatre in groore bollchen, wol firathe boomen, en voar den altwid overuloed whn menlehen hebben, alzoo "t dahir wan hier over al brioelt.

Die is wel 'c voornamilte, dat wy van cit groot en trocit elhind weren te zeggen, alzoo 'e wan binnen zecr weinig, en matar hier en datr anu de ftranden berogt, en bekent iș. Binnem in "t land is het wol lwilute gebergten, en alomme met zullze digte en akelige bollchigien beter, dat 'er riet door to komen is.

Men heef in de zdwe een foott van Aapen wrat in de befte Bezours, Aapenfteenen genatust, wallen, en ook een loort wan Bokken, uis welke men mede oen Aeger loont wan Bezoartheenen in een groore menigte bekomt. Its hebbe van die Arpen gezien die fpictwir, en ook centige die pikfwate watren; ook vallen 'er Orang Hoctans, of bolchmenfelich, cen loor van zeldzatume Aapen, die regt orer eind gata, in allew decken de gedante en masieren wan een menfeh hebber, en atn de welke niets, fan de lpratk ontbreckt. Ih heb "er twee lewende van gezion, en de latthe by deu Heer Camper, Hecto win Ouwerketk an de Yfel, welke zyn Eerw, tot Leyden woonende, nog (zov nict beter weet) in een fies of pot in liqueur to zien heeft.

Men heefe "cr wall dic foort wan Egels, of telkelverkens; watr in die heerlylke Pedra de Porra, of verkentteen, walk, Mogt men dit lind eans wite dicper onderzocken, men zou 'er zckerlyk tebarten, die nog onbekent zyn, vinden.

\section{TWEEDE HOOFDSTUK.}

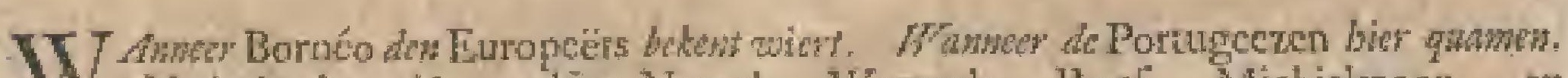
W Nederlinders bio. War Noord. Warwylk, Rout. Michielszoon, th

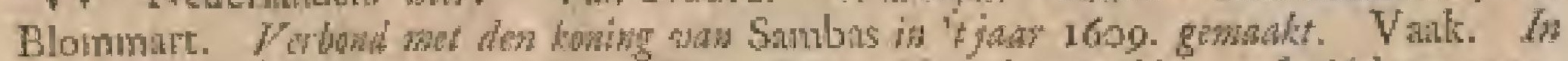

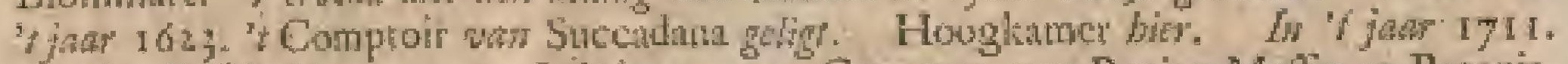

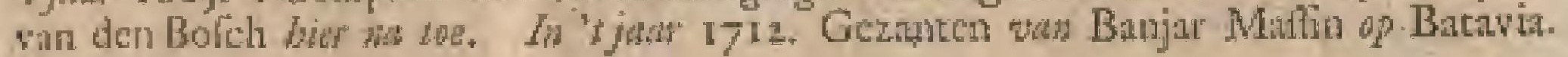
Engelfohen.

Whane Bornt́o derr EHropec̈rs belicut พท่⿰ฺุ.

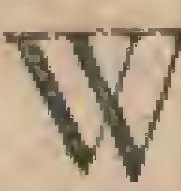

Annee dic elind and de Europeetry cerle betent geworuten is kothen wy jiet zeggen.

By den Iandlyelchryer Ptalonens komt her met den nam wan lothla bewe Furwe, of 't goeder geluts's enland, voor; mat die dat eiland, en de Anra Cbeyfonefus, benevens nodere landen, dant ontent, zoo als hy die in zym, kate vath Indien vertoone, cens andagtis beichnow, zal inoeten beikennen, dat lyy de zelve vodr-:
Ateit, at een matn, die "cr ganfeh niet af weer ; alyou de Arrea Cher/onefos hier by ficm in ' $\mathrm{O}$. geplantet is, dar die cigentlyk Beweften Bornto legt. Ja al dat Jy verder wa Indién opltelt, is geer lezens wastig.

Onder de Europiflac Natien Lomen my "çr drie voor, die dit land eerlt ontdekt, of hier gchandclt hebben, te weten, de Portagecten, Nederlanders, en Engelichen. 
B

O $R$

$1527 \%$

De Portugeezen zyn hier lang yoor ons gewceft, en zyn de ecrite onder de Wanner Europecrs, dien (voor 700 verre ny bede Portu-kent is) de cere van de ontdekking dezes geeren eilands, dat geene der Ouden rehent hier quat- hebben, rockome

De eerthe, die dnar laft toe gaf, was George Mene/er, Landwonge der Moluceos, die in "t jar 1527 . (in plats van Garfas Hewik, die 't van den onderkoning belatt was, matr die het geweigere had $\mathrm{Vaf}$ Lawews langs det weg wan Borneo zont, om dir ciland wat nater re ontdeliken. Hy wertiol met een Cora Cora, en kreeg by dien koning (die by Ororos nict al te net uitgedrulkt word ) door $\mathcal{A} / \mathrm{fow} / \mathrm{P}$ eris, die dade felteen bekent te zyn, toegang, en werzoge wan dien vorft yerlof woos de Portugcezen, om indac eiland te mogen handelen; on "t welk te eer by dien koning tel krygen, hy den zelwen een zeer kolkelyk tapyt atubood, war in 't huwelyk des konings van Engeland met de moeje des Keizers na 'eleven uitgebeed was. De koning van Bornco (mogelylk wel die wan 't wlek Borneof wrangde hero, wat alje dic beelrenifets en figur ren op dic tapyt te kennen gaven, 't geen by hem zeer klmar vitlei ; mat als hy hoorde, dat dir een koning, nls by, en cen gekroont worth wan Engelund was, vermoedde lay, dat deze Portugees heri mict dit tapyt en alle dic becluet oen quaden trek zoge te fpeelen, en dite liy door toovery al deze beelden wel levend matien, en hem mes zyn ganich ryk danr dool bederwen kon, war over ly zoodanig ontltelde, dat hy lalt gaf dit tapyt met ter haft weg to doen, en hy zou die Potugeezen zecr qualyk gehandele habben, 200 Alonlo porez, con eenige Moor'che kooplieden, hem geen nader berige dat at gereven hadden. Egter verbood ly toen de Portugeczen om ei te komen handelen, en belifte hen danthonts dit eiland te verlaten.

Gowhlor Peicher, vierde Landwoogt wan Ternate, gierde, vanneer by Fan Mas lakkavertiok; in 't jum i 530 op Borneo mede Aau, en makkie by die gelegenheid vrede met dicu koning.

Naderhand zic ik, dat eeness pelfo Texwe dic ciland bevalien, en dar tian getuigt heeft, dat hy het van den W. hoek tot de haven yan Bornco langs die latat zeilende, bevonden had antent $200 \mathrm{~m} y$ len hang te zyn, "twelk zoo 't wwaar is, zol 't wel 7 of 860 mylen in den omurek 2yn.

Buiten dit gesal ontmoet ik in de fehriften sier Portugeczen nict meer valu dit ciland; egter is ons klatr uit andete fehriten gebleken, dat zy wan tyd rot tyd zeer terk hicr op gehandelt, en groote voordeelen gedan hebben, gelyla
N. E O.

die van Macino hier op nog fterk bande- noso. len mer kleden, wat tegen zy zoo veel Peper, en andere loftelyke waren, in = rọilen, dat zy "t eche jats door 'tandere hier wel 3, 4, of 5 fchepen mer Peper van dinr gewoert hebben.

De eerlte Nederlander, die op dit ei- Nederland verfcheen, is de dappere zecheld lander Oirvier van Nourd geweell. hicr.

Hy quam den $26^{\text {flen }}$ December 1600. met ichip Matritius in de groore bạa van "c w lek Bornen ten anticr", Woor welke van ly "t zeewiard enige eilanden, Yan vis. Noord. fchers bewoont, leggen vont, en die in hater ontrek wel 2 of 3 mylen beflocgen. Door dien hier nat zeer veel vilch wirel, liele deze koning tot dekking dezet visfichers hier gemeenelyk en moffelvloot van gewapende pratumen, die nok dienen on de rivier wan roovers te bevryden, en om hem boven in "t wlek Borneo, dat nor wel 3 mylen de riwer op legr, van alles kondichap te geven.

Hy zont cen $T$ sjinees met een gefolienk an dezen-koning, hem belient-matkende, dat $z y$ hicr in zyn land atls vrienden gekomen waren, die alicen voos hun geld vertogen van levensmiddelen, witer, en "t geen hier verder valien moge, gedient te worden.

Dangs 'ers and krecg loy veel pratuwen met hoendeters, virch, en fruiter alan boord, war van hy "t een con "cander tegen Guinces lywad (dan zy groote genegenheid toc hadden, hocwel zy geen Hollands lywiad begecrden) verruilde.

Hy kreegook ecnige Edelen en Orangknju 's an boord, de hy zeer triendelyk onthaalde, en aan welle hy ecnige gefehenken gaf, om in vryheid te mongen handelen; miar belafte zyo volk goede whgt te houden, en wel toe le zien, dat "er niet te veel gelyls ant boord mogten komen, om alle ongemaklien, vestaderyen, en 'Ioverwalien wan zyu rehip voor te kamen.

Den $28^{\text {fter }}$ dito kecrde de Chinces, dien hy met het gerchenk gezonden hand, re rug, en brage cyding, dat de kioping, bekommert zynde, of wy nict wel Spanjarts, met welle hy in oorlog was, wezen mogten, in 't cerlt fwaligheidgemalst had, om ons het lauden en handelen hich coe te than ; mardare by, vata de zynen nu beter onderrige zyude, wel cen Nederlander man kind by zich wilue hebber, om op "t gezigt zelf dar over te beter te konnen oorteclen.

De Heer wa Noord zeide, dir by dit geerne doen zoude, als de koning hem nuat een gyzelar in plats wilde geven, "t welk zyn Edelen annuanen hens an te dienco, atr welke hy toen eenige frate roers, en andere wapenen gaf, on die thit zynen nam don kontog te fehenken.

$$
\mathrm{H} \mathrm{h} \text { ? }
$$

Dit 


\section{$2_{44}$ B ESC H.R Y V I N G E ₹ A N}

I6ot. Dat het hici egter niet helder, en ecn neft vol lchelmen was, bleck dezen Zeevooge naderhand zeer klast, alzoo hy den t fien Januní 1601. agter zekeren hoek, ontrent I myl van zyn fchip wel roo prauwen zing vergaderen', wan welke'er naderhand zommige mer eenige zakken Peper ontrent zyn tehip quamen; doch hy, hun coeleg generlit hebbende, verydelde den zelven door an $z y n$ volk lall te geven, wan well op hen te paften, en 'er niet meer dan 2 of 3 binnen boord te laten komen.

Dear drongen "er wel-weelen van hen tegen in 5 mat na dat $x y$ metkien, dat de onzen vuur op hen geven wilder, hiclden $z y$ af, vragende, wamom wy op hen fehiecen wilden', war op hen geantwoord wiert, das zy met humrie prantwen wat verder van ti ichip moellen gan leggen, gelyk zy toen deden.

Zy werichoonder zich naderhand wel by hem, wan geen quaad in den zin gehad te hebben, maar "evervolg toonde het tegendeel, alzoo zy den zden "s nachts vier fwemmers voor den boeg zonden, die de kabel van "E fchip meinden af to kappen, 't welk zoo 'c hen gelukt was, zou trichip tegen de wal gedrewen hebben, alzoo 't maar woor cen anker lig, en dan washer zelcerlyk weg geweet ; doch de onzen de praauw, die zy drywen lieren, gezien, en dar uit humen toeleg gegit hebbende, wierden dit gewar, Ichoten nier weinig op die rwemmers, en beletteden hen dus hun woornemen uit te voeren. Ook hudden $2 y$ de onzen al meer poetzen geffeelt, met hen goedeven te verkoopen, die zy hen noit, ma "t geld al ontangen te hebben, leverden.

Zy hebben hier ( $2000^{\text {"t }}$ my roetchynt) eenige Pepergekogr; doclu alzoo de Heer wan Noord bemerkte, dat $a y$ hem niet wel behandelden, en niec din quad in den zin hadden, is by den $5^{\text {dea }}$ Januari wan dant vertroliken.

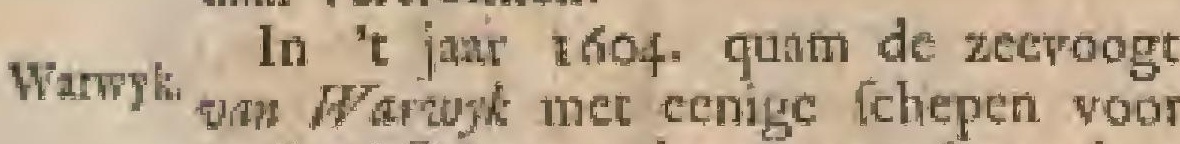
't eiland Crimata, dat onstent Sucendana

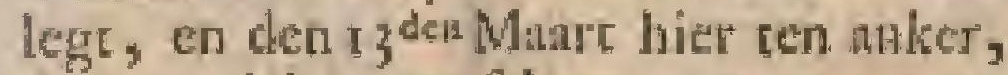
daat zy zich werverfehten, en wan war hy den zf fer een chatoep na Succadana zont, die van daur $100 \mathrm{R}^{\text {dets }}$ and diamanten medebrage, war na de Zeevoogt den 7 der A pril 'eanker gelige lecef, en van daar wertroklien is.

Naderhand, in Juli, tot Patani zynde, quam datr een jonk not een Gezant van Bornco by $\psi$ wroyk, met 8 Nederlandze gevangenen, wan den Zeevoogt Yacub Hewnskerk wolk, met hun ongewa pende lehuit van exnige Bornèers genomen ; doch de koning, hiter over misnoegt zynde, zonk de zelve nu an den Heer Zeevoogt te rug, en lehecf hem cen minnelyken brief, watr by by hem ibo der thandel in zyn land ook ambond.

Hy, en den adel alduat, hadden ons solk zeer wel gehandelt; doch $z y$ hadden veel familheden wa het geneen volk moeten lyden.

Ontrent 't jat 1607. lac op Succadana als ons sppethoof Hans Korf, koop- Roef math, die volgens de berigen val dama, in grool gevaar was, om van die inwoonder's vermoort te worden, altion $2 y$ wiften, dar hy een groote party diamaneen by zich had, wantom hy verzogt ten certen'an day' verlolt ie worden. Ook hourde men in Juni cot Bantam, dat de koning van Basjar Malfin een jonk, door de Heer Herflbor, ons Bantams opperhoofd, gezonlen, overvallen, en den koopman, Gild Midbielszobs, door hem Michiels. vermoord had, watrop de Heer $\nabla e w d$ hopr den $1 y^{\text {den }}$ duto een chaloep mer volk en. animunitic, en Sanwi Blowmant als bevel- Blom. hebber danir na toe gezonden had, om onze math. kooplieden met bunne geftecnten wan Suceadana teligten; hy quam den I3 Juli weer op Bantum, met tyding dat Hows Rouf vyf dagen voor hun komit, alzoo hy zich daar nict langer vertrouwen dorft, nat Patani vertrokken was.

In 't begin van "t juar 1609. blylat my, dat de Heer Simulal Blommat, opperkoopman met de chalopep de viegende Drank op Stuccadana gelegt was, om hier als Opperhoofd onze zaaken war te nemen. Hy lereeg in Mant laft om wegens den diamant- bandel een werbond zoo mee den koning van Banjar Maffin, als mer de koningin van Landa, die den koning, hatren gemital, in Januari uir jaloezy had doen ombrengen, te maken.

Den rofteu September 17 10. quam by wan hief met het jagt de Vliegende Dratk op Batram, en verzogt, na dat hy nu een frotaje party diamanten by een werzamelt had, on zyne werlofling, stzoo zyn tyd, of werband om hier re leggen, uit was.

Hy was by eer berigt, in "t jar 1700 . gegeven, winnordecl, dat Teyen, (een plats in de rivicr wan Latwe, yan war cen rivicrken na Landa Joopt) Sadong, (Benoorden Simbas, onder den koning van Borneo ftaande, en wan war men in een dag over land na Landa gaan kan) Manpana (Bezuiden Sambas) en Borneo, de batte handslplatzen hier waren, hoewel hy Sadong nog voor beter keurde.

Hy zcide ook, dat op Sumbas veel nege goud, als mede bezoariteenen vielen. Hy had daar op de laxite plats ecnen Pieter Aartszow gelaiten, on den handel wan Landa wate te nemen, en ook wernomen, dar 'er ontrent Sambas cen rivier was, die zich net cen Ipruit 

B
$\mathrm{O}=\mathrm{R}$
$\mathrm{N}$
E
O.

in de riwier van Landa ontlaft, langs welke men dus zeer gentkkelyk op Landa komen kon.

Hy werhalde, dat die van Sambas en Landi te dier tyd met malkanderen in oorlog waren, ea dac in de eerilte plates. de ryit ved beter, en tot minder prys, dan wel tot Succedana, te bekomen was.

De Heer Blownat hat ook en brief van den Heer Prince van Omagie bekomen, om dien atu den koning van Bomèo (te weren dat vlek in ' $\mathrm{N}$. gelegen') te behandigen, en ook laft om mer den koning wan Binja Matfin cen verbond to malken, twee der grootite sylien hier, van 'e welke 't cerfte aan de N. kant, en "t ander aan de Z, kane van dit eiland' gelegen wis.

Den $22^{\text {tem }}$ April had men met cen jonk van Grefle hiè berige gekregen, dat die val Palimbang van voornemen waren, om met 40 pratuwen hier te komen, en om dan Succadana, en den diamantondel onder hun gewelt te brengen. Wy verzogten toen ann de koningin van Landa wel (na anblieding wan hume riwier met cen wan onze jagten te dekken) om wan alle Europilche Natien hier allecn re mogen hindelen, doch zy gaf tor nurwoord, dar baar land wan Landa on de viwer de Lawwe wor yder en open flow, om welke reden $z y$ met ons in gecin verbond wilde treden.

In 't midden van 't janr 1609. was de Hoer Blowmart wan Succadana ba den koning van Sambas gecrolken, en 'er den I $^{\text {ten }}$ fuli gekomen, hebbende verder met den zelven gefproken, on cen verbond wegens den diamant - handel te maken, ten welken einde die vorlt reets met den koning der Wilden (dnar eigentlyk de diamanten vallen) datr over hadde doen handelen, die ook tor een monfter een diamant van tufchea de 30 en 40 carate medegezonden had, neveiss een berigt, dit dast veel iteenen wan 4 tot 24 carast vielen; cen handel, watr op toen de Portugezzen ook fterle vilélien, die zich ten dien cinde met die van Boineo rects verenigt, en zich dar valtgemakt haxlderi.

Ondercufichen mankte de Heer $B$ lomwat dit Verbond net den koning wan Sumbas:

Eeuwig Contract, ende Verbond van wegen do Houg Megoude Heeren Shabtu Generabl der Veresiggde Nederlandze Provimticn, zyn Primelyke Excellentit, ende de Heeres Bewindbelderen van de zelve Landen, traffiquerende op Ooitindiën, tet ectre, ende den Door- lugtigen Koning wan Sambas, ende roog. omleggende Platzen op 't ciland Borme, ter andere zyde, genaalit ende valtelyk befloten het naarvolgende.

\section{I.}

$\mathrm{T}^{N}$ den eerfen is gecontwateert; dat de Verbond 1 Hoog Mogende Heeren Stanten Ge- Vebond neraal, zyme Princelyke Excellentie, ende kơnisig dit Bewinthebberen den Zeer Mogenden yan SamKoning van Sambas, zyme onderianen, bas in

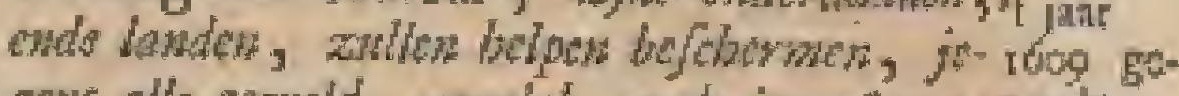

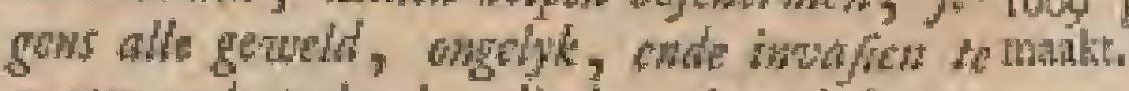
rovater ende te lands, die hon door de Span. jarden offe Portugeczen zonden fnoges aangedan weorder.

\section{I.}

Ende by zoo verre yenast wan bwilen des Koning in zym land quame asjdoes rexigen wrigg, zullen de Gapiteinen ende Gecommitteerden der Vereenigde Nederlanden tot Sutabas refolerende met alde law wodt en wagl de zolve refferen, ende wew Koning ven Sambas afferen, zoo vel bat mogdyk ir. I I I.

By zoo were dhe wa Sambgr dorr but

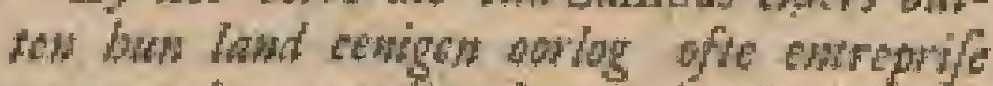
aanuararden, zullen de wow/z Capiteinen ofe Gecommitterden, wr brar mast te

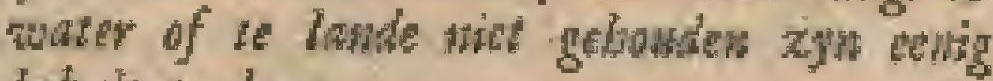
bobulp te doest.

$$
\text { I } V \text {. }
$$

Hier tegen zal de zer mogerde koung van Sambis, ende zy onderianch, wair under begrepen cuord Mompan, Landa, ende alle andere hoden, die onder zyn gew

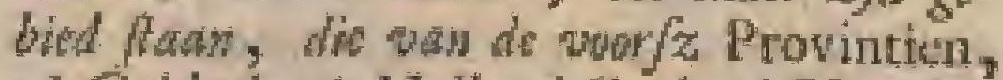
als Gelderland, Holland, Zecland, Utrecht, Vriesland, Overyffel, ewde bare Geallieerden, van de worfz Provintien commi/he bebbende, in zyn hasd warlenen uryen bon-

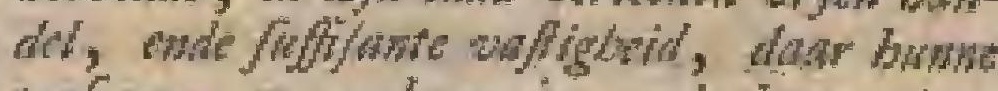
perfoonen en gocderes in poede beapacringe magen zyn, wide ds zelve beformen acgens allen, ende iegdyk, zonder dat zy lieden, uft bume gocderch, zulden befroar worden wat cenige laften; man bant goederen wy wit-ende invorrs zondict entgen ofl, offe andere ontgelden te botalen.

$$
\text { V. }
$$

Desgelyli $x a l$ de vournomde Koning dt genen, die commi/fs wan de won/a Provintien bebbes, wry in alle ayn landen lanten bandeless, als Mompana, Landa, ande vowts bed tot fe Widden, daw de diamasten growfoht warden, zonder dat varn zyno onderaten de zelven ectige verbinderinge of to overhth aingedian zal woorden.

$$
\text { V I. }
$$

Zal wan gebken de houggelage haming wan Sumbas, eade de zymers, wict toclacten offe wergwnen cenige bandelinge, of rwonplats, an ennige Spanjares, Porlagezen, Engelichen, Franichen, ofte abare Europila Natien.

$$
\text { H I } 3
$$




\section{I I.}

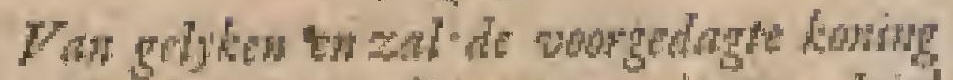
wan Sumbas gees dinnantew wit zym tont laaten weren dow zyn thooowden, of ecnige oremde Notien, die is sym lowden zavden nogen komen lraffemeros; watr alle

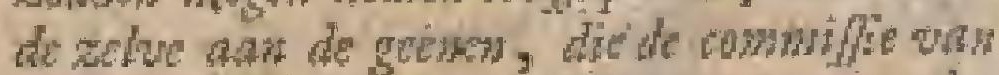
de vour 2 Provintien beblen, tor cen redebhe prys serlown.

\section{I I I.}

Ende by zoo wowe di deats Landa, desgeighs de Wilden, daat de dianonten gewiflot wordas, wolkomently tot Sumbas caillen konen bondelen, ende Suecadan

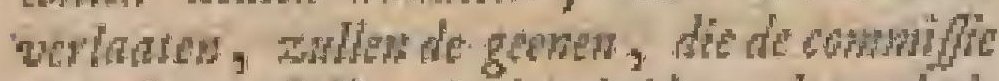

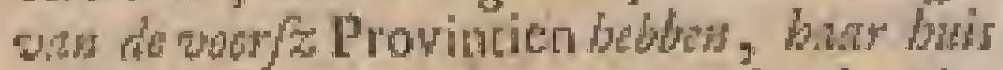

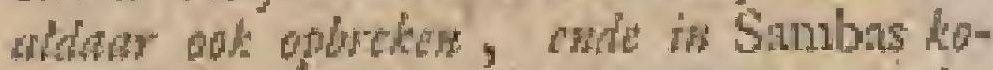

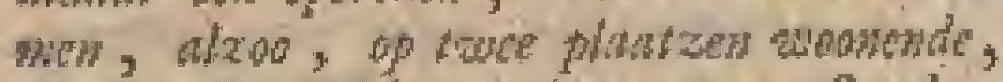

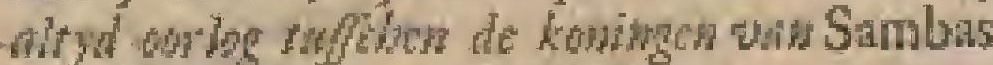
ende Succhdatn zoude ondrom.

$$
I X \text {. }
$$

Znllen de Hoog Mogende Hecren Snzten General, zyse Princelyke Excellentic, wde syse Capiteinen ende Comtnifen, in Oofindien trafhaderenle, wet dea lonitag wan Sumbas, ende zyne onderdown, wa

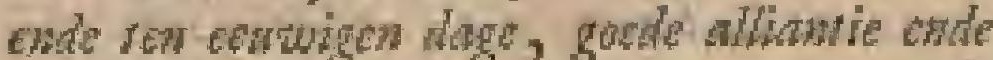
wriendlatp onderhowden, ente de vory/z Point? in alles hasternes; ende nog weer-

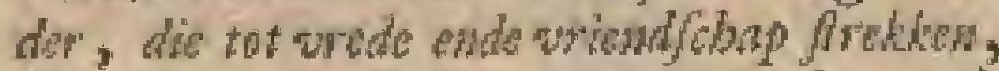
des wodle zwhe gemalet to worden, de quelke by bede Partyen, gelyle deze, ondertethen ende geconfinmert wallen zyn.

Alum loi Sambas dezn ner/ten ORobr I700. Was onderteilent in Arabifobe detters, den nasm war de Koning, datr ouder font, whis den sorme was de Hoog Mogende Heeren Staten Gemerat, zyw Princelylic Exellentie, wide de Hocron Bewind hebberen dor wereng de Oplindifhe Conpagne, wens onderteiken,

\section{SAMUEL. BLOM MART.}

Ook lereeg men hicer nuryding, dat die war Calca, Seribns, en Melanogge, volkeren Benoorden Sambers, wan dic wan Borneo afterallen waren, en rich onder de mage van den kounity van Djoluor begever hatder. Dit waten phinzen diur grooten bundel wiel, alzoo men hier weel goud, bezonfteenen, pecten, en meer andere dicrbane wathen, tront.

Anngeracs nu die var Borneo die wan Sumber gedreigt hadden, om hen met 1 go gewapende prawuen to komen be* zoeken, waten ry zeet bekonmert, en werzoyter ons erultig, on doch lier een velting re trouweu.

Den r gen Nowember waten hig tor Sambas wel 20 Wilden ner enen Kijay Cabe gekomen, die woon den koning na de Wilden wan Landa geneett was, en enige van hunne Ornglkaja's mede brat, - om met det koning win Sandas

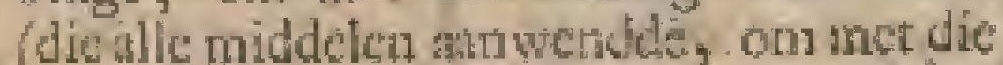

van Landa in een goed veriftand te lewen IGo. cen werbond te maken, gelyk ook gecelisici is.

Pas ni het vertek dezer Wilden Ierecg de koning der Sambns berigt, net een brief yat den koning wau Soby, een ciland, digt by dat van Borneo leggende, dit die wan 't viek Borneo met ifo prasumen kiar lagen, wat in 40 koringen waten, wat by men hunne mugt afmethen kon.

Ook hadden zy met die moflewloot al in zee geweeft, doch haddres wegens on- weder mocen te rug loopen, zynde nu vits woornemen orn 't nog en mand in te zien, en dan isa Sambas te kowen, om dar 6 manden lang te belegeren.

In 't jar 1616 . hadden wy hier den koopman Herrik Vaak als ons opperhonft, zonder dat my blykt, wannecer by hier aut quathy of hoe lang hy hier gelegen heeft. In 't jar 1619. quam 'c rechip Delft wan Succadan poor Jakatra ula de vioot van de Hear Cack, een bewys, dat wy coch hicr nog liandelden.

De volgende trden hebben ons egter geleert, dat de handel voon onze Maticluappy nice al te voordeclig, of altoos In "t jans rict ia hun genoegen geweett is, alzoo de $\mathrm{r}$ ciz $\mathrm{z}$. Heeren Zeventienton by hain lohryvens compoin van den $23^{\text {teu }}$ Oetober 1623 . lait gaven, yen Sueon, nevers meet andere comptoiren, ggeligt dat van Succadana te ligren.

Nadezen tyd aic ik, dat de Heer Jacol wan der Mewlew (nadertand Equipagicmeenter op Batavia) in 't hasr 1644 . na Amboint met "I fohip prins Fredrik Henrils gande, op Bajur Maflin angeweett is.

In 't jatar I 664. bezogten wy hier een plats, Martapoen iename, on de peper en 't goud, ditur vallende, in te handelen. En in "t jan 1665. brage de koopman Awon Hordt man 36 lailien peper wan datar; doch by land nu het concrabt, met dien Pungerang angegan, beveltigt. In " 5 jar. 1666 . en al in veel juaren te nooren, - hobben wy hier geen Logie gehad, mas haa: Edelheden zonden jauJyks a fchepen herwants, onde diananten, in zelae Myne allhier vallende, en beter (zoo men wil) als be Kutt- of Golcondafche diamanten, mitggaders ongemeene fchoone en grootc peerlen, nts en dan hier gevonden, wan daar te halen, niet genegen zynde het leven wan hunne dienatren, by "topregten wan een comptoir, hier wedent re. wagen, alzoo de crvarenheid hen nier dan te veel, tor hun leedwezen, geleer hid, dat dit een velthatderich, bedricgelyk, en trouwloos voll was:

In ennige volgende jantu hebber wy hier geen hindel ter wereld gohad, mant 1671 . Was 'er nog een wymans claloep 
17ot geweel, die wel twee lwofdom non op allerlei Banvilate goweren, en Macts zanze klenfen, gewonnen had.

Na dat de Heer Jacoh Hookhaw (van Hoogka welken wy elders breeder fipreken in

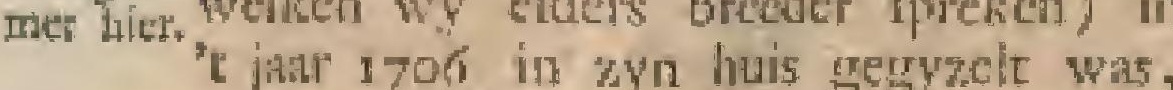
wegens eenige pentingen, dic men wan hern eifehte, en wegens cen fwatr proces, datar ower, als over eeln atdere zaak met den Ed: Hetr de $F_{a s}$, zoo is hy (gelyk men datr breeder jign kan) met ecruge Engeldethen van diar na Banjar Matlin gevlugt, alwatr men oordecle dat by, alzoo de Engellichen toen thet die Inlanders overhoop lagen, ecn drocvig einde in "r borfeh gevonden hecte, welkers onoltand gheden wy elders breder heb-

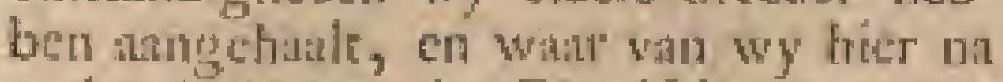
onder" de zunken der Engelfohen nog iets zeggen.

In "t jar In 't jatr 17 I 1. is de Capitein. Lieute17 I. van nant $N$. van der $B o / c h$, als hoofd vat een den Bofch nicuwe onderneming; en den onder koopbuter na man Abrabom Poele, als zyn Tweede hier toc.

na toe gezonden, otw te zien, of men "et" weer een comptoir (watr toe groote hoope was) zou konnen oprigen.

Egter is 'ert toen (zoo 't my toefchynt) niet vet afgevallen; doch "r jarr dakr an gejeck liex "er beter na.

In "t jaur 1712, zonden die van Baryjar

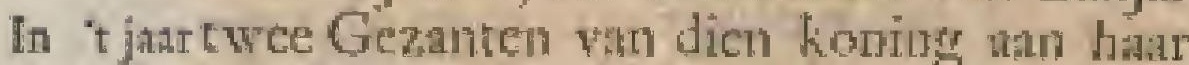
1712. Ge- Edelheden, die d/n 27 ten Juli doot den

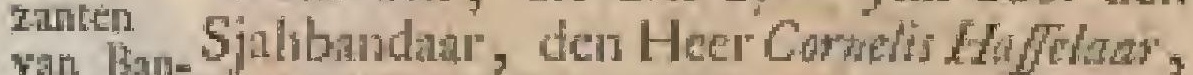
jar Mallin en den Opperkoopman Srlowon Stom, op Buat"s morgens ruffichen 7 en 8 untren met veel wia, ftatie ingetrialt wierden.

Een der zelwe was "s horings oom; doch geleck it ayn gewad mar eco gemeen Javan te $x y$ n.

Zy waren met hun eigen wantuig * 45 koppen therk, cn rret + bethen, cr 2 of 3 teine ftukjens, voorzien, in gezelfchn van een chulocp der $\mathbb{E}$ : Maratehepy op Batavia gedromen.

Onze Gecommitrecrden woothoemt hen op hun vantruig verwelkome hebbende, en van boord vilarendt, wiert er woor hen wal lhun wartuig zevermak, en zoo dik wils ook van 't galpoot gefehoter.

Ook brasten $z y$ roen een fehenkagie mon hunnes koning atus batr Edeiheden and land, die in twee kleine aspen and goude ketenkens (wan welke de ene hagel. wit, met cen goude ring atan wder poot, ca de andere fwart, met een fola wek fo op de news gateckent, en yder in een byzothder kortje, tempelswyzo gematat wias) ca in cen fratye dianstri, nigufing 2000 Reer wardig, bellone; en welk juwed, in cen bimbouste, met 's konings briet an Guar Edellieder, door een helbandiat op cen zilwere feliotel voor uirgedingen wiet, terwyt eenige van bunne" dienaurs de andere gefchenlica woor uit droegen.
Mogelyle zal men vratagen, waar dic 171 . getchenken blywers. Zy wonden ten roordeel wan to E. Maticlsappy operbar verkogt, dos 200 yersunt wan hant Edel. hoien er zis in heeti, die kass ze voor den prys, wanr op zy gelichatzyn, voor alle anderen natf:

- Na dat $z y$ ontrent her hoofd in de rivier gekomen waren, wiert de felunic way Stant, wata in $7 y$ zitten, anet een pilind na 't hafted getrokken, en coen does" de foldaten, dour geplatit, "driental geLchoten, 't geen datr lat, als zy by oen boom quancon, door indere foldiation driemal hervat wielit.

Nit dat $z y$ te land geftapt waren, flont het volk van de waterpoont tor de Hed Genomals wooning fo de wrenen, terwyl zy in "t midden wan one twee Gecommitueerden uht de zclve, en zoo herder over de groote zanl, en langs een fmatle galdery in de Vergaderzilal gingen, al watlo zy den Heer Generat wan Riched an 't eatue eind wa cen Jange ratel, en zymer Geheimichrywer ana " $\mathrm{a}$ ander einde wonden zitten.

Na dat zyn Edelheid ben de hand gegeven, en dus werwelkoms had, gringen zy op twee thoden, tulfchen hutron gele:ders in, mede ana die tatel ritter, rondom welke 7 helbatrdiess met hum roode rokken wan Sant, en honne helbataden in de hand, zeer onrzaglyk itowlen.

Als zy pas zaten, wierden 'er 9 kanonteloten wan 't katteel, on hen teverwelhomen, gedaun, wala na 't getchenk der twee aupeth getoont, en 't bamboesje met dien diamant ('tgeen zy Edelheid wat verugtelyk op derafel ter zyden lag) neFens 's konings brief wiert overgegeven; die door den Capitein der Maleyers geopent, en bevonden wiert in 'c Malcits opgellett te $2 y$ r.

Lyt Ldetheud wraggde, hoe hum koning voer"; en zy zeiden, dat hy au teer wel, miar dit het voor frem eet groot geluk geweeft was, da ecn yan onze fehepen; en 'e woornoemt gitjoor 'er lag, alzoo ty anders mue eenige wan zyn nabutrels ith ecru fwarea oof Iog (want wat zy door ons folup nu afgelchrikt waren) beralkt zou helblen.

Zy bragten ook jo pikol peper mede, cu zeider, dac de Chinceacen in dis jastr weel pikols van dint geverere liadden.

Als botelatus (volgens de gewoonte der meefle Oolterlingen, verzogten $z y$, zoo ras ty $^{2}$ hun gefchenk overgegeven hadden, ats in vergelding wan 't geelchonkcne, ro Iniphanen, 30 pikol kruit, en werlof om meer geweer re mogen koopen, alzoo hen belitt wis ten eerflen weder te konien.

Zyn Edelheid gaf hen tot ancwoord, dat nen 's lionings brief eerit overzetten, 
248

B E S C H R Y V

ITะ⿰冫欠.

dien lezen, dun over den inhoud dé zelis randplegen, en dat men her dim op dit hun rerzoek nater ancwoord geven zous.

Ondertuffehen wicrt hen een kopje Thee aungeboden, en na dat "er over deze en gene onverfeljillende zanken nog wat gerproken was, wierden zy nat hume verblyfplaats, by den Medicynwinkel der E. Mantechappy, gebragt.

Men verttont maderlyand, dat $z y$ den Peperthandel atr de E. Malatchappy alleen, by contract quanten anbieden; wat toc zy zich eenigzins geperit vonden, alzoo zy met dic van 't wlek Borneo, en met de Bergoollteren, over hoop latgen, verzoekende dat wy de peper, die er nu was, ten eerften met onze fchepen wilden komen aflaalen, en dat wy hunnen koning tegen zyne vyanden de behulpzaame hand doch wiklen bieden. Hatar Edelheden, deze goede gelegenheid waarnemende, namen deze nambieding des konings zan.

Ondertutchen zonden die wan ${ }^{t} \mathrm{t}$ wlek Borneo ook Gezanten na Butayia, en verzogten haar Edelheden, dat zy humnen koning tegen dien van Banjut. Maffin geJiefden te helpen; doch dit wiert hen op een beleefde wyze afgellagen.

Dar op nu zonder har Edelheden den Capitein Lientenant van den Befdb als Opperhoofi, en den voornoemden ondercoopman Abraban Poele, als zyn Tweeder na I3anjar Mafin, on daar weder een comproir op terigeten, en onzezatiken whar te nemen; doch nat dat zy hier met ecrige feliepen geckomen waren, bevonden 79 , dat eenige Chineerche jonken het wet hicr al wan de ketel gefehuime, en met een menigte picols peper nå Clima vertrokken waren, zoo dat "el woor ons maaulyks eene felocepslaading overfchoot, wanr uit klaar bleck, dit $z y$ onze fchepen mert, onn dar door tegen turne vyanden gedelst te zyn, dan wel om die af te latiden, werzogt hadden, 't green ook de reden wass, dit onze nienue Opperhoofden wry flegt vergenoegt hier van dant quamen; endit is het alles, dat ik van onzen handel of Borneo wete te zeggen.

War nu de Engelichen siangat, de den gevihen, dat my toefelyynt ontrent 't jath 1600 . certt een nauvang genoment te hebben.

In ' fchtp op Cotaringan, war mede Cipitcin Joes de Roy wan daar ma Succadan, en werder na Malikkn en Arsjien vertrok, zynde "tecte, dat bir op Cotatingan geweelt was.

Ju t jar s 702 . hebluen zich de Engctrcluen op Banjar Mathin oot vattgezer.

Het berigt, dat men tocel wan Macafar gan biat Edelheden dar van gat, was th0

dus: dat 'er toen groot en kicin $40 \mathrm{En}$ - $170 \%$. gelfchen op Banjar when, orer welke. cen Genemal van 27 jarten " 5 gezag land. Zekere Topatwen, hoofd der Boeginezen en Wadjos, zeide, dat hy Ahaas, of Oldewlict, genamt, endat hy eenigzins van "t magichap wan de Heer fohm can Hoorn (toen Directeur General op Butavia) en en kindskind van 'E Engelfeh Hoold was, dar eertyds op Bantam gelegen had. Deze had nog cen Tweeden, of en Adminiltrateur, en cen Geheimchryver, onder wich.

Dit Hoofd hick huis op ecn plot van Bambecen met zolderingen, wat op geen Engelletien, matra alleen Boegincezen, de wagt hietden. Zy hadden arn' de kant der rivier een lierlite wan lofle arde, met pallifinden befchocid, en die met een planken wloer belegt, welke al fucde wan Boegrieezen bewiart wiert, en met lo yase tukken, en cenige ammanitic wootzien was. Het hoofd dezer Boeginceren was Ange Bowi genatme, en een onderdatn wan den Macafisarzen Capitein Daria Marma op Bataria. Dere Hocgineeden, bevoorets wel $200 \mathrm{~min}$ uitmalende, waren nu nog matr 100 man fterk, alzoo dezc ch gene that Pafir en Cocti, dorper an de O. kant van dit eiland regt, tegen ower Celebes gelegen, en onder den koning van Gon op Macathä al zedert 40 of 50 jamen ftande, wertrokken waren.

De Engelfethen gavel tan yder van deze

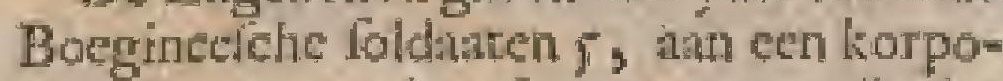
rnal $G$, en wh den fergenut Ange Bon 7 Ruers ter matind.

Topatowan, die zich bier mode by de Engelfehen wervocge had, whis Hoofd den vrye Boegineezen, dic we] 300 koppen fletk waretr; doch men had hier (gelyk de roep wis) geen Mandbaresen of koningskindencn.

Vericheide Engelichen waren hicr ath "t fohcubuile overleder. Zy ligen ${ }^{i}$ er met 2 fehepen, en 2 chatoepen, zynde 't een fchip vat I2f vaten; co over twee mantden meinde de General met alles van Lier op tebreken, en na Batavia te vertekken, ulzoo de zynen nict genegen waren hem dant wace af te wagten, hocwel by 'cr "r jagr: èr aan weer dage te komen.

$\mathrm{H}$ y had hier een oud dehip met 48 ftukicen gebrage, en zyn linding beftont: in conigen Antioen, Chinedche Itoftern, yzore ankers, dteggen, lood, cn Spanze realen, wart wan dit Opperhoofd van zich zelwen 300000 , en wan wegen hatate Matefchapy 700000 R ders by zich had, whar woor ty hiser pepet, enz. ingckogr, en war uit hy dan de voornoemde foldyen gevonden had.

Ook waren 'er, geduurende dit Moefton 4 Chinetche jonken, 5 , waden lang, en

4 bicedi, 


\section{B $\quad$ O R N E O.}

1702. 4brectr 5 gelsomen, diehier allerici porcelcin, Chinectiche syde, theelictels, zonifefchermen , enz, bragetr, die hen door de Janantiche kooplieder, en toor de Chineezen van Samarang wicrojn afgehatid, en deze Chinesiche jonken wanen van hier weer peper na Chma mede

DeChincezen hadden de zyde gelogt tegen 200 Rders Spaans, alzoo 'er gecn ander geld gatat. Ook lagen "er die 4 jonken nog, en alle de Chineezen hadden whagen en paffes wan den keizer van Chinik.

Deze Engetfchen, utit hun land vettrokkenzynde, staren 30 fchepen lterk, en onder twee vlaggen veddecte geweett, van welke 'er ir na China vertrokken, en de andere if onder dezen Capitein Moor (of Generalal) Alonden, wair wan 'er 8 na Bengale, 4 ma de lute, "2 na China, en I hier na roe vertrokkers was (wan uit men ook eerngzins de grootheid van hamnen handel op China en Bengale afinemen kon) met een voornemen om nu, by zyp togt na Batrvia, tha de [4 andere; onder zyn foraldeel behoorende, te vernemers.

Deze Capitein Moor fprak goed Maleis, en woingde an een fpion van ons, yan Macaflar herwarts gezonden, of de Heer Gouverneur Becrmok op Macafar 2ulken ongeluk (als men woorgaf) gekxugen had, en, terwyl hy in 'tpaleis des konings van Goa te fluimeren lag, door Sampowalia belprongen, van agteren doorregen, en dus mer 2 varandels Europianen, dic hy by rich had; vermoerd was; inmers dit wil men dat de Bonifche colt, Cordyows op Java had vitgettroit, en hy had dir van een Djohorees, die in November 1701. over Java op Banjas Mnfin gekomen was, gehoort.

Op dezen ryd hadden de Engelíchen met die van Banjar Malfin moejelykheden gekregen, zoo dat her mer hen tor ecn vollingen oorlog uirgeberilten was, by wellke de Engelthen o dorpen der Banjteezen, te weten, Bumpr Maftri, Burjit, Cajoe Taungi, Tatas, en Cetrat Poera veronéct hadden. De buit, hist by hea beliomen, beftont in - metale ftukjens, 100 basjens, en 20 cojang (of latteri) prper.

Geen Banjarezen, groot nog klein, hielden bee met de Engelfehen."

De koning wan Banjar wiert toen de Panombobam geniam, en was uit het Koninklyk huis van Stmbive, en zyn rylsbellierder, Pantrang Potabaja, uit hec gedlagt พan den Macullaarzen Grain Gromgrong gelproien

De Lingelichen kogten toen hier de peper regen 40 Banjarze gautangs (wel-

111. DEEL

ker 5 Banjarze 'er 4 van de onze, tegen tyou. 7- pound yder, doms) voor I Ryksdalder Spans, en verkogten die dan atu de Chineezen, en anderen, weer tegen de I 3 gantants: i Rykdnalder, dat Juim twee hoofdommen wintt gat.

Zy bemneiden zich met de tollen en inkomlten des linds niet; doch zy haddesn van der koning van Banjar Matin 3,os R ders voor hume gedane oorlogsonkoften by hamen optoge tegen de Binjarcezen bedongen, welkede koning aun hen roldan, en war op de $\mathrm{C}_{\mathrm{api}}$ tein Mor 4 van dezeveroverde dorpen an hem wedergegeren, hocwel hy Basiat Mafin, als econ verblyfplates der Engelfchen, voor zichl behouden hitd.

De Engelichen hadden de Banjareezen niet eerlt gemoeit , maar die hadden zonder wetrige reden hen orwerwage willen befpringen; waar van de EngelTele berige gekregen hadden, en wai op zy, in devoorbatt geweet, hen atageralt, en de voornoemde dorpen hen afgenomen hadden; hoewel $2 y$ toen mat: Io man van hune Natic, en 40 Bocgineezen fterk gewett waren-

De lpion, die dit berige aañ den koning van Boni gebragt had, zoide, dat lyy te Banjur Mallin op te geweerrale van dit Engelicls oppeshoofd zekere fpies of hazagati, met goud overtroklen, en een mer goud bellagene kris thad gezien, met een vitgefneden vilchbeene greep, welke Aroe feko wel cer op Tambora een buit bekomen had. Dir gefchenk was vań Goa na Mangarai ata zckeren Macaszatas, Papo genaime, en in Potta woo. nende, gezonden, en die bazagazi had

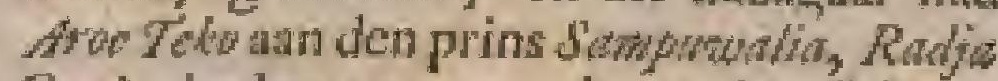
Gua "s dochters zoon, als cen handblotn gefchonken, en cenen ra-Adam had dic gelchenken uit Crain Bowto/onggols huss zelfs ma 's yauruig in de river wan Goa zien brengen, welke hy, tot zyne uiterlic verwondering, nu hier op "I geweerrak van dezen Lngelichen Genersial loggen zag. De zelve was an itukken, al 700 hy, wen de toge tegen de Buijareczen thuis tromende, de zelve te hard tegen de grond gedrukt had, wan door zy mjidden door gebroken was

Dus verre ging dit berigt, want thit men befpeut (gelyk wwy ouder de toffe van Macaflar en Celébes al angemerk hebben, dat die vat Goa met deze Fagelfchen (ath welken die koning enige vararjen kruit, en cen brtef gezonden had) zich nugctitaten hidden, en door hun he hip eenige gronden tot het herftellen win hun oude regecring zogten te leggen

Ook dede dese General zyn bet, on alle misnocgden, en zcli verfcheide Magdlarecze koningen wa zich te trokI i dien, 


\section{B ESCHR Y I N G E * A N}

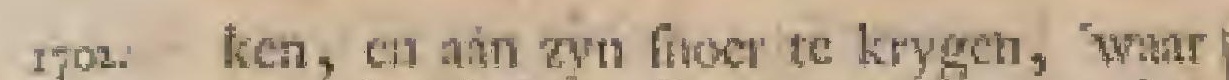
regen by de Macafturze regerimg en den koning van Bond (nlzoo zy kennis van zyner coeleg hadders) 200 wel gewatk wiert, du alles van rels (belvk de volBerete ryd geleert heeft in jook en damp verdwenen is, hoeweldie, zoo Arot Tho op vrye vocten geraake was, wan een gewailyk grevolg had konnen worden, dat watalchynelyk wel de gronelte reden yeweeft is, warom hat Edehheden (berigt vath zyo meniguldigedregenentent, van rich by deze Engellichen, zoo ras hy mar in wryliend was, te willen begever, bekomen lyebbende) gocdgeronden hadden hem ma Ceylon te zemalen.

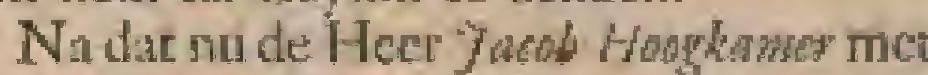
cenige Engelfolien van Batuvin in "t jom 1706. gevluge was, en zy pour Banjar Maflin gekomen waren, lwbben $z y$ mee dic Inlanders weder cenig getchil geleregen, whut door zy, nevens meet andere Nutien wath datar verdreven zy. Zy wierden zeer fors wan dien Inlatider antigetaft,

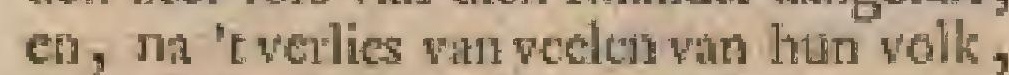
niet allecen hol over bel na hunae vatarEuigen, duar woon de "wall leggende, gejuagt, juar ook genoodzatkt met hunne ftergeloone fehepen zeer verbath na Batavila de vlugt te newen.

Ook hiduen dere vertrokkene Enigelfehen gezien, dat de Banjarcezen een wan hunese fchepen, wiar op de Heer Hogrkaner, cu ecri Engelfeh Heer tan atnzien was, in brand geftoken, en henidart door in ' $\mathrm{L}$ gevaias" van met het zelve te verbranden, gebragt hadden,

Matar in 't juer 1708. heb ik in Amboint van zekeren ftieman op de chaloep de Romindpot, $y$ an Gowerizoos genam, bericht bekomen, dat het voomoemde njet allecis water was; mant dat hy "cr nog by te yoegen had, dat hy den $7^{\text {den }}$ Sepsem ipo7.utedrukkejy, 'om na den Hecr Hogkanwar te zoeken, getonden, en den 2 khe Uctober daur mer akeren Engelfehen Prefidene van Bunjat: Maflin, hiham Thems gename, gekomen wis.

Deze Hecr Thich was 3 jiaren te roo-

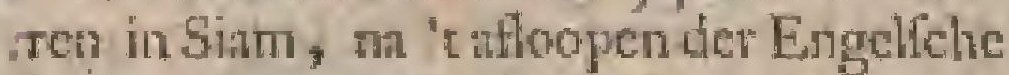
logic, gevangen geze, en van dart met een Chines of ander vartig ontvluge, en hitd in Runde ober Engelfchen verzoge, alzoo de oude Prefiden overleden, en lyy al voor 2 jetren Prefident gemankt, en 'er' niet een Engeds lichip by de hand was, men hem herwasts wilde doon zenden, 'c geen hem (die in Siam genoeg geleden, het kriflen wan zyn wolk gezien had, en zulf matr met cen folmpleheut wryetreke, en lang gevangen gehonden wits? tocgeftann wiert; wall op hy toen ood smet de chaiotp de Mercelinus, en mer dezer Itumman, herwatuts vertiokleen nuar'er zoo hath niet geliomen was of

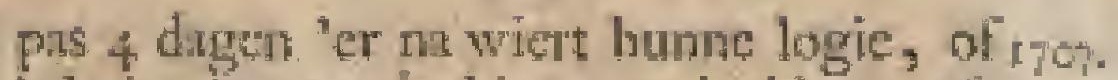
"thus, "r geen zy hict nog ludden, atgelooptn.

- Aangande den Heer Hogkawer, wilt ly uit de, mond der Engelfchen, die hy luse vont, en it "t byronder wit de mond wan dien Ligelichen Capitein, die in dat brimdend reherje by hem was, en 't hats vin hem afging, nog dit ('L geen wy ook cliters ambalen) te zeggen, dit by (Hogglamer) en ecn flinf, ma dat de Bunjareczen hem gedwongen hadden, na een feheepje, dac ry weer opmatken wilden, en dat by 2 chnloppen digt by de wal Jag, te whigen, na de kaljuit van 't zelve voor een tyd geweten warén; doch dat $z y$, "er weer tir willende komen, alzoo dit fcheepje door de Iilanders reers in brand geltoken was, de deur zoodanig bebolwerke vonden; dat zy thun oogunerk in dezen niet badden konnen berciken; doch vonden egrer cen middel on door de kajuitswenfters in een kifein vasutuigien te geraken, en met dezen Engeltchen Caputcin, die hem gered had, wiaj dar ta lind, en zoo ftil, als 't mogelyk was (niet regenftuande hy een lterke koorts, en in drie dagen niet gegeten had) nit "t bolch te y.jugten, en zich da:ar roe den swond vanden volgenden dag te bergen, ma welken tyd dede Engeliche Capien hem gežegt had: $M$ w Hecr Hoogkamer, mo is if onse tyd on

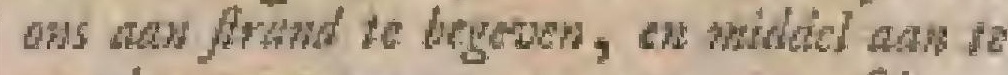

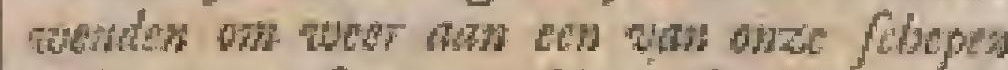

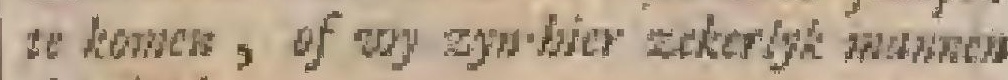
des doots.

Lgter wont men goed oin door zyn flawe voor af nogeces te haten zien, of de Banjareezenal wat ftrind geweken waren, waar op dan berigt krygende, dat "er geen meer pernomen wetuen, mande deze Capitein den Heer Hooglomer nu nog to Aterker atn, on zich uit het bolet na thrand te begeven ; doch allao hy klargde doon zyne zickte afigenna, on nict in itant te wezen, om nu der warks te gatr, nath die Capicein ann, om zels voor af nog cens ann ftrathd te gann zien, hoe 't "er itont, met belofic, dat lyy hem, nat en van hume ftengelooze fchepen bereikt te hebben, zou komen athituten. Hy dode dir ook doags 'er min, doch vonic dien Heer dood, en and zyn ziekte overleden. Dit alles nu verharalde deze Stuurman ats zaken, dichem zeer wel bekent, matr die egret cerft na tyn wertuel (alzoo zy roen tegen hem zeiden van den Heer Hog kanter niets te woten) voorgevallen waren.

Hy worgde oolk hier by, dat hy ract exnige Engelfehen, toen dar op de reede leggende, wel 2 of $;$ mylen land wathd in seweelt was, alwar $2 y$, by een Orangkaja gekomen, zcer wel onthinalt

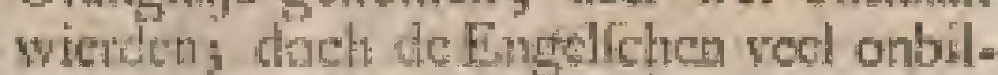



B
O
R
N
E
O.
291

Ijo7. Lykheden, met zelf tot in 't wertrek van zyn vronwen te loopen, plegende, had die Orangkajadat over tegen hem groot misnocgen betoont, ea zeel over de Engelfehe Natic geklarge; mat dar en tegen met veel lof wan de Hollinders gofproken.

De Ornngkija, ziende, datt zy net hume baldiadigheid voortginger, belaltte hein anuttonts, $z 00 \mathrm{zy}$ dic net nilicten, te vertrekken, walr vali sy de minen mankende, veroge de Oringkija den Seumratin dat te blywen, grelyk hy dede, alzoo hy hem dat andertial, enook de Engelfchen, zoo zy zicis ftil wilden houden, verzogt; doch $2 y$, misnoegt op den Orangkaja, vererokken alleen van danr.

$\mathrm{N}_{\text {: }}$ han vertiel bragt dete Orangkija den Sturman zyn gntilch huis door, en zelf in zyn wow wer-vetrek, onder welke Jy verflicide felloone blanke vrouwen vont, die voor geen Miftiçen behoefden te wyken.

Hy stg "er ook 4 of s lchoone geweerrakken inet uirgetezene blanke fraplaitrien, pieken, piltoolcn, en ander geweer vervult; al te welke ty meclt by tafwezes van dien Oranglaja (alzoo die iers tedoen kreeg, en hem eenigen tyd allecen lier) gezien lind.

$\mathrm{H}^{\prime}$, weer by hem gekomen zynde, vatagde bem wat hy al gexien trad, en of hem van zyn vtouwen wel cens cen pinang autgeboden was, waal op hy neen gezegt hebbende, nam by dit zecr quaalyk, eeggende, dat zy wel wilten, wat hatie plige outrent zulke lieden was, die lyy toeltont in "I wertick san syme viouwen te komen; war op hy hatiatnitonts belatte hem pinang te geven, en als zy die mencen jong meisje zonden, gat hy

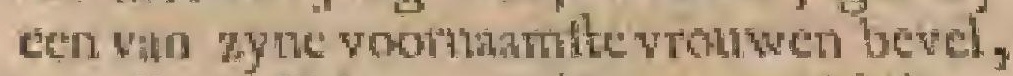
on die zelf hem te komen anbieden, gelyk zy deden.

Uit al het welke hy fond fionnen befpeuren, dat deze Oringkaja groote

agting voor onze Natic fclucen te heb- jo\% ben.

Hy fad hier wan deze Engelfehen toen ook humen Tweeden, en een Derden, Sir Baldewyn genatane, gelaten, en wan hen vertlaan, ditt de Banjareezen hee voornoeme fcheepie, wan op de Heer / bog kaner geweett wiss, en die 2 chaloepen al mede verbrand, en wel 5 unren ling een der grootle feliepen ingehad hadden: doch endelyk waren het te Engelfchen mer die twee, en nog cen klein reheepje, dat pas op de Recder gekomen wis, en nogen dat $2 y^{2} \mathrm{er}$ by kiregen, ontionen, ct mot hunnen Prelident, ch meer anderen, op Batavia zecr reddeloos ver fehenea.

Die nu is lace alles, dat wy ran de Engelfehen hier woten te zesgen, dar maar by te voegen hebbende, dat it, wanneet ik in to jar 1713. and: Katp der Goede Hoope was, dan entelyle Engelfohen, en daas onder een opperhoofd vin Banjar Matin (noo men reide) gr"zien heb, die men toorgaf een felat van diam manten in tolier Koffertje, dat hy dant mede ala lind gevort had, by zich te hebben. Ook kon men dic eenigzins zicn aал zyn hoedcicmad, dat ongevecn dart" yan, en val cen diergelyken hoedland met fchoone fteenco ( 200 men my berigt heefe) voorzicn was.

Hy lig by den Borger-Rad, Monfr. Botroman, newers exitge anderw Engelfchen t'luas, alwaar $x y$ al wy groote figuuren matiten, el war by ons dan blykt, dat de Engelfochen Banjar Manfun wict ontrent 't jazr 1705 . "gelyk Wolks Rogers in zyn reize fol. $37 \mathrm{I}$, zegt, ten ware hy diar by dar geval, ten tyde wati de Heer Hougkaner vourgevillen, peritonty mati", zoo dut al waldy zoo is, gelyk hy zegt, wy later verlaren hebben, hoewel ik vech eer geloove, dhe $2 y$ nog lanter op dit ciland guhindelt hebben, en 'er' mogelyk non wel handelen, alzoo "er te fchoone wawen vallen, om dat land zoo te veriaten.

\section{E R D E H O O F D S T U. K.}

\section{Van den GODSDIENST op 't Filaríd BORNEO.}

Niven men met ordie wan den Godsdienft der Bornecrs, en van de Ingezerenen deres eilands fpreken $z^{2}$, moet men acggen dac hice dricdetlei foorten wañ Godsdientter, de Heidenfiche, de Mohhammedanaliche, en de Roomfehe bekent zyn.

De Hejdentehe is de oudte, en die by de meelte Inlanders, voor nl doch by de berglieden, geoffent, en tot nog toe onderhouden word.

Zonurnigen van hen bidden de zon, $m$ a en ftarnen, en andere weer alkes, dat hen 's morgens manr cerfte tegen koine, als esen Godheid and. Zy zyo wol bygehove, en geven meet allen op wogelicluei en meer andere soortekenen rati geluk of ongetak, zoodanig agt, dat $2 y$, erm 


\section{B ESCHRYVINGE $\mathrm{V}$ A N}

reis ondenonen, en ex ongelutswogel, die tepers hen man kemt sliegen, ontmoer hebbende, hum reire aantonts dtiken, en weder na huis zullen keeren; doch zoo dic pugel mee hen mede, en ma die plats, dant zy na toe gatn, vliegt, zullen $x y$ hume reice gerult werwolgen.

Zy wenen him egter wan geen Tempels of Pagoden, en nog minder wan Priefters, alzoo zich yder ecneia God ma vyn zith verkief, th dien ook na zy welgewallen diest.

De Molhammedanche Godstivent word hier doongans by de flratdvoldeven geocfent, die ook al zer veelen warn de berglieden datr toe bewogen heblen, die nual mede hice en dar een Tenipelken en cen Priefter bekonen ; ate hen nu en dan Befingder ; mara die zich rykelyk voor zyne nocite doet betalen, alzoo yder Infinder, die Montch wict, aun een Prielter I gaving flofigoud, en I gantang loode picjens, geven moett, dnat zy 't rykelylk voors kothen doen.

Zedert de Portugeezen hicr gehandelt hebben, zyn'er u en dian ook wan hunne Prielters gelsomen, die den Inlander, en yoor al de Heidenen (alzoo zy by de Moorcis weinig ingang yonden) tot den Roomlchen Godsdiente liebben tragten te brengen, war wan zy "er al verleheide op hunne manke, er loffe sronden, tot her zoogemande Clutendom gebragt hebben.

Zoodarigen had men "er lings de rivier van Caljong Compang at zer vecl alzoo die van Macho bier ecn frielter ecnigen Lyd voor "I jatri 1690. gelaaren hebben, die hier slus on ftrecks wel 3 of 4000 Chrittenen genaakt heeft ; man die Puter, door lant des konings van Banjar Mallin eenige jarendanr na, by zekeren opftan, mode ombats gebragt zynde, is thet dotar by geblewen, zonuter dat hier weer een aniter Prictter gekomen, en wala dool deze bedrocfde Chritenfchan op ech beklagenswhardige wyze veritroid, etr weder zoolanig cot hume oude duifterboid wan gect vervallen is, dat zy van hunne Chriftulese niets onthouden, en geon ander bewys, wan dat zy wel ees Chrifen geweent zya, ust ecn liruisje, dit ay on den hatsdagen, overgehouden heblien.

Enl dit is het al, dut wy wan den Godsdicntt van de inu uontiens des cilands Borthéo weren te reggen; warr mede wy dan hict vath aticheshin, om nog kortely in het volgendt Hooldtuk iets wan "t eiland Buli te ueggen.

\section{I E R D E H O O F D S T U K.}

\section{Van het Eiland B A L I.}

$\mathrm{V}$ Au bet Eilond Bali, Wra" "xleg. Dorpen op dif Ellasd. Kant pan Bali. Ingezetenen. Watren bier whonde, en gotrobkes. Wapenen. Fus Speltuigen. Howelyken. Lykbelundelingen, en sin 't medebranden wan bwhe Vrouwen. Be-

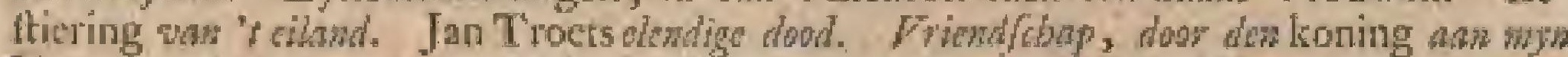
Voorzant bewzen. Ontekking was dit allat door de kngelichen on de onzen. Godsdientl fer Baliçss.

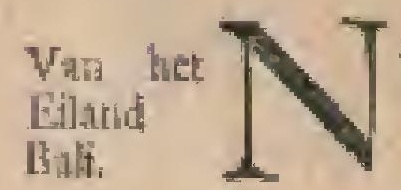

A dat wy nu Bornco doorloom pen hebber, meinen wy dat wy ook fers var to tilatid Bali, om dat her zoo na slin "teillusd Jawa gelegen, en mar met de ftrat van Balamboung dati van alfigelelejden is, dienden ex zeggen, of ten minfter, 't geen ons

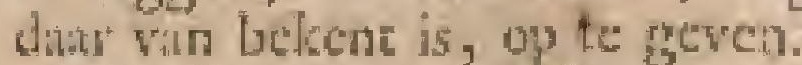

Het lege op 7 grituder , 55 min. Z. ence en 33 min. felken cu wotd vals zommigen gevordecte mane iz, doch bin anderea wel ;o mylen in den outrek te hebben: hoewel "e wel ontuent 60 mylen if den ontrel hotales 7 anl.

Het is en fohoon en zeer vrugtbat eiland, tea decten in lange ryllianden, twa deelen in probergten beltande, gelyl fren die ook wel in onze kutr van Java zion kan, atwat ons een deel wan dit ciland, meE de ftat van Balambong op zomnige plimzen, war de $\mathrm{N}$. kiant, mate I myl, doch an de Z. kanc wel $z$ of 3 mylen wyt, tegen over Balintrbong tecer net affectuect, woorkamt.

Men zict daar klatr een berg, de doodKift genumt, gelyk nor een andere in "t W. leggen; doch voomamely ls is 't ann de.N. Kane zer bergrgtig. Aan de andere zyde wan 't eiland heef men nog ewn ftrat, de ftrat wan Bali gendamt, dic tulfehen Bali, en 't cilind Lomboc kont.

Het word pan zommige onlkundigen Java mwor, of klein Jnvi, genaamt, een masm, die wy getoont hebben, dat alleen regt san 't eiland Sumatra pegewen word.

Men zict dit cilind in de eerte reize wan de 4 eerfic lichopen onzet Mantichappy 


\section{B A L I.}

afgebecld; doeli dat gelylut 'or in "t gehed niet ma, gelyk dat wit dedorper, che " op Jeggen, cn die wy in onze nieuwe Kans anmyzet, klar blyken zal.

Hex is om zyne hooge gebergten zeer groot wit uitbretang in de hooge, altzoo dit land ores at bewoont, en alomme 200 vol dotpen (want fkeden heef men "er nier) en kleine vlekken is, dar men gift, dat hicr op wel een millioen menfehen husishouden.

Wy kernen riet slle dedorpen; miatr wel voornamentyk deze volgende, wat over wy nader zuilen handelen.

Aan de Ooilkant wat die cilind heeft men aan de N. O. hock een groote bati, dic wel of of 7 mylen breedt en by nut wel zoo diep, gelyk zy ook zeer goed is, om hier ren anker ex komen, te meer, dewyl men dar en folnone rivier heefi.

Wanneer men nu de $Z$. hoek dezer bati on is, komt men by eer kleine bati, die a mylen breedt, en wel 4 mylen diep, in welkers midifen en eilandeken ontrent een fraje groote riricer os , dic boven 2 tatiken of fpruiren heef, welle zich ontrent 6 mylen van ftrand vereenigen, endus te zamen in bie bua in zee llouten.

Pas Bezuiden deze riwier, de rivier wan Gilgil gen:amt, heef men her dorp Gilgil, dat zeer groot is, en alwat de Salhow Mgore, of opperkoning van Ball, zyn hot lioud.

Een myl' verder Z. wa theeft men het dorp, on de rivier van Blancinja, welke plats ook al zeer groor, en wol memlehen, doch wat wetder land ward in gelegen is.

Anderhalve myl Zuidelyker hecte men het dorp en de rivier wan Panatijong, cen half myl verder" "rdorp Pedifn dats dic rivier; nog $t$ myl verder Sifeythan nald een klein lpatije; nog eca balwe myl Zuidelyker Bulajoe and een kleine rivier, en outent den $Z$ hoels, anders de Werkenshoek genastme, hee dorp Bocliling, alle welke dorpen zeer tia by de zee ley. gren. Ook vertoon zich die hock ats cen fnulle flrook lands, die pas 2 of 3 mylen bredt, mat wel 7 of 8 mylen lang is

Van dith W. and gande legt pas aan de antere wde san de Werkenshoek het dorp Moenssing; dar na cen halve myl Nooddelyler he doup Badong, nog een half uth verder 't dorp Padangan, ecth groote myl verder her dorp Baha; nog 1 myl verder Sandi, nog een halwe myl verdet Marmbal, nog ecla viende myls verder Capal, een halve myl verder her dorp Kaliangat, ech vicrde myls verdes Batoematsong, chrog 1 myl verder het dorp Patamon. Esn lialve myl Noorde. lyker ziet men het firlid dorp kajoe loeteh, I myl vedder Boeliagg, en nog een wei- fixfyerder, by man "reinde inn dien irmillen hals lands van de Verkenshoek, thigt by aen rivien val den zelven nain, her dorp Baranan legset].

Van dital tehict deze luft WV. N. W. 5 of 6 mylen ath, nivat rich day weer errit het dorp Abinn, een myl welder Samit, een lrulve myl verdeg Todar, cen vierde myls werder Geliunjer, nog cen vierde iny is verder, an cen fehoone tir yier van den zelven mam, Lampidja al vry wyd dirgeltrekt lnings thisud, gelyk de anderen een wejug landwayd in $\mathrm{Jeg}$. ger, vertant. Deze rivier kamt mee fwate fpruten, decenevan t 0 , ch be

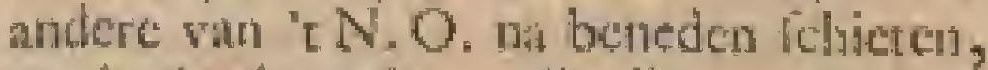
ch is de lwandte, die ik op dit Jaud kenine.

Een myl verder heere men Kathaftan, nog cen weinig verder, doch wat van thand, Koen; en en halve my Uoltelylier Kalahan ; cen halve nyl verder, W. N. W. an, Tadjem \& en wennect men nog anderhalve myl werder tome, heef men op den hock van een groote rivier van den zelven nan, die mer 2 lipuicen zich I myl win zee veteenigt, en dan hier ju zee flort, het groot darp Koeftamba nath een rivjer valu dien num leggen, alwatar een wan de hine Balifiche koninkjers zys hof houd.

Een halwe myl verder lege het dorp Salice, alwain" de kult allenskens na " $\mathrm{N}$. W. dratat, en darthomt men, na 2 mylen marclierens langs het akelig gebergie alduar (gelyk zich hier om trects a an weerylen teze rivier meet over al vertoont ) by her frai dor'p Tabunn; een myl N. Ooftelyker wertoont zieh Koekoe; dar men groote boffchen, en lware gebereten ontrenc bect.

Dan tomt men hoe langs hoe meer in de Atraat van Balmboangan, die an de Z. kante wry wyeder dats and de $\mathrm{N}$, liont is, ontrent welker's tridden het dosp Djudi Benoonden een groote rivier van dera zelven mam lege, welke, met 2 takken wir het 0 . en N O. vootlkometrde, wan "t U. ma ' $E$ W. alftuont, ent thar zoo in $20 \mathrm{ltort}$.

Op den N. W. hoek Jegt het groot dorp Boclongan ; wistr nit men dien hook on $\mathrm{O}$. angande, atu dic $\mathrm{N}$, hithe van her eiland de durpen Boangeafia beeft, en dalr na dan N. hock, diê redalyk dile is, pas Beoolten de welke zich eerff de berg de Dondkift, N. sn Z., en dan mog een groote berg, medk $U$. en W. Belliekt, vertoont.

Dan heeft men 't Harten-ciland eda hal we myl buicen de $\mathbf{N}$, kitht van den $\mathrm{N}$. hoek leggern, watr ma deze wall wel i' myl inichiet, en thdar de St. Nikolanbati mathe, welke ontrent $\mathrm{I}$ myl wyt is.

Pus Beooften dezelve vertoont zich het

$$
\text { I i } 3 \text { dorp }
$$




\section{B ES C H R Y I NGE Y A-N}

dorp Mongoi, en I myl werder cen bati-

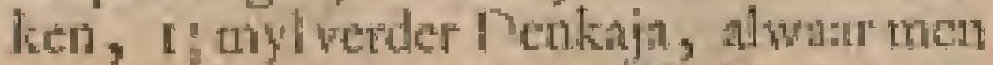
atreren kat, envlak op den $\mathrm{N}$. O. hock het dorp Batocan Jeggen heeti', wait ontrent rich pas I myl bititen de woul 4 cilandekens of een rif, $O$. man gedtreler, zect vertmalkelyk vertoonen.

Een ved grootel getsl ven dorpen, welker namen ons na njet te binnen fehieten, heeft men landwatad in ower nl op het fwat en hoog gebergte, dhat men daar wine, in de lchoonfte bolTelien, dice men zich zelven wetbelden kun; mitar alzoo de oppervort zeer beknmert woot zyu land is, is troor ons een yolAlagen onmogelykhed, on enige kewrists van de geltelemis wan die land wan binnen te krygen, of datar wath jet verder, dun reess efefhict is, op te aever.

Eenelyk konnen wy nog dit 'er byvoegen, dat dit had wol lehoone bolichen vol rimmerhout, en van atherkei tato wee zoo overylodig woorten is, dat men datu voor weing geld als een groot Heer leven kitr.

Ook is dit ciland door zync lwate gebergten, en digte boftchagiti, wan mtuute zoo tterk, dat het pich zelve teger buitenwyanden met zeer wcinig yolk zou konnen verdedigen.

Aan de N. kant is het wan den W. tot den 0 . hock wel i8 of 20 mylen lang, en het fchyn my rondom zeer fchoon, zonder rever, kitskappen, droogten of zonkter eenige cilanden ontrent bet zelye te zyn, dan dat men "er cen klcin eilitndje Beootten den Verkenshoek, by na in 't midden des zelfs, een hatwe tuyl pan de wal ziet.

En dit is wel het woornatm lte, dat wy yan dit cilund in zynen omtrek, en in opzigt wati des zelfí gelegenlecid van binnen konnen optueven.

Om den Lezer een netter denkbedd hier van te atoen larygen, hebben wy befi Kaart was gekeut, hist wan een byzonder Kantje, P. P. P. gemerlit, op te thellen, en "t zelve hier by te wogegen.

Het ciland Lombae retoont zich $\mathrm{Be}^{-}$ ootten Bali vol bolichen wa berger, en then het $W$, thrand heefe men wercheinle dorpen, welker manen ons onbelente zaY 17 .

De ingezerenen vin dir eiland zyn doon-

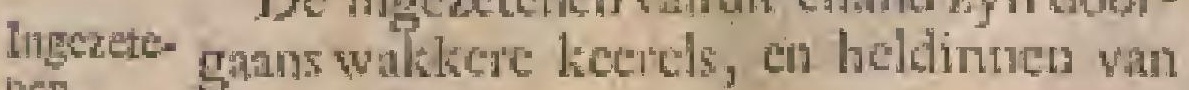
neri. troumen.

Wat de mans alangant, zy zyn doorgatus blanker, of blecker, als de Jawatneh, en fragier belneden wan wezen, dan de zelwe, ook noo plat wath sturecrigt niet, Iwemende wat mecr na de Macasfatren, duch wry hooger van neus. Men moet de zelwe geticel nnders, als oy op hum zelwe, hun ejpen meefters, en in ban land zye, - din buiten het zelve, wamner zy farver zyn, aanmerken:

In hun land zyn zy doorgagms luj, en Eroote funjeurs, die, fun dat $7 y$ zich gewallichen hebber, zich wan humac wvyen laten ramallen en oeroeten, co alle de laden klopken en wrywen, en wel met Happrascic en bebori beltyken, en rieh din van de zclwe zeer net likeden en pallecren, watr ma zy met de kris op zyde, als banderheeren door het dorp gata fpargeren, locrende hier of dtar, of an ten of "t inder te fteden, of, $2002 y$ hum belang day in winden, dezer of genen te vemoorden, of wel on den eenen of den anderen vatn hunne vrienden, buiten hun weten, ats dezen of genen vrym:tn, dis 'er met zy'n chaloep kome, te verkoopen, dat zy das zeer liftig weten te beitcllon; makende die gene, die zy verkoopen willen, gande, on mede an zulk een chaloep te gain, die zy datu, beneden gelomen, en in de bocjen gefloten zyлic, woorde fomme, die $x y$ er trouwloos vor getroklien hebben, zitten laten, hoedinige, donr hun eigen broeders en matle blocdverwaten werkoyse, ik verlcheide onder myn Balifche flawen gelad hebbe.

Indien men nu de $z$ lwe sls doaven atrimerkt, moer ik, by eigen onderwinding, allzoo ik "er vecle wan gehal bebbe, "er af getuigeis, dat het de bette, narlligfte, en trouw the flawen san Indiën zyn, en die in verruft voor cen Macaftar (date jonkerties, en die egter wal zoo geeltig zyn) niet veel hebben Ie wyken; mat dar en tegen weel beter te vertcouwer, can zoo moorddatig niet, belbalven dat $z y$, in tyden win nood, wok veel klockmoedigel, als andere Indianen, zyn,

Men vint onder de zolve zeer veel fraaje ambagtlieden, wan timmerlieder, fmits, keur'ylic fehryowerkers, cyfterats wat Saguwer , of Towne by andere Suri genatme) merzelars, goudineden, kleermukkers, fteenbakkers, en 2 , dic doorgans zetr zedig, gemuicr, gehoorzam, en zoo futoenly faren) geen andere dataven by hen zyn te vergelyken, watrom ock alle lieblen *at kenjis tragten zullen zich wan de zelve te voorzien ; komende een kloeke mans flave donrgyans op 75 of 80 , matar, zoo hyeen ambing kan, wel op 100,120 en r ro R ders (na dat zyn anbagt is) en cen flawira doorgenans op 70 of 80 R ders doch zoo zy frai wan weren is, (hoedfirige ik "er zeer nooye gezien liebbe, en die zeer net doof de Heer Conths de Bimy op een cler wooningen vat de Hect Cbapetoju buiten Batavia afgebecld zyo ) of zoo zy iet forid "s najien, of maken kan, mede wel op 100,120 of $130 \mathrm{R}$ der te It antan. 


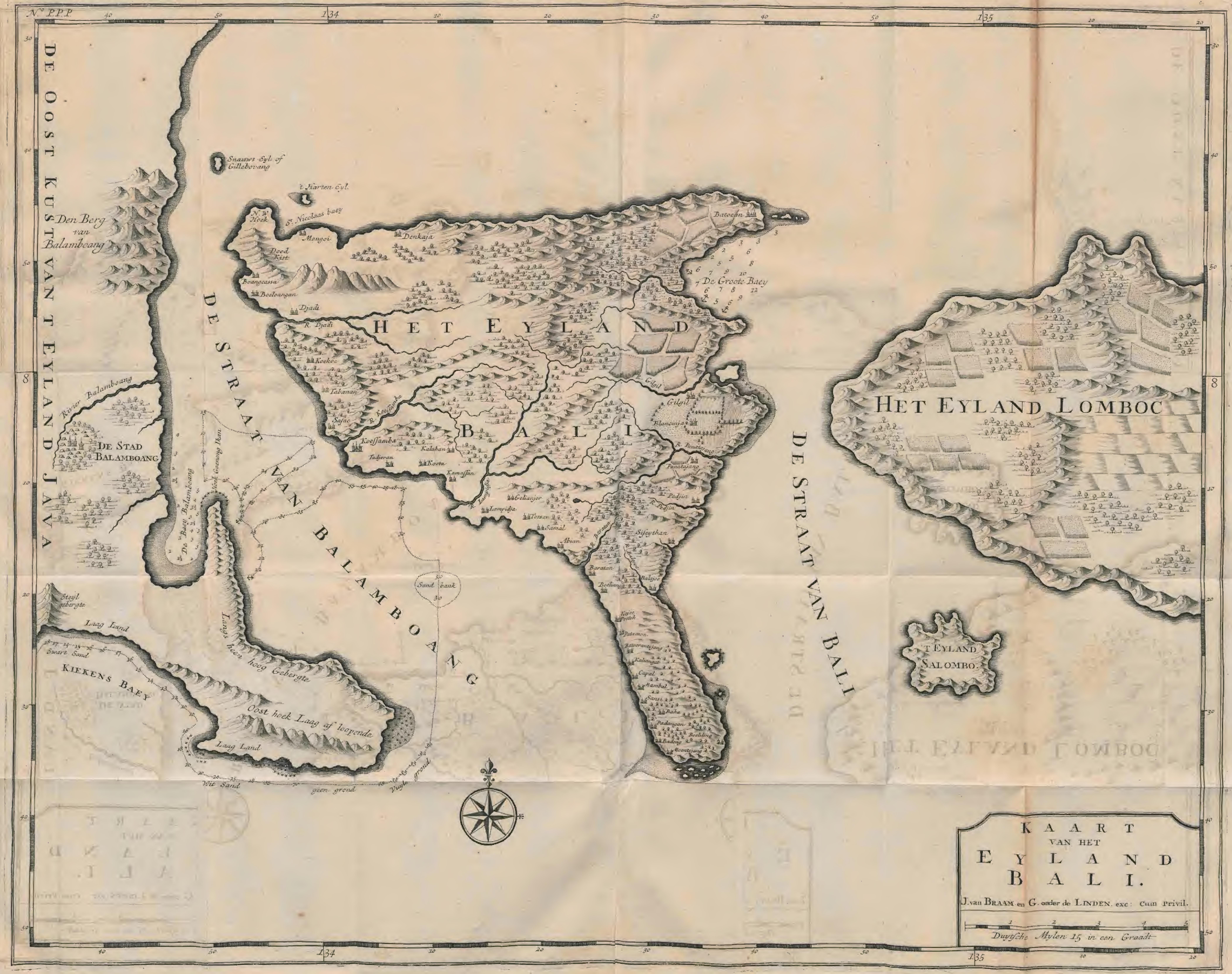


De Balifhe vrouwen z.5n in har eigen land niet veel beter als finvitunen, alzoo zY als muilezels moeren arbeiden, en zelfs agter de ploeg loopen, zonder dat zich de mans datr exnigzins unede bemoejen. Veele der zelwe zyi zeer goede vroedvrouwen, en, Jhit "s hands wyze, al zeer bequame doctorefen, hoewel al hase bequamheid mect in hare dage lykze bevinding en ongegronde offening beltant. Zy zyn in "t gemenn alle zeer martig en wernultig, en de meette vrouwen der Chincezen op Batavia, en elders, Jyn gewezene Balifeche flanwinnen, die in zulk een huishonden ongemeane goede preuwen wan hatre bequamheid, nariligheid, goedandigheid, desgd en trouw geven ; ook worden "er zeer veete tot Macy di Cala, of opperfte der llavinnen, en thin welke men st opperoprigt ofer zilver, groud, juwelen, limuen, enz. in eca luishouden van de vermogende lieden op Batayia toevertrouwt, gebraike, in wellse poft zy zich zeer trouw en terlyk dragen, gelyk it dar zelfs bevinding valn gehad heb.

Zy ruagendoorgans zeer fterk na linate vylueid, dat een woornme reden van hate trobwe dienten is. En das zyn 'er veclen, die zich wan hate Heeren op dic voorwatude viy lcoopen, wan duc zy hen maandelyks of 5 of $6 R^{\text {dess }} 2 u$ llen opbrengen. "1k heb 'er gekent, wan die Batiche doetoreten, en yroedvrotiwen, die wel 10, if en 20 Ruters, en meer, ter miatud gewonnea, en door hunne naarftigheid otrolyle duizenden Rues magchatten hebben, dic, als $x y$ geen kinderen hebben, an hare meetlers of der zelver crfgenumen, volgens 'c lnudrege dasr, varvallen oyn.

$\mathrm{Zy}$ ernceren zich in han eigen land meelt of mex de landbouw, of met het fpinnen van kattoen, en "E wesen van deze en geene kilęederen, dic hen de Jivatuen, Chinezen, en andere volken, komenathandelen, hocwel 'cr' anders zeer weinig buitenhandel vale, behalwen dat de diaverhandel de troofuludadel van dit land is.

Doorganas worden zy zecr oud in lun Jand, en ik labb " $\mathrm{er}$ in $A$ mboint gelienc", die liunne kinds-kinds - kinds-kinderen gezien heblen.

De landbouw beftat lyier in 't antec len van ryll, die hier in de ligge landten zear owerwloedig valt ; doch hoe veel men dar"was zou mogen over hebben, nrag er op lyftiaf nicts valn thicgevocr worden; matr het overige word door 's konings bettel boven op 'r gebergte bewart, bni in cyden van ootog, wanneer de landen brakls leggen, of by een quand gewalch, tot cen troep vin onderfteuning en voortorge te konner diengun.
De Warren, hier vallende, zyn deze:

Goul at watecti Goud, dat cer zect wed is ; doch dat, op lente, ch Jyftraf, niet mag werwoert worden. gerthRyit, als rooren.

Koper.

Yxer.

Kiatoent.

Slaven.

Calimbac.

Schoone Korjen, die 't ftuk pas I Ryksd. hier gelden.

Parden, doch weinis, en kleir.

Buffels.

- Bokken en Geyten,

Gember.

Calmus.

Bangle, ect gewatch als Gember,

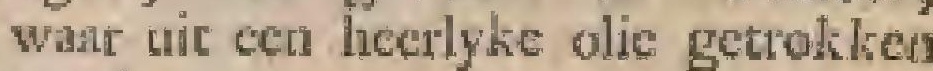
word.

Wrat tegen de Chineezen hier meef zabels, porcelein, en eenige andere geringe watuen brengen, hoewel "er glu en dan wel Hollandiche wrylieder komen. alle wellic hun meefte gading in goede Alawen winder, nlzoo dic alonme zees getrokken zyn. Hier is nok overyloed van allerlei gevogelce, wifch, en wan veelerlei nardgewaflchen, alzoo de Biliers zeer" goede chuinniers, en doorgatajs wan fchoone kool, ridys, booncjens, fatade, kondommers, whtermelenen, en wan overvloed van alletlei Indifche vrugecn พoerzien $2 y n$ n̆.

Humie wapenen zy byata de zelve, als wapedie der Javathen, bettatade neeft in lange ven. en kotre picken, ksiffen, fpatten; en ditar zyn 'el" ooli, die zeer wel mer een fraphaar en zabel weren om tes gathn, en it heb 'er gezien, dic zoo in 't buhandelen wan fchetgewer, en in dupperbeid von" geen Hollinder zouden geweken hebben; mate door de bank zyn bot groote banevegters, watr in zy by tha liun weergat nice heblen.

Gelyk zy in kleeding (die men in dic ecthe reize der onzen itgebeeld riet ) ved Hun overecalemit met de Jivathen hebben, nem. en gelyk de mans, mode doorganis kat vas batrd zyn, alzoo $z y$ die ool met klene tingerjens uitcreklen, alzoo bedicnen zy zich oolk getneenelyk by nut พan de zelve fpedtuigen, we weted, van cen Intelsoung (whit by cwee groote Gongen hehooren) by welke zy doorgantis cen Gindiel (zynde een lpel van nuerale Aathens, die op bamboezen oregelsgewyze geplatit zyn) en twee cimbalen, die zy tegen een kloppen (twoe fpeter, hen op en byzondere wyze cigen) gebruilect.

Zy hebben doetganis veel vrouten, Hawetr die zy me en brudfehat van de ouders ken. moetcr hoopen doch onder de zelve is 


\section{B E S H R V I N G E V N}

'er altyd eene die "t oppergebiod ower de andered hect.

Lylthe Een groote. blyk van de genegenheid hamdelin en onderdanigheid derer vrouwen bepen " en fpeurt tren ter tyde, als hatre mannen val "t kenmen te Aterven, alzoo $a y$, whnteer branden hunhe lyken na 's lands wye werbond wan hus= worden, met hare juweelen atis, en ne vots- onder 't geluid yan hunce preeleuigen, fil wen. danzende in "t vutur fpringen, enzjelh her hen zcer wel gemoed laten verbianden, zich watt irbecldende, dat $z y$ in de ans dere wereld, ton, zoo zy elders fterver, in hus wderiand, op 'c eilland Bali, ten ecriften zullen herleven, en diar in cen veel heerlyker ftat weer by hatere mannen $z y n$, om wolke reden zy te minder fwarigheid maken, on hen te volgen. Men zict van dit werbranden dezer" wouwen een nadrakkelyk yoorbecld in de ecrfte reize van ons wolk na Oollindien, toen zy voor dit ciland ten anker litgen.

Wy hebben dit ook elders met ecn gewal van cen overleden prins wan Balamboung (dit mede meeft Baliers $2 y n$ ) wangewezen, met welke eenige honderd vrouwen toen dierven.

En om een nader bewys yan die fterke inbedding der Baliets, en hunne onbevreetheid voor de dood, te geven, kan men dit liaar uit dit geval afnemen.

Myn voorzats chaloep, op zeleren fyd Van Butavia na Ambotan te rug komeryde, en op Graltic willende alangieren, wiert onderweeg, terwyl $z y$ etgens ten anker lag, door enige roovers angedatin, dic hen tragtende te owervallen, en zich neefter van de chaloep te ntaken, "er eenige flefer met kruid en oen brandende lont in lineten, valt flellerde, dat de Biliers (gelyk ook gebeurde) alle oxterboord fpringen, en $z y$ dan aldus ter ecriten mecller" van 't watreuig zondern worden; docly alhoo 'er ook ecenige dappere Macaflaren an boord waren, wiert de chaloep behouden, en eengen-dezer Baliers wierden weer opgewifeht, hoewel de meelte werdronken wawn.

Men vragde an de weder +0 poevilchte, warom zy zoo overboord gefprongen waren. Zy zeides, an door "I leruid niec te verbranden, want op zy, uader gevrage $7 y 11 d s$, of $2 y$ din niec wreesden te werdrinken, tot antwoord gaven, dat dit cen zagte dond wis, en dat zy diar gavich nier bang woot waren, alzoo $2 y$ in butn wolerland in Bali, doch weer anfonts by alle hume vrienden quamen; matr deze hunce fleiling quam ganfela nier met de rekening van myn voorzast over een, thlzow by by dut wooryal verreheise van zyn belle Adawen verlooren. had, hocwel hy bly was date door de dapperhejd der Maculfatiren toen zyu chaloep was behouden geworder, mitar by heet zyn andere flawen raderhand wecl beter gelecrt; condatur was "er in myn cyd geen een meen, dic lutt had oun dus ower boord te fpringen, of nich mer die dwaze in beelding te werdinken.

Het eilind wort door verlcheide Ko: Belliering nirikjens, en Orangknja's, beltiert; docts wen "s over alle de zelwe is cen opperkoning, eiland. dat cen zeer magtig vorft is; matr die zich zeer weinig met andere worften, of met den butrenhandel benoeit, en "tzelve, witwreze dat men dan zich ook wel mogt zoeken meefter wan zyn lind te matken, zon voel nils 't mogelyli is an zyn Ingexenenel belet, zyule de eerige net welke hy, myn's wetevs, gemeenfchop en vriendfchap onderhoud, de vorlten van Balamboing, "r geen nier te vermonderen is, alzoo dat doorgatins Baliche princels zyol.

In de woorige tyden tor ontrent in "t jar I670. waren hien Ewee opperkoningendie nu en dar om 't oppetbewint wel over hoop lagen, alzoo yder wan hen Guf Agong, en de opperheer, wilde zyn.

Een van dete twe wicrt vort diar an nu en dan door cen Ambor $/ \mathrm{ch}$ wrymar, Jow Troet genaame, bezogt, dic met dien Jar vorf nice allecn als ecn broeder lectide, Troets matr hem ook Gace, dar is, ouder broe- elendig der, noende ook leerde by hem nuec allerle geweer omgan, en wees hen, op wat voor een wyze by op dat land dterkten en weltingen maken nott, dat by onze Narie, en meer andere ganich ried wel opgenomen, en wats over berm wat veclen vech quads toctewenfehe wiert.

Noit quan by op Baly, of liy was by dien koning, als aynen broeder, t'huis, en gelyk die hem allerlei bedenkely kermalk atndede, alzoo onthialde hy den zelwen doorgaans zecr hecrlyk of zyn chaloep. Ook wil men, dar deze vorft hen, na dac hy twecmal fchipbreuk geleders had, en weer op Bali gekonen was, yder reis gered, en van geld, dlatven, en alles, dat by wan nooden had, weel voorzien heeft.

Ondertufichen wict deze koring ontrent de jawen 1672 . en 1673 . tegen dezen man, die weel benyders en wyetden zoo op Bali, als elders, had, zeer vuilaardig opgentakt, en den zclver ingeburzemt, als of by een axallag tegen zynen ftate en leven hid ; en hoewel ik niet geloove, dar de man dit in zyne gedagten gehad heeft, zyn zommigen egter nog wel zoo dwas geweelt, on te gelooven, dat hat Edellieden hern tot dit fehelmigrig vertad latt gegeven, en heri, $z 00$ hy 't geltakig volvoerde, groote beloften zouden 'gedian hebben, all 't welke een zeer vail verdigezel is.

Het is egrer watr, dar de koning een guand vermoeden op hem had, en dar 
zyn "er, die willen, dat lay voor had den koning, by hem nan boord gekornen zynde, met een dronk Towak ie vergeven; doch andere willen, dae ty hem met ecu lerisftects zou woorgenomen liebben te ontriclen.

Hec zy dar mete zoo " $t$ wil, de lioning geloofde, dut hy, hoe vrolyk en vergenoege hy zich ook by zyo latitte komft op Bali antitelde, voorhad hen watl kant te helpen, om 't welke dan woor' te komen, by hen dow ocnige dar toe beftelde perfoonen jammerlyk ombals dede brengen ; een beklagelyk cinde, dut hem egter wa veele, docli mogelyk op zeer quade gronden, gegunt wert.

Her oude houis, dalar de Hecten Gouverneus in Amboim plagen te woonen, is 't zyne geweeft, en de wedtwe van myn eerften huisheer in Amboina (die zyn koebcelten, dit buis, en al zynen onyfag, na dat men de tyding wan zyndood kreeg, kogt heeft my dit geval meer dan ecos zerer omthudig verbath.

Naderhand is myn woorzat, de Heer Vriend- Flomik Leydekle, verfcheide malen by door den dezen zelven loning mer zyn chaloep op boning Bali geweelt, en met alle teekenen var san myn wriendichap ontingen, in zooverre, dut bewcreml. by hem; by zyn lateftevertrek (wanneer

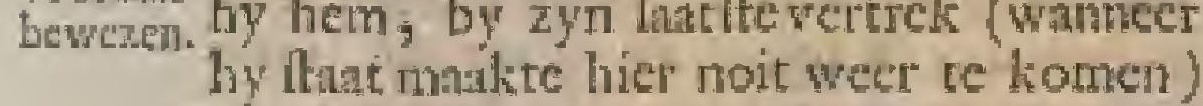
tot cen reeken wan zyne looge agting $\mathrm{en}$ genegenlicid, zyo kris van zyn zyde, die mer een goude greep, whar in eenige robyun grezet zyn, werciert is, vereerde, welk koninklyk gefolienk ik tor nog toe beiste, on wh ' $\tau$ welke ik verder zeggen moct, dar de lcheede van kearlyk hout, en met etn zilvere fchuif overtrokken is. Ook was 'cyzer wan de kris an wederzyden ongencen frati gevhamt, ats of het mee zilver tngetegt was, en men beeft roor" to blone yzer nenigmat een Far de befte Balifiche fanve te vergecfs ath mya voorzat geboden.

Hy had wel een zecr groot viouwentimmer"; bioch was egter (zpo men zeide) een mroot Sodomicr, houdende vecl Achatujongens, dic even als forvanze wouwen gekled to opgetchike waren, en zich ook buiten dien met ecnige geiren, wellser hoorus verguld of met goude febeden overtolken waren, op een lehandelytue wyze vernengende.

$B y$ de Ouden is dit ciland noit bekent geweett.

En il weet niet, dat oit entige andere Ontde En Enropeers, din de Engelfehen en $\mathrm{Ne}$ king manderlinders, dit ontelit of angedann dit ciland hebben.

door de Van de Engelfchen is hier in 't janr Finet- en I rot. de Ridder l'rampris Drake, en de door de eerite wan alle de Europecers, en 6 of 7 onzen juaren lanter ook zeer wanfchyoclyik Thum Candis geweet.

II. DFEL.
De cerfte wan onze Landslicden, dic rser. hier ten anker gekomen zyn, waren die van de fehepen Mauritius, Hollandia, en het Duitken.

Zy wierpen hun anker in de thrat wat Bali den $27^{\text {iten }}$ Jamuari 1597 , liregen een praalw wats boord op den $39^{\text {thers }}$ dico nace een haner Grooten, die werzogt wit "s konings natar te mogen weten, wib zy waten, dat zy zelf mee een pricm op ecn koliosblad, dat hy medebragt, moelteo ichrywer.

Den $4^{\text {den Februari ging eenig volle wath }}$ ben aan de wal, nwwat zy zer wel bejegent wienden, en ece wan "s linds Grooten door zyn volk en llagven in een dragtatol op de fchouderen zagen dmgen, terwyl "er wel zo ftutks, met pichen gewapent, voni hem heenen gingers. Hy zone, ons volk, die hier gekomen waren, om na cetr waterplats te zocken, wat vrugten, efr verzogt twee wan hunne makkers mede te mogen nemen, dat zy toeftonden, mits dat by ben ook $2 \mathrm{gy}$ zelin's gat."

Den flsen dito zeilden zy van dant wate Noondalyker ann, enzonden hunne fchuie met 2 dawen, of gyzelars, an liand, on de 2 van hun volk wederom te cis relven. Schoon tou deze Grangkaja zyne gyzelans weder hat, wildo hy egret ons valk nict ouergever, alzoo hy, die cenige wintt by "t leggen der onzen dair op zyn theede gehoope bad, over hun verzeilen wan diar uu zeer misnoegt was. Na weel belolten egetr quam de een nog door de branding anu de fchair; en deze wift te zeggen, dat die gene; die nen duags re vooren bad zicn dragen, ecn wan 's lands Grooten, cn over "e verzeilen der buzen ganfel niet wel te vieden was, gelyk hy damon ook nog een Portugeclehen flast, varde onzen alls tolligeconden, gehouden had.

Onze andere man wiert daags 'er aan, newens dien laaf, by den lionigg par Bali na 't wek van dien zelwen nam gebragt, van wair hy am die van 't fehip Hollandia fehret, dae hy, en die liat; van den koniug zeer wel onthalt waten, want op die van 't fetip, om heas te ect weder te krygen, 10 ellen geblocm Aluweel, cen doel rood korat, enige kryitalyne glazen, fpicgels, en eenige andere dingen, an den koning ten gefehenk ronden; war op dic man en dhat ten eerften los gelaten wicrúen, werhaslende, by hun komit an boord, dat de lioning aan de onzen alles, wat in zyn vermogen wis, ninbood, en hen woorectit 4 rerkens, en 2 vater met water zond.

Onderufichen was 't ichip Matritius

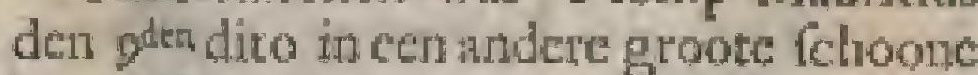
bay, Padan genama, ten anker gekomen, alwar hen de ingercenea ver lnalK k

den, 


\section{${ }_{25}{ }^{8}$ B ESCHR Y INGE $\mathrm{VA}$ A}

I597. den, dac "cr oner 18 jart dictgelyken volk, als $z y$, endic een touw in fukken cn weder heel maknten, gewerlt was,

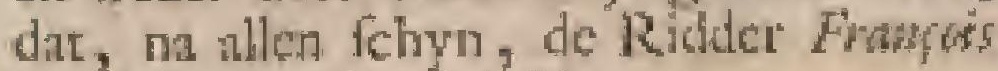
Drake geweet wal hebber.

Zy zangen ooli hier den koning wat Bali in een zeer konflig gefnaten wagen ryden, die dnor 2 witte buffels, wall op zoer friaye kleeden lagen, getrokken wieft, terwyt 'er, wolyens's lands wyze, ech ly fwagt wan ecnige piekenicts en putewocrders, wellker punten verguld wireis, voor uit gingen.

Hy wertoge, dat men ret eere wan hem (die op dien zelwen wagen en zonnefoliermanger thet een geopente zonucfcherm agrer zich zieten had) ecaige ecrfehoten wilde doen, dat de omendeden; warr op hy hen dags 'er an 4 waten met water zond.

Die van 'c rehip Hollandia (of den Hollandfehen-Leow ) verneniende, det bunne makkers in zullew fohoone bata lngen, hebben hun anker geligt, en zyn den $16^{\text {deu }}$ dito by de 2 andere rehepon gelsomen, otzoo diar zeer goede ververIching to krygen was.

Zy hadden toen ook al ontdelet, dat hier weel goud vich, gelylt ty dat genoeg an 's honings goude en vergulde dritols qaten badder komnen befpeuren, die ay bier mecr, en loftelyker, dan by den Pangenang va Bantam, gezien hadden; mas ay hadden ook vertann, dat ly de goudmynen dezes cilands op Iytiliafic nict wilde geopent hebben, om dian door geen quande nabmuren te krygen.

Zy zagen ook, dat die Voilt wan zyne ingezetenen, en zels walle allo Grooten, met vecl cerbied, en nifet dan met gevouwen handen, al fombryende alangefproken wiert. Egcer waren "er ecnigen wan hen, Io of 12 jat geledin, geweeft, dic cen aulfigg gemalct hadden, om hem in zyn paleis re vermoorden; ' $\mathrm{E}$ welk uitgekomen zylnde, wienden zy alle in "t cerft ter dood verwezen, en naderhand egter nog, wit medelyden, na Poelo Rolla, cess woert cilind dezes konings, in "t 7. O. van Bali gelegen, dosh ben gebannen, dat $z y$, th andere Banditen, naderthomb hier mede na toe gezonden, meter lyd zeer fraai beboure, en wat al her noodlige voorzien hebben.

Gelyk nu ons wolk hier dagelyks an fand woer, alsoodeden dir die van "r fohip Mauritios den $20^{\text {ben }}$ I'cbrum roor de latite maul, van de welke ewee inatus, Lmand Rondenbwg, van Amiterdam, en Jacos Classzon, van Delt, Jandwatite in gegaan, noit weer te poorfehyn gekomen zyn, zonder dat mevegter weet, of men hen datr met of tegen hun wil schouden hect. Hune mats zeiden hen, dat zy niet te lang moeften uit- som, blyven, whoo men her dinn nict wageen zoth Uoli hoblen $z y$ cen thy of twee er ann klesderen ontboden, zonder dat men maderhand iess meer van het vernomen heefit ; watar op toen de 3 lchepen

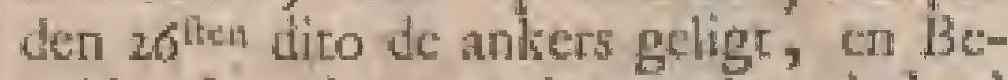
zujden law hanne reize ris to vaderland vervordert hebben.

In "t jar T60I. den sten Februari is awonds is die wakkere zeeheld, Olivier wan Nord, in de mond van de ftrat van Balamboang gekonen, dar zy certige dagen con moker fchymen getegen te hebben, zonder ditt my egcer blykt, dit zy hicr ann de wal geweeft zyn, hoewel het zeer warlchynelyk is, dac zy of hier, of wel op Bntamboang, om warer en verwerlching an land zullen gegaan zyn. Den ro rent dito verzeilden zy vin daar, en getrakreu buiten deze ftrate, hoblende den Verkenshoek (die in " $Z_{s}$. wat 'c eiland mee een fmalle lirook uintecks) in ' $\mathrm{Z}$. O. wan hen affeggen.

Iı 'r jaar I 604 , in Januar', gaf de zecwooge Wybrad was Warwek nat die van, 'r tchip de Main latt op Bali an te loo. petr, om zich dar win rylt en kleedjens te woorsien, en dar ma binda te zcilen. Diergelyken latt lyad by ook anta de Overbeden wan 't fehip de Zon den 25 filen Ficbruari gegewen, on, by hwo toge $\mathrm{na}$ Ternate, op Banjar Mafin on rylt an tc loopen, en, zoo zy daas njec konden te regt maken, dan rua Greflic over ec fteken, $\mathrm{cn}$, ook dalr nier vindende, dan op Bali, Bimi, of ecuige andere platzen, ath te yicren.

Fo dit is wel 't woornamfte, "t geen it wan dit ciland Bali wete te zeggen, dan dat naderditnd nu en din (gelyk wy rees gezicn hebben) de thmbonfehe of Bandalche vrylieden hier wel plegen aan te gian, om zich wat goede llanten te voorzien.

Ook tedkent Corflofel friks in zyn teize atan, dat hy met telip Hollandia, ontrene 't joar 1684. of 1689 . na 'c eiland Bali getelt is, daar lyy zegt coen een Hollinds onderkoopman, als hooft "ev" leggende, grvonden, en wan den relven ook cen lhavinnetje voor I \& Rers gekogt te hebben.

Hy had, hice zyode, dit verbranden wan de lyket der munnen, en "t lpringen ran hunne vrotwen in "t vulr gerien, diens svyze hy foll. Iof. en 106. omftandig verhalt, en toe welke wy den Lezer wyzen.

Na dat zy nu 3 weken hug voor Bali gelegen lradden, is hy met zyn felip weer na Batavia gekeert, zonder dat my blykt, watrom zy hier geltomen waren, ditn dit hy zegt, dat zy hier hunne watace loften, en aderen, die hier ge- 
L

I.

1684. matake wierden (watrfehynlyk conige) kattoene, en zyde kledjens, die hy zegt, dat zy hier matuten) dati tegen inmmens.

Gods- Wat nu humnen Godsdient betreft. dientl de Het zyn alle Heldenen, wn welle zom-

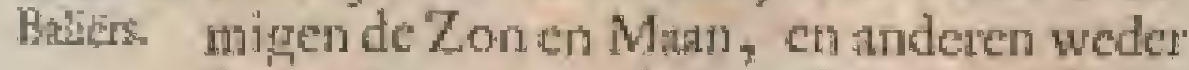
deze en gene vogels; doch wel meetk dat als een Godheid, 'i geen hen 's margens eerlt ont mot, dicnen etr ceren. Eenigen wan hen matken ook weel werk wan eenise zonderlinge wierkinte groote ftenen, op welle $z y$ tha hame wyze offeren.

Zoozy, buiten lum land gerakt zynde, fterven, geloowen zy thit, dat zy in hun land weder woot den dig komen, en by hune bloedverwanten herlewen, dat hen ook in alle roorwallen zeer moe- 168 . doet zyn.

Veelen det zelyen zym by myo aamezer in Amboina Chritten geworden, gclyk ik "er zulke zells gehad hebbe; moetende getuigen, dat ik "er geen wan geketo litbbe, die nict zeter wel humen Doop belefden, getyli zy an alle andere ook ecri zeer goed en figtelyk voorbeeld met hun leven gaven; zynde, myns ourdeels, cen van de bette Indilche Na tien, wan tle welke iets goeds in dezen oprigte te hoopen is.

War mede wy dan dit Hoofdltat fluites, om nu tot deranken van Tombin over te gatan.

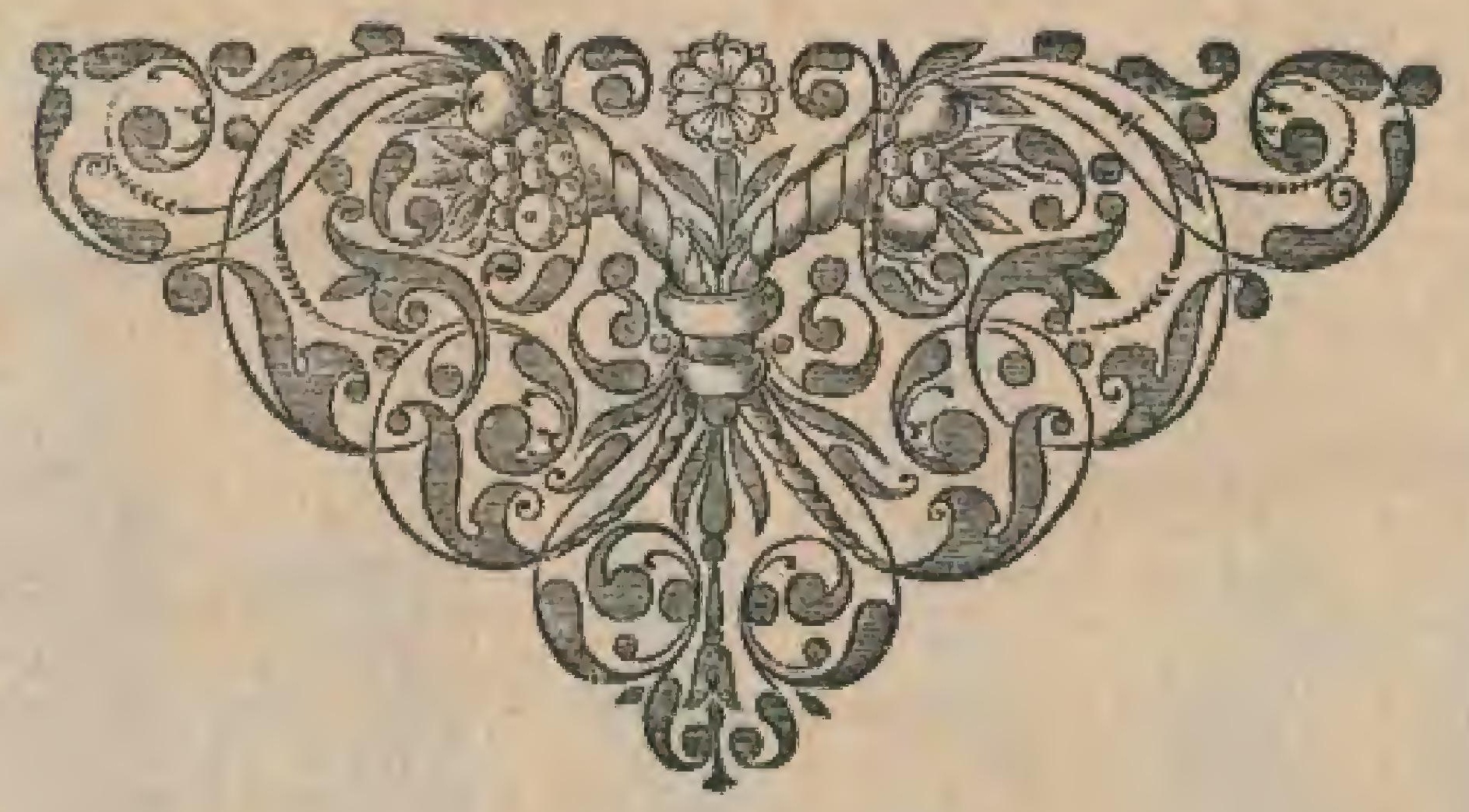




\section{B E S C H R Y I N G E}

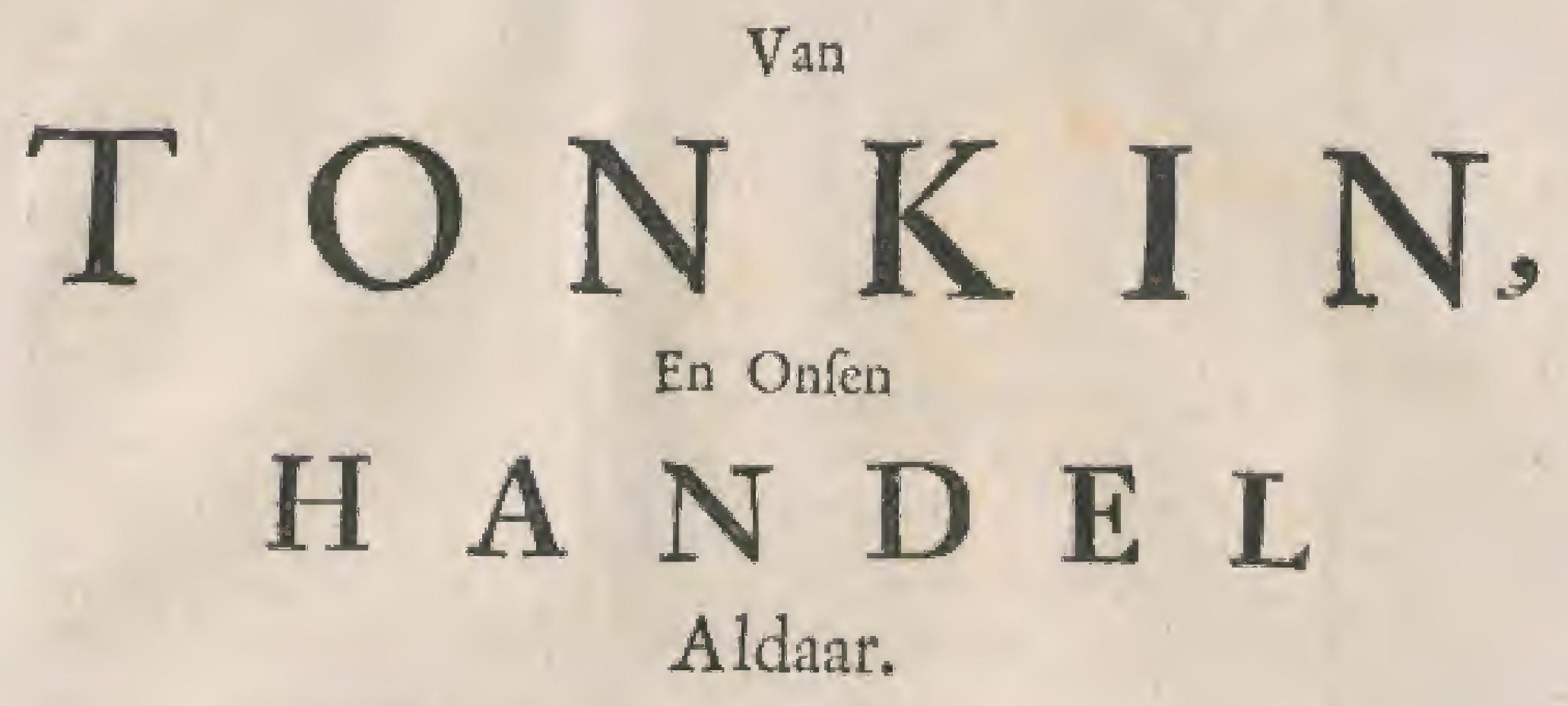

\section{I E R D E B O K.}

\section{EERSTE HOOFDSTUK.}

TON K IN cen ded uan China, Dog de Ingeletenen worpen omrow Anno 1368.

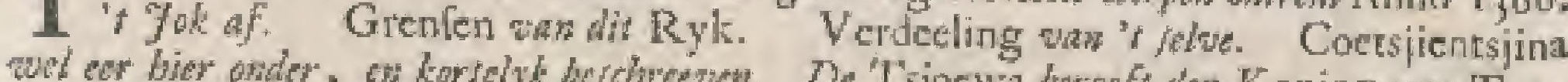

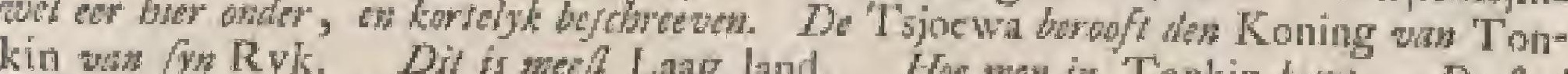

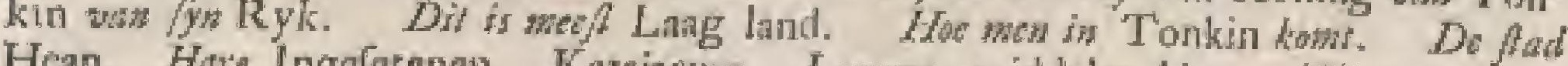
Hean. Hote Ingectenen. Kursjecuw. Levens-middelen bier. Waren, bies wallend, en ook but getrocken. Gedante on Aard des Volks. Huysman. Home Huwclyken. Ambagtslieden. Hun Taal. Schryf-wyle, Ec. Wy/c qan Regeeren des Konmg. Syn Krygs-mache. Bediong van i Gericht bicr. Begraveris. Waner onen Handel brer bgon. Inftructic aan de Heer Hartink Anono 1637. wede gegents.

$\mathrm{N}$

A dat wy het annmerkensweer. dige van Bornéo en Bali voorgefield hebben, konnen wy nict nalaater nu ook icts yan onlen Handel in TONKIN to fpreken.

Men moet fich geenfins verbeelden, dat ons pootnemen is dic Koninktryle te befchiyven, vermits ons alles, dair toe noodig ombrecke, on dac onve Natie noit toegelater is dat Land te drorteyren, weshalven wy daar van alleen, die fralken, die ens bekent zyn, fulten opgeven.

Toxhin plagt voor 410 jaren een geeerryds deelte van Corba to zyn : ywant uy den cendeel Brief yan de Heer Baron Anno 1663 . China. aan de Heer Buflof f Predikent tot Batavia gefchreven, blykt dat $X i c o$, cen Tartarilch Vorft (uyt 't 2 ifte geflacht der Weft-Tartaaren, onder de naam van Juen bekend) Anfo I280. de Koninkryken var Laos of der Louwen, Siam, Cambodia, Tsjampa, Quinąm, Tonkis, en meer andere naburige Ryken, veroverd heeft, gelyk dic 'Tartanen dit ook 8.8 . jararen onder fich behouden hebben; dog ty ralkten dit onder Humwa guy t, die de Weft-Tartarecn Anno 1368 . III. DEEL. verdreef, en fich toen ook te gelyk meefter van 't Koninkryk Torkin makkte; derwaards een der Onderkoningen, Lieutbaney genaand, fendende, om dit in fynen nam te beftieren ; mar de hen were Ingelerenen wicrpen fich biet lang hier pen ommat regen defen Chinefchen Keyfen op trent Ao. en hebben fich roen ook vollog fter Acr van dit $R y k$ gemaakr, hoedaustg deIe Komingen van Tonkin het ook zedert beteren hebben.

Dit Ryk grentt in 't Ooften azn Can- Grenfen ton in China, of wel tegen de Land- sandit voogdy van Quanfi. In 't W. paald Ryk, hes atin 't Koninitrylk van Brams, of an dat vin Laos of der Louwen, en in 't Z (wcl foo Ooftelyk) vertoond fich 'tLand en de Zec wan Coersjientsjima, en in 't N. de Landroogdy wan Junnan in China, gelyk men dit klatar in de groote Kare van Indien fien kan. Het legt op de N. Breedte varl ruym 20 Graden; dog wy konnen niet feggen, hoe verre 't fich uytftrekt, hoewel het in't gemeen getteld werd wel foo groot als Portugal en by anderen als Vrankryk, en vol groote Sec. den en Dorpen te zyn. Verdee. ln de oudite cyden plagt het in twanlf ling van Land. "trelve. 
Landwoogdyen verdedd te zyrn; dog die "er lant geweeft zys, fprecken maar wan ache der lelue. De leven in "t ZW. atan de Rivier Poetfit regen de ltad Quinam (de Hoofdtid van diergelyken Ryk) geleyen, omringd de groate Zee niet een groote bogt, gelyle men dat verder in do voormoemden Brief van den Heer Baron fien kan.

Men moeregter een groot onderlcheyd tufichen dir Ryk nu, en voor honderd jaren maken, alloo hee toen vry groo. ter dan nu was, dewyl zeder die tydgeCantities. heel Coebjonesjina, dat dar mede onerfha derltond, "cr afgelcheurd, en een Ryk wel eer op figlelwen geworden is.

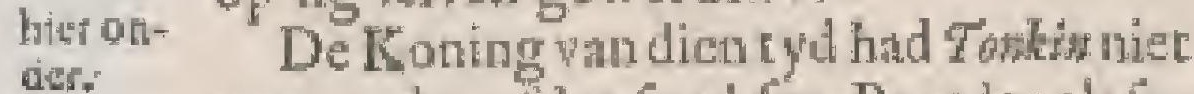
veroverd, of by fond fyn Broeder als fynen Stadhouder na Coushomigina, otn dit in fyn nam te beftieren; Matri hy was"er nanulyks gekonen, of hy heet dich weten das Mecter van te maken, en bet vin Fonkin af te feheuren, gelyle het wh dien tyd ook een Ryk op fich relven gebleven is.

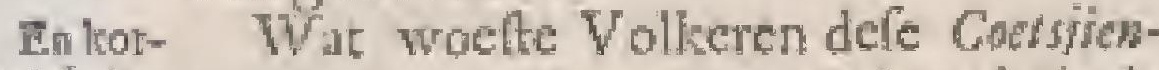
telyk be- trime/ch $2 y n$, lean men in 'tbreede in de fenteren ongeladige Reys wan 'c lichip den Arion op $\mathrm{r}$ Rif wh Pancelles gebleven, endoor A. Bogam belchrewen, fien.

Men lieeft berorens (om foo te leggens) noic wan dit Land hooren reppen, maar zedert dat ongeluckig woorwal wan onte Japurebe Vrienden, die met een Vatreuyg van tha de Paracths in Coetsjisming cot hun ongeluk quamen atm to haden, hebben wy nog eenig befiche wan de gefteltenis defes Roninliryles bekomen. Het grenlt an Trjampa, en anth Cowbodia, dat ontrent twee etmaal พan Sian af lege. Ook willen foumige, dat dit laxute Anno 171 r. an den Koning van Coerstentsina Cynsbar was.

Het is over meer dan 300 . janren in ftand gebrage, en certt bevolkt door een Cbines, gebumen Príns, die ook de eerlte Koniog wan Siam was, gclyk wy ook onder die thoffe dar breeder vall fprecticn.

Dat hetalcen vry groot Land is, blykt Wuar anth de tocheen, die deOnlen toen na "r Hof des Konings, foo te Land, als te Wacer, gedaan hebben.

De Landwoogdy, daar fy ecer dt ancquamen, is Niallang genatand, wan waar fy "s morgens na Nieroe, dat de mazm van een Stad of Vlek, en ook yan cen Landfelunp fichynd te zyn, wertrockenzynde, savonds ausquamen.

Van Warve nu zyn eenige te Watcr, en andere ten deeled ower lchoon Zacy. land, en hier er dats over heswel-en bergugcig Land a de fad Fayfo vertrocken, dis: 17 ctmal 'er van datal lag.

Eer zy das an $q$ uamen, $2 y n$ ly door vericheyde andere Lindichappen, en door veel Dorpen get rocken.

Het cerfle dorp, by hen ontmoet, was Qvemenat, in "t landichn Foy gelegen, darry denderden dag tha hun vertrek anthquamen, na dar fy over cen lteylen fwaren Berig getrocken wiraren.

De vierde dag quamen ly in "t Dorp Bandar tegen de wind, dog (na dat fy door veel andere groote plaafen getrocJaen waren) en namen 's nachts hun ruft in 't dorp Rawan, dae al redelyk groot whs.

Den felden dag quatren fy in "t Dorp Tangun, wat na Fy orer een moejolyken Berg, en over een Zer-boefem doon weel gebroken Land getrocken zynde, in "t dorp Kiompry anogeland ayn.

Den negenden dag wan hun toche quamen ly by 't Landrehne Mokway of Nuokman, con deden den twatfden dag hun middngmanl in "t dorp Kotquey, en quamen dings"er nan tot Bodln, en Bendaan dat onder ants 't gebergte van 't Landfchap Qwablia lig.

Den vecrticnden dag qumen $\sqrt{y}$ 's awonds tot Diolay, den 15 . tor Kabran, en den 17. dag in "e dorp Tjolo, dat aan een $R$ icvier lag.

Den I $S$, dag gerankten fy in 't Lendrchap T Jam, der 19. s" awonds tot $\mathrm{Ha}$ lam, en den zolte. te Todily, wh war fy, na dat $\sqrt{y}$ over ecn groote Ricvier getrocken waren, by en in de fad Fofyfee quamen, die fig van buyteu lecr wel opdede.

Sy gingen die nader befohouwen, en bevonden dan in cen gemeene ftrat wat Chinedelie fteene Huyen, mitsgaders vecl Wiskels mee allerley Waren voorzicn, dewelke lich dant langs ecn Rievier vertoonden.

Agrer defe Huyren en Winkels dederi fich verfeheyde '1'empeis, cin daa" buyren nier anders dan geringe Wooningen, \&c. op.

Den zuftedag quanen fy tot Haw, en den 22le. in " $\mathrm{D}$ Dorp $T / \mathrm{Em}$, dat onder tegen een hoogen Berg ontrent her laijdichad C/m lag.

Naalt ant dit Lond fchap grenlde weer cen ander, Hoe genuamd, dair fy in 'c dorp Caske, gelyls by nier lang dar ba, na dar dy over ech wyde Ricvier getrocken waren, in de hofltad Fo gekomen en voor den Koning verfchenen zyn, diens Paleys ly al wry groot, en wierlantig, en alwat ly een groot getal wan wal 400. Metnle en Xiere ftucken Gerehut 


\section{IAN T O}

ender vier groote Galderyen., en nog vecl andere onder eenige statucken vonden

De Lyfruggen wan defen Vort, die den nant had van vy gierig te ayn, quitintan hen feer prachig woor, atloo dy ann ider fyde des l.lfs Goude Houwerdragers pernamen, ch wat verden war hem af nog andere Lyfwachten met Silvere Houwers, hocwel hy, gedurig voor fyn leven, en voor verrad efgen hem bekoninerd, fich buyten dien nog op andere Wachent vertrenwde. .

Het Land in ficla felven beftanc feer weel uy tchoone Zaey landen, en uys herriyke ten deelen Rylt-, ten declena Suyler velden, die fy door eco menigte vait Water-molens, welke fy ontrent de Rievieren, die men hier menigualdig heeft, gemalke hebben, op fyn tyd wa noodig water weten te voorfien.

Ook levere her relwe, behalven de Rytt cu Suyliér in overvloed, nog veel andere Waaren, te weten, Marmer, wilde Cancel, of Cafla Lignea, veel Y ler, (alloo 'er weel Mynen zyo) Sour, Wafeh, Sappon-hout, Zyde, Cattoen, Agel-hout, ved leboone Peerden, en niet minder Buffels en Olifanten uyt, dat dat hier ook een grooten handel met Olifantstanden (hoewel dat hiemand, dan den Koning, geootlofd is) en mer Buffelshuyder gecef.

Gelyk fy dood-yyanden wan de 2owkinders zyn alfoo zyn fy dat ook wan de Aaeyer, Jaritamen, en andere Volkeren datar om firceks, en lebynen meet wart den rouf te lever.

Het Wolk is feer trots en hoogmoedig, fchoon dood am, en hecft ganfeh geen agcing woor Vreendelinger, dat onle -elendige Tchip-breukelingen tot hur Imert nict dan al te war beronden, en foo ecuige Frantiche Priaters (ondecF welke ry de liefdadigheyd van de Paters Trancifens Godefroy en Plerre de Hoto geweldig-roemen') hem wan tyd tot tyd nict onderfteund hadden, fy fonden, in allen fehyn of wan honger gettoryen, of altoos noit van darar gerjakr, cn in een elendige flawerny gebleven ryn, alloo hen de ryd al geleetd bad, dac 'tr opde groote belofen van dentChinefeher $\mathrm{O}$. verften $L$ formia nier meer that, dar op de barmhertigheir der Coetsjicnefineeren te maken, en dat het hen minar te doen was, on de gans, zoo lang zy vederen had, te plukken, gelyk wy dat uit ecn origineel dag rr.gitter wan Pister Keftelues, ons door cen Jepans vriend ter hand gelleld, gezien bebber.

Deze Vort folynt geen ommeging
N $\mathrm{K}$ I N.

met cenige andere Vorthen te hebben. hoewel hier nu en dan nog al cen varttujg van SHam, thet deze ch gene watren aanlandd s waur mede zich ook wel een Franliche Priefter herwars begaf, gelyk wy onder de zalken vanden Gods. dienft nog mee een leucr zullen asnhalen.

Men heeft hice ook reel Chineczen, onder dewelle al zeer rermoogende Kooplieden gevonden werden, en var welke ter al veelen tor Overten in eenige phat zen angefeleyta bowel het land andex meeli door Mianilar yris en $R$ anden des Konings befterd wierd; mar hoe godloos en roofugrig $2 y$ dat doen, kan inen khar, aan ' $\mathrm{t}$ geen onze arme felipbreukelingen ontmot is, zien, dat cg* ter hun Koning, na dac hy het verftann had, fcheen te werfocjen; miflichien wel, om dat hy, ben door ch door kennicnde, zeer well wilt, dar dar van niet veel in 7.yn Fehathitt komen zonde.

Liu dit is 't ectige, 'c geen ons van dit woelt volk, en wath hum land ie woren gekomen is, 's geen wy egter noodig oordeelden met een Jekterken hier an te halen, on dat dir laud wel cer mede onder Tonkin geftan heef, hoewel wy anders noit eenigen handel dan gedrecven hebben.

Gelyle zich nu "s Konings broeder' in die woornoende tyd meefter van Coe-Tsjoema tsjientsjuria gemalce had, alzoo wrift ook heroofd de Veluheer van dezer Vorf, ontrene ooladen dezen zelven tyd, zich an dat quaded yoor- natonbeeld yan "s Koning broeder fpiegelen. kin ran

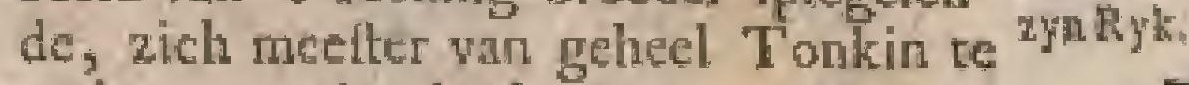
maken, zomder dat hy eguer goed wond zich wan den recheen Koling te ont flasar, alizoo by zag, dar hy wan ${ }^{5} \mathrm{~s}$ tolk zecr bemind wis, warom hyden zelven in zya Palleys met wywen en leinderen belloten, en zoo wel bewante heef, dat by niet in tant was, om hem cenig quad te doen.

Dus waren hyer Lweckoningenopen en dezclwentyd, wancen en "t zelve Rykz dog de ecn mat in nara, en de ander in der dat ; hocwel de jonge Koniag Tjoewg, nog zoo cenige fchinduwe van Regecring aan den ouden liec.

Wy weren hiel verder niets wan te Dit is zeggen, dan dat deze Landen van Tou meeft kin na de Zeekant, wel zo mylen land- Jasgland. ward in, doorgans laig en zonder gcbergre, uitgenomen de Olifinas-berg, hoewel de hooger op gelegene linden, boven deszelfs Hoofdtad nog 20 a 30 mylen, zich wat bergagigeren verheve ner wertoonen; dog hoc men meer na 'c Noorden koms, hoe men zwaterber gen licefo. In daze latge landen nubect 12

Dict 
men overal zware dyken, on se water in den Regentyd te ftuyteri $\mathrm{cn}$ on de Ryltwelden op zyn tyd te bewateren, herte men ool: water graten.

How

On in Tonkin te kamen, met men de Rivier van Coersjicntsjüa op, die uit het Noorder+gebergte if a 16 mylen boven Katsjacuiw haren oorfprong neend, ftromende dus nat 't zuyden toe, endewelke 2 byzondere monden of takken herfi, ann-welkers cene de ftadt Quinam legt. Men zeild de grootle talk eerft 6 il 7 mylen op, dar de gcrueene Ankerpluats van onue foleepen plagt te zyn. Ontrent een myl verder plagten de Engelzen hicr hun Anlacplanis te heb= ben, eir nog 20 mylen hooger heefimen cen ftad, Hean genamd, die al redelyk groot, en wan zooo huyzen woorzien is; hoewel dic meeft zeer flege gefteld, en var arme lieder, hier als Soldaten in bezetting leggende, bewoond zyn thet is mat; en open wlek, zonder wallen, of moturen, en zeer flege van alle kifggs, oortagd woorzich.

Fn baare In die Hean onthouden zich, buiten Ingeze- die Krygtheden, ook wel Chinectche tenen: Kooplieden, die zich eerft in de Hoofuftad in zoo grooten getal neder quamen zeteen, dat de Vorft, bang voor hen geworden zynde, goed yond, hen dieftad te onezeggen, water ta zy zich herwarts na Hean, en darr ontrene, begeven hebben; ook woonen 'er veclsiammers, die al mede om den handel wry fterk op deze ftad vataren.

De Franfehen en Engelfehen hebben al zedere veel jaren ech Komptoir in deze fad geliad; hoewel de latuten, montrent 33 a 34 juaren geleden, vin daur na de Hoofdicad opgekrant zyn. Het huis van den Irmifchen Biftehop is 'r frmeiltedezer ftad.

Katuja- De Hoofdrad Katsjacu genanmt, legt suw. ontrent 32 mplen van de Zce sit, nawelke men de Rivier op al mede dus met lilene fohep-wanreuigen gevoerd werd.

Zy wertoond zich aat de Welt-zyde der lkivjer'-dthar op een vry hooger grond, dan de beneden-landen; en dut zy al wy groot moet zyu, Jan nuen daar by afnemen, dat men er wel 20000 huizen, behalven ettelyke palcizen, in hecfe.

De meefte gebouwen cgter (weynige van fteen uitgezondert) zyn niar latge Indiaante huizen wan ecne verdieping, met lecme mutren, riete daken, en wan een zeer flegten opitul; dog om tegen den brand verzelserd te zyn, hebben de meefe huizeu ecn brand-wrye Godòng, of Pakhuis, on datar hune goederen in te bergen.
Men heft 'est eger" zeer rohoone en brecte ftraten, dic, fithoon "cr hier en danr ook wel cen litein flratacn onder loopr, al cen zeer frajevertwoning doun. Ook zyn weel der zelven mer itrenen, dog wry wat flordig, belthat. Idervan deze ftraten is ools mec ceriwache wan Soldanen, on de gemene rutt, bezet.

Zy is wede onbemaurd en open, hoewel "er om 's Koning Paleys cen groote muur, wel wan if a i 6 vocken hoog, en by na ook zoo breed, is, die men zege dat zich " wel cen. groote myl in 't rond uitfrelit. an deze ftad hebbcn wy van onds hier an de Zutdzyde een tracje Logie gehad, gelyk oolide Engelzen nu zedere in de derig jatren herwates in ' Noorden, tegen over de onze "er mede een plageen te hebben.

Het land is in zich zelven ecin zeer Lewentfehoon en wohkry land, "t gecn over- middovloed van lewens-middelen lieete; zynde lenter. voor al ook ween fchoon $\mathbf{R}$ yth-hand.

Men heeft "er overvloed wan Mard- en Boom-wrucheen, hoewol de ecrit: dnar merkelyk, zedert de komft der Hollanders, verbererd zyn.

De Boom-wugreti zyh byild alle de zelve, die men in garich lindier door vind; als de Calitppus- en Pinang vrugteri, Manggas, Gojaras, Lanças, Laccielen, Limbenen, en een loort van Oranje-Appelen, diergelyke ik op Bathvia gegeren, dog welkers weerga in groote en fmak ik nergens gevonden heb. De fchil is zeer diti, en (zoo zis ik dic op Bataviagezien heb) zeer groen, dog vañ birinen is de appel goud ged. zeer lappig, en onuydpreelselyk lekter צa Imak. Allerley Piellang-boonen 2 yn ook hier; ook heefe men "er overvloedig Moerbeziën boomen, dog allecn on Zy-wormen te vodicn. De wruge is cen kleene foort, en werd ook weynig hicr gevonden.

Men heefe "er van de Arid-vrugien allerley foorten pan zoer' goede, ch ook groote gecte wortelen, die de Waderlandze nict behosven te wryken. Ook Meloenen, en wat-Mcloenea.

Met hect hiet weel Ohianten, in de boffen ved Tygers, onk zyn hier vecl Buffels, Peerden, Otien en Koejen, Bolken, Harcen, Schapen, (Jog de twee larfte wenig) Vetkens, Aapen, Katren, Honden, Slangen, Hagediften, en allerley werder Inditch Ongediertevath Scorpioenen, Kalkerlikken, Duyfentbeenen, Kikvorfchen, Padden, en ęen Jileine bort van'Sprinkhaunen, die zy woor een lekkerny eren; gelyk ook die fchadelylie wite Mieten.

Het 


\section{VA $\mathrm{T}$}

Hed viedeh wat Olifunen, Peerden, Honden en Karten werd by hen nier alleen openbar op de marke verkoge, nunar ook voor een groote lelckerty gegeten, en rot fpyze tobercit, zyude de Ineye van ecn Olitarde icrs, dae metl gewoon is and de ecrlte Mandaryns atrin to bieden,

Hoenderea, Tortelduiven, End-wogels, en allaticy wilde water-Vogels, zyo et zeer wecl; dog weinig Gnnzen. Dar zyn ook weel Reygers, Pellitanen, en mest andere foorten, die wy geen nam weren te geven; alzoo dic loorten op zich Ielven zyn.

De Rivieren geven ook owerwoed wan fchoone Vifeh, gelyl mede alkertey Schelp-vifch, veel Schild-padden, (een yan bunne befte onthalen uitlewerende) Kreefter, Garneclen, Erc.

Men heeft hier ook zetr goede Vógelineftens, welke met een hoen, of etnig ander veelch getloobd, een fohoo. nen fchotel esten uitheveren.

Wha Jende, en melyli: Zyde floften, en ookruweZ Zute,

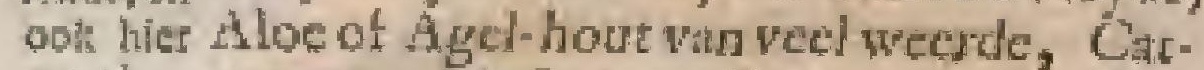
petrok- toenen, Mulcus, (die zeer weel uit "t ken. had der Lauwen kom, en voor 25 il 26 'T huyl 't hati verleogt word' vecl Goud, allerley fchoone Lak-werken, Cardamon; Sappar-hout, flecht Porcelyn, Marmer-en Albaiter-fleen, zeer veel Zout en Anys-żad; ook verfcheide Droguen, als Rhabarber, Radix China; Gember, \&ce. ook valt hier én foort wan Kaneel, $\operatorname{dog} z y$ is zoo goed niet nls de Ccylonze; en men voerd "er zelper allerley Speceryen, Latienen, Stofien, en veclerley foorten wan Kleeden, Lood, Salpeter, Zwavel, Gefchut, \&ce. preder Des. toe.

Gedatn- Wat nu ditwolk in zich zelven betrefe, te en de "Tonkinders zyn rant-ged van kou-

Volts leur; dog cenigzins bloozende, en nier 7oo plar wn alagezicht cn neus, als de Chineezen, dog ganfelt niet onbevallig yan wczen, zwart en lang wan hair (diac bet over de fehouderen haugc) en doorgaans pik-zware van canden, dat een groot ciernal by hen is, en 'c geen $2 y$ door Konit zoo makes, 'war toe zy wan jongs af al gewoon zyn eenige dagen to beftedetr.

Zy zyn van geftale de langften niet dog anders bezwind en and war leden, ven mufig wan begrip, zecrncerltig, gedientlig, en hune Heeren zecr geerouw en gehoorzan. "Zy zun nict zecrklockmoedig, wallende mect an de kilcenhertige kant; tog gelyk her dobbelen en Ipeelen den Chineczen doorgans cygen

\section{$\mathrm{N}$ K I N}

is, alzoo is dit de Tonteinders zoodinig anngeborcn, dat zy zomtyds alies, wh at zy hebben, verfipeclen en vertoppen, dac zaelfs wan de groodten tot de geringlteraldaar overgoar, en als zy nu nicts ter wereld meer hobben, din zerten zy "er han wy en kinderen by op.

Teren de vrecmdelingen zya zy zeer vriendelyk en beleeld; dog de grooter (dat meelt gefinedene zyo) zyn zeer hoogt moedig, dat men ook veel by 't Krygs' volt vind.

De drage der geringen hier is van Cattoen, en der rycen wan Z Fde, of Lakenen van allerley kouleuren, en voor at rood, groen, \&c. meett lange tabbarden of roliken gebruilende, yooral, als zy vool de grooten verlchynen.

Hunne huizen zyn riet alleen door. Hulfsgans (gelyk alle de Indiantehe) Necht, raad. matr ook, op zyn Chimees, van llegten huisrand voorzien, die meert in ftoelem, tafcls, banken, rufbanken, en bedden, Pinang-gereedichap, \&c. beftat:

Men heefe hier gecn cenc, manr weel Hune vrouwch. Zomnjge der zelve werden Huwe: plegrely's gerrouwd; dogdemeefteman Jyken. als byzitten gebruile, cenige wooralryds dog ook zommige miar yoor een tyd gebuurd.

De vrouwen dezes Innds zyn fihrander, neerftig en groeke Loop- Prouwen; en weten met 'er tyd cen fraeje ftuiwer geld te winnen; maar zoo hier geen fehepeIl wan buiten komen, lege 'er de ganfchen trandel toe: want om den zelwen atri de gang, te helpen, moet de Inlan der doorgaans cerlt eenig geld op de hand liebben, ecr by in fane is om re werkers.

Men liefef hier, buirende groote Koop* Arabath licken in ruwe of gewerkic Zyde, en liedea. Zyde ftoffer, ook zeervecl Ambagtslicden, vin Wevers, Schrynwerkers, Timmerlieden, Snids, Drojers, Porcelynintaks, Schiders, Lalwerkers, Papier. makers, Klokgieters, Geld.wiftehars, \&c.

Hun papier is byna als "t Chineefch of Perfianich, zominige foore wan Zyde, en andere vas baften yan boomen gematk. Ik heb onder han Lakwerken, en voor al onder hunue Bandeczea, "er fracje gewonden; dog zy konnen egtex gectzins by 't Japandeh Lakwerd bailen, waar toc zomiyds 'e hout zelf, en ten declen ook de Lulk-floffe of 't Vernis zeer vecl doet.

De Tonkinders maken nier alleen een Huri byzonder volk op zich zelwenuyt, matr Tad: zy hebben ook een Tanl opzich zelven, die wat ben zeer fterk agter uit de kecl 
opgehaald, en ten declen al fifiende door de tanden uitgebrage werd. Schoonzy vecl overecnkon ft met- die der Chineezen van fehrywen heef, is 'er egter zulf ecn groot onderlcheid tuffehen beide dite tales, dat die twee volkeren malkanderen geenzins konnen yerftaan , en lehoon hunne Cluaraters en letter-greepen unterJyk dezelve in gedaance zyn, fpreeken zy die egter ieder geheel anders uit; dog de geleerden ander hea konnen uir de werken der Chineczen, Japanders, est der Quinammers ook andtonds te rech raken.

\$chyf f- Hunne wyze wan felwrywen is even eens, wre, als die der Chineczea, mee een griffe of te. pencel wa boven na beneden, en dus van de rechter na de linkerhand gande.

Zy oeffenen zich nu cn dan ook in de Landmetery, Wiskunde, Stertekunde, Natuurkunde, en wat dies ncer, hoewel hunne kesniffe in allen dezen mat matig is.

Wyze De Koning regect hier Oppermachan Re- tig, Aatande onder nicmand, zodanig dat getren alles van hem afhange. Zyn grootlle neidso- Mandiryos zyn gelubden, die hy hier en diar als Landwoogden verdect, en dic in die Lundwoogdyen zich als kleene Koningen, weer crots en hoognoedig houden, en hun werk mar maken, orm de arthe ingezeterej, die tegen hen niet kikken durwen, uit te mergelen; manral wat zy vergaderd hebben is voor den Koning, alzoo die na hun dood hun erfgenatat is.

De honing houd cen zeer grooten flat, niet alleen van een menigte lyfwagten, die op hem palfon, maar heef ook ecr fchoone ftal, mer ercelyke honderden Peerden, en wel 2 a 3002 watare Olifanten, die alleen tor vertooning van zyn prage en grootheit dienen. Oolk op de been, beftande meeft in woervolk, die gemenclyk een zabel en cen lang roer van 4 voce woeren; matr zy dienen beter om hunne nette wapens re vertoonem, dan om te wechten. Men wil, dar hy "er wel rooooo hier en dnar door zyn Ryk werfpreid leggen heett. Ook heefe ly fchoone Ruytery, die fchoone Peerdew, cn fraeje Schilden hebben, cn van cierlyke pluimmagien voorzien zyn.

Tor zyn Zee-magr, dic in 70 of 80 Galleyen, ieder met 30 of 40 man, beftat , heefe hy mede eenig vaft volk in dienft, en daar over mede cenige Zeehoofdert.

Gelyk nu de Tonkinders doorgtans beleeft en vriendelyk, voor all tegen de vreemdelingen, zyn, alzoozullenzy ook

zelden iemand ies te kort doen, ten ware dar da dere of gerne zerr veraroude, hen atan deze en geene kleanigheden quamen te vergrypen, dat egter de wet wan "t land niee duld; matn na verdienite flrate. Indicn zich ienand met dicwery te bui- Bedie-

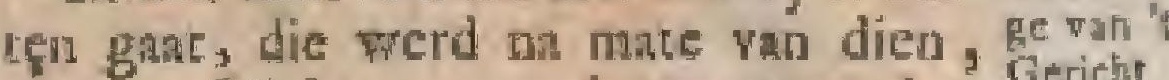
zwalr of licht, zomidyds maar met het bericht atkippen van cen lid, tomtyds mer verlies van zyn vinger, en, na dat de misdad is, wel wan de geheele hand, geftraft. Zwarder misdaaden werden door onthoofding, en de lichter, mer een geetfeling afgedan; hocwel ditalles juitz in dic bridre nice, als wel in onze landea, gefchied.

Zoo de zakk, want over iemand woor it Geriche geroepen werd, van dien and is, the 'er een ced roor gedann moer werden, fryden z.y eer hoen dêta hals af, laten des zelfs bloed in een. Fom met Arak loopen, en die den eed doen zal, mostr een kopje wan dezen met bloed-gemengden Arak driulen, na dat hy de zitak, wat over hy geroepen is, werkland heet zus of zoo te $2 y n$.

Branditjchters ftellen $z y$ bloots hoots op een floel, van I 2 of is vocten hoog. drie dagen aan een, in "c hestft vañ de Zón, te pronken.

Orerlpeelfters werden woor den $\mathrm{O}$ lifant, en door den zelwen in de lachr geworpen, en te pletteren getreeden.

Zoo icmand bier kome te lterven, die Begrave? werd, van anzien zyode, verbrand, en tisk daar na begraven ; nies op een gemeene plans (dic hicr niet is) matr clk op ayn eygen erf; en een miand datr na werd "er een groot mal, wan de rrienden des overledenen, op zyn gralgegeven. OHtreat deze begrateris zyn ook altyd deze en geene Priefters, al wis het mant om te zien, dat de zaaken in de behoorlyke ondre nagekoomen en bezorge werden. Zy hebber tot het verbranden van hunne dooden hourftapels, die wel 10 woecen in 't vierkine, en well 25 woeten hoog zyn.

Dus verre nu "t voornamfle, dat wy vooraf wan Tonkin re zeggen hadden, voorgefteld hebbende, gan wy over om te zien, wanther onze Matichappy hier heefe beginnen te landelen.

Dit nam onder den Heer Opperland- wathecet yoogd Van Dienen zyn anwhng, is wel- anzen kers tyd biar Eutclheden den I3 Mey hier bey Ao. 1636 een betuic namen, om een be gon, zending na Tonkin te deen.

Hiet op hebben zy $\mathrm{AO}_{1} 637 \mathrm{den}$ Koopman Kavel Hatefink, derwatrds met het Schip Grol, \&ce over Tayouan en na 


\section{$V \wedge N \quad T O N$ K I N:}

Japan, gezonden, van war hem de Heer Kockebukker een zeer nette Inftututie mede gegeven heefe.

1637.

\section{Inftudie voor $S_{\text {r. Karel }}$ Haytfink, Koopmsa, en den Raal wan 't Selsip Grol, ende "t Yagt deWh- thloozs Werve, zeilends wata bicr wer Tayowan nat Toklin:}

InfFuetisugor de Hert" Hevilink A. .637

" TAdemaal tot vergrooting ende "I aunwaich der" negonic code com2, mercie in 't Keizerryk van Japan, by " den Ed. Heer Gouverneur Gencraal, " en de Heeren Randen van India gere3, Folveerd, en goedgevonden is cen be"zending ma her Koningrylk yan Ton" kin te doen, ende den Zyde-hmudel in " gemeld Ryle, ten dienfte ende voor"deel van de generale Ooft-Indilche "Compagrnic, van hicruit Jupan te ver, volgen, dar by ordonnecrende her "Schip Grol, ende 'E Jacht Warerloo. "ze Werve tot voorn. bezending te ge") bruiken, ende derwalats te lastenwer5) zeilen, zoo zulten Ul. in Godes raam " dezen anultande morgenftond ảe mon;) Atering yan 't volk, en de vifite van "'t Schip by de Japaniche Bongioys geb) daan synde, onder zeil gannde, en 2) uwen cours beweften Meaxima regt 23 door Zee ftellen, tragtende de kuft 3, พan China, op de hoogte wan 25 gra" den ontrent de Eilanden Oncouw ofte 3) Stormbiey, and boord re hirygen, en3) de verkend te gerakaken.

"Van welke Eihanden, ofre yoorn. "Kuft verkend zynde, zult van das, "by mooi weder, ma de Eilanden wan "Pehouw overftecken, alcyd gifinge "ende calcularic makende twee vloe"den voor een ebbe.

"In 't anndoen van dito Kuft, ofte 3, ter Rheede loopende, werd Ul, ren ", hoogften gerecommandecrd wel op uw "hocde, flagveerdig, ende, "L gecr " voor Braudess noodig verdacht te zyn, ", op dat van Roowers of andere trouw"' loore Chincezen, Ul. geen ongeval ") onverwagt toegcbrage werde.

7. Zoo loet geviel Ui. hard weder ofte , Atorm quanen te beloopen, zullen zig " niet van de Kult af begeven, man " onder den hoek van Sabouw, Enge"ling, ofte eenige andere bequarne "Bajen, ten Anker loopen; ende al" daar goed weder waarneemen, om 3et 't zelve na gemelde Eilanden van "Pehouw over te flecken: war op by "datag dienca te veryallen, en in de
, Zuid-Ooft Bacy ter Rheede te loo"pen, gaande van daar "s middernagts "2 met een achter-ebbe, op dar des mor 32 Gens in tyds op de Kuft yan Formofa " moge, yerkend gernaken, ende alzoo 3) uwe Reize gevoeglyk, zonder voor", by te dryven, gelyls, woor dezen me5) nigmaal, (God betcid) door verzuim „2, van Officieren gebeurd is, op Tayouan ") re mogen gewimnen, "I welk Ul. by "dezen op her allerhoogtte en fericutte ", wcrd gerecommandecrd.

"Door hard weder voorby geraaken, 3 de, zult niet vreesagtig of betctireund "3 wezen ageer den hoogen hock wan $\mathrm{T}$ : $1 \mathrm{n}$ 2) coyat ten Anker re loopen, wau waar 3, met goed woder, chde in twee getyen " opliveeren, ende onder 'r Nourder3, Rif na wenleh ter R heede komen kond, ", altyd in 'c aundoen wan de Rheede ", Van Tavounn na de copye des Seyn" briefs, by den Gouverneur van voorn. " plats beramd, ende $\mathrm{Ul}$. Icr hand ge") tteld, Ul. rergulecrende.

13 Met lief voor Tayouan ter 12 heede is gekomen, en geankerd wezcnde, zal ", de Koopman Harrfink gich dadelyk, is ten waare by verlyijudering van weer "en wind, tan land by de Heer Johan „, van den Burgtranfporteeren, ende on"20 miffive met de bygerocgde papie") ren zyn Ed. overleveren, mitsgaders 3) mondeling van de bevinding der dexen ", jaare gezondene ftoffen behoorlyk rap3) port doen, gelyk UI. zoo in 'E uitleg3. gen, verkoopen, van gelykien over des "zelfs deuge ende lengte en breedte als "3 andere difcourfen met de Kooplieden "s gevallen, by ende prefene geweett $7 y$, 3) daar by verzockende zoo vardige uje2) pelche, als gevocglyk zal lionnen ge13 fohicden.

"De Rederen, die den Raad alhier , helbben gemnveerd dir Schip, hoewel "tot liet hantte, ervide dat in't regerard "van de verwathe koneanten wan bo"ven, hatde behooren opgezonden te "werden, voor Rarop ende de Swan "te preferecren, zyn Ul. ten wollen ," kennelylk, thamelyls on des te tyde"Iyker of? de Tonkinle Kuft te mo3) gen geralken, endic den weg tor djen ". handel gevoeglyker te openen, $\mathrm{cn}$ in "t "werk te fellen; als andere contide"ratien, die materic rakende, mitsga") ders mer goedvinden van gemelden $\mathrm{Ed}$ "Hecr Gouverneur, ende ryn Edelheits 32, aanfchryven yandato 5 A Auguifty paffo, "3 in palline Quirana an te mogendoen, ") ende aldaar te genieten, 't geen Sr. "Dugter, geduurende zyn aanwezen in "Quinam, nopende Tonkin, ende hoe $n$ de 
1937. " de bezending derwards by den Qui" nanzen Koning vertatu werd, zal " Jebben vernoomen.

"Her Jage de Witerlooze Werve, "dat by de Ed. Heer Generaal, volgens "zyn Ed. ordre, geprojedteerd is, ne" vens Grol, na Japan, en van daar we"der te verzeylen, is by relolutie tinda;) to 28 July paffado vari de Ed. Heer "Gouverneur Putwons, en den $\mathrm{R}$ and in "Tayouan, geoordceld en goedgevon, den aldaas te blyven, on nevens an21 der bequaam vastuig tol het Kruys"fen op de Portugees, als anderé onzer "ryanden, rendecrende na Tonkin, 1. Quinarn, en Combodia, zoo buiten " en binnen Aynam, uirgezet te wer"den, en de komll wan Grol opeenbe"quame rendevous plats te verwach, ren, welken wolgende dez woornoem-

, den Jagts reunite Uh. in Tayouan heb.

3, ben te vertlan, en in 't retcontrecren , deffelfor mede anndoen, en verzeylen " मа Quinam, uit redenen liter buven , angeroer, des Ed. Heer Gouverneur w ordre te werwachten.

, Deze ordre wan zyn Ed. hebbende 3) achtervolgd; en 't voornoende Jagt, ,y of zoodannig พatrtuig, als U1. dar zou , mogen toegevoegt werden, gerelcon", treerd, zuilen UL. van die plaats, die "by ons allier voor her tegen woordig 3, nier lan werden woorgeteld, zonder ,yerzuim van tyd, zoo veel doenlyk is, , de reize na Tonkin, bezuiden, en , nier benoorden "t Eiland Aynam, al3. zoo dat vararwater voorg root vartuig, "als Grol, vermis de menigruldige vu-

"len en rudzen zeer periculeus en veel

") onweder eu ftorm in e navigeren, on") derworpen is, vervorderen, en ondev ," "t Eiland Frachachy, gelegen onder "s de noorder breedte van is $\frac{1}{2}$ graden, "ontrent een groote halwe myl Oolt ren

"Noorden van de Rivicr Giang, ach". ter wellk Ejland op 5,6 en 7 vademen 3. goede Rheede en Ankergrond is, en " men roor alle winden meeft befchue "blyft, ter Rheede loopen, ons werder ", and 'i katric en 't uitwerpzel van "t "Tonkins land, deflelfs hawenen, en "daar ontrent gelegene klippen en "droogen, U1, ter hand gefteld, refe"rerende.

"Eenige jatren geleden, plecgen de "Japartehe Negotianten met hannejon, ken ina Tonkin navigerende, de rech2, te Rivier of fpruic van vaomoemde 3. plarzen, gelegen op de Noorder breed"Le van $20 \%$ graden ahin te doen, dog 2) by verongelukking eetrer huner Jon"ken te dien tyde in de mond vant de
3, voorn. Rivicr, als medc om dat de 9. Kutt atdanl Noord-Ooft enZuid-Weft 1637 .

3. fluck, men, on buiten in Zue re ko" men, veel mociten onderworpen is, "ch bezwarlyk uit de boche boven "E "Filand Aynam in de maand July, ats 9, wanneer, en nier vroeger, wermuts het "Ppofe leveren van"s Koning zyde, win , daer fcheiden honnen, geraakion kan, "hebben anderhand de Kivier Giang, " of Tzyncphy, voor die wn Tonlu " Eepreferect : egter dic van Giang "voor die wan Trynephay, gemeske de "Kuft ontrent dino Rivier Tzynephay , zich N. N. O. firclit, en de Zuide "winden ten decle noch op "e land wate"jen, en door het getladig nanbratiden "Tan de Land-Zce, als natrmiddag de , Zec-wind, die vry dicht anklueld, ," wanneer men in de gezegde Riwier 't , water (en dat woor den tyd valu 24 "uuren) op zyn hooglte heeft, veet 9. moeite en perylkel, valn buiten te ge"r raker, onderwotpen is, des nagts ,3 vermits hel hoog water, hoewel de "Land-wind doorwacit, veeltyds ge, noodzankt werd te blywen leggen.

"Dit zyo de moverchite rederen dier "Natie in de Riwicr van Giang troor de "andere an te doen, en aldane te have, nety.

, Ot her geviel, dat U'l.onder 'E voort. "Eilandje ter Rheede wezende gekoo"men, zoo tydelyk en in 'I korte, th "wel wenfche, eenige Japanders, Chi, neezen, of andere Natie van 't Land , (alzoo gcen Volk, nit onderrich wer"den, op 't woorn. Eiland woonachetg , is) aมn boord quitamen, gelyk jarlyls "op de aavkonit der Japanfehe Jonk ge" fchied, en gewooniyk is, zoo zal UL. , door cenige Viftches of ander varu", tuig, die dar in abundantic $2 y n$, de ") were vof u arrivecren aan den Opper"Aten, of aldan "c Gefing hebbende van "Giang, zynde een van des Konjugs 3. van Tonkins blocdverwaten, doen, 3) en defielfs ordre net ecnige van woor, verhualde perfooneu verwachten, om "tizoo geen mis flagen of misconicnte"ment aist de Grooten aldiar, als we, zende een Natie, noir dac Ryk heb"bende gefregenteerd, te begann; dog ". by werloop wan 2 a 3 dagen, hoewel " de wete aan Land gedaan lind, engecn " ordre of iemand tatin boord kreegen, 3. zult mogeñ cen พan de bequatamite Af" Giltenten, cri den Jipanzen of Chi"ncefchen Tolk, dic Ul. uic Tayoum "2al werden medegegenen, of by any) docning van Quimam, by den Opper"hoopunan Dugher dienc seprocurecerd, 


\section{$\nabla A N \quad T \quad O \quad N \quad K \quad I N$.}

I637. 9. tha Giang ontent 3 mylen de Rivier , opwaris met de boot zenden, mits 3) dat bimen of voot ast de Rivice, al2. Waar de Viftchers woonitigen ftan, , I n 2 -petloonen tot Guides werden 3. Geluuru, en dico booc na boven of in 2Ging brengen, en alloo destezclecr2) der wan uwe fondte mogen woler ver2) witrigt; zulks zoude mede tar eertlen 3) intantie no bevinding van zadeen al, dhar tgonnen gefchieden en in 'c werk g) getteld werders; nee welken Tolk ,2 dient cen bivene exhentenis of verec, ring wu ontrenc 6 a 8 Tayil, beltun, de in Wuejers, Carcafter, als Iac, quans, of ietanders, gefonden te wer 3. den, mec darar by verzogre licentie van ", perloonelyk mec gemulie Grouverneurs " te mogen iprecken.

2. Hier op finc woord en licentic betro* 3) men hebbende, zal Sr. Harymh, net , noch jemand uit den Rand, of Sr. 2) Thiche Roncys, fich met "t Jagt de 3W Werlooze Werwe ha Giang, of al "s war gemelde Gouverneur zoude to "Preckenkomen, vervoegen, denzelyen de motive1, cn redencn, warom , aldatar verfonecnen, was Natie zyt, , cn wan watr gezeild kome, in derbe, fte forme dechaseeren, endary by oot" moedig verfoeken zyn Ed. op "t fpoe, digtten gelieve cen exprefre ni de , Hoofdtad wan Tonkin ara den Ko, ning af ee wandigen, en te verforgen, 2. Jat in "t kare antword en liccitie 2, van "c Hof mogen kamen, on de be3) wersgatade milivo en vereering an 4, zyn Majelteit pertoonelyte te mogen 3) overleveren.

, Volfens ouder gewonte, ch, geis Fyle dic van Tonkin met de japanders " pleegen te handelen, en har anuge"brache carga tatu ie teekenen, zal 3. UE. buiren twy fiel mede, en dat wel 3) precifelyk de guaneiceir cn qualiceit der 3) Concanter, goederen, als anderfins, 3, die zye mede brengende, van vonra.

3) Gouverneur afgerratagd werden, die 1) afles rondelyk angeven $z u t$, uitgc2, zege de, contanten, welke ten hoog3. Aten tne 40000 Tyyil genoeg $7 y n$ yl, 3) fockende her relteciende binnen "Scheeps boord te werbergen, zoo weel 3) docnlyl is, en dax ten principralen on , vnor te komen, van den Koning, of 3. Lyoen greordonncerden Mandary, fo 3) veel concunsen als wel begceren, en 3) verfoeken, nict ter hand to ftellen, "3en anderen gewar wordende te me3 nigruldigheit des Seress, de Zyde, "Zyde Stuk-goderen, alsandersteilcu 3 doer, whar by de Compagnie geen

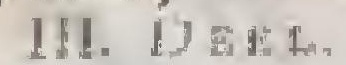

Geen voordecl, mats madecl ter con-1637

"Irarie by "t verfwyget, tan gelchit-

" den, of Ul, cenigongeval totgebrach a) werden.

"Licentie gewerderide uit 't Hofram ", den Koning, om perloonelyk, ennace 3, uwe verder medegebrache Cargafoe" nen, ren Howe ba de Hoofilfad van 1. Tonkin te mogen komen, zal U/, mer "T Jache de Waterloole Werve rot "2 inecrder verfeckering en betryding u", wes kapicuals nier alleen woor Inlind"F fhe soovers en moetwilligen, die geen 3, en ontbrecken, matr culi voor de lor"togecten cor Spanjarden, onle open, bare Vyanden, at Chinceren, onte 3) geveinsde Vrienden, mitsputers zoo ", vecl Inlandich Varruig, als tot over", voering atcr goederen noodig is , dat 3 op belecf werrock wan den geordon3, neerden mandatyn of uit "t Hof ge"Fonden Caphlo des Konings niet ge3, weigerd, mar verleend werden zal, "op 't fpoedight mec Reife op watrds? 3, 'I $z y$ dan buten of binnen door, nat ", wind en weder toelnaten zal, forde, ren, alsyd verdache bivende in den ", avondfond, dicht by den anderen ic

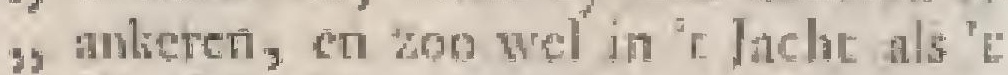
, Tonkins Vartug (dat ieder cen min. , fen met 2 a 3 drie Nederlanders en "Mufguers als Zyat-gewcer diend noor3) fien te zyn) goede washe te houden, 3) op dut, als gelegt is, gecn ongeval 13. Ul. overkome, dac andermal zoo in "' gan als kecren ten hogglten, of 'c "geviel, "c voornarnitte Jacht niet qua" me te relconereeren, met het Tonlins 3. Wartuig te doen gerceommandect 3, werd, en zah "t woonoemde Jacht of 2. Vaarcuig tot de ner wegene contme "ten, die des te fecuurder en behende"Yyker, ma 't vifiteeren des Venruigs, "in Tonkin a uwe wooning zal konnen 3. werden gebrach, dienen, om welke, alls 7 andere confiderarien, UH. bekend is, 9. dat op 19 itanti by Rade qerltan is. ", Jache de Waterloode Werve by de 2, Ed. Heer Gouverneur Generat Lor ad 3, yys ma Baswita, hoe fich den hantel ", in Tonkintoedragenzal, cen wat quan\$ titeit wan Zyde aldan werhoope word, "geprojecterd, by UT. te haten vet" , blyen, en gemelde attending vou " déle Voygic gefurcleerd hotden; $\mathrm{eg}$

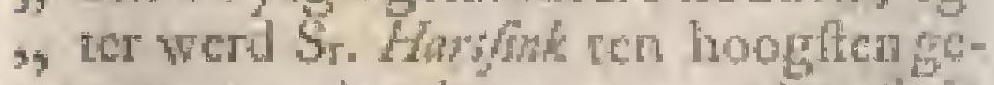
3, recommandect, op ings atrhom it in "Grang (alwaar, wa hier werder oth2) derriche, den mppatenico Zyder- hati, del, en onter $\mathbf{V}$ yanden doencen Hogm

3) ve, en met wate Viaruig aldar ant-

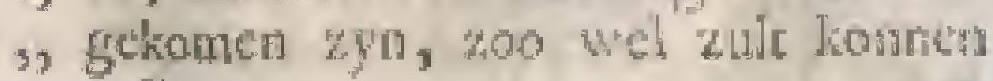
If $3 \mathrm{yet}^{\mathrm{t}}$ 
1637 , vernecmen cn verftar, alsin Tonkilo)

3) daar van advys ana de Ed. Heer Gou-

") vernelir Generat tot contentement

"Wan zyn Ed., Too veel doenlyk, over

3. Cocrsjientsjia te gewen, allon,wy ons

b) vesfekert houden regen ultimo Maatt

2. noch een advys-Jonk of Vaartuig uit

3, Tayouan Comprgnies Refidencen in

"Quinam zal toegetonden werden.

, Dele advertentie of advys kein be-

9. quamelyk mer Barken, die fluips- of

"ftecls-wy $[$ c uit die, als andere daar on-

3) trent gelegen Rivicten met liasre Gne-

3) deren en Koopmanfchappéri na Qui-

3. nam vertrekken, gefchieden, gelyk

3, mede te Lande, en dat over de Rivier

"Poftheyn, alwatar de Koopluiden van

"3eide de Koningryken Quinam s en

"Tonkin, hare Waren en Koopman-

3) fchappen te marke brerigen, en met

3) den andefen negoticeren konnen.

"Voor en aleer een gedeelte des treyos is van Tönkin vertrekken $\mathrm{zal}$, blywen Ul. , bevolen een goede en verlekerde Rhee") de woor't Schjp Grol te werkielen, 't 9) $z y$ dan onder " $t$ Eiland Frachachy; of 2. wel een ander by de Japanders 't Roo\#, vers Eiland genamal, gelegen ontrent $\Rightarrow$ de 8 mylen Noordelytier als Fracha3) chy, na de Riwier van Senephay, al-9. Whar de Koning zyn wachte of tit, fiender in Zec, hecfe. Dog zoo het 3 Schip gewoegelyk en zonder prykel, , in de Rivier van Giang en debatien 3 of inkoomen, geen werloop of toevloc-

"jen enderworpen weiende, weder uit" gebragt $\mathrm{zal}$ konnen werden, is "t gera" den tot meerder fecuriteit en voorko" ming, by florm en onweder, van an$\rightarrow$ kers en couwen te fpillen, binnen te ", loopen, gelyk zulx eenige Japanders, w. gedurende dar navigecrden, als hicr 3) vooren verhald is, met hare groote 3. Jonk in "t werk gefteld, en by conti3) nuatic deffelfs gehcelyk gefchied zou ") hebben, alfoo haat Jonk op 12 Japan3) fiche voeten waters, dat wel is 3 Hol5) landfe dito is, en dat fiet cen gemeen 3) thye binnen te loopen plecgen. In de 2. Rivier van Giang niet komende, zal ", "t Schip onder 't Eiland, dar "s Ko", nings wage op is, na dacbericht wer3en, eenigfins beter Rheede; als op "Frachachy, vinden; dog is "t zelve " mocjelyker by het Zuider-Moeffon, "3 als wel Frachachy, boegwantes uit te ", geraaken, na bevinding zal by Ul,de3. fen rakende her recuurfte in 't werk " gefteld, ca by der hand genoomen s) werden.

3. "I Zal mede woot uw vertrelk noo\$) dig zyn, gelyk by de vreende Natica "gebrikelyk is, dac gendide Mande- 16,3 -

"Iyn wan Giang, over de genoten fa-

" weur, en toctlan wan "L schip in de

"Riwier te laveren (

" is) bedanken gat met een fchenkngie

w ch vereering van ongevarlyk de $\mathbf{x} 00$

„. "Tiny il eens, foo in Luropif́che als Ja-

" panfche goederen. Van zyn Ed. zal "Ul. werden gevergd, en hard nange; houden eenig geld op leverantic yan , Zyde Canecl, als andere goederen hen 2. ter hand te ftellen, "I welk met alle "belecftheit en gevoegelylatte middelen 3) dient te excutecten, dog egter, vol" gens de gewoonte der Japanders, een "lecning, dic op rooo Tnyil dat ook "mag beftan) fcharte niet zulckomen "Dirfleggen, te meer foo 't Schip kont "binien te havener. In Giang zal cen 1) partye Caneel, dic fildaar meeft valr, " dienen geprocurecrd, is gemeenelyk "woor a $10 \mathrm{en}$ "t I 2 Tayll Pikol in"koops te bekomert.

3. By den Ed. Hew Gouverneur Gene" ranl werd lerieufelyk geardonneerd de 3. Portugeelen en Spanjairden, dar men $n$ de zelve op dere Voygic fou komen " te bejegenen (londer relpeet an des "Tonkinders Rheede, hawenen, noge "Rivieien te drageny nlle mogelykeat3, breuk te doen, in ans geweld te nee, men; met dien verftande wan th aan , klecnigheden, of geringe Prinlen, niee is te amuleeren, nog fich kennen te law ten, on dierhalven zyn Rheede ex "Rivieren te riolecren, en ongunft op " onfen hals te halen, matr Prinfen wan s. importantie, dant ecn, twee, drie, , en vierhonderd Pikols Zyde, of de 9 watrde wan dien sou konnen bekomen "werden, zal men niet exculeeren ; s* mar zocken to weroveren, en voor b Goeden buit andfan, daar kome dan 4s af wat "er wil \&c.; doggetnerke door , verlcheide Japantche Kooplieden, als " andere daar te lande gefrequentecrde 3) perfoonen ons waflelyk werd te ver3. Itaen gegew en, en geinformeerd by 3. diergelyke nttentar de ongunft van "wooŕz. Koning nier alleen op den lials 1) zouden halen; maar ook de Negotie 3) werden ontzegt, en meer fwarighe" den en ongeval des Compagnies diena, Ten apparentelyk te genalken ftan, dier 3. als andere goede redenen is mede by "s de Ed. Heer Gouverneur Pumans en " den Raad wan Tayouan goed geron" den, om in geen verwydering met de "Koningen, zoo in Quinam, als Ton3) kin te komen, een uitzecting op $V y$ 13 ands Vaartuig buiten de Quinammers , en Tonkinders limiten te zetten, en 3. inllo 


\section{$\begin{array}{llllllllll} & A & \mathbb{N} & T & O & N & K & I & N .\end{array}$}

5 637 , 3i alle mogelyke af breuk te doen, gelyk "Ul. volgens refolutic dato ig ftaniby " ots en den Rad in Firando over dey ze z akken genomen, buiten kennis wat " 't land in "t gatn en komen te effec"tuecren, geordonneerd werd, gelyk , by weigering, en de Negotie nict te s komen gencten, in wat havenelt, 3. Rivicren, of Rheede bet $z y$, zal gen fehicder moeten. Echter verftan wy " fectetelyk door de befte middel, die s, aldar 2 u megen woorkomen, onder3) Atan, bne her ten Hoove by den Ko" airg en Grooten zou werden genoo"anen, delelwe in zyne havenen en Ri, viere refcontrcerende, ian fe catten, 3. veroveren, on alle mogeigke afbreuk "2 te doen, "t zy dun mex eén gedeclte, 35 of redelyhe Ichendagie wan den buic of , a angchasis goederen te genieten, en "sliko nuet oogituiking toclanten, zulx 3 Miet lomen werden onderleid; en gé"oordecld by zyn Majafteit nier wel ge9) nonmen zou werder, zou 'e Jacht de , Waterloofe Werwe (cot nakoming zoo 2. Feel doenlyk wan de welgemelde Heer , Genernals ordre) woor 'E verifek der "Portugee en honnende miften, under क de ech of de ander pretexs na be3 reden gefonden werden, en op n hatieder Vartuig een ftuk wecgs voor

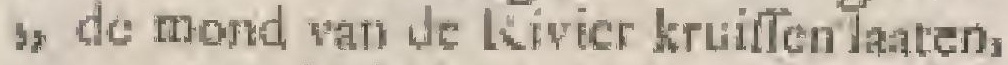
3) en zou de buteting voor de rechte s. fpruit wan de Kiver wan Tonkin, of 3) datr outrent, behooren regefchieden. 2. en rier Zuideither, alfoo volgens in. 3) formaric verfeckerd houdsn, das des ba zelfs Vartuig nergenselders, als voor 3 de llootdfad wan Tonkin zuld komen s, te refcantreenen, terwyl met ondiep* gande Vartuig dar verfehynen, en 3 van daar verzeilen, haren cours be" noorden, tuffehen de valte Kuft van 2. China, en 't Eiland Aynam en Ma" cutw fitellen; dog defe befetting wacrw dende in 't werik getteld, zal dienen " geordonineerd nan de Overhoofden van 3) "I Jacht, hoe lang te continuceren, $n$ en wel na Grol weder te komen affak", ken, of wel na Tayoun, mits't $V_{\text {aar }}$ "Water, euffchen voorlz. Kutt, en het 3, Eilund, behoorlyk oncdelkende, very. zeilen liaten. Wy houden defe ontअ. dekling gehed confiderabel, en oor* declen noodig Ien dienft van de gene3) rate Compagnie te weien, $200 \mathrm{zulx}$ "door onle Jachten dic fatfoen niet ge"Fehied is, op dat in 't tockomendemer ;) des te meer vertekering op har zou" den mogen kruilten, ten welken fine " war couss in "r gats en komen ftellen, " 's zy gehedyk de Kult gieren, of 'I
2 Eiland Ayman, ftat zekerlyh re ver- i637.

, necmen, om alfoo onic Wyanden e"ce-

", nemal uie Tonkin to wocren, en hat" re Commericic geheel vrugteloos te s, ninken, watr noe den Aluogende by $n$ tyd en wylen zynen Zegen geliere te , verleenen.

"Defe dalu, als andere onfer Vyan" den Varrcuig, in "e gan en kecren, " excepto die van Macituw na Japta "tenderen, hoomende te bejegenen, „zult de zelve alle mogelyke atbretik " doen, ell zoeken te vermeefteren, "t "wolk wel bowaren, en van de zelre w verleketen, mitsgiders hase goede3. ten onder belloorlyke Inwentars, in "prefentie en kennis des Schecps-Raad ", neemen, verdach blyvende geen gea "vangenen hier in Japain, man de zel"we un de Plifadores of l layoura te bren" gent.

3. Volgens des Konings ordre, en oud "gebruil, wal mee de konfte in Ton" kin al uwe Koopnanlchap en goede"ren, ontrent 's Fonuges Paleys, ant , Land gebrache, geopenu en wel nanuw " gevifiteerd werden, op dat, 't gent ,2 zyn Majeftcit mogtaanltan, in geen 3. andere, als zyne handen zour komen \# te yervalken; 'c welk metalkebehoor, Jyke refpeet zal diencn nagekomen te "werden, en niet gedogen, da de ge3) Commitrecride Manday yis, of andere 3, bevelhebbers door onfe reukeloore en "by wylen ongefchikte Matroolen ec"njge quade b-jegening ang daan wer-

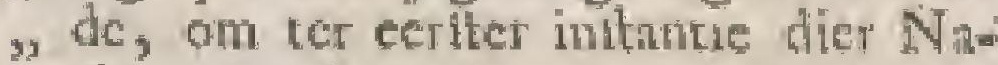
"lie gecn disgund van ons te geven: i. doch zou wel konnen gebeuren, cer, wwl dan moic hebben gofrequentecrd , dac don humble werloek of valte bo"Jofte en coelcgging wan alles ten dien"Ite des Konings te weren, en wathen 3. mogr behargen, ter hand zou gefteld 9. werden, deic publique vifite voor "s Konings Paleis zou werden gexcu, Feerd, en alloo meer vrybeit en voordeel, als wel Japanders, Portugeefen, "als Chineclen, gelylk zuls in " $\mathrm{c}$ Rylo "van Quinam volkonelyk blylit, get 2, nieten, niesgulers de verborgen con" 5) Enten te gevoeg/yker mogen uerber" Gen, en ter gelegenen tyd an land „, brengen, watar op dient reguatd ge3, nomen.

n Zoo al "t geenerall, en undere Jices, nigheden des Konings aangentam voon " hern gehouden, en naggenoomen werd, , zal inede mee "c Brood, Kroper en $\mathrm{Y}$ "Fer gelchiedea, en dat voor defen go3, meenlyk her Koper cot Tryil 8 en $\mathbf{X}$ "fer tor Tayil 4 fyn Zilwer, of 'T'on$E_{2}$

tinfe 
16:7, " kinfe munt: dach tcrwyl gefegde mi" neraten dierder in Japan als wel in ") voortyden moeren werden ingekogt, "z zal bolk noodig z.yn mer dier voordra3s gen tor hooger makkt te gernaken.

"Boven alle deze watreerning des "Konings, zal ook door zynen gemel" den Mnndaryn het meerendecl twer क arngegewene contanten woor den Ko, ning mogen genieten, angehouden, "En tehoone beloften, van goede en wel " gecondinioneerde Zyde tydelyk te le" veren, gedann werden, dar Sr. Hast"fink zal zocken met vriendelykicit te , excufecren, als dat wiet alleen Zyde, a) maar werfcheide andere goederen noo3, dig hebt, en koopen moet, ook me3) de dne de comptanten diverfche lieden 3, 2yn tackomende, als anderc belectde 3 , redenen, tot ontllaging disnende.

"Aldus 't Contraet met den gezegden 3) Mandaryn nangegaan zynde, (dat wy " gifing maken na den loop by de Jas. panders daa jantlyx in gehoudets, of "I I a I rooo tayil ten hoogiten loope) 3. zal by den oudfter Konings Zoon me9. de ecn fomme geld, en dat vry groor, "n gelyk by den Mandoryn, daar mede "2, zult hebben gecontracteerd, verfocht ; en inflantelyk sangchouden werdev, "3. welke beide niet wel, behondens 3) wriendfchap en courtoifye zullen koni) nenaflaan ; dog op voorverhaalde rede3, nen, in 't reguard van den Koning g, gedaan, en by zyn Majelteit zoodaniin gen grooten forme gelds is nangenco 5) men, zocken te excufeeren, des neer, 3, dienen ieder een duifend tayil, ook " nict meerder, zo wy verftain, op lev veramic van Zyưe, ter hand ftellen.

3) Ten dienft en voordecl van de Comin pagnie, mitsgaders Ul, verfeckering, " en caprering van gumt werd onsalhier 3, aungenanden ter eerfter aankomen, en 3) des manten Konings Capado's of Mun3, daryns, mer een prefentje te gasu ver"folken, dat onder zyne belcherning " en fauveguarde mogen ftaan, en zyn "faveur over UI, bewyzen wil, alhoe3j wel een van de voornaanifte Capado's " of Meefters wan de Cavallerye geor" donneerd werd over de Vreemdelingen " en baare goederen, voor brand, die" ven, als ander ongeval, mitsgaders " van wrooning on te logicren, goede 9) zorg te drasgen, ten wase ' $t$ zelve ,3 nię zoo brand-wry, als wel tot terfee") kerring van de Compagnies middelen "s en goederen werd vereichethe, daar op 3, zal dienen gelet te werden; in wel\#, ken gevalle een ander en zoodanig, ", als begeerd, verfoeken moogt, dae "wel het fecuarfe en mint den 1635 2, brind onderworpen, in de Carm"po, ontrenc cen lalve kartouw. fehoot * nata de Rivier in de ftad gelegen zou "wejen. Nevens dele werd mede go*s oordectd een en wan de bequanmite 3) woonirigen, wan zekcre Vrouw, Ba"foms genama, dic voel by de groo". $4 c h$, ook by den Koning zelf, gefien $n$ is, cn wry war vermag, war door by ") wylen beter acces tot de grooten, als " metic Comps. voordeel zou te wisnea 3) xyn; doch willen Ul. noch ana de ech m of de andere binden, matr op U1. be," vinding, wat beft dient gedan, en 3. watr voor brond, als verthald is, very. zekerd zult zyn.

"Gefecureerd en uwe mode gebrachte , gocderen gebergt zynde, zalsr. Hin". Phat met den eeriten audientie voor den 3) Koning te mogen beleomen, ea dele ") onfo nevensgaande miffive athier in een "tant, by Tonkinders, Quinammers, "Japanders en Chinecion lecsbar, mer " de bygevocgde fehenkigic over te le3. veren, mitsgaders perloonelyle me " hem te mogen precken, verzocken, , en zyn Majefteir re verllann geven, , hoe een Natic en Ingeferen vath den 3) Prinee vatn Holland zye, tratiqueeren, en den handel in verichide Konirik,. ryken in defe Oricntallehelandendry "vende, en dicnvalgende hobbende wer"ftran, zyn Majefleit een ieder van de , vreemde Nacici intunce en rocgang , in zyn Ryk, mitsgaders Negorie is , werleenende, en onder wyn belcher3, ming nemende, dat dienvolgende uit ," "E Ryk van Japan, wan den geencin dis aldat de Negotic, wegens de Ne") derlandethe Narie is exercectende, en , de tyd wan ontrent de 30 jararen in 'E 3. woornocmde $\mathbf{k} y k$, in de heerlylheit "van Firando gerefidecrd, eri de Com3. mercic jartyx met onfeschepen, zoo " uit Holland, Jakarra, Sinn, "Tayou, an, als mdere quartienen gedreven "hebben, dazr by ootmocdeiyle verloc"kende zyn Majefteir nevens de nudere "wreemdelingen, den lrandel gelieve te " verlechert, en toe teflaan, mitsgaders "onder zyn fauwegarde protedic te ne, men, on ryoe goedertierciheit on fn3. vour over ons ichytren laten, als andere "redenen cot woordel wan de generale "Compagnie en uwer bezendinge dienende.

,Gelyk aldar door vricudenzou mo* , gen aungernaden werden, waar toe, y, als zynde liet principalite en appa"renlte inftrument tot dele onve wootyexhalde redenen wan faveur' en bos) foher: 


\section{$\mathrm{VAN} T$}

$\mathrm{O}$

1677,3 . Fherming zou noodig weeten, enots 3 alluer angertaden werd, dac woorn. "Kand Horjinh den Koning tor zyn Va"ser en voorltander, zoo her dan zon 9. Jonnen gefchieden, "twelk, in loco s wefende, gevoeglyler zult werlasu, y 200 weifocken, gelyk by onle nevens") Gande mintive zyn doende, zulks de " Japaniche Kitpiteinen van de Jonken, " rot verlechering haser perfoonen, "volk, en gocderen altyd eenige der " principatife of natafte Mandaryns van 2 den Koring te doen plegen, en door y dac middel, niectegenflande voor een " perfidieufe en lehelmachrige Natic 1, werden gercpulcerd, en ook zy? al s, tyd in hanren angedanncin overlaft en , anteche wan gemeene Tonkinders ges hardhovend, envoorgettanzyo. In : "t doen val de audientie en mondelins. go antprak net den Koning zal diej, nco noodig verfocht des Majeltcis pass 2, en zyn VJag tor verfekering onfes , Vartuigs met die verklating, datal4) le janen (zyn Majelteit gelicpende ¿2 zulx toe te haten) van meeniog en ") gerefolvecrd zyti aldar te landelen, 3, en trafiqueren tomen, dit tecken of 2, gezegdo Vlag werdende opgeheren, , en, Waar "took is, gefien, werd dar * yoor by de Tonkinders, met driet, mal op de kniecen te vallen, ide han" den boven 't hoofí, ea het annge. , ficht tegens de starde, ceremonie en b. reverente gedan.

„Het zou wei konneih gebeurev, dat 5) Ji gedanac audicntic, verfocken noch " cenige geruimentyd, eerdes Konings 2. licentie van te mogen in , en verkoo"pen bequatan, en luct bord public "asingedigen wierd, alfoo zulx ten cy" de der Japanders, die ecrit in 'e latafte " van May gewoon waren bowen te ko, men, op den $f$ a 6 July te geichieden 27. phgt, wolker volgende 8 i 10 minn der of unecrder dagen, na fich dezat 3) aldaar vertoond, en gebakend flatat, 1. ftil hebbende gezeren, en puincipanl 3. noch eenige van de winter.Zyde en 3 ltofien onder de man te knopen zyn.x de, en by onfe Vyanden de Portugec" ren werdende den handel geexcercecrd , en de goederes ingetsogr, zal by alle 3. mogelyke middelen, dic Ul. dar nié 3, zullen ontbreeken, en wy hier niet 5. ramen konnen, "E $z y$ door" hulp des w. naaften Rats wata den Koning, of i, Vrouwe, hier vorea angelanald, trach" ten mede van den handel te moger? b gatudecren, en onfe Vyanden, als an"dere, daar in to verkloeken; onderj2 tuliclien altyd natum reguard on ken-

\section{N $\mathrm{K}$ I N.}

3. nis nemende, wat in de Negotie om" gate, en tot war juys de ruwe Zydo "by de Portugereron ingeloge, en wer. " ders by hen gebeloignerd werd.

" Hee bord of tectien van wrye Nego, tic angefagen, cn dar toe conient "verlirgen wefende, zal alle uirerite s devoir ch nareftigheir tangewend moe, ten werden, zoo weel rauwe Zyde en „3. Scuk-goederen van goede afgeloden ,Zyde en wel geweren, mitsgaders zo"danige lengte en brecdie, als de ne3 vensgande houten en nndere matem 3. Ut, rer hand gefteld, in re kooper, 3. op dat de generale Compagnie dnat , wan de rechic cn gewenchte profyten " genjeten mag; doch de mindere lenge , te dantom met dienen verworpen. " maar gelyk de Japantche Negotianten, ,200 aldan als in Quinam te doen ple"gen, pro rato reberalen, zulx necit: "by het gewiche of zwatrte mede ge, Fchied, wara na dan, als volgl, inge, kogt werden, te wetcen:

3) Hockings, wegende Tayil $10 \mathrm{cn}$ क I I tot 5 en 6 Mias.

"Chio, wegende 'Thyil \&, 9 cn ro, , tot 8 , 2 , cn Io Mais.

3. Troumongy, wegende Tayil zo nin " of meer, tot 15 en 16 Mitas.

s Bhas, wegende 38 a 40 Tayil, tot ". 16,17 en 20 Mans.

13 Pelings, wegende 'Tayll I 1 ea Iz; b) tot 15,16 en 17 Mans.

"Wy hopen en vertrouwen, terwyl * geen Natien met groote capiralen ver"Ichynen, de rouwe Zyde op cen lagge \# prys, dat God geve, ten dienfte van , onfe Hecren en Meefters vinden zult, ") dat 30 of ten minften 2 r Fichary " gewichte wan de fynfte Zydo tegens 3) een gowiche gelds $\mathrm{cn}$ de ftoffen na "y advenant, die genvecnelyk in koup van 39 de rouwe Zyde volgen, en nutry yern leocht werden.

"Orn, zoo weel mogelyk is, de Portt" geefen in defen Zycte-handel te fturcen, "zinl 'e noodig zyn; dat alle middelen n. darr toc angrewend wienden, "t zy dan 3. de Zjde mer wat hooger te betalen, 3, en dac op planten, dar men weet dae: "2 de Portugeclen de hare gcwoon zyn $\rightarrow$ te koopen, of gecontrabeerd hebben: , want de Toukioders geen werk mua"ken, al hebben zy de Zyde tot zelie, re prys verkoge, en, exr dis leveren, " een ander konende, die meerder , bted, de relve te laten volgen, en de "2 meete penningen te neerners. gelyk 7. eenige Nederlanders voor dezcra geby fried is.

, Ook zyn ia de Atad Tonkin 4 a 5

\section{$6 y$}

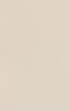

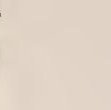


1637, perfoonen wan redelyke middelen, met 3) natmen Kin Angifon, Angery, Aigock 3) en Onwaby, wien de rouwe Zyde als 3. Atofien te landwards by kleene party, kens werden opgelogr, en in meerin der quantiteit ann de Japanfche Koop3) lieden wedet verkogt, zoodele lieden "nu met de Portugecter, vermits'tach37 cerblywen dier Natic mochten in han3) deling en contract getreden welen, zal "' zetue op 't gevoegelyh dienen ge3) weerd, al waar'c de merler, gelyk hier 3, vooren angeroesd is, wat doen ry"Fen, en de Portugeeien door dien, als " wudere middelen (zoo veel nochtatss "zonder prefudicie van de Compagnic) 3, als mogelyk, en 'c weinige datr op 9, profitecren zullen, mitsgaders de ri3ico ter Zec, dic wan wale Scheepen "loopen, dien handel meter ryd ge" noodzatke ryn zullen te ftakcm, ge3) Jyk ons hier na apparentie te gefchie3) den, geafirmeerd werd.

, Zoo Ul. quam te merken, of wel i) vaftelyle te verftian; dac de Portugce3) fen zelf, of door hare Paxpen, die aldare eenige grooten cn bunne kinde3) ren rot Rooniche Chriftenen hebben j) gemalkt, ons zochten roor de Maje3) Iteit te denigreien, odicus en ran ons 3. afkeerig te masken, zal zulx monde"ling met werfeheide goede redenen, " die nier manquecren, en ter dier ma". terie dienen zouden, by gelegenheit 3. aan de Majefteit zelfs en andere groo2. ten, of wel door onfe verkreegene "Vrienden aldari, , zoo reel mogelyk 3, is, wederlegt diẹnen, man in tegen" decl zoo zulx mocht geraden vituden, 2. en wefen, zoo reel docnlyk is, wat 3, onfe zyde gevorderd.

, Het zou odk wel konnen gebeuren, b) dat de Portugeten, nevens Ul. weiren" de kian en vaurdig on te wertrekken, , en 'e jache de Waterloofe W erve, als "Wier yooren anngeroerd, om op de "zelve te krtiften, haddetafgevandigt, "of wel voor de fiad Tonkinbehouden, " dat door toedoen rán gemelde Pappen, , of de grooten, Roomiche Chriftenen "zynde, UI. wan den Koning werdege3) ordontieerd, noch cenigen tyd tebiy"ven, in welken gevalle zal Sr. Hartink ") trachten by alle bedenkelyke midde3en "t zelve voor te komen; des neen, 31 en de Compagnie in "c vorderen harer i, Voyagie merkclyke prejuditic zou i, toegebractit werden, volgens ons en y des Rads dar over getrokkene refo") lutic, op 19 Attari vool dien tyd, "t क $2 y$ mondeling of fohrifuclyt mogen "belooven haar nier te zullen befchad:-
3. gen, war wan 't Jacht zal dienen ge9) stwerteend te werden.

\% Verítheide Europifche Wareng als 3) mede Nagelen, Romipen, cin anders, "W werden lot een preuve mede gelot: ", den, om th Tonkin bekend te mate"ken, en te ondervinden, wat in het , tockomende met de werticring deffelfs, ". ten dienfte wan de Hecren Mnjores al ", konnen werden gevorderd, want op "Ul, dan ernftely le hebben te lecten, ch " daar yan pertinente nontic te nemsen, "or in 't andtande ons dast na cemo, gen regalecren.

3. De mede pelonclite compramen "2ult in fyn Tonkins Zilver moeten , doen fwelten en rafiuecren, en dar op "zoodanigen allog, als in de negetie 9 en opkoop wan Zyde, als andere goe" deren, zou mogen valeeren, 't welk 3) ordinar tergen tayil $8_{3}$ fyn Zilver, , 100 tayil ichuygeld getrocqueerd 3) werd, of ecuige maafen min of mecr, "Th beloop wan cyden, welendeden ot"dinarillen ten rechten wificl.

"Het zou wel konnen gebcuren, de " negotie gedreven, en alles tot "I ver2, trek gevardigd wefende, dat, eet des "Komings Zyde werd geleverd, cnont"fingen, noch cenigen tyd zoude ver 1) fyeen, en aldar tandecren moeren; 5 om 't welts re waklereng voor defen "gebruikelyls is geweelt, dac door ds 3. Vrouwen (dic UL Foor de Majefteie als. "Tolk zulien dienen, als darr is de prin3) ciparilte, ince mame Owy ra, vonde"Fen gewelene byfic van den Koning, 2) meboren wan Corea) alloode andprail " door mannen niet verd gedan, san ") cenige aangenaamite wyven des $\mathrm{K}$ o* 4) nings de valear wan ontent 20,25 , a is 3o tayil in flaff-Zilver verecren cher, 3. of die gene, die de Zyde te leveren 9) gewoon zyn, gelylk mede in die ge"Iegentheit met zya Zoon, en nasiten ,2 Rad, of grootlte Capado, ant wien " geld zou mogen ter hand geiteld hel"ben, dienen te gefichieden; doch tot , cen befluit blywe Sr. Hartink in dele, 5, als andere gelegenheic, dar by lelee"nigheden wat zal dienen gegeven, en ", nice kan geexcufeerd werden, gere3, commandeerd, ten profytelylitte van ") de Compagraie en achtbrarlheicder Nej , derlandfelse Natie te handelen.

y, De Koning van Tonkin U1. om , cen Conltapel, en Bofehfehicters, alo "werdere Ammunitie van Oorlog quan ", te vergen, (gelyk voor delen de Por"tugeefen en Jipanders gelehiet is) tot. " den Oorlog tegen die van Coersjuen") tsjing, to zelve met alle belecfatheir $n$ zult 


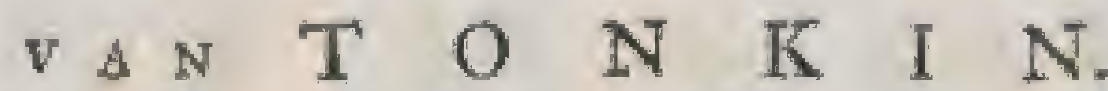

4637. "zult tmehtien te exculeeren, dat zelf บ บพ w'olk en verdere defenfie van her "Seluip en goed voor uw $V$ yanden noo" dig zyn, en dienvolgende tot zulx " geen ordre hebbende over u te nemen " onvermogend zyt; docls anneemende 3 " uwe principalen te kennen te geven, " en dalár van ordre te verwachten; on"dereufichen feherpelyk verneemen wat " gunft, profyten, en beneficie de Com"pignie in 't annitaande, met de Ton" livinders tegen de Quinammers te affi" flecren, zou mogen genieren, op dar den " Ed Heer Generaal hier af prompread. " vys mag werden gegeven, waar toe "by wylen zou dienen konnen, hee " ongelyk dat met weerhouden van ons " geld gefchied, en andere goederen uit "het verongelulist Schip Grootenbroek, "'en 't Jachi de Kemphaxn, van den " Quinamfen Koning ons werd aangc"daan, wan gelyken dier Natic perfidie " en trouwloosheic en ten Oarlog niet "kloekmoedig, zulke, als andere, re" åenen, dic altyd by de Tonkinders te " hooren aungenanm zyn, ecluter dic als " "t geene tot onfer V yanden nadecl zou " moger in 't werk geiteld werden, zo-

"danigg te menageeren, dat de Compa"gnie dant by geen verhindering toe" gebrache werde

Voor en al eer tot Ul. vertrek na "beneden alles zal wefen geprepareerd, "' en daar toe met beleefde verfoeken by " de Majelteit zult licentie hebben be" komer, zal ecn expreffebode, die uir " "t Hof werd gerecommandecrd, over "Land na beneden aan de Overhoofden "van Grol werden gelonden, en van n uwe komft advertentic doen, met or" dre ' $t$ Schip, zoo het in de Rivier van

" Giang zal welen geankerd, onder "t

"Eilandje Frachachy gereed en flagvarar-

" dig houden leggen, en zal mede noo-

" dig zyn, St. Hartfint andermaal by

" den Gouverneur in Giang fich tran-

"Sportere, om defehenkagie, zoo weel

" doenlyk is, te excuferen; maar zoo

" lets noch van de Zyde en Caneel van

" voorn. Heer te ontfangen ittond, door

" den Tolk en een der afiftenten inwor"

"' deren laten.

"De Japander Strit, of wel cen an-

" der uir Quinam, Ui, werdende toe-

" gevoegd, zult den zelven met't Jache

" de Waterloole Werve na Tayouan,

" of de Pilcadors fenden, gelyk medede

" 8 a to Soldanten, dic Ul. vandeHeer

" Gouverneur in Tayouan ftan te ver-

" foeken, en zyn Ed. daar ook ovcr

" Schrywende zyin, doch met manquement wankleen Vartuig zult met Grol
" voorn. plars, en ten voriget fine, $16 ; 7$

"moeren andoen, wall gelylecn nier wol-

"Laden zynde, uw verdere latt te pro-

" curceren, daar ter contrarie wolladen "zyode, gelyk hopen, de reilewir Ton-

" kin ua Japan, on verfeheide redenen,

" direct zule performeeren, en van uw

" wedervarien door gemelde Waterloo-

"fe Worve an de Ed. Hoer Yoban wan

"der Burg percinent ndyys geven, ten

"warc op uw manwelen wan Toyonat werden.

" Geduurende dele Voyagie werd de

" Koopman Karn Hartifm getteld tot

"Hoofd en cerite Rads - perfoon des

" breeden en Scheeps-Raad, en zal de-

"felve by gelyke flemmen, wolgens de

" ordse van de Heeren Majores cendub.

" ble hebben, dnar ant zal volgen Picher

"Thewnifen, Schipper op 't Jacht de

"Waterloofe Werwe, de Onderkoop-

" man Pieter Nacbrglas, nitsgaders de

"Opperituumin wan gemeld Grol, en "al zulke perfoonen meer, als na gele" genheit des cyds en bevinding wan zat" ken zouden mogen noodig zyn.

"Houd alle goede ordre, en uw rolk " in goede difcipline, late in geenendec"Len toe, dat iemand by mache op de " ftrat in de Hoofditad van Tonkin, " of in de Rivier wa Giang, fich an " land begeeve, alfoo by die trouwlonte " en moordadige Narie van iemand te "vermoorden en om te brengen, op ho. " lileederen te genieten, menigmalen " andere vremdelingen gefchied is.

" Obferveerd, en adminiftrecrd be-

th hoorlyke Jultitic over de misdoendery " en overtreders, u verder na dengene-

"ranlen Artykel-brief der Hecren onfe Meefters, die de Scheepen gemeene" lyk zyn mede woerende, reguleerendic.

"Daar en boven zym en blyven Ut. * ten hooglten de goede melnagien, foo " in gaftos, als zulke fchenkagien, wits" gaders "c geene ten dienft wan de gene" nerale Compagnic, geduurende dele "berending is vereifchende, gerecom"mandeerd, en bevolen.

" "E Sclaip Grol is woorfien met pro= "vifie woor 60 koppen wan Rys, en A${ }^{3 *}$ zyn woor 8 maznden, en wan Wleefch, "Spek, en Arrk woor, manden. Lathe * de oude koft, of Nederlandifche pro"vifie ten beften menageeren, en tot "de Voyagie dienen, fchaftende ann 't "Volk, gelyk wy verftan in Tonkin, " zeer gocde koop te bekomen is, ver" fche fpyle, tweenal ter week, en
" van zyn Ed, anders geordonticerd nogt

"pe van buit, al was 't matr om de 
1637." dat jedelyk tot confervaric cu behou. tenis harer gelondheit.

"Tor mectder verkekering defer $\mathrm{u}=$

"Wer Comitatic en belendnong, "zoo on

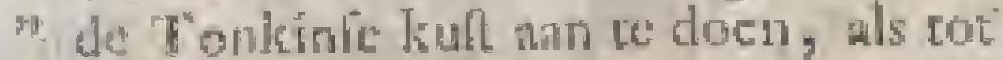

" behulp, en ecn belten dientt van de

${ }^{*}$ Campagnic in 't procumeren con wor"

" telgy hiarer Negurie in "koort. Ryk,

" en le meer 'c zelue memand van de u-

" wen voor delen heeft gefrequentecrd,

" en b"waten, is by Rande op den Io

* December parfado verftain en goed-

3* geronden Si. Vinctist Romens, wry

"Koopman in Nangalacki, op zyt ge-

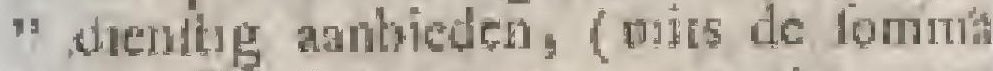

"var "Tayil s5oo cens, en nict meer

" voer zyn pariculier zal mogen aan-

" leggen, en mer "s Compagnies Schip

". weer ha Jepan voeren, ca dat onder "zoodanige relerve en limintic, als

"synde io diend van genclde Compa-

" enic verbondeçn, mede derwarts te

" Jinten vertreliten. Wellicn volgers

"ST. Hartjhe truer getnelden St. Fincess

* Romon, die Lwee Voyages derwarts
" hete gedian, alryd goede correfpon"dencic houder, fin voorvallende $z$ an

" ken 2yir advys hooren, en alles ten

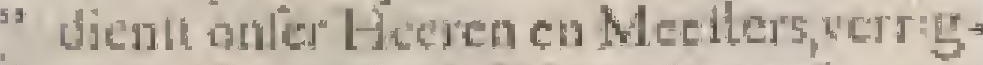
"isn zal; ondertuffchen Jertende, en "Wel in ache iscrinende, geen meer ats " de gezegue 2500 "1"uylen by woorn. Roweyw, en dar al mede net in debe"fte en courante waaren werden be"lteed, en arngelegt, gelyls mede nille " particulicre bundeling, 7 , 0 vecl tho" gelyk, volgens de Artykel-brief te weren, tot alle welle uwes verriches

"in ielen als verders onter algeneerien - Vyands af breule den Almogenden God "synen mildryken zegen, en behouden "reize in "I guth on komen gelieve te "w verlecten.

In 'I Conspoly Fined

defen 49 7nandw Ao:

46,77

NICOLAAS KOEREBAREER.

\section{TWEEDE HOOFDSTUK.}

$\mathrm{H}^{\mathrm{s}}$

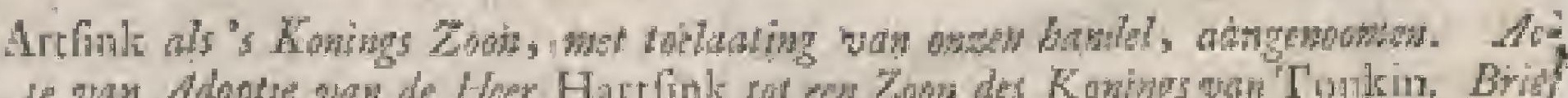

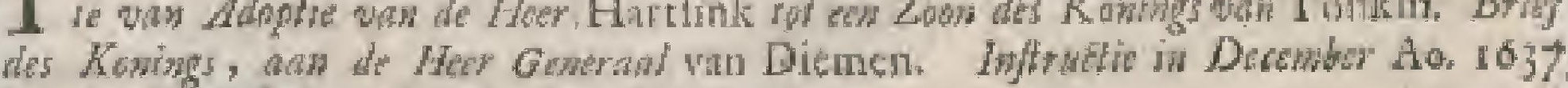
de Her Hartink m Tonkin mede gegenen.

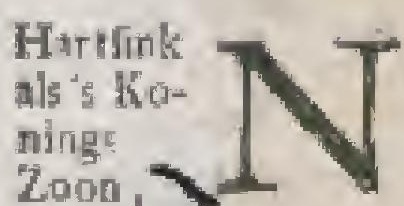

ning

2000

liming.

wan on-

fẹthan-

handelen miar liy wierd van den $\mathrm{Ko}$

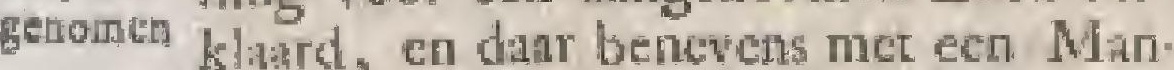
dayns kleed, cen Konings Vlag, met eenige Eertitels, con Paficdel, en cen fohifelyke acte ran dit zy Zoomehap belichonken.

De Acte wnit deselfs maneming tot ect Zown des Konings, witt men hier by No. 3., mieguders een Brief ant den Hect Gouwerneur Genernal wan Diomen diar over gefelueever, er No. 4 gemetkt.

No. 3 .

Ale was Alopite, wat by de

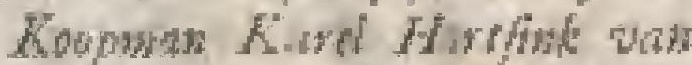

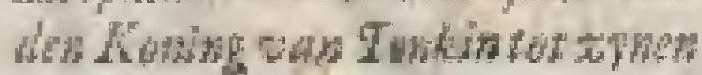

677.

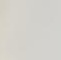

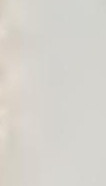




\section{$V_{\Lambda}$ N $T O N$ K I N.}

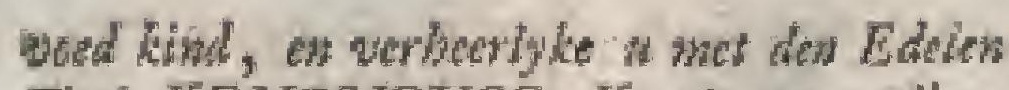
Titel KENTSIOUCO Karel; ow weikers bechlyen nams will wyne ergierigbeit ywefor zal at alyd to beninues, 't welk in 't winge nit zill failferen. Darren dit bo. penge/z. aldhs gc/told is.

$$
\begin{aligned}
& 3^{\text {de Jar, }} 4^{\text {dis }} \text { Mano Onderfow } \\
& 1 \sigma^{\text {te }} \text { dig. }
\end{aligned}
$$

Het Zegel des Kothings,

$\$ 637$

Tram/aat Mifive van den $R$ owing van Tonkin, and de Her Generdal Anconi van Diemen.

tiriet da " $\mathrm{K}$ Koning van Aynam, Syto, KocTonings, I kuffery, Boinceijwo, feliryve met aan den " alle hoogwardigheit ani den HollandHeerGe-" "chen Koning Seffche Quan Kichio, Fan Die- , defen Brief, on de gelegenheit wan men, "rand land te vertoonen, dat hier de , goede ordontantien Icherpelyk wer, den onderhouden, wy voorfigtig, en 3) kloek in Oorlog, en natuw op onfe ") hoede syn, wàt door alle myne on* ,1 derdaanen, zoo de Heeren, en Ede, len, als gemeene lieden, Landbou3) wers en Slaven, wel gebooren zyn, ," om welke ootfalk het Koninklyk Lid 3) vau den beginne tot heden op "trech, te geflacht, zonder van iemand Fer, hindend te werden, gefucedeerd is; "3 als mede, dat de Koningen van onze

") landen myn land in warde bouden, en 3. genegen $z y n$, om met my in wriend"I lehap te komen, en teblywen, behal. "ven de Hollanders, warr van nognoic , ecnig Vaartug hier verchecnen is.

, Ik hebbe voor delen van de Hollan, ders wel gehoord, en gewenfeht me"de met bat in kennis, en gemeen3, fchap, te geraken, "t well juilt, tot "myn groote blydichap, thet de komit , van ecn Schip uit dat wardig Land 3) defen jare woor de eerftéreile gefchied ,2 is; waar doot gefien, en bevonden 9) hebbe, dat de luiden van uw hand wys, " en klockmoedig ror den Oorlog zya.

,Ook hebbevernoomen, datzy koni, ftig fchieten kontren, warom ilk té 3) meer genegen ben met $u$ in alliantie, 3) en gemeenlchap te komen, want al "zulke lieden van my zeer bemind, ge5) relpeotecr, en wel getractecrd wer3. den. Ingevalle mynen wenteh vol, btagt werd, en ik met u in alliantic ") komen mag, zullen wy als bloed"wrienden malkaderen in liefde en eere III. DEEL.
3) houden, 't welk ftrekkein zal totwel 2637 . " vatre van beide de landen; wat doot 3) de zelve duifenden jatren wel gegou"s verneerä zullen werden.

"Zyn myne onderdannen zoo fterk, 5) en furieufe Soldaten, en "t getal dens , Ammunicic wan Oorlog, zonder iets , te ontbrecken, in zoo'n groote abun"dantie in myn land, zoo is het dan im", mers wonder, en niet wel geloofelyk, " dat ik ww Land wolk tot myn bulp s verzocken wily dog de redenen, en "s oorfaak van dien, mirsguders alle de " gelegenheid van myn geheel Land, zal , It in "t breede verhaleo. ik hebbe?

$$
\text { 3) } 300000 \text { witgelefene Soldaatert: }
$$

,2000 groote Olifanten.

3) 10000 Parden tot den Oorlogge, oeffend.

3) roop Oorlogs-Galeyen.

"Soooo zwate Rocrs, die men op i) rivden, zoo wel te land, n) als op Galeyen gebrui, ken kan.

3) 30000 Rocrs, met roode werlakte , Janden, en lange kol$\Rightarrow$ ven, die 30 kogels tefin fenss fchicten.

i) 20000 Roers, met zwarte werlak3. telanden, en korte kol2. ven, die 70 kogels tetb) Eens chicten.

25 tooo Metale Atuken Geichut.

3) Met alle welke woor $\sqrt{z}$ middelen ike v myn land met goede ondonnantien over 5) lang en dwas ma myn behagen gou3) verneere.

"Myn Land Tonkin legt in 't mid , den, en daas komen de Koningen en "Hecren van "c Ooften, van 't Wef', ten, en wan 's Noorden, and my re3) verentie doen, behalwen in 'c Zuiden, " datar is cen Land-volk, dicns leven en 3. ommegang dood is, en alle goede en h gepreiene disgen reche verkeerd doen, "Har gemoed is vol arghttigheic, des zy " ide beeften der aarde gelyk zyn. Zy 3. verhaten, en troolten hatr op onge3. bruikelyhe wegen, en gehoorliamen " my rice.

"Zoo it die net Galeyen ower Zee ") beoorloogen wil, dan is my den weg 3) derwarts te verre, en de baren ic "hoog, den wind, en règen contraric; "des ik zulks door dit middel nier by, brengen kan, war door defe boos3, wigten nog hartnekJiger', en na han, ren verkecrden wil leven, eu doen; ;) wat has wel gevalt.

"Dic zyn dan de redenen, warom it 
1637. 7, de Hollanders tot mya hulp te verfoc;, ken, voorgenaomen hebbe. In ge3. valle u Majefteir danr toe werftam wil, , zoo zal ik myn Land voor ceuwiglyk 2, aลn uw Land verbinden.

" Gelieft my dan 3 Scheepen, en 200 " uirgelefene mannen, dic wel mer Ge". Tehut weten ons te gaan, tor hulpe te "2, lecveren, en in Tonkin te laten toc" komen. Ik zal myn bloedverwanten, " en naafte Edele Soldaaten, met fó "Galcyen, dar nevens ordonnectern, " om dere luiden te warer te bcoorlogen. "Als dan zal ik ools regt op die tyd met " alle myne magt over Land aldaar aan"komen, om zoo gelykerthand van bei" de zyden de platts Quinam te betrec$"$ den, cri te yerniclen.

,Zy-lieden fiende, dat de Landen 3. van Tonkin, en de Hollanders haar " gelamentlylk op "t lyf willen komen, ", zullen zig, zonder cenige tegenwoer ") te bieden, uit groote felirik wan zelfs " confumeeren, en verloopen. UMn3) jefteit zal fien, dat dit werk zoo kort, ", als in eens om te fien, verrigt zyn zal. "Ingevalle u Majefteir daar toe refolw. veeren wil, zal ik de weldaad grooter "achten, als alle bergen, grondelyleer ", als de Zec, en dic in ecuwigheit nim" mermeer vergeeten. Alle onlkoften ", van Vietualic, als anderfins, die daar " toe geguaftecrd werden, wil ik libe"rial beralen, tot 2 a 300000 R yxd. roe: , want als wat dant in werd gelpendect, is en werloren gaat; my gaurch trict en " verweeld.

"Dare en boven zal ifk u dat Land, met alle de zietert, die dane in woo3. nen, en danr ovider forteeren, fchen"ken, mirsgaders alle inkoomen, en " vrugten, die dat Land opbrenge, ;o zullen uwen wille onderdaanig zyn. "Uw volk zal aldaar blywen woonen, "E en hant fortificeeren, en ontfangen, "7, 't geen 't land opbrengt: want ik het "u gegeven heb tot dankbaarheit van u 3) Majeiteits halpe.

9. Dat uit myne eergieriheit doe, be3) loove, en volbrengen, en daas' (dat 3) verfeckere ik) niet een thair ann ver3. fchillen, nog ontbreeken zal.

"Dit is de grond wan myne meening, "geliefr u Majeftit daat toe te bewilli"I gen, innerlyk werlange ik, om zulx "2, te veritann, en wenlche haaftelyk ant"woord daar op te hooren. Dar bidde "3 ik andermal, "t geene ik gelegt heb, "zal niet faljecren. Dit myyn doen, en b) voorflag zou konnen gehouden en ge" nomen werden, zoo als myth vitge"S Eroolene woorden miet itandvaltig,

" mat plumitrykers wyle gefegt wa* 1637 9, ren, dat ik mee andere Landen wers, ectigd was, cn geconpitecerd had de э) Holianders alfoo bedricgelyle re ver" nielen, en have ammunatic van Oor , log zoo t'mywartis te nectien. In* gevalle dat zoo, en myne meening , als voorla, niet optegt en zuiver is, "zoo moet my de groote Godt Anf9) Fen. De overvloedigheic van defe my 3, ne meening en kas niles met de pen" ne niet uitdrukken. Maar den Gode , is myn getuige, dat ik in defen Brief , opregtelyk aan u Majefteir geichreven , hebbc:

, Ik verecre d Majefteic 20 ftuls wit") te bicede Holjens.

$3^{\text {de }} \mathrm{Garr}, 5^{\text {ate }}$ Madn, $8^{\text {fet }} \mathrm{Dag}$.

In het lantite wan 'E jar I 637 werdde Heer Harifsk wer hier na toe, met het Schip Sandwoord over Tayouan en uit Japan, gelonden; en de Heer Kockebak. ker gat hem roen weder cen nieuwe Inftructie mede.

Inthate wou don Kopman Karel Hawlink, en den

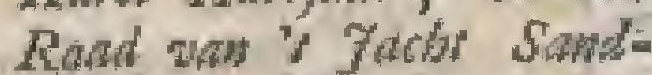
vord, wertrelkende van bier over Tayouan me Tonkin, tot werwalgdes bandels in gemeld Ryk.

"T Efen andtanden morgenftond, Infruca " 13 zoo Gods weer en wind het toe- tie inDe"Lac, mitsgaders de monftering van "t cemb. A: "Volk, en de wifice wan "c Jacht by de Heer 1. Jupariche Bongiois of Regenter ge- Hartfink dann zynde, zult onder zeyl gan, en fie Ton" in de nanm des Hecren uw cours ttel- gegeven? " len beweften Menxima na de Kuft wan

"China, tragende de Eilanden wan On"couw, of Stormbacy, gelegen op de "hoogte van 25 graden, ana boord te " krygen, en behoorlyk verkend weras"Ken.

"Welke Eilanden, of voom. Kult; " verkend zynde, zulc van danr, by moy " weder, na de Kuft Fomofa overitee"ken, on benoorden Gylen, of on" trene de Zand-duynen ie mogen ver"vallen, in 'c overitecken altyd gifling "s en caleulate makende twee wloeden "voor cen cbbe; dogbyaldien hard we" der of ftorm quam te beloopen, werd Ul.

" ten hoogften gerecommandeerd, fich

" nier wan de kuit van China af te bege" ven, maar onder den hock van Sabouw, " Engeling of eenige andere bequame "Bicjen, en Anker te loopen, en al- 
$\forall \rightarrow$ N $T$ O

$1637 . "$ datr goed wer watr te necmen. In "1 "t ahdoen var dico kuft, ofter Rhee" de loopende, werd U. ien hoogiten " gerecommandeerd, wel op uw hoede, 4, fingvardig, en op 't geeneroor Bran"ders noodig is, verduche te zyn, op * dat $v$ a Roowers, of andere trouw. " looté Chineefen, geen ander ongeval " onverwagt rocgebragi werde.

". De kult van Formola an boord kry"gende, zult de zelve niet mader als op " I2 vademen axugieren, als mede niet " " verder als op zo vademen rev Zee loo"pen, allyd goede zorg dragende zoo "by dagen als by nagt, "t lood niet ge" Ppand, matr gettadig gebruilit wer"de, alloo dir by dinilerendeylig wee" der, dat men in dezen tyd des jairs al-

" date continued ontmoetende is, uw wen " eerigen wegwyler weren moec.

"Wacordes offernen, byden Gou.

" netir in Tyyouan yoor de Schepen wan

" Datrivia, als in 't Noorder Mouftón

" var Japran komende, ten dienft varide

" generaale Conjpagnic zyn beramd,

"werd de copye pan dien nu mede ge-

"zeven, war an U. in "t andoen wan

" de Rluede wan Tnyoun geheelyls fich

"hebben re regulecen. Her vourby of

"misdryven werd UI. ten hoogften ge-

" recommandeerd; by welle tocwal of

* voorby geraken (dac Godt werhoede)

" zult nier rrecsagtig, of befchroomd

"F wefien agter den hoogen hoek wan $T_{i 2}$

" youar ten Anker te loopen, wan war

" mer goed weder in twee geryen opla-

"veeren, en ander 't Noorder Rif na

"wenfel ter Rheede komen konde.

" Ter Rhecde voor Tayouan wefende

"amgeland, "zal door Sr. Harthink defe

* onleneren:gaande miffive, mer dever-

" dere bygevoegde papieren aan de Ed.

"Hect Gounerneur Joban wan der Surg,

" zonder enig verlet van tyd, werden

s, behandigt, op dat gemelde zyn Ed.

" niee alleen her gebefoigneerde allier in

" de Negotie, zulx Ul, volgens de ge-

" houdene difcourfen, volkomen ken.

" nclyk is, matr nok het voorgevillene

" in 'Tonlin, behoorlyke onderichting

" en mondelinge communicatic mag wer"-

" den gedar, en zal. UE. an gemelde

"Hecr Gouverneur verfouken, goede " parcye goud wefende in voorraad, en

" "r selwe zonder vermindering vañ des

" Ed. Heers Gouverneun" Gener'aals eilch,

" en veragkering ran den Perfichen, Su-

" ratlen, en Choromandelichen hindel,

" konnen werden afgettecken, dat mer

" de valido van ontrent defe 8 a 10 , al

"was ther tot I 2000 taylen, om alfoo

" cen gedcelte yan mede genomen con-
N $\mathrm{K} I \mathrm{~N}$.

" tanten capiral ce gevoeglyker konneñ 1637

Iluiken, en des Konings, Princen, als andere principalfte Hecren afperfing der contanten te mogen ontgan, mat " $\mathrm{c}$ principarifte tot procure en beloo: "ming yan grooter partye fyner en bo"ter Zyde, mitsgaders civicler pryle, "als wan woon. Koning, en anderes Heerer mogte geriete, en geaccoms modeerd werden.

"By miflive van daro 57 Augufly "fado, advitecre voun. Hecr Gouverneur vall vootnenen en refolutic te wefien, de Jachoen Klecu Breedamme, en Waterloofe Werve, in de manden var Mast, April, en May, cuflichen 't Eilant Ayram, en devalte "Icult van Clina, op onfes algemeenen "Vyands Varruig, de Portwgecfen, om har Zyde rerouren te mogen in bekomen, te Laten krtiflen ; dog conitra ftant te beduchece, ja valtelyh "af te meter, zyn gemelde Ed. (zyndo on scheeps-ruim totoverwotr der $V_{\text {st }}$ derlandle Cargafoenen ma Bativia, verunits het Ipade vertele der Scheeper uit Japan ceu hooglten verkegen en benoodigt geweeft) dezelve, nevensan"dere, ten the ills wooren, mede zal " hebben verfonden.

" Zulles dan zyade, zal UI. wan zyn "Ed. verzocken, en in confiderntie ge* wen, gelyk wy over defe zale mede " zyn advilecrende, dat en Jonk, die "Ul. zoudt oondeclen in 't voarnoemde " varwater, 200 tot ontekting wan dien, als afbreuk wan onlen 1 yand re gebruiken, bequam re zyn, nevens 1" "t Jache Sandwoort derwaards mogt "werden gelurgecd, whir an wy nir ". twyfelen, alloo genelue zyn Ed. ten " vollen en genoegtian kenmelyk is, wat " de generale Comprgnics dat eonmal " 'c vantwer data ontrenc werd ontis dekt, en bequamerendevous-plantien "woorde kruiffende Jachten werden on" dervonden, "er hangelegen $z y$, te meet "de Tonkinic Koning, volgens UI. "gedane Rapporten rondely dech" reerd, dat in geencr maniere of wyle "zoude of wil toeftan, dat by iematud "zyn Rivicren, Harenen, en Rheede "werden gevioleerd, en onveilig ge" mankt,

"By uitecting van voorn. Jachten, of "wel eenige Jonker, ten fine hier voo" vet werhald, zullen ons in defen niet " onderwinden eenige ordic te geven, " slfoo ner gecin fondament (nier we" ende wat mache gemelde Heer Gou" verneur, volgens Tayouans confítu" tic, datr toc zou mogen goedwinden C 2

1) to 
te ptojectecren) konnen (ppteken; mat ' geheel ain zyn Ed. wysicn woorfich"tig beleid, cn "x geene dnar in zal ge" licken te difponceren, berolen laten, " dan alleculyk annoeren, en by root" vallende gelegentheden Ul, te rooom" matecren, dat het Poerl Eilind, ge-

" tegen 4 mylen benoorden ale veche Ri" vier wan Tonkita, ncwens andereplaat" fen mede behoorlyk werde onedelit.

Uwe zaken dan in Tayouan ver"richt, en depelche hebbende bekoo. " men, behoudens nochtans de nader or" dre van de Ed. Heer Gouverneur tut "der Burs, zult mee 'c Jache Sandvoort * van daar c'zeil gande, bezuiden de "Eilander van de Pifcadores, rechedoot " na de kuft wan China owerlteeken, om " eco weinig boven Pedre Branco te wer" wallen, "t zelve in 't gefiche te loo" "pen, en alfon des te walter en zeket"der cours buiten de Eilanden van San-

1. fuan, PocloTay, en Gon, rechedoor " na de Eilanden T'inhola, digt aan 't " groot Eilatrd Aynam gelegen, te mio" gen thellen, werdngt blyvende gemel" de Juaft te beminnen, en an boord te

"houden, op dat te gevoegelylice de

" bochr inraken, en zonder mecopltop"pen cenigentyd te verleren, hoogge"noeg op de "Tonkinle kuft zoude mo". Gen verwallen, tragtende poor eerit " onder een des Konings Eilanden, ge-

3) Jegen onder de Noorder breedte van

"19' graden, 45 minuten, by de Ji" panders 'c Roovers Eiland genamis, " datar. "t verleeden jane "c Jaehr Grol ge" havend heefe, ten Anker te loopen; " en van uv komet deming te doen.

$\checkmark$ "Van welk Eilund of Rheede, met " "E Jache nier etr na de Rivicr van Ton-

" kin terzeilen zule, voor en aleer door " een der hequamite Inlandiche, by " sebreeken of derwen wais 'c Hollands * Vaartuig, "E zy met dea Schipper of "Seuurman, die wel cenige van de fprui" ten verfcheidemalen uit eningevaa en

"heefe, de rechte Rivier behoerlyk "hebt doen onderfocken, en afdiepen; " 't welk wel zyode verriche, zult uwe

"reife met 't Jache na gemelde Rivier,

" en dat tegen het Spring, zoo meteen

" gemeen tyo geen water ten overwloe"dc wierd bevonden, gelylk wy van "te

" contrarie onderricht werden, vorde-

" ven. Doch werd U', in "t generrat

" ren hoogtten, en op "c ferieutte gelnft

" en gerecomminderd, goede toeficht

" en zorg, in "t binnen- otover den dor-

" pel loopen, te gebruilen, op dat de

* Compagnie by ongelegen weder of

m. wind, ea misteekrning wat 't getye

geen ongeval toesebring werde.

Of her gevial, dat by yerloop van

" tyd zoodanige diepte in de mond win de Riwier, alswelvereilich werd, niet " werd bevonden, zullen U!, 'E Jache", dan Grol gelegen hecfe, onder hat voorn. Roovers Lithid Arkeren latet, en Compagnies gooderen, door "th" lands Varruig mee de mectte verkes"ring, als de verlwcgene contanten op " "t gevoeglykfte, gelyk 't vooulceten " jaat gefohicd is; boven ma de ltad Ton"Nin voeren, ten ware nocheen Var"* tuig by de Heer Gouverbent in Tit " youn UJ. was bygevoegs, "c welk.by - zulken incerval wel zot re pas koner.

". en gronten dienfte de Compangnedoen; " blywende Sr. Hawhonk tea hooghtenge-

recommandeert de gelegde boven-rere

" op "t.alleripoedighte by de cen ofdean" dere occalie in 't werte te ftellen', en " te vorderen.

"Het Jacht dan moeterde buiten bly" " ven , werd UI. geordonneere 't zelve " tegen "e verchek der Portugeefen Vatar"tuig op re doen homen, en cen ltuk "2 weegs, of buiten 't gelich van Latid "voor de Ririer, dna" gewoonelyk met " hanr Vasruig buiten looptn, to hat "ten kruiffen, met Jult ain de Over"hoofden zoo lang té conemueren, tot "dat zelere advertentic uie de Hoofd" Atad wan Tonkin van harkieden weder onder ${ }^{2} \mathrm{t}$ Ravwers. Filand te vervolgen, "zolien hobben bekomen.

"Op uwe bowenkomet in de Hoofdw. ftad var Tonkin, zal de Koopman " Fartank (habblande al worens belorgt - en ordre gelteld to een goede en brind" vrye wooning, "te zy din in de Campo " onder huweguardesinden \pm Randshee " des Konings, dar "c voorlesuen jan gelogert zyc geweeft, of wel res hui" fe van zolker Mandaryn, aynde cen "van des Majelteits bloedverwanten, " woonchig op de Rivier, die op UI. " aftcheid toriegging en preluntacie heet "gedan wan cen huthig, boven-woo" ning, en onder een pilehuts op UI.

"Wederliomft gereed te maleen, en te " preparecren, "L welk wy roor die cenripo " (hocwel woor brand en diever dat " mede wel werzekerd zyr, en dat door " de ongerictylkheit, wermits van de Ri* vier is geleger, en Compagnies got" deren in'e loffen en weder atleheepen, " niec zonder rifico wan geftoolen te i) werden, loopen) zouden prefereeren, " en zoo dasir gocde conmoditeiten wa"s ren germake, to logerent By delén " ordonnetren; wat in delen belt dien" de gedaan, zal op U1. berinding moc- 


\section{A N $\mathrm{T}$}

16,77

, triachen doot een wan 's Konings eer3. Ate Rinalen audientie voor de Majefteit 2) te mogen obinecten, onfe miflive en *- Prelenten van gelyken ann den Prins y of jongen Koning, met behoorlyke "cerbieding overleveren; dat by in"1tantelyk verfocken, dit zyn Majefteir s. met den eerften getievo toe te ftuan, y. ell ordac te geven, van met cen ieder " der Ingeferenca wryelyk re nugen ne* gociecren, en den handel te drywen. "Zoo zal-U1. mede, "h geen by, hatr "Majefteiten is verloclat, geeilche, en 2 bu derwates werd verlonden, yol" gens de menorie, Ul. terhand gefteld, 1) doen orerhandigen, op datalzoo hatr 9. Hoogheden werdende contentemene

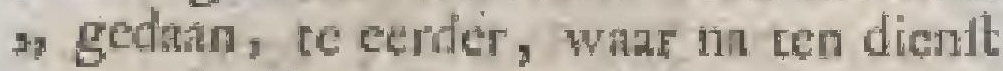
3) Van de Compagnic werd geafpireerd, $\Rightarrow$ en tot uw voorneemen genaaken s moogt.

„Wy cn twyfelen niet, of gemelde 3) Majefteit zal Ül, gelyk vóor delen, , volgens uwe rapporten menigmal "heeft voorgehouder, in 't geven en , verleenen Vin audientie, andermal 2 mondeling aftrigen, wat wy ande 3. Ed. Heer Gouperneur Generat con2 cerncerende, den Oorlog tegen die van "Quinatu helbben geadvileerd, cп wat 3. tons gevoulen daa af $2 y$, of de ver3) fochte affitentie wel zou mogen rols gen of niet, Sc. Defe zaak zal nier 2) Vorder, nls voor defen door U1. is gew. tichied, dicnen ontleedt; matr totons "aniwoord op zyn Majenteits mifive w gereferectu, ten watare by gelegenthe3 den fecretelyk nan zyn Hoogheic de3. clareeren, dat wy niet tww ffelen of " zyn Majefteit znl behoorlyk antwond "Will de Ed. Heer Genciatal, nopende ,2 zyn verfoek, ontangen; doch dicnt , mer zoodavige circumfpectie en voor"fichtigheir gehandeld, en dele zaak, yict ruchebaar gemake, dae Compa3) gnies relidentien en middelen in "t Ry Is "van Quinati, door fecrete correfpony dentien, die de Grooten van beide die -Hoven zyn houdende, geen ongeval, 5. of eenig gevam rocgebracht werde.

, Niec regen ltanade zyn Majefteic op "Ul. woordrigen, wan de Rorkggeren, onofe Vyanden, op zyne Rivieren, Rhee3. den en Havenen, vyandelyk an te "taften, te veroveren, en voor goe"den buit ant te fana, heeft doen ant3. woorden, dat in gecnerhnde manieprej zulx gedoogen en toeftate wilde, "wat in Zec gelchiede, alloo wyuden 3. warren, had liy fich nict an te trek" ken, \&c. zoo zullen Ul, by gelegen-

\section{N I I I N.}

, hedes, "t $z y$ den eerften Ryx rad, 1637 . ,y of wel ecnigeandere Miguons, en fa"milianen des Konings, doen fondee,3 ren en final ancwoond (of de violatie "s nier imet een filvere pleifter, of eenge3) declte des buits te cureren zou we, Jen, en mer oogluiking door de vin"geren gefien werden) zocken tebeko", men, al watr ' $E$, dat her een kleene , en ecrlyke recognitic zou koften, op " dac eenmat zekerlyk mogen te weret "komen, won na Ul., en is Compa3) gnies gande en komende Vantuigen " lich, deten takisende, zouden hebben "te regulecren. Zoo dan zyn Mrajefteit " to[ vorenwerbalde nier kan veritan, \#, noch dir in geenen declo wilde ge" doogen, zal echter hoognoodig zyn, ") (gelyk in onfe voorjarige Inltudue 3, onder anderes hebben angerocrdyalle "middelen tot krenking van hare ne" gocie by UL. werden gepmetifeerd en ", atagewend, op dar allenshensdatruir " mng gewortteld, en woor de Compa, grie dien handel univerfecl behouden , werden.

, Zoo zullen U1. mede by de Maje" iteir mer eerbiedigheit verloeken, dar "volgens zyne toctegging de drie $\mathrm{Ne}$ 5. derlanders van 't jonk, en I oncjouw ") by den Mandaryn in de Rivier van 3) Polin autgehouden, พan gelyken de "3elichte twee Yere Chincelche Go" telingen, 4 deenftukicen, demuiquets " en de verdere ammunitic van Oorlog. "Ul. weder werden geintrageerd, en , ter hand gefteld, duar by allegecten3) de, wat contentement by reititutie, 9. datr ter contratre onangenambeic by . ", weigering Vin den Ed Heer Gouver , neur Genemal gefchicdenzal, gclyk wy y' gemelde Koning zyn andeliryende.

"By gelegentheden zathpede de Ma"jefteit zelf, of ren minftenden ceriten 3, en principaliten Rasd des Ryles, die, ren angedien en klachtig gevallen, ", tọ woukoming wan overlait en outra"trage, hoe op 't uireritte uwes wer", treks nit Fonkin in "t affechecpen on"fer gocderen zekere Soldunten, on: "2 trent de 30 in geral, twree onfer Of"Ficieren van 'e Schip, in 't opkomen ") na do Canspo, met fakken en bam"boeten ter aurde hebben geflagen, en , zoodanig getroften, dit den eenen, , zynde de principalife van de quetrure , in 't hoofd, weing dagen dar nade, Fer wereld overleden is. Vorders nits "dan syn Majeltetes faweur, tegen alle , ongelyle en geweld der boole men, Fchen over Ul., conde verdere Nederian, ders verfoekende. Wi 
6677. "Wy willen boopen, of volgens des 3. Konings, als mede des Princen min" nelyke briewer, zoo nan den Ed. Heer 2. Gouverneur Generaal, als nan ons ge"z addrefeerd, als mede dat, of voor" s. Kounges Zoon, en opgeroed kind z.yt " aangenomen, misgaders met Eerite-

, Ien, en andere donatien war meerder " laberteiten begifige, zullen Ul. in "t 3. afperften wan de contanten voot de "Grooten, als mede in "c tluk war de 3. Negotie, niet zoodannig werden ge3. vexecrd, en llepende gehouders ge"lyk wy niec [wyffelen, mee 't Jacht 2. voor de Hoofditad wan Tonfín ko9. mende, of zult de voorgetteldeen wern hoopte foordecten (watarn 't zelve n, in de plants var een grooter Schip, tot क dele berenting be lugeeren is verftan, "Ul. ten vollen kenriclyk zynde) ton a) meeften dienft van de generale Cont 3. pagnie, ch ma Ul, cigen delier, erlan2) gen, en wolkonen genieten; dac de n goede Godt geve. Her contrarie 5. vitvallende, zoo blyfe Uh. een hoog 9. Iten gerecommandoert, de befnyding " iv liee cer hand dellen wan de contan"ten antw de Grooten, als mogelyle is, , en met dien vertande; dat bet geen " werachtering on dilay in de Negone, , of wel ecnige disgunt, enafkecr van 3, de onfen komt te biarcil, gelyle UI. 't * voorlecden jarr tot natecl war de Com3. pagnie genoegzadm cen preuve bekos. men hebr. Derhalwen "t telve tor Ul. " goed beleid, en 't geene in deien ten ". dienfle van onfe Hecren Mas is ver, eilchende, en tot captecring tán der -3 voornoemdel Heeren ganit bewo-

* Ien lanten z zulx echer voorvallende, "of icn lafte gelegt werdende, zaldoor " den Koopmin Gartfink ten Howe, "t , $2 y$ dan ay de Majetteit zelf, of wel 1, nan andere Heeren, den inhoud van 1, voornoemde miffive, en de verderc 13 gepaffecte Acten, war van de crans"Jiten in copyen Ul. behandigt zyn, "zulx dan ter muteric zou mogen die" nen, met mimnely kheir en diftretic wer.

"halen, en haw Hoogheden de zelve " gelieven indachtig te wefecn, anama"nen.

"Hobbende dan licentie wan vrye Ne3) gotic bekomen, en het reken van 3, dien voor de Gemeente angefligen ". werende, zullien UL, trachten het me"degebrache contant Capital in goede 1. I'uwe Zyde, tor zoo ecn civiclen prys, , als dienlyle welen zal, en de navbl") gende fluk-goederen wan goede Zyde, " en zoodannige lengte, breedte, en $n$ gewich $\mathrm{E}$, als Ul. woor defén angewe-
* Fen en ter hand geftelt is, mitegaders 1647

" hul mondeling van de Kooplieden in "t

1) verkoopen warl de Tonkinie Atuk got -

") deren wolkonelyk hebt verftanch in-

" formeeren laten, verfetem, en zot 2* de navolgende quarticeit floffenalliei

w in Jepan met goede advance, na adve") nanc ieders deuge, konmen gebenefi". ceerd, en an de man geholpen wer${ }_{3}$ den, gelyle dit jasi meerder profyten; ,3 als de rouwe $Z$ yyde heblyen gerendecrt. 2 10000 Hockins, of 200 vecl als et i, te beliomen zouded we" len.

1000 Htux Bhan.

3. 2000 ftux Sumongy.

" Iooo Rtur Chio, doch wite dito's: " 2000 ftux brede gocde Forts.

" 1000 Rux Pelings, doch dienert , ech duim breeder te we"fen, fils dic van dit jaas"

"Om de voorliz ftoffen in quantiteic; w) ter plante, dar delelwe meef vallea, "en van beter Zyde, als jún anderéntar"tieren geweven werden; mitsgaders "goede partye Caned vall ontrent 30 4. Picols rot civilen pryie te bekomen, 3. zal UI, cen van de bequanatte Ouder" kooplieden met een affitent, en den "Tolk net een behoorlyke Konings , fauregarde, of tsjap, diewy nier wwy, felen of toc de meette werleekering van " Compagnies volk en har Capiral UL. "wel zal gewerden, na de ftad Sene" phay voócertit coc een prenwe met 3 3 a 4 kilten gelds, gelyk by de Japan3. Tche Negotianten woor defen ten voorlz. ". fine gebruikelple is geweelt, commi3. tecren, micsguders by apparenten en ,2 voordeeligen handel, tor procure van 3, de verifolute ftoten en Cancel, of 3) wel mede goede fortecring ran Zyde, 3. gedourende U1. nanwefen in Tonkin, "s continhecren laten, blywende altyd " verdache den perfoon, die derwarts 3. zult commitreeren, met ecnige mon "Aters wan floffen te verlien, chi zooda1, nig te inficuecen, dat zyn werricht, 3) ten dientt van de Compagnic, en uw w eigen ecre, uirwallen, en fuccedeeren " mag. Zoo dar de zakk, ofde Nego3, tie in die plats van zulken importan\$) tie werd geoordeold, dac mecrder conw tanten; wolgens de advy[er, derwarts "behoorden gelonden, zal $\mathrm{S}^{\mathrm{t}}$. Hardinte "wel dienen woorcert cen tour over , land, dat binnen drie dingen gevoeg") Iyk gefchieden kan, of wel te water", „zoo cenigfins de tyd dit lyden wil, na ys Senephay te doen, om thet des re bew ter fundament het gerequireerde con3) tant Capitaal te mogen providecren, s) WhE 


\section{\begin{tabular}{llllllllll}
\hline & $A$ & $N$ & $T$ & $O$ & $N$ & $K$ & $I$ & $N$
\end{tabular}}

1037. "Wat in de Negotic omgat, behoor"lyke infpectic te neemen, en volko93 wen ordre te ftellen

"By de gehouden Tonkinfe Negotie" boeken, wcinecmen wy de Europilclie "2 n's andete goederen, tot een preuve "voorlecden jaar derwarts gefonden, "met wcinig profye, ja tot ichade van " de Comprgnie, gebeneficeerd, en "meett by den Koning, Prins, als an"dere Grooten, va hen genomen, en " de reftecrende te rug gebracht zyo; s. wasrom Ul. niet, dan 'e geen haar "Hoogheden ernftelyk zyn eifchende, " virgeleid het Koper, dat uir te qoe" ren, by den Japanfchen Keifer verbo: 3. den is, woor tegenwoordig werd me"2 degegeven. Wy hebben goedgedachr nde geifchte goederen wan den Prins, s of jongen Koning op zekeren prys, "2 terwyl zuls zelts by zyne mifive is wer" fockende, te ftellen, en dat op hoope " by den Koning, en andere Capado's 3, na advenant mede zullen werden be" taald, zoo dat na gemelde memorie, "Ul. ter hand gefteld, zult hebben te 3) reguleeren,

"Na wy alhier werden besicht, zo 3. zou op de wortel Hifin in Tonkin goc: 3y de profyten voor de Compagnie, als " die onder de hand of fecrereiyk mogt ", verkoge werden, tedoen zyn. Waar" s om Ui. tot cen monfter to katti's van "3 de middelbaare fortecring werd mede " gegeven. Ul. blywen verdache, wat " quantiteir, en met wat profyt jaarlyx "aldatr zoulden konnen debiteeren, te , onderitaan ; gelyk mede na zekere for3, reering wan rouwe Zyde, Bottor ge"snatmd, dewelke 20 ten honderd min" der als de goede Zyde aldar re beko3) men, en heer in Japan weinjg minder, "als de goede dito, zou rendeeren. Zulx "2ou mede met noch een andere for", tecring wan Zyde, genanmt Forrangoy, "Sefchieden, en als de Bottor na adve" "3, Dant advance geven.

"Zoo wallen dar mede verlcheide "Drogues, dinar af, als van de voorn. "Zyde, in toskomende monfters zullen 3) verwachtes, om te bevinden, wat "2. vondecl voor de Compagnie met de 32 zelve zal welen te erlangen.

"Gemerke by refiumptic van "t gepafis feerde in Tonkin, als mede monde" iin:ge voorftellen wan den Koopman "Harthak, wel icmand aldar zou be* "s hooren met een contant capitaal wan " Ontent 1 zodo thaylen, tot werwolg " vatt ten handel, als verfeteide andere "s confidcratien, ten dieñfte van de ge"neriale Compagnic oyer te blyven,

"zulks by ons alhier mede nict vicemd, 1637 .

" maar hoognoodig te gelchieden, ge" oordeeld werd, cehter is met deSche„, pen Amfterdam, en die Gallias, na "Batavia, an de Ed. Her Gouverneur ", General en Rnaden pan India, dast w over gefchrecven, en har Ed. nader 3. orde verfocht, die Ul. met 'i Schip, ") dat tot overvoer wan de geprocu eerde "rouwe Zyale, ftukwerken, en Cil" neel, Toukin zal andoer, gelyk me, de antwoord op des Majefteits Brief 3. Wan zyn welgemelde Ed. zullen hebben "s te verwachten. Zoo dan de Ed. Heer * Generaal moge relolveren iemand al" das over te blyven, on woorn. Hirm"1) fimk dar toc wierd geordonneend, zal " den Onderkoopman Damiel Reinieryz, 13 om ons mondeling van "i gepafleerde " volkomen rapport, en weder over de " bevinding wan het Tonkins Cargaloen *. te mogen doen, met een der Jachten " herwatits keeren.

1) Metwclkancwoord, en eenige pren fenten awn den voorn. Koning, zyr " gemelde Ed. wel mogt refolveren, " gelyliwy hoopen wan ja, cenexprefen n gecommitteerden, on met $2 y$ Majes. tteit in nader onder handeling, wegens w den Oorlog tegen die van Quinam te , komen, of wel nader infoctie van de " getegenheit des handels aldaar te necn men, tot welken einde Sr. Mrabas "Duyker dí faifocn is expreftelyk geot" donnecrd gewcelt wan Batawia te zen" den. Ul. zullen dethalwen, verforgen "voor "t uitgaan wan de mand May, " onder 't Roovers Eiland iemand wan 3) de Tolken, of eenander bcgunam per3) foon, dic alduar in dienft zoude mow "Ben hebben, me cen miffive, en tidn vertentic an de Overhoofden wan hee " komend Schip af te $z$ drken, met or3) dre aldau hare kondt te verwachten. 3 op dat zy behoorlyk mogen weten, * war hen in "t nit boven reifen zullet "hebben te reguleeren 3 Gecomniteterdens bovenkomftwolko3. then kennifte van zalken mocht beko" men, op dat alles, zoo zulks zal ver3. cilchen, met goede ondre cot reputa" tic van de Nederlandfohe Natie toe, Gan, en uitgevoerd mag werden.

s Of het geviel, gelyk wy nice opi" nceren, by een fehars Zyde-gewilch, " of wel verchyning wan meer andere 3. Negointuten, de Zyde, en ftuk-goe"F deren, tot zoodanigen prys quamen te " rylen, gelyk voor defen wel gebeurd w is, en men oordeclde met den inkoop "van de Chincefche goederen voor Jil" pan meerder, al wate het egiale, 
I677. " profyten zouden wefen te doen, zoo "2ullen UI. alworens een goede en ver, fekerde calculatie, en met den Rand ") hier over relolutie hebbende genomen, \% het mede gebrache Gapitnal te ver"fetten, fuperledecren, en weerna Ta3) youan, om voorfz redenen, voeren, "Wan gelylken de atagerocrde impedi3) menten niet voorvallende, en echter 3, zulken quantiteit Zyde, tor wollading 3) van beide de Schepen, alfoo 'c Schip 3) dat van Batavia U1, toe te homen ftant, " grooter van laften, als danrom is ge"dchreven, wel mocht weten, kon wer" den geprocureerd, zal Ul. 'E grootite " tot fupplement zynes vorderen lalt na "Tayouan tydelylce depefche geven, en " net 't Jacht Sandvoort uw reife op 't , fpoedighte herwairts iperformecren, "blypende ten hoogite gerecomman"decrd in 'c afladen der Schepen, tuf"Chen de Zvde pakken, en alle hoe" Jen en winkels, wel verftande niet "an, madr een liage van boord, en 3) daar "t geen vochtigheit onderworpen ", is, 200 vech Sitouw, of grof werk , pan rouwe Zyde, los ite doen inftop"pen, als immers doenlyk is, gelyk Ja. 3) panfehe Negotianten in havie Jonken y tot foulaas hater gedaane onkoften "plegen, en gewoon waren te doen.

, Ook zou mede, "L geen zyn vol, komen laft nict had, ten watre het " defoet te groot, en rset kaftelyler " goederen in Tayouan te laden, de , Compagnie mecr dientt gelchieden "zou, geoordecld wierd met goede par"L Lye Silouw zyn verderc laft bekomen, , die volgens de rapporten, zoo veelats v, begerente tot toyil 3 , en minder te 3i. bckomen is, ja nil watr de parry vry 1) groot met goode adwance, gelyk dit s) far tayil gerendectd heet, alhier " Fonnerí werden gedebiceerd, dare op "Ul. te letten ftat ; en ook behoorde " in plares wan Tayouanlehe ruige wat3, Ien effect te forteeren, doch zullen 3. deren ratkende ons aan de nader ordre " vin de Ed. Heer Gouverneur Geney rahl, en de Ed. Heer van der Burg, , Gourerneur in Tayouat, geheelyk ge1) dragen.

2. By refcontre wan ecnjge orifer Vyar, den Varrtuig, zoo in " $\mathrm{g}$ gaan, als kec, ren, airgezeid dic van Maceauw na 2Japan komen, zult de zelve zoeken te 3) vermeefteren, en in uw geweld tebe3, leomen, alcyd over de veroverde van "wel te verfekeren, en wakend ooge 3. hebbende, en de goederen behoorlyk 3. doende inventarifecten; doch verdage 2. zynde geen gerangenen hicr in Japan,
" mar wel in de Pilcadores, of in Ta. , yount, te brengen. Zoo werd Ul. " mede fericus gerecothtiandeerd in 'c "herwates komen, of in "c Vautwater. "Van Japan, geen Chineelche Jonken " tan te halen, en cerig volk dar in 3, te laten avergaun; gelyk $\mathrm{zul}$ dit rai" foen by de overhootien wan de Keile 3. rinte onbedacht gefchied is, en wat "rufie by de Gouverneurs Wwan Nanga". Tacqui heeft gebaard, is Ul. ren vol" len kennelyk.

, Vone den tyd van 6 manden gaat " dic Jache Sand woórt wan weelch, fpek, , olie en nzyn, mitsgaders rys en arak "Van Lwee unanden yoor 66 koppen ge "providecrd.

3. Last de Vaderlandfe provific tot de "Voyagie dienen, en in Tonkin voor 3) "t volk verfche koft fchaften, gelyk "wy vernemen dar die darar redelyks "koops te bekomen is.

מ) By voorwallende zaken, en Rads3. plegingen ral de Koopman Kover Hat " sink in de zelve prefidecren, en by ge") lyle ftemmen wolgens ulantie een dub"ble hebben, en uit zoodanige perloo3. nen beftan, als de noodwendigheit 2. wan zantien zou mogen wereifchen, ea "by voorn. Hartfink geconwaceerd tiper"den; houdende altyd goede ordie on3) der 't volk, en adminittreerd behoota " Iyke Juftivie over de misdoenders, vol3. gens de reglementen by de Ed. Hec, Jen Majores daar over gegeven. Zoo 3) Werd UL. op "E ferieufte belaftalle par, ticuliere handeling, volgens den Ar, tykel-brief, te weeren, en, by ach3) terhaling, ons daraf wolkomen ken, nis te doen.

"Van gelyken blywe de gotde melina* " Bic in de te doenc gaftes, als tehen". kagie, mitsgaders "c geen tot nur en 17 profyc wan de generaale Compagaie "vereifchi werd, sen hoogften gere" commanderd, en bevalea.

"W W willen den Almogende bidden, 3) defe uwe annitande bezending zooda3) nig gelicye te zegenen, dac de zelve s ten profyt onler principalen wel fuc" cedecren en uycwallen mag, whar coe 3) geluk, als mede behouden Reire wy "Ul. gezamentlyk zyn wenichende. A9. rets.

\section{In " Comploir Furando}

ady 18 Dechuler $\mathrm{A}^{\mathrm{D}}$. 1637.

Onderfond

NICOLAAS KOEKEBAKKER. 


\section{$\nabla_{A} \mathrm{~N} T \mathrm{~T} \quad \mathrm{~N}$ K I N.}

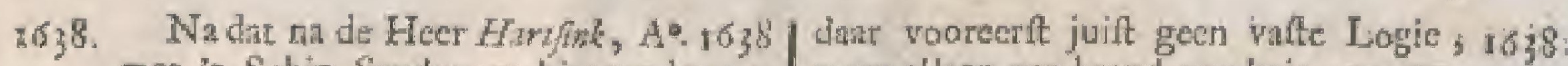
met 't Schip Sandwoor hier weder ge- manr allcen een brand-vy huis, om yykomen, zecr gunttig vardien Vorllone- ne waren daar in te bergen, dat hem fangen wris, en ayn oogwit in opliche vergund witrd.

van den handel bereike had, zogt by

\section{DERDE HOOFDSTUK.}

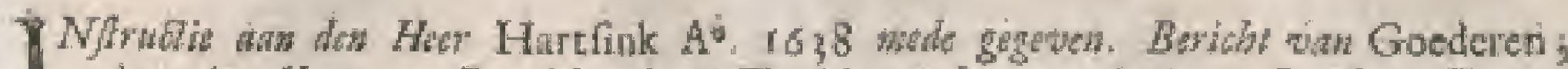
1 door den Her van Brockhorft wil Tonlyits ma Jiphan gefonden. Brief des Kosings

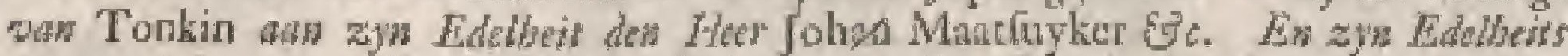
antwowd 'er op. Sibens, Commifaris ber, Dit Comptoir $A^{\circ}$. 1700 phedroken. Van den Godsdienift. De Heidenleshe. De Romiche. $V_{a n}$ den Gods= dientt van Coessjentsjing.

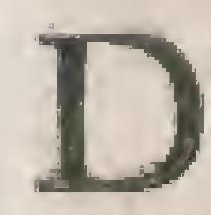

Efe handel na rinm onder oplicht wan de Heer Hart/ink zulkeen gelukkige voortgang, dat has Edclheden goudvonden hem $A 0,1638$ "er weder ha toe te zenden, dietoen met het Schip de Ryp wan Japan derwarts vertrok, en wan den Heer Kablabakkr de navolgende Inttructe lirece.

Ordre en laidrute woot den Keopman Karel LFinters, en den Rad wam 't Fuir Solip de Ryp, wripdetes. de wan bier ower Tayoum na Tonkin, lot werwolg diss basdels ingeweld Ryk.

Inthac: - TTOe by de Ed. Heer Gouwerineur Hr.Hart- " -1 Generaal, en de Ed. Heeren fink Aon "Raden wan India, ten dicnlt en voor1638 na , deel van de Ed. Heeren Majores tot menke in ondervinding en accrefecmenc vanden geren. "handeldoor de garfiche Indièns, geen "s diligentie nog onkoften gelpard, mar "s alle middelenatingewend, en in't werk 3) gefteld werden, is ons al te zamendoor ") de jarrlykie en contjnucele gegewen ") ordres ten volleri bekend, gelyk ten is voorlt. reguarde, nu rwee jararen gei) leden, met "c Jache Grol in "r Ko. 3) ningryk van 'Toukin de handel is on3, deritun, redelyk, en ru jonglt met "Sandwoord mer allerley profyten heef "gerendech, welken volgenite by ors "en den Raad op den 2 r Oetober pal". fado goedgewoulea, en gerefolveerd ,3, is, met vergrooting wan contant $\mathrm{CA}_{4}$ "2 pital den handel rigoureufer te ver"volgen; "t Fluit-Schip de Ryp, ver. mits zyn ondiep gatan en gevoeglyk de w. Rivier op, tot woor de ftad Catchou 3. zal konnen verzeilen, mirsgaders het " geprocurecrde genocgham weglec3. Pen, zoo wanneer tyd en gelegenheit ", dit zou coclaten re depelelieeren, en " na Foorn. Ryk te lasten vertreken. III. DEFL. s; Ui. zullen derentinthatande morgenw ftond, in Godes nanm, zoo weer en 5* wird dat coetiat, mitsgaders de mony ftering van "t Volk, en de vilite van " de Fluil by de Japaniche Bongois of ". Regenten gedran zynde, onder zeil n, gan, en in den naane des Heeren " uwen cours ttellen beweflen Meani") Ja木, rnchrende de kuft wan China op 2. de hoogre vald is grateden aan boord "te krygen, en van de Krokadillen, of "s de Eilinden Oncouw verkend te ge, Taken.

s, Welke Eilanden, of woorn.kult wer" kend zyude, zult wan dast by moy "w weder na de kuft varl Formola over3. ftecken, giffing makende bcnoorden "Gylein, of onkrenc de Zand-duinen te s, verwallen, des neen, dat Ul. ftorm, of hand weer, quam te belospen, zule * 11 nitet van de kuft wan China af bege" ven, mant onder den hock wan Sa 1) bouw Engeling, of ecnige ando э bequame Baejen, ten anker looph. w en aldnar goed weder whecmon, en ") by aldien genoodialkt wert-Zoo zui* " delyke R heede te zocken, dat niet ge") volglyli benoorden de Pilcadores; of 3) de Eihanden van Pehouw, na Formo"3 da zoude homen overzerten, zule na $n$ dito Eilanden uwen cours ftelten; op 2) de welke by dige dient te verwallen, n en in de Z. O. Bucy ter Rheede te 3. looper, on wan dairdes middernachts 1) tonet een achrerabbe t'zcil te gian, op 3. dat "s morgens in ayds wan 't woor $[x$. ". Eiland mooge verkend rasken, en al. " Coo 11 wers gerougelyk winner.

3) In 't overfteeken na de woors. Ei. s) landen, of na de kult van Formola; , zulc altyd gifling en calculatic maken 3) twee vloeden woor ean ebbe in "t aan") doen wan de kult wan China, en aldaar $n$ ter Rheedo loopende, werd Ul. ter n hoogiten gerecommandeerd wel op ") uw hoede, Magreerdigy th, "t geen 3. Foot 
1639., voor Branders noodig is, werdach te

"zya, op dar wan Roovers, of nulere

"trouwloore Chineeter, geen ongeval

s onverwacht toegebracht werde.

"De kult wan Formofiam boord kty-

"Gende, zule de zelve niet nader, als op

"12 yaden gicren, als medie niet werder,

" als op 30 vadern ter Zee loopen, altyd

" Goede zorge dragende, zoo by dagals

, by nache "t lood niet gelpaard, matr

3, continuecl gchruikt werde, alloo by

" duifter en dyfig weder, daf mendefen

" tyd des jars geftadig ontmoerende is,

x) uwen eenigen wegwyler welen moet.

s Wit ordre en leynen by den Gou"v verneut in Thyouan woor de Schepen

3. van Batavia, als in 't Noorder Moef-

"fon uit Japan, Ikomen, ten dienft

"van de generate Compagnic zyn

s hefratmd, werd de copye ran dien nu

" mede gegeren, war na Ut. in "t aan-

" doen wan de Rheede wan "Thyouan lich

w geheclyk hebben re reguleeren. Het

3. Woorby of misdryven werd Ul, ren

s) hooglten gerecommondeer, by welk

3. coeval of voorby ratien, dat God ver-

" hoede, zult niet vreesachtig of be-

". Tehroome wefen onder den hoogen hock

, van Taneoya ten anker te loopen, van

2. watr met goed weder in twee geryen

"oplaveeren, en onder "t Noorder Rif

„3 na wentch ter Rheede komen kond.

„By mifitwe vañ den Ed. Heer Direc-

3) teur Generaal, en de genflociecrde

"Raadcn in dato I 6 Juny paffido ons

"s per 't Jacht Akkerfloot toegekomen,

"s verneemen, hoe har Ed. "t Jacht wy-

" ders in Compagnic ran vooro. Jache,

3) En de Fluit Brockoord wan Batavia,

to met ordre on Quinam an te doen, " hadden afgelonden, en den Opper-

M toopman Araban Daker angelchre-

s) Wen, alle recle cfieten mede te nee-

" Inv, zyparíe na Tonkin te perfor-

3. mechory de milfive tan de Koningly-

3) ke Majelteic te behandigen, en zyn

"verdere Commiffie verrichs hebbende,

" met meer gemeld Jacht, om wan zyn

"wedervaaren, engebefoigneerdegron-

y dige kennis asn onsalhier over we bren-

j) gen, in Japan te verichynen, dat wy

"var harten wenfehen effect watre ge.

"Corteerd, om ons in 'reveven van prompte

, en anpelder order teniglins te mogen

, regulecren, dat my uir "Tayouan, na

" de rapportes wan wootn. Opperkoop-

s) man Duyker, en "t gepafiecrde aldatar,

is door den Ed. Hecr Gouverneur wa der

;Burg gevoeglyk gefchieden zal, en na-

" der by zyn welgemelde Ed nevens on=

s, fo mifive an de Majefteit geadver-

, teert werden, of wel zoode zala zulx

w mogt vereifchen, iets ofbygednan, ja

s) wel geheel verandert werden, waar*

\# om de zelve alhier niet is getranta-

we terd, mant in Thyoun in de Chi1. neelche fpratk, die by de Tontinte 1. Natie vollomen, en beter, ats dege, leerde Japandche taal, kan werden wer. 3) Itaur, zal dienen te gelchieden; wita" " toe Se. Hartfonk het gecietd papier tot ", de nillive vall den Koning, en Prins, ,s ter hand gefteld is.

, Na lich de znaken in 'Tonkin taten s. atufien, en wy uit de mondelingerap13 porten van den Kooproan Haryink wer=

3. Llan, zoo zou 't wel hoognoodig wer" eifchen, terwyl de Fluit de Ryp met " geen meerder getal, dan fo koppen "Sicheepvarend Volk verfien is, dac " noch meerder Soldaten tot meerder n furcte en perlekering wan "s Compa"gnies groot Capital, mitsgaders in ", andere voorvallende gelegenheden, , in Tayouan wierden bygegevoegt, " en zulfen Ui. dierhatven ain de Ed. 3. Heer Gouverneur wan der Burg wrien", delyk verfotken, gelyk wy zys ge" melde Ed. mede zyn aarifchrywende, ", met noch 8 a 10 Soldaten nevens de "twee, die wan hier zy roerende, zoo "I cenigfins zal kontien gefchieden. " mochten bygevoegt, en het geral tot , Go koppen gereduceere werden. Zoo "blyft mede werdacht de verfochte roo 3) pikols Aluin by den Japander, ge, niamt Ry/onosdo, wootnchtig in Ton3, kin, te procurecen, gelyk wy niec " en twyffelen, of volgens ons voorig 3. amichrwen per Akkerlloot, de zelve "zule in voorisad vinden; watr mede 3. de voor[z. perfoon zal werden gezc$n$ commodecrd, mirgginders de Compa3. Pagnie dienft gechieden.

1) Zoo her geviel, due de gehuurden " by UI. gevangen Jonk op de kuft $n$ van Tonkin, in Tayoun nier wante w werfcheenen, dat de Almachrige "Godt verhoede, zal Ul. den Koop"man Yan de Wrard, die numede gar, " tot den Tonkinfen handel gebruiken, " gelyls mede den Onderkoopman Pie" ier Byereld' by 't Fluit-Schip blywen " laten; doch ter contrarie, dat wy in " 't binnenfte onfes gemoed wentetien, "* verftann wy mer die geene, die Ton"kir alreede hebben gefrequenteerd, en " roor regenwoordig wan "I Comptoir "UI. werden bygevoege, den luandel "z zoo wel ter platafe, datar refidecrd, ", als in Sencphay, zal mogen wange"nomen en volvoerd werden. Derhal"s ven beide gefoerde perfonen in Ta"youan tor de horndt der Schepen uit "Japan zuller dienen te verblywen, en "1 de Scheeps bochen by den Onderkoop" man Nachuglas, als op de Sandvoor "1 heefe gedara, waargenomen werden, 3. ten ware de Ed. Heer Gouverneur al; dar anders goed Yond se ordonnetren. 
$\forall A$ N T O N K I N .

37

1638. "Wy hebben wie de ontlekhing hee

- Butededen jarar, met it ficht Kleen

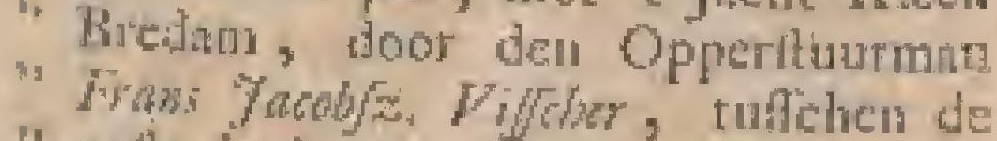

" valte kuat wan China, en her groote

". kiland Aynam gedaan, geficin, en

"door rionfelinge sapporren vertian,

". dat de paftagie benowren niet zoo veel

"Pryhels en lwarigheir met onle lichte

"Schepen te pafteren (als wel is ge-

"fintineerd, en gehouden) ondurwor-

s) Pen te welen, waram rot volbren-

" gen van een lpuedige en korte Voys-

"gie, mitsgader gecn on mutten tyd met

. opftopen in de bocht, loopende be-

" wetten Aynam, t'loel te brengen,

"Wy nict ongeraaden zouden fouden,

"vertreklende dic Tilyouan, to ver-

"richtinge uwer zathen aldara, en be-

" kimencin depclehe, de Eilanden Poelo

"Tajo (hebbende alwooren uwe gettel-

" de courfen van nu wee achter een

"volgende jateri wel geobferveed) in

3. I geficht te loopen, en win de telwe

"verkend zynte naden Noord-Ooft hotk

"van Aynam, of den berg Manopin,

"by de onfen inde Kanse alloo genatima,

" over te fecken, en van dnar langs her

" voornoend Eiland benoorden, en dc

" vafte kult op Io, $y$ en 7 vademen wan

" de bochrin te loopen, en uwen colis

" reclie door na de Rivier Arquaron, op

* de hoogec van 20 griaden 48 mim-

"ten, en ontrent 9 mylen Noordely-

" ker, als de Rivier Rochbo, by het

" Jache Sandwoor bewaren, dewelke

" de Portugeelen met hon Vartuig uit

" en irikomen, en met cen fpring-ftroom

" I6 a 17 vadem waters gevonden werd,

" te ftellen, en op 't Ipoedigft binnen

"te geraken, dir werttan wy zoio Gods

" weer en wind zulx cenigfins wilde toc-

" laaten, en UI. behoorlylic kemis vat

" "t land beliomen haddern; des neen,

" ordonnecrenals de vorige Voyges het

" gedina, beweften ' woorn. Liland Ays

"tham de reile te yorderen, en zondes"

It de Viftchers of Konings Eilinden ant:

"te doen, na de Rivier Arquaron, hier

"voren getocmt, te loopen; doch in

st "t weerkecren na Japar, of 't verzey-

* len van de Tonlinfe liuft, wiwen cours

" binner door, als hier voren hebben

" nangeroet, 'c welk gevolglyle zonder

" ecnige Icrupel zal konten gelchieden,

" nemen, en alfoo de reife eer winnen.

"Voor de mond van de gefegde Ri-

" vier" welende geankerd, het gety, of

"wel weer en wind nict willende toe-

" Jaten, vat dadelyle boven te zeilen,

" mar aldanar ecnigen tyd vetraits de op-

"watering re moeten blywen leggen, en

"de eyd des nieuwen jaars, of harar Son-

" gunes, beginnende to genakiker, zat

"fich de Koopman Harloth, na op al-
"Ies goede orde is gefteld, mee een bs- 1637

quairn lniands Vartuig nia de ftni Cac-

chon vervorderell, audientis voor dos

"Koning en Prins verfocken, en ondo

"mifive mer de bygevoegde verecrin-

"Gen, ch vereifche exbieding ( 200

"dit behoord) overlevenen, misgiders

" onle goode genegentreie en wil rot haa-

"te Majeleien volkomelyk declaree-

"ret1. Wy willen niet cuyffect met

" de vertehyung van den Opptrkoop.

" man Doyw, of zule wan den honing

"minnelyker, als welop uw vercrelige-

"Iclied is, bejegent werden, zooda-

"nige vexatien en quellagien in ver-

"Joheide gepleg gde actien (als ajperfing

*. Fin een groote ca merkelyke fomme

"Zilver, nit-neming der goederen rnet

weinif wirdk, ja ecnige met verlies,

, en daar en boven levering van growe

"en Mleche Zyo it beraling des Ko-

" nings fehuld, waar tegen mé alle ci-

"viliteie en bondige swenen, gely, tot

noch roe publieg hebe gedian, Gude geve mar by die onrodelyle Natic, zer heaten mig werden genonica, zil "dienen anngehouden, en zoo mogelyle "is, voorgekomen werden) onderworpen zyo, nuar meer libertciten en voordecien in den handel genieren, gelyl mede wegens de werlochte afl-

- ftentio riec notyelyk gewllen, en daar

" over angelprooken werden; matr toe

" mader folryvens co ancwootd wan den

"Ed. Heer Gouwerneur Genernal, den

" Konings fich gerult zal houden; ech-

"ter zulx voorvallende, zalin defe zaals

" niet verder mocten werden getreden,

"als kot noch tot denor Ul. getchicd is,

" zullen UL. voorecrit niee als Kooplie-

" den monter dragen, en de Stanss/.

" ken dootghans, orn tyd te winf,

" na Bataria getenvoyed wonda, "

" onie mifliwe over dele als andere ge-

" parferrde taaken ter decle wydloopig

"arabryver, ell alloo efted fortecrde

"Gastine zayen, zal Ul. uí de copye

"der zelver ecr hand getteld, volkome-

" lyki konen beoogen.

Oatangefier de Koning in 't lefen

") onlter mifive, 'c voosleden jatr ant

". hem gedirigetrd, feheen geen goed

" genorgen over her wedereifichen vajt

" de geblewene Nederlanders in de Ri-

" vier var Polin, "mirsgaders de ange-

"houden ammunicic $\operatorname{van}$ Oorlog té

"Icheppen, en op. uw mondeling ge-

". dain verfock geen antwoord wegens

" de gexegde ammunitie, mar dat de

" twee perloonen hadden vrotwen ge-

noomen, en uit hat wryen wil be-

" goerden date te blywen, \&S. hadde:

beliomen, zoo tal. Ul, echrea by ge-

." legenlieden van tyden zpn Majefteit D) 2

" zolls,

$\gamma$ 
* $A, 3$, , whlfs, of wel Aoor 's Contprgnies ", wrienden doen antiprecken, en in " $\mathrm{E}$ , vriendclyk werlockith, dat doch g:"lieve ardre te geven, voom. Neuer" landers on 't werdene angeflagene, "Ul. weder mag werden ter hand ges. lteld, met werkinaring, her mant an ") "t grbod wan urn Majelteir dependeerd, " terwyl in zyn land en gebied zyn ont"houdende, en zonder eenig tegenfpre, ken var iemand U1. konmen rocge"2onden werden, des neer, weeren "niec hoc langer dew fid. Hecr Gouver" neur Getreral defen ratiende zullen " contentement doen. Ondertufichen , dient niet verfitime beide de fugitiven 3) dour cen exprefte, "t $z y$ met briewen , of mondeling nangedient, dat wal heb, ber voor zig te sten, 200 in dit haar 3) moerwillig oplet continuecren, en haar 7. buiten den dicnft vors de Compagnie on2) des fanweguarda vas een Heiden ont\% houden, wat han in tyd en wyle faat "-te gentien, en wy niet zullen natat 3, ter, too niet vigwillig, en dat voor Ul. vertek van daar wederom tot 3. Ferfchynen, door de en of de ander 9. middel in onfe hindel te bekomen.

, Den Opperkoopman Duker is in con-

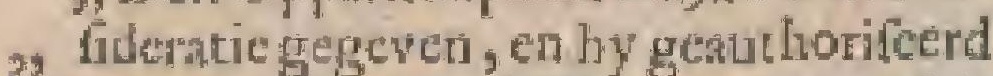
3) nee den $R$ and te delibereren, on den 3, Koopman Hard/un aldaar mer weinig 3. Capitalial te laten overblywen, en te , doen onderfoeken, wat in den handel, 9, als nudere tanken, na "E vertek der * Schepen pafeerd, en of de Zyde niec -, tor civielder prys met kikene partyen, "2 als, wanner wy cn de Porcugeelen die 3) met groote quantiteit andlan, zou 3, te bekonen wefon, ch tulx meer, als 1) 7 werberering der Negotje geobfer-

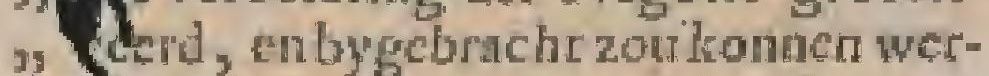

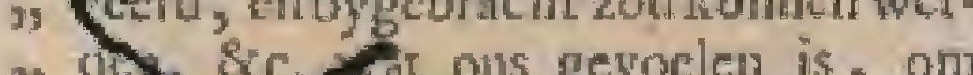
3. iculatidar met enig Capital over i, te blywen, na wy uie het gepalfecrde „2 var derwarts fien, hebben ten deele 3. na Batavin geoordecld, gelyk Ul. me-

${ }^{2}$ de diar over zye fehrywende, en door 3 onfe gehoudene mondelinge commu3icatien genoegzan bewult is; ecil. ter om de zeekerheir des handets ten 23 regunde hier voren angeroerd, ectr3) mal te moogen bekomen, zot woor , tegenwoordig den Koopman Hawfork, 3, of wel een der bequamile Onderkoop-

"lieden by non employ van alle de con-

, tanten, net een wemig Capital lover 3) te blyven, ondontecreti, doch niet 3) weerende, of meergenclde ST. Doy, her, terwy wy verneemen met moch , cen redelyk Capitanl, beftande in 2uinass Goud, Zilver, cn. Koper 3ener derwarts is vertrokken, tvel g noche entige Compagnies dicnamen 3) moch ecuige Compagnies dicnaten

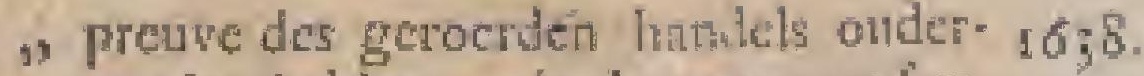

3) vonden heloben, nier konnen met fart"damene dare af fprecken, matr zullen , op de nadet ordre yan den Hecr Gene, rat, aloo her appareor is anderinal 3. belending ' 5 annltande lithen vain Ba3) Lavia zal werden gethan, of wel op 3. "I goedvinden van de Ed. Hear Gou", neur wan der Barg, na de bekomen ". ad yyen van daa gedifierect lanten.

"Hct zil noodig, en ten dientt van $\Rightarrow$ de generale Compengric vereifleliende "zyn, du Ul. licentie unde Majelteir, 3, on de Negotic te mogen exerceeren, " hebben bekomen, of wel ecr een der "bequamite Onderkooplieden cen aff. "tlene en Tolk onder 'c Tsjip cn fau, wegürde des Konings, met een be, hoorlyke inftructic, ills 's voorleeden 3) jart gelchicd is, na de dind Senephy 19 commitcenter en werlorgen, dat her , weven pan ftoffen op laare aandomith ; by der land genomen, en dienvolgen, de meerder itul-goederen, tot wer" grooting van zoo een profyrgecten". den handel, geprocureerd werden, tha "wy ons allice lasen informecren, en " de ervaring, ten cyde de Japaniche $\mathrm{Ne}$ " Gotimen net hare jonlies dae Ryle "is frequentecren plachen, ten volié "Hermeefter is, xal de quankiteit yan " de ftoffer, als Hockins, Bha, Su" mangy, Chyo, en Pelings, uitgefgr "de Foras, die aldan in de tyd uwer "Refidentic zouden konnen werden ge"weven, altyd met treffelyleprofyten, "gelyk ma twee nchtereenvolgende jax* Ien ondervonden hebben, alhier ge, beneficeerd, en man de man geholpen , werden; warom getn quanciceic in "defen UI, zullen preferibecten, man , zoo vecl contanten tot belkoming var , meerder profycen, ren hooglten gere,commandeerd lacen; gelyk wy "c ata"befteden wan cen goede party wita Pc"liogs op de lenge van con Japanfche "Rok wan blocmen en werk, th te mon, lter U. ter hand geftele, wata af 73 "flux tot eet preuve door Ul, ons $z y \mathrm{y}$ 3, rocgebrache, koltende aldear coyil 2 , \$, 4 fehtuitgeld, en hier woder tayil 6,7 , 11. gerendeerd hebben. Zno zal mode 3oor al vercifichen onderleic her we, ven van fwarte Fluweelen, onder de "Chincelen aldan", gelyk wy bevinden 3) folgens de beliomen monfters genoeg, Fam zal konnen in "c wer ligetheld wer" "den, alloo wy uic Tayoun, volgens , de advyfen aldaht, vernits een driche "by de Grooten tan China geworden is, , en met nuesnigte na de Koninglylseftad ,Paccan gevocrd wierden, geen of wei"thig te yerwachten hebben, on hicr " woor tegenwoordim meer als voor de, "en getroklen en gewild zyn, gelyk 
YA N $T O \mathrm{~N}$ K I N.

29

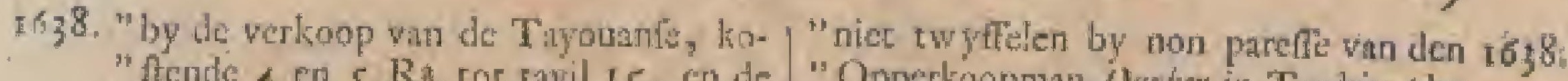

"fende \& en o Re toc eayil is, en de

"Tonkinje vin tayil 3.7 7 lohicgeld, ta-

stil is $2 \mathrm{yn}$ werlochi, ton declen itge-

meten kars werden, doch zullen we!

"dienen op zondanigen lengte wan pool

"en rware verw, abue Clinedche, die

"de onfe in Tayoutan tot $f$ en $6 R_{3}$. in-

"koopen, zoo T praticabel is, a anbe-

"Iteed te werden, zullen na advenara

" meender profyren geven, en on de

"Chineeren geroeglyker tat her weven

"van gelegde Filuweelen [e mogen on-

"derrichen, zal her noodig ayn Hart-

"for 5 at 6 ftuk goede diso's tot een mon

"fter uic Tayouan mede neeme, de pro-

"cure van goode quantiteic Cancel, al

"wat het tot pilkols, en mecr, of het

"gevicl in 'c andtonde van Batavia een

"Party van 'c Vaderland wierd gecifeht,

"blyit Ul.gerecommandeerd, gelyk me-

"de ren hoogtten in "t verletcen van uwe

"wegvocrende Capital in goede rouwe

"Zyde tert ecri ciriele prys, zoo weel

"docnlyk zynde, "E wellis op uw alreede

"betiomen crvaring en geprelteerden

"dicnlt, rolkomolyk zullen vallinten,

" en gewenflite cfecten, ten voordecle

"var, onle Heren Primcipaten, in her

"danftande ver wachen. Onderufuchen

" moet men niet tolcreren, dat om gee-

"nerhande motiven onder ecn bepaalden

"handel gebracht werden, veel min, in-

"dien 't voorkomelyk is, dat deontrou-

"we Japanders u als taallieden bygeroegt

"werderl, en met 's Conpaguies midde-

"len rpeelen, mara de minite gemeen-

" "chap in den handel met dien beroiden

"hoop te hebben, zal to befte vriend-

"Cliap bejegenen, en geen occalie wan

"mistivegen geven, zal dienvolgendeden

"Tolk Srik, zoo in Tayoun ver[chec-

"nen, die fich de jouglte Voyagie woi-

"gens Ul. rapport wel gequeen heefe,

"wederom der warts dienen gebruike te

"werden.

"Her zon welknnen gefehieden, dat

"de lid. Heer Gouverneur vaw der Barg

"goed rond, gelyk ons advys dar ge.

"heel roe is drigende, dac een da liter

"blyvende Fluicen in "e verzeilen na $\mathrm{Ba}$ -

"tavia, de boclit yat Tonkin andeede,

"en wan de ViTchers of Konings-Eilan-

"den ter Rhede gusm, onde Tonkin-

"fe alvylen, hoc aldar var den Koning,

"Prins, en andere Grooten zule beje-

"gene zyn, de apparenticn ฬan zon een

"groor Capitan te verfeten, wat quan-

"ticeic Zyde verhoope werd, en vorder"

"doen der Porrugeelen, onfe Vyanden,

"mirsgaders mee wat Vartugen encir:

"gafoenen aldanr geland $z y n$, in 'c laneft

"van Februmy, of 't begin wan Maare,

"varn darar aan de Ed. Heer Gouverneur

"Gencral over te brengen, gelyk wy
"Opperkoopnun Disker in Tonkin (dac

"den groeden Godt anders grev) of (tane

"zillx valtelyk te gelchiecien, wharom

" tegen voorn. tyd een exprefle met uwe

"Bryeven cu verdere bufcheiden tegende

"konft vin 't Schip, nangeicgde Eilan-

"den zal dienen ee verbeyden, of wel,

"zoo zulx de tydkon lydea, ende noot-

"wendigheic van zanken vercifchte, op

"de belomen tyding van zynarrivement

"zelf in perfoon cen leer na derwates

"te doen, om de vrienden des te beter

" ch grondiger te konnen onderrichten.

"W byutem ondercufichen gerefolveerd

"' I" tuit-[chip Broelioord zoo tydig zy-

"ne depefches te geven, als zal konnen

"gelchieden, en de voorgeltelde Voya-

"gic gevocglyk kotacn gewonnen wer" den.

"On cemmal de volkomen ondek-

"king van de Tonkinfic Boche te beko-

"men, word den Rat gecommandecrd

". "geene by de wren niet bertiren en

" ondervonden is, als wan de Rivier Roch-

"bo, tor de Rivicr Arquatón cn dellelfs

"Prujeen, ultwatar her Noondelylier, en

" "t geene noch vereifcht, bevaren te

"werden, by gelegenheie door den Op-

"perthutroan frass Viffler, of wel ecir

"Ander bejuantis perfoon, te doen on-

"derfocken, en nevens her alreede ont-

"dekte percinent inde Kart te leggen.

;De Koopman Karel Har/onk blyve

"Nerdacht mee licf in Tontin, gearti-

" veerd, niet alleen onder de Portugec-

3, len, onle Vyanden, nuat, onder de

3. Inwoonders, als mede de daar refidee-

" rende Japanders ce divulgeeren, en

, ruchibatr te maker, hoe de Kapi-

"2 tein Moor Don sjum dit jaar tog $d$

"Reis na Jedo, en reverentie wo/ do

, Keiferlyte Majefteit todoen, gegam-

3) en vardig was de reife an te nemen, 5) Belyk gemeenlyls 6 a 7 dagen na "i vertrek der Galliotten getehied, wer" de door cen exprelfe uit "c Hof ge, thadeerd in Nangafacli, by den $\mathrm{R}^{2}$. piccin Moor Don Pramijo Cahollo Bhy, to in hame Detentie plats tot nader , otdse, gelyk noch doee, rc blyven,

w en mi men zegt, en affirmative ten Hove luftucerd het gefehapen ftats

, rockomende jast de Portugeten den , handel en trafycq op Japan zal ont-

"zegt, en gen langer intrance gedoogt,

"matr grehel yerboden werden; doch by de Majefteit en 't Hof hier over,

" als 't ftuk van Arima en Amakra, fi: "s rilyk noch nice gedeccrneerd.

2) Dit fífoen hebben de Portugeefen op harenangebrachte Koopmanictiappen in Nangafacki meer ndwance als tiet voorleden jar genoten, cri darenboD 3

viti

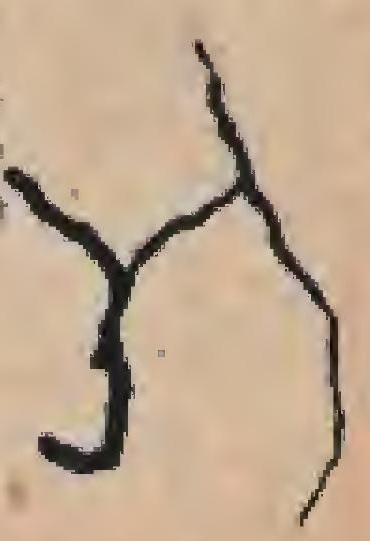




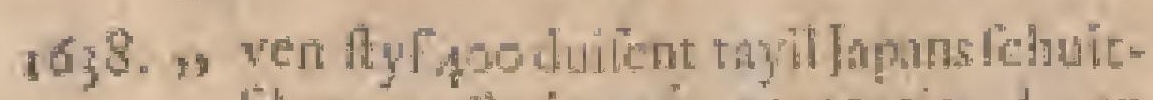

" hitwer on Bodemery genegoticend, en

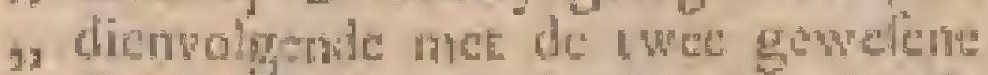
y) Galliocien broma vy millimetien Gouds " Ma Macum gewoetd, zalx wel zou "konners g.butuen, dis hiloen mee 3. Genecr Capital tot opkoop van rou-

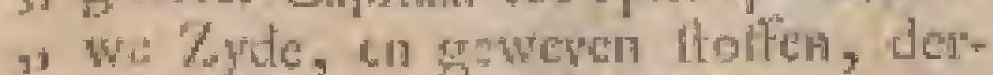
3) warts zublen aymperficenen, enU. , atroo in den bandel meerder, als 't "voonteden jasu, hinderlyk welen, de "Zy de un hongeps sopjigen, en fere " Geren doen, dar mer hee verteten van "I genonen Capicul, "6 zy dan by

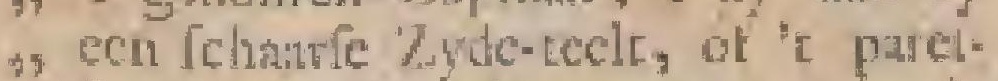

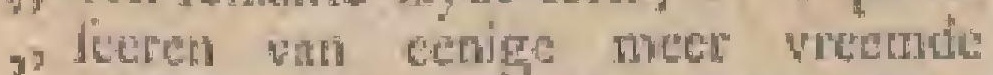
, Negotianten daif voor tegenwoor" 3) dig hier nee komen yerneemen, dan "aleen zeker kleen Jonkjen met ; a "4000 inyils derwatris ftan tevertrek.

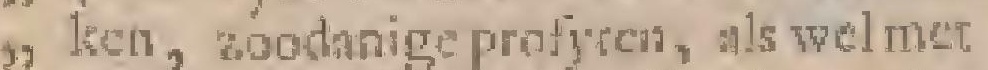

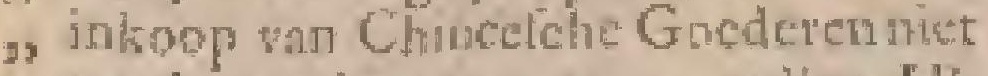
9. zoude re erlang th weden, zallern UT. " dan als "x voorkden jnat hobbet ge, ondonneerd, met her verferen luper 9 Federen, en weer ma Thyotan poe" ren; doch thant hee contradie vie te "vallen, en ecrder onnanten, al $2 y d e$ 3) en fluk-Goederen, watr af de berin3) ding un twee achter cenvalgende pan3. ren een wolkomen pretwe heefe yege-

- , ven, sallen komen te manquecren, " zulx zyode, en 't Schip met de pe2 proeureerde Koopmanichappen zyn \$) volle linding niet belomende, gelyk 3) wy calculeeren wan ja, werdSr.Har. 21 Firk ca des Rad in confideratic ge1) gevear te ondergana, of niet van eeni7 ge dea pribcipalifte Capado's, dan wel 3. Kooplieder, dar woonachig, aen 2) Narty rouwe Zyde op bodemery of "Algen increti, ja mex beraling rot 1)

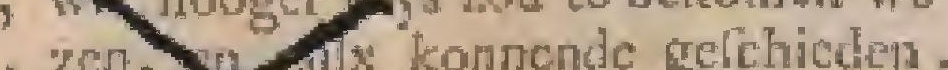
1. geauchoriferd hee protyelylkte voor , de Comprgaic dar by uic ke werken, " cis cen preuve af te doen nemen, des 13 neen, zil de wanhding mee Syrotw 3) of grof-werk wan rouwe Zylde dienen "gelippleerd, of by manglument yan " dien Tryouan of de Pifcudores ange3) dant, gedenkende niet te mun tultcher 3) de Zyde pakken alle hocken on winkeds " vol te ftoppen, als doenlyl zal wezen. 7 Wy bevinden uit "c gepaffecte en " vootgavallene in Tonkir, dat her antu-

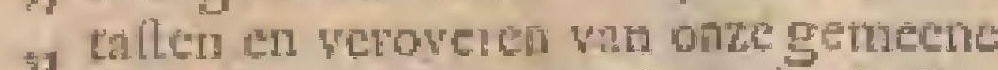
3) Vyanden de Portageefen, op de Ri3) vier des Konings een apparent nadeel " voor de Compagnice en henre dienants ", aldare flatit na fich te willen llecpen, 37 als uit de atien wan den Prins of jon3) gen Koning, klatar blyts, dat op de 3. antik tachecen vertooning wan de Portugedfori wan hatare Jonken en ander

2Vartuig meenden te volgen, en in 1638 . ,2 ons geweld zochen re betomen, Ul. ", hadicr getnandeerd ta dagen na ver,2 Treth viln votrn. Watraig te blywen,

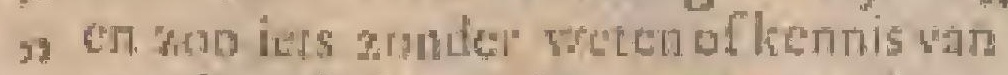

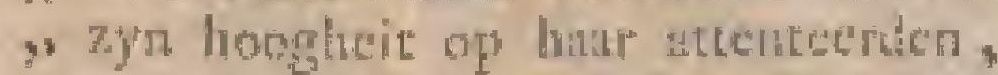
, Haee de cthod doen dreigen had, hee 13 wedl by zoodanigen Heidentenen infi, declen hoop, ecrder als men wel opi,r mecrd, in tyd en whlen in "c werkge3) fteld zot werden, wi zal diśrnolgen, de ter voomoctudes plints met betwy-

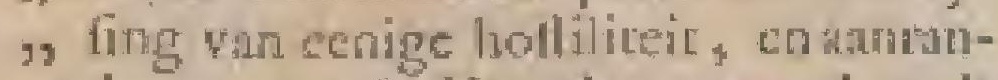
"den yan onfe Vyanden vout al noch " tor dae door de een of de ander mide " del meer aumfen of kourdeel in dat "Ryk zulien libben kerkegen, moe3 ten werden gelupet fedecrd, en acher2Woger gutaten; doch zullen Ul, bui3. Een voorla. Rivier en Rheede, als. 39 mede de cantr van Macauw en Japara "200 in 't guan als keeren, by recleon2, trecertige onler Vyanden Vanutuig, de 3. zelve zouken te vermecteten, en in "Ul, geweld te bekomen, zorg dra* 9) gende wan de zelwe wel te verzecke3. ven, roitsgaders hame goederen onder i) befroorlyle invertaris, ter prefentie 3. ten kenus der Scheeps-Rad te ne men, "blywende mode verdnch geen gewan"genca hicr in Japan, mak de relwe " in de Pilcadores of Thyoum te bren" gen, gelyk Ul. medt ierins gero" commandect werd in "t herward ". komers, of in "t wall - water wan Ja" "pan, geen Chinectche Jooken anir te " hater, of eenig wolk over te lanten - gann, op dat met klachten, gelyl " voor defen is gelchied, hier niet moss. jelyle gevallen werders.

3. Tot bedlait willen den Koopman "Rarl Hawting on den Raad, die by "den zeliren thal werden geconvoceend, " dar in prefuteren, en by gelyke ten" men nia ulnuric cen dobble hebben, " mirsgaders beltan uic zoodnnige en "zoo weel perfoonen, als de noowwen* digheit wan zaken zou mogen wereif3. fehes, op 't lerieult recommudeeren goederi regel en difcipline onder " cvollo , te houden, behoorlyke jultitic over „) de mistoenders, volgens de reglemen. nten by de Ed. Heveren Majodes datar , aver gegeven, teadminiftrecen, mitsb gaders alle particuliere handeling we, ren. Yoonts te verlorgen 'c geen sot " nut en profyc van de generante Com3, pagnic is vereiffchende; watr toe wy a UE. den Zegen des Heceren, en be"houden" Reile, gelamentlyk willen 3) wenlchen.

Jo 't Compon Firando

defen $\mathrm{I}+\mathrm{Decw}$ ber $\mathrm{AO}_{4}$

1638.

NICOLAAS KOEKEBAKKER.

Ool: 


\section{$\nabla A N \quad T \quad O$}

Ook blyke ons uit defe Inftuctie zeer klatrat, dit wy te dier, wyd al een $O p$ perhoofd, te weten, denOpperkoopman Mboham Dacher in Quinam (die 'es Ao. 1537. al quam) hadden leggen, en dat die oufen handel in dit Ryk toen mede whar nam, die al mede zyne betrelking tot defen Tonkinten en des Japarien han= del had, alfoo wy in ofefe Rylken W wa. ren moeften opfoeken, die in Japan getrokken warco.

Ook wis toen het poomemen harer Edelheden, on de Heer Harifink woorcerlt in Tonkin cenigen tyd te laten, om atles, den bandel hier rakende, eens rer degen un te fpeaten.

\section{N K I N.}

Dierhalven is hy hier eanige jaten, om onfe zakaken tyal te neemen, geblevent, Doch men heeft dit Comproir in Quinam niec lang angehouden, om dat de winften te gering waren; hoewel de Koning nadertund menigmal om de herftelling van ons Comptoir daar verzocht hefe. Lchter zyn 'er A0, 1665 ' noch 2 Jonken met goederen van Barawa gezonden.

Wie hier in zyn plats gekomen is, De Ton"wecte it niet, mar zal nu vervolgens kintoop nanwylen, wie hier (zoo verre my dit delloo bekend is) yan tyd tor tyd als Opperhootden onfe zataken wargenomen hebben.

\section{OPPERHOOFDEN van TONKIN.}

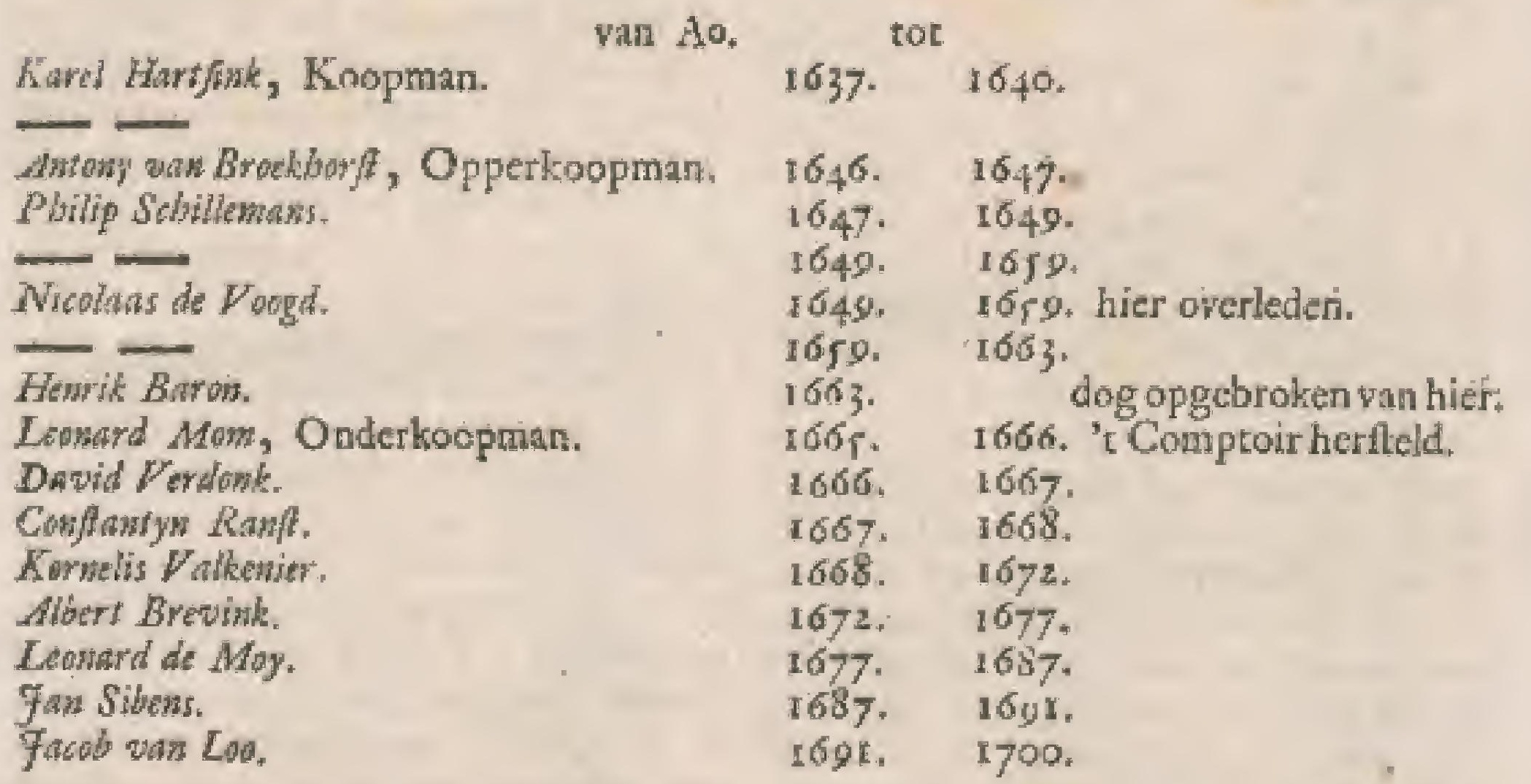

Berichit Uit cenige Japanfche Schriften blyte FanGoé my, dat de Heer wan Brokborll den 4 deren September $A^{\circ}$. 16.7 uic Tonkira na Japan H. pan mer de Fluit den Zwarten Beer, nan Broek: Zyde, Zyde Stuk-werken, Caneel, Carhort uit domon, \&c. overfond $f 355658$ : 7 : I ra Japan En per Hilleganus Berg,

celonder ain fchuir-filver, $\mathbf{R}$ yit, Caneel, \&u.

En verder belicpen de fchenkagien, mondkolten, extradito onkoli= ten op de Koopmatimanichappen, kTuisonjoolten, en yan de twee Schepen, en de Jonk Hoorn tot Torkin toc belkoftigt $f$

En op die Voyagie an gewonnen noch $f$

En liet de Heer van Broekhorf by zyn wertek van dasar an lchulden, by den Koning, en Grooten gemankt, etc of $56440:$ 6: 9

En was den Koning toen LeRowa Towarg genaamd.

Borizi: 0: 10

$21367: 10: 5$ $7035: 17:-1$

\section{A}

Na dien tyd is 'er ontrette $\mathrm{A}^{\circ}$. I 664 een ftiltand in den handel hier geweet, watr op hee Comptoir voor een iyd geliche, hoewel het $A^{\circ}$. 1665 op verloek vanjen Koning weer herltelt is, zedert 1 deen ryd wy hier verwolgenenen Oppoloofd met $n_{y}$ eweeden (wall wate eerfte Koopman, en de tweede OnderlioopInan was) gehad hebben, mitsgaders ge= legendheit, on de zelwe wicht Zyde, bevorets met zoo chayl betald, yoor 120 en 116 Thayl in te koopen.

A. "1671 fehrcef de Koning ana zyn Edelkeit Marfuykerdefen Brief, welken wy, met het ancwoord hier uitgedruke zien.

\author{
Een Brief wan den Koning $167 \mathrm{r}$ \\ $\tan$ Tonkin, anden $\mathrm{Ed}$. \\ Heer Juban Mal/agker, \\ en de Ed. Heeren Randen \\ vàn India.
}

Namlocham, Kwing wan Toxkin, be-Brich den answerd den Briff wan Johan Mat- Konings

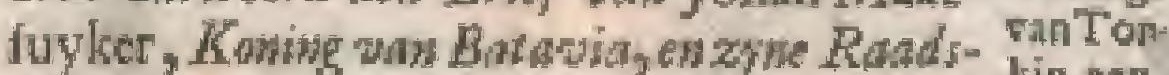

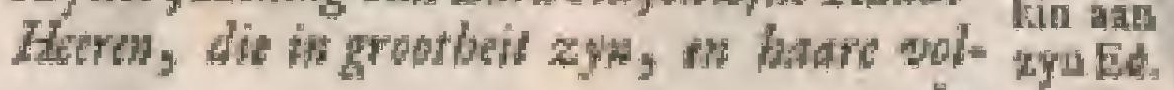

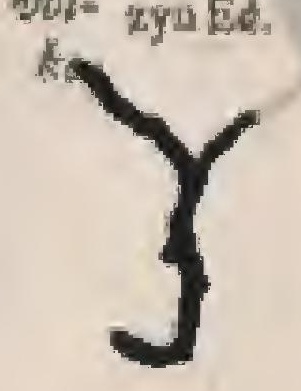




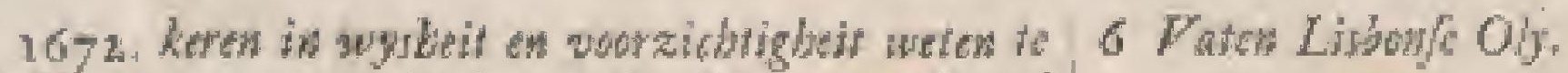

deHeer regerten, die asn alle Natien weel goed Joan dow, datrom on ieder genegen is op Bata-

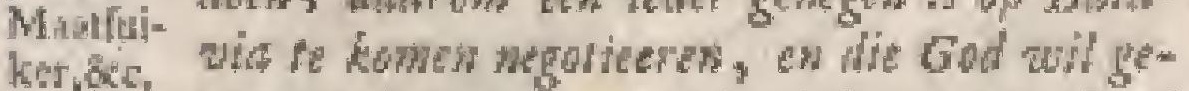
wen cen ling leven, weel geduk, en worrfoed in defe wustid?

Vorders bedibe ren Brief, newens de fobenkagie, wie UE. wet bet Selipherfigelonden,

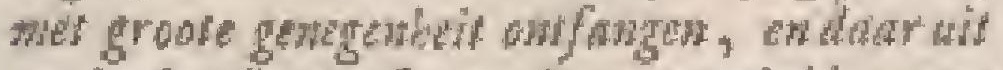
tot heduefen wer han, "I werorgelakden wath en Scbip, was wer zeer bedrod ben ge-

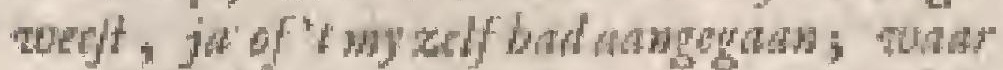
wit $U E$. Kund zien, dat wyong gentgenbrit wer tor UE., ah andere Negorinwer, is flreklende:

Ferders beble wit den Bricf velefen, dat whisig Salpever of Batavia was, dierbalow

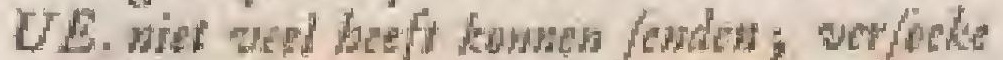
dadron wot den neaffen metrater quanriteit gelieft te zenden; it zal de warde van de zeloc in $Z$ yde betalen. Wut angaat de

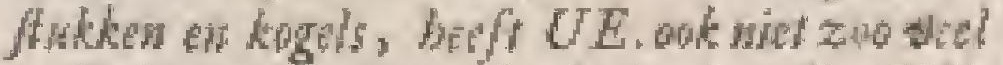
gefouden als wel gerifh bad, door dien UE. zelf daaroin benondgt quals deb al/ow

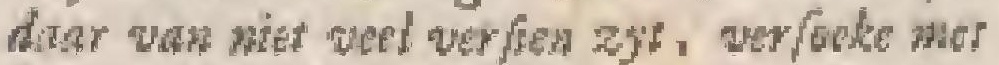
bot eerle Sibip, dat na Tonkin wertrokr. da UE. wynen cifob geliafi te woldeen, ge-

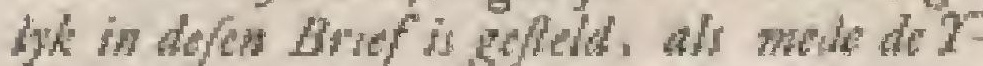
fere fraken, die UL. woor defon ge/dhrewen hebt, welke nat alfoo wan meening ben wen Oorlag te gaan, whel zonden te par komen:

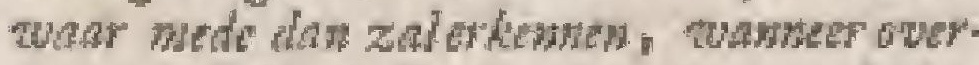
vinning beb, de $E$. Compagnie my gebolpon beft, en zal des zelfs matwe nu noth win-

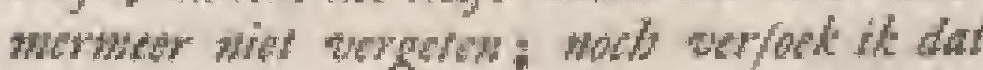
wy en goede Fonflinbl mog roege/onden aterdon, on in Tonkin to rwooner, quar aanzal bowerken UE gode genegenbe it t'mysoadti,

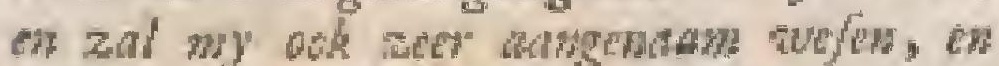

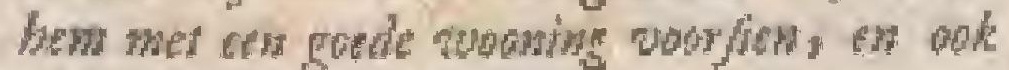
his gorde bryaring newath.

Met wh Ship, dat na Batavia wertrot,

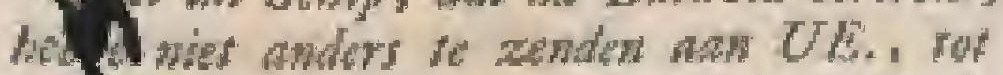

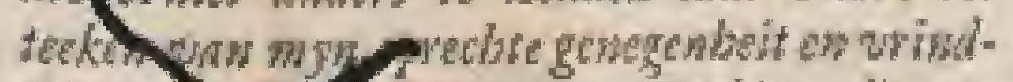

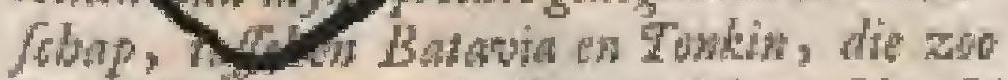

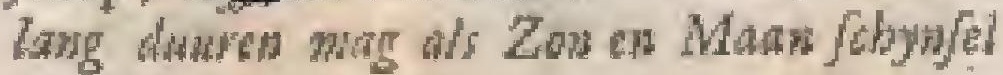
gewen zal.

Nu ver/orke wan UE. 't woliterde: 4 Stux Mroalo Rakkn van 6 pand knwt. I 000 pl. (pikal) Solpter.

500 pl. Z wavd. 4000 growe kagels.

15000 gcmene hayds.

38000 hleial diro"s.

I p. porart Laken.

f p. bhatale dito.

Io /t. groure Barnfleme koradle ketem; ols wat dejes beble geticht.

Eew party gefolilderde kircdew.

En part's witte dito"s.

Een pariy groose fukken Barnflecw.

Een party Koper.

Een poriy Tin.

Stande Realen, als wow defen gedifab hebb.

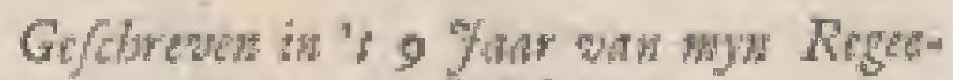
rins, den 27 was de Math.

\section{Brief ran zyn Edelheit de $\mathrm{H}$. 'Yohan Wawfwher', atunden Koning wan "Tobkio.}

TOhan Mathyker, Gouvwear Gehe- En zyn

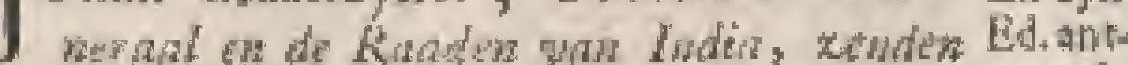
defen Briff wam Anamkocham, Koning van woond

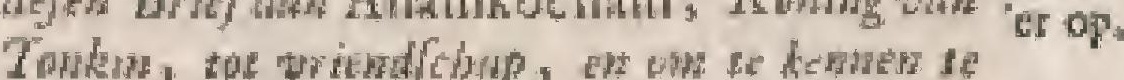
geeven den antang vas der kuning Brief, die zyn Mojelter met be laatle Selup; beer

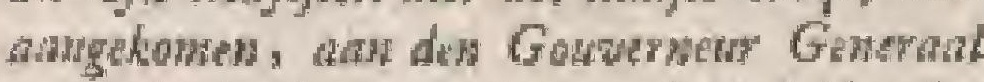

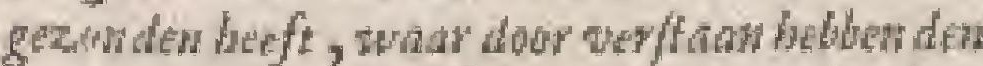

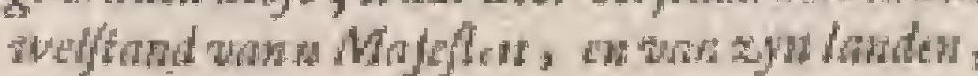

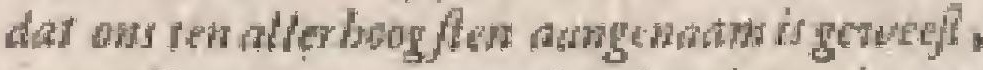

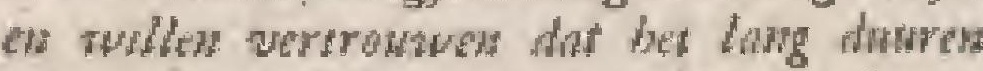
mag. Noch heldew wit de zaelve Ericf verflath, dar UE. Hogheit gatane met ech mpwhte Silperer was gednont, daar toe wht

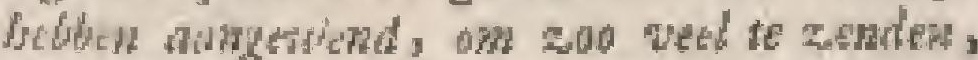

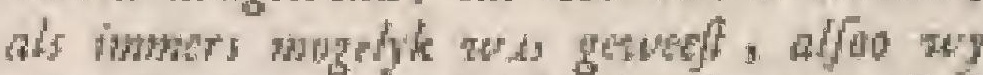
weren, dat wo merklyke dim/t wan bet $R$ y

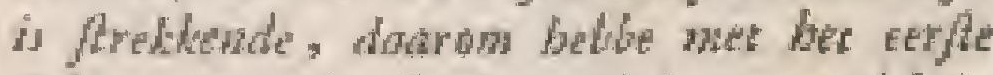
Sclup zal wel gefonden, als 'er gewoght in konde geladen puerdens, maar me defe ruve wolgende tehom UE. Majefleit, zoo God de

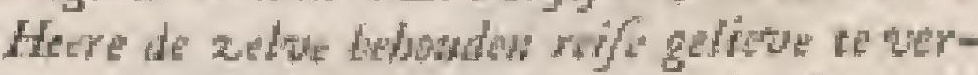

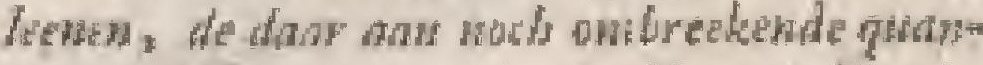

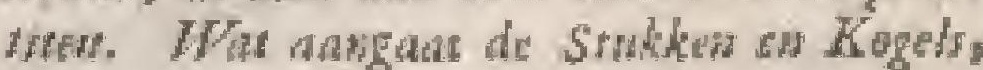
doar mede is "t zoodang geldgen, dat "er mer bet erilte Suldip zoo wed Kogels gegan ayn, als 'er voorlecden jast gefowles zyn, ent wh defe scluepen zunden ouls wel enrge golonden beblen, zoo whe haddes waten te bekoment, on dat bet ons behend as wit de Bricven vam wave Majefteit, dat deflue geford is renOorWh te gran; doch 't is ow net magelyk ge-

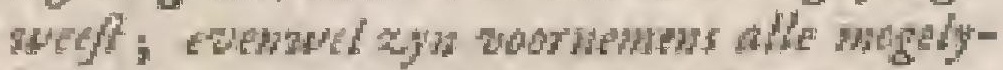

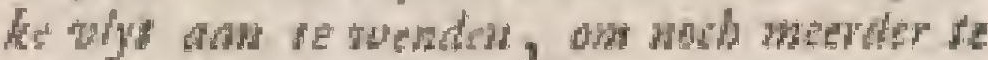
bekowers in tokownde, endan ternden alles, what allow boben knues ben brengen boven

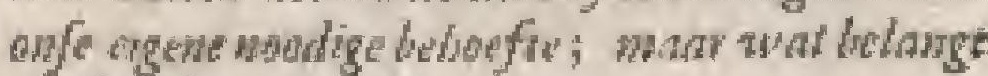

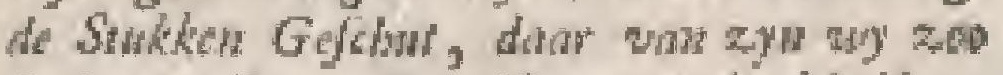

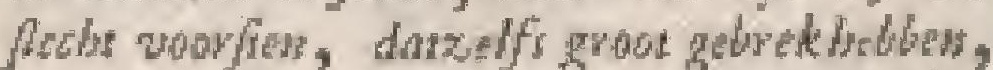
te weer, desyl wy grape gedadten hebry van Oorlos, zoo dat wy alle berdenkthlee middelon ranusaden, om ons selven darar wan na blhoren te wonffen; walbons op dat niet aowde folywen, als of renge onwilligheit

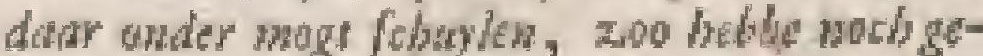
watden rase fohoone Metale Scroutders, die

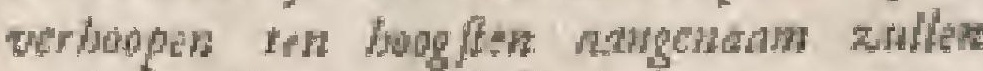
weren: Het is ons befonder angewarn gewheft te werflan, wit den Briff wan a Ma. felteit, wiesgaders "i folrywen wats onfe Kapitein, wo 600 ponden fruarte $Z$ yde wederom befchonden water, dar art dar bope fobepen, dat onfe wriendichap of en goede grond geweft ajnde, zoo lata zal dwaren als Zon en Man bar fobyef ant 


\section{$\checkmark A \times T O$}

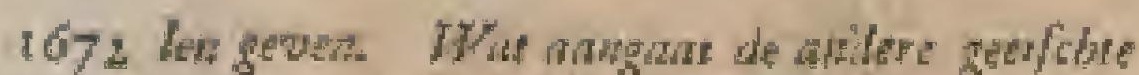

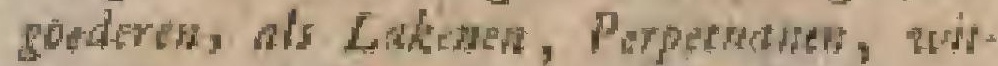
re geforterde Lywaten, Liflubole oly, de-

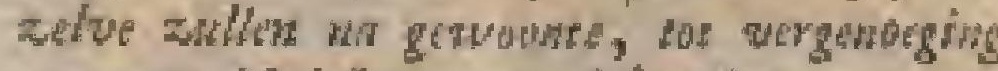

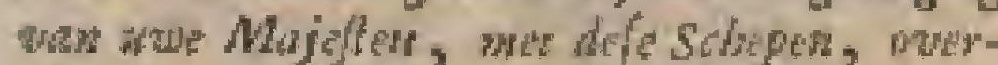

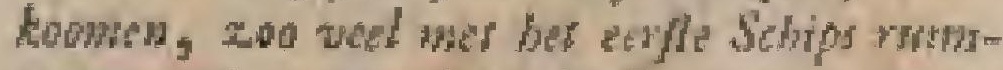
It te zenden, nagelaten breft modton werden, witgefondert dat an jour weer fober wath $L \mathrm{Cl}$ -

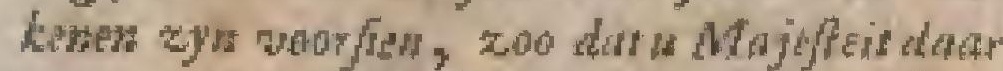

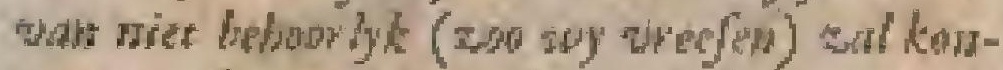

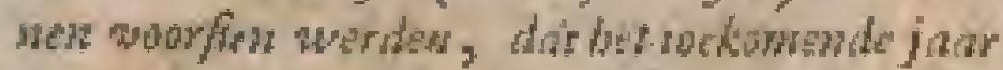

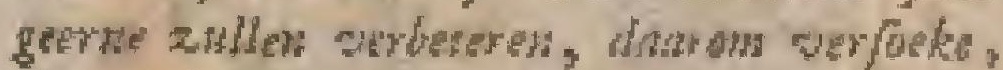

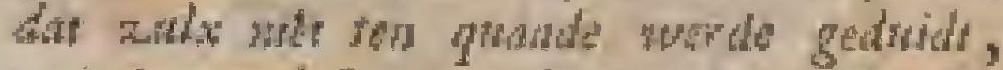
mperder ow defu te wrlagen nist hebende, datarn endigen wet eocwanching wat alle

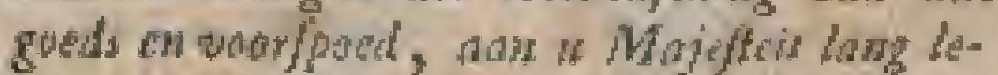
ven, welltand zymer donden, in werneserdering der zolve, dow en war foedtigen Oor =

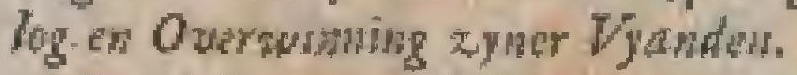

On defe te vorgefercuppen, en onfegoede gengenhis for UE Majelteit te bownen, whar niet om dat bet wan eenige watrde zy, zod gant het wevent bet naturolgende, te witen:

2 F. Stharlskest.

1 p. Grom Laken.

1 p. Zwart dito.

I pi. Bhanw dito.

5 fux diver $\sqrt{e}$ Kronradtent.

10 diso fyne Mrezidfer.

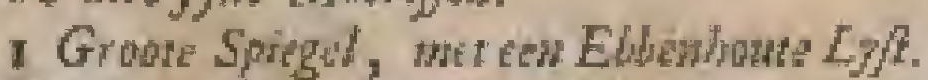

Wy verloten dat w Mojteit het mete est gotde gowgenhein geth ve te anworarden, th
N K I N.

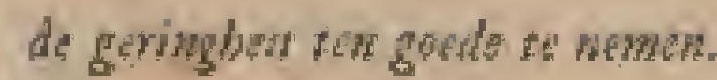

1672

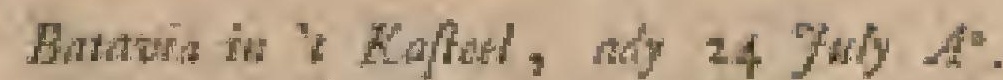
1672 Onderlewd de Gonvernter Gone raul, en wat gretekend.

\section{JOHAN MAATSUYKER.}

A. I691 wierd de Heer Silwas wel sibeas over enige berchadigde Pelines ma Wa- Coun-

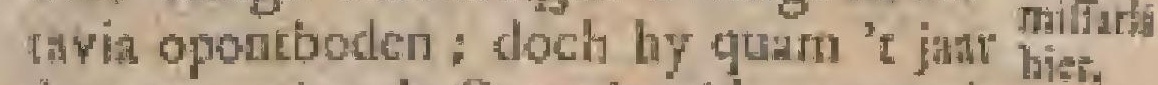

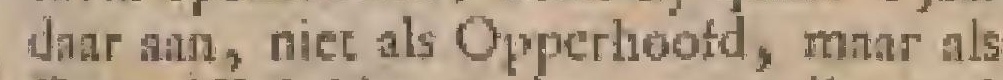
Commiflatis bier weder, en na dien cyd is hier de Kooprian de Heer Facol was Loo, eerft met zyn tweeden $N$. Lenderdfow en daar na met een ander, tot $\mathrm{A}^{*}$. I 700 geblewen.

Wat geweldentyen delen Heer (zoo by my zelf wel verhatid hecf) wan cyd cot tyd door defen Koning angedaan zyn, is niver wel op te noeraen. Zelf is hy in perloon ook verlchide maten gewangeri gezer, als "t gelchenl harer Edetheden, ma "s Konings gedachten, te gering, of riet na zyn zili was.

Eindelyk is yyn E. dit rier largger Dit komende harden, volgens ordre haser comp-

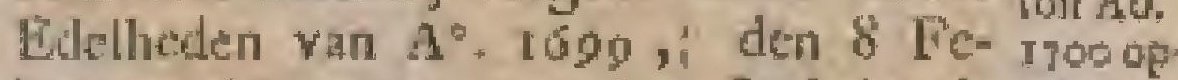
bruary $A^{a}$. T700 mer her Jachrie de pubro* Cacuw, mec zyn twede, Copralis de kea. Fives, en met onze ganfchen omflay van datrop Bata. gekomen, na welken cyd wy op dit Rylz" niet gehandels kebbęt1.

\section{G O $\quad$ D $S S$ D

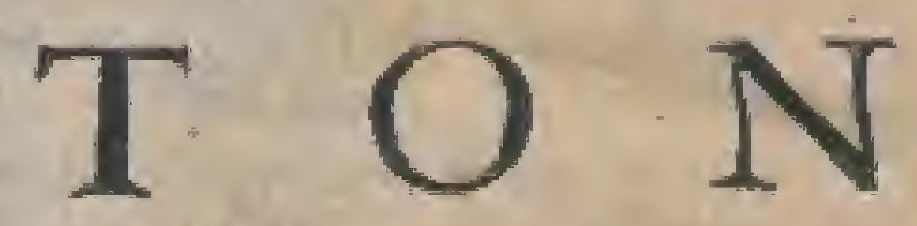 \\ Van den T T then Godsdicnl, in't Ko- \\ weren de Heidenl he en de foonto die hicr van gebrailk, of noch $2 y n$, of gewcelt zyn.}

I $N$ Gods:

dientit in

Tonkin.

\section{DE HEIDENSCHE GODSDIENST} bicr.

De Hej- De oudle en de rechte Godsaienft der denfthe. Tonlinders is de Heideniche, enzy zyn, gelyk de Chinecten, en andere volkeren dasar om fltrecks, Afgoden-dienatars.

Zy Alellen wel waft, dat 'er cen Op' pernachrig Weien is, dat alles beftierd, en op alle de daaden en bedyyen der menichen let, en die bes ook hier na,

III. DEEL.

\section{I $\quad \mathrm{E} \quad \mathrm{N} \quad S \quad \mathrm{~T}$}

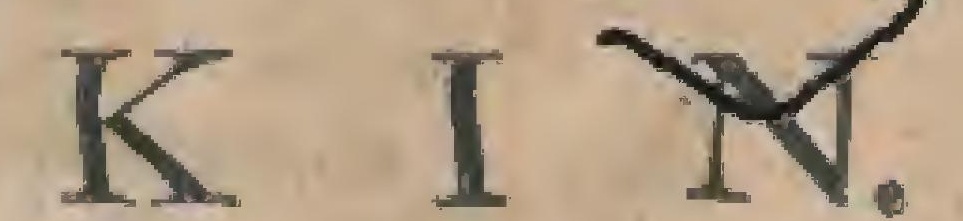

zoo na de Zicle (die zy als onflerffelyk aammerken) als ma den lichanase of atraffett, of beloonen zal; matr hee begrip, 'r geen zy 'er af hebben, is zeer neche, gelyk' zy dat zeer klar in de verfcheiden wylen van hen re verbeclden, doen byken.

Ook ftellen zy vaft, daş zy hem juift 7.6o neerftig niei behoeven te dieneri, alfon by dog valkomen goed is, en atn alle goed doer; matar de Duivel is hen een groot Vyand, wan den welken zy vart itellen, dat hen alles quads gedaan werd, dien zy derbilven door veel Offerlianden trachten te verfoenen.

De Afgoden, dic zy nanbidden, hebben zeer wanftallige gedfanten, zommige na dele en gene tnenfehen, wel E

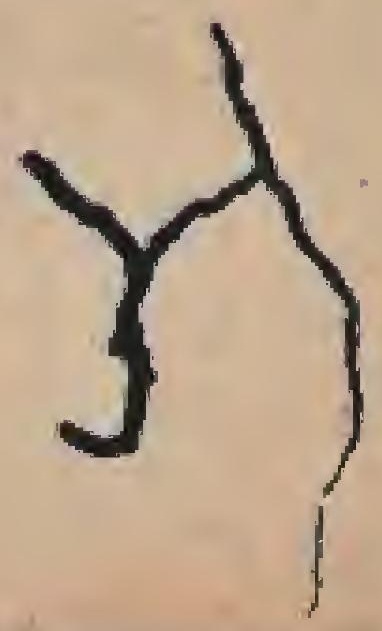


erer als groore helden by hen bekend, andere were delecngene $W$ angedrochen, of gerantylse dieren verbectende, gebyk men us telve in menigte in hume

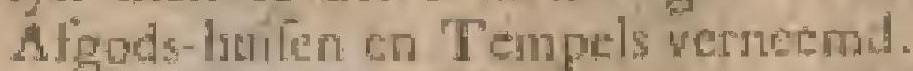

lins defen diente humaer $A$ tgaden heb-

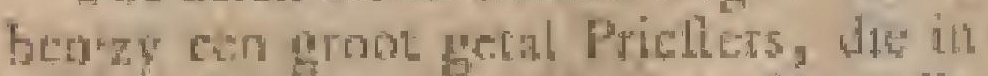
dient, klecting, exe. niec ves wan die der Chinerlenverteisilten, gelykook weel

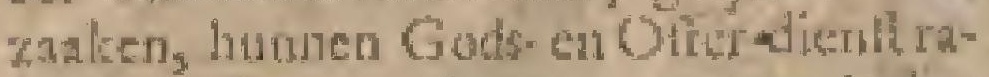
kende, war mede ten grooten deelch vier con limea.

Zu hebben oolk juift sem valte én gelette kylen, on humen Godstienth war te nemen, mage dragen datu zorg voor, nat dat hen dele of gecre by fondere nooden drukken, als wameer lacis de Priefers de otferhande, welke zy in dat gewal et doen betben, en welle in burne handers komen moer, woorlchryven, wan in wel 't voorandende ven humen Godsa dient beltair, wan den welken $2 y$ ook, zoo lang 't her wel gaat, geen werk ter weredi, gely $z$ y ook gect vitzondering wall dagen maken, din alleen, dat zy wee groote Feet - tyten hebbat, van welle 'e cesle op han Nicuwe-janr, of wel op de ecrlte nicuwe Mazn vais hun Nieuwe-jasr, na het midden van Jantiary, en het rweede ontrent hee begin war Juny, the dat zy in Mcy hunner Oegl in de fehuuren perfamelt hebben, begine, op welk eerlte Feclt.2y wel een weck of twee an cen mooi gekleed, en zeer wolyk zyn, brengendedan, en ook op 't volgende. Feelt, al humen tyd met defe en geene fpeten door.

\section{De ROOMSE GODSDIENST bir.}

De Schoot de Roomithe Godstientit hier

Roonfe. Anweing belang, en "er nu byna niec ma bekend is, wocten wy "er echer vill hegeny geen wy tär witu weo[e]:

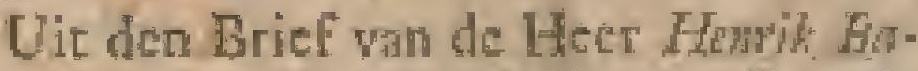
row, nan den Heet Buih fohop op Batavia A. I a 3 blykt ons, dat Atresmadr de Rhodes, een Jetuit vin Arignon, hier $A^{\circ}$. $36 \pm 6$ alleverd gekomen is, om op. de wrye der Roomsgefinden hunae Lecre hict voort te zerten, dite il echige iatren nan cen ingung by defen lulander gehad, hoewel die dat op geen anderen grom nangenowen heef , dan met dic hoops , dar hen dic nieutwe Godsdient gelukikiger dan de Heidenliche maken zoude, mas toen $z y$ befpeurd hobben, dat $z y$ naceft arm waren, en arm bleven, en dac hen zelit ook meer plagen, dan wel beworens, overquamen, bebben de Tarkinders hen zedert $A^{3}$. I 663 nier alleen begtimen te verwolgen; max den Koning hecf alle de Jeluiten, en de werdere Chrifteneth, die 'c mer hen hoiden, den zo Sepumbit

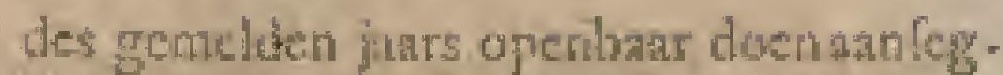
Ben, dur zy wis zyo Rykzouten helben se verreklem, dit dat op ook gevolge is, zorder dat men luen zederte har west de villermintle Eoegang vegevern heth.

Dic besic echer niet beler, dat er ondertutichon is thile dete en geene Pricters getoneo zyo, onder wellec lich mede her wands rervoerd hebben Domnisws Fucis, een Napolienar, cn Lha-

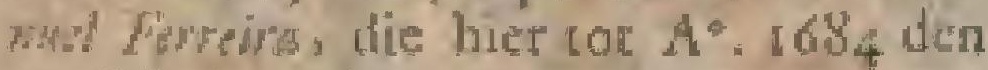
29 Ootubergeblewen, enden 23 Decenber des gemulten jats, meteen Hollands Schip op Batavio geliomen zy.

De cerfic was ontrent 30 jarien in Indien, en ib hicr geweedt, enwel ho a I I jaten datar, dat hy by dag niet dorft th vooslchyn komen, en lich dan in cen Varruig ophield, beloekende 's anchts de Chritenem, on zyn dienft te dneta. Ook had by "er alkier sooo gedoopt. Hy was na Roomen ontboden, on lich te verant woordem; doch zeyile eerlt over Siam nogeens na Macao de fullen gata om dat de ordre van zy overlte Bie af te halen. En zulle zyo 'ce warrich nelyk meer geweft, rchoon die my otibekend żyn.

Derhalwen zyn "et hier" en dar noch wel eenige wh die Chriltenen is 's resborgen gebieven; mas indien die uitquan, zouder zy raet de dood geltraft worden, watrom hich rut geen andere, dan de Heidenfche Godstient, beliend is,

\section{Fin den GODSDIENST won COETSJENTSJINA}

Wat den Godsdienfl ran die ran Coc- Van den isjentsjtm berrelt, dic ver[child in den Godsgrond nict yaf die der loukirders, of dienft de Heiderilche, gelyk zy ook ewen de tsitem!sjzelve Joore wan Tenupels, Prielters, Fee- $\mathrm{ma}$ Ater, Plechigheden, en H. dagen hebben.

Mat buicen defe is onk eenige jaren herwards de Roomiche Godsdiendt dasm ingevoerd, hoewel dit theeft in der filic, en juift zoo openbaar niec lehynd to pefoliester.

Ten tyde der onfe Schipbreukelifigen van 'c-Schip den Arion hier quamen, vouden $2 y$ hier eenige Franlche en andete Priefters, ondtr welke my dere met rantre voor homen: Pierre de Bewe, Pas-

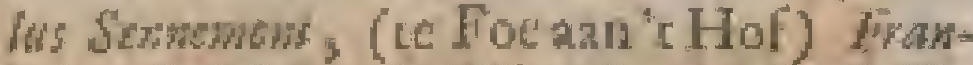
isfas Godefray, (ceTleun) Antowiode Das Cordilas, (te Faytoe) Pierre de Flenty, (de vy de Frantche Pricter, dic hier quam)

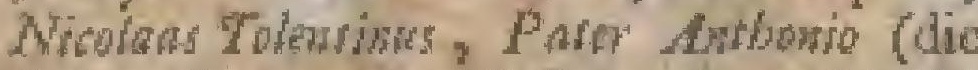
fich te Foe ath 't Hot mectt onthicid) cn Parer Emanud.

Door den ywer defer Priefters zyo dar (zoo zy voorgeven, en ook den on en geblecken is al zeer veel Chriftenen op. huane manivere gemakt, dic ook 


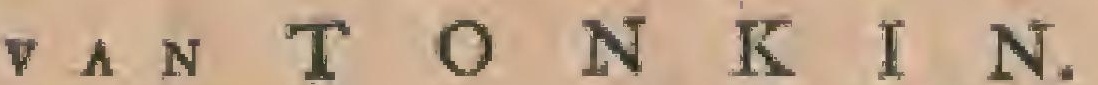

al viy neerfig ter Mifte fomen, en hunnen Godsdicnift zeer ywerig warnemen.

Ook hebben werleheide vandefe Chriftenen groote bewyzen van liefde an de onfen gegeven, met; hen te fpylen en te trooften in hut ongeval, waar toc dic brave Parers de Heare en Godefray woor. al het huntie gedan, en cindelyk gema ak hebben, dat sy, wan allen verlaren, en wan het hunne beroofd, noch zoo weel geld bequamer, als zy wan nooden hadden, om uit dit boos Roofneft in Siam te gershen, on die penningen datir fan zeker Franich BitTchop weder te geven.

Ook was hicr te Niaroe een Biffchop, Maryn Labe', con in 't dorp Daing noch een Frawgi/cos do Bruge genaand, door welker ywer, met die van hunne mede. fendelingen, dac gan ech land door in die korte jurren reeds zoo veel Chriltenen gennale waven, dat in 't Landfchap Cjam alleen wel 40 Kerken en 10000 Chriftenen, en in 't Landrchap Hoc, dar natt an gelegen, wel Bo Kerken, cn wel zoooo Chriftenen gevonden wierden. In voorige tyden ontrent $A^{*}$. 1680 , of wel cer, zyn bier Dominicur Futit en Emawhel Ferreira mede gewreft, en de ecrthe wel 8 jarr; in welken cyd hy wel 4000

pertoonen gedoopt had.

War reden nu de Koning heef, on dit in zyn land ce dulden, is ons onbeken , hoewel ikgeloove, dat hy dit nier doet, zonder daar tuit groote woordeclen en nutrigheir te trekken, behalven dat liy ook hu en dan wel wan defe Priciters (war onder men zeer bequasme mather vind) tot het warneemen van Gefantichappen, en tot het verrichten wan gewichtige znaken in andere Ryken, gebruilis, gelyk by, cenigen tyd geleeden, Pater Antomie zoo nis Batavia gefonden heet.

Mari, om rechruit de borlt ec lpreken, it geloove, dac het mee den ChriftenGodsdienft darar ewen cens is, gelyk op weel andereplanten, darar lich defe en gene Priethers hebben nedergefer, en dar zy wel veel mocite angewend; maal zeer weinig gevorderd hebben. alloo 't den Inlander weinig ter harten ging, of ook weinig ingang hebben kan, om dar hen de zaken nier in dengrond, en alleen matr in hate buiter-fchor voorgefteld werden, om wellke reden zy er ook al zoo heht weer af ftappen,als zy zulken Godstienft angenomen hebben. Zoo dat dit mocite en kolte verloren is.
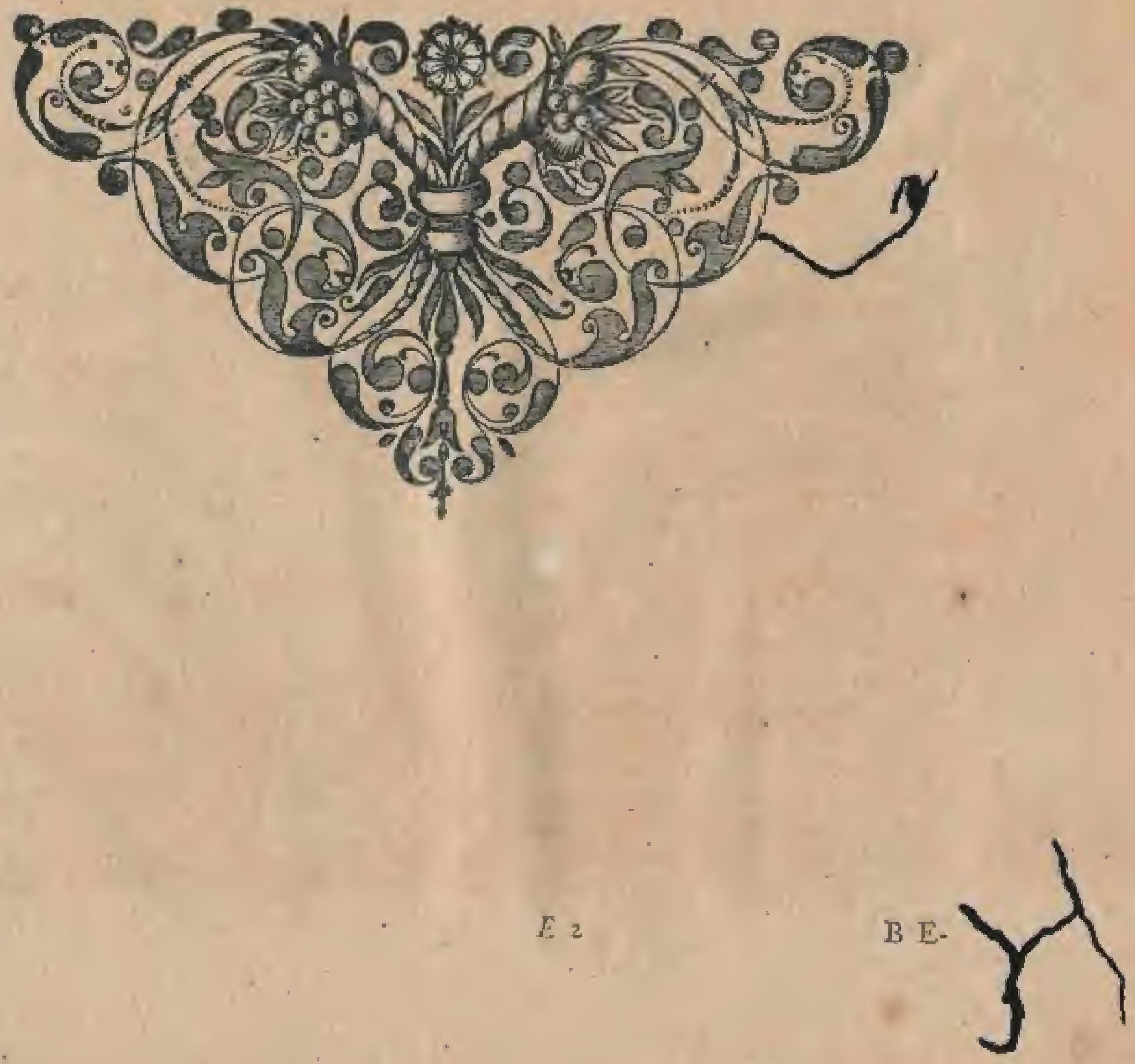


\section{B E S C H R Y V I N G}

\section{VANONSEN}

H A N D E L

I N

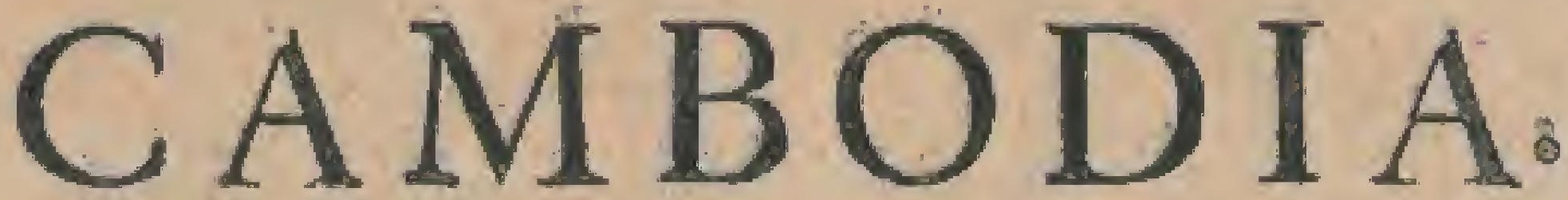

\section{Y F D E B O E K.}

\section{EERTE HOOFDSTUK.}

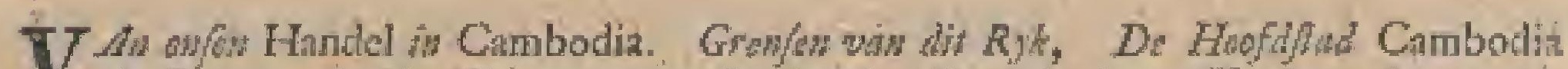

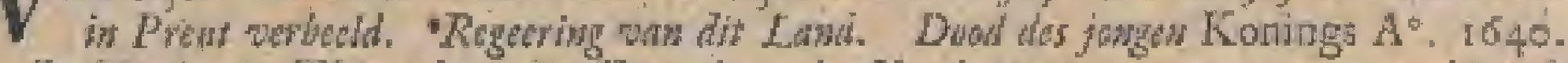
De Koningin Thimeds. De Zow do waten Konings als zy wervanger we dhard. Dod des onden enjongen Konings $A^{\circ}$. $1 \alpha_{4}$. Onjendig vorbal. "s Lands Edelen, en

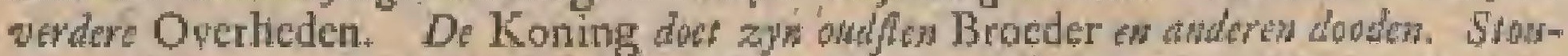
ten eflch wan zyn Geheim[chrywer, dien hy ook won fon belpt. Elmdige dood der

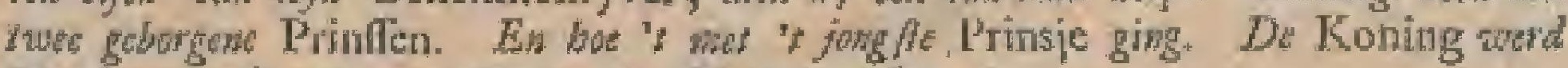
Mohbrammedans, ons zoler op des Throoli to byver.

Varn on-
Jea Hañ
dicl in
Cambo:
dian kcghe
T dae wy ron Tonkin, als zecr groote betrekking tot den Handel pan Japan gehad hebbende, leat ft getproo

ebben, konnen wy nier nalater As wan diers, dic wy eenige jalaren in " Xouingrylorn CAMBODIA dreven, to keofen, thoo die sroornamelyk mede op den Jupratoluen Handel gefien hecfor, hoc wel wy darir niet zecr vee! wat zullen voor te ftellen heblen.

Het werd tan rommige Camboyn, wai andere Cambodia, en ook wel Cambodja of Camboetśa gemant, gelyk ik thet een Maleyts Tractant, darivan handelende, zou komnen tooner.

Dit Koningry grenft allernanit an dat yan Coersjientsjina, what aan men cok wil dat het al zedert $A^{\text {th. }} 171$, zou cynsbant geworden zyn, en "t geendoor cen groote rey wan gebergten, die wan't N. W. na 'r Z. O. looper, van een gefeheiden is.

Grenleh Het lege wat bezuden die Riviej yan wan dis Ripk

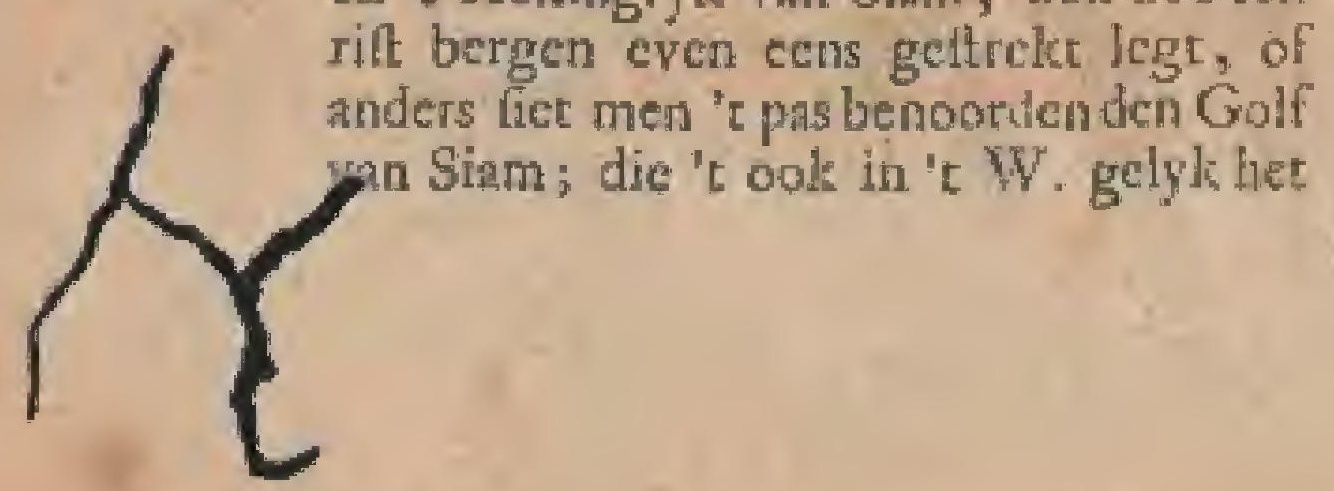

in " $\mathrm{O}$. al riede de openbare Zee heef of anders fteld men ook wel, datde kuft

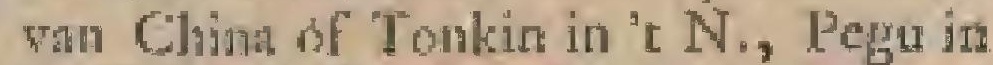
"E W.,en't Koningryk der Lowwen in 't O. lege, cn dararangrenls. Menkata het nee ind de Kant No. I. A, woor aan die Werk, dien, dat men alle die nuby gelegene Rylesi ook zeer nee by een lieefr.

Het legt op 1 i gradetibenoordenden Eventan, en op de lenge tan 128 graden en 5 minuten.

Hoe groot die Ryk in zyn utubreiding

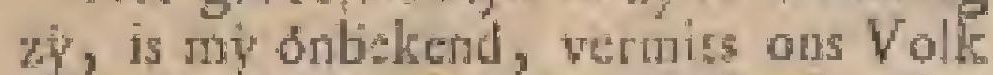
dit, noik wan binuen bereifl beefe, dad dac $2 y$ eens gelegenheit hadden, om eenige bedienden in gefantichap na "t Koningryt der Louwen te zeniden, whar van wy hier nia biceder zullen fprecken.

Hee bett van allen is noch beliend de $\mathrm{De}$ Hoofdltad van dic Ryk, note Cambo-Hoofddia of Eeavwelk gentame, doch wel 60 Canbo mylen de Rivier Menon of Mecon op- djain gelegen, wellke wy $\mathbb{N}^{\circ}, 33$. A in Prent Prent zeer cierlyte qerbelden.

Hoe men wan Batavia dast na toe zyo kours fteld, kan men uit dele volgende Inlluctie, $\mathrm{A}^{\circ} .164 \mathrm{f}$ door de Heerenva

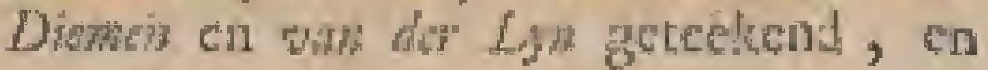




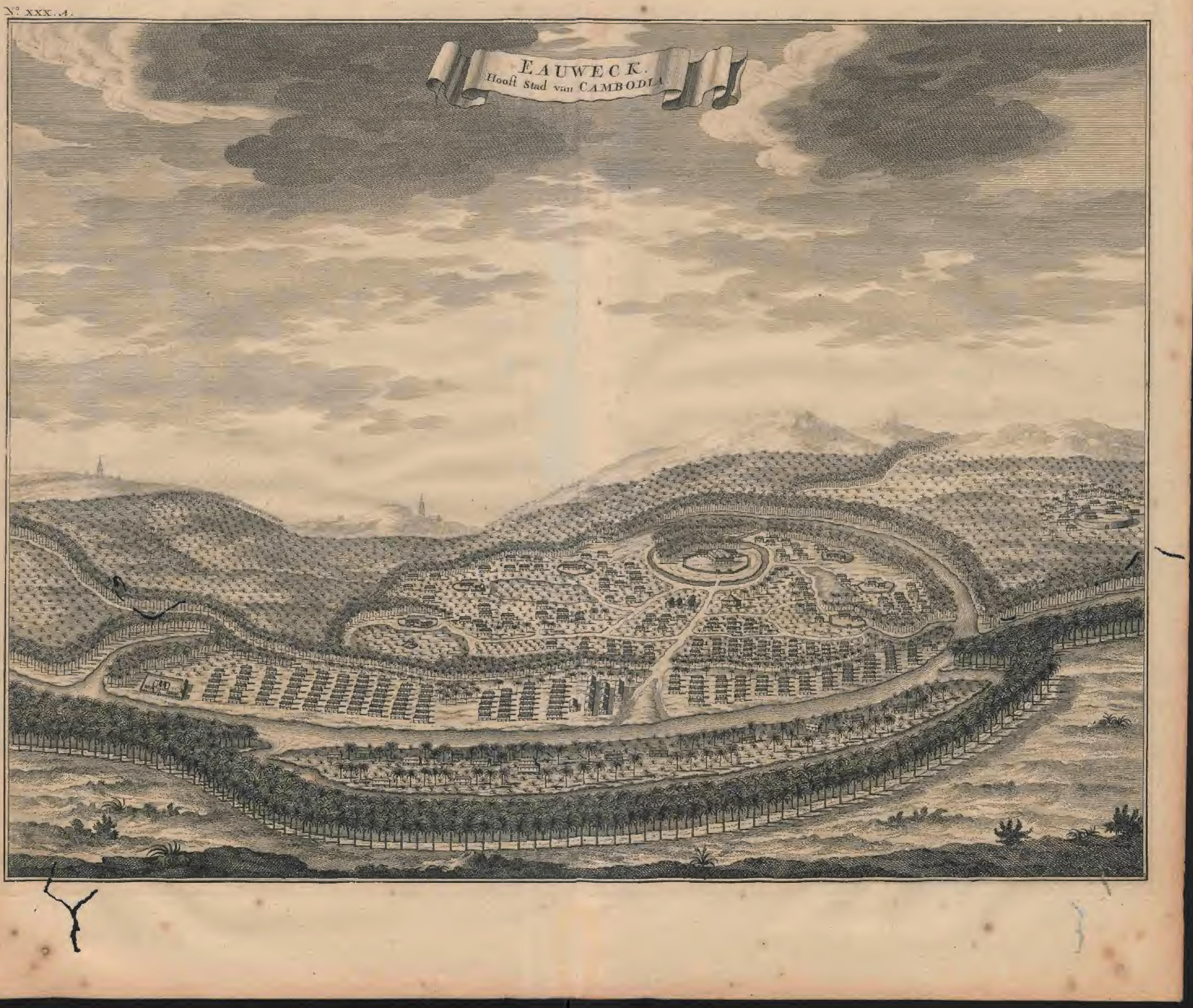




\section{BESCHR YVINGE VAN CAMBODIA.}

nan de Opperhooften $w_{\text {an }}$ he Sclip Ootthapel tnede gegeren, lics.

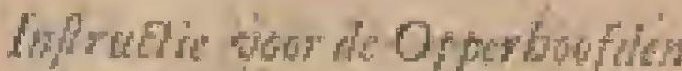 wan "t Fut Sebio Obll-Ca. fol, wn if zalen san def Whate, the de Nivier vat Combodia, co cuders nis Tayen.}

$U$

L. werd by defert fordontinect op morgen rroeg; nia gediane s monftering de voyagic tan te vangen, 9 en datr toe de cours wath hier na de 3. Atrant vin Palimbang te zerten, om 9. bcooftein of bewelten Lucipra te par 3) fecren, cn too poorts it' 'gefiche vat? "Linga en Biniam ann de Ooit-zyde te 3, loopen, wyders na de Eilanden Poelo "Picflang, Pocto 'Timon, die gy mort

,2. trachten te verkennen, om van datir x, cen walte cours na Poelo Condore te 2 Atellen, en alfoo de Rivier an re zocb ken, by of ontrent de Rivier met lifef * gefomen zynde, tuhten UT. voorvifehtig zyn, en wel docn uicfien, de "3) boot, om te diepen, voor al zender, s. en 't lood van gelyken bimen boord 3n gettadig laten gebruiker.

3. Om het oper van de Rivier Balliale 3) wel te vatten, en niet is de Zantbar. $\Rightarrow$ ken te geratken, wat door uw Schip j) en volk in perykel gebrache, en by is gevolg de Compagnie zulk een fchi, delyk ongeluk, als har (Godtbeterd) is thet hec verlies wan 'r. Schip Noord. 3) wylk $A$. 16,6 owergckomen is, on3. derworpen zou werden, "t welk UE.

3) ten hoogiten aanbevolen blyfe.

i) Zoo hart Gul de Cumbodiate Ri35. vier hebe gewat, en dan binnen gelo. is men zyt, zal de Onderkooproars of 3. Botkhouder defer Fluit fich tentond 3. per Schep-Praetu met onte no3) vensgande brieven na by de $\mathrm{Op}_{\mathrm{p}}$ " perkooplieden Pieter tan Regewortes, 3) en Herman Beokwasts werwocged, on "van Ul. ankomith repport te doen, 5) ten eifide $z y$ nict alleen ordre ftellen mop het loficn van bet iuhebbende car3 gnloes voor dat Comptoir; masr ook 3. dadelyk afzenden, "t geen wy ordons neeren yan dagr na Tnyouan we woeren, 3. om 'c zelve in der yl over te neemen, 5. ch darar mede; zoo halt doenlyk, det" waats te narigecren, watr toc ook j) dienftig zal zyn, geroende Rivier zoo w verre trache op te komen, als 'c mo. "gelyle werd, zonder ondertultich liet ". lofen en Jaden te verzumen.

, Wr yeconmandecren con belalten UH. "dienvolgens tot fpoedige bevordering 3) van 't een en 't andier geen itver te 3. Cparren, ten einde van daar na Japan " gebruikt werden moogt, war toe u wa de Almogende zynen mildryken ze2) gen gelicve te valechen.

"Alle Sparjatarten, Portageeren; en "andere Natien, die zonder onfe paf3) fen vearen, belsaken die var Palims bang, Jambi, Siam, Patani, Djo: , lor, en Cambodia, als nu geen $\mathrm{vy}$ " ands platitea gan, zult gy antaften, " en in uw geweld fien te belomen, " hatre goederen in eco befoorlyke in" venturs over necusen, en $L$ vandeper") Coonen wel verfetecren, infonderheit 2. aok in diervegen lnedig uitfen na 3. Coetsjiendienteen Matame Vartuin " gen, "t sy die vath das komen, of

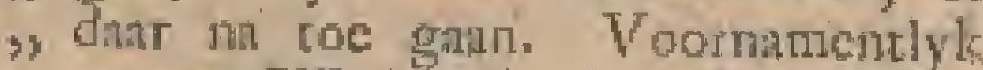
"Moeren UE. ierter, dac vatitonfe $\mathrm{Vy}$ , anden (gely. $\mathrm{Ly}$ nu door 't vocren wan $y$ onle en andere Vhagen prablecten) " nice misleid ofbedrogen werd. Wes"Thlven niemand, dien mar bezeilen ", kond, wat Viagge of tcelten de zclvo "voeren, onbckend zult laten varen, "motar woorliclucelyle vifiteden, er "Vyanden bevindende, datat mede han, delen, als voomen gelegt is, mirs dit "zulx gefchiede zonder merkelyk ves„ fuim van tyd, atloo an uwe lpoetige "werfehyning er belcheiden platic de "Compagnie te vecl gelegen is,

"UE Gan gemant mee 40 koppes, wen te dier bohoefte geprovidect wan „3 Alles voor 12 manden. Mrakt 't ec" De en "t ander ftrelkke ha behooreu. "Adminiftreerd Jultitie volgens denge" nematen Mrtykel-bricf, en blyfe wyin ders Gode bevolen:

\section{Th \% Kafled Barawa}

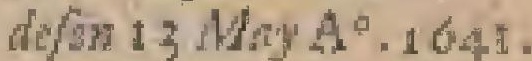

\section{Lager Aolit \\ ANTONIO VAN TUEMEN. \\ CORNELIS Y YADEUT $I_{1} X N$.}

Een groot cjelud der tha is "s Ko- te Plet

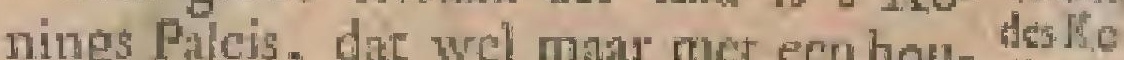
te lheldurs omict, doch van binticn zoo pings. neE gebouwt, en datr al her hourwerls zoo tohoon vernift cn verguld is, dat hee 'er alles win enkel goud fehyne te zyos, gelyk men dan ool zeer vel heerlyke disgeri van Goud en Zilver genaake fiec.

Defe vefting nu, fehoon war hour, is hier en daar met zuer veel Chinees Gefoltur, ook tmet z. Holtandfolie ftukken Finnoh verfterlec, die de Vorlt su en dan wan de Jichteen Goa en Noordwyk gelasegen heeft. Ook zou men dic ten eerften, lonmige op zee cierlyke blauw. gefehilderde; en ardere op lwart-verlakte atfuyten leggen, alle zeet net yan wiffers; $E_{3}$ 
lepels, die wel Zilver fchynen te zyn, en verkenfteerten, die mede zeer blank gehouden werden, woorfien.

In de voorige cyden plachcen dele Koningen te Batsjong, ertelyke mylen en dagen reifens landwante in gelegen, hun Hof te houden, om dat ay daar dichter by de landen, dar 'c Goud wale, waren, doch zedert de Koning der Jourwen hen met den Oorlog dreigde, zyn zy de Rivier af vect lager na de Zee-tente afgezalke.

Dele groote itad nu werd doot verrcheide Volkeren, die op dit Ryl batideleri, doch woorimamelyk (buiten hunge Inge(ctenen) door de Japanders, Portugeelen, Coetsjientsjincelen, Maleyers, en mecr andere Volkeren, bewoond, die ficht zelven daar meeft langs een zecr langen dyk neergellagen hebben.

Zommige woonen dar altyd, andere weer maar' voor een korten tyd, om hunnen kandel ce dryven, en hunne Waren te vertieren.

Het is in fich zelwen cen lchoon vrugtbagr land, dat owervloed hecfe van Rylt, Sluwen, Matren, Zpde, Rontingen, Gomniclak, Walch, Chinectele Yicre Punnen, Kopere Bekkens, Rochevellen, Pecrden, weinig Peper en Tin, Murcus, Rhinocer-hoorns, Benzoin, Hurte, wellen, Goud, Olifants-tanden, en andere Waren, " $\mathrm{z} y$ darar, of wel in de nabuarige linden wallende. Doch het is meet onbewoond, en "t liefe veel Kieden, Rivieren; ftilftande en loopende Wateren, alle de welke hraren oorlpronk uit een binnen-Meir hobben, dat zon veel waters wan fich geefe, dat niet alleen de Japantehe Rivier, die tr. melyk wyd is, maar ook de Matfoante, cn de Rivier wan Cambodia, fich lisommende on de Ooft, al hat water zeer gemakkelyk konnen verwelgen, gelyk ook de zelve antrent de muand Augultus woornamelyle wel s, D, ja i en mecr woeten hoog lonnetr zwellen, wamneer zy wiet alken de boorilen hier en datr, maar zelf́ ook hee gebecl land alom blank zerten.

Regee- Dit Land is riet altyd op een en de ring van zelve wyce befticrd. Dat her in oude dithad. tyder zelfs onder de Chinicen geftatan hecft, zal ons uit de Brief wan de Hecr Baron, onder de ltofte ran China, hies na blyken.

Ook hecf het ontrent $A .1626$ noch onder den Koning van Siam gettaan, van welken zy naderhand weer afgevallen, en met welken $z y$ darom ook doorgans in Oorlog zyn.

$A^{*} .16: 2$ wierden $z y$ doorden Koning Fan Siam met 2 groote Legare, te water en te land, doch te sergeefs, anigetalt, alloo by, ta lang in de Rivicrvan
Cambodia gelegen, etr die bulegerd te hebben, eindelykopbmk, en elendig wan de Cambodiers golligess wierd, dar by wel menigmal hecte trachen te wieeken, doch dar niers op gewolgt is, nict tegenftande onfe Hecr Generaal lacm onle hulp en Scheeper $A^{0}-163+$ noch anngeboden heefe; datr van hy maderhand alle hoope, doen" 't oprechen van ons Compeoir hier $A^{\circ}, 1635$, velloor.

In de latel tyuten wil men dat $z y$ wer fcheide overvalien van den Koning wan Coetsjicntsjina geleden heblen, endoor den zelven $A^{\circ}$. 1715 overwonnen zyn.

Toen zy noch in der beften bloen wa* ren, of ontrent $A^{\circ}+1635$, waren hier wel dric Koningen, dic ook dit Koningryk in drie gelyke deelen op dele yoorwataden werdeeld hadden, dat de langlt-levende eindelyk alles befieten, cn aan alleen Koning van dit geheel Ryk oy zoude: hocwel de oudite wan dele drie Vorften toen echter in alle voorvallen mect geeerd, ontien, en gehoorfams wierd.

Onder den zelven, die beide de anderen noch overleefde, was dir Ryk in veel ruft, en in die iyden hecf onle Matfchappy bet darr ook zeer wel gehad, hoewel de Portugeelen, die hier op zeer ferly tandelden, ons veel nadeel toebragten, gelyk wy hier na breder zullen ficn.

Relts had defe oude Konting in vel voorvallen veel goedbeit voor ons over, ons vericheide dicnften doende, wan toe hy geenfins werpliche was.

A. 1640 in de magnd Juny therf de Dood jonge Koning, over welken de oude des fonKoning Oom was, doch lier dic jonge ninge $A$. noch een ouder Broeder na, die nader- 1640 hand noch Koning geworden is. By 't fterveh wan dien jongen Vortl verlocren wy zeer weel in weel oplichten, alloo hy ons overal, watr hy mats kon, zcerbeguriftigde.

Hy bleef atn ons Ior 2 Thayl, 8 Maas, rchuldig, die de oude Konimg an den Obna Calbom wil belikte te doen beratlen, doch door zyne hatafige dood is zulx beler, en op zyn tyd nier gerolgt.

Dele oude Koning hid ook een ou- De Ka= der Zufler, Nappra Thimeda gentand, Thimedie dar na isvede als Kaningine geéerd da is, cnvan welke has Edelheden $A^{\circ} .1639$ zeet veel weth gemalnt, gelyk $z y$ in dac jaar ook mee de Fluiten B rockoord en Oolt-Kappel in 't by ronder ana har Majelteit felureven, en heerlyke gefehenken fiar toefonden, "t geen zy wel meelt gedaan hebben, om door harewoorfprat, ontrente zelere parry Zyde, hen dooreenige moorddadige Chineclen ontvreem, wat berer te reche te raken, alloo zy toen wiet alleen een groot deel in de be- 



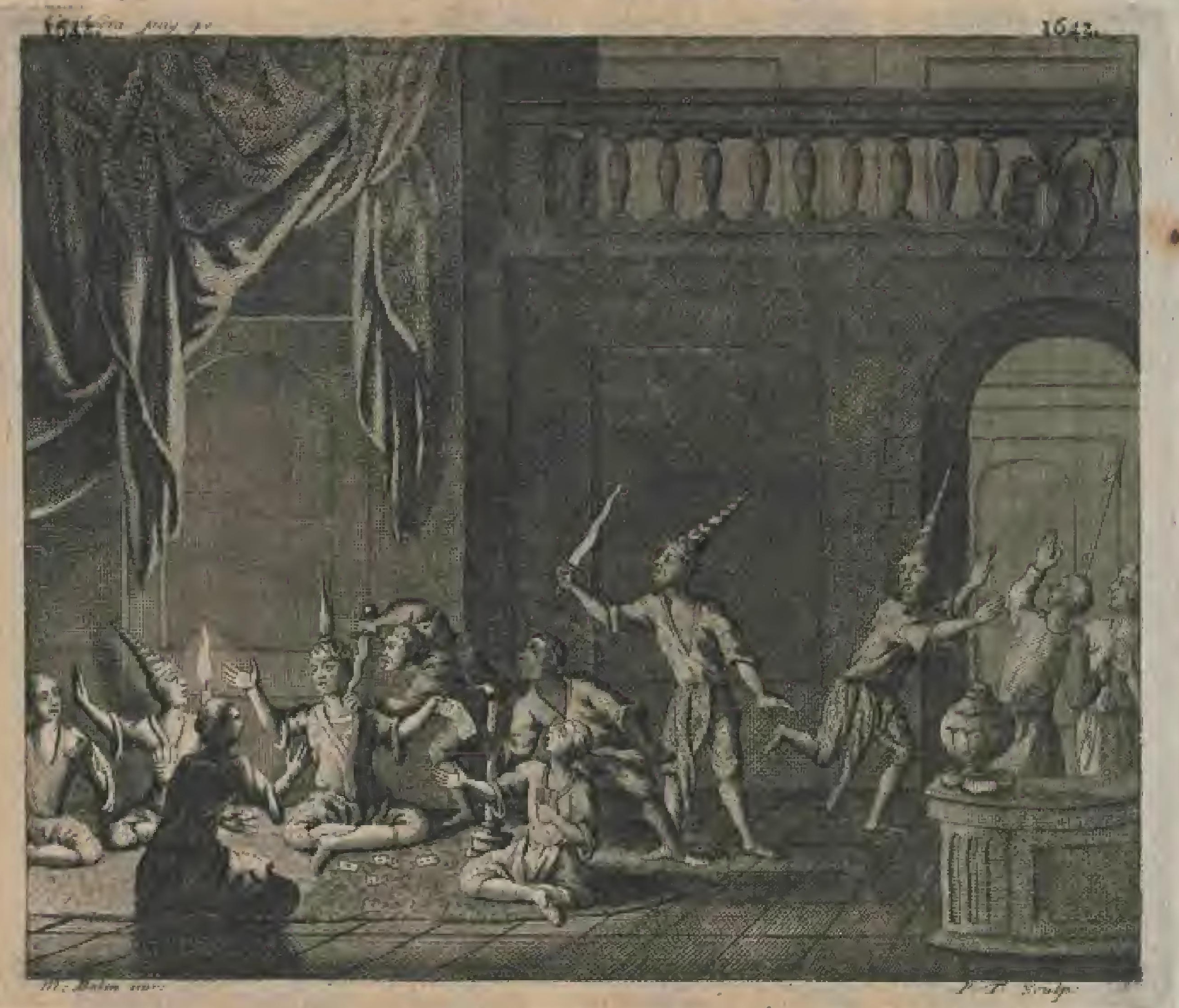

(dien hy tot zyn werwanger werklaard, en die fich na de Zee kant in de beneden. landen mer 6 a 700 man op de OlifinesJache begeven bad) om den zelven kennis van zyns Vaders dood, ea wan zyo makend gevare re geven.

Shoon de oude Koning nu dood woas, en, a veel Grooten, die hem in zynen toelèg hinderen konden, uit den weg gerum waren, was hy echter ther ftuk noch niet metter, alloo de jonge Vorft noch in "t leven was; dochi oin fich ten eeriten ook wan hem te antflaw, zond hy 3 of 400 wan zyne bette. en getrouwlte trocpen na de beneden. landen, daar zy dien Prins nog in zyace Jacht (alfoo hy nergens van wirt) befig vonden, en ten eeriten gelegenheit kegen oin hern wan kant te trelpen.

Maar daa" warea nog drie jonger Zoonen wan den ouden Korf, wan welke de een 6 , de ander 12, ein de ond. fte 17 of 18 jataren had, na welke meri wel flerk gocken deede; dog alloo de Pricfters dic onder hune befcherming genomen hadden, en zy nă een van bunne Kerken (daar hen niemard withalen, en waar an ook defe geweldenan, hoe flout liy ook was, niet komen dorft)

gevlugt waten, moeft ly dit verder op zyn beloop laten, agrende fich nu valt genoeg op den Throon gefet, als hy maar Meener var de Randen des ouden Konings, die nog hier en daar lwicrven, werden kon, die menter tyd alle in zyne handen viclen, en meelt aan een elendig einde geraksem.

Zommigen wan hen wierden gelkruifigt, anderen gecmpaleerd, eenigen wierd her vlectch van hun lichaam geineden, en lsan gebraaden zoo lang te ceten gegeven, tor "er niter meer dan rel en been aan was; en zoo zy dan nog nier beliweken, wierden zy door midden gelabeld.

Na dat lry nu de gevaarlykiten dus verre meefter geworden was, onbood hy de Owerheden wa alle de Natien, die fig hier mee der woon onthouden, en dee ben allen den ced van 'getrouwigheir aan fhern doen, uitgenomen den Tevinia, of 't Opperhoofd der $\mathrm{Ma}$ leyers, dic niet komen wilde, om dat by nog an des Konings dood twyffelde, dog eer by verleckering dar van kreeg, deet hem de nieuwe Koning gewangen nemen, elendig (om anderen af te (chrikken) ter dood brengen, en ianftonds een ander in zyn plats ftelien. 


\section{VA $\mathrm{C} A \mathrm{M}$}

I643. Ook ftelde by antonds veel nicuwe tr Land Okwea's, zynde decorfte en natte R $y x-$ Edclen, Randea aas den Konimg. Dere maken dereo. als cten Adel van her Lind, die doorvetie- Bants op de groose Land-vergaderingen 4sp. verlchynen, en lich door hurste bedienden een goude doos wan Stant (wane isi verfeticide kleener goude dooskens met Candamon, Cherjoe, Pinanggereed(chap \&c. zyn) doen nidragen, on dair door hun pragt, rang, en wermogen zan te wyen: want dit hen werdeo de eerlte Landwoogden en Gouverneurs der buiten-Landen gemaake.

Dus ftelde hy ook indere Tontmines (welker bedienden lien met zalke filvere doufen volgen) Tevinia"s, en Nappres, (ecn toout wa minder Overheden) aau, gevende alle de voornaume ampten ian geca anderen, dan dichy zeker wift voor liem te $2 y n$.

Hy nu vergens meer vopr te fichoomen hebbende, had egter nog een ouder Broeder, dien hy wel juitt niee vreesde, alloo hy wan cen goeden imbortt was; mar alloo hy zeer van 't gameen volk gelief, en hy in cegendecl zeergehatat was wan ieder, licunde hy beft, defen zynen goeden Broeder in "e begin van zyn Ryk decl in de Regeeritis te DeKo- geven, belovende ana hem diczoodanig, ning zoo lang ry lecfden, te zullen vervoldoet ook gen; dog unt hy dit geenfins meende, is zyn oud- naderhand klazr genoeg uit andere geBroeder volgen geblecken, alfoo hy, die gemeendooden. Ichap met 'er tyd moede werdende, fich niet onteig zynen onmoofelen Broeder te befchuldigen, dat by gefogt had met zyn Gemalin Perkale Sariry te bocleeren, dic nader met een setuigenis wan deltelfs Broeder bewcltigende, watr op ly ook kort dar na dien Broeder Atil uste de wereld hielp.

Dic vuil Atuk werd, zoo by ale Grooten, die zelfs zyn belte vrienden waren, als by de gemecute, zeer qualyl opgenomen, zoo dat hy nu en dan voor quade andlagen tegen hem bang begon te werden; dog on dit weer ecniglins gocd te maken, Ici lay alle de fchuld wan zyn Broeders dood op zyn Gemalins Broeder, van welken by coen zeide, dae niet zyn Broder, mar zyn Vrouws Brocder atn "c voornoend ituk felorldig was, alfoo hy zelfs gelogt had zyoc Gemalif tot owerfpel te brengen, enondertufichen de fchuld ann zymen onmoolelen Broeder, dien hy in zyo hert beklagde, té geven, om "I wellke dan weer tc ftraffen, hy nu goed vond den zelsen wanftonds cer dood ic nerwylen, om dar door, war 't mogelyk, de gemeente (die wel beter wift) weer wat zand in de oogen te werpen; hocivel men niderhand klimu'-

III. DE ELL.
B $O$ D I A.

$4^{\mathrm{t}}$

det ontdeft heef, op wat loofe gron if.t. den by dic ondernosisen hind.

Ondereufehen dasgde ook zyn Ge Stonter heimfehryver tegen hem op, dien hy be- eith wat loote lind newens hem decl in de Regee- heimeting te geven, en dic fich verbeclde, fenryet. dat hy fich om geen andere reden van zyn audten Broeder ontflogen had, dar om zyo belotie ontrent hem (gelyis hem dic wware ook al verlcheide malen wys gemalke had) zoo veel te beter te konnen nikomen; max als hy nu wan tyd tot, tyd verman, dit "er wan die belote mies quan, en dae men hem zelf nict eens Oknea, en nog maar een Tonimne, of Tovitia, Matake, begon hy niet alleen tegen dicn lwat, mar zelf regen den Koning z aer ftout te fpreckem, in zoo werre, dac by hem dreigen dortt 700 by zyne belofte niet naguan, wel middel te weecen, on hem, dien by toe de Kroon geholpen had, nog ved gemakkelyker dar van te berooren.

De Koning, die zullen ranl onge- Dien hy woon, en nive genegen was dit meet te metle hoorer, zond dien zelven awond eente woll, wan thant op hem uit, dat hem, eer den dag anquam, ftil watu hant hiclp.

Terwyl 'er nu niess meer lchecn ducrig te zyn, dat hem in zypo zoo vaftge. ftelde regecring oncruften hon, dangde "er eindelyk, ecn jatr na zye verlueffing tot de Kroon, een nicuwe fwarigheic op, die by wel ecnigfins gevreed ; dog zoo ras nog niet te gemoed gefien had.

Het waren de jonge Princen Kinderet, van den vorigen amgebrageen $\mathrm{Ka}$ oiug, dic ondertulichen een grooten manhang van ecnige duifenden, die hero beminder, gennakt hebbende, woorgenonomen hadden de lood van hunuen $V$ ader en Brodete te wreeken; dog de toeleg der twee oudlten quam wat te vrge tiic, 'want door hun anflig opedon wierd, en $z y$ gevangen raskten.

Zy wierden eenigen syd mer han ei- Elendige gen vlecich, dar men met riemen wit hun dood der lyf lneed, en hen gebraden te eeten gaf, borgenegerpyt, en eindelyk op cen Piefang. Princen. boom leggende, dwirs door midden gekapt; dog hadden voor defe hunueclendige dond nog de nieuwsgierigheir om de Sabels, want mede nuen hen doorkappen zou, te willen fien, om te beproewen, of die, on die te verrichen, ook wel feherp genoeg waren.

Ook zou hy zekerlyk zyn moorddadi- Lubot "f ge hander atan den jongiten Pring, nu thet het pas 7 jaren oud, at raede gellagen heb- Prinje ben; dog zyne Moeder, damis met dit verder kind hebbende, nam her "in haare be- ging-

fcheming, en voor har lithd atr, zonter dint if wete, of zy "c altyd tegen zyne ligen becti weten te dekken.

Nulcheen by al zeker op zynen Throon

F 
2.4\% to fiten; nater zyn cigen gowifie, en "t gettudig hocwel ftil morren wan "r gemien dede hem vreden, dat "er de een of de ander tyd nog wel iers tegen hem nitber flen ingge.

On dit nu voor te komen, en wat Then nier af te havigen, begon hy wan tyt tot ryd met de Jayanen, en wod bylonder mer den Landwoogd wo ]apara, wriendfehap te maken, er fig mer den zelven ook zoo verre in te liach, the hy, om lig by de Javatien en Maleyers te ana- 1642. genanter te maketi, Mohhanamedatins De Rowierd, cn aict allecn weel viyheden an tuing bejde die Narien in zyn Ryk begon te ver- Wrest

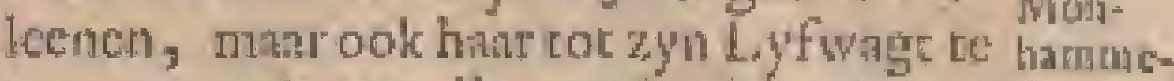
nemen, zedest welken tyd, deztaken in dama. die Ryk eer wonderiylken keer genomen bebben, war van onle Natie wel hec Tmercelykilte gevoelen zehad heet, gelyk ans uit her volgende Hoolditul, ioe ons leedwelen, nader blyken zill.

\section{T WEEDE HOOFDS TUK.}

D E veoraamfe Kooplieden ther, De Heer van Galen $A^{\circ}$. 1635 mo eaffe Hoofu

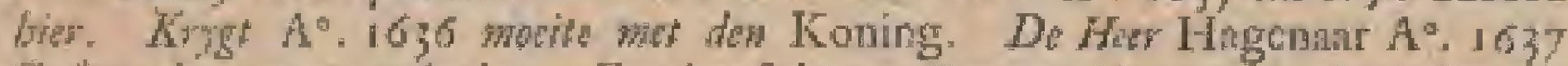

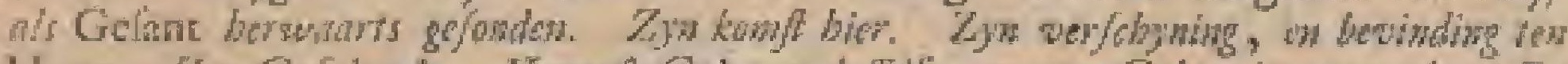
Howe. Zyn Gefchenk. Vergefs Gethor defflfs, en wan Guten in orgenade. De

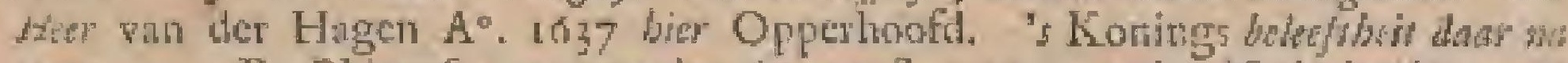
tigen ons $D_{e}$ Chineefen vermoorden $\mathrm{A}^{0} .1638$ a 1639 eenige Nederlanders, wi Tonkin geforden. De Herr van der Hagen A. I 640 owerleden. Raife ha "t Lasd der Louwen door de On/c gedan. Jeremits de $W$ aal, on ees Bootsman doer de Bor-

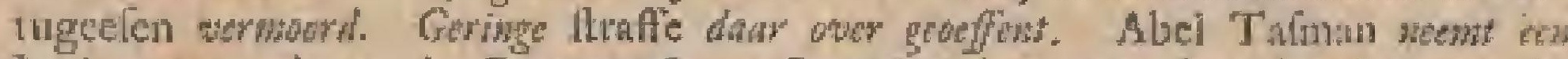

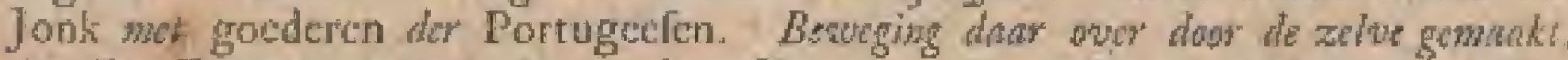

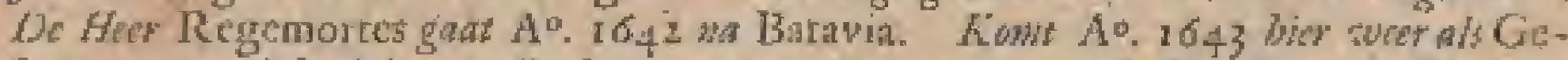

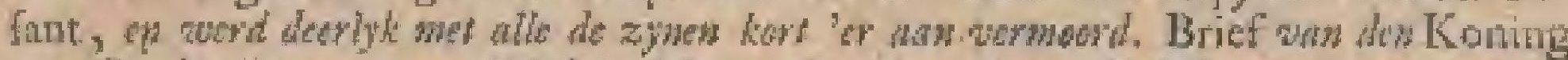

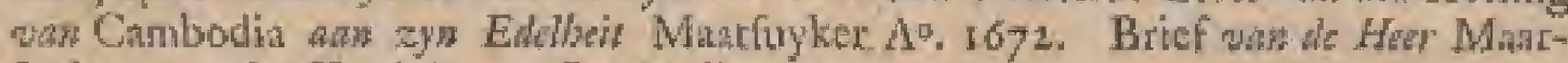
fuyker ada den Koning van Cambodia.

Da troormartle lingoplicdin line:

mers,

Nuler de Volkeren, dis in en op dic Ryte landel dreven, witren de Japinhers, Chineclen, Siamde voornamilte.

De ecrlte waren lier juilt nies heel Aterk; mata hadden lig mer 80 huisgefinner, te gelyk vit Japan gebannen, hier neder geftedd; cn fig by den Koning, dis 10.1637 regerde, $t z e r$ angenam werd te maken, met hem, tentyde dar. syn oudte Zoon reger hen opttond, en fich met geweld ecn weg tor de Kroon bannen wilde, in allen deelen debelnulp. fame hand re bieden, en zedere heet Hun Sjahbandaar ook zoo veel ingang by dien Vortt gehad, dar men geen ander, daz hem alken, noodir hat, om dezafetis wel te doen gelulkien, die men gereges was atn dicn Joning woor te ficl Iำ.

In ved grooter getal waren hich de Chinecten, dic ook, wolgens liunne gewoone, de ftid op en neder liepen, om den footrinamitten handel meelter te werden, zonryds de Warren tot zullien hoogen prys opjugende, date 'cr geen andere na denkei dorlten. Zy dryen hier Heoocon handel, es vans hice ook op Ja. ju, 'Tunkin, Quinala, Siam, en meer andere Rulen.

Met wat Woren hier gehandele wicrd, hebben wy bevorens al aangewerein; dog voornanclyk mec ruwe Zyde, en Ferrebeidene gewerke Zyde foflen, en mer Harten- en andere Veljen, die zy na Ja[3al, en elders met groote winfen vervaerden.

De Siantiters warch 'er. wel niet ved; dog handelden 'er fterk, alloo zy uic hui Land met een groote menigre van Karwen en Wagens data", en in "c Land der Louwer guamen, on de Wharen, dart vallende, na Siam te votren.

Ved grooter handel nogtans dreven hier al van wiy oukter tyden de Porthgeelen, die, door humne groote ge[chenken ana der Koning, cu an de Grooten, fich al mede zecr mangenatm hadden weten te maker, hocwel $x y$ by alle Koninger hicr nier cvenved ingang gewonden hebben.

Volgens hunnen gewoonen nard makk ten zy hun werk "cr af, om ons datar, gelyk elders, als "Zec-roovers met allerbei fwarte loufenren af te malen, waint niede zy by zommige Vorften, dool groote gefchenken verblind, nil weel ingang nu en dan gelinegen liebben.

Wat nu de Nederlanders betreft, die hebben hier mode een walt Comproil ze-

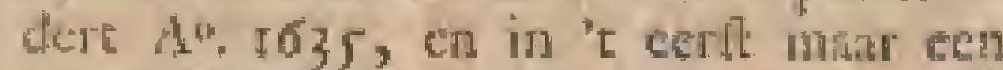
llegre Bambocle Logic gehad, hoewch

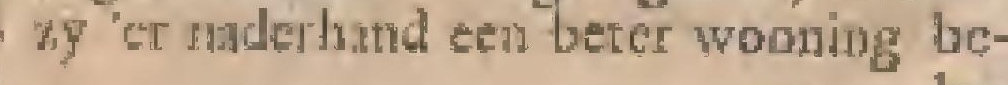


$\nabla$ is $\mathbb{N} A \mathrm{~A}$

165\%, homen hebden. Hier fohyd al wor the iyd een Comploir geweet te $2 y n$, alloo

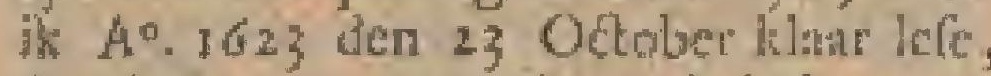
dat de Heeren zeventicnen belaften, dit te lichen; $\log A^{*} .1 \delta_{35}$ is ${ }^{*} \mathrm{t}$ eerft regt aㄱige gath.

De Heer Be eerfle, die onfen handel hier begonmongi nen, en hier waft gelegen heeft, was de

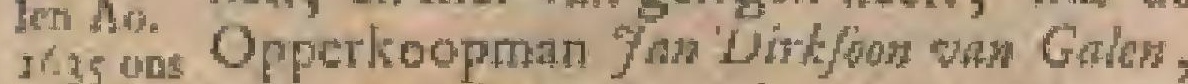
re ibe ren mun, die ontezatien hier met neer Hodd weel yver watargenomen heefe, en door

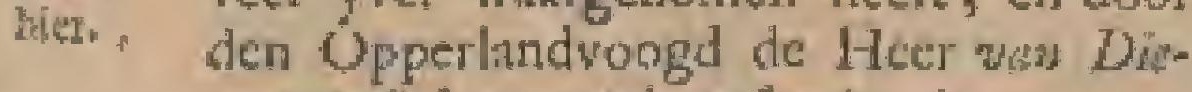
wen ecrlt herwards gelonden is.

Hy wiend wan de Koningis lier ats haren Zoon angenomen, dac hier ools een gewoonte, byrma als in Tonkin, is; dog waer by by hier geen voordecl ter wereld, dan den blooten Eer-tirel, liad.

Hy ftond by den Konting van dien cyd zeer breed, en had fig, nier rogenitande alle de fnorkeryen en lafteringen der Portugeelen, 700 antrgenam by dien Vort weten te maken: dut hem byn wots, van 't gene by verogt, geweigerd wicrd.

Hy hag hier mer een Onderkoopman, die xyn weede was, en werzamelde alle zoodinige goederer, met welke hy oordeckle de onlen in Japan dienlt te zullet doen, relyte er jourlyx van dear verficheide Schuept-ladingen mer Zyde, Zyde Atofien, Hurten-, Buffelfs-, Roche-vellen, en mecrandere Waren, derwarss veryocrd wierden, en wat door hy in grootc agting, zoo by de Koning ende Grooten, als by ry op Oppergebieders, was, te neer, dewyll by de zaaken zeer beyverde, en als de nood het vereifche, rond uit de bort fpreken, en $\sqrt{i g}$ roor zyn Mecters zalien in de bres ftellen dorft; dit hem in 't einde egter zeer qualyle betomen is.

Wirygt Men zig dat Ao. 1636, wanteer hat

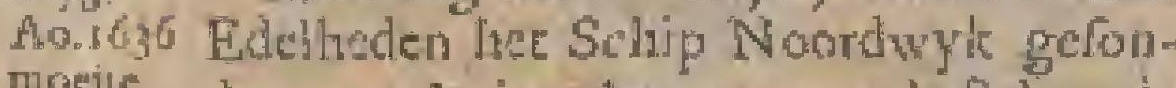

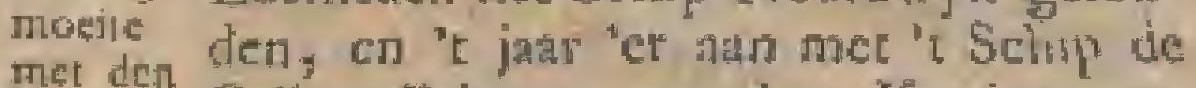
Loning Golis Bricven ata den Koning gechreven fradden, war in zy han bekend makleten, dat $x y$ toen ook 2 Ýterc ftukien Getchut over zondes, die zy hem toellonder te maogen koopen, alfoo ty wilten, dat hy date op zect fierle gefer was fldogangerien't Schip NoordWyk ondertultichen dat op ecn groote droogte, Padrenpays genamt, ch in 't inkomen der Rivier gelegen, door her misloopen der Japanfehe Riwier geblewen wns , co de Koning dertien Itakken Gefchut, en soo pikol Koper, van dixgebiewen Schip na fig getwomen had, zonder dic te willen weder geven, nordeclde de Hecr was Gales bett, die teluyen hater Edelheden (die hier nog nier al wilten) noo ten ecrlten niet op re volgen, mats', hat alvorens kesnis hier at te geven, on hate nader onter data op in te wagren.
B

D I $A$.

43

De Koming ondereffichen dic in hay 46,4 . Edeltheden felirywens zoo klatrwindende; effochte die wee fukken wel zeer fors vath de Heer wan Galen, wal op hy den Koring zoodarigantwoordde, al hy meinde voor dien tyd noodig te zyn s dat eguta dien Vorft geeli voldocning gat.

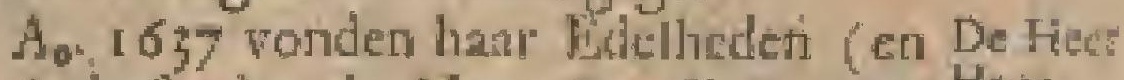
in 't bylonder de Heer Lucaloon, toen Haseals Direacur Generaal her Oppergelag 1637 als roerende) goed, om in de mand Marrt Gelant den Opperlicopmath den Her Hewric Ha. hesgenatr, als Gefant anden Koning, en warta itls Comanandeur over 4 Schepen, herwarts te zenden, on te fien, of men de gerefen getulillen miet zou komen by leggen,

1.y vercrole dan in dic hoedanigheit mee de Galeas, Warmond, Weltaanen, ел Waterloole Werve den 26 difo, cil quam den II May by cen Portugec Scheepic, ontrent de Rivicr van Cambodia, tt well: onle gewapende Boot* niec weigig met zyore Baften befchoos, en hen ondertultichen gedurig coericp Fenica, whacos, Borahos, Lubleranos; dat is: Kom bicr, $g y$ fowken, gy dronkatats, en gy Luhbrabes, met al weellk fchelden zy rier beletten konden, dat de onfe dic hun Vartuig veroverden, wart uit zy I 39 pakken Benzoin, 30 foukken Walch, ecrige Ytere Chinetche Panmen, veel Kopere Pelikens, eerigge ongeopende Potten, en merir andere Wastren geliche hebben, latende nog veel RyR, Porcelyn, Koper, Ec, in het zelwe.

Ondertugehen zand de Her Gefant den Onderkogpman Pieter wan RegenorWe, van Schoonhoven; met een welbemande Boor ma bover, om anden Heer wan Gues kennis van zyne komfte getwen, the diar op eǵter den is dito eyes vertrok; dog do Hecr wan Galen h/ all zorg gedragen, or zyn E. Foris yanffon, Schipper van de geblevene Fluit Noordwyl, coe re zenden, met lalt, on de Brieven hater Edelheden an der zelwen over te geven, gelyk dart op geichiedde.

Den I fi dito quamein zy met de Schepen in de Rivier Maclian, die ip "t inkomen nacuw is, en an wederfyden hooge boomen hecte, in welke zy doot" de vloed en mee een moye kocle tracyen voorigang laings cenige klecne Eilanden hadden, rot dit zy eindelyl de opening val1 de Rivier Simmeding (wan" in "t jakn" re woren "t Schip Oudewater gckomica was) gewar wierden, dat zy op 3, vadem ten Anker rnakten; dog nadertand wreder "t zeil frande, quamen zy, na veel almeryen, den 23 May by de Jipuleje Rivier, dar de zelve fig reel wyder, dan te soren, vertoonde, en

deit 
44

\section{B E S C H R Y I N G E}

1637 en tan 26 dito kiegen zy den Heco von Gath zelfs num Boord, brengende nog 9 kifken mee feld, die hy uit hee Jugt Noordwyk geborget had, op welken tyd men dera Heer Gelane ook cen om ltandig berige wan "t blywen wan dien bodem, en van "s Konings onregt weerdige handiting gaf, om fig, by zyne verichyning voor dien Worft, diat na wat te Cetiitken.

Zgn Het licp eguer nog tot den i j jury homer aan, cen dele Hers" voor onte Logie hier ten Antier quam.

Den 14 dito wierden de Brieren root den jongen en ouden Koning ara eenige Grooten, ten dien cinde afgelonden, overgeleverd; dog men bevond, dat de Opflivifen werkerd gefletd waren, dat nadertand weratuderd wiend.

Den 16 dico krecg zyn E. by fehryvens van den Heer whalem bericht, dat hy heden met de Brieven en geichenken na bowen trekken moent, an doof cen Nampra ter gehoor geleid te werdeti.

Zya E., toen zeer onpafielyk zynde; zoge dit wel eenige dagen ie vertchuiven; dog diar was mict an te doen, en by maet, zoo goed als hy kon, mele optrekken.

Zynwer- Hy naw, tor zyn gevolg, 20 Musfonying guecticrs, en a Trompeters mede, liep vinding met zyn Vanteuig langs "t Japans, Pot-

ten Ho- tugees, Clinees, Coctsjentsjinces, en Te. Cambodich Quartici, en flocg, his 1 is 1. myl varens, een nieuwe fpruit van een halve myl in, dar by mer de zynen man Land trad.

Hy vond daz een grooten Olifane zonder tanden, newens 3 of 4 kurreu.

Des ouden en jongen Konings Brieven wierden door een Nampra, onder een Zonnerchem, op den Olifint gedrageri.

De kamen wierden verdecld. De eerThe dic eenigfinswerguld was, gebruikte de Oxlane, de tweede de Heer ving Galew, de derde de Tomimne, en de vierde de Schipper, die met zyn E. mede gegaan was, en de zelve wierden ieder door 2 OHCA, rua 's Konings wyle, gCtrokken.

By 't Paleys gekomen zynde, traden zy $a F_{;}$dog de Gerant was too rwak, dat hy doofden Heer wan Galen, enden Schipper, by de hand geleid inoell werden tot by de Gehoor-zal, datiy op een grooten Cambodifenen floch te ruflen gefet wierd.

Hy vond dar cen fchoone lange Zaal, vol wolk, zag daar een menigte Tonimnes met hunne filvere, en Oknens mee hunne goude Pinang-doofen, en dasa na den Kotung, die over een boute leuning. woot over bukte, ontrent zf treden verder gewar geworden zynde, boog by fig zeer nederig en line woor hem net der.
Hy $x_{2}$ grvee Pecrden by den zalven, 1637 . of wat lager, ftan, die mer grasgewoe. Zrn Ge derd wierden; ook ligen "er 7 roode fit- rebed. klecden, wari op de Getchenken, door hem mede gebrage, guthilitwaten, bethande in 2 I-1akicfiutien, to Spanfulle Roers, 2 Piltoolen, * Lemmers tor Slaglwarden, dog her verdere wits zeer nee ufgeperk.

De Briet van zyn lidelheic wierd, in een lap Chines goud Laken gewonden, en op cen gouden Kop, in en verlatten bal gelegr, met toewertching wan the beil en geluk over zyn perfoon'en Regectirg, en door een Tonimneaneen Oknea, en door een Olenea añ den Vorft overgegeven, die lalt gof de zelve ren eerlten te verioltiten, en dae de Gefint, alloo hy befpeurde dat hy aper vermoeyd, en nice wol was, in de Voor- toal zyn ruft lion gaan nemen, dati zy hand op een geftikir beddeken, en cenige kuffens neer leiden, terwyl de Koning, by de Heer As Galen fitconde, belootde zeer goede geneesmiddelen ann den Gehar, van welken by ten eterten beser werden zou, te zullen beforgen.

By die gelegenbete fprak de Koning weer mek den Heer san G-ins over de 2 ftukden Gefchut, hern in den Brief harer Edelheden beloofr, ja zelfsbegonby ook den Heer Gefant or van ce precken, durvende wan den zolven, in plats wati 2, wel a ftukken verfoelien; mat de Heer on Golo Ineed dit zeer behendig af, met atri den Koning (die in "t Maleyts den Gefint aniprak) ce zedgen, dar die Heer geen Maleyes verhtond, dog die voldede den Koning nice alleen niec, marar hy geralake daar over verder: met den Heer wam Gales in zeen harde woonden, die hem tot antwoord gaf, dar by hen die Atukken noit geweigerd, cn alleen mat verloge had, dant mede zoo lang te wagten, tot dar de Gefant zynen lalt zou afgelege, cn zyne ratken by den Koning verige hebbent

Her whs zoo verte van dara, dat dit vergeeft den Koning ter neder zou zerten, dat gehoor hy fig naderhand nier eens verweerdigde des zelis, op eenig poorftel van den Heet Gelant so de Hr: ic antwoorden, en op de Heer wal Ge Jen in len bieef hy zoo veritoord, dat hy hem ongena: naderband niet meer onder zyn oogen heeft willen fien, werbiedende uitdrukkelyk, dat by oic meer ren Howe zou komen, alfoo hy hem geengehoor meer verlectnen wilde.

Dit bewoog dan hat Edelheden, by de te ruglionit ven den Gefant fiende, hoe Degr daar alles dir jaar virgevallen War, on de Hecr wan Galm op ayn verCock van dat te ligeen, gelyk lay o ik Ao, 1637 door den Commandeur Krath van dair gevoerd, en. de Heer Opper- 
$\forall A N \quad \mathrm{C} \quad \mathrm{A}$

1637. koopmat Jolawes van dor Hagev in zyn De Hecr plars als Opperhoold gelteld is.

vender Ock gaven hazr Edelheden ant den Ho I ser selvert latt, otn den Koning noir meer hier $O_{p}$. over die 13 Jtuliken, of over de rop pjicol pethoofe Koper, ala te forecken.

Zoo ras de Koning belpetrde, dat hy nict meet dar oper aangelprooken wierd, was al zyne verbolgendliest over, ja 'c was zoo vere win daar', dat hy ons nieuw Opperhoofd ecniglios qualyk befegtenen zoude, dnt hy hera, en ons, in tegendeel allen cenftede.

Ook gaf hyeen groor bcwys daar af, Wantiec lay fig in 't 1'roces, doorde Por: tugeefon reger ons, over "t tyemen wa hun poonoert Schetpjen Bafth in de Rivier" Yar Cambodin, door 2 van onie Boors, vollemeri op anfezyde verklar"de, on dat to ans voordecl vitwer. "s To- Onk lecndedelc oude Koning A" I638 ning be- den p April noo thayl, of pooogl, ann

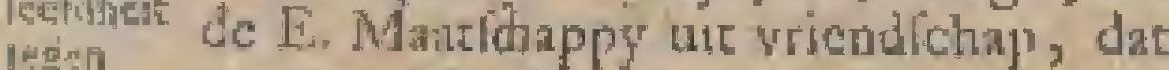

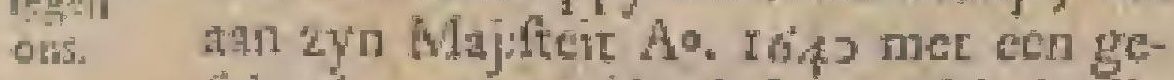
fcherit van too thayl Japans lchuis- filver, en nogecis ltu]l: Ge[chur, om onfe dankbarhes te tobnen, weder gegeven wierd: hoevel by anders, 200, hy toen geldgierig geweeft wis, nog wel 600 thaylen wat dat geld lad konnen thetRer.

$A^{\circ} .164$ werlooren wy ongemeen veel by "t overyden wan den jongen Kowing? die een zer goed Wort, en ons in allen declen guthig was, gelyl hy metrer tyd over de enak der Chincefche Moordehasars win ons volk, zoo by dat verder beleeft hind, ook fekerlyk becoond zou hebben, hocwel de zelve naderland een gobecl andere dicer nam.

De Chi- De Heer, Kare Hat jimk had Ao, 1638 mererl a 163 g cen Chines Jonk mer cenige Zyver- de de in Tonkin bevigent, en 8 NederlanAo.1638 ders 'er by gewoend, om dare mede na a 1639. Japan te ftevenen; dog de Chincefen, een ennge beftuit genomen hebbende om dic Holhander fint laters, zoo ras zy in Zee zouden gekomen $2 y n$, te vermoorden, en de lading met milkanderen te declen, ftelden dit ook in ' $t$ werk, en bentmes hen allen "t leven, voornemens zynde on na China, of na " $\mathrm{E}$ Elind Kclang, in de plants vin na Japatr, te vertrekten.

Na dat zy nu den buit te zamen gedecld, en de voornzamite wan hen een Warlkan (ccn kleener Chinees Varuig) gekogr had, gertitkten de zelve met ecnige pan defe baalen 'Lyde, door een wonderlyke folsiklsing Gods, en tegen hunne gedagten, in Cambodis, alwar men onfer de goederen, die zy dar' verkogten, de briefkens, die to delo Tonkinle lading behoorden, en zelfook fonmige flofien vond, nog met bet bloed deier Nedertanders belpat, wax op de
B $\bigcirc \mathrm{D}$ I $\mathrm{A}$.

onfen veel grond kregen, on defe Ch: $16_{4}$. ocefen te denen vatten, en hen in proces te betrekken.

Mer wees ons atle de Zyte wel ift "t eerft toc, met belofte van ook die moorddidige ichehmen tis zullen ftraffen atsoo de jonge Koning ondertufichen quan te flerven, vonden die felichen (warlchyelyk doot gelichenten) middel om te ontvlugten, hoewel wy 'er nitderhand nog een, door rocúben van den anden Konng, belowen, en laen he Bitavia gefonden hebben, dar by Ge* rabraklt is.

Ook hebben wy vandie ganfchelading halar of picol weder gekregen, dar men anders, 'ware de jonge Koning in 'c lewen gebleven, zckerlyk ook al de anderefchelmen, en ook weel neer Zyde, in hinden gelregen zou hebben.

Dic proces nu in 'c jatr I 640 woorgevallen, en de Heer val at Hogen genegen zynde, on van hier na' $c$ Vaderland te wertrckken, relureef om zyne verloffing na Baravit, en de rwecde perfoon, de Opperkoopmian Rogemontes, vetrok toen mede derwards, om by hat Edelheden te verfoelken, dat hy in wan der Hogens plasts hier Opperhoofd werdera mogr, zullende ondertufichen de Onder-koopman, Gerard wan $W_{\text {and hof }}$, hiei her ampe van tweede in zyn plants waatnemen.

Terwil Regenowes tha Batavia was, De Hect ftierf de Heer wan der Hagen in de maand wat der July 1640 and een heere koorts, die hem $\mathrm{Aa}$. it 24 uuren, iegen aller gedagten, zeer owesle: richielyk weglecepte; na welken tyd den den.

E. Wufthof de zalien wan dic Comptoir tot de konif wan het nieaw Opperhoofd warnam.

Den Latien September, verfeheenende Heeren Regemortes, en fisman 5 ark. wow hier als Opperkinoplieden, extegelyk beiden als Opperhoofden, om dei handel en de zanken der E. Maatlichappy hier met zoo veel meer luifter wat te. remen, dar zer wel quam, alloo $\mathrm{zy}$, tor hunne rerwondering den Hecr wan der Hagen, dien zy vervangen zouden, overleden vonden.

Danr na hecft de Onderkoopman Reisma Whabof een Reife van vecl belang in Ju- Lander ly $16_{4} \mathrm{r}$, nevens eenige andere, na het Lourent Koningryk der Louwen ondernomen. dog alloo wy daar van hier na in 'c by" zonder fprecken, zullen wy vooraf maar foorgan, ord dic zalker, die tor de ftoffe wati Cambodia behooren, te vervolgen.

Tewyl ons wolk nu op dien togt was. is 'er ecniggefehil in Cambodia, wutichen ecmige Porufeclen, en cenige Mrtrooren van de filuit de Sacyer, misgaders ecrige wan onfe Logie-gatten, gerefen, $F_{3}$ 


\section{${ }_{46}^{6} \quad$ B ESCHRYVINGE}

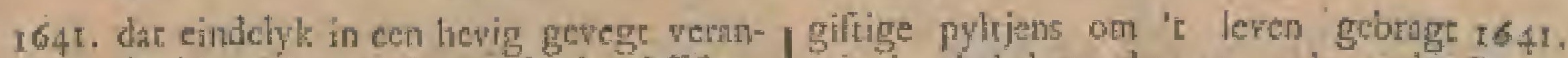

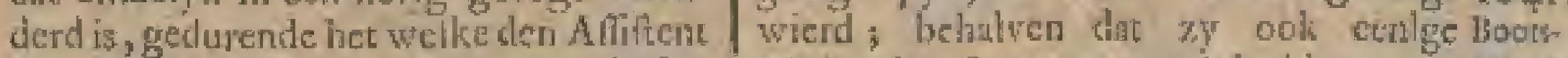

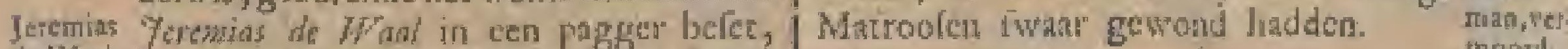
de Waal, en door de Porcurecten inet ecnige ver. Mn en,eni en door de Portugeclen inet echige ver-

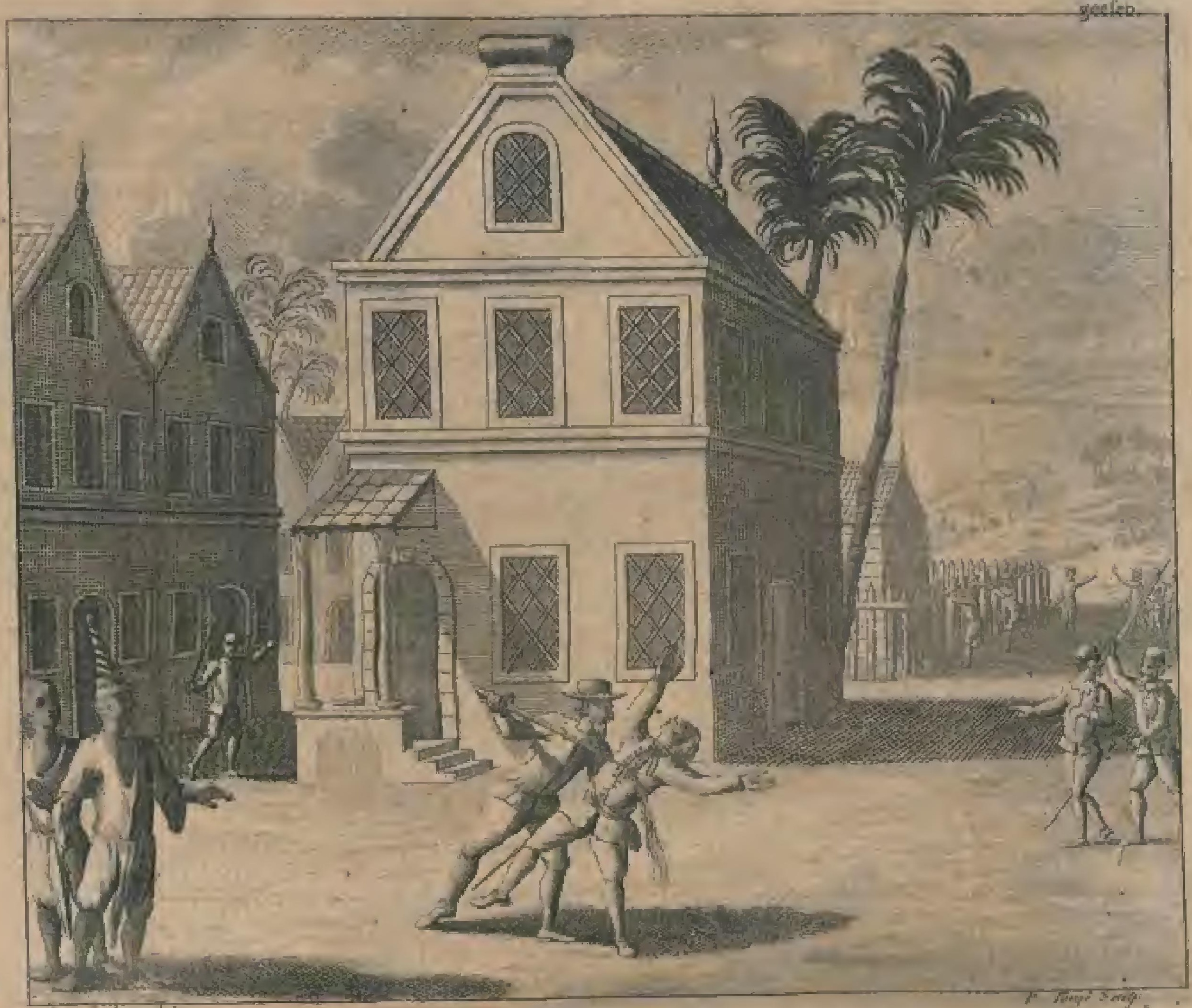

Kórt na dit soorval komt de Bootsmars van die Fluit, wan alkes onkundig zynanvin "t quartier der Porcugeefen wandelen daar hem door een Portugeces zeer moordd $\mathrm{x}$ ig "t hart afgelleken wiend, over wellee twee fchenddaaden men de Portugecfen by den Koning amklaagde, ten cinde de fchuldigendan over geltraft inogten werden.

Na dat hier over Rigters gefteld, en die twee gevallen in al hare oinftandigheden war bevonden waren, wilt men geen middel ona aan te wylem, wie de regte moordenaars van delé lieden warens dog on hier egter uic te raaken, velden dicle Regrers het vonnis aldus, dat de oudfte Portugees in 'L huis, daas do Whal gedood was, zou fterven, of anders den fchuldigeı moeten anww/en, gelylk by ook darr op ren eerften valtgefec wiend.

Wegers den Bootsman zouden zy, volgens "s lands wetten, 300 thayl, en cen boet an den Koning, beraten. Want temen de Opperhonfien irbragren, dat ons bloed yoor geen geld te loop was, en dar de dood wan den Bootsman door de dood wan zynen moordenar alleen te boco ten was, weshal wen zy werfogten, dat de Kosing dog nier getiefde toe te ftan, dat men die met geld af hoopen zod, al[oo zy dan dagelylss van de Portugeten zulle moorden at re wagren hadden.

Ondertufichen wwitten de Portugeelen Slegte met lyone gefchenken by den Koning ftratio en anderen i zoo veel uir te werken, dat orer. de ter dood gevonnitte Portugees los gelaten, en mer het betalen van zoo thayl vry gekeurd wierd, warr mede ook de zaak van den Bootsman voor afgedaan gehouden, gelyk 'er tan ons in 't gelinel 600 thayl voor die twee moordenaange boden wicrd. En allog brife Opperhoofden dit blocd-geld nier wilden aannemen, belafte zyn Majefteit dit geld in handen van zynen Geheinlchryoer, Okma Tiremedols te inclien.

In dit zelve jagr verfecheencen de Portugeefen hicr met eel andienlyk Catpatoen van Zyde, en verricheide Zyde itoffes, met rootnemen om die op den 
V $A$ N C A M B $\quad$ O

47

164. I, nam wan dele on gene Cunbodiche Keoplieden na Japan ec vervoeren, on dat door te belcuen, dat wy ben in Zee niet antraften, en ons ann lien wrecken mogten.

Zy deden dit ook, gelyk zy diedan in 2 Jonken geladen, en dic in ftat gebragc hebben, on onder optigt wan cen Chness, en cen Sylibandarr, na Japan te zeiten; dog alloo zy yreesden, dae onle Fuat Oollkapnel, die met een lading van Cambodiche Waaken lou Japan nu mede zeil-vathdig lag, hen warnemen moge, deden $z y$ den Koning werlotken, dat ly an die Fluis Opperhoofden belicfde re doen verbieden, van hen in Zee an ce talten.

Onfe Oppertioofden deden den Koning aanfeggen, dat de Overheden van dien Boden hunnes geheiven laft var har Edeheden hadden, on alle $V_{y}$ anden, die zy in Zee ontmoeten mogren, an te rafter, weshaluen hee in 't sermogen der Opperhoofden alhier niet

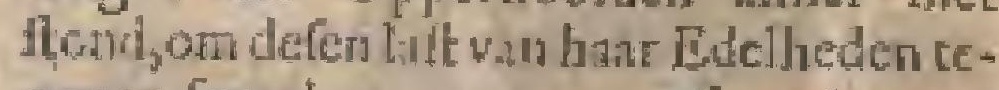
gen ae [pejken, whar na zy figooligecufins gedragen zouden, weshalvea de Heer Regemorles by 't langer ophouden vandie Schip, oter alle fchade en verdere moc jelylihaden, ew zeer kragrige betuiging dede, alfoo dic Schip zyn tyd wan nooden had, oin in Japan te konnen gera. liçn.

DeSchipper deler Fluit, AbelFumien, betuigende niet langer te mogen wagren, aentont liep 3 digen vonr defe Jonlien in Zec, kruide cenigen tyd op de zelve, liteegle beide cindelyk in " $\mathrm{rog}$; dog wierd matar" meefter vande ene, alfoo de andere hem door de duilternis des avonds onelinapte.

Hier over betrokken de Porrageefen de onfen naderhand in regten; dog terwyl dit A 1642 voor den Regrer diende, wierd die groowely ke moord wan den onden Koning en zyn Zoon uirgevoerd:

Na dat fig die voomocmde geweldenaur nu raft genoeg op den Throon getet had, wilten de Portugeclen door siontc gefchenken aan hem, cn cenige van zyne Vrouwen, het zoo verre te brengen, dat de Koning niet alleen, over 't memen en anntaften deler 2 Jonlien, an den Heer General na Bactuia fchref, Isaar hy ontbood ook den Heer Kegenostes by lig, eifehende vanden zelwen, dat hy alle die goederen, dic wy in dic Jonken genomen hadden, an de Porkugeefen zoude hebben weder re geven. De Hecr Regemortes, dar ganele niet toc genegen, overlei die zalk rypelyk met de zynen, en vond goed een preuve te nemen, ofmendoor gerchenken zyn Minjefteit niet zou konnęu winnes, ons wers andering ontrent dit vounis ce krygen.

Die gelukte, tegen werwagting, zeer wel, zoo dac de Portugeren, wanteer 164 s. 2y na onfe Logie quamen, om dat gye- Heweweld Vonus uit te vocren, laft liregente ging daer moeten varercken.

over.

Zy deden dir wel; dog giugen met een weel grooter gefchenk, dan hur worige, na 't Paleis, beflande in cen gift wan 600 thayl, die hen belaft wierd dar in zeker vertick ce Jaten, en tot cen nader tyd, alfoo de Koning na buiten gereden wits, tc wagten; hoewel zy nicr. lang das na hon ooguic 200 vecl te beter bereikten.

Aangelien nu onfe zatien tier tioe langer hoe-meer na hun einde rcheenen te hellen, en defe Koning nergens ordre op felde, manr in regendeel den genen, die hem 't meelt gif, beguntigde, vond de

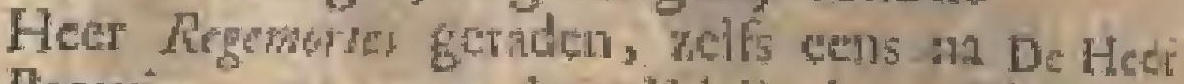
Bacavia tc gand, om has Lidelheden een kegenec werflag van onfe zisaken, en wan 't mortes gedocnte des Konings, Te gever, en, woor prat fo: al, on fig zclsen, itfooliy donkere wol- Bataris. ken Eornen zag, van dic Comptoir te ont flatan.

Hy vertrok in demand December des jates $16+2$ mat dast, by wellse gelcyen= heit oot de Onderliogpman W/aktof usi zyne verloting van hice vertaker dede; alfoo zyn verband ten eirade was.

Daar op quim de Flait de Oranjeltons. in de mand May A. 1643 hier, nast wellie de E. W whof rerloft, en mee het Gambodich Cargalocn den 20 Jury over Tayouan na Japan gefonden wiend.

De. Heer Regmorres, woor zya verteb wan hier verlobeide bewyien van den moorddadigen and des $\mathrm{K}$ anings ontrent anderes beipeurd, en zelis gevallen gehad hebbende, waan by hy roo' zyo cigen leven begon te vieerion, had date wan, by zyn kom lt op Barawia zoo veel opening an har Edelheden gegew dat hy verloge wh dit Comproingatiagen ie zyn.

Alle de anbiedingen wan has Edel- Fon $h_{\text {. }}$ heden waren in "t cerit thet begunam, ibylyet om hem te doen werwateren; matr wan-Gerant, neer ef cindelyk voorltelden, heru als en werb Gelant te zenden, mee vercooning, dat deerlyl: hy dien nict wan 'o leven zou durweis ko. unet de men, liet hy lich cindelyd wadei bewe- pergen, hoewel dat nier zonder groote wree. mots ic, die hem nog altydbyblet, gichisde.

Hy vertrok dun in dic hoodanigheit herwates, cn gquam 'er den 3 o Stprember deles jars, mec cen lichoon Oorlogs Jage.

Den 77 November dar aha, verfoge hy gellyor by den Koning tehebber, dat hen wierd coegeftan.

Hy ging dan op dit bekomen verlof, met is oppafters, en met ten graten. treyn wan Kooplieden, Selippers, an

A.ti. 
i643. Aftiftenten, dic, on zyn untien tewermeeseren, alle te peed ligvertoonden, nat 'r Hof, alwar hy zoo haaft nictin cen breeder disant, ontsent de Mukt gelao. men wis, of zy wierden door ect groot getal Solduaten des Konings omeingeld, en nedrer gotabeld.

Opdnt zy rui ook werder meelter yan orts ander wolk in dic Logic werden, en die geen bericht van defe aningerechte moord krygen mogien, thadden zy vool af alle de wegen belce, behalwen dat de zelve wel 3 mylen van "s Konings Paleis afgelegent was.

Zoo tas $\gamma$ y nu al het valk van dit Ge- Fintichip dus van kane geholpen hadden, zonden $z y$ ook eenig volk ma onfe Logic, om hee datr verder fchoon, en fich ook meelter van alle on maken,

De Ondertioopnan Bukkn, die in bet tweede huis der Logie was, dit gefpuis zeer wild fiendenanlinomen, en voor onaad beduge, liep mec een zils geld, die hy wan twee Japanders eerft even ontfingen bad, ten huife tit, hetwelledoor cen van defe moordrugtigen gemerkt zynde, wierd hy ten cerfen van hem agrerhaald, en neder getake, welk droevig Jot ook al ons ander volk, dat nog in de Logie was, en ook den Opperkoopman Brocknan, ceu Brener van geboorte, trof.

Dant op wierd de Logie wat hencer $\mathbb{t}$ geplunderd, en das ma om verre gehatd, en of dat nog niet genoeg was, zoo hebben zy ook kort dar an eer't het fehoon Jache Ryswyte, 3 mylen beneden de Logic, ontrent her dorp Fononsbing leggende, en diar na ookde Fluitede Oranjeboon, die pas uic Japn gekomen was, zeer behendig (atfoo vay als micnden, gelyk wel mecr gebeurde, dar an (exmenj afgeloapen, en at 'c volk, dat zy mat in handen krygen konden, wermoord; dog in de 60 ftux, dic "c onefwommen, en na "t Bofch gewlugt warei, werden naderhand, door den hon" ger gepert zynde, gerangen bekomen, wellie de Koning toen als flaven onder zyne Grooten nerdeclde.

Een moond, die wel op lall wari den Koning uirgevoerd, maar die vande onfen voornamely den Portugeelen, als de cerfte nanftokers hier toe, geweten is.

Na dat nu ons wolk (war onder cen Wondheeler, cen Stuarman, eri ecr Timmerman was) dus drie jaren indefe clendige llaverny geweent waren, heefo defe Koning fich eindelyk over hen erbarnd, en die gener, dic wan hen nog leefden, nier allecn in wryheit gefteld, mant (dat te verwoinderen was) henoole verlof gegeven, om mee her Schip den Oranjeboom na Batavia re verteklen,

daar zy ook cindelyle, that lang omfwer- I665. wen, en na veel elenden, alloo die Fluit zecr l]egt gefteld was, don Gods zonderlinge goedlieit angokomen zyn.

Om nu echer ecnigen fichyn wan hum Jege cor dic risoorddadjg bedryf te gewen, hecfi men hier naderhand voorgewend, dat dic grechied is, on dat cenen Broedsman, met de F'luit de Zaejer na Japan gefchikt, cenig filver uit de zelwe geligr, en dat door hulp van eenjge Macrookn in 't Bofeh geborgen had. Exu onnofele jeden, die gunfeh niek klende, en watr over men hem kon geftraft hebben, zonder dat zoo weck andere onnoofelen daarom zoo droevig hadden behoeven te lyden.

Na defen egter folwhen har Edelhe- Ons det weder bewogen te $2 y n$, om hier op compvicuw ecn/Comptoir op te regten, alloo Ao tórg ny uie de Malakfe papicren van $A$, I6rg weer afKlan gebleken is, dat zy het toen we- gébroder wan alles beroofd, en afgeloopen heb- ken, en ben.

Ook hebben wy $A^{\circ}$, 166 h hiter weder seregk. ecn Comptoir en Logyie gethad, om de Muteusegn Benzoin, die hier wir het Land der Louwen gebrage wierd; wiane fehoon hier zecr veet andere Waren viclen, die kon men ook in andere naburige Ryken krygen, dant wy reeds Comptoiren had. den.

$A^{\circ} .1667$ hebben wy hier weder een groote ramp gehad, alloo al ons volk hicr weer door eenige baldadige Chineeren vermoord, en onle Logic van alles beroofd is.

Men oordeelde in 't cerft, det dit door laft van den Koning weer gefchied was ; dog de relwe heeft, om zyn onfchuld in delen te vertoonen, defe moordenaars poorbecldelyk doen itralfen, met beloften wan de 3 Nederlanders, die by nog onder fig had, ten eerften na Batavia te zullen zenden, wat wan wy 'ct $\mathrm{A}^{\circ}+1669$ at 2 in handen hadden.

Dac wy nu nog ecnige jaarent na dien tyd op dit Ryk gebandeld hebben, is zeker, behalwen dat men dit ook khanran dele z volgerde Brieven fien kan.

Brief des Konings van Cam= bodia, an zyn Edolheit de Hecr Mantholker, en de Fid. Ed. Hecren Ras= den wan Nederlands India.

$\mathrm{D}$ Efen Brigf how wit cen zaspere gene- Brief san. gewlish en opects gemot, wet bet den ko-

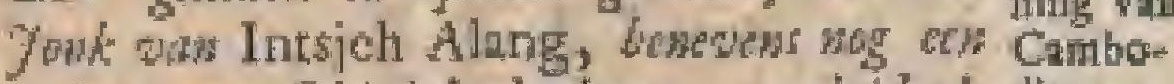
anders von Okiniate Labom, zy lhidals dia, am wolst:

Defe Briff lom wit een zutuere gengen- Mat Ao. beil wan Jang de Pertoclian, Kang way 1673.

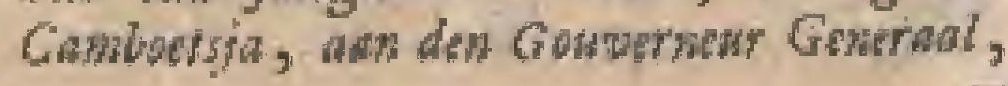


$\forall A N \quad C \quad A \quad M \quad B \cdot O \quad D$ I A.

49

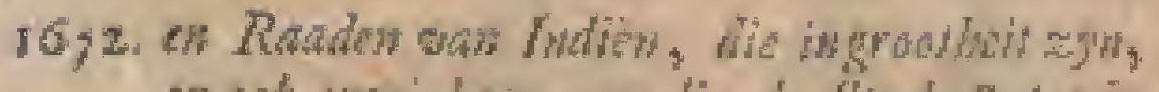

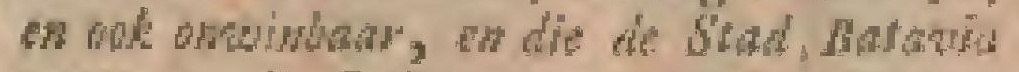
regeron, die Gald wil geven ben lang lewa in defe wiredd.

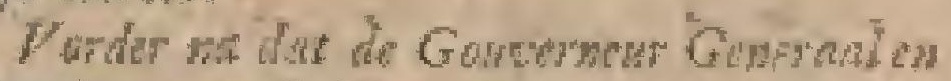

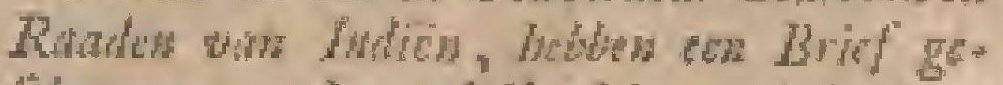

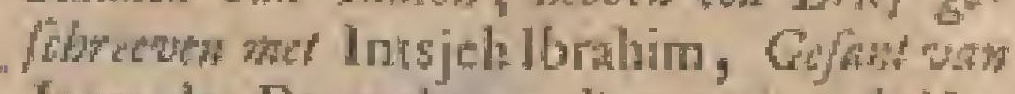
Jang de Percochan, dit mes exs bebien onflangen, on wy ouk rangentam is gawed,

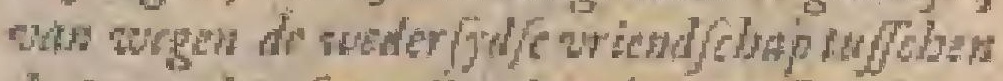

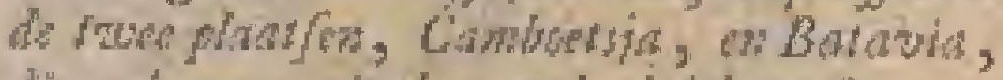

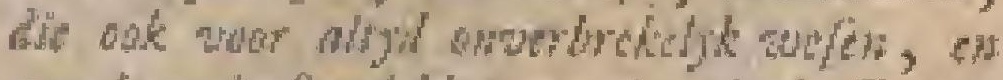
zon hos in fard byon zal, als to $Z$ on in

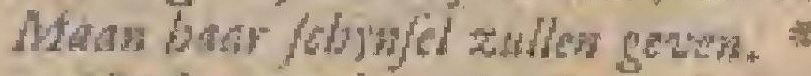

Faders wa "i zelve befl Jang de $\mathrm{P} \mathrm{Cr}-$ tochan met atders te zenden atas din Heer Grhatal en de Raden van fidten, das 's gene in defon Brief ge/theon /aar, ic sw. rem, 50 Cati Cably en cuits Benzoin, an

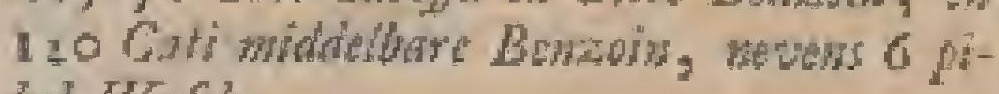
Kol $W T_{i f} 6$.

Verfocke don Generad en Raades was Itdich die in virgendichop geheven ath te ne-

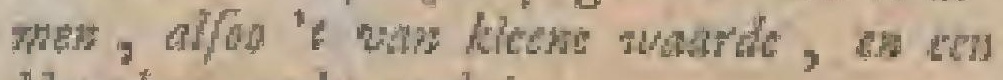

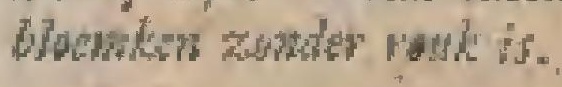

Dele Brief was it 'c Maleyts met cen Arabilche leter zecr cierlyk gelehreven, zeer lcontig toegevouwen, en wierd in een tluk goud Liker gewonden, overgetonden, en zoo ook overgeleverd.

Briefuan trin Edelheis de Hr.

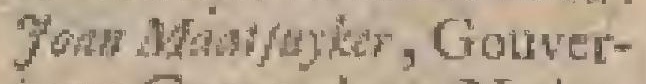
neur General wan Nederlains Indiés, an den $\mathrm{Ko}$ ning warn Cambodin.

Brief ran TE Gotwermen Generiad, m de Rota-

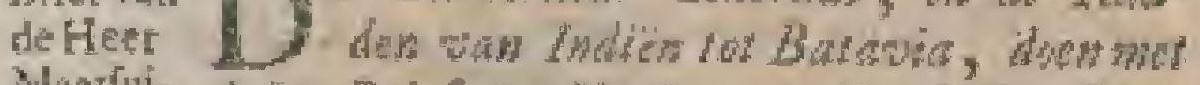

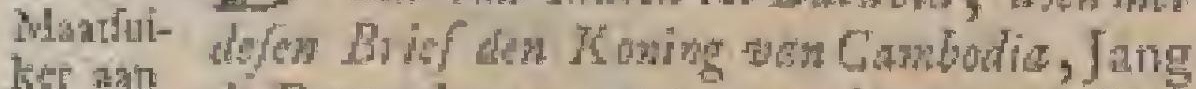

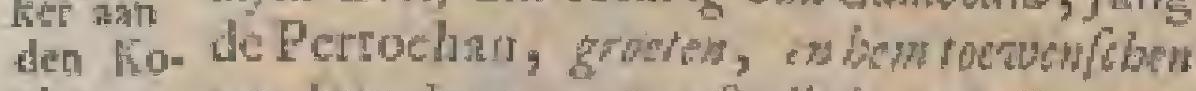

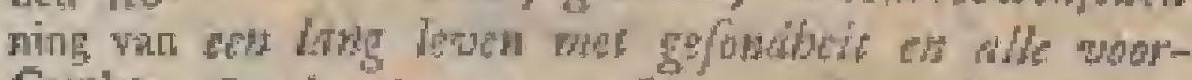

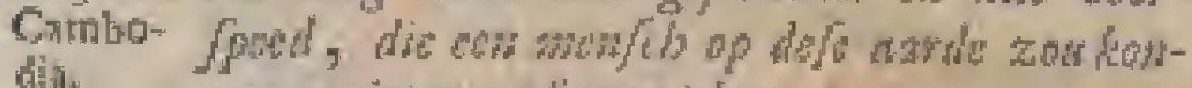
wen genides, of wen/cben.

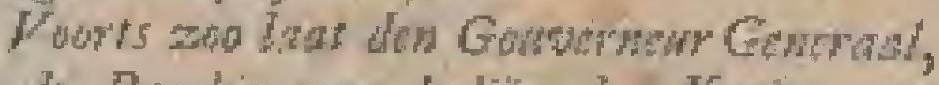

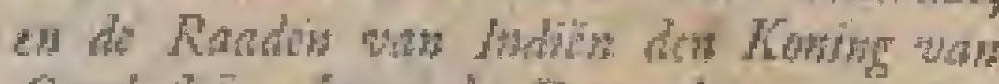

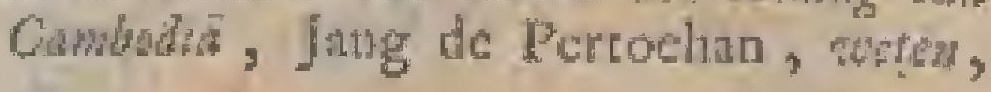

- Defo relec fpiekwyra boga, winden wy Pr.

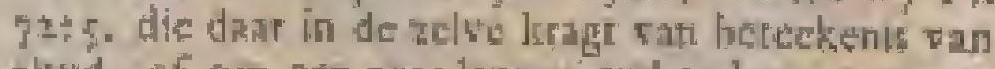

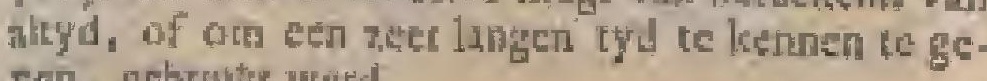
Fien, gebrutat wets.

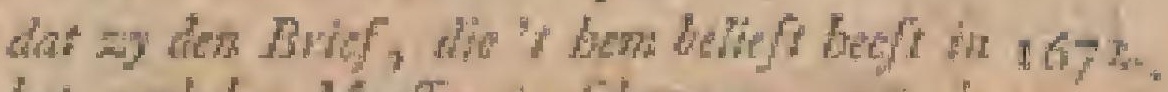

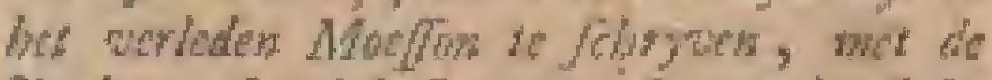
Jonk was Intsjeh Sanam, Whowder defer

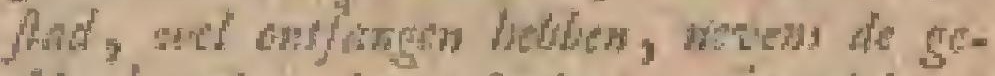

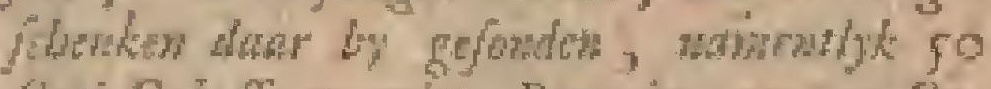

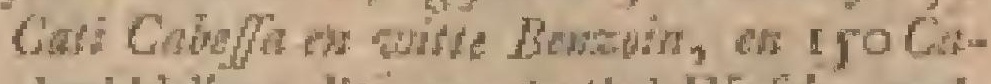

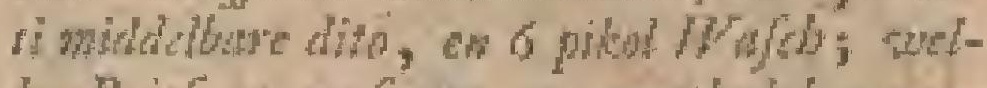

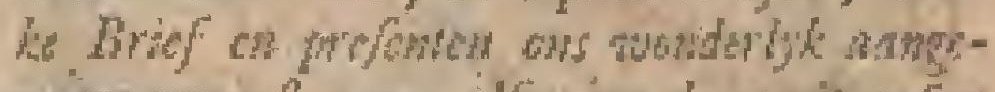

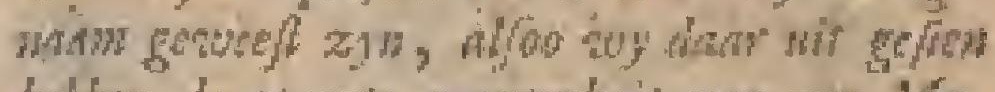

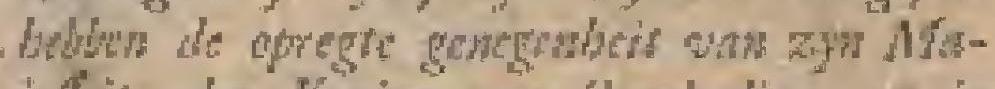

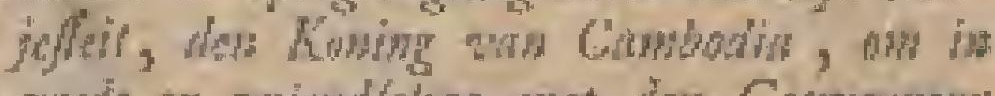

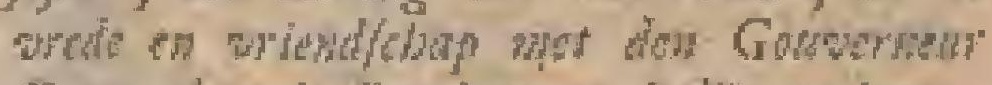
Getarad ca de Radden was haden ic leven,

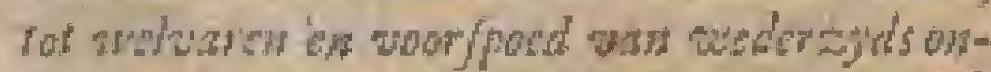
dordonsh, zoo wan Cambolid, ais wich it hand wan Butaria, de den Hewel swil' se ven, dot ze zula lang dwen nag, als de Zon

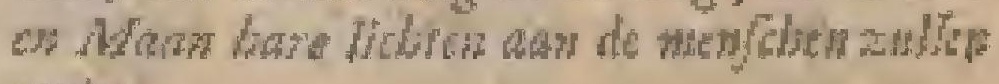
gewen.

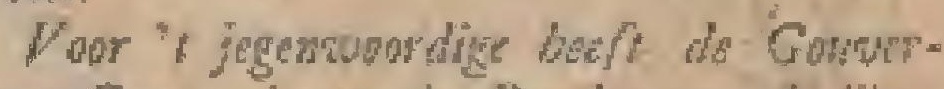

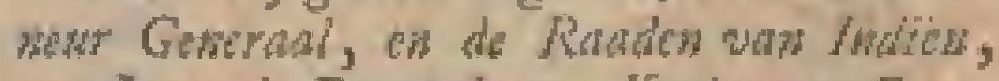
ann Jang de Pertochan, Konitg pon Combodia, nith anders lan Gerebow te zenden;

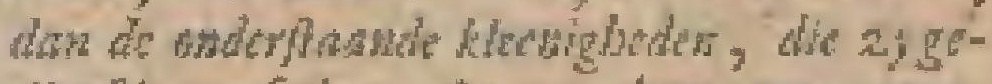
dienfig verfocken, dat wan ben mogew ont fangen werden, wh kownde wit ews good th opreds bat, waver wede batr cere gefobiedest zid. fir befatin in

20 p. Cala Bengald.

$28 t^{2}$. Bethillis.

In 'r Katfect Batavia

den 2 Juny $A^{0} .167 z^{\circ}$

JOAN MAATSUYKER.

En wis dere Brief mede in "L Maleyts gerchrewen.

Hoe lang wy hier nog hobben blywen landelen, of wameer dit Comproir dagr 'I ver at mede wain de ketel rajpe, opgebroken is, weer ik nier, yh dat inderhand dic Rys aun den Konirg vati Sinn cynisbar geworden is; en die is "o at, dat wy hier van wetentezeggen; meghalven wy her mes de zaken witr Camibodia zulden later bsituten, hebbende allecen tog ecn woord war ${ }^{-} t$ land der Lowwen te melden, dat wy in "e volgende Hoofituk zullen doen,

III. DEF L

G

DER- 


\section{DERDE HOOFDSTUK.}

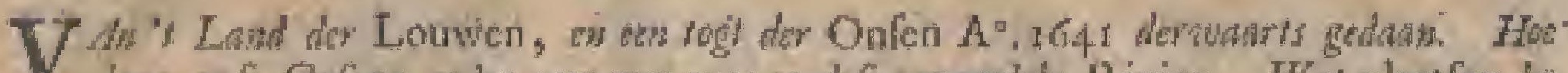

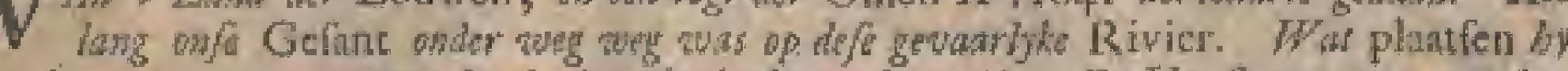

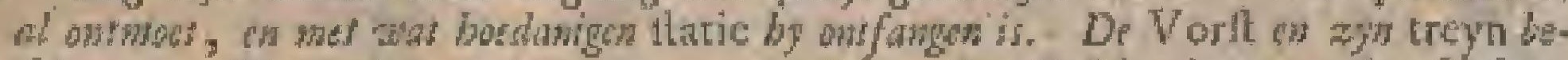
folrewen. Novens het werdere Jeen weorgeuallen. Zgn Gelchenlicn aan den Gelant,

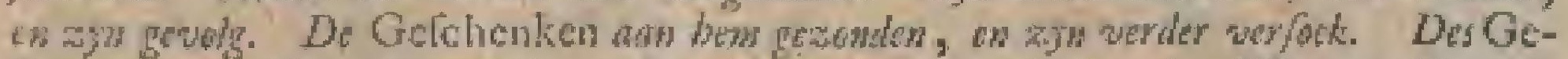

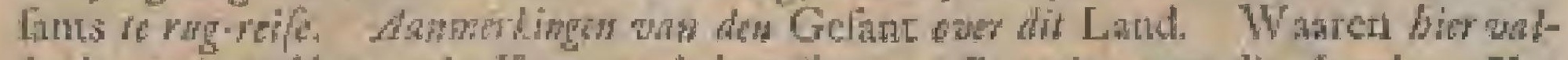

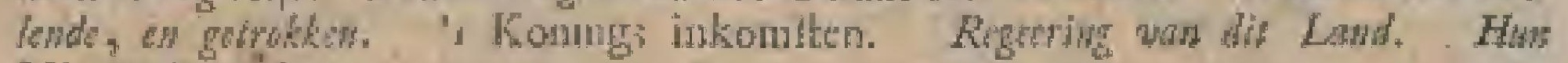
Nieuw-jars-dng.

Van Jet
Land der
Lotuwell, En kan nier wel wan 't Koningryk Cambodia fprecken, zonder ic gelyk her cen of " $\mathrm{t}$ ander en ecan war 'L Koningryk der Lotwen, dat ten OnfeAo. $\mathrm{O}$. win Cambodia gelegen is, te melden, Iú alfoo defe volkeren, fchoon zy ieder ect

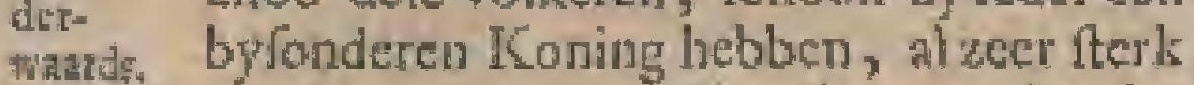
wasds gewoon zyn met malkanderen ce handelen, behaken dat 'en' in dit hand der Louwen verfeheide dierbatre Waarea vallen, diç niet alleen in Japan, matr ook clders, zeer getrokken zyn; hocwel $z y$ daat mede meet op Cambodia en Sinm haitdelen.

Uit dit Koningryle nu zyn $A^{0}$. 1641 in de mand Mant, de eerfte manl eenige foorname Kooplieden, met het Fluit-Schip Ooftkappel, wan Cambodia na Butavia vertrolken, om uit eigen bevinding te beter van onfe Natic, en van haar vermogen (danr de Portugectan geftadig met zulken verachting wan fpreeken) te konnen oordeclen.

Zy waren zoo ris nice of Butevta werreheenen, of has Edelheden maaken in allen déelon hun werk 'er af, on dele

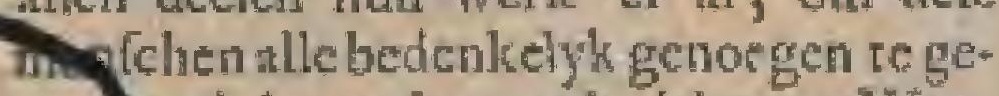
ven, velyts zy hen ook al hune wirtren tot zulken prys affekogt hebben, dut 2y betuigden, hicr in cell zeer groot welgevallen te hebben, en genegen re zyn om jarlyx dant ce verechynen, warar toe zy onk met veel ernft wan har Edelheden verfoche en witgenoodige wierder.

On die werk echer noch wat meer ann te binden, vonden hatr ledelheden ook goed, on cerige van ons volts met een Brief en ecnige Gerchenkeu an den Koning der Louwen in Gefantehip re zender, zoo om mer slen zelven in een nader verbond te treden, als om daat in "c Intud zells cens van naliy te conderloeken, wat voordeclen 'er woot onfe Mazttchappy tedoen waren, te meer, alloo delè en gene Mooren en anderen over Siam, en door de Rivier พan Tanafery zeer grooten handel met allerlei kleeden daa op drecten.
Oole wentehten zy, by "t docn wan zulken tocht, ook wel was nader jenniffe, zoo wan dat land zelfs, als van des zelfs Regeerongen flekten, ic hehben,

On dit dan werkttellig temaken, ordonnerden har Edeheden by een Brief van den 14 May $A^{\circ}$. 164 win de $O p$ perhoofden van Cambadin, dac een van de Opperrooplieden, de Heeren Regewrowes of brophon, of anders de Ondertoopman Gerardvan Wafibof, met cenige Aliftenten derwants met haren Brief en Gelchenli ant dien Vortt zouden gelonden werden; warr op men hier nader goedgevonden heefr, om den E. wan $W$ riflhy als Hoofd van dit Gerantfantehap den I Juhy an te fullen, en hem de Aflthenen Whem de Goper en Hobuer wa LAbrif, bonevens nocheen Wondbeeler, 2 Nederlandfe fongens, en cen Tolk Insjeh IAning, een Maleyer wan Patani, toe te wogen, den zelven tot een proeve mas eci kilecn Cargafoentje wan wer/cheide gecouleurde Lakener, cenige fyne Cattoene kileeden, en een lasje mer Esmaraude Ringen, te za * men $f$ 6oor = B-10 weerdig, mede geveride.

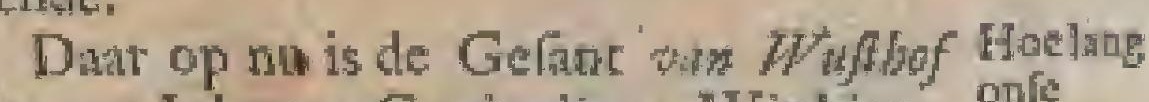
der zo July van Cambodia na Winkjan, Gefat de Hoofdrad wan 'c Louwen land, daal' ondwe de Koniag zyn Hof houd, met cenige weeg prouwen vertrokken langs een Rivier, was. die zomtyds zeer breed, enzomeyds weder vry eng, en ooli zeer klippig was, behalven diz z.y in de zelve ook hier en data afgryslyke Watcriallen ontmaet hebben, die hen nu en dan noodhaken al hunne Waren uit de Pracuwen te nemen, en die op an af te dragen.

Defe Rivier, doergans de Louwfe Rivicr genama, fome van de boven-landen van Pegu, verdeclende fich na het Koningryk der Louwen in "L O., enten declen na " $\mathrm{Z}$, en ftort by Cambodia, tha dat $x y$ wel 300 mylen verre geloopen heef, in Zee. Ook komen de Pegui* aen hier dagelys mee hume Robynen, en andere fed Geltecnen, handelea. 


\section{$\mathrm{V} A \mathrm{~N}, \mathrm{C} A \mathrm{M}$}

IOfr. Over defe reifo was de Gafane wm Wh/hat' 2 matnden en 3 weken befig, eer hy tot Winkjan, dat zfo mylen do Rivicr of legt, toet de zynen quam.

Hy ontmotre onder weg daneenseen wek, dan eens ecn dorp, die na "s lands wyle colk al jelelyk wel bebouwd waren, whar onter men hicr en dar ook al een feenen luvis of Tenupel zig,

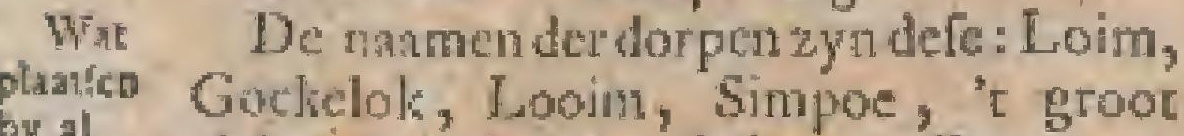
by al vick sombolk, Sonbaboer, Barsjong

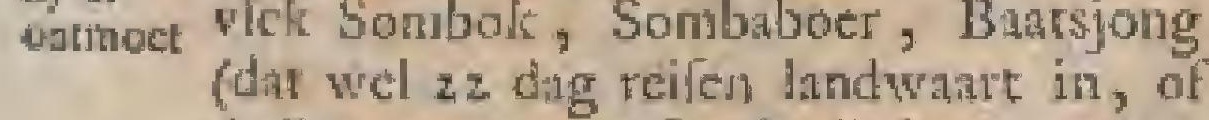
de Rivicr op, van Cambodin legt, en dat ook de. Koningen ran Cambodin voor fo jataren hun Hof plegen te houden) Nam. noy (dnatr rech goud valc, en voor by 'c wilke noch eenige dug - reifen men de grens-parl tuftchen Carbodia en der Lou. wen land aritmoer) Baffak, Ocmum, Naewein, "t wek Samfant, Beenmock, Siymoen, Tapanom, en Lochati (daje cen ftad wan groote als Schoonhoven is, en dars fich een onder-Koning, of Land. voogd van den Koning van Cambodia onthoud Huyloen (dnar ved fchoone Zyde Wheten vallen) Meunleok (een groore Koopplans, tor welte alle de Lotwie Koopmanlioppen toevloejen) en meer andere platefen, die wy wourbygaan.

Men ontmoet hiej" en dar ook fwatr gebergec, en ook eenige Eilanden, de Eilander wan Suxenham genarmd.

Na dac zy nu in 't begin van Nowember tc Winkjan nangeland waren, қwierden (wolgens 's lanats wy (e bier) de Bricven, door zyn Edelheit ann den Konirg gelonden, eerft nacukeurig ngelefen, ou te lien of zy wel gehoorlyk opgefeld waren; al 't welke zeer wel bevondésynde, werdenzy den 5 dico mee een zeer groote fistic in 3 groote Pracuwen in. geldanid, in clk van welke wel 40 Scheppers, nevens ere Vorlt des Lands, om des Generatls Brief te mecr eere man te doen, die onk in de groorfte Prneuw, onder een vergulden hemel over cen goude Doelang of bak, watr acher de Hollanders, faten, geptinte was.

Dus Jchepen zy by noch ecn dag, eer $2 y^{2}$ stwouds ineen Logement, door de Konng wook hea beseri, quamen, alwatar zy door een Tewinis of landwort, uir Konings than ver welkome wierden, met betuging dat zy den zeluet zecr mangenam waren, die ook, am dit te meer te beveltigen, ten eerlten weet wolls landward in zond, om ma Mulcus en Benwoin Cabelfa te doenzoelen, ten ems de dic weer an den Gooverneur Gergemal te vereeren, alfoo "er wry noch wat tyd toe vereifcht wierd, on die tebetomen. Cok lier hy een goude Pindrg: doos, wel 2 cati war maken, ondieal mede aan den Heer General re zenden.
B. O D. I A.

Ondertuffien dede de Foning ee- I $\sigma_{4} t$ : nige leswen me $\mathbb{R}$ y Matalen met Bijangs (een foort van geld hier) an de Gefan verecren, en dede hem anงlegren, dat hythem gelioor verlecoen toude, mits dat hy fich in "te bewys van ecrbied and den $V$ orft, $n$ a ss Jands wyle, hon met zwee kanren inde hand groeten, en fich driemal met het hoofd eer aarde buigen wilde*

Datt op wierd den 16 dito 's morgens En met vroeg, des Gencranls Brief met 6 Oli- wattide fanten (dar andere Gefarten wall Ko- tyonitnitigen "er man 3 gethad hadden) xeer Anelykingehaald, en op een gonde Doelang die op den voorften Olifant geplant it was, gelegt.

De indere Olifanten waren voor den Gefint, en zyn volk, mirsgaders voor de Gefchenken, die zy mede braçhen.

Zy crokken in dele ftutic voot by 's Konings Hof, datr de ftraten an wederzyden met Soldmaten, wel ten getale wan fooos, belet waren, komende cindelyk by een land poore, dar zy ook de Itad zagen, dic met eç roode fteene mutur omringt was, dic licl nocle wel 2 a 3 roes hooger datt $2 y$, woo als zy op de Olifanten zaren, vertoonde, en ande wetke zy ook eer zeer breede grache zonder water, doch met veel ruigte begrocid, vernamen.

$\mathrm{N}_{2}$ dat zy nu noch een $\frac{1}{4}$ uurs verder gekomen waren, traden zy van hunne Olifanten, en gingen zoo lang in Tenten, roor hen bereid, orndaar's Konings ontbod af ic wachien.

Het krioelde hier van Overiten, en hunne Olifanten, mitsgaders van peerden, en Soldaten, dic ook alle hunne Tenten hadden.

Nid da zy hier een uur gewacht hadden, verleheen de Koning op een $\mathrm{O}^{2}$ fane uit de ftad, en reed voorby, $z y$, buiten de Tenten gegaraynde, hem op den weg lumu cerbiedigheicbeweren.

- Het was cen Vorft pas za a 2 j jaren De Voith

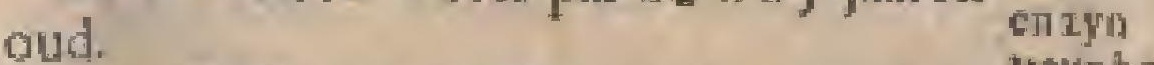

Zyn Lyfwache beftond üit 300 Sol- felmerem. dattei, ten declen met Roers, ten deefen me Pieken, gewapend.

Datr an zag meneen treyn wan verreheide Olifanen voorby gaan, die alle gewapende Otheicrs op badden, die ook van cenige Speclieden, en van ettelyke honderden Soldaten, gevolgd wierden.

Kort daar amn vertcheenen 's Konings Gemulingenop is Olifanten, zynde nieusgictitom defen Gelant te zien, alfoo dit de cerlte Chrittenen waren, die hier verfoheenen zyı, na 't vootby trekten s'an welken treyn ieder weer ma zyn Tent ging, dari de Koning antufonds tan de onlen î Doelan met roebercid ecten zond. $6^{2} 2$ Ten 


\section{$5^{2}$}

164t. Then 4 uxen na de middar wierd de Gelane aer peliagr ontbaden, en ower cen groor plein in cen vierkant geleid, da met een Atecrie maur wol Cehiergaten brumingd was, in welkers midden $\sqrt{1}$ wh ecn groote breedie Pyramide vercoonde, boven mer goude plaaticns bedekt, en "war an (zoo men zei) wel 1000 pond goud verwerkt whs, woor dewelke alle de Louweri, die hier binnen quamen, hunne eetbied, als woor cen God, vercoonden.

Dow nat wierd de Schenkagic ook gebrach, en onier den blacuwen bemel, outrent io treden van den Vorft ge* plaat ft.

Nevens Niet lang fer na bracht men hew in beret- cen groote Kerk, dari de Koning met dere toen alle zyne Grooten was, alwanr de Gelant vuorge-I met zyn gevolg de gewoone eerbiedigvallen. - heit met 2 karien in de hand, en met de hoofuer driemanl ter aarde te buigen, 4ал den Koning bewees.

Toen liee de Koning hem door ect Tevinia na de gefondheit wan den Her Generaal wragen, te gelyk betuigende, hoe augenatio hem die Gefantichap was, gelyli by ook woornemens was weer een Getunt nevens hem ata den Generaal te zentien.

'Hy noodigde ool zeer wiendelyk alle Nederlanders, die mar in zyn had koinen wilden', onder toelegging wan hen mer veel genegenlacit te zullen ontfangen, dair by roegende, dat men dog jardyx de wriendfchap onderhouden, en den $\mathrm{H}$. Goneral, uit zyn nians, hertely k groeten, en alle heil toewentelien wilde, dac de Gefant annam te doen, wenfehende zyn Majelteic weer alle heyl, zegen, en ling leven.

Lecen das ra fethond lyy an den Ge-

Thyen gond Water-belken, wegende I ho (wata van ier s in cen cati gats)

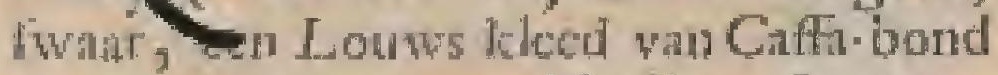
Ecwerwid, ca cen rood badjoe of opperMleed.

Aal icder Afiftent dede hy cen bel: kentje, een half hoy fwar, een kleed en cen bedjoe tehenhes, en gaf atan den Wondheeler een Zyde lileed, en een ba djos, en an den Tolk 2 roode Bethilles.

Hy dede hen ook "t wermakk van zyne Sclucrmers, Worftelaars, Goochclaars, en Poef femakers te dinen fien, gelyk hy ook zyne Vrouwer, lommige in een feldfaum gewand, andere mee cen Pacuwerfteer, zagen danfen, voor welke moejtc ieder Schermer een kleed, en ieder Vrouw 2 fyne witce badjoes krdeg, al welk vermalc mer een vertooning van cenige fracje Vuurwerken befloten wierd. Zy llicpen datr, gelyk ook de Koning, buten de ftad (dat ier foldrams was) en

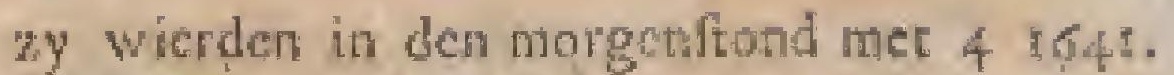
Olifunten thais getrache.

Naderhand ts de Gefine van den Koning mecrmalen deftig ondhald, en zyo hesa allerlei foorten wh veromats tungedian, by welke gelegenheit hy zyn Majefteit in een Zetel van zuiver goud heeft fien voorby dragen.

De Gefichenken waren hem zecr asa. DeGegemam, en voor al cen zeer frajejo til- Pchenken ver-gegravecrde Verrelyker, en exr gan heforide ketrlyke Houver, als mede 3 ftukken geel en groen Laker, weike kouleur jn die land gen anderen, dan de Hovelingen, dragen mogen, en 4 ftukled $D_{\text {ih- }}$ maft, mirsgaders nocis eenige byzondere Damaften, door defen en genen daze by gevoege; doch de Koning verlogt, dac men hem in 'c toeliomende eenige $W_{a-}$ ter- en andere groote honden, Cacatocha's, Agralche Duiven (of Paeuwenfarmkens) allerlei Konynen, langebrecde Tapyten, en fyne Lywaten zender wilde.

Na dat ria de Gefane hier tor den 24 Des OeDecember $164 \mathrm{I}$ geblewen whas, vertrok fants ie hy van Meunkok, en quam den t i $A$ - tugteis. pril, 13 een reile van a manden ch 3 wecken, ecrft weder in onde Logie tot Cambodia atan.

By zyn anwefen in dir Joningryk, had hyr vernomen, dac her zelve tultçhen defe yeven Rylen, te weten, China, Tonkin, Quinam, Pegu, Sinm, Tsjan$\mathrm{pa}$, en Cambodia, zoodanig intege, dar het fich wel 's meeft tuffchen China en Pegu uitfrekt.

Ool had by gemerke, dat defe Koning der Louwen veel voor een manier had, wan alle vreemde Geranten, die by hem quamen, ten minlten 7 a 8 maan= den nan zyn $\mathrm{Hof}$, uit cen footr vati Starlucht, op te houden, "t geen by $A^{a}$. 1040 nan een Gerant ran Tonkin mede $h_{n}$ d zoeken te doen; dog defe, wiet genger] hier zoo lang te blywen, was, zonder werlof te verfocken, hier wan daan gewlugt; welke zath men in "t cerlt dache, dar zeer liche weer bygelege zou werden, alfoo defe Koning de dochter des Konings wan Tonkin tot een van zyoe Gemalintien had; $\operatorname{dog} A^{\circ} .1642$ quam hier den ro Matre weer een Gefant vara dien Koning, mee een Gelchenk van eenige Rocrs en Cantonfe thoften, benevens een Briet, dic 3 dagen data na in ecn Kerk gelefen wierd, over den welken de Koning zulken ongenoegen apyatre, dat hy nog dien Briet, nog dic Gerchenk, anneemen wilde; ook verklaarde hy den Koning wan "I'onkin voor 2 yn $V$ yand, en belufte aynen Gefanc analtonds te vertickiken.

Met den Koning van Cambodia had Aantmethy wel gech Oorlog; maar date was kingen 
v $A$ กิ $\mathrm{C} A \mathrm{~A}$

B

O. D I

$\$ 3$

$164 r$. zedert 8 jotren, tufehen hengelehil geGerant refer, over 'c wederzender van ecn Bricf, Lared, san den Koning van Cambodit door defen Koning geronder.

Hicr over was de Koming der Louwen zeer moejelyk, cu hoewel hy darom her Vratederbend nierbreken wilde (alloo dete Narien malkanderen in veet opfichees niet wel miften konnen). res kliarde hy nochtans door onsen Ge. fane aan den Koning van Cambodia, dat, nangelien de ichuld ain des zelfs zyde was, hy wel genegen was weder wriendrethap tnet berin te houden, matr dat by, zonder zyn eere te querfen, niec weder aan heni ichryven kon, voor dat hy cerlt an ben gelchreven, en ham over dat wederzenden van zyn Brief ceniggenoegen gegeven had. Ecluter meinde mea, dar dir gefchih door den opperiften Pricfler, nnders Rafha Poorfon gennamd, wel hatit (gclyk hy ook beloofd had) zou weggenamen werden.

Met den Koning van Pegu was hy gedurig in Onlog; doch die van siandrewen llerken handel op dit Ryk, niet regentliande zy wel if a 5 rialnden mec humu: gotuleren, op Buffels-karren gevoerd; doch zonder de zelve in 't weetkneren echeer noch wel 3 manden onder weeg waten, alfoo zy over zwar gebergte moeten trekken. Dus lsomen zy

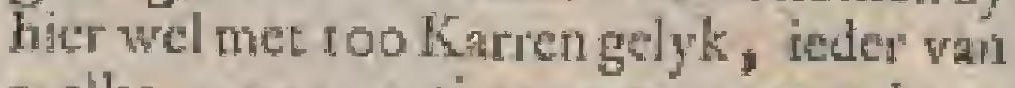
wellec pas 220 cati zwarce voeren kan; maar" zoo iemand voor zyn perfoon al. lecen derwants reifen wil, kan hy diea toche in cen mannd doen, ten ware hy op zyn reife door Tygers (die men hier veel heetr) cerigen ydwerler en opgehouden wierd. Zy brengen hier allerlei geftrecpte kleden in groote menigte, whar van fy ter jatrlyx wel 40000 pr.tegen goud vermilen. Wanned hier echier een Gelane Varn de Siammers kome, handelen zy hem niex weel beter als cen gevangen yan Stati, verbiedende hem uir $z y$ n wooning Ie gaan, of icts te moogen koopen of verkoopen, alfoo zy malkanderen ten viterfe mist rouwengmat, on in alles zeker te gnan, thellen zy' wachten by zym huis, on op ill zyn doen en liten te paffen.

De ware reden echter, warom $2 y$ dit doen, is, dat die van Siameven cens tmet humen Gefint in Siam leeft."

Met den Keifer van China onderhoud hy etn valte vrede, ook komen de Chiniefera alle a janren ecos cor Meunswat, ech vemand wiek op de grenfen var $\mathrm{Pe}$ gu, handelen, das zy met Praeuwende Ritrier aflomeis, en dan Mulcus enveel fchoone Zyde ftoften mede brengen.

Mec dic van Quinam was hy mede in cen vesbond; alog met die van Tsjarpia (illoo dit zeer whelte volkeren $L y$ ) big hy, gelyk ouk de Cambodien, gedurig over hoop, van watar men hijer dan ook 164 t: cen grooten Staveti-handel had.

De Warten, by hen indirland der Lou- Wanela wen gevonden, waren dele: Muleus, hier valGoud, Gommelat, Slaven, Rhinocer- lende, do hoorns, Olifants,tinden, Harten-vellen; getrok Gn méer abdere, rehoone Benzoin, Zyde, en wat dies ineer is, warr tegen laier allerlei geftrecpte, en Zyde kleadeñ, Chineciche Kranlen, Y Y er, en voor al Zour, zoodanig getrokken werd, dac zy voor een Mass Zour een Mas Goud geven, 'I geen zy ook gemaklelyk doen konnen, aingefien hice zeer veel gaud, zon in de Rivier, als wel voornamelyk in 't gebergte, wat boven Namnoy, walc, Welke plaats janrlyx aan den Koning der Louwen ro eaci goud leveren moeten.

De levens-middelen zyn hier ook zeer overvloedig, en dierhalvenalle zear goed koop, alloo hier weelHercen, Reedjes, $\mathrm{Ver}$ kens, Hocnderen, cu allerlei frtuten zyn.

De inkomften detes Konings bertatin "s kot ook meett in Goud, Gommelak, Ben- kitggt in zoin, Olifants-tanden, \&c. en alle 100 huisgefinnen moeten hem tor een jazrfcluatring een Hoyning, of $\frac{1}{\ddagger}$ pond gouds leveren, dat door de menigte des volls al cen grooten fchac opbrengt, hocwel hy een groot deel wan dit goud ann zyn Prietters tot het optoyen en vergulden Yan bune Tempels en Beelden geef.

Hec land ward door den Koning $\mathrm{Op}=$ permachíg en zeer geruft beftierd, die mar drie groote Lind roogden onder tich hecf, door welke hy dic groot land regeerd.

De ecrfte was Tewhid Afen, ect zect Reges: detrig en onczaglyk Heer, cen man wan ring wit 40 janr, die ook den roem had van een itout Soldat te zyn. Hy was Gouverneur van Winkjan, en van die Landvoogdy daar de Benzoin valt; ook ans by by afywigheit des Korings, vordien culfchen-tyd, beftierder des leyks, tot er ecn ander Koning gekroond was. En zoo 'er wettige erfgenamen ontbraken, wis hy ook de naafte cot de I rroon. If zeg wetrige erfgenamen, om dar alle kinderen wan bylitten als onwetrig torde Kroon en erfenillen lier werworpen werden.

De twede Landroogd was Tevimia Pro J crbin, een Heer wan go jaren. Hy beficerde he Landichap Namnoy, what over ly Pra, dar is, Onderkoning was, een Eertitel, die hy alleen woerde, geJyk by in mache byma zoo groot als de cerlte yas.

Hy had in ons Hollands gewad zulJeen lin, dat liy zulk een klecd met al. zyn todbehooren, regen een Louwle zyde rok, een zyden kleedje, en cen Mufcus kleed, verruilde.

De derde was Tewha Laman, cen IE.

G

Yin 
54

1641. van 36 jarea, doch de mache van defen is w'y bepratder, als die varie w weecerften.

Dele drie echter beftietden die land keer ordentelyk, dónde om de 2 a 3 mathden vertigg azn den Vorth wan 't gene $x y$ ondertuffehen verricht hebben.

Zyo Krygs-mache is al wy groot, at: foo hy des noods wel 70 of 80000 man te veid brengen kan; marar wermits hy die juift nier allyd by een, cn indew. penen heete, is by door den Koning van Pegu nu en din wrel eens in de bovenhanden overvallen, en van cenige platien beroofd; doch hy kon ber diar niet lang houden, zoo dat hy "er dan marr een fichictyken roof dede, wain 'I geen hy imet 'cr hatal by ece lichrapen kon.

Hun Nieuw-jatrsdagis den 7 April, op welken $\mathrm{y}$ d hier een grootevicugde, gelyk de Koning met al zyı Gemalininen, en met zymen Adel den 10 dito ook ge- wroon is tha zekere nond plate to gatm, $164 \mathrm{I}$. daar by dan fich in eenige huilen van uermakk ; daar toe wirdrukkelyk gefchisc, onchoud, ton dar $z y$ malkanderen nice wynig thet water (zonder icmand te ontfien) begiercn, war it zy groore weugde fcheppen.

Due nu weten wel de voornanthe zatken, die onte Gefant wegens dic land der Louwen (by andere ook wel "e lanit der Laos genaand) amgemerk had s crn men was van oordecl, dat han IEdelladen hier meter tyd cen fraejen handel gedreven zouden tieboen, by aldien hua toeleg door "t vermoorder wan onfe $O_{p-}$ perhoofden, newens de verdere Bedienden, en door "t aflopen thin onfe Logic in Cambodia, niec zoo rehendig en onverwache geftemd was. Of zy nu naderland weder iemand herwards gefonden hebben, is ny onbekend, en noit her allerminitc das van gebleken.

\section{VIERDE HOOFDSTUK.}

W An den Godsdienft der Cambodiers, en Louwers. Het werjoek der Pórtugeefen, on busman Godsdienlt in der Louwen-land in te voeren, afgelager.

\section{$\forall A N D E N$}

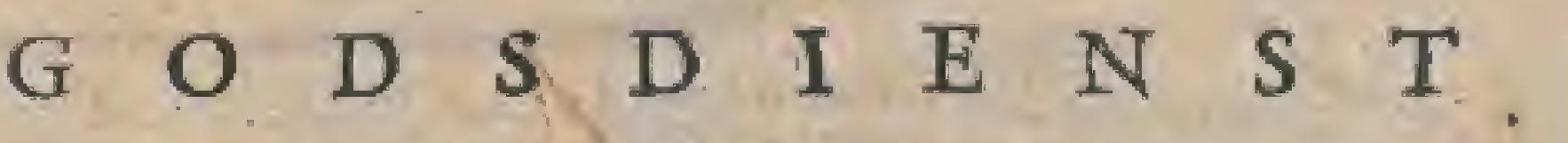

D $E$ R

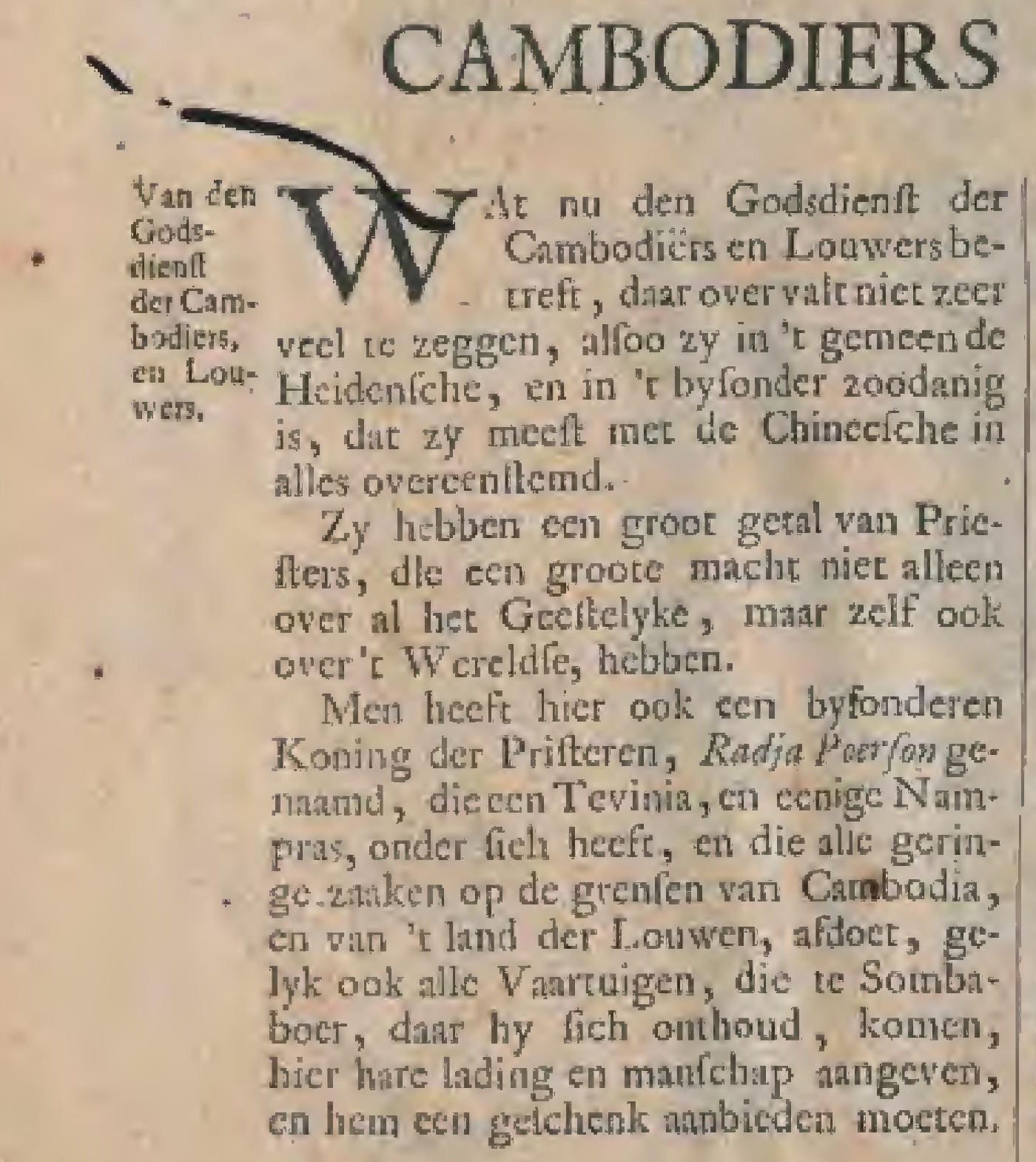

\section{en LOUWERS.}

Men fiet hier oolk voor al in 't land der Louwen, een groor getal van $A$ fgodifche Tempels en Pyramiden, romruge van houre, en ook eenige war fteen, $\mathrm{cm}$ zeer dicht by een gebouwd, welke van binnen zeer koftelyk verguld zyn, watr in men, byna ever cens alsinde Tempels der Siamtners; en Peguannen, veel groote en leerlyli vergulde beelden heef. Ool: roemen de Louwers, dat hiun Gode grooter, dan die van Siam cn Cambodia, is, en zy achen hunne Prielters byna als balve Goden, gelylk zy hẹn ook ry kelyk van alles veriongen.

Ook is het anumerkens waardig, dat dele Prieflers ieder maar cene vrouw hebben, hoewel zy omfichtig en rein met de zelve moeten leven; daar dit nochtans den Cambodíche Priefters ongeoorloft is vrouwen te helben: want zoo men dir aan dele of gene Priefter madr gewaar wierd, 


\section{₹ A N C C A M}

wierd, zou hy aunftonds in daverny vervalten.

De ganlche Leere nu defer Priefteren ast die wolk betlatat alken, in dele Beelden, die in humae "Tempels zyn, an te bidden, en an de zelwe ryle Oferthanden toe te brengen, daar de Priciters beit vas varen.

Die nu doen zy, metz brandende keerfen in de lasnd ben naderende, met honderderici bygelonyige grillen, waw van zy yol zyn. Ouk beloven dele Priefters de groorlte gevers het grooulte geluk, zjonde het ten uiteriften te verwordderen, hoe defe menfehen fich van dele bedriegers zoo konnen laten blindholsken.

Zy zyn ock gewoon veel ache regeven op het brullen der Tygers, (dat $z y$ voor een quad wonrcken houden) op 't blecten esi felarceuweñ der Harcen, op de kuu. reñ der Aapen, en op 'f Vogel-gefchrei. Dus houder zy 't miefer van een menfch, 't 1чwemmin van ecn Slang dwars voor haare Pracuw over, ic-vallen van een dritern tak van een boom, en wat dies meer is 4 foof een quatad teeken, al "t weille ben deie Priciters zoo wys maken, en dat $2 y$, zonder verder onderfoek, maar anniemen en gelooven.

Ools is het wonder, der de Portugeefen, die anders ten ecriten over al, daar zy maar ingang hadden, hunnen Gods-

\section{B O D I A.}

dienft hebben zoeken in te voeren, niet voor lange getrache helben, den zelven ook hier te planten.

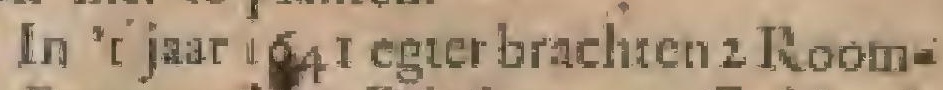
ic Pornuged die Prietters een Gelchenk ata den Koning der Louwen, beftande in 2 witte Hondeliens, een Konyn, cn enige fchoone Cantonfe Goude Zyde rollen. Ook vereerden zy ain Pra La chan een fraeje.Verrukyker, met veriock, dat hy ontrent het vooritel, dac zy in 'c korte ano den Koning meinden ic doen, de behulphame hand zou bieden.

Her beitond daar in, om den Chrifte- Het war: lyken Godsdienft in 't Ryk der Louwen foek de? openbaar te mogen "invoeren; dog hen gertea. wierd geantwoord : dat $z y$ dit noit on- om hum. dernemen moetten, ien Ware iy hen Godszelfs genegen waren, orn fich in allen dienft in deelen na den Godsdienit der Louwen te der LouFchikken, en dien aan te nemen; dog dan wen land moeften zy nog eert de Louwic Taal interoelecren, fig op zyn Louws kleeden, hun hagen. hair laten afichecren, en fig in den Heiderilchen Godsdientteertt zoo lang orffenen, tot dat de Louwe Pasen hen bequanm zouden keurea, orm tot zekere geetlelyke weerdigheden onder hen gevorderd te werden; maar zy hadden daar geen fin in, en lieten hetdaar by freken.

Wast mede wy dan ook wan de zaaken van Cambodia aficheidea, om tor die van Siam oper te garn.

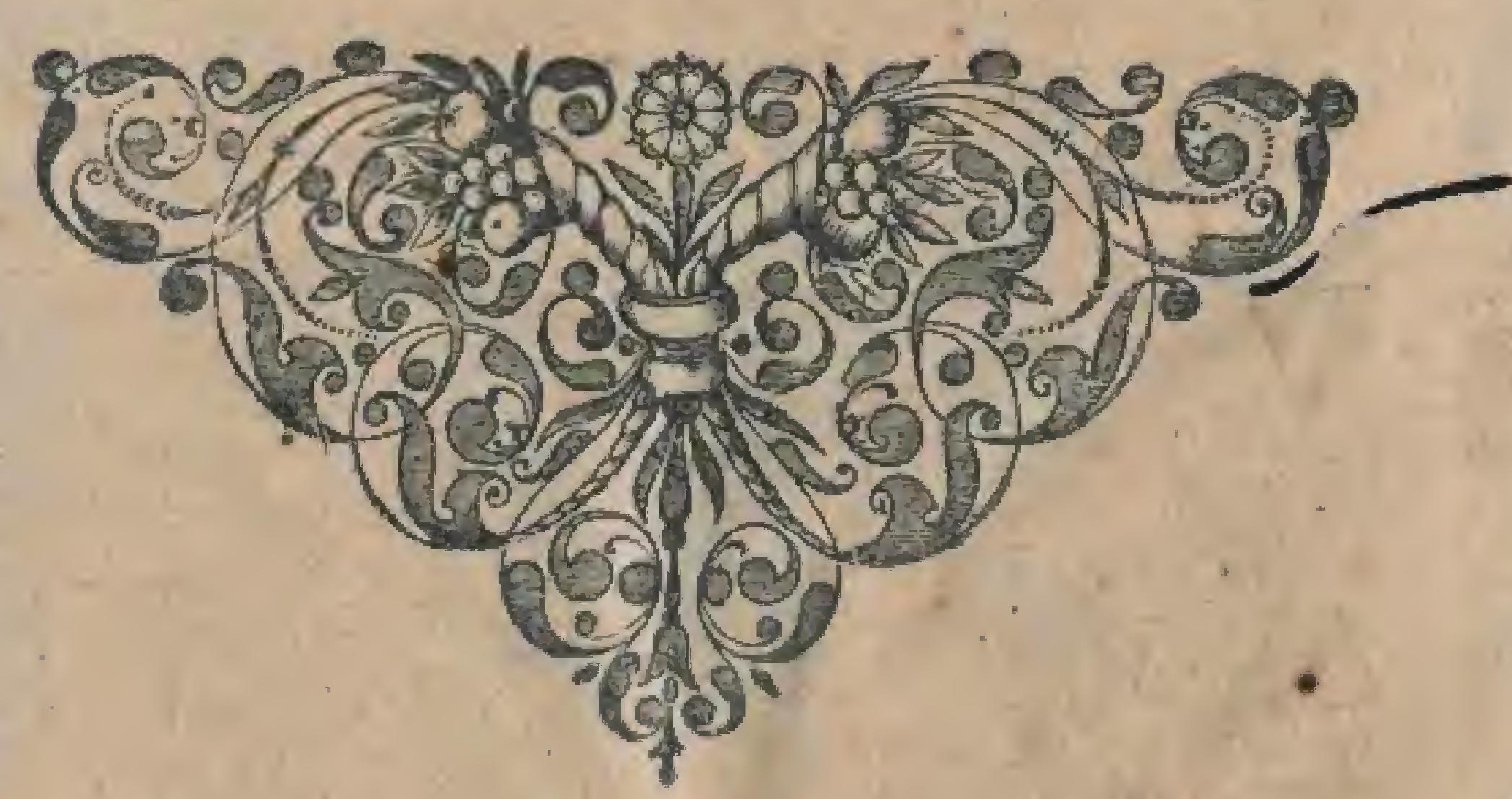

B. E. 


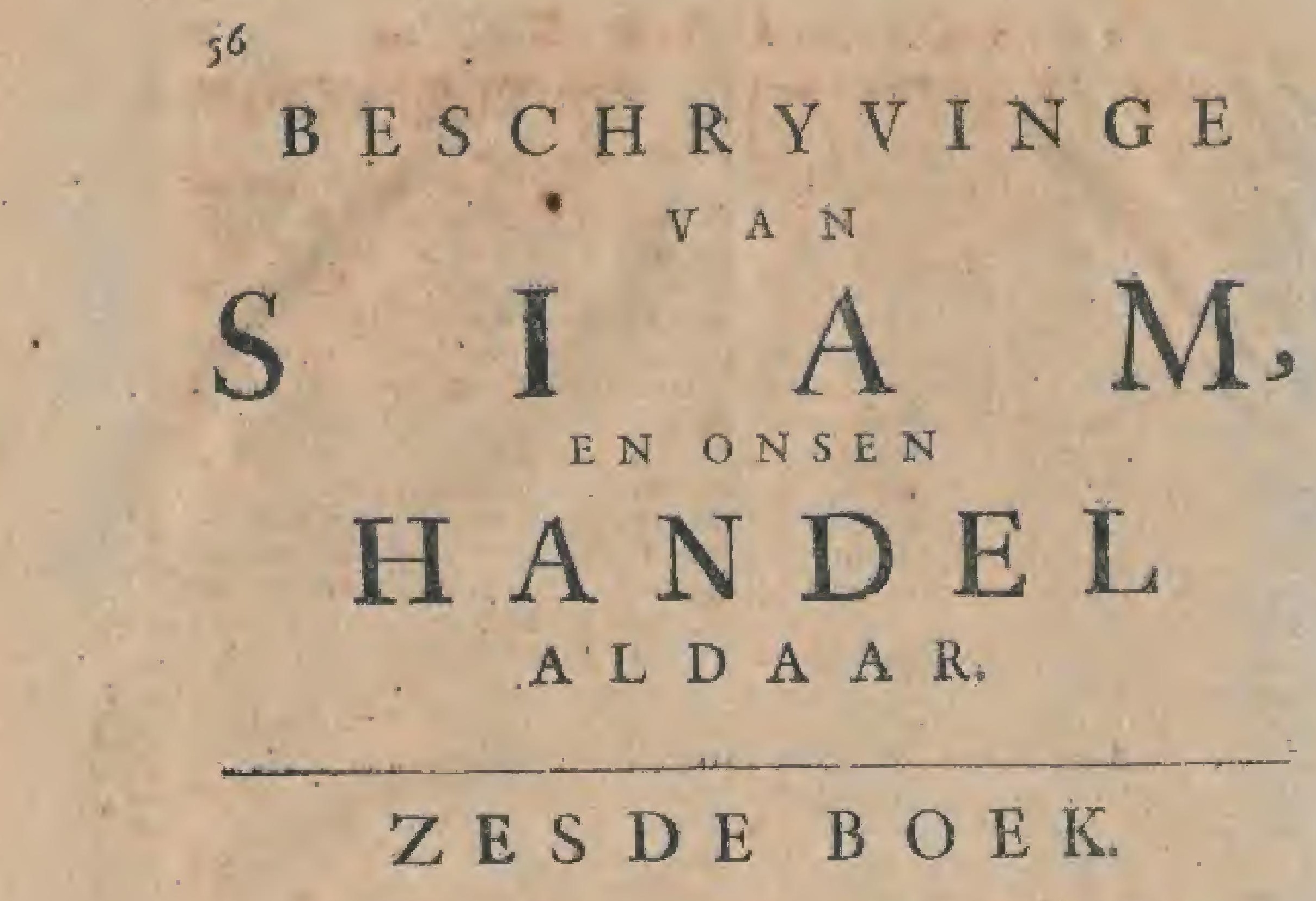

\section{EERSTE HOOFDSTUK.}

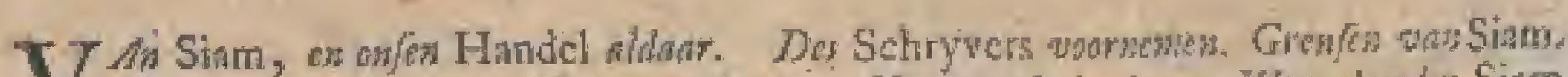

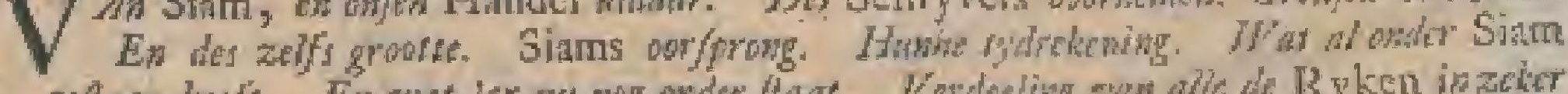

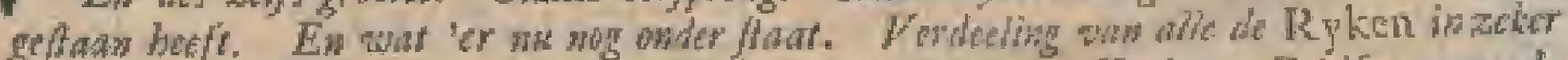

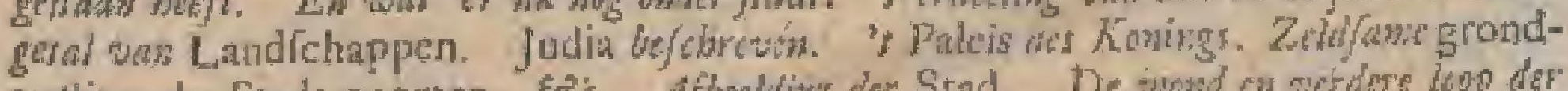

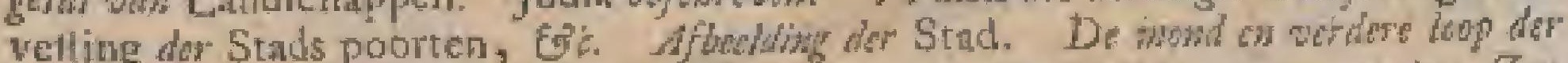

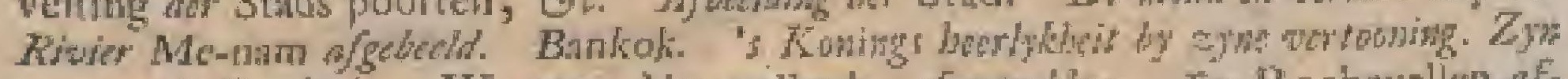

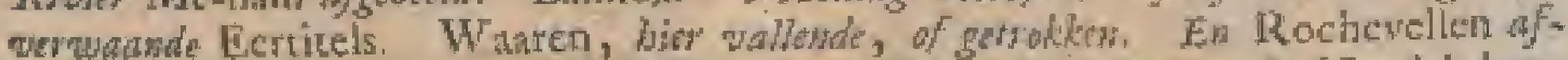

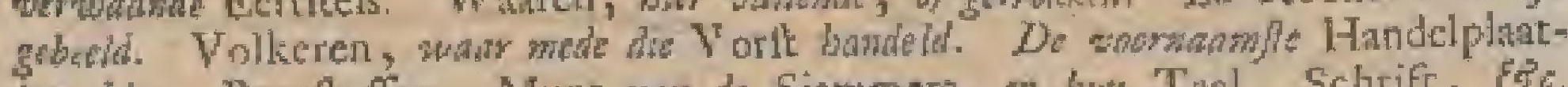
ien bier. Bereftoffen. Munt van de Siantmers, en bua Tual, Schrife, Eic.

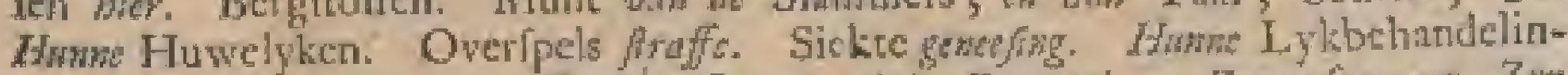

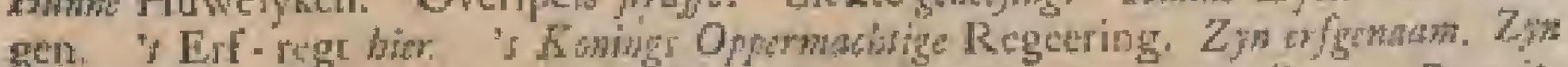

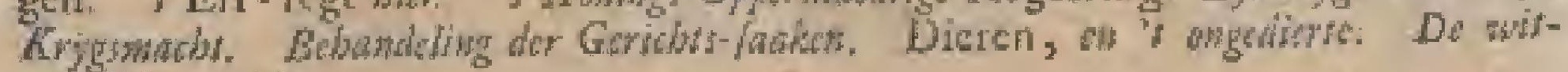
w Olifant, हic.

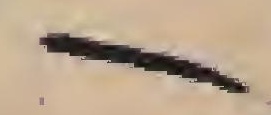

Van Sismi, en onlen

Hand:I alditas.

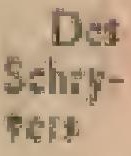

V

Ermits wy van ouds hier thede in het nugtig Koningryk van SI $A M$ gehandeld, cr diar al wrocg cen vaft Comproir yehad hebben, gelyk'er tor nech toe ook een Opperhoofd yam ons lege, meinen wy, dat wy nict wel voorby konnen, hies van nok " $t$ noadige, op een geheel indere wye, dan tor nog van anderen gelchied is, ten woor al om zullse zatken hier wan op te thilten, die zy of niet geweten, of voorbygegaan, of altoos zoodarig niet voorgedrugen, noch zoo verte verwolgd lubbers.

En tangefien de Handel wan dis Ryk zyn medte berekking tot den Handel vân Japan heefi, oordeclen wy dat die de rechte plaats is, on 'er wan te Ipreeken.

Men moet vaล ons bicr geen wydluf Selist- ige Betchryving, wan dir groor Koning- ryk, werkhehten, zoo, on dat wy hicr soornemaar als Koophieden geduld worden, en men. geen cigendom ant dit land Incbenen, als Wel voomimelyh, om dat ons noit tocgelaten of gelegenheir gegeren is, on dit Ryk te cioorreifen, of in het binnenAte te lecten kennen.

Wy zullen derhalven maat' in 't gemein hier van zoodanigge dingen tanncé Iienen, die wy oorderien zullen tot de nantle Isennis, die men hicr van geven kin, of wel tor her bedlag vari onfen Handel te bebooren.

Het Koningryt, by ons Sian, doch Grerefen by de Starnmers Meung Tai, dat is, "E ven Siam Ryk der V ryen, gerzamd, legr wanden 17 tor den 18 of 19 gratd N. breedre. 'It 't N. grenit ber ann China, Tsjanany, (of Chamay by anderen genaand) en is dagen verre benonden de grenfen van Stam gelegen, en Lintsjing; in "E 0 . 
nan Cumbodic, "F Rylk det Lnos, en Coetsjicntsjima, dar ieder met een fware Richel van Gebergre, dic $N$. W. en 7 . O. Irch uithekken, van den anderengefoheiden, hoewel tuldehen die twee doorgande reyen Bergen, wan "t cen tor "c amder cinde fich de lware Riwicr wan Catnbodin, Mecon genatind, moch "er warfehen beiden verroond, die al zeer verre bowen de ftad Lantsjang, cn door de zelve kgek mede door de flad Cambodia) zoona berneden loope, en meerwee monden bcoolten den hoek van Cinbodiz in Zee ftort. In "t N. W. palt hieran "c Koning yle Pegru, in "e W. Martayan, Mergim, Tanufery, Juufilam (vanan-

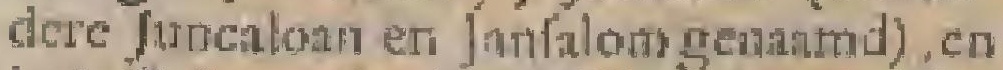
in "r Z. hee geheel farte Eilatid wan de Matheitefult, wair op ment an de buitezkurt thi 't Z. W. onemoer Bordelong, Keda, anders Queda, of reche Keidah gensamd) Perith, in Malakkx, gelyk men fat de binnem-kutt Ligoor, Patasi, $P_{t}$ hang, en Djohor, (by atuderen fohor en Jor gendam gapoera, gelyk men dan in ' 6 '2.O. ook 't Eiland Burnea ontmoet.

Defe ltrook Intuds der Maleitfo fort is op romanige plateren wel fo, en by Ligoor en Tuntfery pis 20 mylen breed, zynde het verfte land van de watte kuf wan Lndièn, on de Z. gelegen.

Tulichen de Kap van Lambodiz en. tufichen den hoek van Ligoor vertoond fich cen zeer groote boche, gemeenelyk de Golf wan Siam genanud, zynde cen groote opene Zec, die danr op aan de nond wel 80 a yo mylen wyd is, hoe: wel zy stilenskens neurfer werd, en fich als toc cen kleenc znk, of bacy, die pas I5 myl wyd en wat langer is, by de Rivier Menams mond intrekr, en aan wetkers Weft kane M. en Z. I Eilandekens Surgory en Cornam, leggen, behalven dis men noch 8 kleener wat Weftelyker ontmoer, hoedanige men in een grooten overvlocd ook langs dele kuft beweften Tandiery, wan Maravan af tot de Eilanden van junfalasa befohoud, al watr de Golf wan Bengale de Welt-zy= de van Tanafery bekabbeld.

War de grootte wan dit Ryk betreft, wy zullen wit het rervolg fien, dag het net alcyd cven groot gewectt is, was win daan het ook kont, dar zommige dic langs de Zee op 600, doch andere in de later tyden tic matr op 300 , of wel op 27 r mylen $Z$. en $N$, begroot hebben; doch als men liat zelve ( $\mathrm{g}$ dylo nu meeft

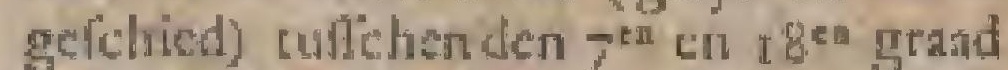
bepandd, dmon kan men zeer lichr nureekeneth, dac thet mitar a or mylen hasken kin, hoewd her in zinen oujtrek (voof al, als men de R yken wan Gimbodin en Cocrsjiensing "el" onder betreds) wry meer IIL. DEES. beloopt. Mea fteld dec zelfs begin in "t W. eigentlyk by Martawan.

Wanneer wy de alleroudife tyden wat sians die Ryk (roor zoo treire ons poch uit oor-

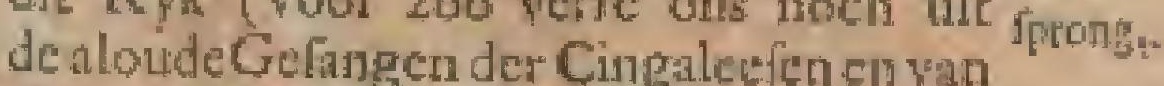
die yom Tanaftery blykt, war in zy de voorname gefchiedeniffen siat hun land nts noch bewaren) audachtig rifpeuren, geren ons de Siamners, en wooral die van Tanaflery (een der oudfle en mogenlte keningryken van defe kioon) op, als een zatk, die by hen lelat blykt, dir zoor 2024 jaren Siatreenzed woeth Land, zonder eentg Oppervorts of Koriug was, en dar re dier tyd cen Keiters Zoon wan Chira, die lig de Zoon der Zon noçmde, en díc zynen Vadet na de Kroon en a leven thond, en dasir over gebsnnen wierd, met en groote troep volks uit Chisn wertrokken, en eerth op 'T sjampa en Cambodia angeland is, vai watir hy allenskens, den hoek on, de boge van Siam ingeloopen is, en fig by zekeren hock, Cuy genaumd, nedergelet, en ditir ectu voorname ftad geboud heef, voegunde dar een heerlyken Tempel by om zyn Goden te danken voor de gentde, hem bewefer , am zoo gelukkig in dit fchoon land and te handen. Van dagr zond hy volle om de Zuid uit, Joppende aldar tot nan 't geweft van Djambi, gelyk fy Gg on de Noord, tot nan die plats, dani nu de ftad Pirfanocloec legt ('t geen de Portugeefen, en andere her navolgende, qualyk Porlcloes, en wy Poecelock genawne hebben) vitbreidde, zyode dic ook de eatrge reden, watom defe Provintic voor de allerheiliglle plingts in ganlch Stan gehouden, gelyk ook defelfs beltiening doorganos tan de grootfe Princen on Vorften des Ryhr gegeven] werd. Ook gham men cindelyk mede by die phats, das na: derthond de pragtige Hoofditad Judy op en wonderiyle wyle getoud is, wat Wan wy in "t vervolg breeder zullen fpreken.

Defedan, heeft lig nite alleen a]s Koning van dit hat hier nedergefer, man lig van lyd tot fyd ook zoodanig uitgebreich, dat by fig, na "coverwinen van verfeheide Landen en Koningryken, al. foo hy zoo juaren golect heef, enover honderd en een getiroonde Komingen heerichte, det nama wan Keifer weerdig gemanke heef.

Defe werd by hen ook als hun Wetgeveraugenerke, alloo hy alle de Wetren des Ryks, on gronden van hunnen Godsdientl, met zyn eigen hand belohewen heck, welke gedenkweerdige boken nog heden by hem in de flad Judia, binnen ton Tempel, Wat- li-ler-pudt gen matnt, ter ceuwiger geheugenis wat de

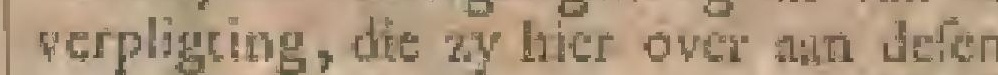

Vorlt 
$5^{8}$

\section{B E S C H R I NGE}

Vorft hebben, beward werden.

Hien uit dan is woor hem, alsecn weergadeloos Keifer, nict alleen ecracer hoogeverwondering enngting gerefer, triat rede, meinende dat zyn geeth nog ander hen woond an lweef, buden hem mer de allerdieple eerlyed, als den grondvetter van her Rys en wan haren Gotsdient, op en Goddelyke sy leam.

Schoon nu dele Vort wie China gebunnen was, heeft lyy den Keifcr van Cluind allyd als zynen Opperheer, en tig magr als cen Valal wan den zelwen, geagr, cr dan an, zoo roen, als namats; fehatetng betald; orn diar door verlof te verisygen, on met zyn jonken op China te daggen waren.

Met moer hier wan my geen hete L.ylt van humbe Roningen verwagten, altoo my die noit ter liand getteld, man wel eenig berigt van delen congenendhar ontrent gegeven is.

Honthe

tyd-re:

keniog.

De Sinmmers, die cen thd-rekering op fig zclyent hebben, dic $A^{\circ}+1-24$ net 2.69 jaren vervatte, zeggen, dat de nu regecrende Koning de 70 tte is, dic $z y$ in 970 janren gehid hebberi.

Zy beginnen die tyel-tekening vast de dood wan Sommona-Codom, een wan hunne Goden, van welken ay nok vecl verdigtrelen voorhouden, en welkers rand en voet $\mathrm{zy}$ nog ecren; gelyk wy hier aa breeder zullen tooneri.

Hun eerfte Koning wan wellen rygeheugen bebben, begon $A^{\circ}$. 1300 wan de voomoemuse tyd-rekcning te regecren, van welke $2 y$ 'er egter madr 24 of 25 weten te noemcrs, ens roor al wan $R$ latmatilondi, als Bouwhecr wan Jwdia, zeer peel weten te reggen.

Eer wy neu vorder.gan, om van de bediyven wan defe Koningen te fpreken, zullen wy exrft cens want de landen, dis hiep, van onds onderftonden, of "cr nong andertian, ondericheyden firedien.

Watza Wy hebben reeds al anigemicrlet, dat
onder Sian wan de oudite tyden af al een $V_{\text {it- }}$

Sham ge- Siam wan de oudte tyden af al een Vit-

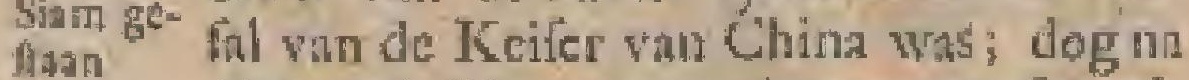

heeft dient tyd fchynen z.y dane weer afgerallen, en op dig.zelven gebleven te $z Y \pi$, tot dat de Keiler Xico, een Well-Tarters Vorlt van 't genagr juen, $A^{\circ}+1280^{\circ}$ nevens vericheyde andere danr ontrent gelegene Ryken ook Siam weroverde, na welken ifd $z y$, zelf nog tot de komft der Hollanders, datr aan cynsbanar fehynen geweeft te $z$ y.n.

Onder defe Koningen, van Siam nu plag. ten in de oudile ryden ook de Rylicen van Pegu, Brauna, Ava, Martawa, Jnngoma, Malnkla (tor dat Korsing Mav mud $A^{*}$. if ró'van den Koning van Slam afwiel) en mecr andere dare oncrent gelegen, te ftan, die egter by onwerieling van ftant wel ecos weer verloren gebleven.

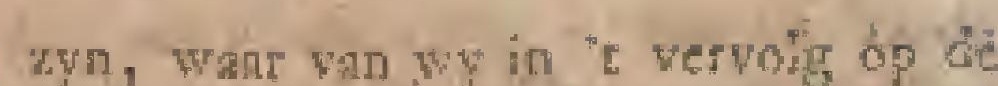
juran, dar hoe voorvicl, nog wel iets zullen andititer.

In ta allerounte tyun der Maltycte

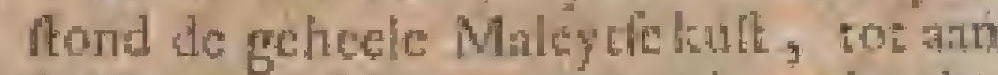
de Rnap we Sincaproera, mede onder deren Vorta, als werigen land- en grondHect, dor bet yelwe is hem nu en dat

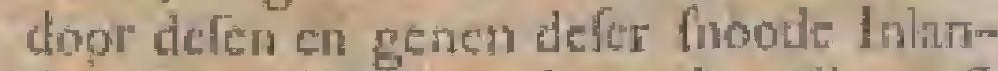
ders afhandig gendalet, dae allerecuth ontrent $A^{*}$. Cl. 1160 Anot deri eertach

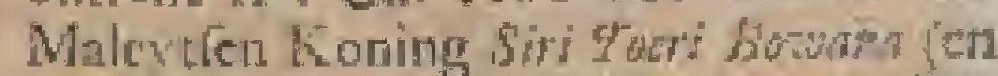
niet gelyk somnige onkundiget woorgeven, door een Mohhummedan, nliod zy lang daar na nog Heidenfeth waten, gelyk men onder de ftotic van Molalcia breeder lien kat1) gelchied is

A ${ }^{\circ}$. 1340 vond de Sirmfe Koning Bowativa goed, on Sulthan Modrisisjab, Koning vith Malaklia ; dit Ryk als syn hand land zynde, wece aE te vorderen, dreigende anders hen ic zatlen bylomen; dog alloo die Vorft geen hit diar toe had, Fafte hy hem mer ocn ywat Leger aas, onder" zymen Veldhecr $R$ at

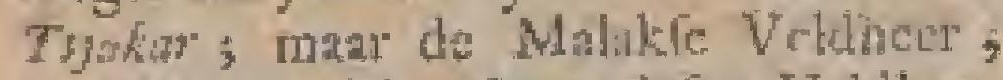
Sin Nardevida, Noeg defen Weldheer wan Sfahar Natuw, of Sornat (wantzoo wiend Siam toen tennamd) zoo decrly hy dat de Kaning Bosbatrian " van dit ré

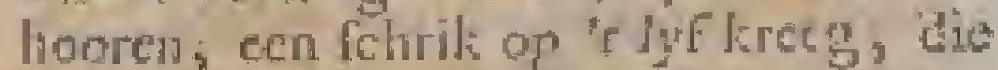
hern loort das ann in ' 2 grat Decpec.

Het is war, dat zon vertahger, Tos pardan, dit wert miet veel dipperheif hervatte; dog 't mislukte hem even eens; als zyrten woorzant. Hy wierd riede ge beel vic het veld gethagen, en quam ools liort daar ant te flerven.

Echrer is Malnkliz wat woor $A^{2} .1447$ ten tyde vaj Sulchan Alowalden S1obs

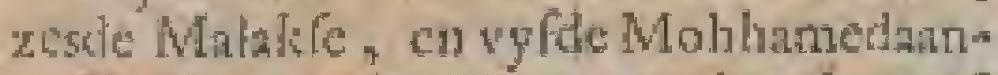
ie Rouing, odder Sian gernalit, hocwel 't nick Jung "er onder gebleven is, allno Koning Mollwhwd Syal, vervanger des vorigen, $A^{2}$. 5 gog van den Koning vari Siant trouwloos afriet.

Tunatley, dac al owet 2000 jaten cen xecl mathig Koningryle was, en toen nach op fich zelwen jtond, is al nede axn z.yn Kroor gehgge, en dar onder

Dus becte hy in oude tyden ook famolity, en in de later tyder de Koningryken yun Lintsjang, Bordelong, Parani, Pabang, Cambodia, Coetsjentsjinin, en $A^{\circ}$. 16,3 Ligoor, en Lycoon vicrowerd.

In de latere tyden nu fonden onder wated hem de Ryken van Pegu, Martivan, nu nog Lantsjang, Bordelong, Ligoor, Ly- pnder coon, Patanj, Cambodta, biaya, Uedjonglalang, en meer andere, die hem cot noch toc een zeer gloote migc en anfien onder de Oofterfche Vorlten geveln. 


\section{$\nabla A N \mid S \quad I \quad A \quad M$}

Zelfs phohten de Koningen an Sian w woond, en zonder punten of bolwer ook eenten cifch op Pallencatre te üoen, Jien.

gelyk oolk ettelyko onte Landeoggden hen, ren bewyle van dien, en oul hea te vleyen, jaralys wel goude en livere bloemen (cen yecken wan onderdanigheri) plachen te zenden.

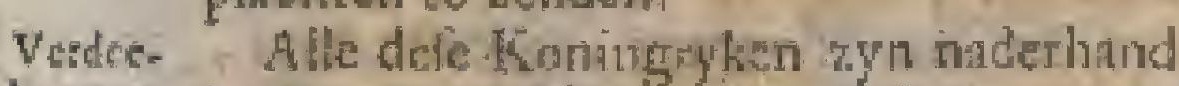
ling sin in Provintien en Landvooguyen veran-

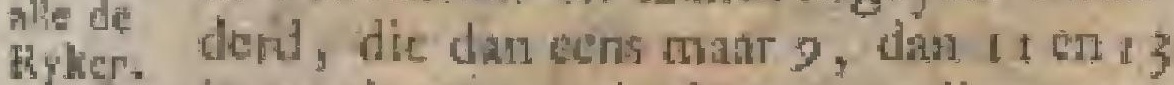

Whice. ingetal waten; doch nu zyn die totech gecel vou $t$ \& tingegrocid, en ma hare Hoofulteden aldus genatud, Porfeloek (ook Poukelouk gentand) Kampengpen (olkeprenpit) Irfein, Sorkclock; Sulkahry, lekonzum, Poewenongs, Bonjetong, Situklang, Konlei wran, Lowevo (ool- Livo geraasud) Sjuriboun, Marcenijo, Thernu, Koraftima, Sangon, Ligoor en Tanafiery, of Tubattermon.

Belbalren udefe groote, zyn 'er nocly es. riige mindere, Brinkok, Melong, 'I watoyn, Banthe, Paranthong, Koon, Pitstaboeri, Pineri, Cuy, Sinja, an Wulergirn genand, welk hatite op etr Ei. fiod gelegen, en de volmasmitehande)-

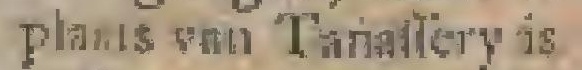

Zuminige valu deje Honfufteden zym al ving vecle jom ren bemulud, en op zyn lintilich vorthel, en ook oenjge natier. hand hier en-dar door Finalche Irgenieurs waterbeted; mar van de mesfto fiet men muar de dechte overbiyffeter; zoo dae men na werti zon hebben (yoor al zoo men wat dieper laudwand ifrgat) om 'er-mant cene te vinden, die 'er ni geleck, thoo de loye Sianmers de werken, die "er wan oude ryden noch overig waten, gehed en al hebben laten vervallen, wijgenomen Bunkok, Tamalfery en Mergim, die ren deele wan natu-

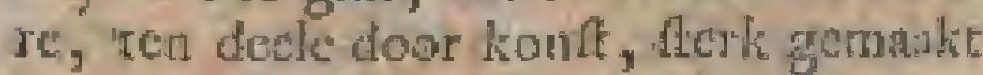
2yn; doeth men moct in th algemeen wan dit land zeggen, dat het een grook get deelte wan 'L jazr ftesk is door hec overloopen der groote Rivier Menam, die áe meefte landen wal 7 of 8 manoden zeodanig onder water zer, dar geen, anburig Vortk in dien cyd dnar ontent zou durven kowen.

Judia he- De Hoofutied wan dit Rgtis is Judia, feliteven. atdere noemen de zelve Odji, of Oljea; de Poreugefengercri her den nam van Strin; mara de Sinmuers zelf dien van si yo-thitya, wat wan metter tyd by verkortiug Juàia gegroeid is.

De zelve legt op cen Eiland, in lict midden van werkheide andere, op ${ }^{14}$ grten 20 mintten $N$. breedte, en 28 myicn de Rivier op.

Zy werd geoordeuld ontent twee us: Ton gatans in den omrick te beflaan, en is wel mer cen redelyke muar charingd; coch binnen de zelve nier. over al be-

De huifur yyn toorgans ling; en op

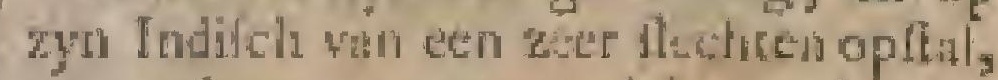

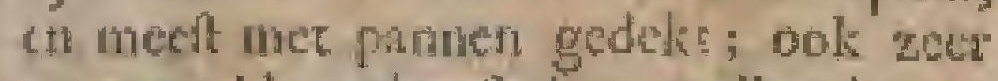
ongercgeld geplatat door malkanderens. mase men hecte ' $\mathrm{cr}$ wel 4 a joo ichoone Teimpels enkloolters, die gelyle zy van een groot genl werbatende groore gulde beelden, en andere koltely he cictaden, yoorfien zyn, van bujeen alomme mei vergulde tpiten, teorens, en dalen piatlert.

Gelyk men nu datr allerlei foorten win Natien heeft (die 'cr in de liter tyden wel tor vect tigderliei gevonden wierden) alto hebben the zelve ieder hun bylonder quarter. Dus woonen hier de Sianners, de L'egnanen, Chinecten, Macalfarien, Japanters, Maleyers, Lortugeden, CoeIsjensincetan, Cambodiers, en Nederlanders, ieder in een bylorder deel of Eewelt; bidacn of buicen defestad, onder han bylonder Hootd.

Went ning de zelve enigfins by Venevion verpelylieo, om dat 2 y overal mer gragen algelnader is, alloo "cr 7 of 8 Krivieren door henen ftronmen, die iêder stan wederzydo hare bylondere pooren, hotwel die zeer weinig uanlien of tineihicit hebben.

Wea heeft bier zeer veel feloone lange en reclie ftraten, warar in doorganas clle foort van Ambachts-lieden in een fratar afgefonderd by een woond; doch dnar ayn ook veel nacuswe ltrantjens, en flopjens, vol kleene gracheen en kreclen.

Men fiet in de zelwe ook cen zeer friseje Haven of Bicy, een fchoon Dok roor groote Scluecpen of Varruigen, en nog ectn ander yoor hunne Galeycnen Schep-

Vartuiget, of Bulons. Verlcheide frueis lleme en andere Logion, onder wellot die der Nederlanders, A, I 4 f door de Heer Jouf Selowhe, op latt wan de Hecer Opperiandyoogd van Lndiën, BrowIret, van lleen op een bylonder Eiland buneri de ftat gebouwd, een van de fracifte is, behalwen vericheide andere fracje gebouwen, hierdpos de Frabchen en Portugec fert opgericht.

Onder" alle defe yobowwen echter munt "Paleĩ 3 Konings Puleis uit. deskoHex Itsat in "i Noorder-deel der ftad, nings. alit de groore Rivier, beflatat zeer ved plancs, enis wan hegte muturen voorfien; doch niec in that om fich rekonnen verdedigen tefen cenig Eurapitch geweld.

Het is ais een kicen ftedeken op fich zelwen, wat in men weel lehoonefterkvergulde wootirgen, en ook fye corens, boyen uitheken lict. Voor het zelue is cen grooz plein, dat in de later tyd mé

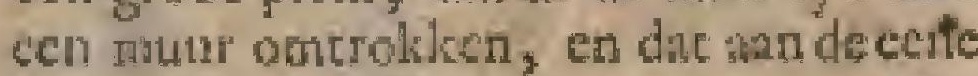


zyde met vecl wach-huiten des Keilers cn der Hovelingen, en tan de andere zyde rter verficheide ftalien voot zyn Olifanten; befet zyti.

Eer men in "x binmente Hol komst, thoet men "et wel 4 of 5 doortekken, die alle met muren iffefondend, en met andere wachtender Howelingen, die hier elk op litu tyd de wacht hebben, voorJicn z Jin, gelyk men die Solktaten dar op de grond ruce de beenen onder 's lyf' by hun geweer fitcen fiet.

In t $t$ ifde bismen-Hof onthoud fich de Vortt, en dair geeft hy ook doargains (linewel 'c ook wel op Loevo geichicd) an alle de vreende Gerancen gehoor, dar zciden meer dan tweemanl, by hui liomit en vertek, gefohied.

selame Het is zeer annmerkenswardig, dat Grond-, ment tan de flylen der poorten, zoo van Fefling dic Paleis, als wan die der ftad, verlatid, derftads- te weten, dat de Siammers, die al hunpeorten. nie pooten (gelyk ook die der Tempels, Klootters, \&c.) voor heilig houder, die vertocjelyle gewoonte habben, on onder ieder ftyl wat cen poorte een levendige bevruchice vroum te leggen, cn dic "er ander te verpleteren, houdendedie, welke "t hast a an 't biaren $z y n$, noch wel voor de befte daar toe. Zy oordec. len, dat de Duivel mache over alle poorten hecf, en dat dir her beite middelis, om alle rampen van hidne Poorten, Paleifen en Steden af te weeren, en atle juagde Duyvels er van dan te jagen, altoo zulke verpleterde Vtouwen anflonds in ecen sreedelylen [Daivel veranderen, en atn zulke poorten tot befchermers verderckiten.

Men doet defeclendige Vrouven matr wan de ftrent opuraten en na dat men hen cenige tyd likker con wel in "I ver"trck der. Konngin onthald hete, werdert zy op die rerfocjelylie wy onder defe then verpletierd.

In de later tyd echtet heft men Siam. mers geironden, die nier alleçn berer wiften, en dit zoo wet als wy verfoeiden; mat date zyn "ef ook onder de Hovelingen geweent, dic door den ongang anet ons, en anderc volkeren uit Eufopa, merkelyk weslicht zyode, de vry. hes genomen hebbes, uin aar" hunne Koningen de ongerrondheir wan dieftéling te verthonen, , in das door ecn menigre van zulke clendige, en reeds daar toe gegrepetic vrouwen te behonden, hocwel "e nothims doorgans (on hec volles en de Priefters, die char befwara-

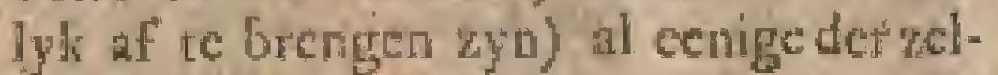
ven "t leven kefte.

Guly in de Regen-tyd, in September, October, November, \&e. dir land woor 't groothe gededte, woon al de lage lathdét, drata, co onder water Jeggen, alloo heft defe fad, fohoon foo veel hooger de Rivicr opgelegeri', medo wel 6 manden lang "t gevoelen datat af", alloo nen dan meefterneral and de huilen varen moer, wermits de Rivier Menam, ditt is, de Moeder des nurers, dan alles dar, even als de $\mathrm{Nyl}$ op zekeren tyd des jats Egypten, overitroond, larende dan over al cen flibbe en modder op 'i land, die 'c zelwe, als ware het daitr door dan geruef, angemeen wet on vruchtbatr malut, bahalven dat $z y$ ook "c land von feel ongedieric zulverd.

Dit Judia hecfe jegctwoordig $\Lambda^{\circ}, 17^{24}$ al 373 jarengeftan, en men wil, dac zy door den Koning Rbamallowd, in het I 894 jar der Sinmfe tyd-rekening, go= boud $z y$.

Wy zullen wan dere fad, die reeds wan zoo veel anderen al vry net befcheven is, en watr onder de Reile wan den Fianlehen Gelant, de Ridder was Cboumon, die wan Loubre, cnz. uitteken, hier niet meen zeggen, dan dat wy de zalve hier by $\mathrm{N}^{\circ}$. 34 zeer net affeloecld wer- Alasettoonen, hoedanig wy die noic by ande- tat. ren gefien hebben; behalven dat $2 y$ ons noch mer vecl andere cieraden voorkomt, datr w y dic, zoo als zy nandie Riviter is myl hooger legt, nevens den loop van die fehoone Rivier, onder No. 3) zoo uitwoerig vertoonen, als noit beForens van iemand gefchied is.

Men fiet hier, hoe voor defe fchoone Derame Rivior, rer plats, darr zy met 3 mon- ca retdeden in Zee ltort, cen breede modder- Teloof $\mathrm{R}$ banle legr, die fich ten $O$. cn cen $W$. vier Me noch al wy breeder uittrekt.

Men kin ten Welten en ten Oofter, mear voor al in 't midden, door een byfondere Guyl de zelve oploopen, zynde de middellie ook wry breeder, als de z andere Guylen, die fich op dele bank vertoonen.

Men loope door de middele Guyl $\mathbf{N}$. ann, alwwar men ter recher en ter linilec havd, op de hock des lands, ani wedenzyden ecn wache-huis van den Koring ontmoet.

Dant na heeft men ter rechter conjge Sianliche fracic wooningen der Grooten, Banthuw Pia genamd, met een kilecne Ipruit of twee ter recher en ter linker hand, dast de Rivier cen ftukweegs honeco na 't W. dranid, en diar guen ter Iinker hand een fchoon Pakhuis en Fort der Nederlande Mazerchappy, Amfterdam gemand, en ter reclicer een geot, en wat Noordelyher ook op ecn Eilandje, een klect Buffels-veld, an eerige traje Sirmfe wooningen wa "r vlek properten, an die zelie zyde, golyk men ann de linker" land, of de Wettkant, een flumpe Iyraide, en cenige 


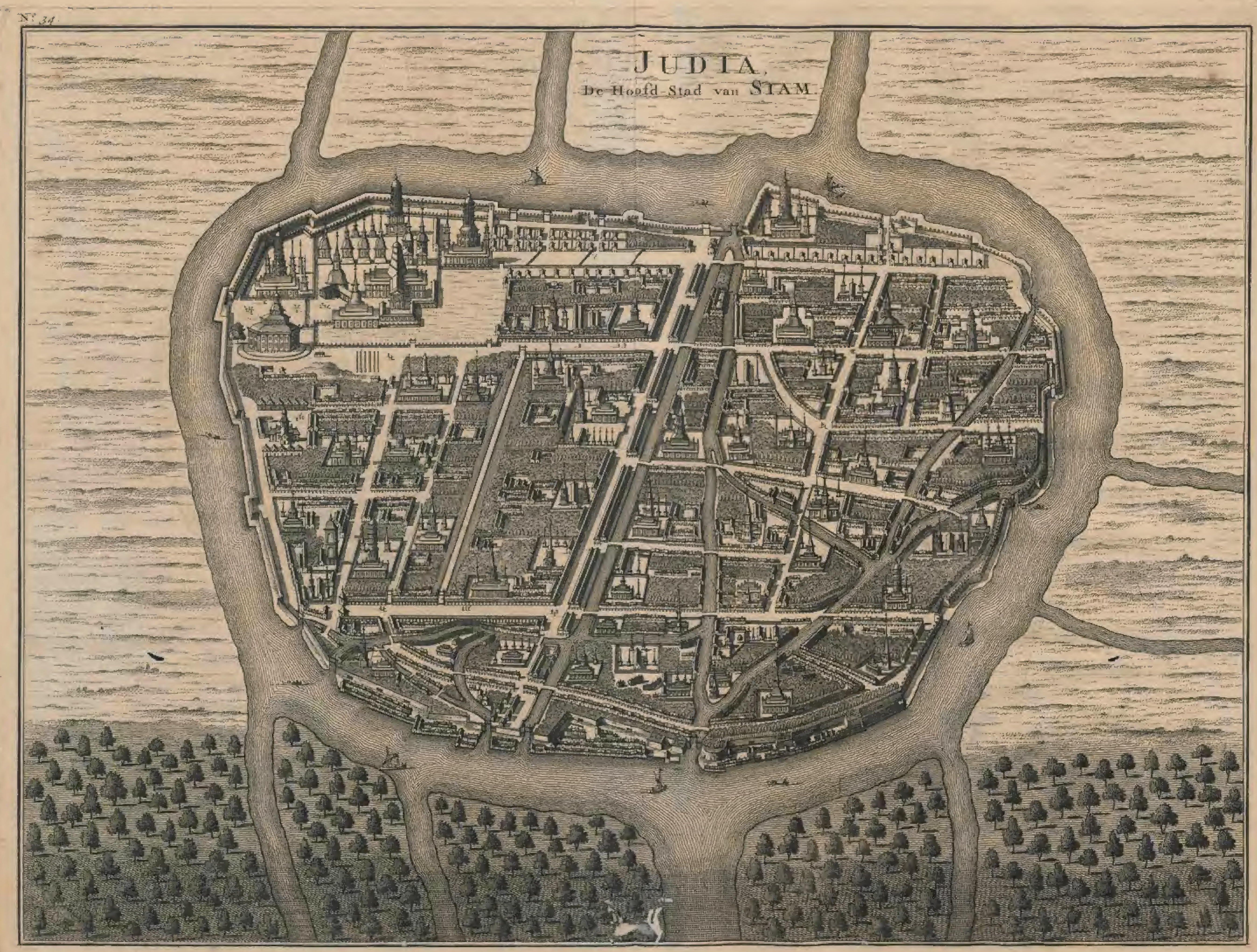




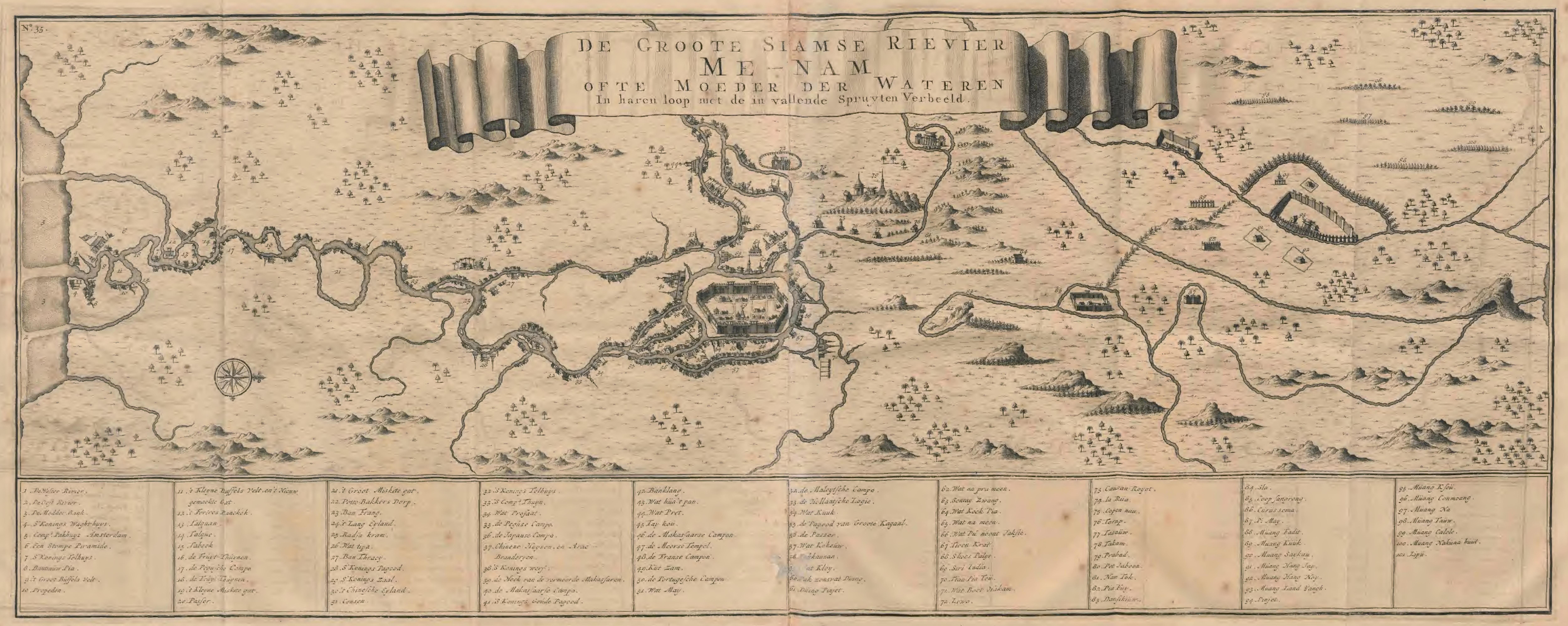




\section{V $A N \quad S$}

Stamie wooningen beeft, alwatar Gich de Rivier weer, tha cenigen $y$ d $\mathrm{N}$. $W_{\text {, dan }}$ weer $\mathrm{N}$, en dan weer eengeruime itrek henen mee 2 talken na 't $N$. W. en trat 't N. O. geloopen te hebben, ons, na ant de rechter hand of $O$. kane exnige Fult-thuinen voorby gewaren te $z y n$, (daar men ook Tabeli, een zakere Innds itreek, leggen hefef) ter linker hand N. W. op certt een grnot fluk weegs opbrengt, datar de Rivier dntu whak na "t $\mathrm{O}$. draeid, en ons by een Tolhuis wan den Koning op de Wefter wal doet komen; doch eer men zoo vetre gekomen is, lompt die talk by Tabek een auk weegs berien tha ' $\mathrm{O} . \mathrm{N}, \mathrm{O}, \mathrm{g}$ en draeld dan, na dat zy fich ook met cen nieuwe tale roudom 't Eiland, wate op 'c Jieen Buffels-veld legt, werdecld heeft, eerft wat na 'e N. O., en loope dan Z. O. an oenige mylen verre, meeft recht ftrecles henen, tot dat by fich, cindelyk vlak na'f Z. draejende, by de O. modder.bunk in Zec ftort.

Zoo als mon ru ph bowen "t Tolhuis: des Konings is, ontdekt men, shan de Oofter-wal, rer rechrerhand een tehoon groot vlek, en er linkerhand trome men by de ferke velting Banliok, die 7 mylen de Rivier op lagt. By de zelve, ewen eer men dar by konte, fier men, dar de Me-nam fich hier in tweeẻn fcheid, loopende van boven af, van zelset fraci beboud en bermmerd Eiland, Talquan gennamd, ontrent anderhalf myl vlals nat 't Z., dog zootarig, dat de zelpe fich ter linkerkand mee cen fmaller tak W. ath afficheid, $\mathrm{cn}$, na roo cenige mylen geloopen te bebben, allenskens na " $\mathrm{Z} Z$. W'. en 200 verder wol a a mylcin werredin mat 't Zu dracid, datat Ty mee cen breeciter throom by de Welter nodderbant in Zee Alort.

Bukok. Dit Bankok is een zeer fterke vefting, aie gelyte zy, zedert de Franlichen hier getomen zyn, door de Heer la Mare, merkelyk verbeterd, jegenwoordig ook de dwingeland van delc ganlche Rivier', en aan dic kant cen woorname theutel des Ryks is. By de relve lege an de roversyde cen fracje beboude itad rerrehterhand, Jangs welke niec alleen de Menam, max ook de Rivier 'To-n[zy], loops.

- In dar lafteel plachecn in de vorige tyd de Traniclien hunne befetting onder ecn Thevelhebber te hebben; dog hoe zy naderhand hier vit verdreyen ayo, zullen wy hicr na aanhatien.

Hooger op na 't W. heefe men "t Eiland Talquan, (dat de Rivier rondom gelyk on ' $x$, volgende loopd) en dan het Eiland Talque, ieter wel 3 a 4 mylen in den omttek, en frei betimmerd, ter o. en W. van welk ladfte Eiland nen
I A M.

twee zeer fracje dorpen legen hecf, behalyen dat fich aan de Weft-lant nok ecn nienwe ipruit rectoond, dic in de Me-nan ftort, van watr men dan weer N. en N. O. anngande, ter linkerhand ecrige fracje "Thuinen, ent ter recheerhand de Pegulche Camp ontmoer, dar een zeer frael gebouy by is.

Dan al hooger op komt men weder byeen Eilandje, "t kleen Misquitert- (of Muggen-) gat genand, rondom belabbeld wan de Rivier, zynde zeer weinig beboud; dog an de linker zyden met een Markt; dog ter rechrer met een zeer net dorp vootfen, hoednig men 'er $z$ a 3 myl Noordelyker heef, daar de Rivier figr wa " $N$. $O$. ter linkerhand draeid, terwyl $2 y$ ter recher $\mathrm{Z}$. ten $\mathrm{W}$. anloope, war na $z y$ fig ween fan ' $E N$, W. en das weel ra 't N. O. dracid, datr nen dan by een groot Eiland, wel 7 of 8 mylen in 't rond, het groor Miskitengat genaamd, lome, dat ain zyn WW. kant redelyk betimmerd is; gelyl men and de W. kant de Rivier ook cen fchoon dore heeft.

Hooger tan draxid de Rivier weer na "t N. W., dak men ontrent-anderhilf myll werder ter linkerhand her Porcebakkers-dorp heefit.

Van dar dratid de Rivier $\left[\frac{1}{2}\right.$ myl $O$. ann, dase men dan rer linkerhand het wlek Banthrong voorby wart, loopende dan weer N. ann, wel 3 at 4 mylen, daat men weer een Imal Eilandje, dat eenigfins beboud is, en ten groot dorp ter linkethand heefe, ontmoet; pas hierbowen doer fig ter liukerhand cen tchoone Plantagic, Wat-Tipagenami, mee ce: nige fraciegebonwen, op; dogrer rech terhand fiet men, hoe hier de Me-nam vain " 0 . mex een fuare, en $\tan$ "r $\mathbb{N}$. mee een fraller ' $T$ ak van de ftad fudia komt afftroomen. Wy zullen eerit fien, wat ons hier nan de Oolter+tak ter recliter, en daar na wat ons aan dic W. tol ter linkerhand nntmoet.

Aar die $O$. cak kome mien, na een korten diaei der Rivier door "c 0 . ma "c N. ecrit eet recherhand by een LandAreck Radja Cram genamd, dan byeen zecr kleen, en data na by eeti grooter: Eilandje, 's Konings Zanl genamd, ten Ooften wan 't welke men cen hecrly ke Prgood des Koning leggen heef, dar cen lchoon dorp bygeboud is.

Van detc Eilandje dractd de Rivier $\mathbb{N}$. W. wel $1 \frac{1}{3}$ myl, dinx men, na dac $z y$ fich hier na " $\mathrm{N}$. $\mathrm{O}$. ettelyke mylen gedracid heets, in 's midden vandele ftreck "t Chineefch Eiland (zynde wel ruim nog cens zoo mooi als 't vorige, en zeer fraci betimuerd) leggen ziet, duiter linkerhand een zeer groot whek zonder narth, cher rechuer exn plats, Crafen genand, nati $\mathrm{H}_{3}$ eed 
ecr fpruit, die in de Mc-nam ftort, heefe:

Hooger op weer $\mathrm{N}, \mathrm{O}_{\text {, nahn, een fluk }}$ weegs henen, heef men weer een fraei Tolhuis des Koning ter rechter, goty ook een weinig hooger de Thuin wan onfe Martelappy, en eenplats, "WatPrelint genamd; dane lich de recher weer door "t $\mathbb{N}$. na "t. N. W. kromt, en dat men wader by een kileen Eilandje

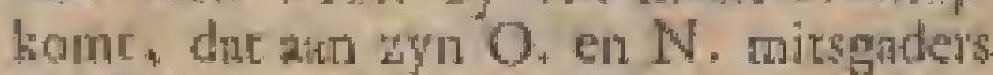
N. W. zyde met eent rifje befee is. Tegen ower die Eitand rer linkerhand heefe men 's Konings Wert, warr na men al hooger $\mathbb{N}$. ain gande, by 't quartier' der Pegemanci, der Japanders, by de Arates-branderyen, 't quartici der Portugelet, en 7oo verder dan ann de ltad Judia komt, zoo als zy fich zonder ce. nige bruggen op een Eilland in de Mienan, cn rondon wan de zelve en van andere beknbbeid, yertonnd.

Pas voorby "s Konings Werf, N. an gande, hecfe men den hoek der wermoorde Macaffitren, en hur quartier, voorby 'e wellie men 's Konings goude Pigode, en veel andere heerlyke Teupels, Klootters; en Tchoone gebouwen, ieder met zyn nam uitgedruk, fiet.

Dos verte gefiem hebbende, wat 'er ann de Oolter-tnk vas de Me-nam, daar wy 's pers bevorens licten, fich vertoond, zullen wy nu echs langs de W. tals de zelwe vervolgen, en ficn wat dara is.

Men ontmoer cer Jinkerhated 2 , en ter recherhand een dorp, Ban Thraty genand, wast by cen zeer fraei gebouw des Konings legt. Hooger z a 3 mylen N. atan heefe men ter rechterhand een fprait, die in de Mc-natn flort, en er lukerhand weder een dorp; $\operatorname{dog} z \mathrm{my}$ Jen Noordelyker doet fich een groot wek zonder namin ter' techer, en herwlejc Ban Klang ter linkerhand, en pas beroorden "t zelve weder cen fpruít op, die in defe Rewier fich ondtat ; war ba men icrlin-

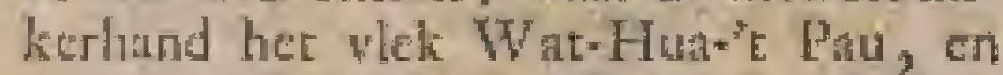
zoo wat verter de flad Judia wan die zy. de mee al here prachtige 'Tenpels, en verdetegebouwer, ontmot.

1 lier lone de Rivier mer een hrotrmen draci on 't Wefter en ' $\mathrm{L} Z$. W, alwatr mea de fchoone Pagode, WatPree gentamd, en de fraeje Plantagie '1joen Krot woorby zynde, zoo wan dic zyde, alls ook.nog wan de N. O.zyde der fad, langs een andere tak der Riwier na Liwo (anders Liwo of Loevo genaamd) loopen lan; dog als men langs die eerite takloopt, daar de Riwiergeheel na "t $O$. ectelyke mylen an een draeid, dara men al mede een frimei vlek loggen beeft, dog dracid zy lichdaar sil ten eerferl obk woer na 's N., dare zy din cen groot langwerpig Eilindje, war op men "ci vlek Wnt-boet-Hakim genamu, her, endarvry wel becinnerd is, thake.

Liwo vertoond fig bewelten de $1 \mathrm{ki}$ vier. Hoe de Heen Ridder at chapwort hier zyn cweede gehoor' litecg, firen wy kilagr in zyn Retic, Finl. rgo.

Ik $2 \pi l$ my ock niet ophouden nnet de werdere platien, hooger op on de Noors? leggende, te belchryen, alloo de Lefer die klanr genoeg hieruitgelfoke frer, met dele en gene gebergten, of wel wekken en dorpen met hare Siamfe natmen, en telgelyk, ook angewelen, hoe de Rivier Me-nan al hooger orn de $\mathbb{N}$.

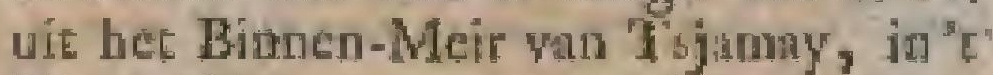
N. na "Tartaryen zyn oorfiprong, zoo zomrage willen wel is a io dig reilen boven de grenfen win sium, neerte, ent dus thet een fwaren ftroetur wan ' $t$ N. nit "t Z. langs de lladd Judí, en zoo verder na de Zee rne loope, en met ecen grode geweld daar in ftort, ha dat boven drie groote thomen lig met denanderen vereenig 1 hobben.

Dis de Koningen win Siam onder de swogrootfe Koningen werden, hehoeve ilk, alfoo dne reeds Hectyl: door zoo yeel anderen geficgt is, niet te heit by melden, behalven dat dic ook secr wyd- tooning. loepig in de Reife wan den Ridder de Charwant, en by anderen, blykt.

Men fier dit ook alle jaar hier op cen nadrukkely ke wyle, wanneer fig die Vortt na den Tempel vass Nap-pe-tar, in het lageft wan October, of in November, begeeft. Men kin die in de Reile van de Heer van Fict, fol, Ig. fien. De Majefteit, die by dan, en op werlchcidenandere dagen, als hy ma Wat-fi-fer-pte gat, vertoond, is ongemeen, hoewel by anders dagelys driemalt wor zyne Uverften en we Grooten des Ryks feet priguig, eens met Zons opgang, dagr rat tegen den middig (wameer hy ongemeca koftelyk nirgedoft en fter k gejuweeld is) en einiklyk tegen 't onder. gann der Zonne, vericliynt, danr dan de grootle Mandaryns zelts voor de roet. van zynen Throon rer ande uitgeftrelic legged, eri, zoo ras fig de Vorft wercooud, fig wa? oprechtes, om woor bem mer hande gevous e handen boven "t hoofd, dat zy dricmanl tcgen de gront moeten buigen, op de allernedelyglte Oplterle wyle ce Sombaren, een itat, war in sy din als de allergeringte flaven woor hunnen Heer woorkomen.

Nog meer blyken geven zy dar van zyn wet mec de Titels, waar mede $2 y$ hen ano- wandz Fpreken, en die hy fich in zyne Brieven Eexutels. Wan andere Vorften lata anjletinen, latende fich Pressiun Salcos, dat is, "clidmaat Gods, den Goddelylien Heer der onfterffelyke Zielen, den Goddelyken Heer, en wat dias meer is, notmen, 


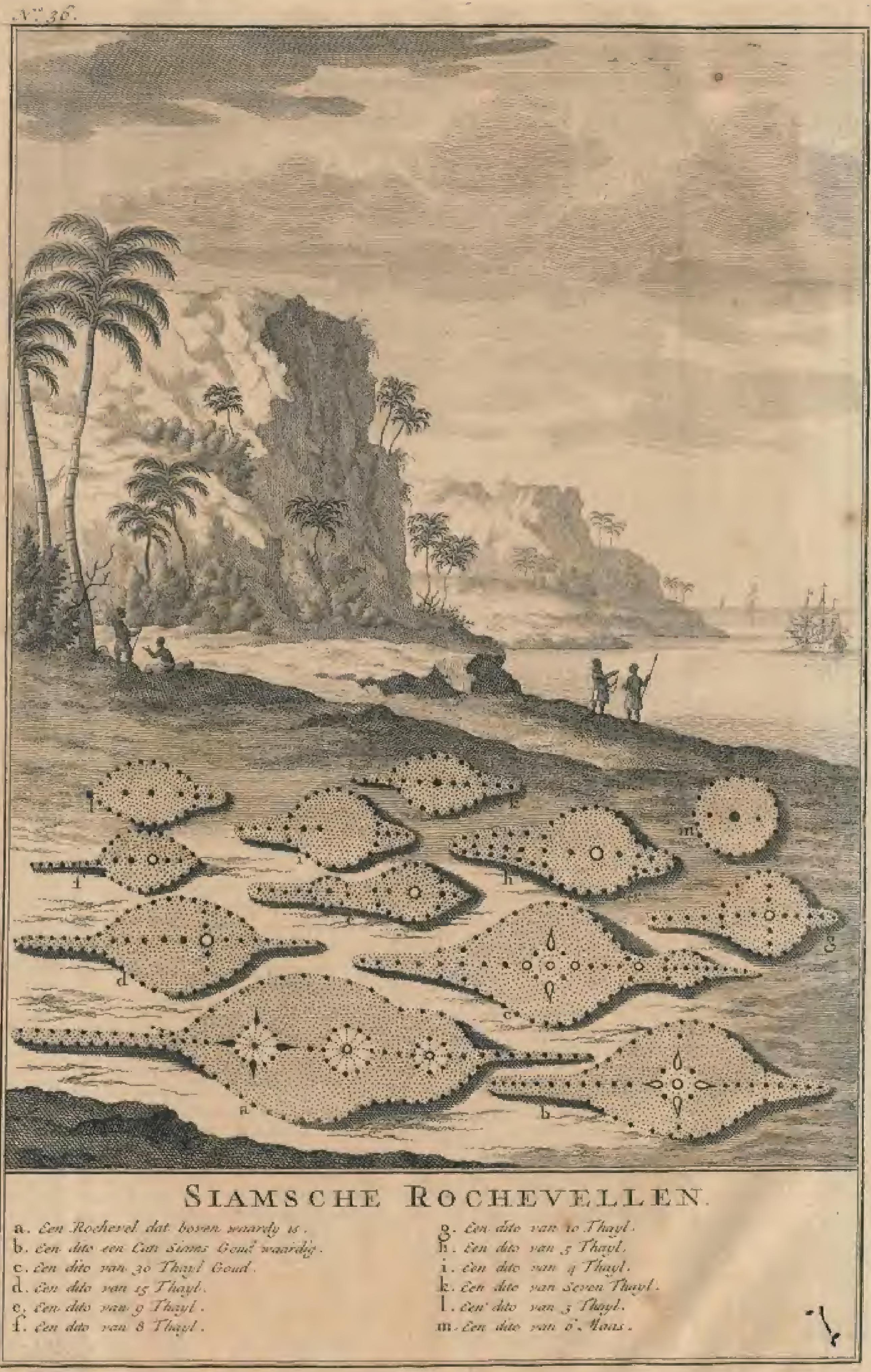


WA iN $5=I-A-M$.

63

gelyte met in 't breede by wan $F$ hit, en / den, en Konftenaars, witleveron. adideren, lefen lian. Jat zelfs een Gefint, voor den Konisg verlichyonende, gatit, zou als by in 't l'aleis toms, op de antde fiteen, en legt-zyw hapden op zyn hoofd, ten teeken wan eerbied, ea, wan de woet ton de Gehoor-zaal gekomei zynde, wite hy op zyn knién, en liruipt op zyn handen tot in de Zatal, verfebynende zoo voor den Koning, ontrene jo woeten war de plages, daar hy op den Throon fit, die 10 of $i z$ voeten hoog is.

In oude cyden phgt hy eon irkoncis, wan cufichen de 3 en 400 tomnen gouds te hebbens dog in de later tyden is dat merkcly. vetminderd, alfoo het nu mast 4t of 5 millioenen bedratgd; "I geen uit de Waren, in zya land wallende, en uit den handel, die daragedreven werd, voortkomen moet.

leder ploeg. moce hem een Foeving opbrengen; ook geniec hy de thiender des welds, behalven dae "er" nok groote velden woor hem bezaeid werden.

Waten,

De Waren, die hicr vallen, zyn dehier wal- fe: Ryft, Gountelak, fwart of nat Lat, lende, of Wierook, Olie, Caffie, rwarec Candysen. Ein fuyker, Sappan-hour, 'Tin y Olifines: Roche- thonden, Arik, Koejen- en Buftuts-huivellenaf- den; Cambodifche Nootjcis, HartenEpbeld. vellen; Guta Gambar, Poscsjoc, Vo. Eelneftiens, die uit Tonkinen Coetsjientsilina hier, komen, \&xe. en voor al oole Eoftelylke Roche-vellen, dic wanderlyk ted in wecrde verrchilien, gelyk men ann de gene, die hier op de plat $\mathrm{N}$. 36 afgeteckent zyn, fien kan. Ook Tale hier veel dog flegt Goud, Zilver, Lood, eenigegelteenten, als, Dintmanten, Styaten, Agat, Magnect-liecn, Yier, Stal, Salpeter, Indigo, ntterlei Timmer-hout, Djati-balken, A gel-houc, Zour, Peper, dog weinig; gelyk truen Fol. 62, in de Belchryving van was Pltur in 't breede fiet, wan alle wellec $W$ agren de Koning de opper - Handelar, gelyk iti meer Rylen wan 't Ooften de gewoonte is.

De Warren, die men hier invoerd, of trekt, zyn defe: Lakenen, Cattoengaren, Klatergoud, gemeen Lywad, Salampoeris, Imalle Suratie Chirien, gebleck ce Dongris-pakken van Jaftanapatnam, rood-Cattoene Garca, Madafons, Vermilioen, Goud-ledere Spiegels, Caleatours-hott, ook allerlei Speceryen, met groote winft.

Volke- De Volkeren, met welle dele Vorft retr, wair over defe Waaren handeld, zyn verfcheidie den. De Chinecen zyd onder de zelwe Vorft" niet altecen de oudfte, riani onk wel de hustid, voominarife, die dras', gelylk over al, een groot leven in deti hindel brengen, behalyen dar zy vecl goede Ambagrs.lic-
Dus hatudeld by oole met die van Arracall, nise wellen Worft defe Koning in goed werflsind was tot $A^{\circ} 1628^{\circ}$, whander cen geweldenar aas de Kroon quan.

Grooten handel plagen de Jnpunders op dit $\mathbf{R}_{\text {yk }}$ te doen, gelyle men tier ook eç groot Japatss quartier, al van oude ryden, bad, alloo mea de Jiertern, Buffels-, en Rochen-vellen, 1terk vauhier derwarts trok; en fchoon deje Vorften ook wel nu en dan Gefanten ann malkanderen gelonden heblen, heeft dat eger met de Japanders man tot $\mathrm{A}^{\mathrm{a}}, 1630 \mathrm{gc}$ duiud, alloo $z y$ dien dwingeland nict wildeb enkennen, om welke en werlcheide andere redenes men de Sianfe Gefanten onvertichter zalke uit Japan terug gelonden heetit.

Even zoo haidelde defe Koning wan Siam ook wel mec die van Assien, $P$ cani, Keda, Perals; en met die run Banjar-Mallin op "E Liland Bornes: dog heeft wel denmeefteulandel net de Polcugeefen en Nederland crs ged rewen ; wat: vin wy tolderhand breder zulleo fpreckien.

De voornambe plateren, duar defe Devacia budel gefchicd, zyn, buiten de Hootd- gamille

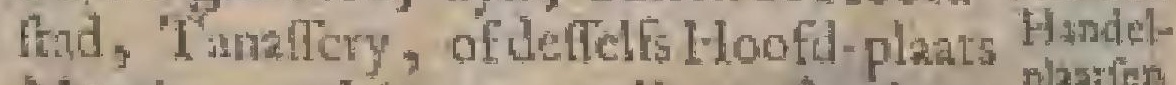
Mergim, en Ligoor, wolke eerfe plaats fier. op It, gelyl de twede op 8 graden, 30 minuten Noorcier breedte legt, en die tan Moste. Lawdere, Tacbsir, Bosgetwd, en anderen reeds zoo wel belchre-, ven zyn, dat wy nier noodig oorteclen, datar meer af re leggen.

Her land wan Sian brengt ook, gelyk alle andere landen va Indién, allerlet Indifche Vrugt-boomen voort, roo als wy dic reds meet onder de ftothe ran Amboim befehreven hebben, of die verder door den Hecte oth Nhede, in $2 y \pi$ Horris Malabaricus belchieven rynjdebapa par-boom is hier cen zonderlinge boom, hocuvel hy ook op Birsa vait.

Men wil, dac er ook eenige Rancel grogt, dog dieved flecher, als de Ccylonle, is.

Het Agel- of Aloes-hotk, ondecld men hier wry beter, als 'e geen in andere landen wan indion valr; dog eclieer zoo goed nier, als. 't Calimbac-hour (cen byfondere foort wan a dlerichifundte Agelhout) 'L geen in Coursjienitsjina, "Tsjam$\mathrm{pa}^{\mathrm{a}}$ con darar om ftreks, grocit.

Gelyle men hier een menigte wan frae- Bere. jc. Mincraalen en Bergltoffen ljecti (te Moftim voren onder de Wearen te fievg) alloo is 'er een, die zy hier Tacnbue; dog die nen anders doorganns Sowalli uocmi, zymde cigentlyle geen zujwerminemal, math ecn zeker mengtel wan goud en koper. Datr zya "et, die meinen dat her een dienglyle foorit was loper geveeft $y y$, 
nis men wel te Gorimethend, die'rgond zecr na quitm; andere houden her von Orichalcum der Ooden; dog dic dichymen niet we weted, dist Jiet dowr loont gemader werd. Her vait hier vech i dog zoo goed nite , als op Bornco cn Sumatri.

Mant Demulien, die men hich heetr, zym vert

dersiam= folyide. De Tikal, cen fracje liwere interis. mune (dic by Monfs Loubre zeerwelatgebeeld is) doet $3 x$ ftuivers. Hec lehy. nen twae heupean regen cen te zyn, war op men z kience merkjens fiec, Dant zynonk halve, en quart Ticals, en Manfen, dic ook par 'c zelve latioen, dog

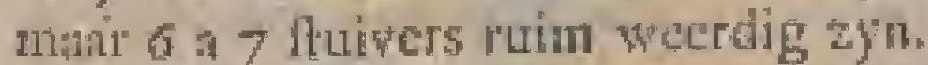

De Focwing, dieal medezoo is, Joet maur 3: fturwer; de Simpay $1 \frac{1}{2}$ thuiver, coll de latyning 12 ponthingers rum, Ool:

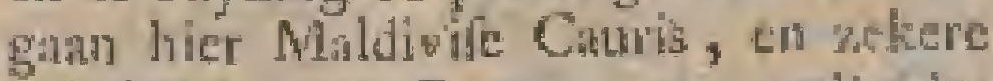
Sclyelphens valn Bornco, wath welke 'cr 6 a 7 co cen Toewang doen.

Geiyk de Siammers ten declen van de Chineelet, Peguatren; en Coergjicmesjifor oorfpronkelyk tyn, alloo fwoemen zy in weelen, tatit, en gebeerden, zeer ferth na de zelve; dog zy vallen bruiner als de Chinecten, en zeer phe van wefen; ools zyл zy de langlteniet, korten wat ftomp omgekromt wan neus, lware Fan tanden (dic zy met zeker wernis zoo makela, en dat by hen cen groot cierand is) zonder baard, en zeer groot wan ooIent.

En han Hun tal is als een by fonder Dialeftus taal, van "c Chinecs, en becte dele, gelyk de fchiff, Tonkinfe, Coetsjientsjincele, Cambodifche, en Quinamte taiten, zoer groote overcenkomit mer de zelwe, en hoewel ieder cen enal op fich zelven is, thonnen nogtans de Geleerden malkanderen in hume fchrifien meelt verttatn, alfoo hunne Chancters, en lecter.greepen (wair van fig wel de Gelcerden, doch geenfins de gemeene lieden onder hen bedienen) een en de zelve zyrn; dog de uitfprate van ieder defer volkeren, wan zulken Charater, verfelitd gewcldig weel.

Buiten hun gemeene, hebben zy nog cen Hoofd-tal, watr in de zadaen wath den Godsdienft door luuane Prielters bechreven wierden. Zy wierd ookwelde Bulitelte, cn oole de Sinfcritle tal genatamd, die met haren Godsdient ook bayen oorfprong van de Kuft Choromandel hecf, en alleen hune Talapoins, Priefteren en Geleerden bukend is.

Zy maken hun papier wan oud Cattoen, err wok van defchors wan den boom Ton Coe; dog het vale $200 \mathrm{ghd}$ en offen wiet, als 't onle.

Hier op fchryven w met Chinecen Inkt, en met een grific of een priem, onk op bladen, byta als de Palm boon, Tan en de bladen Brilan genamd, die wy lang-werpig rierkatat linyden, fon min- fen hunne bocken uit een lang blad, dat 2y niet roliten, mar even alsecnicherm, in de lenge, dog niar in de breede, tooพDUwen.

Zy ichysen niet by Chuneters, ats de Chinceren en Japanders, mar by vegelis val de hand, en duridelyke woof

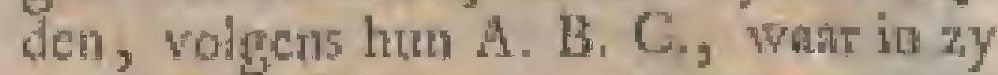
46 letters luebben. Dog weren wangeen ortographin, en maken eutichen kinkers en medeklinkers getn onderfcheic. Ook liennen zy geen tedkenen wan ondertcheiding in een lin, als commatis, punetr, \&c. Egter is hun felvife fraci, en gelyke ceniglins ta Iralians.

Het is cen zetr gocolwertig, dog luy ch trang rolle, wan mede eguer wel om te gnan is; howel oy trista en hownatdig yan gang, wry wat betrieglyk, leuger= en finp-ngtig walken. Ook zynzy doorgants ficenbertig roor dem vyand, dog wreed ugen die genen, dar zy meefter over geworden, of die van hen werwonnen zyo. Zy hbben van fieh zelyen, en wan at wat un hun land is, suli.c groore gedagten, dit zy meinen, that diar niets by te wergelytern is. De Mans zyndootgatans groote Heeren, en de Vrouwen hunte flawinnen, dic 't werk doen, en merens hunactiaven werken moeren. Eenige egter erneren fich met viffhen, vataren, den landbouw, of mer eenig Ambicht, en ook wel mer "ranquelien was Fen i hotwel 'er odk groore Koopliedon onder hen gevonden werden.

Hume dicoling enfpy fe verichild trice vecl wan-andere lizdionen, gelyle mendie zecr net' in 'c Wet wan $A$. Bugadyd en andere, belichreven fiet.

Zoo men hiej crouwen wil, moct men Hume mer de oudcrs wan de dochte fycelsen, Hep. en zyn Bruid uree oen Bruidlichat wn hen Loopen, ca fichootsy'er verfelueide hebben, hebben zy egter mat exti voorname Vrouw, dan al de andere onder ftanti.

Ook ontdebt men dit onderfcheid tan de nanuen, die defe verfcheyde Kinderen aen butwen Vader geven: want die wan de ecrfte Vraw noenen hem Po, of Wader, en dic wan de andere Vroutren Po Tspon, of Heer Vader.

Een' min mag hier zya Nicht, enook wel twee Zublers na inalknteren, dog hiet te gelyt, trouwen; dog de Koningeri fren dal niet an, en trouwen niet atheen hunner Vrouwen Zulters, motar ook wal de Moeders an Dogters re gelyl: (gelyte $A^{2}, 1633$ gelchier is) ja dat zyn "cr geweeft, die fich mer lum eigen Dogers vermengd hebben, om dit $x y$ oordeclen geen wer diger nog hooger bloed te komnen verkicten.

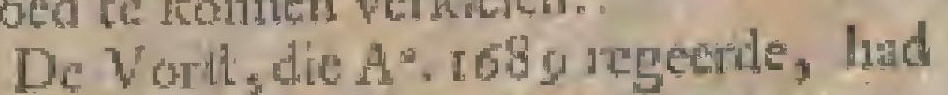
zyn eigen Zuttersen Gemalin genomen, 
A N S I

A

M.

69

teclde dat een Dochter by, met welke by naderhand gerrouwd J, en die $N_{\text {ahy }}$ $F_{a}$; of den jongen Hemel, genmand wierd. Onder de gemeene lieden egeer wind men doorgans matr een Vrouw.

Hee recht wan een man is hier zoo groot, dat by zyn wrouw en kinderen (uifgenomen zyr eerfte vrouw, die hy egter wegzenden kan) mag verkoopen; mand zy mogen nog malkitideren, nog hunne kinderen, Jooden.

OnerTpess fliafie.

Hy mag ook van zyn vrouw fcheiden, als hy wil, en weer met een anderetrouwen; matr vals overfpel hoort men hice weinig, alloo een operfeclder en owerfpeelites, beids voor den Olifint, den Beul van die en veel andere Ootterle landen, gewarpen, iry de luthe getlingerd, op zyn randen gevangen, en vorder te pletreren getrapt werd.

Hunne hutsmad is meeft gericlte nade Alegte huiten, in welke, gelyl ook in rpyfe, $z y^{\prime}$ ' natt by de Chineefen tevergelyken, hocwel die wel zoo prachtig $2 y 11 \%$

Siekte- Wamnecr zy hier fiek werden, genee.

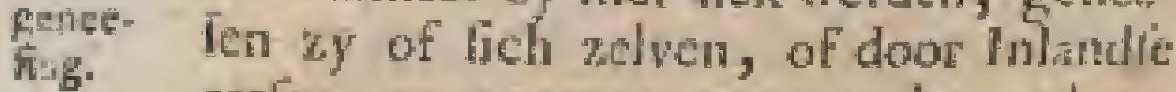
arren, en gences-vronwen, hocwel zy geen kennis van de Genes. Hecl- of Onteed-kunde hebben. Ook zyn zy wol Bygeloove, en dan door ook an die gedagen walt, dat veele door roovery fick genaakt, en dierhalven ook zoo weer Inoeten genezen werden, war in zyved andere Oofterlingen gelyk zyn.

Hire

Lyk-tho lingets.

Hunne dooden zyn zy gewoon niet re begrawen; mar teverbranden, vitgenomen van zulke, die fich zelwen on $h$ ds gebrage hablen, of verdronken, onder de poer geftooren, of ook vandekinderpokken gettorven ' $\mathrm{Ly}$, welke $\mathrm{zy}$ of inde Bollehen, of in de Ritwer werjen, geloovende, dia der zelver zielero alomso nog werveth, om ook andere menfehen 200 veel quat, als zy mat konnen, te doent.

Mer war voor ecn prage die verbran. ding der Grootengelchied, welkers toeflel wel cenige maniden of rwelien aan een duaren kn, zou men naeuwelyx gelooven. In wellen cutchentyd de dooden gettatig beweerit, en wan de bloedverwanten rouw, op hume wyle, gedrigen, dat wel "t kragtigfte door 'L afleherent wan "L hoofit-luir wertoond, en't geen, by de tood wan ecu Koning, wan alle de onderdaticr, op cen hooge thraffe', gedatan werd.

Hoe bedroefd men dan is, kan men dast uit afiemen, dat "er ondertullichen op allerki ipeteugen, en op flutengefieeld, ipecien vertoond, en vuurwerken nangelteken werden. Nograns is men dan met $\mathrm{H}$. bedryven befig, 't $\mathrm{zy}$ mer antmoeften dan arme lieden te geven, of wel met de Priefters woor de Ziel, en welitand vath den owerleden te lates bidden.

Eri alfoo dit verbranden met zybun rotftel geld kolt, zal de arnfte simmer zelf alryd zorg dragen, tat "er een penningstien over blywe, watr wh hy eerlyk kan werbrand werden.

Datr na werd de afiche des otetleden by ecis gefaneld, in een liftje byronder gedant, met $\mathrm{H}$ Ohe gefialt, en dan in cen van husne Tempelen begraven.

Wy rouden meer das van konneth fehryven; dog dan 't zelve 'er af moeren. reggen, dit by andenen reeds overwloedig getegt is, weshalwen wy hicr vat aflappen.

Zoo de audes komen re fterven, er- "t Eifs yen de kinkeren, en by gebrek der zel- taget biter. ven, de brocders en zufters, Jaar wa de ouders, en als die ouk onbreeken, zuf tets en brocders kindercn, war nis, altoo men her aiee werderierven mag, de Kowing erfgetuatm walles is; dog tro]. gens de wrtere der stammets, gran hee deel kan de geflorvene is drie decteru, ecn dee reor den Koning, het tweede voor de Priefteren, on "t aan de vityatate te belultigen, en 't derde voor de vrouw of kinderen, dat dan weer in ten minder deel' voor de by litecn enbare kinderen verdeeld werd.

De Koning van Siam is een Vorth, "s Kodie volilagen Oppermagig heerleht, en nings opvan geen Grooten des $12 y k$ senightins af permezhange. In tegended noeren de Groo- ring. ten (gelyls wy reeds getoond hebben') als Alwen, ganich rer alitile neikrgebulkr, voor hern wer fchynen, gelyk hy ook vara

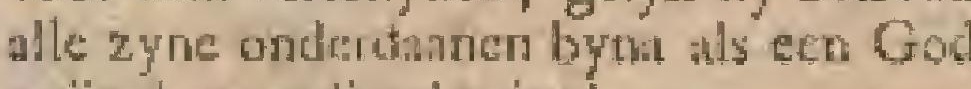
gëerd en gediend wierd.

In oude yden phige hy wel cenigline onder de Wercen, by hunnen ecrilen Vortt gemalis, te ftuas, by welke hem belatt wierd, zyn Raaden te mocten hocren, en fich ma de meerderheit wan ftenmen te richeer; matr zodere dist her aloud Koninglyk bloet, doon zekeren gewaddenar $A^{\prime} .1630$ vergoten wierd, $24 n$ ock at dic Grona wetien, me alle de macht der oude Mardiayns, met poeten gerteden, en lyy, en ayne naziacen hebben vollagen ona hankelykgebertche. Hn folioon ly dete en gene zaken noch wel aan zyne Rytis-Kitiden voorfteld, z..1 niensind was bes zoo llout zyn, om hatri iets te randen, dat hem nodecligzou konneth weren.

Zoo by lterli, erfe zya zoon, en an- Zyn Erfders zyn broeder, de Kroon; dar ech. Beranis. ter, na dat de mache vali defen of genen Vorlt was, wel cens verwitteld is; mata dochters erven hier geen Kroonen.

Zyn Krygs-mach te warer en reland, Zyn is zecr groor, enzya Oorlogs tuignzyn kiryge 
goed en menigvuldig, In eene wwek kan hy 2 a 300000 man by cen krygen, en zyne Legers beftan gemeenelyk wir ettelyke horderdduifenden, die hem op hun eigen kotten, als hy "t mat vorderd, moeten dienen, daxe "t hem behangd; hoewel by noch zomtyds an de zelven wel ecrs de gunft bewyit, wan hen eenige drooge Ryft te geven, watheer $7 y$ daar zelf niee voor hebben konnen zorgen.

Zy voeren meelt pylen bnog, ook wel lange en tiorte pielien, doch veelen yan hen weten ook met Rocrs vry wel om te gan, andere weer gebruilien fólilden lwand.

Katon, Donterbuflen, endiergelylke Oorlogs-tuigen, habben zy nu en dan mede wel; mant weren "er nifer wel mede om te gatan, alfoo hen in alle de Krygsvoorvalen 't hert ontbreckt.

Zy zyn ook van Ruitery voorfien, dog hebben dami niee veel nan, vermiss dic mat ecn houwer en een ledere fohild hibben.

Zy gebruikm ook veel Olifanten, met gewapende mannen 'er op, in den OorJog, die wal de woornamte Ruicery wan hun Leger, en 't grooulte deel van hunne hope, wegens een goeden uitiflag uitmaken, alloo zy hen daurop voornamenrlyk vertrouwen. Weshalven $z y$ ook dagelyx hun werk "ci af maken, on dele dieren ten Oorlog te oeffenen, en te gewennen, dat zy woor geen Kanon fchinkken; hoewel "er ook ved tot het no-vocten wan 'c Gcfchut, bagagie, en de levens middeten gebruike werden.

Dus hect by ool cen groor gand wan Gakyen, en andere Vaaruigen, dieten Oriog tocgeruft, en พan al hęe noodige, om zy i $V$ yanden daar mede afbretsk re doen, voorfien zyn. Dog zy votren geen fwarder Gefchur, dan klecne Bar1en, warr nuede zy egrer noch al veel zouten vitwoeren, zoo $2 y$ zoo klecthrIig niet waren.

Wat factoen hunne Vartuigen, of hunne Balons en Spect-vanruigen heb. ben, en hoe koftelyk en cierbly die opgetoid zyn, kan men in de Reiten pan den Ridder de Cbanmon, van $A$. Bogaat, en anderen fien, danir zy zoer nee afge beeld werden.

Bithat Ourent hunne Gerichts zaken hebdeling ben de Siammers eet zeer netre oidre, der Ge- alloo men by hen, volgens de werten richrs- des lands, die alle in de H. Taal belchreven zyn, vonnilt; mar behalven be Ge. rechis lranken in alle de flederi, is "er' als een Hooge Rand, of oppertic Hof des Gerichts, in Judia, beftunde u:tpegen Raaden, zynde yyf Owas, cwee 0 pra's, en rwee Olangs, dic de zanker zonder verder beroep afúocu.
Zoo "t nochatatis gebeurd, dat hen eenige fware doch twryftacheige zaken vooksomen, watar aak de noodige getutgen of bewyien ontbrecken, moeren de verfeliflende partyen mec een zonderlinge en zeldfane wyle wan ecd-lweering hunne zuak goed maken, cu de zelve bewyzen, "c zy met onder warer te duiken, "t zy mer de handen in ziedende Olie te fteeken, of wel bloots voets over 't sour, of heete platen te gaan, of ook wel met oen befworen klomp in te flikken, wase wan wy breeder onder de zagken wan humen Godsdienft zullen Ipreeken.

Gelyk de Siammers hume tyden van droek heir hebben, ahloo oole van vreugde, op welke zy Gich mer wer fcheidenerlei Speeluigen, na hunne lands wylé, vermaken, $\mathrm{Zy}$ hebben cen foort wan Vioglen, mee 3 linaten, die zy Trònoemen; en een foort wan Blass tuigen, $\mathrm{Pi}$ genaimd, die exniglins na onle Hautboís gelylien.

Ook hebben ay ecs foort van Trompetten, en hunne verdere Speel-tuigen zyn Gongen, entrifi s, of Ooftetle Trommelkens, die wy bevorens reeds beichreven, en afgebeeld hobben.

Men beeft hier ook veclerlei foorten Dieren; van groote en kleene dieren, enzer veel en 't onongedierte.

Ongemeen werd men hicr van demicreu, en voor al wan de witte miterengeplangd. De muggen zyn hier zoo ongeloovelyk weel en groor, dat $z y$ in fagc zyn om icmund by dan dood of blind te iteken. Dus heft men 'cr ook duilendbeenen, en wutr-vliegen in mecnigre.

Gelyk onde de groote dieren hier de De witte Olifint de voothamfte is, alfoo fiec men Olifant, die hier zeer groot, van io a i i woeten hoeg, en menigvaldig in de Boflichen van werloheide foorten.

Men luefe 'er getmeene wan liouleur, en ook witce, en roote Olifancen, gelyk de Koning vin Siam in zyn trotle bertitels wok daar op rocnd, dat hy die belit.

De roode is mede wel zeer zeldfinar, ran welken de Siammers ook wonderen weten te verhalen; maar de wirce is veel ongemeener, en woor honger en Heiliger, niec alleen by ben, muar voor al ook by dic van $\mathrm{P}$ c gu geach, alfoo liem die als iet heiligs aunbidden.

Dele werd zeer zelden gevonden, en als hy al geworpen werd, werd het woor ecn wonder geacht.

$A^{5}$. 1568 zond de Koning vat Pegu, gehoord bebbende, dae 'er in Siam een witte Olifant was, een Gelant mer groote Gefchenken ano dien Vorft, biedende verder ann die wan Siam, om hets atles, wat $2 y$ woor die dier begeerden, re 


\section{$\checkmark A N S$}

willen geven; doch die vath Stam, nict genegen dit dier ie millén, wilden na geen bidden en fnecken rim het zelve Imilteren, wanr over de Vorft wan Pegu zoo vertoornd wierd, dar by goed vond, hem datrom alleen den Oorlog an te doen, gelyk dat ook werder zyn welwanen gekoft, ch zynen ondergang weroor liakt heeft.

In "c jast I 570 had de Koning van Pegu (zon Vimen lo blankgetuigt) vier wicte Olifanien voor zynen wagen.

Wat yoor $A^{\circ}, 1633$ wierd er een jon. ge witte Olitant in Siam gevangen, war over die Vorlt wel zeer verblyd was; doch hee dutude nier lang, alloo by in "t gemelde jaat fchiclyk tijerf, wagrover zyn Majefteit zoo ontect was, dat by belatle alle de tawen, die op dic becit gepaft hadden, on tc brengen. Ook betoonde de Koning zelt woor dit dnod beetl woch een groore cerbiedigheit, belafteride het zelve by een wat de voornotanfle Tempels te begraven, cn cen Pyramidal huisken boven het gratf te malien; doch naderhand wierd het weer opgenraven, en thet een grooter practht en thate, din men oit ontrent degrootfte Mandaryms had fien veroonen, werbrand, de nffehe verfancld, en weder by den varigen Tempel berraven.

$A^{\circ} .1635$ wierd "er in " $\mathrm{c}$ Boleh boven Judia cen geworpen, way van de Siatemers, en zelf zecr gchoofweerdige en anfienlykelieden ander ben, dingen werhaalen, dic byna niemand, als lyy die hoord, gelooven zal.

Dit dier quam in de mand Mey lpierwit te voorlchyn, en zoo ras de Koning "er bericht af gekregen had, zond hy Oya Porclook, mer vier anderen van de groot fte Manderyns, om te vernemen, of het ook zoodanig gelegen was, als men hem betiche had.

Na dat $z y$ nu by dic dier gekomen waten, wonden zy het fehoors, en ongemeen wit, watr van zy den Vorft ten eerften kennis gaven.

De Koning, lier, over zeer verblyd, alloo hy dic voor een groot geluk hicld, ging zelf met en zeer prichtigen ftoer van Grooten 'er na toe, om die zelf' te befichigen, en dan her dier als in een proceflie of ommegang tha de thad te geleiden. Doch hy was zoo ras nice ter plats, datr het fich onchield, re land geltapt, of dit dier was Iwart geworder, war over alle dere Mandaryns zeer werbuaft wierder, ten deten uit verwondering over dit zeldfam voorval, matr voor al uit vreele wan doon den Koning yoor leugenars en bedriegers angefien, en daar over dan wan bem gettraft te wer-

- den; mati Oya Powcelork ien volle vande Warhejt dezer zak overtuigd, en door
I A M.

de ngeing, die den Koning woor hem hat, verickerd zynde, dat z.yn zeggen by den $V$ orft irging hebbon zoude, nam de rrytejt wan hem dic te melders, walt over de Koming, wel were wan dit qualy wan hera, of van anderen te nemen, niec minder, dastin zy, verba柱

Hyging dit wonderbaar beelt ten eerAten fien, en bracht het nls degrootete zeld fantnheir, oit in zyn Haf gefien, in de Itad Judia, al waar' $c$, wa cenen nach Koper-rood geworder en geblewen is, gelyk dic ons 'Opperhoofut toen $z e$ lf uit de mond var den voomocmicr Oya, een zeef nee en nucukeurig Heer, verftan hect.

En om te tootien, dat 'er meer zulke roode Olitanten zyn; de Koning van Siam had in dat zelve jaar noch ecnvolwatfen en ongemeenen grooten Koperrooden Olifant, dic, om zys wonderlyke Choonheit, enzeldiame grootheit, van hem voor den Prus der Olifanten gefehat wierd.

Ontrent defen tyd wass "er aokeen witte jonge Olifant, by Corafima, diche tha 'r gebergte van Cinbodia, gevangen, die thoch in "c Bofch opgevoed wierd.

Eerige janten voor $\mathrm{A}^{\circ} .1636$, zoo de Heer foof Sdhouten getuigd, zyn hicr ook twee jonge witc Olifinten retramgen; doch nies lang dat na, tot groote werlagenheit wan dien Vort, gefterven.

Ten tyde, als de Ridder de Gbomon hier $\mathrm{A}^{\circ}, 1685$ qunn, was "er een witte Olifint; $\operatorname{dog} A^{\circ} .1687$, wanneer Monl* de la Lowberewericheon, was defenal dood; doch dic limertelyle verlies wiend noch in dar zelire jaar, den 9 December, door lice tc voorlchyn komen van een undeten vergoed, hocwel hy toen noch niee gevangen, en noch in 'f Bofch wras. Ea in dien tyd was 'er in Siam geen witce Olifant, dan defe alleen, te licn.

DeSianmersecten delen witcenOlifant nict alleen als de Prins $\psi_{a n}$ alle anderen, maar zyn ran oorded, dat 'er, buitendeie Vorflelyke wardigheic, zelf iet Goddelyks in dele dicren te belpeuren is wanron $\mathrm{zy}$ die nier alleen zeci verre bowen fille andere achten, maar ook als Goddclyke etre bewyleri, nicralleen om zyn witce werve, matr voor al oth derfelwer groot en boven-natumlyl verftand, 't geen in de zelve allenthalven zeer therkidoorfchituerd: gelyk dit ook de cenige reden is, warom zy gemecnelyk uit filvere en goude feruelen gediend, en, by tyden wan fiekte, zelfs wan de grootfle Mandary bewalkt, en opgepan wicrdeo, en gelyk $x y$ fich; na 't zepgen der Sintumers, wayneer men hem reel eere sandoet, en een pracheige flacie geef, zeer yedblyden, 
en zeer moedig 'eropzyn, alloobedrocven zy fich zeer, wannect zy belpeuren dat men ben weracheclyli behardelis, en die eare beneemd.

Butien den Olifint (van welkers vang ft elders breeder geiprooken is) heete ment hief ook den Rhinoceros, en een groot getal van defe dieren ; die zelden levend, en meen in ftrikken gevangen, of geichoren werden, cn wannecr de Siammers den Hoorn, of ook 't fweet, en "t water der zelve konnen bekomen, meinęn zy een fchat gewonden te hebben.

Hicr zyn onk zeer vicl [wäre Tygers, withe Buffels, Stieren, Koejen, kint den, zeer vel Herter, Hinden, die $z y$ meell mant on de vellen dooden. Pans. den, Bokiken, Gayten, Katten, en diergelyken, vallen hicr ook veel. Caymans, of Krocodillen, zyn tier menig. wuldig, ook weten hune geellelyken die te belweeren, en geven noor, dat $x y$ die ook verte van Judia bannen, dwin. gende de zelve om beneden Bankek te blywer, en, 200 zy nader komen, wan- geri en ftraften zy de zelve; doch, burme befweering ungefpend aynde, is erikel bedrog, allon zy dic met cen hond, of jet anders anin cen hoek gethegen, behendig vangen, en san "t wolk wysmikein, dat zy die belworen hebben. How well "er zyo, dic lich, deor de relve dagelyz te voeden, zeer gencen 'er nucde weten te maken.

Men die hier ock woterloi nng when Vogelen, namertlyk: Arenden, P'neuwen, Ginfen, End-rogets, Howenderen, Duiven, Papeghejer, Pesicten, Kraten, by witifek, wet, Mulfohen, cin een foont van onbekende Vogels, die zeer cieslyk wan vederen, en welke zoo wonderlyk net allerlei tioulenten gecekend zyn, dac men'er ower rerbath noge ftwa, watron zy ook zeer Aterk wan de Chineten, en andere volkeren, gefocht werden.

Nu en dan werneemd men in de Golf of Bocht van Sista, wel echs cen Pors: kep, of een foor wan Noordkapers, of Vin-vifthen.

\section{TWEEDE HOOFDSTUK.}

$\mathrm{V}$

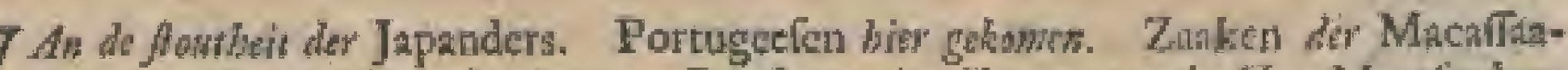

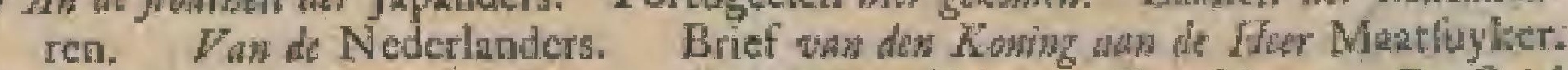
Lyyl der Siamfe Opperhaofden. Fan de Engelfehen en Frntchen. De Griek

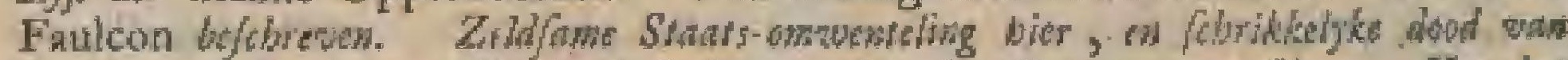

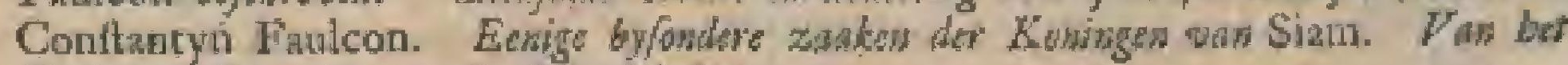
Koning re Patani, wow Handel adar.

Fande ftontheit der latpanders.
Elyk de Koningen van Sinm alıyd zecr fterk voo: den Handel, es de wettiering wan Koepmanlchappen geweeft zym, alloo licbben $u y$ wa ouds hice grooe werk wan de Japanders gemalk., voorsamelyk, on dat zy ditit jarlyx mer groote kapitnalen filver, die zy met hun eigen Jonken overbrach. ten, vertehecnen, wail mede $z y$ een groot getal van Herten- en andere vellen, in Japan zeer gerrokken, inkoguen, wal op zy grooce wintten fuadden. Behalven die japanders, dic dan zon over en weder woeren, wares "er ook rerfcheide, dic, doordevichebanteitran dir land, en door den overvloed der levens-middelen, gelokt, fichhier nederfetteden, van welke metter cyd het Jat pars quartier hier angegrocid is, en war door dan onk euffchen defe Vorften over en wedei verlcheide gefantichappen opgeliomena zyn.

Her duude al oen geruiner tyd, dat zy hier in veel rutk leefdem, cri groote voortechien genoten; gelyk de Japanders een trotlo Natic zyo, dic zich of uit wrak, of wel git andere groote infichten, nict ont fien de ltoutfe, zaken, die men lich verbedden kna, uit te vocien, war wan wy een klaar bewys in "c gevangen nemen wan de Heer Nay H, Lminusoogd van Tayounn, in zyll cigen wefling aldar gegeven hebben, alfoo hebben zy hier in Sinn ook een zask ondernomen, wast over de gandehe wereld moet werbatalt ftand: walas wat woor $A^{6} \cdot 1636$ vry fierk hier in getal toegenomen zyndc, hobben $2 y$ frch verllout her Phieis wan tiefn Koning met de witerfte wanhoop atr te inften, en den Vorit in zyn eigen vere trek met een weergaloole hoogmod en floutheit mier alleen gevangen ie nemen manr den zelven (alloo de Siammers zeor lnthertig, en egen hen in verftand of in dapperheic nict opgexwafen zyo) ook zoo lang in hun geweld te houden, rot dat by hen eerit mec vel woorrechten beguntligd, de zelve zeer dier befworen, on Thet zwarare eeden beloof bect dic noic te zullen wretien, en hen nok tor hec einde van zyo leven als ryo ly fowaclat te zullen gebruiken, gofyth dat ook (no. 
$\because A N$ S I A M.

69

gelyk om dat men to b niet anders kon) nagekomen is.

Naderland echter, ar dat dle dwingeland, die al 't Koninglyle bloed hier uitrocite, wat lin zy hem feer betulpfarm geweelt $\sqrt{y n}$, aan de Krom gerankt was, heefr by, wan Jen mede eenige donkere wolken weerende, middelen bedacht, om fich vari hen eensklaps; on dus te gelyk van alle vreele ie oniflaan, gelyk hem unt cindelyk foodanig gelukt is, dac fy alle, oncrent 600 man iterk, vir dit Rys vertroklien, of heimelyk gedoodzyn, war door "er pas 70 of 80 in Jарал weder keerden.

Hier uit fou men moeten en mogen waft ketlen, dat die Koning noit weer eenige Japanders in fyn dienft fou heb. ben willen gebruiken, al was 't maruie vreefe, dat ly, volgens hunnen wrakkfichtigen ard, da laathe bedryt des Konings hem fouden trachen beraale te zeten; matr tegen veler gevocien en rath heef hy diegenen, diegevlagt waren, felt's weder ingeroepen, om dat hy (for nen voorgale) vreesde, dar ty on fich arin hem re wiecken, ectuter wel middel vintes zouden, wats op ter dan 70 of 80 weer gekomen zyn, aati welken hy eenfohoon thk landsgegeven, enverfelucide groote warrechrem werleend heefe.

En hier vant is hee jegenwoordig Japan: quartier metter cyd gegroeid. Hy gaf tom and liunne dric voornaturle Houtten ongenmeene Eertitels, en verdeclde hen ondzr een wan zyne Mandaryns.

Dara bowen hect hy door den Berkelamg verlcheide byrondere Gefanten mer golchenken man de Gouverneurs van Narsgafacti gelonden, om fich wegens $\mathrm{zyn}$ vorig bedryte verfchoonen, en benzyn yricnatchap ann re bieden, henzeif, om te koonen handelen, vitnoodigende, hocwel de Jipanticrs hem (gelyt wy onder de Japuliche znaken hier en dar in her Dag-regilter anhalen) zeer verachiclyk dar op behandeld, zyo Gefanter met mandheit teruggetonden, en hem open. baar verweren bebben, dae by een Ufurpateur, cen Rooter, en Geweldenaar was, dien zy niet erkennen wilden, alfoo hy zys hend n mee hee bloed der regte Konngen 2 o ichandelyk berwalke had. Ja zy zonden licin de jonk met goederen, 200 getzuten als fy was, te rus, 2onder 'er iers wh in hun land te. willen hebben, of ronder den Gelane te willen hooren ipreken.

Dele imand heet hy moeten opkroppen, en naderhand, op atarading der fapnoders , hier noch woonende? doch zeer veratud, en datr uir cenige voorde len hoopendic, verfeheide malen

* gewach, orr tit thok te bowen te liomen, en den handel herfelien; doch al. les is vergeels geweeft, alfoo de Keirer wari Japan atin atle Japanders reeds geboden had, nict vit hun latad te gaan, on te gelyk aza alle, die er bui* ten witren, verboden, oic weer in hun land te komen.

Dat de Portugeefén lang voor onle Na- Rorni² tie hirer geweet, en gebandald hebben, geclen is fil eengfins, wit ' $\mathrm{r}$ geen wy betorens hier gegefegr hebben, gebleken; dog hier zut. komez;

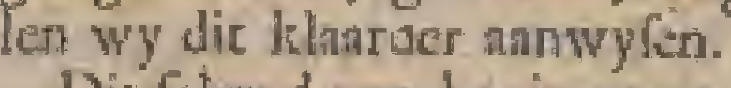

Die fchynd zyn begin genomen te hebben, zedert dat Alfon/as Abukers $A$. gro Malakka ingenomer, en aan der Konirg van Siam dar kennis war gegewen heefe, "t geen dicn Koning zerangenantw was, gelyk hy ook cen verbond met liem gemaki heeft, zeer verblyd zynde, dac zyn land, dewyl hy herdog niet had konners peroveren, in hume hat den geriakt was.

Na dien ryd hebben de onder-Konirgen yan Indièn, mitsgiders de Portugeefche Landwoogden wain Malakleat, verlicheide Gefanten en koltelyke gefchenken ahr delen Koning gelonden, die wedel door zyne Gefanten, en met geen mindergelchenken wandar, beantwoord zyn.

Daar op is dan verder het toeflan wan den handel aris de Portugeefen, door dit. ganfeh Ryk, en daar berneven die gunft gevolgd, dat de Koning hen tocgettan? hecf, hier cen Kerk te bouwen, en hunnen Goddicnit hier te oeffenen; werleenende ook atan den Pater of Priefter wan die Kerk een mandelyx inkomen: en gelyk de Portugecten hier quamen. handeler, alfoo ftond de Koningook adn zyne onderfaten toe, om op Malaklia re vaeren, en alleriei levens-middelen daar thet hunne Jonken te brengen.

A. 1516 of irit is Dowre Cotio hice ook als Gefint met Brieven wan Koning. Enand geweet, dien toen zeer thatelyk cn vriendelyk valu den Samlen Vorth onthingen, en met zeer anfienlyke ge[cheilken [e rog gefonden is.

Hier door zyn $\mathrm{zy}$, fchoon won natute rrors en quadaratig tegen ons, nog: opgeblafener en quatdardiger geworden, fig riet ontfiende om ons hier ook, ever als in Japan, den voee dwars te zerten, met ons by den Vort als een decl Zeeroovers, en een wolk zonder regeoring, die nie te vertrouwen waren, af te maalen.

In de cerfte tyden wicrd datar al yeel wan geloofd; mar, na dac dic Vordten wat meer liche hier at kregen, en zoo ons, als de Portugeelen, wat beter hadden leeren kentacn, wierd er niet theer van aan-

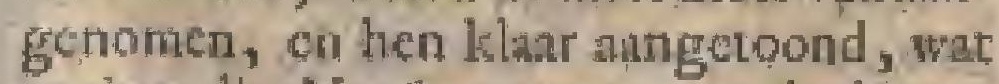
agting die Vorlten foor ons batden. nier tegentande $t y$ al voorgingen mee

ont 
I624, ons fwait te maken; war mede zy wol niets wornen; mare egrer hunnen aard volgden, zynde dir, dewyl $z y$, monle komft hier, zeer begonnen te veratruch, het eenige, wast mede zy lig nog wat konden kicrelen; hoewel hen de Konimg anders nu en dan wel openbare blyken wan zyn ongenoegen, over 's on= gelyk dat zy ons fomtyds deden, gctoond heeft, walt wan geengeringcbly k was, dat hy hen $A^{\circ}{ }^{*} 1624$ mier de wapens dwong, on 't Neuctlands Jigt, 'c gecn Don Fermando de Silva binnen de Sumfe Rivier van ons genomen had, aan ons weer ower te geven, wal op ook een Oorlog rufichen hem, en dic van Manilthit, gevolgd is.

Wel is watr, date de Portugeefen egter hier nog bleven, en fig dic riet eens axntrokken; mat zy zyn ledert by den Koning, cu de Grooten, zeer werdage en verage geweelt, en hun Vicaris lion gecn gehoor lirygen.

Hicr op volgde, 4 jaren datr nat de wpandelyke daid, $A^{2} .1628$ mer 2 Gallioenen, onder Don Jam Alrafla, ter ordre van den Landwoogd en Rad wan Manitha, woor de Rivier van Siam bedreven, wanner niet allecn des Konings Cantonfe Jonk verraderlyk genomen, en, na dat zy geplunderd was, met man en nus werbtand is; mar thet zelve hebben ry ook aan een Japaniche Jonk yan Nangafacki gedan, al 't welke den hat des Konings, cn der Grooten, zoodanig heefi doen tocnemen, dat zyn Majettei 's Galjoot, cn de goederen van Ga/for Swares, een Portugees, $A^{\circ}, 1630$ met eenige Waren wan Macao hicr gekomen, nangellagen, werbeurd werklatid, cnalle die l'ortugeefer 3 janren lang zeer nauw gevargen gehouden, en hengedwongen heef, on hun kolt lnings de ftraten to moeren gano bedelen.

Die wan Malakka zondendaar op, $A^{0}$. 1633 in July Sebaphan Mendes d"Avila, als Gelant, die mee ro Portugeelen, en 30 Inlanders hice met een fral gefehenk werleheen, on de verloting defer andgehoudene Portugeefen reverfoeken. Hy kreeg gehoor by den Koning, matr hem wierd reer weinig ecre bewelen; ork wicrd hen de worige vriendichap wel weder toegefege; matr even gelyk hem 's ontllag der gevungenen beloofd wierd, dat is, 200 flanw en geveinst, dat lyy vel redencn had, om te rwyffelen, of 'er wel iec wan komen zoude. Om dan zeker te gaan, altoo hy zag, dat by matr opgehouden en befpor wierd, nam hy met zyn Vartuig, en met al de gevargenen, ftil de vlugt, en zakce de Riwier gefwind af, en fchotón de Koning; 'er de luge af gekregen hebbende, hem dede verwolgen, is ly egter het ontkomen; her welk de Vorll 200 gualyk optem, dar by daar bver zoo wel mé de portu. geefer, a is met de Cultilianen, in groote vyandichap geraikic, wal toc zy $\mathrm{mgg}$ een nieuwe anthliting gegewen hadden, met de Rivic valn Tanaflery mex 2 Fregarcenteberatien, endar doof 'c bisnendiomen wars "s Konings Whatengers in Sim niet alleen tc beletien, nutar ook werlcheide wan die nog w dit zelve jatr weg te nement.

Defe daad vertoornde den Koning by uitnemendheit; dog hy kreeg nogindat zelve Noorder-fíloen gelegenhert, om fig aลn cenige Caftilizanen te wroken, alloo zetiere Chineciche Wankang, nuct ecnige aanlienclyke Caftilinanen ( watar onder fig Don Lawis de Gawhan, Sergeant Majoor wan de Spantele Velung op Formofa, als hum Hoots, bevond) van Kelasg tha Manillha wertuoklitu, door cen fwaren ftorm Walt- eniRocr-loosop Liggoor vervallen was, welke de Koning Jier gewangen nemen, en nevens de gucderen, (beltande in 125 pilol Zyoe, en cenige andere Chineeiche Waren) na Judia voeren.

A. 1635 yerwiel "er weer een Portugees Kapiceit, Francifo Corngr de Magalano, net zyn Vaartuig op de Wal wan Tanatiery, wan wan hy met $t_{4}$ Portugeefen, en etcelyken fliwen, паa Judia gebragt, en, even als de vorige zecr clendig gehouden wierd, tot dat de Koning hew allen nadertiatid, wir infigen van Stust, goed vond te begenatigen, en hen $A$ * 1636 nevens ecruge Gelanten Brieven, en Gufchentien, ten declen na Malakka, en ten deden nit Manilha, te zenden, mee latt om de vorige vriendIchap te herftelien.

Het jar dar an is hier cen Gefant wan Goa, cn een wan Manilha, met tretfelyke Geflienken, zoo wan der onderKoning, als van den Landwougd van Mawilha, vericheencn, dic alle de vorige wonden zoodanig hebben weten te zalwen, dat de vrientlichnp darar door we! cenigfins, matr meer in folyyn, dan ibderonad, wernieud is, dat in de volgende ryden wat henen gelleurd hoef, alfoo de Vorft dit niet zon zeer om de Porcugecten, als wel om zyn andere verborgenc belangen, ingetchik, how wel hy na sien tyd tor zyn dood toe, zeet weínig werk var hen gemanke heef.

By de rolgende Konngen is dit nu en dan wel een weirig veranderd, ra dat zy de hulp der Portugeelen, den cenen ayd meer, dan den anderen, vam nooden hadden; mar zy hebben gecn reden gehad, orn datar veel op re roemen, in wellien Anat het cot nog toe gebleven, hoewel 'er nu en dan turfchen beiden wel een luchije gekotien, mane "t gecn door-
1637. 


\section{$\vee \mathrm{N} S$}

1650. gans wan korten dutr, en van wcinig belang geweelt is. En dit is wel 'r voornaamite, "r gene wy van de Portugeefen weten te zusgen, die ros nog toe hiver bun bylonder quartier hebben.

Zaken Wy hebben bevorens onk angeliald, der Mi- dat de Macalianren hier mede een byloncaltader quartier hebben; dog zullen nu zeggen hoe, en watineer, zy hier gekomen zyn.

De Koning vas Macatiar, Crain Sonkbah $\%$, die pntrent $A^{\circ} .1090$ leefde, heft een Brocder gchid, Dain Mangali genetand, (een matm, die ons in 's verhat der Mucaftarle zuaken, onder de Volflen van Goa, voorkomen zal) die van zyn Broeder 'zeer benind, by allede $\mathrm{Ho}$ velingen zeer onelien, en een van zyne vorrnatwite Raadslieden was, wolgens wetker ontwerpen by dooyg gass ge woon Was zyne matregels wan stale ce nemen.

Hue voorfigcig en Stanckundig nu defe Heer weich mogt, had hy $\mathrm{cg}$. ter nilut konnen beletren, dat de Koning fig icn grootiten decle an 't welgevallen van een van zyne bywyen, wie hy witnemend beminde, zoodanig overgegeveti en als verlanafd had, dat zy hem dour han grooten geuft, ongevoelig, tot hee gene $x y$ geerne had, wit te doen overhilien.

Defe Princes had aloverhagbelpeurd, dat havr niemand meer, dan Dain Manga$f i$, in de weg was; ook hid zy uir "s Konings eigen mond al vernomen, dac hy de itoutheic gehad hadde van den Ko. ning af te raden, wich zoo ver re wan har over te geven.

Dit zetec hast test eerflen tot wrak ath, en zy wilt triddel te vinden, om hern by den Koning, zyuen Broeder, zoo werdage te miken, voorgevende, dar by na $2 y$ K Kroon en leven ftond, dat hy genoodtalkt was op fekeren nagt, nee 2 wan ayn getroulte vrienden, en wha gereedite fehatren, de whige na Jara ie nemen, dathy, zoo otn zyn hooge seboorte, as vic andere infichien, zeer' Wel onf fingen wierd, behalven dat by dast ook met de Dochter van een Japans Prins op Socrabaja quam te trouwen. Mer kretg 200 ris op Batnvia geen bericht van 't landen en neftelen wan defen Prins ildar, of hatar Edelhedenvonden gaed, dien Lundheer te doen begry. pen, dat zyn langer veiblyf aldar hen ricet angenam was, weghalven hy, $1 \mathrm{y}$ delyk wan de lagen, die men hem ley, Erwarlchoud, en ondertuflchen doos den Koning van Siam verfogtzynde, om fich in $\mathrm{zy}_{\mathrm{H}} \mathrm{R}$, $\mathrm{k}$ te komen nederletien, goedvond de groote voordeclen, hem door dien Vorft meer dan cens aangeboden, aมn te nemen.

De Koning, hier af bericht bekomen
1 A $\mathrm{M}$.

hebbende, zond herm ontrent $A * 16041650$. ecri groot Schip toe, om hem en zyn gevolg (dat nu al tor inde 60 huisgelinnen aang groeid was) over te voeten, en onding hem mer zeer groote bewylen valn agring.

Hy dede nier alleen ten cerflen een fraci huis woor hem bouwen mar by wereerde and den Prins, en aan zyn $\mathrm{Ge}-$ malinnen, ook werfeheide heerlyte Dia. manten, en andere keurlyke Gefteenuen, mitsgaders zecr veel goude vaten, torati it voornamilte was, dar by iedor van hen cen inficomen na hun ttat $\mathrm{g} F$

Ook maulice hy Dain Mongal, Dokja Pakdi, of grone Sclatubwarder des Ryks, en gil atars de Macalfuaren in "t gemein zow weel bat in eigendom, als $2 y$ var noodten ladden, on te beboum. worn, ner laft om diar wan de thienden an hunen Prins, evenals of by hun Koung wors, te geven.

Dele groore weldaden des Konings,

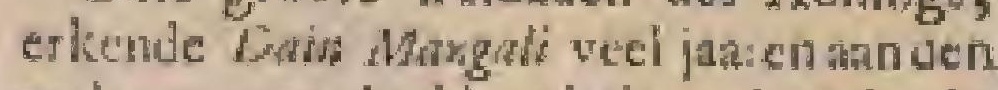

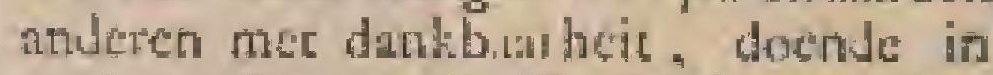
"cel gewallen an den Koning biyken, hoe zoer hy ana zyne belangen gch ge was.

Eimblyls cyer vickn eq nu vericheide taken voor, die hem andere mathregels deden nemen, wat onder zyse Priefters, dood-vyanden wan den Afyodilchen dient der Sianmers, nier weinig werliten, te meer, on dat de Ta. lapoins ben zecr flerk in 't ocfienen van hun hen Godsdientl werwolg I hadden, om "t welke te wrecken, zy den Prins oak zoo werre buiten froor witten te brengen, dal by auer hen een ontwerp gematk thad, am fig tegen den Koning, zynen wetdocner, op te werpen, en lig ib Hoofd der Monren, die fig no al jatren segetr delen Vort aangekant hadden, te verklanien.

Het cerite bewys, dat hy diar wan gaf,

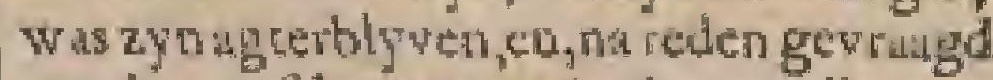
zynde, gaf hy voor, dat het verlies yan ayn Jicfire Gemalin hem tot cen cenram hien overgehald had, en dat die alleen de oorlask was, dac by nier meer zots, als wel poor henen, aar "E Hof ver. Icheen.

De Konisg, die wel beter wift, liet lig gernfins her mede piejen, altoo hen berige was, dat Din Mangali, nevens nog 3 andere voorname Nilicyers, wel 20000 man hier en dhar in "t Rylk verdeeld, en hee voornemen hadden, om met fcoo Mooren den Koning in zyo Palcis te owervallen, en fig zoo meetter van zyn Kroon te maken.

Hy wilt zeer wel, dat zyn gewoone wagc niet in ltant was, om zulk cen troepen. ge weld te wederftan; mar vermils dele bommel zeer rydig uitbak, vand ty gelegenteit, om hier in door de zorge wan 
165o. Cunfantyn Fanlion zoodanig te voorfien, dac die gumche andag op cen tyd, watrneer $2 y$ dic minth dagren, verideid wierd, alioo "er op alle de wegen, datr zy door' treliken moetten, zoo veel volk in thinderlagen gelegt w. Is, dat $z y$, merkende dat we bot vergald was, beft keurden hun werk woor dien lyd re thiken, omeen berer gelegenhat af re wagten; mar de Koning, hice mede niet voldtah, overlei mee $t y$ me Mandaryns, wat hier verder in te ducn, en belloot, tha veel overwegitigen, om defen inishling an de Macallinu'ic Howofien, mits dat zy hem om gechade quamen werfocken, en liguir sym land begiven, te vergoven.

Zy quamen dar op alle by den Koning, veringen hem pardon, en verkrogen 'I ouk; mais Dah mangah terichicen niex, wist arer de/e Vorlt zoo verconcus op h:m wierd, dac by anflinds belatte, hem mee een Vloot, benand met 7000 siammers, in zyn quarlict, dat hy wor therkgemake had, an we tather.

De Griek (anders Comilantyn Fatlon Benaamd, endien wy hicr na breeder belluryen) Was Zec-vongd over defe Vloor, onderfteund van dia meetle Europeërs, hoewel de Nederlanders fig uit andere infigten hier wan hadden weten te vertichoonen.

Men talte de Macafiaren dapperaan, cn Dan Mangah, wel fiende, dat hy dicn dans niet ontfpingen zou, werkogt de Stummers zyn huid zeer ther; dog eindelyk, allow hy mee zyn kleyn hoopje zoó grooten Vloot wan volk, dat getladig angroeide, riet wederthatr kon, wrich's hy door ryf pylen, en een Sotipe hatrichoot, in "t thofd zoodanig ge" troffes, dac hy woor. zyn oudte Zoons voeten, in "t midden wan een grooten Trop Sianmers, door hem verdlagen, dood nederttorte.

De zymen hietden "t nog eemigan tyd gande, mar lieten 'er meet bet leven, ulgenomen zyn rwe Zoonen, die op a con wonderlyle wyle nog behouder, en zeder zect genadig door deficn Koning beliandeld, en na hune geboore Vorftelyk opgevoed wierden, en inen zegt dat zy niderhand ook Chriften seworden, en in de nam des Konings van Vrankify, en van den Heer Jasphin (die over lien als gewaders ftonden) gedoopt zouden zyn.

$\checkmark$ an de weinige Macaftarch, toen nog ócrgebleven, is het Macaftars quarier, dat men hier nus nog heef, meter iyd antugegrocid; boewel hew wan nier veel belang is.

Dat de Nederlanders hicr mede al wan Neder- oude tyden af lig nedergelet, wis therken landers. bundel gedreven hebben, is ecn tath die

onberwiltelyk is mant het zal nier on- 1604 . atingenaan $2 \mathrm{yn}^{\mathrm{n}}$, dit wat verder op te halen.

Waneer de Zee-voogd Wyband pas Warwy, den 20 Mcy 1604 wan Djohor r'zeil gegan, en den 30 op de Rheede var Patani gehomen wis, alleen met roekg, om dar eenige Chineden an te nemen, on hem in de togt ma China behulplatm ic zyo, veritond hy ctate valn eenige Siammers, dat hun Koning gewoon was, jarlyx ecnjge GeGumen and de Grooten wath China, en nan dien Vorit te zenden, om nan den zelyen de ecrbiedigheit, its zy Vafil, te bewten, en uif dien hooflewur hem ie Sombayen (ecn wietken cinde zy ook doorganns, orr te zekerder dien cogt te doen, die alle anderen verboten is, het Zegel en Wapen wan Acn Keiler van China met fig vocren) wond hy goed Gornelis Spex na Sian te zenden, met verlock om door gunft wan welen Koning, onder 't gewolg Wan delen Gelan, met ecnige Getchenken na Chinate mogen gàn.

Hy wertrole met een neef des Zeewoogds, bencwens ecn Bootsming, cheen Jongen, den y Juny ran Parani na Siam, en nam 2 Merale Kaneer-ftukjens, ieder valu 12 of 1300 pond, cen kogel wan 9 pond fchietende, ren Gefchenk voor den Koning, behalven een Cargaloen van 4000 guiden mede, en een Briet, wair in de Zee-voogd wan $W_{\text {al }}$ why a an dien Vorft blyken dede, wat de cigentlyke reden wan zyae berending was.

Spex, ir sian gekomen, en dar zecr wel ontangen zynde, ontbood in Seprember roos meer wootrand tor zyne Clìneciche Reife, die hy vallficide dat woongang hbben zou, zoo men hen mant mecr geld zond, watar op hem nog zooo Rysuakters Loegelonden $2 y u_{*}$

A. 1607 den to Diecember guam 't Schip Mauritius wan Patan, war mede op Bantan cocn odk cenige sianfe Geranden, nevens Cornelis Sfres, verfohedneen, zonder dat de Zee-rongd Cornths Matiluf, die hier nuals Hoofding, with, om wat redenen by die daar brache, alfor dat whik regen de lalt der Heeref Btwindheberen ann was, en matr onnowdige kolten geven kon.

Hy vragde dierhalwen an Spex, warom by de zelve butico laft medegebagt bud; dog hy zende, dat dieniet wy bedryt, maar dek Konings will, wast, dic hem wel uiturukciyk gevrangd had, watam men zyn Gcintun nice zoowel, als die der Konitigen wan Djohor en Arsjten (die mar Konjakjens, by hem te iekenen, wiaren) ont tangen wilde, war mede de Zec-voogd woot Zou werre wel voldan was; mast overlei cout wet- 
$\forall A N$ S I A M.

73

1608, def mee zyuen Rad, of naen defe Gedanter oole mede tha Holland nemen zoude, " geen, on veel redensen, eindelyk by der Rand befoten wierd. Zy quamen dan an laxd, en felronken ecs zeer fraejen kiecnen houwar, mec eengoud gevelt, en owertogen delinde, anden Zeevoogd.

Den 28 January 1608 ham hy, met. Selip Oranje, van Bantani vertrckkeade, dele Gelimten, frelyk ook Comelis Spect, mede na Hollind ; doch Specx den is July benoorden den Evenant axerleden zyndis, ontdekte de Zee. voogd, dat defe Gefancen cenige fteenen ran hem onder fich hadden, hocwel zy zoo thout waren, om dit, wetende dat men mee geruigen hen dit nict bewylen konden, te loochenen, dog de Zec-roogd daar van wel verlekerd, eilchie die zeer fors, toonende hoe weinig zutke leugens eni diefital de Gefanten wan zulken magrigon Koning vocgden; dog als zy cgter bleven volhatden, dis ltyt en ftour ce bochenen, fchold Mrewef, den ecrlten in rang, voor cen rwarten Schelm, en dreigde hem, zoo hy die gelteenten niet andtonds roos den dag brage, de oeren te zullen larenatinden; watrophy, zeer ontlet, vertrok, en zynen nede-Gehame mee een alch-gracuw Damafte zatjen zond, wath in de fleencm waren, ieder in een byfonder papicrken, en elik mer een byronder op/chrif. Zy waren alege, en ongezegcld, zoo dar hy, wannecr ic hen avergegeven wierden, vreesde, ditt de Siammers de belte genomen, en tegen anderen verruild hadden. Dog alloo hy geen nadere bewylen ter frunnen lafte hadde, en de Brieven atan de Moeder van Specis nict opchen dort (dar 't anders wel net in zou gebleken bebben) moeit hy dit hier Jasen berulten.

Na zyn konft in Holland, bragt by defe Gelanten den u September 1,608 in den Hage, by den Heere Prince van Oranje, dane zy hunne Geloofs-brieven, in een gonde doos, wan furei gedreven werk, een fpan ling, en in een youine koker geplaant, nevens 2 andere lilecric goude dooskens, in 't eene wn de welke een Dinman, en in 't nder eer Robyn was, en met 2 fraeje Roers, met goud Joofwerk doorwrogt, en nog 2 tracje Spieften, wan welke de cene ceniglins met goud bellagen was, overgaven. Zy guanien voornamelyh, om ons land te befien, en te vernemen, of berzergender Portugefer, dat wy geen land befaren, en matr Zee-roovers waren, wagr was. Maar gelylk men hen al heel andere gedagren van ons gegewen had, toen onfe Zee-woogd den Portugeten onder. Ka-

- ning, me onlangs zoo dapper gelagen had, alion zagen $x y$, in den Hage ge- komen myde, die ook geheclanders, de- 1613 . wyl zy door geftelde gelciders over al ons land toorgebrage, en ten vollen pan der Portugecten yalikheje en quad. autdigheit overtuigd wierden.

Nia defen tyut kermt ny wan de Siambe ztaken nices van belang voor, dan dat de Hecr Brawher, $\mathrm{A}^{\circ} \mathrm{O} \mathrm{I}_{13}$ als Opperhoord na Japan gaande, toen mei eon in Slitun rangewect is, en toen ook de cerfic gronden coe onfen handel hier, en van danr op Japan, gelege becte, gelyle wy zedert dien iyd hier ool cen walt Comptoir thinden.

Hun hindel beftond toen poornameJyk in "t opkoopen vim Herter", Rhee." Buffels*, en Roch-vellen, en in 't. ver" vocren wan bappanthour, war by naderhand te hadel tan Rylt, Nomrak, Gommeluk, Agel-fout, Tir, Lood, Guta Gambin, Rhinocer-hoorns, en meer andere Waren, wan lyd tot yd gevoegd zyn, war tegen zy hier illerlei klecden invoerden; dog in de ecritte cyden met geringe winften, alloo zy ved fehade door brand geleden hebber. Hoewel hen den Koning alle bejenkelyke cere boven alle andere turopianten mandede.

Vermits zy egrer het dus hier niet langer konden gande houden, b'stiden de Hecren op Batmin, en in "t Vaderland, goed, dic Comptoir, dar Hemil Magighal als ons Oppertioofd allereerft gelegen heef, antrent $A^{5}, 1623$ te ligten.

Ondertuftchen wierden er cgier verfeheyde Brieven, tultchendelen Konitg cn de Princen tan Oranje, Mawis en

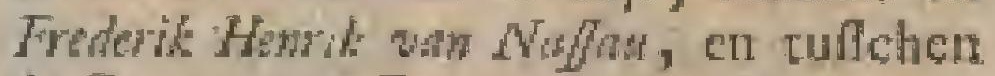
de Gouverneur General, ge wifield, wan" door dan de weg geband wierd, on die Comproir, onder ten Heer Norfegal A*. I627, weder op te richten, hocwel dit $\mathrm{A}^{5} .1633$, en 1634 woornamelyk onder de Heer Jooll Sibouten, dic hier al wan $A^{\circ}=1628$ ats ons Opperhoofd gelegen lad, een geheel ander andien lireeg, watisees hier, op ecn byfonder Eiland, pas buiter Judia, cenichoone ftecne Logie gebouwd is, on voor binnd zeker ic zyok.

Hy wiend door de Heer Joof Sabouten als twode Opper hoold gevolgd, onder welken defe Handel hicr zecr fterk toegenumen beeft,en dic ans ook wel het netite beriche van de Simfe zalken (gelyk an zeker gedruk copttel wan ficn diestangasnde bigkt gegeven is.

$H y$ blect hice 8 jaaten, en is $A^{a}, 1636$ door de Heer Jerensias van Ylor vervangen, dic hier tot $A^{\circ} .16_{42}$ gelegen, en ons mede een net berige wegens Shats magelaten heefe. In 't zelve jaar' 1636 brage de Commitiris Scburen defen Vorlt ook en goude Kroon miet Efma

ratu- 
1655, raden en Peerlen befor, benevens Bricven van den Hear Prince van Oranje, en zyo Fedelheir den Heer Gencraal, aat der Koning.

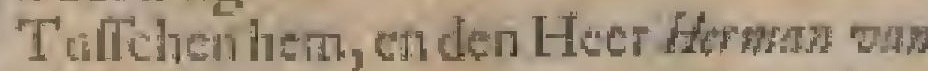
Muyden, is 'er nog een geweett, diens naam ik niee kenne; dog na den zolven is de Hect wav Mrylen $A^{a}$, 1 rí47 gevolgal, cn hicr tor $A$. 16 fo grblewen.

De mathe an hem, die my rootkome, was de Heer Yon was Ryk, die al woor A. 16,8 hier Opperhoof geweett, en dat tot $A \cdot 1663$ gebleven is, in wetk jant hier flenob Polvor quam, die bice tor $\mathrm{A}^{\circ}$, 160 ; blect, en coen, valgens zyn bekomen latt van Batrití, til opbrak, wcintende matr eens vis vaaren te gata; dog hy zakte tor voorby Barkole, eu 'r Fore Amfterdarr, en ttale 200 verder y1 Zee, gewepde de Kanitg roen nllecen b riche wan zyn opbreken, en wan 2y 11 vertrele na Batavia.

De Koning, hier wer niec wel poldann, en geen reden var dit ongewonn opbreken wetends, zond A 1604 zyme Gelanter na foravia, on 'er na te ver nemen, cli toen fprak Poolwot khar ut de borlt, toonde ' $[$ ongelyk ons anagedan, en cilchte vergoeding , en kreeg die ijer allecn; mar de Koning verioge haar Edelibeden ook zeer erntkig, om dog 't Comptoir hier te herftellen, dat zoo weel ingang fond, dat $z y$ den Heer Poglvat 'er $A^{\circ}$. co6r weer ils Opperhoofd 'er na toe zonden, woegende alsCommiftaris den Heer Buter by hem, on over dele en gene zuken mer den Koning te handelen.

Hy blecf hier tot $A$. 1 ro6, en wierd socn vervangen door de Hecr Opperkoopman (gelyk ook al die vorige waren) Nicolat de $k$, dic hicr tot $A_{0} .1672$ blect, en deu Koning amer angenaam wasts, gelyk ons nader uil defen Brief wan zya Majedteic and de Heer Matheyker blykt.

1672.

Brief wh den Koting wan Siam, an den Heer Gollwerneur Genemed Yam Masffater, $A^{0}+167^{2} g^{2}-$ fchroven.

Gitef pan Den 'Briff kom wo Thjiou Priny, de Ko. 1 Siere Demanalia Jadjamatienlic Panthe atn pidredna, Radj" Colatebocdi, Aphicde Heer plucyri Bacharina, Pahad, Kowing whth Mes. Sram, aan Joan Matululzer, Gouruener General as de Randen wan Indat, Dogr dien Jotn Matitryer on Rađden van India, rot een reken was opregit gentgenher ren Brit en Gerlowent was 2 Awher fyn wit Litem. 2 dito ged, an 2 ditu kroon-blanw.

a diro forart Lahes.

2 herfen Roo/d-water, we de Shbiph

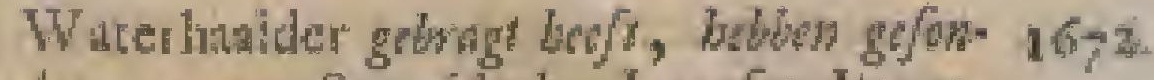
An, en wh Sameidech, lcurat I Iourabousambon, Padaparaponda, Soufou-

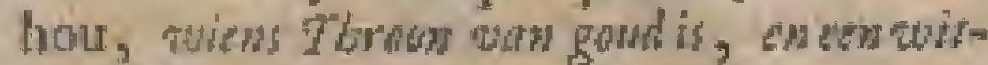

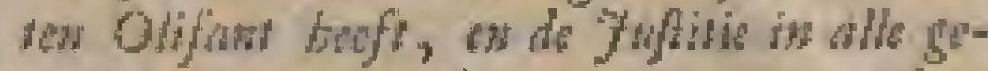

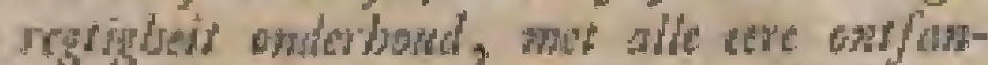
gen, dour des Kafiferw Nicolas do Roy, ithe in de Larie tot siana, wet alleceldeds-

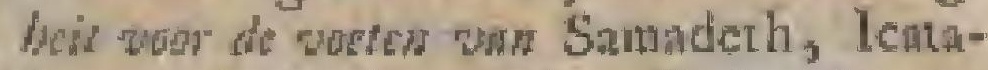
farme, Itomabourando, Padapadapoudi, Soulouhou, niens Thom ran gout it, encen wition Olifont beff, en die in at zys berading aprecht is, des Briff gedrobt op Donderdar den 10 equ menue Man in "Nothe jarar, en wergeft, en dant wit werfan, als dat de Gowurmor Goneral de platfe Balcesa nog at in ruft on vrede ngecrd," tgen den Roming wan Sian acer dodstratam is gewedt, en wen/cht dat bet long mag dwurew.

Gedy ool de Raputin Nicolass de Roy op Butavia zon kowes, en de Koppman

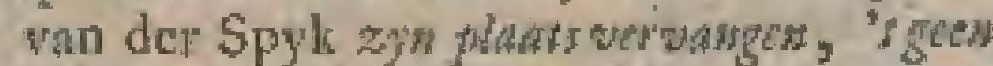
de Kowing Nicolatis de Roy beft togger Nan, to wher dit Hollowders, dhath Guewernew Gemerial gefondenbed, om op Shom

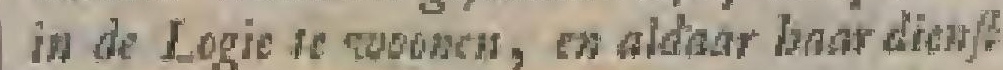
te doen, gata widldhatis, en bat gedocs. te is wel tot vernoeging von wederzhls,

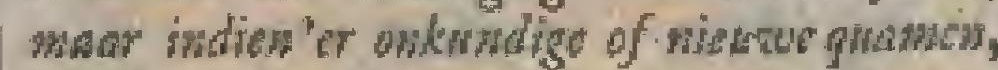

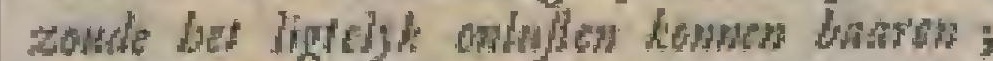
der Nicolnes de Roy is by den Kowng Jer

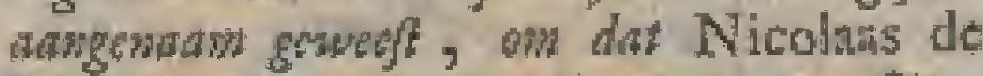

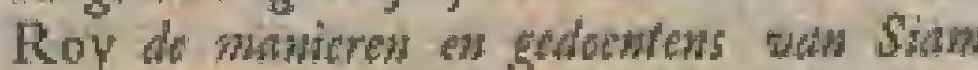
bekond zyn, en indien Nicolass de ROy wedrom of Sham wil komon, bef zal woor

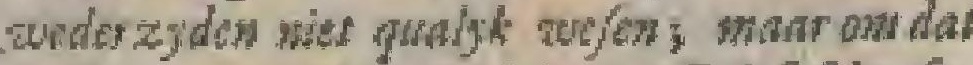
de Gowerwer Gemeral in zyn Bricf flaryft. dat Nicolats de Roy op Batavia mod tho-

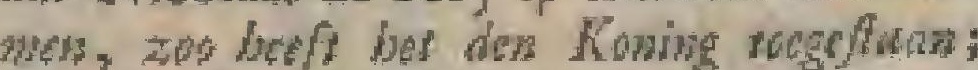
dog Nicolnas de Roy it bet doen en de mawire der Siompers awel beked.

Forders de Gowfmid, diemallowentan, die de Gouentmest Gewrad gefonden beeft, en beeft de kemais nies als Henrik de Wys,

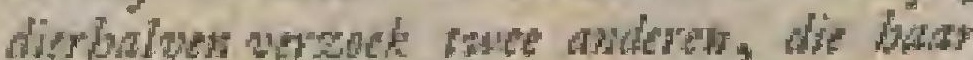
op has Anbagt weflan, en soul gelerd behben, moren oc/enden werden. Nog verfedet don Koning on en Stiesman en andere uwerklicden, watar de Gorverwew Generdats

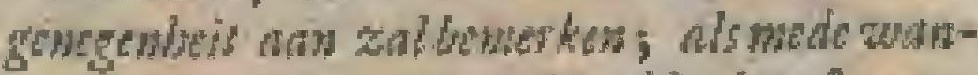
neer ermis wolk ma de Huldande plande vis.

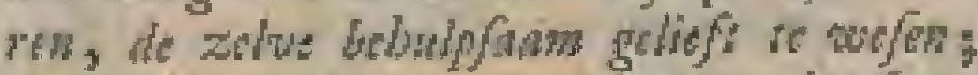

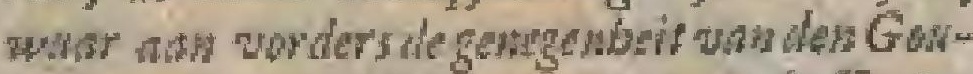
wernen Gewerdal blyen zal,' geen do Kowing wan Siam ann den Gotivernenr Generaih, of

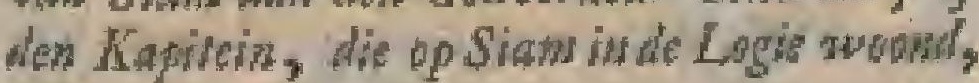
erkmess zall.

Forders is "er en Fonk na Tonkin gezeild, zuicus Nachoda, ch Kopman bw

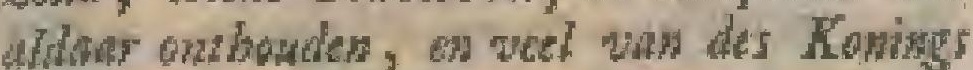

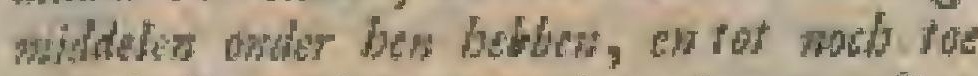

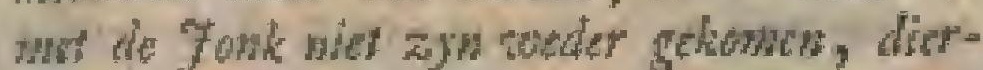
balven werfoek de Ronimg wan Sinm asm

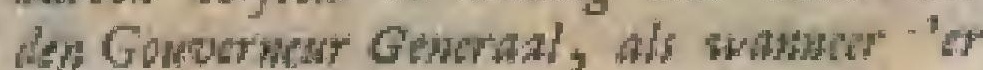




\section{N S}

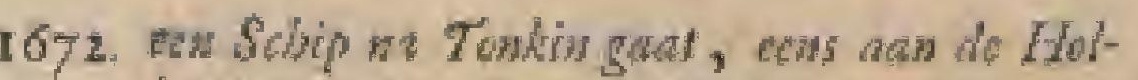
landers, die dar in Tontris romen, ge-

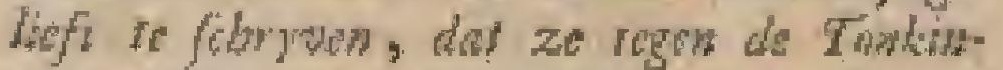
ders zeggen, dat bet whit wan den Roning wan Sam, don Nachoda, Koptnam, Font, en alle goederen onder gude bewat ring weder to rug na Siom zonden, en of den Stuman wghtep, en da "er miemand was, die 'f Jouk konde berwalayds brengen, zoo werfoke, dat den Kapitein, die in Tomkin woond, eth grod Holdand's Strer-

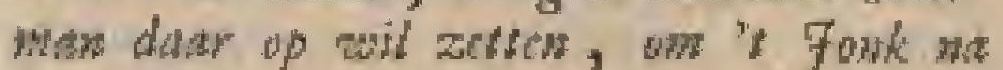
Sian to brengen, en isadios den Nachoda en andere wakeren anwillg waren, zbo

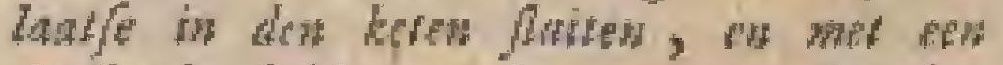
Hollavds Sobip overkowan, on dat bat wolk, dat wer ber Hulandi Schip owerkoni, de blowlofume band mag geboden

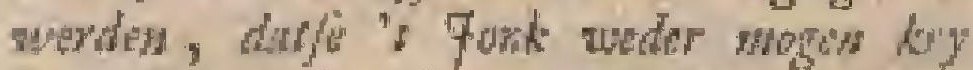
gen. Lulin don Gunwhon Gentak woor des lyd wy daur in greliefl te bolpen, zN

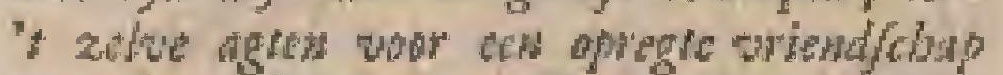
von den Gonwerwent Geseralal. Vorders beeft de Gutwernear geldrewn, dat by wy cen goed Shenbonwer zon gewn, en ers die bem op don Oorlog werftalt, ats cen Konflabel, werien ten Soburgiter, om Wh he Legic op Sian te wwonen, en bas,

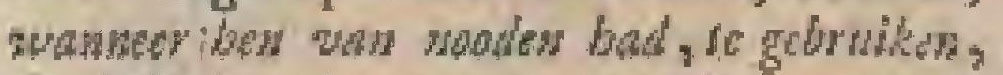
dog bob de zeitue tot wog foe niel werwomen, derbalwen werfod ach des Gowwentar Ge nerant, dat die we den Brief gemed fanm, niy wogks poectonden werdin.

Nog verfore des Gouverneurs Gewerals bulpe om Hollond/e Hodk, als:

\section{Een donkeren Hod.}

Eu ruat licbter dito.

Ech rood en ex dowker-rood.

Een purpose, en cen licliter.

Een donker gron, on en libh-gran.

Een gentrigelde.

Eon owet flote bain gemengl.

En ech van wherbainde koulewren.

Dess en suat meerder, on den ander wat minder.

Gely ood cen brwinen, en an fwatien Hed.

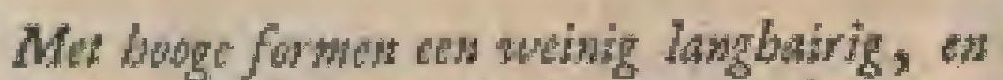
sode wan de alwe kowlenren, 8 for met fmalle, 4 flow wo brede randen, 4 ande, en 4 jonge Brillen.

Forgulde Derrelykers, die vergrouten en werkinges, " pok boller en kladr zyn.

4. Staking gend, en 4 flower leder, wan al labuate blows on op te zetten, war alle great en goed.

Neg verfoedt de Kowing to kppen ecn fat Gamogn rod, cu con als Gafimb. Em dohker, cen ligt-gateno, met cenflow bantje dats dow. Len flut ligh, en tenflut grature doormengeld als Cadjang, engras-grow, deg Nite god en fyn Laken.

Nog wroloh de Konfrg Hollande Tim.
I A M,

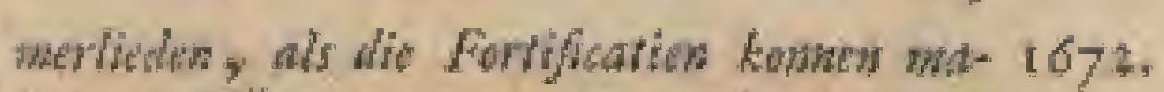

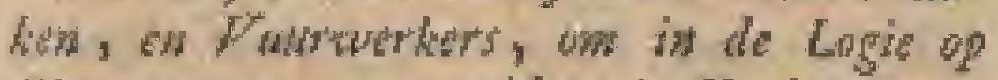

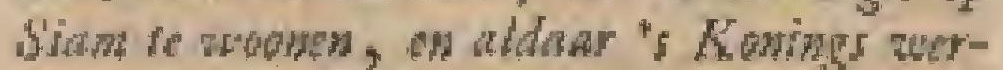
Hen re docn. En indien do ge/owden werden, zal de Kuming den Gonwermen Gonoral zyn gentrenbeit dadr aan hefpenten; dog wolkeres wan grede lempis, als node gaede gaederen a aenden; ch ano de Gourconear Gencral wy

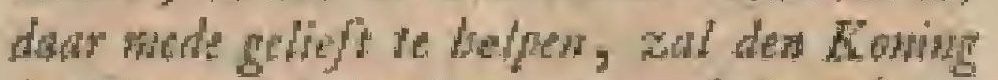

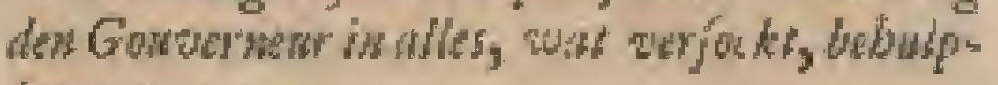
Ja木m zin.

No wererd de Konigy wh Siam as den Gouvernoter General to bharen The, dat asn dit Hollander, die in sayn placts woowh, bebe gegewen, on indien de Goncer-

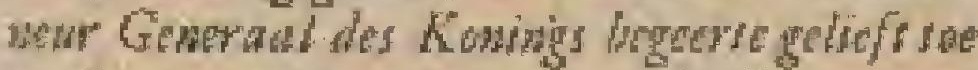
te fuan en te woldon, zal de Gutruerment Gunmals genegenbeit dar ann zien, an de

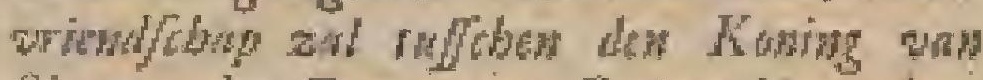

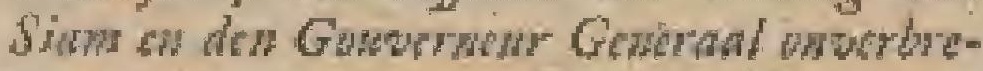

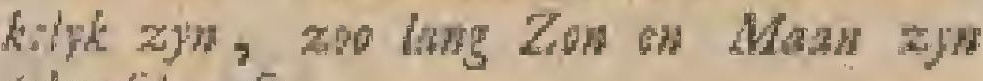
robingl geft.

Hy wierd $A^{\circ}, \mathrm{T} 672$ dont den Heer $N$. vilndo spl wervangen, die hier toe $A$ o. 1677 blecf, en door aten Hecr Dink de Yong gevolgd wiend.

De Hecr Anrnout Fit quam A. $16 \mathrm{~d} f$ in zyn phats, con thierf $A 0,168_{4}$, terwyl hy op ac rug reife was, ea nam toen alle den omfing hrer $\mathrm{A}^{\circ}, \mathrm{3} 685^{\circ}$ wan de Heer Foanses $K_{\text {egrs }}$ orer, welke Heer, newens zyn verwanger, alleen de cere gehat heefe, wan den Koning te fien, en te frecken, terwyl alle de andere $\mathrm{Op}^{\mathrm{p}}$ perhoofden noir met de Koning, en atloen met den Berkelarg gewoon waren re handeleti. Ook kregen defebidecen rooden hoed, een goude doós, en ecri Earenkleed, gunt-bewylen, die nair wan andere Opperhooften gelchied, en merkekenen wan des Konings hooge ingting poor hen geweeft zyn.

De Heer Kewbleef hier toc $A^{\circ} .1688$, en wierd verwangen door den Heer. Pieof wh don $H o w n$, die hier tot $A^{\circ}$. $16 y \mathrm{I}$ bleet.

De Heer Tbonas eq a $S$ w quamin zyn platis, blect hier tot $A^{\circ} .1097$, cn wierd A. 1608 door de Heer Reinier Bom wervangen, die tor Ao. 1703 onfe zakken hier befticrude?

De Heer Gideon Toud verwing liem matr voor cen horten ryd, alfoo hy nog in dat zelwe jaar van dar wertrok, en A. 1704 door de Heer Aarnow Glour verwangen wiend.

Na dat defe Hecr hicr 2 jaren gelegen had, guam lay $A_{\text {om }} \mathbf{1} 706$, mer zeet ilegte tyding, op Batavia, als of one Comptoir ftond opgebroken te werden.

Men zond er den tweeden, den Heer. Wowerfous, wcer na toe, om herftelling van den handel (dat verl van de $K 2$

Hect 
Hecr Powlwots cyden, wnmeer de $\mathrm{Ko}$ ning ons om laerftelling wan den handel verloge, vertehilde, behalwen dat lien nu ook allerlei onbillylie voorwiarden voorgeichreven wierden.

De Toche wan de Her $W_{\text {outer }}$ fon was egter van dien uthlag, dat "er de Hect Char niet lang dar na weer nls OpperLoofd na toe ging, gelyli hy "er ook tot $A^{0} .1712$ geblewer, en toendoor de Heer Dink Blacm, die "er tot $\mathrm{A}^{\circ}, 1717$ gebleven, en toen doot de Hoer Whiram Bhus vervangen is. Dele Heer bevo- rens Hoof wan Ligoot geweef, hect hier rot $\mathrm{A}^{\circ}$. 17 I g gelcgen, en werd $A_{0}$. 17 to buiten gemeen Rind won Indien, ecen bevorderiug, dic han weergac daar nivet beeft ; en in die zelve jant is zyn Ed, hier wervangen, door de Heer Henril vander Burg, die 'er, volgens de laritte berich= ten, in "e begiln var $A^{0} .1723$ noch lag, en doen vervangen is door den Heer Gregorias Wemrid Preanguan.

Wy voegen lier een Lyfl rau de Śamfe Opperhoolden by, woor 200 verie wy die hebben konten ingatr, en opdelwen.

Lyft der Gornelis Spext

Siunife Hewh Moglgat.

boofdcm.

Tufins Sebutent.

\section{$\mathrm{L} Y \mathrm{~S} \cdot \mathrm{T}$ \\ D E R}

\section{SIAMSCHE OPPERHOOFDEN.}

Yerimiat won Vhet.

Hcrwan wow Mujdes.

Fan van Ryk.

Henoch Poolvert.

$A^{\circ}$.

1604 . 1613 .

1628. 1633

I639:

1647 :

1658.

166I. 1663 , "t Compt, opgebroken.

1664. zend de Koning Commifferiffen om the de reden te vernemen, en verfock herlelling.

I665. herftelien wy 't Compt* ${ }^{2} 666$.

1666. 1672 .

1672. 1677 .

1677. 1670.

1679. $\mathrm{t} 69_{4}$.

$168 \% . \quad 1688$.

1688. $160 \%$.

1601. 1697 .

1698. 1793 .

1703. 1703.

$1704 \quad 1712$.

$1712, \quad 1717$.

$1717 . \quad 1719$.

1720. $1722,25 \mathrm{Nov}^{\mathrm{t}}$, overleder. 1723. 19 July.

Egter hebben zy laiet tor $\mathrm{A}^{\circ} \cdot 1704$ nocli een Lagie gehad, die toen ook afgeloopen, gelylk hum meetle volk toen ook door de Sirmmers gekrift, en hun Oppertroofd Mr. Willaw Thiens met een fchamp-fchere gequeft, eenige ryd hier
Dat de Engelfehe hicr mede een Comp toir gebad hebben, zal ons urt het werg blens mar hutanen handel van zoo weinig belang geweeft, dat her niec wecrdig is, om datr van te fpreckẹn. 
$\forall A N S$ I A M.

77

gevangen gehouden, wandar ontylugt, en suderhand hun Opperhoofd op Banjar Mafia geworden is.

De Iranichen hebben fich hier eenigen tyd wy valter on andienelyker nedergeJet.

Waneer zy hier cerft gekomen zyn, blykt my nergens likar; matre men wil, dác zy lum mocite andien gekregen hebben, scrwyl zeker Grizk, Gon/huys Fauleow geniand, hice ecrlte Diennar van Stane was.

DeGriek Dele Heer was ran geboorte, ecis befichs- Cefilontier, Nice, gelyt Monit. Tabart Fer. opgect, de Zoon wain den Gouvernedir vars dac Eiland, cen Venctians Edelmon, man shin cen zeer geringe af komit.

Hy verliet, ontrent 12 jaten oud zynde, zyn Vaderland, en ging mes een Engelich Schip, ontrent $A^{\circ}$, 1660 ma Engetind, dat hy fich door zyn vertand en geett by een Kapitein, die na Indien vertrkken zon, zoo verre wilt in te wikkelen, dat hy hem toeftond root jongen en jong Matroos mede te gann.

Hy wierd op de Reis quartict-Mecfter, alfoo de Kapirein jer groots en deftigs in deles borft merkte, en trud eindelyk, in Indién gekomen zynde, tor hooger Scheepsdientl op; dog na dat by nu wat ouder geworden was, en al cenige jaren met de Engelfchen in Indiën geiworwen hid, guam hy eindelyk mer hen in Sinm, dara hy lich uie hunnen dienlt begaf; en nu zyn eigen zaken begon watt te nemen, die hy door zyn groote geelt in korte jaren zoodanig dede veranderen, dat men nan syn wederen nu fien kon, dac het een vette voyel geworden wis.

Om egter nogg grooter zalken te ohdernecmen, kote hy een fraci groot Vartruig; dog zelfs geen geld genoeg hebbende, on dir Schecpie te beralen, lecnde hy un 't Engels Opperhoofd alhier, Mr. $W y$ th (die ten tyde van de $\mathrm{H}$. Ahrout $F_{a}$, door Mit $P_{a j}$ wervangen is) cenige penniogen, zoo on die lehald te vereftenen, als om fich van een goede lading te voorfien.

Het ging hem eenigran tyd byzonder wel, dog maderhand kreeg hy ramp op ramp; dat hen eger den noce niet benatr, on "E werk te herwatien, en nog cens cets loge na de kuft wan Malabar te wagen; maar dit bequam hem zoo qualylk, dat by door ecn fwaren torm zyn Schip, en byua ook zyn lewen, verloor, werdende nog, door een groot geluli, op de wal gciligen.

Hy werloor daar alles wat hy befat, en borg niec meer, dan twee duifend Ryx-

- daalders van allies, wat liy in dienbolicm gehad hisd.
Terwyl hy darar zoo elendig en radeloos op ftrand zat, zag hy wan wereech Feer danr langs komen, die wat verder wan dar, door dit zelve onweer, zyn Schip verloren had.

Na dat de zelve by hem gekonen was, verlond hy, dir by een Gefint wis des Konings van Sian, aan den Koning van Perfien, dic weer nil Siam leerde; Hotar nu, zyn Schipen goederen verioren hebbende, geen middel zrag, on vandarte geriken.

Fondon, dic will hoe 't fmakkre, zyni Schip en goederen te verliefer, en met. den ftar van defen Hecr bewogen, had de groormoedigheic var hem, nat dat ly here zyo ongeval wan den zelven ard verhatd had, zyn latifte 2000 Ryxdalders, dic hy nog behouden had, an te bicten, in hope dac die Heer hem in vervolg wat tyd dic wel weder vergelden, cn dxar door mogelyl yulegenheic geven zou, om zyne dus were vervallene zahken eens weer gelukkig te herftellen.

En wartyl het viel ook nit zyn ont= werp uit.

De Gelant, verbalt over die onwerwagte aunbieding, nam de zelwe mer dahkbarheir an; war op hy ten eerften een Vaartuig leogt, watr mede $z y$ in Sinm guameti.

Zoo ris whe defe Gelant voor den Berkelang (een Hecr, die alles met de wreendelingen verhandeld) niet verfolvenen, of hy werhatide zy n ongeval, roende de groormoedigeaanbieding van den Heer Fenleon, en fprati zoo veel lof wan zyn weergaloos veritand, dat de Berkelang zeer benicuwd was, om Fanlew te fien.

Hy vericheen 'er op zyn ontbod; maar lity had hem zoo rits nict over verfcheide zatken hoaren redenkivelen, of hy wand in hens zalken doordringende geet, dac hy voottam hem ann den Koning, als een van cle bequatufte mannen, die hy oit gefien had, voor te drigen.

Dat op woorden Vorft gekomen zynde, wond dic hem zoo vaardig en net in alles, dat hy hem voorftclde, te beantwoorden, dat hy hem, op mantanding van den Berkelang, cot " $\mathrm{b}$ wanracmen valn dienften van belang gebruilkte, wax in ly zich bowen reiwagring 200 wel quect, dat her den Koning veel ontrent zyne injzomften feheelde; gelyk die ook de grond lag, dat de Konitug hen, , na de dood van den Berlitang, dic hooge btodiening nanbood.

Hy lad "er wel frn in; malar wetende, hoe veel nyd dit hem by de Siammers baren zou, daar zoo ved Grooten uir hume Nacie *na ftonden, en dat een vreendeling darr mede wou hencen gan ; weigerde die cerft met weel nederigheit, en betuigde, dac hy den Vorlt geene. K 3

ifi 
in alle andere zanken dienen, en fig root zyn welwaren opofferen wilde ; marr dac hy lacm, indien by defe poltannoerde, onmoggelyk verder van dienft zou konnen zyn, het welk ly zyn Majefteit met 200 weel kragt van redenen wilt te vertoonen, dat die figzy ber velooning zeer wel bewallen liec; matr ondertuichen gaf hy fig ande Heer Fatdonzoo polflagen over, dac hy gecn zaaken zonder z yne berading ondernam, wate door hy cindelyls gelegenheit krecg, on alle Mandaryns, dic te voren de neelte ingang by den Koring ladden, "er' wolkomen uit te bonfen, en om allew grer den Geef des Konings re heerlchen, zo date die alleen den naam yoerde, tethyl de Heer Farlow hec ganlch Rylk zoo Oppermageig beltierde, dae "er geen middel voor cen Siams. Mandaryn wots, on dan ecnige verandering in te bewerken.

Dar de Koning alleen hem, en geen Mandaryns meer in 'c betlieren van zyn zaken berrounde, dair wan was de redern, dac by den Vorft klarar nangewefen luad, hoe veel 'Tononen Gouds en milioenen $z y$ bem verkort, en hoe elendig zy "t arm Siams wolk wan tyd tot tyd gedruke badden.

De herten der siatmmers won by, niet alleen door zyn zedigheir, nedrigheit, en geveins de vriendelykheit; mat' ook door dien hy hen van alle die vuile knevelaryen van dic bloedfuigende Mandaryns bevrydde, behalien dat veelen der zelve door $2 y n$ beftel dar over geftraft wierden; war aan men belpeurde, dat hy niet anders dan billykheir, geregtigheit, en 't welvaren, zoo des Konings, als van zyn onderdanen, zogt, zonder fig ergens in te bevordeclen ${ }_{3}$ of 'e allermintte, dat onbetamelyk was, na fig te nemen, wait door by nan alleneven zer, uitgenomen aม่ de Grooten, behagde.

Turwy th de Heer Faulcon tor defen top wan cere opgetleger was, et 't hutc van den Koning zoo volkomenbefat, vich "er iet voor, dite den grand tot de voornatulte zaken der Franfehen lhier gegcven heelt.

Dat 'er toen, chal hang te woren, verdebeide Biffchoppen en Prichters der Franfiches in Sian gekomen waren, blykt ons uie de komit en Reife van den Birfchop wan Berye, gelyl 'er toen ookeen Biffchop wan Metellopolis, en nog lang datr un was, die van de Siammers zoo weel Chriftenen, als "t ben mogelyls wis. zogten qe makeng

Zy deden dat in " $\mathrm{c}$ cerst in 't geheirn, dog kregen naderhand gelegenheit, on het in 't openball' te doen.

Hicr toe had grootc anglejding gegewen de tocleg van eenige Mooren, die, on zoo vecl meer op den Koning uc vermogen, hun beft deden, ons dien
Vorfl Moors te maken. Ten dien einde hadden zy den Koning pan Goleonda vooraf wysgemaakt, dac de Kunng 'er wel gencigenduct toe had; mat dac hy wel door den cenen of den anderen Mo-

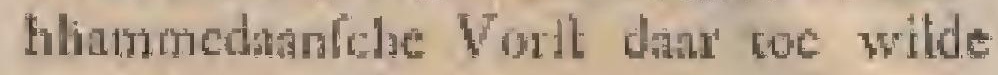
atagelogt $2 y+1$.

D. al op zond de Koning wan Golconda cen cierly] gelchreven Alcoran, of Corann, ann den Kondag wan Siam, met cen viriendelylk wer lork, om ook 't Geloove der Sjuis uan te nemen, cn daar beneven een winde finnanderlte PrieAters, om den Koning dar toe verder over te halen, en in de gronden defer Leere te onderwyen.

Na dat de Koning van Siam nu defe Vorftelyke Gefchenktu, wen dien Ichoonen Coran, ontfangen had, verloge die Moorle Panp den Vorfl met zer ved icver, on "L Geloove, datr it wervat, te tantuaden, en bood, on hem ce eer dinal toe te be wegen, zyn Majelteicaan, nro met zyne 'Talnpoins over de gronder van zyoe, en over dic van de Siamle Godsdiente in zyne tegenwoordigheic te redekawelen, mee verikkering, dat hyde ongegrondheit der binle, en dezuiverher van zyne Leere den Koning middagklar anruy yen zoude.

De Koning, dit sonrldel niee ongegrond windende, num "cr een preswe sf, en de Moor zerede alle de Talapoins ch Sianule geeltelyken $200 \mathrm{pal}$, dar zy geen woord meer witten to frecken ware over de Koning wan hunvent wegen zeer verlegen Wh, te meer alloo de Berliclang hem verfekerd had, dat zy genakkelyls tegen den Moor zouden op: mogen.

Ondertuftchen fprak de Berkelang, op namading wat da Hect fowlon, hier oucr gevallig met den Biffchop van Metellopolis, die reeds cen grooren nam, wegens zyth zanderlinge bequamlieit, hier gelucigen had: weike hem hapegaf, wan deten Mohbammedato pal te zullen zeeten, en de eere der Sizumers teneerften te zullen herttellen, als hycens met hem over den Godsdienft preken niogt wast wan de Berkclang den Koning hennis gaf, dic, om niet gehouden te zyn, dic nicuwe Leere san te nemen, laft gaf, dac de Biffchop mee deien Moorichen Priefter in zyn bywelen over den Godsdientt redeneeren zou.

Daar op dan beide voor den Koniug werfeheenen zynde, wierp defe Bifichop dien Moor ten eerften overttang, en toonde hem de wallebeit en ongegrondheit vin zyo Leerc zoo klaar, dac hy zelf bekennen moell, ongelyle te hebben, 't gen den Koning zoodanig belragde, dat lyy daar uit net reden grond nam, van fich by den Koning yan Golconda te 
v A $\mathrm{S}$

verchoonen, on dien nieuwen Gods
dient nist te konnen sandenen, altoo dient nist te konnen sandienten, alloo had mocen bekennen, dac zyn Leere geonlins de rechte was.

Dit geval gafdefen Biffchop nier allecn groote agting; matr by ten Koning ook zulken ingang, dat lyy zoo an hem, als anh alle andere Roomiche Prielters, op atsmang wan de Heer Itimicon, toeftond, lunnen Godsdien lt door 't ganfeh Ryk voore te planeen. Dan beneven liet hy voor dien Biflchopeen defeig huis, Kerle, en Queck-platars bouven, en bewees hem nile gunfter, die hy mata kou bedenleen hem angenam re $\mathrm{z}$ ra.

Defe Geeftelylen, hicr door zonderling san de Hoer Fonlow verpliche, verhieren hern zoodanig by de Geeftelyken in Vrankryk, en by den Paus van Romen; dar. Lonis de XTV, hem dat on de Ridder-ondre qan St. Michind, en de [ins hem, belalwenzynen regen, iwee filvere Lruifien in zyn wapen coegefonden heeft.

On dir nu weet re erkennely, buet de Heer Fotricon van delen Koting van Vrankryk by den Koning van Sian men geen klecuen ofhef geroemd, enden zelven hem als een Vorlt, witn welkers vriendfich het Siams Ryk ongemeen veel gelegen was, nangeprefen, watar op $A^{\circ} .685$ ook dac aandienly gefautich ip wan den Ridder de Charmom atat den Koning wan Siam, 't geen Mon[r. Th' chart zoo vitwoerig belchryte, gevolgd is, want newens toen ook alle die Jefuiten, die materhand na Chitha gingen, gekomen zyn, die doot hunne kennis in de Sterre-meer kunde, en weel andere fracje oeffeningen, fich by defen Vortt zoo aangenam hadden weren te naken, dae $z y$ reeds vootgiven dien Koniog al meer dan half bekocrid re bebben, en geen twyftel 'er ann fteldea, of die Vort' zou in korte de Chriltelyken Goudedient annnemen, dat cgrer zulken vatr nier geloopen, en cen hel anderen uirflag, ganfch buten hume verwngting, gehnd heef.

Altoos, gelyk de Firandchen rolkomen de gunft van de Heer Foulowbelaten, en de Heer Fonless weer geheel en al mecfter van den Koning was, alfoo meinden de ecriften door hem gu, mee fich bier zoo roordeelig neder te llain, een weg en middel gevonden te hebben, on huroen zoberen handel woortan geheel Indien door vit re breyder, throo men geen berer noch gelegener gewelt, om alle kuften te bzyaren, wentchen kon.

Aan de andere zyde was hee voornemen van de Griek (die nu zeer groote Iclanten receds wergaderd had, mara voor de

- Grooten en Tatapions banger dan oit te voren begon te werden, alfoo hen die
I A M.

te laft leiden, dat hy Sim an den Koruing waln Vramkryk zog over tc geven, ea hen alle Chritentedoen werden) om Siran, dac by nu wars began te werden, te verlater, th om zyo coevlugt metalle uyne fcharten by den Koning tan Vranky yk te nemen, main boe menignaal hy den Koning dhatom verhoge had, hy wilde her noit ontlian.

Wat nu den Vortt betrof, die vond fich met dit grootsen annfienlyle Gelantfliap, van den Ridder de Cbanmont, wel zeer verhecrlyke, atloo hem dic ontfig, atafien en veel luifter by alle de Vorften van Indièn tocbragr; mar hy had geen= fons in zyne gedngren, om san Godsuient te veranderen, hoe zeer hem ook die Gefant, en de Grick, danrom nangelproken had, alfoo by daar in te ved [warigheden te gemoet zag; wordedende het grunft genoeg and hem beweden te zyi, dar hy de Fiandehen en alle andere Priefters cocltond, die in. zyo Ryk te verbrciden.

Echrer is het waar, dat hy, uit dete cn gene infichten van Stane wel eenige upreckwylen gebruile heefe, war uic je Getune, en de Heer Fonlow, nien anders konden varten, dan dac hy groote genegentheic tot den Roomlen Godsdiente hind.

Her is oolk zeker, dat die Koningeen ongemeene zuche voor de Franiflic $\mathrm{Na}=$ tie opgevar had, en fich in alle gevallen van hen bediende. Dus gebruike hy den Vefting bouwer La Marc ook, on zyne voormamfte ann Zee gelcgene Veftingen, tegen over Bankok en Mergim, gehecl en al op de Europilche wyle te verlterken, en wan allerlei noodige Kuygsroorrad te voon'fien, getyk hy ook den Ridder do Forwin, on fich dan van in zyn Legers te bedienen, den Overtten de forysus, en meer nodere Krygskundigen, by fich behouden, en den laatf gemelden mer enige Tran Che Krygsknecl. ten, als Overite in 'c kalteel ran Bankok, geplat ft heefe.

Hy hecft $A^{*}$. I 68 t met de OofterZon, by "t zenden yan zyme Gefanten na Wrankryk, ook zonderlinge bewylen wan zyne aching voor deze Natic gegeven.

In later 1yd, of onerent $A^{\circ} .1687290$ "er door dicin Vortl weer ecrage Sinmli: Gelanter, mer cen Portugees Schip, en groote Gelchenken na V Vankryk gefonden; doch dic Schip is ontrent 60 mylen bezuiden de Tafelbiey, of by de Struis-bacy, verzcild.

De Godverncur wan der Shl zond 'er wel rolk na toe, om 'er zoo veet, als' mogelyk was, af te bergen, en ann de cigenaars weder te geven; doch $2 y$ onthielden 't eerite, wergaect "t lnatfe, en knpeen de goade en filvere Lamperten, 
Kamen, $\mathrm{Va}$ ern $\mathrm{ke}$. met bylen door midden, en wocgen diemalkanderen, by gebrek wan een goud-gewicht, met ech Spek-fichal toe, watr over er verlehei. de gevangen gafer, en gellafe zyn.

Ondertafichon wierden de oogen, niet allecn ter Gronten, mar zelf ooli wan de allerminte Siammers, hoe lavgs the meer gerpend, en die niet weinig tegen den Heer Fawkon, als dien grooren L,andwerrader, angeter, te meeralloode Frantfchen, zeer thout op de gunft wan fraleon, nu en don tot derthlidentegenden Inlunder begomen uitcefpaten, die hen meter tyd weel cyger zalien van ben

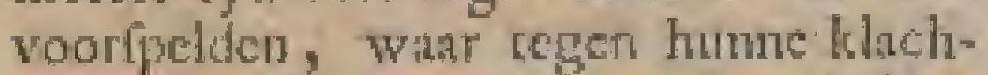
ten, anngefien zy zoo diep in des Korings en Fanlons gunll wares, zeer weinig zouden Jialpern.

Onder alle de Grooten wors "er ecliter geen, die verder $z a g$, en ap alles neter lettede, dan de Opra Pircratjiy, een man waj doorluchtige gebooric, cn zeer

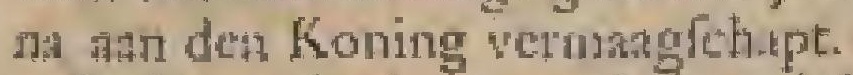

Dele zag wel, war dit werk luenen wilde, muar thich fich voorecrit liil, hoewel by onder de hand niec waing werkic, teruyl hy fich, om den rehyg dara af te bedukteren, ecuigen yd fick hield, en zelfs niet ten hove ver fohen.

Ook had de Koning, alloo zyne twee broeders onbequantin tot de Kroot, of hem alcoos nier angenam waren, ondertufichen een jongeline vaty econgevinge geboorte, Momi genumin, to zynen Low atngenomen, dien lyy woorhad tor zynen verwanger re werkliten, welke ftreng de Heer Futalon mede zeer fterk riols

Dit retholec dos noch zoo wat heneri, tot dat de Koning in 't begin wan $A$ ". 1688 , in den ouderdon wan 55 juaren, dool cen fware lickice aungetaft, en, - gelyk ons her volgende verhasl mader roonera 23 , ook dar door, allonhycirs* delyk de waterfucht 'er by lereeg, weggellecpr wicrd, watr op hicr ook een groote omwenteling van zukiken scvolgd 澡

\section{Belnopt Verhad van de wonderlyke verandering voorgevalles in 't $K_{0}$ ningryk Siam, in't jaar 1688, den Schryoer door den Heer Arnold Cleur behandigd.}

Zoddis क T Th dat de Koning val Siam eenimesiats, 1 gen tyd fiekelyk hadde gegant. renweith "w wierd hy door zyo qualen zoo hard

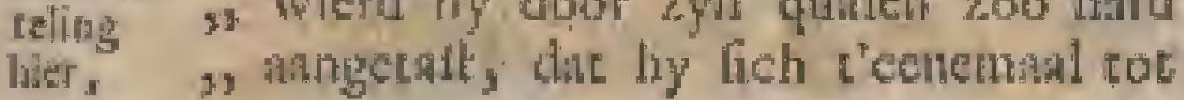

, laggen modt bergeven, 'c geen ea de

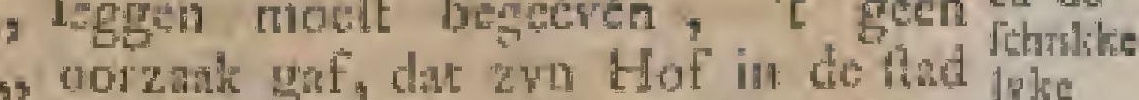
"Iudia was, allocuel to zelfs in livo doo , te bedde lag, en dazi wierd alomme ranCora"oen valich peruche verforcid, dat zy thats "Majefteic albercids overleden waş *cop. 7. Warar dont zocdanige bewegingen on", der de Hovelingen en Grooten ont"Rtonder , dit de Krygs-Oerdle, $\mathrm{O}$. "Pra, Pietratjay, zynde des Kanings Zwager en Schoon-vader, gerooul=

3. Failit wiend door $z y$ a ontrag alles we", der in rulf telbrengen, en ecnigender 3. voomentulte Roervinken in de gevan" genis te werpen, onder de welken ook "w wierd gecte eenen Opra Paula, zyn= " de een voosmana Creaturit wat den 1, grooren Stat Minifter Comfandyn Fanl-

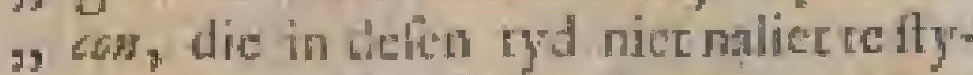
, vern, car onder de bubl ani te zetets "des Korings opqueckiring en nangtro"men Zoon Moors", tor zenowe, dat 3) by genoeglaam epentlyk na de Kroon "durfo ftan, en door behulp vañ zy " cigen Fader en andereth cen nio", tugte wan volk in dicalt thath, 200 " van veclen, die her zeer swel ver"mejnen re weten, woor de watr"heic word verhanld, tot wecrten dui"Fent in 't getal; "I wellk voorcer lt zoo", danig heen gaande, en ecn goed be, gin tchynende ic wefen, wicrd Fon", con veel trocfer en opgcblaiener, als " hy oic re vooren was geweeft: man " dit kon 200 Atil nict loegaan, of de "Krygs-Overite Pittratjay had 'er de de tuchtat, dic het werk, echer 200 "wat op zya beloop lict, tot dat de "Koning door zyn toenemende fickic, , om wat meerder ftilte en rult te heb", ben, hem de vonronamfte beftiering , des Ryles opdroeg; 'c gecen Fuslom niet ") weinig quam of antichicren, wane hy "rakte in defer voegen niet allect zyn "voornasulte Atemlel quy, maar ook "by werleheide Grooten dapper in 't "oog, die zyn lisogmoed, vermetel"hert, en dwingelandy, al wan over , lang gelien badiden, cvenuel vond hy , midde, on fich heinclys by den Ko ", ning te vervocgen, dien hy met veo"Ic omitandigheifen on beweegredenen 3) wilt te vertomen, der hee ten allerhoogften tot verfekering van zyn Majelteis Pertoon en liyk zowde ") fercklen, dat de Fratichen uit her $\mathrm{Ka}$ y fteel van Bunkak na boven geroepen wicrden, on in delen flechren roeltant "พan zyn Majefteit goduovig lace Paleis "te bewaken, en tot zyn Lytwache to " dienen; 't geen den Koning zoo wel "beviel, dar hy andtonds order gaf, , om hen na Livo te haten komen, ge"Iykze zonder uiefteideden, doch wict"1) den zy en hun nieefter Fanilow, door , den 


\section{$\checkmark \mathrm{V}$ N $\mathrm{S}$}

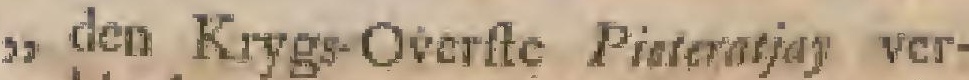
" klocke* w want werltan hetbende, dat "Fumlen by den Koning was geweef, , en wat "er verhandeld was, deed hy "2 Lyn Majetteit begrypen, dia Farlow 3. Co zyn medellanders nier anders zoch"ten, als lich nict alleen mecfer van ,2 "t Palcis, marar ook zelfs van zyn Ma12 jefteirs perfoon en her $R y k$ te maken. 3W War op de Koning her voorheen ge„ geven bevel weder introk, en order 2) Baf, dak ze fich niet na boven zot" ", den begeven; matr dat ook de gee", nen, die albereiss in Judia verlchecnen ", mochten zyn, weder na Bankok zou= , den hebbentekecren, "t gende Fran5) Iche General, Monfieur des Forgws, ") dic fich onderwylen al met 60 vin de ,2 zyocn op weg begeven hadde, moelte , doen, alhocwel hy daar toe vry wat "Thoorwoctejde quam, en in ber te 3) rugvaten ecnige vyandelyke danden ", bedreef, die genoegfiam re kenrien "Saven, wa yan zyn lutten roornemen n was geweelt; "t welk noch nader kon 9. werden befpeurd an "t gedoente van "zyn Majoor, eoen by de Rivier op "voer, beneden gelaten: wane hy wer") liet nanttonds her oude Kalteel, atan 3 de Wett-zyde der Rivier op Bankok "gelegen, en begaf fich met alle tilba". re goederen in her nieuwe, door hem "2elfs daar tegensover gebouwt, Jaten") de het fivar Kanon, dat ze niet kon" den medevocren, feringen en verna, gelen; mirsgaders her buspoeder, "t " geen ze nicr bergen konden, of wel "licht niet van nooden hadden, met "Wazer begieten; "t kruit=huis af brec, ken, en alles onverwerpen, en tot ") puinhoopen maken, 't geen ze dach"ten has in de weg, en tor nadeel te zul"Ien konnen zyn: war tegen de Simi4. mers echter nietanders deeden, als het "oude Kaltecl, dusdanig verdorven en , om vergeworpen, weder wat te her3) maken, alles 200 veel doenlyk te her"Atelien, ej in that van tegenweer re 3) brengen, on werdes op her gedoente " der Franlehente leteen. Onderwy* len wierd her voorgenomen verragd "van des Komings angcromen Zoon, 2. Moospi en Fondeon onidekt; want de "2 zelven mer nog vericheide andere "Mardaryts vat hunnen anhang, diep "in den nagt bintuen't Paleis, en in een " kamer vertimelt zynde, wierden ze "doot een van des Konings wywen, en "den Zoon van Pretrajory, die dagr "buiten op de grond neder, met hatr " ooren tegens de deur man, Jagen, zon" der dar het door dedonkerheic des.nggts " wh jenand wierd gemerlit, zoodanig "beluilterd, dat ze gemakkely le van 2) woord toe woord veritum en hooren III. DEER
I 1 A $\mathrm{M}$.

"konden, wat "er beraldlaagt en be"Alooten wierd, 't welk ten principalen " hier in beftond: Dat zc, zoo draa de " Koning overleden zande $x y n$, des "zelfs jongtten Brocder, albereirs door sf cenige voornatame Grooten voorge" Celivikt tot de Kroon, den Krygs.O". ften Piefrratidy, des zelfs Zoon, en ver3) Feheide anderen, zouden laten ver"moorden ; doende benevens dien alle " de Mooren, folie has in den weg mog" ren weefen, alomme vitrocyen en ver" delgen. Wotar op komende te vol") gen, dat Fanden zyn voornemen met " de Franichen weryelels zynde, fig poor " een geruimen tyd buiten "t Hot ont"hield, en riet quam wertoonen, zoo "als hy voorhecn plage te doen, wierd " de achrerdogt wan zyn wederftreyers " nog meer lier door gevoed; dic dan " oordeelende, dat de zadake nu al hoog " genotg getomen was, hem liseren ont"bicden, op het welk by fig den in "May des poormiddags ten Hove begaf, "dog by quam ecn weinigjedar nawe. " der ; hield in zyn huis het middag", malal, thelde voorts order op cenige "zanken; liet fig tegens zyn Europinan. " Tche Lyfwach ontrallen, dar 'er den "3anftanden nagt iets groots ftond te "geíchieden, war mede her werk over " cen zyde zoude flaan, nam van hatr "3 (zoo 'er van verfcheide geloof waardi"ge perfoonen werd getuigt) vIy wat "beter aficheid; en ging weder ten Ho", ve: maar niet lang danr nit zag men ", zyn Drangftoel, met filver overtrok"ken, Jedir te rag komen, dar by zyn " huisgenooten voor een zeer quand ", voorrteken genomen wierd, dic nier 39 alleen wel hanft quamen te hooren, "dut hy Fuatcom, des Konings aangeno" men Zoon Moospi, en de Kapitein ", wan 's Kodings Lyfwacht, in't Paleis "sangehouden en gevangen waren : " maar wierden noch ten zelven da"3e mede in 't Paleis gelinalt, en in 3) ketenen geftrien, watu na de Siam"mers ansitonds lict huis wan Franlons " van alles beroofden, zyn Huisyrouw "3 nier her gering fle owerlieten, en zyn 3. Bockhouder, een Engelsman, uit "Balbroole, reekening wao zyn Meciters 3, Atat en middelen affirichien; latende ", den Krygs-Overite Pieteratiay, nu het "werk aru 'de gang was, in de zelfde ") drift oolk by de liop vatteneenen Opra "SWipat, uic wiens zak wierd gehald

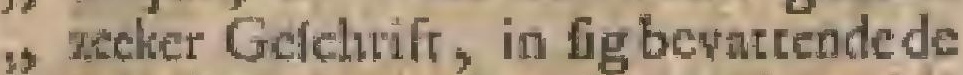
"gehecle t'zamenfweeringe, door den , atagenomen Zoon des Konings Moon3. pi en Fisulcon met cigener hand onder"eeckent, zulx 'er nu geenbewys meet 3. van hur quad voornemen van noden "zynde, kan de Koning zyn alangeno$L$. 
" men Zoon en by fonderen lieveling 2) Motwpi ook niet langer beichermen, " maar noeft hem esndelyk laten diy", ven, en aan zyn wederftrevers over, later, die hen drie dagen na zyn ge. 3) Vangenis het hoofd lieren afflan, en ", het zelwe lieten werpen voor de voe3) teht wan zyn tanvoerder Fashon, nog , Fwarlyk mot yzere keetens om "r lyf, ", mitsgaders om handen en vocten, ge, w wangen fittende, op cen fmatige en i, verachaclyke wyfe dant by doendede"Te wootden: Zilt dat woth Koning , 3) Want by hec vooreerft wierd gelaien: , dog was de Koning; welkers fielce 3) noch dagelyx fterl tociam, over het "ombrengen war zynen 'Loon Mompi "hertelyk bedroef, begeerende, dat ,3 het lighasm geen Imatheden meer aan, gedaan, mar begraven zoude werden, " t geen gedan wierd. Onderwyten ", had men den Franchen Generail, 1 "Monfieur dos Forgat, uit Bankok na , Livo onboden, dienidar eerft op her 3. dercle onbod aanquan, werdende wan , wegens den Koning mer cen goude , Boulette of Pinang-doos befchonken, "zeer wel onthald, en eindelyk bello3) ten, dat hy her Kalteel op Bankok, " door de Franlchen gebouwh, an de , Siamners zoude overgeven, en totna,"kominge var dien berde" zyn Zoonen, , mitsgaders den Frinflien Biffchop wan 3) Mecetlopolis, als Otagiers in Livo la," ten; dan met al zyn wolk boven komen", ?" en te zyluer tyd metecnige Schepen, die , hem zouden werden geleent, uir Sinto 3. vertrekleen; 'c geen hem door denge3. vangen ficcende Fankon, door over en ;i wedergande Boden, (want by mogte 3) hem zelfs aiet (preelen) op bet ernftige ;) angeraden wes , zoo als zommige ge") looven; ". en gramichap der Siamojer t'hemwarts. ," was't doenlyk, eenigfins te veriagten, "i geen dant toe hogtnns zeer weinig " ichynt geholpen te hebben, gernerkt ", zyn wedetflewers de gedagten begon"dente lerygen, dat hy haar wrakk-Iutt "weldoor de dood magt komen te ont"frappen, natien ly door de lware py. , nen (om het voorgenomen verrad uit , tyucigen mond te hooren, en zyn me, depligters te melden) hen op verichei3. de tyden en manieren angedaan, mits," gaders door cen ftyfzinnige onchou, ding var fpyle, zeer wervallen, en , vry dwal geworden was; warom $2 y$ "hem dat opden 4 Juny, even na Zon, nen ondergang, wits hy niet wel garan , Konde, iti een flegte ftoel in zyn huis , bragten, nlwar by over her bouwen , van "e zelve zeer fandelyk wierd beje, gend, latende hem woorts weder op3. nemen, en by zya Huisvrouw dragen,
3. die daar digt by in een Pardefal ge") vangen ligg, de wutke fiende, dat het 3, nu genocglath met har man gedaan "Wus, hem, in plaars wan rrooftelyk " toe te fprecken, zoo "er voor de watrw heit word gezegr, een menigte yan "Fheldwoorden cocwierp, in "L mange"fige fpoog, cn qualyk wilde gedogen, "s dat hy zyn eenigften Zoon, ongevaar "4 jaaren oud, eens voor "i laterli moge "k kiften; watr oxer de Sitmmers zelfs " als reriteld zouden hebben geftan, $v$ die derhalwen te cerder met hetm voots , ginger, on hem buiren de flad te , brengen; 't geen hem deed vragen, , war ze mor liem heen wilden (want , hy wis, zoo het fcliynt, wan gedag, ten geweeft, dat te hem weder na de , gevatgenis zouden hebben gebrigt ) , op her well dan onder veel fcheld, woorden ten antwoord krygende, dat , ze buicen de fad gingen, om hemal"dar, volgens hum ditt, te dooden, 19. wierd hy zeer oniteld, en floeg ver, Fheide mal op zyn borft, 'L geen , door de woedende Simmers met veet , reragrelyke en verwytende redenen , wierd belpot en belachr, duurende, tot " dat ze ter plaarfe quanen, dar hy ", Aterven noeft ; als wameer hy ru ". Ganfoh geen uidkomft mecr ziende, de , order van St. Michal, ca cen Reli, quie van zeker Heilig, rynde atardig , wan goud bellagen, van zyn hals nam, , en aan cen wan ue byltande Manda, ryns overgaf, met verioek, diean zyn "Zoontje te willen geven ; war na de "Siamfe Beulen hera geboden neder te "kinicken, 'I geen hy' niter doen wilde; ", mar by begnf fig tegens de zelven te " worftelen, en wierd hem zoo het "hoofd afgellagen, 't ligham ann drie "Atukken gehouwen, in cen kuil gewor"pen, met weinigande overdekr, des , magrs door de Honden opgegraren, en 3, zoodanig vericheurd, dat 'er "s ande3, ren daugs nict dan de beenderen oyer3) gevonden wicrden; "c welk door ec"nige Europianmen, die tit nietiwg gic,2 righeic ter plante waren gegaan, daar " by omgcbrigt was, cocwerwondering, "vor de watheir is werhanld; en werd " "er door zommige wan anderea nog by y gedan, dar de lantfe woorden voor "zyndood zyn geweeft Hecre $7 e / a$ gedenk "nnow! dog dewylde Schryver van dit "Verhaal niet weer, dat iemand van de "Europiannen zyn ferwen heeft bygey. woond, zal hy daar wan hee gevoclen 3. gaarne annden Leeler owerhten, en een3, Jyk wan 't zynedar by woegen, thdat dit " lice ongelukjig en rampfalig einde var "den Heer Gon/lawym foulon geweeft is. "Dir dasdanig getchiks zynde, kreeg s) de Frantche Generaal, Monfieur des "Far- 

2* werdende Schecpjens wan "t voorge"* valiene te waarchouwen, is 'c afüry3. Ven der Rivier, ewen buicen 't bereik y van "t Jianlehe Kanon, aangetat, " en ma een dappere regenwetr verovert ") ch verbrand, wand door de moel wan ") Monle des Fangres en de zynen zooda" mig quam te verlaclen, datle kort datr

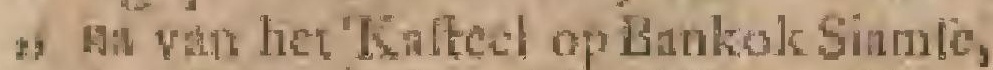
" in plats van Franliche, Vhggen lieren s) Wiejer, daar de Siammers iniet anders 21 dar de fpor mede drecven; en hadden "Te benevents dien, door het vetbree"Kon y 3 ke bedryen, den Krygs-Overtte Pies) teraljay zoo verre gebacht, dat by i, vall hess gaf voornemens te zyn, om "Acn Finfucher Biffehop van Mecello"polis, Monfieur Low's, en beide de "Zooner wan den Generial, na bene. 3) den te voeren, en de zelven tite hee " olde hermalite Kaftecl op Bunkok, "y yer woor een Kanon gebondea, den 2. Frantchen te latentocfchicten; "Lwelk n men getoofe dat hy lichtelyt volbringe n zoude liebben, indien fe nier mer wee„2 le besweegredenen door het Neder"hands Upperhootd vin de dood verbe", den waren geworden; op welkers ver" der verfock lyy dan te rade wierd, bel, de de Zoonen des Generaals hun Va", der onverleetr toe te zenden, zo als is cenige dagen daar na quam te gefchic, den, mer cen briefje, watr by in fub, ftantie den Genermi zyn valsheir, on, trouw , cn bondbreuk verweren wierd, 1, met verdere byroeginge, fchoon hy n als ecn $V$ ader met geen liefde noch 3. medelyden ontrent zyu beide Zoonen, 3. die hy als Oltagiers, tor nukomingeder , oxereenkomlti, in Livo gelaten had3. de, itamgedian was geweent, dar $x y$ ") evenwel by hem Pieteratjay indedoo= ", gen en barmherigheit halden gevon. 2, den; dith hy gunleh niet bloeddordig 3* wis, lig ook nan defe onnotelen nice "had begeeren te wreelen, mant om"trene de gehecle viereld wilde doen 3* Fien, dat de Siammers bet reclie ana 3. hume zyde hiddes, en door de Fran3) Ichen cen hoogiten verongelylit wa" "ren; op lies welk de Genernal hee "voorlyeen gedann werfock, oin een "Schip tot zyn werticle te moger heb"bes, deed vernieuwen, daur ecnlyk " op geantwoord wierd, dat hem ecn "flilteand wan wapenen wierd vergunt, "en dat hy op zyn meerinal gedian "verfoek her belluit wan "c Hot zoude 3. moeten afwagten, nangefien men nict "had konnen befluiten, on hem en de "2ynen datr in tot nog toe te wille te "wechen, on sat ze, toen ben zuilks " angeboden wiord, 'c zelwen nitet al" lech a fgetlagen;mar net houne wyrant- n lyke bedrywen gronocg finan uit Siam $t^{\mathrm{C}}$ * vertreliken, geneirer ladden; en * kreg de Uwertle Osjo Dierpo, die a de Siamle Krygs-mage kommandecr3 de, onderwylem solikumen order, ins dien ze fich nu andermal wandelyk is quamen nath te flellen, heri tis dutop 3) lyee lyf te vallew, ende zelve, zon: n der hen te ontien, wite to roejen y en 3. tc verdelgen: wat by hec din veor "deles by met de Funfohen geliten 2. wiert, nat dien 'er, zoo 't tcheen, " voor den Krygr- Overite Pieterajin , wail anders te doen viel, als ligr met " hen te bemoeyen, gemerke des Ko3. nings fickte nog digelyx rotnam, en "zyn jonglte Broeder, zooals hicr root $n$ is gelegt, atbereids by cenige woorth" me Mandaryss voorgeferifit tot de "Kroon, beinelyk hoende wine met econ " groot getal wolk ant re twasen, on " Ireh, 200 drat de Koning; zys biroe"der, overleden zoule $2 y n$, nicufler 3) พan 'e R,k en de Kroon te maken, w dat buiten rwytel Opta Pineratjay, " lich mu al zoo werre in de Regeeringe " ingelaten hebbende, hor oog nede op " geworpen hadde, allocwel by een "wyh te vooret, op atunginge des 'Konjugs, of hy na des zells dood de "Kroon wel zonde willen ansarardeth, 3. fich hadde weren te vecinten daar toe " geen de minfte genegentheir te heb$w$ ben; "t geen hy attans, het werk ge9* noegfan mectler welende, anders \% deed bylien; want by liet deswonds " op der 9 July beide de Broedes' des 3. Konings waten, en ewen buiten de " ftad Livo in een Pagond, mer randel. w houte flokken doud flian ; watar wan s de Koning kennifis gekregen hebluen, de, werd er gefegt, dat hy dast over is zeer bedroefe is geweelt, cin quan lyy " cindelyk uwee dagen dagi ma, op den p II Jujy an ste Wacerfucht te overly"den, hebbende of Sinm Koniagryle " mee groote glorie 31 jaren, 8 matar , den, en 1.4 dagen gerepeerd, geen "andere Kinderen mitande als een ee"n nige Dochter, oud ongersar 20 jua3. ren, dic lyy weinig uuren froot zyn 37 dool her kylig- fwatd onergegeven ") hadde, wo welkeneinde, of net hoe1, dinigen meeninge, heefe de Schryver " defes nooir veclic hooren verkinten ; , manr is het what, dat, lchoondedood ") des Kosings nu genoegfrum rugtbaa", , en san een iedor bekent gewarden was,

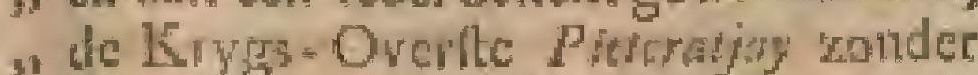
2) enige de minfte beweeginge in de "Regeeringe blet tot den I Augutty, ", als wannecr by rue cen ongemeene 3) Groote prage con ftatic, modewoerendo " Piet Lylk van den overleden Koning ") uit Lipo in Judia guam, lig nog ten y 20l- 
จ $A \mathrm{~N} \quad \mathrm{~S}$ i $\mathrm{A} \quad \mathrm{M}, \quad 85$

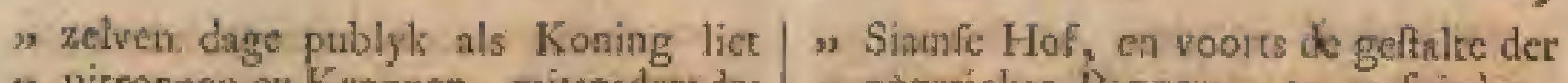

2) uitroepen en Kroonen, nitsgaders des

* overleden Konings eenige Dochted

s ten Wyve nami-y hebbende voor zyn

3. vartrek uit Liwo het onde Paleis atan

3. de Taltatus, en de ftad met al hat

3. buifen atin de Inwoonders gefchon-

"ken, en wyders atle de andienelyle

क. Timmeragien, Schoolen cn andere,

3) voorheen door den grooten Stants-

" Minilter Foulons, zoo door de Fran*

23. Felue Paters, als hen zells in de fte-

" den Livo en Juâil gebow wt, ann wer-

"Feheide Mandaryns, en tot wooningen

" ans particuliere Chincelen ingerume;

2. megecrende vorders zonder eenige de

" minfle tegeniftrevinge wan iemand, tot

" verwonderinge van veden, mee zuJk

, een gefag, en zoo volitrelk, als de Mo-

3 Harcher in 't Noonder deel Fan Indiën

3. gewoon zyn, even of ty at van aver-

3. Invo op den Troon gezeren was ge-

3. weeft, "t welk zmm rigen hecf doen

" Gelooven, dat de voornannite Grop-

3. ren, en dic wan de gemeente, frch te

" cerder toE $2 y$ m gehoor ambeic hebben

3) getedikt en gevlyt, on dat hy fich

* voerheen alsyd met zyn artpt en rtat

" te sreden hield, de kleinen en gerin-

" gen nodit hate cu laltig viel; "t over-

"2 matig inwocten wan rollen en fohatein-

"gen, door den overleden Koning, in

4. de laathe jaaren zyouer Hecrfchappye,

3. butitch gewoonte gedian, met onge-

2. nocgen anoug, de bedryven wan zy

s grooten Stants-Minifter, Confanisw

"Fanlcon, op het ernitiglte halede, ca

3. daarentegen de Talapoys, of 3iam-

- Ie Geeftelyher, vierig beminde, en

"roegedant was, hebbende tot bewys

3) van zyn goede meeninge, ook met den

, astwang wan zyn Regectinge, noch

"zelfs by her leven win den ouden Ko-

3 ning, ahedenicuwe folantingen, door

"Raadgevinge wan Fulen ingevoert,

$s$ afgelchafe, en nderthand daar en bo-

"wen ata alle zyre Onderdamen over

" her Sintile Ryts, een nigemecne tol-

s, vryheit, vool den tyd wa 3 achrer een

, volgendejau en gegeron, op dar her at

\#, me volk, tie door defwavelchatengen

"op her groot en hein Vee, alderlin-

" de Vifeh, Boom-en Aurd-wruchten,

". gehcel alls uigengergele waren, hun

", aden xis halen, ch weder zot eenige

, verquikkinge kamen zoude.

2. Ondew wylen dar de zanken in dit

" Koningryl dusdanigen koer had-

3. Uen genomen, en het werle omtrent

, de brantichen uen merendeele ita zoo-

, dangeton fliat was gebleven, als wy

"hier voor hebben gelegt, hadden twee

,Portugete Mixilen lich doorden Ge-

- g neranl, Monfieur des Fingues, laten

s gebruiken, on het gedoente van 't
3 apgeficlice Paggers, te verfieden,

, en hern dar van dan rappore te bren"i gen; docb zy wierder, albioewel op al de Siamfe wyle gekleed, hatt "ont"s delit, en gewangen genomen, "t welk 3) de nicuwe Koning zoo euvel nam, ;s dat hy alle de Portugecen, zonder " anfien van perfoonen, het dragen "van geureer liet verbieden, en wier" 3 den benewers dien alle de kinderen, w door die wan hunne Natie, by Pegure " of Siamie Vrouwen geceelt, opgevar, 32 en ten Hove gebracht, walr over een "jammerlyts geluil en wee-klagen alom " op de lyuten wierd gehoord, zonder y da "er eenige de geringtte hoope fohyne is te wewsh, dat ze lume lainderen ooit 3 neer zullen fien; want fiet Noder" lands Opporhoofil op bun crbarmalyk " gerchrei, en veclyuldig amnhouden, " lich ress J-Jove begcuen hebbende, on , te vortoeken, dat zyn Majefteic de 2. Goedheir doch wilde habber, on an " de troofelooke en bedrukte Vaders en " Moeders hanre Kinders weder te ge"ven, wierden alle de Kinderen, door "Chiflen Vaders verwelt, wel doot s den Koning ant hem gefehomben, mark 3) wierd ' $\mathrm{cr}$, toen het op een wederge"ven aа quan, mar eon gevonden, " zynde het Dogrertje van lier geweze" ne Engels Opperhoof, Mr. Hrbin, " "t gecm tor hum byfonder geluk door a des Konings Nederlandelien Chirur

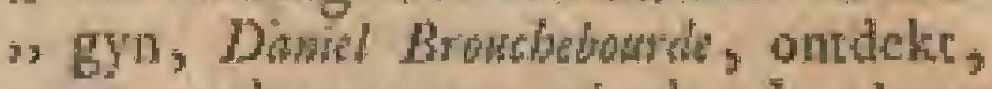
"y en medegenomen wierd. In dozer. 3) voegen thalken ook de onfchuldigen s, over de quade lutndelinge der Fran"fen in fware ongelegentheden, "t welk "dae volk fig zoo weinig bekrcunde, " dar het by veclen qualyk geloofd zoum " de kannen werden, en kan her volis gende ftaltic genoeglarm dienen, om sh te bewylen, Gat ze fig nier hebben , ont fien outrent alle Natien, zoo Eu" ropinnter als anderen, alles te onder" vernen, wat zemilardogten hen voor1. declig ic zyn, zonter cens age te llam is ap de verbonden en wrendichappen, , chor hun Koning met de Koniggen " en hooge mageen wta de welven op" gerige en gemalk, whe wierd het "Scheepje van den Engelfen Koopman, ") Mr. Teyler, voor Twnalfery, met Rylt „) beladen, gereed leggende, ow nat

3) Cormandel revertrekken, op zekeren , nige, door hen owroorfiens overval" len cn afgeloopen, zulx de cigenar. 2, des morgens zyn Jagcje met de lieele " ladinge quyc was, maar de Siammers "hadden de verdere Franfchen, die van ") het deftein wilter, en an land geblen ven wares, of her gefelfchap niet rus n. genoeg konden volgen, ten meeren= $L_{3}$

decle 
3 decle dood gethgen, en de reft ge"nomen, en kreeg nu de Tranlche Gene"rital, MonGeur der Forgure, eindelyk

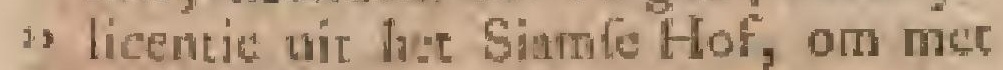
". at "zyn volk uít "c thy'k te mogen veT" rrektecn, wonder gediouden te zynecrlt th to moercts boten formen, en lig wein gens huir gedoente fe verintwaorden, "vits zy alfan de Sehepen, die hen 2. yoos heen ter leenangeboden waten, 3. als made de voorrat, zelfs zouden " moezen koopen; en zonde wyders de ". Butchop wan Mctellopolis, Monticur "Luris, co hee Opperhoolider Jagie, "Nonlieur Veret, beide woor de ge3) Treawngheic op weldragentheic war

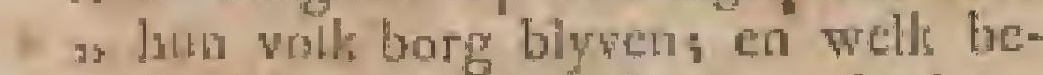

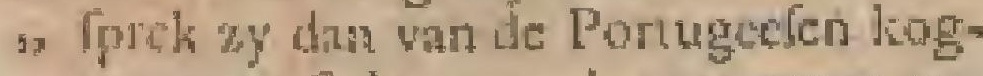
s, tern twee Schecpen, "t eene groot ons Bciant 100 latten, woor $6000 \mathrm{Ry}$. 1. Lialiters, "t andet groob ruim po hal. " ten, voor zoos Rysdahluers, zoo dat " Jin dele 3 bodentyes te manca qua* tren fe kollen ecn fomma wan a opoo n Ryedalders ; ch zouden ze bowen dien „n dain noch yoor de noodige provilicu y, ato de Sianmuses betrien, ech Comma y. vall 6000 Ryxdialders. Watr na zy 3. lich voorts and 't werk begaven, om " fich sot het vertrel te vervardigen; " dog onderwyien het Schip d'Orphe. ${ }_{3}$ lin, op den 9 September uit Vrank3, ryk, rer Reede van Sian gekanen "wefende, feheen hen de moet weder "zoo zecrangewanchente zyn, dile zy "andermaal hun gedane belotict, on क niess onbehoorlyke regen de Siammers \# te ondernemen, quamen te vergeter, s. Hatende op den 4 Oetober, door hunne 3. Panoen, dic noch boven gebleven wa" ren, en an huo bel jeven ap en af lion 3. den varen, de Huisvrouw en het "Zoonkje wan den geweten grooten

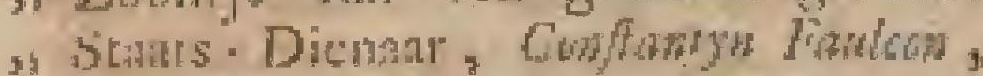

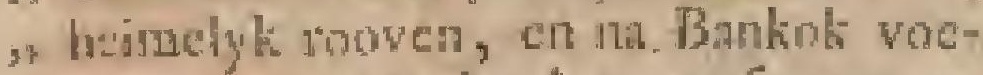
"ren, alwant ze by hen onffangen en "verborgen gehouten witerd, noe dar "es" ") de Konigg kennis vankieeg, of, zoo "zomtrige zegged, de Gencrial het zyn "Mojelteit uelts weren lice, diedit werts "700 quals kam, dar hy Monlieue des "Forgets lice dreigen, indien ly delo "Vrouw en ham Loontje, nict na bo. 3. ven liet brengen, dar *e vandange"roerd waten, dae hy, nog gecr yan ") alle te Frinfen, uic Sinm zonden wer"treklen, "t welk hera cirdelyk deed "befleniten, on de zelve niet han Zoont3, je, na dac ze tot den 19 Oetober by "; ben in "r Kafteel op Bankoli was grem "weel, zveder na boven tezenden, en "des Konings dienars over te geven, "werdende nu, zoo "er weth gecuige, 3. in 'c hof wry wat natuwer ats voorm 3) heen bewaatt, eq to leuken-werk,
3. ca andere fulle ch werachelyke dien"Tten, gebruitr b behalven dat ze door 3) hase viuge ool heef fromente neroorys $Z 1 \mathrm{ken}$, dat hata Moeder, Groor-moo" der, en verdere trienden, die vont"hoen, nevens hat, , wel gevangen; s. max nader has oncllagen waren, voor "de I weedemat uit Jun wooningenge"h halt, gevingen gencmisn, en is kew tenen gellotenzyn. En nadien de Fran" ken tot dus verre nee de. Stammers vIy "wat liegr gehandele hidden, feliyne ", bet, dhe $x e$, nu hun wertrek bugonte 1. naderen, bevreelt wierden, dia bet "1. hen wel vergotden moge werden, , watom $z y$ dan 2 of 3 siamfe Ofta,1 - giess citchuen, tegens de welken $z y$ "er " Loo veel in de plates zouden geven, "orn ze ra hiun sertrels op " $\mathrm{K}$ Kaltee! 3. Barkok eerft tegencien anteren rewer* wifflen, wameer ze tic de Rivicr ir y, ecn fuime Zoo, en benoeg antri buiten 3) de magt der Siammers gekomen zou"den wefer, 'L geen din zoodinig in" gelchike zynde, bralen ze den 7 de, $x$ Ler lopende manad November op, en , begrwen fich buiren de Riwier; wat ") de Bei Jiclang. ginfich geen mistrouwen " helbuende, elen Eranichen, bun Otta "Giers rosfond, zynde cen der Zoonen wan 3) den Generaal, Monfieur des Forgines, 3, en ecrn ander Ofteicr, in verwngtinn ge dar ze de Siatnle Oftagiers ook, "Volgens her belprek, na land zouden " laten keeren; 'I geen hem grheel quan " te ontelicten, want zy namen de zel" vell, genaamd Opra Nong fop Krotrs, " en Oloech Rad, metongevaar zoper". Fonten van bun gevolg, mede, en " licen eenlyk wan hun boord vertiek" ket her Varruig, Jaeu door den Ber") keflug voor 'c hath wol ververting "tocgelchike, na dat ze hec volk alstor "sen coemat raakr uitgrfclut, en dap" per afgerolt hadden, rukende op deze 3. Wye drie dagen na lice verhaten van "Baskok, met 4 Bodems, uie'c geltge , van de Sianc Rheede. Ook haddeo n. $2 y$ berorens, nedien ze war weinig * Matrooten voorlich waren, rulm 30 ., Eogratre Zcc-lieden, mee licentie van 9. den Sinnlen Koning by hen gekregen, , otl, zoo "er gezege werl, voor de , kolt ma Cormandel over te waren, zon, der vorder man hen vesbonden te we3. Ten, mar of de Fraten liur woord wel "zullen houden, van de Engelien mec" fler wefends, daar an zou men, yol3. gens hunde nianiervan doen, met reden "mogen cwyteleus te neer, om darze

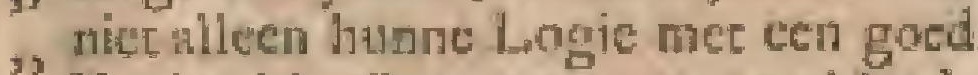
"Kapitanl in Contanten, pirtye bloed "Kornal, en nodere goedenen, mitsgi" ders cenige ftuklicr Kanon, tegens " bet befprele, mar zell's noch ruim 20 $n$ pert- 


\section{$\begin{array}{lllll} & A N & S & I & A\end{array}$}

3) perfonca, en datir onder eenige fie9. ken van hunne eigen Natie, acliterge") Iaten hebben, benevens hunenBifichop " van Metcllopolis, Monfieur Lori's, en „10 gentecose Parjen, die nu neeft al") te met ketenen aan handen en voeten , gevangen zitten, ct in groote ellen"2 de en benatheic zyn, werdende de 2. Biflchop, zoo als "er voorde waar heir ", werd getuigd, wel het natuw te be, wald, en 'e f́cherpfte geplangt, na "t "r rehynt, omuth hy, die nevens lien hei3) melyk vercrokken Opperhoofd, Mon3, hieur Fere, roor de weldragentheir , en rrouwe der Franien borg heefr ge3) ftanci, tot hun afficheiden uit Bukok , geduurig by hen gebleven is, en derbal") ven by vele noor den eeniglten tan3) voerder en geheimen randsman van den 3) gewafenc srats-Dienar, Confonty "Fatileas, ningefien, en alfoo voor den principadiften anfecter wan al hee quad , bedryt gehouden werd, watr mede wy , dic Verlant betluiren.

Uit het gene wy bevorens wan de Konipgen van Siam verhanld hebben, is ons wel gubleken, dn $\mathrm{Aleagar}$ (of Cbaratgem ) Koning van Pegu, Siana, ne-

whclan vens meer andere Rylken, weroverd, maar nies de wyfe, op welke by dat verigt heeft.

Na dat hy aan den Konifig van Siam te vergets om den witten Olifant ( van welke foort 'er nu 2 in Siam winen) wer. foge had, en die hem gewcigerd was, belegerde ly Judia $A^{\circ}$. 1568 met cen Leger van thienmal bonderd duifend man, twee honderd duilend Ruiters, (wclk cindelyk tot 1700000 man anngrociden) eerf rooo, en dur na 17000 Olifanten, en zooo Karicelen, en veroverde die ftad, en geheel Sian, na een beleg van 12 siatariden, niet als cendapper Held; matr eindelyls door vertand van ecn trouwloolen Sinmer, wan over de Koning van Sian zoo ontlet was, dat by fich zelwey aanitonds vergaf. Na dien tyd moett de Koning van Sian, ten tecken wan onderdautighsit ann defen Vorft, des zelfs rok op zyn Kroon tyd kuffen, en hem din ook een Kroousanbicderi,

De Simmer blecf echter niet lang dara na onder den Koning van Pegu: want na dar Alagar overleder, en zyn Zoon tot de Kroon geratike was, ontftond "er A' 1579 een Oorlog, tuftchen dien jongen Vorft en zyn Oons, den Koning van Ava, in weltke de lastle door de cerfe in een rwee-gevecht op hunne Olifanten averwonnen wierd.

Tot defer Oorlog nu had de Koning wan Pegu mede eenige hulp-trotpen van den Siammer verlogt, want of defe Koning zynen Zoon met eenig volk zond, die na zrn kom lit tot Pegu datr zect verachtelyk wn de Zoon des Koning van Pegu, terwyl hy zelfs reeds tha Awa gen trokken was, gehandeld wierd, welke finad defe Prins nier langer konnende verdrngen, keerde by ftil met de zynen te rug.

De Koning, syn Vader, en de Grooren wan Siam dit fiende, en de redenvan dien werfta:n hebbende, waren hier over zecr rerilagen, en belkofinmetd, dat $z y$, na " $\mathrm{t}$ eindigen van den Oorlog des Konings van legu, met dien wan Ân, dien verbolgen Vorft ten ecrften weer met een fwat Leger op hun dak zouden krygen, om lich oyer den hoon, hem hier door sargedain, to wrocken, mant de Zoon, die meer moet had dan zyu $V a=$ der of alle de Grooten, verwierp dit alles, en moedigde hen hier tegen aan, en wierp in dit zelwe jar dic jok af, taftende den Koning van Pegu indie tuffchenryd, dat by met den Koning van Avanog Uorlogde, zoo gclukkig ana, dat hy meefter van Pegu, en wan zyn ganfeh R yk wierd, verlicfende de exne ftad woor en de andere na, zoodanig dat hy (gelyk wy onder de ltofte wan Pegu reeds getoond hebbein) "er gehecl uit rakte, hoewel de Koning van Siam $A^{\circ}$. If en 1590 ecrit rechi meefter van Pegu, Martayan, en meer andere Ryken, zodanig wierd, dar by 't ook behield, in welke tyd hier ook, nict verre pan Jodia, een ftryd tutehen een Pegu's cn een Siams Prins woojgevallen is, war in de Siammer de owerhnd had, ter gedagtenis wan welk gewal das ook een tchoone Pagode gebouwd is.

Het is egrer zeker, dat, boe zeer de Koning wan Pegu 'er toen onder geraakt is, men naderhind weer een byconder Koning, zoo van Pegu, als wan Av, gehad hecf, gelyli die cerfle ook $A^{*}$. $1634 \%$ at Gefand ann den Ufurpateur geronden heefe, om met den zelven een verbond te makten; dog hy eifchte ' $\mathrm{Ko}$ nings Dogter voor ayn Broeder ten $\mathrm{Hu}$ welyk, en begeerde, dat hy als Oftagier in Pegu woonen zoude, dat de Koning พan Sinm niet wilde doen.

Ook verfeheen een jagr of twee later een Gefant van dei Koning wan Ava, die de hulp van de Koning van Sinm tegen den Honfcha, of Koning van Pegu, doch op zeer Dechte gtonden werzogr; waar op hy afgewefen wierd.

Van $A^{\circ}$. 1608 heefe men hier een wettig en wakker Koning gehad, die de Siamle zaaken wonderlyk opvy felde.

Hy wierd Ragibapi genaand, regeerde 20 jaaren, en liet vecl Zoonen, en een Broeder na: roor zya dood vielen 
de Cambodiers $A^{\circ}$, 1622 af, die by wel vericheide malen getragt heeff, tot hunne worige gehoorhamlieir te brengen ; dog alle zyne ondernemingen waten te vergeefs.

Na dac nu defe Koning in 't beft van z.yn lewen geftorven was, lict hy, behalven 5 Loonen, ook en Broeder na, dic volgens de oudte wetten erfgemam van de Kroon was; dog de Koning had by zyn witerfte wil zyn oudten Zoon, cen Prins yan 18 jararen (Cehoon dit met de wetren der Silmmers (treed) tot-zyn verwatger verkland, in welk recht hy ook door weel duilenden Siam= mers, en door 6000 Japroders, onder- fteund wicrd.

's Konings Broeder, niet weinig hicr over gerank, wierd daar op Prielter, 't welk de jonge Koning zeer qualyk opnom, en war over hy hem niet alleen wit 't Anad bande, matr', on zyn Kroon zeker ie hebben, ook te gelyk beforgdo dar hy by zyn weretele van kant geholpen wierd, nevens atle zoodanigu Grooten, op welke by fich niet al te vequ vertrouwên kan.

Onder anderen was hern ook zyn $\mathrm{Va}$ ders Ont zeer in den weg, dien hy in een zeer donker hol, mer cen weinig Ryft, water, en liche, met een wacht 'er by, gevangen zette; in hope dat die het dat niet lang maken zous matr de Pricters, medelyden mer dien ouder Prins hebbende, grocven uit zekeredar na bygelegerie Tempels een gat onder de aarde rot in zyn gevankenis, brachten "er een lyk in, en reddeden hem dus uit dit hol, en roo behondig, dat men in ' $t$ eerft niet beter" wift, of die Prins was warlyk in zyne gevankenis overleden, gelyk dit den Konug ook zoo geboodichape wicrd.

Kort dart ha ontdekre mencgter, dat hy nog leefde, en dat hy, liltig onkomen zynde, te Piperi wis, darid ich verfeheide Grooten by hem werwoegd, en fich voor lien werklaard hadden, gelyk by fich dhat ook voor Koning uitroepen, en kroonen liet.

Hy brache ook een Leger van 20000 man re veld, om den jongen Koning nan te taften doch de zelve rrok hem mee 30000 man en 800 Japanders tegen, llocg hom decrlyk; kreeg hem ook gevangen, en lier hem met Sandelhoure flokken (een ecre, die niemand, dan de Princen van den bloede, gebeuren mag) doodflann.

$\mathrm{Na}_{\text {a }}$ 'c owerwinnco van zyoen Oom, begaf fich defe Vorft tot een zeer welJultig leven, liet alles op $7 y^{\circ}$ gunfteling, en bevorderant, Oya Swarwan (dicn hy nu cot Calahan, of General der Olifarsen verheven had) than, die woor alles in 'c Ryk ook zeer goede zorge droeg.
Naderhand wierd de Koning, door ${ }^{*} \mathrm{c}$ anditoken von zyn Moeder, zoo foornig op defen Mandaryn, dar ly latt gaf om bem te dooden.

Dit gefchiedde eclicer zoo Ril niet, of Oya fuarowas kreeg 'er de lucht af, wan op hy fich manfonds tegen den Koning opwierp, cn hem, door nulp wan eenige Japanfiche Soldaater, in zyn Paleisoverwiel, en hem, zoo nis hy op zyn Olifane over de Rivier vluchte, gevangen kreeg, cn op de zelve plants, dalar hy zyn Oom had haten dooden, en op de zelve wyfe, dede ombrengen, zonder hem te verbranden, welt lot ook $z y n$ Moeder, en vecte anderen, trof.

Hy verhief, mee goedvinden der andete Grooten, "s Konings broeder, die die hem in jarren volgde, hoewd by "er" noch maar 22 bereike, in zym plats, dog alfoo by noch te jong was, wiend de Calahan dool de Grooten des Rylss voorfiter van "s Konings Rata, en tor Oppermachrig R phsbeltiender in "s Konings taam germatk, , dat lyeenigen tyd zeer wel witmrntm; matr op dic Oppergezig nu vry verlekleed, en nier genegen die miche, dis hem zoowonder wel anftond, aas den Vortk na zekere bepaalde jaren weer ower tegeven, beltelde hy den zelven in een Klooter, om lich dane in de Werten en Wysheit der Siammers re oeffenen: en ad dat hy 'c ftuk nu, too door de Japanders, als by de meefte Grooten, meefter geworden wists, dede hy lich ecrft tot Koning wan Sinn $A^{\circ}, 162$ (hoewel anderen $A_{0} .1630$ ftellen) verhefficn, en den Koning, en atle, die wan 'e mannelyk oir wan $\mathbb{K}$ oninglyken bloed waren, dooden, latende mar 2 a 3 perloonen, die van zynen whhang warefi, over, en trouwde des Konirgs Zutter, war na hy defe Kroon zeer geruft beleren hect.

Hy nam $A^{\circ}$. $163^{2}$ de Koning $y$ ken Ligoor en Lycoon in, en ftelde in yder Rylkecn onder-Koning, om dar in zyn uam te beltieren.

Nier lang hier na was "cr ecn onderKoning wan Ligoor, die na "s Konings fin te Oppermelutig regetde, zoo dac lyy voor hem wat bekomnerd begon te werden.

Hy was in th eerlt mar Landroogd hier geweeli; mar de Koning had hem onder-Koning, en die Tirel hen 200 opgeblafen gemank, dar by den Konitig byna nier meer liennen wilde.

De Koning had hem dit egree met die hope gemalkt, dat hy nubuigfamet werden zou, en dagt hern zpo mee een zoes lyntje alan "r Hof tekrygen, en hem dun te doen wan kmat helpen.

Defe nituwe onder. Koning nat die ampt, dar heor z:ce wal geleck, met 


\section{$\nabla \wedge \overline{\mathrm{N}} \mathrm{S}$}

dankbaarheit an, dog zei Hale tit tegens 's Konings Gelant, watsueer by hem ten Howe roepen quam, dac by niet genegen was darl te verfchynet, on even als zyn voorzant van dien Tirandood geAlagen te werden.

Naderhand ontbood hem de Koning weer dool ecn Gelane, man hy gafder zelwen geen antwoord, en lict hem jade keten llant, wiar op de Koning, hem door cen groor getal welgewapende Vartuigen, en weel Krygs-wolk, nantaften dede.

De onder-Koning wan Ligoor ondertuffchen ftont op de belofic, hen door dic pan Tartaftery en Patari gedian, meinde dat hy met zyn Moflel- Vloot wel in faat welen zou, wan die Vaa". tuigen des Konings af te weren; man zya Bondgenooten, bang geworden, lieten hem in de pekel, en zyn Vlootje wiend deerlyk dool 's Konings volk ge. Aagen.

Datar op triden zy te land, belegerden Ligon wel ecn jant lang, en beletteden den onder-Koning daar in zyn Paleis,
I A M.

alwat hy geen vitkonft nee eiendc, fich met al zyn Wywen in cen kamer, watr in zeer veel liruit was, opnoor, dac tiy, zoo als "er de Vyand meende ifl te berlten, zelfs in brind ftak, wair door $z y$ tllen in de luche opplogen.

Men wond dans echter noch, na lang zoeken, 12 Martavanen met filwere $\mathrm{Tj}$ cals, en a dito met goude dito inderade begrivert.

Hy heefe naderland tot $A$ : $1677 \mathrm{ge}$ regeerd, en is toen geruft overledu', gevolgd wan zyn Brocder, en zyn Zoon Priefter geworden.

Wat mosite die valn onfe Mantfhep= py den 7 Augufti 1637 onder defen Vortt. gehad hebben, kan men in 't Dag- regiiter van Japan onder dat jaar fier

Tuftichendelen Vorft, wn den Koning, die $A^{\circ}$. 1688 den 1 J july, na cen Regecring

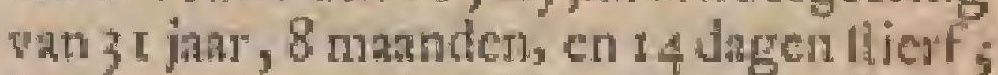
is geen auder op den Throon geweet, cn de zelve is door Opra Piereraing (gelyk wy gelien hebben) gevolgd, in wiens plans al vout cenige jaaren weer een ander gevolgd is.

\section{Z A A K E N}

VA N
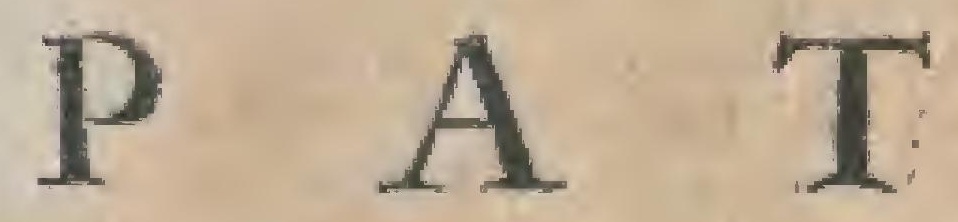

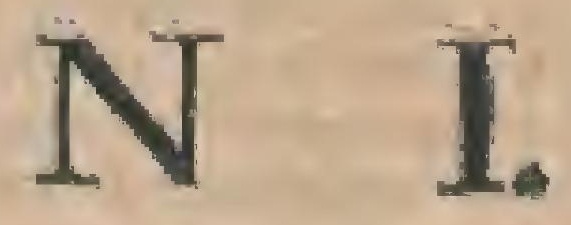

Edelheden, en eerige Schepen tot on $\mathrm{x}^{-1}$ derftand verfogt, waar op die hem zes Schepen, onder der Commandeur Khas Brugh, toefonden; doch alloo 't Leger van den Stamien Veldheer te voren (nucinende dat hy Patani al in had) opgebroken was, quamen zy te has, ende Siammers wierden door dic van Barmi decfJyli op de vluche geilagen.

Na dae nu de Siamfe Leget-hoofden humnen misilag gemerkt hadden, zochtch zy ons, en onfe Vloor, nls te Jat gekomen zynde, de fchuld wan defe nederlag te geven, 't geen wan den al te liclit geloowigen Koning zeer qualylk genomen, ent waar over ons yolk in Sintr nict weinig door hem geplaagd, en als in hunne Logie gevangen gehouden is, toe dat hy lecnniskretg, dat wy op onten behoorlylen tyd mee onle Schepen verecheenen, malar dat zyne vollesen te Frocg apgebroken, van ilen yyand geflagen, en wy toen tice in flait waren, ont hem met onle Schepen dienfit tedoen.

Hy fiet daar over nok ennige defer Hodiden opeenban itrafter, lien's hoofd afflan, dat op een ftakl zetten, en bet M 
Jatro, dey de anderen dric etmanhnoen 1or liun Arafic onder den blaewwen hemel dagr by blyeen, en rypelyk overwegen zouden, of hume medertefellen Jeclinweetig gelleraft wuren, Dus linen ry lwee elminal in grooten fmad, en werden toen wan verdere itraf door $O y a$ Pertodok, en Oya Syery werbeden, etr, Nh noch cenigen cyd gevangen geleten te hebben, onder cen wware bedreiging, zoo $x y$ weer iet diergelyles deden, ont11agen.

In opficic wh 'c zeoder van onle Schejen, roonde by fich daskban", in 200 verre, dat lyy de onfen ook wook ontrent ecn half jatr wan de gewoone gerectitgtheden", by hen woor deren alryd wol. dan, ontfloeg.

Ondertulfehen twas zyn poornemen, om dic พin Parani wweer met cen Leger $A_{0 .}$ I 636 an te talten; doch door het tuficherifureliea wan den Koning vatu Keth (of Queda) ea door de voorbede der Gecfelyken, wierd de tank! bygelegt, wart op de Koningin yan Patani noch dic zelve jas hare Gefinten nu Judin zond, en de goude en filvere bloem, nevens cenige zeldfaumheden wan Klecden, Fluweclen, Scharlakens, Ecc. nan den Koning, ten teeken wan have onderdanigheit, anbieden liet, dic by zyn Majelteir autgenomen, en wanr op toen de vrede volkomen getroffen wijerd, zonder iets verder vat het voorgevallene te reppen.

Dic Patani legt op $6 \mathrm{gtad}$ con $\mathrm{c} 56 \mathrm{mi}$ nucen benoorden den Evenaat, war bezuiden Ligoor, en tegen over Keda, of beooften die ftad, nan de binmen kane wan de Golf wan Sian, hocwel noch wel 5 daguteifen "er wan daan.

Men placlst dar in oude tyden een zeer groote voorltad, diezeer lang, doch nict breed was, te hebben, ook wis de ftad mede zeer lang, doch niet breed, aan de land-kane in een moeras, en ten deelen ook aan den oever der Zce gelegen, en, in cle plants van musuren, met Iwarewichathe balken amringd, die met groote krache in de ande gcheid, hocwel zy echer noch wel zoo hoog datr boven waren, dat zy roor hegte mutren, of woorecn tehoonen Pagger, konden verfteltaken, alfoo zy mee hate hoogte wel cot and de Mars vali cen Sclip reiken konder.

Oolk was ay in oude tyden ( 200 de onlen coen wilten te zeggen) oolent wry wel-wa Metal Gefchat voorfich, what otder ereen grooter was, nts de onlen oir te Forch gefien hadden.

Zy had een kleen Riviertie, dat heel fichece de ftad wegloopt.

Men becfe 'er meef houten bambocfe huilen, cea fetoon Palcis van de Ko. ningin, encen becrlylen Moorfen Termpel yan ftecn.

De terfte vath onte Natie, die hier ren lrandel gekamen is, was de Zee-voogd

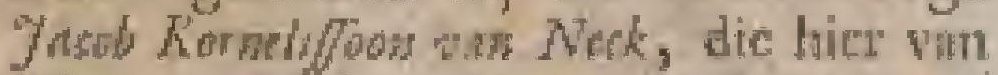
Wheno nes de Schepen Amtterdam en Gotuda, den 7 Nowember in i 60 retfeluest, on te fich, of hy hier zyn lading vas Peper, cnandere Waren, tot konmer vinden.

Hy quam 'er den 6 Deccmberana land, Fia dat hy de Bhar Peper wan 380 pond, tegen 30 Ryxdalders, cti s ten tronderd nan tol bedongen had, en wierd zeer fturelyk op ecen Olifune ingetiatid, m des Sjabibandars huis geloracir, dar vriendelyk ontangeu, en naderlaand wan ecn by tonder huis verlorged.

A. 1602 quamen liej by wen Necks Schepen noet z Zecurche den $26 \mathrm{Mcy}$.

Hy besond dit een grnoten zecr volkJyk land te zyn, watr wan men in de hter tyder ondeld liaeft, dat hat 180000 weerbire minnen opbrengen lon, wan welke 'cu in Patnti ower ac 10000 , ten decle Mooren of Maleyers, ten decle Sinmmers, en pen decle Chioeden, woonder, en werke lataten woornaticly lvier van dian grooten handel op Siam, Bordclong, Ligoor, Canbodia, Coersjientsjitin, l'ahmng, Macafsar, Greffic, Djambi, Djohor, Atsjicn, Bantam, Banjar Mafin, en Succadama, op Borneo, en op veel andere liuftendreven, alloo hier zeer vecl Ryft, Peper, Rotang, grotne Erten, Klappus-Olie, Buffels= Offer- Koejen-huiden, Botken, Martert, Konynen, Haten, Vogel-neftens, wilde Verlens, Ganfer, Endrogets, Hoenderen, Pacuwen, en allerlei Indifche vruciren overwloedig wallen.

De Koningis fchonk an vas Net, die er eenig wolf lier, cenverguldehris, en liy vertrok den 23 Auggutly.

Zedert defen tyd hebben wy hicr ean Comptoir opgerich, eth ect walt $O_{p-}$ perhoofd gelind, alwar th de gedagten wan zommigen Gowd Arms, stan Dowhl, als Opperkoopman, encerfe Hoofd van $A^{\circ}, 1602$ folyytre gelegen te bebben; dog ik oordecl, dat ons eerfte Hoold hier de Heer Dawil was dor Lek gewecte is, dien de Zee-woogd wa Mek hier voor zyn vertel: gelacen had, en dat Arus Inem venl later gevolgd is. IH tog hier tot $A^{\circ} .160$ en vertok toelz van liet na "t Vaderland.

$A^{*} \cdot 1$ Go quam onfe Zce roogd $W_{y}$ * howl wan Warwak den 30 Mcy ook hier, hocwel allect, om ma cen Chincelche Toll voor ons te fiens.

Gelyk wy nu hier 2 by fondere Comptoiren hadden, ecn Amiterdums, en'een Zecuws, ntfoo had ieder der zelwe zym by fondere Opperhoofden, war randan 


\section{$\checkmark \mathrm{A}$ S}

het dan licht ook wel kome, the Artas by zonmigen al van den beginne af ats Hootd wan her een, ea Dantal wa der Lek Hoofd wa het ander Comptair hier geweclt is.

Dus untmoet ith $A$, 1604 hierden Herr fond Rond/el, als Hoofd der Zecuwiche Matrchappy, en $A^{*}$. 1605 Ferdinand Midid/fon, als Opper koopman en Hootd der gemeene Martichappy.

Dat nograns de handel hier nice zeer veel was, fchynd ons $A * 1607$ zeer klan toe, wantier onfe Zee-voogd, de $\mathbf{H} \mathbf{r}$. Matrlief, on de geringe winften en grootc koften hier wallende, als mede on de geringe moxjelykheden, dic ons de Man= daryns hier aandeden, noodfakelyk oordeelde dir Comptoir op te breken, te micer, alloo bleck, dat de trouwloole Pataniers onfe Opperhootien, zoo wy de zeege regen de Portugeelen nier bevogeen hadden, atan hen zouden overgeleverd hebben.

Dat egter dic Comptoir later by ons
I A M.

aangehouden is, blykt, alfoo de $O_{p}$ perkoppman Fikor Spreskd $A^{\circ}: 1607$ in November, met een Inftructic var de Heer Marelief, op 't Schip Manditius, herwards gezeild is, die 'er van die tyd af als Hoofd rehyn gelegen te hebben, hoedanig by her nog $\mathrm{A}^{0} .1616 \mathrm{lag}, 200$ ons klasir uit de papieren der $\mathrm{E}$. Matatfchappy blylke.

In zyn plats fehyne de Heer Direcreur Henik Jangoon, die met de fwarte Leeliw A: 1618 vandar quam, en toen wan de Engelifehen (gelyk wy onder de zakken wan Batavia's Grondvefting agrgemerkt hebben) door krygs-lift genomen wierd, gekomen te zyo, $\operatorname{dog} A^{\circ}$. r623 gaven de Heren zeventienen lat, on, benevens vericheide andere Comptoiren, ook dit te lichten, zonder date ik verder iers wan die wan Patsui lefe, weshalwen ik raftelle, dat dit Comptoir niet lang na delen tyd opgebro: hen is.

\section{$V A \mathrm{~N} D \mathrm{DE}$

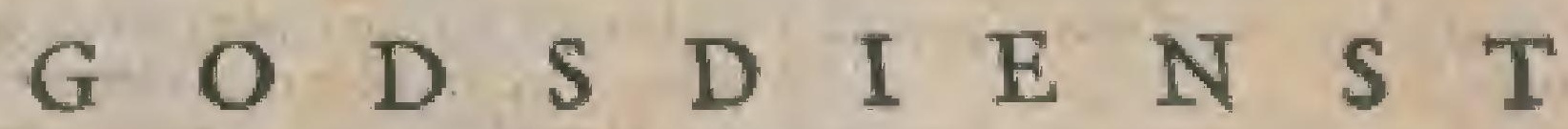 \\ D E R

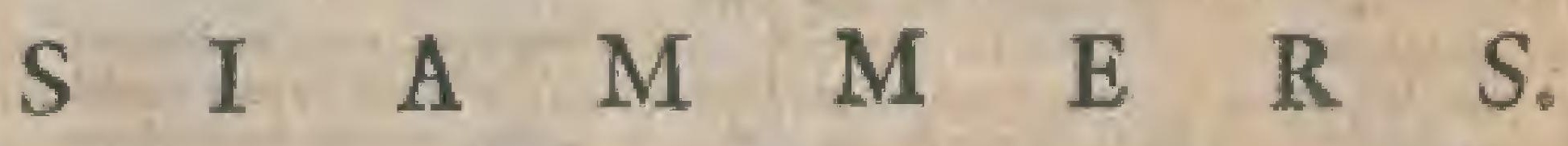 \\ DERDE HOOFDSTUK.}

Than den Godsdienft der Siammers. Derder beriblt van Sommona.Codom. Des zelfs Beeld. En de wh ayn twe Lerlingen. Zy Dood.

Wad den Gods: denflider SLITmerts

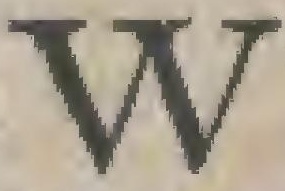
te den Godsdienft, die men hier in Siam otftind, of toe= lant, becrefr, datr zyn "el" drit, dog dari is mar cene Hoofd-Godsdiente, es weten, de Heidentclue, wanl in zy met die van de Kut, Bengale, en Ceylon in ved Hoofd-zalken oretecnkomen.

In "t algemeen gelooven zy ook de ver" huifing der Zielen, 't gecte de reden is, dat zy woo weinig Ofen, Koejen, en andere dicren, dagicn.

Schonnzy een Opperwefen, "t geen alles befticrd, crkennen, cooncen zy wat cen fegte bevatting $2 y$ 'ct af lobben, alfoo zy ook gelooven, dat hemel en tan" de van eeu wigheit is.

Ook bemocjen zy fich meinie met dat Opperwefen, en miten ongctyk meer werk van hunde mindere Goden, waat onder zy woorat hunnen ecriten Koning en Wergever, mitsgarders eenen SomonaCodom (die veclen poor een en den zelven inet Budbum, en Xass, bouden) ecren. Van defen laarlten yerhalen $2 y$ groote Wonderen,

Men hetef eenige mylen $W . N W$. wan Liso een Rots, wat in een menichentwoer, wel zesmanal zoo lang ex breed, ats oen gemeene, ingedruki is, welke de Siamssers Pra-bac noensen, welk eerite anthiddelyk, gelyk her laatfte een roct in hutne $\mathrm{H}$, enal, of die der Geleerden, beteckend,

Defen voet bidden $7 y$ ook warryls aari, gelyk de Koning yain Siam mede ianilyx eens gaar doen mitt een grootece ftoet, en met ved uiterlyte Kerk-ge$M_{\text {z }}$

bitsto 
bectden. Hy is met cen goutc plat owertrokken, en in een byfondere $\mathrm{Kn}$ pel opgefloten, en werd nier, dam by zulice plegrelyle gevallen, vercoond.

Zy fyeven woof, dat de plants, dawr nu die Rots cu voce is, wheleer cen fwat gebergte geweet $2 y$, hee welk 700 als

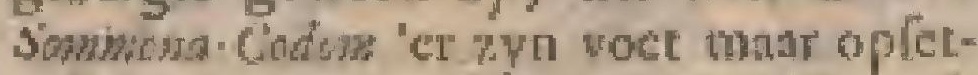
tede, anftonds effen en zoo whik, als men liat nu fiet, geworden, gelyk ook het afdrokich van zyn woel 'er zedere in gebleven is.

Men swil, dir defe Sommona - Codom

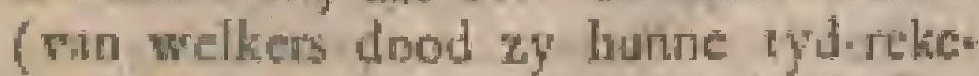
uing beginnen) een san hurne ecthe Komingen, of de Loon wan hunnen eerften Krning graweeft, endat by nat syndood, en mo zecr veel onwentelirgen en veranderingen van zyne grdintute, in een God veranderd zy. Zy zeegen dat defc voetitip van hen zect gerallig, door cen wan hunnc Talapoins (die er moge: Jyk ook wel de maker wan was) onedek $2 y$, horwel anderen net vecl grond mei nen, dita hy niet boven de 100 jauren oud, en dat bet mateen na-geapte woet is van Adams voet rop Ccylon, die men roor vecl Ecuwer daar plige te ecren, en sparfchynclyk alleen cen yond der Portugeelen is.

Nu voegen de Siammers, om "twonder nog grooter te maken, hier by, dat die voct op Adams berg zyn linker voct, en dit defe, dien by op hun Pra-batzette, zyn regtcr soet geweeft is, zonder dete het lien eenigfins angerymd voorWont, drit 'er de hecle Golf van Bengale, en 't gelacel Koningryk wan Maravan tuttichen beiden komb

Duar zyn-er, die meinen, dat zy

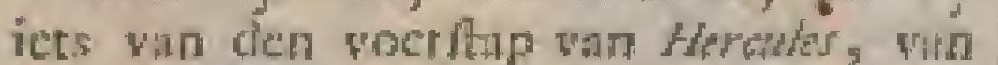
welken Herodost in zyn IV. Boek, en LXXXII. Hoofdltuk tpreck, en oole anderen, die oordeeten, dir eenige wan hunne Prielters, mogelyk wal het verdige werhalal wan defe en gene Roonsgefunden, wegens de nagelatene en ingedruke roctitappen ran Chriftus op den Olyl-berg gehtrord, en necde ier diergelyks verionueu hebben, wan san wy niec ackers bepalen; hoewel dat lante zeer warthynelyk is; dog roegen hier allect matar by, dat zy deien SummontCotlom, crideicu zynen woet itap, harr, ch rand (die zy nog zeggen te bebber, en we like lan ite al mede wartichynelykees pldrulich en na-aysog van defen Coylonfen wermasten Aapeu-tand is\} een groote ja Goddely ke ecre bewylon, gelyk zy dar buicen dien an eer grone getal van andere a figoden doen, weller beelden $z y$ van etr mbnttrenic groore, an stev ther's verguld, in groor getwl, in laune Pagoden en Tempels plarien,

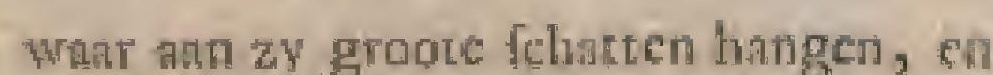
die door hume ongemente groote, en menigte een ongeloufly ke fomme gouds doen weg linciten.

Dete Belden of Afgoden (die men even ecus mede op Ceylon hecf, en aantbid) betoeken $2 y$ op zeliere vaftgeltelde tyden, eerende die dan met gelangen, ofertanden, morgen en avond-Gobeden, onder cen damp van Wierook, Toorien, Flambauwen, en Keerien, valliteliende, dat die mindere Goderi alleen op han doen en hicen lerten, en dat $2 y$ alleen in ftat $2 y n$, om ben good of quad te does, alfoo dac Opper-wefen lig met hen tiket bemoeid, en allede zorge dast of ann dic mindcre Goden antbevolen hecti.

Defe Tenpels en Goden beloelit de Koning op wekere tyden met een groote menigte van roci-Varcuigen, on dan of de plegrelylefte wyle nan zyne Goden re offerert.

Zy luebber ook drie manden in ' $\mathrm{c}$ jarr, in weike zy op verleheide cyden vaitem, gelyl zy mede hume vathellelde Feeitem hebien.

Zy bidden en offeren ook woor de Zielen der verttorwenen, even gelyk de Chinefen, en geloover wath dat 'er nies cen Hemel, maar verfchejden zyn, tot belooninge der vroomen, gelyle zy ook cen plants tot ftraffe der quaden tielIen.

De Tempelen, war in hunne Godsdienft werrich werd, $z y^{\prime \prime}$ ' ganich Ryk door oneindig, en zeer koftelyk vercicrd met alles, wat de zelve, en hunne Beelden, luifter en beerlykheic toebrengen kin.

Tot her wartmemen wan hunnen Goulsdient hebben zy cen groot getal Pricflers, zoo gemeene, als opper-Pricters, die door han rooden onder- en bovenrok, en hun kleed mer een geel kruis "er over henen, en famtyds ook wel door een gelieel geel kleed, ondericheiden, en zeer kennelyk zyn; dog hunne groot fle Pricfters dragen nog een robeden lap over hun reger folsotuder.

Zy heven hecl fteng, voor' al is hunne Vaften, wwantieer zy marr cons datags eeten, noit 'e lhoofd dekken, niemand grocten, en dus 120 pegels nacukewrig onderhouden, gelyk zy oole mer geen Vrowwen eenigen omgang lycbber, en welfs ook niet zitten mogen, daat een Vrouw gefecen heef, hoebanig zy ools gen geld, Reuk-werhen, nog fpechuigen, mogen belsurdelen.

De zakes, hupnen Godsdicndt betreffende, zyn bok is een bylondere tanl, de $H$. of de Balifclie genaand, befchreven, en allecen den Priefteris bekend; 
$\begin{array}{llllll}V A N & S & I & A & M\end{array}$

93

log zy verviten niets wefentlyfer, ca zya vol bewylen van ham onnoaselheir, bygeloove, en duifinderlei dwasheden, ontrene welke zy eger dir dom wolk zoer liche ween gerult te ftellen, alfoo men hen nergens in tegsufpreken mug-

Mee alle de Indianen hebben zy dit ook gemen, da zy therk voor de "Thovery $\mathrm{z} \mathrm{yn}$, geloovende, dat ook de geeflen der overledenea hier en diar warein, en hen werfohynen, om hen defe en gene verborgenc zaken bekend te molk"n, en gelyk zy zeer nicusgierig $z y$, om het tockomende te weten, alloo zyn "er oole veelen onder hen, die voorgeven, on dit door $z_{t}$ kere middelen te komen weten, $c \pi$ 'c vermagen te hebben, on zulke gedten, als zy mar willen, te doen werichynen.

Buiten dien gebruilien zy nog eenige andere middelen, on agler verburg he zalken in 'E gericline te rakker, wasucer hen de vereifche bewyten onthreken, dat by hen op de wyle wal een eed gebeuilk w .rd

Dit doen zy by een Tempel, en in " $\mathrm{T}$ bywelen wan hunne Gueftelylien, die na hen door gebeden cerft tegen alle toovery en betweeringen verterkt, en dar regen bovryd, hen ontkleed, con tuet zaviver linnen bejkled te hebben, hen van 'c hoofd tot de voeten met $\mathrm{H}$ twater waltchen, al mede om alle quatid, date hen wan buizen zou konnen andoen, te weeren, cn Jant ua noeten $z y$, dielw:ren zullen, de proeve tuittán, het $z y$ mact onder whter te duiken, 't zy mee de Janden in dets heeten Olie re doopen, 't zy met bloots vocts over "t vaur te Fath, of 't $z y$ on den befworen klomp Kyit door te flikken.

Het duiken onder water gefchied tulfehen beide de paryen, Jangs rwee ituk ken, die mee her ende in de grond ituan, en die win hen "t langfte onder water blywen dan, zegepraild by den Rechter.

De handen der genen, die fig in den heeten Olie doopen, werden eerflt met limen owwoeld, en 'er dan ingedoope; homes 'er die dun onbefecrd uit, zoo is don cet goed.

Dic door "twutr gastr, mocten dat $v y f-$ mal anneen mee thingame tredien doen, zonder bunne woeten, zal den eed goed 2yn, cenigfins tc befeeren,

Maar cen wan bic fwarlte ceden onder hen, is den befworen klomp Ryft zuiver door te fwelgen, hec welk, zoodac behooryly gefchied, zoo werd die gene, die fig dus by eed gezuiverd heeft, van den Rechier wy gukend, en de fehuldige, trolgens ss lands wetten, naar mate van do mustad, lwate of liche gettafi, en in cen geld-boere, of tot de gevankenis, den keten, ntrper-ontheming, of weltet dere of gene avyle wan cen wreede dood gedoernd.

Zy Atellen wathdat de Goden van hen willin gediend zym, en dat zy, 'r quade harende, de deugd behooren ie berragech; mar zy oordeclen ouk, dat men dini toe nicr wel, dan ma verfeheide Ziels.verbnilingen in volmanker lichtmen, gernaken kan.

Hua porideel over de zonde ftemt juit met met dat พan andere volkeren over een, maar zy mocren fich, volgens de Jefien var hume Tapoins, voornameatlyk andere di geboden binden.

1. In God mer de allerdieptle tede. righeit atn te bid len.

2. Geen driatl, die ientands herffenen bedwelnen, of tronken makenkan, te drinken.

3. Nier ac liegen, of iemand door w:arder of Jaaden te misqleider.

4 Gst m mentieh, of dier, te dooden.

5. Nięt te fleceleti.

6. Geen vuligheit ter wereld te bedryen.

7. De gefétte Vaften- en Feeft-dagen te onderhouden"

8 Op de zelwen niet te werken.

Ook is ben "t $z$ ondigen tegen hume: Geftelyken, her berooven wan hunie Pigooden, en "E rehenden wan hume Afgoden Beelden op de iwiarte itraffen werbonden.

Eer wy nu egter gehecl en al van den Heidenfeben Godsdiente der Stammers aficheiden, moecen wy nog ectrige zar* ken hicr byroegen, die tot den zelviń, en voor al tot het nader en grondig kenneri van huñen sommona Codgh, wutr van wy pag. pi fipre.ken, behooren.

De ervaren Heer dirabam Regeriles Verder zegr, dhat de Heidenen der kuft Chwo- bericht masdel, ontrent Palcucata woonende, wantons van oordeel zyn, dat hun Gad Brima Codor (zoo nen in hunne Heilig: Bocken geichreven vind) matr pas nus Summona - $C_{D-}$ dow gebneres $2 y$.

Lndaar zyn weer anderen, die lien voor ecis en den zelven mer sommons Codum houden. Eien getchil, danr niet wel tuit tce komen is, on alar hua ganfebe Grodsdienlt uit duiftere Thbelen son VeritgrfeJen te zamengelapt, zoso dat "er bynabegin nog cinde ann exe pusden is.

De Siammers weten ons eger verder whin delen Summona. Codsm re zeggen, JaE zyn Moeder yenmand wis Maba mart, dar zoo weel uls de grate Maria zisggen wil.

Anderen nogtans, dic grondige kennis

$M 3$

Yhn 
van de Siame tal hebbch, zeggen, dat

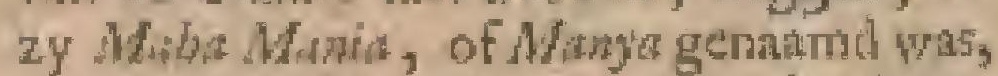
voor ralen gevende, on dat de Sinmmers in bunne tal ner gewoon syn de w en de r onder malkunderen te mengen, dan in " cende wan een woord of fyllabe, war op een meilehilnker rolgd.

Hier wit is weer oen ander Werdicht fel van de Siammers gefproten, van welke men $z e g h$, dac zy gelooven, dat $7 f$ for, de Zoon van Mark, de Broeder van Somnong-Codon, en dat by, gekruicigd zynde, ook geweent is die frhelimagtige Broteder, welke zy zcggen, dai Sommono. Collow gehnd, en diede anam van Tho. wetat gevoerd heete; wan wellezy fehryven, dat hy in de helle mee eet ftrafte, cenigfins na die wan "c kruis gelykende, gettrite $z$.

De Vajer van \$ommona-Codom wascen Koning war Teve Lanca, of war 't ver. mawd Coglon; zander ons noginns den nama wan thick konng, of den tyd san zyne geboorte, op te geven, van welken zy wel veele wonderlyle dingen wertellen, maar war by ons egter khar blyke, dae by van de meischen gefproten ty.

Ook blykt ons hier uit anitonds, waar het wan daan komt, dat de Godsdienft, cn de Goden of Beelden der Siammers, zon wel tuet die der Cingalcelen overcenkonen, vermits de Vader van deten Siamicn God ecn Cingaleess Koning geweelt js.

Om nu te toonen, hoe milddadig defe God geweet $x_{y}$, verhalen de Sianmers, dat by alle zyne goederen aan den armen uitdeelde, en dat hy, of dir nog niet ger noeg wis, fich zelven de oogen uitge ruki heefr, op dat hem die totgeenzonden zouden leonnen Ferleiden; maar zy vocgen "er nog iets by, dat by de meeften yoer geen werk vin verdiente, maar veel eer voor een verfocjelyk grouwelftuk, zal doorgann, te weten, dit hy $2 y-$ De Gemalin en. Kinderen doodgetlagen, cn die and a Priefters van zyn Eetrw tot loyle gegeven heefi, cen zak, darom te vreemder voorkomende, dewyl zy nicts too zeer verbieden, das eenig morkh, of dier, te dooden; ten wate men mut zomnigen wattlellen wilde, dar de man onder de Siammers Heer cr, meeller van zyn wrouw, kinderch, en laven is, da egrer tang zoo klat, als zommigen hig verbedden, niet beweten is.

Behalven delen Sominona Codom, per: wagen de Siammes nog een tweeden, wan ywelken zy mede nogeengrooten op. hef maken, als wan eenen, die groote wonderen onder hen ftond te doen, en dien zy Pra Narorre noemen. Zy gelo. ven dir te valter, Alewyl Sommon-Codow zelf dit hen woorlëgt heefic.
Ook weten $z y$ voor af al wan hem te verhalen, dat by twe wan zyoe kinderen dooden, en die al mede man de Taltpoins, of Sianie Priefters, te ecten gewen zal.

Zy lichryven hunnen Sommoma-Codom ools verder, ons zyne fterke te toonen, nier alleen de overwinning over Pra Soum, een zekeren God, dienanalle de volmask heden wan Sammona-Codom twytfelde, mar ook over werfcheiden andere vermogende Goden, toe.

Hy fon lig ook, zoo zy zeggen, zoo groot en too kleen miken, als hy wilde, behalven dat by nu en dan wel geheel verdwynen, en op dien relven ryd weer op " $\mathrm{E}$ hoofd wan eenig ander nentch lich zao licht vertoonen kon, dar die hema zyne zwante niet eens gewar wierd, hoewel andeven hem daar klaar on onderfeheidentyle kondes zien.

Zy getuigen wan hem, dac by alle zunken der werelu grondig kend, 200 de vertedene en tegenwoontige, als tockomende, en dat by in zyn leven niet anders gewoon was dagelyx te doen, dan te valten, te bidden, en anderen mec een zeer heilig leven woor te gaan.

Zyne Bceltenis vertoohen zy van Fer- Des zels guld koper, in hume Tempels, zitten- Betul de met de beenen kruifeling onder " $\mathrm{l}$ lyt, houdende de rechrer hand tegen zya rechter knic, ende linker tegen zyn butk en boven op zyn recher voek, 200 als die boven de linker heenen ichiet. Op zyn hoofd heeft hy cen zcer fracjemuts, die boven op een rond togrentje, een fpan hoog, en an wederzyden wan zyn ooren cwee lange nederhangende lapkens heeft.

Aan zyne rechter en linker hand, pas agrer hem, vercoonen $z y$ doorgatans mede twee wanzyne Leerlingen, omar luen= ne Becltenis, hotwel mede verguld (de ecne van koper, dog die ter linker hand wan fteen' is ongelyk klecner, als de zyne; ook ltat die ter linkethand in een fraci huisje, zoo konftig, cierlyk, en zoo net dar toe gemandst, dat het "et even in thuit.

De Lecrling, ann zyn rechterhand ge- Endje plate, werd van hen PJd Mogld, endie van zyma ter linkerhnd, Prat Saribout genaumd. Leerlite

Agrer deze drie Beclden planczen de gen. Siammers donrganas nog vertchejde andere, zynde nier anders dan Oflicierer, dic rot her Paleis wan Snmmona-Codom behooren, 't geen fich vertoond als een heerlyke Tempel, rondon welken een groot Kloofer loopt, "t welk mede vercict is met verfcheidene Beelden wan athdere Officiers en bedienden, welke buiten dat Paleis hun werk vinden; onder meer andere namen geven zy ook dien Fath 
$\nabla A N S$ I A M.

95

van Pre Pont Tyjoc, ala Smimora + Co dow.

Zyn Zy zeggen, dat fyy flierfan cen kolyk, dood. "E geen ly door 'e ecten van rpek kreeg; hoewel zy zeggen, date by door de Ziel van een Mon zelerverwatyle volk, met een breede tronic, zeer groore rander, mer langen, in de plaiss wan lairen, zan 't hoofd, en 't geen fig alscendoodvyand van Sommon-Codm, wan ouds her verklantd had) gedood zy, die fig onder de gednance vin een Verisen voor dien tyd verborgen had.

Zy ltellen ook, dat hy getondigd heet, co daar ower geftaft, hoewel ly daar na tot den itaa der getukzaligheit gekomen is.

Voor zyn overlyden had by hen eg. ter zeer endtig nabibvolen, om noor hem Tempels en Betden te bouwen. om hem ie ecren, en hoewel zy valtfitelen, dat hy tur hen nog goed, nog quad kandoen, richten ty echecr nog dagelyks hume gebeden tot hem, verfoekende van hemalles, it geen zy wan nooden hebben. Ja zy meinen, dat Sommond Codom alleen poor lien, en woor gecn andere volkeren, gegeven is, hocwcl dit ons hier en datar geheel anders blyken zal.

Hoewel fiet nu buiten kyf is, dat $z y$ en groote menjgte van Beelden, welke zy veel eare bewyen, opgericht habben, blyfe het egter nog zeer duifter, of $z y$ wel warlyk cenig God eeren en anbidden; en veclen zyn van oordeel, dat dit maar Beelden zyn ter cere van hunne Heten, gelyk men dit mede onder de Chinecfira lieefr, cu wel ex ook onder de Gricken en Romeinen zoo plag te gefchioden.

Wannect wy nu den Godsdiente der Choromandellers en Cingaleejen, mirsganders de Beelden, welke zy ter cere van bontie zoogenatude Goden oprich. ten, eens tcgen maltanderen vergelyken, zullen wy ons genoodfake vinden; na een netre opmerking ofer alles, te bekennen, dar zy in de meete gronden en zaken overenttemmen, en da $z y$ dierhalwen meell door cets en den zelven heilig relaynen op en ingetteld, en, by de verhuifing der volleren, maar var "c ecne na 't athere land verwoerd te zyn; wans ontrent ons de oude Heer was Goens in zeker beriche an har Hoog-Edellieden, 'e geen wy mder de ftoffevan Ceylon ontrene $\mathrm{A}^{\circ} \cdot 167 \mathrm{~s}$ tanhalen, groot lielic geven zal, wanecr zyn Ed, wan defe Cingalecfehe Afgoden fpreckende, zege dat zy thet de Beelden der Siammers yeet groote overecnkonft hebben,

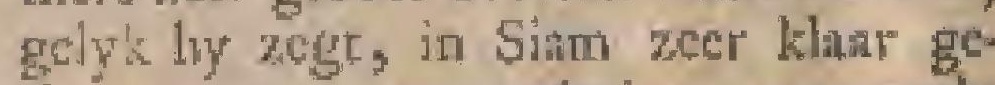
fien, cn met perwondering angemétht te hebber.
En dit is wel het voomannte, dat van den Hcidenfche Godsdiend? der Siam. mers (dic verder groote overeenkomit met den Godsdientt der Ginguleefer, en Kult-Heidenen heef, alfoo humegronden ten grooten decle etn en de zelwe zyii) se zeggen walt.

Wat nu de verdere Goulsdienlten, die men hier duld, en ocfend, bekngd.

Men hoef 'er, buirende Heideniche; nog deMohbntmedanvela, cn deRoomle.

Een groote merigtc van Maorer, Macaffaren, Malleyers, Javatnen, en andere Mohhamanedanche vollierea, hebben wyheid om humen Godsdient hies te oeffenen, gelyk zy ook hunne Pricfters hier in menigre hebben.

Daar beneven is "t gehecl Koningryl van Patani mecit Molyammedanas.

De Roomfche Godsdienft inu (gelyle wy reeds uit hee vorige gelien hebben is hier meet door de Franlele zendelingen, Jefuiten, en andere Prielters, nu zedert 70 of 80 jaren herwards ingevoerd, wat door (vooral tha dat de Koning, die $A^{4}$. 1688 overleden is, ben volkomen wryheir, on die alomme voort te planten, gegeven had) men't ganich Ryk door een groote menige van $200-$ genaande Chriftenen onder de Sinmmers gefien beeft, hoedanige "er ook nog wel in "t geheim hier en dat onder her zyon, dog bet is zeker, dat zy, na hec doodilan vanden Grick Fallow, en na 't verdryen wan alle deF rantehen, dienGodsutient weer neeft immers zoo gemakkelyl verkaren, als zy dien arngenomen hebben; tc meer, alfoo $z y$ noic wifte gronden gehnd hebbea; om den zelven met ernht te konmen aanlangen, en vermits $z y$ te klair befpeurden, met boe groote bitterheit de naeure Vart op de linalchen, en hanreen Godsdient, gebcten Was, war of if dan wattltelle, dat die mecelte naamChriftenen ten cerften weder afgevallen, eri wolifingen Heidenen gewarden 2yz.

Een zalk war over de ganlche wereld heefe verbanat geitan, hoo dit mee de gronden der Finulchic Paters lieeft konnen overeentiomen, dat zy ann Koning Lodew we de XIV. cerlt zoo hoog wn humer voortgang en de vooveletting butnes Geloots in Siam hebben opgegeven, dat zy geen twy ffel 'er in ftelden, of de Koning wan Sham zou zelf in 't kort Clariften werden, en dat ditc alles in zoo korten tyd in rook en wrind verdweenen is ; wan hoedanigen aard meef alle hune bekeeringen in indién, whar zy die ook ondernamen, geweef zyns een reer klati bewys, dat de groucien, want op xy gebouwd bebben, niet goed พwaten.

Wy 
Wy konden nog wel nndere zakken, ben anngehtald, als ondat ools weel andehier toe behoorende, hier byvoegen, ren daar meeft alles reeds owergefegt hiebdog laten dit na, zoo, om dat wy mons ben; weshalven wy de zalken van Siam, erite Deel, onder de ftoffe van de za.* | en ons Derde Deel, hier tuede zullen bekender Franichen daar reeds veel wan heb- Iluiren.

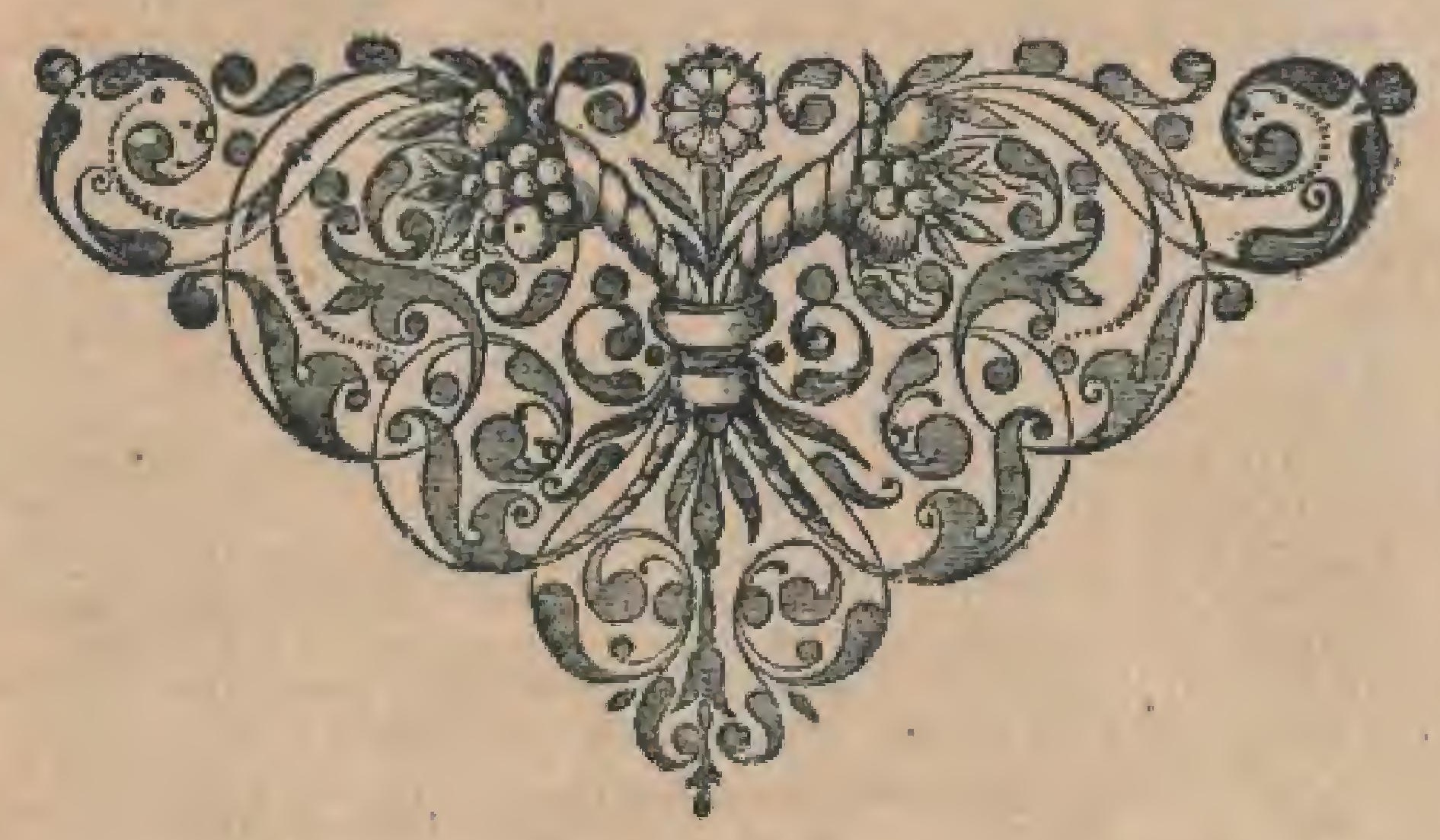

REGIS: 


\section{BLAD-WYZER}

Van het DerdeDeel, behelzende Amboina's Kerkelyke zaaken, Boomen, Planten \&e, Land-Dieren, Vogelen, Viffchen, Hoornen, Zee-gewafien, enz. gemerkt met de Leter a.

Als mede Banda, Solor, Timor, Macaffer, Borneo, en Bali, gemerkt met de Letrer b.

Mitsgaders Tonkin, Cambodia, en Sian, gemerkt met de Letter c.

A.

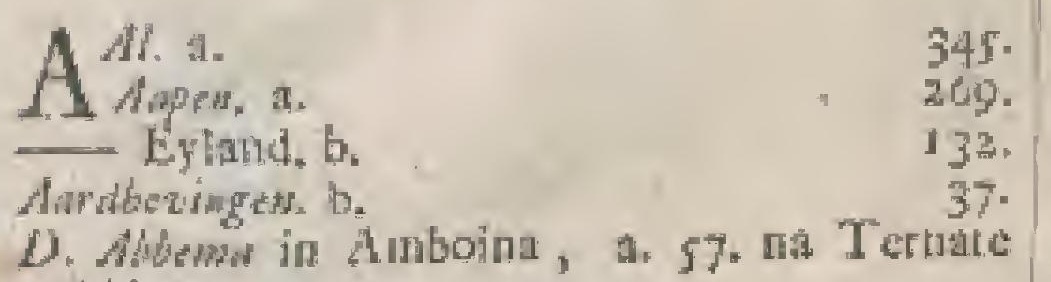

D. Alutema in Amboina, a. 57. na Tertuatc
ibid.

D. Ab. Engffo in Ambolat, en na Honimos, er $2 \%$ d diod.

d'Heer Acusty's Lewen.

A.E hillowar.

Aleware.

Adir-bifols.

d'Her Admiral bourd een Veltige in Banda. b. 9 . Zur Jeven.

D Ahodua in Anbing. a 6r na Termate 6 . Alake. 10 . Alus Chriften, a s.3. Agadery hicr ontdeth , ys. Alutudition 5 i

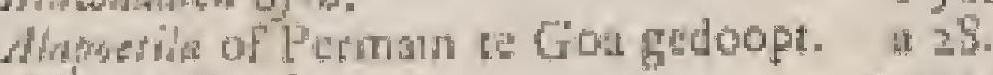
dikama-did.

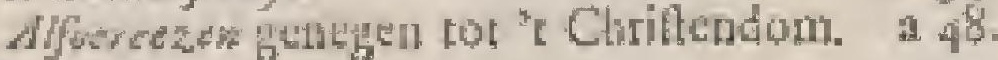

Alse.

Madien.

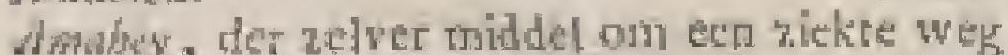
Le nemen 213 , werToge nut de a adre Dut= pen '1 Chrittudum. 54.55.

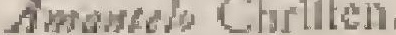

Amarafin.

diver's Mfynd.

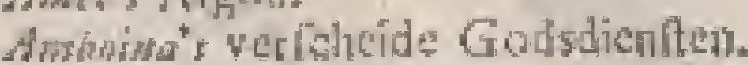

Gorga Ariss ju Parmi.

$c 9$

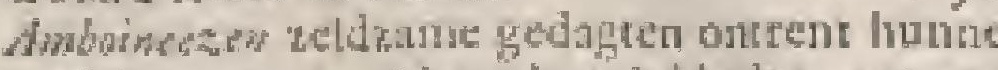
rickren. a 13. Hon plejtelykbeden ontrets

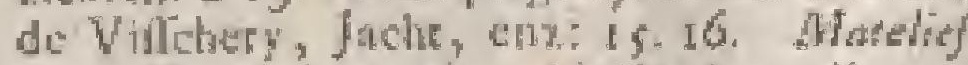

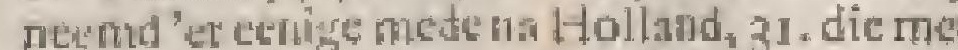

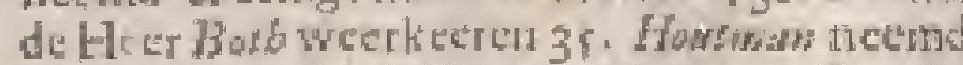
cr ceitige meds, ibiJ. en cenige met Gytels.

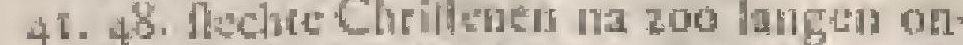

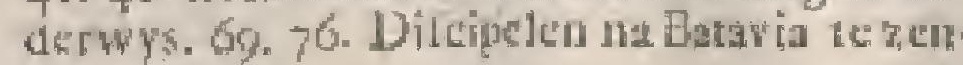
dun verlusder.

Angel-riang. $\quad$ a 290

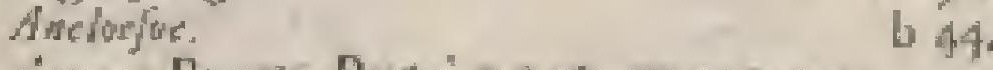

Nugrec Barma Poetri. in 259 , en zoorten.

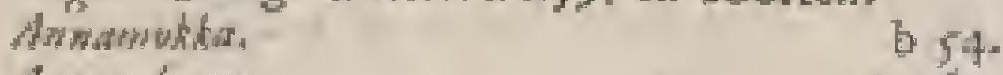

Anama-bovi: $\quad$ a 164

Awsilon. c 14

Aiguch.

Angery. ex

Anys-bosm. 194.

Ariat. $\quad$ n 181.132.

Arewd Zee-Mrend, enz: a 304.

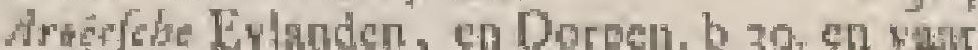

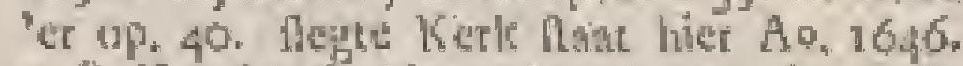

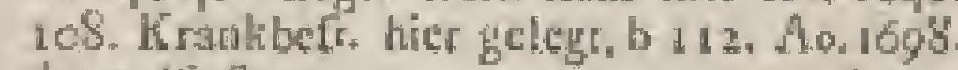
des. 2 altis far

Arue Balofoe varmourd. bl>z

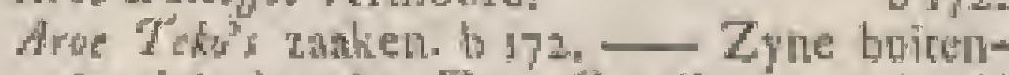
fparisheden 18. Zye Giveling. 194 bulyd

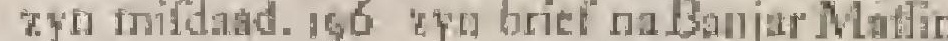
an de Engelded, 207. Spreck met 2 n Ed: de Hr: Becruith. Befolupldigd de Hr: van T bye en Arae Ponizonder bewy. Verzoth om Z hers:

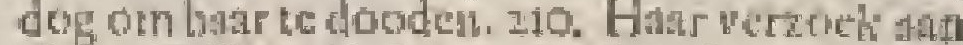

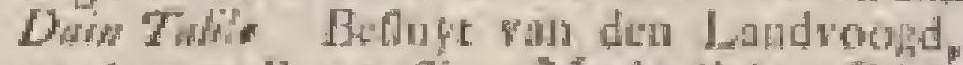

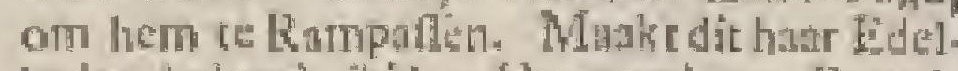
heden bakend. jbid. Hy werd Jak [3atavia gezordan. 2II. Zyne woorden over Arto

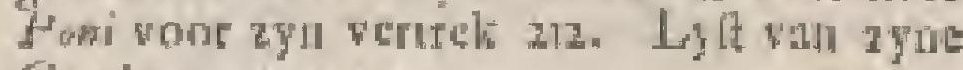
Goedsu. 212. 213.

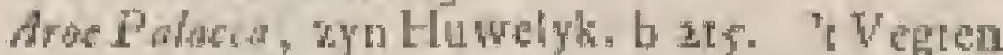

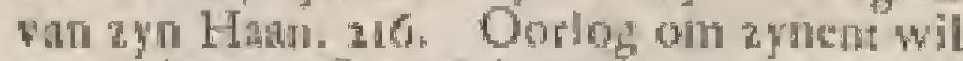
refren die van Goia ondernornen. 215223 . Zvie overate verzogt. 220. Hy komet OLS OVer 222 , en "[ vitde toen wooregra]len. $223.25 n$ verde zalien. 224.

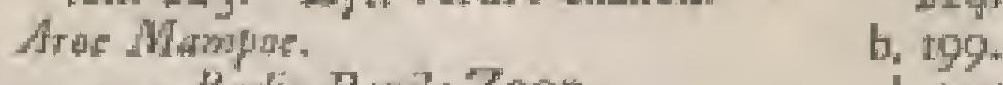

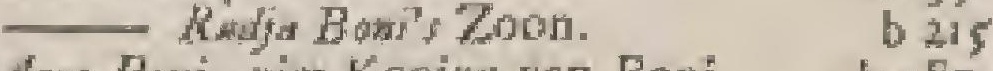
Are Pow, zun Koning Arocparbost. 231 Apopporwa. 4 . D. Appelderv in Amboind, cri gerchit met $W$. Nartuge. 56 . Apte', fr zoete Limoen-boomen.

Aflshasg. 299 .

Alap, $\quad 176.178 .181 .18$.

Arpupon. b $12 \mathrm{I}$

Ainobonom. a no.

Ath en Ifaldata onder Ternate, biy.

Anwr. bist.

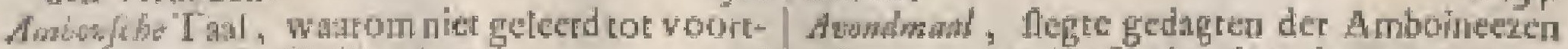

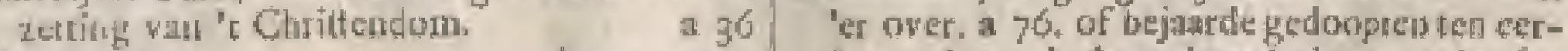

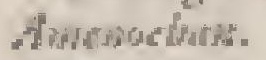

Amers.

Amparan. Nipe Ampardo.

Awordat.

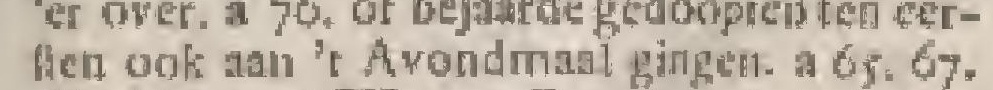

b 134. 69. Hoe veel Wyn eis Brood tot 'i bedicnen

at. 18

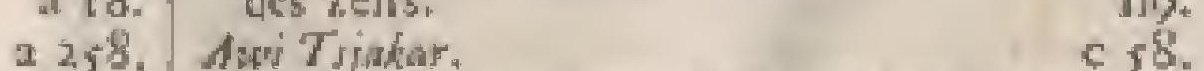

Amplerdim, by S. Panto.

Amandr-firwh.

Mireppits.

D. Amitric ma "

III. DEEL.

b $68.7 \mathrm{I}$.

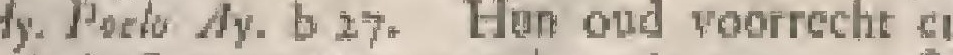

24 bedryf. 35 - gewonnen door de omze 8

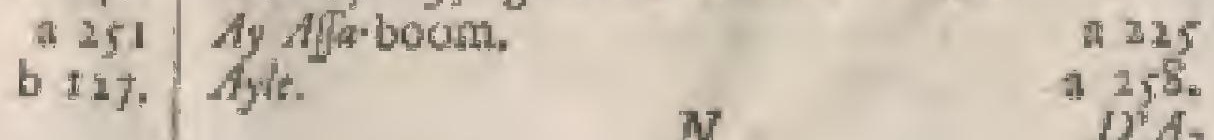

Ayt $\quad N \quad+\frac{25 .}{D^{i}}$ 


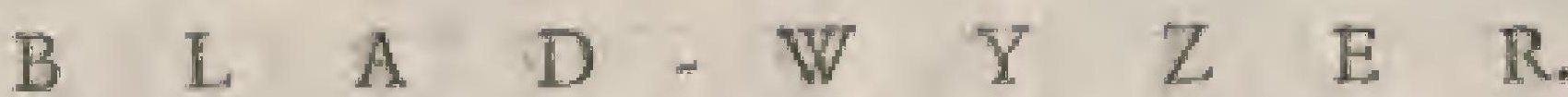

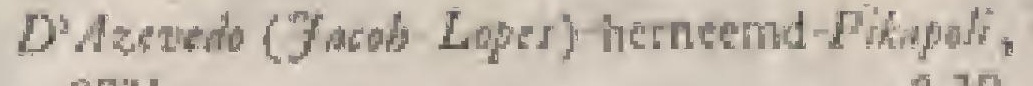
eni:

Didzeredo (Gonsalwe') in Bandi.

근. 20 .

$A z)^{\prime \prime s}$, vericheide coorten.

B.

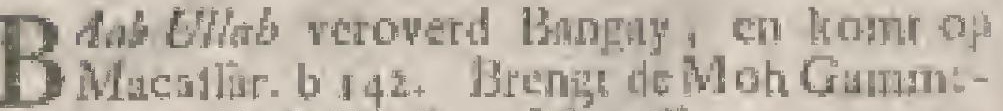
dante Godsdicrilt op Macaliar.

$B$ a arjonts.

Bablator Boggis.

Bobi Mandi,

Buli Ruera.

Babler.

Bubre fie Bab Uhab.

Beckr.

Buthior $B$ ofs.

Bardoe. Irolkten, ibit.

Badjotide.

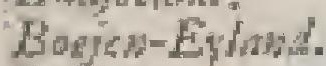

bisthle.

Bwilt,

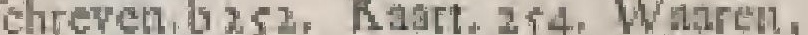
Wapenen, Speelinigen, z5. Lyken. Bellic ring. "s Koning handel ountent Troen. 256 ontrent Leydekter. Godsdienlt. 25\%. Bali-

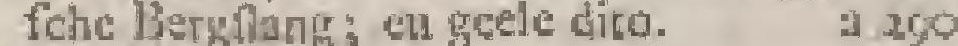

Bugromblit.

Bilarilan.

Balingent.

Bumbers- bow , en zootien.

b 121.123 b 39

1.123

Banda, en namen der Eylanden. b1. Zielbefehryving. 30. Onde zalien. 3t. Later zaghen, 73. Veroptra door de Heer Coche 8. Beftierd doot de Nederlauders, en we gaderingen hícr. 8f. Landroogd, en zyn inlionen.

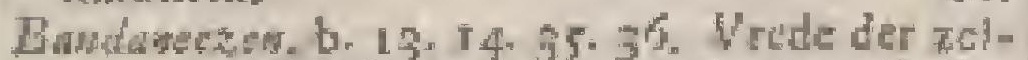
we mace de Nederlanders; Hum nieaw Verbond. 81. Weer gebrokici.

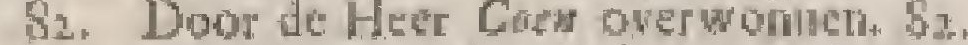
Fen nicuwe moord doer hej gepleegd. 84 Bandua.

Baprastefe Caftanie, a 260 , dito Vitch.

Benghodse brom.

Botgign Laki Laki.

Biarte.

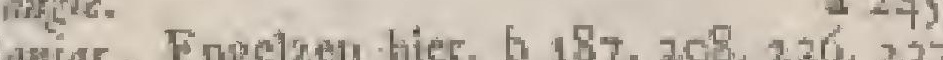
230. Gezateli up Bataria.

Barghos.

Barue Trjina.

Di harbema in Bathda.

Beflifichs vatu Celebes.

Batfack

D. Baflidass

Baffing na Batlda.

Duth Carimat.

Beseling

Bremela.

Bifiti.

Batoe Poesteh.

Bacee Holvanida.

Butor P'andjagrs.

Batoer?

Aluctars.

De Hear Beercumb Landroot van b $178, Z^{2}$ Ed: beliandeling van Aroe Tekos andi, enz: 470-214 Zyn Ed: Gerralit's riekte I87. 190. Dood. 190. IgI. Be* gravenis-lypt. 191. Tombe van loar Ld. 193 . Dain Mangali door $27 n$ Ed: als Spion van Stat petsuilei. 202. Zin Ed: verblyf cenire tyd in 't Kaftecl wan Gou atjekewd door Ean Edeheden. 204, Aros Tekos gefprelk

c 51 .

b I.07. 8. 79.

b 118.

bi21.

b.2I.

CI2.

b) 10 .

b. 6 .

b 65 - met zyn Edi, helthmldiga ile Hers sou Thye,

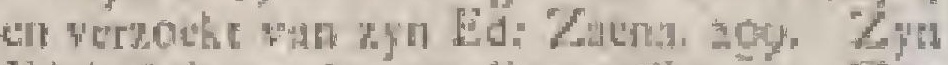

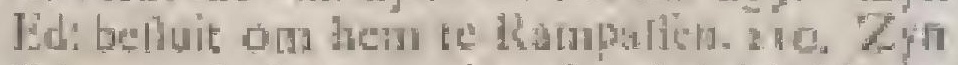
Ed: bordecl over de athatheirkteid der

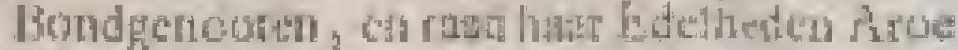

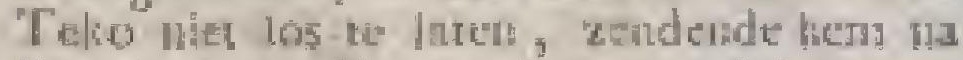
Batayia. zil. Zya verdicis ongelul: zars.

Mremoch.

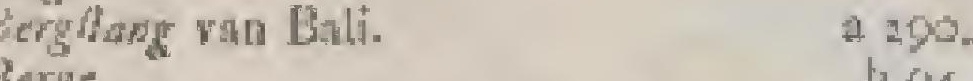

De re Bocken. a $6 \%, b .234$.

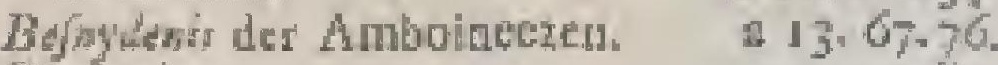

Preterting de

Bhation

Binfe.

Brataralsounts a ter.

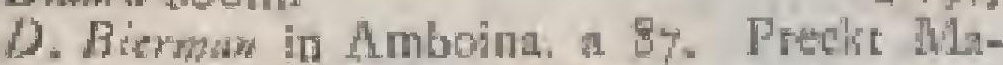

leys, gast na Banda, en ketheder-gr. Werd verloft. 94. b Iiz. Bilak-boom,

bisligation. G. 24 .

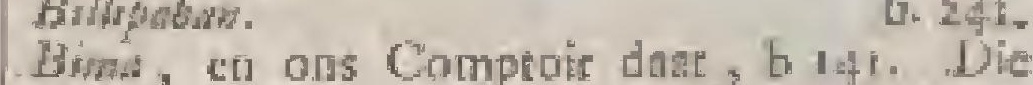
Koning berchuldigd. 227. One Hoolden dalar.

Bingharpag Brwater-Laot, of Zec-Bitsatgor-boom a

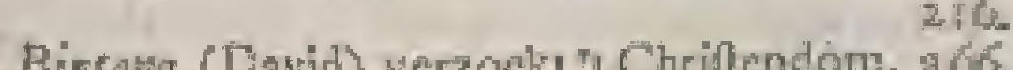

Biwioge. Birv Negri.

Bitsjnar-boom. at 234

Bha, Wandelend bad, a 206 Bhat, Capiteyn Blad. b 7 Capitern op Maciffir. $126.178+18 \mathrm{I}$

Blwhing-boom. $\quad 1160$

Binte liang. 28 .

Bhos's Koning.

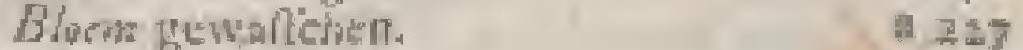

Blommors up Borneo, b 24 .

Bukn, GeYctil.

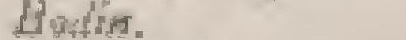

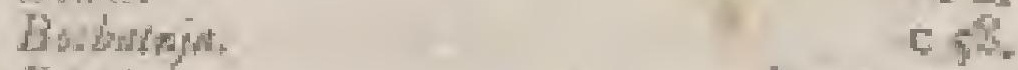

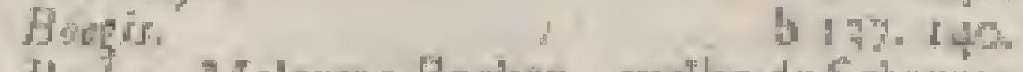

Hothew. Malevere Boshen, wellie de Sehrywe

ber.it.

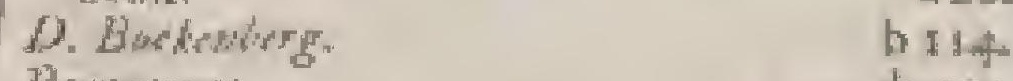

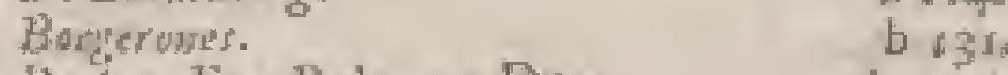

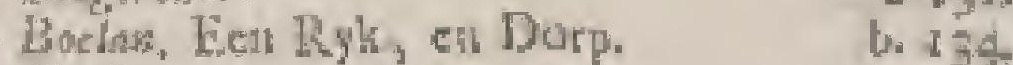

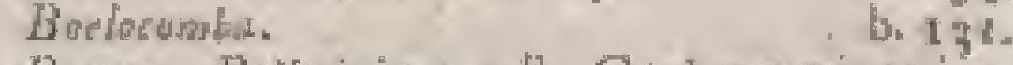

Bumga, Balitsjuja, a 128 , Goelong tsjomesjos.

32\%

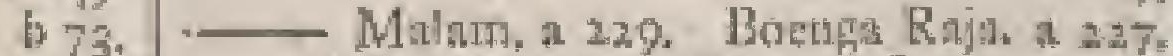

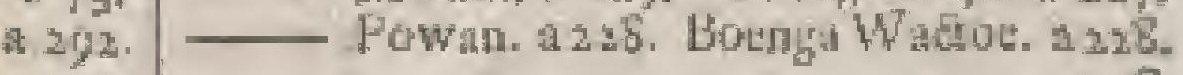

Borm

Delitiwa.

Butum. b y. J3i. Beoorlogd door Mincatint.

CMaldk tad-boon.

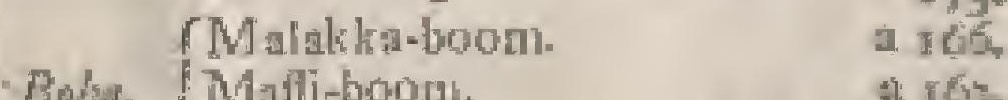

Siriti. a ijt.

Bajanu.

पHai-boom, 3 ack

Bomaxnas Ze-HJorentiens. a 549-510

Bondow. 


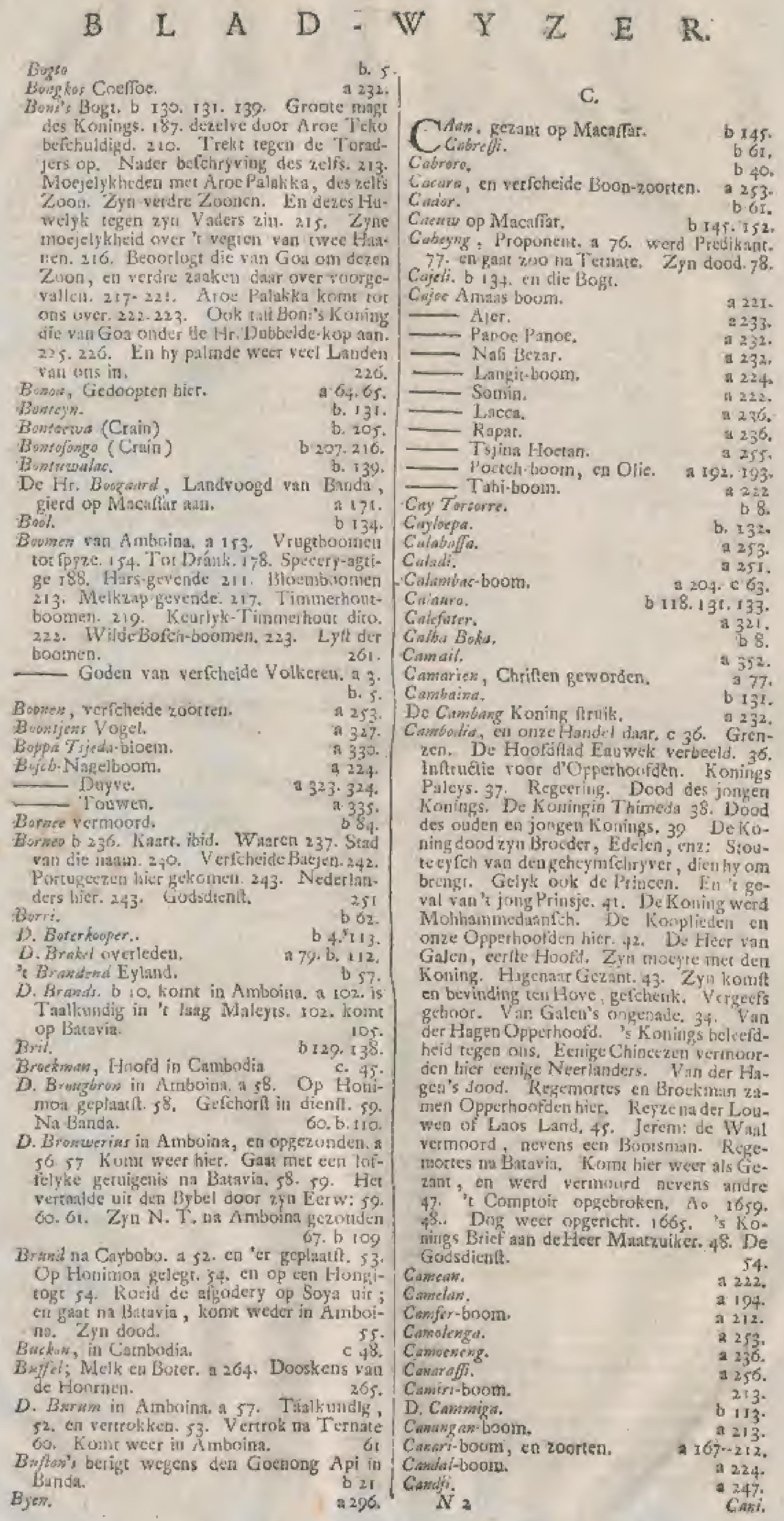




\section{B I A D - W Y Z E R.}

Cins:

Capei.

1). Cuppelle in Anomingt.

Caralimant

Caras b. 5 . Fylanden,

Carsoloryg-Niruth-

1758 . Cer.

a $10 S_{+}$Cusber.

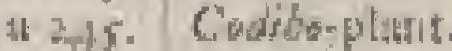

6.4. 66. Coedrame

il 234

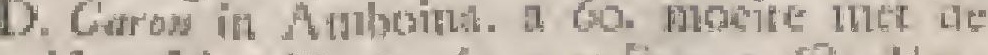

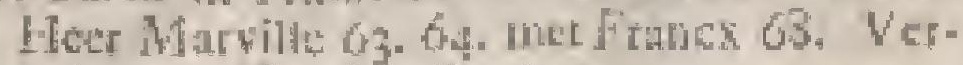

trek. 57. Z u l'redicatien.

De He Carfie.

77.

1): Couphas on Amboina in 78 . nu Dotavia. 78. b. ItI., Ha Timor. b 127 Cintud (Craing)

I): Culier.

Cuffombatlruyt.

Gedintaris thoum

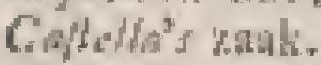

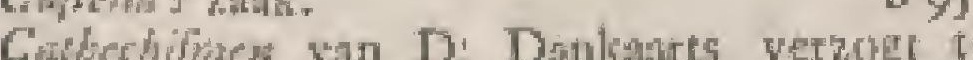
dituked.

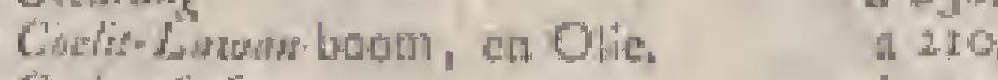

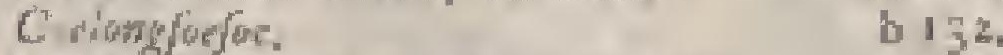

Goth verzoge Chillen ie werder. a fo.

C'uepang. bu 12

Corer, wase verwarela: bo

Corjest,

$\longrightarrow$ Voged. a 3ะ3.

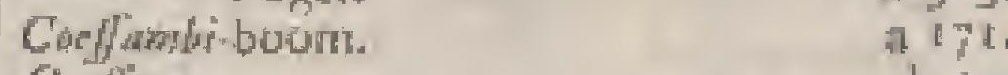

Coufferdey. b 37

D. Gucterier in Ambointan, zyn dood. a by

Cenet, b 2 i. 1 .

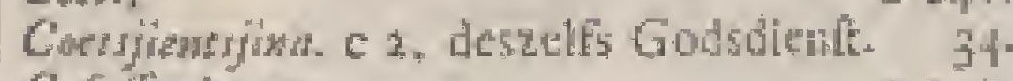

Cafellar-bnoms. 4220

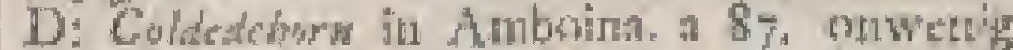

065.67.

๒. J.2.

op Orna gelegr. 89. Prediki hoog Malegrs.

Carjapisi-ilruyk, en bloctm.

Chitafo

1230.

b 38

Canger.

b. 38.39 .

Convolo wetrage Chrilten te werden. a $52-50$.

Caldang

b $\sqrt{34}$.

CelAtide.

Celudes. b 128. ten decten onder Ternate. 133 .

Cara.

Cersm, Lanoct.

bi it

Cirter

Cierenastien.

Croptat.

Clarmulent

Cbultelown hoogte.

Cbnecen Slakgen-dient.

Cbro.

b $37.6 \mathrm{r}$.

246.

$b+5$.

b 17.45 .

it 283

b g.

3287 .

Chervolud doos a te Hito

woor d'Anevedo gefed. a 28 . Vervolgad door

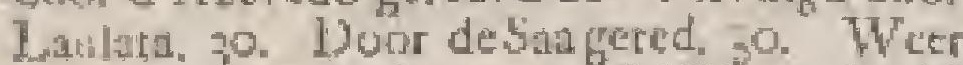

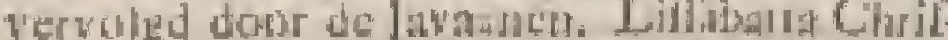
ten. 31. Ook Murarelo, 29. Noctlativel. 31. 33. d'Ambeninesen Kylt Chilhenct. 41 Vervigd duot Kimeland Loelioe. 48. Ja-

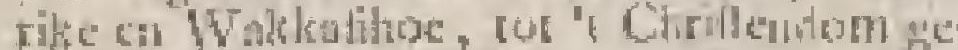

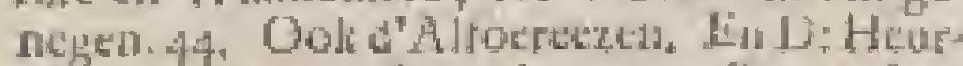

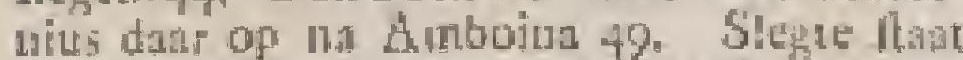
derkerie, re. Caybobo gentgein "er tae. Alang cn Lilibay wer Chrilen. 53 fin

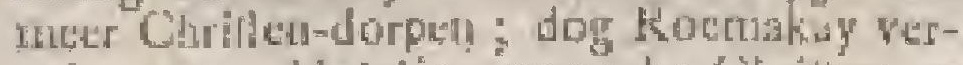

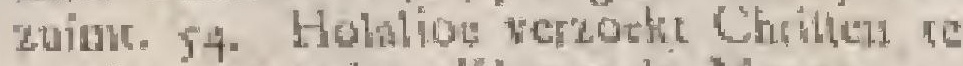
werden, cti andre. Kanten der Wooren. Alte Chrillen-durpen ons door Mandarsjah Eetchunken. In Nollot ver foteide Chrittem, 56. Roemalay en Costor verzocten 't Chriflendam, en mater abdre Dorpen, gt

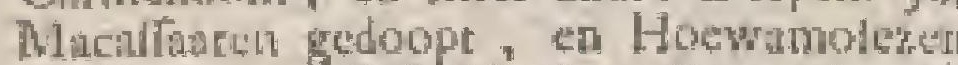
Chriften. 57. Ook Manipa, Banou 65. 66 .

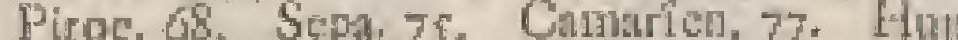
ltegte flant, Ao. 16S6, en klaguel, reden deir over, 80.81 .83 .83 .89$. T'iboulate

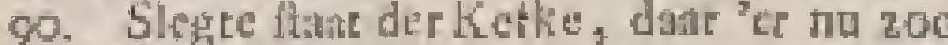

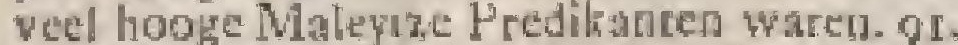
Klagten des Kierheraids over den flegren ftate der Kerke. 102. 105. Stast en Ledetraten der Nederdult cene gemeinte hie. 110 .

Chin.

Crtrow-boom.

Civet that.

D: Charenters

c 2.

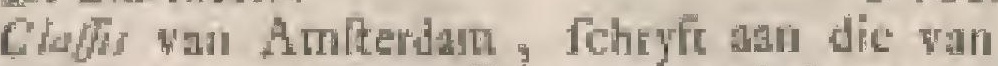
Aunoina. a 64. En antwontd hate 65 . Ourdeel derter Kerk uner "t vorderen pan Protponenter hier tot Predikanten, Perzogt door die wan Bupvia 6j. Arawoord oer Chaffis uver werfehtide vragen. $\quad 67.68$

Clungasaboom.

224 ty. Wut yerlolit.

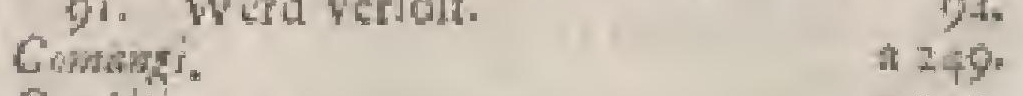

Combin. 1253

Crswher b 5.3 .

Commify is Politycq ingevoerd, in Ambuhna

— Rumplaius. Moet vall onze Godsdient cen Lidmat eyn; dog Storm, dit kim aynde, afiezct. 80,102

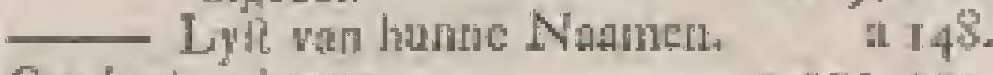
Condordong-boon. a 170.171 Comilyor - 246

Coud. Copo (doude IHeer) 's leven in Banda. bor.

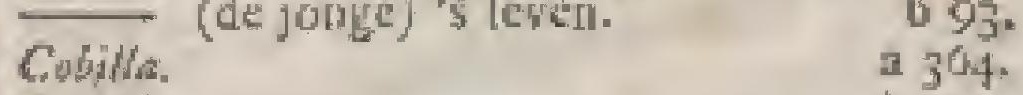
Corsini.

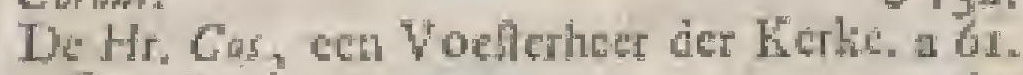
2 y

Cosjets

Chater, bist.

I'Hr. CGyrs's lewen. b5.

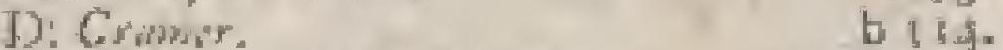

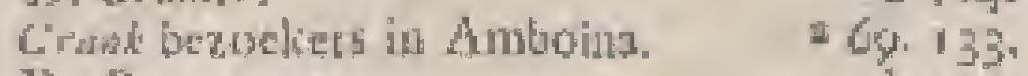

D: Gryeanger. b $23 \frac{3}{5}$.

Cracods.

Croters. b 110 .

Coublus. a 2,2 .

Dhon Bahroe. a 217 .

10 Potrit.

Jarada.

Sanght.

it 331 .

Tsjocinge. Rambot.

Kocrip.

Papedo.

Lilect.

Soedoe Soedoe,

Ginh Gambir.

Gindi.

Tesbeh.

Alfam Kitsjil.

Poepor.

Hati Hati

Sabran.

Btol.

Karam katand

Kuntoet.

Kapialoe.

Aflan Beras.

Cuecoer:in.

Girpo.

Piti Besal.

rat 232 .

\}

4) 233 -

(a) 234

a $2=5$

a. 242.

at $2+5$

a 1 into

0.250.

i

a $253 *$

$\int_{2} 25$

f

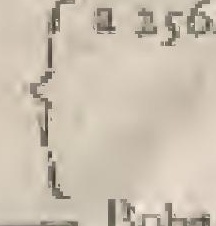

4 


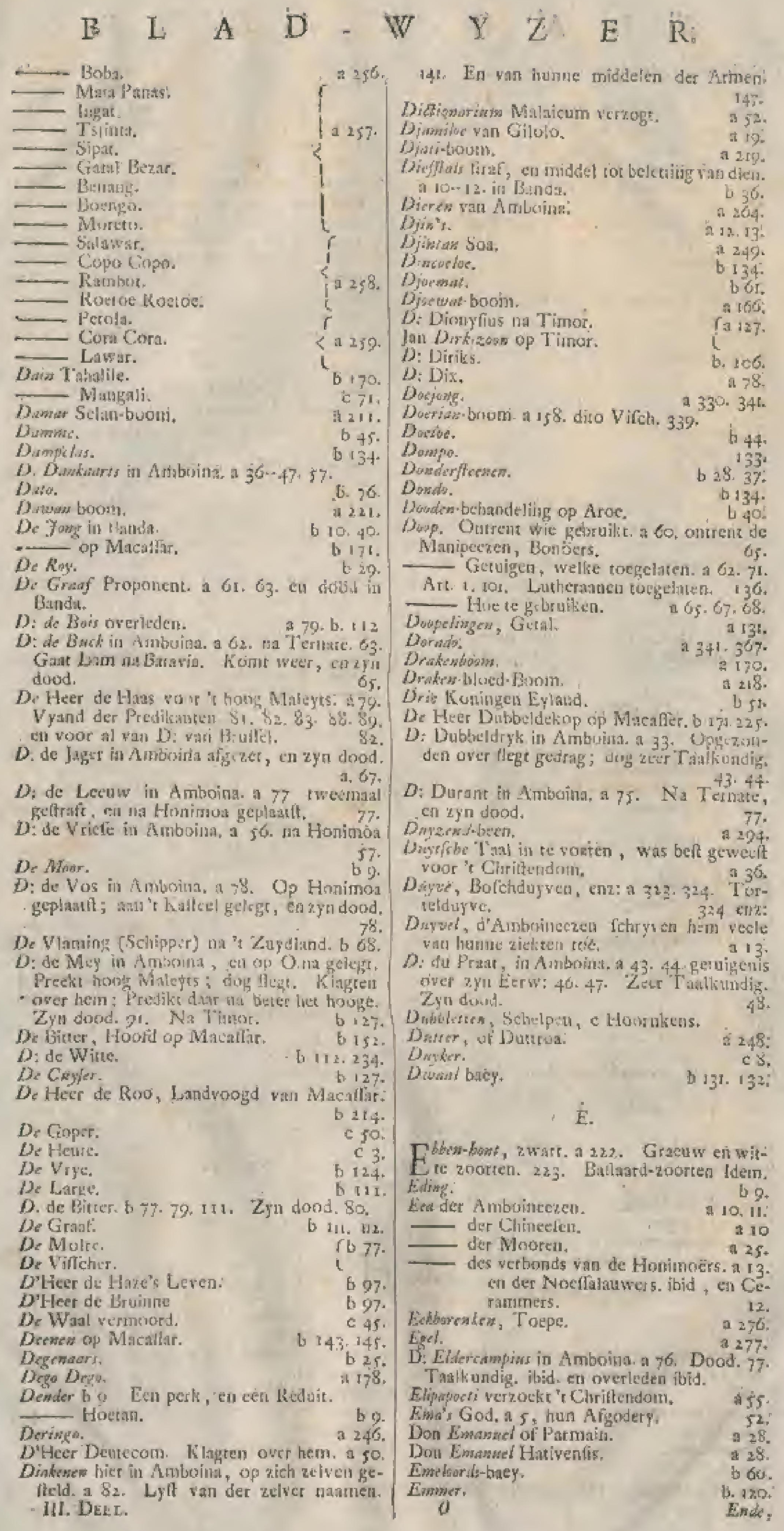




\section{$B \quad I \quad A \quad D=W \quad Y \quad Z \quad E \quad R$.}

Find, een Lipland.

Enowerth.

Harerther, Hoofd ap Timoin.

b. 1. 8,133

1320 .

by 120.

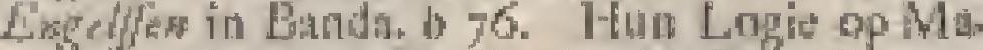
callit. b r45. Op Banjat Mastia. 187 , wh

Radja Goa bield met hên. 187, 189. Aroe Teto lehoft a an ben dar.

D: ent $_{\text {, }}$

207

D: Heer Erberweld Landroogd ran Maçalfar.

Eflir-boon.

is 215 .

Niter.

a2T.

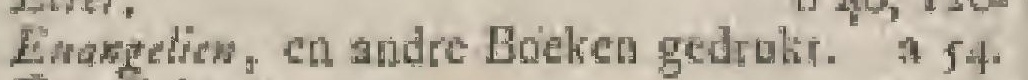
Exulfa-hout.

Ewers.

Ey lis Boomen. Goden; en zeer feeterd, a 3

1

TAdsol, en Eyland.

If $F_{n h a g}$

$b_{3} 8$

Pitef des Hemels.

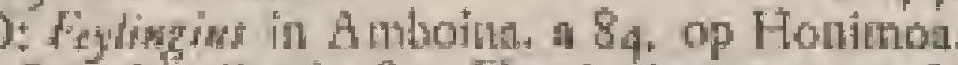
87. Na Landa. 89. Zyi buticht wegens de Goenong Api, b 2r. en anntuerking over ante dasd. b 26 , In Bands.

b 1 t 3 . Fide.

Filurder.

b. 122 .

a 275

Firulans, of Paradis:-Wilch.

Fifrad in Banda 687. Honne namen. 102. Fot.

Foki Fokk-litoyls.

D: Follisus in Amboint.

Fow.

De Hee Francx wefchil met D: Gron.

Frediride-Heltritis the

Don Andr: Furtado, a 21. Herncend alles wat de Amboincefen.

\section{G.}

\section{Aldar Gabba. \\ I D: Heer Gidry. \\ Garrag-boom.}

Gafatibloem, en Struik.

Galisifed.

Galedocper boom.

Gawat.

Gimmer.

Gouda Socli.

Gexdolat.

Gaht il $32 \%$ Krop-Gats. 300

Garmiter-boom.

Gatab Gathr-blad.

Gekk.

Gedrog.

Gdihlsw.

Geinter.

Gerda Poers-ftruilh

Geridang Corffoe.

Gevdareefre-bogin.

42.

a 248 .

in 43 .

D: Gerarei, na Amboind

Gewen.

Girs-sjangen. Hare giltmaking

Gilad-Boomen

Give",

De Heer Gyeds gedrag ontrent de Predikan-

cen da Praat en Vitriaris.

Givaly

Ghatholo odratur.

Glowe-Plant.

Gatmon-Buori

Tras.

Gol op Macater b

a 178 .

b 07

1 173 .

त $230^{\circ}$

년 327 .

7200 .

a. 3.30.

$2+240$.

21 $25+$

a 224.

i 238 .

1293 .

A 249 .

b I 30.

1) 245 .

a 234

1 is 3 ,

a. $213,252,257$

a 247

a. 246 .

11 250 .

$3 \mathrm{~J} / 4-$
En the Lander. 139. Palme verleheyd

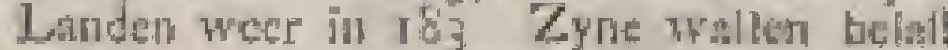
te legren. Stowe Takl der Konings-dint

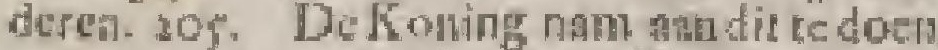

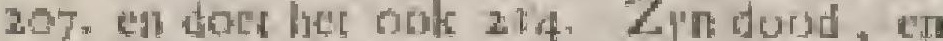
vervanger. 216 digg buiten de gewpone Wy 2e. 117 . werd door den Koning van f3ofti beoorhord, dog dic werd to If gelligen. Fen Weede tenting, Gor Gon's Koning gewont. 219. Arot Pubcha rati hem geterfeit, 220. De onke diant ant die van Got te weel Landen af.

b 112

Gudefry (4en Pricthet) c

Gowen der Aubointuen, se Hemel-lichen.

Pripil

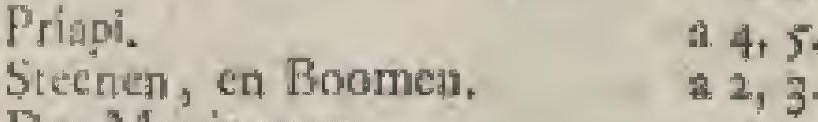
Det Maniperezth. da

- Van Honimon, Noefliloget, a 4 - 16 IS 19 . Van Way, en Ema. sirifort.

a 4,5 J I I I I Der Hervoriden.

Godrdentes in Ambina, de Heiden fore a

- Wieu wigheden verboder. Vats Binda. b is. Nohthamedastfolma 105 . Herpormde 136, Op Ti mor en Solor

127. Op Macallur Hódenfelye, Roumflhe b 32. De Wolumamedianlehe. 233 De Hermormde. 234.

- Van Bormo. b $25 \mathrm{f}$

B.li. b $25 \%$

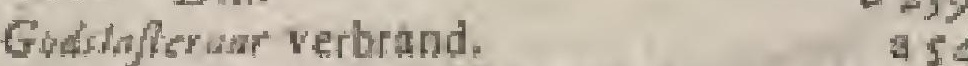

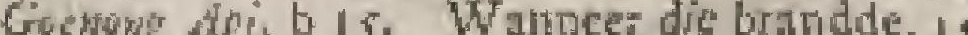

Druevig geval dvor der zelve vetuoriankt.

18. Berich wan Maurits Hefrifos vala der Spelt. ry. En von D. Feyingins an Lblon uner die Berge $2 t$ Groote Slangen hier. 26. Schars kyk ik de Por. a 26 . Goerocting.

owic.

605 .

Gowidit hoouth. 124

Govalue ltruyti. $\quad$ it 740.

Govgry.
Goriam:
137.

D. Gordos in hroboina 82. Na Oran gezon-

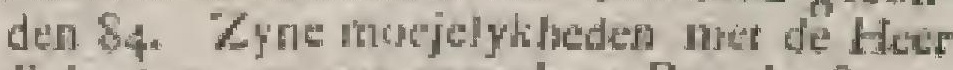
Schaghell, et zjli pertecti na Bartvia, 87

\section{Gouley.}

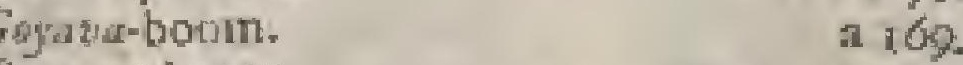

D: Gropervent, in minsoing

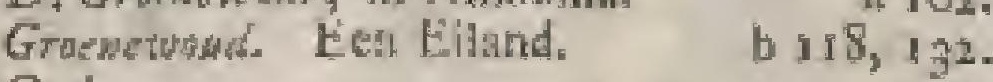

Grol.

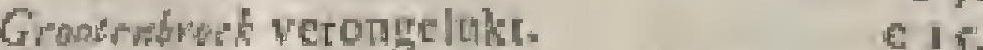

Ganatr. b 39 .

\section{T-This}

H.

\section{Muchast.}

Hageris, viggende, se:

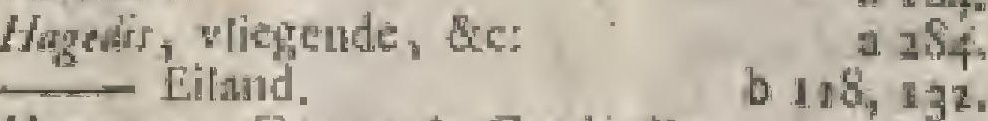

Hociar Gerone in Cambodia 108,132

채. $2.2 \mathrm{I}$.

Howmer's bodret.

Hameres.

Hoppsy, of Macaftar.

Hardekon.

Noter:

a. 34

b. $273 z_{1}$

b 4 .

04

84

i 345 


\section{B L A D - W $\quad$ C $\quad$ Z E R.}

Ciriel Hivida

Howlers-byland,

D. Horsey.

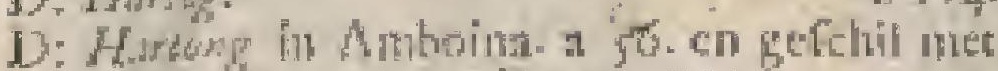
t: Apothown, aha 13atavia ibiad.

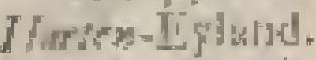

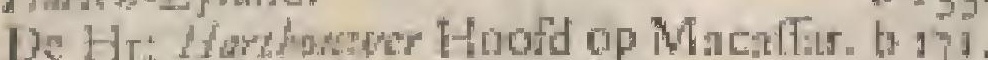

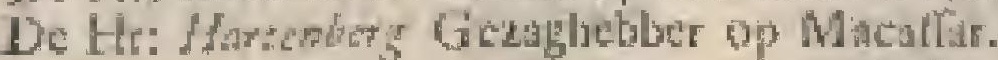

b 224

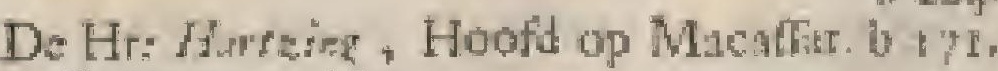
Goviernente hic

172

shlleuelte, wegeris Tonkir. c 7. en $\mathrm{Hy}$ als 's konings Zom anderiomen, 64. een Adte wan Adortic, 16

Finelaht Hofs.

it 21

Holfanditu, Koning van Macatlar, $10_{53}$. h

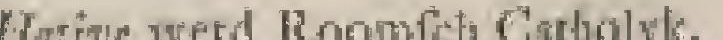

Hatwori, een gellachr.

fiatdils.

Hityr.

Mryado.

Heism, in Tonkin.

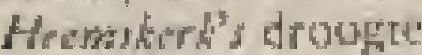

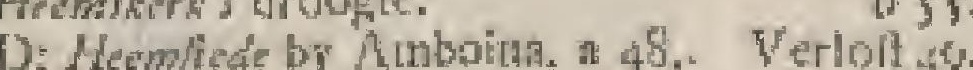

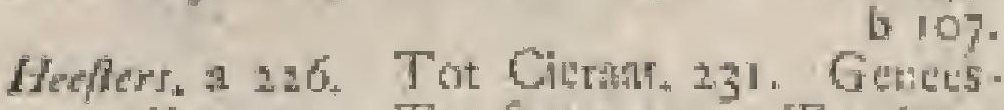
huduge, zzz Tor fpyze, zзz. Tot lise

D. Het op Ambrinas a 78 . Oosdecld dat de Verkjezing van Ouderlingen enz: fard den Landroond flond. 78 . to Ternate. 78. ch in

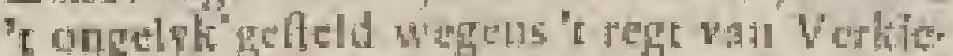
zing. ibid. Gas over Amboina gefchor lt na Bapavia.

D: Hefieritur in Amboinai, a 7g. op Honimon: dog yochok lam pa Baravin.

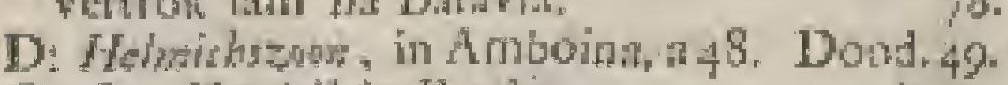
Garfials / Kandrik bu Bandu.

Gerenials,

Herbant.

b 73

b.

Herfen. a 267 , en der rewer Jathe ibid. zeid-

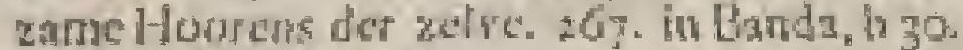

- Heremite op Machltar.

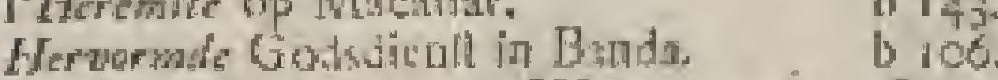

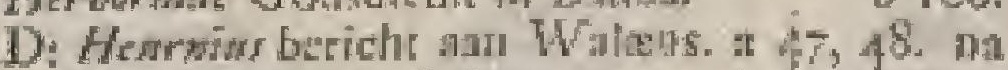

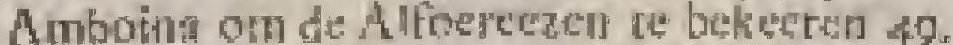
Op Oelat ibld. bynat vergeven dooe de Moo.

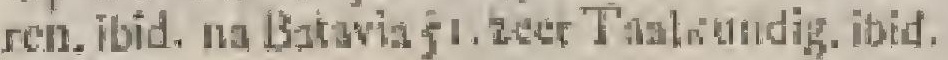

De Heate.

De $H e y / h s^{*} s$ droogte. $\quad$ b 118.133

Heyzlibers.

D: $H_{\text {c. }}$.

Drote cloriftenem- b 234

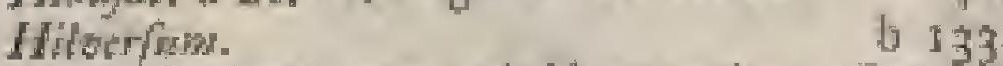

Hiturefen bedingen wryeid voor biten Gelpos

a 2I- Geी.uph dor d'Azevedo. 29. Roepen de Javanen te hulp. $\quad 31.32$.

Hos

cis.

b) 234.

D: Hoghan

Hocking.

c 13.

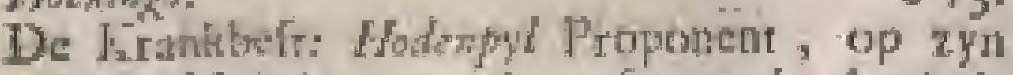
hoog Malty's gemsakt, a 83. en in A mboj112 als Predítint, ibid. Vertrok na T"erriate. 82. in Ambutna, en of Howimen. 80. Z Y dood, en tyre overzetriags des N. T. in "t hoog Maleyts.

Hodomalo onder Haipe.

De Admir: Sitnon Hoen.

D.' Hoen Hougerdorp wa Timor.

Hoendersis.

Hoerery in banda toegedalen.

Horfira.

Hortuanoi.

Hof mon,

Hohrioe verzoekt 't Chrittendom.
D: Molectosy in Bandia

De Hr. Houghomer hiet

How.

Howimean' Goden

it llog Land wan bandh

thoug Eilsnd.

Di Hog lats

is 274

Ateras, Zev-Hurens. a fir. Van de Gur thertehe, mer hare Indirelie en Eunpeilehe Narmen. 510. Schedpen of Dubbuter. 5 ? 2 Hoornen en Sthelpen beworels by den schiry. ver bezeten, 536,537 . Wend Indiletae en Luropeitiche ZeetHorcniens.

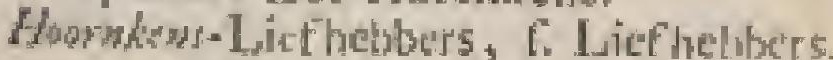

Pre uimunterde thaken des Selrywers in Pient. a soz-. Harsze EiTanden. b 52 HoHf-Snip. D: Moyr. bir

D: Wheros in Amboina yerdronketi. a 47 .

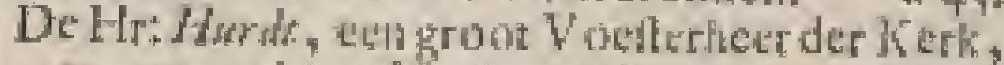

ell een walliker Landroogd. 69,77.

Hardt (Antonil) Hoote of Timor" b

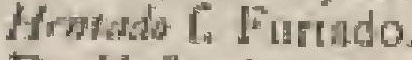

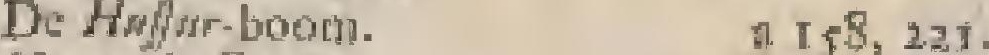

Manter in Banda. b $50,146$.

Hotudinter, der Mooren,

Haychi-Buleb (Gerard) Comulitaris wat Ti-

Thus.

b 126.

D: Rrysman op A traboilta a 67. hevolet $\mathrm{Ma}^{-}$ lepis te leern. 60. en cer Maleyts kon na Ternate ter vilite gezonden. 69. na Teruate 76. cwerleder. ibid. Hrysuer. Fen Louwe Stad. efl.

\section{I.}

Thartoge

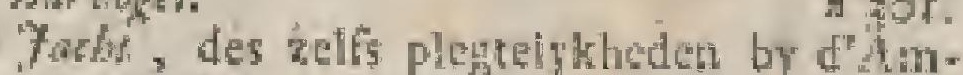
bolnezen. - der herten. a 267 . Van wilde Ofen.

foed Frerffer, a 543. Druine ong 206.

- de roode dito. $35 \mathrm{~s}$. De jeffer. a 40 . Jember-boont, a 167- 64 - en zoorten. Jawhor. b 57 .

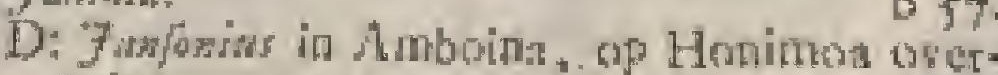
ledtch.

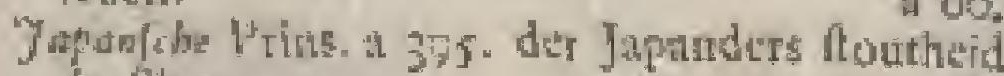
in Siatn: Fardamew in Amberisat, en verwolgen de Chril:

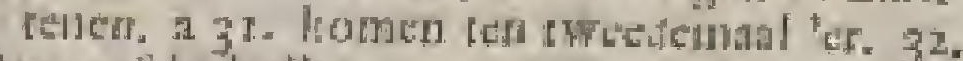
Jowemofich Lelit. -Tiffe. Wezel. 1279. Jef. bis, 64. Fist. Crain Jermica. b 775 . ho.

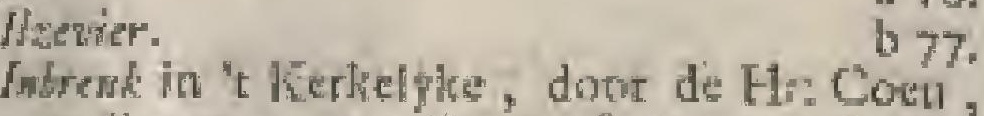

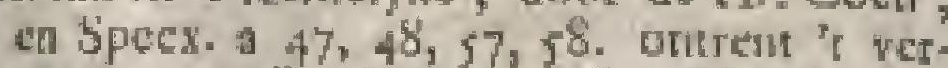
zendet. ran l'redikanten. $5^{8}$. Alkendan na Ternate buiten liennis verLonden. 62. Kops flock Moutalus 68. Ouderfingeu en Diakesten werhiezing matigd zig de Hr: PadbtugRe aan 78 . Sehtyver onwettig toa Banda 70 De Hats cen Diluker der Predikanren. Br. Vander Poort als Diaken ariferce \& 8 . "i Ge: †ел van Kerkelylie getuigenis door de Regeering belet. 8g. D; Colwedehorn onwetlik na Oma ger,onden 80. Mr: op Seroewawan doer de Regecring gettedd, or. met

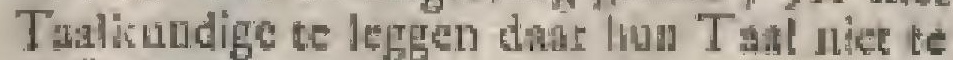
pas 


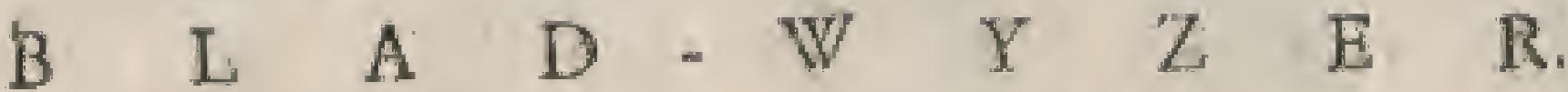

pis koms, als D. Poleman in Ambon en dar ma wecr op Bularia, ca ander. 94. De Hr: wat det brels growt freags, CL onvomaigtige bedrywen in 't Karkelyke. $13 \%$. Thatgoplatit

Tabarling de honingen wan Boul eu Goa in katten ap Macilitis.

thas var de beerhoufden in opsing ran dem Gudsdiend. a 139 . Foor de Krichbelr: 133. Oree de Nagelen. 194. - Voor de Hr: Harduk whentent "1m kin e $7=16$. a11 19-26. an $29=30$ Voor de Opperhouften der bchepen Sa Combutin.
Sich 7 wof.

Capicits Janker.

Fording Wifch.

Jerit.

Jidis betchreven.

$$
\text { If:- }
$$

b 208,209 .

b 125 .

349.

53

c 59

$+$

a 295

a 259 .

Aotertak

K Rist

Kactede.

Kugmand-blit.

thidge Mataburatoom

Jkan Krite of Stokiviteh.

Katud.

Ralspa-brom, a 178 . win 200

thigeden wan deren Boom.

11 233

14 217 .

2 362

a 25

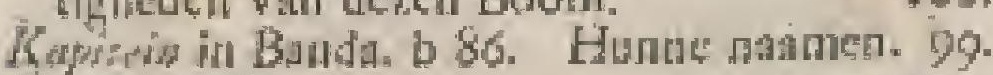

Krapol boom.

L idroe Joag Mabu-El's:

hítand Drevt.

Kunrocww.

政

Karapontobun.

Reri Band.

Kar Kar Kisjil-0rulk.

Rararw-ltruiti.

Katruatir.

Ketret:

Feletwan b

Krlitaria. b.

Kelwr-boon.

Kindiras.

Kring-heringat

Kerk op Neirtar.

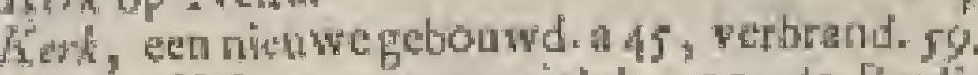

Vidien zeer monelyk volor de Predi-

karited. $a<6,75$. En hn tecrlt weing finc-

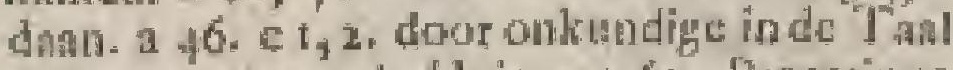

xyargenomen, als Huisman 69. Peetgrinos

76. warcu in lange ayd nite fudan $7 S_{j} .91$.

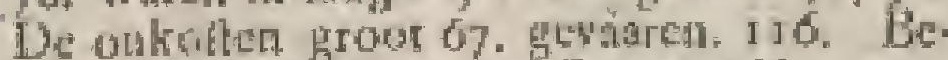

richt van een Kerti- en School. vitie. IIg.

Schers in "i kort wan Boero, Minapa, Bonon

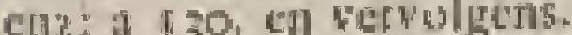

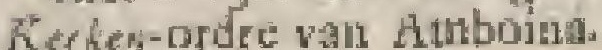

hetember.

Kateria.

a. 6 .

b. 43 .

a. 61 .

Key Wrata. b jo. KTeyt Keq. ibid. Geot

39. dus relf Doupen.

39.

Keyzar, b 29. D* Keyzersinal ni Timor. b

De Hr: Kegls togt na Nora Guimet.

Hithendict.

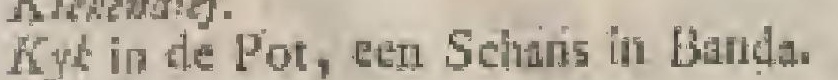

Rillowon.

Kilinida.

Mitilay.

Rimar-booin.

Kind, (gebnerd Zee-kind.)

hiomacy.

rijas Japot?.
Kirastopath.

b. 4 .

Krene th Huwelys-7uken vergadering in Paludg

K wistsute.

Reppolotin.

Rinoples.

187

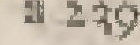

a 250 .

b 11

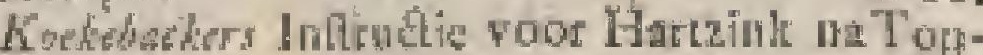

Hill. C 7 Korjer, Melle, th boter a $26 \%$ in Bund: b

fiof this.

thopde Kelise.

Kocptrats.

32

239

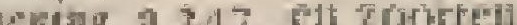

Kowm-flrogli.

Kerop-Litunden.

hempen in Badd.

b. 39.

ti 244

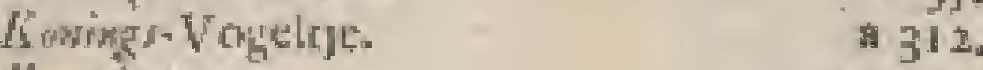

Kurebrom, 221 .

Forjuchas. bas.

Reficr. b 72

Krop-Gatts. If 300

Wratem cot fpys, etr: a 243 modre zich over-

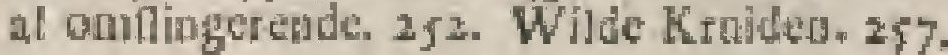

L.

T Abet:

b 121

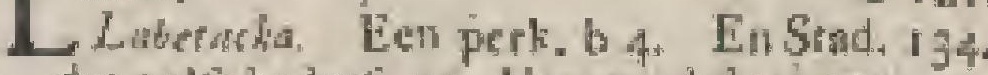
des ictls bedeyt 34 Veroverd door ons. 79 . Luiba.

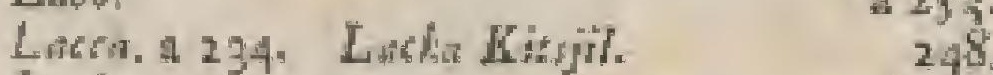

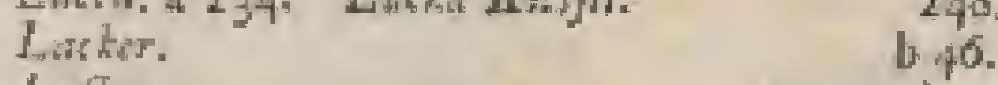

LukT.

Lifond.

a $32 x$

LAEAT

Lullowe $\quad$ at 5

Lrikg.

Lrakgy:

Loalo Ay.

and ato

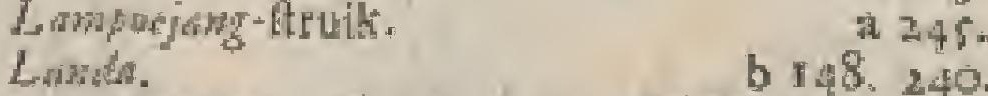

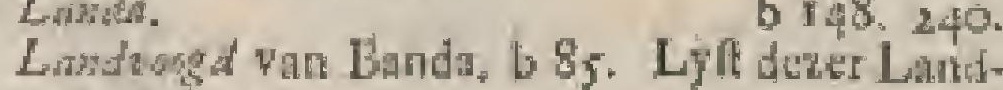
4otigden. 38

— yath Macaliars werk, b izg. Hun

magt cower de honiugth. $20 \%$

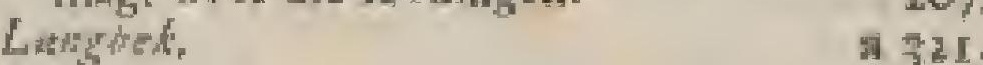

Labion. - a 244

Labjanthom. a 165,233 .

Lasirm, een perti in Binda. by

Lasin an $20 \%$

I G

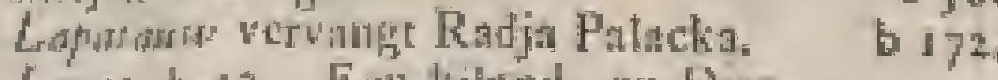

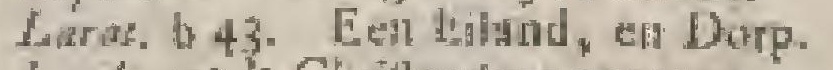

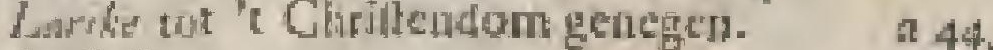

Lifithoma $\quad 1223$

Lotion fly

Latoc Becton. b 125

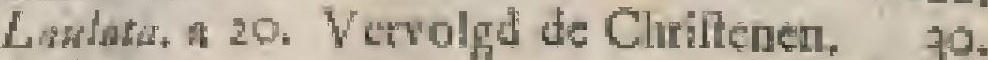

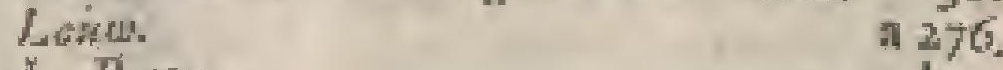

Le Bsref.

Le fowebest

61. Learoviti, a 33

i 306. Licatisati.

Ledomars in Ambotina a 60 Inlahdze. 33 .

b. De Lent. bi 120

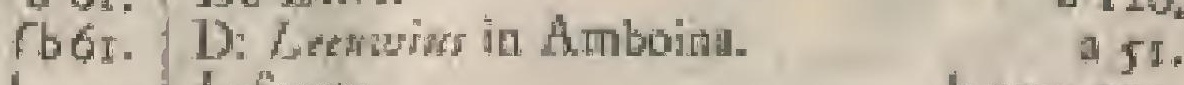

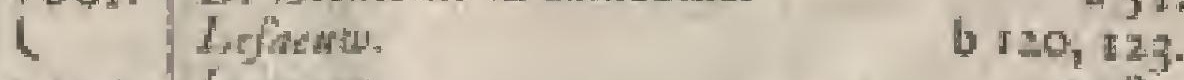

224, LeXmars. a 280

404. Lefie (]avanfct:

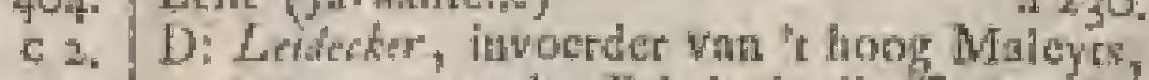

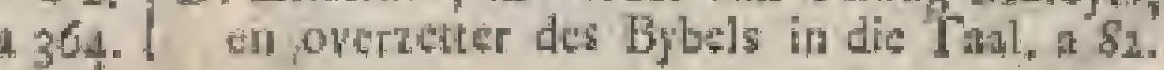




\section{B L A D $=W \quad Y \quad Z \quad E \quad R$ :}

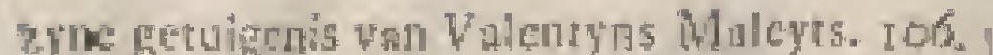

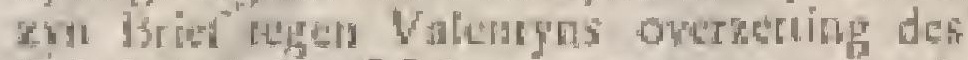

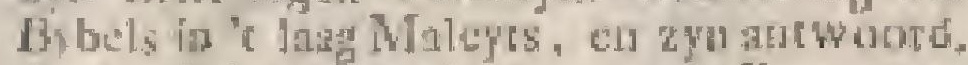

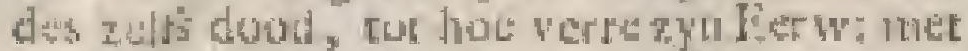

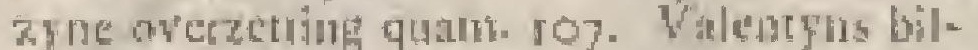
Toke hardeling "er ontrent, ro's, $10 \mathrm{~g}$. De

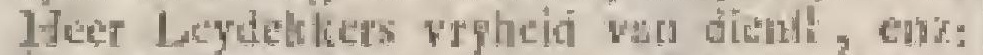

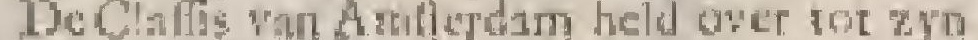

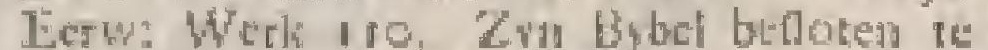

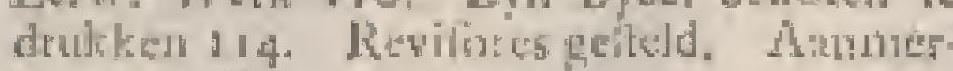

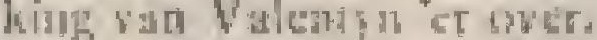

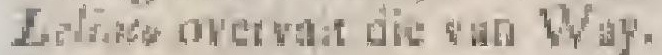

Tidis.

Lua boaja. Intiduldele en atultis.

Indilinge.

559

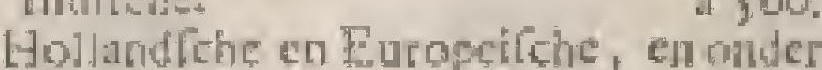

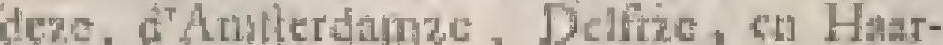
latye.

a 561.

Hagre, Romerdame, Hoorate, en Discditechtise

a $562,163$.

- Zuteuffle, Zwolfele, teldzane

Hopris van d'Hr: Wybers. 563 .

- Als mede vall de Het Schprovot a

- Growns

$564=565$.

Schot:

1565.

. 566.

567.

Schajd.

Hifuecto

De la F"zllie, d'Mudited.

Tigethat,

silptide.

Ditur

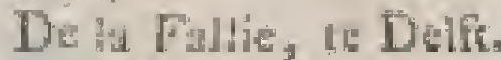

Jicaeth.

_ Van Scy and

Wori.

de holdige,

568,56

ra $5,0$.

i a) 57

in

i.

7. $573-575$.

$515 \%$

군 177 .

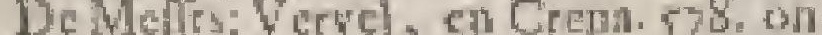

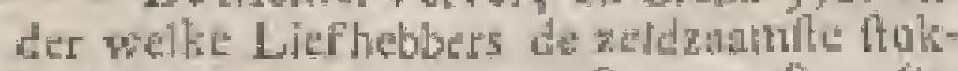
fieta zya.

Limape.

Lidwing intrib.

Lifferas.

Jiliby, Cheithen.

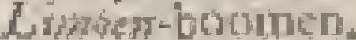

Litighat-1300 nt.

Tipnaniwa.

D. Lipting.

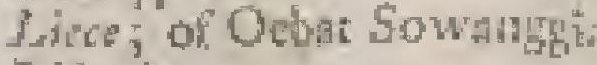
a $58,5,5,50-5,3$.

b 172.

in 394

bis.

T3,

189.

$245,2,22$

2 is.

b. 100.

a. 257.

(5)

31 .

1221.

Lyadra, Chilten.

I.ne-Bootin.

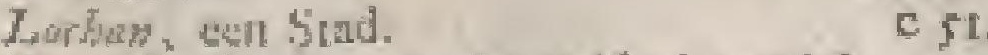

Daro hoth. b 202 des zells fatrelylk 202.

205 .

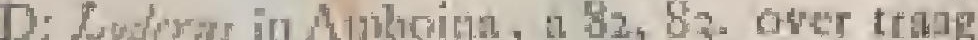
heid in in Malerts lecren belchuldigd. 84 wpgeroladen rat bativin, $\$ 6$, gl. Gatt tia binda.

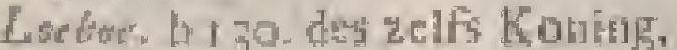

140,18

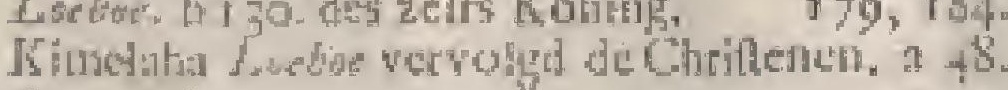
Lim Histos.

Lorrs, हैh zourted.

Los Red $\mathrm{R}$.

Ludar and Stind.

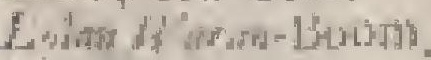

Lan-Lund.

Lwontere.

Lombist

Loratiar-130om

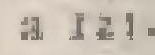

II 313

b 119,133

c 51 .

th 2 il

nit? 23

(1) $120,149$.

13 i $3 \pi$.

a $18,2,18 \%$

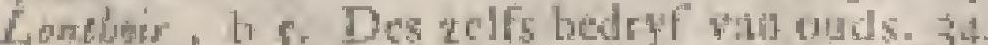

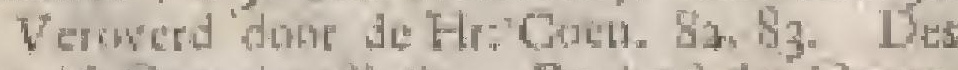

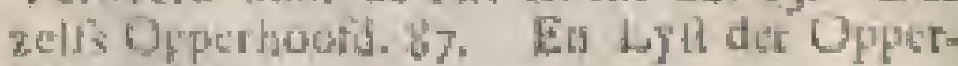
III. DEEL

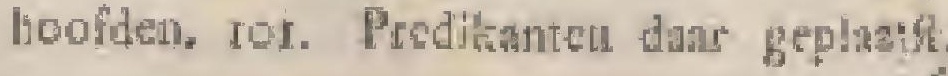
Solsarit.

116.

a 10. ro, so. rorlt, en 2 ya Percoon en Ireyn belchrewen. r. Vetdrezaker, tots perien. "J Vor-

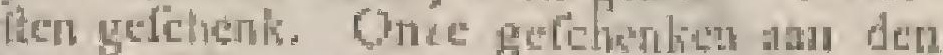

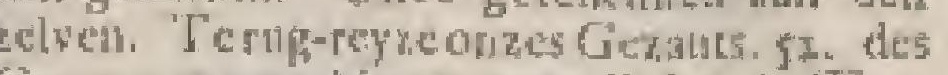
Gozoncs tanmerkingen over dif Land, is the

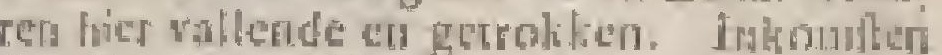
des Konitias. Zyne Regetring. 57. Hum

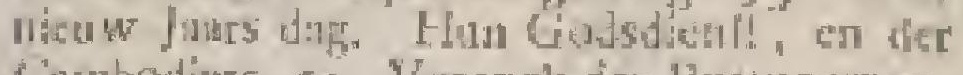

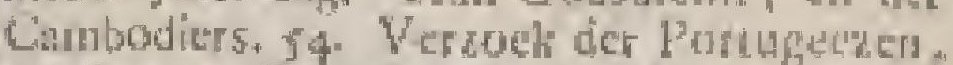

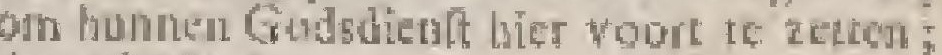
dog atgellagers.

J). Luydr

1) $5 j$

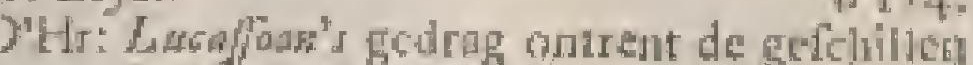
yan D: D: du Prait el Wiruaje, $45-47 *$ Litigy.

Layrewants in Banda.

b 5 is.

M.

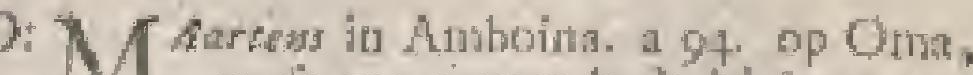

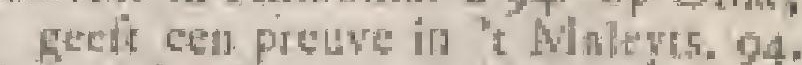

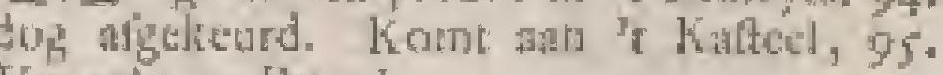
Verredit a batavia.

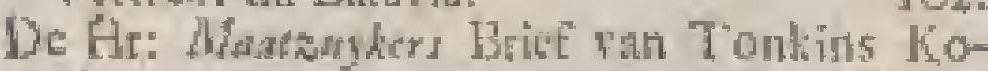

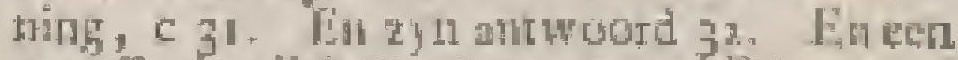

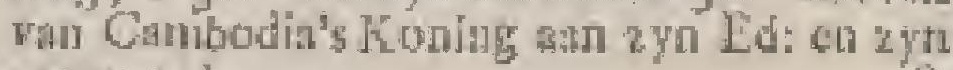
antwoord. 8

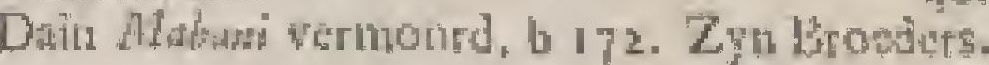

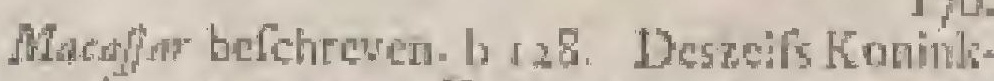

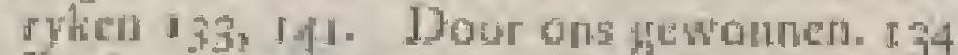

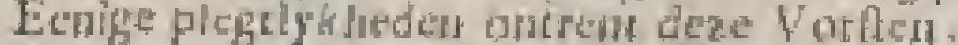
verwanger des Konings hier. Die Siad bo-

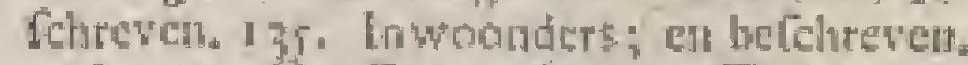

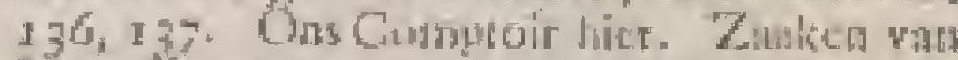

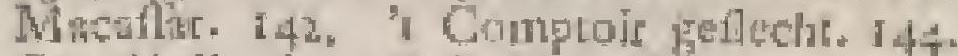
Ons voli Ao. I 618 . thier veroncord. Itr De Hr: Real, hiser. 't Comproir Jrclicht 1623. De Hr: vall Spent, hitr. 1625. De

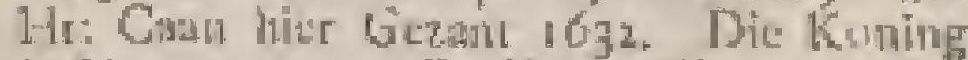

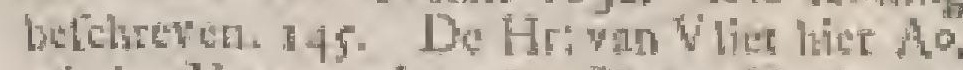
1636. Yermuord. 1ao. Slege Vreũe Val de He: van der Betk. 147. Onze Orrag fnet Macalis. 1660, 147 . Verrigring ber Hecrem Fan Dam en Truitman. I 4 s. De Mlncafraren maken Wrede; dag bieksuze

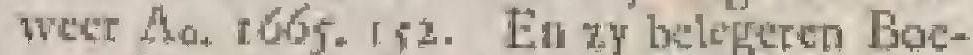
ton; " welk de H1: Speclman red. 153. en Micallar tot Veode dwinge i $166 \%$ dog 2y bretcen die weer, on by temt fren gebec Ao, $1666.153-168$. Cantrist 460 en die ynu werfehede houidgen 164,160 . Onze Macaflaste Opperhoofden. iz. De Hr.

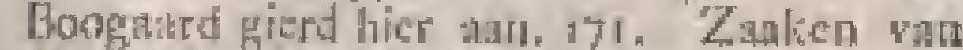
Drin Mulati, Ziena, en Aroe Tuko, 172. De tfr: wan Thye Landwoogd, e[ zyo doud. 172, 178. De Hr: Beeruink Landruond

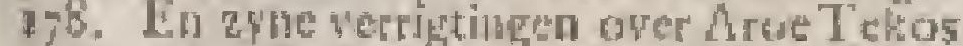
walis 175. Gicfehenken lurer Edelheden an de grooter hict. It 3. Verdre handelingen

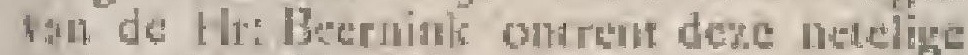

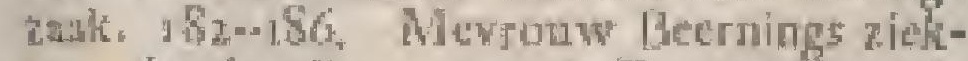

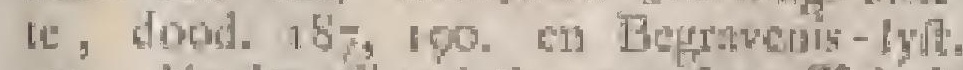

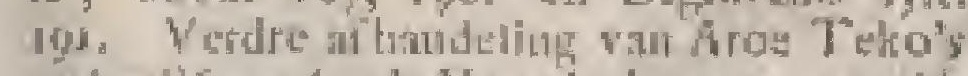

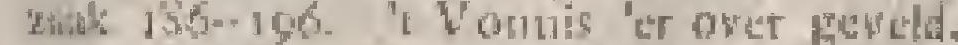

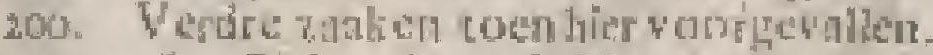
100-20S Sjeich Joweris Zaot hice. 208.

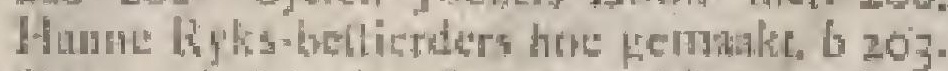

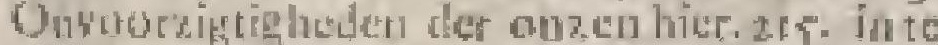

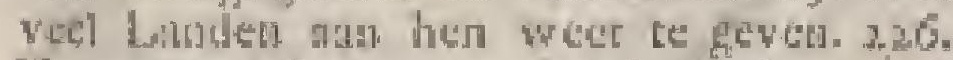
Zy moten itreng gertgend werdem 227. 


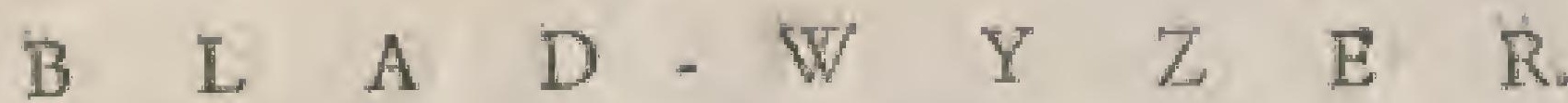

Konimgen hier. 195. Latudvongden hice. 229. Opperhoppliederi, cer vetdre bedien

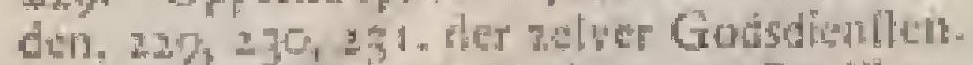

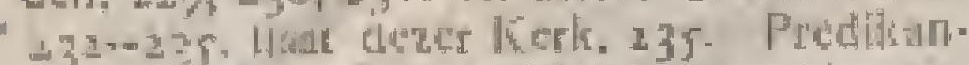

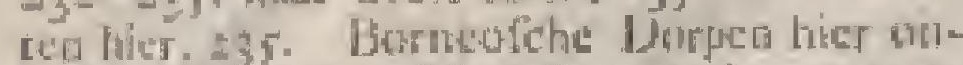

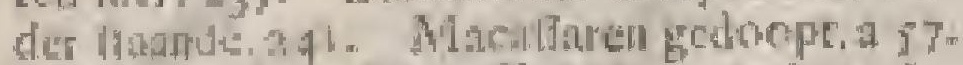

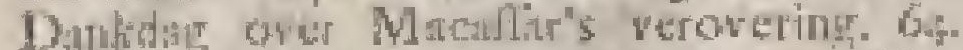

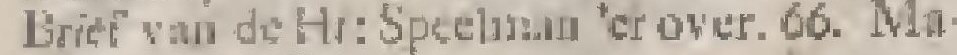

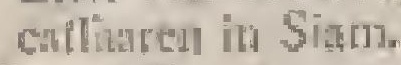

Mocoarifi.

Mvesuri-lleniti,

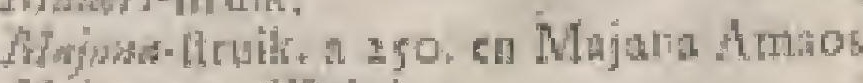

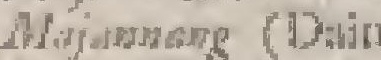

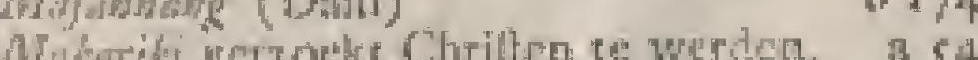

Mididsw boosin.

Nhborrpers.

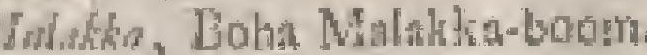

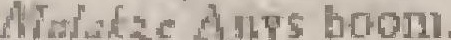

Muldopiars-bogm.

chifen, welke de Seliry

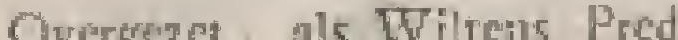

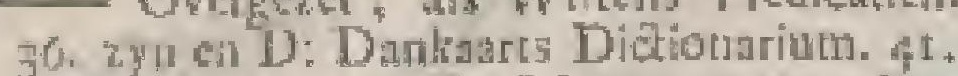

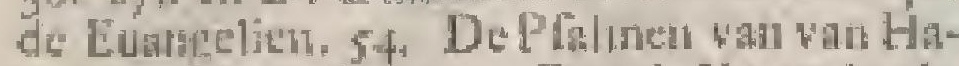

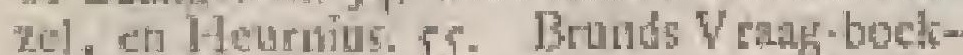
jen. Catedhilinas yan Spele. 55. En Van Damkatris, s7. Eu die ran Roman in 'b houg Maleytsverworpen. 57 . Genefis, ${ }^{\prime} \mathrm{N}$.

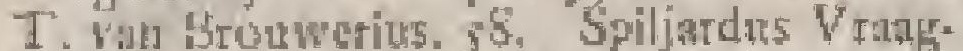
boche, met cenige Pfalnen en Gezangen nd Buavia rezonder. 59. als ook zyne ver-

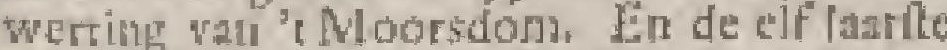

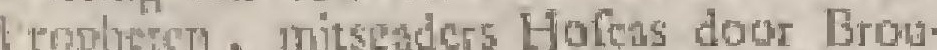
werian. 6o. Molanus Predicaten in "t hoon

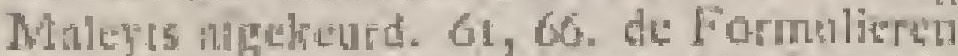
door Cigheyg orerpez: 76 . De Bybel in "t liar Maleys oretgeret door Witemen. bo. beweringen her tuen an vor de Hr: Leydeleters Br bel in it hoog Maleyts. go.

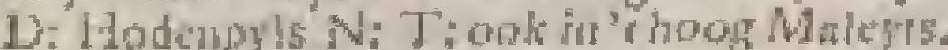
100. IE theer atudre Bueketh overgezé en gentakt 109. Aantherkiagen over "t Mithlevts op Macalar. 235. De lage Malcytze Tant is de belle, en redentu "er voor. $35-43$ Det Taalkublige Predknaten buiten-roorderten. 571. Dieze Tual herdi ingevuerd. 60, Laft harer Edalheder an de Regenter om in fie Rork te Foment. 65. Lage Maley Le Boedren verzout dow die val Bunda en MicafEn, 66,68 Whontatus mubteding, am

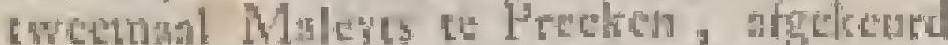
by de Rerecting, 76. Whidelen tor voor 2etcine was 'I hoog Maleyts angewend. on belant dar te lemren. Bo, En iwee zullie Predikners atgethnden, ect midel or

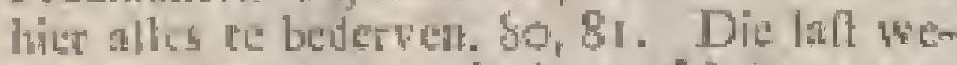

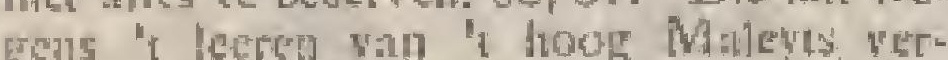

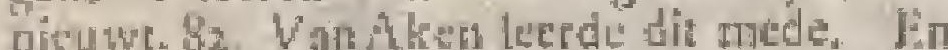
dit alles gefohicd on dat D: Leydekike den Bubel in a hoog Maleyts oweremede, 82. Vatentys aanmethingen en ouk die valt

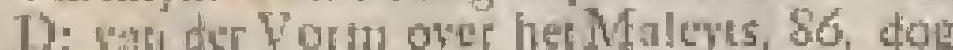
"I thoog Mlalefes door den Kerkenrand, wit mees vor bast Edetheden omhell, fchoon

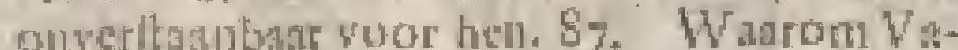

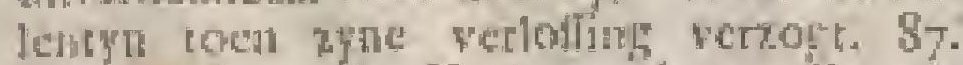
Asdrmerkingen des Rerlentads van Bațivia over de onte, whit by ef "r hoog Majeyts

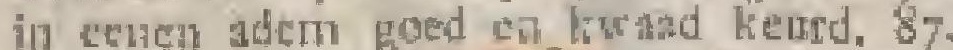
dog dit danc has redetie. \&S vitur by "I aldithatren der Butens door

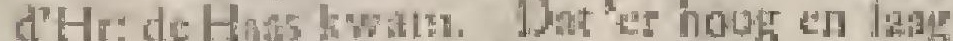
Mhlats is "bith klar ute een Butavize

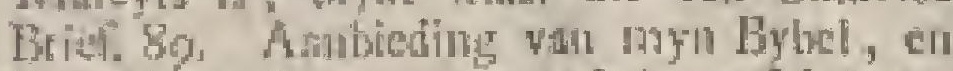

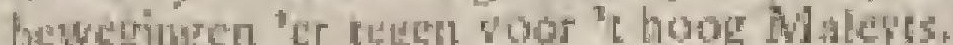

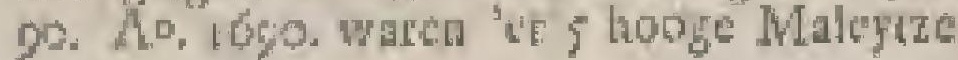

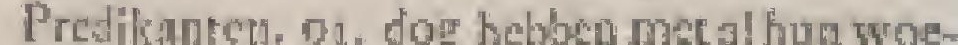
Jots niets uirgewark.

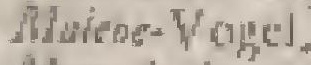

$9 \frac{4}{4}$

a. 323134 gellowted. 42

Mewadorita.

Marda.

(C) b 200

Matidir. b 130

Mranert. 306.

Dain Marpali, one Spon in "Hof des tho

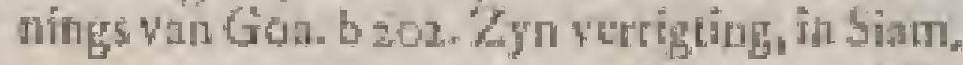

Mange Bôth.

c. Ti.

Masgat.

7. $15+15,156,318$.

b $6 \mathrm{x}$.

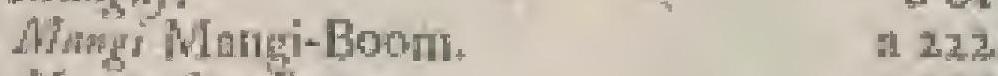

Mtomptar-Boom.

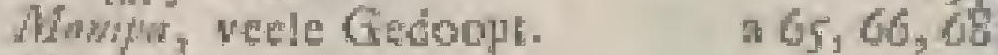

Mangmeten.

Mraner-blowuen. a a 4 , of Mloggri.

D: Mtamena. b 79

Muscuch.

Marcl. " a 304

Martor. is $\mathbf{3} 50,131$

D) Mafier. b 1 do

Malide.

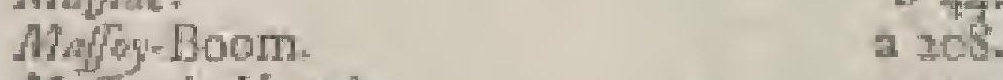

Mufrreke- Wogel. a $3 \pm 1$.

Now-Boom. 대 162

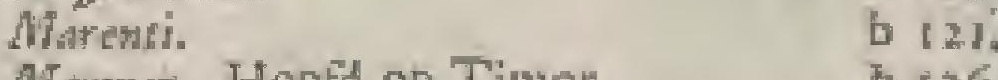

Marmet, Hoofd op Timot. O izG.

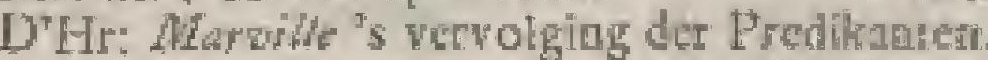

$62,64,65$

Malatar. b $121, \pm 22$

Ahadeda boost. $\quad 0217,232$.

Morrakents. a 10

Hatu Ordise. $\quad 1256$.

Mropritszas. " b 29.

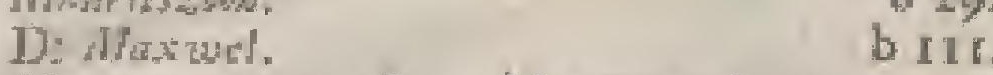

Mayam, a 19, 181. Mayeoot. b 39

Aitarera

Mintiverit.

Matedilo.

b I: 1 .

$x+70$

b 37.

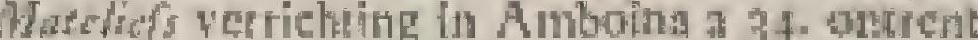

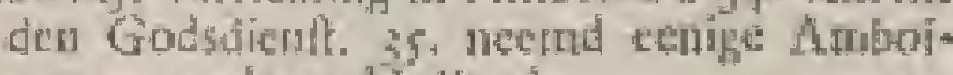
necren mede nu Hollind. 35 St. Marber Eilathen. b 13 . Des Sclurywers

Eeval hicr. I32.

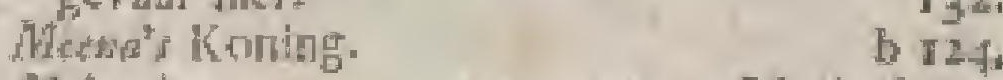

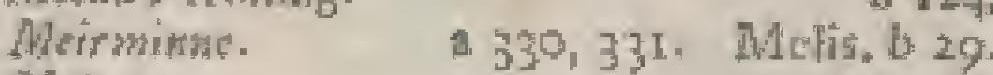

Meden. a 25.

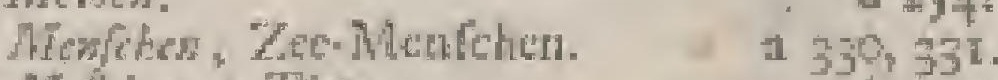

Mefdap op Thimut. b j7y.

Misle Katsuter. b. 44

Mirhisson op Bomen. b 44

Madibarg. b ji.

Wreres: a 295

Mrou Mizs. a 249.

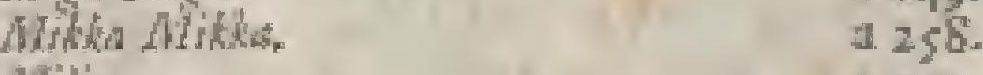

Millie. a 747 .

Mor

Horgi-Blown, a 7144.237

Tonkin-Blocat. $\quad \begin{array}{ll}230 \\ \end{array}$

Morriezien-Bools.

Thitce Hachows a 174

Maflon-Yogel. a 326

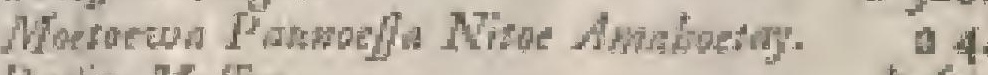

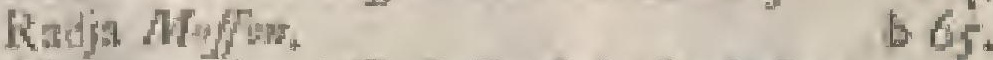

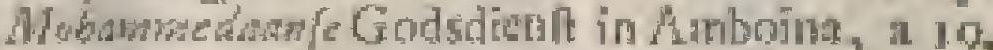
20, 2t. Onderfiched rufteher Sunbits en Sjais. Hut Kerkdien dorr dat Schrywer getall. $23,24,25$. In if verdre rot dece dientl behoerende. 26,50, 50, 78,94. Dete

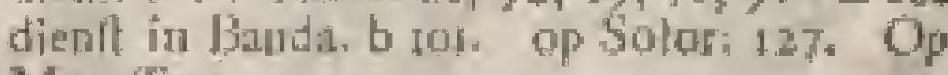
Mricellit:

907.

D: Molum in Bunda, zyna Looge Malerte 


\section{B L A D $=$ W $\quad$ Y Z E R:}

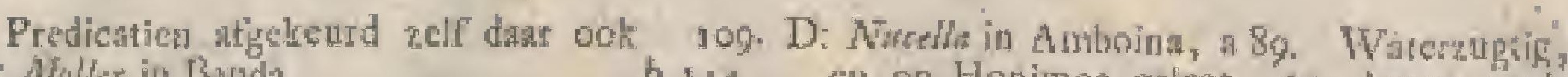

\section{D: Moller in Barjda}

Alowher.

Momi Wortel.

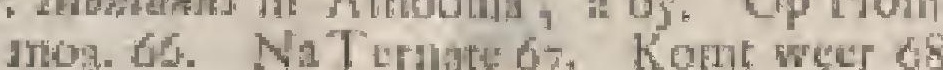

Klatage awer d'Hr. Cops, die hem lloeg. Op

Oma 68. Gara na "Liateel. 69. Bied an tweenalal Malcyts te Predilich 76. Gaat

We't ath Teenste, en flier dat

Momidewars-Baey.

$\overline{\text { Moris. }}$ Ricvies.

Morfath-boom.

Mwrit, soti $M$ isod.

$M b r$.

Mo's.

N.

TAbor.

Norbrelat.

Neghafor:-Bootss.

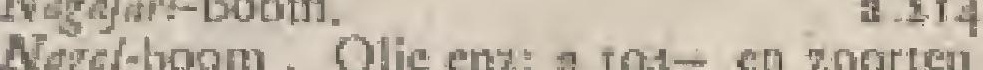
ibid. 느 2 z

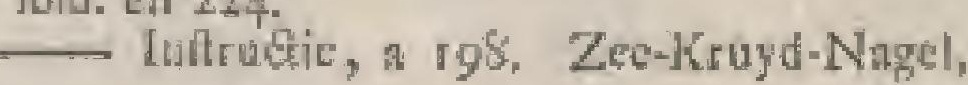

Nitheres.

77

b. 67 .

b) 67

a 222

다. 19

b.

$66 \mathrm{I}$

Nablabia, hoe zy lfun Goten dienets.

Nammoy (Louwre Seedent. c $5 \mathrm{~L}^{\prime}$

tutection.

Wamolok, exis Eiland.

Nam-Nan-Boom

Nismers

Nimatorite.

Nay-Boom.

Nispar en Bolgich.

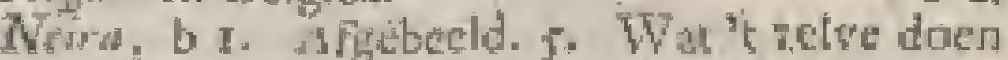

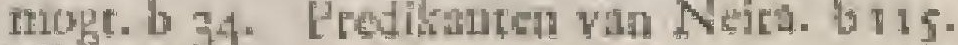

Wirlint boom.

Negesplaticule.

Nionemes Eithid.

D) Nichdar it Ambioing

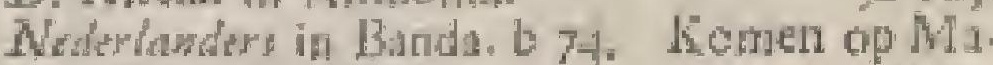
cntar. $143^{-*}$ in 5 iand.

Niaroe.

Nivis

Nroug -bogn.

b 54

4772

b. +4

60

10

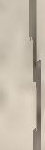 \\ (1)} , ,

c 2.

c 2

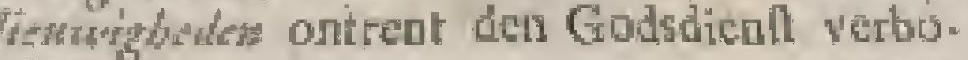
den.

Mila. 59 .

b 45 :

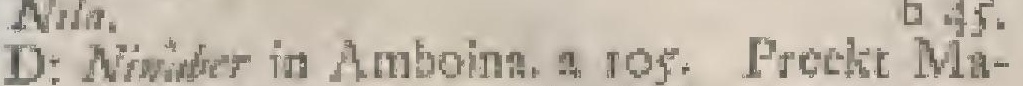
levi[ch, jtod. nal Betavin, ibid.

Tha

183.

Nhot's a 3. Nitoe Labba, a 4. Niroe Anpotalo.

Nofldwer, Goden, f. Goders.

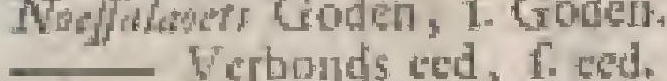

—. Werbonds ced, ficed.

Nobfingivel, Monrich.

Goss-denf 3. Wund Chriten 39.

Noefror Pinlos.

inter.

Mortia Tdo. Onder Brada's Eilanden, b 38 .

Noribur.

D) Neut :

b iाg

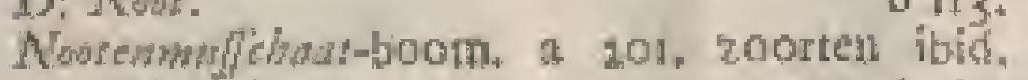
Ijurtighedern.

Eeter.

4203 b $6 \%$.

Beliandelisg.

5il $324+$

bi. 1 .

Sheli werle ontent de Nontets. b If

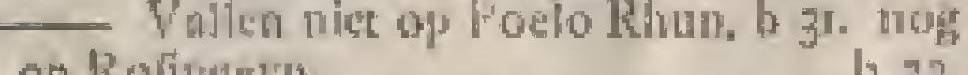
og Rolingeyli.

193.

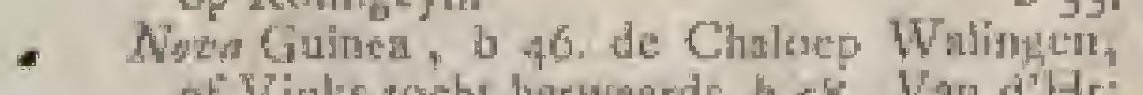

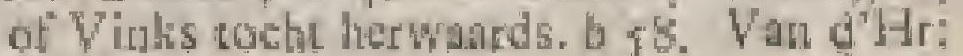
Keyts. weyteren dif te werlen a 6? Hurb, on

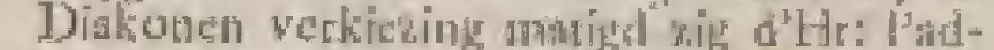
bruge na 78 . dog werd is Tongehth Refleld: 75 .

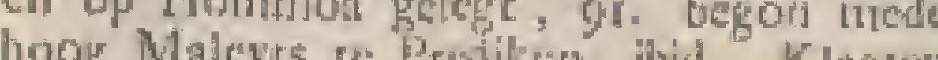
over hertibs. Zyudood.

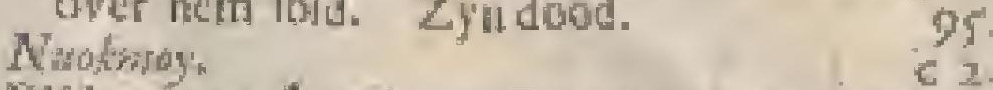

D'Hr: Neyt Land, en Pury's rechat ter wan.

b $7 I_{3}$

O.

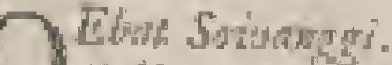

Dis $25 \%$

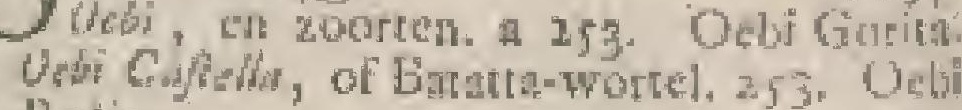
hadits

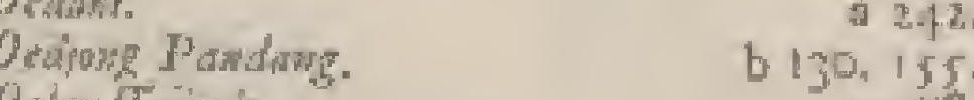

Welew 7 ginde.

che, U: Hetrofits hict a 49,5

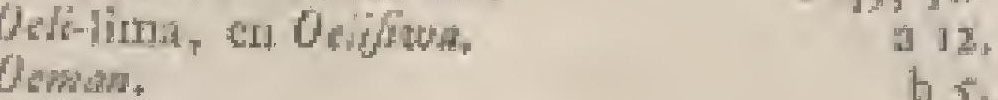

Oensin:

Oepar Bidil.

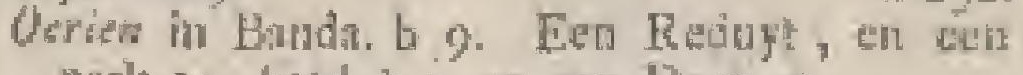

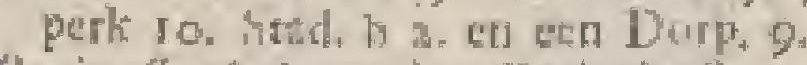

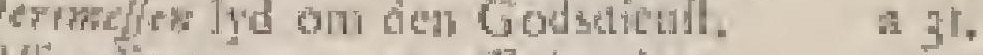

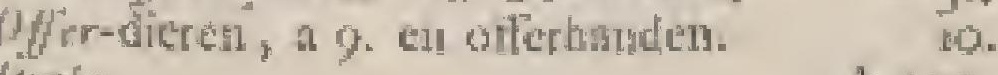

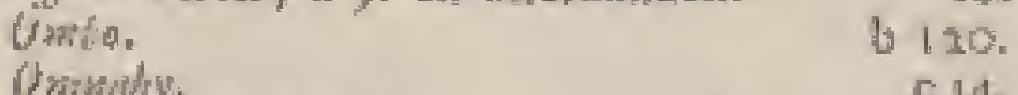

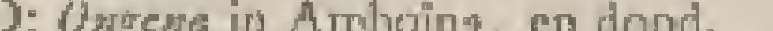

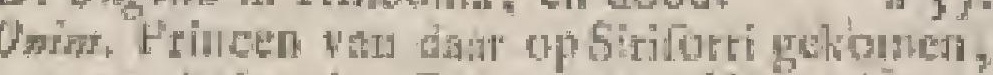
at 1). b 61. 62-Grensmant, Hupe begraventis

Ortong lawa, Eilanden. b 5 .

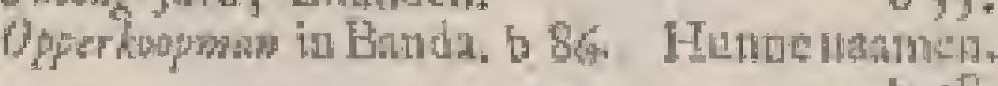

Optomes, Hoofd op MIantro

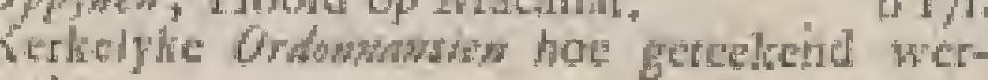
der. a 13 . Diorindy. by

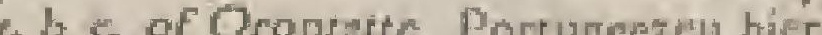
b 74 derloger, die wan den politroquer hitad

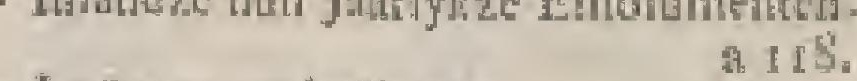

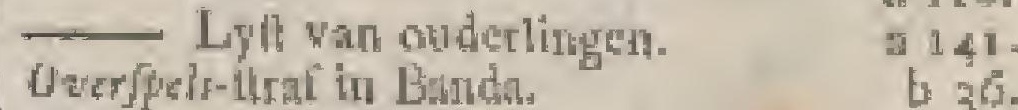
Onerfin

다 1 네요

\section{P.}

Dater Capiteyn zit als vootilter der Din1 hetien. 1135 .

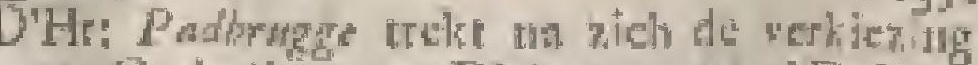

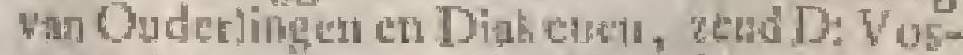

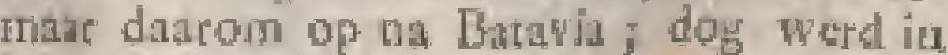
'tongelyh gelteld. a 78 . Paides-diosten. $\quad$ a 250. Padi. $\quad$ a 247.

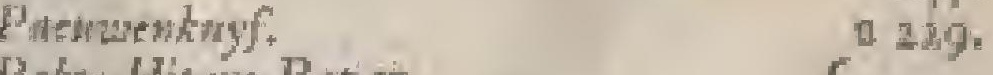

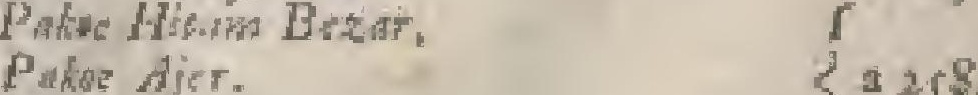

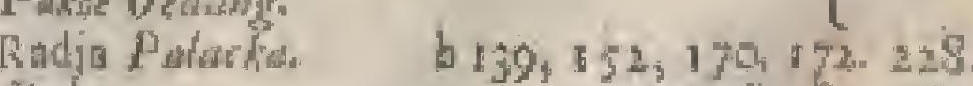

Italiny.

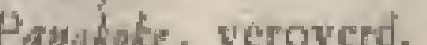

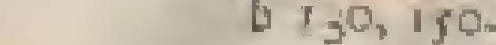

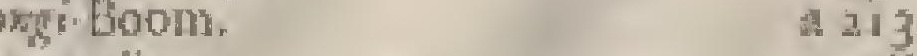

omplocfing,

D: Panderas, - blog.

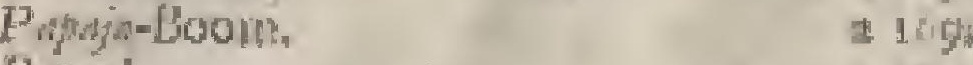

Pari: $\quad$ it 254 


\section{B L A D - W Y Z E R.}

Papedit.

Coclit Papedo-Bontr.

2 178. Gate weer ha Barian 54

b 10\%, 10\%.

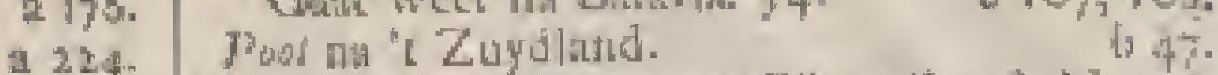

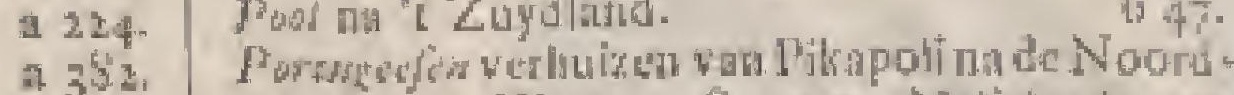

Papegary (degete)

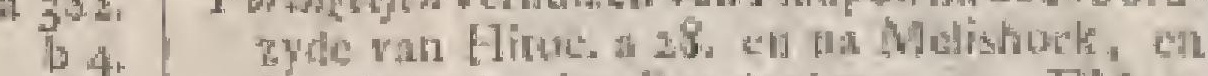

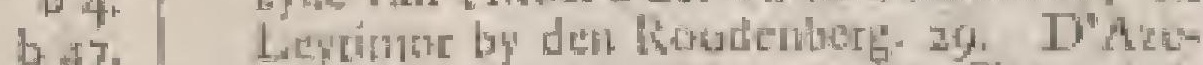

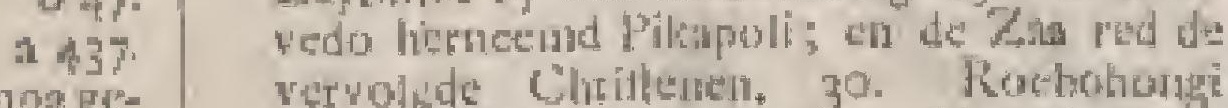

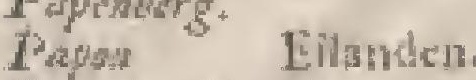

Potradys-Wogcls.

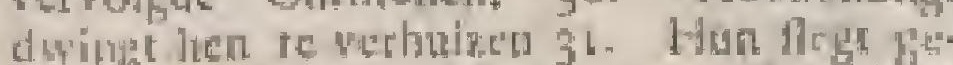

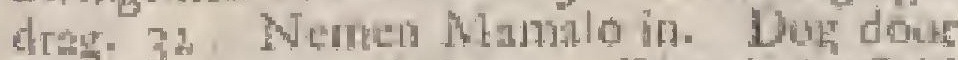

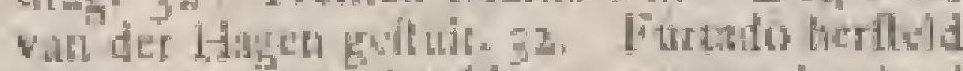
alles; dog wata der thitgen veroued geheel

Amboind.

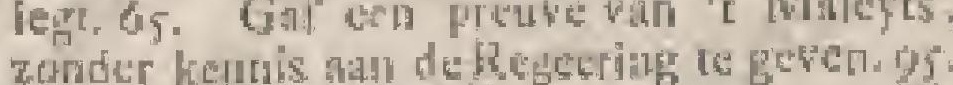

Parman te Goa toubopt.

n. 28

Dr Pars.

114

Pof

Paspolombed.

Pabab Toedomg-ftuyts,

$255 \%$

a 250 .

it 234.

ำ

Param.

b 62 .

Pusi Mole.

b. $14 \mathbf{y}^{2}$.

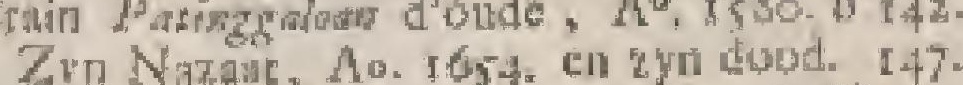

Si Panlo.

Patmeds, aen afgod.

b $6 \$, 71$.

a. 18.

D: Peys, in Ambana. a 65 . Thalkundig. Gate riels ma Barata.

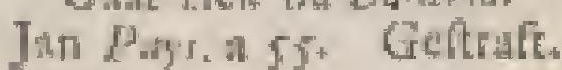

Herdes.

$\frac{67+}{56 .}$

Pecrlbank op Aros.

Prokiatom.

Peingus.

Pelor Yjodatagas.

Peper, latige Peper. Tsjibe

a 266.

$b$,

1314.

c I

ज 237 .

D. Percerrec in Amboina a $69,76,77,78$.

Perken, op Neira 6 429. Op Lowithoir. hare namen. 7. Horte Schers det retwe i f. Op Poelo AY.

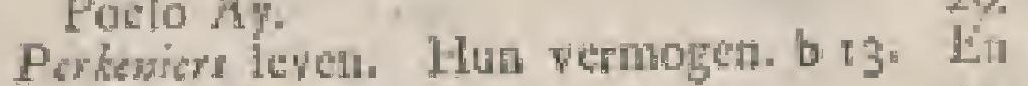
Atsunineid.

Perolda Tijised.

P Slang.

123, 124, Op Macallar. 14\%. Werden done

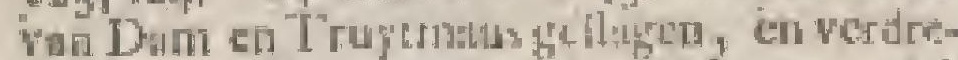
wen. 194. Hun vercesti by de Louwela at-

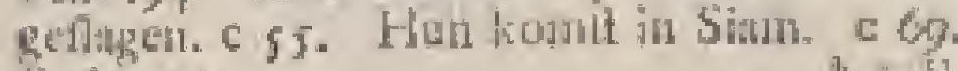
'Poffiecris.

PuLarage.

b 118 .

Pro de]d. 55,58 , buixch-vobdteten der Tnal-

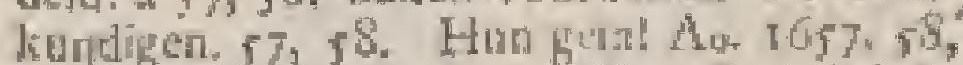

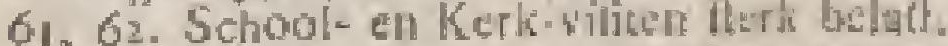

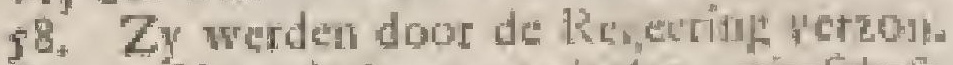
den. Hun buiten-woordecten digedelast. Huis getal if gan feh Indièn. $58,59 . \mathrm{K}$ aggteu harer Edelheden ower hen, or. Builen. roorderlen ialn de Tautkundigen wetr totgeftan. 62. Hune klaget over die Hatr

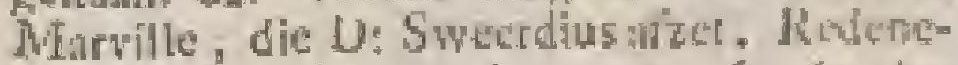
rinur der Predilanien dant ovit. 63, 64, be paling wa hume baiten - wordeelen. Batwy dat 'r voordeet dir 'Tatteundigen boven dat

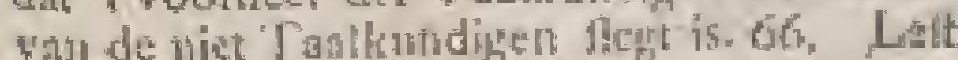
onterte hun tahe $6 \%$. Vier Predih-benten. Ao. 1607,67 Lah om has bicew., en walk de Suiten-Opperbootden te ecrow. 68 . Hun werzock am eenine meerter buiternvoerdechen wertens onlloden by de Kerki- en School-beroction afineflpera. 8I, B2. Lafi om de Rereering lebrifutyk pan alles berigt te geven, 37 . Age Predihanten, Ad 16g4. in Ambount 80 . Werboder hen oir on te aendeu buiten Isll haret Edetheden. Hen

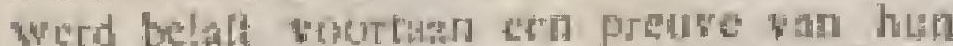
Maleyts and de Jerecring en Kerlint Rand

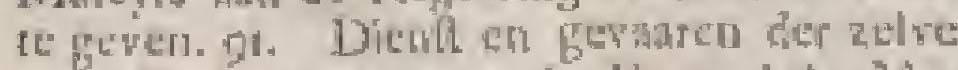

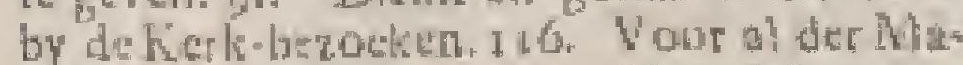
lertac Predileanten. is

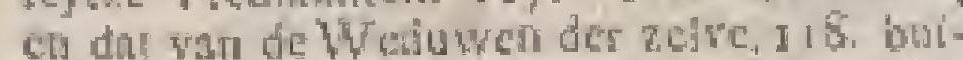
tert-voudeden op een Tosht wan en that Bh-

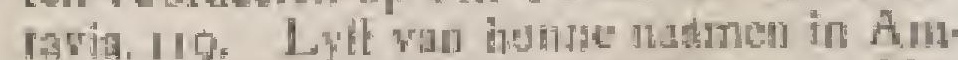
boing s7o. Ouk wals die op Onm, tar Ho-

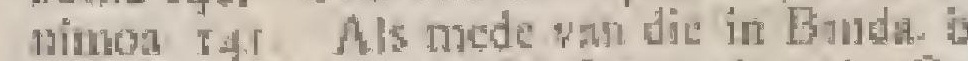
It. Op Neira. 15. Op Lonthoir 416. Op

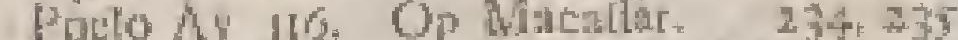

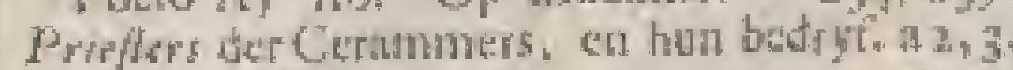
Sowanggi. Pinotikat. Flores.

Rhun b 30. Geen Nonten hier. Gefẹthilen "er oret met d'Engellehtel. 3" Oude vart.

35

Put Purte

Pordat - boom.

a 19,20 .

2224,225

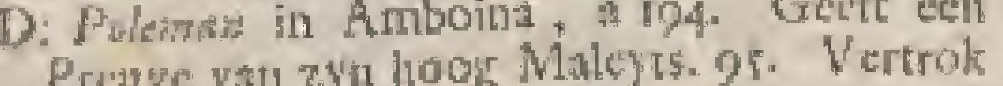
nut Barawia.

Pomaltian (Ctaiti)

Pomplatar Boont

a 188.

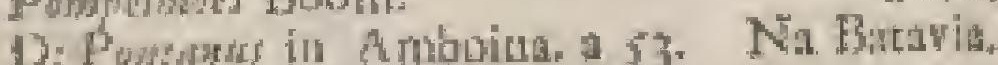
56. T'alkundig.

Pontarie.

b t20.

D: Pand hers, Mr: a 46. Kont it Amboina,

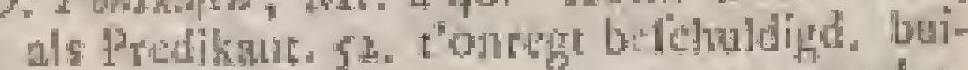

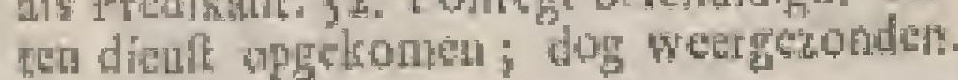

Der Mooren-diagt. 1 a 25 .

D'Hr: Prims op Macaliar Hoofd. 15 172. Land-

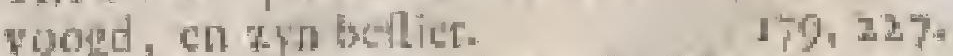

D: Prifries weteangen dnem de Mooren vala Noeffalaoto a yo. Gant ma Butalit, Kome

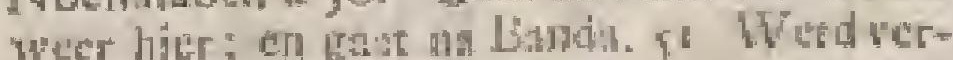

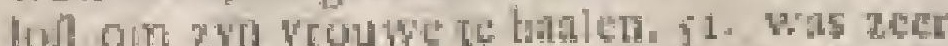
Taulkundig: $\quad j \mathrm{~b}, \mathrm{~b} 7,10 \mathrm{l}$.

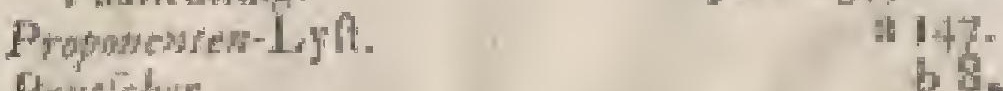
Prupiour.

Jwry's vertmal.

b $\rightarrow$. Patwan.

c 10 .

\section{Q.}

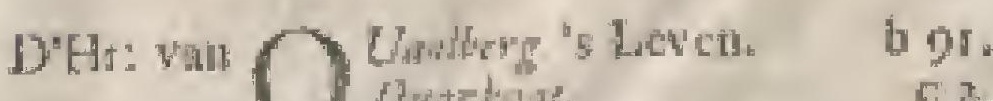
Otawhis. Qwitatias

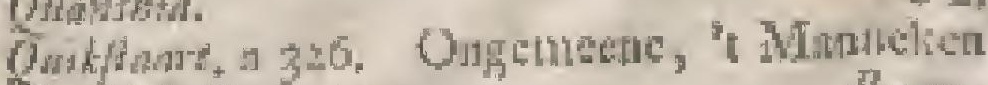
en Wyiku. $37 \%$ R日ari- 


\section{B L A D $=$ W $\quad$ Y Z E R}

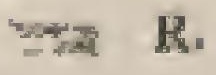

R Amburge

R Radys.

Radja Poerfoss.

Rasnatilowdi.

Rismboetsy.

Rintor Poutri.

Romit.

Rasan of Ranc.

Rawar.

Rarak Boom

Rated lituid.

Ratue, b 4. Een Stad. b 2. Een Dorp op A-

roc.

Rarlowi,

Katen, Groene Rawent.

Ratritiogf.

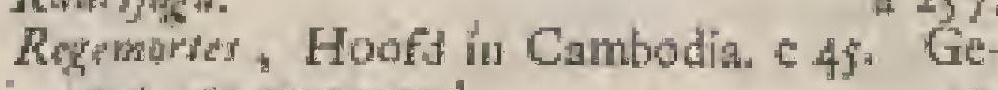
zast, en rermoord.

D* Rever in Anboing.

Revengri, Een Colleet.

Reyter. En zoorten, Jo Ay ; wetr verloren; dog berwonnendoor "L Lam.

Reprisily b ut na Timos.

Rromi-Aiog, een A pigad,

Rilded. Op Macaftar.

Ribrad-Plant.

$R_{y} /$, , 247 of Padi lbid.

D. Rimgins in Amboina, a 26. Dood. s8, b iog.

D: Rutions

R've, op Macaltat hecrlyk.

Kuebubongr dwingt de Purtigeczen te verhus. 2 en.

Ror-Oewor Oborwa, een Algod.

Ref op Borneo.

Rum $B$ it i,

Rocmus Elij, Limeri.

- N1arue.

- Toms

Remaksy om de $Z$ a

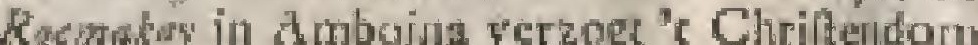

Roeres.

Roeto-Pid-Botm.

a 3 I $\mathrm{I}_{3}, 32$. in 19. b 244 b 6 b 6. 100

bis, 6 I

$b 81$.
127.

10.

b 197.

$2+4$. 1. 9. 5 8. Strat then

jinga-Boon

sip.

Hopts-ntayk.

Sirrien vopels,

Seforur $T^{\prime \prime}$ ina

Sucmbans Sighon.

Jenas.

Sirb-apen.

a. 54,56

a. 340 .

120.

D: Rugrisas in Ambuina, a 44, cen andre van

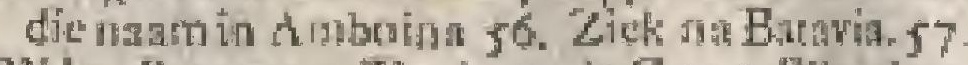

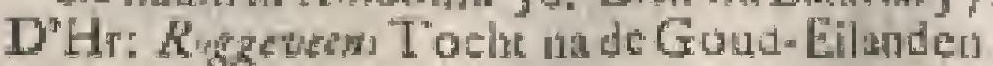

D. Romaw op Batais Tathutig ; dog iti "c hong Maleys, hiet verworpen.

a 5 is

Vincent Rpmeys.

c 9.16.

Romper lirban, a 257 . en wertcheide zoorterl.

Roozenture.

Konor

b 40 .

Roforeva, b 32. Horenkens, Kosien. Een Reditit. Zeidzam Gras. Geen Nupten hitr. b 33. han oude varr.

$R=$ Kalabia a 2 on 35 .

iscen. foud 241 . Rofla Gosat.

Ret

Rorm. a 294 Rotten-Eyland, b riz3.

Roucwer. Een Evlatid.

Roterdan. Een Eyland.

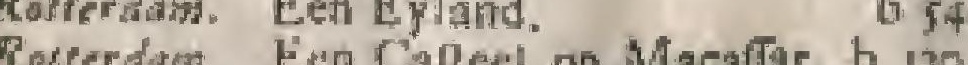
135. Afgebeld

D: Kowwenres in Auboima, 67 , op Oma ibid. overlenden patr.

D: Rwel op Ceylon.

Risyr wirch.

D. Rater.

III. DEE L Saking.

a 207

44,55

Sact $\operatorname{man}$ Bandi. b 34

224

b $172-212$

sape Bnom. a 175. dito. Hedler, 27 . diro.

Ther 295

apuser. Boom. b 39 .

a Jorborldom 4

jor Ajam a 24 .

colig. sajter Songut foppla. Sajor can-

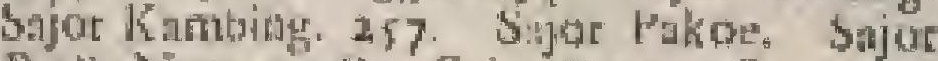

Tratere, $7 y^{2}$. Sajor Pups. 238. Sajar

b.

246,257

213

IIT Wonderlyk gerat op M

onder Ternate.

"b37.

rin 221

that-Biont.

Ferbond inet ben. 245.

756

byopo. $\quad$ 130, 139, I42.

miswa,

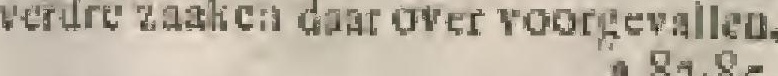

Stran, kyk in de Pot, op de Gocnong Api.

a 245 .

b 55

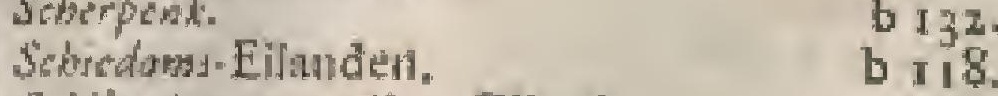

Solifforl. a 279 . dico. Eilund.

Sicholatisem. 65,77

3edsoles in Amboina, $34,44,46,53,18$

- Kinderen, wanner resm Behoefer gevtcht. a 59,61 Duytche op iericht. Meallers Loul. a 65. Han getrl. gr, $11 \mathrm{~T}, 131,117$.

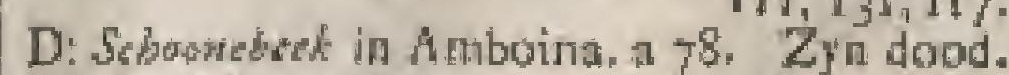

D'Ht: $s b^{2}$ op Solor. bi23. [24. Sitomen (Willem) b 52 (jooll) "s Lagie in Sitr. c 59 Sobelpen, F. Hornen, of Hotrakens.

brappion. $\quad$ a $240,294$. Searian.

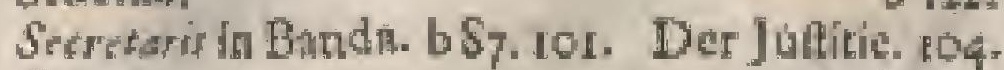
beman. bliz. Sengadj Paramparam, a $35 \%$ ibilit 68. Siph, Chritten.
a 79.8 arbite. 19. Sergento-bollew-Boom, 2157

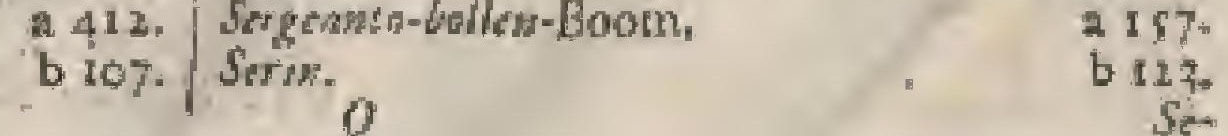




\section{B L $^{1}$ A D $-W \quad Y \quad Z$ E R.}

Seroene.

a 249

D: Serritus, in Ambuina a roj. Predilt Malepes in Banda.

D: Sibulius ith Amboina lam.

b 154. a 62 .

"er on er. 13 . middelen "er teget 14 . en na 15 3. agter ieder Boom-befchrywing.

sink.

b. 2 .

Siam, en onzen Handel diar. e 56.58, Ryken hicr. Jadia 't Paleys, onte Logie, 59. Loop der Menam. 60, Bankok. G1. De Koning, te[1 zyn Titels, 62. Waren, Handes-volken, Dereftofficn, 63, Mune, Tual, Schrifr, ent: 6 , Ditrem, 66, 67. Japanders hier. 68. Portagezen. 69, Macailaren, 7L. Noder landers. 72. Comelis Spek. 73. Wuaren, Hoofden hier wan otss. 73-76. De Griek Fulcon. $77 \times 87$. Enige byzondre zalken dezer Koningen en die van $\mathrm{Peg}$, 87. Han Gousdient.

Shan Commitriris in Tonkin.

Sieth " Joerct.

Midue.

wirk-Boom.

Sidkitar,

Shlewforls.

Sille thats.

Simbint.

D. Wikny in Amboint

Sirothos

Sindur-Boom

D: sinjer.

Ditir Sipman Latidroogd qan Macadtur.

Siri Torr Botudes.

Firi Naraderidg.

Givils en Bubla Srith.

Sirita.?

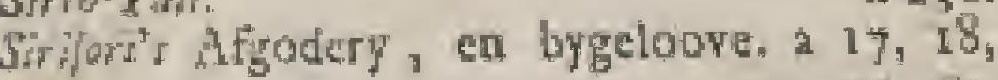

Rudju sifroeloe.

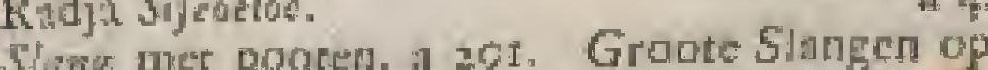
de Guenonr Apti b 26. Op Poelo Rhut 32. Shangen-4teen. a 297 . Slaugen-dienft. 19. 285,280 . '5 Inngen-Eiland. b 118,133 . stem-wurk is 't Nooen-perk. b II. Hun mide Wetten in Banda.

D: Shoed val Kleef.

Surri-hout.

Sodkn- loong.

Siver (Antoni)

botumber

Soelas/f, a 249. Ajam Soelstith.

sobas

Siffore Mocriars.

Suktiogel

suldy-Bothiouder in Banda.

sowomber

solur b I7, I 20. Sethe bier. De Veltin veroverd, 123, Dorpen. 124, Koningin. 125

Soluta Plant

Cowholioer.

Sombangh, Koning op Mactiar: en zyndood

Santrok.

Sombrige

Sommorta Codum. c 91,93, Zyn Leerlingen. 94 Dood. 95

Soy, Maras, Goden der Amboineczen + en Spieckwyen dan ran onteend by de Heidentu, en oude Jooden, Grieken, enz: is: Sondab-Millam.

D'Hst somk

De Sowadour:

Sanmegat.

b r 5 ,

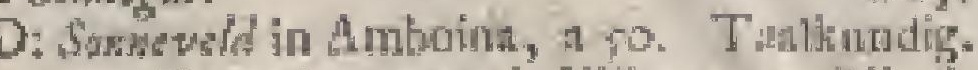

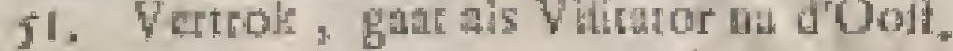

Sorzalk-Boom. a $55 \%$.

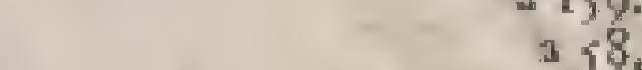

Solop-bootsi.

Soping, b 1 30. Princen van, 372, 179, 152, 144

Setury. . tos, 200

Sonvari. 276 .

Sowndf of Tambak. $\quad$ c $b_{3}$.

Soya's onde owdrlevering wan tiut Pot op 't Geberste. a 9. Werd Chrillen. zo. Hurne Afyodery uitgeraeyd. 55. Des zelts Koning een Afjodendienast. $\quad \mathrm{Sl}^{\mathrm{s}}$

Thomas de Styor, werd Chriflen. a 33

Thaveste dy

D. Spandan in Anboina, a 95. Geefr een Preave wah zyn Mateyts. 10i. Zyn dadod.

spat-Wurtel-

DHHe: Spex, cen protet onderdruktier der Kee

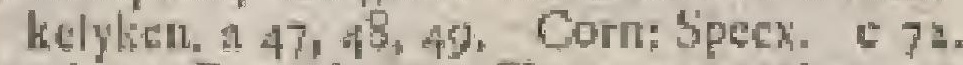
Spedhath-Bacy. b 65. Zwhe verowesing ralt

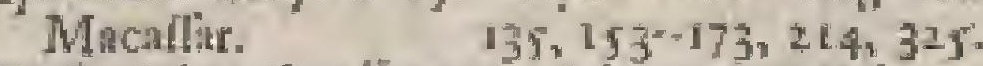

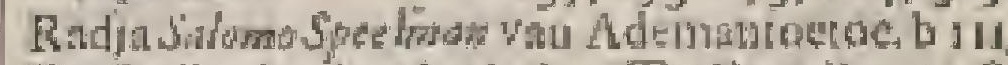
D: Spelifardes in Anboing Taslkutudig. a 58 .

Betockit Ternate. 59. 60. Zyne netigheid in 't overzenct van Boeksa, enz: 60,68. Affezet.

Sorestal in Partiti.

62.

J. sian 59 87. Banda. in 3. Timor. 127

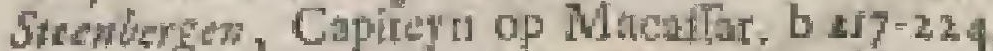

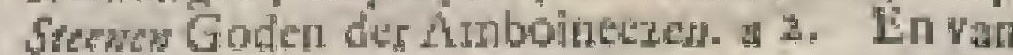
andre Volken. के.

Seembop. b 178 .

Sirentors.

D: Srevewfor Proponed hier geworden, a 77 . Gant ual Banda. ? 106 Simberd-Botm. a ist. Sitoketels (Schipper) b2

D'Hr: brom ver worpen als Comtnilatris Poliเyeq, er getopt, 132 Srit:

c 15

D. Strays in Ternate gefohost in diendt. a 6 ? Kont in Ambuita op O ma, to lagten over hem

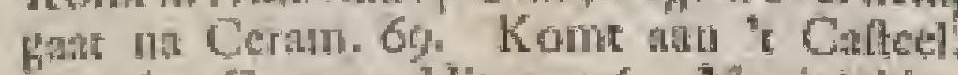
75. 76. Gant on Hitoe, 7o, Mocjelykhe-

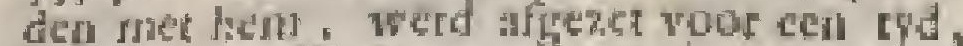
herfteld, on Teruate geronden, en gentel

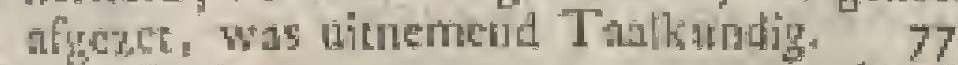
Sirny-Hack. b 50 Shéduma b $23 \%$. Ons Comptoir hice gelichr. Siryduyd Hoofd op Macafint, b 147 .

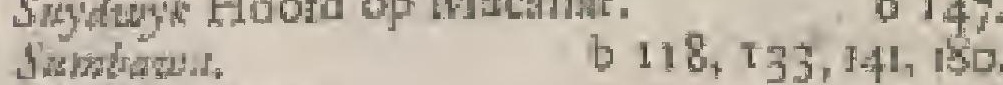

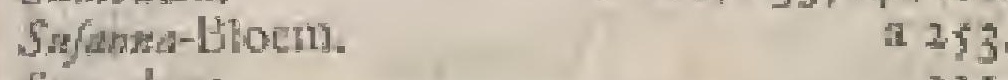
Sinreshopes, Swaluwe. De Vogelneskens trakende. a 328 Sunalo's werzock om Chrilten te werdeñ. Laur: de Sy trua, een AFgodendenar, Koning wan Soya

$$
\text { its. }
$$

TAal van Banda.

$$
\text { T: }
$$




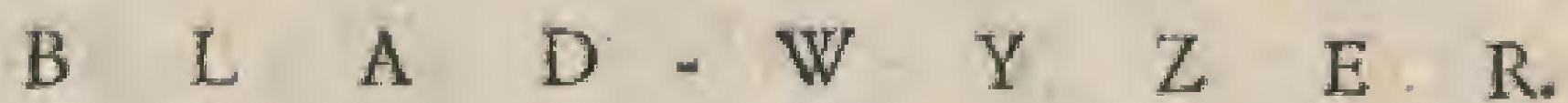

hat Ed: 1S3. Hate woden in Grain Bon-

toewas wati. $23 y$. Zaena's verzoek a an hat

210. what teer gengt by ons.

Tabi Ant

Talinall, een Afgot.

Tram-Vogel.

Tali baed ist.

Gnernon.

Api.

Karbium

Tali firib. a 23\%. Thali Morea.

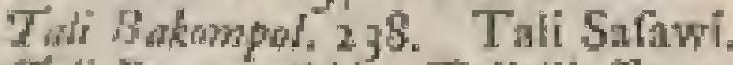

Tals Buserm, ibid Tali Piefling.

Twi Cotpang 25t. Tali Baboesij, ibid, Tali Gorita

258 .

a 18.

a 303 .

a 235

a $235^{\circ}$

a 235 .

- 235

$23^{8}$.

ibid.

256.

Tali beektri, en Tali Couwer, wyzen van te Villohen in Banda.

Tomarinde-Boom.

b. 31 .

Tamble of Sowafta.

a $19 I_{+}$

c. 63 .

Tamalfi.

Jinkbard.

Timed, een Eiliand.

a $25 \%$

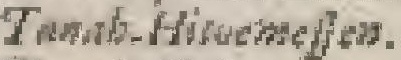

Thand Ruke

Taxamedp.

Tand howe-Boom.

- Hoetong.

Tortita,

Tangerang.

Tasilanga. Een Pridecs.

Tarjols,

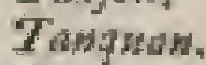

Tarangan.

Topustom

Tapstatzud

b I 35,14 b 132 .

a 20 .

E 129 .

b 33 .

th $215 *$

b. 8 .

b1 130.

2 232

20: 131.

b $13:$

b 39 .

c 5 iा.

a $\pm 33^{2}$.

Tasman's (Abel) Revze ta "k Zuydland, b 47.

$\begin{array}{ll}\text { by neemd een joak. } & \text { e } 47 . \\ \text { Tawds. } & \text { b } 6 I_{\text {. }}\end{array}$

Tectey.

Tentw,

Tello, b t30 des ojzen.

Tempe 't Meir wan die naan.

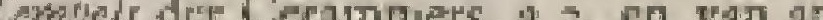

menber.

Teng.

b. 4 .

Tempotsto

b 38.

Topalan, ect der dre Cerme Capiteys a 4 . Iope.

rocratic.

औิ 10.

Toetra.

Twerang:

racteros the bis.

uetewamat.

Thes babe.

b. 10.

Tulot.

Inowisis Bogt. b 123 .

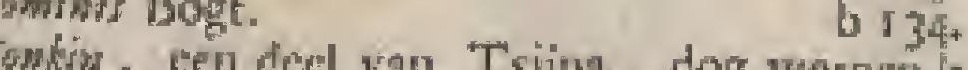

Joh af, $\mathrm{c}$ I Verdecling dem acts nisg hite 3 De T sjouwa beroofd den he-

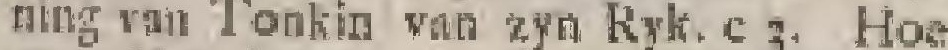
Then hier hognt: 4. Leveusiniddelcn 4. Waren. y. 'L Volk befchreven 5. T"ant. 5. Schryf-wyes Regering, Krygsmelst, Gem riahs-bediening, Bepravenis, wanteer on-

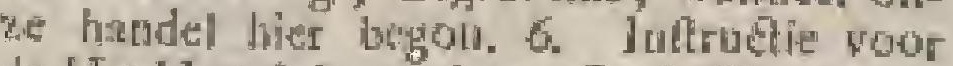

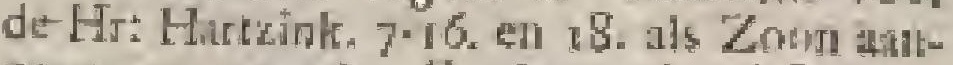
genomien van den Koning, 16. Acte dar valu ibid. Urief des Koming and den Gou-

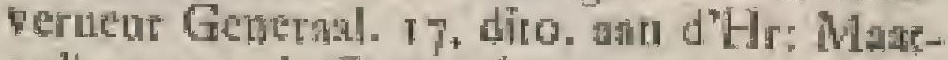
zuiker. 31. "t Comptoir opgetroken. 33 * Thante Upperhoolder. c 31 . Godstenfer.

33 34.

revifit: b 134 .

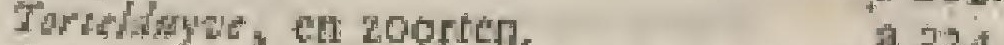

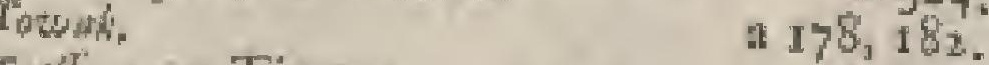

repters op Timor. b $12 \%$

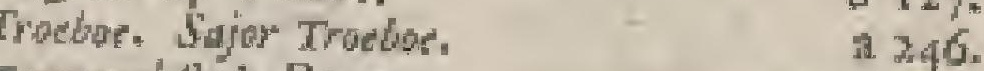

Tronsuch-1tok-Boom.

Truphans Admiral, na Macalin a i 660 b

Tifuls

147.

Tyole Becan. a 276 .

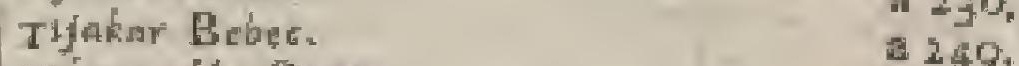

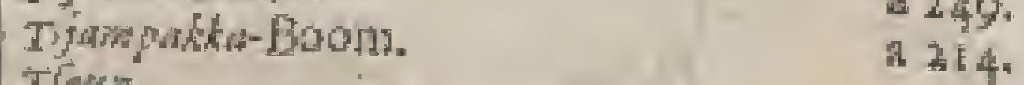

J]ent

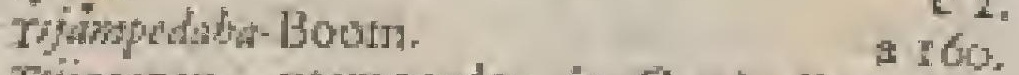

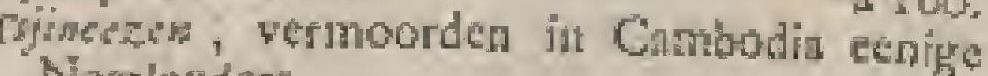

c4t.

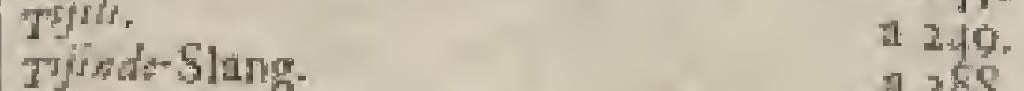

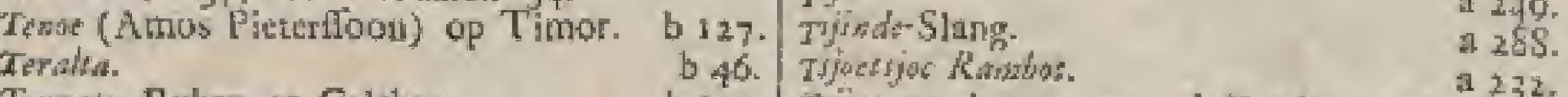

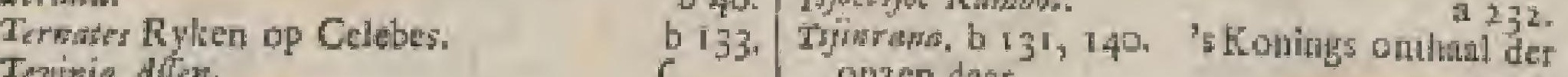

Tevinis Afen.

Tetimia pra Laban.

Tetion Lanham,

Thever.

Tjam.

Tiamida,

P: whensifopr.

Ityyjon (Pieter)

D: J barmus jat Timor

r

Tyjetr-Vogel. $\quad 14 \mathrm{I}$

Tjongetor,

18.70

Tolomorty.

Thiba Brifis.

a 36 .

a 236 .

b 38 .

c $\mathrm{i}$.

bs.

Thrier.

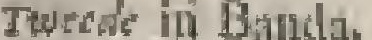

b 127 .

b 34 .

b I 31 .

b 122 .

Theoro.

Tibedifin Chritten.

De Tyers-Eilandets.

a. 70 .

rikos=1300m.

b I 18,133 .

a 221 .

Tises-1300T1

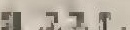

Tinon Tiks.

156 .

Timar. b 1 77, IzI. Opperhoofden. I26. door

wis betogt.

Thar Luet: b 43 . an Dopel

b. 1.27 .

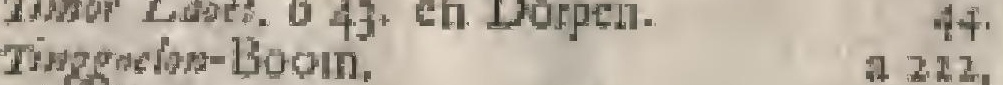

Tin-1300ा.

Todilay.

Therast Befs Eilanden.

Toebarky.

Teldom.

a 221.

c 2.

b. $13 y^{2}$

a1 $31 \%$.

b 31 .

T Ta

Vhatrigs tu Banda. bi 246 .

Adragy in Amboina, a 78 . Leerd b i35

teys in zeer kurien eyd, en disar ayer

bererd in foldse, 79, 81. Werd regen do

orire na Bunda gezonden, tot nadeet der

kerken in haboina, theerd weder hier zoekt Honinoa, cn Noeffalaoct. 7o. beyihd den Lybal over te zeten in "t lage Malcyts. so. geprizell over zyne neerligheid door dive valn Amboint, ficent the overzetten des Bythels, Moet alleer wondle de Prodikanten hier tweemanl Precten in 't Mateyts; en roen de Kerken-rusd hem be-

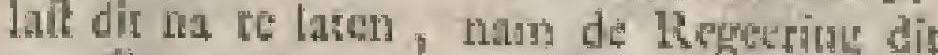

$$
22
$$

17 


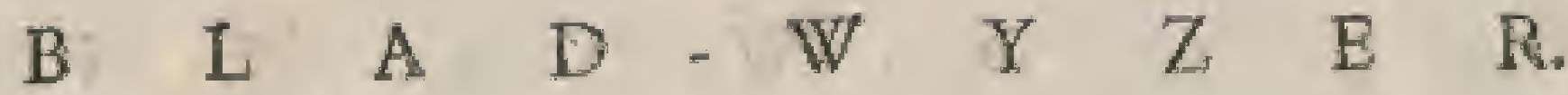

Ewalyli, ent belat hem dit weer. $S_{2}, S_{4}$. 't hoog Maleyrs werd mee peweld hier mingevoerd, en dow den kerkenzad hil vreeze atogenolten ; wath op liy zyne verlolfing

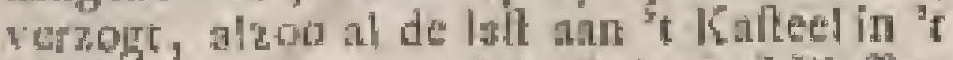
Mateyts op hers, gelylo dit in de Uliafters op. D: vasi der Vorm tablkwam, die hem daze na van cen bourt ontlate. \$7. Zyo vertrek nit Eatawit, das hy hennis yat ayn overzetrinc des B? bels gaf. S9, 90. Waarom hy own Werk aan den kerlcepras in Amboina nietgaf te rien. Woulingen en lacwegimgen van D. D: vala der Worm, Hodentyl, en de verdre Predileantet regen topne overzetting, en

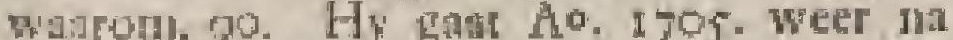
Indiêt. 05. Verfen op 7ye 5ertretk. g6-100. werd tegen d'ordre der Heeren zcuentienen, Juer geweld als Lerer-Predikant na Javas, N. O. Kuill gezonder door hase Edelheden, en de Hr: พал Rieberks bittre woorden, tyne zickte og dic tocht. Wederkomft op Butavia. Zyn rertreds na Ambaina. Zyo werdigheid in "it Walcyts Preeken woor de

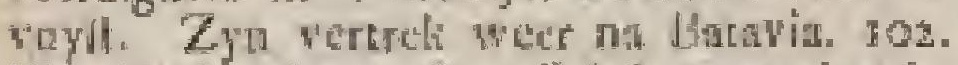
Zwo Kerkelyke ontl]ags-Brich., en getuigenis. Roml op Baravia. Latf larer Lidelheden om nan Ternate te gasn, dac hy zedig, weygerd. Zyn wereet na "Yaderland. 103 * Dagr by th zye Hifenden operlejen wond, en wan twee armer befte Kiffen berabla werd, 104. Liefdalone belandeling der ambonfche Brocderen zedert 1604 . nuer hem. 105. Etwyace was syne belwwamheid in "t Maleys. 101, 103, 10, "t voorgevallene hier over voor de Synodus van finkhuizen, Mo. 1696. ea kerwolgens. D: wan der Vorms vuilardigheid. I 6 . DeHeren zeventienen tcren des Schryvers Wert angezer. Dis zelf woor 'e lage Maleys waren. 107 . is om

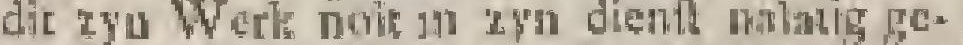
weeft, en dede dir zonder Lown te bepteerent? daar voor. Hoe onredes yt hy hice soor toehandeld is. D: wan der Vorins atubieding, ata D: Leydekter en des Seluryvers Werth in twee colommen to drukliken ; en dnar op ondernetnd de Schirywer zyne tweede Reyze na Indich, 108, rog. Komt op Batsuia met ret voutchicyens ; dog werd fegt behandetid aldalr. Hae in Mnboina. Ser andermital den Bjbel over in "t hogg Maleges. Verdre Boelect door hem overgezet. top. De Claflis an Amlterdam held over tot D: Leyuchliers Werk. 1 ro. Eerige AF intrincen was des Sehrywers Bobel doon die Clafus verzor, ner die win D: Leydetier vergeleken, en berigt "er over aภn den Sichryver ur. D: wan der Vorms Lofferylate ge tuigenis vandec Sehrywer, en ranzyn WWerk fu een Biter, en wan wat nitwerling die was.

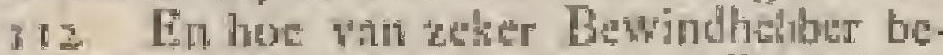
handeld. De Schryfer zoelit zyu Bybed door ce regtc deur in Jndien te krpgen: dog is

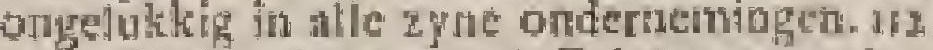
1 4. Votropd worn awe de Bybel-overzerting Zyne Bede tot de Heeren zeventicnell. if 2 Dor at zelve befluitect D: Lerdeke lites Brbe te drukken, en belakten Revilires re fiellem. Des Schryvers anantrking "er over. 114 115. Zyn misnoepen ower de Hr: wan der Srels pezas in 't Kerlielyke, en varn eagige smvoorwigtigheden, die hy, mer zyl Ijedebroeders nfer konnende herfellen, door cen Brief trigt in beter fhat te bretugen , die hy and den Gemeral den Hr: wan Ripheck zend. Onvoorzigtige behandeling van dien Heer onteent den Brief; wast op de Selaryver, op

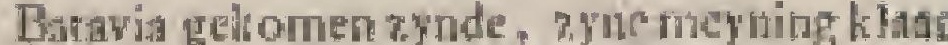

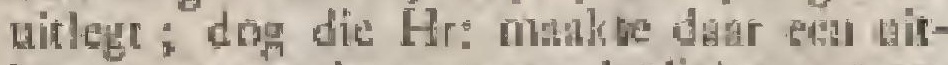
lek op na uyn zin en regen des Schryvers gedagten. Bedreygd den Schrywer dan op mer den Fifcial 136,157 . Werd betah aarernate te gaan, tegen de ordre der Hetren zeventieners, hem medt gereven- Fn, ma die peweygerd te hebben, woor de [Rad van ] if titie over die Drief gedagtard; dog woor den zęlwen nok vollogiten in allen dectengereguveerdigd. 137. Slegre dasd des Hecren yan Richeek. 130. Des Scluyrers katalt in Banda. bu is. Zyn gevar by den Brit. 1z9. Valcosy (Jacubus) b b g6. Valr

Val Alem, als Predifant ma Teruate. a 87. Van Alem. b 126. D. Von Bech $b \geq 34$.

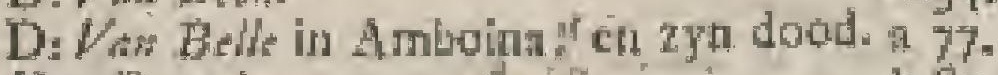

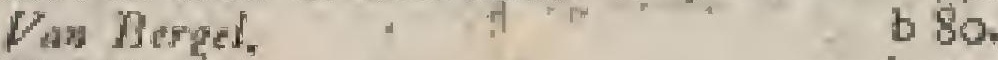
Vam Berkl. " b35.

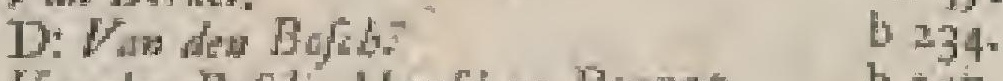
Vas den Berbi, Hoofd op Borner. b 247 . Van dien I reeh. Vas den Brmehe, (Picted) in Bonda b so.

D. Vor Bratsmas in Amboina, a 135 . Vertrot: กa Fintsia.

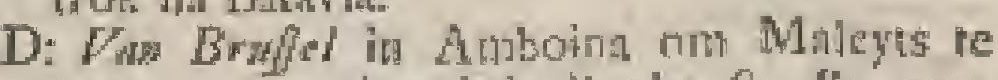
leercn, a 70 . dar dede dis nich 80,81 , var-

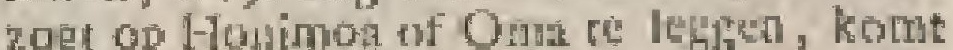
op 't latulte, en ltierf dagr. 8 . DiHr. Vow der Burg in Tayouan. ' c 15. Vars Cordan Vas Dalkn, up Macaltar. 171.

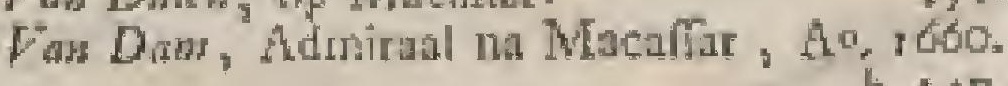
Pre b 147.

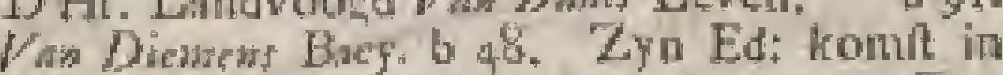
Banda yo. Kumlt in Amboina, a si. Z $\mathrm{m}$ Ed: Bricf van den horsing wan Cambodia.

Vam $D$,

$617+$

Tas dor Datres in Bunda. b $50,8 \mathrm{~s}$.

Van de lis deps.

Pan der Enden.

20

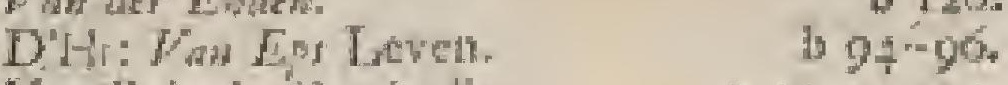

Vom Galen in Caunbodian e 43,93 , 94.

Fan Guens Eilanden. b 64 .

D'Hr: Vom der Hoger in Amboina, a 32. veraverd dat. 33 . Fan der Magers, Honfa in Cambodia. c 45 .

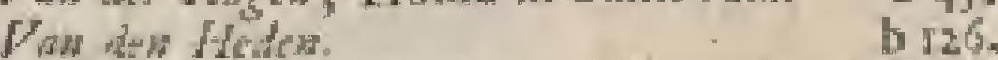
D: Vor den Hower, a 41 . Vertrok na Butavia. 51. b tos. Tas der Let, Hond in Parati, c

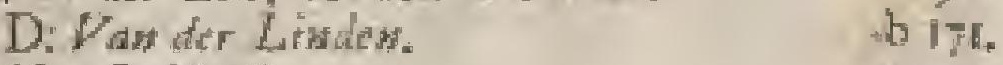
Van Lodfarit.

Van der siri?

Fan Narrd ap Boritem

Fas dir Par wermont.

Fan der liant.

Tinor.

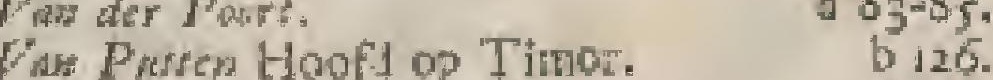

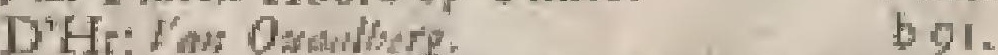

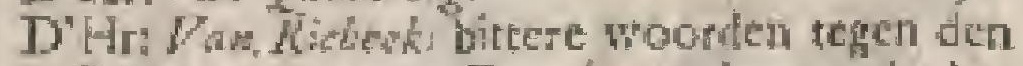
Schrywer, a $43 r_{2}$ En 2 乌̧n verdre quade behandeline yan des Srhtryers Brict aan zyn Ed:

D: Vas selfie in Bendil.

D: Van der Shay, Proponeint in Amhoiela gemaaki, al 75. Op Oma gelegt, 7 . Werd Predikant, en gnat nat Ternate 77 . Kount weer bier 78. Bezoglar Boero, Mamipa, en

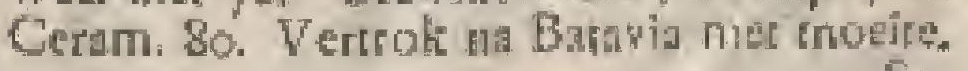

Van Soll op Macafar. Y th b 143, 144. 


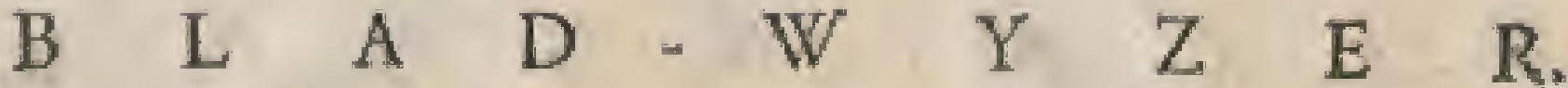

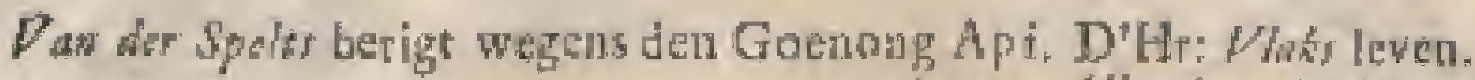

b 7.80.

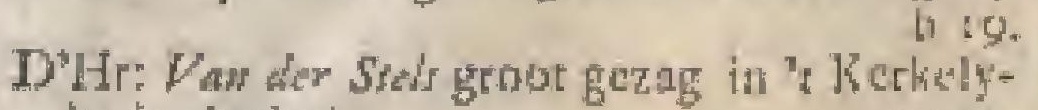

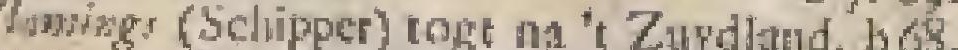

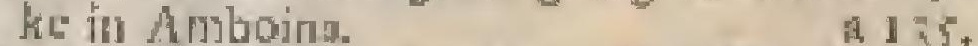

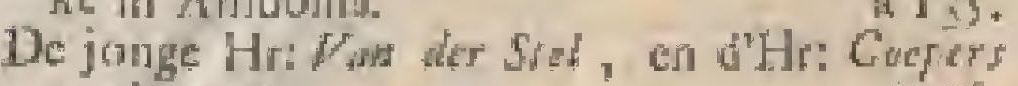
Weder waten.

b $6 \mathrm{~s}$.

D'He: Henrilk wan dor Sid op Macafiar. b 223 .

Van ibuthel.

b 7 .

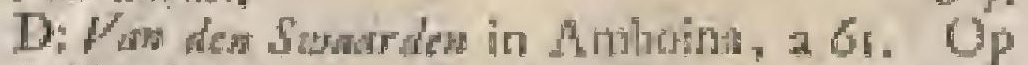

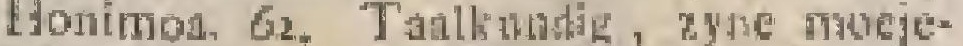
lykheden nus de Hro Marvilte. 63. Kagren ower zyn Lerw; en getithori nu dienft, vertrok na Teenate.

63.

D'Hr: Van The Landwongd op Macafiar, b, 172, 177. Zyn verblyt in "t Caflece fan Goa 204. Befehuldied door Arote Tuko. zor? Hertheld de thak wall de $\mathrm{Hr}^{\text {* }}$ Prins. 22 . 7.yn dood.

178,179 .

D'Hr: Fan Tol, Lardpongd op Macafla , b. 2 г5. d'onluiten tufleinen de Koningen wan Goa et Botil totn beronnen, war inde $\mathrm{Hr}$ : Erberweld zyn Ed: oudertand met Rand, dog beloond hemb garlyk. 233 . Wonderlyth workal met enrige Saleyereczed. Zyo Ed: dand.

D'Hr: Vors Uadelen.

Pan ale Veide.

224.

an Vliet, vermoord op Matedfir. b 140 .

D: Perrus $V_{\text {an }}$ der Vurm in Anboina, a 80. Predikr hoor Mateyts, on gat ha Hon:mon. 8. Zya feherpe Bricf and die san Batavia. \$2. Werd and 't Cutlecl gelert. S7. Vertrok na Batavia, sts Maleyrs Predisant dater beroepen. 91, ayn vuilatirdigheid tegen $\mathrm{Va}$. lentyn, en syn Werk. 106, 10\%. Vervolgd de overzening tin D: Leydekleer tha zye dond. 107. zyo Lhief a Val Ventyn tot veel lof van zyп Perzoon en Werk.

$11 \mathrm{I}$

Di Jacobus Vas der Prm in Amboina, an 94 .

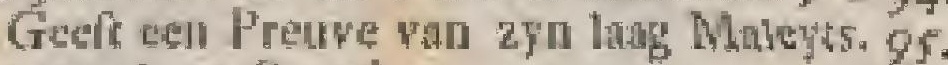
vertrolt na Bataria.

Van Warauld

102.

Fan der Wes" Proponenc op Noeffalaet, en 7.y no dond. As 5 , 63 . D'Hr: Van Zylls Jeven. b ga.

Varate

Vafconcet bo.

Vaflendagen, den Amboines onbekend, in í.

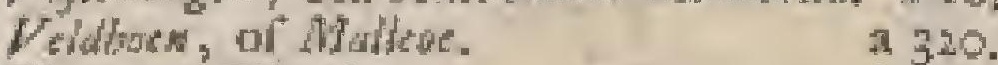

Veldboest-Eiland. b Iz2.

Verboeven (Jaly) b 8 1 .

Verbeglen, de Zeeroogd, in Banda b 76,77 . Werd datar termoord.

Vesadering van Politic. o 85. van de Weeskamer, en varn k]eene Huwelylis-zaaken in Banda, b 87. Wan deu Kerken-radd in Amboina.

Verrif Boom

D: Verbiges.

Verkensit

Verritert.

a 63 .

ก 218 .

b 107.

a. 264 .

D: Vertrectit, in Amboind 49. Veriecrde opvatting van zckere datd wan ayn berw; werd opkezonders; dog hetfleld, 50 , zeer Tal. kutudie.

Vind na Nova Guinea.

Uyterdow, een Eilland.

Vifribers - Eillande.

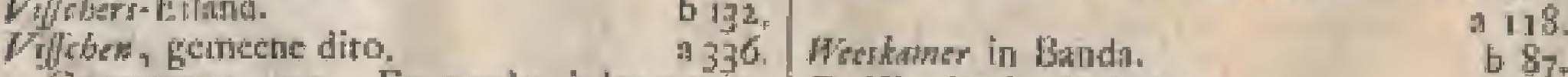
He: de Vhange een dellig Voequerher der Kerle, a 33, y4. t'onregr befonuldigd. 55 . zyll yver. 56. 2yo ongetuktig geval op Ti-

Vofferberen der kitrlie. V lathing, Cos, Ho

b. 328 : Ititire, Hordk, Onder yders Regeering in Ambina te zien.

Vogrlen. in 198 . Vogelneskens. 3328 Voserfo. Eyland. b5. 45. Viterer. bit.

D: Vonk in Amboina, 257 dood.

Voute in Zee geworpen, door de Hr: de Vlaming

i1 $33^{2}$

Voorsechom, goede un quabe. $\quad$ 8, 9

D: Tasposar in Amboina, a 77. Opgezonden door de Hir: Padbrugge, on dat hy ryo Ed: betwille de Vetkiezing van Ouderlingen en Diallienen; dog wierd geregrverdigd, eth Derthe

Troutis.

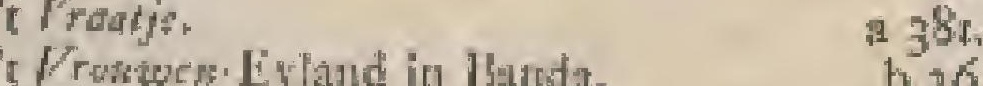

Uyler.

a 328 .

\section{W.}

Wharen, op Macaltar vallende, en getrokWhen.

b. 135,142 Waarzeggers of Wichclatars. Wathisher tot to Cleiftendom genegen. at 44 Hagewan op Macaltar. b

Wallagew, by. Groot en kleen dito. by

De Chatoep Walragen's Tocht na Nopa Guinen.

b. 8 .

D: Whatrat in Amboina. a 69. Dood. 62

Wed edberg.

Wateifh. a 3ak en Tanden, ibid.

't Selip de Waltifb verongelukit. a 62 .

Whoms.

Wrandend Biad.

Wasgi dialdata.

Wing thaxp- Eyland. b 132

W'aras-Baoun.

Wartion. by

Whringin-Boomen als Goden geeerd. a 3 zoor

ten. $\quad 123,224$

Wartuxd op Borneo.

D: Warmelos in Amboina, Tanlkundig, en na Batavia, a 57 . weer hier 58 , uit Banda weer hier, Ma Macalar, en dood. 61. b log. Van Warzeyl.

Water-Hour.

Water-Wietocn,

Water-Slatg, a 292 , en Water Dieren. 33 .

Wawo.

Witer, wit-Water b is. Waterloore Wer-

sce

Wotales. b 44

a 23 .

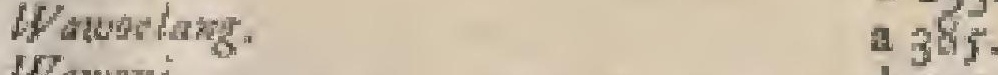

Whani. b135

Why, des zelfs Afigod. a 4 doot Leliato over-

vallen, 49. flrat over hutuc Afgodery. 57.

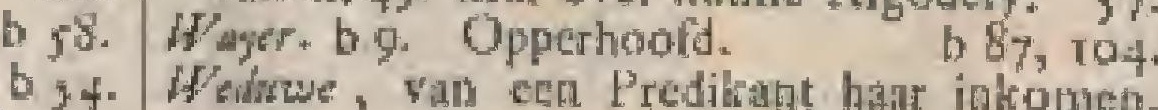

zien by de Lyll agrer deongemecne Viffchen. Herftar in Bandas b 88 .

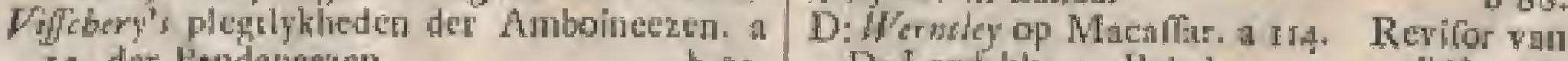

I5* der Bandaucezen.

DeViffer.

D: Visriarims in Mmboina, a 44. Zyngedrag.

1I.T. DEE L.

$46,47$.

D: Leyduthers, Bybel.

ibit. $25 \%$.

DiH: $H$ Ww Leven. b or.

Wryties wermoord.

Wetel (javaniche.) a $279^{\circ}$

itivit 


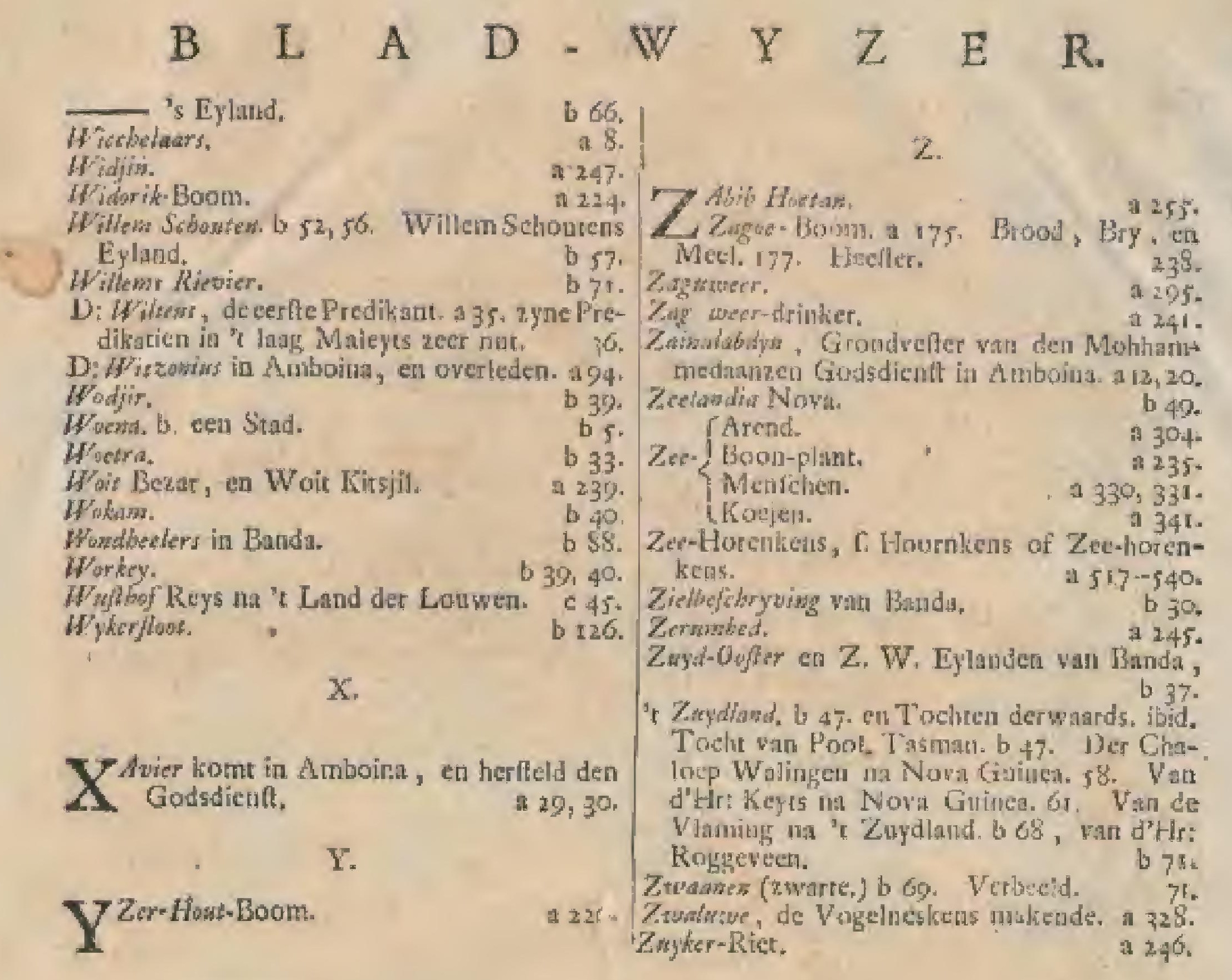






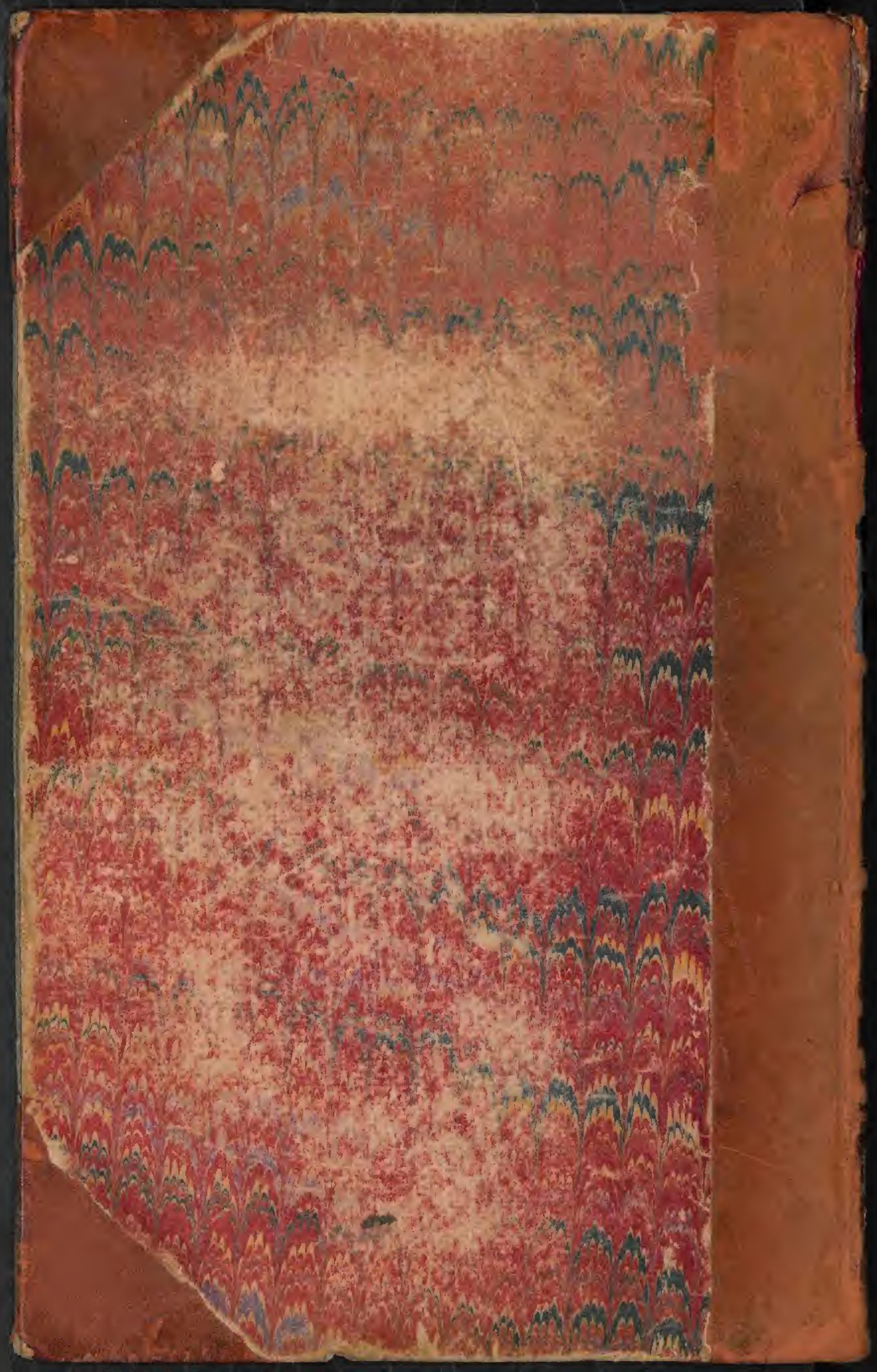

